
PROCESSES

Submitted by: ANNETTE S. ORTIZ MIRANDA

Advisors:

Professor Dr. María Teresa Doménech Carbó

Professor Dr. Antonio Doménech Carbó

Dr. Laura Osete Cortina 



\section{Universitat Politècnica de València}

Facultad de Bellas Artes

Conservation and Restoration Department

Instituto de Restauración del Patrimonio

Laboratory of Physico-chemical Analysis of Cultural Heritage

\section{Reviewed by}

Professor Dr. Carlo Lalli Galliano

Laboratorio Scientifico

L' Università degli studi di Firenze

Professor Dr. Francisco Vicente Pedrós

Department of Physical Chemistry

Universitat de València Estudi General

Dr. Ana Vila Espuña

Centre for Art Technological Studies and Conservation

\section{Doctoral committee}

President: Professor Dr. Juan José Baeza Baeza

Department of Analytical Chemistry

Universitat de València Estudi General

Secretary: Professor Dr. Susana Martín Rey

Department of Conservation and Restoration of Cultural Heritage Universitat Politècnica de Valencia

Spokesperson: Professor Dr. Carlo Lalli Galliano

Laboratorio Scientifico

L' Università degli studi di Firenze 



\section{INDEX}

\section{Part I. Overview}

$\begin{array}{ll}\text { 1. Abstract } & 10\end{array}$

2. Acknowledgements 13

3. Objectives 16

4. Work schedule 18

5. Motivation 22

6. Introduction 27

6.1. Painting as multilayered objects 28

6.1.1. Pigments 53

6.1.1.1. Definitions 53

6.1.1.2. Classification $\quad 53$

6.1.1.3. Pigments studied $\quad 58$

6.1.1.4. References $\quad 68$

6.1.2. Binding media 71

6.1.2.1. Definitions 71

6.1.2.2. Classification $\quad 72$

6.1.2.2.1. Proteinaceous materials $\quad 72$

6.1.2.2.2. Lipid media 94

6.1.2.2.3. Polysaccharides 105

6.1.2.3. References 109

$\begin{array}{ll}\text { 6.1.3. Deterioration of paints } & 117\end{array}$

6.1.3.1. Physical factors $\quad 117$

6.1.3.2. Chemical factors $\quad 121$

6.1.3.3. Biological factors $\quad 123$

6.1.3.4. References 129

6.2. Analytical background: an overview 132

6.2.1. Analysis of pigments 133

6.2.1.1. Pigment identification 133

6.2.1.2. Alterations 143

6.2.2. Analysis of binders 147

6.2.2.1. Identification of binding media 147

6.2.2.2. Characterization of the mechanical properties of paintings 155

6.2.2.3. Alterations 155

$\begin{array}{ll}\text { 6.2.3. References } & 160\end{array}$ 


\section{Part II. Characterization of the deterioration effect of pigments on tempera painting}

7. Materials and methods 177

$\begin{array}{ll}\text { 7.1. Reconstructed model paint specimens } & 178\end{array}$

$\begin{array}{ll}\text { 7.1.1 Reference materials } & 178\end{array}$

7.1.2. Reconstructed model paint specimen's preparation 179

7.2. Analytical techniques 180

7.2.1. Weight measurements 180

7.2.2. Fourier transform infrared spectroscopy - attenuated total reflection (FTIR-ATR) 180

7.2.3. Field emission scanning electron microscopy (FESEM) 182

7.2.4. Atomic force microscopy - nanoindentation (AFM-nanoindetation) 184

8. Results and Discussion 189

8.1 Characterization of paint specimens 190

8.1.1. Pigments 191

8.1.2. FESEM 195

8.1.2.1. Egg yolk tempera reconstructed model paint specimens 195

8.1.2.2. Egg yolk-oil emulsion reconstructed model paint specimens 201

8.1.2.3. Final considerations 206

$\begin{array}{ll}\text { 8.1.2.4. References } & 207\end{array}$

$\begin{array}{ll}\text { 8.1.3. FTIR-ATR } & 209\end{array}$

8.1.3.1. Characterization of egg yolk tempera reconstructed model paint specimens 209

8.1.3.2. Characterization of egg yolk-oil emulsion reconstructed model paint specimens 226

8.1.3.4. Final considerations 241

8.1.3.5. References 243

8.1.4. AFM-nanoindentation 247

8.1.4.1. Binding media $\quad 247$

8.1.4.2. Reconstructed model paint specimens 249

8.1.4.3. Final considerations 256

8.1.4.4. References 257

Part III. Characterization of the biodeterioration with fungi and bacteria on tempera painting

9. Materials and methods $\quad 259$

9.1. Reconstructed model paint specimens 260

9.1.1 Reference materials 260

9.1.2. Reconstructed model paint specimen's preparation 260

9.1.3. Biodeterioration of the reconstructed model Paint specimens 261

9.1.3.1. Microorganisms 261

9.1.3.2. Microbial inoculation of reconstructed model paint specimens 262

9.2. Analytical techniques 263

9.2.1 Weight measurements 263

9.2.2. Optical microscopy 263 
9.2.4. FESEM 263

9.2.5. AFM-nanoindentation 264

9.2.6. Electrochemical techniques 264

9.2.6.1. Voltammetry of microparticles (VMP) 264

9.2.6.2. Atomic force microscopy - voltammetry of microparticles (AFM-VMP) 269

9.2.6.3. Scanning electrochemical microscopy (SECM) 270

9.2.7. References 272

10. Results and Discussion 275

10.1. Characterization of biodeterioration patterns 276

10.1.1. Pigments 277

10.1.2. FESEM 279

10.1.2.1. Characterization of the uninoculated egg tempera and egg oil emulsion reconstructed model paint specimens 279

10.1.2.2. Characterization of the inoculated egg tempera and egg oil emulsion reconstructed model paint specimens 283

10.1.2.2.1. Egg tempera reconstructed model paint specimens 283

10.1.2.2.2. Egg oil emulsion reconstructed model paint specimens 295

10.1.2.3. Final considerations 302

10.1.2.4. References 303

10.1.3. FTIR-ATR 304

10.1.3.1. Characterization of the uninoculated egg tempera and egg oil emulsion reconstructed model paint specimens 304

10.1.3.2. Characterization of the inoculated egg tempera and egg oil emulsion reconstructed model paint specimens $\quad 329$

10.1.3.2.1. Egg tempera reconstructed model paint specimens 329

10.1.3.2.2. Egg oil emulsion reconstructed model paint specimens 364

10.1.3.2.3. Discussion $\quad 396$

10.1.3.2.4. References 398

10.1.4. AFM-nanoindentation 400

10.1.4.1. Egg tempera inoculated reconstructed model paint specimens 401

10.1.4.2. Egg oil emulsion inoculated reconstructed model paint specimens 411

10.1.4.3. Final considerations $\quad 423$

10.1.4.4. References $\quad 424$

10.1.5. Voltammetry 425

10.1.5.1 Binding media $\quad 425$

10.1.5.2. Pigments 426

10.1.5.3. Egg tempera reconstructed model paint specimens 431

10.1.5.4. Egg oil emulsion reconstructed model paint specimens 437

10.1.5.5. Description of voltammetric processes 442

10.1.5.6. Complementary electrochemical techniques 443

10.1.5.6.1. Scanning electrochemical microscopy (SECM) 443

10.1.5.6.2. Atomic force microscopy - voltammtry of microparticles (AFM-VMP) 444

10.1.5.7. Voltammetry of microparticles testing biodeterioration 446

10.1.5.7.1. Iron oxide red reconstructed model paint specimens 446 
10.1.5.7.2. Verdigris reconstructed model paint specimens 448

10.1.5.7.3. Lead white reconstructed model paint specimens 451

10.1.5.7.4. Cadmium yellow reconstructed model paint specimens 453

10.1.5.8. Discrimination of biological agents 458

10.1.5.8.1. Iron oxide red reconstructed model paint specimens 458

10.1.5.8.2. Verdigris reconstructed model paint specimens 459

10.1.5.8.3. Lead white reconstructed model paint specimens 462

10.1.5.8.4. Cadmium yellow reconstructed model paint specimens 464

10.1.5.9. Modeling biodeterioration 466

10.1.5.10. Final considerations $\quad 470$

10.1.5.11. References 471

11. Final Conclusions $\quad 473$

12. Annexes 476

13. List of abbreviations 507

13. Publications $\quad 510$ 


\section{Part I. Overview}




\section{Abstract}

Egg (the whole, the yolk or the white) is a natural product used since ancient times as tempera painting medium mainly in Europe and the Mediterranean Basin countries. In addition, egg is a complex multicomponent microstructured system susceptible of being influenced by the pigments that compose the paints, as well as a source of nutrient susceptible of biodeterioration. Modifying effect of artists' pigments on the binding medium as well as, the microbial biodeterioration are responsible for changes in the structure and composition of the binding medium and, consequently, on the physico-chemical properties of the paint.

For this purpose, analytical techniques such as Fourier transform infrared spectroscopy attenuated total reflection (FTIR-ATR) was used for the chemical characterization, Field emission scanning microscopy (FESEM) and Atomic force microscopy - nanoindentation (AFM-nanoindentation) were run for morphological and mechanical characterization of the deterioration processes resulted from the pigment-binder interactions involved in tempera painting.

On the other hand, the current research report the application of the voltammetry of microparticles (VMP), complemented with FTIR-ATR, FESEM and AFM-nanoindentation techniques to monitor the deterioration of a series of tempera reconstructed model paint specimens under the action of different biological agents. This methodology would be of application for identifying the type of biological agent causing deterioration of painting, which is an important problem affecting cultural heritage. The analysis of biodeterioration processes is complicated by the fact that the action of microorganisms can affect both pigment and binding media. The deterioration of pictorial specimens by Acremonium chrysogenum, Aspergillus niger, Mucor rouxii, Penicillium chrysogenum and Trichoderma pseudokoningii fungi and Arthrobacter oxydans, Bacillus amyloliquefaciens and Streptomyces cellulofans bacteria was tested using sample-modified graphite electrodes immersed into aqueous electrolytes.

Finally, the study carried out by means of FTIR-ATR, FESEM and AFM-nanoindentation confirms that egg proteins attached to the pigment grains changes their secondary structures. The results obtained also confirm that proteins and phospholipids are prevalently established linkages with the solid particles of pigment whereas triglycerides should be integrated in the complex binding network responsible for the cohesion of the paint film. Interactions between egg components with solid pigment particles are described and correlated with micromorphology and mechanical properties determined at micro- and nano-scale on the reconstructed model paint specimens. As a result of the crossing of VMP data with the results obtained by means of FTIR, FESEM and AFM-nanoindentation, the voltammetric signals obtained were associated to the electrochemical reduction of pigments and different complexes associated to the binding media. These results were particularly relevant in the study of biodeterioration, to allowing the electrochemical monitoring of biological attack. 


\section{Resumen}

El huevo (entero, yema o clara) es un producto natural utilizado desde la antigüedad como medio aglutinante en la pintura al temple, principalmente en Europa y los países de la cuenca mediterránea. Además, el huevo es un complejo sistema multicomponente microestructurado susceptible de ser alterado por los pigmentos que componen las pinturas, así como fuente de nutrientes susceptible de biodeterioro. El efecto de los pigmentos sobre el medio aglutinante, así como el biodeterioro microbiano son responsables de cambios en la estructura y composición del medio aglutinante y, por consiguiente, en las propiedades fisicoquímicas de la pintura.

Es por esto que, se utilizaron técnicas analíticas como la Espectroscopía Infrarroja por Transformada de Fourier en modo Reflexión Total Atenuada (FTIR-ATR), para la caracterización química de los procesos de deterioro resultantes de las interacciones pigmento-aglutinante en la pintura al temple. Así mismo, se utilizó Microscopía Electrónica de Emisión de Barrido (FESEM) para el estudio morfológico de las muestras, y para el estudio de las propiedades mecánicas Microscopía de Fuerza Atómica en modo Nanoindentación (AFM-nanoindentación).

Por otro lado, la presente investigación propone el uso de la Voltamperometría de Micropartículas (VMP), en conjunto con otras técnicas de análisis como FTIR-ATR, FESEM y AFM-nanoindentación para el estudio del biodeterioro producido por hongos y bacterias sobre una serie muestras pictóricas sometidas. El estudio de las alteraciones causadas por el biodeterioro es complicado por el hecho de que la acción de los microorganismos puede afectar tanto al pigmento como al medio aglutinante. Para esto, se prepararon una serie de muestras de pinturas al temple y emulsión que fueron inoculadas con los hongos Acremonium chrysogenum, Aspergillus niger, Mucor rouxii, Penicillium chrysogenum, y Trichoderma pseudokoningii, y las bacterias Arthrobacter oxydans, Bacillus amyloliquefaciens y Streptomyces cellulofans. El estudio voltamperometrico se realizó utilizando electrodos de grafito modificados con las muestras inmersos en un electrolito acuoso.

Las conclusiones obtenidas de manera general, apuntan a que las proteínas presentes en el huevo cambian su estructura secundaria al adherirse a los granos de pigmento. La información química, morfológica y mecánica obtenida por las diferentes técnicas de análisis instrumental es consistente. Finalmente, como resultado del cruce de los datos VMP con los resultados obtenidos mediante FTIR, FESEM y AFM-nanoindentación, las señales voltamperometricas obtenidas se asociaron a la reducción electroquímica de los pigmentos y a los complejos formados con el medio aglutinante. Estos resultados fueron particularmente relevantes en el estudio del biodeterioro de las películas pictóricas inoculadas, para permitir la monitorización electroquímica del ataque microbiológico. 
Resum

L'ou (sencer, rovell o clara) és un producte natural utilitzat des de l'antiguitat com a mitjà aglutinant en la pintura al tremp, principalment a Europa i els països de la conca mediterrània. A més, l'ou és un complex sistema multicomponent MICROESTRUCTURAT susceptible de ser alterat pels pigments que componen les pintures, així com a font de nutrients susceptible de biodeterioració. L'efecte dels pigments sobre el medi aglutinant, així com el BIODETERIORI microbià són responsables de canvis en l'estructura i composició del medi aglutinant $i$, per tant, en les propietats fisicoquímiques de la pintura.

És per això que, es van utilitzar tècniques analítiques com l'Espectroscòpia Infraroja per Transformada de Fourier en mode Reflexió Total Atenuada (FTIR-ATR), per a la caracterització química dels processos de deteriorament resultants de les interaccions pigment-aglutinant en la pintura al tremp. Així mateix, es va utilitzar Microscòpia Electrònica d'emissió de Rastreig (FESEM) per a l'estudi morfològic de les mostres, i per a l'estudi de les propietats mecàniques Microscòpia de Força Atòmica en mode Nanoindentació (AFMnanoindentació).

D'altra banda, la present investigació proposa l'ús de la Voltamperometría de Micropartícules (VMP), en conjunt amb altres tècniques d'anàlisi, com FTIR-ATR, FESEM i AFMnanoindentació per a l'estudi de l'biodeterioració produït per fongs i bacteris sobre una sèrie de mostres pictòriques sotmeses. L'estudi de les alteracions causades pel biodeteriori és complicat pel fet que l'acció dels microorganismes pot afectar tant el pigment com al medi aglutinant. Per això, es van preparar una sèrie de mostres de pintures al tremp i emulsió que van ser inoculades amb els fongs Acremonium chrysogenum, Aspergillus niger, Mucor rouxii, Penicillium chrysogenum, i Trichoderma pseudokoningii i els bacteris Arthrobacter oxydans, Bacillus amyloliquefaciens i Streptomyces cellulofans. L'estudi voltamperomètric es va realitzar utilitzant electrodes de grafit modificats amb les mostres immersos en un electròlit aquós.

Les conclusions obtingudes de manera general, apunten que les proteïnes presents en l'ou canvien la seva estructura secundària al adherir-se als grans de pigment. La informació química, morfològica i mecànica obtinguda per les diferents tècniques d'anàlisi instrumental és consistent. Finalment, com a resultat de l'encreuament de les dades VMP amb els resultats obtinguts mitjançant FTIR, FESEM i AFM-nanoindentació, els senyals voltamperomètrics obtinguts es van associar a la reducció electroquímica dels pigments i als complexos formats amb el medi aglutinant. Aquests resultats van ser particularment rellevants en l'estudi del biodeteriori de les pel·lícules pictòriques inoculades, per tal de permetre la monitorització electroquímica de l'atac microbiològic. 
For you ... 


\section{Acknowledgements}

I am especially grateful to my parents and my sister that endured the distance and the years and for understanding my life choices. To my grandmother for believing in me and always supporting me. To my partner for all the words of support in the most difficult moments.

To Dr. M. Teresa Doménech Carbó for giving me the opportunity to continue instructing me, for believing in me and becoming a member of your research team.

To Dr. Antonio Doménech Carbó for transmitting to me his passion for electrochemistry and support me at every moment in the elaboration of this thesis.

To Dr. Laura Osete Cortina for all her advice in the scientific study of heritage.

In Universität Greifswald, I would like to thank Prof. F. Scholz and Prof. Heike Kahlert, for their hospitality and trust for allowing me to wander freely in the laboratory.

This work has been performed by members of the microcluster Grupo de análisis científico de bienes culturales y patrimoniales y estudios de ciencia de la conservación (Ref. 1362) belonging to the Valencia International Campus of Excellence. Financial support is gratefully acknowledged from the Spanish "I+D+I MICINN" projects CTQ2014-53736-C3-1-P and CTQ2014-53736-C3-2-P supported by ERDF funds. The author wish to thank Dr. José Luis Moya López and Mr. Manuel Planes Insausti (Microscopy Service of the Universitat Politècnica de València) for the technical support. 
3. OBJECTIVES 


\section{Objectives}

This project is focused on the development of new analytical methods for the study of the deterioration and biodeterioration processes involved in tempera paintings.

More specifically:

- Characterization of the morphological and chemical changes at micro- and nano-scale induced by the pigment-binder interactions in tempera paint films.

- Characterization of the morphological and chemical changes at micro- and nano-scale induced by biodeterioration with different fungi and bacteria in tempera paint films.

- Study of the mechanical changes at micro- and nano-scale induced by the pigmentbinder interactions in tempera paint films.

- Study of the mechanical changes at micro- and nano-scale induced by biodeterioration with different fungi and bacteria in tempera paint films.

- Development of an electrochemical analytical protocol using solid-state methodologies and potential application for the characterization of the pigment-binder interaction and biodeterioration with different fungi and bacteria in tempera paint films.

From the results obtained, a correlation between the changes observed in chemical, morphological and mechanical properties of the paint films can be carried out. This enables the comparison of the behavior of tempera paint films when they are subjected to biodeterioration with different fungi and bacteria. 
4. WORK SCHEDULE 


\section{Work schedule}

The present investigation has been developed in three different phases for accomplished the objectives previously described as illustrated in the flowchart in Figure 4.1.

The first phase of the thesis project was focused on the bibliographic research aimed at: i) the clarification of the binding media included into the term tempera based on traditional painting techniques receipts; and ii) the identification of microorganisms commonly involved in the biodeterioration of pictorial films. Once the concept of tempera was clarified and the microorganism for the study of biodeterioration selected, reconstructed model paint specimens were prepared.

The second phase of the $\mathrm{PhD}$ thesis project was aimed at the study of the morphological, chemical and mechanical changes at micro- and nano-scale induced by the pigment-binder interactions in egg yolk tempera and egg yolk-oil emulsion reconstructed model paint specimens. To achieve this purpose, a multi-technical strategy that includes micro-invasive and micro-destructive analytical methodologies was carried out. The chemical characterization of the paint films was made by means of Fourier transform infrared spectroscopy (FTIR-ATR) and electrochemical techniques. Characterization of the morphological and mechanical properties of the paint films was made using field emission scanning electron microscopy (FESEM) and atomic force microscopy - nanoindentation (AFM-nanoindentation).

The third phase of the PhD thesis project was aimed at the study of the morphological, chemical and mechanical changes at micro- and nano-scale induced by biodeterioration on egg tempera and egg oil emulsion reconstructed model paint specimens. The first step in this phase was the biodeterioration of the paint films with the different fungi and bacteria chosen because they have been frequently found in biodeterioration studies of cultural heritage. The second step was the multi-technical strategy that includes micro-invasive and microdestructive analytical methodologies was carried out. The chemical characterization of the paint films was made using FTIR-ATR spectroscopy and electrochemical techniques. Characterization of the morphological and mechanical properties of the paint films was made using FESEM and AFM-nanoindentation. Finally, application of voltammetry of microparticles (VMP) for analyzing chemical changes upon fungi and bacteria biodeterioration. 


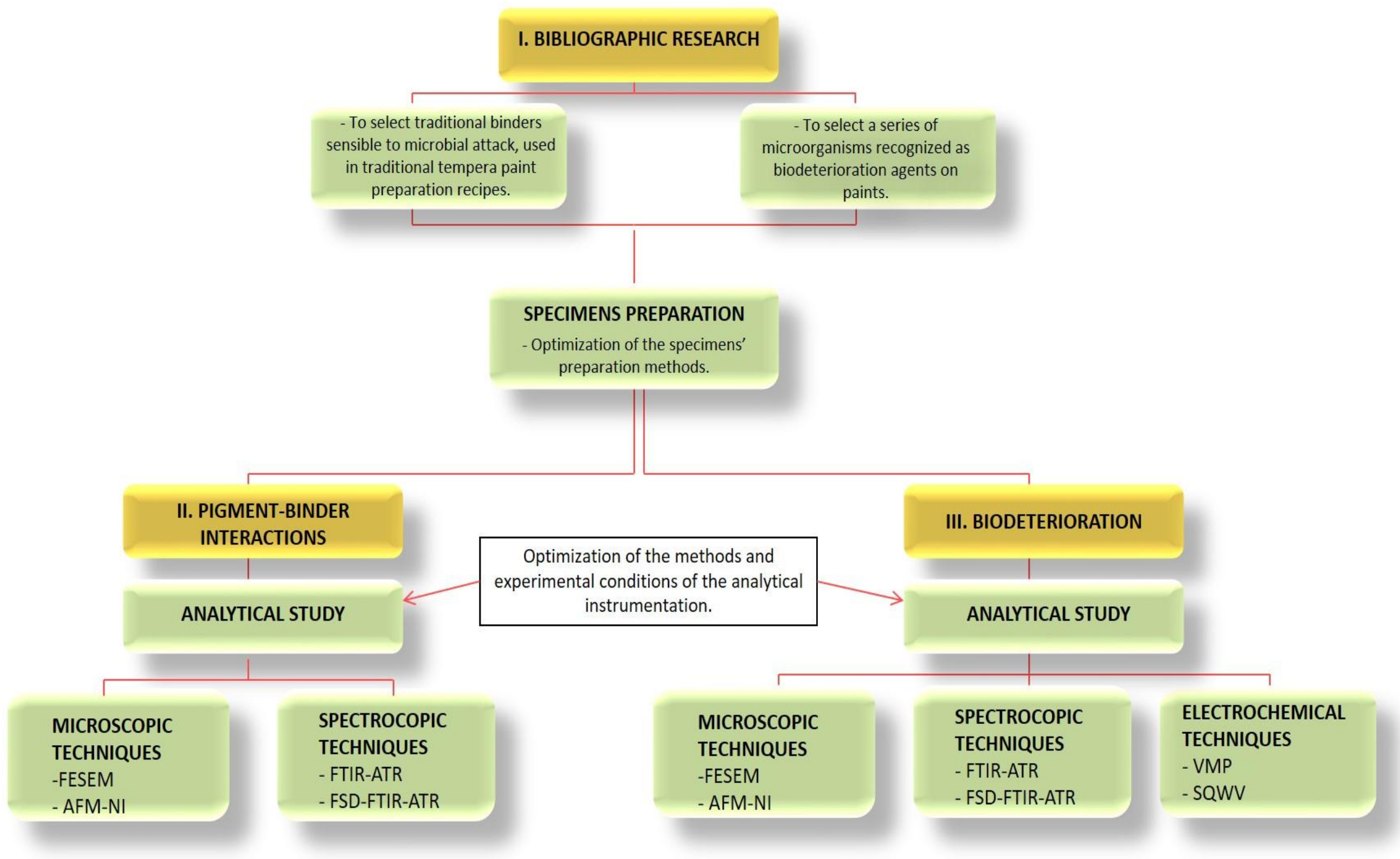

Figure 4.1. Work schedule flowchart. 
5. MOTIVATION 
Historically, all type of materials produced by the nature have been used for making cultural artefacts and for their conservation and restoration. Among the organic natural products more commonly used as paint binders of paintings since Antiquity can be include proteinaceous materials, such as egg, casein, animal glue and blood. Use of egg and blood as been reported as binding medium in prehistoric rock pictographs (Williamson, 2000; Mori et al., 2006; Rampazzi, Campo and Cariarti, 2007). By 2500BC the Egyptians improved the painting methodology by grinding pigments with natural products such as gums, and wax (Prise and Kaper, 2000; Lucas and Harris, 2012). The artist's curiosity and preferences resulted in an important shift in the evolution of the artistic technique that passed of the use of egg-based to oil-based paint media along the Middle Age and the Renaissance. During this transition, also a tempera grassa, an egg-oil emulsion, was developed and used by a few artists (Mayer, 1993).

Nowadays, we find cultural artefacts that have been created using a wide range of materials of both inorganic and organic type. The development of chemistry and the industrial production of polymers and many other synthesis substances has put us the reach of a wider range of film-forming materials. In particular, paintings and polychromies are made using waterborne paints that are prepared as complex multi-component system that consists of a suspoemulsion in which the pigment is dispersed in an emulsion of a synthetic polymer in water stabilized by surfactants and other additives.

Nevertheless, these new products still have not managed completely replace the traditional materials and methods of paintings. Thus, besides, waterborne paints, oil paints that use linseed-, poppy seed- and hempseed oil as binder and tempera paints that use egg or white yolk or whole egg as binder are found. These pictorial artworks are accompanied by an equally wide variation in the chemical and physical constituents' behaviors caused by physical, chemical and biological factors that interact with the constitutive materials inducing changes both in their composition and structural characteristics. Indeed, these alterations have been known since early ages. Thus, Greeks let constancy in their manuscripts of the artwork materials discoloration due to the incidence of light (Deribere and Paulette, 1979). In 1815 Sir Humphry Davy reported the results of his analyses and observations of pigments used on wall-painted plaster from an excavation in Pompeii (Davy, 1815). But is not till the 1888 with the first scientific investigation in conservation of artworks made by Russel and Abney that institutions and stakeholders be aware of the problem of the degradation of artworks (Russell and Abney, 1888). The development of this research caused that in 1900's many of the most important museums start to include laboratories among their facilities. Since then concerns in the deterioration of artistic paintings has grown.

Deterioration of paintings prepared with traditional artist's media includes oxidation processes involving free radicals and hydrolysis reactions catalyzed by pollutants agents presented in the environment (Sayre and Lechtman, 1968; Miyoshi, Ikeya and Kinoshita, 1982; Miyoshi, 1987; Kockenkämper, Bohlen and Moens, 2000; Spyros and Anglos, 2004; Peris et at., 2005). These processes cause chemical and mechanical changes in the paintings and many of these alteration processes suffered by the traditional artist's media still have not been studied in depth. Also, in the appropriate environmental conditions of relative humidity and temperature most of the traditional materials used in paintings are a suitable substrate for the growth and reproduction of fungi and bacteria ( $\mathrm{Gu}$ and $\mathrm{Gu}, 2005$; Giacobini and Firpi, 
1981; Giacobini et al., 1988; Ross, 1963). These microbial attacks type involves biochemical and enzymatic processes which are another frequent form of deterioration in paintings $(\mathrm{Gu}$ and Gu, 2005; Giacobini and Firpi, 1981; Giacobini et al., 1988; Ross, 1963; Sterflinger, 2010; Ciferri, 2002; Crispin and Gaylarde, 2005; Romero-Noguera et al., 2010a; 2010b).

In the past decades, have been developed a wide range of analytical techniques with high resolution and sensitivity, which have been applied to the identification of materials and their corrosion products wielded as result of physic-chemical and biological (microbiological) factors as well as to the identification of microorganisms that cause biodeterioration. Nevertheless, there are a limited number of studies aimed at systematically understanding the mechanisms of alteration and changes caused by the pigment-binder interactions that take place during: i) the process of formation of the paint film, ii) natural light ageing of the paint film and, iii) the microorganisms attack on the paint film. The difficulty for performing this kind of studies is due to certain critical issues related to the object and the analytical methods. Concerning the object:

- Degradation processes frequently affects the surface and the outer layers (nm - $\mu$ m range) of the object, so that, while only a small part of the artwork is affected, changes in appearance are drastic.

- Many of the most damaging alterations for the object or monument are caused by photochemical processes, mechanisms involving free radicals as reaction intermediates, which are hardly recognized by conventional instrumentation.

- In some cases, alterations in the object are due to changes in the oxidation state of species present in the materials, which are not easily identified.

A number of critical aspects related to the analytical methods can be also mentioned:

- Limitation of the sample amount which can be extracted for the analysis due to the unique and inimitable character of the art piece.

- Currently, most of the analytical techniques used in the field of heritage conservation have limitations in obtaining analytical and morphological information simultaneously at submicroscopic state.

In this context, is proposed the present Ph.D. project aimed at study the chemical and morphological changes that take place in paintings caused by deterioration agents of chemical origin such as light and microbiological origin such as colonizer microorganism. This research has been carried out in an attempt of having a broader perspective and improved understanding of degradation processes. For this purpose, a multi-technical approach that enables the study at micro and nano-scale of reconstructed paint films that mimic historical pictorial techniques have been performed that improve the critical aspects previously mentioned.

The Ph.D. project is framed within an electrochemical research project Nanoelectrochemistry: a new advanced analytical tool in heritage conservation (CTQ201128079-C03-01, 02 y 03) of the National Program R+D 2008-2011 of the Ministerio de 
Economía y Competitividad carried out by research teams of the Instituto de Restauración del Patrimonio of the Universitat Politècnica de València, the Departamento de Química Analítica of the Universitat de València and the Departamentos de Pintura and Microbiología of the Universidad de Granada.

\subsection{References}

Ciferri, O. (2002) The role of microorganisms in the degradation of cultural heritage. Reviews in Conservation, 3, 35-45.

Crispin C.A., Gaylarde, C.C. (2005) Cyanobacteria and Biodeterioration of cultural heritage: a review. Microbial ecology, Vol. 49 (1), 1-9.

Davy, H. (1815) Some experiments and observations on the colours used in painting by the ancient. Philosophical Transactions of the Royal Society London, 105, 97-124.

Available online at: http://rstl.royalsocietypublishing.org/

Deribere, Maurice and Paulette. (1979) Prehistoire et histoire de la luminère. Ed. FranceEmpire. París.

Giacobini. C., De Cicco M.A., Tiglie, I., Accardo, G. (1988) Actinomycetes and biodeterioration in the field of fine art. In: Houghton DR, Smith RN, Eggins HOW eds. Biodeterioration. New York, NY: Elsevier; 7: 418-423.

Giacobini, C., Firpi, M. (1981) Problemi di microbiologia nei dipinti su tela. In: Opificio delle Pietre Dure e Laboratorio di Restauro di Firenze. Atti del Convenzione sul Restauro delle Opere d'Arte. Florence, Italy: Edizioni Polistampa, 203-211.

Gu J.G., Gu, J.D. (2005) Methods currently used in testing microbiological degradation of a wide range of polymeric materials with various degree of degradability: a review. Journal of Polymers and the Environment, Vol. 13 (1), 65-74.

Kockenkämper, R., von Bohlen, A., Moens L. (2000) Analysis of pigments and Inks on oil paintings and Historical Manuscripts using Total Reflection X-ray Fluorescence Spectrometry. X-ray Spectrometry, 29, 119-129.

Lucas, A. and Harris, J.R. (2012) Ancient Egyptian materials and industries. Dover Publications, New York, pp. 327-366.

Mayer, R. (1993) TheArtist's Handbook of Materials and Techniques, $2^{\text {nd }}$ Edition, Hermann Blume, Madrid.

Miyoshi T. (1987) Fluorescence form varnishes for oil paintings under $\mathrm{N}_{2}$ Laser excitation. Japanese Journal of Applied Physics, 26 (5), 780-781.

Miyoshi, T., Ikeya, M., Kinoshita, S., Kushida T. (1982) Laser - induced fluorescence of oil colours and its applications to the identification of pigments in oil paintings. Japanese Journal of Applied Physics, 21 (7), 1032-1036.

Mori, F., Ponti, R., Messina, A., Flieger, M., Havlicek, V., Sinibaldi M. (2006) Chemical characterization and AMS radiocarbon dating of the binder of a prehistoric rock pictograph at Tadrart Acacus, southern west Libya. Journal of Cultural Heritage, 7, 344-349.

Peris, J., Gimeno Adelantado, J.V., Doménech Carbó, M.T., Mateo Castro, R., Bosch Reig F. (2005) Identification of lipid binders in old oil paintings by separation of 4-bromomethyl-7- 
methoxycoumarin derivatives of fatty acids by liquid chromatography with fluorescence detection. Journal of Chromatography A, 1076, 44-50.

Prisse, A. and Kaper, O.E. (2000) Atlas of Egyptian art. Cairo, Egypt: American University in Cairo Press.

Rampazzi, L., Campo, L., Cariarti F. (2007) Prehistoric wall paintings: the case of the Domus De Janas Necropolis (Sardinia, Italy). Archaeometry, 49 (3), 559-569.

a) Romero-Noguera J., Martín-Sánchez I., López-Miras M.M., Ramos-López J.M., BolívarGaliano F. (2010) Biodeterioration patterns found in dammar resin used as art material. Electronic Journal of Biotechnology, 13 (3). online

at:

http://www.ejbiotechnology.info/content/vol13/issue3/full/7/

b) Romero-Noguera J., López-Miras M.M., Martín-Sánchez I., Ramos-López J.M., BolívarGaliano F. (2010) An approach to the study of the fungal deterioration of a classical material: Mastic varnish, 13 (6). Available online at: http://dx.doi.org/10.2225/vol13-issue6-fulltext-11

Ross, R.T. (1963) Microbiology of paint films. Advances in Applied Microbiology, 5, 217234.

Russell, W.J., Abney, W. de W. (1888). Report to the Science and Art Department of the Committee of Council on Education on the Action of Light on Water Colours. Eyre \& Spottiswoode. Available at: http://www.forgottenbooks.com

Sayre E.V., Lechtman H.N. (1968). Neutron activation autoradiography of oil paintings. Studies in Conservation, 13, 161-185.

Spyros A., Anglos D. (2004) Study of Aging in oil paintings by 1D and 2D NMR spectroscopy. Analytical Chemistry, 76, 4929-4936.

Sterflinger, K. (2010) Fungi: Their role in deterioration of cultural heritage. Fungi and Biology Reviews 24, 47-55.

Williamson, B.S. (2000) Direct testing of rock painting pigments for traces of hemoglobin at Rose Cottage Cave, South Africa. Journal of Archaeological Science, 27, 755-762. 
6. INTRODUCTION 


\subsection{Painting as multilayered objects}

Since the appearance of the first forms of man artistic expression in all cultures, the painting is an ongoing river that continues fluxing into $21^{\text {st }}$ century. The search of coloring pictorial materials has been a common issue in all civilizations. Generally, the term painting is used to indicate a surface coated by colored layers. In most manuscripts and artist's treatises written since the antiquity until nowadays is described that, in general, paintings are made by a superposition of layers on a support formed by one or more ground layers (eventually can be found an imprimatur layer between the outer ground and the inner paint layer) followed by one or more colored paint layers, which are usually covered by a protective coating or varnish. Thereby, the ground, paint and protective layers will be structural elements present in most painted cultural artefacts (Figure 6.1.1).

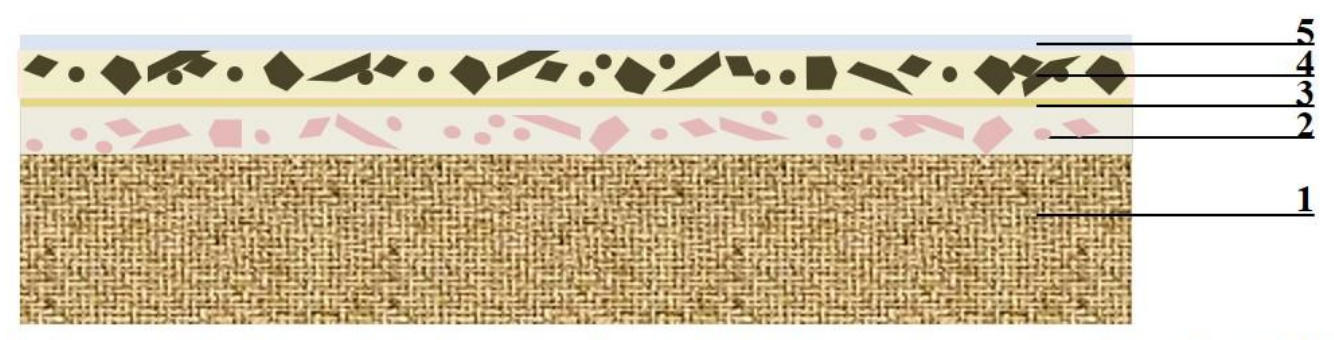

1. Support 2. Ground 3. Imprimatur 4. Paint layer (pigment and binder) 5. Protective layer

Figure 6.1.1. Schematic representation of the painting as multilayered object. 


\section{Support}

The composition of the support in cultural artefacts in its role of "rigid substrate" for paintings has been changing along the history and includes a wide range of inorganic and organic materials.

The inorganic supports usually are rigid and porous materials. Stony materials and adobe (mud bricks) are the supports most commonly used in wall painting. Metals and alloys have been less frequently used as painting support and their use has been, mainly, in the decoration of military accessories of high-ranking military figures.

The organic supports used in painting artworks are derived from living things. The oldest organic support used in paintings was the wood. Its use dates back to the Greeks and Egyptians times and it's remained until the $19^{\text {th }}$ century. Egyptian painting on wood was mainly manifested in the polychrome of the sarcophagi and other decorative and funerary elements (Figure 6.1.2). Polychrome of wooden sarcophagus appears in the Middle Kingdom (circa 2040-1640 BC., $11^{\text {th }}-14^{\text {th }}$ dynasty). In the case of large surfaces and sarcophagi several wood planks were joined using wood spikes and then covered with linen. Finally, a ground made of several layers of gesso (calcium sulphate dihydrate) and animal-skins glues were applied (Prisse and Kaper, 2000).
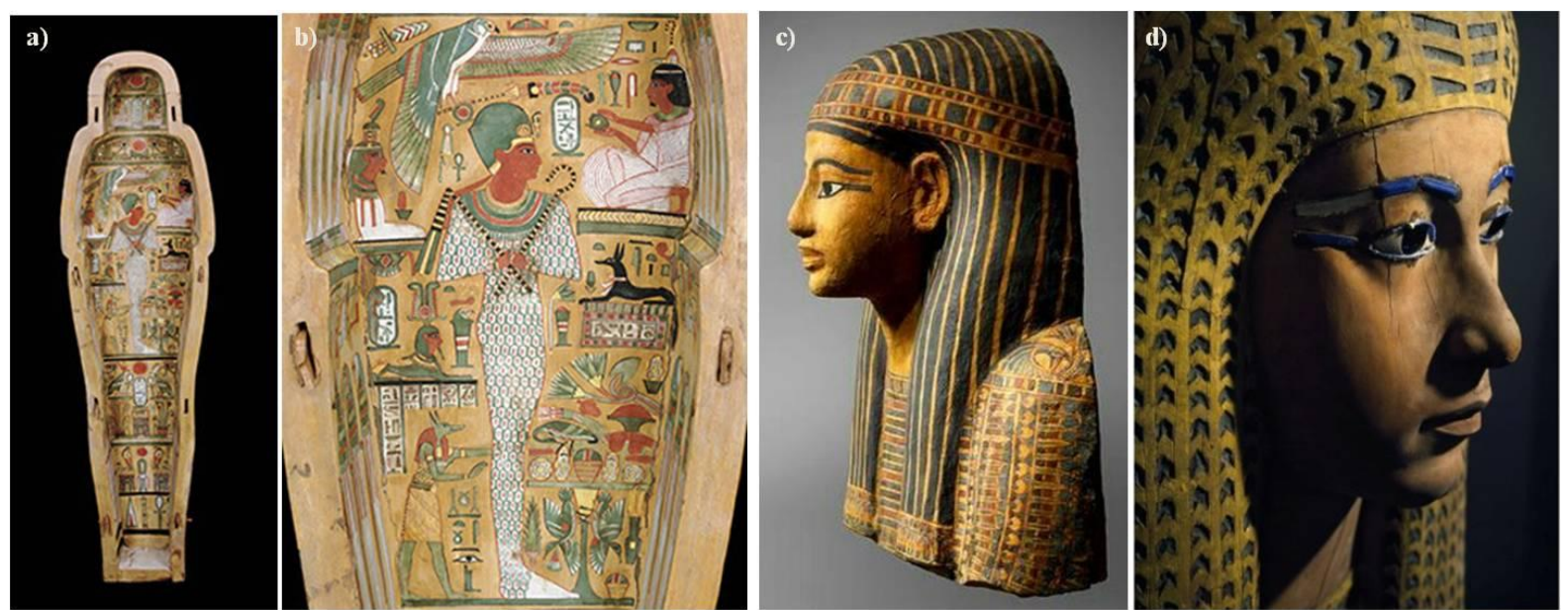

Figure 6.1.2. a) and b) Polychromed sarcophagus of Neskhons, Dynasty XXI, ca. 900-940 B.C. OThe Merrin Gallery; c) Sarcophagus of Merit-Amun, Ramses II's Daughter, polychromed wood; d) Ramesside Period Partial Sarcophagus New Kingdom, early $19^{\text {th }}$ Dynasty, reign of Ramses II, c. 1300-1230 B.C., wood with painted stucco OGetty images.

During the Roman Egypt, encaustic and tempera portraits painted on wood were used to decorate mummies (Figure 6.1.3). The majority of mummy portraits are encaustic on thin wooden supports inserted into the linen wrappings over the mummified head. This practice was a part of Greco-Roman funerary portraiture in Egypt from approximately A.D. 35-350 (Prisse and Kaper, 2000). 

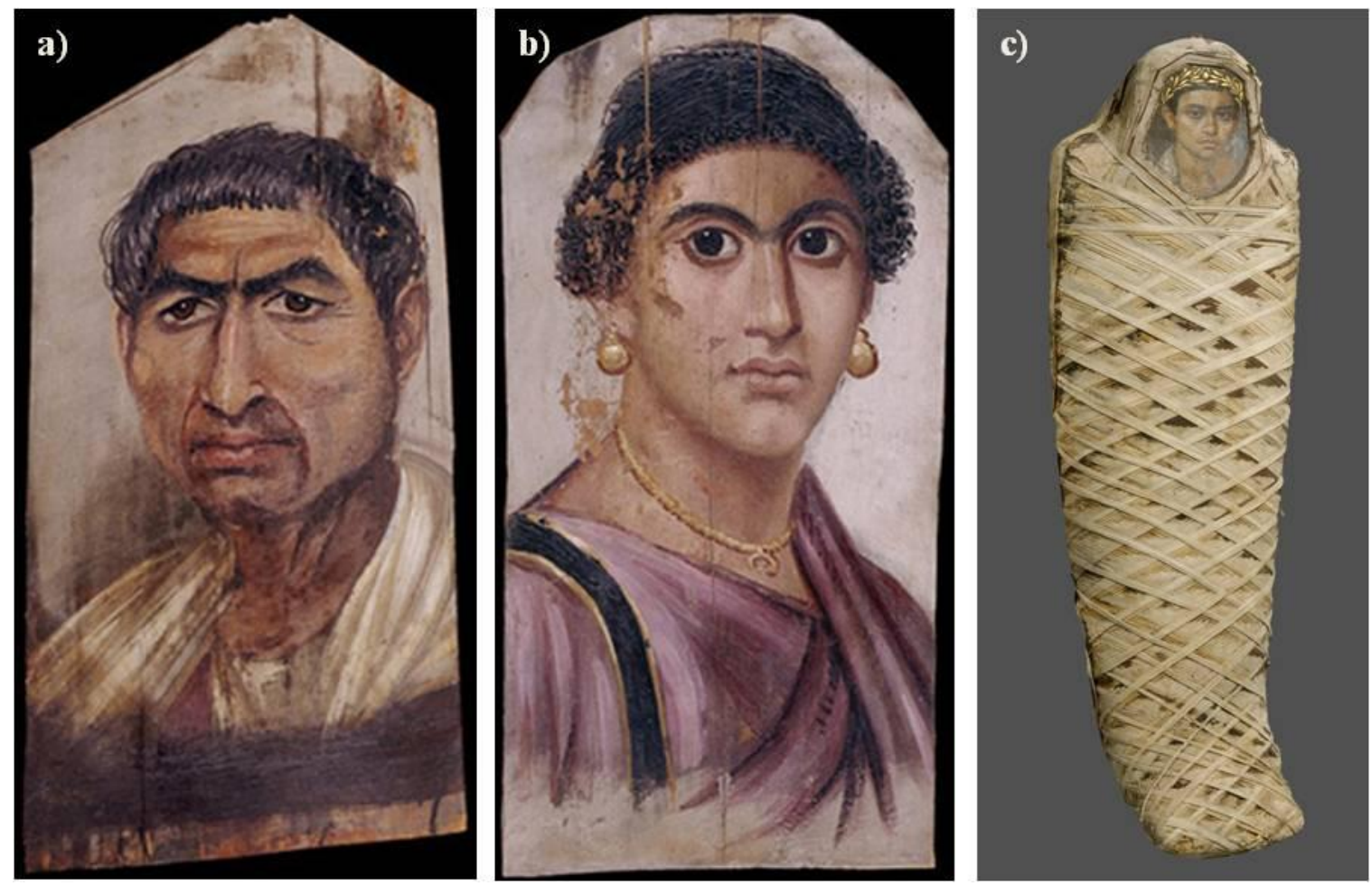

Figure 6.1.3. Fayum mummy portraits: a) a man, c. 100-120 C.E. (OTrustees of the British Museum; b) a woman, c. 55-70 C.E. (CTrustees of the British Museum; and c) inserted panel portrait of a youth Roman Period A.D. 80-100 @The Met.

In the sixth-century A.D. medieval painting was subjected under the ecclesiastical hierarchy with a Christian blurb purpose. A standard feature of icons from all periods is a wooden support, which remained with certain structural modifications, even after Western European artists adopted canvas support. Romanesque painting spanning the $11^{\text {th }}-12^{\text {th }}$ centuries and in some places in Europe $13^{\text {th }}$ century, has an evident continuity with the medieval painting and follows the economic, social and cultural influence of that time. From that period few panel painting survived due to the greater acceptance of wall painting and mosaics. It was important the decoration of coffered ceilings, altar frontals, baldachins and liturgical furniture elements which later give rise to the altarpiece (Figure 6.1.4) (Vivancos-Ramón, 2007).

From the $12^{\text {th }}$ century with Gothic, must be highlighted the importance of panel painting in Italy with a strong Byzantine influence. During this time an intense diffusion of panel painting across Europe occurs, being the altar paintings and altarpieces the most relevant evidence of the expansion and hegemony of it. For the particular cult, tables or small portable altars were made, while in the churches, altar paintings increase in size and complexity: the polyptych and the altarpiece. The polyptych is one of the favorite forms of Gothic painting and can consist of two (diptych), three (triptych) or more panels joined by hinges (Figure 6.1.5, right). The basic format consisted of a pedrella base, a main register, sometimes a secondary register, and a narrower angelic register that tapered to pinnacle points. This movement had its greatest expansion throughout Europe during the $14^{\text {th }}$ and $15^{\text {th }}$ centuries, due to the liturgical practice and an upsurge of religious fervour (Vivancos-Ramón, 2007; Cennini, 1988; Stoner and Rushfield, 2012; González-Alonso, 1997). 

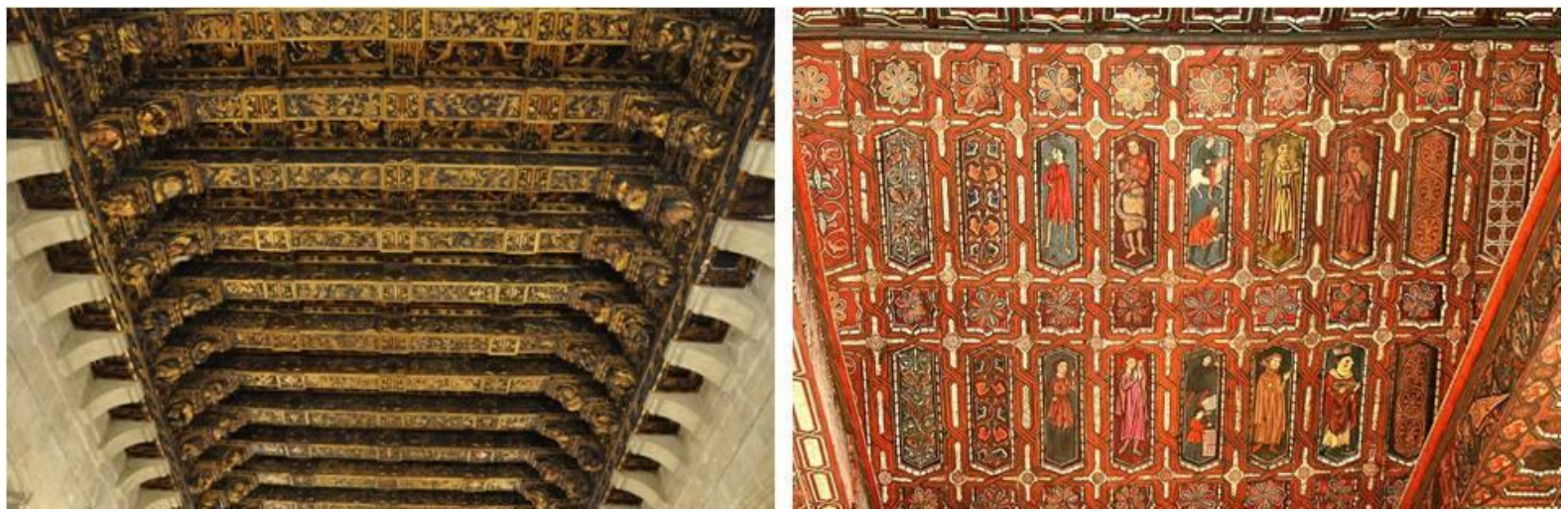

Figure 6.1.4. Coffered ceilings from Cámara de Dorado del Consulado del Mar la Lonja de Seda, Valencia 15th - 16th centuries (left) and Mudejar roof from Teruel Cathedral, 14th century (right).

Parallel, to these panel paintings, wood has served as support for many artistic expressions, such as sculpture, furniture, decorative accessories, ashlars, coffered ceilings, doors, musical instruments, etc. Also throughout the $11^{\text {th }}$ and $12^{\text {th }}$ centuries had also given a characteristic sculptural production, "The Seat of Wisdom" or "Throne of Wisdom", an icon of the mother of God seated on a throne with the Christ on her lap (Figure 6.1.5, left). These wood painted sculptures were commonly carved out of one piece of wood or made of joined panels of wood, once the carving was finished; in the latter, thin linen was normally affixed to the surface, followed by a gesso ground and paint layers (Forsyth, 1972).

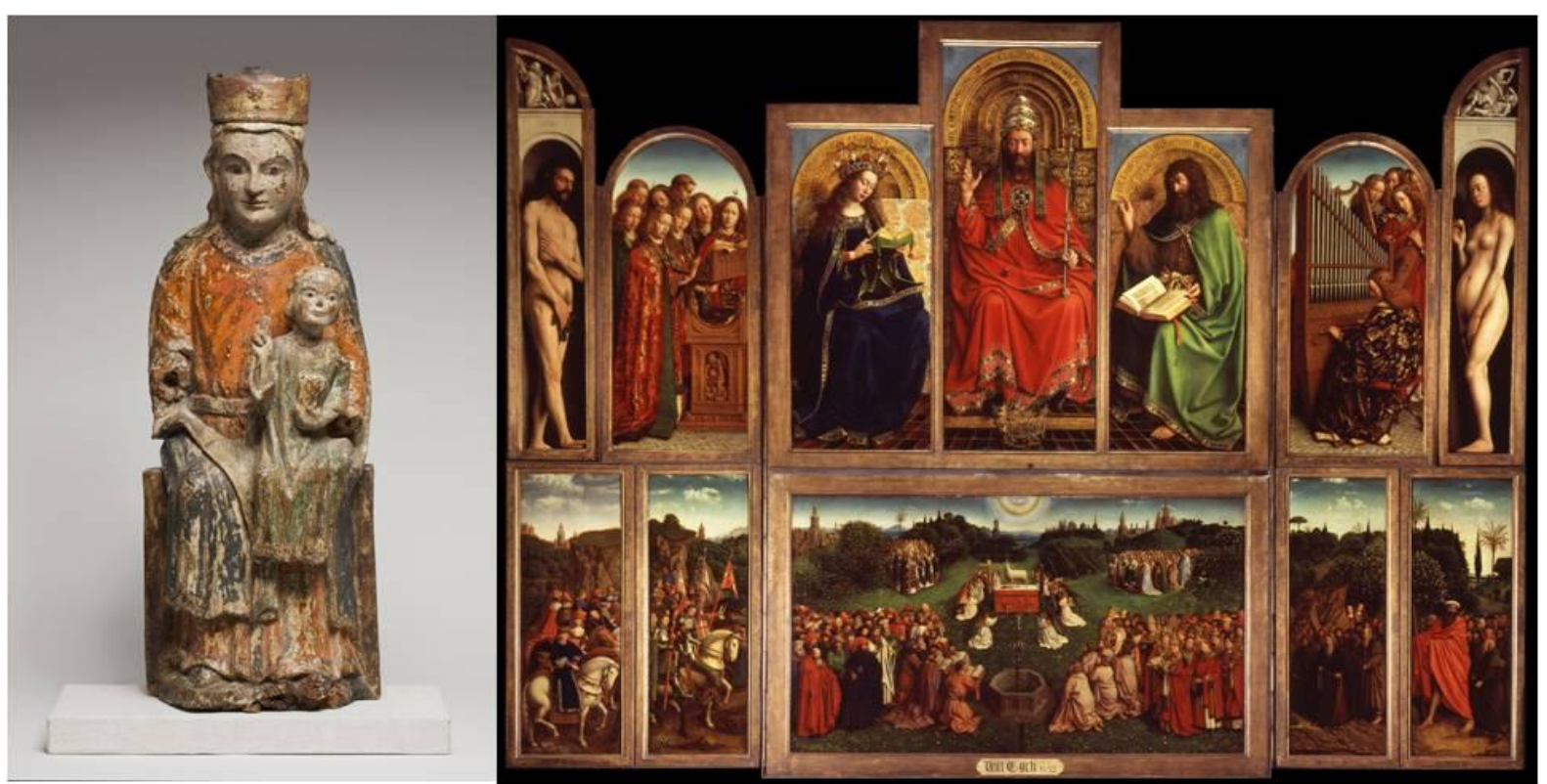

Figure 6.1.5. Medieval "Throne of Wisdom" polychromed wood sculpture, c. 1300 C.E. ${ }^{\circledR S S m a r t}$ Museum of Art, Chicago (left) and The Ghent polyptych altarpiece painted by Jan van Eyck, the Cathedral of Sain Bavon, Ghent, $15^{\text {th }}$ century (right).

It is noteworthy that wood has been used as pictorial support worldwide in all periods and regions from the ancient to the new world (from pre-Columbian to post-Columbian times). As in Europe the religion was the main source of inspiration for artists around the world, and as the European artists these others found in the wood a good support for their cultural artefacts. These cultural artefacts may include: households items, decorations, weapons for fighting, hunting and fishing, ceremonial objects (e.g. Western Africa and Native American masks, and Australian Dreaming boomerangs), temples, transports such as canoes and 
travois, etc. Ethnohistorical sources of Maya art mention the mastery of wood and stone carving, as well as, the use of stucco and painting of these objects (Figure 6.1.6a) (Miller, 2010). As in Europe, most of the Maya art was made by order of the kings to be immortalized and guarantee their place in history. Whereas, Native American art objects has a more spiritual essence. For example, masks were an essential part of important winter ceremonies. These masks made from cedar crust were representation of beavers, bears or crows painted with red, black and white pigments from the region (Figure 6.1.6c) (Leung, 2006). As well as the Native American, the African tribes used the wood for their spiritual art. Wooden sculptures carved with stone or ivory and painted with locally naturally derived pigments (e.g. ocher and indigo). Ceremonial masks made with wood and decorated with ivory, animal hair, plant fibers, and pigments, were also a common art of Western Africa (Figure 6.1.6b) (Clarke, 2006). Other interesting artistic expression is the Aboriginal Australian were a hunting tool, the boomerang (woomera), was often used in religious and cultural ceremonies. This would be heavily decorated with various carving and colours, and were made by the Ancestors in the Dreaming (ceremonial stories) (Figure 6.1.6e) (Jones, 2004).
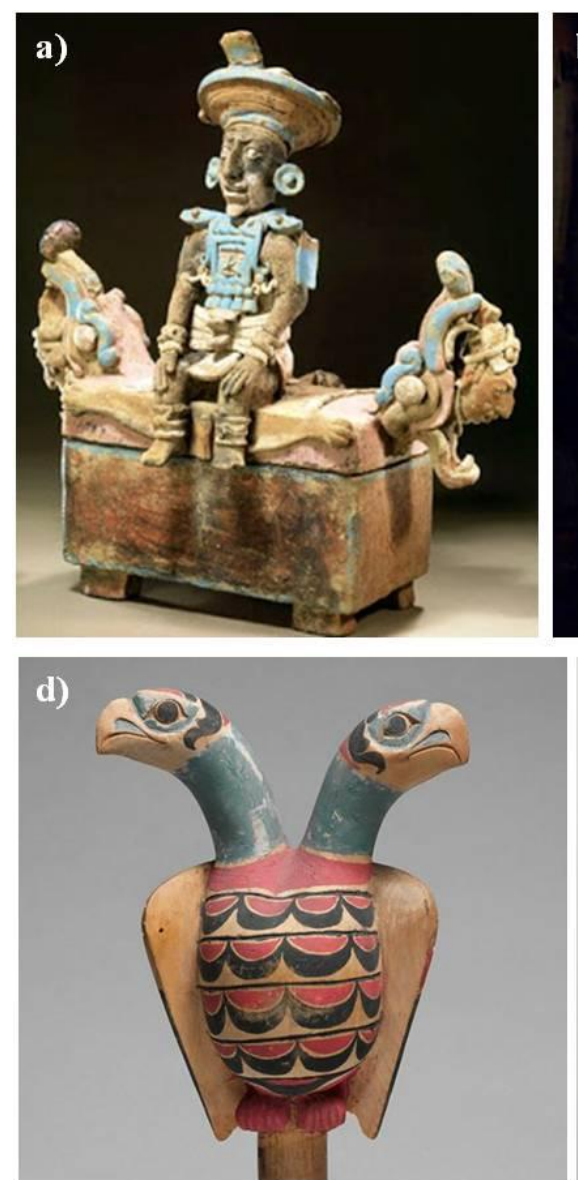
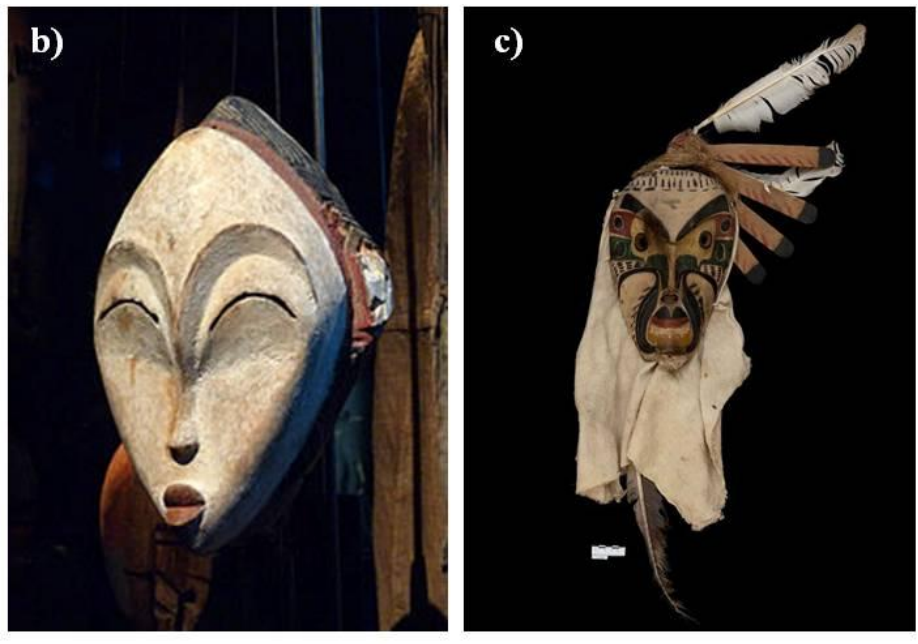

e)

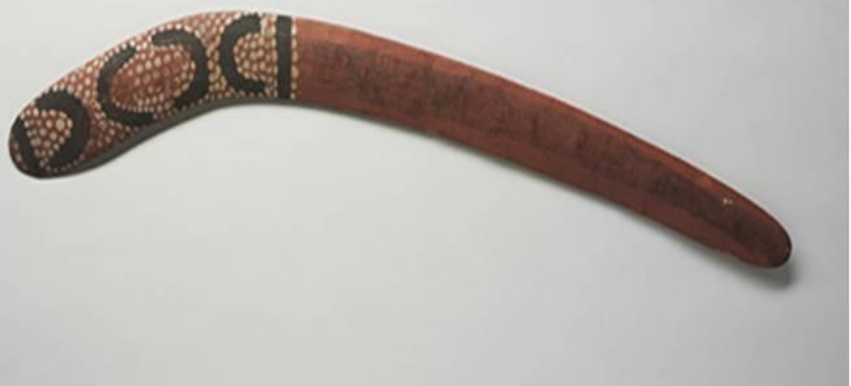

Figure 6.1.6. a) Kan Balam Mayan sculpture (OPalenque Archaeological Museum; b) Wood painted mask, Gabon CMusée du quai Branly; Kwakwaka'wakw 1938; c) Northwest Coast (CMuseum of Natural and Cultural History University of Oregon; d) a double-headed eagle wood painted sculpture, Northewest coast, $19^{\text {th }}$ century, Sitka, Alaska, US Native American (CThe Met Museum; and e) Old Man's Dreaming aboriginal boomerang 1975, by Mick Wallankarri Tjakamarra @National Museum of Australian. 
Aboriginal and indigenous art were a reflection of their lifestyle and culture, regrettably most of these cultural artefacts date no earlier than the late $19^{\text {th }}$ century because of the systematic destruction carried out by the settlers, obeying the religious ideas of the time and its sensitivity to the environment.

It is also important to mention the Asian art, whose wooden sculptures and temples don't let anyone indifferent. As in other cultures and/or continents most of the Asian sculpture is associated with religion (Figure 6.1.7) and culture. Particularly, the Japanese artistic techniques of the wooden sculptures and buildings, include a ground coating, pigments (in a medium), and application of a Japanese lacquer (Yamasaki and Nishikana, 1970; Dorge and

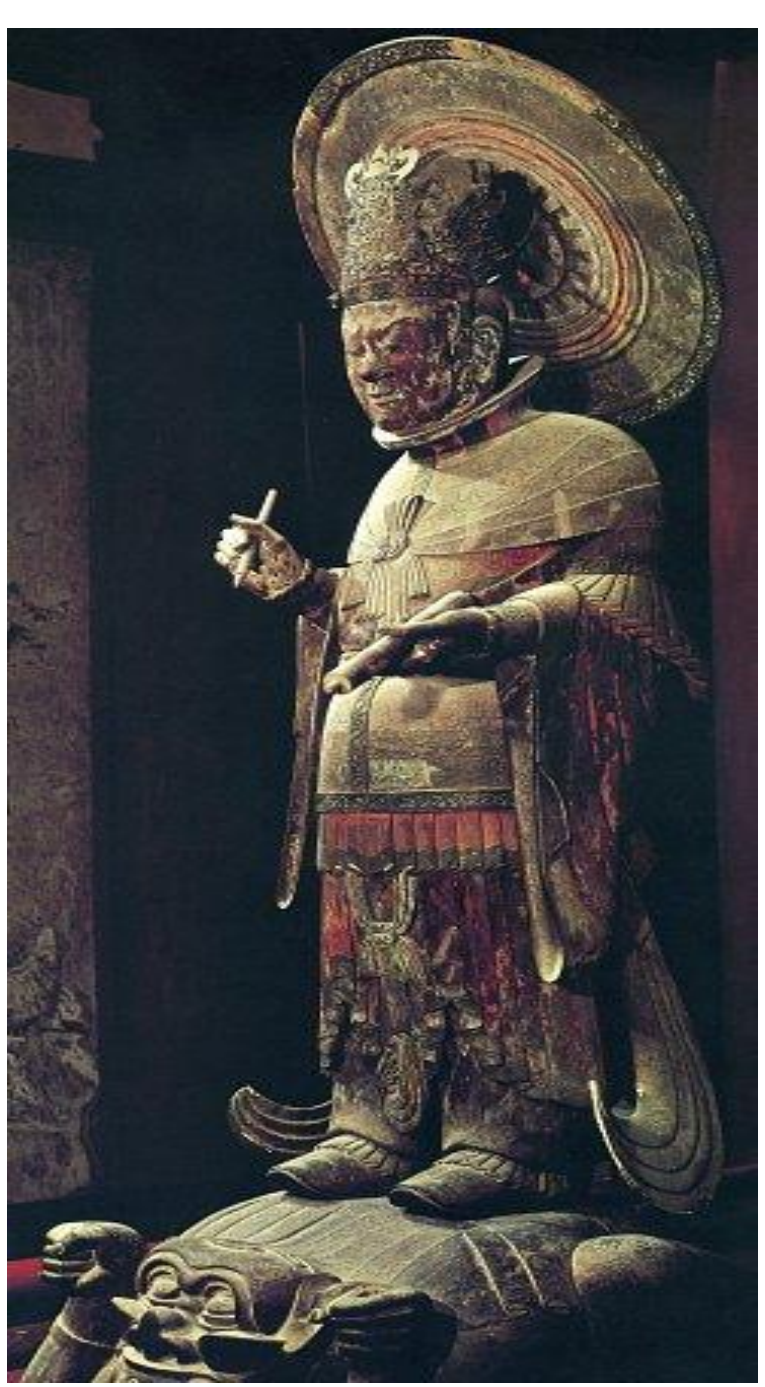
Howlett, 1998; Ward, 2008).

During the Renaissance the wood support began to be replaced by textile supports giving rise to canvas paintings. But it's not till the early $16^{\text {th }}$ century in Florence and Venice when the use of textile starts to take a strong role revealed as a much more accessible material in many aspects. It is cheaper compared to wood, large sizes can be obtained (to date possible only in wall painting), easily transportable, and versatile for religious objects including banners, hangings, altarpieces, and palls (Bomford et al., 1990). Nevertheless, in the late $19^{\text {th }}$ century and early $20^{\text {th }}$ century panel painting flourished in Europe, this artistic movement is known as Gothic Revival (Neo-Gothic), even after artists adopted canvas support for their paintings.

Figure 6.1.7. Kōmokuten (one of the four guardians of Buddha's realm), wood-core dry lacquer and painted, mid- $7^{\text {th }}$ century, Hōryūji Temple in Nara, carved by Yamaguchi Busshi OComprehensive Dictionary of Japan's Nat'1 Treasures. 


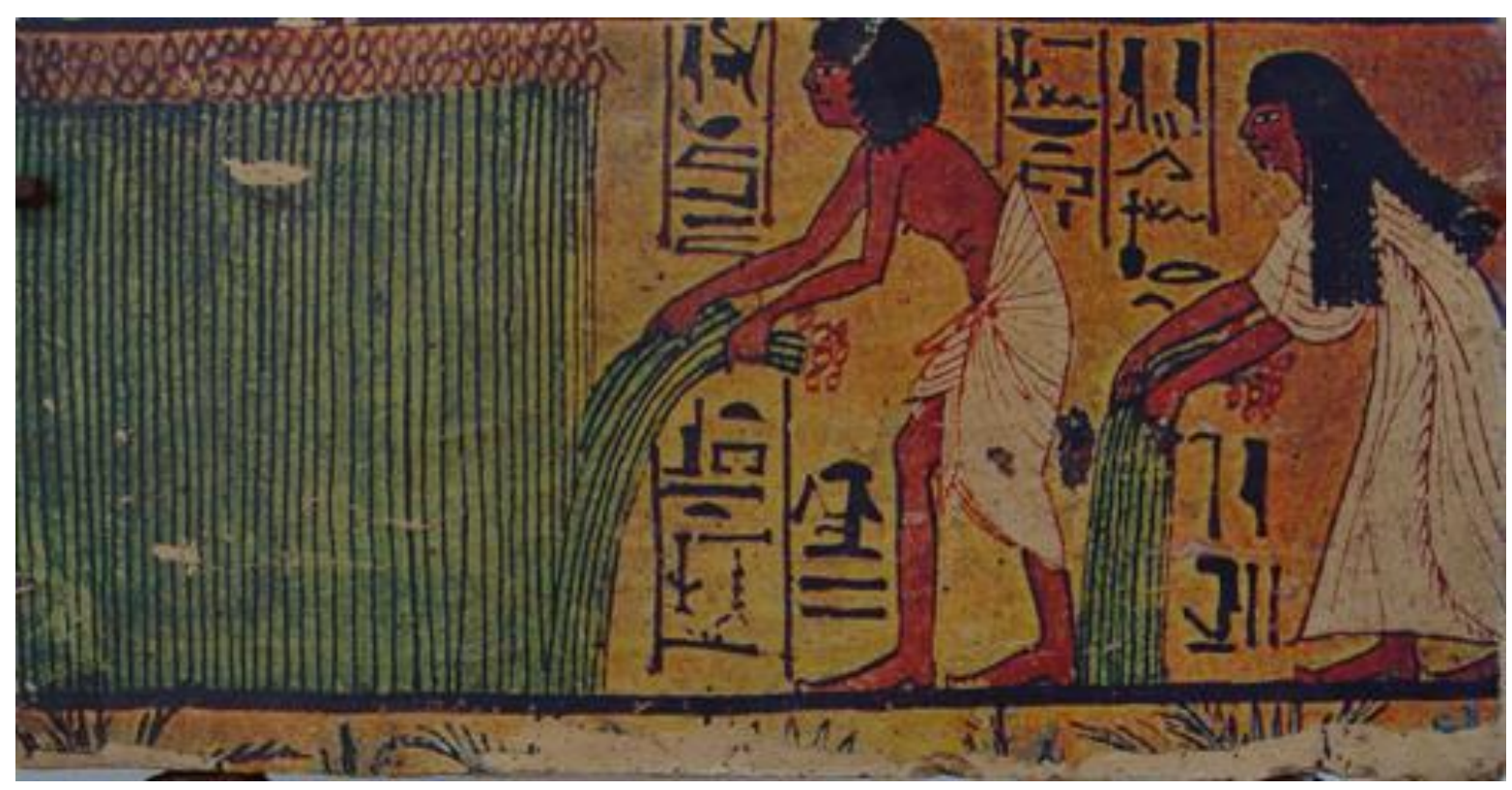

Figure 6.1.8. Representation of the linen harvest from a tomb at Kom-el Ahmar, Egypt.

Anciently, the textile supports used were of natural fibers (linen, hemp and cotton); nowadays textile supports are also made with synthetic fibers. Linen is the most common ancient plant fiber and is thought to have originated in West Asia. Evidence of woven fabric artefacts made from linen dates back to the Neolithic period (before 5000 BC) in Egypt (Hall, 2001) (Figure 6.1.8). While cotton first documented reference appears in $700 \mathrm{BC}$, but is not until the Islamic conquest in the $17^{\text {th }}$ century it became a more important fabric. In the early $19^{\text {th }}$ century with the "wedged frames" or "wood stretchers" valued by painters as high of mark supports finest textiles of hemp in large sizes were made. Silk and jute were other fabric types less commonly used as painting support. Silk fabric had its origin in China, extant painted silks from the Song dynasty (AD 960-1279) have been found (Harris, 2006). While jute fabric was known only from the $18^{\text {th }}$ century and it was cultivated in the Mediterranean basin. 


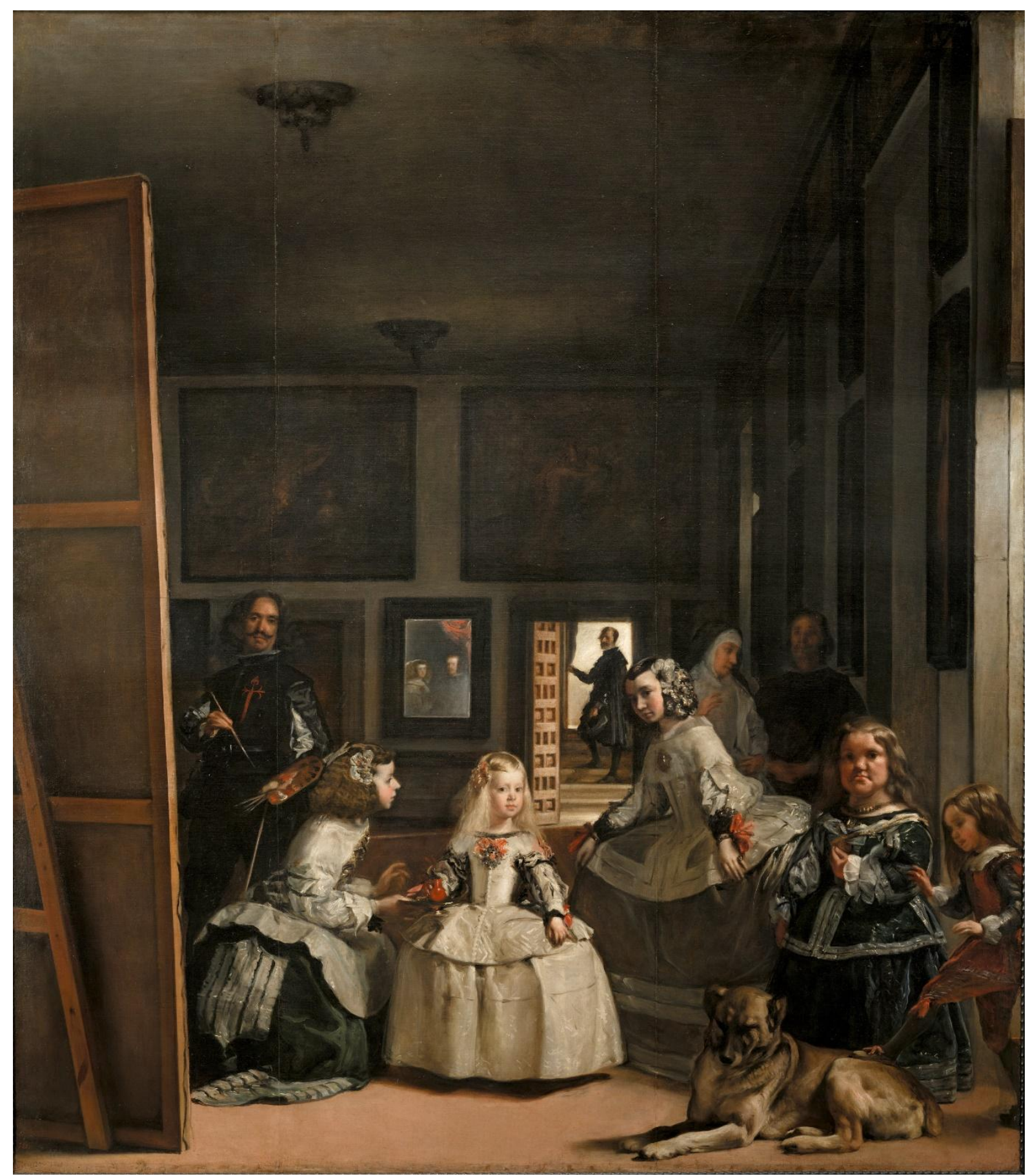

Figure 6.1.9. Las Meninas de Velázquez, oil on canvas, large size painting @Museo del Prado.

The demand for liturgical objects in the Middle Ages constitute a strong justification for the emergence of fabric as a painting support. There is documentary evidence that indicates that linen was used during the mid $17^{\text {th }}$ century during the shift from portraits on panels to a mixture of canvas and panel (Hayward, 2010). The main painting support fabrics during the $18^{\text {th }}$ and $19^{\text {th }}$ centuries were hemp and linen. By the $19^{\text {th }}$ century, linen became the main canvas fabric. Due to the reduction in the manufacture of hemp in the $20^{\text {th }}$ century, linen and cotton were both used (Figure 6.1.10). Although major changes in the choice of the support began with the large-scale works (Figure 6.1.9) of the Abstract Expressionists, also after the 
Depression and the Second World War, linen was a scarce and expensive commodity being cotton the main support fabric used for canvas painting.

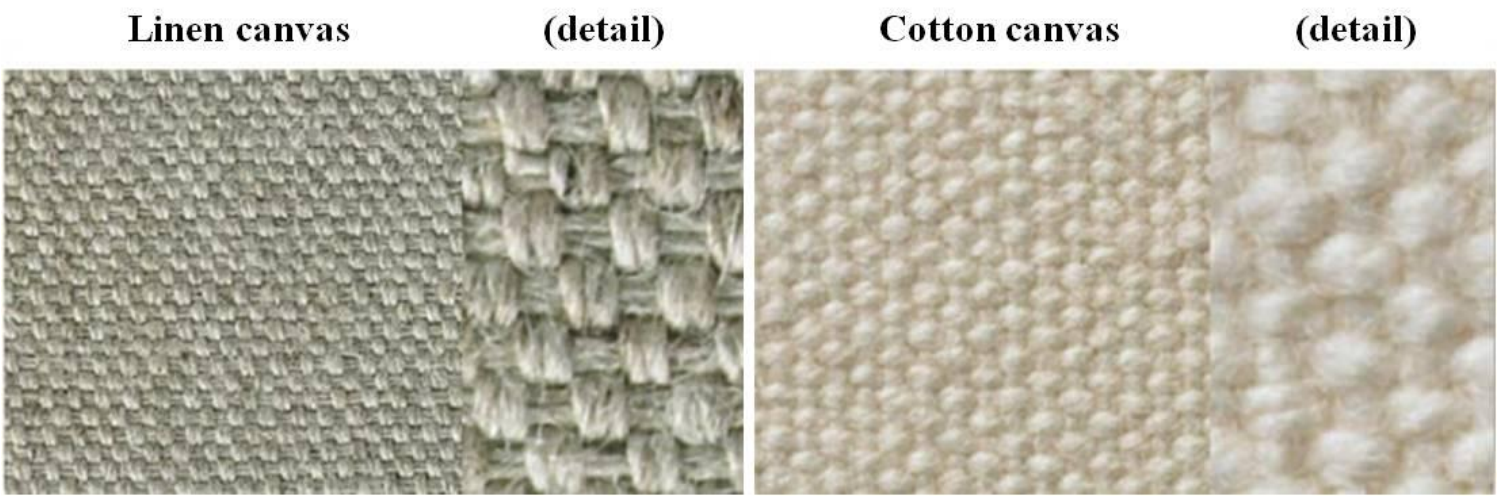

Figure 6.1.10. Image of linen and cotton canvas texture.

Nowadays, attempt in order to improve the properties of natural materials as cotton and linen has been made and to introduce synthetic alternatives considering the desired chemical, physical and aesthetical properties. In the early 21 th century, polyester provides a starting point to improve the performance of artists' canvas even though it has yet no math linen or cotton kinaesthetically or aesthetically.

Another organic support widely used has been the paper, developed by Ts'ai Lun, in the $105 \mathrm{BC}$ and was the surrogate of papyrus and parchment used in the ancient Egypt (Prisse and Kaper, 2000). The precursor of our paper is papyrus, which was used as support to write and to paint; the oldest preserved papyrus date back from 2000 B.C. The paper developed by Ts'ai Lun in China was introduced to European painters by the $12^{\text {th }}$ century through the Dutch ports (Carter and Carrington, 1955). In the $9^{\text {th }}$ century the Arabs learned in Baghdad papermaking processes and spread it very quickly throughout the Mediterranean. The oldest recorded paper mill in the Iberian Peninsula dates back 1151 in Xàtiva, Spain. From the $14^{\text {th }}$ century paper became a support material known in the artist's workshop, at least in Italy (Fuller, 2002).

With the introduction of paper as support in the artist's workshop apart from the Western and Byzantine traditions a more illustrative tradition take place in Europe (Figure 6.1.11). From origins in manuscript book decoration also developed into single-sheet small paintings, which are also called miniatures, as the Western equivalents in watercolor. Miniatures are colored drawings similar in style and treatment to the pictorial art of the Roman classical period. In the $16^{\text {th }}$ century, with the appearance of the printed book, the miniaturist's occupation was brought to a close. 

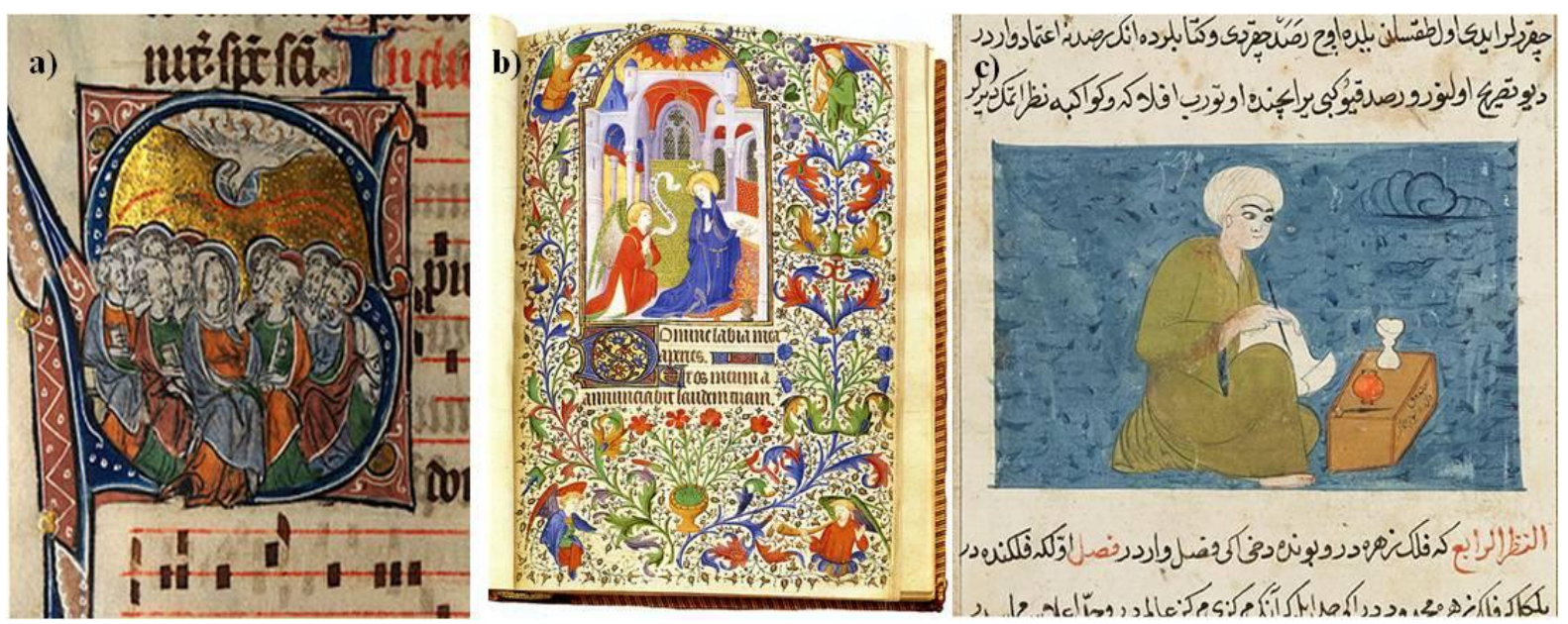

Figure 6.1.11. Illustrated manuscripts: a) The Pentecost, from an illuminated Catholic liturgical manuscript, c. 1310-1320; b) Annunciation: Medieval books c. 1410; and c) Book of Wonder and Oddities, Istambul, 1553 (C) Getty Images.

With time other artistic expression based on paper as wallpaper were taking place (Figure 6.1.12). Hand-painting, woodblock printing and stenciling were the main historical techniques used. The earliest known wallpaper is thought to date from 1509 and was found covering the beams of the Dining Hall at Christ's College, Cambridge (Hoskins, 2005). Wallpaper gained popularity in Renaissance Europe mimicking the large tapestries hanging on the walls of the social elite homes. These early papers were usually handmade small sheets were pasted together along an edge to make up a length, and then printed by wood block or stencil, using distemper or oil based colours. Until industrialization in the $19^{\text {th }}$ century this was the common wallpaper production (Nylander, 1992).

Has been demonstrated that artists exploring rigid supports for painting has evolved and

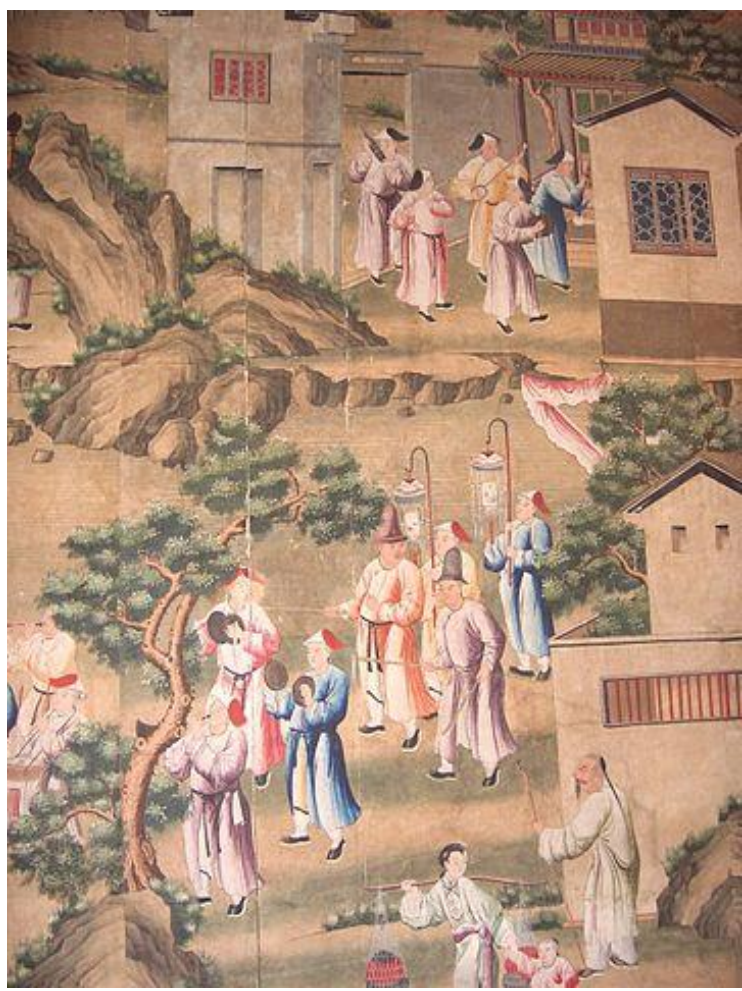
includes a wide range of materials, as much as, artistic techniques. Apart from the organic support mentioned above other rigid supports have been used for example slate and other stone as the portrait of Baccio Valori painted by Sebastiano del Piombo, the Stemma Martelli attributed to Donatello painted on sandstone. Also painting on metal plates such as copper, zinc, iron and more recently aluminum plays an important role in the miniature engraving during the $16^{\text {th }}$ and $17^{\text {th }}$ century.

Figure 6.1.12. Hand-painted Chinese wallpaper showing a funeral procession, made for the European market, c. 1780 CDr. Meierhofer. 
Metal plates were easily handled and transported and constituted a perfect support for engraving and etching and these properties attracted the miniaturists. Even thought engraving has been practiced from the earliest ages documentation exists of a prehistoric Aztec hatchet of jade given to Alexander von Humboldt in Mexico that could be clearly a modern engraved copper plate, less sophisticated than the European, but with the same art technique (Humboldt and Bonpland, 1814).

Copper was the most used metal due to its smoothy surface and the "warm" base obtained. The earliest known painting on copper seems go back to the third quarter of the $16^{\text {th }}$ century

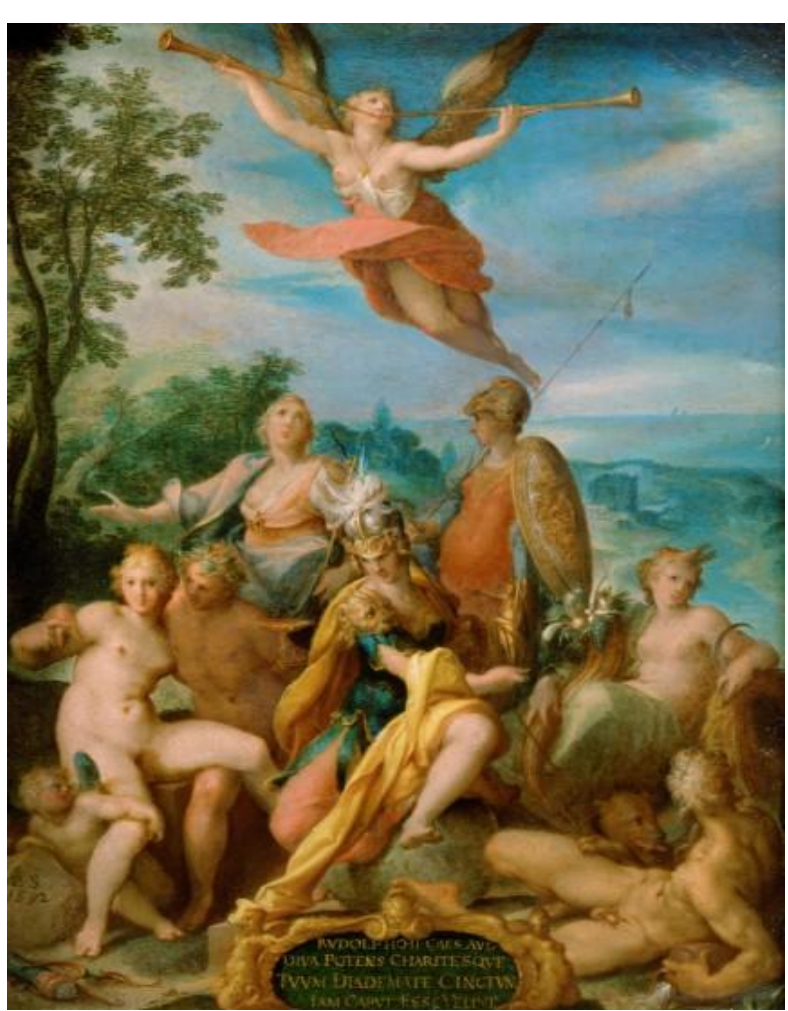
in Italy, but it spread to other important artistic centre's such as Prague, Antwerp, and throughout Europe (Komanecky, 1999). During the $17^{\text {th }}$ century many of the Northern and Italian artists painted on copper at some stage in their careers (Figure 6.1.13).

Figure 6.1.13. Bartholomäus Spranger, Allegory on the Reign Emperor Rudolf II, 1592 oil on copper OKunsthistorisches Museum, Vienna.

Nowadays, new technologies offer the artists a constantly evolving world of artistic techniques. In the $20^{\text {th }}$ century, with the development of the electrographic techniques, a new artistic current based on the practice of technological art forms starts (Figure 6.1.14). The most prominent exponents of this technique were Pol Bury and David Hockney. At the beginning of this current the electrography term was associated to images produced by the interaction of light and electricity. But up-to-date the electrography includes images originated by the digital video and new media procedures, classified in two groups: the xerography and the digital graphic or infographic. Considering this definitions the electrographic art works can include the traditional and electrostatic engraving and digitals as the xerography and infographic (Campal, 2001; Marchán-Fiz, 1994) 

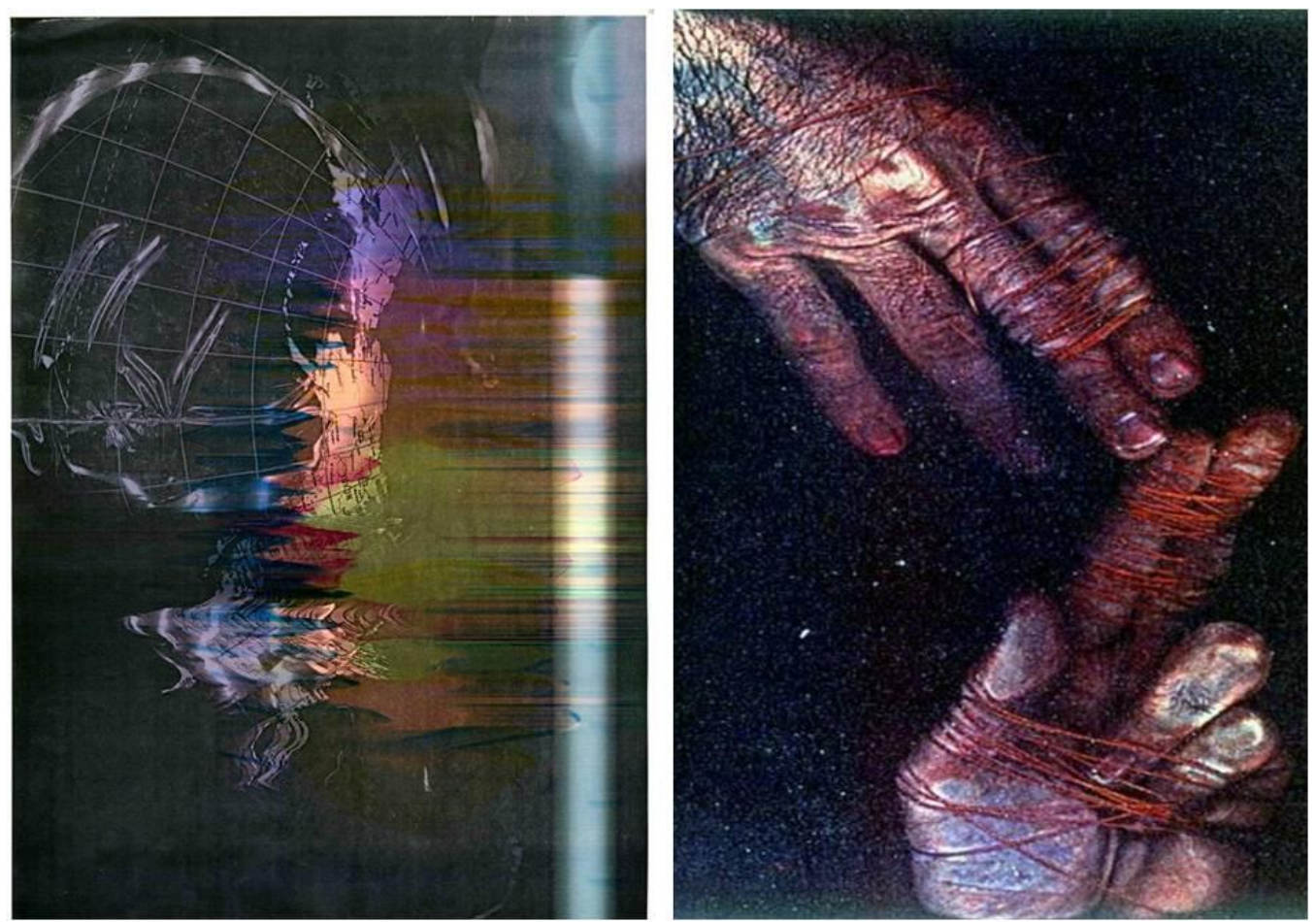

Figure 6.1.14. Electrographic images of Philippe Boissonnet: Aurora Borelais (Artic) 1993 (left); and MainChinalement Dependant, 1984 (right).

As seen above artists exploring rigid supports from soft to hard and from metal in all its variations, the individual properties of these materials help the artists on its own evolution and creation. Independent of the techniques used, artist always found the proper material to enhance their artistic goals. In the case of antique and traditional techniques these supports were usually covered with a ground layer in an appropriate proportion for the particular support and then over this ground layer or sometimes directly to the surface of the material the paint layers were applied.

\section{Ground}

The principal functions of this ground layer are:

- Flatten the irregularities of the support for the artist's intended purposes.

- Ensure a homogenous absorption across support's surface.

- Stabilizes the support, by reducing the effect of environmental factors, chiefly changes in temperature and relative humidity, acting as a sealant.

- Provide the desired optical, chromatic or luminosity results to the painting.

As shown for the support, the artistic technique for preparing grounds has evolved in a way in the different cultures and throughout the historical periods. Formerly, during the decoration of sarcophagi the Egyptian artisans covered the entire surface of the sarcophagus with a layer of stucco or gesso (calcium sulphate dihydrate) and then painted over. The use of dark colored (dark kaki or gray) backgrounds in mummy portraits to mock the color of wood providing a depth effect to the portrait is documented (Mazurek et al., 2014, Castwright and Middleton, 2008). The application of this white or colored gesso layer is still used in our 
days. This preparation layer is known as ground and the permanence of the finished artwork depends of both that and the support.

The ground layer is a bridge between the support and the paint layer. Its application is necessary in cases where the support surface has an excessive porosity or is not uniform enough to allow the direct application of the paint layer. Generally, it consists of an inert filler or a pigment, or a mixture of both, bound with organic materials that give the appropriate elasticity and impermeability (Figure 6.1.15). The ground may consist of one or several layers of similar composition applied on.

Each ground is suitable for a particular support (wood or fabric), and its composition will be depending of the pictorial technique used (oil or tempera). In the case of rigid supports (wood panels) preparations of any kind can be used, while for flexible supports (fabric) the best

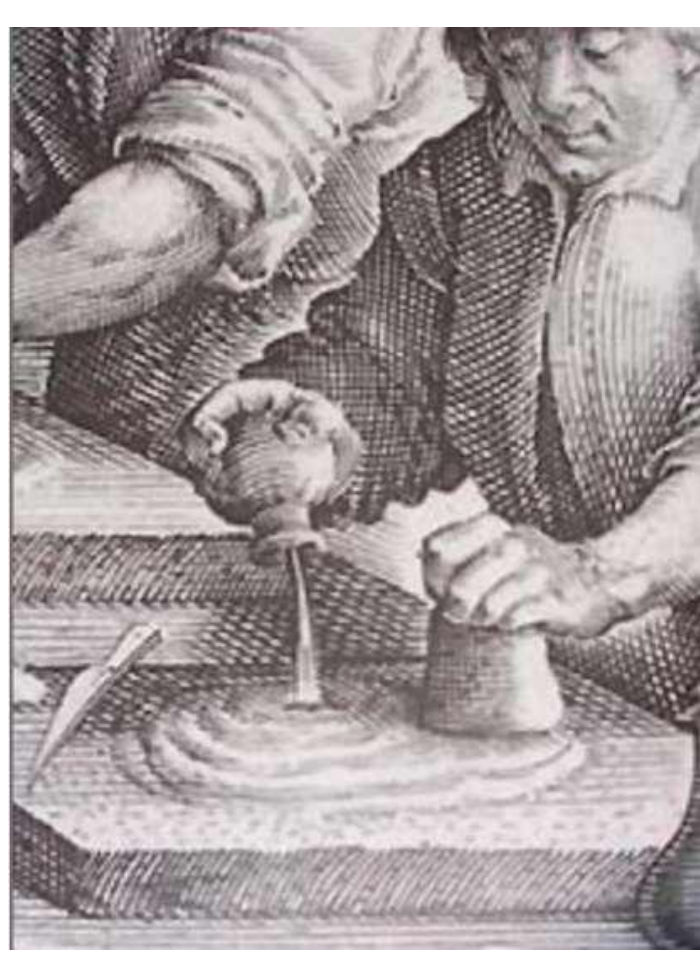
results are obtained using flexible grounds.

As mentioned above grounds could consist of filler, filler and pigment or pigments alone. The most commonly used fillers are lime carbonates and calcium sulphates.

- Calcium carbonate $\left(\mathrm{CaCO}_{3}\right)$, lime carbonate, white of Spain or chalk is more opaque and consistent than calcium sulfate and is more insoluble in water. It was the most used filler by the northern Europe artists and the Flemish school, as well as, in ancient Asian civilizations for making polychromed objects.

- Calcium sulphate, gesso or gypsum (calcium sulphate dihydrate, $\mathrm{CaSO}_{4} \cdot 2 \mathrm{H}_{2} \mathrm{O}$ ) is more sensitive to water and this kind of ground is commonly found in the southern Europe, the Mediterranean area: the Italian and Spanish schools.

White grounds were the most commonly used grounds until the $16^{\text {th }}$ century, when coloured grounds spread through Europe with the change in painting technique and the increase emphasis on chiaroscuro. Red ochre, grey and (-reddish) brown single oil-grounds became the most common types. For example, El Greco initiated the transition to coloured grounds in Spain with the use of reddish-brown grounds. Despite this white or pale-tinted grounds reappear in the $19^{\text {th }}$ century with the Neoclassicism. At the end of the $19^{\text {th }}$ white, cream, 
beige, or light grey grounds played an aesthetic role in many Impressionist paintings. Van Gogh used grounds consisted of thin layers of lead white, of barium sulphate mixed with lead white and chalk, or of pure barium sulphate or pure chalk. In the $20^{\text {th }}$ centuries traditional grounds were replaced by white pigments such as: zinc and titanium white (Stoner and Rushfield, 2012) due to the health and safety regulations and to the modern manufacturing techniques. During this period the another significant development in the grounds became with the introduction of an acrylic dispersion ground under the Liquitex brand. In the case of the new generation artists and new technologies most of the materials have industrial grounds to fulfill the properties offered by the manufacturer.

Grounds could be classified in two groups following its composition:

1. Lean or aqueous-based calcium carbonate and gypsum grounds. These are the grounds typically used in panel painting, polycromed sculptures and ceilings and gildings. In these grounds the filler can be bound with glue according to the European tradition and with animal blood alone or mixed with flour according to the Asian tradition (Lee, 2015; DoménechCarbó et al, 2012). Sometimes, especially in Spain the ground consisted of a flour thin paste (Villarquide, 2004). According to Cennini (1988), the gypsum ground used in the Middle Ages in altarpieces and panel paintings consisted of several layers. A first rough and thick layer of poorly refined gypsum, gesso grosso, applied with a wooden stick over tables or bigger panel surfaces (e.g. altarpieces). Followed by multiple thin and regular layers of a refined gypsum, gesso sottile, applied with brushes and diluted on animal glue.

2. Fat or oil-based grounds, use a drying oil (linseed oil, walnut oil and poppyseed oil) as binder. In this case, white or coloured pigments (ochre, red, gray) are used. In the case of toned grounds the most used pigments are natural earths. Another pigment widely used was the lead white, for its siccative properties.

\section{Imprimatur}

Imprimatur or priming is often confused with ground. The term imprimatur refers to an overall coloured layer applied over a ground layer, whether this layer was oil-, protein-, or emulsion- bound is not clear (Traft and Mayer, 2000; Stoner and Rushfield, 2012). Despite this, many studies have reported the use of oils as binding media in the imprimatur layer (Berrie, 1994; Noble et al., 2005; Hannaford, 2013). This layer between the ground and the paint layer prevent from absorbing too much paint binding medium, acting as an isolation layer (Cennini, 1988). Many artists' treatises mentioned the use of an un-pigmented or pigmented isolation layer (imprimatur) previously to the paint layer to obtain some characteristic chromatic or optical features. A white imprimatur, offer more color intensity and confers more clarity to the painting, while a coloured imprimatur absorbs light radiation, losing color intensity (Figure 6.1.16). During the $15^{\text {th }}$ century the use of an imprimatur layer was occasionally, and only in non-gilded areas, then it became an indispensable feature in the painting build-up because they prevented uneven absorption of the oil binder into the ground (Doerner, 2005; Ward, 2008). 


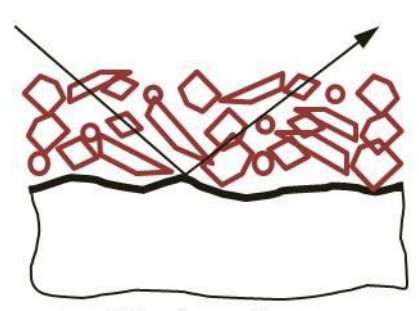

white imprimatur

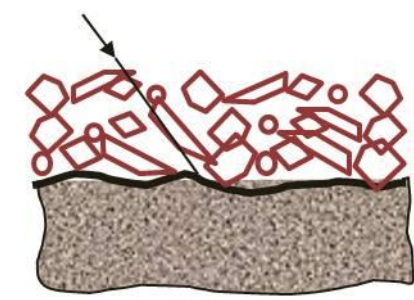

coloured imprimatur

Figure 6.1.16. Scheme of the chromatic effect produces by a white and a colored imprimatur.

From the mid- $15^{\text {th }}$ century and coinciding with the transition of tempera to oil the first lead white and oil isolation layer appear in a Flemish painting. The development of new pictorial concepts makes the importance of the isolation layer increased, and it became more diverse in material composition and colour. At the end of the $15^{\text {th }}$ century the use of imprimaturs was a regular feature of the Italian panel and canvas painting. Artists start to use blacks, grey, pink, red, ochre or yellow earth pigments instead of the pure white; for example, Rubens (Figure 6.1.17) was a lover of the red, grey and green imprimaturs (Plesters, 1983). In some cases the imprimatur was applied very diluted with the intention of toned down the whiteness of the ground, in other cases the color was distinctive (most popular on panel painting).

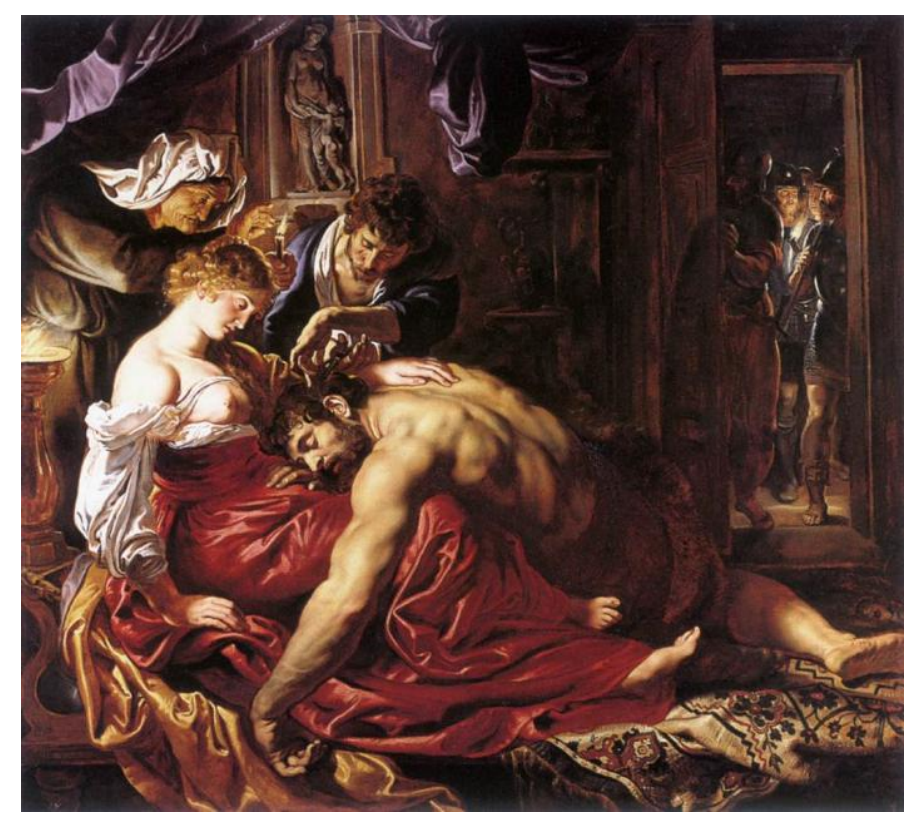

Figure 6.1.17. Samson and Delilah's oil on wood, by Peter Paul Rubens, 1609-1610 @National Gallery London.

\section{Paint layer}

The paint layer is the stratum responsible for the color of the object, which is applied over the grounds or, eventually on the imprimatur. The paint consists of particles finely ground and dispersed in a liquid medium or vehicle, which has the property of drying forming a thin, continuous and adherent film, when applied to a surface. This paint layer may be applied in a single or several layers constituting the facing of the artwork.

Pigments are the principal component of this layer, however, is necessary the use of a binder to create a colored film with the adequate mechanical properties. The binder, usually, consists of organic materials even though in some artistic techniques such as fresco this role is played by inorganic materials. In all the cases the binder would depend on the support, the final 
nature of the painting and the painting technique. For the choice of the pigments shall be deemed the stability achieved with the binder. Table 6.1.1, shows the easel painting techniques, whose designation is made according to the binder used (Gettens and Stout, 1966; Mayer, 1993; Gómez, 1998).

Table 6.1.1. Traditional easel painting techniques with their corresponding binders.

\begin{tabular}{|l|l|}
\hline \multicolumn{1}{|c|}{ Painting technique } & \multicolumn{1}{c|}{ Binder components } \\
\hline \multirow{5}{*}{ Oil } & Drying oil (linseed oil, safflower oil \\
& walnut oil, poppyseed oil, tung oil) \\
\hline \multirow{3}{*}{ Tempera } & Egg yolk \\
& Egg yolk + white egg \\
& Fish or animal skins-based glue \\
& Plant gum \\
& Plant gum + an aqueous or non-aqueous substance \\
\hline Encaustic & Saponified wax + natron \\
\hline
\end{tabular}

Use of egg and wax has been reported as binding medium in prehistoric wall paintings (Rampazzi et al., 2007; Reeves et al, 2012). The encaustic technique consists of wax, alone or mixed with natron (Lalli et al., 2016), has been used since ancient times (e.g. mummy portraits, byzantine icons, etc.).

In artists' treatises (Palomino, 1988; Brunello, 1992), has been reported that gum arabic and egg white were commonly used binders. Eventually, while fish glue, cherry gum, blackthorn gum and almond tree gum were less employed.

\section{Tempera}

Egg: Use of egg and wax has been reported as binding medium in prehistoric wall paintings (Rampazzi et al., 2007, Campo and Cariarti, 2007, Reeves et al, 2012). The use of egg proteins as binding media in art date back to ancient Egypt (is not yet definitive proof that early Egyptians worked in egg tempera). Even when most of the mummy portraits were executed in encaustic, several examples exhibit the linear brushwork of egg tempera and, when analyzed, show the fatty acid patterns typical of an egg binder (Mazurek et al., 2014; Ramer, 1979; Sack et al., 1981; Scott el at., 2009). Roman's were also familiarized with the use of egg yolk or egg and oil emulsion (tempera grassa) as mentioned Vitruvius and Pliny in their artist's treatises. Egg tempera was well studies by the artists and became the primary medium of Byzantine and Early Christian icon painters. The egg yolk together with whole egg were used as tempera painting on panel paintings until the XV - XVI century. The use of egg yolk tempera was also commonly used in illuminated manuscripts, miniature codes, paper and parchment (along with paints made from egg white, gum arabic, and animal glue). During the late Middle Ages bright, intense colours and transparency were paint properties associated with the quality of materials and were highly valued by artist of this period. The addition of oil to the egg medium would change the refractive index of the paint and thus produce a more saturated tone. Throughout the Middle Ages egg proteins were wide used, but in the early 1400s and with the Renaissance the egg tempera become the principal form of easel painting in Italy, as well as in other parts of Europe. The materials and the working methods of egg tempera at this time are described by Cennino Cennini in his treatise Il Libro dell' Arte. Even when the commercial renaissance makes the use of egg tempera painting 
technique "obsolete", many notable artists experimented with egg tempera and continues to grow. On the other hand, in the Renaissance began to be found mixed or intermediate binders type, formed by emulsions or tempera and later appeared the oil or lipophilic binders. Some artists preferred pure egg tempera for light colours and tempera grassa (egg-oil emulsion) for darker colours such as reds, browns, greens and blues (Campbell et al., 1997). In the 16 ${ }^{\text {th }}$ century, drying oils were the indispensable must have in the artists workshops, between them linseed, walnut, and poppy oils, even though the most commonly used of the drying oils was the linseed oil (Figure 6.1.18). Despite this, during $19^{\text {th }}$ century the egg tempera painting reborn from the hand of some artists like, Samuel Palmer, Gustave Moreau and Gustav Kilmt. In the last 50 years the synthetic polymers have evolved the contemporary painting and joined to those binders used in traditional techniques.

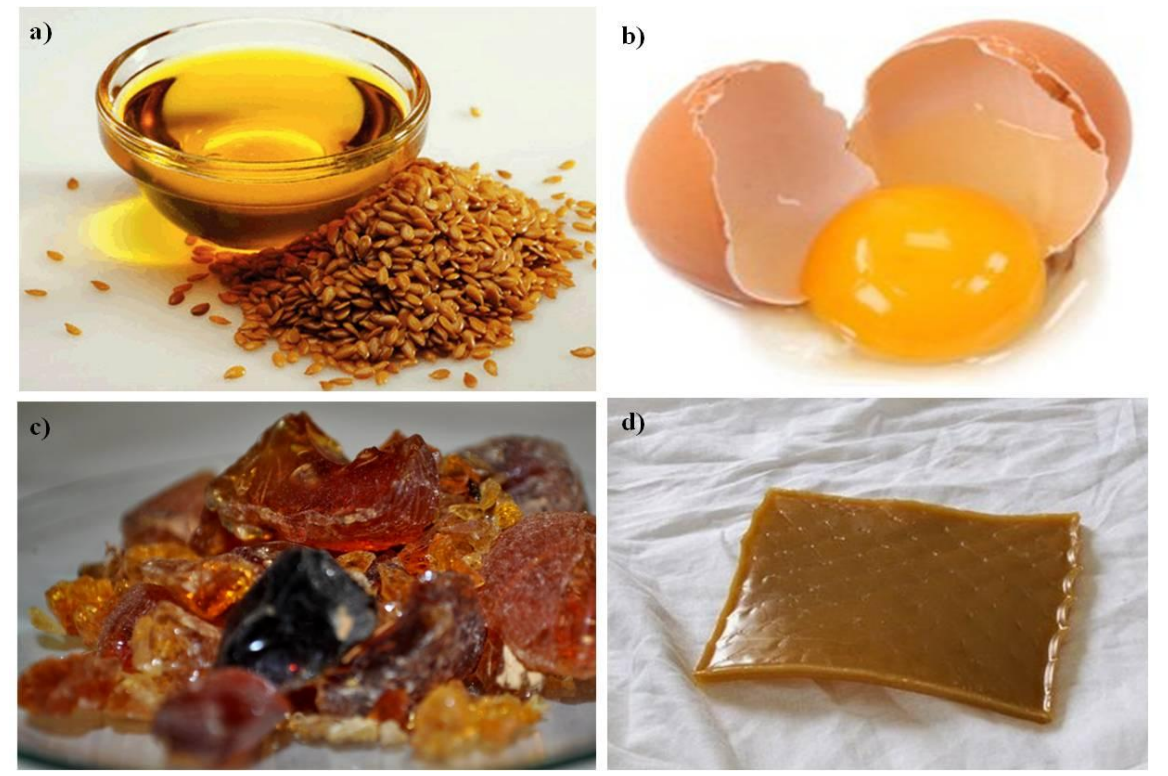

Figure 6.1.18. Most commonly used binders in traditional painting techniques: a) linseed oil, b) hen egg, c) Arabig gum, and d) rabbit skin glue.

Casein and milk: The most commonly used caseinates are the ammonium caseinate obtained by the reaction of casein with ammonia and the calcium caseinate obtained from the reaction between casein and the slaked lime $\left(\mathrm{Ca}(\mathrm{OH})_{2}\right)$. Ammonium caseinate has been used as binding medium retouching in wall painting, easel painting and water-based tradional paining techniques. From the $19^{\text {th }}$ century, it has been used for the grounds in canvas painting and for the lining of canvas paintings. In spite of this, casein has been used relatively little as a binder in the history, if compared with other proteinaceous binding media, due to its fast deterioration that affect the mechanical properties of the painting. It should be mentioned that casein was the preferred glue for the boards joining by the Spanish schools during the $13^{\text {th }}$ $16^{\text {th }}$ centuries, as well as in Italy and France. Milk as also been used as binding medium for painting with better results than casein. Milk is a very stable binder and has an appearance very similar to the obtained with egg tempera, which also resembles in its composition.

Animal glues: as binding media were first introduced in Ancient Egypt some four thousand year ago, which is the earliest known confirmation of use of glues that were made by prolonged boiling of animal hides, hooves and connective tissue. The most popular uses of glue in that time was reinforcing the durability of papyrus scrolls, and creating furniture for 
nobility. Several examples of such furniture were preserved in tombs of Pharaons, including casket of Tutankhamun (Figure 6.1.19).

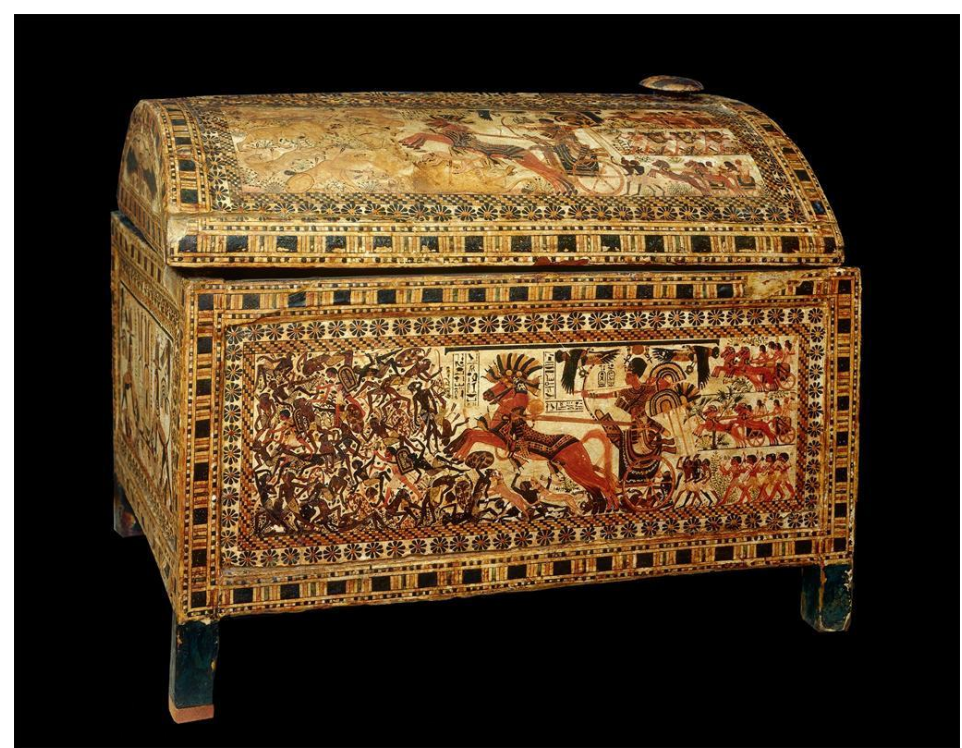

Figure 6.1.19. Painted casket of Tutankhamun (®Getty Images).

Glues as binding media become very popular in Ancient Greece and Rome until the fall of the Roman Empire (Mayer, 1993). Some artistic techniques of animal glue uses remained in China since around 900 - 1000 A.D., mostly as toll for furniture makers and for images conservation (Gettens and Stout, 1966). Similar uses of animal glues were reported in North and South America, Asia and even Africa (Andrew, 2010).

In Fine Arts glue has been extensively used in painting grounds (Mayer, 1993). Glue was the most used binding material in the preparation of gesso grounds, in combination with chalk or gypsum as inert material. During the Middle Ages glue was extensively used in painting, emulsified alone or as an addition to egg and gum tempera (Mayer, 1993; Stoner and Rushfield, 2012). Also was used as binding media in medieval painted books. In the $16^{\text {th }}$ century, when the advances brought by trading, the emergence of science and the spreading of Renaissance enable woodworkers to start experimenting with new designs that were possible only with the use of animal glues. Their efforts were applied not only for creation of fashionable furniture for nobles, but also creation of many types of wooden instruments that were impossible to be created before (many types of guitars, violins, pianos) (Andrew, 2010). Animal glues are commonly used in conservation, have been available for centuries and remain an important group of adhesives because they have been thoroughly researched, and their behavior is understood. Due to the natural origin of these materials, their properties can vary from batch to batch, and conservators should develop standard sources and recipes to use them consistently (von der Goltz et al., 2012).

Before arrival of industrial revolution, glue factories were focused on animal-based glues that were made and sold by individual animal owners and meat factories. By mid 1800's, first rubber-based glues were introduced, and in 1930's modern chemist started heavy development of fully synthetic adhesives. Today, synthetic glues, rubber glues and mixtures of plant and animal glues are used all around the world. (Gettens and Stout, 1966; Pocius, 2002). 
Plant gums: Vegetable gums have been used as binding media in artistic painting techniques since ancient times. The most used gum since antiquity was the Arabic gum extracted from Senegal's Acacia tree, variety Verek. Cherry gum was mentioned by Theophilus to be used in painting practices, and was still in use as binding media in the $19^{\text {th }}$ century (Mills and White, 1994). Like tragacanth this gum is only partially soluble. Gums have been the principal binding media for watercolours paints as used for watercolours of paper supports, such as miniatures and manuscript illumination. They have also found uses as adhesives, i.e. mordant for gilding (Ward, G.W.R., 2008).

\section{Oil}

Drying oils: The first treatise which refers to the use of oil for tempering colours was Theophilus, in the $12^{\text {th }}$ century. In the $13^{\text {th }}$ century linseed oil was the most popular medium for painting in northern Europe. It was not until the Renaissance when water-based media where replaced by oil in the southern Europe. During this transition to oil-based media some artists added oil to the egg medium or use a combination of tempera-based layers with oil glazes, it is known as tempera grassa.

\section{Encuastic}

Wax: The encaustic technique, that consists of wax, alone or mixed with natural resin of terpenoid type, has been used since ancient times (e.g. mummy portraits, byzantine icons, etc.).

Aside from the evolution of painting techniques through history should be emphasized that each painting has special requirements regarding the degree of roughness or absorbance more suitable to facilitate handling of the paint and its permanent adhesion. For example, oil paint films are continuous and vitreous in comparison with gum, glue or casein paint films that are powerful adhesives but do not form very durable films by themselves. It means that each binder has its specific physical (porosity and moistening), optical (brightness, opacity and colour) and mechanical (flexibility, hardness and adhesiveness) properties (Villarquide, 2004).

The prime requirements of a painting technique for artists are the ability of a paint film to remain attached to its ground and the color stability. Several properties contributing to these requirements are needed, including the natural adherence of the binder, the nature of the surface, the elasticity of the dried layer and its resistance to chemical and biological attacks. Stability of paint films and its deterioration will be widely discussed in section 6.1.4.

\section{Protective layer}

The protective layer completes the sequence of layers used for making a painting or polychromed object. This stratum is a thin film made of organic materials, applied in order to isolate the paint layer from the environmental agents responsible of deterioration processes, although, in some cases, its application responds rather to aesthetic reasons. Translucency, impermeability, elasticity and a high refractive index are the properties required for any substance to be applied has protective layer. A wide range of materials have been used as surface coatings or varnishes along history. These surface coatings or varnishes can be broadly classified with respect to their composition and drying process: 
- Oil/resin varnishes: a mixture of a drying oil with a tree or fossil resin, made by dissolving molten or powdered resin in hot oil. This type of varnishes dry essentially by oxidative crosslinking of the oil to produce a tough, insoluble film which, on account of the oil and heating, may become darkened.

- Solvent-based varnishes or spirit varnishes: are essential-oil varnishes - solutions of tree resins, as well as some other resinous materials (e.g. shellac), in a solvent which evaporates during drying. Volatile solvents used commonly are alcohol, naphtha (petroleum distillate, olio di sasso) and essential oils such as those derived from turpentine. These varnishes are less resistant to physical degradation, and are easily removable, because they do not form insoluble crosslinked networks.

- Water-based varnishes and coatings: these coatings could be applied and removed in water. By the $19^{\text {th }}$ century, in Britain, egg white appeared as the most cited material for this purpose (Carlyle 2001, 233).

Throughout history regardless of the materials used, the aim of varnishing has been to protect the paint layer for a very long time. From the Middle Ages to the beginning of the $16^{\text {th }}$ century, the most varnishes applied to painting would have consisted of glair (egg white), or of an oil/resin commonly referred to as vernice liquida or vernice commune based on natural resins. Egg-white varnishes have been found on a number of paintings around Europe and the most consulted artist's treatises such as Cennini, Palomino or Mayerne mentioned the use of this type of varnish as a temporary varnish. In the early $16^{\text {th }}$, with the developments in oil painting, the oil/resin varnishes (vernice liquida) were replaced by spirit or essential oil varnishes (Cennini, 1988; Mayerne, 1967; Palomino, 1988). By the $17^{\text {th }}$ century spirit varnishes were commonly use throughout Europe, in a wide range of formulations. During this period the most commonly used resins were mastic, sandarac and colophony (Figure 6.1.20 (left)) (Doerner, 2005).
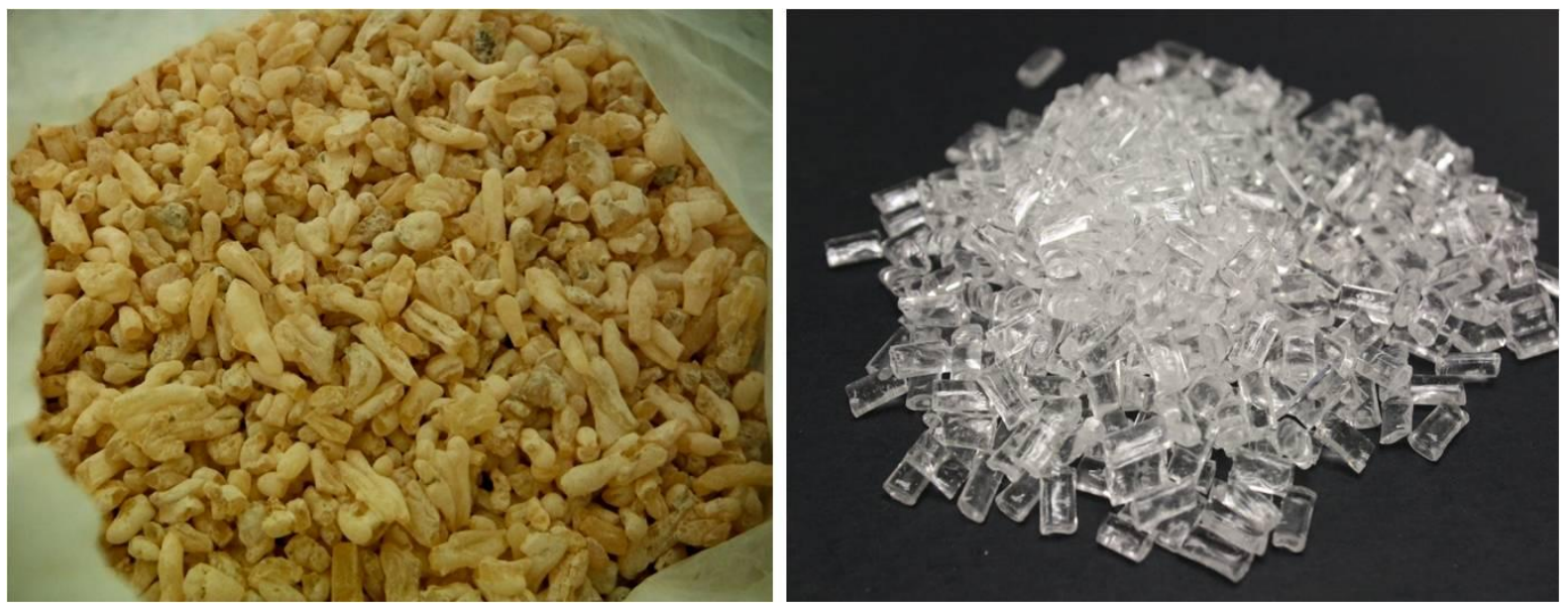

Figure 6.1.20. Natural resin, sandarac (left) and synthetic resin Paraloid B72 (right).

By the $18^{\text {th }}$ century, as a consequence of increased trade and the rise of the dedicated artists' colourman, there were a number of varnishes based on copal resins. Besides, with the technical innovation and the industrialization the variety and the quality of materials available to the artist increased. The best documented materials introduced as varnishes were the 
dammar and the shellac, but also copal, oil/copal and spirit copal were produced. Copal and dammar varnishes seem to have been widely used in the $19^{\text {th }}$ century. Particularly, dammar varnishes which were the first varnishes developed for conservation treatments of old paintings (Stoner and Rushfield, 2012). Up to date dammar varnishes are a viable choice for many European conservators. In the late $19^{\text {th }}$ century, with the new the painting techniques of the independent artists and as the Impressionist, the artist no longer considered varnishing as an essential operation in painting, some preferred matte and/or unvarnished surfaces (Mayer and Myers, 2004).

The $21^{\text {th }}$ century brought with it a wide range of products (synthetic resins) suitable for varnishing acrylic dispersion paintings (Figure 6.1.20 (right)). These coating products, recommended by artist's paint manufacturers, ... can be classified in two groups: the low molecular weight (removable) varnishes and the non-removable topcoats. Some of the low molecular weight resins used for varnishing are the ketone resins (e.g. Laropal@ K80), the styrene resin (e.g. Regalrez ${ }^{\circledR}$ ) and the urea-aldehyde resins (e.g. Laropal® A81). A few of these non-removable coatings have pretended to be water-borne polyurethane polymers as well as blends or co-polymers of polyurethane and acrylics, and PVA 'isolating varnish'. These acrylic dispersion polymers topcoats suffer from lack solvent resistance, yellowing, loss of gloss and a low $\mathrm{Tg}$ (glass-transition temperature), this means that will exhibit dirt pick-up and porosity (Scicolone, 2002). These resins not replace the natural resins traditionally used, but constitute a further contribution in the artistic and conservation fields.

The current available 'removable' varnishes can be removed using either water or mineral spirit. The varnishes include: alkali-sensitive waterborne acrylic colloidal polymers, solventborne acrylic solution polymers of iso butyl and n-butyl methacrylate, and a new synthetic resin varnish system developed by René de la Rie (1993) including a hydrogenated hydrocarbon resin soluble in a low aromatic containing hydrocarbon (vinyl acetates and acrylics). There are many studies focusing on the surfactant migration, potential crosslinking and solvent resistance of these coatings (Doménech-Carbó et al., 2010; Learner, 2001; Ormsby et al., 2006; Osete-Cortina and Doménech-Carbó, 2006; Silva et al., 2009, 2010; Withmore et al., 2006). 
References

Andrew, W. (2010) Handbook of adhesives and surface preparation technology. (S. Ebnesajjad, ed.)

Bomford, D., Kirby, J., Leighton, J., Roy, A. (1990) Impressionism: “Art in the Making”. London, National Gallery Publications.

Brunello, F. (1992) De arte Illiminandi e Altri Trattati Sulla Tecnica Della Miniatura Medievale, first ed., Neri Pozza Editore, Vicenza.

Campal, J.L. (2001), "Unas escuetas notas sobre electrografía y copy-art”. Available online: http//www.abaforum.es/merzmail/electrografía.htm\#inicio. Consulted: 2016-10-01

Campbell, L., Foister, S., Roy, A. (eds.) (1997) The Methods and materials of Northern European painting. National Gallery Technical Bulletin 18, National Gallery of Art, London.

Carter, T.F., Carrington, G. (1955) The invention of printing in China and its spread Westwards. $2^{\text {nd }}$ edition, Ronald Press: New York.

Castwright, C., Middleton, A. (2008) Scientific aspects of ancient faces: mummy portraits from Egypt. The British Museum, Technical Research Bulletin, 2, 58-66.

Cennini, C. (1988) Il libro dell'arte (14 ${ }^{\text {th }}$ century), Akal, Madrid.

Clarke, C. (2006) The Art of Africa: a source for educators. Published by The Metropolitan Museum of Art, New York.

Doerner, M. (2005) Los materiales de pintura y su empleo en el arte (6 ed.). Editorial Reverté, Barcelona.

Doménech-Carbó, M.T. (2013) Principios físico-químicos de los materiales integrantes de los bienes culturales. Servicio Publiaciones Univeritat Politècnica de València (SPUPV), Valencia.

Doménech-Carbó, M.T., Silva, M.F., Yusá-Marco, D.J., Aura-Castro, E., Martínez-Bazán, M.L., Más-Barberá, X., Kröner, S., Osete-Cortina, L., Fuster-López, L., Doménech, A., Gimeno-Adelantado, J.V., Mecklenburg, M.F. (2010) Multi-technique approach for evaluating cleaning treatments in acrylic and PVAc paints, in Preprints of Cleaning 2010 congress: New Insights into the Cleaning of Paintings, Valencia 26-28 May, Universidad Politécnica de Valencia, Valencia (España), 39-40.

Dorge, V., Howlett, C. (eds.) (1998) Painted Wood: History and Conservation. Los Angeles, CA: Getty Conservation Institute.

Forsyth, I.H. (1972) The Throne of Wisdom, Wood Sculptures of the Madonna in Romanesque France. Princeton, Princeton University Press.

Fuller, N.B. (2002) A Brief history of paper. Available online: users.stlcc.edu/nfuller/paper/ Consulted: 2016-10-14.

Gettens, R.J., Stout, G.L. (1966) Painting materials: A short encyclopedia, Dover, New York. 
Gómez, M.A. (1998) La restauración. El examen científico aplicado a la conservación de obras de arte, Cátedra, Madrid.

González-Alonso, E. (1997) Tratado del dorado, plateado y su policromía. Servicio de Publicaciones UPV, Valencia, Spain.

Hall, R.M. (2001) Egyptian Textiles, Shire Egyptology 4. Shire Publications.

Hannaford, J. A. (2013). A literature analysis examining the potential suitability of terahertz imaging to detect friction ridge detail preserved in the imprimatura layer of oil-based, painted artwork (Doctoral dissertation).

Harris, J., ed. (2006) 5,000 Years of Textiles. British Museum Press.

Hayward, M. (2010) The London linen trade, 1509-1641, and the use of linen by painters in royal service. In Trade in Artist's Materials: Markets and Commerce in Europe to 1700 (J. Kirby, S. Nash and J. Cannon, eds.), pp. 375-385, Archetype Publications.

Hoskins L. (ed.), (2005) The Papered Wall: The History, Patterns and Techniques of Wallpaper, Thames \& Hudson, London.

Humboldt, A., Bonpland, A. (1814) Personal Narrative of Travels to the Equinoctial Regions of America, Vol.1 During the years 1799-1804. Cosimo Calssics Inc., New York, pp. 100.

Jones, P. (2004) Boomerang: Behind an Australian Icon. Published by Wakefield Press.

Komanecky, M.K. (1999) Copper as Canvas: Two centuries of masterpiece paintings on copper 1575-1775. Phoenix Art Museum, Oxford University Press, New York.

Lalli, C.G., Lanterna, G., Andrasch, D., Innocenti, F. (2016) The review of analytical data on the portraits of the Fayum in the light of new investigation techniques. In Encaustic, history technique and research (S. Omarini, ed.), E-book Nardini Editore, Firenze, pp.33.

Learner, T. (2001) The analysis of synthetic paints by pyrolysis-gas chromatography-mass spectrometry (PyGCMS). Studies in Conservation, 46, 225-241.

Lee, Y. "La técnica de la policromía en los artesanos de templos budistas en Taiwán: caracterización cinetífica y estudio de la aplicabilidad de consolidantes biocompatibles para su conservación.” PhD Thesis, Universitat Politècnica de València, 2015.

Leung, C. (2006) An overview of Pacific, Northwest Native Indian Art. Ebook by Free Spirit Gallery http://www.support-native-american-art.com/support-files/ebook-nwcoast.pdf

Marchán-Fiz, S. (1994), Del arte objetual al arte de concepto, Akal, Madrid.

Mayer, L., Myers, G. (2004) American Impressionism, matteness, and varnishing. Journal of the American Institute for Conservation, 43(3), pp. 237-254.

Mayer, R. (1993) The Artist's Handbook of Materials and techniques, $2^{\text {nd }}$ Edition, Hermann Blume, Madrid.

Mayerne De, T. (1967) Le manuscrit de Turquet de Mayerne 1620-1646. Lyon, Audin Imprimeurs Lyon. 
Mazurek, J., Svoboda, M., Maish, J., Kawahara, K., Fukakusa, S., Nakazawa, T., Taniguchi, T. (2014) Characterization of binding media in Egyptian Romano portraits using enzymelinked immunosorbent assay and mass spectrometry. e-PS, 11, 76-83.

Miller, V.E. (2010) Water, colour and the Maya. ANTIQUITY, 84(326), 1199-1201. Doi:10.1017/S0003598X00067235.

Mills, J.S., White, R. (1994) The organic chemistry of museum objects. Routledge, NewYork.

Museo Internacional de Electrografía (1991), Electrografías, Universidad de Castilla, La Mancha, España.

Nylander, R.C. (1992) Wallpapers for Historic Buildings, Preservation Press, Washington DC.

Ormsby, B., Learner, T., Foster, A., Druzik, R., Schilling, P. (2006) Wet-cleaning acrylic emulsion paint films: an evaluation of physical, chemical, and optical changes. Modern Paints Uncovered. The Getty Conservation Institute, Los Ángeles, 189-200.

Osete-Cortina, L., Doménech-Carbó, M.T. (2006) Characterization of acrylic resins used for restoration of artworks by pyrolysis-silylation-gas chromatography/mass spectrometry with hexamethyldisilazane. Journal of Chromatography A, 1027, 228-236.

Palomino, A. (1988) El museo pictórico y escala óptica. Tres volúmenes. Madrid, Aguilar.

Pedrola, A. (2006) Materiales, procedimientos y técnicas pictóricas. Ariel, Barcelona.

Plesters, J. (1983) 'Samson and Delilah': Rubens and the art and craft of painting on panel. National Gallery Technical Bulletin, vol. 7, 30-49.

Pliny, Natural History

Pocius, A. (2002) Adhesion and adhesives technology: an introduction. Munich: Hanser: Hanser/Gardner, $2^{\text {nd }}$ ed.

Prisse, A. and Kaper, O.E. (2000) Atlas of Egyptian art. Cairo, Egypt: American University in Cairo Press.

Ramer, B. (1979) The technology, examination and conservation of the Fayum Portraits in the Petrie Museum. Studies in Conservation, 1979, 24, 1-13.

Rampazzi, L., Campo, L., Cariarti F. (2007) Prehistoric wall paintings: the case of the Domus De Janas Necropolis (Sardinia, Italy). Archaeometry, 49 (3), 559-569.

Reeves, T., Lenehan, C.E., Jones, P., Popelka-Filcoff, R.S. (2012) Characterisation of binders in aboriginal and European painted works Using Pyrolysis Gas Chromatography Mass Spectrometry. Journal of the Anthropological Society of South Africa 35, 104 - 106.

Sack, S., Tahk, C., Peters, T. (1981) A technical examination of an ancient Egyptian painting on canvas. Studies in Conservation, 1981, 26, 15-23.

Scicolone, G.C. (2002) Restauración de la pintura contemporánea. Editorial NEREA, Donostia-San Sebastián. 
Scott, D.A., Warmlander, S., Mazurek, J., Quirke, S. (2009) Examination of some pigments, grounds and media from Egyptian cartonnage fragments in the Petrie Museum, University College London. J. Archaeol. Sci., 36, 923-932.

Silva, M.F., Doménech-Carbó, M.T., Fuster-Lopéz, L., Martín-Rey, S., Mecklenburg, M.F. (2009) Determination of the plasticizer content in poly (vinyl acetate) paint medium by pyrolysis-silylation-gas chromatography-mass spectrometry. Journal of Analytical and Applied Pyrolysis, 85, 487-491.

Silva, M.F., Doménech-Carbó, M.T., Fuster-López, L., Mecklenburg, M.F., Martin-Rey, S. (2010) Identification of additives in poly(vinylacetate) artist's paints using Py-GC-MS. Analytical and Bioanalytical Chemistry, 397, 357-367.

Stoner, J.H., Rushfield, R. (2012) Conservation of easel paintings. Routledge.

Taft, W. S., \& Mayer, J. W. (2000) The Structure and Analysis of Paintings. The Science of Paintings, 1-11.

Villarquide, A. (2004) La pintura sobre tela I: Histografía, técnicas y materiales. Editorial NEREA, San Sebastián.

Vitruvius, Architecture (Book III)

von der Goltz, M., Birkenbeul, I., Horovitz, I., Blewett, M., Dolgikh, I., (2012) Consolidation of flaking paint and ground. In: The conservation of easel paintings. (Stoner, J.H. and Rushfield, R. eds.), pp. 369-374, Routledge: New York.

Ward, G.W.R. (2008) The Grove Encyclopedia of Materials and Techniques in Art. Oxford University Press.

Withmore, P.M., Morris, H., Colaluca, V. (2006) Penetration of liquid water through waterborne acrylic coatings. Modern Paints Uncovered. The Getty Conservation Institute, Los Ángeles, 207-223.

Yamasaki, K., Nishikana, K. (1970) Polychromed sculptures in Japan. Studies in Conservation, 15 (4), 278-293.

Consulted web references:

www.trueart.info

Consulted: 06/05/2015

http://eclecticlight.co

Consulted: 08/12/2016

http://www.explorandomexico.com.mx/about-mexico/5/237/

Consulted: 01/03/2015

www.australia.gov.au

Consulted: 01/03/2015

www.aboriginalculture.com.au

Consulted: 14/10/2016

http://users.stlcc.edu/nfuller/paper/

Consulted: 14/10/2016 


\subsubsection{Pigments}

The responsible materials for the color in a paint layer are pigments, which are highly insoluble in inorganic and organic solvents and are prepared as very fine powders. Pigments are mixed with binders to be used as a fluid that can be applied evenly and smoothly in a uniform film.

\subsubsection{Definitions}

The Color Pigment Manufacturers Association (CPMA, 2016) defines pigments as "black, white or fluorescent particulate organic or inorganic solids which usually are insoluble in, and essentially physically and chemically unaffected by the vehicle or substrate in which they are incorporated. They alter appearance by selective absorption and/or by scattering of light. Pigments are usually dispersed in vehicles or substrates for application, as for instance in the manufacture of inks, paints, plastics or other polymeric materials. Pigments retain crystal or particulate structure throughout the coloration process".

For the preparation of a paint the pigments are suspended in the binder forming films perceptible to the naked eye or optical microscope. These particles have more than $10^{9}$ atoms and its diameter is greater than $200 \mathrm{~nm}$. This property allows them to be mixed with binders and be applied as thin films on the surface of a painting artwork.

\subsubsection{Classification}

From the point of view of its composition, pigments are derived from a wide variety of organic and inorganic substances of natural or synthetic origin.

Most inorganic pigments exhibit structure of ionic solids. Earth pigments contain oxides and clayey minerals together with other accessory minerals. Some materials occurring as chemical metallic elements such as gold, silver or tin and their alloys are used as inorganic artists' pigments. Organic pigments consist of polyunsaturated molecules, heterocyclic 
aromatic compounds or organometallic complexes (Vaillant, Doménech and Valentín et al., 2003).

The inorganic pigment can be grouped according to their structure:

a) Pigments exhibiting structure of ionic solid

Many of the pigments commonly used in artworks are ionic solids formed by an ionic bonding between a positive and a negative ion which are held together by electrostatic forces (Figure 6.1.1.2.1). Ionic bonding results in the formation of a large crystal lattice (Figure 6.1.1.2.2) rather than individual molecules. Ionic bonding is common in inorganic compounds but relative uncommon in organic compounds.

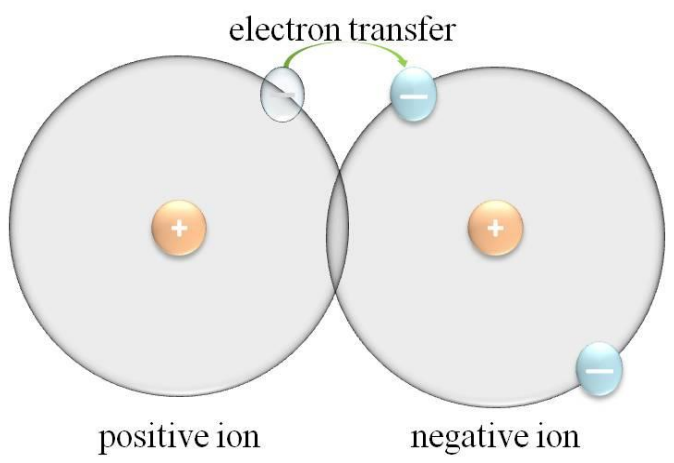

Figure 6.1.1.2.1 Ionic bonding.

Ionic substances are soluble only in highly polar solvents and its solubility depends on the nature of the solute, solvent and temperature. The lattice energy of solid ionic difficult the dissolution, while the solvent solvation energy promotes the dissolution. The solubility generally increases with temperature.

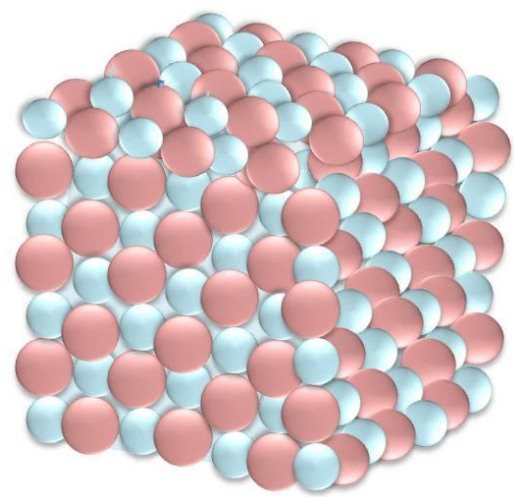

Figure 6.1.1.2.2 Crystal lattice of an ionic compound, face centered cubic.

The artists' pigments that exhibit ionic structure can be classified in four groups as shown in Table 6.1.1.2.1. 
Table 6.1.1.2.1. Classification of inorganic pigments with structure of ionic solid based on their chemical composition.

\begin{tabular}{|c|c|c|}
\hline Type & Generic formula & Groups and examples \\
\hline Oxides & $\begin{array}{l}\mathrm{M}_{2} \mathrm{O}_{\mathrm{x}} \\
\left(\mathrm{M}^{\mathrm{x}}=\text { metal cations; } \mathrm{O}^{2-}=\text { oxide }\right. \\
\text { ion })\end{array}$ & $\begin{array}{l}\text { Simple oxide: } \mathrm{ZnO} \text { (zinc white) } \\
\text { Double oxide: } 2 \mathrm{PbO} \cdot \mathrm{PbO}_{2} \text { or } \mathrm{Pb}_{3} \mathrm{O}_{4} \\
\text { (minium) }\end{array}$ \\
\hline Salts & $\begin{array}{l}\mathrm{M}_{\mathrm{y}} \mathrm{B}_{\mathrm{x}} \\
\left(\mathrm{M}^{\mathrm{x}}=\text { metal cations; } \mathrm{B}^{\mathrm{y}-}=\text { mono }\right. \\
\text { or polyatomic anion })\end{array}$ & 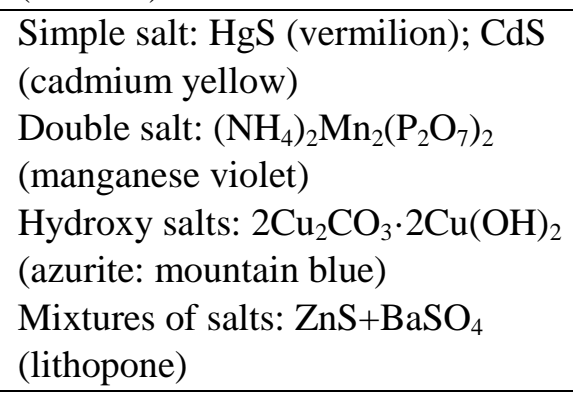 \\
\hline Mixtures of substances & $\mathrm{M}_{\mathrm{y}} \mathrm{B}_{\mathrm{x}}+\mathrm{M}_{\mathrm{y}} \mathrm{B}_{\mathrm{x}}$ & $\mathrm{CdS}(\mathrm{Se})$ (cadmium red) \\
\hline
\end{tabular}

The earth pigments (red earths, ochres, siennas and umbers) of natural origin are composed of iron oxides, iron hydroxide and hydrated iron oxide at different extent that are accompanied by clays and other accessory minerals (quartz, gypxum, chalck, etc. Whereas the Mars colours (yellow, orange, red, violet) are artificially prepared.

The development of the chemistry at the beginning of the $18^{\text {th }}$ century marks the bases of modern synthetic pigments. The Prussian blue, the Scheele's green and the chrome yellow, are examples of synthesized pigments and are ones of the most commercialized pigment during that time. Up to these days the range of synthetic inorganic pigments has been expanded considerably including titanium white pigments, iron oxides, molybdenum red and cadmium yellow and red pigments. An example of this, is the recently development of a carbon-based pigment named Vantablack, in 2014 by the Surrey NanoSystems. Finally, the compound mixture pigments that are obtained by incorporating metal ions to the crystalline lattice of an oxidic compound which in its pure form is colorless.

b) Covalent networks

b.1) Carbon

In covalent bonding the electrons are shared between atoms (Figure 6.1.1.2.3). This is the most common type of bonding in organic compounds. 


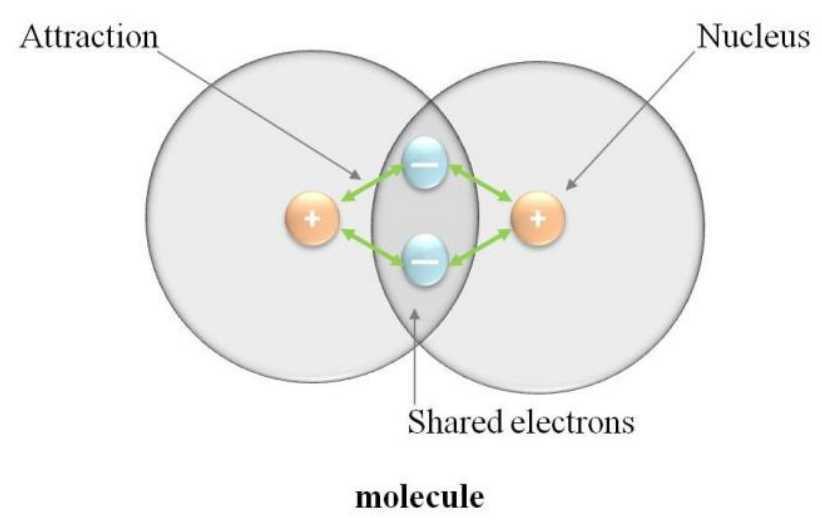

Figure 6.1.1.2.3 Covalent bonding

Unlike other elements, carbon forms strong bonds to other carbon atoms formed tridimensional networks in diamond. The high bond strength of the covalent bond makes this type of structure characterized by its high hardness, melting and boiling point. Graphite variety, and the noncrystalline carbons as cokes, chars, coals and carbon prepared by combustion of oil, wood, vegetables and other organic matter were used as pigments in ancient times (Winter, 1983; Tomasini et al., 2012).

b.2) Clay minerals in earth pigments

A wide range of pigments are found as minerals or rocks in natural deposits, whose structure corresponds to a type of crystalline silicate, in which the primary structures $\left[\mathrm{SiO}_{4}\right]$, are linked together to form a covalent network structure (Figure 6.1.1.2.4).

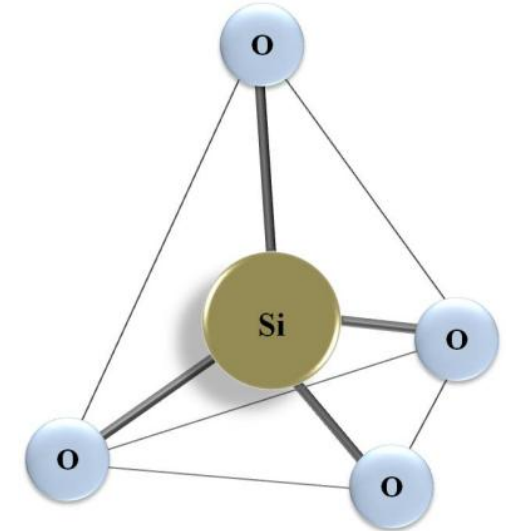

Figure 6.1.1.2.4 Primary unit structure of a covalent silicate network.

Among the pigments that contain clay minerals formed of a covalent silicate network are included green earth (complex aluminosilicate minerals), lapis lazuli or ultramarine blue artificial (sulphur-containing sodium aluminium silicate), Egyptian blue (copper and calcium silicate) or smalt (cobalt(II)-containing potash glass).

c) Metals

They are insoluble in all solvents. Metal atoms interact with other metal atoms to form metallic bonds. The metal cations from a lattice and the valence electrons form a surrounding "sea of electrons". These valence electrons are mobile and delocalized; there are apparently no associations of particular electrons with the particular cations. Because of the delocalization of the negative charge, metal crystals are easily deformed and reshaped 
making metals malleable and ductile. Metals and alloys as gold (Figure 6.1.1.2.5), silver or brass can be beaten and transformed into leaves of extreme thinness, and then used to cover large surface in polychromed objects. Their melting points depend on the strength of the bonds, and the range varies from quite low (e.g. $-39^{\circ} \mathrm{C}$ for $\mathrm{Hg}$ ) to very high (e.g. $3422{ }^{\circ} \mathrm{C}$ for tungsten). As well as, the melting point, the hardness could vary from firm to alloys so hard that is the necessary the use of special tools to cut them.

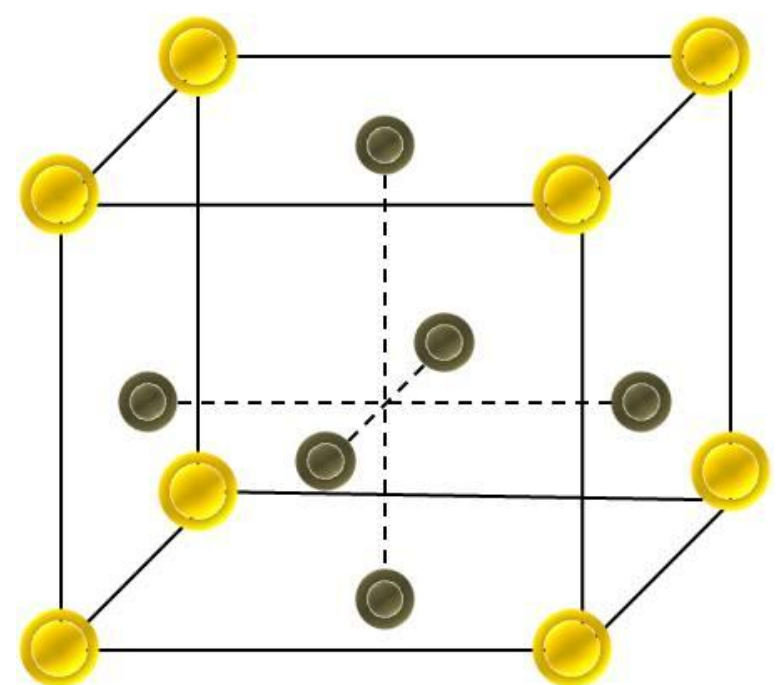

Figure 6.1.1.2.5 Crystal structure for metallic gold, face centered cubic. 


\subsubsection{Pigments studied}

The pigments considered in this work are part of the colour palette that has been used since ancient times to the modern age. All of them are mentioned in almost all the literature sources and pigment catalogues consulted (Mayer, 1993; Feller, 1986; Ashok, 1993; Gettens and Stout, 1966; Cennini, 1988). The critical aspects in consideration for its selection would be later described in the "Materials and Methods" section.

\section{Iron oxide}

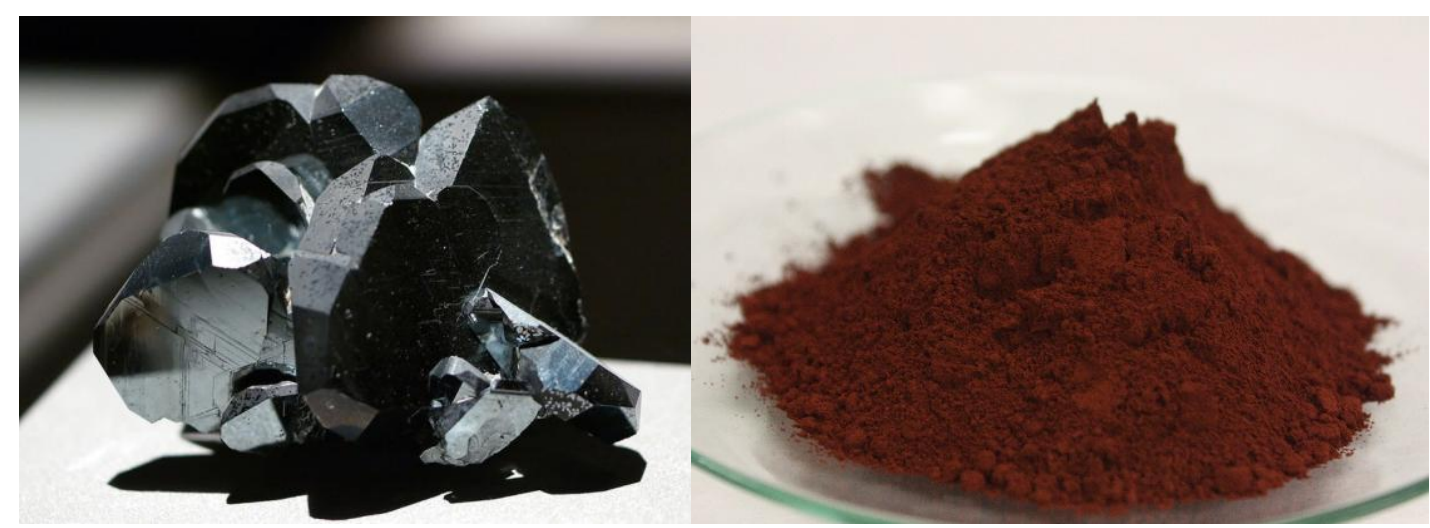

Figure 6.1.1.3.1 Specular iron oxide mineral occurring in natural outcrops (left) and iron oxide pigment used in this research project (right).

Origin: Natural mineral

Color: Dark red saturated

Chemical name: Iron oxide (haematite), an anhydrous iron oxide mixture, usually contains more than 85 percent of $\mathrm{Fe}_{2} \mathrm{O}_{3}$ and other minerals (e.g. quarts and clays).

Formula: $\mathrm{Fe}_{2} \mathrm{O}_{3}$

\section{Brief historical review}

This pigment consists of variable mixtures of iron oxides. It is a natural mineral pigment used as coloring material in all periods of painting since prehistoric times, even today is commercially included among the most important pigments (Mayer, 1993; Helwing, 2007; Gettens and Stout, 1966). Formerly, the term iron oxide pigments referred to mixtures of iron oxides and oxide hydroxides all derived from natural sources, but at present the term encompasses both natural and synthetic materials. Both natural and artificial varieties of iron oxides are known by numerous names. Some names show the source; some originally were applied to natural products but are now used for artificial ones. Red pigments based on anhydrous iron oxide, are referred to with names such as hematite, red earth, Indian red, Venetian red, rubrica, sinopis, terra di Sienna, Spanish brown, etc. (Smith, 1890). The name rubrica was used to refer to natural red earth of low quality, whilst sinopis indicated a wellcrystallized, relatively pure hematite ore. The name terra di Sienna generally indicate a warmer yellow earth originating near Siena, Italy. On other hand, Spanish brown referred to a natural, red-brown earth pigment prior to the $19^{\text {th }}$ century; but was also used in reference to an artificial iron oxide pigment. 
The naturally occurring iron earth pigments were among the first coloring materials known and have a long continuous history of use. By the Paleolithic earth pigments were used extensively for both ritual and artistic purpose. The range of iron minerals used at a specific site was related to aesthetic criteria, as well as, the composition of available pigment sources. Archaeological evidence suggests that the technology of producing iron oxide by burning iron sulfate or by oxidizing iron-rich metal was known to medieval alchemists. Manuscripts demonstrate the use of these pigments in European painting from the $16^{\text {th }}$ century (Barnett et al., 2006). For example, earth pigments containing iron and manganese have been identified prior to this time-on medieval English wall painting (Hradil, 2003). During the $13-15^{\text {th }}$ centuries the use of both mixed browns and brown earths in mordants for oil gilding on Italian panels (Bomford et al., 1990; Dunkerton and Roy, 1996) was frequent. Another important application of clay-rich red earth was as bole for water gilding, as well as, an orange-red bole typical of Sienese painters. During a long period $\left(16-19^{\text {th }}\right.$ centuries $)$ iron oxides were the main component of canvas painting grounds.

From the Middle Ages to the end of the $18^{\text {th }}$ century, different types of manufactured iron oxide were mentioned in treatises on artists' materials. The most common of these procedures was red iron oxide prepared by the calcinations of yellow earth. During the latter part of the $18^{\text {th }}$ century large-scale processes to manufacture a range of colors of iron oxide pigments by the precipitation of a soluble iron salt, such as ferrous sulphate (FeSO4) and aluminium sulphate $\left(\mathrm{Al}_{2}\left(\mathrm{SO}_{4}\right)_{3}\right)$ or alum $\left(\mathrm{KAl}\left(\mathrm{SO}_{4}\right)_{2} \cdot 12 \mathrm{H}_{2} \mathrm{O}\right)$, with an alkali, such as lime or potash. There are numerous references to these synthetic iron oxides, generally known as Mars colors (Franquelo and Pérez Rodríguez, 2016). Although synthetic pigments have captured most of the market, both natural earths and synthetic iron oxides are currently employed as pigments.

\section{Type of degradation}

Generally considered stable, with some solvent sensitivity. In some aged paint films a relative high concentrations of lipid degradation products as consequence of chain scission promoted by the pigment acting as catalyst has been observed (Gettens and Stout, 1966; Matteini and Moles, 2001; Stoner and Rushfield, 2012). 


\section{Massicot}

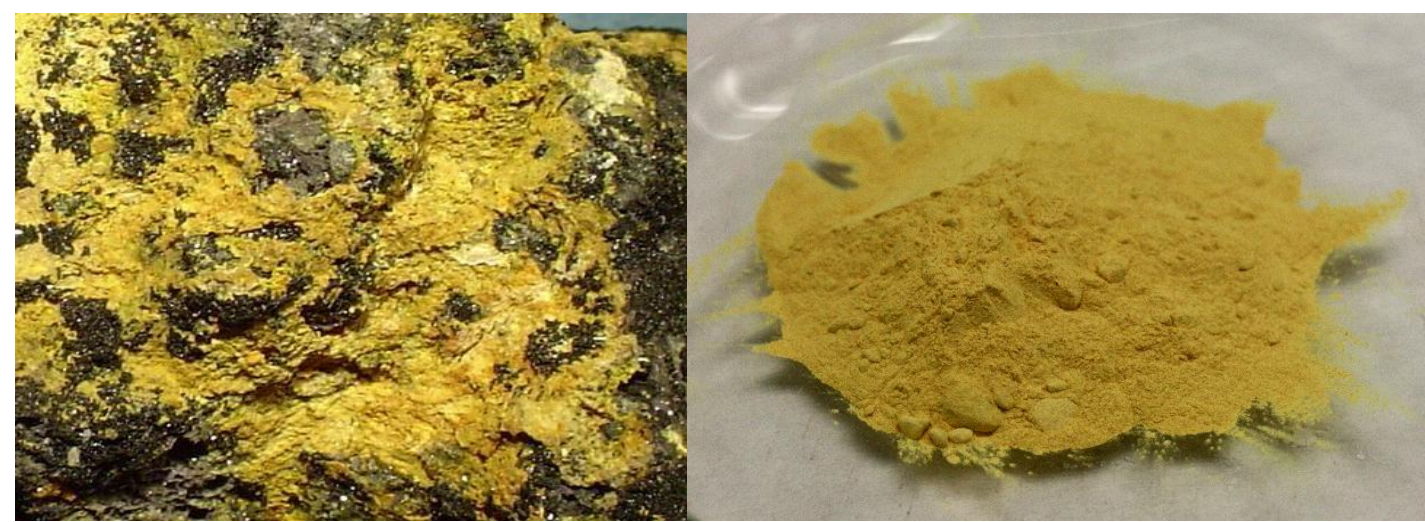

Figure 6.1.1.3.2 Mineral massicot (left) and massicot pigment used in this research project (right).

Origin: Synthetic

Color: A yellow variety

Chemical name: Lead monoxide

Formula: $\mathrm{PbO}$

\section{Brief historical review}

Used since Antiquity as early as 400BC, in pre-dynastic times in Egypt, in Roman monuments, and found in paintings mainly made from $13^{\text {th }}$ century to the early $19^{\text {th }}$ century (Le Fur, 1990; Edwards et al., 2015; Sakr et al., 2016). The name massicot is derived from the Arabic term sabb kubti, meaning Egyptian alum or soda. Through the Spanish this became modified to mazacote, which referred to glaze on ceramics of the type known as faience, which are essentially a tin-enamelled earthenware. A further transition took place, perhaps as a result of the association of tin and lead in ceramic glazes, whereby massicot came to mean a lead tin yellow pigment (Maggetti et al., 2009). By the $17^{\text {th }}$ century recipes described in treatises and manuscripts leave no doubt that massicot was used to referred to lead tin yellow. In the 1841, Huot made the original description of the mineral, and massicot then became applied to a lead monoxide (Huot, 1841; Eastaugh et al., 2008). The recipe for the production of massicot, by heating lead white at high temperatures, for painting purpose was later described by Zerr and Rübencamp in the 1906 (Larsen, 1917). It is not an intense yellow but it has good hiding power and is similar to lead white in pigment properties. Due to its toxicity with the arrival of the Industrial Age, it was replaced by pigments that preserved all the positive aspects but without the undesirable dangers.

\section{Type of degradation}

The pigment-medium interaction promotes saponification of lipids, and bound with oil may lead to form soap aggregates or protrusions. These saponification processes make paintings appear darker. Furthermore, lead soap formation, sometimes in the form of surface protrusions, results in the breaking up of the paint layer. Other alterations like a translucency increment and whitening of the paint surface have been mentioned (Kotulanová et al, 2009). 


\section{Verdigris}

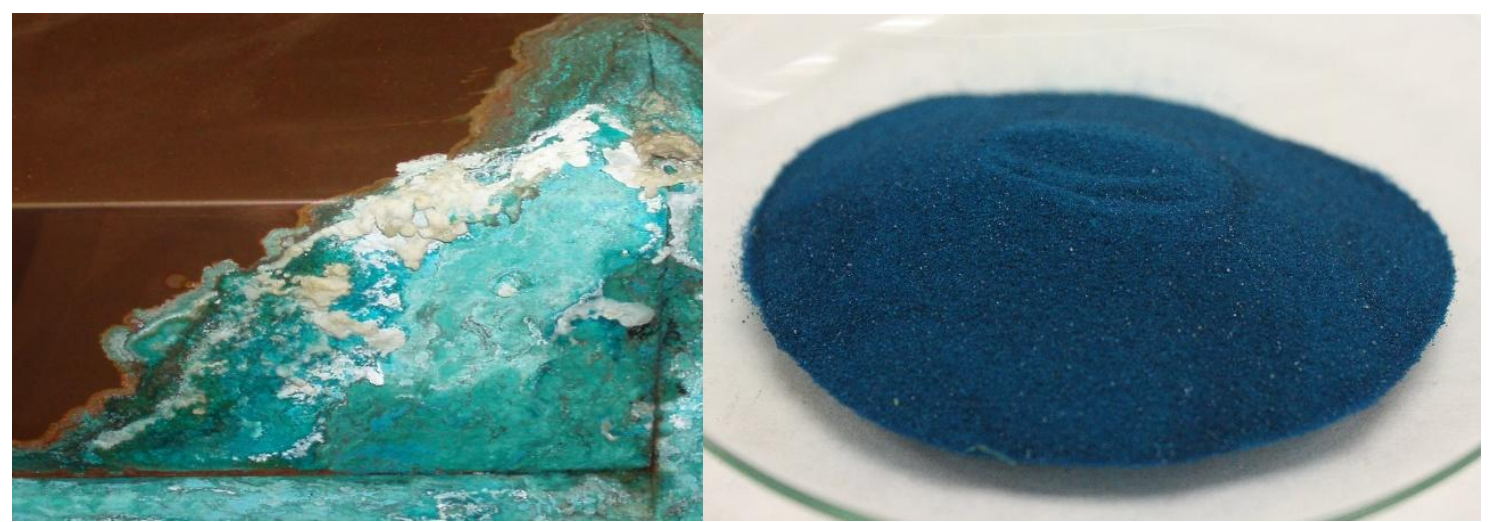

Figure 6.1.1.3.3 Copper plates exposed to acetic acid (left) and verdigris used in this research project (right).

Origin: Synthetic

Color: Bluish green (teal) of low intensity

Chemical name: Neutral copper acetate

Formula: $\mathrm{Cu}\left(\mathrm{CO}_{2} \mathrm{CH}_{3}\right)_{2} \cdot n \mathrm{H}_{2} \mathrm{O}$

\section{Brief historical review}

Prepared and used by artists from the ancient Greek and Roman times to the beginning of the $19^{\text {th }}$ century, also it is known by other names such as vert de Grece, Van Eyck green and verdet de Montpellier. Verdigris was the most vibrant green available until the $19^{\text {th }}$ century, and it was used to produce intense pure green tones for landscapes and drapery. Nonetheless, verdigris is rarely found in paintings from the $18^{\text {th }}$ and $19^{\text {th }}$ centuries, due to the development of new green pigments hardly surpassable in its brightness as, emerald green or viridian. In spite of it, verdigris was commercially available in oil-medium as a tube-color till 1928 (Hermann, 1993).

This synthetic pigment was formerly produced by the action of acetic acid vapors on strips of metallic copper, forming a blue-green crust which was scraped off and ground to be used as pigment. This procedure usually yielded a mixture of basic and neutral verdigris. To purify it, the pigment mixture was often dissolved in acetic acid and neutral copper acetate separates from the solution in form of crystals, called "distilled" verdigris. Neutral verdigris pigment particles are composed of tabular crystals with rhombic and hexagonal faces.

\section{Type of degradation}

This green is the most reactive and unstable of the copper pigments. It is well known that copper and copper salts react readily with resin solutions to form copper resinates, and these solutions become green-stained. Pigment-medium interactions in oil media may cause a colour change from blue or blue/green, to an intense green owing to the conversion into copper carboxylates soaps and further the paint can turn brown over time due to the promotion of oxidation processes. The magnitude of the color change depends on the kind of verdigris and the kind of binding medium. The color change is less pronounced with neutral verdigris in oil and egg tempera. Verdigris reacts with binding media; with resins it forms copper resinates; with oils, it forms copper oleates; and with proteins, it forms copper-protein 
compounds. Copper (II), commonly present in older paintings, has long been known as an effective oxidizing agent of organic compounds. Artists treatises mentioned that verdigris leads to deterioration of other pigment, and it can only be used under special conditions which should be strictly followed. For example, mixtures of verdigris with sulfur-containing pigments in aqueous media may darken due to the formation of copper sulfide (Banik, 1989; Naumova et al., 1990; Santoro et al., 2014). 


\section{Lead white}

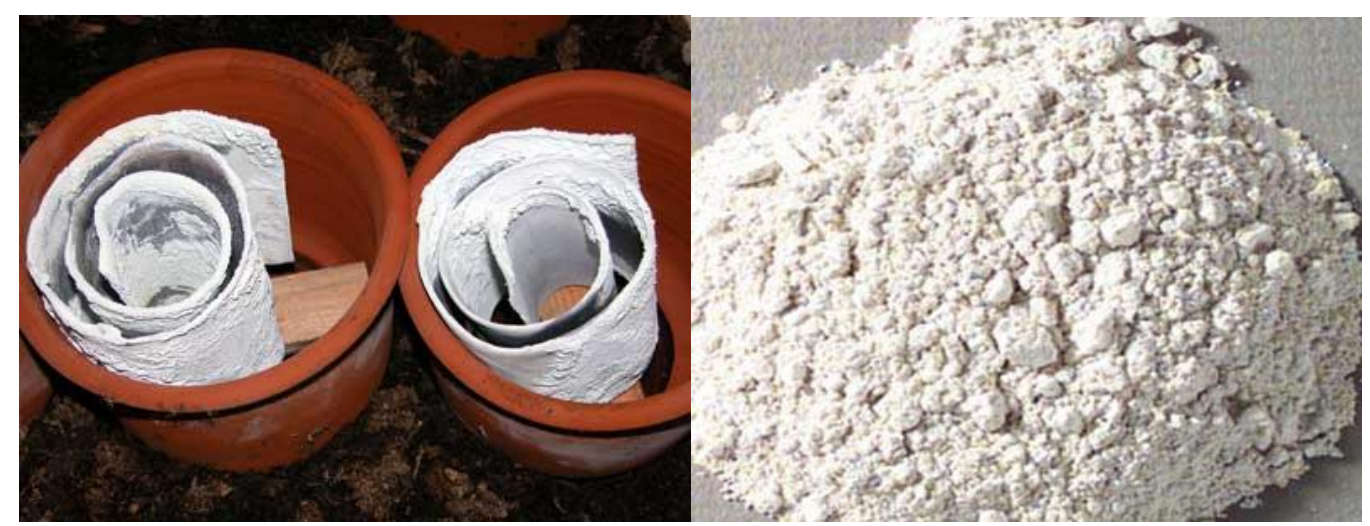

Figure 6.1.1.3.4 'Stack' process, corrosion on the lead coils (left) and lead white used in this research project (right).

Origin: Synthetic

Color: White with a remarkable hiding power

Chemical name: Basic lead (II) carbonate

Formula: $2 \mathrm{PbCO}_{3} \cdot \mathrm{Pb}(\mathrm{OH})_{2}$

\section{Brief historical review}

It is the most important of all the lead pigments that was known in early times and was one of the first artificially prepared pigments. It was the only white pigment used in European easel painting until the $19^{\text {th }}$ century, was also used occasionally on wall painting and in tempera painting on paper. The siccative or drying action of lead white upon oils was one of the reasons for its being so widely used as pigment. The product resulting of binding with a drying oil is a hard and resistant film, unaffected by light. Pliny, Vitruvius and other writers described its preparation from metallic lead and vinegar. The 'Dutch' or 'Stack' process was the most used, even today some artists drawn on of this method to produce their own pigment. There are also numerous medieval recipes for making it, but the most used is called the. The method for the 'Dutch' or 'Stack' is: metallic lead in the form of strips is exposed in earthenware pots, which have a separate compartment in the bottom containing acetic acid. The pots are stacked in tiers over a layer of horse manure in a shed. After the shed is closed, the combined action of the acetic acid vapors, heat and carbon dioxide from the fermenting manure, carbon dioxide in the air and water vapor slowly transforms the lead to basic lead carbonate. The product is then scraped from the surface (Gettens et al., 1993). A large part of the lead white used today is made by a more rapid chemical process from which result pigment particles fairy uniform in size varying from 1 to $2 \mu \mathrm{m}$ and individual grains often tabular and hexagonal in outline. Since lead white is a poisonous compound if inhaled as a dust or if ingested, grinding and manufacture into paint was long regarded as a hazardous industry and it was curbed by legislative action. Now, because of improved factory methods, such dangers are no longer attendant. Today its place in watercolor has been largely taken by zinc white and in oil by the titanium pigments and is also under the names; flake white and Cremnitz white. 


\section{Type of degradation}

It is commonly understood that the lead hydroxide, $\mathrm{Pb}(\mathrm{OH})_{2}$, part of the lead white molecule, is able, partially, to saponify linseed oil and to form with it a lead soap. Lead white with all media forms homogeneous, durable, strong and non-porous films. On indoor exposure, it has tendency to yellow, particularly in the dark. It is darkened by contact with sulphide pigments and hydrogen sulphide in the air because of the formation of black lead sulphide. Also it turns yellow when heated to a low temperature because of the formation of massicot (lead monoxide, $\mathrm{PbO}$ ). 


\section{Zinc white}

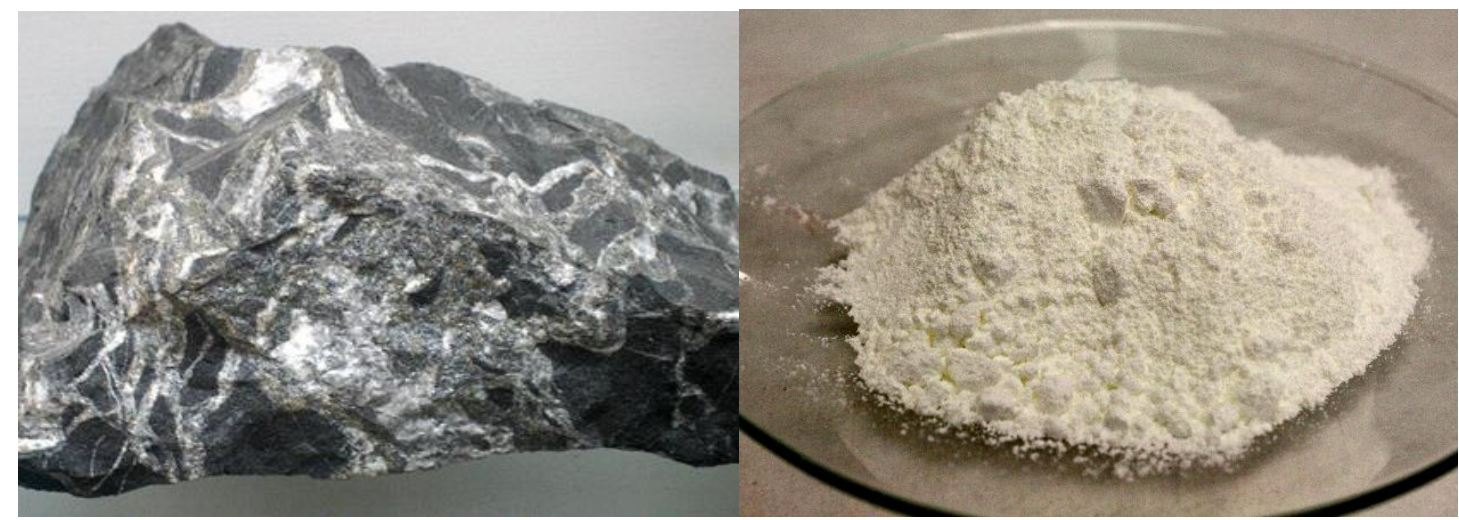

Figure 6.1.1.3.5 Mineral zinc (left) and zinc white used in this research project (right).

Origin: Synthetic

Color: White with a remarkable hiding power

Chemical name: Zinc (II) oxide

Formula: $\mathrm{ZnO}$

\section{Brief historical review}

A synthetic inorganic pigment, also known as Chinese white. In antiquity zinc oxide was used in medicine to preventing inflammation and has had special significance in the field of ophthalmology. It appeared as pigment in the 1782, by the hand of Guyton de Morveau a French chemist, as result of the artist's expectation for non-toxic materials, but it wasn't commercially available until middle of the $19^{\text {th }}$ century. Metallic zinc had originally come from China and the East Indies. When zinc ore was found in Europe, large-scale production of the extracted metallic zinc began. Most of the world's zinc oxide is manufactured via Indirect or French process, popularized by LeClaire (Paris, France) in 1844.This process consist of melting metallic zinc in graphite crucible and vaporized it at temperatures above $907^{\circ} \mathrm{C}$. The zinc vapor reacts with the oxygen in the air to give $\mathrm{ZnO}$, accompanied by a drop in temperature and bright luminescence (Porter, 1991). Zinc oxide represents one of the three white pigments of good hiding power that are of principal interest in the commercial world of artistic materials, has been widely used in water-dispersed mediums. In oil, its hiding power is not as great as in watercolours, so today many manufacturers incorporate it as a supplementary pigment in titanium and lead white oil paints, to improve the properties. Its excellent suspensions properties and absorbance of UV radiation have made it highly appreciated in the artistic world (Kühn, 1986).

\section{Type of degradation}

Lead to formation of zinc soaps/aggregation during the pigment-medium interactions in oil media in some cases associated to increased translucency, cracking and embrittlement of the paint layer.

Zinc oxide absorbs UV radiation. In paints this may help the pigment to protect an organic binder from destructive radiation, but may also 'be the source of troublesome photochemical reactions'. Zinc oxide with interstitial zinc or other lattice irregularities is considered more 
likely to dissipate energy capable of initiating photochemical reactions in adjacent materials. Degradation of binding media and fading of organic pigments, and weakening of supports including paper and textiles have been associated with zinc oxide. Zinc tends to react with the fatty-acid components of the drying oils, leading to the formation of zinc soaps. In the case of linseed-oil zinc oxide paints this action is considered to harden the films. Studies on particle size effects, however, describe zinc oxide pigments as forming stable aggregates in the dry state. These aggregates essentially function as a kinetic unit, translating primary particle size of $0.25-1 \mu \mathrm{m}$ to effective particle size of $1-5 \mu \mathrm{m}$, and typically of more spherical shape (Osmond, 2012). 


\section{Cadmium yellow}

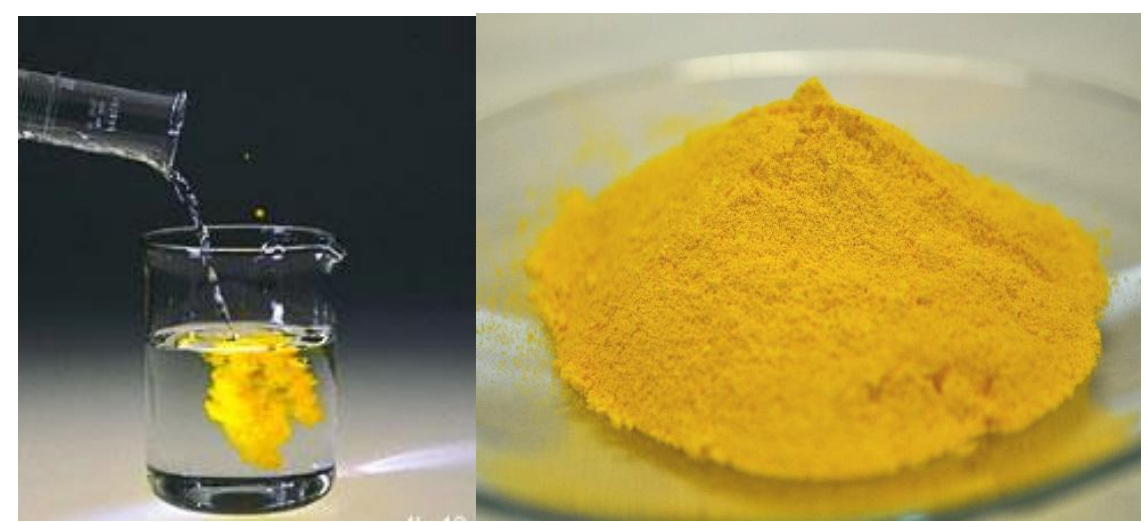

Figure 6.1.1.3.6 Cadmium sulphide precipitation reaction (left) and cadmium yellow used in this research project (right).

Origin: Artificial

Color: Varies from lemon yellow to orange

Chemical name: Cadmium sulphide

Formula: CdS

\section{Brief historical review}

An artificial pigment product of the evolution of the Industrial Age, discovered by Karl Hermann in 1817, did not become commercially available as pigment until about the second half of the $19^{\text {th }}$ century, very used in oil media paintings. Cadmium sulphide exists as two different minerals, hexagonal greenockite and cubic hawleyite. The cadmium yellow pigment production involves the precipitation of cadmium sulphide from an acid solution of a soluble cadmium salt (chloride or sulphate) with hydrogen sulphide gas or an alkali sulphide. This process is followed by washing of the precipitate to remove soluble salts and calcination to convert it into the hexagonal form. Other names for cadmium yellow were: cadmia, radiant yellow, daffodil, Aurora yellow, Orient yellow and neutral orange. Most of these names referred to varieties of cadmium sulfide prepared containing a small quantity of other minerals. Cadmium yellow has good hiding power and it is permanent and fast to light.

\section{Type of degradation}

This pigment may cause photochemical (light induced) degradation, forming a thin superficial alteration layer.

Since the late $19^{\text {th }}$ century cadmium yellow paints (in particular the paler shades) were known to react with their environment to cause fading and discoloration, and the phenomenon was noted in the art conservation literature in 1986 (Fiedler and Bayard, 1986). At the time this deterioration was attributed to adulterants or to use of smaller particle size of the paler shades. Recent research has revealed that the synthetic inorganic pigments used in the works of George Seurat, Vincent van Gogh and Pablo Picasso at the turn of the $20^{\text {th }}$ century, in particularly cadmium yellow, are undergoing degradation phenomena ranging from the lightening and color shift to flaking and spalling (Casadio et al., 2011; Monico et al., 2011; Leone et al., 2005). 


\subsubsection{References}

Banik, G. (1989) Discoloration of green copper pigments in manuscripts and works of graphic art. Restaurador, 10 (2), pp. 61-73.

Barnett, J.R., Miller, S., Pearce, E. (2006) Colour and art: A brief history of pigments. Optics \& Laser Technology, 38, pp. 445-453.

Bomford, D., Leighton, J., Kirby, J., Roy, A. (1990) Art in the making: Impressionism, National Gallery London Publications, Yale University Press.

Casadio F., Xie, S., Rukes, S.C., Myers, B., Gray, K.A., Warta, R., Fiedler, I. (2011) Electron energy loss spectroscopy elucidates the elusive darkening of zinc potassium chromate in Georges Seurat's A Sunday on la Grande Jatte-1884. Analytical and Bioanalytical Chemistry, 399(2), 2909-2920. DOI: 10.1007/s00216-010-4264-9

Cennini, C. (1988) Il libro dell'arte (14 ${ }^{\text {th }}$ century), Akal, Madrid.

Doménech-Carbó, M.T. (2013) Principios físico-químicos de los materiales integrantes de los bienes culturales. Servicio Publicaciones Univeritat Politècnica de València (SPUPV), Valencia.

Dunkerton, J., Roy, A. (1996) The materials of a group of late $15^{\text {th }}$ century Florentine panel paintings, National Gallery Technical Bulletin, 17, pp. 21-31.

Eastaugh, N., Walsh, V., Chaplin, T., Siddall, R. (2008) Pigment Compendium: A dictionary and optical microscopy of historical pigments, pp. 262, Butterworth-Heinemann.

Edwards, H.G.M., Vandenabeele, P., Benoy, T.J. (2015) Raman spectroscopic study of "The Malatesta": a Renaissance painting? Spectrochimica Acta Part A: Molecular and Biomolecular Spectroscopy, 137, 45-49.

Fiedler, I., Bayard, M.A. (1986). Cadmium yellows, oranges and reds. In Artists' Pigments. A Handbook of their History and Characteristics, Vol. 1 (R.L. Feller, ed.), pp. 65-108, National Gallery of Art, Washington DC.

Franquelo, M.L., Perez-Rodriguez, J.L. (2016) A new approach to the determination of the synthetic or natural origin of red pigments through spectroscopic analysis. Spectrochimica Acta Part A: Molecular and Biomolecular Spectroscopy, 166, 103-111.

Gettens, R.J., Kühn, H., Chase, W.T. (1993). Lead White. In Artists' Pigments. A Handbook of their History and Characteristics, Vol. 2 (R. Ashok, ed.), pp. 67-82, National Gallery of Art, Washington DC.

Gettens, R.J., Stout, G.L. (1966) Painting Materials, A. Short Encyclopedia, Dover, New York.

Gómez, M.A. (1998) La restauración. El examen científico aplicado a la conservación de obras de arte, Cátedra, Madrid.

Helwing, K. (2007). Iron oxide pigments: natural and synthetic. In Artists' Pigments: A Handbook of their History and Characteristics, Vol. 4 (B.H. Berrie, ed.), pp. 39-110, National Gallery of Art and Archetype Publications. 
Hradil, D., Grygar, T., Hradilová, J., Bezdička, P. (2003) Clay and iron oxide pigments in the history of painting. Applied Clay Science, 22 (5), pp. 223-236.

Huot, J.J.N. (1841) Massicot, in Nouveau Manuel Complet de Minéralogist Première Partie, A la Librairie Encyclopédique de Roret Paris, 346-347.

Kotulanová, E., Bezdička, P., Hradil, D., Hradilová, J., Švarcová, S., Grygar, T. (2009) Degradation of lead-based pigments by salt solutions. Journal of Cultural Heritage, 10 (3), pp. 367-378.

Kühn, H. (1993). Lead-Tin Yellow. In Artists' Pigments. A Handbook of their History and Characteristics, Vol. 2 (R. Ashok, ed.), pp. 83-112, National Gallery of Art, Washington DC.

Kühn, H. (1993). Verdigris and Copper Resinate. In Artists' Pigments. A Handbook of their History and Characteristics, Vol. 2 (R. Ashok, ed.), pp. 131-158, National Gallery of Art, Washington DC.

Kühn, H. (1986). Zinc White. In Artists' Pigments. A Handbook of their History and Characteristics, Vol. 1 (R.L. Feller, ed.), pp. 169-186, National Gallery of Art, Washington DC.

Larsen, E.S. (1917) Massicot and litharge, the two modifications of lead monoxide, American Minarelogist, 2, 18-19.

Le Fur, D. (1990) Pigments in Egyptian painting. Pigments and dyes of antiquity and the Middle Ages, Editions du Centre National de la Recherche Scientifique, Paris, 181-198.

Leone, B., Burnstock, A., Jones, C., Hallebeek, P., Boon, J., Keune, K. in ICOM Committee for Conservation 14th Triennial Meeting (James and James, The Hague, 2005), 803-813.

Maggetti, M., Neururer, C.H., Rosen, J. (2009) Antimonate opaque glaze colours from the faience manufacture of Le Bois d'Épense ( $19^{\text {th }}$ century, Northeastern France $)$. Archaeometry, 51(5), 791-807.

Matteini, M., Moles, A. (2001) La química en la restauración. Nerea, Guipúzcoa.

Mayer, R. (1993) TheArtist's Handbook of Materials and Techniques, $2^{\text {nd }}$ Edition, Hermann Blume, Madrid.

Monico, L., Van der Snickt, G., Janssens, K., De Nolf, W., Miliani, C., Verbeeck, J., Tian, H., Tan, H., Dik, J., Radepont, M., Cotte, M. (2011) Degradation process of lead chromate in paintings by Vincent van Gogh studied by means of synchrotron X-ray spectromicroscopy and relates methods. 1. Artificially aged model samples. Analytical Chemistry, 83, 12141223.

Naumova, M.M., Pisareva, S.A., Nechiporenko, G.O. (1990) Green copper pigments of old Russian frescoes. Studies in Conservation, 35, pp. 81-88.

Osmond, G. (2012) Zinc white: a review of zinc oxide pigment properties and implications for stability in oil-based paintings. AICCM Bulletin, 33, 20-29. (and references therein)

Porter, F. (1991) Zinc Handbook: Properties, Processing, and Use in Design. CRC Press. 
Sakr, A.A., Ghaly, M.F., Geight, E-S.F., Abdel-Haliem, M.F.F. (2016) Characterization of grounds, pigments, binding media, and varnish coating of the Angel Michael' icon, $18^{\text {th }}$ century, Egypt. Journal of Archaeological Science: Reports, 9, 347-357.

Santoro C., Zarkout, K., Le Hô, A-S., Mirambet, F., Gourier, D., Binet, L., Pagés-Camagna, S., Reguer, S., Mirabaud, S., Le Du, Y., Griesma, P., Lubin-Germain, N. (2014) New highlights on degradation process of verdigris from easel paintings. Applied Physics A, 114 (3), pp. 637-645.

Smith, W. (1890) Dictionary of Greek and Roman Antiquities, Albemarle Street, London, John Murray, pp. 285-286. (Digitalized in 2012)

Stoner, H., Rushfield, R. (eds.) The conservation of easel paintings. Abingdon, Oxon (England), New York: Routledge.

Tomasini, E.P., Halac, E.B., Reinoso, M., Di Liscia, E.J., Maier, M.S. (2012) Micro-Raman spectroscopy of carbón-based black pigments. Journal of Raman Spectroscopy, 43, pp. 16711675 .

Vaillant Callol, M., Doménech Carbó, M.T., Valentín Rodrigo, N. (2003) Una mirada a la conservación preventiva del patrimonio cultural (Ed. Universidad Politécnica de Valencia), Valencia, Spain.

Ward G.W.R. (2008) Grove encyclopedia of materials and techniques in art. Oxford University Press.

White, R. and Roy, A. (1998), GC-MS and SEM studies on the effects of solvents cleaning on Old Master paintings from the National Gallery, London. Studies in Conservation, 43(3), 159-176.

Winter, J. (1983) The characterization of pigments based on carbon. Studies in conservation, 28(2), pp. 49-66.

Consulted web references:

www.colour-index.com Consulted on September 10, 2016

www.naturalpigments.com/lead-white.html Consulted on November 20, 2016 


\subsubsection{Binding media}

A series of natural products has been used as binder in the elaboration of paints, since Ancient times. Binder is the word usually applied to the binding material or vehicle that confers fluidity to the paint enabling the formation of a thin layer or film in which the pigment particles hold together and providing the film formed the suitable rigidity and flexibility after the curing or drying period.

\subsubsection{Definitions}

\section{Tempera}

Along the history of art, this artistic technique has been evolving. Originally, the term tempera was wide as explain R. Gettens and G. Stout (1966): "The meanings of the word, 'tempera', as used to define a painting medium, have been many and have changed from time to time in the history of the art. As late as the $15^{\text {th }}$ century this term probably included all mediums but, with gradual prevalence of oil, its limits were narrowed until it has often meant only a medium prepared from egg. A broader definition which allows it to include albuminous, gelatinous, and colloidal materials is also in use. For specification this requires a second term, and the whole would be, for example, 'glue tempera', 'gum tempera', or 'egg tempera'...".

Following Antonio Pedrola (2006) we study the term tempera by searching the origins of the word: "The tempera name comes from "temper" which means a material condition to give specific properties. In painting, temper means to give the binder the right degree of adhesiveness and flexibility required to behave optimally. According to this author, paintings prepared using egg as binding medium were formerly called "tempers". This term was extended later to the whole emulsion made with oil and egg. Today the name of tempera is given to all kinds of aqueous paint having water as diluent." 
Most recently, Mauro Matteini and Arcangelo Moles (2001) wrote a definition based on the use of the term in the Italian language: "Italian terms "tempera" and "temperare" originally designated the action of mixing powdered pigments with a binder to obtain a paste applied in the form of colored paint layers on a support. From this point of view, any binder could be considered a temper. However, with the gradual flowering of the techniques in oil, tempera passed the word to designate gradually reduced binders used exclusively in aqueous dispersions together, and this is the actual meaning of the term."

Based on the literature consulted and considering the most appropriate definitions for this study of the term tempera we can said that greater part of pictorial artworks in history has been done using tempera (with some kind of aqueous medium).

\subsubsection{Classification}

Based on the previously described definition of the term tempera, in this part will be described the natural binding media encompassed by the term. From a chemical point of view materials historically used for preparing tempera media are part of three different groups in the chemical classification of organic natural substances (See Table 6.1.2.2.1).

Table 6.1.2.2.1 Chemical classification of the natural film-forming substances used as tempera media of artworks.

\begin{tabular}{|l|l|}
\hline Group & Natural product (source) \\
\hline \multirow{3}{*}{ Proteins } & Gelatin, animal glue \\
& $\begin{array}{l}\text { Casein } \\
\text { Egg (yolk, white and whole) }\end{array}$ \\
\hline Lipids & $\begin{array}{l}\text { Drying oils } \\
\text { Waxes }\end{array}$ \\
\hline Carbohydrates: polysaccharides & Plant gums and mucilages \\
\hline
\end{tabular}

\subsection{Proteinaceous media}

Proteins are macromolecular compounds present in most lives forms, widely used as binders in artworks due to its film-forming properties.

\section{Chemical composition}

Proteins are the most abundant organic molecules in animals, playing important roles in most aspects of their metabolism and as materials constituents of support tissues. Proteins are macromolecules of polymeric structure composed of amino-acid residues joined by peptide bonds, contain the elements carbon, hydrogen, nitrogen, oxygen and usually sulfur, and occasionally other elements (as phosphorus or iron). The peptide bonds responsible of the protein chains are formed by condensation reaction between amino acids. Peptides are compounds consisting of two or more amino acids linked in a chain, where the carboxyl group of each acid is joined to the amino group of the next by a bond of the type -OC-NH-. These peptides are bonded together forming polymeric chains called polypeptides consisting of a large number of amino acid residues, forming part of the whole protein molecule. Long 
polypeptide chains (6000 to 41,000,000 unities) fold into a well-defined structure in a specific manner to have a specific function is known as protein. The physical and chemical properties of a specific protein are determined by its constituent amino acids residues and respective side chain R (Figure 6.1.2.2.1.1) (Spassoy et al., 2007; Bischoff and Schlüter, 2012). An important feature of amino acid residues in respect to their role as the basic building blocks of proteins is that they are assembled from two distinct units - the peptide backbone (non-variable) and the side chain groups (highly variable). This characteristic design suggests that interactions between amino acids chains are important intramolecular interactions in the structural realization of amino acid code. Side chain interactions play the major role in side chain packing, in stabilizing the folded structures, and in differentiating the folded structures from the unfolded or misfolded structures. (Pallarès and Ventura, 2016; Berezovsky et al., 2017).

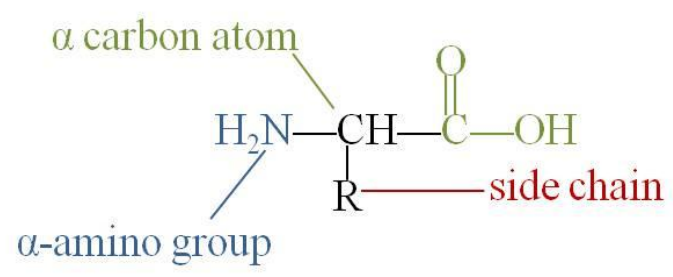

Figure 6.1.2.2.1.1 Formula of an amino acid.

As mentioned before amino acids are the primary building blocks of proteins, over 20 naturally occurred amino acids are known. Amino acids contain at least one amino group ($\mathrm{NH}_{2}$ ) and a carboxy $(-\mathrm{COOH})$ group. They can be classified on many ways according to: the core structural functional groups locations, polarity, $\mathrm{pH}$ level, and side chain group type. Considering that their chemical, physical and structural properties depend on the respective side chain R, we would classify them according to the side chain residues group type (Figure 6.1.2.2.1.2). According to the reactivity of their side chain amino acids may be grouped as charged (e.g. carboxy or amino residues), polar (e.g. hydroxyl or amide residues) and hydrophobic (e.g. alkyl, indole, thiol, thioether or seleno residues) residues. Hydrophobic amino acids residues build up the core of the protein, polar and charged amino acids residues preferentially cover the surface of the molecule and are in contact with solvent due to their ability to form hydrogen bonds. Positively and negatively charged amino acids often form so called salt bridges. These interactions may be important for the stabilization of the protein three-dimensional structure (Bischoff and Schlüter, 2012). 


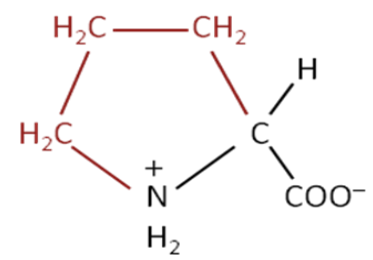

Proline

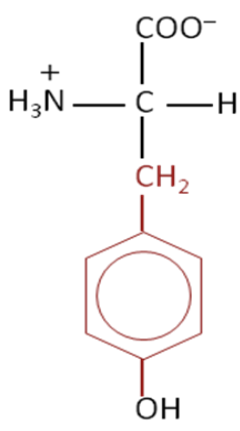

Tyrosine

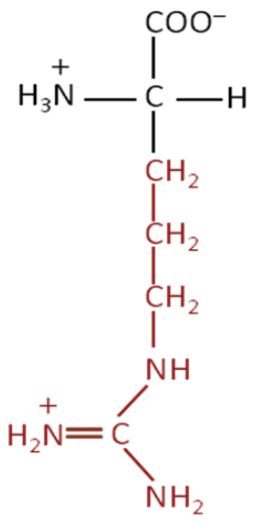

Arginine

Figure 6.1.2.2.1.2 Proteinogenic amino acids structures with a: hydrophobic alkyl residue (proline), polar hydroxyl residue (tyrosine) and charged amino residue (arginine).

\section{Structure}

\section{Primary structure}

The most frequently occurring reaction of amino acids in living organisms is the formation of an amide bond (-NHCO-), termed peptide bond, between the $\alpha$-carboxyl group of one amino acid with the $\alpha$-amino group of a second amino acid of the growing peptide chain. These amino acid units are linked together by -NHCO- groups, known as peptide linkages (Figure 6.1.2.2.1.3, up). The complete amino acid sequence results in large molecules usually known as proteins. Each protein has a unique and precise amino acid sequence that is known as its primary structure (Figure 6.1.2.2.1.3, down). All the properties of the protein are determined, directly or indirectly, by its primary structure.
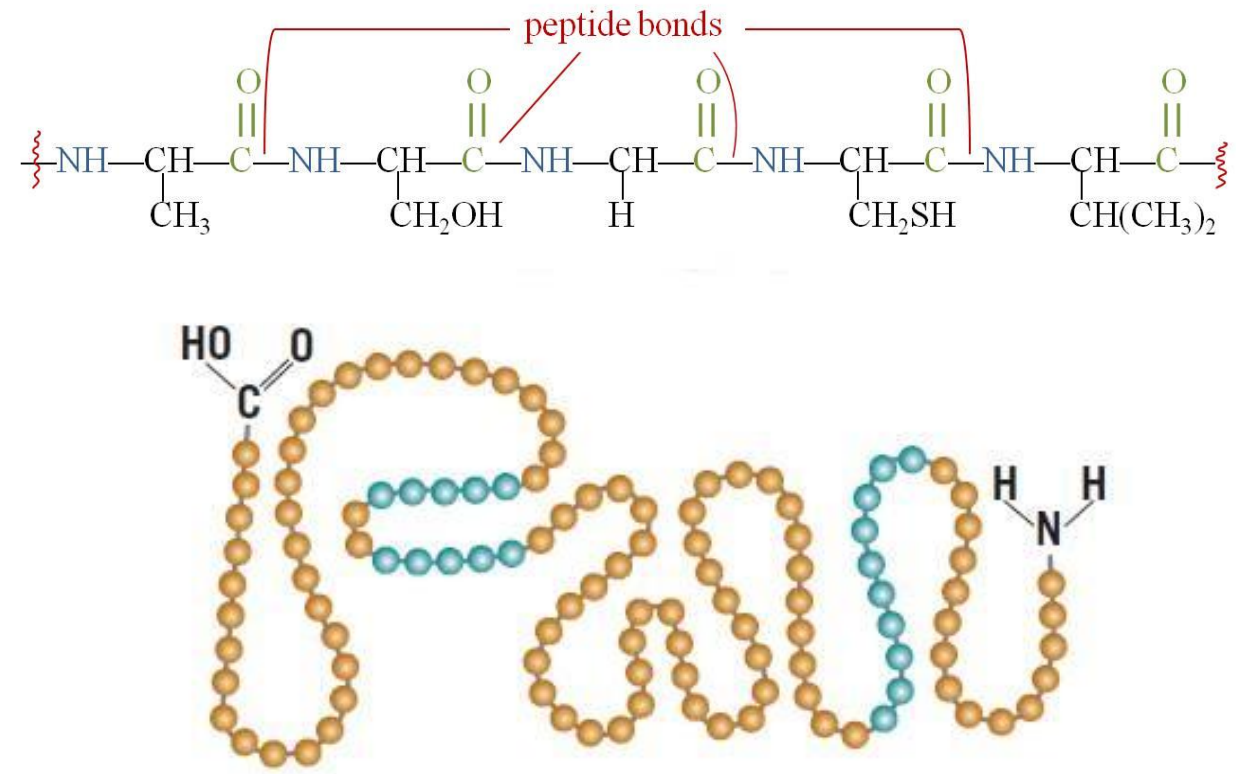

Figure 6.1.2.2.1.3 Formation of a molecule of polypeptide or protein by means of peptide bonds established between amino acid units (primary structure). 


\section{$\underline{\text { Secondary structure }}$}

Besides the basic primary structure, most of the peptide chains in the protein molecule tend to forms an orderly arrangement of intramolecular bonds established between the functional groups contained in the residues of the amino acid molecules that conform the primary amino acid chains. This arrangement is called the secondary structure or conformation of the protein (Chitturi et al., 2016).

There are several arrangements based on the formation of intramolecular links between the residues of the amino acids:

\section{a) $\alpha$-helix conformation}

The $\alpha$-helix is a right-handed coiled strand. The side chain substituents of the amino acid groups in an $\alpha$-helix extend to the outside. Hydrogen bonds form between the oxygen of the $\mathrm{C}=\mathrm{O}$ of each peptide bond in the strand and the hydrogen of the $\mathrm{N}-\mathrm{H}$ group of the peptide bond four amino acids below it in the helix. The hydrogen bonds make this structure especially stable. The side chain substituents of the amino acids fit in beside the N-H groups. For example, the fibrous protein $\alpha$-keratin is arranged in the $\alpha$-helical structure, and most globular proteins contain segments of $\alpha$-helix (Figure 6.1.2.2.1.4).
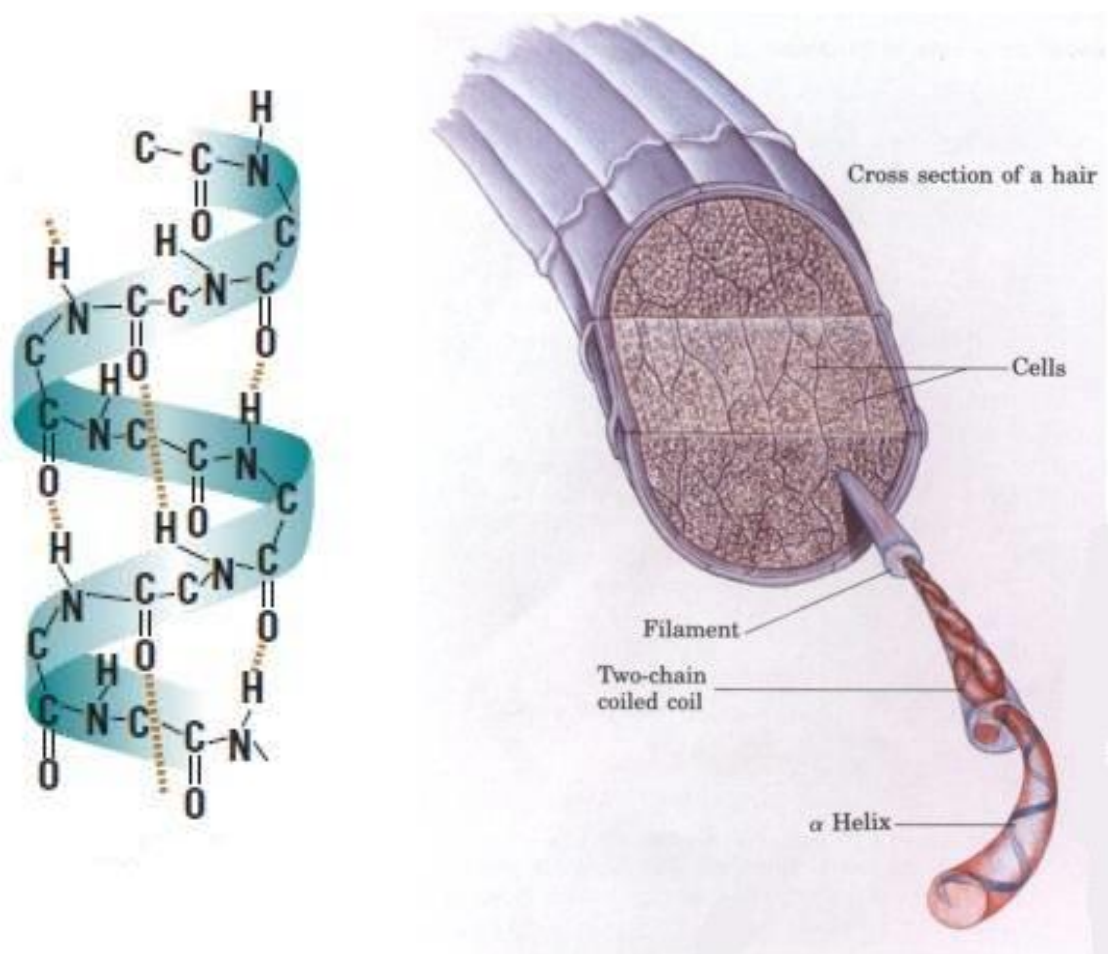

Figure 6.1.2.2.1.4 $\alpha$-helix protein conformation structure (left) and $\alpha$-helical structure in the fibrous protein $\alpha$ keratin (right). 


\section{b) $\beta$-sheet conformation}

The hydrogen bonding in a $\beta$-sheet is between strands (intermolecular strands) rather than within strands (intramolecular strands). Peptide segments form an orderly arrangement of hydrogen bonds called the sheet conformation that consists of pairs of strands lining side-byside (consider a strand as a continuous and contiguous polypeptide backbone propagating in one direction). The carbonyl oxygen in one strand forms a hydrogen bond with the amino hydrogen of the adjacent strand. The bond angles between amino acid units are such that the sheet is pleated, with the amino acid side chains arranged on alternating sides of the sheet (Figure 6.1.2.2.1.5). The two chains can be either parallel (Figure 6.1.2.2.1.6) or anti-parallel (Figure 6.1.2.2.1.7) depending on whether the chain directions ( $\mathrm{N}$-terminus to $\mathrm{C}$-terminus) are the same or opposite. The anti-parallel $\beta$-sheet is more stable due to the more well-aligned hydrogen bonds. Fibrous proteins have a pleated sheet secondary structure.

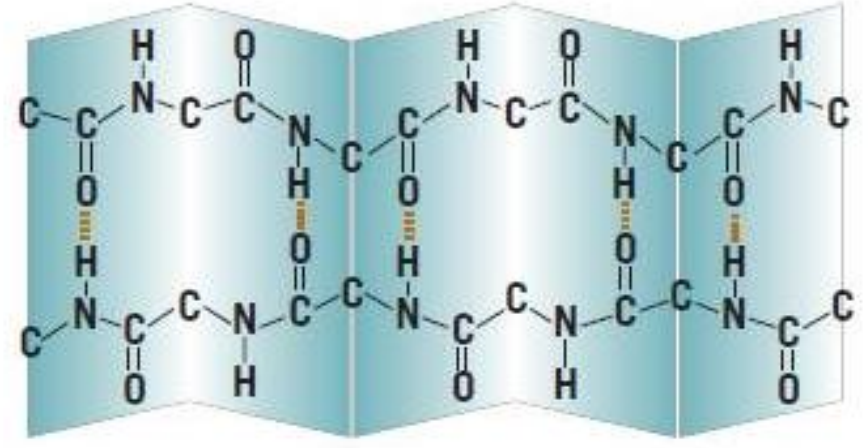

Figure 6.1.2.2.1.5 $\beta$-sheet protein conformation structure.

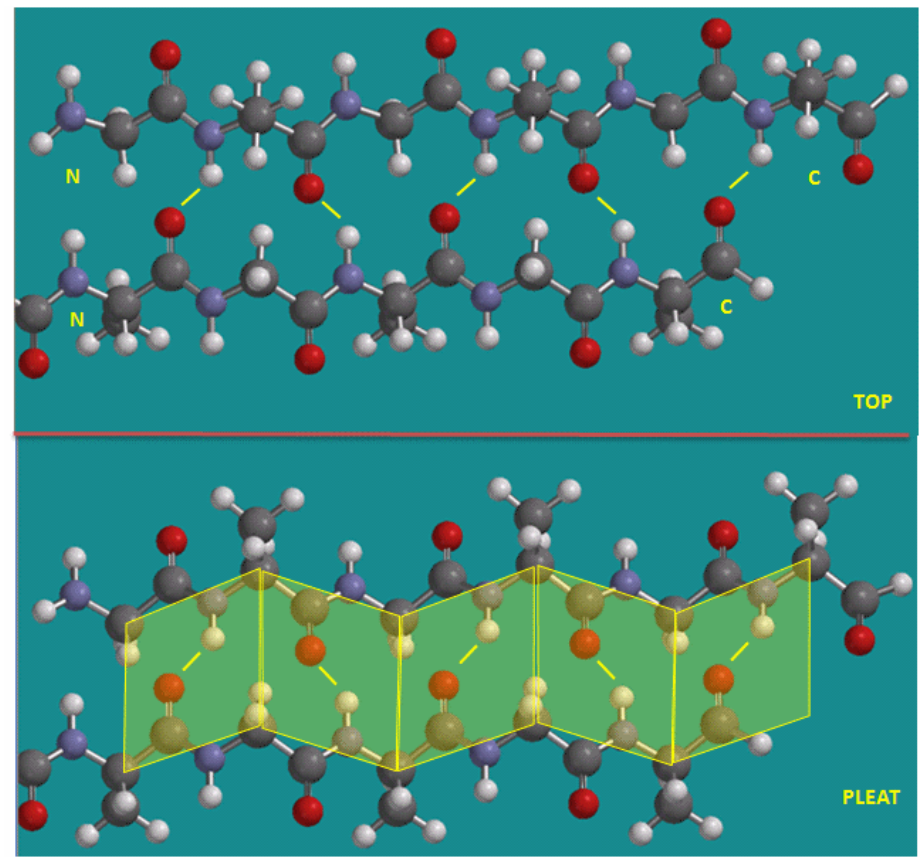

Figure 6.1.2.2.1.6 Parallel $\beta$-sheet protein conformation structure (Image obtained from: bio.libretexts.org). 


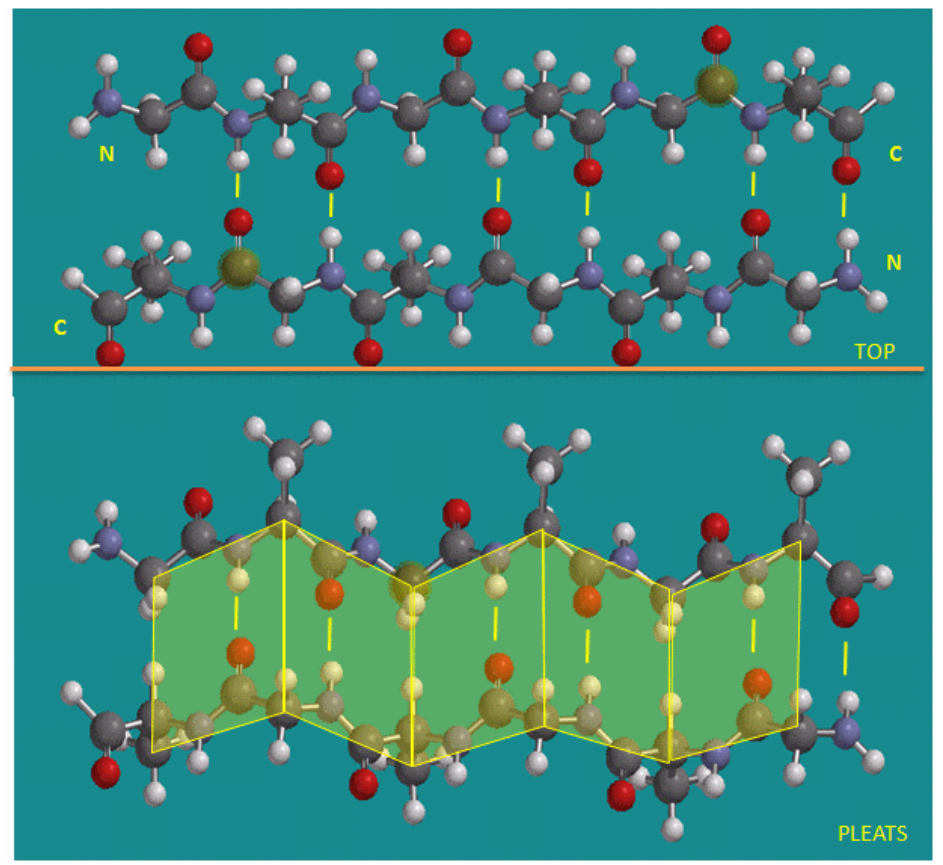

Figure 6.1.2.2.1.7 Anti-parallel $\beta$-sheet protein conformation structure (Image obtained from: bio.libretexts.org).

In a parallel $\beta$-sheet conformation structure, the optimal hydrogen bond pattern leads to a less extended structure than the optimal arrangement of the hydrogen bonds in the antiparallel structure. Also the hydrogen bonds in the parallel sheet are bent significantly (i.e. the carbonyl oxygen on one strand is not exactly opposite the amide hydrogen on the adjacent strand, as it is in the antiparallel sheet). The side chains in the $\beta$ sheet are normal to the plane of the sheet, extending out from the plane on alternating sides. Parallel sheets characteristically distribute hydrophobic side chains on both side of the sheet, while antiparallel sheets are usually arranged with all the hydrophobic residues on one side. This requires an alternation of hydrophilic and hydrophobic side chains in the primary sequence. Antiparallel $\beta$-strands are presumably more stable, even though both are abundantly found in nature. Antiparallel sheets are found in silk with the sheets running parallel to the silk fibers.

\section{c) Random coil}

Additional to the $\alpha$-helix and $\beta$-sheet structures, there are other non-repetitive elements of secondary structure called coil conformations (see Figure 6.1.2.2.1.8). The lack of repetitive order in coil conformations does not mean that these structures are unstable. These disorder regions in proteins, referred to as random coil, play an important part in the protein's function. For instance, random coil may be involved in the binding ligand, with consequent changes in the conformation and activity of the protein (Smith et al., 1996). For example, globular proteins contain segments of $\alpha$-helix or pleated sheet separated by kinks of random coil, allowing the molecule to fold into its globular shape. 


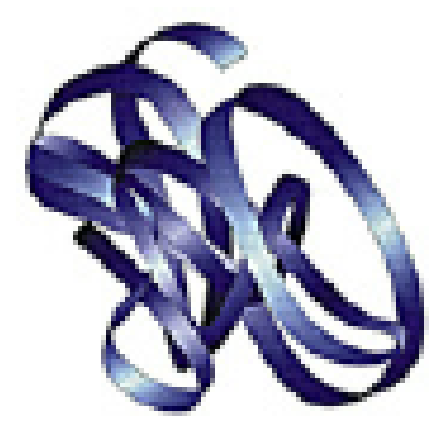

Figure 6.1.2.2.1.8 Random coil conformation protein structure.

\section{d) Turn}

In proteins, a polypeptide often makes a sharp turn called a reverse turn. These turns links adjacent strands in antiparallel $\beta$-sheet conformation. Also known as $\beta$ bends, reverse turns involve four amino acid residues with a hydrogen bond between the $\mathrm{C}=\mathrm{O}$ group of the first residue and the $\mathrm{N}-\mathrm{H}$ group of the fourth (see Figure 6.1.2.2.1.9). Exist two types of reverse turns ( $\beta$ bends), differed by the torsion angles for the residues. If we look at the $\mathrm{C}_{03}$ in the Figure 6.1.2.2.1.9, a difference of $180^{\circ}$ in the torsion angle between $\beta$ bend type I and II can be observed. These turns are tighter than the turn in the $\alpha$-helix confirmation. Other type of turn is the omega loop. Both turns tend to located at the surface of proteins where they play an important part in the recognition role of proteins, such as the recognition of specific antigens by antibodies (de Brevern, 2016).

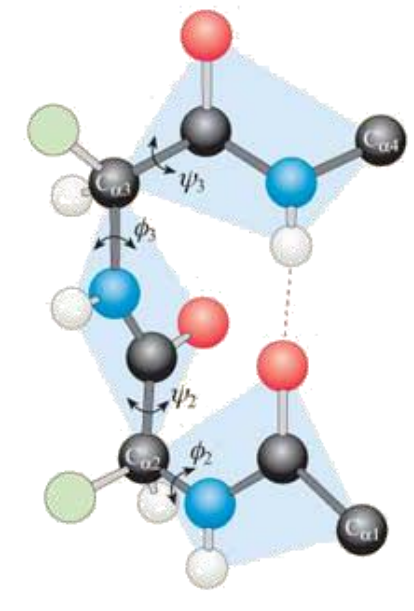

(a) Type 1.:B bend

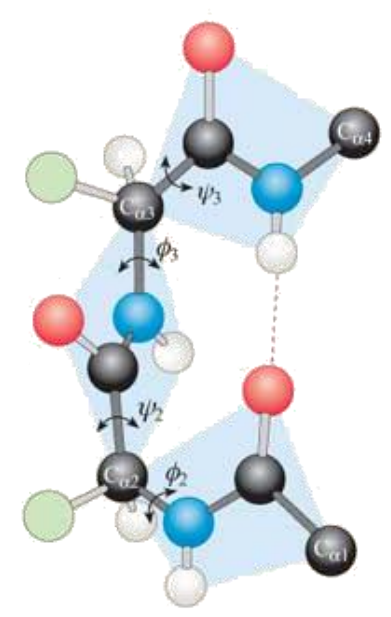

(b) Type II B. bènd

Figure 6.1.2.2.1.9 type I and II structures in reverse turns ( $\beta$ bends) conformation (Image obtained from: www.open.edu).

\section{$\underline{\text { Tertiary structure }}$}

The helical secondary structure usually is refolded between itself adopting a tertiary structure by hydrogen and disulfide bonding bridges between different parts of the molecule to achieve maximum stability or lowest energy state. This tertiary structure is its complete threedimensional conformation, which includes all the secondary structures and all the kinks and folds in between (see Figure 6.1.2.2.1.10). The tertiary structure is mainly evident in globular 
proteins. In their three-dimensional structure polar (hydrophilic) side chains are oriented toward the outside of the globule (Kister, 2013). Non-polar (hydrophobic) side chain groups are arranged toward the interior thereby shielding them from aqueous medium. Hydrogen bonds may form between different side-chain groups. As with hydrogen and disulfide bonding bridges, salt bridges consisting of ionic interactions between positively and negatively charged sites on amino acid side chains, also help to stabilize the tertiary structure of a protein. For example, the formation of disulfide bridges by oxidation of the sulfhydryl groups on cysteine is an important aspect of the stabilization of protein tertiary structure, allowing different parts of the protein chain to be held together covalently (see Figure 6.1.2.2.1.11).

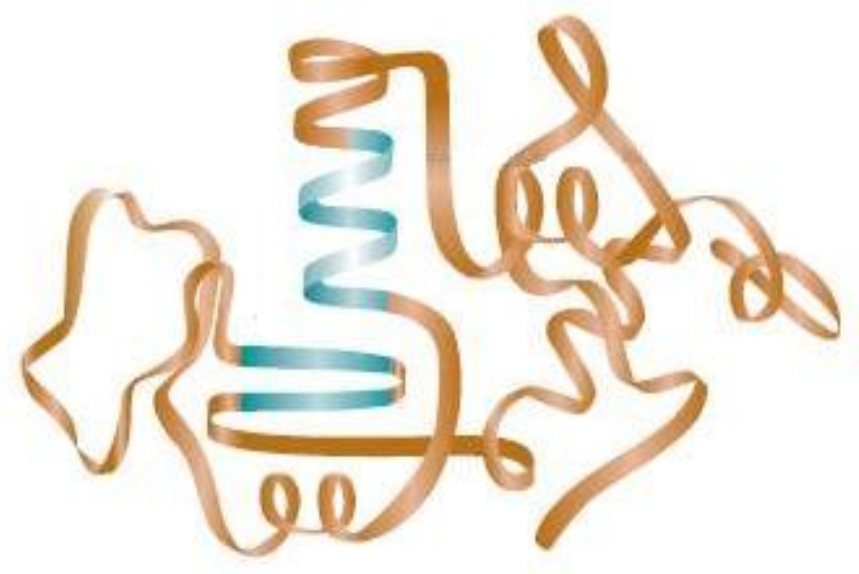

Figure 6.1.2.2.1.10 Protein tertiary structure.
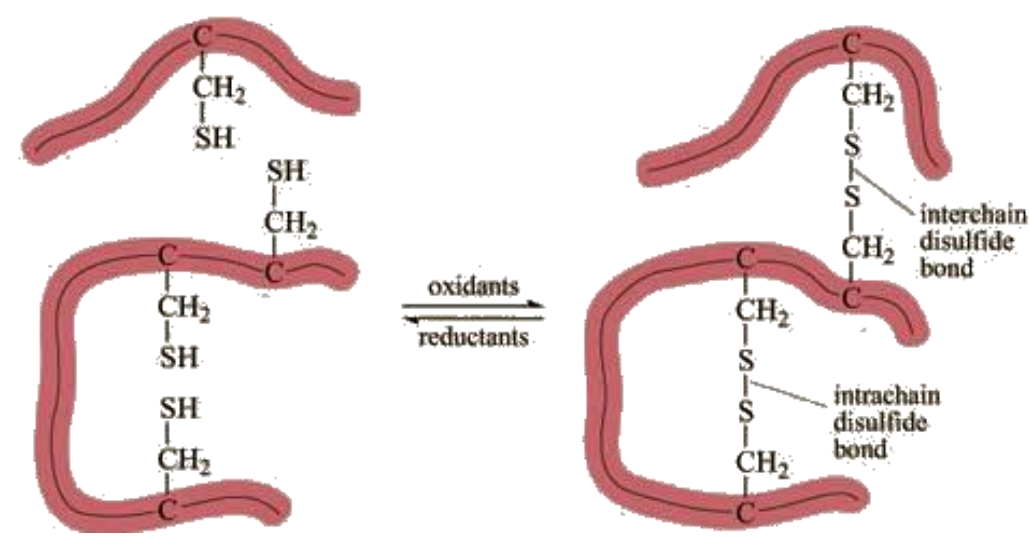

Figure 6.1.2.2.1.11 An example of the formation of how a disulphide bond between cystein side chains stabilizes existing structures in a polypeptide. These bonds can form between two polypeptide strands or between residues in the same polypeptide. 


\section{Quaternary structure}

Many proteins are made up of multiple polypeptide chains, often referred to as protein subunits. These subunits may be the same (as in a homodimer) or different (as in a heterodimer). The quaternary structure refers to how these protein subunits interact with each other and arrange themselves to form a larger aggregate protein complex. The final shape of the protein complex is once again stabilized by various interactions, including hydrogenbonding, disulfide-bridges and salt bridges. For example, hemoglobin, consists of four peptide chains fitted together to form a globular protein (See Figure 6.1.2.2.1.12).

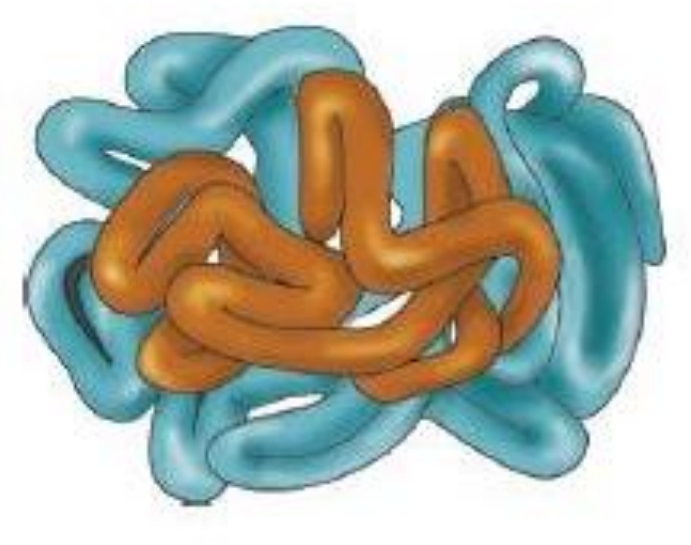

Figure 6.1.2.2.1.12 Protein quaternary structure.

\section{$\underline{\text { Classification }}$}

According to their composition proteins are classified in simple and conjugated proteins. Simple proteins are composed only by amino acids. Within this type are included the albumins as the ovoalbumin from the egg white, the scleroproteins such as silk fibroin, the elastin from the tendons or the collagen from the cartilage or bone tissue. When these colloids are heated, stir or suffer the addition of acids or alcohols, an irreversible coagulation process occurs.

Conjugated proteins are composed of amino acids and additional organic and inorganic groups, certain of which are called prothestic groups. Conjugated proteins include glycoproteins, which contain carbohydrates; lipoproteins, which contain lipids; and nucleoproteins, which contain nucleic acids. Thus for example, milk casein a phosphoprotein in which the prothestic group is the esterification product of the phosphoric acid and the free hydroxyl of serine. The egg yolk contains important phosphoproteins as the phosvitin, besides a sterol, cholesterol and lecithin the phospholipid which confers emulsifying properties to egg. 


\section{Proteinaceous materials used as binding media}

a) Collagen and animal glues

Animal glues: used as binding media are natural polymers derived from mammalian or fish collagen - the major structural protein constituent of skins, connective tissue, cartilage and bones. Among the amino acids present in the hydrolyzed proteinaceous materials of the glues are glycine and hydroxyproline. These glues may exhibit varied physical, chemical and mechanical properties depending on their origin and method of preparation (Colombini and Modugno, 2009).

Collagen: is the main structural protein of connective tissues in animals, including the skin, muscle tissue, bone and hide. Collagen constitutes one to two percent of muscle tissue, and accounts for $6 \%$ of the weight of strong, tendinous muscles (Shoulders and Raines, 2009). The collagen extracted from animals (mammalian and fishes) are substances widely used since ancient times as adhesives and binders in Fine Arts.

Collagen consists of long protein molecules constituted of amino acids linked in a specific sequence by covalent peptide bonds (Table 6.1.2.2.1.1). Due to the spatial conformation of some amino acid groups (notably proline and hydroxyproline) and the protein chain, the individual chains form triple-stranded helical coils that are internally stabilized by hydrogenbonding. Structural studies of collagen show that it contains frequently repeating glycineproline-hydroxyproline amino acid sequences (Bear, 1952; Eastoe, 1955; Harrington and Hippel, 1961; Dallongeville et al., 2011). Normally the collagen is insoluble, but it becomes soluble after treatment with alkaline or acidic materials.

Table 6.1.2.2.1.1. Amino acids composition of collagen and animal glues used as binding media.

\begin{tabular}{l|c}
\hline \multicolumn{1}{c|}{ Amino acid } & $\begin{array}{c}\text { Composition } \\
\end{array}$ \\
\hline Glycine & 24.7 \\
Alanine & 10.1 \\
Valine & 2.2 \\
Leucine & 3.7 \\
Isoleucine & 1.2 \\
Proline & 13.0 \\
Phenylalanine & 1.6 \\
Serine & 4.0 \\
Threonine & 2.2 \\
Methionine & 1.4 \\
Arginine & 8.2 \\
Histidine & 1.5 \\
Lysine & 4.1 \\
Aspartic acid & 5.0 \\
Glutamic acid & 9.7 \\
Hydroxyproline & 7.4 \\
Adapted from Mills and White, 1994.
\end{tabular}


Glue is the general term used as a synonym for adhesive and for aqueous adherent solutions. Glues are organic colloidal substance with a molecular weight of about one third of collagen (Mills and White, 1994). It is also associated with other proteins materials such as keratin, elastin, mucin, chondrin, etc. in addition to non-protein, organic material and inorganic salts which may or may not remain in the glue. Glue is prepared through hydrolysis of the collagen obtained from bones, skins, tendons and other tissues. It is a product obtained from the separation of the polypeptide chains as a consequence of breaking of the hydrogen bonds between and then replace these with new hydrogen bonds to solvent water instead. It dissolves entirely in water, when gently heated, and swells without dissolve when is soaked in cold water for a long period of time. It occurs in commerce in a wide variety of forms and colors (Mills and White, 1994; Matteini and Moles, 2001). The colors range through all shades of white, yellow, and brown and glue may be transparent, translucent, or opaque.

Gelatin: is a colloidal dispersion formed by transformation of a glue solution to a highly adhesive gel by the loss of the water from the dispersing phase. Gelatin, the purified active ingredient of any collagen-derived glue (pure denatured collagen), may be obtained from either skin or bone sources and is supplied in the form of colorless or slightly yellow, transparent, brittle thin sheets, flakes or coarse powder. The difference between glue and gelatin is one of purity, the more impure form is termed 'glue' and is used only as an adhesive; the purer form, termed 'gelatin' has a wide variety of applications. It swells up and absorbs 5-10 times its weight of water to form a gel in solutions below $30-40^{\circ} \mathrm{C}$. Gelatin is a hydrocolloid that consists of a heterogeneous mixture of water-soluble proteins of high average molecular mass that forms thermo-reversible films, which have found important applications in pharmaceutical, (Achet and He, 1995) food (confectionery, jellies, ice cream), as rubber substitutes, adhesives, photographic plates and films, matches and clarifying agent (Jones, 1997). In Fine Arts this material has been used since ancient times as binding medium and adhesive (Mills and White, 1994; Gettens and Stout, 1966; Mayer, 1993). Use of gelatins as consolidants and adhesives in conservation treatments performed on paintings has increased progressively in recent years due to the interest of conservators in replacing synthetic polymers by more eco-friendly materials (Vizárová et al., 2011, Doménech- Carbó et al., 2015).

Gelatin is mainly composed of glycine and proline and contains remarkable amount of hydroxyproline (Poppe, 1997). This amino acid promotes the formation of hydrogen-bonding interaction between the hydroxyl groups of the hydroxyproline and the hydrogens of the glycine units. Aromatic amino acids tyrosine and phenylalanine are also present in low amount (Poppe, 1997; Mariod and Adam, 2013).

\section{b) Egg proteins}

The avian eggs, an important source of nutrients for humans, has been one of the most important sources of medium for artist through history. Cennino Cennini describe in great detail how to use egg yolks of different hens - urban ones and countryside ones, with pale 
and dark yellow egg yolks respectively - for different flesh tones (Figure 6.1.2.2.1.13) (Cennini, 1988).

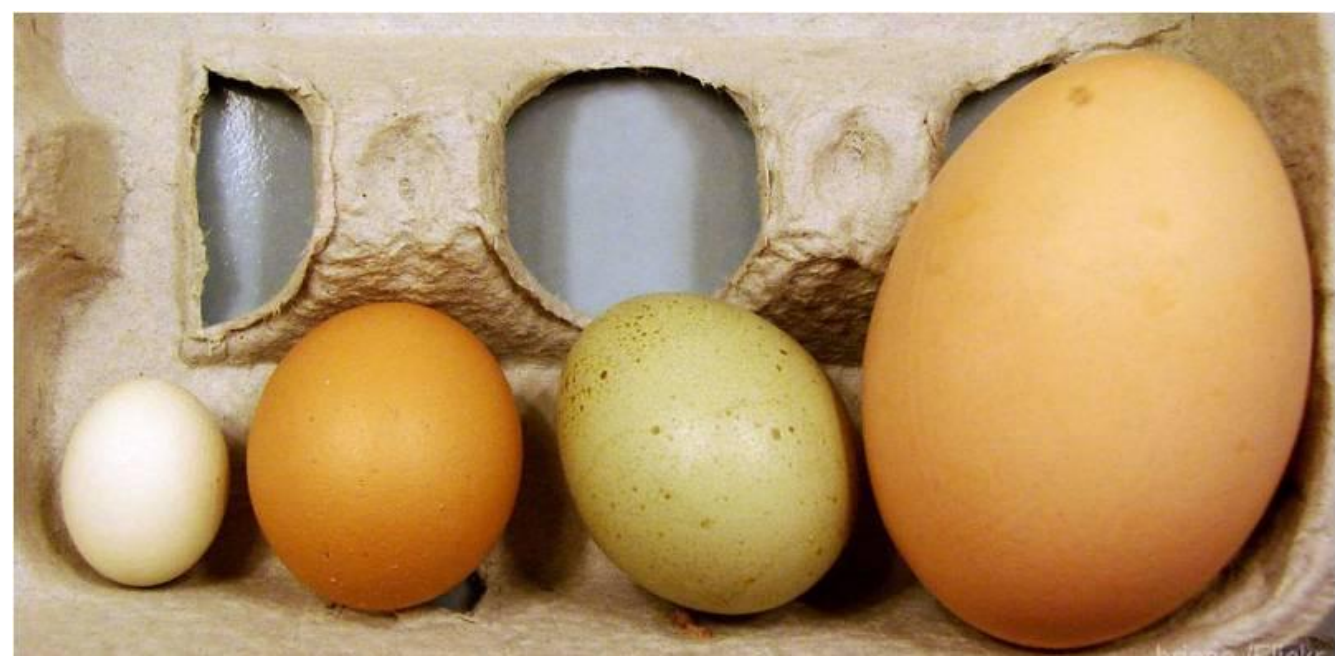

Figure 6.1.2.2.1.13. Image of different hen egg types (Image obtained from www.hobbyfarms.com).

An understanding of the egg's microstructure and chemical characteristics provides the fundamental basis for a better documentation of this binding medium. The chemical composition of eggs includes a wide variety of chemical components as: water, protein, fatty acids, mineral, vitamins, and pigments. Eggs are mainly made up of water, protein and lipids, also contain a small amount of carbohydrates (which includes glucose, sucrose, fructose, lactose, maltose, and galactose). These components are present in varied proportion in the three main parts of the egg (Figure 6.1.2.2.1.14).

Eggs are composed of three main parts; eggshell ( $9-11 \%)$, whit the eggshell membrane, the albumen or egg white $(60-63 \%)$, and the egg yolk $(28-29 \%)$ (Figure 6.1.2.2.1.16). The yolk is located in the center of the egg surrounded by albumen, which in turn is enveloped by eggshell membranes and finally a hard eggshell. The egg is composed of a shell, shell membranes, an air cell, the chalaza, the albumen, and the yolk. The yolk is centered in the albumen and surrounded by the vitelline membrane. The germinal disk, where fertilization takes place, is attached to the yolk. On opposite sides of the yolk are two twisted cord-like strands known chalazae. Their function is to support the yolk in the center of the albumen. Surrounding the albumen are two shell membranes and the shell itself (Figure 6.1.2.2.1.15). 


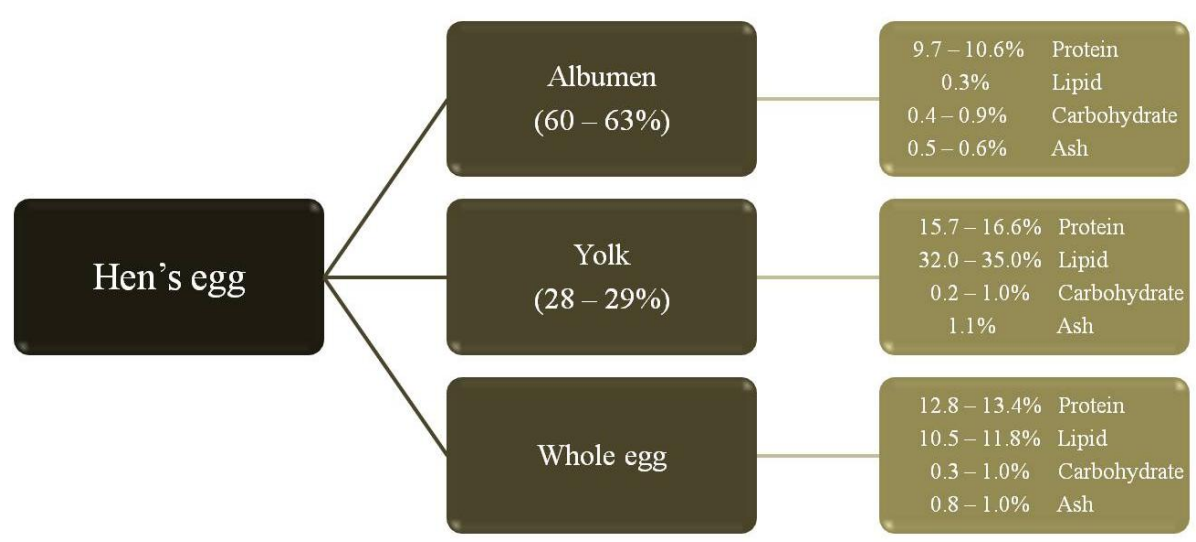

Figure 6.1.2.2.1.14. Hen's egg albumen, yolk, and whole egg composition.

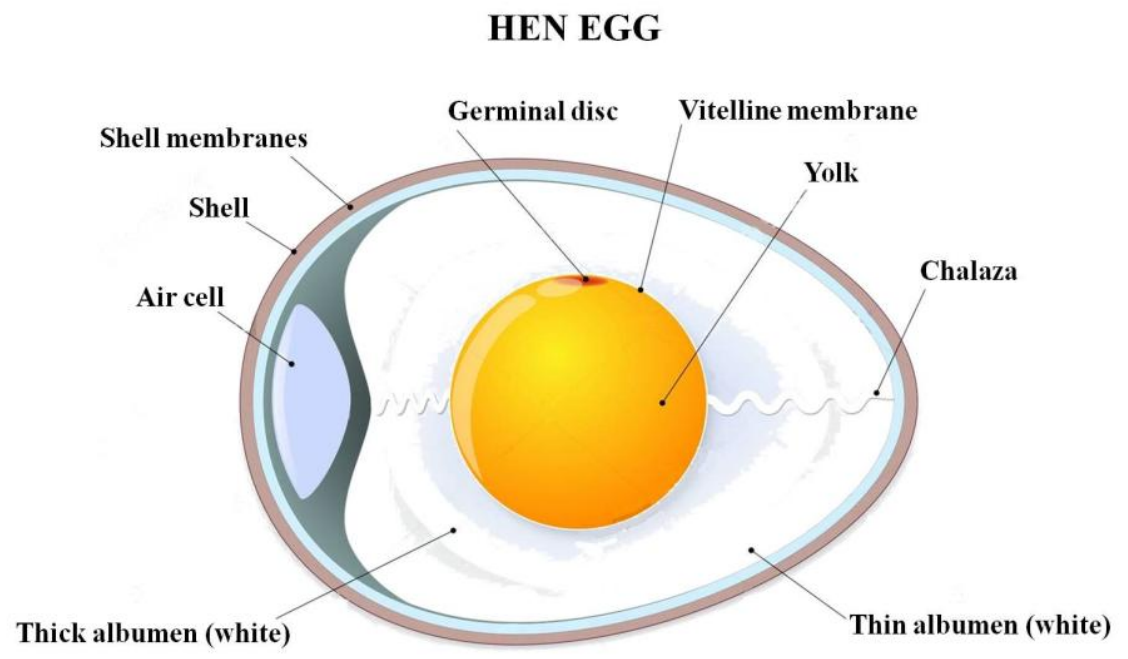

Figure 6.1.2.2.1.15. Structure of the hen's egg. (Adapted from www.shutterstock.com)

The eggshell has a polycrystalline structure which includes a porous layer of cuticle, a calcite layer, and two shell membranes. There are four main layers in the eggshell: the cuticle, the palisade region, the mammillary layer (or inner calcified layer) and the shell membranes. The cuticle is a thin layer of $10-30 \mu \mathrm{m}$ which contains mineralized and organic layers as well as most of the pigment. The palisade region, a dense vertical crystal layer about $200 \mu \mathrm{m}$ thick composed of a calcified spongy matrix with a crystalline structure. The mammillary layer is located in the basal part of calcified columns and includes the calcium reserve assembly and crown region. The last one is the shell membranes, which includes the inner $(20 \mu \mathrm{m})$ and the outer $(50 \mu \mathrm{m})$ membranes which are located between the albumen and the mammillary layer and are formed by organic fibers and used to protect against the penetration of microorganisms (Mine and Zhang, 2013; Anton, 2013).

The albumen or egg white, is comprised of four separate layers. Approximately, $23 \%$ of the albumen is made up of a thin layer attached to the shell inner membrane, other $57.3 \%$ of albumen is composed of a viscous white layer; and a $16.8 \%$ of albumen is composed of an inner thin white layer. The chalaziferous layer comprises the $2.7 \%$ of the albumen. The thick 
and thin layer of egg white had different viscosities due to the different content of ovomucin (Mine and Zhang, 2013; Anton, 2013).

The macrostructure of egg yolk consists of vitelline membrane, yellow and white yolk. The vitelline membrane is a thin (about $10 \mu \mathrm{m}$ ) protein fiber membrane which contains three multiple layers. The yellow yolk is composed of a light yellow layer and a deep yellow layer of plasma which are mainly formed by lipid-proteins particles. These particles have been classified as spheres, profiles, or granules depending on their size (Mine and Zhang, 2013; Anton, 2013). Chemical composition of egg yolk is complex. Average composition of hen's egg yolk in dry state is: $33.0 \%$ proteins, $62.5 \%$ lipids, $1.2 \%$ carbohydrates and $3.5 \%$ mineral matter (Li-Chan et al., 1995) (See table 6.1.2.2.1.2). All these types of compounds are distributed in different structuration levels.

\section{Yolk}

The microscopical chemical composition of egg yolk is complex considering that the yolk has different structural levels which includes insoluble denser protein-lipid aggregates. These protein-lipid particles are classified according to their size in spheres (Ø: $4-150 \mu \mathrm{m})$, profiles (low-density lipoproteins) (Ø: $12-48 \mu \mathrm{m})$, or granules $(\varnothing: 0.3-2 \mu \mathrm{m})$, and are suspended in a yellow and fluid phase (plasma) (Chang et al., 1977). The egg yolk can be separated into two fractions: granules and plasma, by dilution and centrifugation (Anton, 2013; Anton and Gandemer, 1997). Spheres are a minor component of egg yolk in comparison with the other particles. In spite of it spheres contains one or more subdroplets of lipoproteins or lipid drops surrounded by fluid (Chang et al., 1977). Profiles are low-density-lipoproteins (LDLs), constituted of a triglyceride core upon which proteins and phospholipids are layered (Chang et al., 1977, Causeret et al., 1991). Granules also known as lipoproteins drops, are rounded complexes constituted by high-density-lipoproteins (HDLs) also known as lipovitellin (70\%) and phosvitin (16\%) linked by phosphocalcic bridges. LDLs are also present at lesser extent in granules (12\%) (Anton and Gandemer, 1997; Chang et al., 1977). Unlike to spheres that represent a minor component of egg yolk, granules represent about $20-23 \%$ of yolk dry matter (Chang et al., 1977; Anton, 2013; Burley and Cook, 1961). Plasma corresponds to about 78 $80 \%$ of yolk dry matter and is composed of $85 \%$ LDLs and $15 \%$ of soluble proteins, known as livetins (Mine and Zhang, 2013; Anton, 2013). 
Table 6.1.2.2.1.2. Compositional analysis of egg yolk.

\begin{tabular}{lcc} 
& $\begin{array}{c}\text { Fresh yolk } \\
(\boldsymbol{\%} \mathbf{w} / \mathbf{w})\end{array}$ & $\begin{array}{c}\text { Dry yolk } \\
(\boldsymbol{\%} \mathbf{w} / \mathbf{w})\end{array}$ \\
\hline Water & $46.3-51$ & - \\
\hline Lipids & $32-35$ & 62.5 \\
\hline Proteins & $15.7-16.6$ & 33.0 \\
\hline Carbohydrates & $0.2-1$ & 1.2 \\
\hline Minerals & 1.1 & 3.5 \\
\hline Adapted from Mine and Zhang, 2013.
\end{tabular}

Livetins account the $30 \%$ of the plasma proteins in egg yolk. Livetin fraction contains $14.0-$ $18.7 \% \alpha$-livetin (which derives from serum albumin), $41.0-44.1 \% \beta$-livetin (an $\alpha_{2}$-glycoprotein derived from serum vitellogenin), and 32. - 45.0\% $\gamma$-livetin (derived from serum immunoglobulin $\Upsilon$ (Ig $\Upsilon$ ) (Mine and Zhang, 2013).

LDLs are spherical nanoparticles of about $17-60 \mathrm{~nm}$, responsible of the emulsifying properties of egg yolk (Anton et al., 2003). LDLs particles present a micellar complex with a hydrophobic core of triglycerides and cholesterol esters surrounded by a layer of phospholipids (PL) (mainly phosphatidylcholine and phosphatidylethanolamine) and proteins (Figure 6.1.2.2.1.16) (Mine and Zhang, 2013; Anton, 2013; Anton et al., 2003; Dauphas et al., 2007). The surface monolayer of LDLs is probably an amphipathic heterogeneous film composed of charged molecules such as phospholipids, proteins and unesterified cholesterol, which are not so strongly associated between each other. LDLs contain $11-17 \%$ of proteins and $83-89 \%$ of lipids, which are composed of $69 \%$ triacylglycerol, $26-27 \%$ phospholipids, $4 \%$ cholesterol and cholesterol ester. There are six different apoproteins with molecular weights between 15 and $130 \mathrm{kDa}$ in LDLs (Mine and Zhang, 2013). In particular, apoprotein I account the $70 \%$ of total apopproteins in LDLs, and exhibit low water solubility; whereas apoprotein II contains a high proportion of amphipatic $\alpha$-helix chains (Anton et al., 2003).

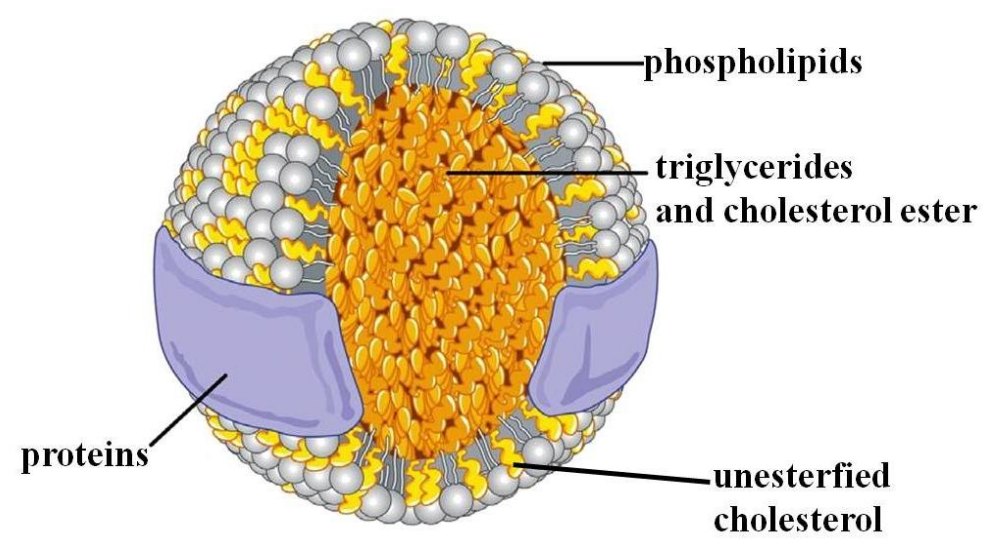

Figure 6.1.2.2.1.16. Schematic representation of LDLs spherical nanoparticles. 
HDLs, also known as lipovitellins are granular structure molecules with a molecular mass of 400 $\mathrm{kDa}$, which contains $75-80 \%$ proteins and $30-25 \%$ lipids. There are two types of HDLs in egg yolk, $\alpha$ - and $\beta$-lipovitellin (Mine and Zhang, 2013). The $\alpha$ - and $\beta$-lipovitellin have different amino acid sequences as well as phosphorus and carbohydrate residues, and contains five different glycosilated apoproteins. The lipid fraction in HDLs includes mainly phospholipids, cholesterol and triglycerides (Anderson et al., 1998). HDLs protein distribution can be structurally described as a protein chain folded in a globular configuration, maintained by hydrophobic bonds, with the lipids held in pockets throughout the molecule with a fraction of them held on the surface (Mine and Zhang, 2013; Schneider et al., 1973; Evans et al., 1968).

Lipovitellin is formed from the vitellogenin; a precursor molecule synthesized in the liver, after secretion, the vitellogenin dimer undergoes cleavage resulting in various lipid-binding polypeptide chains (lipovitellins) (Anderson et al., 1998). During synthesization of lipovitellin in the liver in presence of phosphorilated, and glycosylated it interacts with $\mathrm{Zn}(\mathrm{II})$ and $\mathrm{Ca}(\mathrm{II})$. Complexation of lipovitellins and phosvitin by $\mathrm{Ca}$ (II), and at lesser extent $\mathrm{Fe}(\mathrm{II})$, and $\mathrm{Mg}$ (II) in the liver, has been suggested to justify the important amounts of these metal ions found in granules $(81 \% \mathrm{Ca}, 98 \% \mathrm{Fe}$, and $71 \% \mathrm{Mg}$ ) (Burley and Cook, 1961).

Phosvitin (PVT) is a phosphoglycoprotein and makes up 4\% of solid egg yolk. Represents 11\% of yolk protein and contains $10 \%$ phosphorus and $5-6 \%$ glucidic residues (Causeret et al., 1991). Two subtypes of phosvitin have been isolated in egg yolk, $\alpha$ - and $\beta$-phosvitin and account for $80 \%$ of the phosphorus binding protein in yolk (Mine and Zhang, 2013). The $\beta$-phosvitin contained $9.20 \%$ phosphorus, while $\alpha$-phosvitin contained $2.97 \%$. It is the most phosphorylated protein, with 50\% of phosphoserines inducing an important negative net charge of about -179 . This characteristic due to the high content of phosphoserines residues makes it to present an elongated configuration in aqueous solutions with a good solubility in water (Taborsky, 1974; Anton, 2013).

Recent studies indicate that lipids are located in a cavity, which confers sufficient flexibility to be loaded or unloaded, formed by a single thickness B-sheet structure by bound lipid (Anderson et al., 1998). Phospholipids are placed in a bilayer in contact with the proteins and the neutral lipids (Birrell et al., 1982).

Lipids, triglycerides, phospholipids and cholesterol are the main constituents of egg yolk, and represent the $65 \%, 31 \%$ and 4\%, respectively (Kaźmierska et al., 2005). Important nutrients of egg yolk are fatty acids occurring in it mostly in the form of glycerides and phospholipids. Triglycerides and phospholipids are both glycerolipids with a glycerol backbone, in the case of phospholipids a glycerol-phosphate backbone (Mine and Zhang, 2013). Mono- and polyunsaturated fatty acids such as palmitic and stearic saturated acids which function as plasticizers, as well as linolic and arachidonic fatty acids have been observed in the egg yolk (Kaźmierska et al., 2005).

Smaller amounts of carbohydrates (around 1\%) are also present in egg yolk dry matter, been glucose the major constituent found. The rest of carbohydrates are found in conjugated form bounded to glycoproteins and glycolipids. Traces of vitamins (eg. A, D, E and $\mathrm{B}_{12}$ ) and minerals 
can also be found in egg yolk in low quantities. Due to the high content of phospholipids, phosphorus is the most abundant mineral in egg yolk (Mine and Zhang, 2013).

\section{White}

Egg white accounts about $60 \%$ of the total egg weight, and its major constituent is water, which makes up more than $80 \%$ of egg white. The main component of egg white are proteins, which includes ovalbumin $(54 \%)$, ovotransferrin $(12-13 \%)$, ovomucoid (11\%), lysozyme (3.5\%), G2 and G3 ovoglobulins (2\%), and ovomucin (1.5 - 3\%) (See table 6.1.2.2.1.3). Other proteins as ovostatin, ovoflavoproteins and avidin are in trace amounts, as well as, enzymes (eg. $\alpha$-mannosidase, $\beta$-galactosidase, and catalase).

Ovalbumin is the most abundant protein in egg white. It is a phosphoglycoprotein, with a molecular mass of $45 \mathrm{kDa}$, composed of 386 amino acid residues with the hydrophobic sequence between the 21 and 47 residues (Mine and Zhang, 2013). Half of the amino acids in ovalbumin are hydrophobic and one-third are negatively charged. Studies determine that ovalbumin contained six cysteine residues, two of them are involved in disulfide bond and the other four were composed of a sulfhydryl ( $\mathrm{SH}$ ) group. It also contains three $\beta$-sheets and nine $\alpha$-helices. Ovalbumin is the responsible for the gelling properties of egg white (Ibrahim, 1996).

Ovotransferrin, also referred to as conalbumin, is a monomeric glycoprotein consisting of a 686-residue single polypeptide chain and has a molecular mass of $78-80 \mathrm{kDa}$. It has the capacity to bind with ferric $\mathrm{Fe}^{3+}$ ions and transport it in a soluble form to target cells (Mine and Zhang, 2013; Azari and Phillips, 1970). The release of $\mathrm{Fe}^{3+}$ from ferric transferrin requires the presence of a simple anion such as pyrophosphate, sulfate, and chloride (ChingMing Chung, 1985). Ovotransferrin is a covalent dimmer protein, composed of an N- and a C- terminal lobe (William et al., 1982). Each one binds one atom of transition metal (Fe(III), $\mathrm{Cu}(\mathrm{III}), \mathrm{Al}(\mathrm{III})$ ) very tightly and also have 15 disulfide bridges (Azari and Phillips, 1970). Ovotransferrin possess antimicrobial activity against various bacteria, fungi, and viruses (Ibrahim, 1996; Mine and Zhang, 2013).

Ovomucoid accounts the $11 \%$ of the egg white protein and has a molecular mass of $28 \mathrm{kDa}$ (Mine and Zhang, 2013). It is known for its trypsin inhibitory activity with three distinct domains cross-linked by disulphide bonds (Bier et al., 1953). Nine disulphide bonds are identified in ovomucoid and no free sulfhydryl groups (Bier et al., 1953; Mine and Zhang, 2013). The disulphide bonds play an important role in the allergic reactions and digestive resistance of ovomucoid (Gu et al., 1989).

Ovomucin is a sulphated glycoprotein, which contains proteins and a smaller amount of carbohydrates. It consists of two subunits, $\alpha$ - and $\beta$-ovomucin, which are bound by disulphide bonds and exists in insoluble and soluble subtypes (Robinson and Monsey, 1971; Toussant and Latshaw, 1999). $\alpha$-Ovomucin contains 91\% protein and 9\% carbohydrate with 2087 amino acids residues and a molecular mass of $230-250 \mathrm{kDa}$. $\beta$-Ovomucin subunit consists of 872 amino acids and has a molecular mass of $400-720 \mathrm{kDa}$ (Mine and Zhang, 2013). The 
carbohydrates found in ovomucin are in form of oligosaccharides. It contributes to the gellike structure of thick egg white, caused partly by the interaction of ovomucin with lysozyme (Tousssant and Latshaw, 1999).

Egg white lysozyme, also known as muramidase and $\mathrm{N}$-acetylmuramic hydrolase, constitutes approximately $3.5 \%$ of hen egg white, has a molecular weight of $14.4 \mathrm{kDa}$ and consists of 129 amino acid residues (Mine and Zhang, 2013). It is made up of two domains linked by a long $\alpha$-helix, while also separated by a helix-loop-helix (HLH), which possess antibacterial activity (Ibrahim et al., 2001). This enzyme binds to ovomucin, transferrin or ovalbumin in egg white. Lysozyme has four disulphide bonds and catalyzes the hydrolysis of the (1 - 4)glycosidic linkage between $\mathrm{N}$-acetylmuraminic acid and $\mathrm{N}$-acetylglucosamine in the polysaccharide of certain bacterial cell walls (Salton and Pavlik, 1960).

Other proteins found in egg white include ovoglycoprotein, flavoprotein, avidin, protease, and minor protein as lipocalins, clusterin, and $\mathrm{Ch} 21$ protein. Carbohydrates are also present in egg white in form of conjugated oligosaccharides and free glucose (Mine and Zhang, 2013).

Table 6.1.2.2.1.3. Physicochemical properties of proteins found in egg white.

\begin{tabular}{|c|c|c|c|}
\hline Protein & $\%(w / w)$ & $\mathbf{M}_{\mathbf{w}}(\mathbf{k} \mathbf{D a})$ & Characteristics \\
\hline Ovalbumin & 54 & 45 & \\
\hline Ovotranferrin & $12-13$ & 77.7 & Binds iron and other metal ions \\
\hline Ovomucoid & 11 & 28 & Inhibits serine proteinase \\
\hline Ovomucin & $1.5-3.5$ & $\begin{array}{l}110,5500-8300,220- \\
270,000\end{array}$ & Interacts with lysozyme \\
\hline Lysozyme & $3.4-3.5$ & $14.3-14.6$ & Lysis of bacterial cell walls \\
\hline G2 ovoglobulin & 1.0 & $47-49$ & \\
\hline G3 ovoglobulin & 1.0 & $49-50$ & \\
\hline Ovoflavoprotein & 0.8 & $32-35,80$ & Binds riboflavin \\
\hline Ovostatin & 0.5 & $760-900$ & \\
\hline Cystatin & 0.05 & 12 & Inhibits cystein proteinase \\
\hline Avidin & 0.05 & $55-68.3$ & Binds biotin \\
\hline
\end{tabular}

Adapted from Mine and Zhang, 2013. 


\section{c) Casein}

Casein served as an adhesive and as a paint medium for more than eight centuries. It is obtained from cow's milk and forms a strong glue when mixed with alkaline materials. It contains about $5.5 \%$ fat, $4.9 \%$ of the sugar lactose and 3-5\% protein. Conjugated proteins type phosphoproteins include are: $\alpha$-casein (75\%; MW 27600), $\beta$-casein (MW 19800), $\gamma$ casein, $\kappa$-casein (tensoactive) (MW 26000), lactalbumin (MW 16000) and $\beta$-lactoglobulin (MW 37000) (Mills and White, 1994; Chiavari et al., 1998). Craftsmen and artists favored casein glues over other animal glues because of its better aging properties and moisture resistance. Casein paint resembles an opaque (non transparent) watercolour. It is used on paper or board; for canvas it is too inflexible (http://www.artlex.com).

Milk is constituted of approximately $90 \%$ water, $4 \%$ milk sugar (lactose), 3.5\% milk oil and $3.5 \%$ lactalbumin. Lactalbumin is the most important component of casein and is found as a colloidal solution (Mills and White, 1994). Unlike glue and hen egg white, casein contains phosphorus; and precipitated casein from the milk is insoluble in water. To use it as a binder, casein is disaggregating by alkaline combinations such as lime, borax or ammonium carbonate to make it soluble (Matteini and Moles, 2001). Lime casein was formerly used as cold glue and is one of the most stable binders in wall painting on dry finishing and for façade paints. The lime casein colors (paints) were already known in antiquity (Mayer, 1993; Gettens and Stout, 1966). They were used for the painting of furniture and still used as binder in some "colors" of posters. Like animal skin-based glues, casein solutions are capable of emulsifying oils, resins and waxes; called quenching binders (tempera binders). The colors of casein dry by water evaporation, although unlike the glue colors, casein colors become insoluble in water due to a chemical modification (Lucey and Singh, 1998).

\section{Drying process}

In aqueous solution, the proteins adopt a spatial arrangement in which the hydrophobic groups of the side chains are folded into the molecule while the hydrophilic groups establish linkages by hydrogen-bonding with water. During drying of the pictorial film water evaporates until it reaches an equilibrium level with the vapor pressure in the environment. In this process the protein molecules are rearranged to fill the gaps left by the water evaporation losing partially or completely its tertiary and secondary structures, and therefore complete or partial denaturation takes place. In this state, many functional groups of the side chains are free so the reactivity of the molecule is increased.

Denaturation also occurs by heating or with certain reagents such as ethanol. Denaturation results in the loss of the physiological activity because the catalytic property of the enzymes depends on its tertiary structure.

\section{Degradation processes}

Very little is known about degradation processes of proteinaceous binders, but almost all proteins materials are transformed with time into calcium oxalates. Analytical studies 
performed on easel paintings, wall paintings and stone artefacts always exhibit calcium oxalates. In the case of stone artefacts, the presence of calcium oxalates could be associated to various factors, including the activity of microorganisms or lichens. On easel and wall painting could result from the alteration of organic materials, especially proteins. Is important to mentioned that it is necessary at least a century of time for the transformation of proteins into calcium oxalates. Proteinaceous materials loose water as soon as they are applied has a thin film in a paint layer. The most likely modification event of proteinaceous materials is then oxidation. Moreover, there other factors responsible of protein degradation as chemical reactions, exposure to light radiation, thermal changes, humidity and the growth of microorganisms. Otherwise, studies have been reported that the solubility of proteinaceous materials decrease with time and some cations can give rise to the formation of strong complexes with proteins (Andreotti et al., 2008; Leo et al., 2011).

Alteration of proteins and polypeptides has also attracted interest to scientists in the field of biochemistry for its important implications in most metabolic processes of alive organisms. Many biological functions of proteins depend on the correct folding of their native structures and level of aggregation. Several environmental factors, namely, $\mathrm{pH}$, temperature, extreme salt conditions, ionic strength and denaturant substances are involved in the destabilization of proteins and, consequently, they result in disruption of their conformational structure. Thermostability of proteins has been studied by characterizing conformational changes undergone by the protein molecules, which result among other in unfolding and aggregation of protein molecules (Ulrichs et al., 2015; Haris and Severcan, 1999; Stokkum et al., 1994; Chehin et al., 1999). Proteins are also sensitive to $\mathrm{pH}$ so that changes in the three-dimensional structures by disruption of hydrogen bonds and ionic interactions (Chehin et al., 1999) as well as backbone cleavage (Furlan et al., 2007) are induced by modifying the $\mathrm{pH}$ value.

Among the physical and chemical deterioration pathways of proteins, aggregation is the most common manifestation of protein instability. In addition, there are a number of chemical agents that can directly induce cross-linking of protein chains or can modify the hydrophobicity of the protein, indirectly changing its aggregation behavior (Wang, 2005).

Here will be described degradation processes responsible of the protein deterioration.

a) Protein hydrolysis

Through a process of acid-catalyzed hydrolysis or enzymes peptide bonds of the protein chains are broken regenerating amino acids (Figure 6.1.2.2.1.17). 


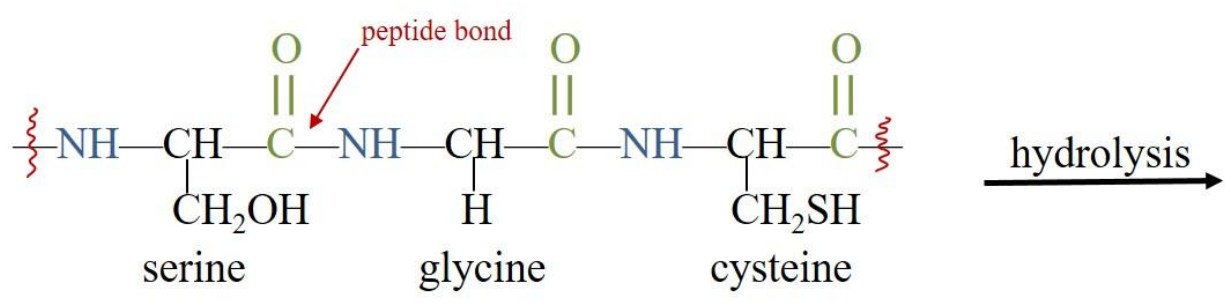<smiles>[R]C(N)C(=O)O[InH2]</smiles>

Figure 6.1.2.2.1.17 Hydrolysis of a protein.

In the heritage conservation field can also be found studies that report alteration processes undergone by proteinaceous media. Proteinaceous materials applied in paint films exposed to the attack of some acidic air pollutants $\left(\mathrm{SO}_{2}\right)$ undergo hydrolysis reactions followed by oxidation, crosslinking, condensation, and dehydration of amino acids (Genestar and Pons, 2005). The result is a total o partial denaturation of the protein with the consequent weakening of the mechanical properties of the paint (Karpowicz, 1981; van der Weerd et al., 2005).

\section{b) Photo-oxidation}

Light radiation induces the formation of free radicals such as hydroperoxide which in presence of photosensitive substances (pigments) could initiate a chain reaction. The most sensitive to photo-oxidation amino acids in proteins are histidine, tryptophan, methionine, cystine and cysteine although the final products are not very well known (Pattison et al., 2012). Animal glue with a low content of these amino acids is the most resistant protein to this type of deterioration processes. The correct combination of moisture and light promotes the formation of $\mathrm{H} \bullet$ and $\mathrm{OH} \bullet$ radicals that accelerate the deterioration process (Mills and White, 1994; Matteini and Moles, 2001). The overall outcome is crosslinking and break of the polypeptide chain.

Sometimes, other components of the paint are inductors of protein alteration processes. During ageing of egg-oil emulsions oxidative processes take place on oil triglycerides (Mallégol et al., 2000; Lazzari and Chiantore, 1999). The compounds formed such as free peroxy-, alcoxy- and lipid radicals are causative agents of protein degradation following pathways similar to those observed in protein exposed to ionizing radiation (Karel, 1975), which results in the formation of protein radicals from amino acid side chains. Browning of tempera emulsions, sometimes reported, has been attributed to the reaction of amino groups of lysine side chains and phosphatidylethanolamine with lipid hydroperoxides (Pokorny, 1977; Pokorny et al., 1973). Free radicals are also responsible for the formation of complex species with side groups in proteins (Nayaran and Kummerov, 1963) and polymerization of proteins by crosslinking of peptide chains if sulphur radicals are involved (Roubal and 
Tappel, 1966; Genestar and Pons, 2005). Chemical reactions of many amino acids in proteins, such as disulfide exchange, require certain local molecular flexibility and thus, the rate of reaction may be higher in denatured states than in native states (Wang, 2005).

\section{c) Condensation reactions}

Condensation reaction links subunits in biological molecules forming a larger molecule between an amino group of a protein and a glucid or carbohydrate (glycoproteins from egg, glucidic impurities in casein, gums mixture and proteins in plaster or additions of honey, sugar, etc.) (Doménech-Carbó, 2013; Goméz, 1998). The condensation reaction between a protein and a reducing sugar is known as Maillard reaction. Millard reaction is associated with crosslink formation, decreased protein solubility, and increased protease resistance (Collins et al., 1992). The products of these reactions are brownish compounds with free carbonyl and phenol groups (Mills and White, 1994; Matteini and Moles, 2001).

\section{d) Reactivity with acids and bases}

Treatments with strong bases on hydroxyl phosphorylated amino acids (serine, threonine), as cysteine or cystine produce dehydroalanine. The reaction promotes an alkaline hydrolyses of the proteinaceous polypeptide and eventually crosslinking. The acids and the acid air pollutants cause denaturation and partial hydrolysis of proteins (Karpowicz, 1981; Baer and Banks, 1985; Brimblecombe, 1990). Strong alkaline media resulting from use of slaked lime in wall paintings in an attempt to improve the binding properties of casein can promote deamidation of amino acid residues (Xie and Schowen, 1999; Leo et al., 2011).

\section{e) Pigment-binder interactions}

Carboxylic side chain groups in the proteins can form complex species with metal cations so that, depending on the cation, the protein adopts different secondary structure for establishing the more stable coordination (Nara et al., 2013; Nara and Tanokura, 2008; Nara et al., 1995). Complexation of free amino acids has been described, which seriously interferes the chromatographic determination of binders in pictorial samples (Colombini et al., 1999; Scott et al., 2004; Kuckova et al., 2005).

Effect of pigments on proteinaceous media and, in particular, egg media has also been studied by several researchers. Odlyha et al., have characterized changes undergone by proteinaceous media on natural and artificial ageing in presence of smalt (Odlyha and Cohen, 2000), lead white (Cohen et al., 2000) and azurite (Odlyha et al., 2000) identifying several oxidation products derived from cholesterol and glycerolipids. Additionally, hydrolysis of triglycerides, which results in the release of long and short chain fatty acids and diacids as well as formation of cross-linked aggregates including cobalt-lecithin complexes has been reported (Mallégol et al., 2000). More recently, Duce et al. (Duce et al., 2012) have considered the ageing behavior of casein and ovoalbumin proteins in presence of cinnabar (Duce et al., 2012) calcite, azurite, hematite and red lead (Duce et al., 2013) identifying alteration processes among which are induced aggregation of proteins by covalent cross-linking, 
oxidation of amino acids side chain and hydrolysis of the polypeptide chain in both pure and pigmented protein samples.

\subsection{Lipidic media}

The study of lipids is of interest due to the wide use of drying oils and waxes as binders in artworks. Drying oils are the vehicle in oil painting while the waxes were used as adhesive and in the encaustic technique. Both have also been widely used as components of varnishes.

\section{Chemical composition}

Lipids are compounds with ester structure (Figure 6.1.2.2.2.1) with a straight and long chain. The lipids are formed from straight long-chain acids commonly called fatty acids (Figure 6.1.2.2.2.2). The physical and chemical properties of individual fats are determined by the kinds and proportions of fatty acids, which enter into the triglyceride composition.

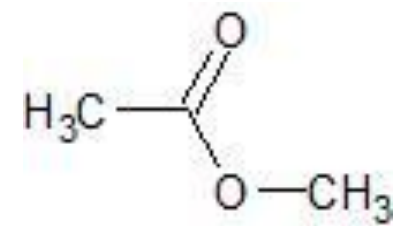

Figure 6.1.2.2.2.1 Methyl acetate

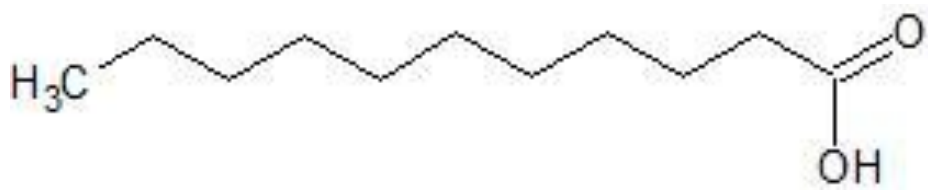

Figure 6.1.2.2.2.2 Structure of a molecule of fatty acid

Fatty acids

Fatty acids contain an even number of carbon atoms, from 4 to 36, bonded in an unbranched chain. The carbon atoms of a straight chain fatty acid are numbered starting with the carboxyl group carbon as number one, and in the systematic names of the unsaturated acids the position of each of the double bonds is indicated at the start of the name by giving the lower number of the two carbon atoms bearing them (Matteini and Moles, 2001). The more important fatty acids of oils and fats found in lipidic materials used as binding media are listed in Table 6.1.2.2.2.1. 
Table 6.1.2.2.2.1. Major fatty acids of oils and fats in lipidic binding media.

\begin{tabular}{|c|c|c|}
\hline Formula & Systematic name & Common name \\
\hline $\begin{array}{l}\mathrm{C}_{12} \mathbf{H}_{24} \mathbf{O}_{2} \\
\mathrm{C}_{14} \mathbf{H}_{28} \mathbf{O}_{2} \\
\mathrm{C}_{16} \mathrm{H}_{32} \mathbf{O}_{2} \\
\mathrm{C}_{16} \mathbf{H}_{30} \mathbf{O}_{2} \\
\mathrm{C}_{18} \mathbf{H}_{36} \mathbf{O}_{2} \\
\mathrm{C}_{18} \mathbf{H}_{34} \mathbf{O}_{2} \\
\mathrm{C}_{18} \mathbf{H}_{32} \mathbf{O}_{2} \\
\mathrm{C}_{18} \mathbf{H}_{30} \mathbf{O}_{2} \\
\mathrm{C}_{18} \mathbf{H}_{30} \mathbf{O}_{2} \\
\mathrm{C}_{18} \mathbf{H}_{34} \mathbf{O}_{2}\end{array}$ & $\begin{array}{l}\text { Dodecanoic } \\
\text { Tetradecanoic } \\
\text { Hexadecanoic } \\
\text { 9-Hexadecenoic } \\
\text { Octadecanoic } \\
\text { 9-Octadecenoic } \\
\text { 9, 12-Octadecadienoic } \\
\text { 9, 12, 15-Octadecatrienoic } \\
\text { cis, trans, trans-9, 11, 13-Octadecatrienoic } \\
\text { 12-Hydroxy-9-octadecenoic }\end{array}$ & $\begin{array}{l}\text { Lauric } \\
\text { Myristic } \\
\text { Palmitic } \\
\text { Palmitoleic } \\
\text { Stearic } \\
\text { Oleic } \\
\text { Linoleic } \\
\text { Linolenic } \\
\alpha \text {-Elaeostearic } \\
\text { Ricinoleic }\end{array}$ \\
\hline
\end{tabular}

Adapted from Mills and White, 1994.

Double bonds can have cis or trans configurations, but cis is the usual configuration found in the natural acids and the one to be assumed if not specified in the name (Rustan and Drevon, 2005). The introduction of unsaturation into the molecule lowers the melting point from that of the corresponding saturated acid. Vegetable oils contain higher proportions of the unsaturated triglycerides and this property made them less viscous than animal fats. Solid fats, as waxes, are usually more saturated than oils (Gómez, 1998). Highly unsaturated oils undergo chemical reaction in the presence of oxygen and light, in which the unsaturated carbon atoms become saturated by reaction with oxygen (Doménech-Carbó, 2013). An important characterizing feature of oils and fats, especially drying oils is the iodine number. The iodine number is an index of the total amount of unsaturation in a fat, a measure of the iodine amount which will react with it by addition across the double bonds (Mills and White, 1994).

The doubly unsaturated linoleic acid and the triply unsaturated linoleic acid are the compounds principally responsible for the drying properties of drying oils. During the drying process these acids become dienes and trienes, respectively, by isomerization (Ochigbo and Alex, 2011; Martin et al., 2007; Tasan et al., 2011).

The composition of a particular oil can vary for a number of reasons as: variety of the plant, nature of the soil, and season or variation on weather conditions (Green and Marshall, 1981). These factors can also affect the extent of unsaturation and, as result, affects the ratios of palmitic and stearic acids since increased amounts of the unsaturated $\mathrm{C}_{18}$ acids diminish the amount of stearic acid (Vereshchagin and Novitskaya, 1965; Mills and White, 1994).

\section{Triglycerides}

Most of the fatty acids present in the composition of oils and fats are found combined with the trihydric alcohol glycerol to give esters known as triglycerides. Triglycerides molecules contain mostly carbon and hydrogen atoms, with only six oxygen atoms per molecule. This means that fats and oils are highly reduced (it means, un-oxidized). There are many studies aimed at formulate theories to predict the way in which fatty acids are distributed between triglyceride molecules (Brockerhoff, 1971; Lichfield, 2012; Coleman, 1963). It was 
discovered that they are not usually found as simple triglycerides, instead of that, they concluded that each fatty acid is distributed over as many triglycerides molecules as possible or distributed randomly through the triglycerides. In both cases is often not possible to determine the triglyceride composition. It is important to mention that the number of possible triglycerides is very high in comparison with the number of fatty acids, e.g. for three fatty acids there could be fourteen different triglycerides (Mills and White, 1994). During the drying phase triglycerides are responsible of the autoxidation phenomenon of the unsaturated fatty acid constituents, which results in the formation of conjugated unsaturations and crosslinking (Lazzari and Chiantore, 1999)

\section{Minor components}

In addition to the fatty acids and triglycerides, oils and fats usually contain a small proportion, usually less than $1 \%$, of so-called nonsaponifiables - neutral compounds which do not react with alkali to give water-soluble soaps. The nonsaponifiables of seeds oils are usually very complex mixtures containing triterpene alcohols, methyl sterols, and sterols (e.g. $\beta$-sitosterol). The unsaponifiable fraction can provide fingerprint for identitying oils in chromatographic analysis (Mills and White, 1994). The sterol cholesterol is usually found only in vanishingly small quantities, alike to the large amounts present in egg yolk (Itoh et al., 1973). Sterols, tocopherols, carotenoids, phenolic compounds, chlorophyll, free fatty acids, and other minor derivatives, as well as trace metals ions are minor constituents of most vegetable oils and they are largely removed during washing or other refining procedures (Ferrari et al., 1996; Kamal-Eldin, 2005). Minor lipid components are of interest because they affect the technical properties of oils. Also tocopherols are interesting, as they are the primarily responsible for the stability of the polyunsaturated fatty acids of vegetable oils (Kamal-Eldin, 2005; Schwartz et al., 2008).

\section{$\underline{\text { Classification }}$}

Lipids are classified into three groups: glycerides, cerides and steroids.

\section{a) Glycerides}

This category includes drying oils, which are mainly composed of triglycerides from fatty acid, i.e. esters formed with glycerol and three fatty acids (Figure 6.1.2.2.2.3). The fatty acids could be the same or different with varying hydrocarbon chain length and the amount of double bonds. The hydrocarbon length varies from 10 to 20 carbon atoms including the carbon in the acid group (-COOH). 


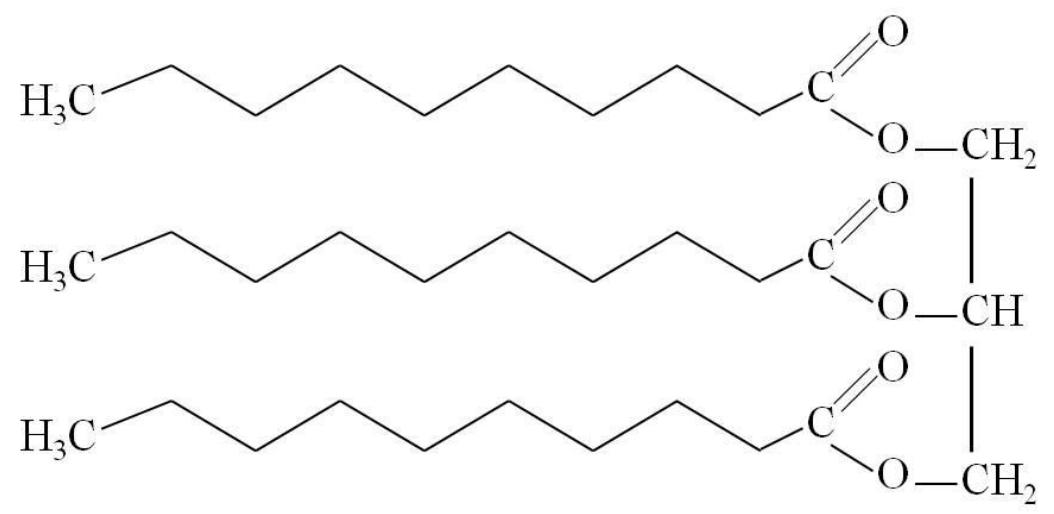

Figure 6.1.2.2.2.3 Triglyceride (ester of fatty acids)

The fatty acids that encompass the triglyceride molecules of a fresh drying oil are of unsaturated type, in particular:

Oleic acid (9-octadecanoic acid): $\mathrm{C}_{18} \mathrm{H}_{34} \mathrm{O}_{2}$

Linoleic acid (9, 12-octadecadienoic acid): $\mathrm{C}_{18} \mathrm{H}_{32} \mathrm{O}_{2}$

Linolenic acid (9, 12, 15-octadecatrienoic acid): $\mathrm{C}_{18} \mathrm{H}_{30} \mathrm{O}_{2}$

These three compounds usually constitute around the $70 \%$ of the total fatty acids present in the drying oils most commonly used in cultural artefacts. In the triglycerides compositions are also involved to a lesser extent, some saturated fatty acids, mainly:

Palmitic acid (hexadecanoic acid): $\mathrm{C}_{16} \mathrm{H}_{32} \mathrm{O}_{2}$

Stearic acid (octadecanoic acid): $\mathrm{C}_{18} \mathrm{H}_{36} \mathrm{O}_{2}$

Table 6.1.2.2.2.2. Fatty acids constituting the triglyceride esters of the drying oils.

\begin{tabular}{l|l}
\hline \multicolumn{1}{l}{ LONG CHAIN FATTY ACIDS } \\
\hline Palmitic acid & A. Hexadecanoic,C16 \\
\hline Oleic acid & A. 9-Octadecenoic, C1:18 \\
\hline Linoleic acid & A. 9, 12-Octadecadienoic, C2:18 \\
\hline Linolenic acid & A. 9, 12, 15- Octadecatrienoic, C3:18 \\
\hline Stearic acid & A. Octadecanoic, C18 \\
\hline Elaeostearic acid & A. Cis, trans, trans-9, 11, 13-octadecatrienoic, C3:18 \\
\hline Ricinoleic acid & A. 12-hydroxy-9-cis-octadecenoic, C1:18 \\
\hline
\end{tabular}

There other substances present at low concentration in the drying oils are named nonsaponifiable. This nonsaponifiable compounds are lipids that are not an ester, such triterpenoids, sterols and prostaglandins (e.g. $\beta$-sitosterol). In the structure of the triglyceride molecules we highlight two aspects that will determine the behavior and properties of drying oils: i) the triple ester function; and ii) the presence of double bonds in the chains of unsaturated fatty acids. Although there is no model to explain the distribution of the fatty acids in the triglycerides molecules, there seems to be a predilection of the unsaturated fatty acid to bond the secondary carbon atom of the glycerin molecule, while the saturated fatty acids bond the primary carbon atoms of the glycerin molecule. 


\section{b) Cerides}

Natural waxes are another variety of lipids whose main components are called cerides, i.e., fatty acid esters of long-chain $\left(\mathrm{C}_{6}\right.$ to $\left.\mathrm{C}_{36}\right)$ and long straight chain alcohols (see Figs. 6.1.2.2.2.4 and 6.1.2.2.2.5:

Ceryl alcohol: $\mathrm{CH}_{3}-\left(\mathrm{CH}_{2}\right)_{24}-\mathrm{CH}_{2} \mathrm{OH}$

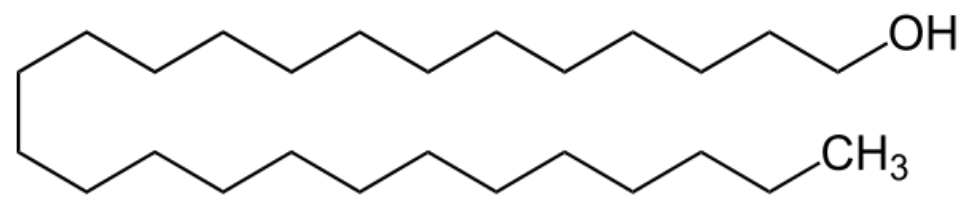

Figure 6.1.2.2.2.4 Ceryl alcohol structure

Myricyl alcohol: $\mathrm{CH}_{3}-\left(\mathrm{CH}_{2}\right)_{28}-\mathrm{CH}_{2} \mathrm{OH}$

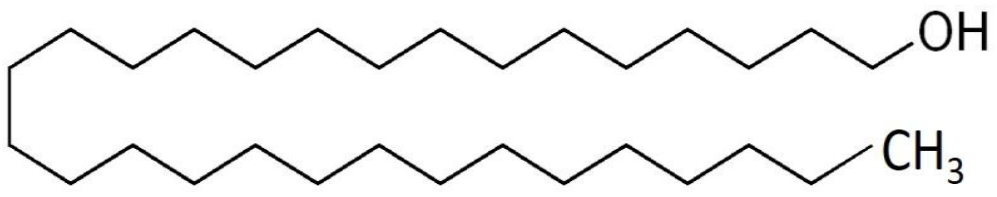

Figure 6.1.2.2.2.5 Myricyl alcohol structure

As an example, the chemical formula of the major component of beeswax, myricyl palmitate is shown in figure 6.1.2.2.2.6.

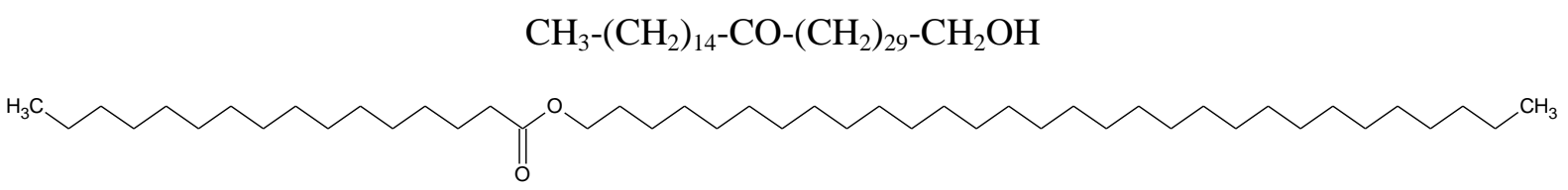

Figure 6.1.2.2.2.6 Myricyl palmitate structure

Other components present in the composition of animal waxes are glycerides, alcohols, fatty acids and alkene hydrocarbons of high molecular weight. Waxes of plant origin are constituted by cerides and its triterpene compounds, alkenes hydrocarbons of long-chain and other materials.

Waxes of mineral origin are hydrocarbons of long-chain containing cycloalkane alcohols with a crystalline structure and a melting point up to about $90^{\circ} \mathrm{C}$. Paraffins and microcrystalline waxes obtained from petroleum distillation are composed of hydrocarbons with a broad range of molecular masses. Table 6.1.2.2.2.3 summarizes the main waxes and paraffins used in cultural artefacts. 
Table 6.1.2.2.2.3. Main waxes and paraffins used in cultural artefacts

\begin{tabular}{l|l|l}
\hline Insect and animal waxes & Plant waxes & Fossil and earth waxes \\
\hline Beeswax & Carnauba wax & Ozokerite \\
Shellac wax & Candelilla wax & Ceresine \\
Chinese insect wax & Esparto wax & Peat waxes \\
Spermaceti wax & & Paraffin waxes \\
Lanolin & & \\
\hline
\end{tabular}

\section{c) Steroids}

In this type of lipid, the sterol group is an alcohol, this means, a compound with a tetracyclic structure (Figure 6.1.2.2.2.7). Some sterols of interest in conservation of heritage are cholesterol, which is found in the egg yolk and phytosterols such as $\beta$-sitosterol, campesterol and stigmasterol thatare found in many oils.

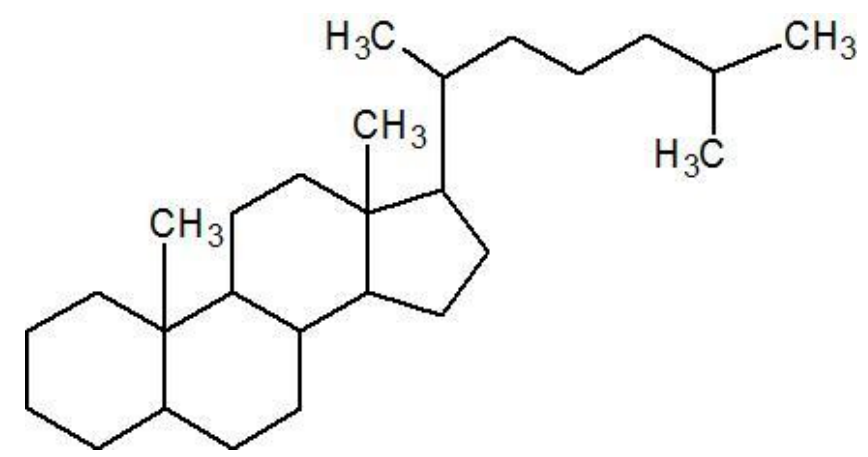

Figure 6.1.2.2.2.7 Cholesterol tetracyclic structure

\section{Lipidic materilas used as binding media}

\section{a) Drying oils}

Apart from canvas and panel painting many work of art, including altar frontals and polychromed sculptures are also painted in oil. The first treatise which refers to the use of oil for tempering colours was Theophilus, in the $12^{\text {th }}$ century. In the $13^{\text {th }}$ century linseed oil was the most popular medium for painting in northern Europe. It was not until the Renaissance when water-based media where replaced by oil in the southern Europe. During this transition to oil-based media some artists added oil to the egg medium or use a combination of temperabased layers with oil glazes, it is known as tempera grassa. The most used drying oils in European old master paintings are linseed, walnut and poppy-seed oils. The oil could be purified, bleached, or heated with or without added driers such as litharge or minium. The purification of the oils was made through filtering and washing. As mentioned before, linseed oil was the most commonly used drying oil whereas walnut and poppy seed were also used but not as widely as linseed oil. Walnut and poppy seed dry slightly slower and yellow less during ageing than linseed oil. Other drying oils are produced around the world, and have a long history of local use. For example, the perilla and the hempseed oils both mentioned in 
Japanese artististic treatises. As well as, the chia oil from seeds of Salvia hispanica used as a paint medium in Mexico and the tung oil from China wood.

Depending on the fatty acid pattern, vegetable oils can be classified as: non-drying, semidrying and drying oils. Non-drying oils contain mostly saturated fatty acids, unable to react and form a crosslinked film by air oxidation. The presence of double bonds increases the "oils's reactivity" to form a solid film, as the double bonds are able to polymerize (crosslink) when exposed to oxygen. Semi-drying oils contain fatty acids with only one or two double bonds, e.g. soybean and sunflower oil. Drying oils are highly unsaturated oils, consisting of fatty acids containing two or three double bonds (Solomon, 1982).

The drying oils used as binding media are constituted of a mixture of triglycerides (See figure 6.1.2.2.2.5) of the unsaturated fatty acids, i.e., glycerol esters and long chain unsaturated fatty acids. In addition to the triglycerides free fatty acids are found in drying oils together with free glycerin and a small account of inorganic materials. The speed of drying (polymerization) of a drying oil is determined primarily by the chemical constitution of its fatty acids and the proportion of the other substances present in the oil. These properties also interfere in the quality of the pictorial technique. Linolenic, linoleic and oleic acids are unsaturated fatty acids responsible of the drying process. Even though the extent to which these fatty acids takes part in the polymerization reaction is uncertain. Table 6.1.2.2.2.4 shows the linolenic, linoleic, and oleic acids composition of the most used drying oils as binding media in western painting.

Table 6.1.2.2.2.4. Fatty acid percent (\%) composition of linseed, walnut and poppyseed drying oils.

\begin{tabular}{l|rcc}
\hline \multicolumn{1}{l}{ Fatty acid } & Linseed oil* & Walnut oil* & Poppyseed oil* \\
\hline Linolenic acid & $48-60$ & $2-16$ & - \\
Linoleic acid & $14-19$ & $57-76$ & $72-76$ \\
Oleic acid & $14-24$ & $9-30$ & 11 \\
Palmitic acid & $3-6$ & $3-7$ & 10 \\
Stearic acid & $6-7$ & $0.5-3$ & 2 \\
\hline
\end{tabular}

\section{Linseed oil}

Linseed oil, also known as flaxseed oil, was the most commonly used drying oil as binding medium in European panel and canvas painting for centuries. It is obtained from dried ripened seeds of the flax plant (Linum usitatissimum). Linseed oil contains only triunsaturates and monosaturated-diunsaturated triglycerides (Vereshchagin and Novitskaya, 1965). Its consists chiefly of linolenic, linoleic and oleic acids, a small amount of saturated acids such as palmitic $(6.58 \%)$ and stearic $(4.43 \%)$ is also present (Popa et al., 2012). Depending on how it is collected and processed, linseed oil exists in a wide range of colors and viscosities. Various categories of drying oils often include cold-pressed, alkali/acid refined, blown oil 
(thickened with air), sun-bleached/thickened, and stand oil (pre-polymerized). For the manufacture of cold-pressed oils, the seeds are ground in a cylinder mill and then heated with steam to add moisture to the dried seeds. This mass is then wrapped in cloths with and hydraulically pressed. In Medieval times, linseed oil was boiled with lead oxide (litharge) to give a product called boiled linseed oil. The lead oxides forms lead soaps, which promotes polymerization of linseed oil by reaction with atmospheric oxygen, the product is an alkali/acid refined oil. Up to date the most used is the stand oil, generated by heating linseed oil near $300^{\circ} \mathrm{C}$ for a few days in the complete absence of air. Under these conditions, the polyunsaturated fatty acids convert to conjugated dienes, which undergo Diels-Alder reactions, leading to crosslinking. The product is a highly viscous oil, that gives uniform and more elastic coatings with less prone to yellowing.

\section{Walnut oil}

Like linseed oil, walnut oil has also been used as binding medium since ancient times (Gettes and Stout, 1966). It is obtained from the fruits of the walnut, usually hand-pressed in small workshops resulting in a yellow oil. In contrast to linseed oil, this drying oil has less tendency to yellow with time but would often take longer to effectively dry (Doerner, 1998). This oil was used more frequently in Italy than in the northern Europe and today it plays no role in painting (Doerner, 1998).

\section{Poppy oil}

The drying oil obtained from poppy seeds (seeds of Papaver somniferum, the opium poppy) has also been used as a binding medium since $17^{\text {th }}$ century, particularly by the Asian artists (Gettens and Stout, 1966). In ancient times it was obtained by pressing the poppy seeds and the oil obtained color varies from pale- to golden- yellow. Although this particular oil has a lengthy drying time in comparison to linseed and walnut it also yellows the least in presence of light. As with walnut oil, artists would often choose poppy oil as the primary binder for white pigments, and as varnish (Stoner and Rushfield, 2012).

\section{b) Cerides}

Resins and waxes are inert compound that form solids, they are used as binders in encaustic technique and varnishes. According to their origin can be classified as animal, vegetable and fossil cerides.

\section{Insect and animal waxes}

Animal waxes are esters of saturated fatty acids and fatty alcohols, also contain a small amount of hydrocarbons, acids and free alcohols and triglycerides. An examples of this is the beeswax, which contains a pair number of carbons, acids of 16 to 36 carbons atoms chain and among its major components we can find myricyl palmitate, ceryle ceroate and myricyl myricylate.

\section{Fossil and earth waxes}


Fossil and mineral waxes could be linear, branched and cyclic saturated hydrocarbons. There are mineral waxes formed by desiccation of petroleum with paraffinic base, i.e. ozokerite. The formation of the film takes place by physical state change when temperature drops. Aging is practically null, given its chemical inertia. Like animal waxes, these are used as consolidants and adhesives and they are good protectives applied as thin films for metals. They can also be used as varnishes in low concentrations.

\section{c) Resins}

\section{Plant resins}

The plant resins are used in the formulation of varnishes, especially the soft resins which forms transparent, quite hard and impermeable films. They are polycyclic compounds constituted by condensation of isoprene molecules that are classified according to the number of monomer units. Among the monoterpenoids (10C) is the essence of turpentine the most important substance because traditionally has been used as solvent of drying oils. Diterpenoids (20C), are known as hard resins. Their basic structure consists of bicyclic (labdanes) or tricyclic (abietanes and labdanes) molecules that polymerize at more or less extent depending of the composition. These resins are obtained by extraction from conifer (gymnosperms) or leguminosae (angiosperms) trees. Triterpenoid (30C) resins, known as soft resins, are extracted from angiosperm species. They have tri-, tetra- or pentacyclic structures with a common oxygenated carbon. Mastic is the most flexible of these resins and dammar is the least acidic terpenic resin and the most stable, up to day is the most used in conservation and restoration procedures.

\section{Drying process}

The drying process of oils is a complex chemical process by which the oil goes from being a viscous liquid to a solid film. These changes are achieved because the triglyceride ester molecules bond itself to form a complex polymeric structure. It is relevant to mention that the atmospheric oxygen plays an important role in this drying process.

The auto-oxidation of lipidic media is the direct reaction of molecular oxygen with the oil and proceeds by a free radical chain mechanism. It consists of a complex series of reactions (Figure 6.1.2.2.2.8). The auto-oxidation mechanism, is initiated by hydrogen abstraction from unsaturated fatty acids containing allylic centers. The allylic radical formed undergo rearrangements and will react either with other radicals or, more probably, with molecular oxygen due to its availability and high concentration. The reaction with oxygen results in the production of hydroperoxides, which will decompose when heated or irradiated. The decomposition can also be catalyzed by metal salts, i.e. driers.

The molecular reactions following the decomposition of hydroperoxides will either lead to intermolecular crosslinking or intramolecular chain scission. The drying process occurs when formed alkoxy radicals either add to double bonds or couple with other free radicals. The addition/coupling reactions must dominate over the scission reactions to obtain drying. This is achieved when the level of unsaturations in the oils is high enough i.e. when the oil is defined as a drying oil. Fragmentation reactions will however occur. There are two 
dominating mechanistic explanations for scission reactions, $\beta$-scission and the Russell mechanism. Secondary alkoxy radicals may undergo decomposition by $\beta$-scission, which leads to emission of low molecular species such as aldehydes. The practical consequences of these scission reactions are the well-known odours when linseed oils are drying.

The drying process is highly influenced by the temperature, which generally increases the efficiency of the polymerization process. The light radiation and some pigments catalyze the drying process.

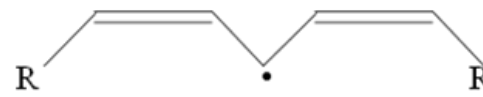

Free radical
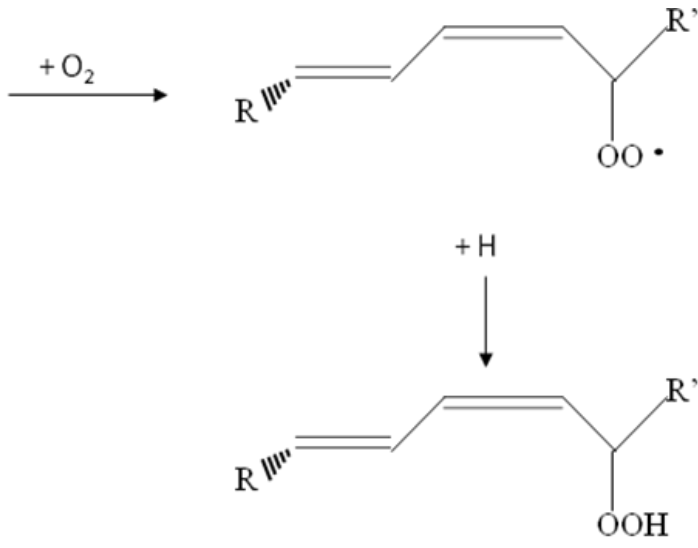

Hydroperoxide radical

Step 1. The oxygen of the air yield the formation of intermediate peroxy and hydroperoxide radical.

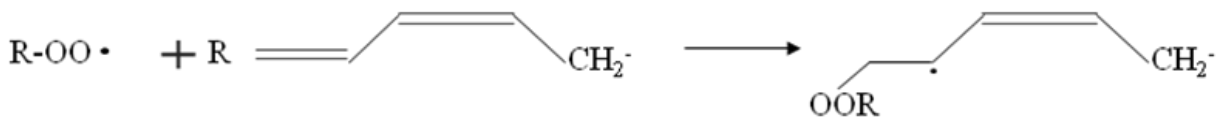

Step 2. The free radical, bond a double bond system (e.g. triglyceride molecule).

Figure 6.1.2.2.2.8 Scheme for an oil drying process.

\section{Degradation processes}

The ageing process of the drying oils has mainly attracted attention of researchers in the last decades due to the importance of oil painting in Art. In parallel to the crosslinking of drying oil reactions taking place during drying, some reaction resulting in the breakdown of the polymer and the formation of low molecular weight degradation products also take place. The result of this combination is a noticeable loss of flexibility of the paint film and migration of the alteration products from the bulk to the film surface, altering the visual aspect of the film.

Prolonged exposure to light radiation and to atmospheric oxygen may cause undesired fragmentation of the polymerized triglyceride ester molecules. This is due to the hydroperoxide radicals formed as reaction intermediates; these free radicals can also lead fragmentation of the triglyceride molecules. As result of this alteration process a series of short-chain fatty diacids, mainly, nonanedioic acid (azelaic acid) are well known alteration products that are formed during ageing of the oil fil (Table 6.1.2.2.2.5) (Mills and White, 1994). 
Together with these acid species other acidic molecules as hydroxyl- and keto- short chain fatty acids have also been described as alteration products formed during oxidative ageing of paint films (Lazzari and Chiantore, 1999; van der Berg et al., 1999) together with conjugated diene type compounds (Mills and White, 1994; Cariati et al., 2000) and lactone or anhydride type products. Epoxy- products have been described as intermediate products formed as consequence of thermal processes (Boon et al., 1996). They can be indicative of thermal processes undergone by the paint during ageing although their presence in the paint film is often due to thermal treatments applied by the manufacturers of commercial drying oils (van der Berg et al., 2002).

Table 6.1.2.2.2.5. Short chain fatty acids frequently found as alteration products of oil paintings.

\begin{tabular}{|c|c|}
\hline SHORT CHAII & TTY ACIDS \\
\hline Monocarboxylic & \\
\hline- & Hexanoic acid, C6 \\
\hline- & Heptanoic acid, C7 \\
\hline Caprylic acid & Octanoic acid, C8 \\
\hline Pelargonic acid & Nonanoic acid, C9 \\
\hline Dicarboxylic act & \\
\hline Adipic acid & Hexanedioic acid, C6 \\
\hline Pimelic acid & Heptanedioic acid, C7 \\
\hline Suberic acid & Octanedioic acid, C8 \\
\hline Azelaic acid & Nonanedioic acid, C9 \\
\hline Sebacic acid & Decanedioic acid, C10 \\
\hline- & Dodecanedioic acid, C11 \\
\hline
\end{tabular}

Drying oils applied in paint films also undergo hydrolysis of glyceride bonds (Erhardt et al., 2005). The acids may catalyze the hydrolysis of triglyceride esters releasing the fatty acids and glycerin present in these molecules. The free fatty long, medium and short fatty acids formed by hydrolysis may react with metal ions from pigments to produce carboxylate salts, whose presence has been reported in pigmented linseed oil paints (Keune et al., 2011; Plater et al., 2003; Robinet and Corbeil, 2003; Salvadó et al., 2009; Meilunas et al., 1990; Mazzeo et al., 2008; Boon et al., 1996). Boon et al. (Boon et al., 1996), proposed that pigment alteration results in the physical change of the paint layer to a hardened, brittle system. These authors describe this hardened system as a polyanionic network in which the several carboxylic and acid groups are stabilized by metal ions whose most probable source are the pigments. Accordingly, pigment particles can be surrounded by an ionomeric layer resulting from the reaction of pigments and the products of oil hydrolysis, carboxylate salts (referred to as soaps in the case of fatty acids) (Boon et al., 1996) or free carboxylic acids (Erhardt et al., 2005) being considered the main components of the paint layer.

Besides the above described alteration processes associated with the aging of the drying oils, there are other processes which should be mentioned such as, i) the formation of diketone compounds as result of high content of linoleic acid, ii) the formation of pyrrole compounds type associated to the presence of amines and ammonia traces in the air or to the formation of diene or quinine type structures. 
Finally, it should be mentioned the pre-polymerized drying oils. These oils are bodied by heating in the absence of air. Due to the heating in absence of air dimerization reaction of the triglycerides ester fatty acids by Diels-Alder occurs. The result is the formation of cyclic compounds which promote the formation of di- and trimeric products that greatly speeds the polymerization. The resulting oil is more viscous oil, with a slower drying process but with the uptake of much less oxygen. The advantages of these stand oils are: i) the smaller volume changes on drying resulting in less wrinkling of the film; and ii) the lowered tendency to yellow due to the reduction in the linolenic content.

\subsection{Polysaccharides}

Glucids, sugars or carbohydrates are another important group of widespread substances from the plant and animal kingdom that play various structural functions in cultural artefacts. These substances have been widely used as binding media and adhesives due to its filmforming and water-soluble properties.

\section{Chemical composition}

As the proteins, sugars (carbohydrates) are polymeric compounds composed of monosaccharide molecules joined together by the so-called glycosidic linkage leading to di, tri and polisaccharides. The number of carbon atoms in the sugar generally ranges from three to seven, designed by the terms triose $\left(C_{3}\right)$, tetroses $\left(C_{4}\right)$, pentoses $\left(C_{5}\right)$, hexoses $\left(C_{6}\right)$ and heptose $\left(\mathrm{C}_{7}\right)$. These molecules structurally are polyhydroxyaldehydes called aldoses, and polyhydroxyketones called ketoses (Figure 6.1.2.2.3.1).<smiles>O=CC(O)C(O)CO</smiles>

Tetrose

D-erythrose<smiles>O=CC(O)C(O)C(O)CO</smiles>

Pentose

D-ribose<smiles>O=C[C@H](O)[C@H](O)[C@H](O)[C@H](O)CO</smiles>

Hexose D-glucose<smiles>O=C(CO)C(O)C(O)C(O)CO</smiles>

Hexose

D-fructose

Figure 6.1.2.2.3.1 Fischer projections of various monosaccharides.

The hydroxyl groups of the monosaccharide molecules can react with the aldehyde or ketone groups leading to formation of cyclic structures called hemiacetals and acetals. When these chemical structures include six-membered ring are known by the term pyranose (Figure 6.1.2.2.3.2). 


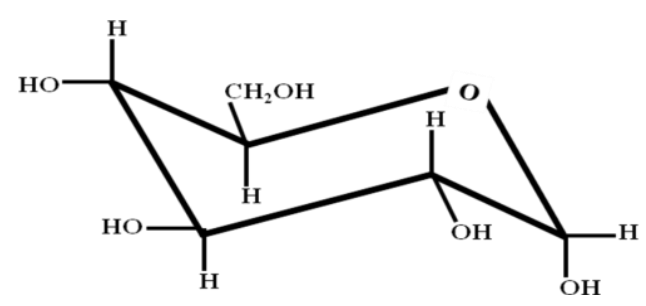

Figure 6.1.2.2.3.2 Pyranose structure.

The combination of two monosaccharide molecules through glycosidic linkage is called disaccharide. For example, cane sugar or sucrose, obtained by the combination of glucose and galactose or the maltose obtained by the linkage between two glucose molecules (Figure 6.1.2.2.3.3).

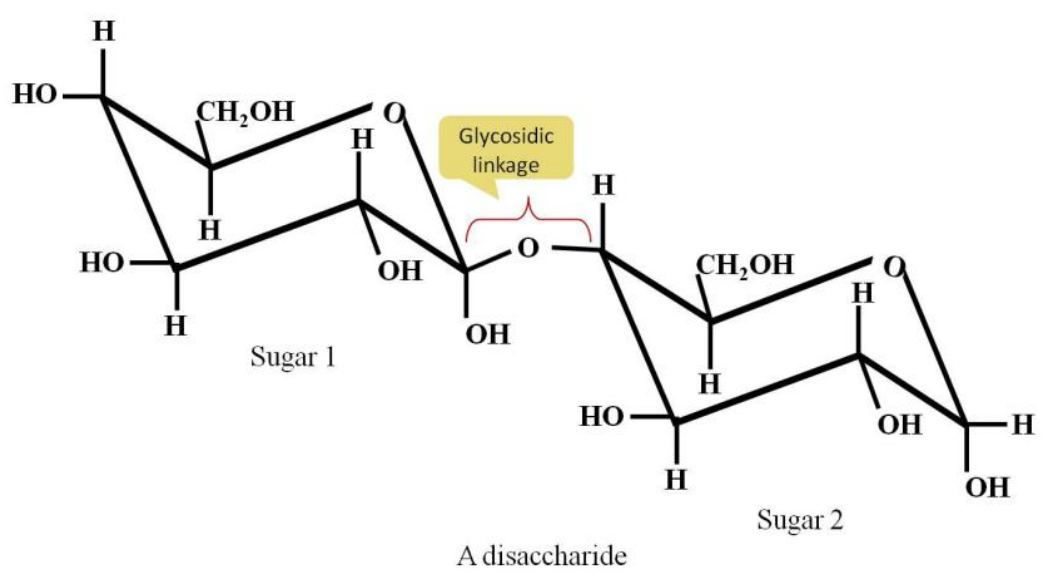

Figure 6.1.2.2.3.3 Formation of a disaccharide composed of two monosaccharide units, through a glycosidic linkage.

Monosaccharides can form links within each other by glycosidic linkages to form large molecules called polysaccharides. The monosaccharides that comprise the polymer are mostly hexoses. Two examples of hexosan compounds commonly used in cultural artefacts are cellulose and starch. Both are composed of glucose molecules.

\section{Classification}

Cellulose. It is one of the major components of plant fiber and wood $(\sim 50 \%)$, and therefore the most abundant compound in paper, textile and wood. A cellulose molecule can contain lots of glucose units, which sometimes exceed the 15000 units.

Vegetables gums. Vegetable gums are produced by certain plants as reserve material to survive in extreme and stress conditions. Gums are polysaccharides of complex structure due to the variety of monomers and the branched structure conformed by the macromolecule. Another feature of these natural products is that they are comprised of uronic acids in addition to the previously mentioned monosaccharides. It means compounds wherein the primary hydroxyl group is oxidized to a carboxylic acid. 
Gum Arabic or gum acacia, tragacanth, and many other trees and plants as cherry, carob and tamarind exudes have been used as binders since ancient times due to its high water solubility.

Many leguminous plant seeds contain galactomannans, a polysaccharide consisting of a linear chain with a 1-4-linked $\beta$-D-mannopyranose backbone with branch points from their 6 positions linked to $\alpha$-D-galactose, i.e. 1-6-linked $\alpha$-D-galactopyranose.

It has been demonstrated that galactose is unevenly distributed, so branched and linear chain zones are present along the mannan chain. The greater or lesser proportion of galactose versus mannose, in relation with the main chain, allows the differentiation between gums.

To those vegetable gums previously described other polysaccharide products have been incorporated. More specific those derived from seaweed used as adhesives and consolidants. For example, agar-agar and funori, in which arabinose and galactose are the monosaccharides predominant. Also the use of polysaccharides derived from the metabolism of certain bacteria, such as xanthan gum it's known. The xanthan molecule consists of a backbone of Dglucopyranoside with $\beta$ 1-4 linkages, as cellulose, with trisaccharides branches of Dmannopyranoside and D-glucopyranosyluronic acid.

Plant mucilages. Among plant mucilages the starch has been widely used as adhesive in cultural artefacts. The starch is the product of the metabolism of certain plants and is the principal carbohydrate reserve of the vegetable kingdom. Starch molecules are smaller than the cellulose, and its particle size may be quite random. For example, the amylose molecule consists of 250-300 units of aligned glucose; nevertheless, an amylopectin molecule reaches 1000 units and adopts a branched structure.

\section{Polysaccharide materials used as binding media}

\section{a) Vegetable gums}

These gums are segregated by certain plants and are distinguished from other vegetable secretions by being water-soluble, alike to vegetable resins that are only soluble in organic solvents. The vegetable gums most used in artistic painting are: arabic, tragacanth and cherry gum (Gómez, 1998; Mills and White, 1994; Matteini and Moles, 2001).

\section{Gum arabic (or acacia gum)}

The most important of the gum historically used in different artistic techniques. It is collected from Acacia Senegal tree and other species (Ward, G.W.R., 2008). It is constituted principally of arabinose, galactose and o lesser amount of rhamnose and galacturonic acid. Gum arabic solutions become less viscous with heating due to breakdown of the polymer chains (Mills and White, 1994).

\section{Tragacanth}

Another widely used gum, obtained from the Astragalus species (Legumiose family) (Ward, G.W.R., 2008). It is of higher molecular weight than gum arabic, resulting in more viscous solutions, but it shares the same uses (Mills and White, 1994). 
It is the generic name for secretions collected from related Prunus species such as plum, peach and almond

\section{b) Starch}

The starch is constituted of a mixture of two polymers: amylose, a linear polysaccharide, and amylopectin, which has a partially branched structure. Its complex structure made it insoluble in cold water, although in boiling water it almost dissolves, resulting in a gelatinous mass very similar to a colloidal solution of great viscosity (Ward, G.W.R., 2008). Starch has been important for sizing paper, and it was a common ingredient of relining adhesives (Mills and White, 1994).

\section{Drying process}

The formation of the film occurs by the water evaporation process and its adhesion is due to the hydrogen bond linkages.

\section{Degradation processes}

The main deterioration processes of polysaccharides are hydrolysis and oxidation processes. In both cases macromolecules are fragmented with the consequent change in physical properties. In the case of polysaccharides used as binding media of paint films a loss in the flexibility may result in chalking and flaking of the painting. Oxidizing agents convert the primary $\mathrm{OH}$ groups into carbonyl or carboxyl, depending of the oxidation level, the result is a loss in the degree of polymerization (Mills and White, 1994; Gómez, 1998; DoménechCarbó, 2013).

The acidic substances from the own gums or external agents as contaminants hydrolyze the polymer breaking the glycosidic linkages causing a reduction in the polymerization degree. For example, some mucilage has been used as binder in mural paintings. The mucilage in contact with the alkaline medium produced by the slaked lime could undergo an important reduction in the polymerization degree and a loss of the paint film strength (Mills and White, 1994; Gómez, 1998; Doménech-Carbó, 2013).

Polysaccharides are a good source of nutrients for microorganisms as fungi and bacteria and as consequence, the exoenzyme activity can cause serious damage by decomposition of the polymer. On the other hand the metabolites produced are organic materials responsible of irreparably modifications in the structure of the painting (Allsopp et al., 2004; Ratledge, 1994; Ciferri, 2002). 


\subsubsection{References}

Achet D., He XW. (1995) Determination of the renaturation level in gelatin films. Polymer, $36,787-791$.

Allsopp, A., Seal, K.J., Gaylarde, Ch.C. (2004) Introduction to biodeterioration, $2^{\text {nd }}$ Ed, Cambridge University Press, Cambridge.

Anderson, T.A., Levitt, D.G., Banaszak, L.J. (1998) The structural basis of lipid interactions in lipovitellin, a soluble lipoprotein. Structure 6, 895-909.

Andreotti, A., Bonaduce, I., Colombini, M.P., Modugno, F., Ribechini, E. (2008) In new trends in analytical environmental and cultural heritage chemistry; Tassi, L., Colombini, M.P. (eds.) Transworld Research Network, Kerala, India, 389 - 423.

Anton, M. (2013) Egg yolk: structures, functionalities and processes. J. Sci. Food Agric., 93, 2871-2880.

Anton, M., Gandemer, G. (1997) Composition, solubility and emulsifying properties of granules and plasma of egg yolk. Journal of Food Science, 62, 484-487.

Anton, M., Martinet, V., Dalgalarrondo, M., Beaumal, V., David-Briand, E. Rabesona, H., (2003) Chemical and structural characterisation of low-density lipoproteins purified from hen egg yolk. Food Chemistry, 83, 175-183.

Azari, P., Phillips, J.L. (1970) Action of periodate on ovotransferrin and its metal complexes. Archives of Biochemistry and Biophysics, 138, 32-38.

Baer, N.S., Banks, P.N. (1985) Indoor air pollution: effects on cultural and historic materials. International Journal of Museum Management and Curatorship, 4, 9- 20.

Bear, R.S. (1952) The structure of collagen fibrils. Adv. Protein Chem., 7, 69-160.

Berezovsky, I.N., Guarnera, E., Zheng, Z., Eisenhaber, B., Eisenhaber, F. (2017) Protein function machinery: from basic structural units to modulation of activity. Current Opinion in Structural Biology, 42, 67-74.

Bier, M., Terminiello, L., Duke, J.A., Gibbs, R.J., Nord, F.F. (1953) Investigations on proteins and polymers. X. Composition and fractionation of ovomucoid. Archives of biochemistry and biophysics, 47, 465-473.

Birrell, G.B., Anderson, P.B., Jost, P.C., Griffith, O.H., Banaszak, L.J., Seeling, J. (1982) Lipid environments in the yolk lipoprotein system. A spin-labeling study of the lipovitellin/phosvitin complex from Xenopus Zaevist. Biochemistry 21, 2444-2452.

Bischoff, R., Schlüter, H. (2012) Amino acids: Chemistry, functionality and selected nonenzymatic post-transitional modifications. Journal of Proteomics, 75(8), 2275-2296.

Boon, J.J., Peulvé, S.L., van den Brink, O.F., Duursma, M.C., Rainford, D. (1996) Molecular aspects of mobile and stationary phases in ageing tempera and oil paint films, in Italy Painting Techniques and Analysis, Bakkenist, T., Hoppenbrouwers, R., Dubois, H. (eds.) Limburg Conservation Institute, 35-56. 
Brimblecombe, P. (1990) The composition of museum atmospheres. Atmospheric Environmental. Part B. Urban Atmosphere, 24, 1 - 8.

Brockerhoff, H. (1971) Stereospecific analysis of triglycerides. Lipids, 6, 942-956.

Burley, R.W., Cook, W.H. (1961) Isolation and composition of avian egg yolk granules and their constituent $\alpha$ - and $\beta$ - lipovitelins. Can J Biochem Physiol, 39, 1295-1307.

Cariati, F., Rampazzi, L., Toniolo, L., Pozzi, A. (2000) Calcium oxalate films on stone surfaces: experimental asssesment of the chemical formation. Studies in Conservaiton, 45, 180-188.

Causeret, D., Matringe, E., Lorient, D. (1991) Ionic strength and pH effects on composition and microstructure of yolk granules. Journal of Food Science, 56, 1532-1536 and references therein.

Cennini, C. (1988) Il libro dell'arte (14 ${ }^{\text {th }}$ century), Akal, Madrid.

Chang, C.M., Powrie, W.D., Fennema, O. (1977) Microstructure of egg yolk. Journal of Food Science, 42, 1193-1200.

Chehin, R., Iloro, I., Marcos, M.J., Villar, E., Shyrov, V.L., Arrondo, J.L.R. (1999) Thermal and $\mathrm{pH}$-induced conformational changes of a $\beta$-sheet protein monitores by Infrared Spectroscopy. Biochemistry, 38, 1525-1530.

Chiavari, G., Gandini, N., Russo, P., Fabbri, D. (1998) Characterisation of stantdard tempera painting layers containing proteinaceous binders by pyrolysis (/methylation)-gas chromatography-mass spectrometry. Chromatographia, 47, 420-426.

Chin-Ming Chung, M. (1985) A specific iron stain for iron-binding proteins in polyacrylamide gels: Application to transferrin and lactoferrin. Analytical Biochemistry, 148, 498-502.

Chitturi, B., Shi, S., Kinch, L.N., Grishin, N.V. (2016) Compact structure patterns in proteins. Journal of Molecular Biology, 428(21), 4392-4412.

Ciferri, O. (2002) The role of microorganisms in the deterioration of cultural heritage. Reviews in Conservation, 3, 35-45 and reference therein.

Cohen, N.S., Odlyha, M., Campana, R., Foster, G.M. (2000) Dosimetry of paintings: determination of the degree of chemical change in museum exposed test paintings (lead white tempera) by thermal analysis and infrared spectroscopy. Thermochim Acta, 365, 45-52.

Coleman, M.H. (1963) The structural investigation of natural fats. Advances in lipid research, $1(2)$.

Collins, M.J., Westbroek, P., Muyzer, G., de Leeuw, J.W. (1992) Experimental evidence for condensation reactions between sugars and proteins in carbonate skeletons. Geochimica et Cosmochimica Acta, 54, 1539 - 1544.

Colombini, M.P, Modugno, F. editors. (2009) Organic mass spectrometry in art and archaeology. Chichester: Wiley. 
Colombini, M.P., Modugno, F., Giacomelli, A. (1999) Two procedures for suppressing interface from inorganic pigments in the analysis by gas chromatography-mass spectrometry of proteinaceous binders in paintings. Journal of Chromatography A, 846, 101-111.

Dallongeville, S., Koperska, M., Garnier, N., Reille-Taillefert, G., Rolando, C., Tokarski, C. (2011) identification of animal glue species in artworks using proteomics: application to a $18^{\text {th }}$ century gilt sample. Anal. Chem., 83, 9431-9437.

Dauphas, S., Beaumal, V., Gunning, P., Mackie, A., Wilde, P., Vié, V., Riaublanc, A., Anton, A. (2007) Structures and rheological properties of hen egg yolk low density lipoprotein layers spread at the air-water interface at pH 3 and 7. Colloids and Surfaces B: Biointerfaces 57, 124-133.

de Brevern, A.G. (2016) Extension of the classical classification of $\beta$-turns. Scientific Reports, 6. Doi: 10.1038/srep33191

Doerner, M. (1998) Los materiales de pintura y su empleo en el arte. Reverté.

Doménech-Carbó, M.T. (2013) Principios físico-químicos de los materiales integrantes de los bienes culturales. Servicio Publiaciones Univeritat Politècnica de València (SPUPV), Valencia.

Doménech-Carbó, M.T., Lee, Y., Osete-Cortina, L., Martín-Rey, S. (2015) Influence of plasticizer and biocide on the functional properties of gelatin-based adhesives used in painting consolidation. Journal of Adhesion Science and Technology, 29, 1774-1795. http://dx.doi.org/10.1080/01694243.2014.975999.

Duce, C., Bramanti, E., Ghezzi, L., Bernazzani, L., Bonaduce, I., Colombini, M.P., Spepi, A., Biagi, S., Tine, M.R. (2013) Interactions between inorganic pigments and proteinaceous binders with reference paint reconstructions. Dalton Trans, 42, 5975-5984.

Duce, C., Ghezzi, L., Bonaduce, I., Colombini, M.P., Tine, M.R., Bramanti, E. (2012) Physico-chemical characterization of protein-pigment interactions in tempera paint reconstructions: casein/cinnabar and albumin/cinnabar. Anal. Bioanal. Chem., 402, 21832193.

Eastoe, J.E. (1955) The amino acid composition of mammalian collagen and gelatin. Biochem J., 61(4), 589-600.

Erhardt, D.C., Tumosa, S., Mecklenburg, M.F. (2005) Long-term chemical and physical processes in oil paint films. Studies in Conservation, 50, 143-150.

Evans, R.J., Bandemer, S.L., Heinlein, K., Davidson, J.A. (1968) Binding of lipid to protein in lipovitellin from the hen's egg. Biochemistry, 7, 3095-3102.

Ferrari, R.A., Schlte, E., Esteves, W., Brühl, L., Mukherjee, K.D. (1996) Minor constituents of vegetable oils during industrial processing. Journal of the American Oil Chemists' Society, 73, 587-592.

Furlan, P.Y., Scott, S.A., Peaslee, M.H. (2007) FTIR-ATR study of pH effects on egg albumin secondary structure. Spectroscopy Letters 40, 475-482. 
Genestar, C., Pons, C. (2005) Earth pigment in painting: characterization and differentiation by means of FTIR spectroscopy and SEM-EDS microanalysis. Analytical and Bioanalytical Chemistry, 382, 269-274.

Gettens, R.J., Stout, G.L. (1966) Painting materials, a short encyclopedia, Dover, New York.

Gómez, M.A. (1998) La restauración. El examen científico aplicado a la conservación de obras de arte, Cátedra, Madrid.

Green, A.G., Marshall, D.R. (1981) Variation for oil quantity and quality in linseed oil (Linum usitatissimum). Aust. J. Agric. Res., 32, 599-607.

Gu, J., Matsuda, T., Nakamura, R., Ishiguro, H., Ohkubo, I., Sasaki, M., Takahashi, N. (1989) Chemical deglycosylation of hen ovomucin: protective effect of chabohydrate moiety on tryptic hydrolysis and heat denaturation. Journal of biochemistry, 106, 66-70.

Haris, P.I., Severcan, F. (1999) FTIR spectroscopic characterization of protein structure in aqueous and non-aqueous media. J Mol Catal B Enzym 7, 207-221.

Harrington, W.E., von Hippel, P.H. (1961) The structure of collagen and gelatin. Adv. Protein Chem., 16, 1-138.

Ibrahim, H.R. (1996) Insights into the structure-function relationships of ovalbumin, ovotransferrin and lysozyme. Hen Eggs, their basics and applied science (Yamamoto, T., Juneja, L.R., Hatta, H. and Kim, M. eds.), 37-56.

Ibrahim, H.R., Thomas, U., Pellegrini, A. (2001) A helix-loop-helix peptide at the upper lip of the active site cleft of lysozyme confers potent antimicrobial activity with membrane permeabilization action. J. Biol. Chem., 276, 43767-43774.

Itoh, T., Tamura, T., Matsumoto, T. (1973) Sterol composition of 19 vegetable oils. Journal of the American Oil Chemists Society, 50, 122-125.

Jones, N.R. (1997) Uses of gelatin in edible products. In: Wards, A.G., Courts, A. (eds.). The Science and Technology of Gelatin, New York: Academic Press, 365-370.

Kamal-Eldin, A. (2005) Minor components of fats and oils. Bailey's Industrial Oil and Fat Products.

Karel, M. (1975) Free radicals in low moisture systems. Water relation in food, Proceedings of International Symposium 1974 (ed. R.B. Duckworth) Academic Press, London, 435-453.

Karpowicz, A. (1981) Ageing and deterioration of proteinaceous media. Studies in conservation, 26, 153-160.

Kaźmierska, M., Jarosz, B., Korzeniowska, M., Trziszka, T., Dobrzanski, Z. (2005) Comparative analysis of fatty acid profile and cholesterol content of egg yolks of different bird species. Polish journal of food and nutrition sciences, 14, 69-73.

Keune, K., van Loon, A., Boon, J.J. (2011) SEM backscattered-electron images of paint cross sections as information source for the presence of the lead white pigment and lead- related degradation and migration phenomena in oil paintings. Microsc. Microanal., 17, 696-701. 
Kister, A.E. (ed.) (2013) Protein supersencondary structures. Totowa, Humana Press: New Jersey. Doi: 10.1007/978-1-62703-065-6

Kuckova, S., Nemec, I., Hynek, R., Hradilova, J., Grygar, T. (2005) Analysis of organic colouring and binding components in colour layer of art works. Anal. Bioanal. Chem., 384, 275-282.

Lazzari, M., Chiantore, O. (1999) Drying and oxidative degradation of linseed oil. Polym Degradation and Stability, 65, 303-313.

Leo, G., Bonaduce, I., Andreotti, A., Marino, G., Pucci, P., Colombini, M.P., Birolo, L. (2011) Deamidation at asparagine and glutamine as a major modification upon deterioration/aging of proteinaceous binders in mural paintings. Analytical chemistry, 83, 2056-2064.

Li-Chan, E.C.Y., Powrie, W.D., Nakai, S. (1995) In: Stadelmen, W.J., Cotterill, O.J. (eds.) Egg Science and Technology. Food Products Press, New York, 105-175.

Litchfield, C. (2012) Analysis of triglycerides. Elsevier.

Lucey, J.A., Singh, H. (1998) Formation and physical properties of acid milk gels: a review. Food Research International, 30, 529-542.

Mallégol, J., Lemaire, J., Gardette, J.L. (2000) Drier influence on the curing of linseed oil. Progr. Org. Coat., 39, 107-113.

Mariod, A.A., Adam, H.F. (2013) Review: gelatin, source, extraction and industrial applications. Acta Sci. Pol. Technol. Aliment, 12, 135-147.

Martin, C.A., Milinsk, M.C., Visentainer, J.V., Matsushita, M., De-Souza, N.E. (2007) Trans fatty acid-forming processes in foods: a review. Anais da Academia Brasileira de Ciências, 79, 343-350.

Matteini, M., Moles, A. (2001) La química en la restauración. Nerea, Guipúzcoa.

Mayer, R. (1993) The Artist's Handbook of Materials and techniques, $2^{\text {nd }}$ Edition, Hermann Blume, Madrid.

Mazurek, J., Svoboda, M., Maish, J., Kawahara, K., Fukakusa, S., Nakazawa, T., Taniguchi, Y. (2014) Characterization of binding media in Egyptian romano portraits using enzymelinked immunosorbant assay and mass spectrometry. e-PS, 11, 46-83.

Mazzeo, R., Prati, S., Quaranta, M., Joseph, E., Kendix, E., Galeotti, M. (2008) Attenuated total reflection micro FTIR characterization of pigment-binder interaction in reconstructed paint films. Analytical and bioanalytical chemistry, 392, 65-76.

Meilunas, R.J., Bentsen, J.G., Steinberg, A. (1990) Analysis of aged paint binders by FTIR spectroscopy. Studies in Consevation, 35, 33-51.

Mills, J.S., White, R. (1994) The organic chemistry of museum objects. Routledge, NewYork. 
Mine, Y., Zhang, H. (2013) Biochemistry of Foods, In: Egg components in food systems, $\left(3^{\text {rd }}\right.$ ed.), Elsevier, 215-241, and references therein.

Nara, M., Morii, H., Tanokura, M. (2013) Coordination to divalent cations by calciumbinding proteins studied by FTIR spectrocopy. Biochimica et Biophysica Acta, 1828, 23192327.

Nara, M., Tanokura, M. (2008) Infrared spectroscopic study of the metal-coordination structures of calcium-binding proteins. Biochemical and biophysical research communications, 369, 225-239.

Nara, M., Tanokura, M., Yamamoto, T., Tasumi, M. (1995) A comparative study of the binding effects of $\mathrm{Mg}^{2+}, \mathrm{Ca}^{2+}, \mathrm{Sr}^{2+}$ and $\mathrm{Cd}^{2+}$ on calmodulin by fourier-transform infrared spectroscopy. Biospectroscopy, 1, 47-54.

Nayaran, K.A., Kummerov, F.A. (1963) Factors influencing the formation of complexes between oxidiced lipids and proteins. J. Am. Oil Chemists Society, 40, 339-342.

Ochigbo, S.S., Alex, A. (2011) Effect of presence of free fatty acids on the drying of oil/drying catalysts mixtures. African Journal of Pure and Applied Chemistry, 5, 198-203.

Odlyha, M. Cohen, N.S. Foster, G.M. West, R.H. (2000) Dosimetry of paintings: determination of the degree of chemical change in museum exposed test paintings (azurite tempera) by thermal and spectroscopic analysis. Thermochim Acta, 365, 53-63.

Odlyha, M. Cohen, N.S., Foster, G.M. (2000) Dosimetry of paintings: determination of the degree of chemical change in museum exposed test paintings (smalt tempera) by thermal analysis. Thermochim Acta, 365, 35-44.

Pallarès, I., Ventura, S. (2016) Understanding and predicting protein misfolding and aggregation: Insights from proteomics. 16(19), 2570-2581.

Pattison, D.I., Rahmantoa, A.S., Davies, M.J. (2012) Photo-oxidation of proteins. Photochem. Photobiol. Sci., 11, 38 - 53.

Pedrola, A. (2006) Materiales, procedimientos y técnicas pictóricas. Ariel, Barcelona.

Plater, M.J., de Silva, B., Gelbrich, T., Hursthouse, M.B., Higgitt, C.L., Saunders, D.R. (2003) The characterization of lead fatty acid soaps in "protrusions" in aged traditional oil paint. Polyhedron., 22, 3171-3179.

Pokorny, J. (1977) Interactions of oxidized lipids with proteins. Rivista Italiana delle Sostanze Grasse, 54, 389-393.

Pokorny, J., Phan-Trong, T., Janiček, G. (1973) Non-enzymic browning. VIII. Autooxidation and browning reactions of phosphatidylethanolamine, Zeitschrift von Lebensmittel Untersuchungs-Forschungen, 153, 322-325.

Popa, V-M., Gruia, A., Raba, D., Dumbrava, D., Moldovan, C., Bordean, D., Mateescu, C. (2012) Fatty acids composition and oil characteristics of linseed (Linum Usitatissium L.) from Romania. Journal of Agroalimentary Processes and Technologies, 18, 136 - 140. 
Poppe, J. (1997) Gelatin. In Thickening and gelling agents for food. Imeson, A.P. (ed.), Springer, 144-168.

Ratledge, C. (ed.) (1994) Biochemistry of microbial degradation, Springer.

Robinet, L., Corbeil, M.C. (2003) The characterization of metal soaps. Studies in Conservation, 48, 23-40.

Robinson, D.S., Monsey, J.B. (1971) Studies on the composition of egg-white ovomucin. Biochemical Journal, 121, 537-547.

Roubal, W.T., Tappel, A.L. (1966) Polymerization of proteins induced by free-radical lipid peroxidation. Archives of Biochemistry and Biophysics, 113, 150-155.

Rustan, A.C., Drevon, C.A. (2005) Fatty acids: structures and properties. eLS.

Salton, M.R.J. and Pavlik, J.G. (1960) Studies of the bacterial cell wall. VI. Wall composition and sensitivity to lysozyme. Biochimica et biophysica acta, 39, 398-407.

Salvadó, N., Butí, S., Nicholson, J., Emerich, H., Labrador, A., Pradell, T. (2009) Identification of reaction compounds in micrometric layers from gothic paintings using combined SR-XRD and SR-FTIR. Talanta, 79, 419-428.

Schneider, H., Morrod, R.S., Colvin, J.R., Tattrie, N.H. (1973) The lipid core model of lipoproteins. Chem Phys Lipids, 10, 328-353.

Schwartz, H., Ollilainen, V., Piironen, V., Lampi, A. M. (2008) Tocopherol, tocotrienol and plant sterol contents of vegetable oils and industrial fats. Journal of Food Composition and Analysis, 21, 152-161.

Scott, D.A., Dodd, L.S., Furihata, J., Tamimoto, S., Keeney, J., Schilling, M.R., Cowan, R. (2004) An ancient Egyptian cartonnage broad collar-technical examination of pigments and binding media. Studies in Conservation, 49, 177-192.

Shoulders, M.D., Raines, R.T. (2009) Collagen structure and stability. Annu Rev Biochem, 78, 929-958.

Smith, L.J., Fiebig, K.M., Schwalbe, H., Dobson, C.M. (1996) The concept of a random coil: residual structure in peptides and denaturated proteins. Folding and Design, 1(5), R95-R106.

Solomon, D.H. (1982) The chemistry of organic film formers $2^{\text {nd }}$ ed., Krieger, R.E. (ed), Publishing Co. Inc., Malabar, Florida.

Spassoy, A.Z., Yan, L., Flook, P.K. (2007) The dominant role of the side-chain backbone interactions in structural realization of amino acid code. ChiRotor: A side-chain prediction algorithm based on side-chain backbone interactions. Protein Sci, 16(3), 494-506. Doi: $10.1110 /$ ps.062447107

Stoner, J.H., Rushfield, R. (2012) Conservation of easel paintings. Routledge.

Taborsky, G. (1974) Phosphoproteins. Adv Protein Chem, 28, 1-210.

Tasan, M., Gecgel, U., Demirci, M. (2011) Comparison of geometrical isomerization of unsaturated fatty acids selected commercially refined oils. Grasas y Aceites, 62, 284-289. 
Toussant, M.J., Latshaw, J.D. (1999) Ovomucin content and composition in chicken egg with different interior quality. Journal of the Science of Food and Agriculture, 79, 1666-1670.

Ulrichs, T., Drotleff, A.M., Ternes, W. (2015) Determination of heat-induced changes in the protein secondary structure of reconstituted livetins (water-soluble proteins from hen's egg yolk) by FTIR. Food Chem, 172, 909-920.

van der Berg, J.D.J., van der Berg, K.J., Boon, J.J. (2002) Identification of non-cross-linked compounds in methanolic extracts of cured and aged linseed oil-based paint films using gas chromatography-mass spectrometry. Journal of Chromatography A, 950, 195-211 (and reference therein).

van der Berg, J.D.J., van der Berg, K.L., Boon, J.J. (1999) Chemical changes in curing and ageing oil paints, in Preprints of the $12^{\text {th }}$ Triennial Meeting of the ICOM Committee for Conservation, Bridgland, J.(ed.) James \& James, London, 248-253.

van der Weerd, J., van Loon, A., Boon, J.J. (2005) FTIR studies of the effects of pigments on the ageing of oil. Studies in Conservation, 50, 3-22.

van Stokkum, I.H.M., Lindsdell, H., Madden, J.M., Haris, P.J., Chapman, D., Bloemendal, M. (1994) Temperature-induced changes in protein structures studied by Fourier Transform Infrared Spectroscopy and Global analysis. Biochemistry, 34, 10508-10518.

Vereshchagin, A.G., Novitskava, G. (1965) The triglyceride composition of linseed oil. Journal of the American Oil Chemists Society, 11, 970 - 974.

Vitruvius, Architecture (Book III)

Vizárová, K., Reháková, M., Kirschnerová, S., Peller, A., Simoň, P., Mikulášik, R. (2011) Stability studies of materials applied in the restoration of a baroque oil painting. Journal of Cultural Heritage, 12, 190-195.

Wang, W. (2005) International protein aggregation and its inhibition in biopharmaceutics. Journal of Pharmaceutics, 289, 1-30.

Ward, G.W.R. (2008) The grove encyclopedia of materials and techniques in art. Oxford University Press, Oxford.

Williams, J., Elleman, T.C., Kingston, I.B., Wilkins, A.G., Kuhn, K.A. (1982) The primary structure of hen ovotransferrin. Eur. J. Biochem., 122, 297-303.

Xie, M., Schowen, R.L. (1999) Secondary structure and protein deamidation. Journal of Pharmaceutical Sciences, 88, 8 - 13.

Consulted web pages:

www.proteinstructures.com Consulted: 22/11/2016

www.particlesciences.com Consulted: 22/11/2016

bio.libretexts.org Consulted: 22/11/2016

www.marquetrycentre.com Consulted: 22/11/2016 


\subsubsection{Deterioration of paints.}

All cultural artefacts are subjected to adverse environmental conditions and, eventually, to unappropriate procedures such as restorations or storage in no optimal conditions. In such instances, the object is exposed to deterioration factors that induce in the object changes, often irreversible and, consequently, affect the durability conditions of the cultural artefacts. Deterioration of an artwork is due to the action of various physical, chemical and biological agents from the environment and from itself. (Doménech-Carbó, 2013; Gomez, 1998 Vaillant et al., 2003).

The specific deterioration processes caused by ageing of the artistic materials used in the elaboration of tempera paintings have been discussed in the sections 6.1.1 and 6.1.2.. Now it will be described the different deterioration agents acting on the paint layer.

\subsubsection{Physical factors}

\section{Relative humidity}

The action of water is due to changes in relative humidity $(\mathrm{RH})$. Water is present in the atmosphere as vapor. When the air becomes saturated with moisture, the water condenses on the objects surface. The effects of the changes in $\mathrm{RH}$ on the different supports used for paintings such as wood, paper, fabrics, plasters and mortars) are well known and have been widely studied (Stoner and Rushfield, 2012). Moisture may cause severe damage to easel paintings, such as warping of a panel support or separation of the entire paint film from the support, but this is generally the result of repeated cycling of $\mathrm{RH}$, a long exposure to increased humidity, or a catastrophic event, such as flooding (Saunders and Kirby, 2004). 
The humidity sensitive substances are:

- Organic and hygroscopic materials, containing around $60 \%$ of water. These materials tend to equilibrate its water vapor content with the surrounding air, so dry up and moistened. Among them are the supports of vegetal nature (textiles, paper and wood) and animals (tissues, parchment, leather, bone and ivory), natural hydrophilic binders (sugars and proteins) and synthetic (dextrins and vinyl resins). Cultural artefacts containing materials of this nature increase in volume with increasing relative humidity and contract when it descends. These phenomena of contraction/dilatation produce cracks and deformations.

- Porous inorganic materials contain capillaries in all direction and absorb water by capillarity. When moisturize may be covered with water-soluble salts, weathering the surface breaking the internal structure to produce microcracks. Soluble salts present in wall paintings and polychromed sculptures migrate to the surface in dryness cycles, crystallized and lose their water of hydration, forming efflorescence that break the paint surface. The most insoluble salts are responsible of the surface crusts (Piqué et al., 1992).

The $\mathrm{RH}$ of the air plays an important role in the deterioration and ageing of all the organic materials used in cultural artefacts. The relative humidity of the air is the ratio between the absolute humidity of the air and its hygroscopicity at a given temperature. This is expressed as (Thomson, 2013):

where:

$$
\mathrm{RH}=\mathrm{A} / \mathrm{A}_{\mathrm{t}} \times 100 \%
$$

$$
\begin{aligned}
& \mathrm{RH}=\text { relative humidity of the air } \\
& \mathrm{A}=\text { absolute humidity } \\
& \mathrm{A}_{\mathrm{t}}=\text { air hygroscopicity at } t^{\circ} \mathrm{C}
\end{aligned}
$$

Many authors coincide that the rate of ageing reactions increases proportionately with the increase of relative humidity, and that oscillations in $\mathrm{RH}$ values may cause alteration in the organic materials used as artistic materials, as well as, promotes the metals corrosion and the growth of microorganism. For example, high RH levels favor the growth of microorganisms and it is difficult for microorganisms to develop below $80 \% \mathrm{RH}$, but this parameter may vary depending on the cultural artefact.

As mentioned before all components of paintings are hygroscopic. Considering that these materials are constituted by organic macromolecules, with different hygroscopic characteristics and different hygrometric variations, when some of these materials swells others not, causing tensions on the artwork structure (Figure 6.1.3.1.1). These RH fluctuations promote fatigue cycles that will cause different structural damages. In addition, moisture goes out and into an artwork, in response to the environmental RH changes, this may cause migration of dangerous compounds from the bulk of the painting, reactivated with changes in $\mathrm{RH}$, continuing with the deterioration of the painting. For example, cleaning the surface of an oil painting with soap or with sodium hydroxide, practiced by some ancient 
restorers has resulted in an irreversible degradation of the binder that confers a powdery surface appearance.
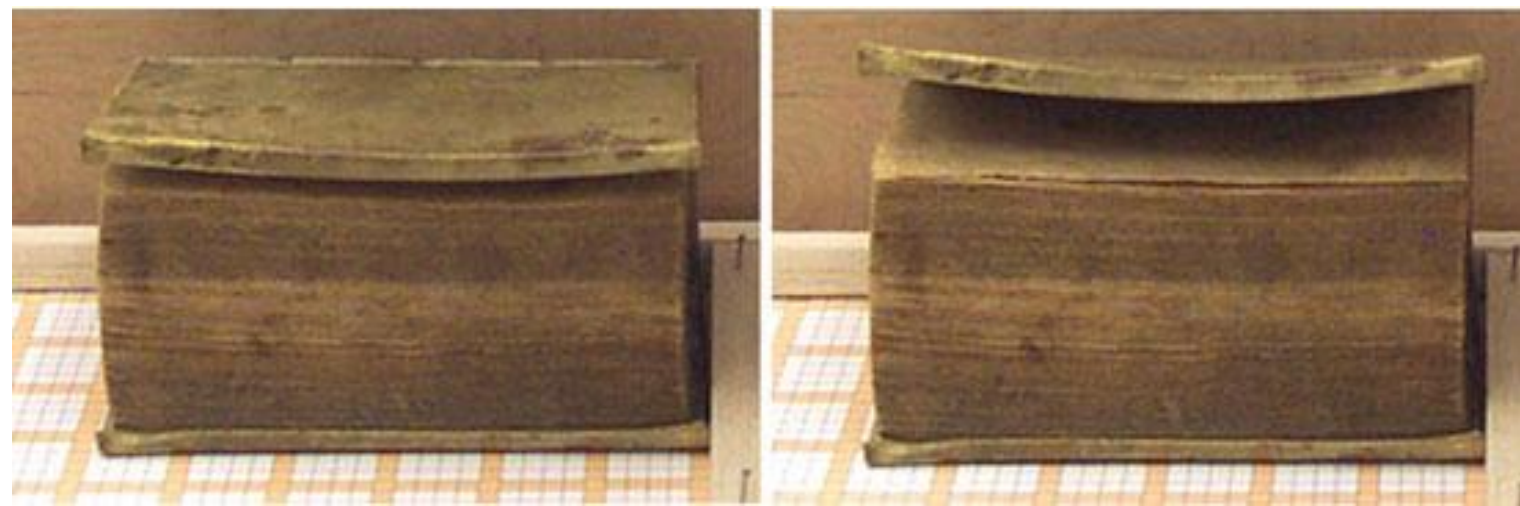

Figure 6.1.3.1.1. Example of deformation in the cover of a vellum book block at $50 \% \mathrm{RH}$ (left) and $20 \% \mathrm{RH}$ (right), () Image Permanence Institute. As you can see, the volume retained at 20\% RH has cambered more than the one stored at $50 \% \mathrm{RH}$.

In general, the RH variations produce some materials to swell and contract due to the absorption or loss of water, respectively, which results in alteration of the size and form of the organic materials constituents of the artwork, e.g. $\mathrm{RH}$ levels below the $40 \%$ can cause cracking of the most rigid materials. It means that each material has a specific response to $\mathrm{RH}$ fluctuations, which is related to its nature, environmental conditions and its deterioration state.

The chemical action of water results in hydrolysis the process already mentioned in binding media section 6.1.2. for proteinaceous, lipidic and polysaccharide materials used in artistic traditional techniques. Proteins and polysaccharides are more sensitive to acidic hydrolysis, while drying oils undergo basic hydrolysis. Water is also a very polar solvent, which acts as reaction medium that allows the pollutants to migrate and react with the paint or seriously dissolves materials of the object during inadequate treatment.

Chalking is another term that refers to the break down on the binding medium of the paint where the pigment particles become exposed to the humidity on the paint surface. In general, whitening may be expected to occur mainly with all hygroscopic pigments rich in silicates.

\section{Temperature}

Temperature is another important factor in the deterioration of paint films. It acts sometimes in combination with light. It has been shown that the chemical processes taking place during the ageing of an object accelerate with an increase on temperature by $10^{\circ} \mathrm{C}$. Elevated temperatures have negative effects on organic materials, for example the degradation reactions of cellulosic materials and other macromolecules are accelerated on increasing temperature. Also, an increase in temperature leads to a decrease in the resistance properties of the constituent materials of the artwork.

For example, polishes, waxes and resins are sensitive to higher temperatures. High temperatures affect especially organic materials, which are flammable. The combustion reaction occurs at temperatures below $250^{\circ} \mathrm{C}$. Before this, around $70^{\circ} \mathrm{C}$, caramelization of sugars and protein denaturation occurs. Therefore, animal glues and starches cannot be heated directly to the fire, and it is necessary to prepare those binding media at bain marie (double 
boiler). The resins are not subjected to direct fire during the varnish preparation, due to the highly flammable properties of the solvents used. Many film-forming materials melt at moderate temperatures and have to be heated to be used, as encaustic or wax in the preparation of matt varnishes. Changes in temperature are also responsible for changes in RH because temperature and $\mathrm{RH}$ parameters are inversely proportional.

Light

Many organic pigments are fugitive to light, in particular the synthesized in the $19^{\text {th }}-20^{\text {th }}$ centuries, modifying the aesthetical aspect of an artwork, also light can cause decomposition of materials which result in weakening and destruction of the binders (Figure 6.1.3.1.2).
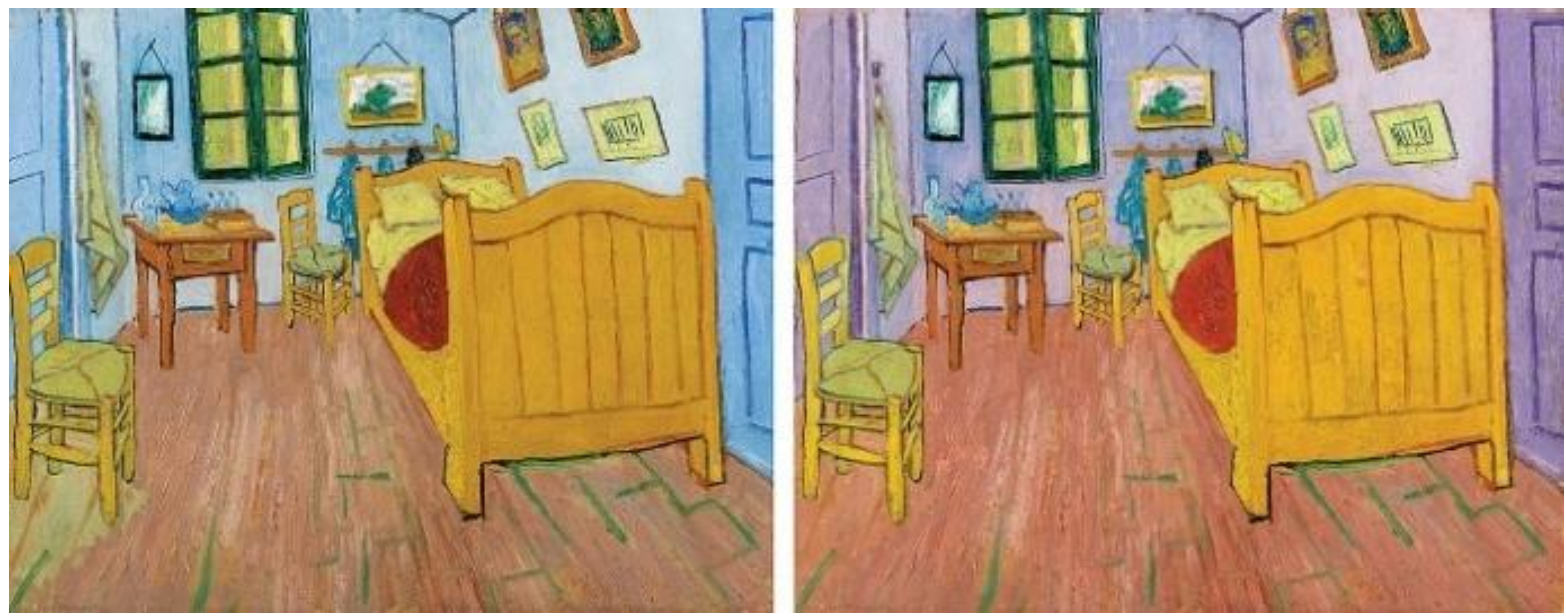

Figure 6.1.3.1.2. The Bedroom from Van Gogh, as it probably looks when first painted (right) and how its look today (left), $\odot$ Van Gogh Museum.

Radiations of characteristic wavelengths between 400 and $700 \mathrm{~nm}$ are emitted in the visible or natural light zone. These radiations lead to reactions that result in the breakdown of glucosidic bonds, C-C bonds and C-O bonds of chains of various polymers, which cause a reduction in the degree of polymerization.

Infrared radiations have higher wavelength and are less energetic, but they produce molecular movements of rotation and vibration, producing a lot of heat. When these radiations are absorbed by a material they produce molecular absorption with the macroscopical effect of the increase in temperature, which explains the breakdown of some bonds in the polymeric chain.

Ultraviolet radiation, X-rays and gamma rays are emitted in the short wavelength area (below $400 \mathrm{~nm}$ ) of the electromagnetic spectrum and consequently they have higher energy content. They are very damaging to the cellulosic supports, and can cause photolysis, also known as photodecomposition.

It can be said that any material with low resistance to light will suffer with visible and UV radiation. For example, colorless materials such as varnishes and binders hardly absorb visible radiation, but they can absorb ultraviolet light easily. While in the case of pigments, for the more sensitive it will be necessary to reduce the visible light radiation. For oil paintings, it is more convenient to eliminate UV radiation, and it is also suitable to have visible light controlled. 
The recommended lighting levels depend on the sensitivity of the material in question although it is recommended to avoid the direct incidence of any type of light source on the cultural artefacts. Visible and UV radiation produce the activation energy necessary for free radicals' formation, from the unsaturated chains and carbonyl compounds. For example, drying oils and terpene resins containing fatty acids.

\subsubsection{Chemical factors}

The most important are those related to its composition, structure and manufacturing process. Most works of art are composed of materials of organic origin, which undergo physicalchemical transformations with aging. Some examples are the degradation reaction of the cellulosic chain that occurs in the supports, inks and dyes made with natural pigments, pigments, etc. In the case of natural pigments used in painting artworks, the biggest problem is their ability to react with the oxygen in the air and their capability to absorb the environmental humidity, which provides an acidic character, catalyzing the degradation processes that occur in the support. For example, verdigris can cause irreversible damage to the support due to copper constituent of this pigment.

It should be mentioned that new or non-traditional materials such as photographs, microfilms, cellulose nitrate films, tape or disc recordings, etc., are not exempt from deterioration due to internal factors as well as materials used in traditional artistic techniques.

The acidity favors the degradation of almost all the supports and materials used in the elaboration of works of art. The main sources of this type of degradation are: the chemical components of the works and the atmospheric conditions.

\section{Atmospheric pollutants}

Pure air contains mainly oxygen and nitrogen, but also smaller amounts of water vapor, argon and carbon dioxide, and lower amounts of other gases (Baer et al., 1985; Thomson, 1965). In addition to the substances present in pure air there are the impurities provided by man because of the use of fossil fuels. In general, in the atmosphere we can find two essential groups of atmospheric pollutants: aggressive gases and solid particles in suspension (Camuffo et al., 2001; Lalli and Lalli, 2004).

The most frequently found pollutants are sulfur dioxide, nitrogen dioxide and ozone. Sulfur dioxide appears in the air when a fossil fuel is burned, that sulfur combines with the oxygen of the air and forms sulfur dioxide. This substance is a weak acid, which tends to combine with other oxygen particles forming the sulfur trioxide, which when combined with the humidity of the environment, produces sulfuric acid (Table 6.1.3.2.1). Sulfuric acid is very corrosive and a strong acid, which also participates in the reactions of oxidation and hydrolysis of the cellulose and constituent macromolecules of the organic supports (Lalli and Lalli, 2004). The high relative humidity accelerated these reactions. The main materials that are affected by the presence of this gas are those containing calcium carbonate (marble, fresh limestone), cellulosic, as well as those of protein origin, and metals as iron and steel (Amoroso et al., 1983; Bear and Banks, 1985; Brimblecombe, 1990; Pavlogeorgatos, 2003). 
Table 6.1.3.2.1. Summary of the atmospheric pollutants and the acids resulted from its interaction with water.

\begin{tabular}{|c|c|}
\hline Atmospheric pollutants & Acids \\
\hline $\mathrm{CO}_{2}$ & $\mathrm{H}_{2} \mathrm{CO}_{3}$ \\
\hline $\mathrm{SO}_{3}$ & $\mathrm{H}_{2} \mathrm{SO}_{4}$ \\
\hline $\mathrm{N}_{2} \mathrm{O}_{5}$ & $\mathrm{HNO}_{3}$ \\
\hline
\end{tabular}

For example, the crusting of sulfates in fresco paintings is explained by the action of sulfuric acid product of moisture and atmospheric pollutants, from sulfur dioxide and the sulfurcontaining impurities of fuels waste (Figure 6.1.3.2.1).

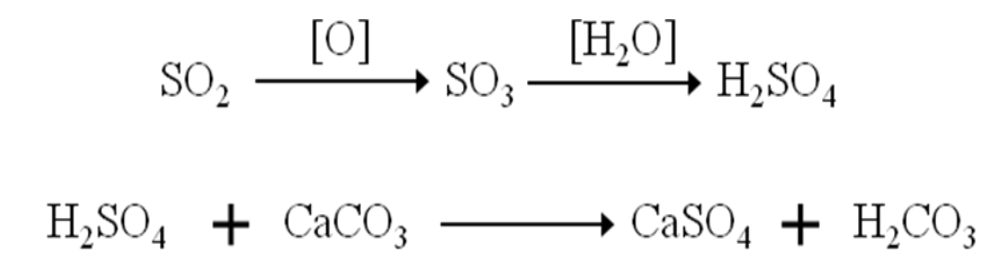

The carb onic acid decomposes to form water and carbon dioxide (gas):

$$
\mathrm{H}_{2} \mathrm{CO}_{3} \longrightarrow \mathrm{H}_{2} \mathrm{O}+\mathrm{CO}_{2}
$$

Figure 6.1.3.2.1 Sulfation reaction of $\mathrm{SO}_{2}$ with calcium carbonate

Nitrogen oxides such as $\mathrm{N}_{2} \mathrm{O}_{3}, \mathrm{~N}_{2} \mathrm{O}_{4}, \mathrm{~N}_{2} \mathrm{O}_{5}, \mathrm{NO}_{3}$ and $\mathrm{N}_{2} \mathrm{O}_{6}$, decompose almost completely into the atmosphere in simpler oxides and $\mathrm{N}_{2} \mathrm{O}$ (Galloway et al., 2004). Nitrogen dioxide is an oxidizing agent that produces nitric acid and participates in metal corrosion, cellulose hydrolysis and limestone decay. Dioxide and carbon monoxide also produce acids that adhere to the surface of the supports, altering its $\mathrm{pH}$. In addition, nitrogen dioxide can be dissolved in water to form nitric acid, an oxidizing agent as strong as sulfuric acid, which promotes the same problems as sulfur dioxide (Withmore et al., 1989; Pavlogeorgatos, 2003; Thomson, 1965).

Another strong oxidizing agent is the ozone $\left(\mathrm{O}_{3}\right)$, formed in the atmosphere at a height of 20 $30 \mathrm{~km}$ by the action of ultraviolet rays on oxygen. It promotes the breaking of all the double bonds of the unsaturated carbon chains with which it comes in contact, causing irreparable damages in the constituent organic materials of a cultural artefact (Lalli and Lalli, 2004; Thomson, 2013). Its effects on certain materials such as cellulose are due to its partial conversion into hydrogen peroxide when reacted with water. Paintings, fabrics, furniture, etc. are constituted of organic matter and the ozone oxidizes them all, in the same way it catalyzes the sulfation of silver and copper. 
Apart from gases another important group of air pollutants are the suspended particles such as soot, dust, and sea salts. The main deterioration caused by soot is the stains at aesthetic level while the dust is a source of dirt, acidity, and sometimes conveyance of insects and microbial spores. Sea salts can cause damages due to alkaline chlorides and nitrates that produce crystallizations on the surface of the supports and are strong corrosive agents. Chlorides can come from the sea, but they are also the product of industry being the most hazardous atmospheric pollutants for metals (Lalli and Lalli, 2004; Vaillant, 2003; Thomson, 2013).

Free fatty acids and metal soaps, that are capable of migrating through the paint layers, can play a role in the formation of surface deposits and may participate in reactions with anionic sources from the atmosphere to form insoluble complexes containing carbonates, sulphates, and chlorides. Substantial surface deposits can severely alter the appearance of a painting, appearing as a whitish haze.

\subsubsection{Biological factors}

Many art materials are susceptible to attack by biological agents. Among the biological agents responsible for the biodeterioration are included macro- and micro-organisms in a broad spectrum. All them can develop in favorable environments given by materials, which serve them as food, and proper conditions for growth such as high and variable humidity and temperature.

Biodeterioration involves processes of chemical, mechanical and chromatic alteration in all the constituents of the artwork. There are different causes, origins and manifestations to biodeterioration, as this depends on the participation of several permanent factors together with the surrounding environment. The mechanism of action will depend on the characteristics and composition of the cultural artefact. The most frequently observed damages are those caused by rodents, insects and microorganisms.

\section{Rodents}

They are mammals with flat incisors, they go to the deposits in search of food and waste. If they are not detected and eliminated quickly, they can cause serious damages at chemical and physico-mechanical level of the artworks. The most common are rats and mice. They use paper, textiles and other materials to build their nests. In addition, they urine and excrement deposits can cause chemical and chromatic damages, as well as they can gnaw the insulation of the electrical cables arriving to cause fires (Green, 2003; Goldberg, 1996).

\section{$\underline{\text { Insects }}$}

Insects are arthropods (six legs) called hexapods, have the body divided into head, thorax and abdomen (Figure 6.1.3.3.1(right)). Many species of insects may cause damage to objects and artistic collections. They cause physico-mechanical and aesthetical damages in the infesting supports or paintings (Figure 6.1.3.3.1 l(left)). Up to 70 species have been described as pollutants of artworks belonging to various families and orders (Stoner and Rushfield, 2012; Zycherman and Zycherman, 1988). Each produces a characteristic type of biological erosion, which allows its identification. The most frequently found groups in institutions and museums are six-leg invertebrate metazoans such as: cockroaches (Blattodea), silver fish 
(Thysanura), booklouse (Corrodentia) and termites (Isoptera) (Rust et al., 1996; Blanchette, 1998). Another group of insects are coleoptera, whose metamorphosis is more complicated.
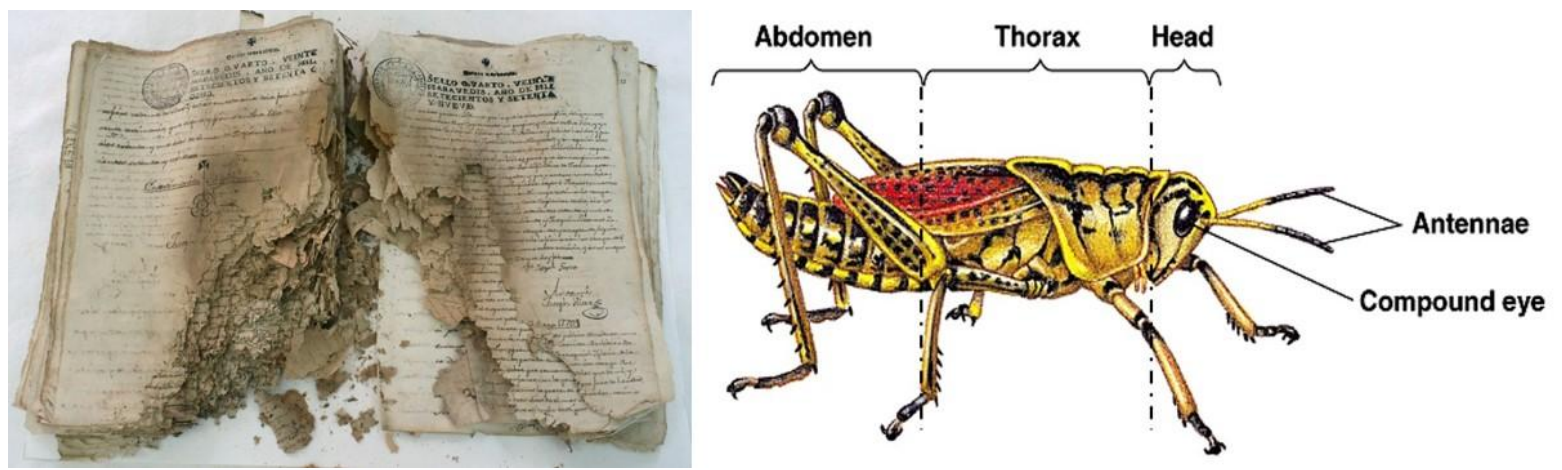

Figure 6.1.3.3.1. Aesthetical and structural damage due to insect infestation on paper manuscript $\odot$ British Library (left) and arthropods body parts (right) (Adapted from www.bio.miami.edu).

The life cycle of insects

Insects usually go through a four-stage transformation during their life cycles. The larva hatches from the egg, with a soft body covered with bristles and feeds on nutrients such as the wood, paper, etc. At the end of the larval period, the insects transform into pupa and then pass into adults, the imago that is able to mate and lay new eggs. The larvae insects are the most dangerous stage of insects' metamorphosis, during this period the larvae consume higher amounts of nutrients and can live several years whereas the other stages last just a few weeks (Vivancos-Ramón, 2007; Vaillant et al., 2003). Pupa, with features similar to adults, are wrapped in a light tunic, which breaks when they switch to the higher stage (Figure 6.1.3.3.2). They neither move nor eat only darken and grow when they are close to being adults. Then they pupate and finally break through the surface as imagos, leave and mate. The most common are moths (Anobiidae) and beetles (Dermestidae).

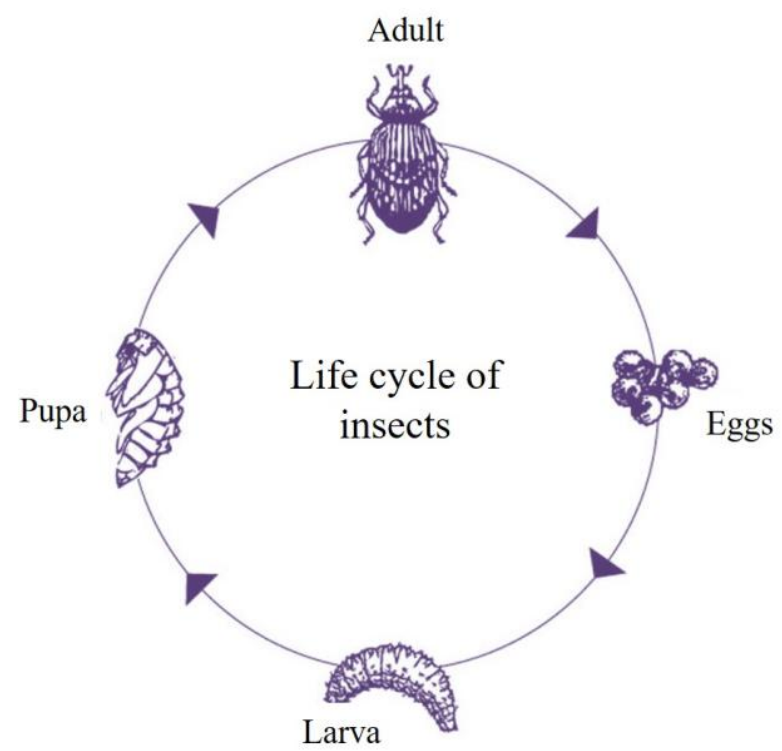

Figure 6.1.3.3.2. Life cycle of insect's scheme. 
The insect infestation may not be visible to until the adults depart from within the structure. The fact that there are groups with different life cycles complicates the problem for conservators, making it more difficult to eradicate and control them.

\section{Microorganisms}

Microorganisms responsible of the deterioration of paintings have different sources of origin: i) from spores suspended in the air; ii) from the water condensation deposits in the surface and filtered by capillarity through the paint layers; iii) improper storage of the cultural artefacts; iiii) conservation and restoration treatments (Allsopp et al., 2004).

Microorganisms have the ability to grow on a wide range of materials that become biomasses. The different biodeterioration forms are:

- That the living organisms use the substrate (paint layer) as nutrient.

- Metabolism products as extracellular lytic enzymes, pigmented substances, Krebs cycle and proteolysis acid products, excrement from the biggest organisms.

- Breaking of the paint layers by: plant roots, rhizoids of lichens or cavities made by insects.

Each organism has optimal conditions for living. Although there are a few parameters that are common in many species such as high humidity especially, algae $(90 \%)$ and some bacteria $(80 \%)$. Also photosynthetic organisms need light to survive; in contrast it is not suitable for fungi. This makes predominant microbial flora founded, in cultural artefacts in museums and in storage, is largely constituted by fungi (López-Miras et al., 2013; Ciferri, 1999; 2002; Seves et al., 1996; Ravikumar et al., 2012; Herrera and Videla, 2009; Sainz-Jimenez, 2003).

Highly acidic or highly alkaline $\mathrm{pH}(\mathrm{pH}<4$ or $\mathrm{pH}>10)$ restrict the growth of microorganisms.

Most natural organic binders are composed of carbohydrates, proteins and lipids, the most abundant constituents of living things. Carbohydrates provide the energy necessary for vital functions, proteins are responsible of the structural and functional component, and lipids are responsible of membrane formation and reverse substances (Crispin and Gaylarde, 2005; Sterflinger, 2010; Tiano, 2002).

Natural polymers are easily degraded by microorganisms in appropriate environmental conditions. Chemoorganotrophs and heterotrophic are the most common organisms found in cultural artefacts containing proteins and carbohydrates that serve as nutrients (Seves et al., 1996). Unlike, the hydrophobic characteristic of lipids hinders to growth of microorganisms. Fungi are heterotrophic microorganisms and are commonly found in film-forming materials, as starch, Arabic gum, casein and animal glue. Besides, cellulosic materials such as wood, textiles and paper are most commonly attacked by insect and microorganisms containing cellulase an enzymatic extracellular lytics that degrade cellulose. Fungi and bacteria with high lipolytic and proteolytic activity are the responsible of the leather and parchment biodeterioration (Ciferri, 2002; Sterflinger, 2010; Ravikumar et al., 2012). 
There are species with affinity for calcareous and siliceous rocks; these species excrete organic acids which forms water soluble mineral complexes. For example, bacteria contribute to the biodeterioration of calcareous materials due to the formation of calcium sulfate. There also bacteria and fungi species involve in the biocorrosion of metals ( $\mathrm{Gu}, 2007$; Beech and Sunner, 2004; Beech and Gaylarde, 1999).

There are many types of microorganisms that damage cultural property, more than 300 species have been identified (López-Miras et al., 2013; Ciferri, 1999; 2002; Seves et al., 1996; Ravikumar et al., 2012; Milanesi et al., 2006; Herrera and Videla, 2009; SainzJimenez, 2003).

\section{Bacterium}

Eubacteria also called "bacteria" belong to the group of Prokaryotes, can be defined as microscopic structures, unicellular, constituted by a simple cell, without nuclear membrane, which multiply by binary fission or bipartition (Figure 6.1.3.3.3 left). Within are include most of the common bacteria responsible for many human diseases. According to their shape, they are classified into cocci (spherical), bacilli (rod-shaped) vibrios (curved rods) and spirals (twisted) (Fierer et al., 2007; Lowy, 2013).

On the other hand, are the actinobacteria, which share the characteristics of both bacteria and fungi, and are quite abundant in soil and aquatic ecosystems where they participate in the decomposition of organic matter and fungal materials. Its morphology varies from coccoid, fragmenting hyphal forms to those with highly branched mycelium. They are the major producers of medically important antibiotics, especially Streptomyces species (Figure 6.1.3.3.3 right) (Fierer et al., 2007).

When the solid media is inoculated with bacteria, its growth gives rise to the formation of colonies, which are observable to the naked eye. The characteristics of the colonies are usually constant for a given species, the most important characteristics of the colonies are the shape, color, surface appearance and the nature of its edges.

Damages associated with bacterium attack on cultural artefacts are: i) the ability to bound to clay and crystal particles on the rock surfaces and pores spaces; ii) solubilize $\mathrm{CaCO}_{3}$ through the release of acid metabolic products and release of $\mathrm{CO}_{2}$; iii) oxidise metallic compounds like Fe, Mn, and lead to precipitation of orange black spots; and iiii) precipitate passively or actively carbonate, oxalate and other minerals that contribute to the patina formation (Milanesi et al., 2006; Crispin and Gaylarde, 2005). 

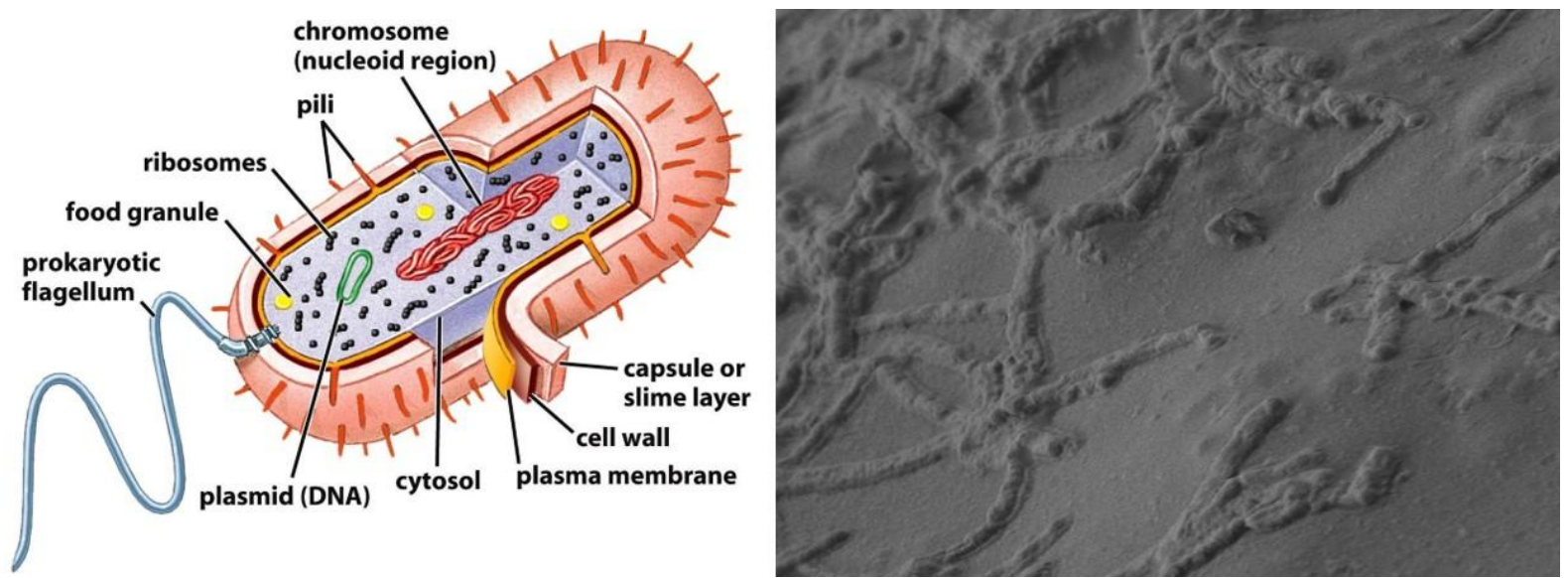

Figure 6.1.3.3.3. Generic bacterium microscopic structure diagram (left) and a secondary electron image of Streptomyces cellulofans (actinobacteria) colonies over a painted surface (right).

Most bacteria are heterotrophic; it means they get the energy for their vital processes from organic substances in the medium. To carry out these reactions, they produce enzymes or biological catalysts, which play a fundamental role in their metabolism. The optimal conditions for its development are at neutral $\mathrm{pH}$ in the range 7-8 and temperature $25-37{ }^{\circ} \mathrm{C}$, although psychrophilic species tolerate temperatures below $5{ }^{\circ} \mathrm{C}$, and others such as thermophiles resist those above $45^{\circ} \mathrm{C}$.

Some species excrete pigments and other metabolism productsthat are depositied in the surface where they grow. All these characteristics give them important potential as biodeterioration agents (Milanesi et al., 2006). They are also able to use a wide range of substances as a source of carbon, especially carbohydrates, certain organic acids, proteins and glycerin (Crispin and Gaylarde, 2005).

\section{Fungi}

They belong to the Eukaryotes group, and many of the genera that cause concern for the conservators belong to the family Eurotiaceae: Ascomycetes and Deuteromycetes. Fungi are multicellular structures with differentiated nucleus, sexual reproduction mechanisms in some species and a complex and versatile metabolism, which are empowered to use a wide range of substances as a source of energy (Figure 6.1.3.3.4).
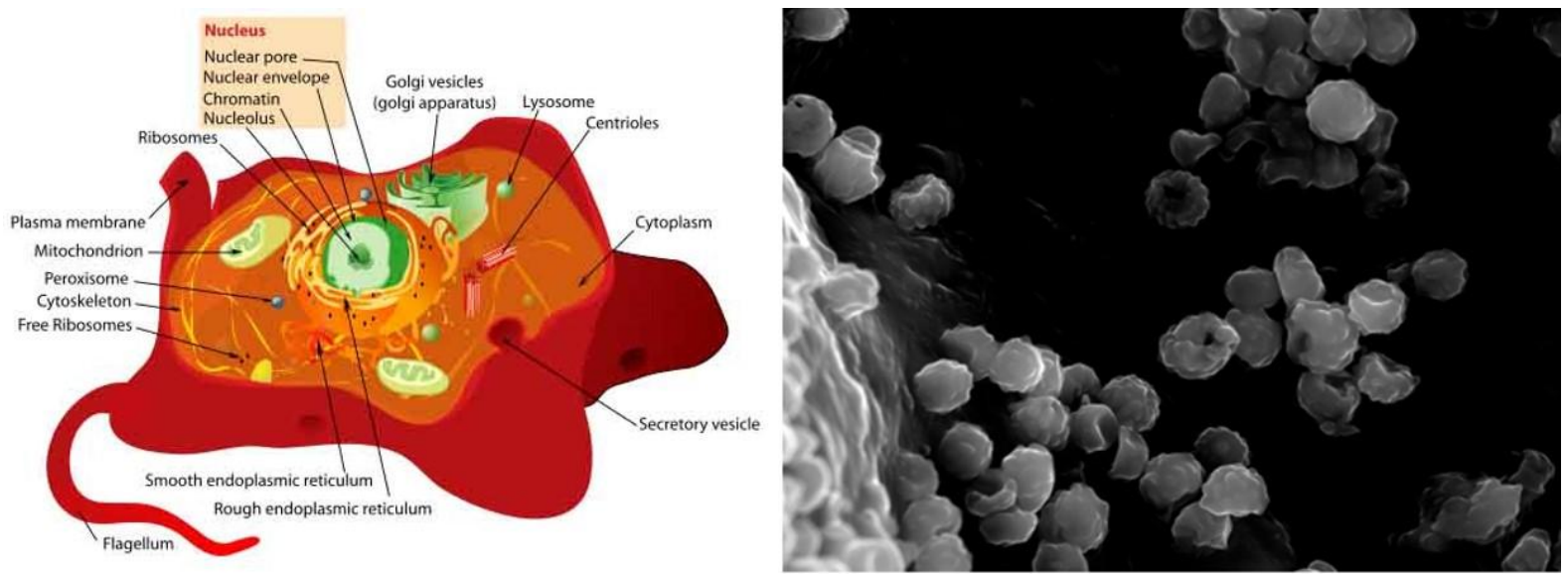

Figure 6.1.3.3.4. Generic fungi microscopic structure diagram (left) and a scanning electron micrograph of Aspergillus niger spores over a painted surface (right). 
From the evolutionary point of view, they are more developed organisms than the bacteria, although they present similarity in nutritional sense by their heterotrophic characteristics. No fungus is able to grow in the absence of organic food substances, nor have photo-synthesizing pigments, nor are they able to use carbon dioxide as the only carbon source. However, in the presence of an external supply of sugars or other organic substance, most exhibit biosynthetic capacity and produce a large variety of metabolites. These include cellular proteins, reserve materials, organic acids, enzymes, pigments and antiobiotic substances. Fungi are also responsible for the crater shaped lesions, chipping and exfoliation of the rock surfaces combined with the loss of materials (Herrera and Videla, 2009).

The growth of fungi is affected by many environmental factors, such as the nature and concentration of nutrient supply, moisture, temperature, light and hydrogen concentration. Changes in these factors can induce morphological and physiological changes, which make it difficult to recognize them and alter their behavior in general. The optimal conditions for the growth of fungi are at acid $\mathrm{pH} 4-6$, relative humidity higher than $70 \%$ and ambient temperature, close to $30^{\circ} \mathrm{C}$ (but also grow at low temperatures), although oscillation of the above mentioned parameters favors the germination of fungal spores.

There are many studies focused in the isolation or the presence on damaged cultural heritage of a wide range of microorganisms responsible for the deterioration, but their contribution to the clarification of the role that microorganisms plays in deterioration of cultural artefacts falls short. 


\subsubsection{References}

Allsopp, D., Seal, K.J., Gaylarde, Ch.C. (2004) Introduction to biodeterioration, $2^{\text {nd }}$ ed., Cambridge University Press, Cambridge.

Amoroso, G.G., Fassina, V. (1983) Stone decay and conservation: atmospheric pollution, cleaning, consolidation and protection. Elsevier Science Publishers.

Baer, N.S., Banks, P.N. (1985) Indoor air pollution: effects on cultural and historic materials. International Journal of Museum Management and Curatorship, 4, 9-20.

Becker, P. (2010) Understanding and optimizing the microbial degradation of olive oil: a case study with the thermophilic bacterium Geobacillus thermoleovorans IHI-91. In Olives and Olive Oil Health and Disease Prevention. Elsevier Inc., 377-386.Bock, E., Sand, W. (1993) The microbiology of masonry biodeterioration. J. Appl. Bacteriol., 74, 503-514.

Beech, I.B., Gaylarde, C.C. (1999) Recent advances in the study of biocorrosion: an overview. Revista de Microbiología, 30, 117-190.

Beech, I.B., Sunner, J. (2004) Biocorrosion: towards understanding interactions between biofilms and metals. Current opinion in Biotechnology, 15, 181-186.

Blanchete, R.A. (1998) A guide to wood deterioration caused by microorganisms and insects. The structural conservation of panel paintings. Getty Conservation Instittute, Los Angeles, 55-68.

Breitbach, A.M., Rocha, J.C., Gaylarde, Ch.C. (2011) Influence of pigment on biodeterioration of acrylic paint films, in Southern Brazil. J. Coat. Technol. Res., 8, 619-628.

Brimblecombe, P. (1990) The composition of museum atmospheres. Atmospheric Environment. Part B. Urban Atmosphere, 24, 1-8.

Camuffo, D.R., van Grieken, R., Busse, H.-J., Sturaro, G., Valentino, A., Bernardi, A., Blades, N. (2001) Environmental monitoring in four European museums. Atmospheric Environment, 35, S127-S140.

Ciferri, O. (1999) Microbial degradation of paintings. Applied and Environmental Microbiology, 65, 879-885.

Ciferri, O. (2002) The role of microorganisms in the degradation of cultural heritage. Reviews in Conservation, 3, 35-45.

Crispin, C.A., Gaylarde C.C. (2005) Cyanobacteria and biodeterioration of cultural heritage: a review. Microbial ecology, 49 (1), 1-9.

Doménech-Carbó, M.T. (2013) Principios físico- químicos de los materiales integrantes de los bienes culturales. SPUPV, Valencia.

Fierer, N., Bradford, M.A., Jackson, R.B. (2007) Toward an ecological classification of soil bacteria. Ecology, 88, 1354-1364.

Galloway, J.N., Dentener, F.J., Capone, D.G. Boyer, E.W., Howarth, R.W., Seitzinger, S.P., Asner, G.P. (2004) Nitrogen cycles: past, present and future. Biogeochemistry, 70, 153-226. 
Goldberg, L. (1996) A history of pest control measures in the anthropology collections, National Museum of Natural History, Smithsonian Institution. Journal of the American Institute for Conservation, 35, 23-43.

Gómez, M.A. (1998) La restauración. El examen científico aplicado a la conservación de obras de arte, Cátedra, Madrid.

Green, B.M. (2003) Critters in our collections. Regional alliance for preservation, (Spring/Summer), 1-2.

Gu, J.-D. (2007) Microbial colonization of polymeric materials for space applications and mechanisms of biodeterioration: A review. International Biodeterioration \& Biodegradation, 59, 170-179.

Herrera, L.K., Videla, H.A. (2009) Surface analysis and materials characterization for the study of biodeterioration and weathering effects on cultural property. International Biodeterioration \& Biodegradation, 63, 813-822.

Inoue, M., Koyano, M. (1991) Fungal contamination of oil painting in Japan. International Biodeterioration, 28, 23-25.

Kinderlerer, J.L. (1994) Degradation of the lauric acid oils. Int. Biodeter., 33, 345-354.

Lalli, C., Lalli, C. (2004) L'inquinamento atmosferico. Danni sui manufatti esposti. In: La vetrina per il museo: caratteristiche e requisiti di funzione atti del workshop, Firenze, 21 April 1999, 17-47. Opificio delle Pietre Dure.

López-Miras, M., Piñar, G., Romero-Noguera, J., Bolívar-Galiano, F.C., Ettenauer, J., Sterflinger, K., Martín-Sánchez, I. (2013) Contribution of the microbial communities detected on an oil painting on canvas to its biodeterioration. Aerobiologia, 29, 301-314.

Lowy, F. (2013) Bacterial classification, structure and function. Web. http://www.columbia.edu/itc/hs/medical/pathophys/id/2004/lecture/notes/Classification_Low y.pdf Consulted on: March 14, 2017

Lowy, F., 2013, May. Bacterial Classification, Structure and Function. Web.

Milanesi, C., Baldi, F., Borin, S., Vigman, R., Ciampolini, F., Faleri, C., Cresti, M. (2006) Biodeterioration of a fresco by biofilm forming bacteria. International Biodeterioration \& Biodegradation, 57, 168-173.

Pavlogeorgatos, G. (2003) Environmental parameters in museums. Building and Environment, 38, 1457-1462.

Piqué, F., Dei, L., Ferroni, E. (1992) Physicochemical aspects of the deliquescence of calcium nitrate and its implications for wall painting conservation. Studies in conservation, 37, 217-227.

Ratledge, C. (1994) Biodegradation of oils, fats and fatty acids. Biochemistry of microbial degradation, Springer Netherlands, 89-141.

Ravikumar, H.R., Rao, S.S., Karigar, C.S. (2012) Biodegradation of pains: a current status. Indian Journal of Science and Technology, 5, 1977-1987. 
Romero-Noguera, J., Martín-Sánchez, I., López-Miras, M.M., Ramos-López, J.M., BolívarGaliano, F. (2010) Biodeterioration pattens found in dammar resin used as art material. Electronic Journal of Biotechnology, 13, 6-7.

Rust, M.K., Daniel, V., Druzik, J.R., Preusser, F.D. (1996) The feasibility of using modified atmospheres to control insects pests in museums. Restaurator, 17, 43-60.

Sainz-Jimenez, C. (2003) Biodeterioration: an overview of the state of the art and assessment of future directions.

Saunders, D., Kirby, J. (2004) The effect of relative humidity on artists' pigments. National Gallery technical bulletin, 25, 62-72.

Seves, A.M., Sora, S., Ciferri, O. (1996) The microbial colonization of oil paintings. A laboratory investigation. International Biodeterioration \& Biodegradation, 215-224.

Sterflinger, K. (2010) Fungi: their role in deterioration of cultural heritage. Fungal Biology Reviews, 24, 47-55 and reference therein.

Stoner J.H., Rushfield, R. (2012) The conservation of easel paintings. Abington, Oxon (England), New York: Routledge.

Strzelczyk, A.B. (2004) Observations on aesthetic and structural changes induced in Polish historic objects by microorganisms. International Biodeterioratiton \& Biodegradation, 53, 151-156.

Thomson, G. (1965) Air pollution- a review for conservation chemists. Studies in Conservation, 10, 147-167.

Thomson, G. (2013) The museum environment. Elsevier.

Tiano, P. (2002). Biodegradation of cultural heritage: decay mechanisms and control methods. In Seminar article, New University of Lisbon, Department of Conservation and Restoration, 7-12.

Vaillant Callol, M., Doménech-Carbó, M.T., Valentín Rodrigo, N. (2003) Una mirada a conservación preventiva del patrimonio cultural (Ed. Universidad Politécnica de Valencia), Valencia, Spain.

Vivancos-Ramón, V. (2007) La conservación y restauración de pintura de caballete. Pintura sobre tabla. Tecnos, España.

Whitmore, P.M., Cass, G.R. (1989) The fading of artists' colorants by exposure to atmospheric nitrogen dioxide. Studies in Conservation, 34, 85-97.

Zycherman, L.A., Zycherman, L.A. (1988) A guide to museum pest control. Foundation of the American Institute for Conservation of Historic and Artistic Works. 


\subsection{Analytical Background: an overview}

Conservation and preservation of cultural artefacts is one of the major concerns in all museums worldwide. The improvement in the information on the paint materials and their alterations relevant to their conservation, beard researchers to continued development of better methods to evaluate paintings and polychromed objects. Microscopy, spectroscopic, and chromatographic are known as conventional analytical methods most frequently used in the characterization of the materials and artistic technique of art objects as well as for the study of photodeterioration and biodeterioration of paintings materials. Besides, a series of molecular techniques have been used in the identification and determination of the microorganism colonies responsible for the biodeterioration of art objects. A more detailed description of the analytical methods used in the study of paintings and their deterioration and biodeterioration products is made thereafter. More recently, electrochemical techniques have proved to be an excellent alternative for the identification of pigments and their alteration products. 


\subsubsection{Analysis of pigments}

The analysis of pigments used in cultural artefacts can provide data and insights of art historical or archaeological relevance. Pigments have been used for all colours of the artist's pallet because of their high colouring power and stability against change of temperature, weather and light. Some natural, mineral or organic pigments have been known since antiquity, whereas others are more recent discoveries.

\subsubsection{Pigment identification}

The identification of pigments used on artworks is an obvious target in the characterization of cultural artefacts providing historical, artistic and technical information. The correct identification of a pigment is critically important in science conservation; an incorrect identification of a pigment could lead to undesirable chemical reactions as result of an incompatible restoration treatment. Nevertheless, the analysis of pigments is not always easy and unambiguous. Occasionally, compounds which differ only by the mass fractions of some constituent's elements can make the same pigments. Other, are found as either natural or artificial pigments which can be distinguished by their impurities only. Pigments may also have different crystallographic modifications, and sometimes pigments are mixed to obtain a particular colour. Various analytical methods can be applied to examine painted cultural artefacts for the identification of pigments. Nowadays there is a wide range of analytical techniques and scientific methodologies aimed at analysis of art/archaeological objects.

\section{Microscopy techniques}

Some of the most used analytical techniques for the morphological examination of cultural artefacts are: light Microscopy (PLM), scanning electron microscopy (SEM), transmission electron microscopy (TEM) and, less frequently, atomic force microscopy (AFM).

Light microscopy provides the starting point for characterization of pigments. Normally, the first technique that is applied to the pigment identification prepared as cross-section or simply disaggregated and prepared in a mounting medium. This technique provides information about strata distribution, homogeneity and morphology of the pigment grains, as, size and form, the state of aggregation and the optical properties (Gómez, 1988; Gayo, 1996).

Visible light- and electron- microscopy methods seem to be most suitable for the standard analyses of the painting layers in the cross-sections revealing their morphology, texture, colour and fluorescence in UV light. There are many studies where optical microscopy is the starting point for preliminary examination and locate regions of interest in cross-section (e.g. Hradil et al., 2001; Franquelo et al., 2009; Pięta et al., 2014). Hradil et al., 2001 in their study for the description of clay structures in paint micro-samples from the Italian and Bohemian Baroque paintings, and on Early Renaissance preparation layer for gilding, establish the use of optical microscopy as a routinely tool in the study of cultural heritage materials.

Optical microscopy with visible light was used by Pięta et al., (Pięta et al., 2015) to analyses two world-famous $17^{\text {th }}$ century panel paintings 'Seven Acts of Charity' by Anton Möller and 'Angelic Concert' by Hermann Han. The optical microscopy analysis of the samples demonstrated that the samples consist of three individual layers. Particle size distribution is 
therefore based on the conventional microscopic image analysis. This is valuable information for a study aimed at determining the artistic techniques influence of the artists.

Scanning electron microscopy is other microscopy technique widely used in the study of the morphological characterization of the pigments (Bonneau et al., 2012; Tomasini et al., 2012). Transmission electron microscopy has been also used less frequently (San Andrés et al., 1997). In particular, this technique has been used in mineralogical, morphological and crystallochemical investigations of clay assemblages. Ma and Eggleton (Ma and Eggleton, 1999) report the use of TEM/HRTEM, which, operated with high resolution parameter, makes visible the external shapes and internal structures of clay particles.

More recently have been reported studies that use AFM coupled with voltammetry of microparticles (AFM-VMP) for discriminating lead pigments at nanoscale (Doménech-Carbó et al, 2007e).

\section{Spectroscopic techniques}

\section{Infrared spectroscopy}

Infrared (IR) spectroscopy is one of the most widely used techniques in the field of art conservation. Feller (Feller, 1954) was the first scientist to use IR spectroscopy for the characterization of organic and inorganic materials present in paintings, due to its versatility for providing structural information of both inorganic and organic materials. Currently, an increasing number of studies are reported focused on the use of IR spectroscopy for the identification of the materials presents in artworks.

Fourier Transform Infrared (FTIR) spectroscopy has been used as the method that sensitively reflects the crystallochemical composition of clay structures and its changes (e.g., Madejová et al. 1998, Madejová and Komadel, 2001). Some of these analytical procedures were also recently applied to pigment analysis in minute historical fragments, but no in exclusively searching the clay mineralogy.

Bikiaris et al. (2000), propose a technique to distinguish among the kinds of iron oxides. For that purpose, $\mu$-FTIR spectroscopy was used for the identification and differentiation of all ochre species used in Byzantine hagiography. In particular, this technique allows the differentiation between pigments present in a same sample of a few micrograms. The use of $\mu$ -FTIR in the characterization of a variety of pigments belonging to the Cultural Heritage of Southern Spain was illustrated in a paper by Franquelo et al. (Franquelo et al., 2009). The $\mu-$ FTIR allowed the identification of compounds containing inorganic polyatomic anions, most of them oxoanions, with bands in the 'fingerprint' zone.

FTIR in Attenuated Total Reflectance (ATR) mode (ATR-FTIR) is been progressively replacing the conventional FTIR technique in transmitted mode due to its high sensitivity and easiness of sample preparation. Vahur et al. (Vahur et al., 2010) studied 40 inorganic pigments of different colours widely used in historical paintings using ATR-FTIR in the low wave number spectral range $\left(550-230 \mathrm{~cm}^{-1}\right)$. The ATR-FTIR spectra were recorded for pure pigments and mixtures of pigment and linseed oil. The results demonstrate that the ATR- 
FTIR spectroscopy can used to identify in paint samples most of the different white, yellow, green, brown and black inorganic pigments.

Apart from the analysis of microsamples removed from the cultural artefact, it is now also possible to view the paint surface directly without sampling. The small dimensions of portable equipments, as FTIR spectrometer, make it possible to move into small exhibition rooms or conservation studios. Portable FTIR spectroscopy assisted with mid-infrared fiber optics was used by C. Miliani et al. (2007) to investigate the paint surface of a Reinaissance fresco by Pietro Vannuci (Trevi, Perugia Italy). The characterization of Perugino's pigments could be performed in the presence of complex binders mixtures. Furthermore, to complement the mid-FTIR data, other diagnostic method was used, X-ray fluorescence (XRF) elemental analysis.

Non-invasive reflection infrared spectroscopy was used by Buti et al. (Buti et al., 2013) for the in situ identification of $\mathrm{Cu}$-based pigments: malachite, verdigris, chrysocolla, emerald green and pthalo green. The FTIR reflection spectroscopy for in situ molecular identification of pigments complemented with the use of Kramers-Krowig (KK) algorithm to correct the distortion arising from the surface reflection gave $\mathrm{k}$ index maxima shifted by more than 20 $\mathrm{cm}^{-1}$ relative to those obtained in conventional transmission mode. The spectra obtained in mock up painting samples showed that different binders do not prevent the visualization of pigments bands in reflection mode, with the exception of a copper silicate (chrysocolla) whose reflection spectrum is characterized by the "residual rays" at $1027 \mathrm{~cm}^{-1}$ and signal from the binding media.

It is important to note that other analytical techniques are necessary to complement results obtained by FTIR spectroscopy, but due to its qualitative and semi-quantitative applications of both inorganic and organic materials has been proved to be an invaluable tool in the conservation science field.

\section{Raman spectroscopy}

Over the past few years, Raman spectroscopic techniques are one of the principal techniques used for the identification of pigment used in cultural artefacts (Barbillat et al., 1994; Davey et al., 1994; Coupry et al., 1994). Indeed, it has been argued (Clark, 1995) that this is the best single technique for pigment identification, since it combines the required attributes of reliability and sensitivity, with those of being nondestructive and essentially immune to interference from the binder. The principal restrictions of the technique lie in the capability of the spectrometer/detection system to collect sufficient signals to form an identifiable Raman spectrum from a pigment as the Raman effect is weak in the absence of resonance effects, and thus highly sensitive detector systems are essential (Burgio et al., 1997).

Clark et al., (1995) report the use of Raman spectroscopy for the identification of the yellow pigments from two late $16^{\text {th }}$ century paintings at the National Gallery, London. Lead tin yellow type I on one painting ('Death of Acteon', Titian) and lead tin yellow type II on the other ('Allegory of Love', Paolo Veronese) were identified. Type I is well known to be $\mathrm{Pb}_{2} \mathrm{SnO}_{4}$, but type II had not previously been well defined. The authors proposed an interesting combination of powder diffractometry with Rietveld refinement in conjunction with Raman spectroscopy to resolve the structural problem of lead tin yellow type II. 
The efficacy of Raman spectroscopy was tested by H.G.M. Edwards (Edwards, 2011) in a study focus in the discrimination between yellow pigments of the Renaissance. The purpose of this study was to highlight some of the difficulties and pitfalls facing the contemporary analysis of Renaissance pigments, describing how the combination of elemental with molecular identification techniques is essential for the unambiguous resolution of the problem concerning the pigment identification of the Renaissance palette. The author conclude that an important care should be take with the interpretation of the data taking based in to important factors. Firstly, the Renaissance pigment identification use to be based only in the natural minerals or their synthetic analogues but the presence associated materials used in their preparation for the cultural artefact is not been accounted for; and secondly, a misinterpretation of mineral nomenclature and its changes with use over the ages.

In other study, Edwards et al., report the use of Fourier Transform (FT) Raman spectroscopy for the identification of the pigments used in two decorative schemes, the late $12^{\text {th }} /$ early $13^{\text {th }}$ century wall painting fragments from the Chapter House of Sherbone Abbey and the late $12^{\text {th }}$ century wall paintings from the Holy Sepulcher Chapel in Winchester Cathedral. The FTRaman measurements allowed the identification of the red pigments vermillion and red iron oxide. The results obtained demonstrate that this technique may be particularly useful where non-destructive in situ analysis is required (Edwards et al, 1997).

The identification of a specifically verdigris in paintings is complicated for two main reasons: first, the wide range of recipes used by the artists. The most commonly cited recipes include copper and vinegar, but other ingredients may be also added: for example, soap, honey and salt. The lack of reference standards of such compounds was motivation enough for San Andrés et al. (San Andrés et al., 2010) to develop a study involving different analytical techniques in order to provide guidance in the interpretation of Raman results. In this study, Raman enabled the differentiation of verdigris varieties complemented with FTIR and X-ray diffraction (XRD).

More recently, Conti et al. (2014) reported a method for Raman spectroscopy analysis for the detection of copper resinates on paintings. The authors described the use of six laser sources $(488,514,532,633,785$ and $830 \mathrm{~nm})$ to register the Raman features of copper resinate powder and in a mock paint film with linseed oil. They conclude that the excitation at $830 \mathrm{~nm}$ gives the richest spectrum of copper resinate while $488 \mathrm{~nm}$ is the most suitable for verdigris. The results were then applied in the analysis of a famous Caravaggio's painting.

Raman spectroscopy has been widely used alone or along with other analytical techniques. R. J. H. Clark (Clark, 2002) reported the use of Raman spectroscopy and laser-induced spectroscopy has complementary techniques for the identification and authentication of paintings. In previous study, Burgio and Clark (Burgio and Clark, 2001) collected Fourier Transform (FT) coupled with Raman (FT-Raman) spectra of 60 pigments and related materials in order to assemble a spectroscopic database of reference. They demonstrate that the materials technique can be applied successfully to the analysis and identification of most pigments. Laser-induced breakdown spectroscopy (LIBS) in combination with Raman spectroscopy was again used by L. Burgio and co-workers (Burgio et al., 2001) for the identification of pigments in a $19^{\text {th }}$ century post-Byzantine icon from Greece and two miniature paintings from France. They conclude again LIBS and Raman two complementary 
techniques, leads to detailed characterization of the pigment used in the paintings. The study provides important elemental information and also clarification on the dating of the artworks.

Rull Perez et al., (Rull-Perez et al., 1999) demonstrate that Fourier Transform Raman spectroscopy can be a very useful tool in the characterization of mineral pigments and to study the biodeteriorative leaching-out of the substrate do to the metal complexation. $\mathrm{H}$. Edwards (2011) described the advantages and limitations of Raman spectroscopy for the diagnostic characterization of yellow pigments used during the Renaissance in consideration of heavy metal oxides and sulphides. The author concludes that Raman spectroscopy possess the applicability and the viability due to that it covers a wavenumber range generally from 100 to $3500 \mathrm{~cm}^{-1}$ and provides access to the characteristic vibrational modes for the identification pigments alone and in mixture. The same author as previously reports the use of analytical Raman spectroscopy for the identification of the calcium oxide/hydroxide signatures characteristic of the Romanesque limewash putty for the determination of the methodology of application that Palomino used in a $17^{\text {th }}$ century frescoes of the Church of Sant Joan del Mercat in Valencia (Edwards et al., 2008).

There are many studies where Raman spectroscopy is used in combination with other analytical techniques in the identification of pigments. More recently, the use of $\mu$-Raman spectroscopy (MRS) in conjunction with X-ray fluorescence (XRF) has been reported by Pięta et al. (Pięta et al., 2015) for the artist's technique characterization of two world-famous $17^{\text {th }}$ century panel paintings from Anton Möller and Hermann Han. There other studies concerning the identification of verdigris-type pigments by means of $\mu$-Raman alone and in combination with other analytical techniques (e.g. Švarcova et al., 2014; Chaplin et al., 2010; Cooke, 2000; Clark and Curri, 1998; Edwards et al., 2002). In the study by Švarcova et al (2014) is described the use of $\mu$-Raman in combination with other spectroscopic analytical techniques in the identification of both mineral-type and verdigris-type pigments, as well as, to study the loss of crystallinity of verdigris type pigments in proteinaceous binding media. A study made by Chaplin et al., (2010) in the characterization of the pigments used in three items from the Worshipful Company of Barbers, Raman microscopy allows the identification of verdigris as the color used by the artist to decorate for the foliage.

The pigment identification in a series of cross-sections belonging to the Cultural Heritage of Souther Spain by means of $\mu$-Raman spectroscopy using visible excitation sources is described by Franquelo et al. (2009). The use of $\mu$-Raman in complemented with $\mu$-FTIR spectroscopy permits a more accurate identification of several compounds in a mixture due to the accessibility of this technique in the far-IR region of the spectrum, which contains many of the vibrational bands of inorganic compounds, such as oxides and sulfides. The author emphasizes the advantage of Raman over IR spectroscopy for the cross-sectional studies for the shorter wavelength of visible, which permits the diffraction-limited analyses of particles of $1 \mu \mathrm{m}$. Even these results, is important to mention that this study was complemented with $\mu$-FTIR and SEM-EDX microanalysis to solve most of the doubts.

Among non-destructive techniques, Raman microscopy has found in last decades many applications in specific studies in the field of science conservation; these have concerned pigments and other painting materials. Main features of the $\mu$-Raman technique are high spatial resolution and low penetration depth for non-transparent samples, both in the micron 
range; in pigment analysis, the microscope objective focuses the laser beam on the sample in order to exclude signals from the medium matrix surrounding the pigment grain. Clark, reported the use of Raman microscopy in the identification of pigments in a series of medieval manuscripts, paintings, ceramics and papyri. Raman microscopy was utilized successfully due to the capability of dealing with the identification of mixtures of pigments at high $(\leq 1 \mu \mathrm{m})$ spatial resolution. Despite this the author emphasize, that the most effective studies on pigment identification are usually carried out by the use of Raman microscopy in conjunction with one or more other technique (Clark, 1995; 1999).

Raman microscopy was used by Burgio et al., (1997) on the study of three illuminated German manuscripts and for the identification of pigments used in glazed and in particular the identification of lapis lazuli in late $13^{\text {th }}$ century pottery fragments (Burgio et al., 1997). The authors consider it a very useful technique for the study of manuscripts where the pigment sampling is not allowed, due to its amenable to in situ applications. The pigments identified were vermilion, iron oxide, azurite, malachite, lampblack, lead white, lead tin yellow type and lazurite. Nonetheless, as do Clark, the author considers that for most effective studies on pigment identification should be carried out by the use of Raman microscopy in conjunction with one or more other techniques (e.g. optical spectroscopy, Xray based techniques).

To avoid sampling at all, instruments for Raman microscopy based on fiber optics technology have been recently developed: they can use for in situ analysis and do not suffer from any limitation about the size of the analyzed object. Vandenabeele et al. (2001) report the use of Fourier Transforms (FT) Raman spectroscopy with fiber optics in the pigment identification of paintings by Lucebert, Degas, de Chirico and Magritte. The pigments were identified even though most of these were covered with a varnish layer. The FT-Raman spectroscopy was utilized focusing the laser beam through the varnish layer to detect the Raman signal of the pigment. For this purpose, a non conventional device with a fibre optic to send the laser beam to the artefact and to collect the backscattered radiation was used.

Gutiérrez-Neira et al. (2013) studied the pigments used by the Spanish painter Diego Velazquez by application of Raman microspectroscopy. The Raman microspectroscopy features allowed to identify the chemical composition and crystalline phases of pigments in different periods of the artist's life. The results revealed that the artist's palette was limited to a reduced set of pigments (azurite in blue pigments, vermillion and hematite in red pigments, goethite in yellow pigments, hydrocerussite and calcium carbonate in white pigments and carbon black in black pigments), which the artist blended to reproduce the entire chromatic spectrum. These results were consistent with the chemical elements inferred from previous measurements, and illustrate the exact chemical composition and crystalline phase of the pigments.

\section{$X$-ray spectroscopy}

The use of instrumental techniques based on X-ray spectroscopy to identify mineral pigments in cultural artefacts has been widely reported (Moore and Raynolds, 1997; Corbeil, 2004; Hochleitner et al., 2003; Artioli, 2013). Technological advancements in the development of $\mathrm{X}$-ray spectroscopy instrumentation and techniques have improved the suitability of these techniques for the analysis of cultural heritage materials. The development of portable 
instrumentation and the use of X-ray spectroscopy combined with imaging techniques are two of the most relevant advances reported in the last decades. Some remarkable examples analyses are given.

The characterization of wall paintings samples belonging to the $7^{\text {th }}-14^{\text {th }}$ centuries from the medieval kingdom of Nubia was performed by Syta et al. (Syta et al. 2014) using a portable $\mathrm{X}$-ray fluorescence ( $\mu$-XRF) combined with laser ablation inductively coupled plasma mass spectrometry (LA-ICPMS) and Raman spectroscopy. Small fragments collected during the excavations were analyzed in the form of transfers and cross-sections. Elemental composition data collected by XRF allowed to identify raw materials and to distinguish the use of diverse pigments in different archaeological sites. Results were integrated with those obtained by LA-ICPMS and Raman spectroscopy, about the elemental and molecular composition of the surface and sub-surface domains of the wall paintings. The authors highlight the utility of $\mathrm{XRF}$ in archeometric investigations due to the direct and fast examination of numerous samples collected. Furthermore, to complement the XRF data, other diagnostic methods were used.

Klockenkamper et al. (2000) reported the use of Total Reflection X-ray fluorescence spectrometry for the analysis of pigments and inks on oil paintings and historical manuscripts. This technique differs from conventional energy-dispersive X-ray fluorescence (XRF) mainly in the excitation geometry, which is a $45^{\circ} / 45^{\circ}$ arrangement for classical XRF and a $0^{\circ} / 90^{\circ}$ arrangement for TXRF. To demonstrate the efficacy and versatility of this technique in the identification of artist's pigments R. Klockenkamper and co-workers present in their paper various examples of TXRF analysis of old paintings and illuminated manuscripts. The first example is a study of several samples from an oil canvas painting from 1520 by Tiziano Vecellio (Titian), the Sacred and Profane Love, in order to reconstruct the palette of the artist. The TXRF results allowed to develop a comprehensive list of the pigments used by the artist. Lead white, azurite, yellow ochre and vermillion are some of the pigments included in the artist palette, also impurities as titanium, iron and copper were identifying. Other of the examples mentioned report the use of TXRF in the authentication of the Portrait of a Woman allegedly painted by Modigliani in 1915. In this study the TXRD results showed that the pigments used by the artist were Schweinfurter green $\left[\mathrm{Cu}\left(\mathrm{CH}_{3} \mathrm{COO}\right)_{2} \cdot 3 \mathrm{Cu}\left(\mathrm{AsO}_{2}\right)_{2}\right]$ and cerulean blue $\left(\mathrm{CoO} \cdot n \mathrm{SnO}_{2}\right)$. A further comparison of the results obtained with a database of Laboratorie de Rechereche des Musées de France revealed that the presence of this two pigments indicate that the work was false.

Olivares et al. (2013) reported the use of non-invasive mobile instrumentation, such as Raman and energy-dispersive X-ray fluorescence (EDXRF) spectroscopies for the characterization of pigments in La Peña Cave in San Roman de Candamo (Asturias, Spain). The analytical procedure makes possible the acquisition of a large number of measurements that allows the representativeness of the average elemental composition of a certain area. The EDXRF results showed that the main pigments used were reddish earths, amorphous carbon and manganese, natural pigments available near the cave.

A number of instruments have been developed in the second part of the $20^{\text {th }}$ century in which the X-ray fluorescence is obtaiend by exciting the sample with ions or electrons instead of Xray photons. Particle induced X-ray emission (PIXE), electron probe microanalyzers (EPMA) but specialy energy dispersive X-ray microanalyzers coupled to a SEM (SEM-EDX) have 
been widely used in the analysis of pigments. The first commercial SEM-EDX was marketed in 1965 (Doménech-Carbó and Osete-Cortina, 2016). Since then SEM-EDX has been increasingly used in mineralogical, morphological and crystallochemical investigations of pigments used in cultural artefacts. Thus, SEM-EDX was used in the characterization of painting cross sections by Kaszowska et al. (2013). These authors propose a very interesting contribution for the interpretation of SEM-EDX spectra. The presented protocol is based on the two devices that comprise an SEM-EDX analysis. First, using the atomic number contrast of the images for the identification of material and next, focusing an electron beam directly on a single pigment grain during the element analysis. Finally, the proposed interpretation is based on the correlation of the detected set of elements with the materials, considering this method a semi-quantitative analysis. Using the method previously described Kaszowska and coworkers were able identify the inorganic pigments as well as their distribution in the different structural layers.

Many other studies report the use of SEM-EDX as complementary technique in the characterization of pigments used in art/archaeological materials (Casellato et al., 2000; MT Doménech-Carbó et al., 2001a; Shimadzu et al., 2006; Švarcova et al., 2009, 2014; Chaplin et al., 2010; Pascual et al., 2011). SEM-EDX in combination with Laser ablation-inductively coupled plasma mass spectrometry (LA-ICPMS) was used by Resano et al. (Resano et al., 2007) in the analysis of several red-colored paintings of post-Paleolithic schematic style found in 10 different shelters in the Vero River, Huesca (Spain). The SEM-EDX results suggest that the composition of the substrate was mostly calcite $\left(\mathrm{CaCO}_{3}\right)$, typical of the Spanish region, $\mathrm{Al}, \mathrm{Si}$ and $\mathrm{Fe}$ were also found in the pigments samples. This data offers suitable information about the difference and similarities between pigments and confirms the results obtained by means of LA-ICPMS.

Recently, Cardel and Guerra (2016) published a review concerning the potentials and limitations of novel hyphenated SEM-EDX/Raman spectrometer, including some examples of its uses in heritage science. In particular, the need to design analytical protocols for the identification of mixed pigments in paint layers and depending on the hyphenated SEMRaman system.

Laser-induced fluorescence a nondestructive method was used by Miyoshi et al. (1982) to measure the fluorescence of pigments of inorganic and organic origin. The study was performed using a $\mathrm{N}_{2}$ laser, with a peak intensity of light on the samples of about $\mathrm{kw} / \mathrm{cm}^{2}$. Zinc white pigment showed intense fluorescence results, while no fluorescence was detected in lead white pigment. The presence of fluorescence of zinc white must be considered as an indicator of paintings made after mid $-19^{\text {th }}$ century.

\section{Mössbauer spectroscopy}

Mössbauer spectroscopy proved to be a useful and sensitive tool to identify into pigments lattice structure the presence of sites that differ from each other as octahedral and tetrahedral co-ordination, and also small deviations from ideal geometry and chemical environment. A study of a series of commercially iron-containing pigments (red or yellow ochre and green earths) by means of Mössbauer spectroscopy to be compared with laboratory mock wall paintings and fragments from frescoes by Piero della Francesca, G.F. Bembo, G. Vasari and F. Zuccari, an analytical challenge reported by Casellato et al. (2000). The Mössbauer 
spectroscopic results demonstrate that the commercial samples, although synthetic, were not pure products and contain additional compounds or additional iron derivatives. When comparing the results obtained from the commercially available samples with the historical fragment samples evidence that an interaction between the inorganic pigments and the organic ligands may occur, especially for the yellow ochre layers. Other studies report the use of Mössbauer spectroscopy to study glazes and ancient ceramics, and less commonly, pigments in cave painting (da Costa et al., 1991; Klingelhofer et al., 1998).

\section{$\underline{X-\text { ray diffraction }}$}

X-ray diffraction (XRD) of hematite and goethite were examined in detail by Perinet and Onoratini (1987). The XRD results allowed the identification of goethite and the presence of an artificial hematite in prehistorical red colouring materials. The study reveals that goethite was heated at temperature range of 250 to $700{ }^{\circ} \mathrm{C}$ which results in a hematite with other crystalline anomalies. A similar study focused in the characterization of red earth pigments was reported by K. Helwing (1997). In his study the use of X-ray microdiffractometry $(\mu-$ XRD) allows the identification of yellow earth pigments as substitute for red iron oxide earth pigments. The $\mu$-XRD features of pigments of known origin provide the evidence to support or refuse the use of burnt yellow earth, a pigment described in some artist's manuscripts that was produced by heating the yellow earth at temperatures below the $800{ }^{\circ} \mathrm{C}$, resulting in a disordered hematite crystal structure.

Švarcova et al. (2009) reported on the $\mu$-XRD investigation of a sacral Bohemian Gothic wall painting in the Czech Republic, the presence of a new type of copper pigment cumengeite $\left(\mathrm{Pb}_{21} \mathrm{Cu}_{20} \mathrm{Cl}_{42}(\mathrm{OH})_{40}\right)$ used as blue pigment. Other pigments as azurite, malachite, paratacamite, atacamite and posnjakite were also identified in fragments of colour layers by means of $\mu-\mathrm{XRD}$, as well as, the corrosion of blue azurite to green $\mathrm{Cu}$ chloride in some places due to the action of salts and moisture. On the basis of the study, the authors proposed a protocol to distinguish between natural and artificial copper salts used as pigments by $\mu$ XRD.

The $\mu$-XRD results of varied artworks; analysis of mock paint samples, cross-sections and in situ analysis, were presented by Lau and co-workers (2007). The commercially paint films were spread on microscope slides and naturally aged for 4 to 10 years. Another set of analysis was performed on cross-sections from the Tiepolo's painting "Banquet of Cleopatra". Finally, the in situ pigment identification was performed on a small panel painting from the National Gallery of Victoria collection by placement of the piece within the instrument. The $\mu$-XRD investigation showed that the pigment composition of the commercially paint films was consistent with their labeling. The cross-section analysis provides information on ground layer composition confirming those previously reported by Berrie (1994). Finally, the in situ study demonstrates the utility of this technique for non-destructive crystalline phase composition analysis. Herrera et al. (2008) reported the study of wall paintings at San Agustin's Church in Cordoba by means of $\mu$-XRD. In their study crystalline iron phases such as goethite, lepidocrocite and hematite were identified using cross-section of the painting thin layer, with a good spatial resolution.

Recently, novel equipment for the in situ analysis of cultural artefacts has been developed, in particular, devices that combine two different techniques in the same system. Field 
investigations using portable XRD/XRF were carried out in the study of Roman and Arabic wall paintings by Duran et al. (2011). A physicochemical investigation on fragments from the archaeological excavation of the Patio de Banderas in the Reales Alcazares' Palace of Seville (Spain), and a comparative study on the pigments from both historical periods were reported. Almost all the pigments present in the Roman samples were identified: vermillion, red ochre, yellow ochre, green earth, Egyptian blue, carbon and phosphor-based black pigments. However, in the Arabic fragments, only hematite was observed. Furthermore, on the basis to distinguish between red ochre and hematite, the size and shape of the particles of the wall paintings were determined with an XRD 2-dimensional detector (imaging plate) and scanning electron SEM-EDX.

\section{Techniques based on the mass-to-charge determination}

LA-ICPMS was used for the identification and characterization of several red-colored paintings of Post-Paleolithic style found in 10 different shelters in Huesca, by Resano et al. (2007). This technique allows the authors a multielemental quantitative analysis of the pigment layer, in spite of the identification of superficial accretions. The study permitted the identification of 40 elements with minimum sample consumption, from which only the truly present in the original pigment were considered to discriminate between various paint pots.

\section{Chromatographic techniques}

\section{Pyrolisis-silylation-gas chromatography-mass spectrometry (Py-GC-MS)}

Domémech-Carbó et al. (2014), reported the use of Py-GC-MS for the identification of Maya blue pigment in 14 Maya archaeological sites, as well as, the demonstrate the multicomponent composition of this pigment. The study is based on the analysis of the oxidized species formed as result of the redox processes taking place while preparing the pigment. The identification was made by comparing the relative content of the compounds formed when indigoid reference species break down during pyrolysis-trimethylsilylation with the species present in archaeological Maya blue samples as a result of the redox process that takes place while heating indigo.

Identification of yellow pigment as the arsenic sulphide orpiment in samples from Egyptian wooden sarcophagus and cartonnage from the 664 - 525 B.C. was made by Chiavari et al., (Chiavari et al, 1995). Pyrolysis fragments of volatile As 4 allow to recognize this yellow pigment in mixtures of wax-based and animal protein-based binders used in the ancient Egypt painting techniques.

Many studies have demonstrated the successfully use of this analytical technique in the characterization of synthetic organic pigments used in contemporary painting (Chiavari and Mazzeo, 1999; Learner, 2001; Russell et al., 2011; Ghelardi et al., 2015).

It's important to mention that there are many other chromatographic analytical techniques aimed at the study of archaeological and cultural artefacts, but most of these studies are focused on the identification and characterization of binding media. 


\section{Electrochemical techniques}

Although electrochemical techniques in conservation science historically has been mainly applied to the elimination of metal corrosion layers (Barrio et al., 2009; Cano et al., 2010; Costa and Dubus, 2007; Doménech-Carbó et al., 2001a), electrochemical techniques can provide conservators information on the artist's pallet and technique, as well as, greater information about the degradation pathways of pigments and those others induced by the pigments on pigment-binder networks on paint layers. Electrochemical identification of solid materials was reported at first time in the 80 's and 90 's of the $20^{\text {th }}$ century by several researcher groups (Komorsky-Lovric et al., 1999; Gruner, 1986; Moskin et al., 1988; Hubbard, 1988). Electrochemical analysis of pure inorganic pigments was first given by Lange et al. (Lange et al., 1993). The electroanalysis of powders has recently been reviewed by Grygar et al. (2002a, b). Advantages in the solid state electrochemistry for science conservation were prompted with the development of the voltammetry of microparticles (VMP) by F. Scholz (Scholz et al., 1989; Nitschke et al., 1989; Scholz and Meyer, 1998). The VMP allows the possibility of qualitative, quantitative and structural information on solid micro- or nano- samples in a nondestructive way. This methodology provides rapid method for analyzing cultural artefacts, assessing their state of conservation, detecting failures, reintegrations or prior conservation treatments (Doménech-Carbó et al., 2009). The solid state electrochemistry of microparticulate pigments and their reduction/dissolution/crystallization pathways has been extensively studied by Doménech-Carbó et al. (Doménech-Carbó et al., 2000; 2001a; 2001b 2003; 2005; 2008, 2011a, 2012a). Case studies considered include micro- and nano- samples excised from painting (Doménech-Carbó et al., 2000; 2001a; 2001b; 2000)., ceramic (Doménech-Carbó et al., 2002), textile (Doménech-Carbó, 2005) and metal cultural artefacts Doménech-Carbó et al., 2011b). In particular, different crystalline structures present in iron oxide pigments from pictorial samples can be discriminate with this novel technique (Doménech-Carbó et al., 2001c). In this same line of study of iron oxide pigments, Hradil et al. (2003) reported the use of voltammetry to document the kinetics of the electrochemical dissolution of iron oxides.

The use of VMP combined with novel analytical techniques such as AFM has been recently developed as an alternative method for identifying pigments (Doménech-Carbó et al., 2007e). The interpretation was based on pattern recognition procedures of reduction/dissolution/crystallization pathways and the mechanisms involving the epitatic growth of lead crystals.

\subsubsection{Alterations}

\section{Microscopy techniques}

Conservation science may require the identification of pigment degradation products and eventually the establishment of procedures in which pigments can be preserved.

SEM images can be particularly useful in the morphological characterization of pigments and chemical changes in pictorial samples such as, changes related to metal soap formation, including the dissolution of pigments or the formation of new products, as well as, migrations fronts/flows and deposition of mobile inorganic compounds in the paint layers. This property allows Loon (2008) to confirm the presence of leads soaps in Johannes Vermeer, "View of 
Delf', oil on canvas through cross-section analysis. Metal soap aggregates have been identified responsible for lumps lying just below the surface paint and the appearance of a rough bubbly surface texture (Gettens et al., 1993, Boon et al., 2002; 2007; Noble et al., 2005; Shimadzu et al., 2006). In many cases the protruding lumps cover the entire painting. Cross sectional analysis has established that the aggregates originate in the ground layer and alteration products migrate towards the surface of the painting (van Loon, 2008; Keune and Boon, 2007; Kaswoska et al., 2013). These phenomena have been associate with paint films containing red lead or lead-tin yellow and copper pigments in old master paintings, and leadzinc containing paint in modern paintings (Kockenkämper et al., 2000; Spyros and Anglos, 2004; Mazzeo et al., 2008; Boon et al., 2002; Osmond, 2012; Santoro et al., 2014).

In many $19^{\text {th }}$ and $20^{\text {th }}$ century paintings, several phenomena were often found to occur simultaneously in the same picture: not only aggregates, but also semi-crystalline waxy surface deposits of metal soaps (usually described as bloom or efflorescence) (Miyoshi, 1987; Shimadzu et al., 2006). Areas of increased transparency have been also noted in paintings from all periods; which looks darker in tone than originally intended, were found to be associated with metal soap formation (Noble et al., 2005; Loon, 2008; Keune and Boon, 2007; 2011; Kaswoska et al., 2013). Exposure to high levels of relative humidity either from storage, display or treatment is the consistent factor for this type of alterations. Furthermore, studies have demonstrated that the process can continue for some time, in several cases the aggregates have broken through later added overpaints (Saunders and Kirby, 2004).

\section{Spectroscopic techniques}

\section{Infrared spectroscopy}

FTIR spectroscopy allowed van der Weerd et al. (2003) to demonstrate the presence of zinc metal soaps (Zn carboxylate) traces thought the paint layers on Vincent van Gogh paint. The authors confirm the mobility of $\mathrm{Zn}$ compounds in the paint due to large unevenness in $\mathrm{Zn}$ concentrations in the samples.

FTIR imaging was first explored by van der Weerd and co-workers (2002) in the studiy of metal soaps formed in paintings as alteration products. FTIR-imaging has also been used by Keune and Boon (2007), as analytical method for the identification of metal soap in paint cross-sections, due to its properties in the localization of meatl-carboxylate bonds. Similalrly, Shimadzu et al., (2006) reported the use of FTIR-imaging to study element distribution of zinc carboxylate throughout paint layers by cross-section examination in $19^{\text {th }}$ century paintings. The conversion of mineral lead white into amorphous organic complex of metal soaps in a various old master paintings was confirmed by means of FTIR-imaging (Noble et al., 2005). The author reported the metal soap formations in the imprimatura by the strong absorption in the 1510-1520 $\mathrm{cm}^{-1}$, a characteristic band of lead carboxylate. Most recently, Kaszowska et al., (2013) applied ATR technique with FTIR-imaging for the detection of cadmium oxalate and high concentrations of zinc palmitate/stearate in paint and ground layers in a series of cross sections from oil painting. Mazzeo et al., (2008) use ATR microspectroscopy for the chemical characterization of a series of reconstruction of oil and egg yok painting specimens naturally aged for 10 years. The study allows them the characterization of metal carboxylate formed through the interaction between pigments and binding media of the reconstructed oil and egg tempera painting specimens. 
The use of mid-infrared and visible spectroscopy to examine spectral changes accompanying the darkening of lead white paints as a result to the exposure to $\mathrm{H}_{2} \mathrm{~S}_{(\mathrm{g})}$, has been reported by Goltz et al. (2003). The effect of the different binding media (egg tempera, linseed oil, water and gum arabic) on the rate of darkening of lead white was also examined. Changes at the $3541 \mathrm{~cm}^{-1}$ (O-H stretch), $1400 \mathrm{~cm}^{-1}$ (C-O), and $680 \mathrm{~cm}^{-1}$ (C-O) were the most significant indications of the formation of $\mathrm{PbS}$ by the $\mathrm{H}_{2} \mathrm{~S}_{(\mathrm{g})}$, which influence in the paint darkening. Other spectroscopic studies focused on the changes occurred on paintings by thermal ageing and pollutants can be found in literature (Manzano et al., 2010; Odlyha et al., 2000, Odlyha, 2011).

\section{Raman spectroscopy}

Iokimoglou et al., (1999), demonstrate the influence of copper acetate (verdigris) pigment in the formation of peroxides, which influence badly the photo-stabilization of linseed oil used as binding medium (Iokimoglou). Other studies have provided useful information on the nature and chemical composition of the verdigris corrosion products responsible of a color alteration on paintings (Švarcova et al., 2009; San Andrés et al., 2010).

de la Roja et al., (2007) reproduced different verdigris recipes to confirm that recrystallization processes undergone by verdigris leads to an almost complete conversion of the initial components into copper (II) acetate derivatives due to the presence of other minor components in the samples (e.g. copper oxides, copper chlorides, and ammonic salts).

\section{$X$-ray spectroscopic techniques}

Scanning electron microscopy-energy dispersive X-ray analysis has become very useful technique in the characterization of metal soaps aggregates frequently detected on the paint surface and within the bulk of paint films (Boon et al., 2002, 2007; Keune and Boon, 2007, 2011, Noble et al., 2008). This technique has been useful in the study of pigment-binder interactions such as the saponification that lead the lead soap aggregates or protrusions to induce darkeness in the panting and, in some cases, to break the paint layer (Mazzeo et al., 2008; Loon, 2008; Gettens et al., 1993).

The chemical degradation of arsenic-containing pigments used in oil paints was investigated by Keune and Boon (Keune and Boon 2011). The research was based on studying the paint cross-sections from several oil paintings with arsenic-containing pigments: the Descente des vaches by Theodore Rousseau, Herald by Christiaan van Couwenbergh, the Still life with five apricots by Adriaen de Coorte and The Dentist by an unknown $17^{\text {th }}$ century artist. The arsenic-containing pigments under study were emerald green $\left(\mathrm{Cu}\left(\mathrm{C}_{2} \mathrm{H}_{2} \mathrm{O}_{2}\right)_{2} \cdot 3 \mathrm{Cu}\left(\mathrm{AsO}_{2}\right)_{2}\right)$, orpiment $\left(\mathrm{As}_{2} \mathrm{~S}_{3}\right)$ and realgar $\left(\mathrm{As}_{4} \mathrm{~S}_{4}\right)$ and the common degradation product was arsenic trioxide. Each cross-section was studied by means of SEM-EDX in other to understand the spatial distribution of the element arsenic. Results showed an altered distribution of arsenic in several paint cross-sections, as well as, high concentrations of arsenic in the bulk and the interface between paint layers. The presence of such arsenic distribution suggests that arsenic can be transported as arsenic trioxide in aqueous form by gradients in relative humidity, temperature or airflows.

Van der Snickt et al. (2009) proposed degradation cadmium sulphide (CdS) processes on a several paintings of James Ensor (1860-1949) from a study performed by means SEM-EDX 
and synchrotron radiation based micro X-ray fluorescence spectrometry (SR $\mu$-XRF) combined with ultraviolet-induced visible fluorescence photography (UIVFP). They conclude that the combination of methods allows the characterization of original and degraded forms of yellow (CdS). Kalinina et al., (2012) demonstrate that SEM-EDX combined with polarized light microscopy (PLM) are complementary analytical techniques in the study of artists' palate. In this study, the authors determine the inorganic material by Lorenzo Lotto on its artist palette. More recently, Kaszowska et al. (2013). propose the use of attenuated total reflectance with FTIR imaging mode and SEM-EDX to identify the cadmium oxalates and its distribution within the paint layer as well as a high concentration of "neat" zinc palmitate/stearate in a series of oil paintings.

A study to investigate the deterioration of cadmium sulphide yellow pigments by means of SEM imaging and XRD confirmed the hypothesis established by Leone et al., (2005) about the link between the manufacturing methods with the instability of these type of pigments. The authors suggest a hypothesis about the oxidation of amorphous cadmium zinc sulphide, yielding oxide and sulphate, zinc oxide and sulphur dioxide gas. Further reaction of these degradation products may include acid hydrolysis of the binding medium and the formation of zinc salts. The study demonstrates that samples containing a high proportion of amorphous cadmium yellow pigment may be most reactive, and pigments made using manufacturing methods where the amorphous intermediate stage is not properly converted to the crystalline product may explain why some pigments are more prone to deterioration.

\section{Techniques based on the determination of the ratio mass-to-charge}

Static secondary ion mass spectrometry (SIMS) has been applied by Keune and Boon, to localize, speciate and map the monocarboxylic fatty acid, lead and lead soap composition inside metal soap aggregates in more detail (Keune and Boon, 2007). Another study reported the use of SIMS in positive and negative ion mode to demonstrate the presence of an ionomeric structure, because the SIMS, in probing the surface layers of the protrusion in the cross-section, leaves the cross-linked fractions in the matrix, but absorbs the non-cross-linked saturated fatty acids and metal soaps (Boon et al., 2002).

\section{Electrochemical techniques}

The use of VMP ha been successfully used by Doménech-Carbó et al., (Doménech-Carbó et al., 2006b; 2007b, d) in the characterization of dehydroindigo, an oxidation product of the indigo molecules anchored to paligorskite as responsible for the characteristic greenish-blue color of Maya blue pigment This product is produced under controlled temperature during the crushing and further heating process to which the pigment is subjected during its manufacture, thus resulting in a wider chromatic pallet of Maya blue from turquoise to greenish.

The alteration of copper pigments in art samples has been widely studied by VMP. Linear scan and cyclic voltammetry protocols have been applied in a study aimed at the characterization of a series of samples from the baroque vault frescoes of the Basilica de la Virgen de los Desamparados painted by Antonio Palomino Doménech-Carbó et al., (2001a). The use of Tafel plots for quantifying electroactive species in solid materials was applied in the study of the fired frescoes painted by Palomino in the ceiling vault of the Sant Joan del 
Mercat church in Valencia, Spain which were seriously damaged. The method proposed allows the quantification of the cobalt smalt/azurite, tenorite/(azurite + smalt) ratios, providing information on the pigment dosage in pristine painting, extent of alteration and the temperature experienced by the frescoes during the gunfire episode. In addition, this study, complemented with other chemometric studies, has provided information about the color palette used by the artist (Doménech-Carbó et al., 2008, 2007a, 2006a).

\subsubsection{Analysis of binders}

In recent years, there has been an increasing interest in the study of historical painting materials. In particularly, studies aimed at the study of the identification of binding materials and its alterations. Binders are very complex materials; in many occasions this makes more difficult to be able to differentiate between them. Protein-based materials such as egg white and egg yolk and animal glues have traditionally been used as binding media, and in (antique) conservation treatments and thus, their identification is critical for conservation. This is the reason for why, there is a constant attempt to develop new analytical techniques more precise, non-invasive, faster and less expensive.

\subsubsection{Identification of binding media}

The identification of binding materials used in paintings is one of the most complicated issues for scientists and conservators due to the complexity of these materials. Identification of the binding media used by the artists can provide valuable information about the painting technique, as well as, the deterioration state of the painted artwork and information for proper conservation interventions.

Spectroscopic and chromatographic techniques are the most commonly used analytical techniques in researches aimed at the study of the chemical composition of these materials.

\section{Spectroscopic techniques}

\section{$U V$-Vis region}

The first time UV-Vis spectrophotometry was applied to the study of organic materials used as binding media, dates back to 1889 (Bamberger and Bordt, 1889). The particular response of the binding materials used in paintings to ultraviolet light excitation is what makes this technique a valuable tool in the field of science conservation to examine painted surfaces. The different colours and intensities of intrinsic fluorescence exhibited by the chemical structure of these materials, allows to study the composition of the painting surface, as well as, the presence of retouching and overpaints (Doménech-Carbó, 2008). Many studies focused on the application of fluorescence spectrometers in the science conservation have been reported (Pelagotti et al., 2005; Fisher and Kakoulli, 2006; Kubik, 2007; Derrick et al., 2000; Miyoshi, 1985; Castillejo et al., 2003). KrF excimer laser as source of excitation was used by Nevin et al., (2006) to identify various proteinaceous media. Based on the fluorescence emission arising from the presence of certain amino acids and their degradation byproducts, the distinction between proteins was possible. Lason et al., (Larson et al., 1991) has reported the use of this technique to differentiate between materials used in the elaboration of binders and finishes, as natural resins and organic binding medias. It proves to be a useful technique in determining the spatial distribution of the components and the 
characterization of chemical difference due to ageing. The high selectivity and sensitivity of this technique was used by Sandu et al. (2012) for the identification and mapping of proteinaceous binders (in particular egg and glues) in painting and polychromed works of art. The authors prepared a series of reconstructed model tempera and oil paints containing these binders, and then the cross-sections from the reconstructions were analyzed to assess the spatial distribution of specific proteins within the paint layers. Reference fluorescence spectra for each layer were acquired and compared after Gaussian deconvolution. The results obtained were used to create a set of fully characterized reference samples for further comparison with those from real artwork samples.

\section{Infrared spectroscopy}

A comprehensive study in order to understand the strengths and limitations of FTIR-imaging in the identification of extenders and binding media used as artistic materials has been performed by Kaszowska et al. (2013). The study demonstrates to be a powerful toll in the identification of degradation products due to ageing and deterioration processes, being these secondary products which allows the identification of a lipidic binding medium. The ability of this technique for the direct identification of the type of binding medium was not possible due to the weak IR bands of the binding media, which were overlapped by strong bands of degradation products. They conclude that the indirect identification is possible through detection of degradation products.

Şerifaki and co-workers (2009) reported the use of FTIR spectroscopy for the characterization of historic oil paintings belonging to a $19^{\text {th }}$ century church in Ayvalik/Turkey. The binding medium was identified as vegetable oil based on the fatty acids, esters and oxalate bands observed in the spectrum. The identification was possible due to functional groups as hydroxyl band $(\mathrm{OH})$ at $3410 \mathrm{~cm}^{-1}$, fatty acids $\left(\mathrm{CH}_{2}\right)$ at 2924 and 2854 $\mathrm{cm}^{-1}$, esters $(\mathrm{C}=\mathrm{O}) 1743 \mathrm{~cm}^{-1}$, oxalate $\left(\mathrm{C}_{2} \mathrm{O}_{4}{ }^{-2}\right)$ at $1620 \mathrm{~cm}^{-1}$, carbonate $\left(\mathrm{CO}_{3}{ }^{-2}\right)$ at 1419 and $875 \mathrm{~cm}^{-1}$ and sulphate $\left(\mathrm{SO}_{4}^{-2}\right)$ at $1118 \mathrm{~cm}^{-1}$. In other study Ajó et al., (2004) demonstrated the efficacy of $\mu$-FTIR spectroscopy in the study of two wall painting painted by Ciro Ferri from the $12^{\text {th }}$ century. They described $\mu$-FTIR as a fast and easy technique for the identification of organic binders in the original constituents' materials of a painting, as well as, in repainting's. FTIR was also used in a multi-analytical approach aimed at the identification of the pigments and binders used in two famous panel paintings belonging to the $17^{\text {th }}$ century: "Servilius Appius" by Isaac van den Blocke and "Allegory of Wealth" by Anton Möller (OlszewskaŚwietlik et al., 2013). The binding media was identified based on the FTIR spectra as linseed oil and protein. The FTIR results were also confirmed by gas chromatography.

FTIR is commonly used to characterize organic and inorganic painting materials present in artworks (Bruni et al., 1999; Derrick et al., 2000). One of the main advantages of this technique is that it provides complex data sets represented by sample's spectra suitable for being treated with multivariate analysis techniques. In fact, in recently years chemometric techniques have been increasingly used in the field of Cultural Heritage since they can extract information from correlated data sets, such as spectroscopic sets (Manzano et al., 2009; Navas et al., 2008; Marengo et al., 2003; Checa-Moreno et al., 2008). FTIR is predisposed for the analysis of organic materials and in most of the cases the samples can be used by other analytical techniques. 


\section{Raman spectroscopy}

Raman spectroscopy is another widely used spectroscopic technique in the study of paintings materials, even when it has been more used in the study of inorganic materials, there is also a wide number of papers that demonstrate its success in the study of organic materials. An example of this is a review recently made by Ropret and Madariaga (Ropret and Madariaga, 2014), which explain the versatility of this technique for analyzing both organic and inorganic materials used in painting. The improvements in instrument technology as coupling a microscope to a Raman spectrometer and the introduction of fiber optics devices have been the most relevant advances for the identification and characterization of organic components by Raman spectroscopy (Doménch-Carbó, 2008).

The use of $\mu$-Raman spectroscopy (MRS) a non-destructive micro-analytical method allow the identification of binding media in paintings (Vandenabeele et al., 2000). The recorded Raman spectra in the $1800-200 \mathrm{~cm}^{-1}$ of different types of proteinaceous, polysaccharides, fatty acids and resinous media were used as reference for fingerprint unknowns by Vandenabeele and co-workers. The set of spectra obtained as references allow the later identification of binders used in medieval manuscripts. Despite this other studies have concluded that the Raman spectroscopic analysis of oil painting and manuscripts is difficult due to the great care must be taken in obtaining small but representative samples and by the presence of varnishes that can give rise to fluorescence and results in poor spectral quality (Perez et al., 1999; Edwards and Chalmers, 2005; Coupry, 2000; Smith and Clark, 2013).

\section{Magnetic resonance spectroscopy}

The application to cultural heritage of nuclear magnetic resonance (NMR) is rather recent. NMR spectroscopy is applied by putting a sample in a strong magnetic field while observing the response or 'resonances' of the atoms of relevance molecules in the sample. The benefit of solid-state NMR is that the atoms sensitive to the magnetic field can be observed directly inside the paint layer. In this sense, the technique is non-destructive. It can be applied to amorphous solids and is not dependent on higher level ordering like crystal packing. Commonly, the atoms observed are the nucleid of nitrogen $\left({ }^{15} \mathrm{~N}\right)$ and carbon $\left({ }^{13} \mathrm{C}\right)$ atoms but also a number of metals can be used for instance lead $\left({ }^{207} \mathrm{~Pb}\right)$. Compared to other analytical methods NMR is considered intrinsically insensitive, implying that a sample volume of, at least, $20 \mathrm{~mm}^{3}$ is required to obtain sufficient signal-to-noise in a reasonable time. Difference between conjugated base or metal carboxylate can be distinguished as well as difference between functional groups. In conclusion, the strength of NMR in the context of analysis of cultural goods is the qualitative analysis of samples with several components in a nondestructive way.

Complex mixtures of organic compounds may be successfully analyzed by NMR based on difference in the molecular self-diffusion coefficient. An interesting application is the analysis in solution of soluble organic residues found in ancient artefacts. This method has been applied for obtaining information on the levels of hydrolysis and oxidation resulting from the ageing of an oil painting (Capitani et al., 2012). By comparing the spectrum of linseed oil used as reference with the spectrum of an oil painting, it was detected that there is a net reduction of polyunsaturated fatty chains in the oil painting extract. In some cases, degradation products allow the identification of the materials used by artists and in others, 
provides valuable information about the state of conservation of the artwork (Castro et al., 2008). Characterization of ancient and modern constitutive materials used on a Siennese panel painting belonging to a Polyptych by Andrea di Bartolo from the $14^{\text {th }}$ century, repainted in the $16^{\text {th }}$ century and restored in the $20^{\text {th }}$ century by means of NMR has been published by Tullio and co-workers (2016). In situ measurements by portable NMR provide information about all layers constituting the paintings. High resolution NMR spectroscopy was applied for the characterization of binders and organic substances. In parallel, ${ }^{1} \mathrm{H}$ NMR spectroscopy in solution was applied to characterize original and non-original materials. The authors conclude that tempera grassa was the painting technique used by the artists in the original $14^{\text {th }}$ century pannels, due to the presence of cholesterol, drying oil and egg white. Egg and oil were also found in the repainted regions probably used to camouflage the $16^{\text {th }}$ century repainting.

A recent development of NMR is the Mobile Universal Surface Explorer (NMR-MOUSE®), a unilateral NMR relaxometry technique that has been used for non-invasive studies of wall paintings (Capitani et al., 2012). Haber et al., (2011) reported the use of portable NMRMOUSE to study ancient Roman wall paintings at the Villa of the Papyri, Italy. The study enabled the identification of organic coatings and revealed the use of two different type of mortar layers. In general, NMR prove to be a suitable tool due to its accuracy and reproducibility, also provide valuable information for elaborating conservation strategies. Despite this is an expensive technique and requires expertise.

\section{Techniques based on the determination of the mass-to-charge ratio}

\section{Direct temperature-resolved mass spectrometry}

Direct temperature-resolved mass spectrometry (DTMS) is an evaporation/pyrolysis technique where the sample at the sharp tip of the resistively heated filament is heated inside the ion source while the mass spectrometer monitors the ions extracted from the ion source. Thus, this analytical instrument enables discrimination of compounds according to their different vaporization temperature (Stoner and Rushfield, 2012). The sample preparation for DTMS is very simple and the sample size can be quite small (a few micrograms), also the organic composition of the sample can be very complex, and the presence of pigments and extenders present no problem during binder identification. Some studies mention the advantage of DTMS for characterization of varnishes, resins, waxes, conservation materials and the organic constituents with very few sample amounts (Shimadzu et al, 2006; Scalarone et al., 2003).

Noble et al. (2008) report the use of DTMS for the characterization of the binder used in a $17^{\text {th }}$ century oil painting, 'Orpheus enchanting the animals with his music' by Roelandt Savery (1627). Binding medium analysis of isolated samples of the brown surface layer using DTMS demonstrates high amounts of oil components. Mass peaks detected are typical of palmitic and stearic acid, at 256 and $284 \mathrm{~m} / \mathrm{z}$, respectively, and from a fragmentation ion of azelaic acid (C9 diacid) at $152 \mathrm{~m} / \mathrm{z}$. These peaks confirmed the use of a lipid binding medium by the artist. DTMS also provides information about the presence of the cross-linked oil network fraction of the paint sample. Identification of animal glue has binding medium in the 'Dilapidated farmhouse' and 'River view' of Jan van Goyens by means of DTMS was also reported by this author (Noble et al., 2008). 


\section{Chromatographic techniques}

\section{High performance liquid chromatography}

High performance liquid chromatography (HPLC) partitions molecules by pumping the sample eluted in a liquid or mixture of liquids at high pressure through a column of microspheres with a suitable polar or apolar coating. Thus, solubility of the components of the sample in the mixture of solvents used as eluent and their interaction with the stationary phase in the column are critical aspects that determine the separation capability of this technique. Depending on the detector placed at the end of the column we can have different applications: identification of binding media and organic dyes by means of MS and UV-vis spectrophotometer or size exclusion chromatography by combining suitable columns and a refraction index detector. This variety of configurations has expanded the scope of applications of this technique in the field of heritage conservation are varied.

Several applications of HPLC to the study of conservation like dyes, varnishes and proteins were review by S.M. Halpine (1998). This same author developed a technique for rapid analysis of amino acids by HPLC and demonstrated its usefulness for analysis in a series of paintings from the $14^{\text {th }}$ to the $20^{\text {th }}$ century (Halpine, 1995).

Application of HPLC for identifying the proteinaceous binding media used by Rembrant in paintings of his last period was investigated by K. Groen (1997). For the interpretation of results, reference proteinaceous materials commonly used as binders in that period were also analyzed. The ratios of various amino acids found in the paint samples and the concentration of other amino acids present, as low glycine and high tyrosine, pointed out to egg as their source and no animal glue. C. M. Grzywacz (1994) developed a protocol for the identification of different proteinaceous binding media in paintings using HPLC analysis with fluorescent detection of 9-fluorenylmethyl chloroformate (FMOC-CI) derivatives of amino acids. The method is based on the calculation of the peak area ratios of FMOC-amino acid derivatives. More recent is the study presented by Vicente and co-workers (2005), an HPLCfluorescence method for the identification of drying oils used as binding media in pictorial works. They propose 4-(bromomethyl)-7-methoxycoumarin as derivatization agent with 18crown- 6 as catalyst to obtain coumarin derivatives of mysiric, palmitic, oleic and stearic acids. This method allows the differentiation among drying oils by means of fatty acid peak area ratios.

\section{Gas chromatography - mass spectrometry}

Gas chromatography (GC) is a technique developed for the separation of compounds in complex mixtures on high resolution capillary columns which are coupled to mass spectrometers (MS) for identification. An increased sensitivity and compound selectivity in the current instrumentation enables the analysis of several compounds classes, reducing the sample volume required. The pre-treatment of the sample and the derivatization of the isolated compounds make it possible to determine the amino acid composition with GC-MS in proteinaceous binding media, or to derivatize hydroxyl and acid groups in the various components of oil and alkyl paints or hydroxyfatty acids in beeswax. Hydrocarbons, polysaccharides and natural resins of terpenoid nature are alos analyzable by GC. The instrumental developments since the mid- $20^{\text {th }}$ century have improved separation resolution, 
sensitivity, handling and data processing. Due to all these advantages GC coupled with a mass spectrometer as detector (GC-MS) has become a must have in all institution and museums worldwide for the analysis of artistic painting techniques. Nowadays, a wide range of research aimed at the characterization and identification of painting materials has been published (Vallance, 1997; Marinach et al., 2004; Přikryl et al., 2006; Doménech-Carbó, 2008). Bersani and co-workers (2008) studied the organic components of the paintings materials used in "Madonna col Bambino e S. Giovannino" of Botticelli, by means of GCMS. The GC-MS results confirms the presence of animal glue in the ground and egg protein media as paint binder. The use of methanolic extracts of paint samples of different composition and age were qualitatively studied by means of GC-MS after off-line methylation or trimethylsilyl derivatization (van der Berg et al., 2002). The analytical strategy presented leads to the identification of typical oxidation products of unsaturated fatty acids in low concentration indicative of a linseed oil-based young paint.

A method based on microwave-assisted acid hydrolysis of the sample, and on the derivatization of the amino acids with a silylating agent and their quantitative determination was proposed by Colombini et al. (Colombini et al., 2013) for the characterization of proteinaceous binders in wall painting samples. The GC-MS method proposed allows the identification of 14 amino acids and some ratios between their concentrations in samples from frescoes from the Monumental Cementery in Pisa, Italy. Lluveras and co-workers (2010) developed a multistep chemical samples pretreatment for the characterization of organic materials. The method is based on the ammonia extraction of proteins and polysaccharide materials, in order to separate them from lipid and resinous materials. The extraction is followed by the separation and purification of proteinaceous and polysaccharides materials before hydrolysis. The analytical procedure proposed allows characterization of glycerolipids, natural waxes, and proteinaceous, resinous and polysaccharide materials simultaneously presented in the same microsample. The authors demonstrated the efficacy of this method by the analysis of a series of samples from the Bamiyan Buddhas and $15^{\text {th }}$ century panel painting.

In other study Andreotti and co-workers (2006) proposed a procedure for the identification of lipids, waxes, proteins and resinous materials in samples from painted artworks. The proposed method is based in a multistep chemical pretreatment, that includes acidic hydrolysis of proteins and saponification of esters, able to separate various organic components present in the same sample into different fractions. The method achieves the separation of an aqueous fraction containing amino acids and of two organic fractions (acidic and neutral), which are both submitted to derivatization reactions. For this, ammonia extractions of the samples are added to the ether extract of the acidic water solution arising from acidic hydrolysis, after saponification/salification step assisted by microwaves, then is followed by solvent extraction, and derivatization with a sylating agent for the GC-MS analysis. The application of the proposed analytical procedure to reference materials shows that it is suitable for the simultaneous identification of several classes of compounds, as proteinaceous material, drying oils, beeswax, plant resins, and shellac, in old samples. The authors also reported the use of this procedure for successfully characterization of painting on a shipwreck of the 17th -18 th century (wood support), an easel painting of the 17th-18th century (canvas support), and an Etruscan painted sarcophagus, 4th century B.C. (calcareous alabaster support). 


\section{Pyrolysis - gas chromatography - mass spectrometry}

Due to the macromolecular nature of most of the organic materials used as painting binders (such as proteins or plant gums), analytical pyrolysis is a fast and efficient approach for identifying such materials in cultural artefacts samples (Vallance, 1997; Scalarone and Chiantore, 2009). Directly coupling of the pyrolyser to the injection port of a GC-MS is the most straightforward configuration for the pyrolysis system (Bonaduce, 2009).

Most natural materials and synthetic polymers used as binders or as restoration materials can be detected by pyrolysis - gas chromatography - mass spectrometry (Py-GC-MS). Despite this some limitations have to be considered. One of the limitations of the pyrolysis technique is related to the low volatility of pyrolysis products arising from natural and some synthetic macromolecules. In fact, the poor volatility and polarity of polar acidic, alcoholic and aminic moieties are not really suitable for gas chromatographic analysis, which results in a rather low reproducibility of the pyrograms, low sensitivity for specific compounds, and strong memory effects. Otherwise, polar pyrolysis products may not be completely eluted by the gas chromatographic column, and may be retained in cold areas of the pyrolyser and the transfer line system (Bonaduce, 2009; Scalarone and Chiantore, 2009; Stoner and Rushfield, 2012).

Application of Py-GC-MS as a simple and rapid tool for the identification of the principal organic materials constituents of paint layers, was described by Chiavari et al. (1998). For this study reconstructed paint model were prepared according to Renaissance recipes for tempera, using proteinaceous binders as egg, glue and casein combined with six different pigments. Identification and characterization of the binding media was made in presence of tetramethylammonium hydroxide (pyrolysis/methylation). De la Cruz- Cañizares et al. (2005) reported the use of Py-GC-MS to the characterization of the Manila elemi and Mexican copal resins, which are used as components of varnishes and binding media of artworks. The use of hexamethyldisilazane as derivatization reagent is proposed for the characterization of mono-, sesqui-, and triterpenoid fractions. Despite this, the authors reported that Py-GC-MS signals obtained were quite weak for all components of the resins.

As mentioned before, Py-GC-MS allows the identification of natural material as well as synthetic polymers (Doménech-Carbó, 2008). A comprehensive study focused in the study of contemporary painting binding media has been published by Doménech-Carbó et al. (2008). They proposed a method based on "on-line" silation-pyrolisis using hexamethyldisilazane as derivatization reagent for the study of polyvinyl acetate (PVA) emulsions a binding media widely used in contemporary commercial products used in fine arts. PVA media used in three contemporary paintings from a private collection and from the Museum of Fine Arts of Málaga (Spain) were successfully identified with this procedure.

\section{Microbeam analytical techniques}

Secondary ion mass spectrometry (SIMS) and laser desorption ionization mass spectrometry (LDIMS) are techniques for spatially resolved organic mass spectrometric analysis. Both techniques are performed in vacuum inside the ion source of a mass spectrometer. Due to the pulsed nature of the ionization process, ions are generally analysed on the basis of their time of flight (TOF-MS). TOF-MS systems have a wide-mass range which makes them suitable for analysis of synthetic polymers as well as traditional organic media and organic pigments. 
A study of painting cross-sections of "The Descent from the Cross" by Rogier van der Weyden has been published (Shimadzu and van der Berg, 2006). The results obtained in this study allow the identification of oleaginous binding media. An analytical protocol was proposed by Tripković and co-workers (2013) for proteinaceous binder identification in paintings using tryptic peptide analysis and matrix-assisted laser desorption-ionization mass spectrometer (MALDI-TOF). The proteins present as binding media in paintings of various artists were successfully identified by the tandem mass spectrometry used. MALDI-TOF-MS on cross-sections of samples for the identification of protein- and oil-based binders was successfully applied on Czech medieval polychromed sculpture, by Kuckova et al., (2013).

More recently, Atrei et al. (2014a) investigate the possibility of identifying proteinaceous binders, typically used in tempera painting, by means of time of flight - Secondary ion mass spectrometry (TOF-SIMS) combined with chemometric principal component analysis (PCA) method. The proposed method allows the identification of egg in model samples simulating real paintings, and also reveals differences in the composition of the protein based binders, but discrimination between animal glue and casein was not possible. A multi-technic approach that combines TOF-SIMS with GC-MS for the successfully identification of organic binding media in the ground and paint layers used in the original and repainted areas of the "Madonna with child" by Pietro Lorenzetti, has been developed by Atrei et al. (2014b).

\section{Electrochemical techniques}

Some advances have been taken place in recent years in the application of electrochemical techniques to the analysis of organic compounds present in cultural heritage. Bottarri et al. (2014) use a nanostructured electrochemical biosensor for detecting proteins of interest in artworks, in particular tempera painting. To determine egg yolk their focus on the determination of immunoglobulin ( $\mathrm{IgY}$ ). The transducers were nanoelectrode ensembles (NEEs), prepared via membrane templated electroless deposition of gold, in an aqueous buffer. The sensor was tested in lab and real samples from painting of the $18^{\text {th }}-20^{\text {th }}$ century, with good results. However, most research published on the use of electrochemical techniques to the analysis of artworks is based on the application of these techniques for the identification and characterization of binding media and dyes due to the development of new methodologies as VMP (Scholz and Meyer, 1994). This technique has been widely applied by Doménech-Carbó et al. (2009) to the field of organic compounds present in cultural goods VMP has been applied by these authors for the simultaneous determination of lead pigments and binding media in paint samples in the range of $\mu \mathrm{g}$-pg (Doménech-Carbó et al., 2007b). A few nanograms of sample are mechanically attached to a paraffin-impregnated graphite electrode producing well defined square wave voltammetric responses for reconstructed model paint specimens. This response allows the identification of pigments associated with linseed, sunflower and poppy oils and casein, egg, and bovine gelatin. Most recently, a method for dating Hemoglobin $(\mathrm{Hb})$ - containing archaeological samples using the voltammetry of microparticles has been described by Doménech-Carbó and co-workers (2012b). The method was applied to the study of the polychromed architectural decoration of the Longshan Temple in Lukang, Taiwan. VMP methodology responses for the $\mathrm{Hb}$ attached to different inorganic grounds evidence the use of blood in composition of this paint layers.

As previously mentioned Doménech-Carbó et al. (2006b; 2007c, d; 2011a; 2012a) have widely studied indigoid compounds present in the Maya blue pigment and the redox-tunning 
processes that take place during the preparation of the pigment by crushing and further heating at low temperatures.

\subsubsection{Characterization of the mechanical properties of paintings}

\section{Nanoindentation technique}

Nanoindentation performed with atomic force microscopes (NI-AFM) is an advanced instrumental technique that allows for differentiation of mechanical properties of materials at nanoscale. NI-AFM has been satisfactorily used for durability investigation and service life prediction of coatings, latex and paint films. The AFM creates an image by scanning a flexible cantilever mounted tip over the sample surface. This mode can produce a topographic image by maintaining constant tapping amplitude. AFM requires no specific sample preparation and provides information about the sample surface in a non-destructive way. However, the surface may have different chemical, physical and mechanical properties from the bulk.

Despite NI-AFM has been largely applied in the plastic industrial sector, research in the field of heritage conservation is scarce. AFM-Nanoindentation in continuous stiffness mode was used to demonstrate the changes of hardness and Young's modulus of coatings after accelerated weathering (Vlad-Cristea et al., 2011). Salvant et al. (2011), reported the use of nanoindentation to characterized samples from two paintings of Van Gogh, the samples were embedded in resin and polished into cross-sections. The technique allows the discrimination between the mechanical response of various layers and establish a relation between mechanical response and layer composition.

\subsubsection{Alterations}

Deterioration of artist's media is mainly a result of oxidation processes involving free radicals and hydrolysis processes of an ionic type. Auto-oxidation reactions are initiated by thermal and photochemical energy input and more rarely by ionizing radiation without oxygen intervening. Apart from thermal or photochemical sources, other agents of deterioration can be mentioned. Metal oxides and other salts present in pigments can have a notable effect on varnishes and media as they promote light-induced oxidation reactions. Hydrolysis reactions are catalyzed by acids or other catalyst, which can be present in the atmosphere as pollutants. This process is particularly important in proteins, drying oils and polysaccharides as it results in a significant change of the film's chemical and mechanical properties. In general, pigments significantly influence the drying and ageing processes that take place in the paint, the degree of oxidation and hydrolysis, and the stabilization of the binder network due to the pigment-medium interactions. These also have consequences to the physical properties of the paint, such as hardness and flexibility.

Deterioration of binding media results in chemical changes such as crosslinking between chains of polymers, chain scissoring, oxidation of the main chain or side groups and the breakdown of molecules, which in most cases are accompanied by the formation of highly oxidized products. These structural changes lead to an increase in the insolubility and polarity of the material, a reduction of the strength, and a change in color, among others. 
Otherwise, the biodegradative activity of moulds, bacteria and other higher organisms, biochemical or enzymatic processes take place on the artwork, which are another frequent form of deterioration.

\section{Spectroscopic techniques}

\section{$U V$-Vis spectrophotometry}

Excitation emission (EE) fluorescence applied to rapid identification of organic painting materials in different naturally aged films (Mannino et al., 2013). Fluorescence spectra obtained were used for principal component analysis (PCA), which allow the identification of the binders, due to the placement of the different materials in the score plot. The PCA results obtained reflect the origin and the age of the binding media identified.

\section{Infrared spectroscopy}

A wide number of papers oriented to the research of binding media alterations by means of infrared spectroscopic methods have been published. A comprehensive study of the application of FTIR to the study of metal soaps aggregation and the formation of protrusions in oil-based paintings has been performed by Keune and Boon (2007). FTIR spectroscopy was applied to monitor and classify the mechanisms of alteration of oil paints prompted by lead additives or pigments (Tumosa et al., 2005).

Differentiation in oxidation of linseed oil in presence of different copper pigments was possible by means of FTIR (Ioakimoglou et al., 1999). The results obtained provide an overview of the whole oxidation process from the early to the late stages and allow comparison of different film composition and processing conditions. They conclude that copper (II) catalytic affects the oxidative changes observed in all linseed oil films. The conjugated $\mathrm{C}=\mathrm{C}$ bonds observed through IR spectroscopy, in the case of copper acetate, indicate carbonyl conjugation as a possible mode for yellowing. A rate increase in the oxidative degradation of films was confirmed in the case of copper acetate and copper abietate.

FTIR spectroscopy has been used to investigate the oxidative polymerization of linseed oil in presence of cobalt 2-ethylhexanoate drier (Mallégol et al., 2000). The study was based in measurements variations of the peroxide value as function of oxidation time. They explain that peroxide value determination in oxidized drying oils can be considered as a measure of the extent of curing.

In their study, van der Weerd et al. (2005) described the changes in the infrared spectra of oil paint as result of ageing. Focus on the influence of pigments on long-term changes in the oil binding medium, by means of FTIR spectroscopy. The authors mentioned that one of the most pronounced effects observed in the infrared spectra of aging paint is the shifting and broadening of the carbonyl band due to the formation of carboxylic acids. Another effect of pigments on the oil binding medium is the catalysis of the hydrolysis of triglycerides, as indicated by the decreasing intensity of the ester absorption. Finally, the nature of the pigment has a profound effect on the $\mathrm{CH}$ stretch absorptions. They conclude that pigments can significantly alter the infrared spectra of drying oil, and should therefore be identified to ensure the correct assessment of the infrared spectra in drying oil paint. 
Identification of aged binders and the reactions compounds formed by the interaction between the binding medium and the pigments in a series of $15^{\text {th }}$ century Catalan Gothic paintings using FTIR and XRD was carried out by Salvadó et al. (2009). Copper carboxylate, lead carboxylate and calcium carboxylate were identified in the paint samples as result of the ageing of the paintings. Most recently, Duce and co-workers (2012) reported the use of FTIR for the identification of proteinaceous binders in paintings regarding the ageing pathways, their protein content and their chemical interaction with inorganic pigments. Interactions between the pigment cinnabar $(\mathrm{HgS})$ and proteins under unaged and artificially aged paint reconstructions created with ovalbumin and casein were also studied. A further publication of this research team describes the use of FTIR spectra peak deconvolution for the quantification of the different Amide I secondary structures in the pure and metal-complexed proteins, both aged and unaged (Duce et al., 2013).

Other alteration procedures have also been studied by means of spectroscopic techniques. A comprehensive approach to the characterization of naturally and artificially aged paint binders using FTIR was made by Meilunas et al. (1990). Castillejo and co-workers (2003) published a study aimed at characterizing the chemical and physical changes induced by exposure to UV in unvarnished tempera paint samples. They conclude that degradation of the binding media occurs in the presence of inorganic pigments. Manzano et al. (2010), reported the use of FTIR complemented with chemometric PCA analysis to study the degradation caused by UV irradiation in glue binder with and without pigment (azurite). The results show that the presence of azurite seems to improve the photostabilization of the glue against UV damage.

Cappitelli et al. (2005) applied vibrational spectroscopies to study the biodegradation of synthetic resins used as paint binding media, including acrylic, alkyd and polyvinyl acetate polymers. Photoacoustic FTIR and Raman spectroscopy spectra of biodegraded resins revealed bands of fungal-derived substances due to the presence of Aspergillus niger. Transmission IR spectroscopy was not sufficiently sensitive to detect changes due to the biological attack in this study. In contrast, photoacoustic FTIR spectroscopy shows to be a powerful technique able to demonstrate the deterioration of synthetic binding media caused by melanin-producing fungi and is also suitable technique for the chemical characterization of binding media. Evidence of paint film biodegradation confirmed by FTIR has been reported by several researchers (Ishfaq et al., 2015; Allsopp et al., 2004). Similarly, and investigation of the structural changes due to the microorganism's attack on a series of reconstructed tempera model paints has been reported by Manea et al. (2012).

\section{Magnetic resonance spectroscopy}

\section{Nuclear magnetic resonance}

The cross-linking processes of drying oils (poppy, linseed and walnut) were studied by means of ${ }^{1} \mathrm{H}-\mathrm{NMR}$ spectroscopy, following the change of the protons signals when oils are heated at $60^{\circ} \mathrm{C}$ in the presence of air or nitrogen gas (Cipriani et al., 2009). Authors reported the use of swollen-state NMR, a method that can directly analyze very small semisolid samples instead of solutions in short time with small quantity of sample required. 
Solid state NMR was used by Boon and Ferreira (2006) to study the chemical properties of amorphous solid materials. Particularly, the ageing and deterioration of oil paintings concentrated around the interaction between inorganic pigments and organic binding mediums, by ${ }^{13} \mathrm{C}$ and ${ }^{207} \mathrm{~Pb}$ NMR. Not only the difference between functional groups e.g. acid, ether or methyl were distinguished but also the difference between the carbonyl groups of an ester, acid, its conjugated base or metal carboxylate, which are relevant to science conservation studies. The study shows the strength of NMR in the qualitative analysis of the chemical composition of samples with several components in a non-invasive way.

Techniques based on the determination of the mass-to-charge ratio

Direct temperature-resolved mass spectrometry

Direct temperature resolved mass spectrometry and tandem mass spectrometry (DTMSMS) was used to characterize the component of egg tempera paints and the fate of cholesterol upon light ageing of egg tempera paint binding medium (van den Brink et al., 2009). Cholesterol oxidation products such as 5,6-epoxycholestan-3-ol and 3-hydrocholest-5-en-7one were identified in light-aged egg binding medium from a German baroque altar piece from the $16^{\text {th }}$ and $18^{\text {th }}$ century. These results show that DTMSMS combined with trimethylsilyl derivatization are useful tools for the characterization of molecular changes in light-aged egg tempera samples.

\section{Chromatographic techniques}

\section{Gas chromatography-mass spectrometry}

A detailed study for the determination of oxidation products, as well as, the hydrolysis degree of triacylglycerols (unsaturated), presented in linseed oil paints was published by Berg et al. (2007). Transethylation of esterified fatty acids followed by a trimethylsilylation of free fatty acids and their salts is the analytical strategy presented in this study by Berg and co-workers (2007). The degree of hydrolysis on oil paint was calculated on the average of the valued obtained for azelaic-, palmitic-, and stearic acid.

Chemical reactions involved in the drying of oil paintings are mainly the result of autoxidation, in which a dry film results from cross-linking reactions taking place between the triacylglycerols. During drying and ageing hydrolysis of ester bonds, formation of new oxygen containing functional groups, oxidative cleavage of the fatty acids hydrocarbon chains, and cross-linked fractions. Most of these processes take place during drying and ageing as result of the pigment-binder interactions. Bonaduce et al. (2012) reported an analytical investigation of reconstructed model paint samples prepared with linseed oil combined with lead white and vine black prepared in 1999 and naturally aged. GC-MS was used to characterized the oxidation and hydrolysis state of the binder and the presence of metal soaps in the lead white paint layers.

Romero-Noguera et al. (2010b) reported the use of GC-MS to determine both the microbiological capacity of growth and the chemical alteration caused by the microbiological biodeterioration in inoculated test specimens prepared with varnish dammar. The main chemical changes were detected in the sample inoculated with Penicillium chrysogenum, which increase the oxidation derivative ocotillone-type compounds an important factor in the 
alteration processes of dammar. A similar study was presented by Romero-Noguera and coworkers (2010a), in this case aimed at studying mastic varnish. In this case, the most aggressive microorganisms were Cladosporium cladosporoides, Penicillium chrysogenum, and Phoma herbarum. 


\subsubsection{References}

Ajò, D., Casellato, U., Fiorin, E., \& Vigato, P. A. (2004). Ciro Ferri's frescoes: a study of painting materials and technique by SEM-EDS microscopy, X-ray diffraction, micro FT-IR and photoluminescence spectroscopy. Journal of Cultural Heritage, 5, 333-348.

Alfeld, M., Broekaert, J.A.C. (2013). Mobile depth profiling and sub- surface imaging techniques for historical paintings- A review. Spectrochimica. Acta Part B, 88, 211-230.

Allsopp, D., Seal, K.J., Gaylarde, C.C. (2004) Introduction to biodeterioration. Cambridge University Press.

Andreotti, A., Bonaduce, I., Colombini, M. P., Gautier, G., Modugno, F., \& Ribechini, E. (2006). Combined GC/MS analytical procedure for the characterization of glycerolipid, waxy, resinous, and proteinaceous materials in a unique paint microsample. Analytical chemistry, $78,4490-4500$.

Artioli, G. (2013) Science for the cultural heritage: the contribution of X-ray diffraction. Rend Fis Acc Lincei. 24, S55-S62 (and reference therein).

Atrei, A., Benetti, F., Bracci, S., Magrini, D., Marchettini, N. (2014) An integrated approach to the study of a reworked painting "Madonna with child" attributed to Pietro Lorenzetti. Journal of Cultural Heritage, 15, 80- 84.

Bamberger, E., Bordt, F. (1889) Weitere Beiträge zur Kenntniss des $\alpha$ Tretrahydronaphtylamins. Berichte der deutschen chemischen, 22, 634-634. Doi: 10.1002/cber.188902201144

Barbillat, J., Dhamelincourt, P., Delhaye, M., da Silva, E. (1994) Raman confocal microprobing, imaging and fiber-optic remote sensing: A further step in molecular analysis. Journal of Raman Spectroscopy, 25, 3-11.

Barrio, J., Chamón, J., Pardo, A.I., Arroyo, M. (2009) Electrochemical technique applied to the conservation of archaeological metals from Spain: a historical review. Journal of Solid State Electrochemistry, 13 (11), 1767-1776 and reference therein.

Berrie, B. (1994) Short communication: a note on the imprimatura in two of Dosso Dossi's paintings'. Journal of the American Institute for Conservation, 33 (3), 307-313.

Bikiaris, D., Daniilia, S., Sotiropoulou, S., Katsimbiri, O., Pavlidou, E., Moutsatsou, A.P., Chryssoulakis, Y. (2000) Ochre-differentiation through micro-Raman and micro-FTIR spectroscopies: application on wall painting at Meteora and Mount Athos, Greece. Spectrochimica Acta, Part A: Molecular and Biomolecular Spectroscopy, 56, 3 - 18.

Bonaduce, I., Andreotti, A. (2009) Py-GC/MS of organic paint binders. Organic mass spectrometry in art and archaeology, 304-326.

Bonaduce, I., Carlyle, L., Perla- Colombini, M., Duce, C., Ferrari, C., Ribechini, E., Selleri, P., Rosaria Tiné, M. (2012) New Insights into the Ageing of Linseed Oil Paint Binder: A Qualitative and Quantitative Analytical Study. PLoS ONE 7(11): e49333. doi:10.1371/journal.pone.0049333 
Bonneau, A. Pearce, D.G., Pollard, A.M. (2012) A multi-techique characterization and provenance study of the pigments used in San rock art, South Africa. Journal of Archaeological Science, 39, 287-294.

Boon, J.J., Ferreira, E.S. (2006) Reporting highlights of the De Mayerne programme.

Boon, J.J., Hoogland, F., Keune, K. (2007) Chemical process in aged oil paints affecting metal soap migration and aggregation. In AIC Paintings Specialty Group, $34^{\text {th }}$ Annual Meeting in Providence, Rhode Island, 16-19 June 2006, Postprints (H. Mar Perkin, ed.), American Institute for Conservation, 18-25.

Boon, J.J. van der Weerd, J., Keune, K., Noble, P., Wadmun, J. (2002) Mechanical and chemical changes in Old Master Paintings: dissolution, metal soap formation and remineralization processes in lead pigmented ground/intermediate paint layers of $17^{\text {th }}$ century paintings. Published in the $13^{\text {th }}$ Triennial Meeting Rio de Janeiro Preprints, Committee for Conservation, James \& James (Science Publishers), 1, 401-406.

Bottari, F., Oliveri, P., Ugo, P. (2014) Electrochemical immunosensor based on ensemble of nanoelectrodes for immunoglobulin IgY detection: Application to identify hen's egg yolk in tempera paintings. Biosensors and Bioelectronics, 52, 403-410.

Bruni, S., Cariati, F., Casadio, F., Toniolo, L. (1999) Spectrochemical characterization by micro-FTIR spectroscopy of blue pigments in different polychrome works of art. Vibrational Spectroscopy 20, 15-25.

Burgio L., Ciomartan D.A., Clark R.J.H. (1997) Pigment identification on medieval manuscripts, paintings and other artefacts by Raman microscopy: applications to the study of three German manuscripts. Journal of Molecular Structure, 405, 1-11.

Burgio, L., Clark, R.J.H. (2001) Library of FT-Raman spectra of pigments, minerals, pigment media and varnishes, and supplement to existing library of Raman spectra of pigments with visible excitation. Spectrochimica Acta Part A, 57, 1491-1521.

Burgio, L., Melessanaki, K., Doulgeridis, M., Clark, R.J.H., Anglos, D. (2001) Pigment identification in paintings employing laser induced breakdown spectroscopy and Raman microscopy. Spectrochimica Acta Part B, 56, 905-913.

Buti, D., Rossi, F., Brunetti, B.G., Miliani, C. (2013) In situ identification of copper-based green pigments on paintings and manuscripts by reflection FTIR. Analytical and Bioanalytical Chemistry, 405, 2699-2711.

Cano, E., Bastidas, D.M., Argyropoulos, V., Fajardo, S., Siatou, A., Bastidas, J.M., Degrigny, C. (2010a) Electrochemical characterization of organic coatings for protection of historic steel artefacts. J Solid Sate Electrochem, 14, 453-463.

Capitani, D., Di Tullio, V., Proietti, N. (2012) Nuclear magnetic resonance to characterize and monitor cultural heritage. Progress in nuclear magnetic resonance spectroscopy, 64, 2969 and reference therein.

Cappitelli, F., Vicini, S., Piaggio, P., Abbruscato, P., Princi, E., Casadevall, A., Nosanchuk, J.D., Zanardini. E. (2005) Investigation of fungal deterioration of synthetic paint binders using vibrational spectroscopic techniques. Macromolecular bioscience 5, 49-57. 
Cardell, C., Guerra, I. (2016) An overview of emerging hyphenated SEM-EDX and Raman spectroscopy systems: Applications in life, environmental and materials sciences. Trends in Analytical Chemistry, 77, 156-166 (and reference therein).

Casadio, F., Toniolo, L. (2001) The analysis of polychrome works of art: 40 years of infrared spectroscopic investigations. Journal of Cultural Heritage, 2, 71-78 and reference therein.

Casellato, U., Vigato, P.A., Russo, U., Matteini, M., (2000) Mössbauer approach to the physico-chemical characterization of iron containing pigments for historical wall paintings. Journal of Cultural Heritage, 1, 217-232.

Castillejo, M., Martín, M., Oujja, M., Santamaría, J., Silva, D., Torres, R., Manousaki, A., Zafiropulos, V., van den Brink, O.F., Heeren, R.M., Teule, R. (2003) Evaluation of the chemical and physical changes induced by $\mathrm{KrF}$ laser irradiation of tempera paints. Journal of Cultural Heritage, 4, 257-263.

Castro, K., Pessanha, S., Proietti, N., Princi, E., Capitani, D., Carvalho, M. L., Madariaga, J. M. (2008) Noninvasive and nondestructive NMR, Raman and XRF analysis of a Blaeu coloured map from the seventeenth century. Analytical and bioanalytical chemistry, 391, 433441.

Chaplin, T.D., Clark, R.J.H., Martinón-Torres, M. (2010) A combined Raman microscopy, XRF and SEM-EDX study of three valuable objects - a large painted leather screen and two illuminated title pages in $17^{\text {th }}$ century books of ordinances of the Worshipful Company of Barbers, London. Journal of Molecular Structure, 976, 350-359.

Checa-Moreno, R., Manzano, E., Mirón, G., Capitán-Vallvey, L.F. (2008) Comparison between traditional strategies and classification technique (SIMCA) in the identification of old proteinaceous binders. Talanta 75, 697-704.

Chiavari, G., Fabbri, D., Galetti, G.C., Mazzeo, R. (1995) Use of analytical pyrolysis to characterize Egyptian painting layers. Chromatographia, 40, 594-600.

Chiavari, G., Gandini, N., Russo, P., \& Fabbri, D. (1998) Characterization of standard tempera painting layers containing proteinaceous binders by pyrolysis (/methylation)-gas chromatography-mass spectrometry. Chromatographia, 47, 420-426.

Chiavari, G., Mazzeo, R. (1999) Characterization of paint layers in Chinese archaeological relics by pyrolysis-GC-MS. Chromatographia, 49, 268-272.

Cipriani, G., Salvini, A., Dei, L., Macherelli, A., Cecchi, F. S., \& Giannelli, C. (2009) Recent advances in swollen-state NMR spectroscopy for the study of drying oils. Journal of Cultural Heritage, 10, 388-395.

Clark, R.J.H. (1995) Raman microscopy: application to the identification of pigments on medieval manuscripts. Chemical Society Reviews, 3, 187-196.

Clark, R.J.H. (1999) Raman microscopy: sensitive probe of pigments on manuscripts, painting and other artifacts. Journal of Molecular Structure, 480-481, 15-20.

Clark, R.J.H. (2002) Pigment identification by spectroscopic means: an arts/science interface. Comptes Rendus Chimie, 5, 7-20. 
Clark, R.J.H., Cridland, L., Kariuki, B.M., Harris, K.D.M., Withnall, R. (1995) Synthesis, structural characterization and Raman spectroscopy of the inorganic pigments lead tin yellow types I and II and lead antimonate yellow: their identification on medieval paintings and manuscripts. Journal of Chemical Society, Dalton Transactions, 16, 2577-2582.

Clark, R.J.H., Curri, M.L. (1998) The identification by Raman microscopy and X-ray diffraction of iron-oxide pigments and of the red pigments found on Italian pottery fragments. J. Mol. Struct., 440, 105- 111.

Colombini, M. P., Fuoco, R., Giacomelli, A., Muscatello, B. (1998) Characterization of proteinaceous binders in wall painting samples by microwave-assisted acid hydrolysis and GC-MS determination of amino acids. Studies in Conservation, 43, 33-41.

Colombini, M. P., Modugno, F. (2004) Characterisation of proteinaceous binders in artistic paintings by chromatographic techniques. Journal of separation science, 27, 147-160.

Conti, C., Striova, J., Aliatis, I., Possenti, E., Massonnet, G., Muehlethaler, C., Poli, T., Positano, M. (2014) The detection of copper resinate pigment in works of art: contribution from Raman spectroscopy. Journal of Raman Spectroscopy, 45, 1186-1196.

Cooke, P.M. (2000) Chemical microscopy. Analytical chemistry, 72, 169-188.

Corbeil, M.C. (2004) Applications of X-ray diffraction in conservation science and archaeometry. Advances in X-ray analysis Volume 47: Proceeding of the $52^{\text {nd }}$ Annual Conference of Applications of X-ray analysis (Denver X-ray Conference), International Centre for Diffraction Data, Newton Square, 8-29.

Costa, V., Dubus, M. (2007) Impact of the environmental conditions on the conservation of metal artifacts: an evaluation using electrochemical techniques, Museum Microclimates, Padfield T (Ed), The National Museum of Denmark 63-65.

Coupry, C., Lautié, A., Revault, M., Dufilho, J. (1994) Contribution of Raman spectroscopy to art and history. Journal of Raman Spectroscopy, 25, 89-94.

Coupry, C. (2000) Application of Raman microspectrometry to arts objects. Analusis, 28, 3945.

da Costa, G.M., Souza, L.A.C., de Jesus, M.F. (1991) Mössbauer study of rock-painting from Minas-Gerais (Brazil). Hyperfine Interact. 67, 459-462.

Davey, R., Gardiner, D.J., Singer, B.W., Spokes, J. (1994) Examples of analysis of pigments from fine art objects by Raman microscopy. Journal of Raman Spectroscopy, 25, 53-57.

de la Cruz-Cañizares, J., Doménech-Carbó, M. T., Gimeno-Adelantado, J. V., Mateo-Castro, R., \& Bosch-Reig, F. (2005) Study of Burseraceae resins used in binding media and varnishes from artworks by gas chromatography-mass spectrometry and pyrolysis-gas chromatography-mass spectrometry. Journal of chromatography A, 1093, 177-194.

de la Roja, J.M., Baonza, V.G., San Andrés, M. (2007) Application of Raman microscopy to the characterization of different verdigris variants obtained using recipes from old treatises. Spectrochimica Acta Part A, 68, 1120-1125.

Derrick, M. R., Stulik, D., \& Landry, J. M. (2000) Infrared spectroscopy in conservation science. Getty Publications. 
Di Tullio, V., Capitani, D., Atrei, A., Benetti, F., Perra, G., Presciutti, F., Proietti, N. Marchettini, N. (2016) Advanced NMR methodologies and micro-analytical techniques to investigate the stratigraphy and materials of 14th century Sienese wooden paintings. Microchemical Journal, 125, 208-218.

Doménech-Carbó, A., Doménech-Carbó, M.T., Moyá, M., Gimeno, J.V., Bosch, F. (2000) Identification of inorganic pigments from paintings and polychromed sculptures immobilized into polymer film electrodes by stripping differential pulse voltammetry. Anal Chim Acta, $407,275-289$.

Doménech-Carbó, A., Doménech-Carbó, M.T., Osete, L. Identification of manganese(IV) centers in archaeologic glass using micro-sample coating attached to polymer film electrodes. Electroanalysis 13 (2001a) $927-935$.

Doménech-Carbó, A., Doménech-Carbó, M.T., Gimeno-Adelantado, J.V., Bosch-Reig, F., Saurí-Peris, M.C., Casas-Catalan, M.J. (2001b) Electrochemical analysis of the alterations in copper pigments using charge transfer coefficient peak potential diagrams. Application to microsamples of baroque wall paintings attached to polymer film electrodes. Fresenius J. Anal. Chem., 369, 576-581.

Doménech-Carbó, A., Doménech-Carbó, M.T., Gimeno-Adelantado, J.V., Bosch-Reig, F., Saurí-Peris, M.C., Sanchez-Ramos, S. (2001c) Electrochemistry of iron oxide pigments (earths) from pictorial microsamples attached to graphite/polyester composite electrodes. Analysts, 126, 1764-1772.

Doménech-Carbó, A., Doménech-Carbó, M.T., Osete-Cortina, L., Gimeno-Adelantado, J.V., Bosch-Reig, F., Mateo-Castro, R. (2002a) Electrochemical identification of metal ions in archaeological ceramics glazes by stripping voltammetry at graphite/polyester composite electrodes. Talanta, 56, 161-174.

Doménech-Carbó, A., Doménech-Carbó, M.T., Osete, L., Gimeno, J.V., Bosch, F., Mateo, R. (2002b) Electrochemical identification of metal ions in archaeological ceramic glazes by stripping voltammetry at graphite/ polyester composite electrodes. Talanta, 56, $161-174$.

Doménech-Carbó, A., Doménech-Carbó, M.T., Saurí, M.C. (2005) Electrochemical identification of flavonoids dyes in solid work of art samples by abrasive voltammetry at paraffin-impregnated graphite electrode. Talanta, 66, $769-782$.

Doménech-Carbó, A., Doménech-Carbó, M.T., Ciarrocci, J., Cialei, V., Monteagudo, A. (2006a) Analysis of earth pigments in Palomino's frescoes in the Santos Juanes church in Valencia (Spain) by solid-state voltammetry and FTIR spectroscopy. Arché, 1, 171 - 176.

Doménech-Carbó, A., Doménech-Carbó, M.T., Vázquez, M.L. (2006b) Dehydroindigo: a new piece into the maya blue puzzle from the voltammetry of microparticles approach. $\mathbf{J}$ Phys Chem B, 110, 6027 - 6039.

Doménech-Carbó, A., Doménech-Carbó, M.T., Edwards, H.G.M. (2007a) Identification of earth pigments in severely damaged frescoes by applying multivariate chemometric methods to solid state voltammetry. Electroanalysis, 19, $1890-1900$. 
Doménech-Carbó A., Doménech-Carbó, M.T., Mas X., Ciarrocci, J. (2007b) Simultaneous identification of lead pigments and binding media in paint samples using voltammetry of microparticles. Arché 2, $121-124$.

Doménech-Carbó, A., Doménech-Carbó, M.T., Vázquez, M.L. (2007c) Indigo/ dehydroindigo/ palygorskite complex in maya blue: an electrochemical approach. J Phys Chem C, 111, 4585 - 4595.

Doménech-Carbó, A., Doménech-Carbó, M.T., Vázquez, M.L. (2007d) Electrochemical monitoring maya blue preparation form maya's ancient procedures. J Solid State Electrochem, 11, 1335 - 1346.

Doménech-Carbó, A., Doménech-Carbó. M.T., Mas, X. (2007e) Identification of lead pigments in nanosamples from ancient paintings and polychromed sculptures using voltammetry of nanoparticles/atomic force microscopy. Talanta, 71, $1569-1579$.

Doménech-Carbó, A., Doménech-Carbó, M.T., Edwards, H.G.M. (2008) Quantification from Tafel analysis in solid-state voltammetry. Application to the study of cobalt and copper pigments in severely damaged frescoes. Anal Chem, 80, $2704-2716$.

Doménech-Carbó, A., Doménech-Carbó, M.T., Costa, V. (2009) Electrochemical Methods for Archaeometry, Conservation and Restoration. In: Scholz F, ed. Monographs in Electrochemistry Series. Berlin-Heidelberg, Germany: Springer.

Doménch-Carbó, A., Doménch-Carbó, M.T., Vázquez de Ágredos-Pascual, M.L. (2011a) "From Maya Blue to Maya Yellow": A connection between ancient nanostructured materials from the voltammetry of microparticles. Angewandte Chemie-International Edition, 50, $5741-5744$.

Doménech-Carbó, A., Doménech-Carbó, M.T., Peiro-Ronda, M.A. (2011b) Dating archaeological lead artifacts from measurement of the corrosion content using the voltammetry of microparticles. Analytical Chemistry, 83, 5639-5644.

Doménech-Carbó, A., Doménech-Carbó, M.T., Vidal-Lorenzo, C., Vázquez de AgredosPascual, M.L. (2012a) Insights into the Maya Blue technology: greenish pellets from the ancient city of La Blanca. Angewandte Chemie-International Edition, 51, 700-703.

Doménech-Carbó, A., Doménech-Carbó, M.T., Lee, Y., \& Osete-Cortina, L. (2012b) Potential Application of Voltammetry of Microparticles for Dating Porcine Blood-based Binding Media used in Taiwanese Architectural Polychromies. Chemistry-An Asian Journal, 7, 2268-2273.

Doménech-Carbó, M.T., Casas-Catalán, M.J., Doménech-Carbó, A., Mateo-Castro, R., Gimeno-Adelantado, J.V., Bosch-Reig, F. (2001) Analytical study of canvas painting collection from the Basilica de la Virgen de los Desamparados using SEM/EDX, FT-IR, GC and electrochemical techniques. Fresenius J Anal Chem, 369, 571-575.

Doménech-Carbó, M.T. (2008) Novel analytical methods for characterizing binding media and protective coatings in artworks. Analytica Chimica Acta, 621, 109-139 and reference therein. 
Doménech-Carbó, M.T., Bitossi, G., Osete-Cortina, L., de la Cruz-Cañizares, J., Yusá-Marco, D. J. (2008) Characterization of polyvinyl resins used as binding media in paintings by pyrolysis-silylation-gas chromatography-mass spectrometry. Analytical and Bioanalytical Chemistry, 391, 1371-1379.

Doménech-Carbó, M.T., Osete-Cortina, L., Doménech-Carbó, A., Agredos-Pascual, M.L.V., Vidal-Lorenzo, C. (2014) Identification of indigoid compounds present in archaeological Maya blue by pirolisis-silylaiton-gas chromatography-mass spectrometry. Journal of Analytical and Applied Pyrolysis, 105, 355-362.

Doménch-Carbó, M.T., Osete-Cortina, L. (2016) Another beauty of analytical chemistry: chemical analysis of inorganic pigments of art and archaeological objects, ChemTexts, 2, 14.

Duce, C., Ghezzi, L., Onor, M., Bonaduce, I., Colombino, M.P., Tine, M.R., Bramati, E. (2012) Physico-chemical characterization of protein-pigment interactions in tempera paint reconstructions: casein/cinnabar and albumin/cinnabar. Anal Bioana Chem, 402, 2183-2193.

Duce, C., Bramati, E., Ghezzi, L., Bernazzani, L., Bonaduce, I., Colombini, M.P., Spepi, A., Biag, S., Tine, M.R. (2013) Interactions between inorganic pigments and proteinaceous binders in reference paint reconstructions. Dalton Trans, 42, 5975-5984.

Duffy, M., McGlinchey, C. (2001) Weeping cadmium paint: a case study. In: Deterioration of artists' paint: effects and analysis. A joint meeting of ICOM-CC working groups paintings 1 $\& 2$ and the painting section, UKIC, British Museum, London, $10^{\text {th }}$ and $11^{\text {th }}$ September 2001: extended abstract (A. Phenix, ed.) British Museum.

Duran, A., Perez-Rodriguez, J.L., Jimenez de Haro, M.C., Franquelo, M.L. Robador, M.D. (2011) Analytical study of Roman and Arabic wall paintings in the Patio De Banderas of Reales Alcazares' Palace using non-destructive XRD/XRF and complementary techniques. Journal of Archaeological Science, 38, 2366-2377.

Eastlake, Ch.L. (1960) Methods and materials of painting of the great schools and masters (formerly titled: Materials for a History of Oil Painting) Volume 1. Dover publications, Inc. New York, (Original edition by Longman, Brown, Green and Longmans, 1847)

Edwards, H.G.M., Brooke, C.J., Tait, J.K.F. (1997a). Fourier Transform Raman spectroscopic study of pigments from English medieval wall paintings. Journal of Raman Spectroscopy, 28, 95.

Edwards, H.G.M., de Oliveira, L.F.C., Middleton, P., Frost, R.L. (2002) Romano-British wall-painting fragments: a spectroscopic analysis. Analyst 127, 277-281.

Edwards, H.G., Chalmers, J.M. (2005) Raman spectroscopy in archaeology and art history (Vol. 9). Royal society of chemistry.

Edwards, H.G.M., Doménech-Carbó, M.T., Hargreaves, M.D., Doménech, A. (2008) A Raman spectroscopic and combined analytical approach to the restoration of severely damaged frescoes; the palomino project. Journal of Raman Spectroscopy, 39, 444-452.

Edwards, H.G.M. (2011) Analytical Raman spectroscopic discrimination between yellow pigments of the Renaissance. Spectrochimica Acta Part A, 80, 14-20. 
Feller, R.L. (1954) Dammar and mastic infrared analysis. Science, 120, 1069-1070.

Fischer, C., Kakoulli, I. (2006) Multispectral and hyperspectral imaging technologies in conservation: current research and potential applications. Studies in Conservation, 51, 3-16.

Franquelo, M.L., Duran, A., Herrera, L.K., Jimenez de Haro, M.C., Perez-Rodriguez, J.L. (2009) Comparison between micro-Raman and micro-FTIR spectroscopy techniques for the characterization of pigments from Southern Spain Cultural Heritage. Journal of Molecular Structure, 924-926, 404-412.

Gayo, M.D. (1996) Pigmentos y colorantes presentes en los bienes culturales, toma de muestras y métodos de análisis, in Técnicas de diagnóstico aplicadas a la conservación de los bienes muebles, IAPH Sevilla, 119-133.

Gettens, R.J., Kuhn, H., Chase, W.T. (1993) Lead white. In: Artists' pigemnts: a handbook of their history and characteristics, vol. 2, (A. Roy, ed.) 67-82, National Gallery of Art.

Ghelardi, E., Degano, I., Colombini, M.P., Mazurek, J., Shilling, M., Learner, T. (2015) PyGC/MS applied to the analysis of synthetic organic pigments: characterization and identification in paint samples. Analytical and bioanalytical chemistry, 407, 1415-1431.

Goltz, D., McClelland, J., Schellenberg, A., Attas, M., Cloutis, E., Collins, C. (2003) Spectroscopic studies on the darkening of lead white. Appl. Spectrosc., 57, 1393-1398.

Gómez, M.L. (1988) La restauración. Examen científico aplicado a la conservación de obras de arte, Ed. Cátedra, 436.

Groen, K. (1997) Investigation of the use of the binding medium by Rembrandt. Zeitschrift für Kunsttechnologie und Konservierung, 11, 207-227.

Gruner, W. (1986) Electrochemical characterization of solid materials in volume range III. Voltammetric studies on isolated $\mathrm{Fe}_{3} \mathrm{C}$. Mikrochim. Acta I, 301-309.

Grygar, T., Bezdička, P., Hradil, D., Doménech-Carbó, A., Marken, F., Pikna, L., Cepriá, G. (2002b) Voltammetric analysis of Fe oxide pigments. Analyst, 127, 1100-1107.

Grygar, T., Marken, F., Schröder, U., Scholz, F. (2002a) Electrochemical analysis of solids. Coll. Czech. Chem. Commun., 67, 163-208.

Grzywacz, C.M. (1994) Identification of proteinaceous binding media in paintings by amino acid analysis using 9-fluorenylmethyl chloroformate derivatization and reversed-phase highperformance liquid chromatography. Journal of Chromatography A, 676, 177-183.

Haber, A., Blümich, B., Souvorova, D., Del Federico, E. (2011) Ancient Roman wall paintings mapped nondestructively by portable NMR. Analytical and bioanalytical chemistry, 401, 1441.

Halpine, S.M. (1995) An Investigation of Artists' Materials Using Amino Acid Analysis: Introduction of the One-Hour Extraction Method. Studies in the History of Art, 51, 28-69.

Halpine, S.M. (1998) HPLC applications in art conservation. In Handbook of HPLC. CRC Press, 903-927. 
Helwing, K. (1997) A note on burnt yellow earth pigments: documentary sources and scientific analysis. Studies in Conservation 42(3), 181-188.

Herrera, L.K., Cotte, M., Jimenez de Haro, M.C., Duran, A., Justo, A., Perez-Rodriguez, J.L. (2008) Characterization of iron oxide-based pigments by synchrotron-based micro X-ray diffraction. Applied Clay Science, 42, 57-62.

Hochleitner, B., Desnica, V., Mantler, M., Schreiner, M. (2003) Historical pigments: a collection analyzed with X-ray diffraction analysis and X-ray fluorescence analysis in order to create a database. Spectrochimica Acta Part B: Atomic Spectroscopy, 58 (4), 641-649.

Hradil, D., Bakardjieva, S., Hradilova', J. (2001) Electron microscopy in materials research of historical paintings. Proceedings of the 5th Multinational Congress of Electron Microscopy held in Lecce, Italy, pp. 53-54.

Hradil, D., Grygar, T., Hradilova', J., Bezdička, P. (2003) Clay and iron pigments in the history of painting. Applied Clay Science, 22, 223-236.

Hubbard, A.T. (1988) Electrochemistry at well-characterized surfaces. Chem. Rev., 633-656.

Ioakimoglou, E., Boyatzis, S., Argitis, P., Fostiridou, A., Papapanagiotou, K., Yannovits, N. (1999) Thin-film study on the oxidation of linseed oil in the presence of selected copper pigments. Chem. Mater., 11, 2013-2022.

Ishfaq, S., Ali, N., Tauseef, I., Khattak, M.N.K., Shinwari, Z.K., Ali, M.I. (2015) Analysis of paint degradation by fungal and bacterial species. Pak. J. Bot, 47, 753-760.

Kalinina, K.B., Bonaduce, I., Colombini, M.P., Artemieva, I.S. (2012) An analytical investigation of the painting technique of Italian Renaissance master Lorenzo Lotto. Journal of Cultural Heritage, 13, 259-274.

Kaszowska, Z., Malek, K., Pańczyc, M., Mikołajska A. (2013) A joint application of ATRFTIR and SEM imaging with high spatial resolution: Identification and distribution of painting materials and their degradation products in paint cross sections. Vibrational Spectroscopy, 65, 1-11.

Keune, K., Boon, J.J. (2007) Analytical imaging studies of cross-sections of paintings affected by lead soap aggregate formation. Studies in Conservation, 52, 161-176.

Keune, K., Boon J.J. (2011) Can dispersed and migrated arsenic from degraded pigments in paintings be a marker for water-linked transport processes? In: ICOM-CC Lisbon 2011; Preprints $16^{\text {th }}$ triennial conference Lisbon, 19-23 September 2011. Paris: ICOM, 2011, pp. 1609 1-7.

Klingelhofer, G., Held, P., Bernhardt, B., Foh, J., Teucher, R., Kankeleit, E. (1998) In situ phase analysis by a versatile miniaturized Mössbauer spectrometer. Hyperfine Interact. 111, 331-334.

Klockenkämper, R., von Bohlen, A., Moens, L. (2000) Analysis of pigments and inks on oil paintings and historical manuscripts using total reflection X-ray fluorescence spectrometry. $X$-ray Spectrometry, 29, 119-129.

Komorsky-Lovric, S., Mirceski, V., Scholz, F. (1999) Voltammetry of organic microparticles. Mikrochimica Acta 132, 67-77. 
Kovala- Demertzi, D., Papathanasis, L., Mazzeo, R., Demertzis, M.A., Varella, E.A., Prati, S. (2012) Pigment identification in a Greek icon by optical microscopy and infrared microspectoscopy. Journal of cultural Heritage 13, 107- 113.

Kubik, M. (2007) Hyperspectral imaging: a new technique for the non-invasive study of artworks. Physical techniques in the study of art, archaeology and cultural heritage, 2, 199259.

Kuckova, S., Nemec, I., Hynek, R., Hradilova, J., Grygar, T. (2005) Analysis of organic colouring and binding components in colour layer of art works. Analytical and bioanalytical chemistry, 382, 275-282.

Lange, B., Scholz, F., Weiss, A., Schwedt, G., Behnert, J., Raezke, K.P. (1993) Abrassive stripping voltammetry the electrochemical alternative for pigment analysis. Int. Lab., 23, 2326.

Larson, L.J., Shin, K.S.K., Zink, J.I. (1991) Photoluminescence spectroscopy of natural resins and organic binding media of paintings. Journal of the American institute for Conservation, 30, 89-104.

Lau, D., Hay, D., Wright, N. (2006) Micro X-ray diffraction for painting and pigment analysis. AICCM Bulletin, 30, 38-43.

Learner, T. (2001) The analysis of synthetic pains by pyrolysis-gas chromatography-mass spectrometry (Py-GC-MS). Stud. Conserv., 46, 225-241.

Leone, B., Burnstock, A., Jones, C.D., Hallebeek, P., Boon, J.J. (2005) The deterioration of cadmium sulphide yellow artist's pigments. In: ICOM Committee for conservation $14^{\text {th }}$ triennial meeting, The Hague, 12-16 September 2005, Preprints (I. Verguer, ed.) James \& James, 2, 803-813.

Loon, A.V. (2008) Color changes and chemical reactivity in $17^{\text {th }}$ century oil paintings, $\mathrm{PhD}$ Thesis, Available in: http://hdl.handle.net/11245/1.292118

Ma, C., Eggleton, R.A. (1999) Surface layer types of kaolinite: a high-resolution transmission electron microscope study. Clays Clay Minerals, 47, 181-191.

Madejová, J., Bujda'k, J., Janek, M., et al., 1998. Comparative FT-IR study of structural modifications during acid treatment of dioctahedral smectites and hectorite. Spectrochim. Acta 54 (10), 1397-1406.

Madejová, J., Komadel, P. (2001) Baseline studies of the clay minerals society source clays: infrared method. Clays Clay Minerals, 49 (5), 410- 432.

Mallégol, J., Lemaire, J., Gardette, J.L. (2000) Drier influence on the curing of linseed oil. Progress in organic coatings, 39, 107-113.

Manea, M.M., Moise, I.V., Virgolici, M., Negut, C.D., Barbu, O.H., Cutrubinis, M., Fugaru, V., Stanculescu, I.R. Ponta, C.C. (2012) Spectroscopic evaluation of painted layer structural changes induced by gamma radiation in experimental models. Radiation Physics and Chemistry, 81,160-167. 
Mannini, M.R., orecchio, A., Gennaro, G. (2013) Microanalytical method for studying paintings by use of fluorescence spectroscopy combined with principal component analysis. Microchemical journal 110, 407- 416.

Manzano, E., Navas, N., Checa-Moreno, R., Rodriguez-Simón, L., Capitán-Vallvey L.F. (2009) Preliminary study of UV ageing process of proteinaceous paint binder by FT-IR and principal component analysis. Talanta 77, 1724-1731.

Manzano, E. Romero-Pastor, J., Navasa, N., Rodríguez-Simón, L.R. Cardell, C. (2010) A study of the interaction between rabbit glue binder and blue copper pigment under radiation: a spectroscopic and PCA approach. Vibrational Spectroscopy, 53, 260-268.

Marengo, E., Robotti, E., Liparota, M.C., Gennaro, M.C. (2003) A method for monitoring the surface conservation of wooden objects by Raman spectroscopy and multivariate control charts. Analytical chemistry, 75, 5567-5574.

Marinach, C., Papillon, M. C., Pepe, C. (2004) Identification of binding media in works of art by gas chromatography-mass spectrometry. Journal of Cultural Heritage, 5, 231-240.

Mazzeo, R., Prati, S. Quaranta, M., Joseph, E., Kendix, E., Galeotti, M. (2008) Attenuated total reflection micro FTIR characterization of pigment-binder interaction in reconstructed paint films. Anal. Bioanal. Chem., 392, 65-76.

Meilunas, R.J., Bentsen, J.G., Steinberg, A. (1990) Analysis of aged paint binders by FTIR spectroscopy. Studies in conservation, 35, 33-51.

Merrifield, M.P. (1967) Original Treatises on the Arts of Painting. ed. Dover, 1849

Miliani, C., Rossi, F., Borgia, I., Benedetti, P., Brunetti, B.G., Sgamellotti, A. (2007) Fiberoptics fourier transform mid-infrared reflectance spectroscopy: a suitable technique for in situ studies of mural paintings. Applied Spectroscopy, 61(3), 293-299.

Miyoshi, T. (1987) Fluorescence from varnishes for oil paintings under $\mathrm{N}_{2}$ laser excitation. Japanese Journal of Applied Physics, 26, 780-781.

Miyoshi, T., Ikeya, M., Kinoshita, S., Kushida, T. (1982) Laser-induced fluorescence of oil colours and its application to the identification of pigments in oil paintings. Japanese Journal of Applied Physics, 21(7), 1032-1036.

Moore, D.M., Raynolds, R.C. (1997) X-ray diffraction and the identification and analysis of clay minerals, $2^{\text {nd }}$ ed. Oxford Univ. Press, New York.

Moskvin, L.N., Kots, L.N., Grigoreva, M.F. (1988) Voltammetric determination of magnetic with an electroactive carbon paste electrode. Zh. Anal. Khim. 43, 1025-1029.

Navas, N., Romero-Pastor, J., Manzano, E., Cardell, C. (2008) Benefits of applying combined diffuse reflectance FTIR spectroscopy and principal component analysis for the study of blue tempera historical painting. Analytica chimica acta, 630, 141-149.

Nevin, A., Carther, S., Anglos, D., Fotakis, C. (2006) Analysis of protein-based binding media found in paintings using laser induced fluorescence spectroscopy. Anal Chim Acta $573,341-346$. 
Nitschke, L., Henrion, G., Damaschun, F., Scholz, F. (1989) A new technique to study the electrochemistry of minerals. Naturwiss, 76, $167-168$.

Noble, P., Loon, A.V., Boon, J.J. (2005) Chemical changes in Old Master Paintings II: darkening due to increase transparency as a result of metal soap formation. In ICOM Committee for Conservation, $14^{\text {th }}$ Meeting, The Hague, 12-16 September 2005: Preprints (I. Verger, ed.) James \& James, 1, 496-503.

Noble, P., Loon, A.V., Boon, J.J. (2008) Selective darkening of ground layers and paint layers associated with the wood structure in $17^{\text {th }}$ century panel paintings. In: Preparation for painting: The artists's choice and its consequences (J.H. Townsend, T. Doherty, G. Heydenrich and J. Ride, eds.), Archetype Publications, 68-78.

Odlyha, M. (2011) Introduction to the preservation of cultural heritage. J. Therm. Anal. Calorim, 104, 399-403.

Odlyha, M., Cohen, N.S., Foster, G.M., West, R.H. (2000) Dosimetry of paintings: determination of the degree of chemical change in museum exposed test paintings (azurite tempera) by thermal and spectroscopic analysis. Thermochimica Acta, 365, 53-63.

Olivares, M., Castro, K., Corchón, M.S., Gárate, D., Murelaga, X., Sarmiento, A., Etxebarria, N. (2013) Non-invasive portable instrumentation to study Palaeolithic rock painting: the case of La Peña Cave in San Roman de Candamo (Asturias, Spain). Journal of Archaeological Science, 40, 1384-1360.

Olszewska-Świetlik, J., Szmelter-Fausek, B., Pięta, E., Proniewicz, E. (2013) Spectroscopic and gas chromatographic studies of pigments and binders in Gdańsk paintings of the 17th century. Journal of Spectroscopy, 2013.

Osmond, G. (2012) Zinc white: a review of zinc oxide pigment properties and implications for stability in oil-based paintings, AICCM Bulletin, 33 .

Pascual, M.L.V.d.Á., Doménech-Carbó, M.T., Doménech-Carbó, A. (2011) Characterization of Maya Blue pigment in pre-classic and classic monumental architecture of the ancient preColumbian city of Calakmul (Campeche, Mexico). Journal of Cultural Heritage, 12, 140-148.

Pelagotti, A., Pezzati, L., Bevilacqua, N., Vascotto, V., Reillon, V., Daffara, C. (2005) A study of UV fluorescence emission of painting materials. In Art '05-8th International Conference on Non-Destructive Investigations and Microanalysis for the Diagnostics and Conservation of the Cultural and Environmental Heritage. Lecce, Italy, A97.

Perinet G., Onoratini G. (1987) A propos des colorants rouges prehistoriques. Rev Archeom. $11,49-51$.

Pięta, E., Proniewicz, E., Szmelter-Fausek, B., Olszewska-Świetlik, J. (2015) Pigment characterization of important golden age panel paintings of the $17^{\text {th }}$ century. Spectrochimica Acta Part A: Molecular and Biomolecular Spectroscopy, 136, 594-600.

Plahter, U. (2004) Painted altar frontals of Norway. Archetype, 1250-1350.

Přikryl, P., Havlíčková, L., Pacáková, V., Hradilová, J., Štulík, K., \& Hofta, P. (2006) An evaluation of GC-MS and HPLC-FD methods for analysis of protein binders in paintings. Journal of separation science, 29, 2653-2663. 
Resano, M., García-Ruiz, E., Alloza, R., Marzo, M.P., Vandenabeele, P., Vanhaecke, F. (2007) Laser ablation-inductively couple plasma mass spectrometry for the characterization of pigments in prehistoric rock art. Analytical chemistry, 79, 8947-8955.

Romero-Noguera, J., López-Miras, M.M., Martín-Sánchez, I., Ramos-López, J.M., BolívarGaliano, F. (2010a) An approach to the study of the fungal deterioration of a classical art material: Mastic varnish. Electronic Journal of Biotechnology, 13, 1-2.

Romero-Noguera, J., Martín-Sánchez, I., López-Miras, M.M., Ramos-López, J.M., BolívarGaliano, F. (2010b) Biodeterioration patterns found in dammar resin used as art material. Electronic Journal of Biotechnology, 13, 6-7.

Romero-Pastor, J., Cardell, C., Yebra-Rodríguez, Á., Rodríguez-Navarro, A.B. (2013) Validating chemical and structural changes in painting materials by principal component analysis of spectroscopic data using internal mineral standards. Journal of Cultural Heritage, 14, 509-514.

Ropret, P., Madariaga, J.M. (2014) Applications of Raman spectroscopy in art and archaeology. Journal of Raman Spectroscopy, 45, 985-992 and reference therein.

Rull Perez, F., Edwards, H.G.M., Rivas, A., Drummond, L. (1999) Fourier Transform Raman Spectroscopic characterization of pigments in the medieval frescoes at Convento de la Peregrina, Sahagun, León, Spain. Part 1-Preliminary Study. Journal of Raman Spectroscopy, 30, 301-305.

Russell, J., Singer, B.W., Perry, J.J., Bacon, A. (2011) The identification of synthetic organic pigments in modern paints and modern paintings using pyrolysis-gas chromatography-mass spectrometry. Anal. Bioanal. Chem., 400, 1473-1491.

Salvadó, N., Salvador, B., Nicholson, J., Emerich, H., Labrador, A., Pradell, T. (2009) Identification of reaction compounds in micrometric layers from gothic painting using combined SR-XRD and SR-FTIR, Talanta, 79, 419-428.

Salvat, J., Barthel, E., Menu, M. (2011) Nanoindentation and the micromechanics of Van Gogh oil paints. Applied Physics A: Materials Science \& Processing, 104, 509-515.

San Andrés, M., Báez, M.I., Baldonedo, J.L., Barba, C. (1997) Transmission electron microscopy applied to the study of works of art. Sample preparation methodology and possible techniques. Journal of Microcopy, 188, 42- 50.

San Andrés, M., de la Roja, J.M., Boanza, V.G., Sancho, N. (2010) Verdigris pigment: a mixture of compounds. Input from Raman spectroscopy. Journal of Raman Spectroscopy, 41, $1468-1476$.

Sandu, I.C.A., Roque, A.C.A., Matteini, P., Schäfer, S., Agati, G., Correia, C.R., Viana, J.F. F.P. (2012) Fluorescence recognition of proteinaceous binders in works of art by a novel integrated system of investigation. Microscopy Research and Technique, 75, 316-324.

Santoro, C., Zarkout, K., Le-Ho, A.S., Mirambet, F., Gourier, D., Binet, L., Pagès, S., Reguer, S. Mirabaud, S., Le-Du, Y., Griesmar, P., Lubin-Germain, N., Menu, M. (2014) New highlights on degradation of verdigris from easel painting. Appl. Phys. A., 114, 637-645. 
Saunders, D., Kirby, J. (2004) The effect of relative humidity on artists' pigments. National Gallery technical bulletin, 25, 62-72.

Scalarone, D., van der Horst, J., Boon, J. J., Chiantore, O. (2003) Direct-temperature mass spectrometric detection of volatile terpenoids and natural terpenoid polymersin fresh and artificially aged resins. Journal of Mass Spectrometry, 38, 607-617.

Scalarone, D., Chiantore, O. (2009) Py-GC/MS of natural and synthetic resins. Organic Mass Spectrometry in Art and Archaeology, 327.

Scholz, F., Nitschke, L., Henrion, G. (1989) A new procedure for fast electrochemical analysis of solid materials. Naturwiss $76,71-72$.

Scholz, F., Meyer, B. (1994) Electrochemical solid state analysis: state of the art. Chemical Society Reviews, 23, 341-347.

Scholz, F., Meyer, B. (1998) Electrochemical solid state analysis - state of the art. Chem Soc Rev, 23, $341-347$.

Şerifaki, K., Böke, H., Yalçın, Ş., \& İpekoğlu, B. (2009) Characterization of materials used in the execution of historic oil paintings by XRD, SEM-EDS, TGA and LIBS analysis. Materials Characterization, 60, 303-311.

Shimadzu, Y., van den Berg, K.J. (2006) On metal soap related colour and transparency changes in a $19^{\text {th }}$ century painting by Millais. In book: Reporting Highlights of the De Mayerne Programme, Publisher: Netherlands Organization for Scientific Research (NOW), The Hague, Editors: Jaap J. Boon and Ester S.B. Ferreira, pp. 43-52.

Smith, G. D., Clark, R.J. (2001) Raman microscopy in art history and conservation science. Studies in Conservation, 46, 92-106.

Spyros, A., Anglos, D. (2004) Study of aging in oil paintings by 1D and 2D NMR spectroscopy. Anal. Chem., 76, 4929-4936.

Stoner, J. H., Rushfield, R. (2013). Conservation of easel paintings. Routledge.

Švarcova, S., Čermakova, Z., Hradilova, J., Bezdička, P., Hradil, D. (2014) Non-destructive micro-analytical differentiation of copper pigments in paint layers of work of art using laboratory-based techniques. Spectrochimica Acta Part: A Molecular and Biomolecular Spectroscopy, 132, 514-525.

Švarcova, S., Hradil, D., Hradilova, J., Kočí, E., Bezdička, P. (2009) Micro-analytical evidence of origin and degradation of copper pigments found in Bohemian Gothic murals. Anal Bioanal Chem. 395, 2037-2050.

Syta, O., Rozum, K., Choińska. M., Zielińska, D., Zukowska, G.Z., Kijowska, A., Wagner, B. (2014) Analytical procedure for characterization of medieval wall-paintings by X-ray fluorescence spectrometry, laser ablation inductively coupled plasma mass spectrometry and Raman spectroscopy. Spectrochimica Acta Part B, 101, 140-148.

Teule, R., Hans-Scholten, A., van den Brink, O.F., Heeren, R.M.A, Zafiropulos, V., Hesterman, R., Castillejo, M., Martin, M., Ullenius, U., Larsson, I., Guerra-Librero, F. 
(2003) Controlled UV cases cleaning of painted artworks: a systematic effect study on egg tempera paint samples. Journal of Cultural Heritage 4, 209s- 219s

Tomasini, E., Siracusano, G., Maier, M.S. (2012) Spectroscopic, morphological and chemical characterization of historic pigments based on carbon. Paths for the identification of an artistic pigment. Microchemical Journal, 102, 28-37.

Tripković, T., Charvy, C., Alves, S., Lolić, A.Đ., Baošić, R.M., Nikolić-Mandić, S.D., Tabet, J.C. (2013) Identification of protein binders in artworks by MALDI-TOF/TOF tandem mass spectrometry. Talanta, 113, 49-61.

Tumosa, C.S., Mecklenburg, M.F. (2005) The influence of lead ions on the drying of oils. Studies in Conservation, 50, 39-47.

Vahur, S., Teearu, A., Leito, I. (2010) ATR-FTIR spectroscopy in the region of 550-230 $\mathrm{cm}^{-1}$ for identification of inorganic pigments. Spectrochimica Acta Part A, 75, 1061-1072.

Vallance, S.L. (1997) Critical Review: Applications of Chromatography in Art Conservation: Techniques Used for the Analysis and Identification of Proteinaceous and Gum Binding Media. Analyst, 122, 75R-81R and reference therein.

van der Berg, J.D.J., van der Berg K. J., Boon, J. J. (2001) Determination of the degree of mycroanalysis of oil paint samples using a two- step derivation method and on- column GC/ MS. Progress in organic coatings 41, 143- 155.

van den Berg, J.D., Van den Berg, K.J., Boon, J.J. (2002) Identification of non-cross-linked compounds in methanolic extracts of cured and aged linseed oil-based paint films using gas chromatography-mass spectrometry. Journal of Chromatography A, 950, 195-211.

van den Brink, O.F., Ferreira, E.S.B., van der Horst, J., Boon, J.J. (2009) A direct temperatura- resolved tándem mass spectrometry study of cholesterol oxidation products in light- aged tempera paints with examples from Works of art. International Journal of Mass Spectrometry 284, 12- 21.

van der Snickt, G., Dik, J., Cotte, M., Janssens, K., Jaroszewicz, J., De Nolf, W., Groenewegen, J., van der Loeff, L. (2009) Characterization of a degraded cadmium yellow $(\mathrm{CdS})$ pigment in an oil painting by means of Synchroton radiation based X-ray techniques. Anal. Chem., 81, 2600-2610.

van der Weerd, J., Boon, J.J., Geldof, M. (2002) Chemical changes in Old Master paintings: dissolution, metal soap formation and remineralization processes in lead pigmented paint layers of $17^{\text {th }}$ century paintings. Zeitschrift für Kunsttechnologie und Konservierung, 16, 3651.

van der Weerd, J., Gedof, M. Struik van der Loeff, L. (2003) Zinc soap aggregate formation in 'Falling Leaves (Les Alyscamps)' by Vincent van Gogh. Zeitschrift für Kunsttechnologie und Konservierung, 17, 407-416.

van der Weerd, J., van Loon, A., Boon, J.J (2005) FTIR studies of the effects of pigments on the aging of oil. Studies in Conservation, 50, 3-22. 
Vandenabeele, P., Wehling, B., Moens, L., Edwards, H., De Reu, M., Van Hooydonk, G. (2000) Analysis with micro-Raman spectroscopy of natural organic binding media and varnishes used in art. Analytica Chimica Acta, 407, 261-274.

Vandenabeele, P., Verpoort, F., Moens, L. (2001) Non-destructive analysis of paintings using Fourier transform Raman spectroscopy with fibre optics. Journal of Raman Spectroscopy, 32, 263-269.

Vicente, J.P., Gimeno-Adelantado, J.V., Doménech-Carbó, M.T., Mateo-Castro, R., BoschReig, F. (2005) Identification of lipid binders in old oil paintings by separation of 4bromomethyl-7-methoxycoumarin derivatives of fatty acids by liquid chromatography with fluorescence detection. Journal of Chromatography A, 1076, 44-50.

Vlad-Cristea, M., Riedl, B., Blanchet, P., Jimenez-Pique, E. (2012) Nanocharacterization techniques for investigating the durability of wood coatings. European Polymer Journal, 48, 441-453.

Winter, J. (1983) The characterization of pigments based on carbon. Studies in Conservation, 28, 49-66. 


\section{Part II. Characterization of the deterioration effect of pigment on tempera painting}


7. MATERIALS AND METHODS 


\section{1. Reconstructed model paint specimens}

\section{1. 1. Reference materials}

Iron oxide red, cadmium yellow, zinc white and massicot, fresh hen's egg yolk and cold pressed linseed oil (Kremer) were used as reference materials for preparing the series of model paint films. Table 7.1.1, summarizes the set of pigments used in this study. The pigments considered in this work as massicot (lead monoxide) and iron oxide are usually found in traditional colour palettes. Cadmium yellow (cadmium sulphide) and zinc white are part of the palette that has been used in the last 150 years. All of them are mentioned in almost all the source materials and catalogue lists of pigments from ancient times to the present (Cennini, 1988; Gettens and Stout, 1966; Mayer; Ward, 2008). The pigment selection for this study was made considering the electroactive capacity, the transparent behavior to IR analytical techniques, as well as the different influence degree on proteinaceous- and oilbinders' type.

Table 7.1.1. List of the pigments used for the preparation of the reconstructed tempera paint specimens and the composition declare by the manufacturer.

\begin{tabular}{|lll|}
\hline Pigment common name & Chemical composition & Supplier \\
\hline Cadmium yellow & Cadmium sulphide $(\mathrm{CdS})$ & Kremer \\
\hline Iron oxide red & Ferric oxide $\left(\mathrm{Fe}_{2} \mathrm{O}_{3}\right)$ & Kremer \\
\hline Massicot & Lead monoxide $(\mathrm{PbO})$ & Kremer \\
\hline Zinc white (Chinese white) & Zinc oxide $(\mathrm{ZnO})$ & Kremer \\
\hline
\end{tabular}




\section{1. 2. Reconstructed model paint specimens' preparation}

Two series of tests specimens containing egg yolk and egg yolk-oil emulsion as binding medium mixed with iron oxide, massicot, zinc white and cadmium yellow have been prepared for carrying the study of the interactions between the binding medium and the pigment in both types of tempera painting.

Reconstructed egg yolk tempera paint films (Y) were prepared by mixing the pigment with the appropriate amount of egg yolk until suitable consistence (10, 3050 and $75 \mathrm{wt} \%$ weight composition of pigment) and spreading this product on glass slides in order to form a thin film. The paint films were dried at room temperature during 3 months $\left(21^{\circ} \mathrm{C}, 50 \% \mathrm{RH}\right)$. Thickness of the films was in the range $0.3-0.5 \mathrm{~mm}$.

Reconstructed egg yolk-oil emulsion paint films (YO) were prepared by mixing the pigment with the appropriate amount of an egg-linseed oil emulsion (1:1) (10, 30, 50 and $75 \mathrm{wt} \%$ weight composition of pigment). The reconstructed paint films were dried at room temperature during 3 months $\left(21^{\circ} \mathrm{C}, 50 \% \mathrm{RH}\right)$. Thickness of the film was in the range $0.3-$ $0.5 \mathrm{~mm}$.

Pure egg yolk and egg yolk-oil emulsion were also prepared and used as control specimens.

Table 7.1.2.1. Reconstructed model paint specimens used in the study of the interactions between the binding medium and the pigment

\begin{tabular}{|c|c|c|c|c|c|}
\hline \multirow[b]{2}{*}{ Binding media } & \multirow{2}{*}{$\begin{array}{c}\text { Pigment } \\
\text { content } \\
(w t \%)\end{array}$} & \multicolumn{4}{|c|}{ Pigments } \\
\hline & & Iron oxide & Massicot & Zinc white & $\begin{array}{c}\text { Cadmium } \\
\text { yellow }\end{array}$ \\
\hline Egg yolk (Y) & 10 & $\mathrm{Y} @ \mathrm{Fe}_{10}$ & $\mathrm{Y} @ \mathrm{Pbm}_{10}$ & $\mathrm{Y} @ \mathrm{Zn}_{10}$ & $\mathrm{Y} @ \mathrm{Cd}_{10}$ \\
\hline Egg yolk (Y) & 30 & $\mathrm{Y} @ \mathrm{Fe}_{30}$ & $\mathrm{Y} @ \mathrm{Pbm}_{30}$ & $\mathrm{Y} @ \mathrm{Zn}_{30}$ & $\mathrm{Y} @ \mathrm{Cd}_{30}$ \\
\hline Egg yolk (Y) & 50 & $\mathrm{Y} @ \mathrm{Fe}_{50}$ & $\mathrm{Y} @ \mathrm{Pbm}_{50}$ & $\mathrm{Y} @ \mathrm{Zn}_{50}$ & $\mathrm{Y} @ \mathrm{Cd}_{50}$ \\
\hline Egg yolk (Y) & 75 & $\mathrm{Y} @ \mathrm{Fe}_{75}$ & $\mathrm{Y} @ \mathrm{Pbm}_{75}$ & $Y @ Z_{75}$ & $\mathrm{Y} @ \mathrm{Cd}_{75}$ \\
\hline $\begin{array}{c}\text { Egg yok-oil } \\
\text { emulsion (YO) }\end{array}$ & 10 & $\mathrm{YO} @ \mathrm{Fe}_{10}$ & $\mathrm{YO} @ \mathrm{Pbm}_{10}$ & YO@Zn & YO@ $\mathrm{Cd}_{10}$ \\
\hline $\begin{array}{c}\text { Egg yok-oil } \\
\text { emulsion (YO) }\end{array}$ & 30 & $\mathrm{YO} @ \mathrm{Fe}_{30}$ & $\mathrm{YO} @ \mathrm{Pbm}_{30}$ & YO@Zn 30 & YO@ $\mathrm{Cd}_{30}$ \\
\hline $\begin{array}{c}\text { Egg yok-oil } \\
\text { emulsion (YO) }\end{array}$ & 50 & $\mathrm{YO} @ \mathrm{Fe}_{50}$ & $\mathrm{YO} @ \mathrm{Pbm}_{50}$ & $\mathrm{YO} @ \mathrm{Zn}_{50}$ & $\mathrm{YO} @ \mathrm{Cd}_{50}$ \\
\hline $\begin{array}{l}\text { Egg yolk-oil } \\
\text { emulsion (YO) }\end{array}$ & 75 & $\mathrm{YO} @ \mathrm{Fe}_{75}$ & $\mathrm{YO} @ \mathrm{Pbm}_{75}$ & YO@Zn 75 & $\mathrm{YO} @ \mathrm{Cd}_{75}$ \\
\hline
\end{tabular}




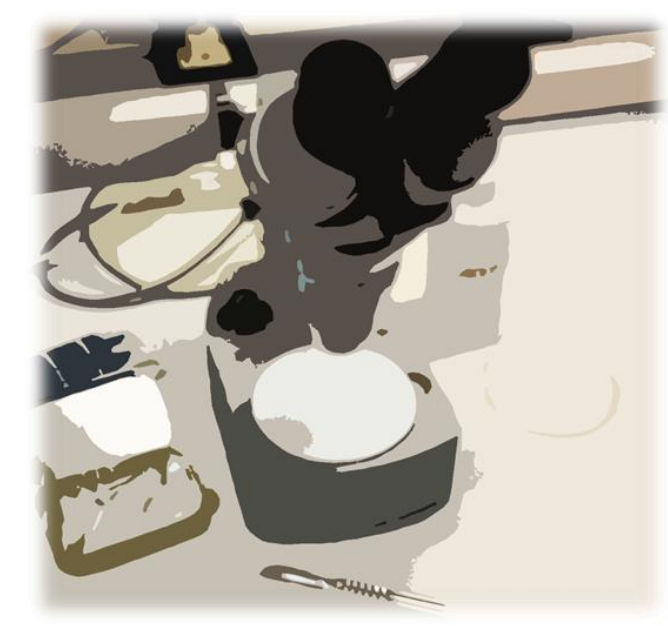

\section{2. Analytical techniques}

\section{2. 1. Weight measurements}

\section{Equipment}

Weight measurements were performed with a Precisa ${ }^{\circledR}$ XT 120-A precision balance with a weighting range of $120 \mathrm{~g}$ and readability of $0.001 \mathrm{~g}$.

\section{2. 2. Fourier Transformed Infrared Spectroscopy in Attenuated Total Reflectance mode (FTIR-ATR)}

\section{Principle}

FTIR is one of the most widely used technique in the field of science conservation. Its value lies principally in the fact that does not need extensive sample preparation, analyses are performed quikly and is capable of simultaneously detecting inorganic and organic materials.

The infrared spectral region, which corresponds to frequencies from the visible red to the microwave spectral region $\left(14000-20 \mathrm{~cm}^{-1}\right)$, is divided for practical reasons into nearinfrared $\left(14000-4000 \mathrm{~cm}^{-1}\right)$, mid-infrared $\left(4000-500 \mathrm{~cm}^{-1}\right)$, and far-infrared $\left(500-20 \mathrm{~cm}^{-}\right.$ $\left.{ }^{1}\right)$ regions. The mid-infrared region is mostly used to identify organic materials in cultural artefacts. The far-infrared is applied for the study of organometallic or inorganic compounds and in the identification of minerals and colorants. The IR spectrum is formed by a number of bands that are formed as result of the absorption of radiation at specific frequencies when a molecular functional group undergoes a vibrational transition. A functional group is a group 
of two or more atoms, bound together in a specific way (Derick et al., 1999). The position of an infrared band is specified by its wavelength $(\lambda)$, measured in microns $(\mu \mathrm{m})$. The spatial frequency expressed in wavenumbers $\left(\mathrm{cm}^{-1}\right)$ is inversely proportional to the frequency $(v)$ of the wave, so it is also proportional to the energy of a proton of this frequency (Low and Baer, 1977; Derick et al., 1999).

A FTIR spectroscope includes moving mirror, fixed mirror, beam splitter, IR radiation source and detector. Radiation from the IR source is collimated by a mirror and the resultant beam is divided at the beam splitter. Half of beam passes through the mirror (fixed) and half refracted to is conducted to the moving mirror. After reflection by these two mirrors, two beams recombined at the beam splitter pass through a cell and after that, the radiation is focused to the detector. The detector simultaneously measures all frequencies that pass through the cell and routes the information to a computer in which is decoded by FT algorithm resulting in a spectrum.

The technique of Attenuated Total Reflectance (ATR) has in recent years revolutionized solid and liquid sample analyses because it combats the most challenging aspects of infrared analyses, namely sample preparation and spectral reproducibility. An attenuated total reflection accessory operates by measuring the changes that occur in a totally internally reflected infrared beam when the beam comes into contact with a sample. An infrared beam is directed onto an optically dense crystal with a high refractive index at a certain angle. This internal reflectance creates an evanescent wave that extends beyond the surface of the crystal into the sample held in contact with the crystal. This evanescent wave protrudes only a few microns $(0.5 \mu-5 \mu)$ beyond the crystal surface and into the sample. Consequently, there must be good contact between the sample and the crystal surface. In regions of the infrared spectrum where the sample absorbs energy, the evanescent wave will be attenuated or altered. The attenuated energy from each evanescent wave is passed back to the IR beam, which then exits the opposite end of the crystal and is passed to the detector in the IR spectrometer.

\section{Equipment}

The infrared (IR) spectra in ATR mode were obtained using a Vertex ${ }^{\circledR} 70$ Fourier transform infrared spectrometer (Bruker Optik $\mathrm{GmbH}$ ) with a fast-recovery deuterated triglycine sulphate, temperature-stabilised coated detector and a MKII Golden Gate ATR accessory (Figure 7.2.2.1). A total of 32 scans were collected at a resolution of $4 \mathrm{~cm}^{-1}$. Each spectrum was processed using the OPUS 5.0 version IR software.

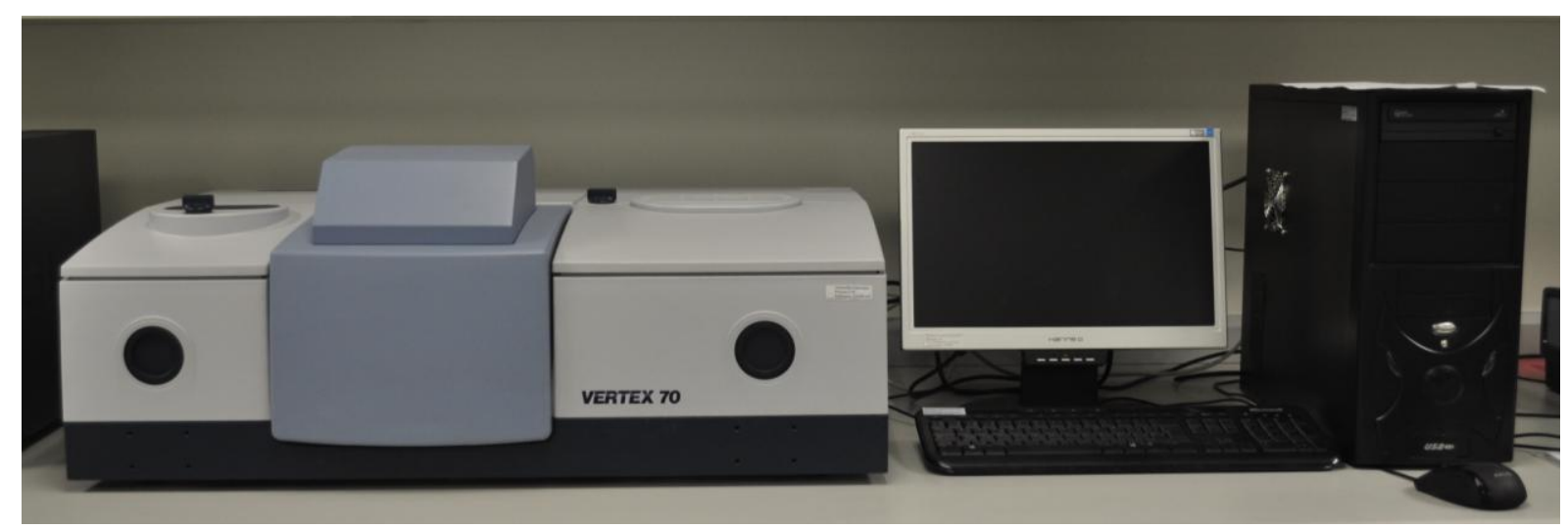

Figure 7.2.2.1. FTIR spectroscopy equipment used in this study. 


\section{Specimens' analysis procedure}

Samples consisting of a few $\mu \mathrm{g}$ of the paint film or reference material are directly placed inside the compression cell.

\section{Data processing method}

For performing the determination of the secondary structure of the proteinaceous materials present in the model paint specimens, main features of the commonly used procedure including second derivative, Fourier Self-Deconvolution (FSD) and curve fitting analysis were applied (Kong and Yu 2007; Byler and Susi 1986; Haris and Severcan 1999; Dong et al. 1990; Pelton and McLean 2000; Swewicz and Mantsch 1988). The position of overlapped IR bands that appear as shoulders of most intense bands in the IR absorption spectra were made to correspond to the frequency of the minima in the second derivative of the undeconvoluted spectra with a nine point Savitsky-Golay smoothing filter (Taddei and Monti 2005). The selected band frequencies values were further used as starting parameters for curve fitting analysis. In a second step, Fourier self-deconvolution (FSD) of the IR spectra covering amide I region (1595-1705 cm-1) was performed using Lorentzian line shape. Apodization with a Blackman-Harris function was always performed automatically at the same time in the software. FSD was performed using a bandwidth at half height of $13 \mathrm{~cm}^{-1}$ and a resolution enhancement factor of 2.4. These values, commonly used for quantitatively estimate the protein secondary structures (Van der Weerd et al. 2005; Byler and Susi 1986; Pelton and McLean 2000; Susi and Byler 1986; Hu et al. 2006; Rajkhowa et al. 2012), were selected in an attempt to avoid possible random noise artifacts indistinguishable from amide bands appearing in samples of paints prepared with the higher scattering effect pigments (Pelton and McLean 2000; Goormaghtigh et al. 2009). Prior to curve fitting, a straight base line passing through the ordinates at $1700 \mathrm{~cm}^{-1}$ and $1600 \mathrm{~cm}^{-1}$ was subtracted (Goormaghtigh et al. 2009). Curve fitting was performed in a third step. As previously mentioned, number and position of the fitted bands was taken combining peaks found in the deconvoluted spectrum and second derivative spectrum. Generally, ten to fourteen peaks are found and are assigned as done in literature (Goormaghtigh et al. 2009; Furlan et al. 2007). Levenberg-Marquardt algorithm was used for the curve fit of Gaussian band shape profiles. The base line was modified again by the least-squares curve-fitting program which allows for a horizontal baseline to be adjusted as an additional parameter to obtain the best fit. The areas of all bands assigned to a given secondary structure were then summed up and divided by the total area. The number so obtained was taken to be the proportion of the protein chains in that conformation.

\section{2. 3. Field Emission Scanning Electron Microscopy (FESEM)}

\section{Principle}

Field emission scanning electron microscopy (FESEM) is a microbeam technique that works with electrons liberated by a field emission source. FESEM is very useful in the characterization of small topographic details on the surface. Researchers in the field of science conservation apply this technique for the characterization of cultural heritage 
materials and their alterations that may be as small as 1 nanometer (Restivo et al., 2014; Havrdova et al., 2014; Guerra et al., 2015).

The electrons liberated from a field emission source are accelerated in a high electrical field gradient within the high vacuum column these so-called primary electrons are focused and deflected by electronic lenses to produce a narrow scan beam that bombards the object. The electron beam scans the object (samples) following a zigzag pattern. As a result, secondary electrons are emitted from each spot on the object that are subsequently collected by a detector that produces an electronic signal. This signal is amplified and transformed to a digital image that can be saved and processed further on a monitor (Operator's user guide; Goldstein et al., 2012).

\section{Equipment}

Secondary electron images were obtained using a Zeiss model ULTRA 55 (Figure 7.2.3.1).

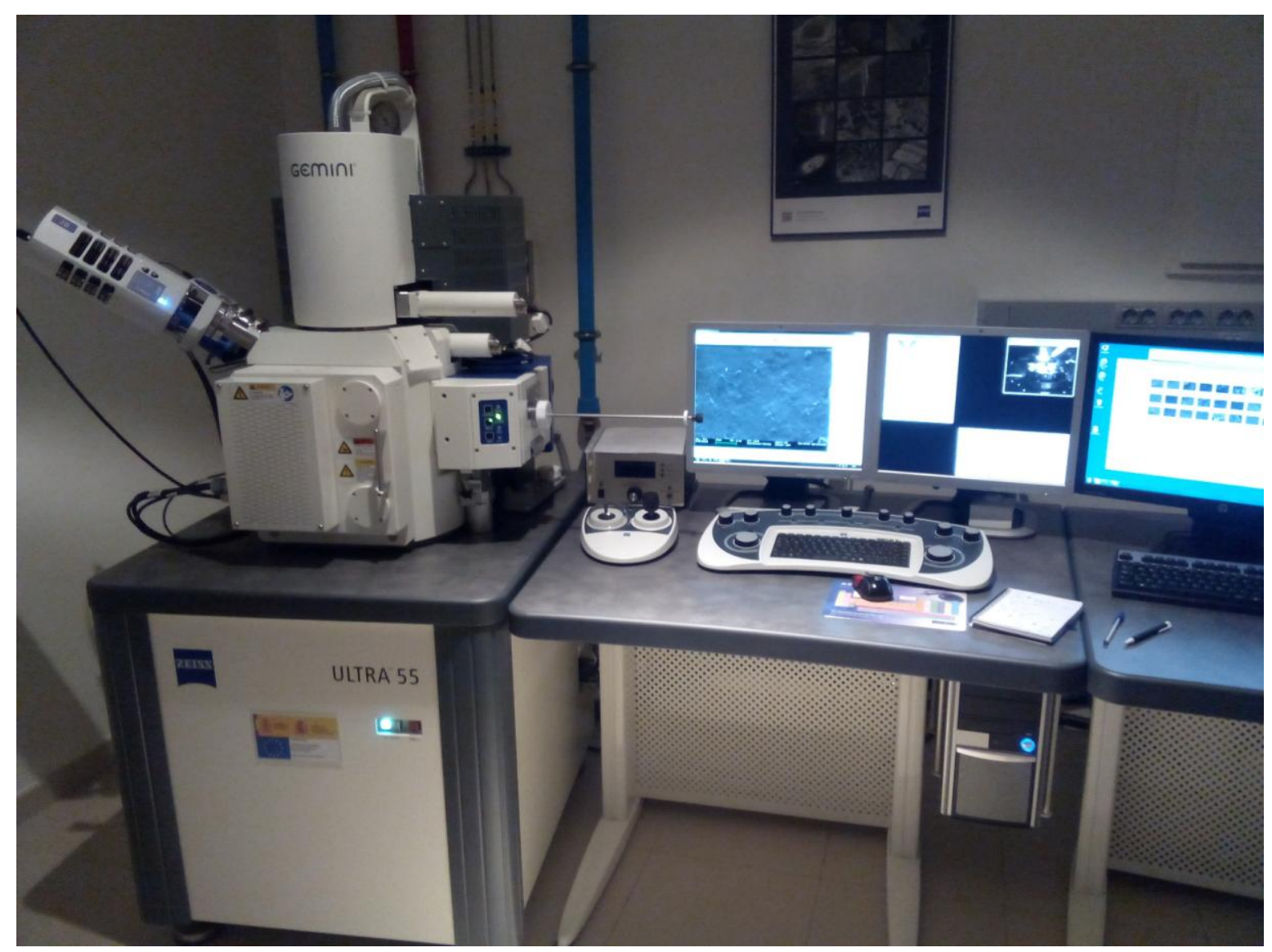

Figure 7.2.3.1. FESEM equipment used in this study.

Specimens' analysis procedure

The analytical conditions were: $1 \mathrm{kV}$ accelerating voltage. Samples were directly observed in order to avoid interference with the particulate structure of the coating element used for eliminating charging effects. 


\section{2. 4. Atomic Force Microscopy - nanoindentation (AFM - NI)}

\section{Principle}

Atomic force microscopy has contributed to ground-breaking research in the topography characterization of a wide range of materials and their mechanical properties. This technique is used in surface science laboratories to obtain images with atomic resolutions of $10^{-10} \mathrm{~m}$. This type of microscopy can be effectively applied in the field of conservation science to study the surface characteristic of an artistic sample as a non-destructive technique.

AFM - NI record the load applied on the tip as it moves across the surface, the interatomic potentials, force the cantilever to bounce up and down with the changes in contours of the surface. The tip is used as an indenter instead of being scanned laterally across the sample surface. Under such conditions a force curve-displacement curve (i.e. a plot of penetration depth vs. applied load) is recorded (Figure 7.2.4.1). With the force-displacement curve, the mechanical properties can be obtained by applying the Oliver and Pharr (O\&P) procedure. By measuring the deflection of the cantilever, the topographic features of the surface can be mapped out with the same tip used to obtain the force-displacement curve. A three dimensional image can finally be constructed by recording the cantilever motion in the Zdirection as a function of sample's X and Y position (Jagtap and Ambre 2006). In addition, the Young's modulus can be directly obtained from the imaging data.

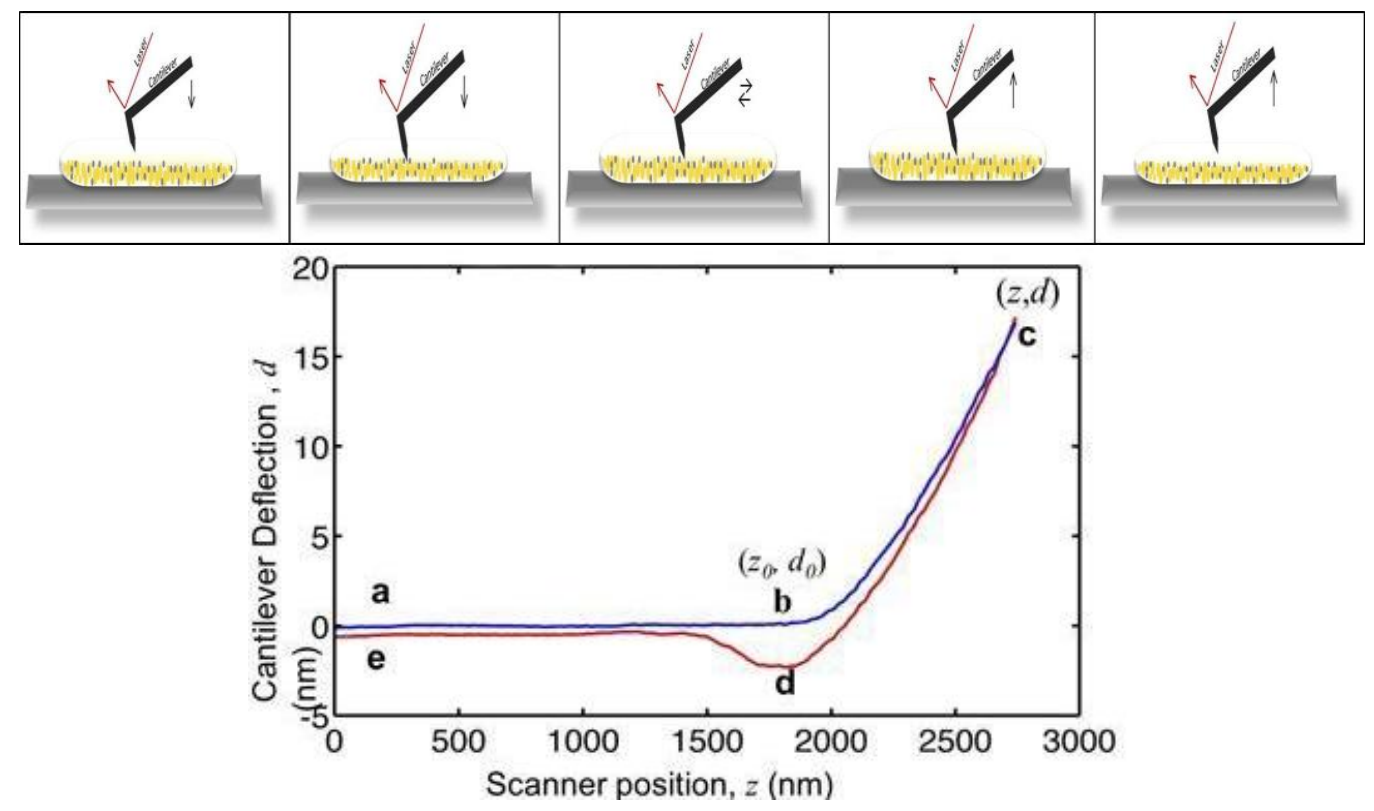

Figure 7.2.4.1. Illustration of AFM - NI and interpretation of the force-displacement curve. The top panel shows the motion of AFM cantilever driven by the piezo scanner. The vertical location of cantilever $z$ and the cantilever deflection signal $d$ is recorded during the process. The cantilever starts from point a, a few micrometers above the paint film. While approaching the cell, the sample indentation $\delta$ remains zero until it reaches point $b$, where the tip comes into contact with the paint film. The coordinates of point $\mathrm{b}$ in the plot are critical values for data analysis, denoted by $(z 0, d 0>)$. From $\mathrm{b}$ to $\mathrm{c}$, the cantilever indents into the paint film until the cantilever deflection reaches a set point, which is set to be the ratio between the targeted maximum indenting force and the cantilever spring constant. Once the deflection signal reaches the preset maximum value, the cantilever is then withdrawn from the paint film to point $d$, where it often be pulled downwards due to tip-sample adhesion, detaches from the paint film and returns to its initial location at e. 
Atomic force microscopy noise based imaging can be operated in three modes to suit particular applications: contact mode, non-contact mode and tapping mode (Farida et al. 2003).

Contact mode: In this mode, the probe is dragged across the surface (Takano et al. 1999). During scanning, a constant bend in the cantilever is maintained. A bend in the cantilever corresponds to displacement of the probe tip equal to $\mathrm{z}_{\mathrm{t}}$, relative to an undeflected cantilever in its initial position. The applied normal force is $\mathrm{p}=k \mathrm{z}_{\mathrm{t}}$, where $k$ is the cantilever spring constant. As the topography of the sample changes, the z-scanner moves the relative position of the tip or the sample to maintain a constant deflection. The motion of the $\mathrm{z}$-scanner is directly proportional to the sample topography. Using this feedback mechanism, the topography of the sample is mapped during scanning by assuming that the motion of the cantilever directly corresponds to the sample topography (Sawyer and Grubb 1996).

Non-contact mode: The cantilever is vibrated near its resonance frequency. The tip sample separation and amplitude area is of the order of $1-10 \mathrm{~nm}$. The tip oscillates just above the surface contamination layer. The resonance frequency and amplitude of oscillating cantilever changes as it approaches the surface due to the interactions with weak long-range forces thus essentially imaging the surface. Either the amplitude or the resonance frequency or the amplitude is maintained constant through the feedback loop and the scanner. The motion of the scanner is used to generate the topographic image. The spring constant ' $k$ ' is greater than the contact mode to reduce the tendency of the tip to be pulled to the surface by attractive forces.

Tapping mode: This mode is suitable for imaging of soft samples (Van den Berg et al. 1994). The resolution is similar to contact mode but the applied forces are lower. The cantilever oscillates near its resonance frequency, but the oscillation amplitude is $20-200 \mathrm{~nm}$ much greater than the non-contact mode. The tip makes contact with the surface for very short duration in each oscillation cycle. The amplitude of the cantilever is such that the probe maintains enough energy for the tip to tap through and back out of the surface.

\section{Equipment}

To determining the Young's modulus $(E)$, a Multimode AFM (Digital Instruments VEECO Methodology Group, USA) with NanoScope IIa controller was used equipped with a J-type scanner (max. scan size of $150 \times 150 \times 6 \mathrm{~mm}$ ) (Figure 7.2.4.2). The $E$ of samples was obtained in peak-force tapping mode with a Scan AsystR tip in the $5<500 \mathrm{MPa}$ range. The deflection and spring constant $\left(\sim 26 \mathrm{~N} \cdot \mathrm{m}^{-1}\right)$ of the cantilever (Olympus Tapping Mode etched silicon probes, Veeco Methodology group) were calculated by pressing the tip onto a Safire disc and performing a thermal tune, respectively. The tip radius was calculated by an indirect method using polystyrene sample with known $E$ of $2.7 \mathrm{GPa}$. 


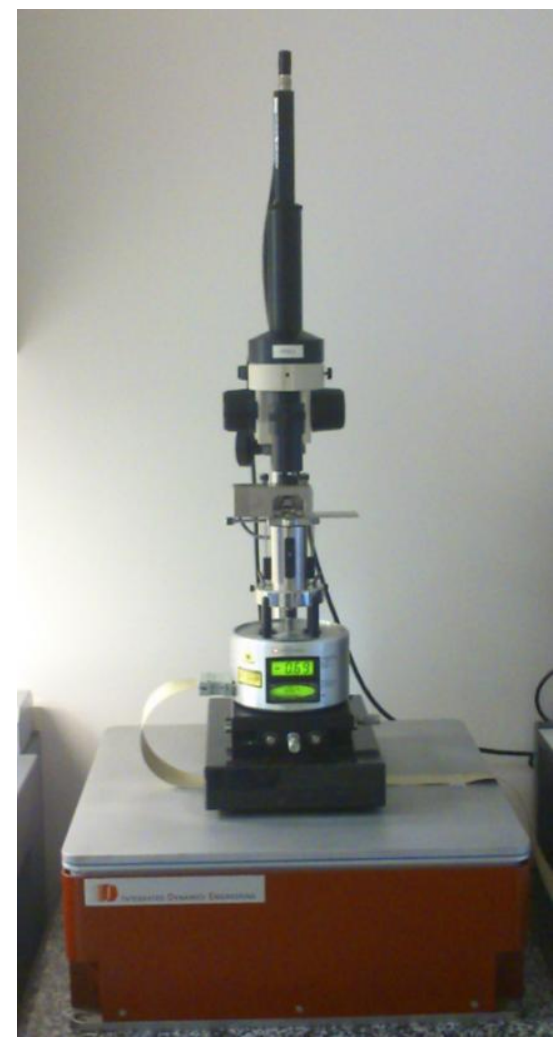

Figure 7.2.4.2. AFM-nanoindentation equipment used in this study.

\section{Specimens' analysis procedure}

$E$ is collected automatically by the instrument for each pixel of the image according to the Oliver-Pharr method. Images with scan sizes of $(1 \times 1) \mu \mathrm{m}$ and $(5 \times 5) \mu \mathrm{m}$ consisting of 256 lines by pixels, and taken at a scan rate of $0.4-0.5 \mathrm{~Hz}$, were made for each sample during one same scan that allow collecting morphological data and $E$. E measurements in different areas of each specimen sample were performed in order to evaluate the reproducibility of the results. 


\section{2. 5. References}

Byler, D.M., Susi, H. (1986) Examination of the Secondary Structure of Proteins by Deconvolved FTIR Spectra. Biopolymers, 25, 469-487.

Derrick, M.R., Stulik, D., Landry, J.M. (2000) Infrared spectroscopy in conservation science, Los Angeles: The Getty Publicaitons.

Dong, A., Huang, P., Caughey, W.S. (1990) Protein Secondary Structures in Water from Second-Derivative Amide I Infrared Spectra. Biochemistry, 29, 3303-3308.

Farida, B., Tatiana, D., Diethelm, J. (2003) Nanoscale mapping of the mechanical properties of polymer surfaces by means of AFM noise analysis: spatially resolved fibrillation of latex films. Langmuir, 19, 10247-10253.

Furlan, P.Y., Scott, S.A., Peaslee, M.H. (2007) FTIR-ATR Study of pH Effects on Egg Albumin Secondary Structure. Spectrosc Letters, 40, 475-482.

Goldstein, J., Newbury, D. E., Echlin, P., Joy, D. C., Romig Jr, A. D., Lyman, C. E., ... \& Lifshin, E. (2012). Scanning electron microscopy and X-ray microanalysis: a text for biologists, materials scientists, and geologists. Springer Science \& Business Media.

Goormaghtigh, E., Gasper, R., Benard, A., Goldsztein, A., Raussens, V. (2009) Protein secondary structure content in solution, films and tissues: Redundancy and complementarity of the information content in circular dichroism transmission and ATR FTIR spectra.

Guerra, I., Cardell, C. (2015) Optimizing use of the structural chemical analyzer (variable pressure FESEM-EDX raman soectroscopy) on micro-size complex historical paintings. Journal of Microsocopy, 260, 47-61.

Haris, P.I., Severcan, F. (1999) FTIR spectroscopic characterization of protein structure in aqueous and non-aqueous media. J Mol Catal B Enzym, 7, 207-221.

Havrdova, M., Polakova, K., Skopalik, J., Vuitek, M., Mokdad, A., Homolkova, M., Tucek, J., Nebesarova, J., Zboril, R. (2014) Field emission scanning electron microscopy (FESEM) as an approach for nanoparticle detection inside cells. Micron., 67, 149-154.

Hu, X., Kaplan, D., Cebe, P. (2006) Determining Beta-Sheet Crystallinity in Fibrous Proteins by Thermal Analysis and Infrarred Spectroscopy. Macromolecules, 39, 6161- 6170.

Jagtap, R.N., Ambre, A.H. (2006) Overview literature on atomic force microscopy (AFM): Basics and its important applications for polymer characterization. Indian Journal of Engineering \& Materials Sciences, 13, 368-384.

Kong, J., Yu, S. (2007) Fourier Transform Infrared Spectroscopic Analysis of Protein Secondary Structures. Acta Biochim Biophys Sinica, 39, 549-559.

Low, M.J.D., Baer, N.S. (1977) Application of infrared Fourier transform spectroscopy to problems in conservation. Studies in Conservation, 22, 116-128.

Pelton, J.T., McLean, L.R. (2000) Spectroscopic Methods for Analysis of Protein Secondary Structure Anal Biochem, 277, 167-176. 
Rajkhowa, R., Hu, X., Tsuzuki, T., Kaplan, D.L., Wang, X. (2012) Structure and Biodegradation Mechanism of Milled Bombyx mory Silk. Biomacromolecules, 13, 25032512.

Restivo, A., Degano, I., Ribechini, E., Pérez-Arantequi, J., Colombini, M.P. (2014) Fieldemission scanning electron microscopy and energy dispersive X-ray analysis to understand the role of tanni-based dyes in the degradation of historical wool textiles. Micros. Microanal., 20, 1534-1543.

Sawyer, L.C., Grubb, D.T. (1996) Polymer Microscopy, $2^{\text {nd }}$ edition, In: L.C. Sawyer, and D.T. Grubb Chapman and Hall, London.

Surewicz, W.K., Mantsch, H.H. (1988) New insight into protein secondary structure from resolution-enhanced infrared spectra. Biochim Biophys Acta, 952, 115-130.

Susi, H., Byler, D.M. (1986) Resolution-enhanced fourier transform infrared spectroscopy of enzymes. Methods Enzymol, 130, 290-311.

Taddei, P., Monti, P. (2005) Vibrational infrared conformational studies of model peptides representing the semicrystalline domains of Bombyx mori silk fibroin. Biopolymers, 7, 249258.

Takano, H., Kenseth, J.R., Wong, S.S., Brien, J.C.O., Porter, M.D. (1999) Chemical and biochemical analysis using scanning force microscopy. Chem Rev, 99, 2845-2890.

van den Berg, R., De Groot, H., Van Dijk, M.A., Denley, D.R. (1994) Atomic force microscopy of thin triblock copolymer films. Polymer, 35, 5778-5781.

van der Weerd, J., van Loon, A., Boon, J.J. (2005) FTIR studies of the Effects of Pigments on the Ageing of Oil. Stud Conserv, 50, 3-22.

Others:

EIGMA FESEM Operator's guide en01. www.iitk.ac.in/meesa/SEM/SEM_manual.pdf Consulted on: March, 2015 
8. RESULTS AND DISCUSSION 
8.1. Characterization of pigment-binder interactions in egg yolk tempera and egg yolk-oil emulsion reconstructed model paint specimens 


\subsubsection{Pigments}

As a preliminary step in the study of tempera paints pigments selected in this research were analyzed by FESEM-EDX.

Iron oxide red

Figure 8.1.1.1 shows the secondary electron image obtained for the iron oxide red pigment, which indicates that pigment particles have irregular morphology and are aggregate into larger masses of around $2-5 \mu \mathrm{m}$. Particles are heterogeneous in appearance with smooth or rough surfaces, and varies in shape and in range size from fine to coarse. These variety in particle shape and size depend on the geological environment where it was formed (Helwing, 2007). Red earths pigments frequently contain associated minerals like quartz, calcite or clays. X-ray spectrum obtained for iron oxide red pigment, exhibited characteristic emission lines of pigment at $0.60,6.30$ and $7.10 \mathrm{keV}$ (Figure 8.1.1.1).
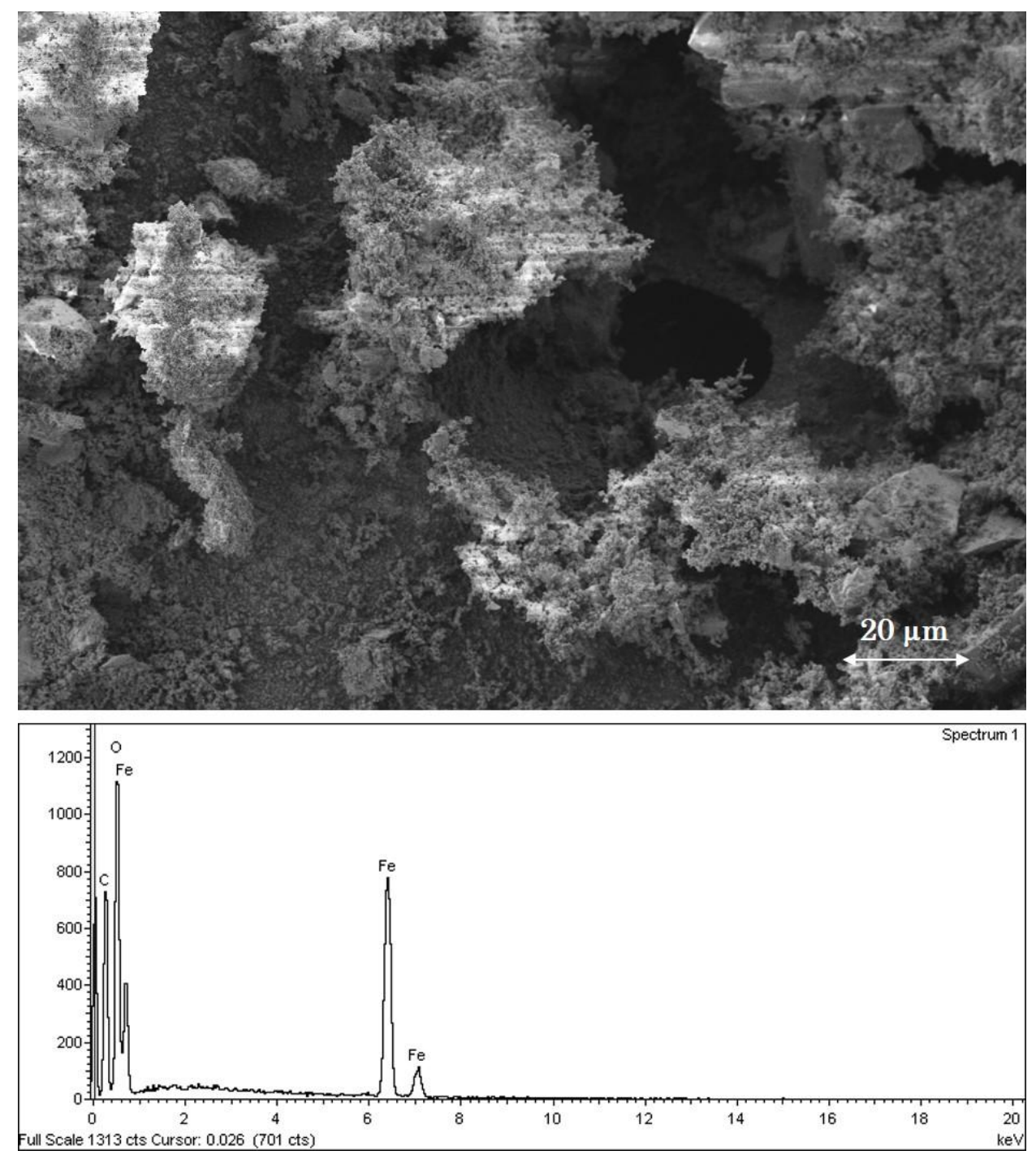

Figure 8.1.1.1. Secondary electron image obtained for iron oxide red pigment (up) and X-ray spectrum (down). 


\section{Massicot}

Massicot pigment secondary electron image shows that particles appear to be nearly amorphous, with thin plates morphology and approximate particle size of $5 \mu \mathrm{m}$ (Figure 8.1.1.2 up). Characteristic emission lines at 1.90, 2.40, 10.60 and $12.60 \mathrm{keV}$ in the X-ray spectrum are observed (Figure 8.1.1.2 down).
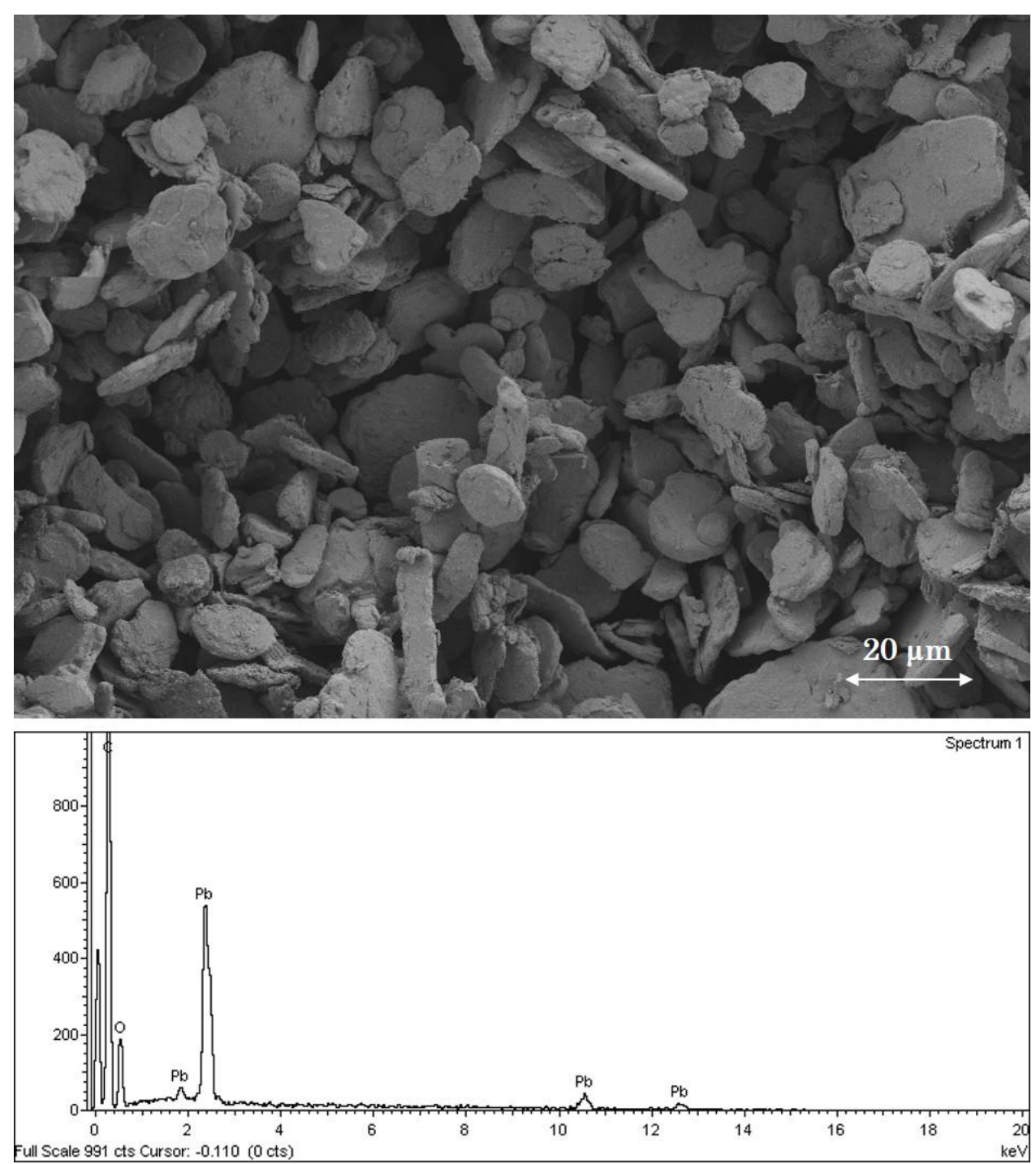

Figure 8.1.1.2. Secondary electron image obtained for iron oxide red pigment (up) and X-ray spectrum (down). 
Zinc white

Figure 8.1.1.3 (up) shows the secondary electron image obtained for zinc white pigment, which exhibit a hexagonal crystal system, where three morphological shapes can be distinguished: planar, isometric, and linear. Emission lines were identified in the X-ray spectrum at 1.00, 8.60 and $9.80 \mathrm{keV}$ no traces of other components added by the manufacture were identified (Figure 8.1.1.3 down) (Kühn, 1986).
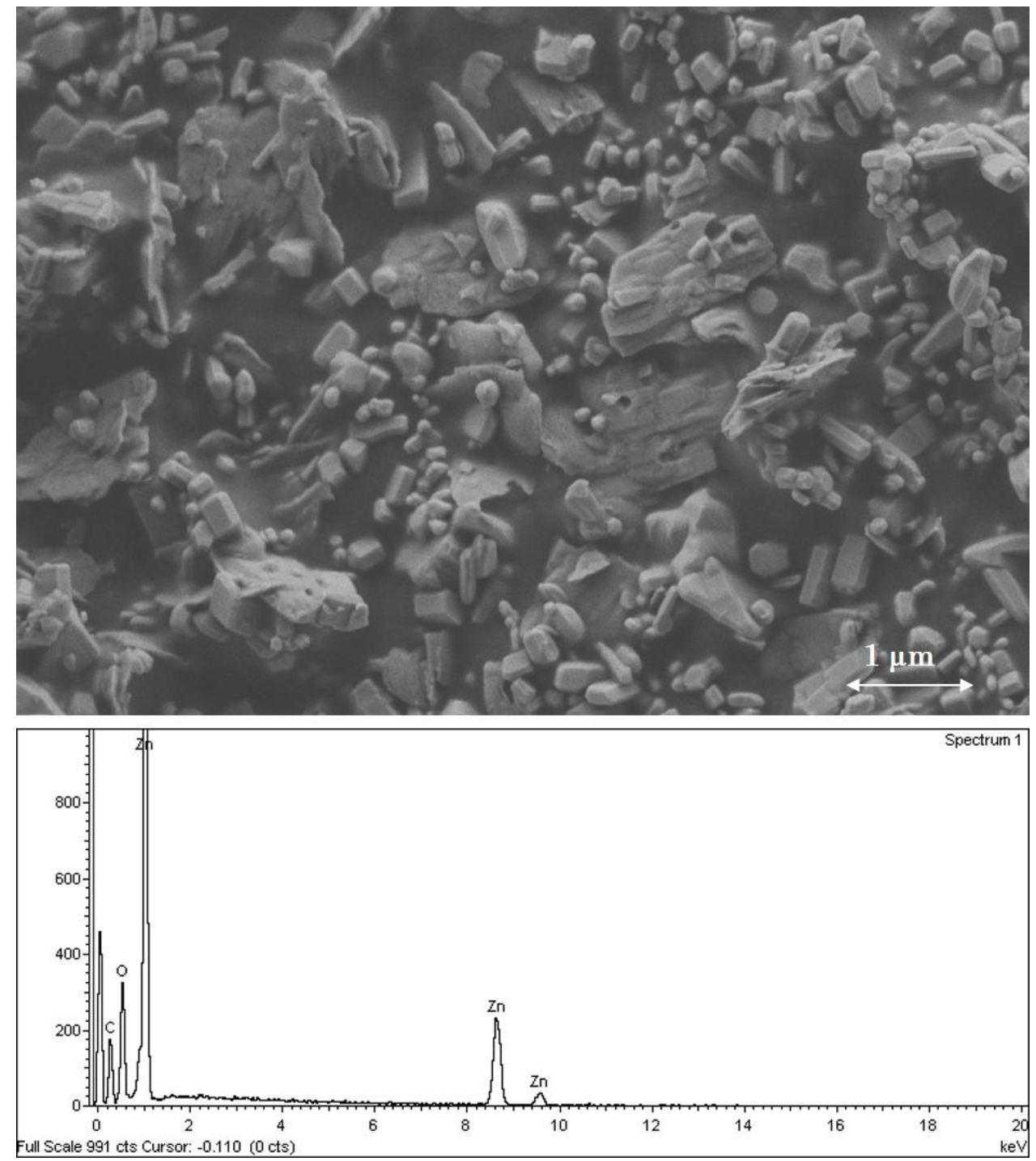

Figure 8.1.1.3. Secondary electron image obtained for zinc white pigment (up) and X-ray spectrum (down). 
Cadmium yellow

Cadmium sulfide exists in two crystalline forms (hexagonal and cubic type). Pigment particles size ranging from crystallites of $0.1-0.2 \mu \mathrm{m}$ to single particles $3-4 \mu \mathrm{m}$ in diameter. Amorphous cadmium sulfide is composed of individual particles or agglomerated which often contain centres with a fused appearance (Figure 8.1.1.4 up). Figure 8.1.1.4 (down) shows the X-ray spectrum of cadmium yellow pigment. This pigment is a cadmium sulphide. Characteristic emission lines of this pigment, namely, $\mathrm{K}_{\alpha}(\mathrm{S})$ at $2.31 \mathrm{keV}$, and $\mathrm{L}_{\alpha}(\mathrm{Cd}), \mathrm{L}_{\beta}(\mathrm{Cd})$ and $\mathrm{L}_{\gamma}(\mathrm{Cd})$ emission lines at 3.13, 3.32 and $3.72 \mathrm{keV}$, respectively, are easily recognized. Interestingly, $\mathrm{K}_{\alpha}$ and $\mathrm{K}_{\beta}$ emission lines of $\mathrm{Zn}$ are also identified at 8.64 and 9.57 $\mathrm{keV}$. It has been reported that many cadmium sulphide pigments consist of zinc sulphide in solid solution with the cadmium (Fiedler and Bayard, 1986). Al and Ti also identified are associated to other sophistications of the manufacturer.
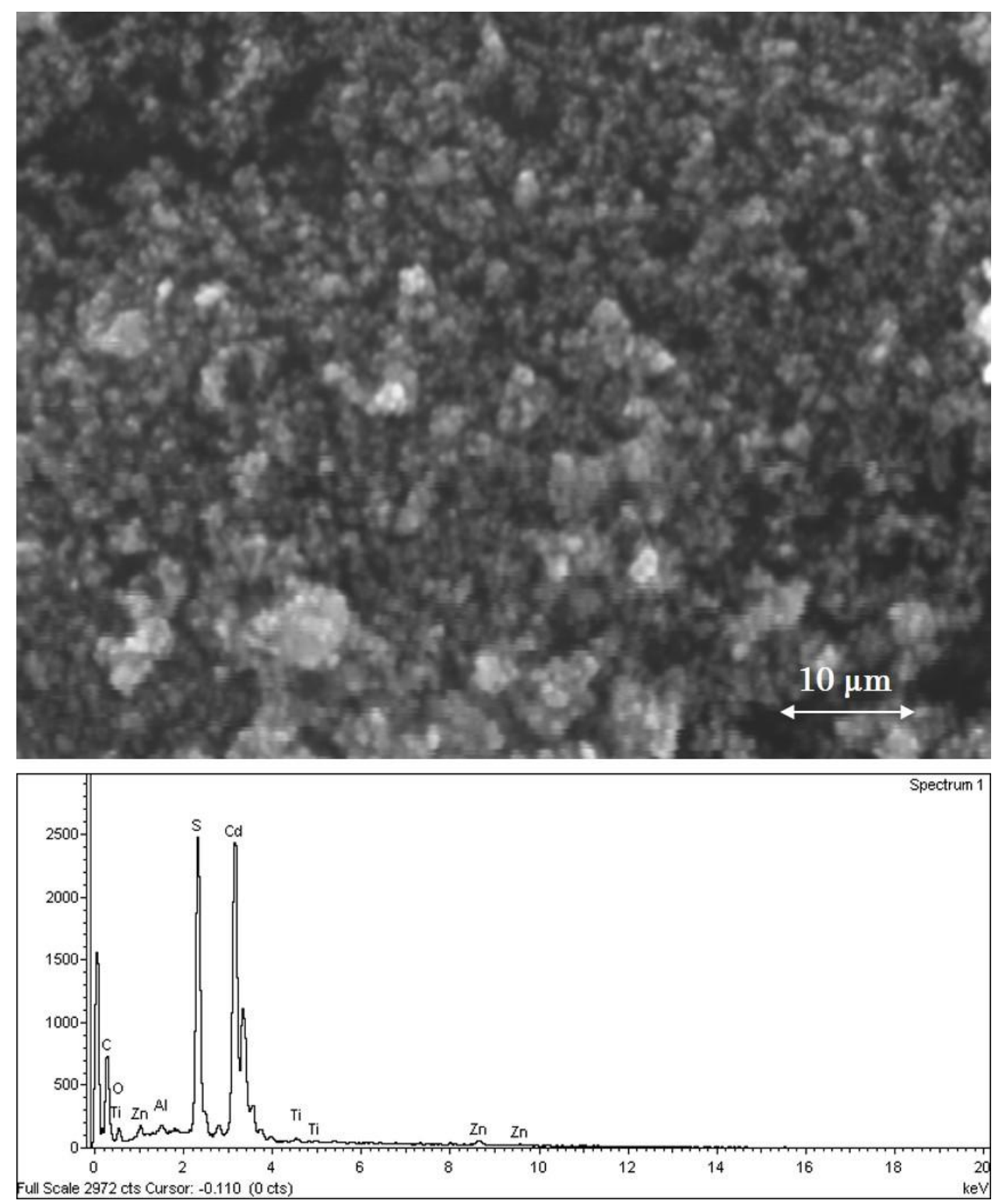

Figure 8.1.1.4. Secondary electron image obtained for cadmium yellow pigment (up) and X-ray spectrum (down). 


\subsubsection{Field emission scanning electron microscopy (FESEM)}

The 30 and $75 \%$ wt pigment content reconstructed model tempera paint specimens were examined by FESEM in order to determine the morphological characteristics at micro- and nanoscale of the surface and cross-sections. Morphology of the paint films are determined firstly by the type of pigment and binder. Is important to mention that the pigment volume concentration (PVC) as well as the particle size distribution and the ability of the pigment for aggregate and agglomerate are determining factors not only of morphology but also of other important paint properties such as gloss, scrub resistance, tensile strength, hiding power, etc. In particular, a low content in binding medium leads the PVC to exceed the CPVC (defined as the point at which all air surrounding pigment particles has been replaced with binding medium) and voids around individual pigment particles are formed. The presence of these air gaps has important consequences in the behavior of the paint film. Thus, in paint films with high PVC individual pigment particles protrude above the surface of the binding medium resulting in greater diffuse reflection and concomitantly in an increase of the matteness of the paint. The presence of air gaps surrounding pigment particles also affects reflectance due to variations in refractive index between air, binding medium and pigment particles. Paint films with high PVC are more porous due to the presence of air within the paint film. This lower amount of binding medium has a direct impact on the cohesion of the film and in the strength and extendibility of the paint film.

On the other hand, the pigment distribution is determined by the interaction of the pigment with the colloidal binding medium, so that if the binder has not the suitable ability for forming a stable micellar dispersion with the pigment grains, they tend to aggregate and form clusters in the paint (Tiarks et al., 2003).

\subsubsection{Egg yolk tempera reconstructed model paint specimens}

Egg yolk

Egg yolk has a variety of multiscale structures that are suspended in a clear yellow and continuous fluid phase (plasma) (Mine and Zhang, 2013; Chang et al., 1977). These complex structures are determinant in the formation of egg yolk based paint layers. In aqueous solution, the proteins adopt a spatial arrangement in which the hydrophilic groups establish linkages by hydrogen-bonding with water. During drying of the pictorial film water from the plasma and that from the pigment dispersion that is added to the egg yolk evaporates until an equilibrium level with the vapor pressure in the environment is reached. The loss of water results in a rearrangement of the entire binder system in which the more hydrophobic features (granules and spheres tend to aggregate) and the protein molecules in the plasma fill the gaps left by the water evaporation losing partially or completely its tertiary and secondary structures and aggregate and reticulate forming a continuous solid phase. 
Figure 8.1.2.1.1, shows the FESEM secondary electron image of egg yolk (Y) film specimen. The surface (see Figure 8.1.2.1.1a) of the film presents an appearance uniform as result of the slow drying of the plasma phase. Nevertheless, the cross-section (see Figure 8.1.2.1.1b) enables the recognition of spheres $(\sim \varnothing: 10 \mu \mathrm{m})$ and granules $(\sim \varnothing: 2 \mu \mathrm{m})$ microstructural features (see arrows) of egg yolk that are associated with insoluble dense protein-lipid particles (Li-Chang et al., 1995).

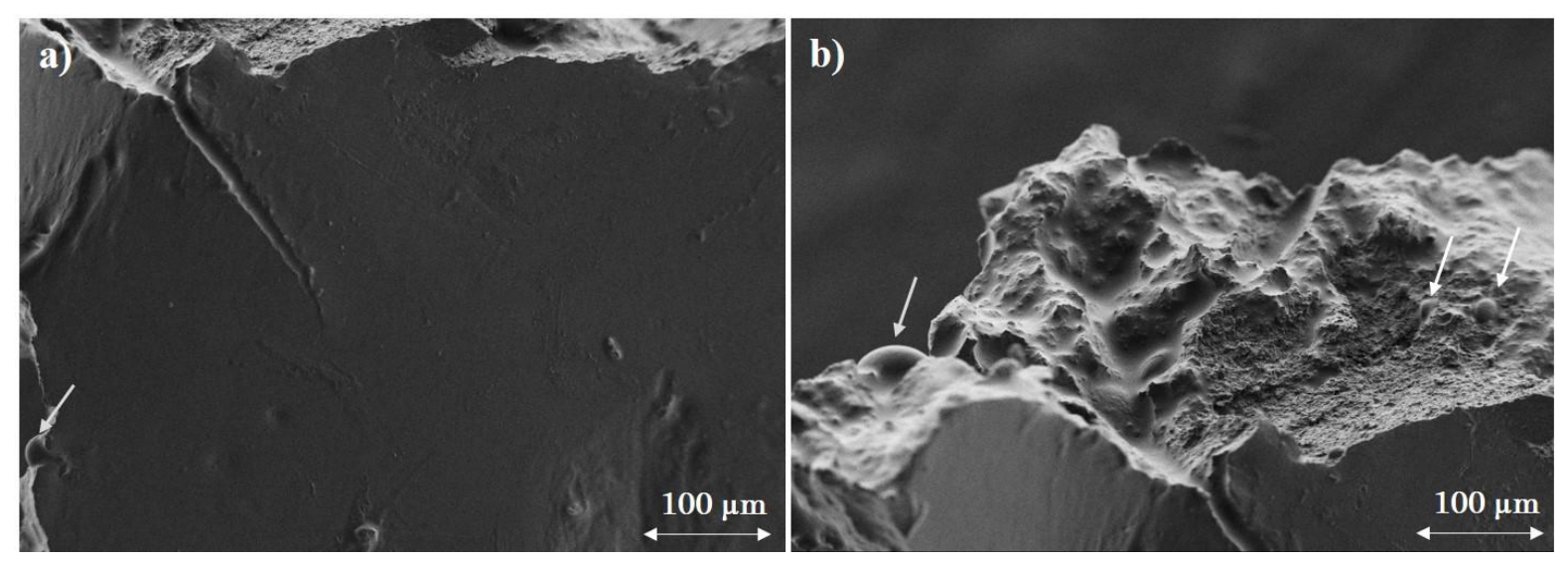

Figure 8.1.2.1.1. Secondary electron images showing the surface and the cross-section of pure egg yolk (Y) film specimen.

\section{Egg yolk tempera reconstructed model paint specimens}

Drying process of egg yolk paint films involves the formation of a protein network from the plasma accompanied by coalescence and reticulation of glycerolipids that results in a continuous medium that binds the pigment grains (Karpowicz, 1981). During the rearrangement that takes place in the plasma, protein molecules adopt more unordered conformations with major chemical activity. These unordered proteins molecules may react with other molecules present in the paint films as proteins, triglycerides, metal ions solubilized from pigment grains, etc. (Prestrelski et al., 1993; Boehm and Abaturov, 1977). In parallel, the different microstructural features conforming the egg yolk the more hydrophobic structures in the egg yolk such as low-density lipoproteins (LDLs) can anchor the metal centers at pigment surface with carboxylate and phosphate groups in their outer livetins, proteins and phospholipids (PLs) via coordinative bonds (Anton and Gandemer, 1997; Anton, 2013). Moreover, evaporation of water forces granules and other microscopic structures in egg yolk to be closer, promoting formation of clusters of microparticles aggregated by intermolecular linkages, which are precursors of further coalescence and complex reticulation of proteins, neutral lipids (NLs) and PLs (Dalgleish, 2004; Duce et al., 2012, 2013).

Figure 8.1.2.1.2 shows the micromorphology of $\mathrm{Y} @ \mathrm{Fe}_{30}$ and $\mathrm{Y} @ \mathrm{Fe}_{75}$ reconstructed tempera paint films prepared at $30 \mathrm{wt} \%$ (Figure 8.1.2.1.2a) and $75 \mathrm{wt} \%$ (Figure 8.1.2.1.2b) of pigment weight composition, respectively. In comparison with the $\mathrm{Y}$ (control specimen), the $\mathrm{Y} @ \mathrm{Fe}$ reconstructed paint specimens show a much less uniform surface at microscale with abundant pigment grains, surrounded by the binder, that protrude the surface forming aggregates of increasing size (arrows $\mathrm{a}$ and $\mathrm{b}$ ) on increasing the content in pigment in specimen $\mathrm{Y} @ \mathrm{Fe}_{75}$. The presence of intergranular spaces in the $\mathrm{Y} @ \mathrm{Fe}_{30}$ film and pores and microfissures in the 
$\mathrm{Y} @ \mathrm{Fe}_{75}$ film suggests high PVC over the CPVC. Granules and spheres alone (arrows c) or aggregated in clusters (arrow d) are also observed in both reconstructed model paint films. In addition, deformation of some spherical features, which show coalescence by lateral contact is also observed in the $\mathrm{Y} @ \mathrm{Fe}_{75}$ (circle).
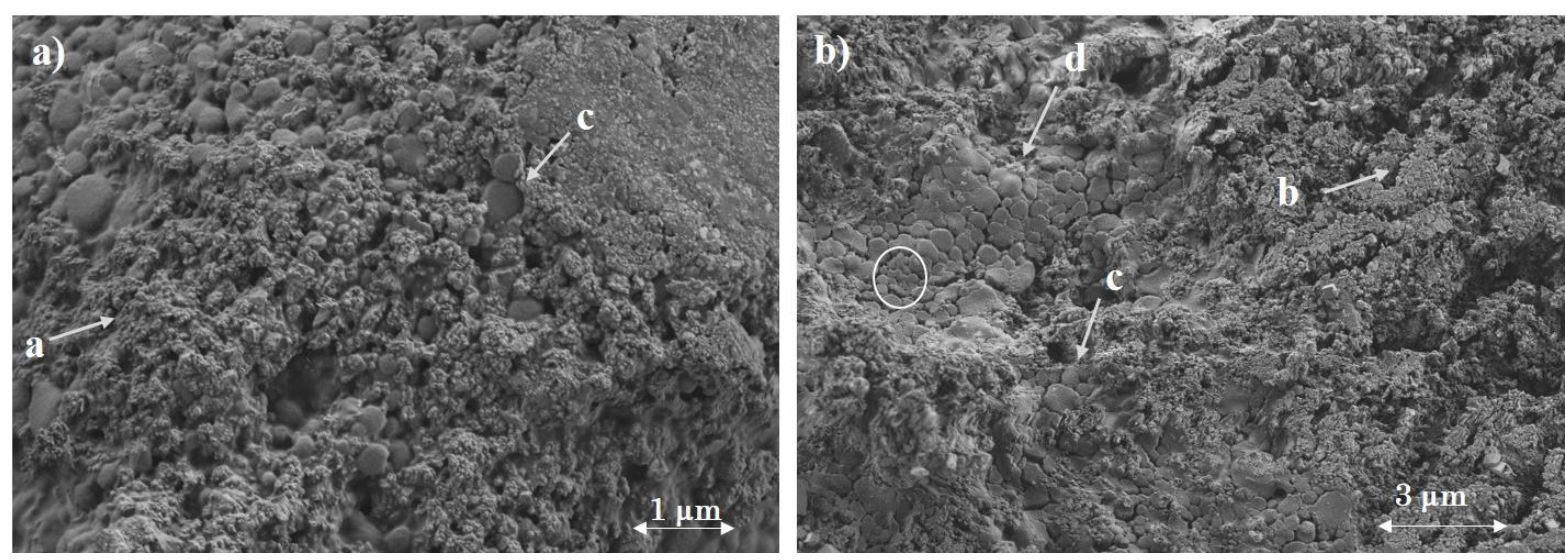

Figure 8.1.2.1.2. Secondary electron images showing the surface of the a) $\mathrm{Y} @ \mathrm{Fe}_{30}$ and b) $\mathrm{Y} @ \mathrm{Fe}_{75}$ reconstructed model tempera paint specimens.

Figure 8.1.2.1.3 shows, secondary electron images of the surface (Figure 8.1.2.1.3a) and cross-section (Figure 8.1.2.1.3b) of $\mathrm{Y} @ \mathrm{Pbm}_{30}$. The surface of this film shows some smooth areas containing prevalently dried egg yolk plasma alternated with aggregates of pigment embedded in plasma and alternated with granules and spheres. Denser protein-lipid particle clusters are observed (see Figure 8.1.2.1.3a arrows) as in the Y@Fe paint specimens. Due to the higher density of this pigment the film clearly has a major content in binding medium. Thus, the pigment grains hardly are seen in the cross-section (Figure 8.1.2.1.3b). Formation of a cohesive cross-linked network structure of egg yolk materials (NLs, proteins, PLs, cholesterol, and cholesterol oxidative products (COPs)) forming pseudo-polygonal voids that fills the inter-pigment spaces in the $\mathrm{Y} @ \mathrm{Pbm}_{75}$ specimen. The formation of this network is associated to the coalescence process taking place between micro- and nanoparticles and the aggregation of molecules soluble in plasma. The hydrophobic interactions between long hydrocarbon chain moieties and head groups in the amphiphiles play an essential role, which favors a microphase separation between the hydrophobic and hydrophilic substances with the formation of many smaller closed interfaces (Andersson and Porath, 1986; Wang et al., 2012). 

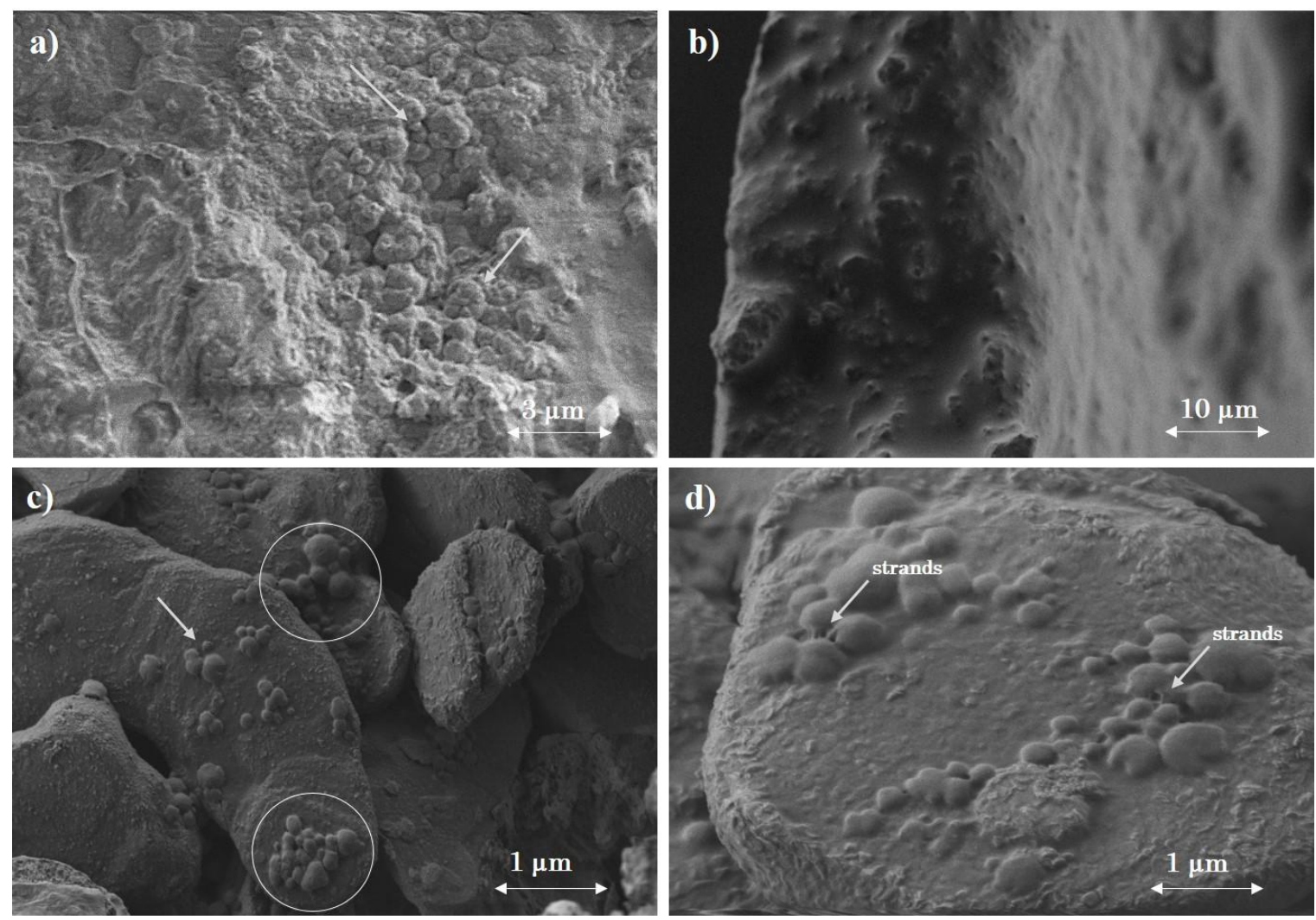

Figure 8.1.2.1.3. Secondary electron images obtained in: a) and b) $\mathrm{Y} @ \mathrm{Pbm}_{30}$, and c) $\mathrm{Y} @ \mathrm{Pbm}_{75}$ reconstructed model tempera paint specimens.

While the Y@Pbm 30 paint film exhibits a morphology typical of films with suitable PVC with scarce voids around pigment grains (Fig. 8.1.2.1.3 a and b), the low content of egg yolk in combination with the high density and large size of massicot grains in the $\mathrm{Y} @ \mathrm{Pbm}_{75}$ (Figure 8.1.2.1.3c) has resulted in the formation of a film scarcely cohesive. As it can be seen, the pigments grains have been easily dispersed when the film is handled with the scalpel for placing in the microscope chamber. Insoluble denser protein-lipid nanoparticles (16-60 nm) as LDLs and high-density lipoproteins (HDLs) are observed in the image anchored to the surface of the pigment grains in this last film (see circles). The features observed are associated to a complex solid network composed mainly of proteins but also of PLs (as put in evidence by the aggregates of granules and spheres adhered to the pigment grains) and, at lesser extent, of NLs, that cover the surface of the pigment grains, formed during the evaporation of water during the drying process. It seems like components present in the hydrophilic plasma creates a layer by direct anchoring of its constituents to the solid pigment surface during the drying process. It can be seen strands (elongated tubular aggregates), from proteinaceous materials that connect neighboring granules (Figure 8.1.2.1.3d).

Figure 8.1.2.1.4 shows the secondary electron images obtained in $\mathrm{Y} @ \mathrm{Zn}_{30}$ and $\mathrm{Y} @ \mathrm{Zn}_{75}$ reconstructed model paint specimens. In both cases a compact film is formed with pigment grains densely packed and surrounded by dried egg plasma. In the $\mathrm{Y} @ \mathrm{Zn}_{30}$ specimen (Figure 8.1.2.1.4a and b) the binder matter is almost completely filling the interstices between pigment grains thus denoting a proper PVC. Granules are also observed that protrude to the surface of the film (see square in Figure 8.1.2.1.4b). The formation of a cohesive cross-linked 
network structure of egg materials connected by strands is also observed (see arrows in Figure 8.1.2.1.4b).

In $\mathrm{Y} @ \mathrm{Zn}_{75}$ reconstructed model paint film specimens a rougher and porous appearance of the surface due to the abundant presence of pigments grains can be observed (Figure 8.1.2.1.4c). In contrast with the $\mathrm{Y} @ \mathrm{Zn}_{30}$ specimen in the $\mathrm{Y} @ \mathrm{Zn}_{75}$ pores and microfissures in the surface can be seen. Spherical granules, associated to insoluble denser protein particles, are eventually trapped between the pigment grains (see squares in Figure 8.1.2.1.4d).
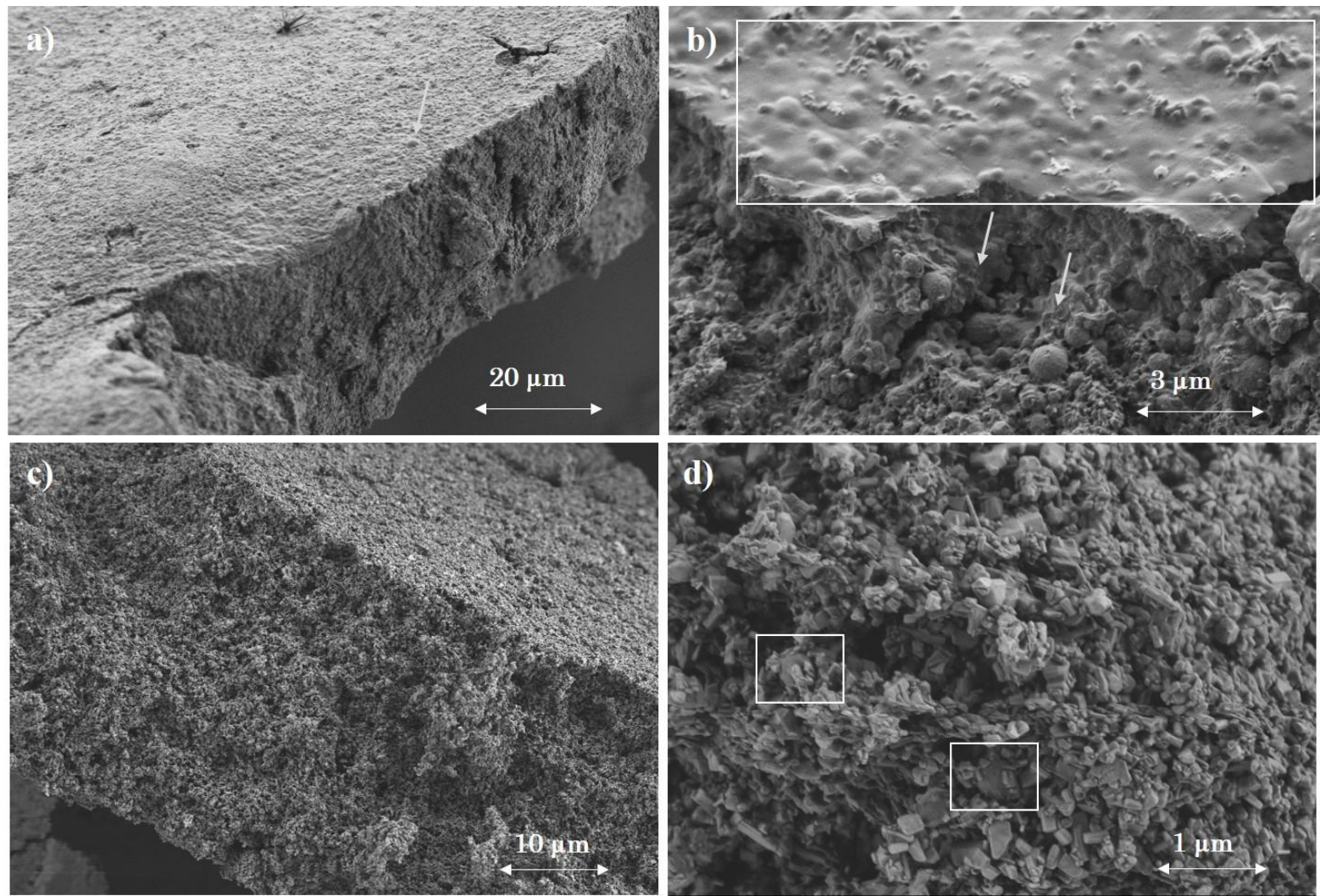

Figure 8.1.2.1.4. Secondary electron images obtained for the a) surface and b) cross-section of $\mathrm{Y} @ \mathrm{Zn}_{30}$, and c) surface and d) cross-section of $\mathrm{Y} @ \mathrm{Zn}_{75}$ reconstructed model paint specimens.

Figure 8.1.2.1.5 shows the secondary electron image of the surface and cross-section of the $\mathrm{Y} @ \mathrm{Cd}_{30}$ (Figure 8.1.2.1.5 a and b) and $\mathrm{Y} @ \mathrm{Cd}_{75}$ (Figure 8.1.2.1.5 c and d) reconstructed model paint specimens. Surface of the $\mathrm{Y} @ \mathrm{Cd}_{30}$ specimen exhibits a texture similar to that of pure egg yolk due to the higher content in egg yolk. The cross section shows a film with suitable PVC. Pigment grains are bound by the dried egg yolk also forming a compact film in the $\mathrm{Y} @ \mathrm{Cd}_{75}$ reconstructed paint film (Figure 8.1.2.1.5d) but some intergranular spaces are here observed. Abundant pigment grains with sizes below $1 \mu \mathrm{m}$, are recognized protruding in the surface of the $\mathrm{Y} @ \mathrm{Cd}_{75}$ specimen. (Figure 8.1.2.1.5b). A few spheres and granules, typical multiscale structures of egg yolk can also be identified randomly dispersed between the pigment grains in $\mathrm{Y} @ \mathrm{Cd}_{75}$ specimen (Fig. 8.1.2.1.5c, see circles). 

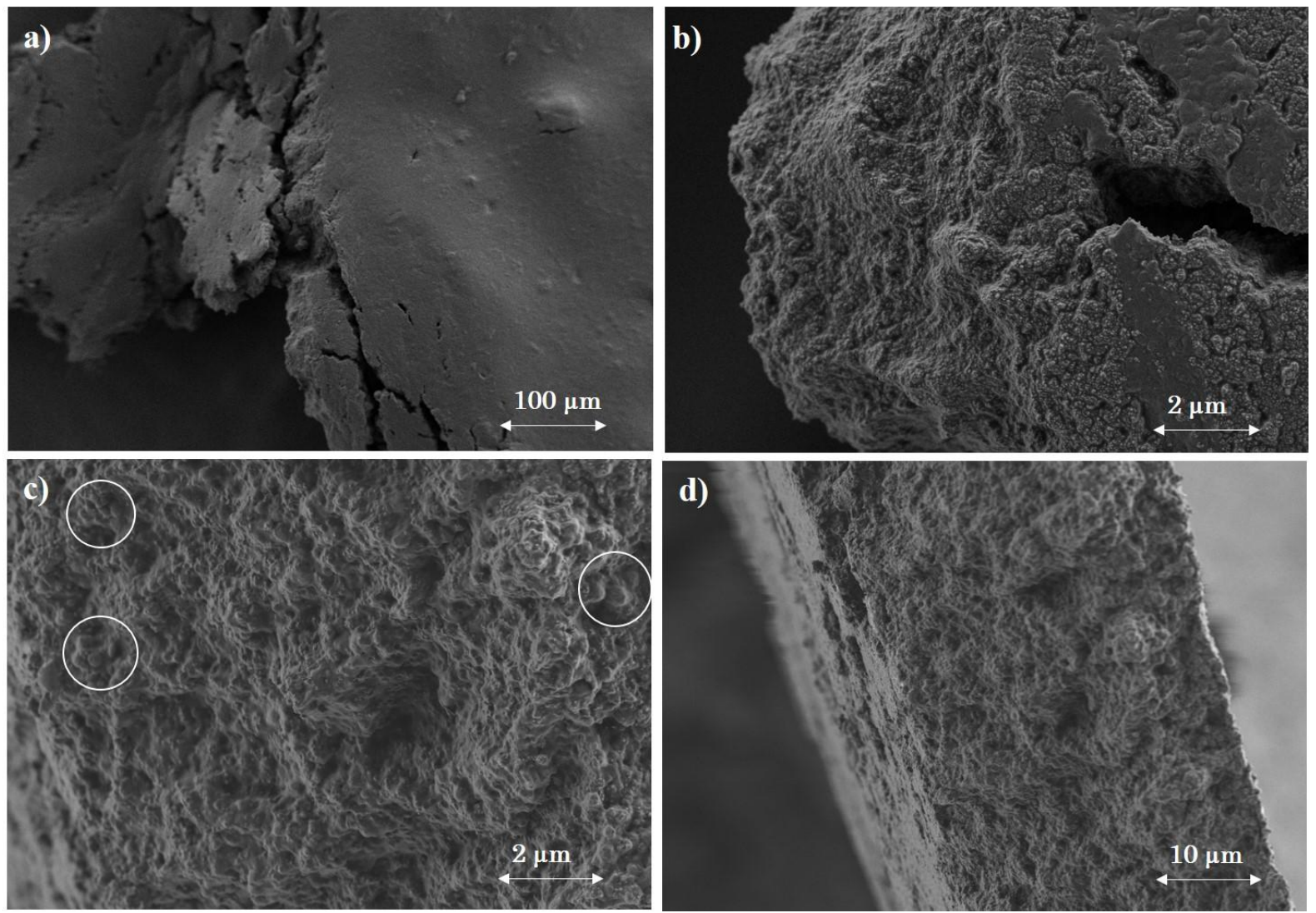

Figure 8.1.2.1.5. Secondary electron images obtained for the a) surface and b) cross-section of $\mathrm{Y} @ \mathrm{Cd}_{30}$, and c) surface and d) cross-section of $\mathrm{Y} @ \mathrm{Cd}_{75}$ reconstructed model paint specimens. 
8.1.2.2. Egg yolk-oil emulsion reconstructed model paint specimens.

Egg yolk-oil emulsion

Egg yolk-oil emulsion (YO) film showed a more irregular surface than that of the egg yolk film (Figure 8.1.2.2.1 a and b). Cracks are formed as consequence of the stretching forces that take place as consequence of the dehydration-oxidation-polymerization processes associated to the drying of the oil forming the film, which results in the macroscopical shrinkage of the film. The spheres and granules (see arrows in Figure 8.1.2.2.1b) are hardly identified due to the presence of linseed oil.
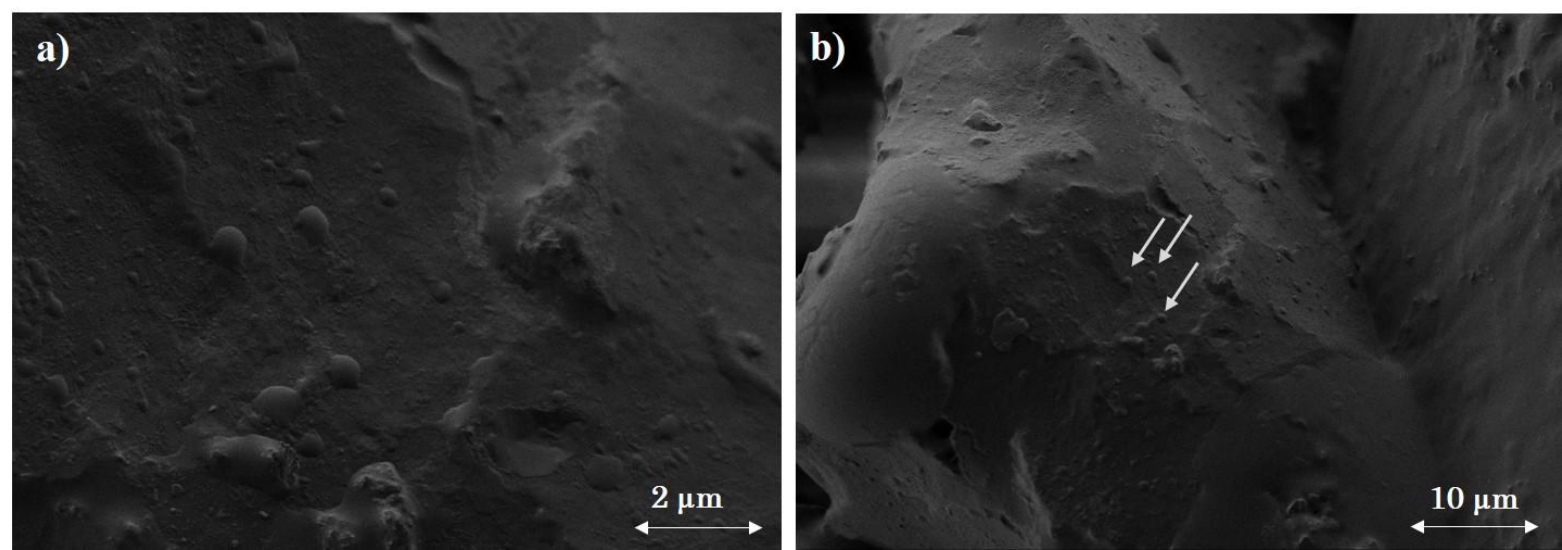

Figure 8.1.2.2.1. Secondary electron images showing the surface and the cross-section of pure YO@BLANK film.

Egg yolk-oil emulsion reconstructed model paint specimens

Figure 8.1.2.2.2a, shows the secondary electron image obtained for the surface of the YO@ $\mathrm{Fe}_{30}$ reconstructed paint model specimen, where a continuous film surface with some pigment protrusions can be observed. The $\mathrm{YO} @ \mathrm{Fe}_{75}$ specimen exhibited a surface with some poorly bound pigment particles can be observed (Figure 8.1.2.2.2b). In the cross-section image (Figure 8.1.2.2.2c) voids around the pigment aggregates are observed. They could be associated with lack of homogeneity of the oil-egg emulsion. Multistructural features present in egg yolk are hardly identified due to the presence of linseed oil. 

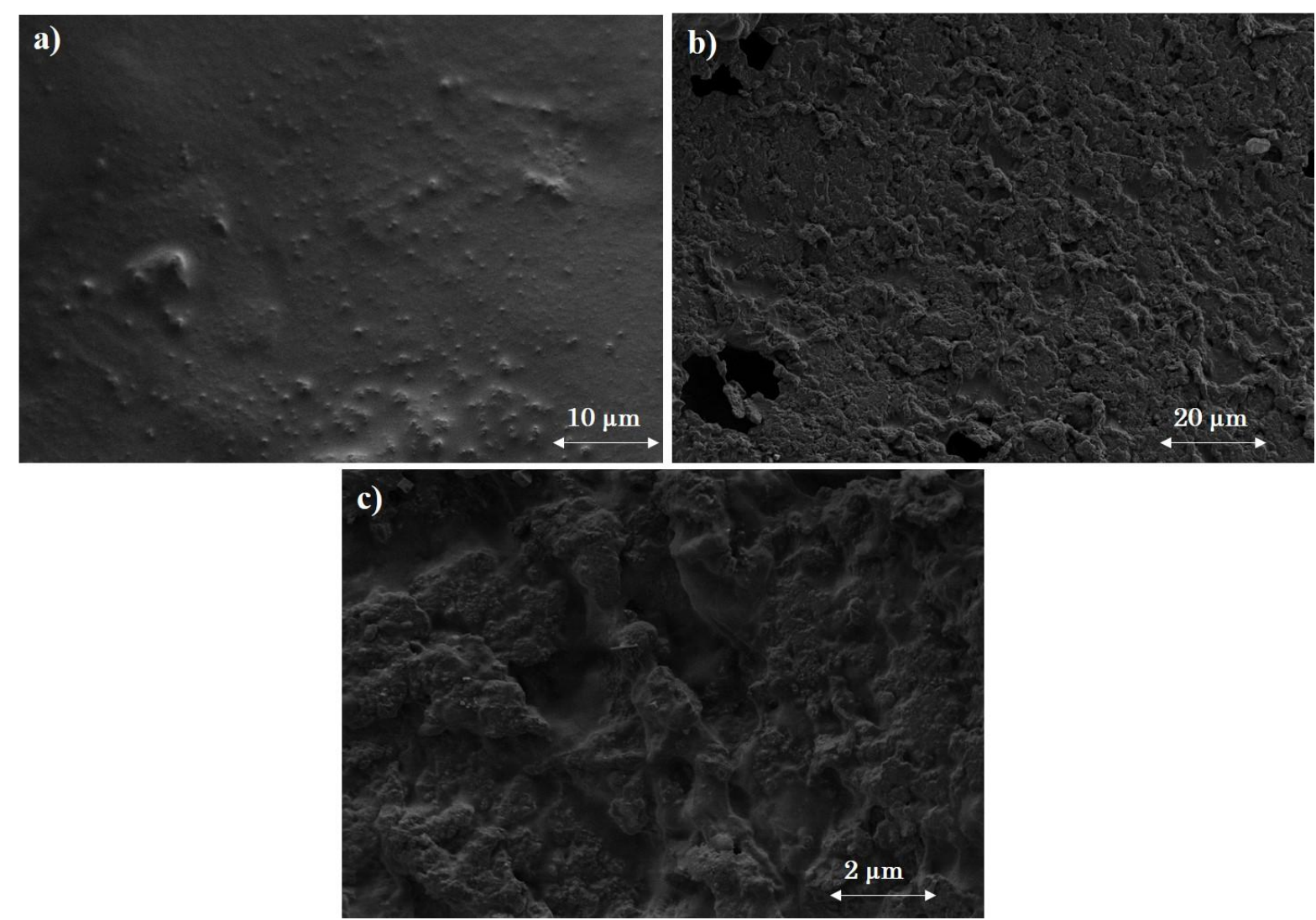

Figure 8.1.2.2.2. Secondary electron images showing the surface of the a) $\mathrm{YO} @ \mathrm{Fe}_{30}$ and b) and c) $\mathrm{YO} @ \mathrm{Fe}_{75}$ reconstructed model egg-oil emulsion paint specimen.

The YO@ $\mathrm{Pbm}_{30}$ specimen exhibited a surface with many heavy pigment grains aggregates (arrows in Figure 8.1.2.2.3a). Similarly, to the egg tempera specimen prepared with massicot, the high density of this pigment in the YO@ $\mathrm{Pbm}_{75}$ determined a high PVC over the CPVC for this paint film that resulted in a low cohesion that hamper the handling of the film as it can be seen in the image (Fig. 8.1.2.2.3b) where the pigment grains are completely disaggregated from the film. Figure 8.1.2.2.3c shows a massicot pigment grain partially covered by the binding medium (see square). Some spheres and granules were also observed anchored to the surface of the pigment grains (see arrow in Figure 8.1.2.2.3c). 

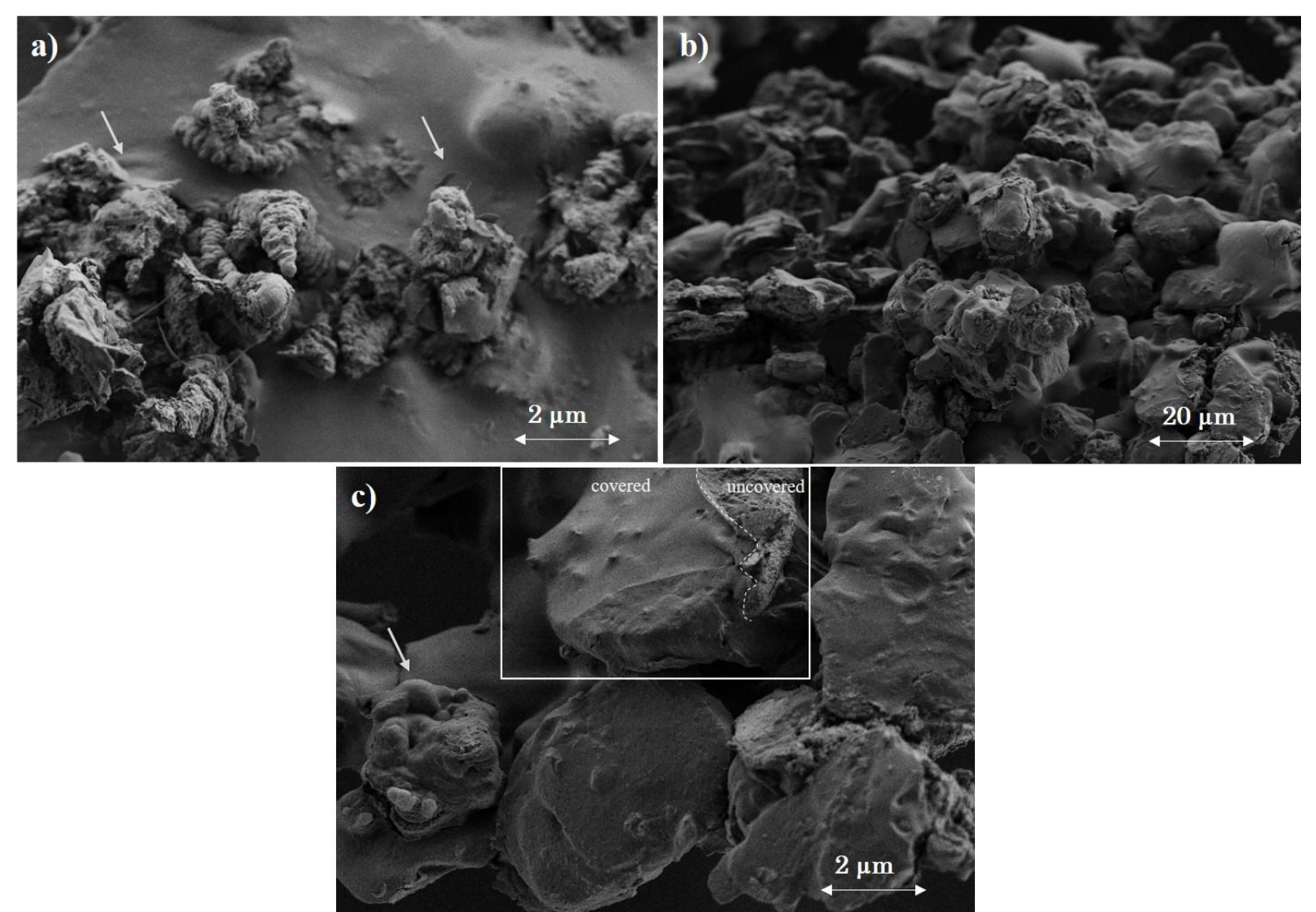

Figure 8.1.2.2.3. Secondary electron images showing the surface of the a) $\mathrm{YO} @ \mathrm{Pbm}_{30}$ and b) and c) $\mathrm{YO} @ \mathrm{Pbm}_{75}$ reconstructed model tempera paint specimens.

The surface of the $\mathrm{YO} @ \mathrm{Zn}_{30}$ and $\mathrm{YO} @ \mathrm{Zn}_{75}$ reconstructed model paint specimen was protruded by pigment grains denoting a notable PVC (Figure 8.1.2.2.4a a, b and c) but not enough for explaining the appearance of some crack caused by the manipulation of the film with scalpel. The latter is rather justified by the tendency of zinc ions in the white zinc to early react with the fatty acids released from the linseed oil on ageing, leading to the formation of zinc soaps, which result in stiffer films (Osmond, 2012). Features associated to free fatty acids, were identified in the surface of the $\mathrm{YO} @ \mathrm{Zn}_{75}$ specimen (see arrows in Figure 8.1.2.2.3c). 

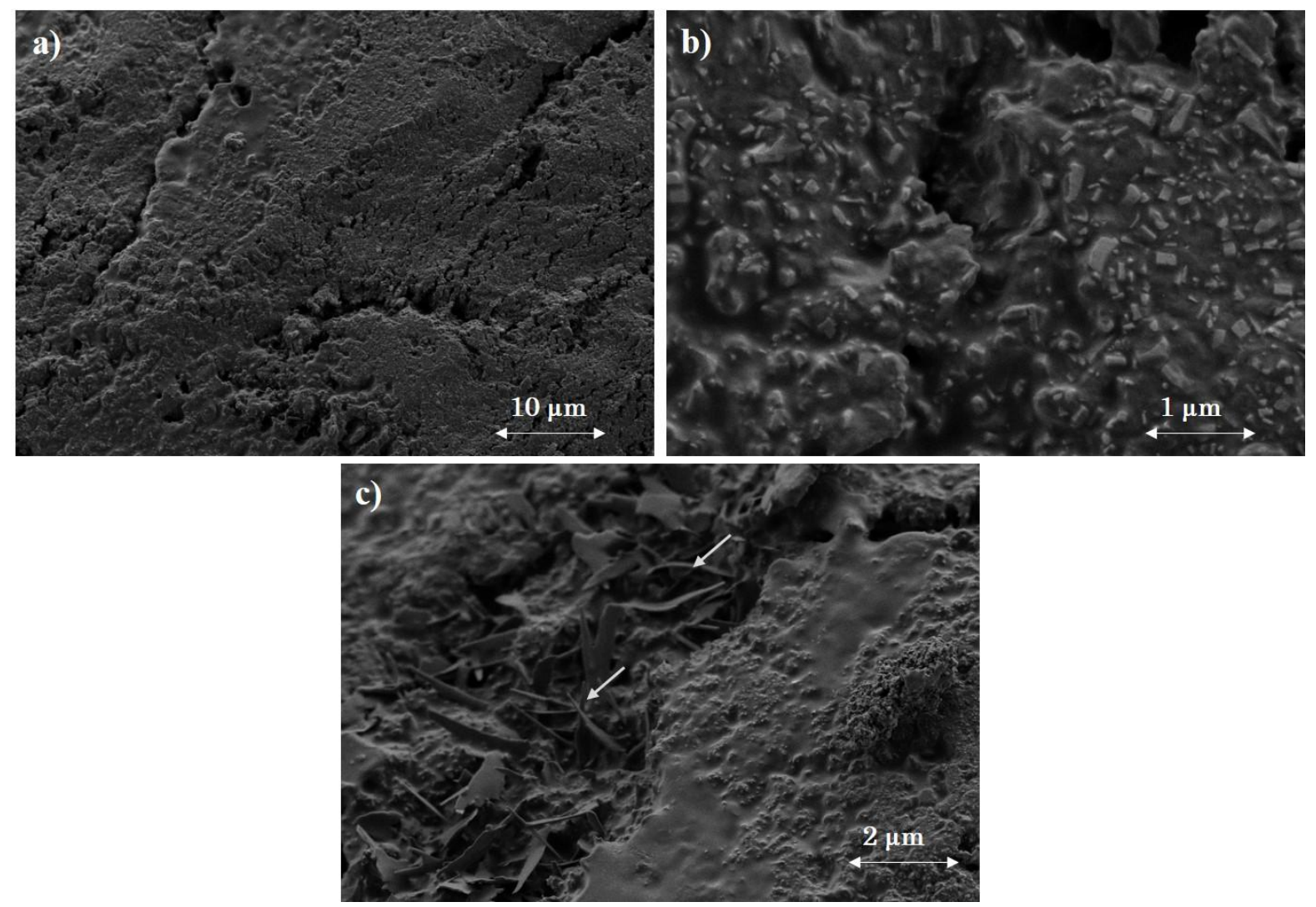

Figure 8.1.2.2.4. Secondary electron images showing the surface of the a) and b) $\mathrm{YO} @ \mathrm{Zn}_{30}$ and c) $\mathrm{YO} @ \mathrm{Zn}_{75}$ reconstructed model tempera paint specimens.

Figure 8.1.2.2.5a shows the secondary electron images obtained in the $\mathrm{YO} @ \mathrm{Cd}_{30}$ reconstructed model paint specimen in which exhibited an apparently uniform surface with some pigment protrusions denoting a notable PVC. The surface of the $\mathrm{YO} @ \mathrm{Cd}_{75}$ reconstructed model paint specimen present a series of fissures and pores, in addition to pigment aggregates are disrupting the uniformity of the surface (Figure 8.1.2.2.5b). A series of voids can also be seen all over the surface paint film (see arrows in Figure 8.1.2.2.5c), associated to the low PVC. Similarly, to the rest of specimens prepared as emulsions, spheres and granules are here hardly identified due to the presence of linseed oil. 

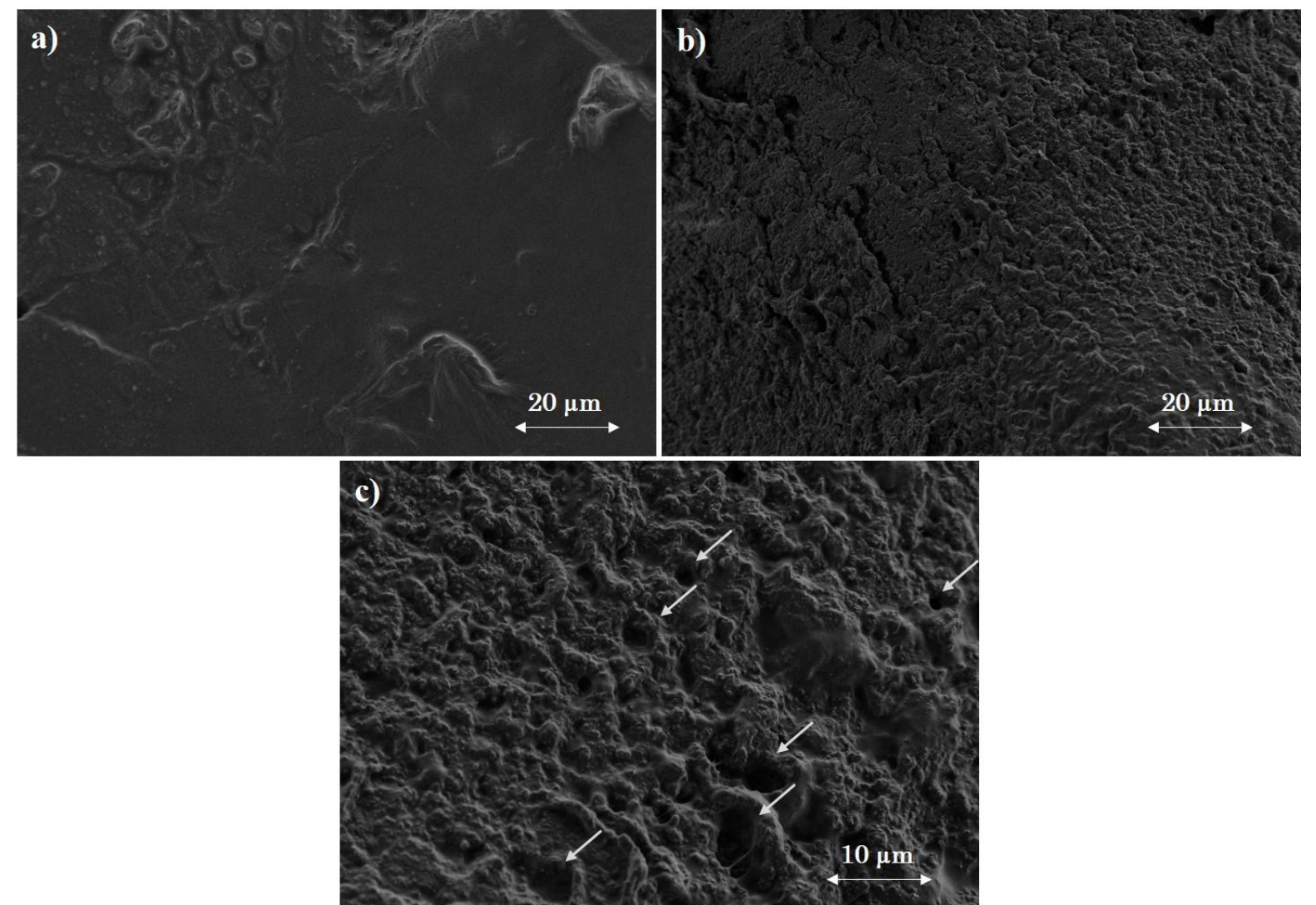

Figure 8.1.2.2.5. Secondary electron images showing the surface of the a) $\mathrm{YO} @ \mathrm{Cd}_{30}$; and b) and c) $\mathrm{YO} @ \mathrm{Cd}_{75}$ reconstructed model tempera paint specimens. 


\subsubsection{Final considerations}

The morphological study carried out in this section has revealed the influence of the type of pigment and binder used in the preparation of these two series of pictorial films as well as the relative proportion between them. The latter has been determinant in the formation of films with good cohesive properties, with low PVC, in most of the films prepared at $30 \% \mathrm{wt}$ of pigment content. Whereas in many of the films prepared at $75 \% \mathrm{wt}$ of pigment content characteristic micro-morphologies of low or poorly cohesive films typical of high PVC films, were appreciated. The different density and particle size of the selected pigments has also conditioned the morphology of the films. Thus, for example, the massicot pigment in spite of its high density, which would favor a low PVC, has given rise to thinly cohesive films due to the large pigment grain size that makes it difficult to mix and form a stable micellar dispersion. In contrast, pigments with small particle size below 1 micron (i.e. cadmium yellow) have resulted in more homogeneous dispersions. In the latter case, a determining factor was the affinity of the binder to form stable micelles with the pigment grains avoiding the formation of aggregates that contribute to the lack of homogeneity of the film. This phenomenon is clearly noticeable in the red pigment iron oxide. Other factor to be considered is the ease of dissolving the pigment, as zinc oxide pigment whose pre-solubilized cations readily form complexes with free fatty acids and amino acids released from the binding medium. These complexes can migrate to the surface of the film forming crystalline aggregates that protrude on the surface.

The composition of the binder is obviously another determining factor in the properties and morphology of the resulting pictorial film. The study carried out shown the difference between films prepared with egg yolk tempera and those prepared with an egg yolk-oil emulsion. In the first case, the cohesion of the film is determined by the ability of the egg yolk to cross-link, which is mainly due to the aggregation capacity of the proteins that constituted the plasma. In the images obtained by FESEM it is seen how the more hydrophobic granules and spheres have not been integrated into the solid reticulum and have remained dispersed along with the pigment grains. The more hydrophilic phospholipids and proteins that constitute the outer layer, however have allowed that these features been integrated and even adhere to the pigment grains. In the case of the egg yolk-oil emulsion, the oil has an extraordinary ability to crosslink through an oxidation-polymerization process of its triglyceride esters. This reticle provides a greater cohesion and flexibility to the pictorial films prepared in this medium. This is probably the reason why PVC is not as critical in this type of films as in those prepared with egg tempera. The images obtained in which there is no disruption or aggregation in the binding medium demonstrated that the components of the egg plasma with an emulgent character (phospholipids) have allowed an adequate integration of hydrophilic components (proteins) and hydrophobics (triglycerides). 


\subsubsection{References}

Andersson, L., Porath, J. (1986) Isolation of phosphoproteins by immobilized metal $\left(\mathrm{Fe}^{3+}\right)$ affinity chromatography. Anal Biochem., 154, 250-254.

Anton, M., Gandemer, G. (1997) Composition, solubility and emulsifying properties of granules and plasma of egg yolk. Journal of Food Science, 62, 484-487.

Anton, M. (2013) Egg yolk: structures, functionalities and processes. J. Sci. Food. Agri., 93, 2871-2880.

Boehm, S., Abaturov, L.V. (1977) Structural changes of methaemoglobin by dehydration. FEBS Lett, 77, 21-24.

Chang, C.M., Powrie, W.D., Fennema, O. (1977) Microstructure of egg yolk. Journal of Food Science, 42, 1193-1200.

Dalgleish, D.G. (2004) Food emulsions: their structures and properties. Food emulsions, 1112.

Duce, C., Ghezzi, L., Onor, M., Bonaduce, I., Colombini, M.P., Tiné, M.R., Bramanti, E. (2012) Physico-chemical characterization of protein-pigment interactions in tempera paint reconstructions: casein/cinnabar and albumin/cinnabar. Anal Bioanal Chem., 402, 2183-2193.

Duce, C., Bramanti, E., Ghezzi, L., Bernazzani, L., Bonaduce, I., Colombini, M.P., Spepi, A., Biagi, S., Tiné, M.R. (2013) Interactions between inorganic pigments and proteinaceous binders in reference paint reconstructions. Dalton Transactions, 42, 5975-5984.

Fiedler, I., Bayard, M.A. (1986). Cadmium yellows, oranges and reds. In Artists' Pigments. A Handbook of their History and Characteristics, Vol. 1 (R.L. Feller, ed.), pp. 65-108, National Gallery of Art, Washington DC.

Helwing, K. (2007). Iron oxide pigments: natural and synthetic. In Artists' Pigments: A Handbook of their History and Characteristics, Vol. 4 (B.H. Berrie, ed.), pp. 39-110, National Gallery of Art and Archetype Publications.

Karpowicz, A. (1981) Ageing and deterioration of proteinaceous media. Studies in conservation, 26, 153-160.

Kühn, H. (1986). Zinc White. In Artists' Pigments. A Handbook of their History and Characteristics, Vol. 1 (R.L. Feller, ed.), pp. 169-186, National Gallery of Art, Washington DC.

Li-Chang, E.C.Y., Powrie, W.D., Nakai, S. (1995) In: Stadelmen, W.J., Cotterill, O.J. (eds.) Egg Science and Technology. Food Products Press, New York, 105-175.

Mine, Y., Zhang, H. (2013) Biochemistry of Foods, In: Egg components in food systems, $\left(3^{\text {rd }}\right.$ ed.), Elsevier, 215-241, and references therein.

Osmond, G. (2012) Zinc white: a review of zinc oxide pigment properties and implications for stability in oil-based paintings. AICCM Bulletin, 33, 20-29. (and references therein) 
Prestrelski, S.J., Tedeschi, N., Arakawa, T., Carpenter, J.F. (1993) Dehydration-induced conformational transitions in proteins and their inhibition by stabilizers. Biophys J, 65, 661671.

Tiarks, F., Frechen, T., Kirsh, S., Leuninger, J., Melan, M., Pfau, A., Richter, F., Schuler, B., Zhao, C-L. (2003) Formulation effects on the distribution of pigment particles in paints. Progress in organic coatings, 48, 140-152.

Wang, W., Bu, W., Wang, L., Palo, P.E., Mallapragada, S., Nilsen-Hamilton, M., Vaknin, D. (2012) Interfacial properties and iron binding to bacterial proteins that promote the growth of magnetite nanocrystals: X-ray reflectivity and surface spectroscopy studies. Langmuir, 28, 4274-4282. 


\subsubsection{Fourier transform infrared spectroscopy (FTIR)}

Characterization of the pigment-binder interaction of two series of reconstructed model paint specimen has been carried out. As previously described in the "materials and methods" section, the first series is composed of tempera paint specimens (Y@pigment) prepared with egg yolk at different pigment contents ranging from 10,30, 50 and 75\%. The second series is prepared as egg-oil emulsion (YO@ pigment) with the same pigment concentrations that the prior series. The pigment studied were iron oxide red $(\mathrm{Fe})$, massicot $(\mathrm{Pbm})$, zinc white $(\mathrm{Zn})$ and cadmium yellow $(\mathrm{Cd})$.

\subsubsection{Characterization of egg yolk tempera reconstructed model paint specimens.}

\section{Egg yolk film specimen}

As previously described (in page 86), egg yolk is a complex mixture of several lipoproteins and proteins. Lipids are also present in egg yolk as triglycerides (neutral lipids), phospholipids and cholesterol. All these compounds exhibit IR absorption bands overlapped which results in a complex IR absorption spectrum. In this section, the IR bands ascribed to each type of compounds have been considered separately. In some cases, deconvolution and second derivative techniques have been applied for discriminating compounds and conformations of proteins.

\section{Proteins}

Due to the major content in proteins, the infrared absorption spectrum of the specimen of pure egg yolk $(\mathrm{Y})$ is dominated by a number of vibrational bands associated to the mixture of proteins (Figure 8.1.3.1.1). Characteristic vibrational bands which arise from the amide A $\left(3278 \mathrm{~cm}^{-1}\right)$, amide B $\left(3069 \mathrm{~cm}^{-1}\right)$, amide I (1700-1600 $\left.\mathrm{cm}^{-1}\right)$ and amide II (1600-1500 $\left.\mathrm{cm}^{-1}\right)$ have firstly been identified. The most sensitive spectral region to the protein secondary structural components is the amide I band, which is due mainly to the $\mathrm{C}=\mathrm{O}$ stretching vibrations of the amide groups coupled with little in-plane $\mathrm{NH}$ bending. The amide I band contour consists of a number of individual bands at the frequencies characteristic for the specific types of secondary structure. The average frequency position of the band at $1629 \mathrm{~cm}^{-}$ ${ }^{1}$ is associated to the $\beta$-sheet conformation the dominant confirmation for these proteins in dried state (Furlan et al., 2007; Pelton and McLean, 2000). 


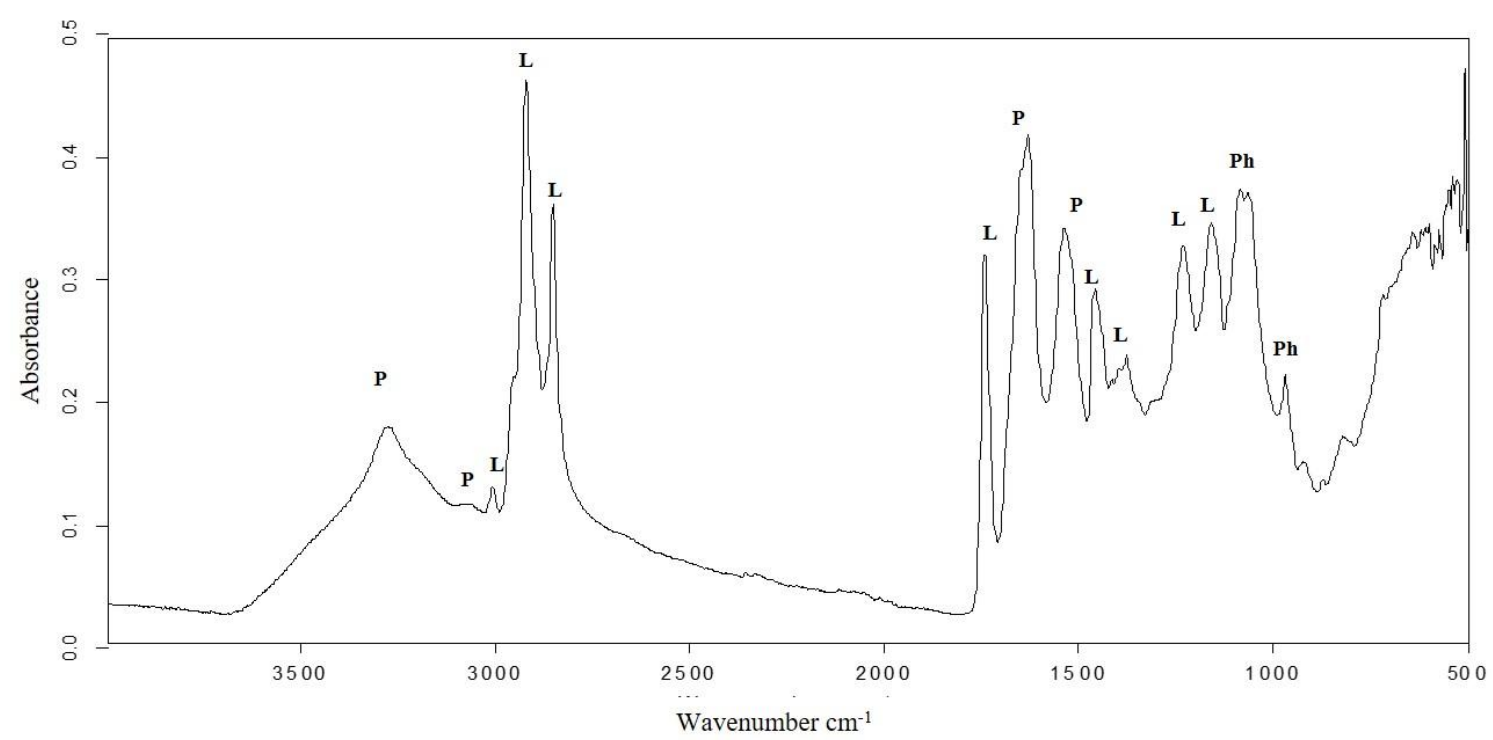

Figure 8.1.3.1.1. IR absorption spectra obtained from pure egg yolk (Y). Assignment of representative bands: proteins (P); neutral lipids (L); and phospholipids (Ph).

The secondary maximum at $1652 \mathrm{~cm}^{-1}$, has been assigned to $\alpha$-helix structure in the second derivative spectra, together with the shoulders at 1648,1657 and $1661 \mathrm{~cm}^{-1}$. Shoulders between 1637 and $1645 \mathrm{~cm}^{-1}$ are ascribed to the unordered component, usually referred to as "random coil". The random coil component has been referred to a structure that is neither $\alpha$ helix, nor $\beta$-sheet, nor turn. Various turn conformations are additional common secondary structures that generally exist in globular proteins. The second derivative analysis procedure provides detailed information of the overlapped bands at 1668, 1673 and $1683 \mathrm{~cm}^{-1}$, associated to turns and bends. Upon deconvolution of the amide I band, a series of overlapped bands at 1633 and $1625 \mathrm{~cm}^{-1}$ arise from intramolecular $\mathrm{C}=\mathrm{O}$ vibrations as well as bands at 1621, 1618, 1612 and $1692 \mathrm{~cm}^{-1}$ associated to intermolecular hydrogen bonding aggregated proteins, antiparallel $\beta$-sheet conformation and aromatic ring vibrations of tyrosine residues in LDL and HDL proteins. Fourier self-deconvolution (FSD) and second derivative, have not only enriched the qualitative interpretation of the IR spectra, but also provided a basis for the qualitative estimation of protein secondary structure (Figure 8.1.3.1.2). Figure 8.1.3.1.2 (bottom), shows the calculated percentage for each conformational structure. In agreement with the position of the maximum of the amide I band at $1629 \mathrm{~cm}^{-1}$, intermolecular $\beta$-sheet conformation $(33 \%)$ is prevalent in dried yolk with remarkable contribution of $\alpha$-helix conformation $(25 \%)$. 


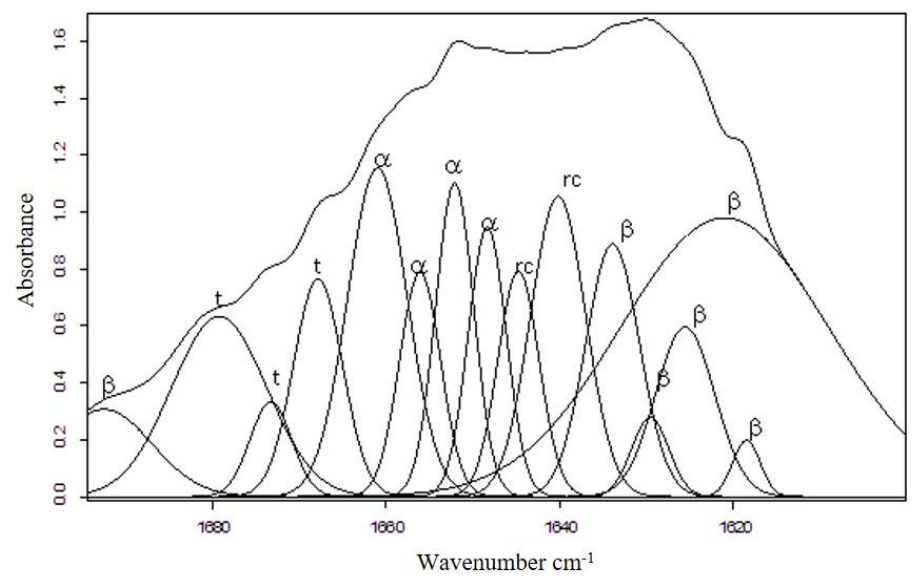

\begin{tabular}{|c|c|c|}
\hline $\begin{array}{c}\text { Predominant } \\
\text { conformations }\end{array}$ & $\begin{array}{c}\text { Frequency range } \\
\left(\mathbf{c m}^{-1}\right)\end{array}$ & $\begin{array}{c}\text { Amide I \% } \\
\text { contribution }\end{array}$ \\
\hline Intermolecular $\beta$-sheet & $1611-1625$ & 33 \\
\hline Intramolecular $\beta$-sheet & $1625-1637$ & 8 \\
\hline Random coil & $1637-1645$ & 14 \\
\hline$\alpha$ - helix & $1645-1662$ & 25 \\
\hline Turns & $1662-1690$ & 20 \\
\hline
\end{tabular}

Figure 8.1.3.1.2. Amide I curve fitted band for $Y$ with fitted band components (up) and $\%$ contribution of each conformation (bottom). Assignment of bands conformations: $\beta$-sheet $(\beta)$, random coil (rc), $\alpha$-helix $(\alpha)$ and turns $(\mathrm{t})$.

The amide II band, in contrast with the amide I, derives mainly from in-plane NH bending and from the $\mathrm{CN}$ stretching vibration, showing much less protein conformational sensitivity than its amide I counterpart. The maximum of amide II bands at $1538 \mathrm{~cm}^{-1}$ with shoulder at $1508 \mathrm{~cm}^{-1}$ also confirms the prevalence of a $\beta$-sheet structure in dried egg yolk proteins (Pelton and McLean, 2000; Miyazawa and Blout, 1961).

Neutral lipids (NLs)

Band at $3007 \mathrm{~cm}^{-1}$ is ascribed to the unconjugated double bonds from fatty acids present in neutral lipids. This band takes part in the drying process with a progressive intensity decrease. Egg yolk exhibits bands at 2922, and $2852 \mathrm{~cm}^{-1}$ with shoulders at 2954 and 2872 $\mathrm{cm}^{-1}$ associated with the methyl and methylene groups corresponding to the hydrophobic tail regions of the fatty acid chains. The band at $1743 \mathrm{~cm}^{-1}$ due to the $\mathrm{C}=\mathrm{O}$ stretching motion in ester groups of triacylglycerol, diacylglycerol and phospholipid molecules was also associated to stable lactones. The second derivative analysis permits the identification of lipids vibration bands at 1736 and $1719 \mathrm{~cm}^{-1}$ attributed to derived aldehydes and ketones, respectively. Band $1736 \mathrm{~cm}^{-1}$ has been previously associated to the lipid protein carbonyl stretching (Nahar and Tajmir-Riahi, 1996; van der Weerd et al., 2005). Meilunas et al. (1990) also associate these bands in the range $1740-1710 \mathrm{~cm}^{-1}$ to the presence of an imide linkage derived from oxidation of protein amide linkage.

Hydrolysis of di- and triacylglycerols and PLs during drying and ageing of egg yolk thin films usually occurs in aqueous environments and may involve: a) releasing of free fatty acids and glycerol, and b) the formation of PLs with only one fatty acid chain, mono- and 
diglycerides (Miyazawa and Blout, 1961, Cagnasso et al., 2010). Characteristic bands attributed to features of free fatty acids at $1701-1710 \mathrm{~cm}^{-1}$ were not observed in the specimen of egg yolk analyzed. This suggests that hydrolysis reaction has not significantly taken place at this initial stage of the egg yolk film formation. It seems that the particular microstructure of egg yolk in which NLs are located inside HDL (Anderson et al., 1998; Birrell et al., 1982) and LDL (Anton, 2013; Kumpula et al., 2008; Hevonoja et al., 2000) complex granular structures appears to have prevented that the process of hydrolysis takes place. (Salvadó et al., 2009; van der Weer et al., 2005).

Bands at 1466 and $1457 \mathrm{~cm}^{-1}$ are mainly assigned to $-\mathrm{CH}_{2}$ groups (Salvadó et al., 2009; van der Weer et al., 2005, Maziak et al., 2007) scissoring vibrations. The band at $1377 \mathrm{~cm}^{-1}$ is assigned to umbrella mode vibrations of $\mathrm{CH}_{3}$ groups (van der Weer et al., 2005), as well as to $v_{\mathrm{s}}\left(\mathrm{CO}_{2}{ }^{-}\right)$due to ester group hydrolysis which occurs in aqueous environments (Cagnasso et al., 2010). Bands at 1233,1160 and $1099 \mathrm{~cm}^{-1}$ are related to diverse stretching vibrations of C-O bonds in triglyceride ester linkages (Meilunas et al., 1990; Salvadó et al., 2009; van der Weer et al., 2005). The trans and cis $\mathrm{CH}$ out-of-plane deformation at 969 and $722 \mathrm{~cm}^{-1}$ support the presence of unconjugated double bonds from the fatty acids previously established from the band at $3007 \mathrm{~cm}^{-1}$.

Phospholipids (PLs)

Egg yolk is a good source of phospholipids, mainly phosphatidylcholyne (PC) and phosphatidylethanolamine (PE). These PLs contribute to the methyl, methylene and carboxylate bands described for NLs. In particular, the shoulder at $1736 \mathrm{~cm}^{-1}$ attributed to stretching vibrations of carbonyl groups in PLs (Cagnasso et al., 2010; Tantipolphan et al., 2007). The second derivative of the band at $1233 \mathrm{~cm}^{-1}$, shows that this band is a combination of two bands, $1238 \mathrm{~cm}^{-1}$ mainly due to $-\mathrm{C}-\mathrm{O}$ of triglyceride ester linkages of NLs (Salvadó et al., 2009; van der Weer et al., 2005) and $1229 \mathrm{~cm}^{-1}$ attributed to antisymmetric stretching of $\mathrm{PO}_{2}^{-}$.

Carboxylic moieties are also confirmed by the weak band at $1417 \mathrm{~cm}^{-1}$ (Cagnasso et al., 2010; van der Weer et al., 2005; Omoike et al., 2004) associated to the diversification in deprotonated carboxylated anion of acidic species formed from NLs, PLs proteins together with contribution from (- $\left.\mathrm{CH}_{2}-\mathrm{COOR}\right)$ stretch of the PLs, phosphatidylcholyne (Cagnasso et al., 2010). Bands at 1142 and $1086 \mathrm{~cm}^{-1}$ are associated to terminal phosphate vibrations, as well as the band at $1063 \mathrm{~cm}^{-1}$, which was attributed to $v_{\mathrm{s}}(\mathrm{P}-\mathrm{O}-\mathrm{C})$ terminal phosphate vibrations of the phosphatidic acid (PA) (Cagnasso et al., 2010). Finally, the IR band at 969 $\mathrm{cm}^{-1}$ is assigned to $\left(\mathrm{N}-\mathrm{CH}_{3}\right)$ asymmetric stretch (Cagnasso et al., 2010; Tantipolphan et al., 2007).

\section{Cholesterol}

Cholesterol accounts the $4 \%$ based on total lipids contained in dried egg yolk. Features corresponding to cholesterol were identified at $1055 \mathrm{~cm}^{-1}$ assigned to the $-\mathrm{C}-\mathrm{O}$ stretching vibrations of the saturated secondary alcohol groups, and the band at $952 \mathrm{~cm}^{-1}$ that is attributed to the $-\mathrm{CH}_{2}$ rocking vibration of backbone. 


\section{Egg yolk tempera reconstructed model paint specimens}

In the analysis by FTIR spectroscopy of the series of reconstructed egg yolk tempera model paint specimens prepared at increasing pigment content the most significant changes were observed in the specimens with the higher pigment content $(75 \mathrm{wt} \%)$ whereas the IR spectrum obtained for the reconstructed model paint specimens with less pigment content $(10,30$ and $50 \mathrm{wt} \%)$ are very close to the pure egg yolk specimen. Therefore, characterization of the pigment egg yolk interactions will be discussed based on the spectrums obtained for the $75 \mathrm{wt} \%$ specimens. Figure 8.1.3.1.3 shows the IR spectra obtained for all the

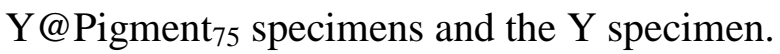

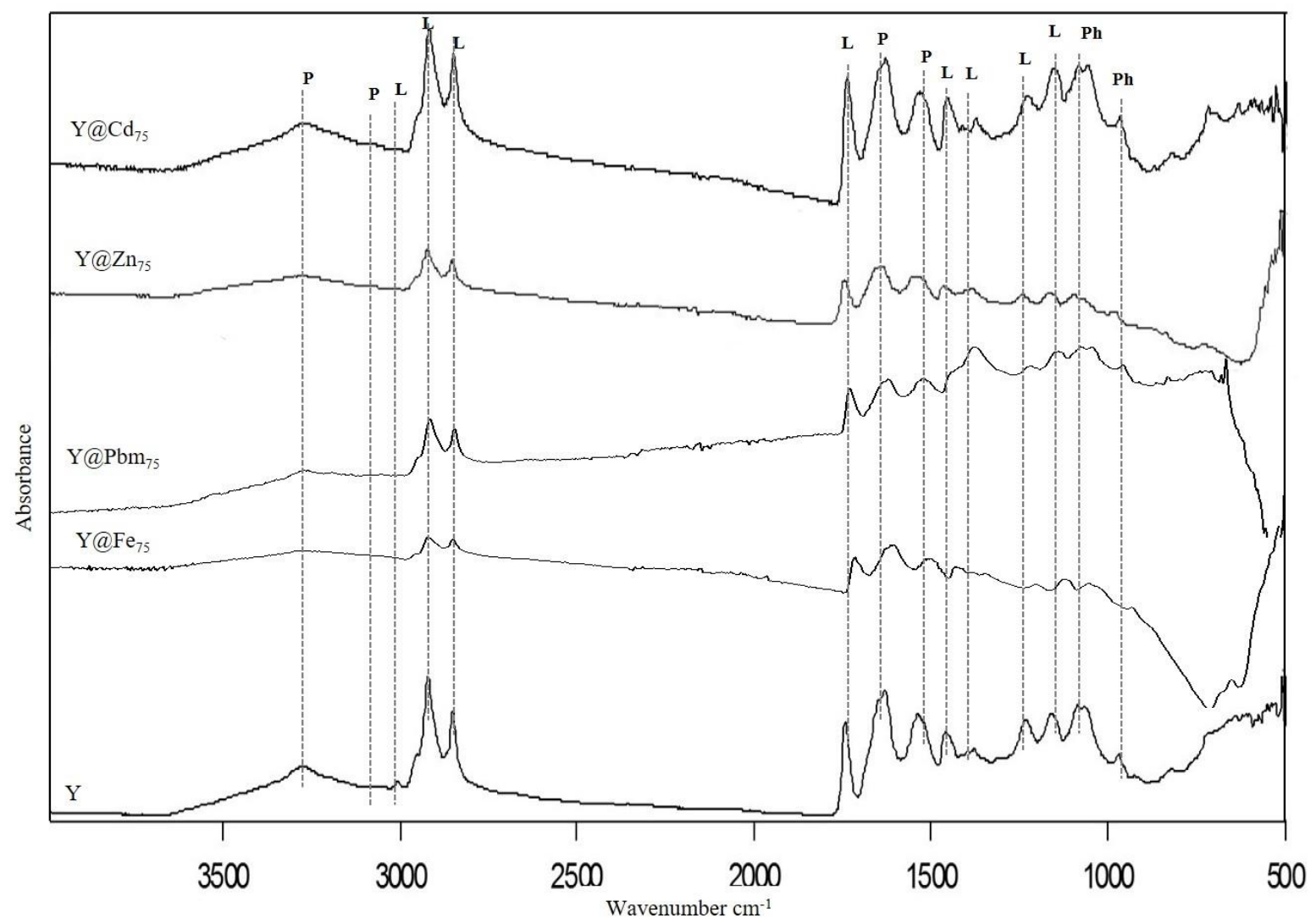

Figure 8.1.3.1.3. IR spectra obtained from the series of egg yolk tempera paint specimens prepared at $75 \mathrm{wt} \%$ pigment content. Pure egg yolk $(\mathrm{Y})$, iron oxide red $\left(\mathrm{Y} @ \mathrm{Fe}_{75}\right)$, massicot $\left(\mathrm{Y} @ \mathrm{Pbm}_{75}\right)$, zinc white $\left(\mathrm{Y} @ \mathrm{Zn}_{75}\right)$ and cadmium yellow $\left(\mathrm{Y} @ \mathrm{Cd}_{75}\right)$. Assignment of representative bands: protein $(\mathrm{P})$; NLs $(\mathrm{L})$; and PLs $(\mathrm{Ph})$.

\section{Iron oxide red reconstructed tempera model paint specimens}

The IR spectrum obtained for the $\mathrm{Y} @ \mathrm{Fe}_{75}$ specimen is affected by scattering effect due to the high content of pigment at some extent (Figure 8.1.3.1.4). Main features observed in the reconstructed egg yolk tempera model paint prepared with iron oxide red at 10,30, 50, and $75 \mathrm{wt} \%$ compared to blank are summarizes in Table 12.1 include as annex to this report. 


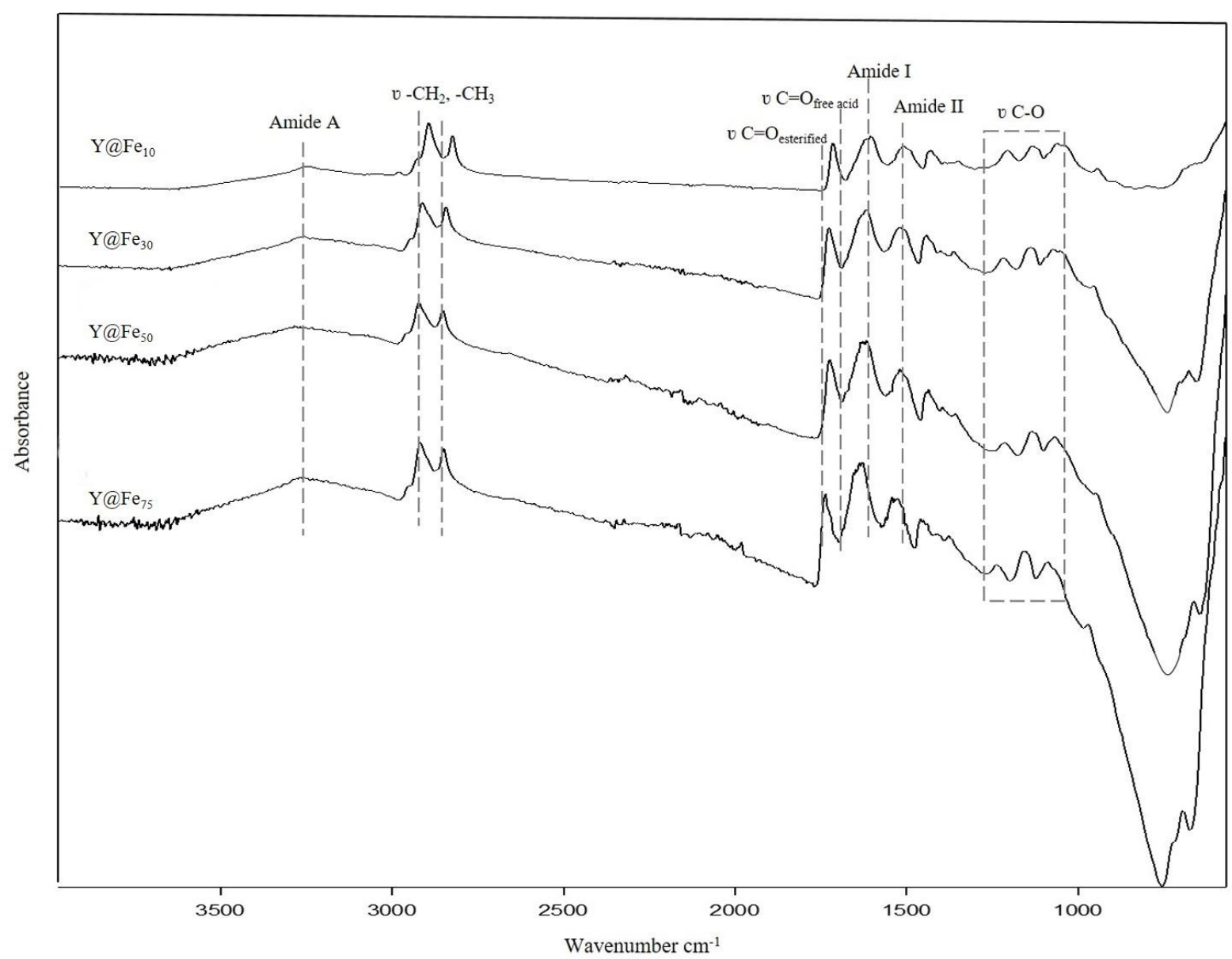

Figure 8.1.3.1.4. IR spectra obtained for the series of Y@Fe tempera paint specimens at 10, 30, 50 and 75 wt $\%$ pigment content.

\section{Proteins}

Comparison of the amide I band between the $\mathrm{Y}$ and $\mathrm{Y} @ \mathrm{Fe}_{75}$ specimens put in evidence no significant changes in the bands assigned to amide $\mathrm{A}$ at $3278 \mathrm{~cm}^{-1}$ and the amide $\mathrm{B}$ band at $3069 \mathrm{~cm}^{-1}$. The main changes were observed in the amide I band whose features are associated to the different conformations of the protein molecules. In order to perform a more exhaustive study the amide I band was deconvolved. This treatment enabled discrimination of several sub-bands corresponding to the different conformations: $\alpha$-helix (maxima at $1648 \mathrm{~cm}^{-}$ ${ }^{1}$ ), intermolecular $\beta$-sheet (max. at $\left.1615 \mathrm{~cm}^{-1}\right)$, intramolecular $\beta$-sheet $\left(1628 \mathrm{~cm}^{-1}\right)$, turns $/ \beta$ sheet (max. at $1674 \mathrm{~cm}^{-1}$ ), and random coil (max. at $1637 \mathrm{~cm}^{-1}$ ) (Figure 8.1.3.1.5). A quantitative analysis of protein secondary structure in the $\mathrm{Y} @ \mathrm{Fe}_{75}$ specimens was carried out on the basis of analysis of second derivative spectra and self-deconvolution followed by curve-fitting analysis. Table 8.1.3.1.1, reports the calculated percent area contribution of the amide I components, for the reconstructed tempera model paint specimens. A notable increase of the percent area contribution of intramolecular $\beta$-sheet conformation is observed, with the corresponding decrease in the contribution of the intermolecular $\beta$-sheet conformation. An increase in the helical component accompanied of a decrease in percent area contribution of the random coil is also observed. 


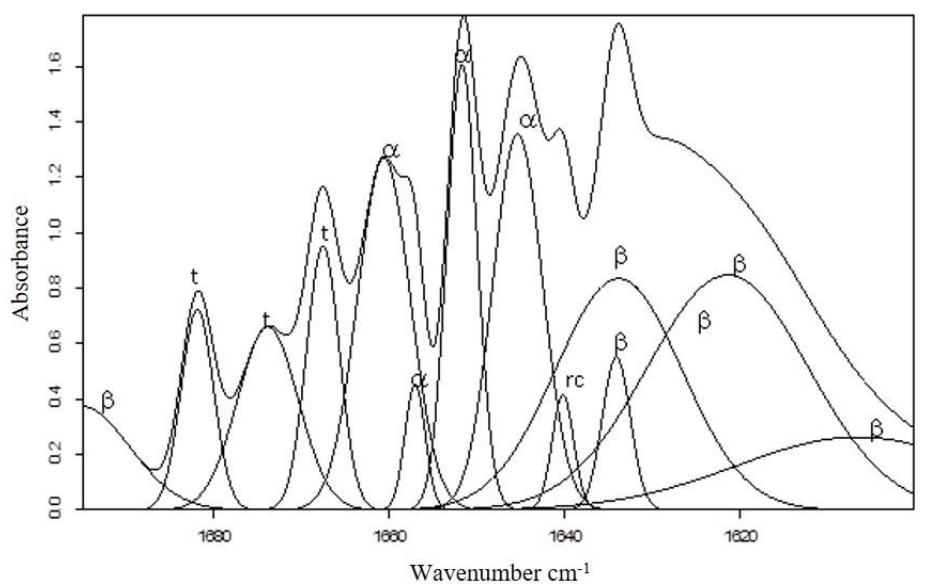

Figure 8.1.3.1.5. Amide I curve fitted band for $\mathrm{Y} @ \mathrm{Fe}_{75}$ specimen with fitted band components: ( $\beta$ ) $\beta$-sheet, (rc) random coil. $(\alpha)$ helical, (t) turns.

Table 8.1.3.1.1. Percent area contribution of amide I components for $\mathrm{Y}$ specimen and $\mathrm{Y} @ \mathrm{Fe}_{75}$, $\mathrm{Y} @ \mathrm{Pbm}_{75}, \mathrm{Y} @ \mathrm{Zn}_{75}$ and $\mathrm{Y} @ \mathrm{Cd}_{75}$ reconstructed tempera model paint specimens.

\begin{tabular}{|c|c|c|c|c|c|c|}
\hline \multirow{2}{*}{$\begin{array}{c}\text { Predominant } \\
\text { conformations }\end{array}$} & $\begin{array}{c}\text { Frequency } \\
\text { range } \\
\left(\mathbf{c m}^{-1}\right)\end{array}$ & \multicolumn{5}{|c|}{$\begin{array}{c}\text { Amide I \% contribution in the reconstructed egg yolk tempera } \\
\text { model paint specimens }\end{array}$} \\
\cline { 3 - 7 } & $\mathbf{Y}$ & $\mathbf{Y} @ \mathbf{F e}_{\mathbf{7 5}}$ & $\mathbf{Y} @ \mathbf{P b m}_{\mathbf{7 5}}$ & $\mathbf{Y} @ \mathbf{Z n}_{\mathbf{7 5}}$ & $\mathbf{Y} @ \mathbf{C d}_{\mathbf{7 5}}$ \\
\hline $\begin{array}{c}\text { Intermolecular } \\
\beta \text {-sheet }\end{array}$ & $1611-1625$ & 33 & 31 & 19 & 12 & 18 \\
\hline $\begin{array}{c}\text { Intramolecular } \\
\beta \text {-sheet }\end{array}$ & $1625-1637$ & 8 & 19 & 22 & 29 & 30 \\
\hline Random coil & $1637-1645$ & 14 & 1 & 6 & 13 & 9 \\
\hline$\alpha$ - helix & $1645-1662$ & 25 & 29 & 35 & 26 & 26 \\
\hline Turns & $1662-1690$ & 20 & 20 & 19 & 20 & 18 \\
\hline
\end{tabular}

Changes in protein conformation that result in a decrease of the intermolecular $\beta$-sheet conformation has been reported for specimens made with albumin: i) incubated with metal oxide nanoparticles $\left(\mathrm{ZnO}, \mathrm{TiO}_{2} \mathrm{CeO}_{2}\right.$ ) (Simón-Vázquez et al., 2014), ii) in aqueous solution containing cations such as $\mathrm{Zn}$ (II) and Cd(II) (Erhardt et al., 2005), and iii) mixed with azurite, minium and iron oxide red (Duce et al., 2013). In agreement with these prior studies, the conformational changes are attributed to preferential absorption of proteins on the surface of the pigment particles associated to drying process. Other works can be found in recent literature, dedicated to the characterization of molecular mechanisms of adhesion between mineral surface and extracellular polymeric surfaces such as proteins. These studies also report an increase in the contribution of the $\alpha$-helical conformation of proteins in presence of grains of goethite (Omoike et al., 2004) and hematite (Parikh and Chorover, 2006). An increase in the value of percent area contributed by the helical conformation of the $\mathrm{Y} @ \mathrm{Fe}_{75}$ specimen is observed in the present study, which suggests the interaction between the egg yolk proteins and the metal centers located in the surface of the pigment.

A new weak shoulder at $1557 \mathrm{~cm}^{-1}$ was identified in $\mathrm{Y} @ \mathrm{Fe}_{75}$, which was assigned to asymmetric stretch of $\mathrm{CO}_{2}^{-}$group in carboxylate metal complexes (Erhardt et al., 2005; 
Venyaminov and Kalnin, 1990). The IR absorptions for metal-protein complexes appears in the region 1500-1630 $\mathrm{cm}^{-1}$. The increase in the intensity (at about $1621 \mathrm{~cm}^{-1}$ ) of the amide I band is tentatively attributed to the direct Fe-protein binding in the $\mathrm{Y} @ \mathrm{Fe}_{75}$ specimens via peptide carbonyl group. Similarly, the increase of the sub-band shifted from $1612 \mathrm{~cm}^{-1}$ to $1615 \mathrm{~cm}^{-1}$ is attributed to the involvement of tyrosine residues, in Fe-protein (binding) complexation (Nahar and Tajmir-Riahi, 1996). Amide II and metal carboxylate complexes from the NLs (Mazzeo et al., 2008; Salvadó et al., 2009; van der Weerd et al., 2005) and PLs (Cagnasso et al., 2010; Parikh and Chorover, 2006) absorption bands that occur in the same frequency range make this band assignment ambiguous.

Neutral lipids (NLs) and Phospholipids (PLs)

Loss of the IR band at $3007 \mathrm{~cm}^{-1}$ associated to unsaturations from PLs and NLs in the $\mathrm{Y} @ \mathrm{Fe}_{75}$, which was still present in the Y specimen, suggest that the pigment is promoting polymerization of triglycerides. The shoulder at $1709 \mathrm{~cm}^{-1}$ confirms the presence of carboxylic acids (palmitic acid, stearic acid, azelaic acid, etc.) from NLs and PLs formed upon oxidation. However, low intensity of this band suggests that hydrolysis of NLs takes place at low extent (van der Weerd et al., 2005; Meilunas et al., 1990).

It is well known that mineral surface is charged and create an electric field. Surface charge of mineral particles depends on the $\mathrm{pH}$. In general, surface charge (zeta potential) of metal oxide particles is positive in circumneutral and slightly alkaline aqueous solution (Omoike et al., 2004; Simón-Vázquez et al., 2014; Omoike and Chorover, 2004; Fein et al., 1997; Phoenix et al., 2002; Schwertmann and Cornell, 1996). Deprotonated carboxylic and phosphate moieties from NLs and PLs could interact with the metal ions exposed on the outer surface. These results are in agreement with prior experiments, were the increment of the $\mathrm{I}_{\mathrm{AII}} / \mathrm{I}_{\mathrm{AI}}$ is attributed to metal-carboxylate complexes from free fatty acids released from NLs (Mazzeo et al, 2008, Duce et al., 2013). According to that, in the set of specimens studied was observed an increase of the $\mathrm{I}_{\mathrm{AII}} / \mathrm{I}_{\mathrm{AI}}$ ratio for all the model paint specimens prepared with $75 \mathrm{wt} \%$ pigment content, the most significant increment was observed in the $\mathrm{Y} @ \mathrm{Fe}_{75}$ and $\mathrm{Y} @ \mathrm{Zn}_{75}$ specimens (see Table 8.1.3.1.2).

Table 8.1.3.1.2 Values of amide II plus metal carboxylate complexes/amide $\mathrm{I}\left(\mathrm{I}_{\mathrm{AII}} / \mathrm{I}_{\mathrm{AI}}\right)$ band area ratio for $\mathrm{Y}$ specimen and $\mathrm{Y} @ \mathrm{Fe}_{75}, \mathrm{Y} @ \mathrm{Pbm}_{75}, \mathrm{Y} @ \mathrm{Zn}_{75}$ and $\mathrm{Y} @ \mathrm{Cd}_{75}$ reconstructed model paint specimens. Wavenumber ranges: AI (1700-1600 $\left.\mathrm{cm}^{-1}\right)$ and AII $\left(1600-1500 \mathrm{~cm}^{-1}\right)$.

\begin{tabular}{|c|c|}
\hline Specimens & Band area ratio $\mathbf{I}_{\mathbf{A I I}} / \mathbf{I}_{\mathbf{A I}}$ \\
\hline $\mathrm{Y}$ & 0.48 \\
\hline $\mathrm{Y} @ \mathrm{Fe}_{75}$ & 0.57 \\
\hline $\mathrm{Y} @ \mathrm{Pbm}_{75}$ & 0.49 \\
\hline $\mathrm{Y} @ \mathrm{Zn}_{75}$ & 0.54 \\
\hline $\mathrm{Y} @ \mathrm{Cd}_{75}$ & 0.51 \\
\hline
\end{tabular}

Using the previously described curve fitting procedure IR bands attributed to the stretching vibrations of the different carbonyl groups were discriminated in the region $1800-1700 \mathrm{~cm}^{-1}$. Ratios obtained for the intensity of the sub-bands ascribed to carbonyl groups in free fatty acids $\left(\mathrm{I}_{\mathrm{FFA}}\right)$ and ester carbonyl groups $\left(\mathrm{I}_{\mathrm{E}}\right)$ are summarized in Table 8.1.2.1.3. A slight increase in the content of free fatty acid in comparison with the blank specimen $\mathrm{Y}$ was 
observed for the $\mathrm{Y} @ \mathrm{Fe}_{75}$ specimen. These results confirm that pigment is scarcely promoting the hydrolysis of triglycerides of NLs.

Table 8.1.3.1.3. $\mathrm{I}_{\mathrm{FFA}} / \mathrm{I}_{\mathrm{E}}$ values for the $\mathrm{Y}$ and the reconstructed model paint specimens at $75 \mathrm{wt} \%$.

\begin{tabular}{|c|c|}
\hline Specimens & $\mathbf{I}_{\mathbf{F F A}} / \mathbf{I}_{\mathbf{E}}$ \\
\hline $\mathrm{Y}$ & 0.001 \\
\hline $\mathrm{Y} @ \mathrm{Fe}_{75}$ & 0.09 \\
\hline $\mathrm{Y} @ \mathrm{Pbm}_{75}$ & 0.22 \\
\hline $\mathrm{Y} @ \mathrm{Zn}_{75}$ & 0.21 \\
\hline $\mathrm{Y} @ \mathrm{Cd}_{75}$ & 0.014 \\
\hline
\end{tabular}

As it can also be seen, the presence of pigment results in an increase of the relative amide II band intensity referred to these of amide I. This behavior should be mainly due to the diversification of protein functionalities among which is included that due to metal carboxylate groups formed from deprotonated carboxylate residues from proteins, in particular, the shoulder observed at $1557 \mathrm{~cm}^{-1}$. Bands associated to stretching vibrations of Fe-carboxylate groups formed from free fatty acids and carboxylate residues from NLs and PLs appear at $1575 \mathrm{~cm}^{-1}$. Mineral particles of hematite and goethite are positively charge, so deprotonated carboxylic and phosphate moieties from NLs and PLs could interact with the metal ions exposed on the outer surface of the pigment grains. Prior studies have also reported oxidative transformation of the phospholipids promoted by iron oxide surface (Cagnasso et al., 2010) and the formation of monodentate diprotonated, bidentate monoprotonated and bidentate diprotonated inner-sphere complexes (Cagnasso et al., 2010; Omoike et al., 2004; Parikh and Chorover, 2006; Tejedor-Tejedor and Anderson, 1990).

Egg yolks are a good source of phospholipids (PL). PLs are amphipathic molecules incorporated into the peripheral bilayer of HDL and LDL particles together with proteins and in contact with the NLs occluded in the core of the granules. The main components of egg yolk lecithin are phosphatidylcholine (80.5\%), and phosphatidylethanolamine (11.7\%) (Mine and Zhang, 2013). Also, contain lysophosphatidylcholine, sphingomyelin, and neutral lipids in minor quantities. Recent infrared spectroscopy studies demonstrated the formation of covalent bonds between bacteria cell surface through phosphoryl groups, were nucleic acids, phosphodiesters (Omoike et al., 2004; Parikh and Chorover, 2006) and phospholipids (Cagnasso et al., 2010; Burnett et al., 2006) mediate the reaction. This represent an energetic contribution, that results in changes of intensity, position and width of the IR bands ascribed to phosphate groups. Shift to lower wavenumber of phosphoryl groups has been reported for cell surface bacteria in contact with cadmium ion solutions by Birrell et al., (1982). Changes in the frequency of bands assigned to $v_{\mathrm{as}} \mathrm{PO}_{2}^{-}$and $v_{\mathrm{s}} \mathrm{PO}_{2}^{-}$are evident for the $\mathrm{Y} @ \mathrm{Fe}_{75}$ specimen. IR band at $1233 \mathrm{~cm}^{-1}$ attributed to $v_{\mathrm{as}} \mathrm{PO}_{2}^{-}$for pure egg yolk is shifted to $1235 \mathrm{~cm}^{-1}$ suggesting PLs-metal interactions of phosphate groups, deriving from phosphodiesters of proteins.

A new weak band at $969 \mathrm{~cm}^{-1}$ produced by stretching vibrations of $\mathrm{P}-\mathrm{O}-\mathrm{X}$ bond $(\mathrm{X}=$ metal atom) confirms the interactions between the polar phosphate and the pigment surface. This band is attributed to the $\mathrm{P}-\mathrm{O}-\mathrm{X}$ stretching vibrations as consequence of the interactions of the polar phosphate present in PLs and the phosphorilated lipoproteins present in HDLs, able to 
bond pigment grains surface. The bonding modes include monodentate, bidentate binuclear, and bidentate mononuclear complexation with metal octahedral of the mineral surface (Cagnasso et al., 2010; Omoike et al., 2004; Parikh and Chorover, 2006; Tejedor-Tejedor and Anderson, 1990). In addition to PLs other phosphate groups from lipovitelins and phosphivitins (Pvt) of egg yolk are contributing to the $\mathrm{P}-\mathrm{O}-\mathrm{X}$ stretching band, due to its strong affinity to bond bivalent metals such as $\mathrm{Ca}^{2+}, \mathrm{Fe}^{2+}$ and $\mathrm{Mg}^{2+}$ (Castellani et al., 2008; Andersson and Porath, 1986; Goulas et al., 1996; Bonnet et al., 2010).

\section{Cholesterol}

Modifying effect of the pigment results in a blue shift of band ascribed to the $-\mathrm{C}-\mathrm{O}$ stretching vibrations of alcohol group at $1055 \mathrm{~cm}^{-1}$. This change is associated to the oxidation processes undergone by this molecule during the drying process, that in presence of pigments result in the appearance of a series of cholesterol oxidation products (COPs).

\section{Massicot reconstructed tempera model paint specimens}

The main features obtained for the massicot model paint specimens prepared at 10, 30, 50 and $75 \mathrm{wt} \%$ are summarized in Table 12.2 in the annexes. Like, in the paints prepared with iron oxide red the changes are mainly produced by the egg yolk in direct contact with the pigment grains. For this reason, changes in composition are better observed in the $\mathrm{Y} @ \mathrm{Pbm}_{75}$ specimen. As for iron oxide red specimen the scattering effect is particularly evident in the massicot specimen (Figure 8.1.3.1.6).

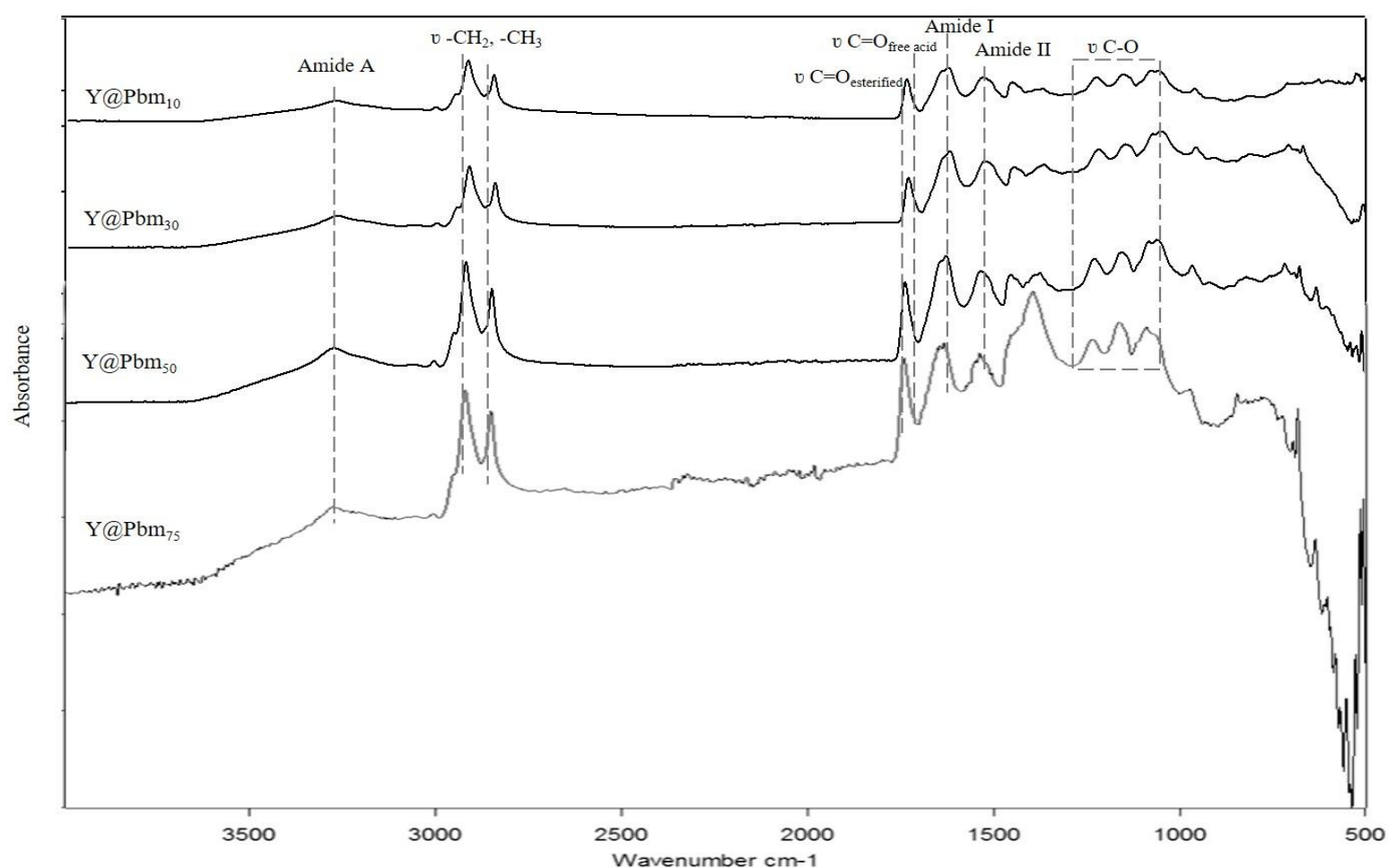

Figure 8.1.3.1.6. IR spectra obtained for the series of $\mathrm{Y} @ \mathrm{Pbm}$ tempera paint specimens at 10, 30, 50 and 75 wt $\%$ pigment content. 


\section{Proteins}

Changes affecting the secondary structure of the proteins were better observed using the second derivative spectrum on the amide I band. The second derivative and self-deconvolved IR spectra exhibit sub-bands grouped in the five conformation components. These components are assigned to the intermolecular $\beta$-sheet (maxima at 1613 and $1620 \mathrm{~cm}^{-1}$ ), intramolecular $\beta$-sheet (max. at 1626 and $1633 \mathrm{~cm}^{-1}$ ), random coil (max. at 1640 and 1644 $\mathrm{cm}^{-1}$ ), $\alpha$-helix (max. at 1651 and $1661 \mathrm{~cm}^{-1}$ ) and turns/bends (max. at 1668, 1674, 1682 and $1692 \mathrm{~cm}^{-1}$ ) (Figure 8.1.3.1.7). Besides, deconvolution and curve fitting of the amide I band was performed to calculate the percent area contribution of the conformations (see Table 8.1.3.1.1). A significant increase of the intramolecular $\beta$-sheet was observed with a corresponding decrease of the intermolecular $\beta$-sheet conformation. Also, notable decrease of sub-bands ascribed to the random coil conformation was observed. These results suggest some interaction between egg proteins and metal centers in the surface of the pigment grains, similarly to the behavior previously observed in the Y@Fe specimens.

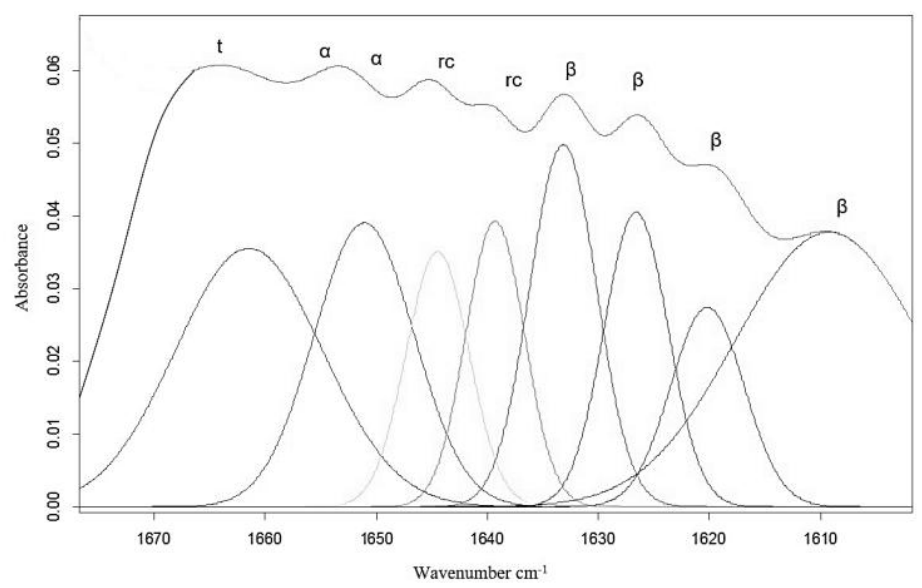

Figure 8.1.3.1.7. Amide I curve fitted band for $\mathrm{Y} @ \mathrm{Pbm}_{75}$ specimen with fitted band components: $(\beta)$-sheet, (rc) random coil. $(\alpha)$ helical, (t) turns.

Appearance of two absorption shoulders at 1574 and $1557 \mathrm{~cm}^{-1}$, in the metal-protein complex absorption characteristic region (1500-1600 $\mathrm{cm}^{-1}$ ) confirms the formation of metal complexes through carboxylate groups from NLs and PLs (Salvadó et al., 2009; Mazzeo et al., 2008; Cagnasso et al., 2010; van der Weerd et al., 2005; Parikh and Chorover, 2006).

Neutral lipids (NLs) and Phospholipids (PLs)

Oxidation of triglycerides due to the drying process is suggested by the appearance of a combination of bands at 3525 and $1770 \mathrm{~cm}^{-1}$ associated to $\mathrm{OH}$ stretch vibrations and $\mathrm{C}=\mathrm{O}$ stretch of lactones in NLs, respectively (Meilunas et al., 1990). The band at $1713 \mathrm{~cm}^{-1}$ ascribed to free fatty acids (palmitic acid, stearic acid, azelaic acid, etc.) released from NLs suggest that hydrolysis of NLs take place.

Like in the $\mathrm{Y} @ \mathrm{Fe}_{75}$ curve fitting of the deconvolved bands in the region $1800-1700 \mathrm{~cm}^{-1}$ was performed, aimed at calculate the ratios of the individual bands ascribed to carbonyl groups in free fatty acid and ester groups $\left(\mathrm{I}_{\mathrm{FFA}} / \mathrm{I}_{\mathrm{E}}\right)$. Results obtained are summarized in the Table 
8.1.3.1.3 and confirm that this pigment promotes hydrolysis of triglycerides at significant extent. Nonetheless, the process takes place at less extent for NLs if compared with the behavior of this pigment in presence of drying oil (vide infra) due to its granular structure that maintain encapsulated the LDL and HDL.

Band at $1535 \mathrm{~cm}^{-1}$ is attributed to the formation of lead carboxylate product of the interaction of the egg yolk free fatty acids and pigments surface (van der Weerd et al., 2005). The bands associated to the presence of metal-carboxylate complexes formed by the interaction of phosphate moieties from PLs and acid residues of proteins with the pigment centers in the grains surface were also observed for the $\mathrm{Y} @ \mathrm{Pbm}_{75}$ specimen at 1574 and $1557 \mathrm{~cm}^{-1}$ (Mazzeo et al., 2008; Duce et al., 2013). A new band in the $1000-970 \mathrm{~cm}^{-1}$ region ascribed to the stretching vibrations of the P-O-X $(\mathrm{X}=$ metal $)$ bond confirms the interaction of polar phosphate with pigment surface. In agreement to that, shifts of bands attributed to the $v_{\text {as }} \mathrm{PO}_{2}-$ (from $1233 \mathrm{~cm}^{-1}$ to $1234 \mathrm{~cm}^{-1}$ ), $v_{\mathrm{s}} \mathrm{P}-\mathrm{O}-\mathrm{C}$ band (from $1063 \mathrm{~cm}^{-1}$ to $1067 \mathrm{~cm}^{-1}$ ) and $v_{\mathrm{s}} \mathrm{PO}_{2^{-}}$ (from $1086 \mathrm{~cm}^{-1}$ to $1088 \mathrm{~cm}^{-1}$ ) are clear enough to confirm the PLs-metal formation.

Cholesterol

Modifying effect of the pigment results in a blue shift of band ascribed to the $-\mathrm{C}-\mathrm{O}$ stretching vibrations of alcohol group at $1055 \mathrm{~cm}^{-1}$.

\section{Zinc white reconstructed tempera model paint specimens}

As with the previously described reconstructed tempera model paint specimen's, changes will be discussed using the specimen prepared with $75 \mathrm{wt} \%$ pigment content (Figure 8.1.3.1.8). The most significant IR absorption bands obtained for the model egg tempera paint specimens prepared with zinc white at 10, 30, 50 and $75 \mathrm{wt} \%$ are summarized in the Table 12.3 in annexes. 


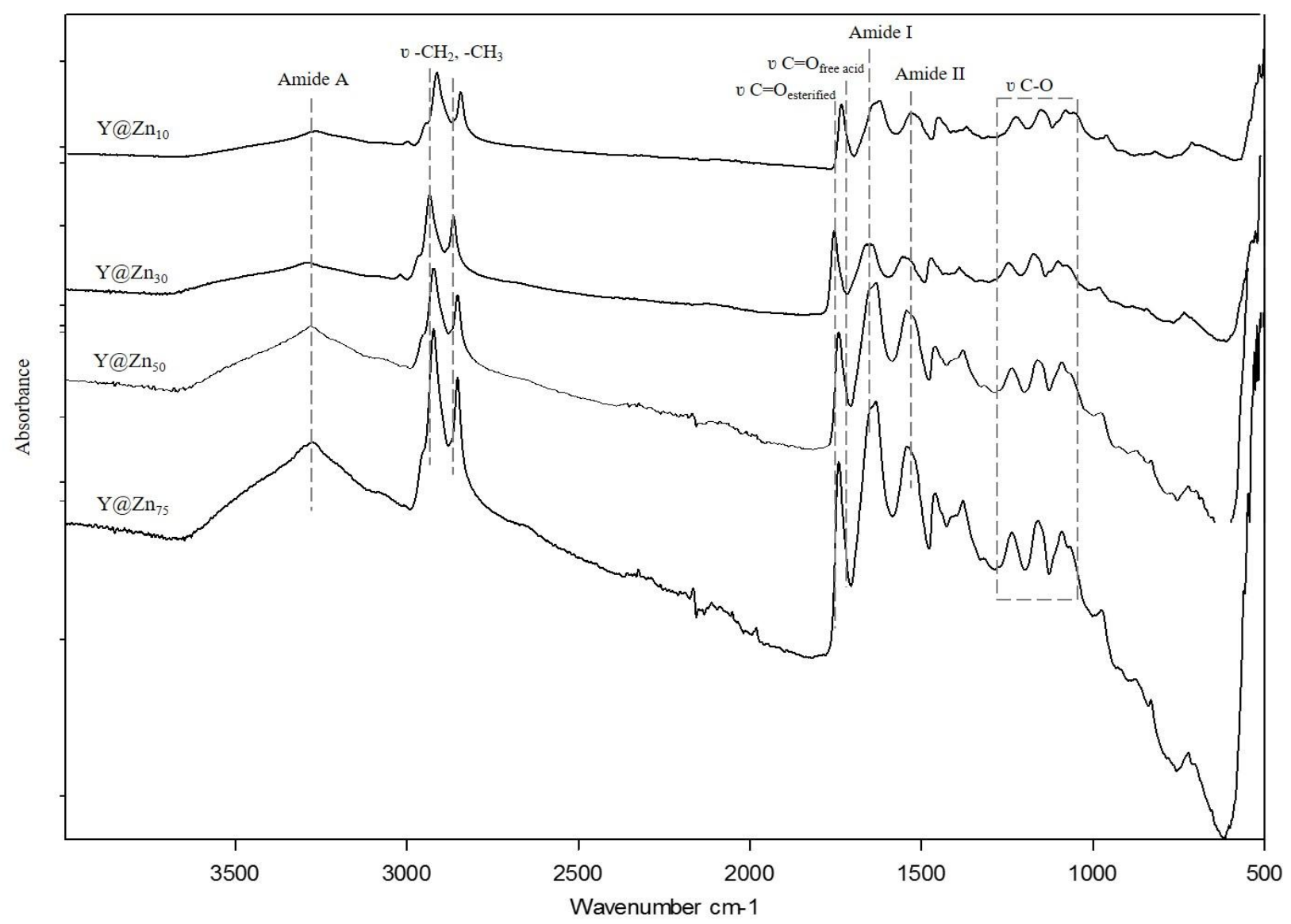

Figure 8.1.3.1.8. IR spectra obtained for the series of Y@Zn tempera paint specimens at 10, 30, 50 and 75 wt $\%$ pigment content.

\section{Proteins}

Using the second derivative and deconvolved IR spectra a blue shift of the primary maximum of the amide I band at $1629 \mathrm{~cm}^{-1}$ was observed for the $\mathrm{Y} @ \mathrm{Zn}_{75}$ specimen when compares it with the blank-egg yolk specimen. Literature associates this band to intramolecular $\beta$-sheet conformation (Byler and Susi, 1986; Dong et al., 1990, 1992; Furlan et al., 2007). Selfdeconvolution of the amide I allows the identification of the amide conformation components. Bands at 1692, 1683, 1674 and $1668 \mathrm{~cm}^{-1}$ (turns/bends), bands at 1661, 1657 and $1651 \mathrm{~cm}^{-1}$ ( $\alpha$-helix), bands at 1644 and $1640 \mathrm{~cm}^{-1}$ (random coil) and bands at 1633, 1630, 1626, 1618 and 1612 ( $\beta$-sheet) (Figure 8.1.3.1.9). Curve fitting of the amide I band determines the fraction contribution for each conformation. Increase of the intramolecular $\beta$ sheet conformation accompanied of a decrease of the intermolecular $\beta$-sheet conformation (Table 8.1.3.1.1). No significant changes were observed in the fraction contribution of the random coil, $\alpha$-helix and turns/bends conformations. 


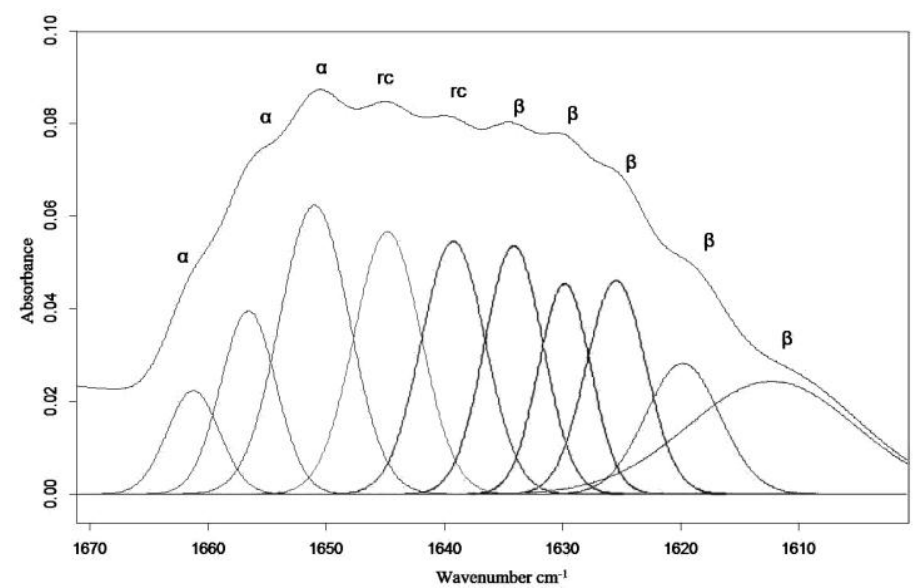

Figure 8.1.3.1.9. Amide I curve fitted band for $\mathrm{Y} @ \mathrm{Zn}_{75}$ specimen with fitted band components: ( $\beta$ ) $\beta$-sheet, (rc) random coil. $(\alpha)$ helical, $(\mathrm{t})$ turns.

In accordance with the above mentioned, prior experiments correlate these changes in percent area contribution to an interaction between egg proteins and metal centers in the pigment surface. The characteristic IR bands of Zn-protein complexes also appear in the region 1500$1600 \mathrm{~cm}^{-1}$ (Erhardt et al., 2005; Nara et al., 2013). The appearance of a new weak band at $1557 \mathrm{~cm}^{-1}$ in the Y@ $\mathrm{Zn}_{75}$ (Erhardt et al., 2005; Venyaminov and Kalnin, 1990) IR spectrum suggests the formation of these carboxylate-Zn complexes at lower extent. But it cannot be said with absolute certainly in this study, due to the overlapping with the amide II and bands arising from the carboxylic group in the amino acid side chains. Besides, bands due to metal complexes formed with the carboxylate groups from NLs and PLs occurs in this same frequency range.

Neutral lipids (NLs) and Phospholipids (PLs)

Fatty acids unsaturation of triglycerides from PLs at $3007 \mathrm{~cm}^{-1}$ has vanished, this means that the pigment is promoting polymerization of triglycerides. The absorption band at $1709 \mathrm{~cm}^{-1}$ has been assigned to the free fatty acids released from NLs suggesting hydrolysis in a small fraction of NLs.

Curve fitting of the bands in the region $1800-1700 \mathrm{~cm}^{-1}$ allows calculate the ratios of the individual fitted bands ascribed to carbonyl groups in free fatty acids and carbonyl groups (Figure 8.1.3.1.10). Result for the $\mathrm{Y} @ \mathrm{Zn}_{75}$ specimen is summarized in Table 8.1.3.1.3, and shows an important increase of the content of free fatty acids for the $\mathrm{Y} @ \mathrm{Zn}_{75}$ specimen in comparison with the blank-egg yolk. This confirms zinc white pigment, like massicot, remarkably promotes hydrolysis of triglycerides. 


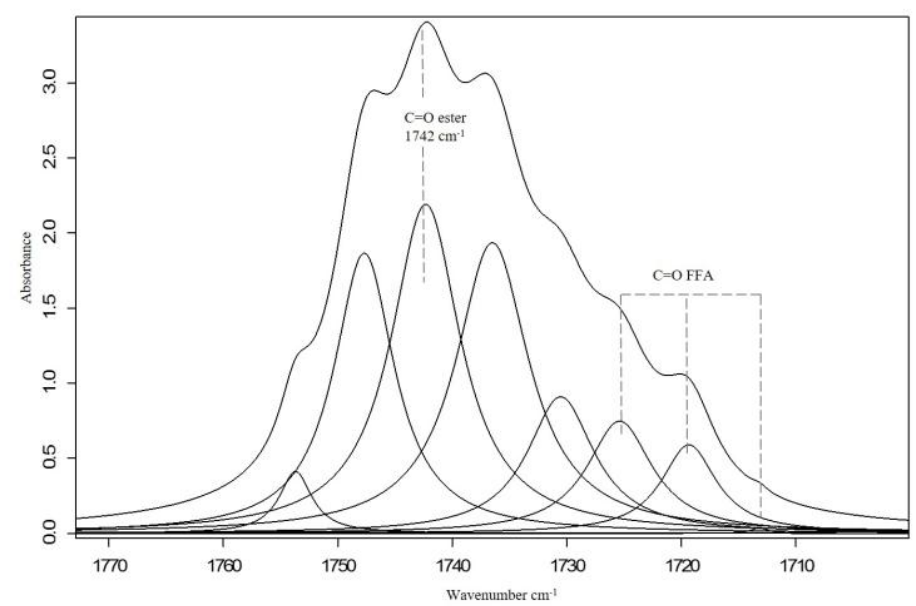

Figure 8.1.2.2.10. Carbonyl curve fitted band for $\mathrm{Y} @ \mathrm{Zn}_{75}$ specimen with fitted band components.

An increase of the $\mathrm{I}_{\mathrm{AI}} / \mathrm{I}_{\mathrm{AI}}$ ratio was also observed for the $\mathrm{Y} @ \mathrm{Zn}_{75}$ specimens (see Table 8.1.3.1.2) suggesting the formation of metal-carboxylate complexes from free fatty acids released from NLs. This result is in agreement with the appearance of a shoulder at $1538 \mathrm{~cm}^{-1}$ which is associated to stretching vibrations of $\mathrm{Zn}$-carboxylate groups formed from free fatty acids and carboxylated residues from NLs and PLs (Mazzeo et al., 2008).

Shift of bands ascribed to symmetric stretching vibrations of phosphate groups associated to metal-complexation of the phosphate and phosphonate groups was observed in the $\mathrm{Y} @ \mathrm{Zn}_{75}$ spectrum. $v_{\mathrm{s}} \mathrm{PO}_{2^{-}}$IR band is shifted from 1086 to $1089 \mathrm{~cm}^{-1}$ and $v_{\mathrm{s}} \mathrm{P}-\mathrm{O}-\mathrm{C}$ band is shifted from 1063 to $1066 \mathrm{~cm}^{-1}$. Shift in these bands confirm the occurrence of PLs-Zn interaction between phosphate groups from protein phosphodiesters and $\mathrm{Zn}$ centers in the surface of the pigment grains.

These results are confirmed by the emergence of a new weak band in the 1000-970 $\mathrm{cm}^{-1}$ region, more specific at $976 \mathrm{~cm}^{-1}$. According to literature, this band is produced by stretching vibrations of $\mathrm{P}-\mathrm{O}-\mathrm{X}$ bond $(\mathrm{X}=$ metal atom) due to the interactions between polar phosphate with the pigment surface (Castellani et al., 2008; Cagnasso et al., 2010; Omoike et al., 2004; Parikh and Chorover, 2006; Tejedor-Tejedor and Anderson, 1990; Andersson and Porath, 1986; Goulas et al., 1996; Bonnet et al., 2010).

Cholesterol

Modifying effect of the pigment results in a blue shift of band ascribed to the $-\mathrm{C}-\mathrm{O}$ stretching vibrations of alcohol group at $1055 \mathrm{~cm}^{-1}$.

\section{Cadmium yellow reconstructed model paint specimens}

Like the previously described reconstructed model paint specimens the results obtained for cadmium yellow specimens will be discussed considering the model paint prepared with 75 wt\% pigment content (Figure 8.1.3.1.11). Table 12.4 in the annexes list the main IR 
absorption bands obtained for the $\mathrm{Y} @ \mathrm{Cd}$ reconstructed tempera model paint specimens prepared at 10, 30, 50 and $75 \mathrm{wt} \%$ compared to the $\mathrm{Y}$ specimen.

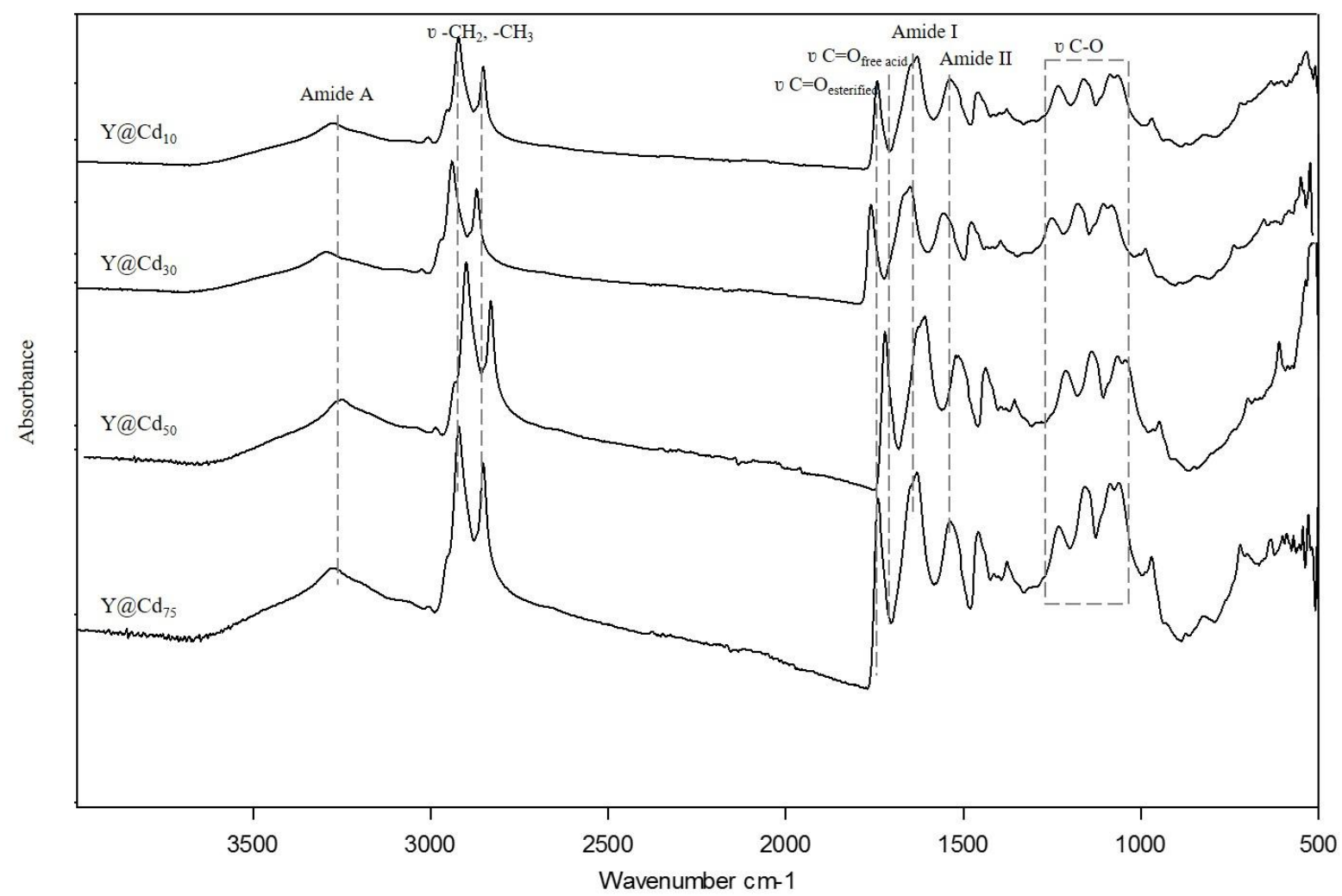

Figure 8.1.3.1.11. IR spectra obtained for the series of $\mathrm{Y} @ \mathrm{Cd}$ tempera paint specimens at 10, 30, 50 and $75 \mathrm{wt} \%$ pigment content.

\section{Proteins}

No significant changes were observed for the band assigned to amide A at $3278 \mathrm{~cm}^{-1}$ and the band at $3069 \mathrm{~cm}^{-1}$ associated with the amide B. The main changes were observed in the amide I range. In the second derivate spectrum was observed a blue shift of the maximum of the amide I band from $1629 \mathrm{~cm}^{-1}$ to $1630 \mathrm{~cm}^{-1}$ ascribed to the intramolecular $\beta$-sheet conformation. The deconvolved spectrum obtained showed several components bands at $1661,1657,1651$ and $1648 \mathrm{~cm}^{-1}$ for the $\alpha$-helix. As well as, bands at 1630, 1626, 1618 and $1612 \mathrm{~cm}^{-1}$ for the $\beta$-sheet component, and bands at 1682,1674 and $1668 \mathrm{~cm}^{-1}$ for the turns and bends structure (Figure 8.1.3.1.12). Curve fitting was also performed (see Table 8.1.3.1.1) showing a notable increase of the percent area contribution of intramolecular $\beta$ sheet conformation for the paint specimens was observed as well as, a decrease in the contribution of the intermolecular $\beta$-sheet conformation. The curve-fitting also showed an increase in the helical structure accompanied of a decrease in the percent area contribution of the random coil conformation.

A slight increase of the $\mathrm{I}_{\mathrm{AII}} / \mathrm{I}_{\mathrm{AI}}$ ratio was also observed for the $\mathrm{Y} @ \mathrm{Cd}_{75}$ specimens (see Table 8.1.3.1.2), thus suggesting scarce formation of metal-carboxylate complexes from free fatty acids released from NLs. Weak shoulder at about $1536 \mathrm{~cm}^{-1}$ of Cd-carboxylate complexes is attributed to the interaction of Cd-protein. Nevertheless, formation of metal-protein complexes could not be ascertained unambiguously in the present study due to the overlapping with amide II and with bands arising from the carboxylic groups in the amino 
acid side chains and individual bands due to the metal complexes formed with carboxylate groups from NLs and PLs, that occurs in this same frequency range from 1500 to $1600 \mathrm{~cm}^{-1}$ (vide infra).

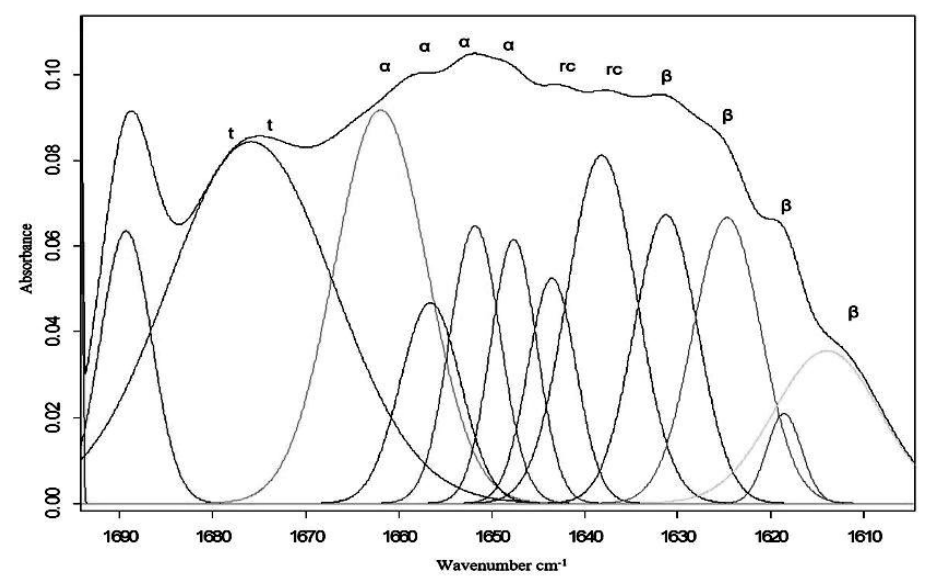

Figure 8.1.3.1.12. Amide I curve fitted band for $\mathrm{Y} @ \mathrm{Cd}_{75}$ specimen with fitted band components: $(\beta) \beta$-sheet, (rc) random coil. $(\alpha)$ helical, (t) turns.

Neutral lipids (NLs) and Phospholipids (PLs)

Appearance of the carboxylic acids absorption band at $1709 \mathrm{~cm}^{-1}$ in the $\mathrm{Y} @ \mathrm{Cd}_{75}$ specimen is associated to free fatty acids (palmitic acid, stearic acid, azelaic acid, etc.) released from NLs and PLs extends. Curve fitting of the deconvolved bands in the region $1800-1700 \mathrm{~cm}^{-1}$ related to the stretching vibrations of carbonyl groups was also carried out. Figure 8.1.3.1.13, shows the carbonyl curve fitted band for $\mathrm{Y} @ \mathrm{Cd}_{75}$ specimen with fitted band components. Ratios of individual fitted bands ascribed to carbonyl groups in free fatty acids and ester carbonyl groups $\left(\mathrm{I}_{\mathrm{FFA}} / \mathrm{I}_{\mathrm{E}}\right)$ have been calculated for the series of paint specimens with the highest pigment content and the blank. The values obtained are summarized in Table 8.1.3.1.3. It can be seen, that the presence of the pigment results in a slight increase of the content of free fatty acids. These values again confirm that pigments, in general, promote hydrolysis of triglycerides but this process is drastically minimized for NLs in egg yolk due to its particular microstructure that maintain NLs encapsulated inside LDL and HDL complex granular structures. 


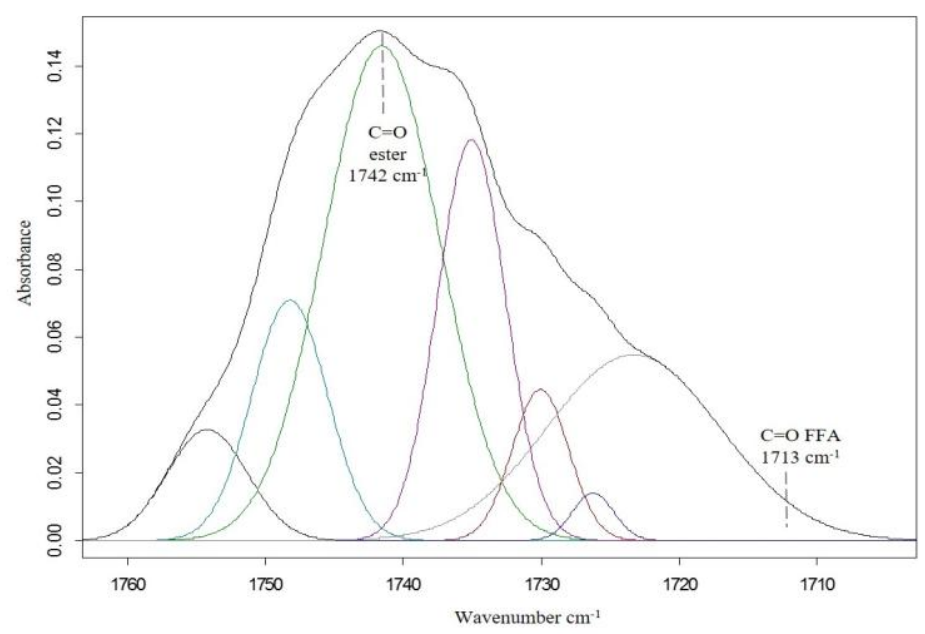

Figure 8.1.3.1.13. Carbonyl curve fitted band for $\mathrm{Y} @ \mathrm{Cd}_{75}$ specimen with fitted band components.

Bands associated to stretching vibrations of metal carboxylate groups formed from free fatty acids and carboxylate residues from NLs and PLs, which appear at $1543 \mathrm{~cm}^{-1}$ for cadmium yellow specimens (Mazzeo et al., 2008), are hardly recognized as they are overlapped with amide II band. Table 8.1.3.1.2, shows the values of $\mathrm{I}_{\mathrm{AII}} / \mathrm{I}_{\mathrm{AI}}$ band area ratios obtained from the four paint specimens and the egg yolk specimen. Nevertheless, contribution of NLs and PLs to the increased value of $\mathrm{I}_{\mathrm{AII}} / \mathrm{I}_{\mathrm{AI}}$ ratios in model paints should be low if it is taken into account the low amount of hydrolyzed fatty acids found in the tempera paint specimens (see low values of $\mathrm{I}_{\mathrm{FFA}} / \mathrm{I}_{\mathrm{E}}$ listed in Table 8.1.3.1.2). The most significant change for the $\mathrm{Y} @ \mathrm{Cd}_{75}$ specimens was a blue shift of the band at $1063 \mathrm{~cm}^{-1}$ to $1068 \mathrm{~cm}^{-1}$ attributed to the $v_{\mathrm{s}}$ (P-O-C) terminal phosphate. While the associated shift in $v_{\mathrm{s}}\left(\mathrm{PO}_{2}^{-}\right)$IR band to $1087 \mathrm{~cm}^{-1}$ indicate the PLS-metal interactions of phosphate groups, deriving principally from phosphodiester of proteins.

\section{Cholesterol}

Modifying effect of the pigment results in a blue shift of band ascribed to the $-\mathrm{C}-\mathrm{O}$ stretching vibrations of alcohol group at $1055 \mathrm{~cm}^{-1}$.

8.1.3.2. Characterization of the egg yolk-oil emulsion reconstructed model paints specimens.

\section{Egg yolk-oil emulsion film specimen}

Egg yolk-oil (YO) emulsion film specimen exhibited an IR spectrum dominated by bands associated to the egg yolk amide A $\left(3278 \mathrm{~cm}^{-1}\right)$, amide I $\left(1637 \mathrm{~cm}^{-1}\right)$ and amide II $\left(1536 \mathrm{~cm}^{-}\right.$ $\left.{ }^{1}\right)$ accompanied by bands characteristic of linseed oil such as methyl/methylene $\left(2948^{\mathrm{sh}}, 2922\right.$ $2870^{\text {sh }}$ and $2852 \mathrm{~cm}^{-1}$ ), carbonyl groups (1744 and $1720 \mathrm{~cm}^{-1}$ ), C-O stretching vibrations at 1235,1163 and $1097 \mathrm{~cm}^{-1}$ and shoulder at $3459 \mathrm{~cm}^{-1}$ assigned to the stretching of alcohol and hydroperoxide bonds formed as a result of the polymerization occurring in the oil during drying (Figure 8.1.3.2.1). 


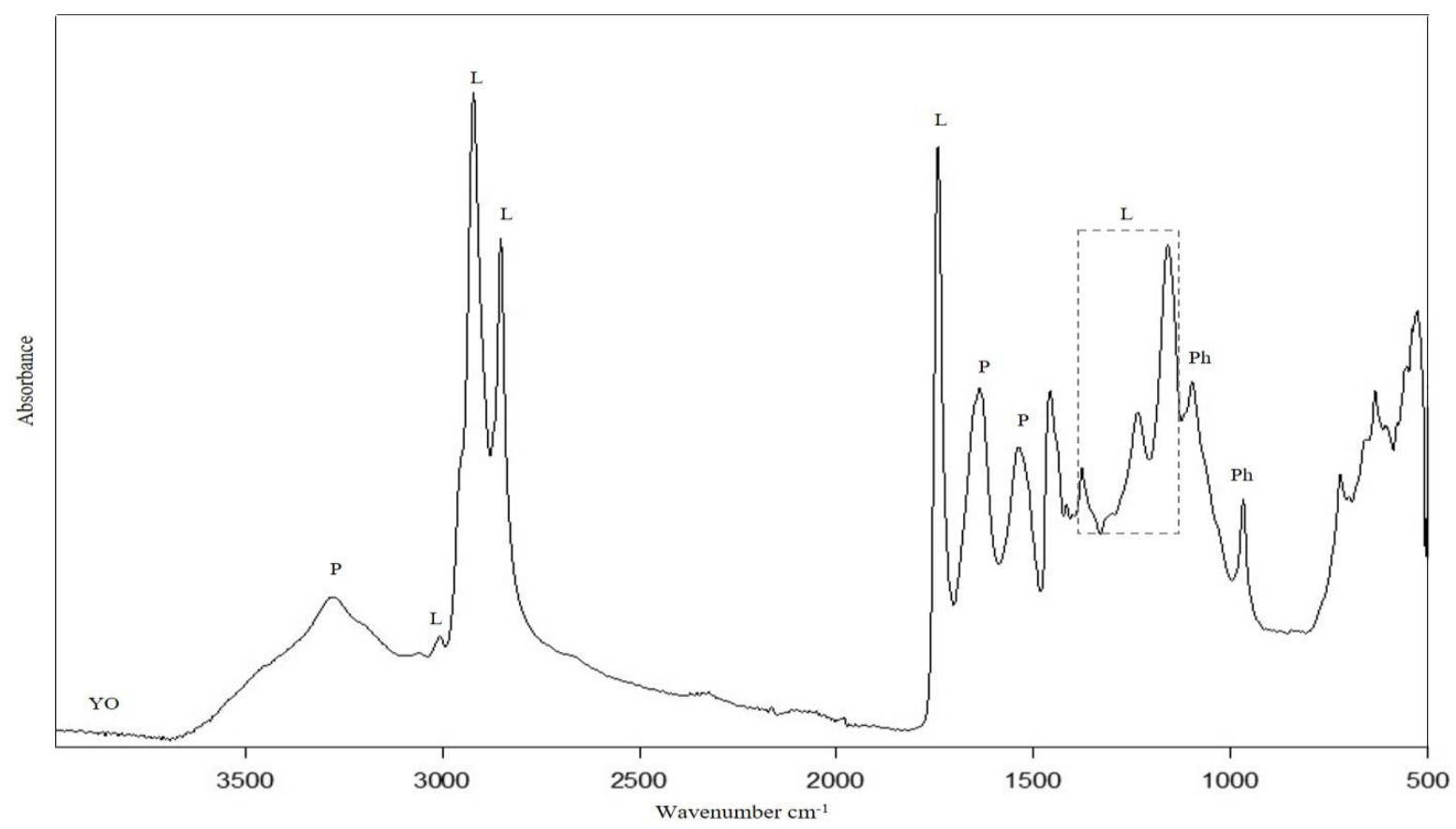

Figure 8.1.3.2.1. IR absorption spectrum obtained for the egg yolk-oil emulsion (YO) specimen. Assignment of representative bands: proteins $(\mathrm{P})$; neutral lipids $(\mathrm{L})$; and phospholipids $(\mathrm{Ph})$.

\section{Proteins}

Characteristic vibrational bands from the amide A $\left(3278 \mathrm{~cm}^{-1}\right)$, amide $\mathrm{B}\left(3055 \mathrm{~cm}^{-1}\right)$, amide I and amide II have been identified. The average frequency position of the main component of the amide I band at $1637 \mathrm{~cm}^{-1}$ is associated to the random coil conformation, in contrast with the egg yolk specimen which maximum appears at $1629 \mathrm{~cm}^{-1}$ associated to $\beta$-sheet conformation, the dominant one for protein in dried state (Figure 8.1.3.2.2). This conformational change could be attributed to the oxidation of $\mathrm{C}=\mathrm{C}$ present in the linseed oil during the drying of the film, which present absorbance bands in the $1620-1690 \mathrm{~cm}^{-1}$ region. (Duce et al., 2012). Shoulders at 1651 and $1658 \mathrm{~cm}^{-1}$ are associated to $\alpha$-helix structure. Sub-band at $1680 \mathrm{~cm}^{-1}$ is associated to turns or loops. Sub-bands at 1618 , and 1625 $\mathrm{cm}^{-1}$ are associated to intermolecular hydrogen bonding aggregated proteins, antiparallel $\beta$ sheet conformation and aromatic ring vibrations of tyrosine residues in LDL and HDL. Other sub-band at $1630 \mathrm{~cm}^{-1}$ is associated to intermolecular $\mathrm{C}=\mathrm{O}$ vibrations. 


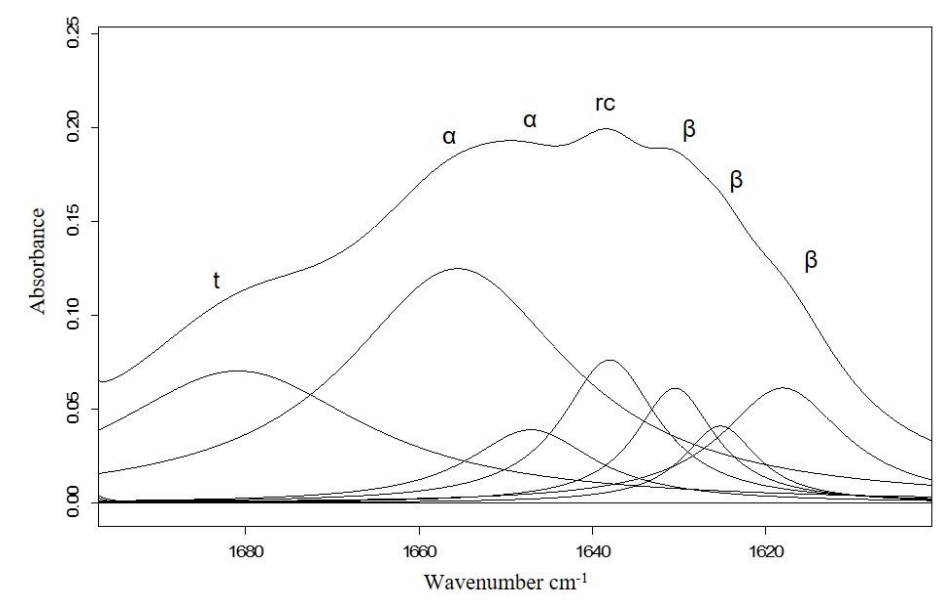

Figure 8.1.3.2.2. Amide I curve fitted band for YO specimen with fitted band components. Assignment of bands conformations: $\beta$-sheet $(\beta)$, random coil (rc), $\alpha$-helix $(\alpha)$ and turns (t).

As with the Y specimen's, deconvolution and curve fitted procedures allow the quantification of the amide I conformation percent contribution. Comparing these results with the obtained for the $\mathrm{Y}$ specimen an important increase of the $\alpha$-helix conformation with the respective decrease of the intermolecular $\beta$-sheet conformation was observed. Increase of the $\alpha$-helix structure suggests the formation of a more compact structure of the protein molecules that now are coexisting with polymerized triglyceride networks. No significant variations were obtained for the other conformations (see Table 8.1.3.2.1).

Table 8.1.3.2.1. Percent area contribution of amide I components for Y and YO specimens.

\begin{tabular}{|c|c|c|c|}
\hline \multirow{2}{*}{$\begin{array}{c}\text { Predominant } \\
\text { conformations }\end{array}$} & \multirow{2}{*}{ Frequency range $\left.\mathbf{( c m}^{-\mathbf{1}}\right)$} & \multicolumn{2}{|c|}{ Percent area contribution } \\
\cline { 3 - 4 } & & $\mathbf{Y}$ & YO \\
\hline Intermolecular $\beta$-sheet & $1611-1625$ & 33 & 14 \\
\hline Intramolecular $\beta$-sheet & $1625-1637$ & 8 & 7 \\
\hline Random coil & $1637-1645$ & 14 & 10 \\
\hline$\alpha$-helix & $1645-1662$ & 25 & 45 \\
\hline Turns & $1662-1682$ & 20 & 24 \\
\hline
\end{tabular}

The amide II band maximum absorption band at $1536 \mathrm{~cm}^{-1}$ is attributed to the $\mathrm{N}-\mathrm{H}$ bending vibrations of amide groups of the peptide backbone in proteins. The $\beta$-sheet conformation was the dominant structure obtained for the amide II by means of FSD, as in the Y specimen.

NLs and PLs

The relative increase in the $\mathrm{C}=\mathrm{O}$ stretching vibration at $1744 \mathrm{~cm}^{-1}$ when compared to the IR spectrum obtained for $\mathrm{Y}$ specimen is coherent with the presence of abundant triglycerides from the linseed oil. The band at $1235 \mathrm{~cm}^{-1}$, is attributed to the $-\mathrm{C}-\mathrm{O}$ of triglyceride ester linkage of NLs (Salvadó et al., 2009; van der Weerd et al., 2005) and to asymmetric stretching of $\mathrm{PO}_{2}^{-}$.

Carboxylic moieties were also confirmed in the YO specimen by the weak band at $1416 \mathrm{~cm}^{-1}$ (Cagnasso et al., 2010; van der Weerd et al., 2005; Omoike et al., 2004) associated to the diversification in deprotonated carboxylated anion of acidic species formed from NLs, PLs 
proteins together with contribution from $\left(-\mathrm{CH}_{2}-\mathrm{COOR}\right)$ stretch of the PLs, phosphatidylcholine (PC) (Cagnasso et al., 2010). Only one band associated to terminal phosphate vibrations at $1141 \mathrm{~cm}^{-1}$ was identified in the YO specimen, when compared to the $\mathrm{Y}$ specimen. The band at $1065 \mathrm{~cm}^{-1}$ attributed to $v_{\mathrm{s}}(\mathrm{P}-\mathrm{O}-\mathrm{C})$ terminal phosphate vibrations of the phosphatidic acid (Cagnasso et al., 2010) and band at $967 \mathrm{~cm}^{-1}$ associated to $\left(\mathrm{N}-\mathrm{CH}_{3}\right)$ asymmetric stretch (Cagnasso et al., 2010; Tantipolphan et al., 2007) were identified as in the Y specimen.

Cholesterol

A band corresponding to cholesterol was identified at $1052 \mathrm{~cm}^{-1}$ attributed to the $-\mathrm{C}-\mathrm{O}$ stretching vibrations of the saturated secondary alcohol groups.

\section{Egg yolk- oil emulsion reconstructed model paint specimens}

A series of specimens (YO@pigment ${ }_{\mathrm{wt}} \%$ ) were prepared at different pigment concentrations $(10,30,50$ and $75 \mathrm{wt} \%)$ as for the egg yolk-tempera model paint specimens. For the characterization of the changes observed in the IR spectra associated with the pigment-binder interactions the specimens prepared at the highest pigment concentration of $75 \%$ have been used. (Figure 8.1.3.2.3). 


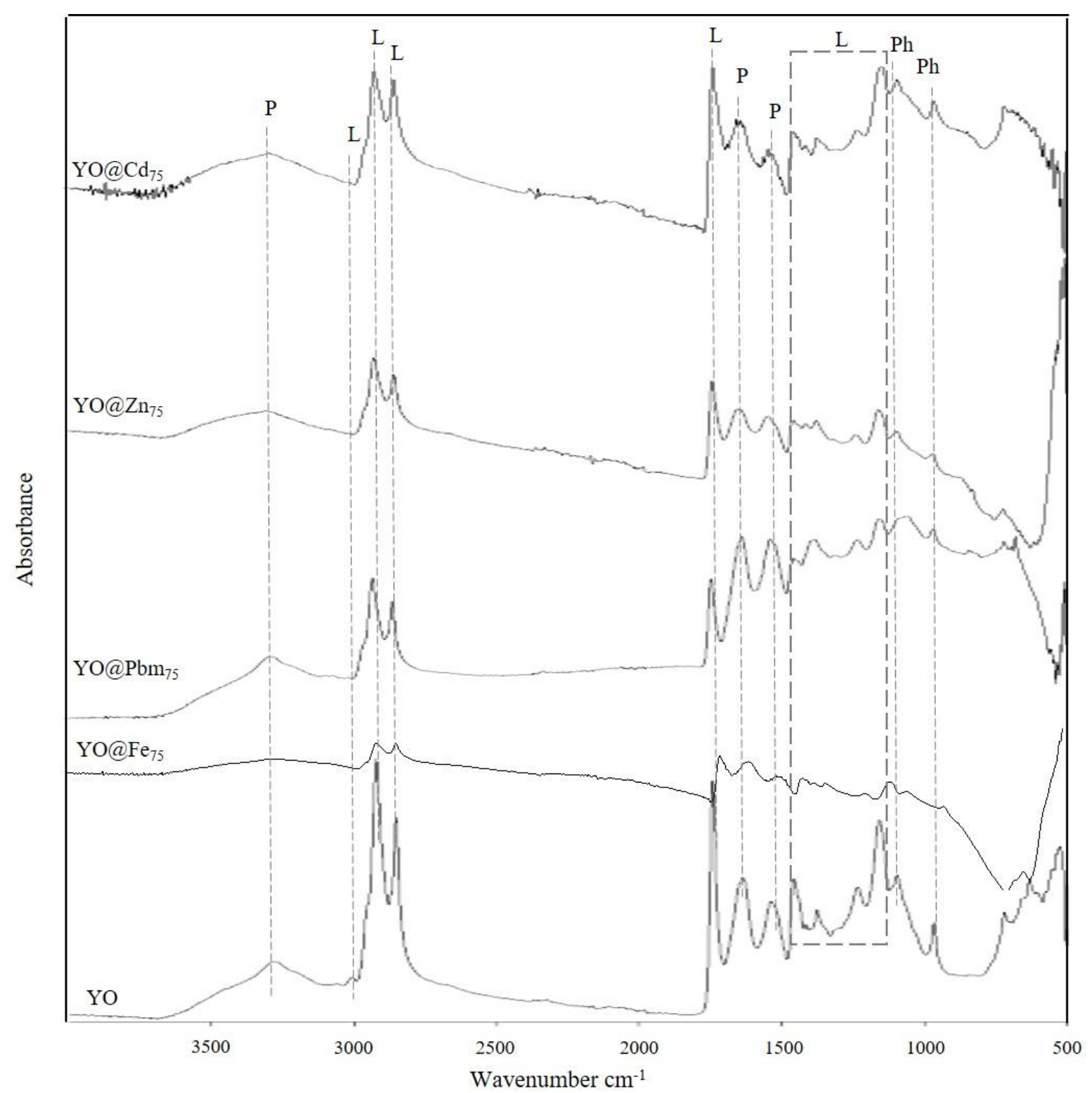

Figure 8.1.3.2.3. IR absorption spectra obtained for the YO specimens prepared at pigment concentration of $75 \mathrm{wt} \%$ : iron oxide red $\left(\mathrm{YO} @ \mathrm{Fe}_{75}\right)$, massicot $\left(\mathrm{YO} @ \mathrm{Pbm}_{75}\right)$, zinc white $\left(\mathrm{YO} @ \mathrm{Zn}_{75}\right)$ and cadmium yellow $\left(\mathrm{YO} @ \mathrm{Cd}_{75}\right)$. Assignment of representative bands: proteins $(\mathrm{P})$; neutral lipids $(\mathrm{L})$; and phospholipids $(\mathrm{Ph})$.

\section{Iron oxide red reconstructed model paint specimens}

The IR spectrum of the $\mathrm{YO} @ \mathrm{Fe}_{75}$ specimen exhibited scattering effect produced by the pigment (Figure 8.1.3.2.4). The main features obtained for iron oxide red egg yolk-oil emulsion reconstructed model paint specimens prepared at 10, 30, 50 and $75 \mathrm{wt} \%$ are summarized in Table 12.5 in the annexes. 


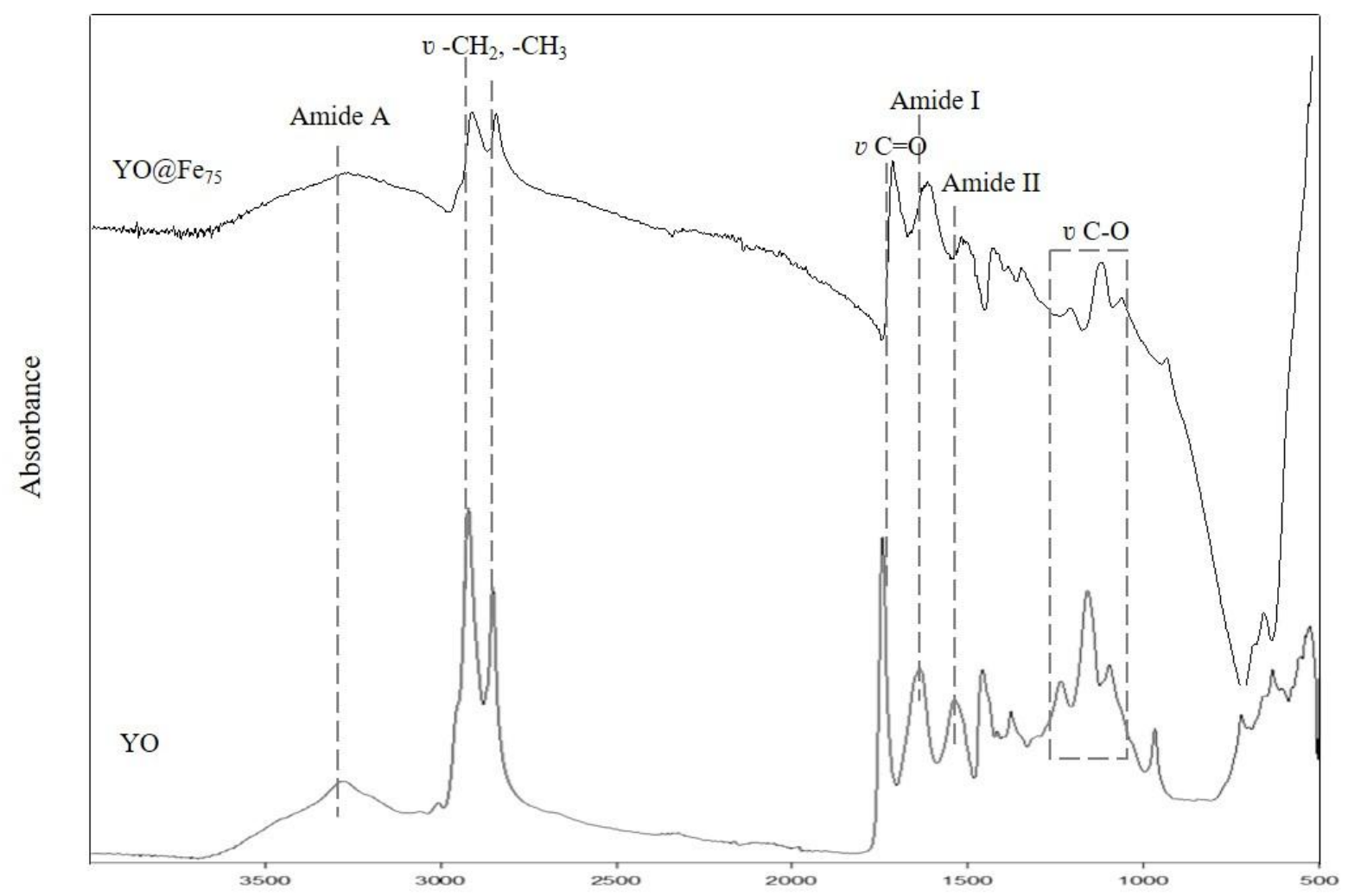

Wavenumber $\mathrm{cm}^{-1}$

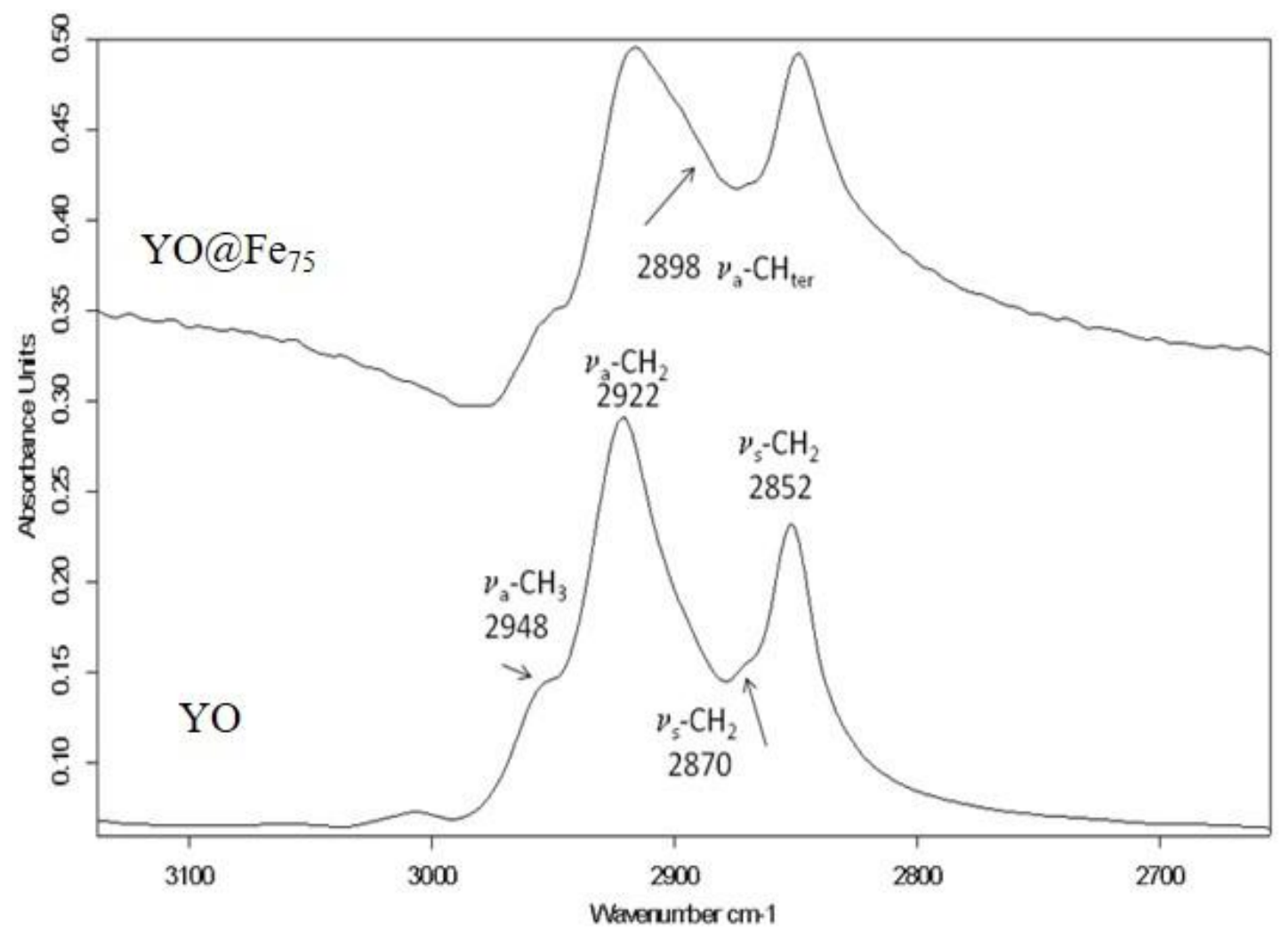

Figure 8.1.3.2.4. IR spectrum obtained for the $\mathrm{YO} @ \mathrm{Fe}_{75}$ reconstructed model paint specimen compared with that of the $\mathrm{YO}$ specimen (top). Detail of the methyl/methylene region (bottom). 


\section{Proteins}

The amide I band exhibits a maximum at $1650 \mathrm{~cm}^{-1}$, associated with the $\alpha$-helix conformation. The shift of this band maximum when compared to YO specimen at $1637 \mathrm{~cm}^{-1}$, indicates a strong interaction with the pigment (Duce et al., 2013) and with the oil triglycerides and their oxidation and hydrolysis products. FSD of the $\mathrm{YO} @ \mathrm{Fe}_{75} \mathrm{IR}$ spectrum allows the identification of the amide I sub-bands (Figure 8.1.3.2.5). The intermolecular $\beta$ sheet conformation exhibited sub-bands at 1609, 1611 and $1622 \mathrm{~cm}^{-1}$. Sub-bands at 1630 and $1638 \mathrm{~cm}^{-1}$ are attributed to intramolecular $\beta$-sheet and random coil conformations, respectively. The $\alpha$-helix conformation exhibited sub-bands at 1646, 1650, 1653, 1655 and $1659 \mathrm{~cm}^{-1}$ and turns and bends conformation showed a sub-band at $1665 \mathrm{~cm}^{-1}$. Comparison between the values of the conformation percent contribution found in the YO blank specimen and the YO@ $\mathrm{Fe}_{75}$ specimen shows an important increase of the intermolecular and intramolecular $\beta$-sheet conformations with the corresponding decrease in the $\alpha$-helix and turns conformations (see Table 8.1.3.2.2).

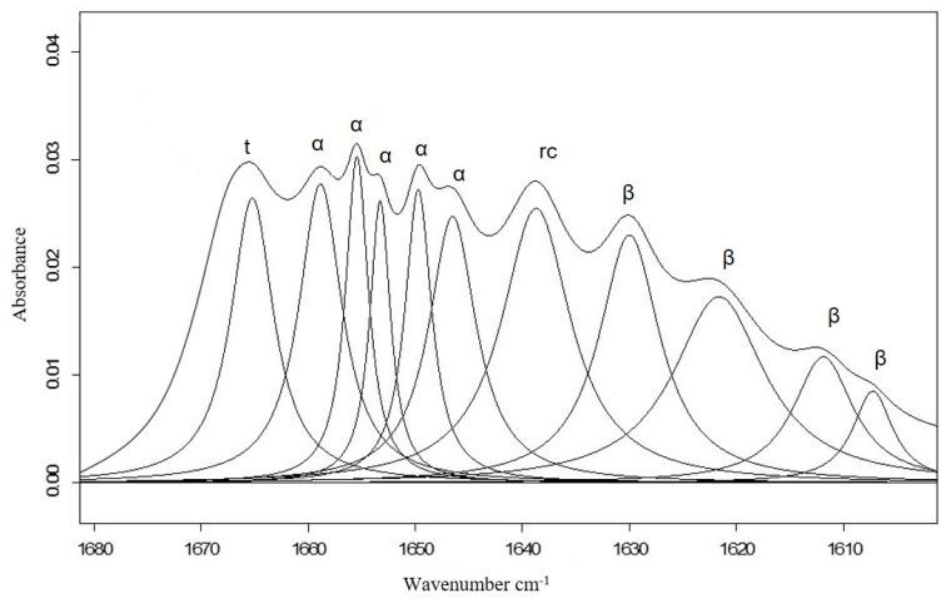

Figure 8.1.3.2.5. Amide I curve fitted band for $\mathrm{YO} @ \mathrm{Fe}_{75}$ specimen with fitted band components. Assignment of bands conformations: $\beta$-sheet $(\beta)$, random coil $(\mathrm{rc}), \alpha$-helix $(\alpha)$ and turns $(\mathrm{t})$.

Table 8.1.3.2.2. Percent area contribution of amide I components for YO@Pigment 75 specimens.

\begin{tabular}{|c|c|c|c|c|c|c|}
\hline \multirow{2}{*}{$\begin{array}{l}\text { Predominant } \\
\text { conformations }\end{array}$} & \multirow{2}{*}{$\begin{array}{l}\text { Frequency } \\
\text { range }\left(\mathrm{cm}^{-1}\right)\end{array}$} & \multicolumn{5}{|c|}{$\begin{array}{l}\text { Amide I \% contribution in the reconstructed egg yolk- oil } \\
\text { emulsion model paint specimens }\end{array}$} \\
\hline & & YO & $\mathbf{Y O @ F e _ { 7 5 }}$ & YO@Pbm & YO@ $\mathbf{Z n}_{75}$ & $\mathrm{YO@Cd_{75 }}$ \\
\hline Intermolecular $\beta$-sheet & $1611-1625$ & 14 & 27 & - & 16 & 22 \\
\hline Intramolecular $\beta$-sheet & $1625-1637$ & 7 & 16 & 29 & 6 & 11 \\
\hline Random coil & $1637-1645$ & 10 & 23 & - & 31 & 20 \\
\hline$\alpha$-helix & $1645-1662$ & 45 & 30 & 41 & 13 & 23 \\
\hline Turns & $1662-1682$ & 24 & 5 & 30 & 60 & 25 \\
\hline
\end{tabular}

The maximum of the amide II band at $1535 \mathrm{~cm}^{-1}$ is associated to $\beta$-sheet conformations. Subbands at 1512 and $1501 \mathrm{~cm}^{-1}$ were identified using the second derivative and FSD procedures. Decrease in the area of the amide II band with respect to the area of the amide I band has been correlated with the formation of aggregates of a high molecular weight, probably due to the oil protein-metal interactions (Table 8.1.3.2.3). 
Table 8.1.3.2.3. Values of amide II plus metal carboxylate complexes/amide $\mathrm{I}\left(\mathrm{I}_{\mathrm{AII}} / \mathrm{I}_{\mathrm{AI}}\right)$ band area ratio for $\mathrm{YO}$ specimen and $\mathrm{YO} @ \mathrm{Fe}_{75}, \mathrm{Y} @ \mathrm{Pbm}_{75}, \mathrm{Y} @ \mathrm{Zn}_{75}$ and $\mathrm{Y} @ \mathrm{Cd}_{75}$ reconstructed model paint specimens. Wavenumber ranges: AI (1700-1600 $\left.\mathrm{cm}^{-1}\right)$ and AII $\left(1600-1500 \mathrm{~cm}^{-1}\right)$.

\begin{tabular}{|c|c|}
\hline Specimens & Band area ratio $\mathbf{I}_{\mathbf{A I I}} / \mathbf{I}_{\mathbf{A I}}$ \\
\hline $\mathrm{YO}$ & 0.56 \\
\hline $\mathrm{YO} @ \mathrm{Fe}_{75}$ & 0.48 \\
\hline $\mathrm{YO} @ \mathrm{Pbm}_{75}$ & 0.77 \\
\hline $\mathrm{YO} @ \mathrm{Zn}_{75}$ & 0.68 \\
\hline $\mathrm{YO} @ \mathrm{Cd}_{75}$ & 0.62 \\
\hline
\end{tabular}

NLs and PLs

A new shoulder at $2998 \mathrm{~cm}^{-1}$ ascribed to stretching vibrations of tertiary - $\mathrm{CH}$ groups appears in the IR spectrum of the $\mathrm{YO} @ \mathrm{Fe}_{75}$ specimen as can be seen in Figure 8.1.3.2.4b. New bands at 1707,1722 and $1738 \mathrm{~cm}^{-1}$ are indicative of emergence of protonated carboxylic groups on fatty acids. Presence of a new absorption band at $1703 \mathrm{~cm}^{-1}$ attributed to fatty acids released from triglycerides was observed. The dissociated fatty acids also produce absorption bands at $1416 \mathrm{~cm}^{-1}$ and at $1400 \mathrm{~cm}^{-1}$ attributed to the $v_{\mathrm{s}}(\mathrm{C}-\mathrm{O})$ and $v_{\mathrm{as}}\left(\mathrm{CO}_{2}^{-}\right)$vibrations. Deconvolution allows to calculate the ratio of the individual fitted bands ascribed to carbonyl groups from free fatty acids and ester carbonyl groups $\left(\mathrm{I}_{\mathrm{FFA}} / \mathrm{I}_{\mathrm{E}}\right)$. The values obtained are summarized in Table 8.1.3.2.4. It can be seen that the presence of the pigment results in a slight increase of the content of free fatty acids. These values again confirm that pigments, in general, promote hydrolysis of triglycerides.

Table 8.1.3.2.4. $\mathrm{I}_{\mathrm{FFA}} / \mathrm{I}_{\mathrm{E}}$ values for the $\mathrm{YO}$ and the reconstructed model paint specimens at $75 \mathrm{wt} \%$.

\begin{tabular}{|c|c|}
\hline Specimens & $\mathbf{I}_{\mathbf{F F A}} / \mathbf{I}_{\mathbf{E}}$ \\
\hline $\mathrm{YO}$ & 0.09 \\
\hline $\mathrm{YO} @ \mathrm{Fe}_{75}$ & 1.29 \\
\hline $\mathrm{YO} @ \mathrm{Pbm}_{75}$ & 1.04 \\
\hline $\mathrm{YO} @ \mathrm{Zn}_{75}$ & 0.39 \\
\hline $\mathrm{YO} @ \mathrm{Cd}_{75}$ & 0.50 \\
\hline
\end{tabular}

Appearance of another new band at $1578 \mathrm{~cm}^{-1}$ attributed to the $v_{\mathrm{as}}\left(\mathrm{CO}_{2}^{-}\right)$is associated to the PLs polar head interactions with the iron oxide red pigment grains. The band associated to the ester groups in triglyceride $\mathrm{C}=\mathrm{O}$ stretching vibrations exhibit a blueshift from $1744 \mathrm{~cm}^{-1}$ in YO specimen to $1740 \mathrm{~cm}^{-1}$, due to the interactions with the pigment. Bands at 1142 and $997 \mathrm{~cm}^{-1}$ are attributed to terminal phosphate vibrations. In particular, band at $997 \mathrm{~cm}^{-1}$ is attributed to the formation of a P-OFe inner-sphere complex (Cagnasso et al., 2010). This band exhibits low intensity when compared to the $\mathrm{Y} @ \mathrm{Fe}_{75}$, probably due to the dilution effect associated to the presence of linseed oil.

Cholesterol 
Bands associated with cholesterol where not identified in the IR spectra obtained for the YO@ $\mathrm{Fe}_{75}$ specimen due to the scattering effect of the pigment and the dilution effect associated to the presence of linseed oil.

\section{Massicot reconstructed model paint specimens}

IR spectrum obtained for the $\mathrm{YO} @ \mathrm{Pbm}_{75}$ reconstructed model paint specimen was dominated by the bands attributed to Amide A $\left(3283 \mathrm{~cm}^{-1}\right)$, amide B $\left(3064 \mathrm{~cm}^{-1}\right)$, amide I $\left(1631 \mathrm{~cm}^{-1}\right)$ and amide II $\left(1538 \mathrm{~cm}^{-1}\right)$ and the $-\mathrm{CH}_{3}$ and $-\mathrm{CH}_{2}$ - stretching vibrations (2922 and $2852 \mathrm{~cm}^{-1}$ ) (Figure 8.1.3.2.6). Table 12.6 in the annexes list the main IR absorption bands obtained for the YO@Pbm reconstructed tempera model paint specimens prepared at 10, 30, 50 and 75 wt\% compared to the YO specimen.

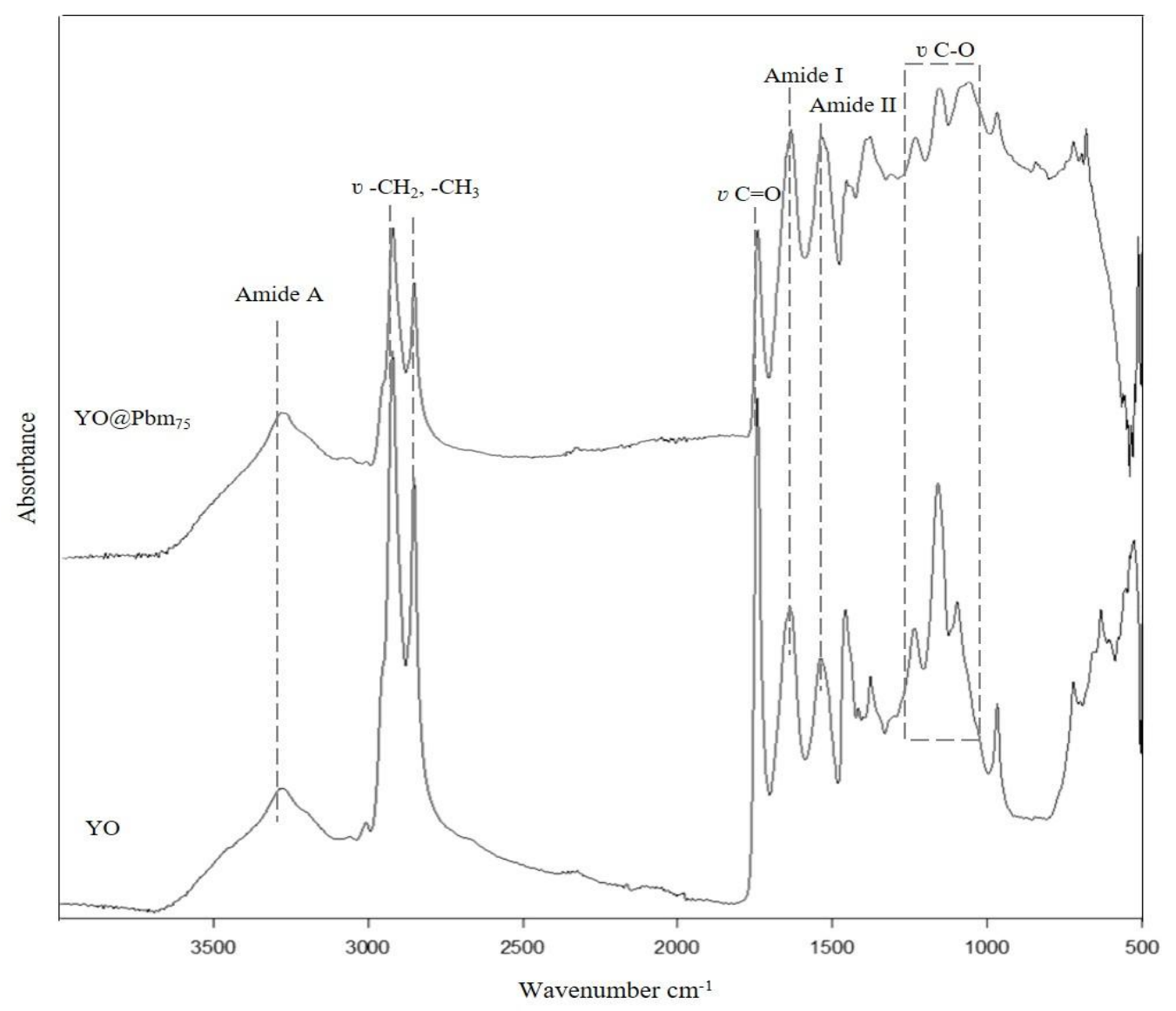




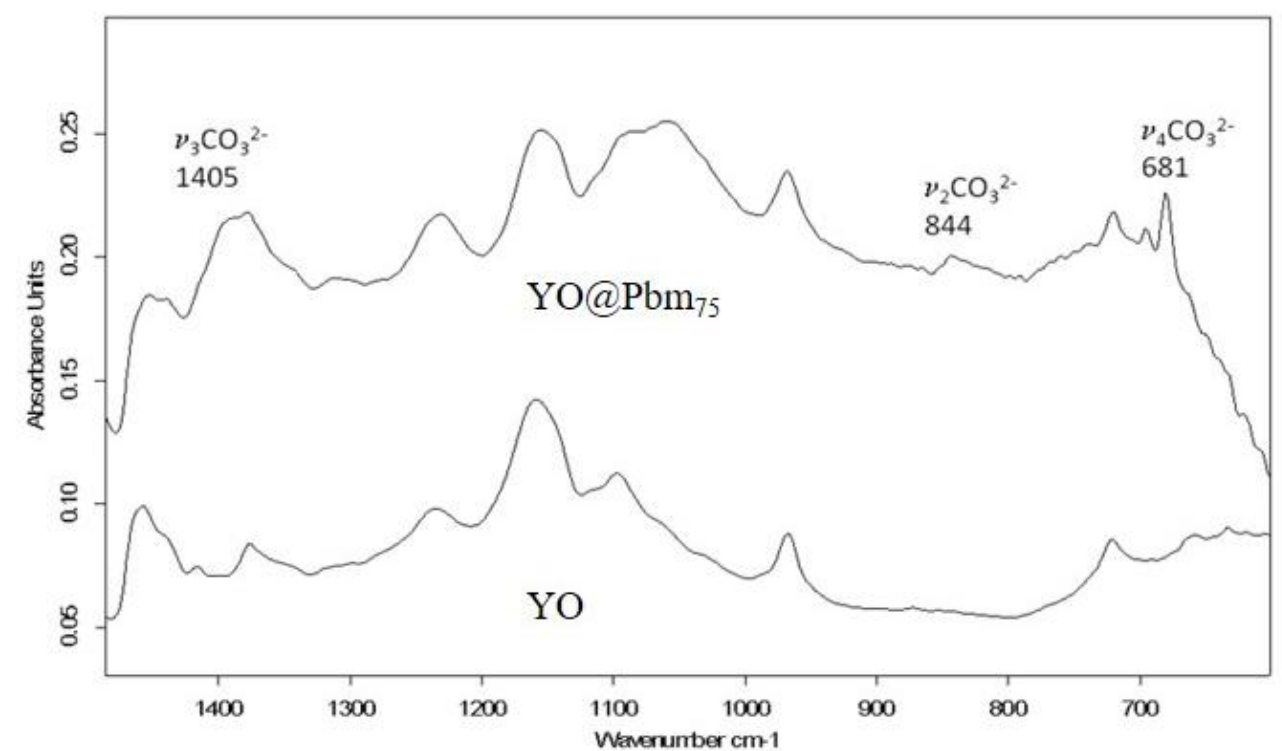

Figure 8.1.3.2.6. IR spectrum obtained for the $\mathrm{YO} @ \mathrm{Pbm}_{75}$ reconstructed model paint specimen compared with that of the YO specimen (top). Detail of the fingerprint region (bottom).

\section{Proteins}

Curve fitting of the amide I band with maximum at $1634 \mathrm{~cm}^{-1}$ was deconvolved for the characterization of the sub-bands components. Despite that, the redshift observed in this band when is compared with its counterpart in the YO specimen is indicative of changes in the protein secondary structure. Intramolecular $\beta$-sheet $\left(1631 \mathrm{~cm}^{-1}\right), \alpha$-helix $\left(1651 \mathrm{~cm}^{-1}\right)$ and turns $\left(1678 \mathrm{~cm}^{-1}\right)$ were the sub-bands conformation identified (Figure 8.1.3.2.7). Decrease of the contribution of the intermolecular $\beta$-sheet conformation suggests a significant disruption in protein-protein intermolecular interaction due to the presence of pigment and oil (Duce et al., 2013). Amide II band maximum was marked at $1538 \mathrm{~cm}^{-1}$ with $\beta$-sheet as predominant conformation.

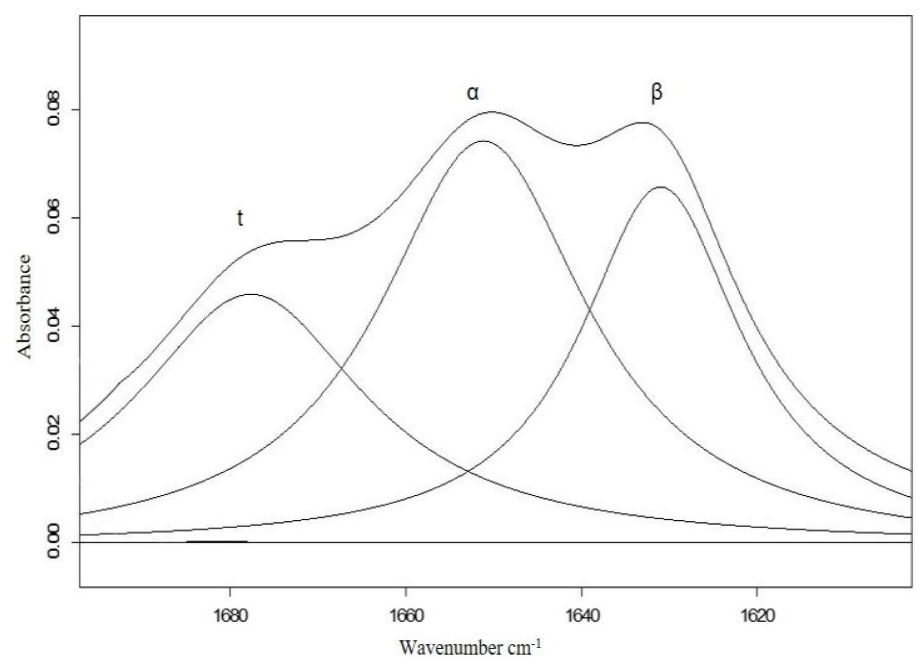

Figure 8.1.3.2.7. Amide I curve fitted band for $\mathrm{YO} @ \mathrm{Pbm}_{75}$ specimen with fitted band components. Assignment of bands conformations: $\beta$-sheet $(\beta)$, random coil (rc), $\alpha$-helix $(\alpha)$ and turns (t).

NLs and PLs 
Formation of lead carbonate was observed in the IR spectrum of $\mathrm{YO} @ \mathrm{Pbm}_{75}$ reconstructed model paint specimen, that exhibited distinctive absorption bands at 1405, 1050, 844 and 681 $\mathrm{cm}^{-1}$ (Figure 8.1.3.2.6). The formation of lead carbonate on massicot, may be the result of degradation phenomena (Mazzeo et al., 2008). Bands at 1541 and $1513 \mathrm{~cm}^{-1}$ attributed to $\mathrm{v}_{\mathrm{as}}\left(\mathrm{COO}^{-}\right)$of lead carboxylates could not be ascertained unambiguously due to the fact that the amide II band, characteristic of any protein-based binding medium, absorbs in the same infrared spectral region of metal carboxylates. The increase of bands in the $1070-1040 \mathrm{~cm}^{-1}$ range suggests the partial oxidation of some aromatic side chains (Phe, Tyr, and other aromatic rings) (Duce et al., 2012). Table 8.1.3.2.3, shows the ratios of individual fitted bands ascribed to carbonyl groups in free fatty acids and ester carbonyl groups $\left(\mathrm{I}_{\mathrm{FFA}} / \mathrm{I}_{\mathrm{E}}\right)$ obtained. New shoulder at $2897 \mathrm{~cm}^{-1}$ associated to stretching vibrations of tertiary $-\mathrm{CH}$ groups accompanied of an increase in the intensity of the band at $1376 \mathrm{~cm}^{-1}$ ascribed to deformation vibrations of $\mathrm{CH}_{3}$ groups suggests changes in the oil network tentatively ascribed to breaking of the polymerized chains.

\section{Zinc white reconstructed model paint specimens}

IR spectrum obtained for the $\mathrm{YO} @ \mathrm{Zn}_{75}$ reconstructed model paint specimen was also dominated by the bans characteristics of proteinaceous binding media: Amide A $\left(3298 \mathrm{~cm}^{-1}\right)$, $-\mathrm{CH}_{3}$ and $-\mathrm{CH}_{2}$ - groups (2923 and $\left.2852 \mathrm{~cm}^{-1}\right)$, amide I $\left(1651 \mathrm{~cm}^{-1}\right)$ and amide II $\left(1549 \mathrm{~cm}^{-1}\right)$ IR absorption bands (Figure 8.1.3.2.8). Main features observed in the reconstructed egg yolkoil emulsion reconstructed model paint prepared with zinc white at 10, 30, 50, and $75 \mathrm{wt} \%$ compared to blank are summarizes in Table 12.7 include as annex to this report. 


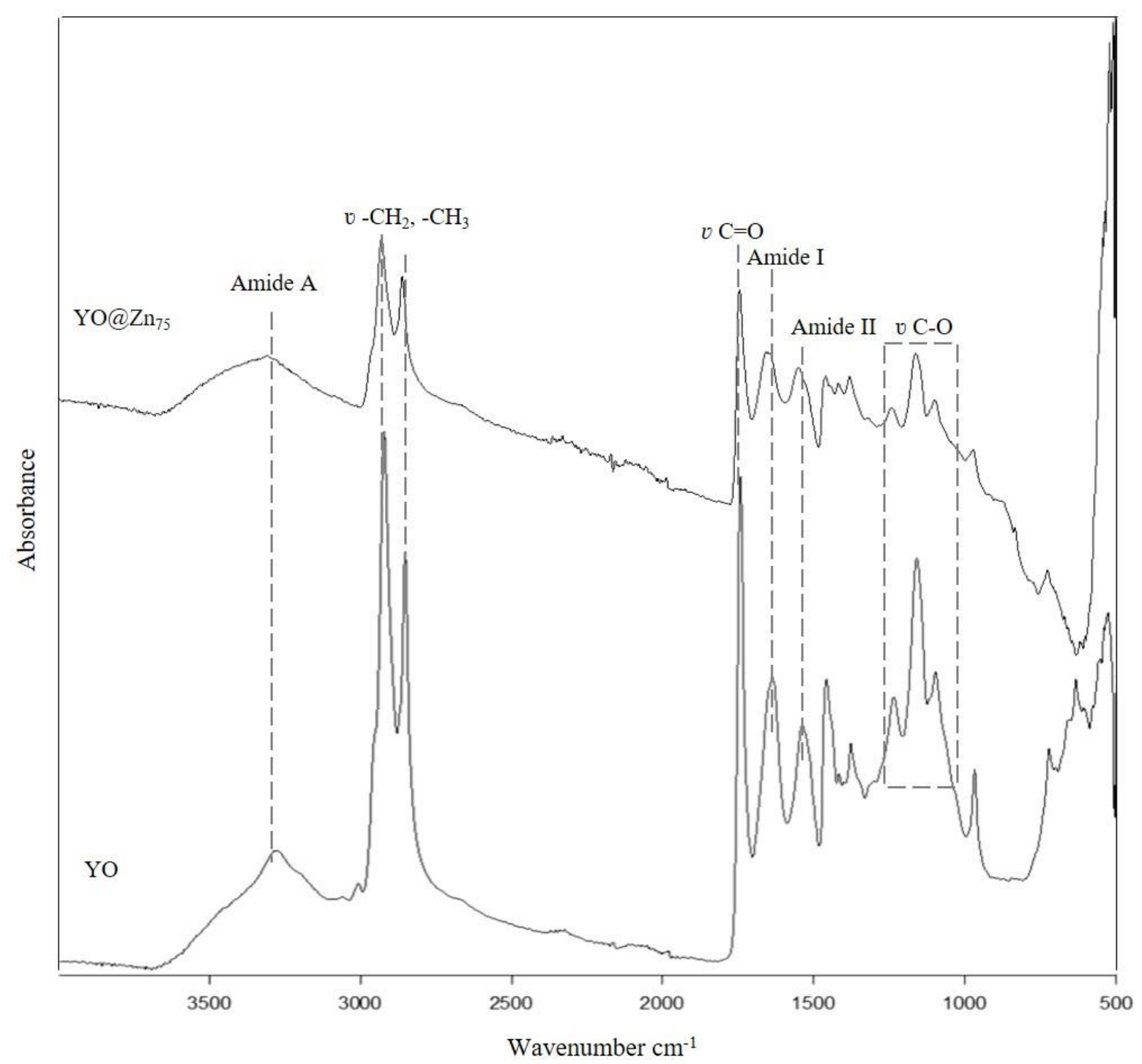

Figure 8.1.3.2.8. IR spectra obtained for the $\mathrm{YO} @ \mathrm{Zn}_{75}$ reconstructed model paint specimen compared with the $\mathrm{YO}$ specimen.

\section{Proteins}

Amide I band maximum at $1651 \mathrm{~cm}^{-1}$ is attributed to $\alpha$-helix conformation. The shift of the maximum of the amide I band appearing at $1639 \mathrm{~cm}^{-1}$ ( $\beta$-sheet region) in the YO specimen, indicates a strong interaction with the pigment. Deconvolution followed of curve fitting of the amide I band lead to the identification of the sub-bands: intermolecular $\beta$-sheet (1621 and $\left.1625 \mathrm{~cm}^{-1}\right)$, intramolecular $\beta$-sheet $\left(1630 \mathrm{~cm}^{-1}\right)$, random coil $\left(1639 \mathrm{~cm}^{-1}\right), \alpha$-helix $\left(1651 \mathrm{~cm}^{-1}\right)$ and turns $\left(1663 \mathrm{~cm}^{-1}\right)$ (Figure 8.1.3.2.9). Table 8.1.3.2.2, summarizes the percent area contribution of amide I components for $\mathrm{YO} @ \mathrm{Zn}_{75}$ specimen. An important increase of turns and random coil conformation contribution is observed when compared to the YO specimen. The increase in this absorption region is associated with an increase in the helix length that takes place when the helix is bent in coiled coils and is solvent exposed (Duce et al., 2013). The shift of the maximum of the amide II band from 1536 to $1545 \mathrm{~cm}^{-1}$ when compared to the YO specimen, could be attributed to the presence of $\mathrm{Zn}$-carboxylate complexes, whose absorption bands occur in the same region of the spectrum. 


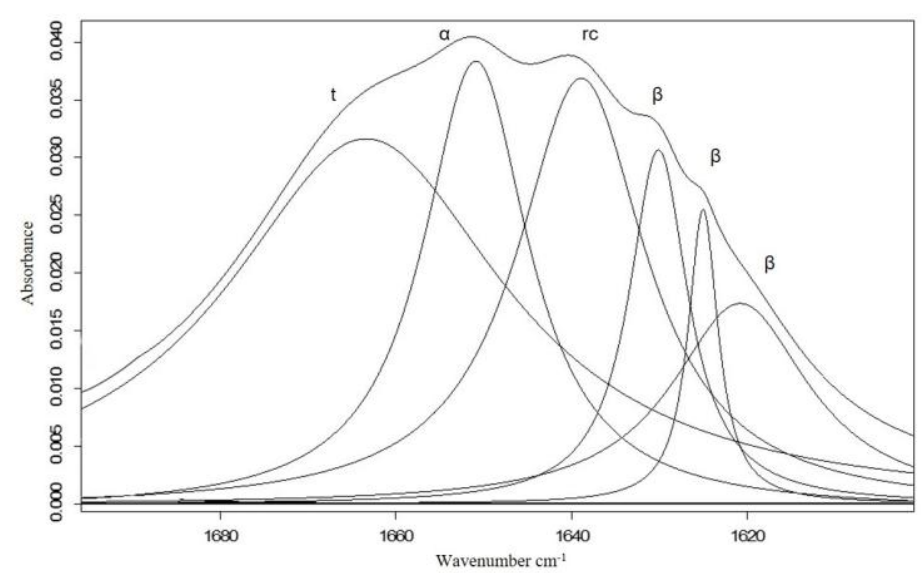

Figure 8.1.3.2.9. Amide I curve fitted band for $\mathrm{YO} @ \mathrm{Zn}_{75}$ specimen with fitted band components. Assignment of bands conformations: $\beta$-sheet $(\beta)$, random coil $(\mathrm{rc}), \alpha$-helix $(\alpha)$ and turns $(\mathrm{t})$.

NLs and PLs

Band at $1545 \mathrm{~cm}^{-1}$ associated to $\mathrm{Zn}$-carboxylate is present, but can ascertained unambiguously because is overlapped by with the amide II band. Band at $1740 \mathrm{~cm}^{-1}$ associated to the ester triglycerides in NLs was observed as well as shoulders at 1239, 1159, $1097 \mathrm{~cm}^{-1}$. Intensity decrease of the band at $1740 \mathrm{~cm}^{-1}$ indicates hydrolysis of triglycerides, a common feature observed in oleic films containing zinc white pigment (van der Weerd et al., 2005). The lower value of 0.39 for the $I_{F F A} / I_{E}$ (see Table 8.1.3.2.3) confirms that the released carboxylic acids have reacted further to metal carboxylates (van der Weerd et al., 2005). IR absorption bands at 1040 and $1066 \mathrm{~cm}^{-1}$ assigned to the P-O stretching vibrations were also identified. Similarly, to the previous specimens studied, Weak shoulder at $2898 \mathrm{~cm}^{-1}$ associated to stretching vibrations of tertiary - $\mathrm{CH}$ groups accompanied of an increase in the intensity of the band at $1376 \mathrm{~cm}^{-1}$ ascribed to deformation vibrations of $\mathrm{CH}_{3}$ groups suggests changes in the oil network tentatively ascribed to breaking of the polymerized chains.

\section{Cadmium yellow reconstructed model paint specimens}

The spectrum of the $\mathrm{YO} @ \mathrm{Cd}_{75}$ specimen, like the other egg yolk-oil emulsion paint films exhibited features of amide A $\left(3279 \mathrm{~cm}^{-1}\right)$, amide B $\left(3075 \mathrm{~cm}^{-1}\right)$, amide I $\left(1630 \mathrm{~cm}^{-1}\right)$, amide II $\left(1544 \mathrm{~cm}^{-1}\right)$ bands. Band at $1737 \mathrm{~cm}^{-1}$ ascribed to the stretching vibrations of ester groups $(\mathrm{C}=\mathrm{O})$ in triglycerides and a shoulder at $1722 \mathrm{~cm}^{-1}$ attributed to PLs, accompanied by C-O stretching vibrations at 1235, 1163 and $1094 \mathrm{~cm}^{-1}$ have been observed (Figure 8.1.3.2.10). The most significant IR absorption bands obtained for the model egg yolk-oil emulsion paint specimens prepared with cadmium yellow at 10,30,50 and $75 \mathrm{wt} \%$ are summarized in the Table 12.8 in annexes. 


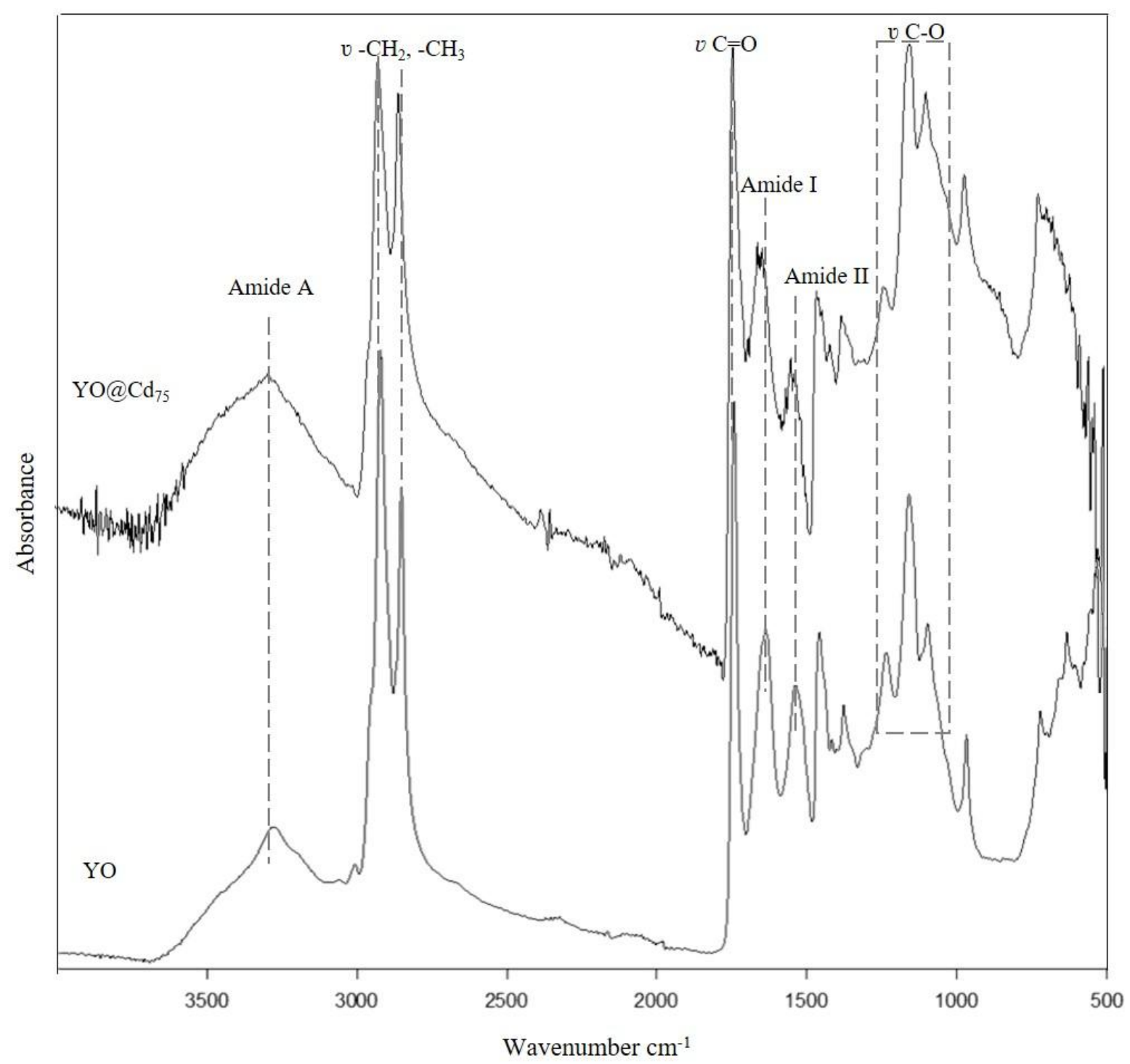

Figure 8.1.3.2.10. IR spectrum obtained for the $\mathrm{YO} @ \mathrm{Cd}_{75}$ reconstructed model paint specimen compared with that from the YO specimen.

\section{Proteins}

The maximum of the amide I absorption band was occurring in the $\beta$-sheet region, thus suggesting that cadmium yellow pigment has not introduced significant changes in the proteinaceous medium. The percent contribution of individual conformation was also calculated for this specimen: intermolecular $\beta$-sheet (22\%), intramolecular $\beta$-sheet $(11 \%)$, random coil (20\%), $\alpha$-helix (23\%) and turn $(25 \%)$. When these results are compared with the obtained for the YO specimen, the most important increase was obtained for the intramolecular $\beta$-sheet, probably associated with the decrease of $\alpha$-helix contribution (see Table 8.1.3.2.2). A similar behavior has been observed in the $\mathrm{YO} @ \mathrm{Fe}_{75}$ and $\mathrm{YO} @ \mathrm{Pbm}_{75}$ specimens, and is attributed to the partial disruption in protein-protein intermolecular interaction promoted by the pigment. In the case of the $\mathrm{YO} @ \mathrm{Cd}_{75}$ specimen this could be confirmed by the shift in the band at $1620 \mathrm{~cm}^{-1}$ attributed to the Cd-protein binding via peptide carbonyl groups (Nahar and Tajmir-Riahi, 1996). Amide II band was centered at $1544 \mathrm{~cm}^{-1}$ denoting a blueshift with respect to the YO blank specimen. 


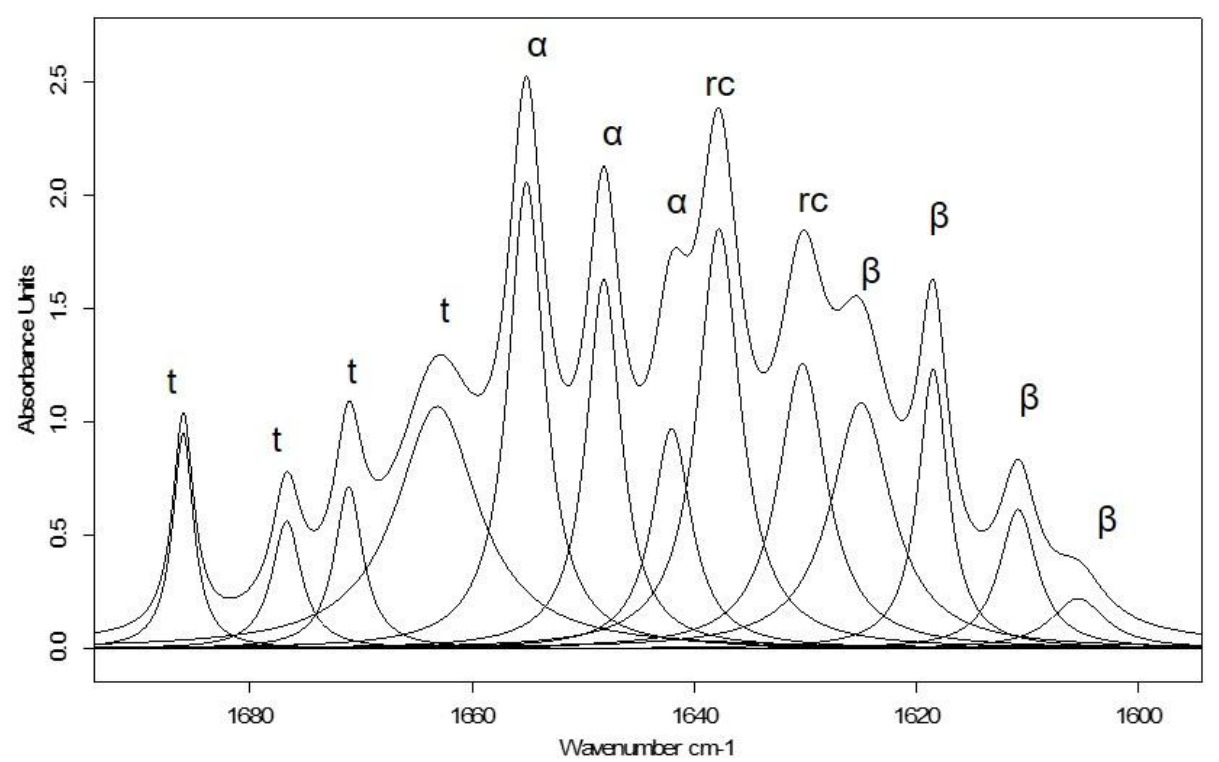

Figure 8.1.3.2.11. Amide I curve fitted band for $\mathrm{YO} @ \mathrm{Cd}_{75}$ specimen with fitted band components. Assignment of bands conformations: $\beta$-sheet $(\beta)$, random coil $(\mathrm{rc}), \alpha$-helix $(\alpha)$ and turns $(\mathrm{t})$.

NLs and PLs

Shoulder bellow $1710 \mathrm{~cm}^{-1}$ is associated to carboxylic group absorptions of free fatty acid released from NLs and PLs (Mazzeo et al., 2008). $\mathrm{I}_{\mathrm{FFA}} / \mathrm{I}_{\mathrm{E}}$ ratio has been also calculated for the YO@ $\mathrm{Cd}_{75}$ specimen (see Table 8.1.3.2.3). The value of 0.50 put in evidence again that hydrolysis of triglycerides promoted by the pigment interactions has taken place. Appearance of a weak band in the range of $1515-1525 \mathrm{~cm}^{-1}$ attributed to the involvement of tyrosine residues in metal-protein complexation (Nahar and Tajmir-Riahi, 1996) confirms the pigment-binder interactions. After secondary derivative and FSD of the amide II band shoulders at 1571 and $1535 \mathrm{~cm}^{-1}$ were identified ascribed to Cd-carboxylate complexes (Mazzeo et al., 2008). In addition, appearance of a new shoulder at $1552 \mathrm{~cm}^{-1}$ associated to the Cd-nitrogen interaction, in metal-polypeptide complexes is observed. All these bands cannot be unambiguously assigned to Cd-complexes due to overlapping with the amide II band.

A shoulder at $1057 \mathrm{~cm}^{-1}$ attributed to the $v_{s}(\mathrm{P}-\mathrm{O}-\mathrm{C})$ terminal phosphate vibration was identified. Increase of bands in the $1070-1040 \mathrm{~cm}^{-1}$ region was also observed, which has been tentatively assigned to $\mathrm{C}-\mathrm{O}$ and $\mathrm{S}=\mathrm{O}$ stretching vibrations that could be correlated with the partial oxidation of various aromatic side chains (Phe, Tyr and other aromatic rings). Studies also associate this behavior to the formation of methionine sulphoxide from the methiodine (Duce et al., 2013). Finally, the IR spectrum of $\mathrm{YO} @ \mathrm{Cd}_{75}$ also exhibited an increase in the ratio of the intensity of deformation vibrations of $\mathrm{CH}_{3}$ to the deformation vibrations of $\mathrm{CH}_{2}$ bands at 1377 and $1458 \mathrm{~cm}^{-1}$, which accompanied by a new shoulder at $2894 \mathrm{~cm}^{-1}$ associated to stretching vibrations of tertiary - $\mathrm{CH}$ groups, could be associated to breaking of the polymeric oil chains. 


\subsubsection{Final considerations}

The spectral deconvolution of the amide I band revealed that presence of pigments causes disruption of intermolecular protein interactions during drying and formation of the paint film. Concomitantly, an increase in intramolecular interactions associated to $\beta$-sheet takes place together with increase of $\alpha$-helix conformation contribution, which is an evidence of the spatial changes undergone by the protein molecules adhered to the solid surface of the pigment grains.

On the basis of the results obtained, the following conclusions can be drawn here:

- Egg yolk tempera specimens exhibit maximum of the amide I band associated to $\beta$ sheet conformations, which is the dominant conformation of proteins in dried state. In contrast, egg yolk-oil emulsion maximum of the amide I band was associated to $\alpha$ helix conformation, as result of the formation of a more compact structure of the protein molecules coexisting with the polymerized triglyceride network. Concomitantly, alteration of the protein-protein interactions was identified in all the specimens by means of FSD and curve fitting, being more evident in the $\mathrm{Y} @ \mathrm{Zn}_{75}$ and YO@ $\mathrm{Pbm}_{75}$ specimens.

- In general, hydrolysis of NLs take place at low extent in all the egg yolk specimens, if compared to the egg yolk-oil emulsion specimens due to the presence of abundant triglycerides from linseed oil and the complex granular structure of the HDL which prevent that the process of hydrolysis take place. Triglycerides, scarcely undergoing hydrolysis, are not directly involved in pigment adhesion processes.

- Identification of metal-carboxylate complexes formed from deprotonated carboxylate residues from proteins and free fatty acids released from NLs were resolved in all specimens using the AII/AI and the $\mathrm{I}_{\mathrm{FFA}} / \mathrm{I}_{\mathrm{E}}$ ratios. Slight increase of these values was obtained for all the egg yolk paint films in agreement with the scarcely undergoing hydrolysis. Egg yolk-oil emulsion specimens show different behaviors. Higher ratio value was obtained for the iron oxide red (1.29) specimen and, consequently, no bands associated to metal-carboxylate were identified. In contrast, massicot $\left(\mathrm{I}_{\mathrm{FFA}} / \mathrm{I}_{\mathrm{E}}\right.$, 1.04) and zinc white $\left(\mathrm{I}_{\mathrm{FFA}} / \mathrm{I}_{\mathrm{E}}, 0.39\right)$ specimens, with lower $\mathrm{I}_{\mathrm{FFA}} / \mathrm{I}_{\mathrm{E}}$ ratio values, exhibit well-resolved IR bands ascribed to the formation of metal-carboxylate complexes. These results suggest that released fatty acids in the massicot and zinc white paint films have reacted further to metal carboxylates due to the complexation properties of both pigments, while in the iron oxide red released carboxylic acids remain free. Similar behavior was observed in the verdigris and lead white paint film specimens.

- On the other hand, comparison of $\mathrm{I}_{\mathrm{FFA}} / \mathrm{I}_{\mathrm{E}}$ ratio values obtained for specimens prepared at different pigment concentration (i.e., $\mathrm{YO} @ \mathrm{Fe}_{75}$ : 1.29: and $\mathrm{YO} @ \mathrm{Cd}_{75}: 0.50$ $\mathrm{YO} @ \mathrm{Fe}_{30}: 0.43$, and $\mathrm{YO} @ \mathrm{Cd}_{30}$ : and 0.22 ), the specimens prepared with the highest 
pigment content $(75 \%)$, showed highest $\mathrm{I}_{\mathrm{FFA}} / \mathrm{I}_{\mathrm{E}}$ values, which suggests that pigment concentration plays an important role in promoting the hydrolysis of triglycerides.

- The FTIR spectroscopic data obtained in the present study also point out to multiple mechanisms of adhesion of egg yolk compounds to the pigment grains among which, linkages to metal centers in pigment of carboxylic and phosphate groups present in proteins and PLs seems to be included.

- Presence of pigment also seems to promote autoxidation of cholesterol as result of the rearrangements in the superficial layer of LDLs and HDLs due to the anchoring of PLs and proteins to the surface of grain pigments in all the specimens with a $75 \%$ of pigment content. 


\subsubsection{References}

Anderson TA, Levitt DG, Banaszak LJ. (1998) The structural basis of lipid interactions in lipovitellin, a soluble lipoprotein. Structure 6: 895-909.

Andersson L, Porath J. (1986) Isolation of phosphoproteins by immobilized metal $\left(\mathrm{Fe}^{3+}\right)$ affinity chromatography. Anal Biochem 154: 250-254.

Anton, M., Martinet, V., Dalgalarrondo, M., Beaumal, V., David-Briand, E., Rabesona, H. (2003) Chemical and structural characterization of low-density lipoproteins purified from hen egg yolk. Food Chemistry, 83, 175-183.

Anton M. (2013) Egg yolk: structures, functionalities and processes. J Sci Food Agric 93: 2871-2880.

Birrell GB, Anderson PB, Jost PC, Griffith OH, Banaszak LJ, Seelig J. (1982) Lipid Environments in the Yolk Lipoprotein System. A Spin-Labeling Study of the Lipovitellin/Phosvitin Complex from Xenopus Zaevist. Biochemistry 21: 244-2452.

Bonnet M, Cansell M, Placin F, David-Briand E, Anton A, Leal-Calderon F. (2010) Multiple Water-in-Oil-in-Water (W/O/W) Emulsions. J Agric Food Chem 58: 7762-7769.

Burnett PGG, Daughney CJ, Peak D. (2006) Cd adsorption onto Anoxybacillus flavithermus: Surface complexation modelling and spectroscopic investigations. Geochim Cosmochim Acta 70: 5253-5269 and references therein.

Byler, M., Susi, H. (1986) Examination of the secondary structure of proteins by deconvolved FTIR spectra. Biopolymers, 25, 469-487.

Cabiaux, V., Brasseur, R., Wattiez, R., Falmagne, P., Ruysschaert, J.M., Goormaghtigh, E. (1989) Secondary structure of diphtheria toxin and its fragments interacting with acidicliposomes studied by polarized infrared spectroscopy. J Biol Chem., 264, 4928-4938.

Cagnasso M, Boero V, Franchini MA, Chorover J. (2010) ATR-FTIR studies of phospholipid vesicle interactions with $\alpha-\mathrm{FeOOH}$ and $\alpha-\mathrm{Fe}_{2} \mathrm{O}_{3}$ surfaces. Colloid Surf B: Biointerfaces 76 : 456-467.

Castellani O, Belhomme C, David-Briand E, Guérin-Dubiard C, Anton M. (2008) The role of metal ions in emulsion characteristics and flocculation behavior of phosvitin-stabilised emulsions. Food Hydrocolloids 22: 1243-1253.

Chang, C.M., Powrie, W.D., Fennema, O. (1977) Microstructure of egg yolk. Journal of Food Science, 42, 1193-1200.

Dong, A., Huang, P., Caughey, W.S. (1990) Protein secondary structures in water from second-derivative Amide I infrared spectra. Biochemistry, 29, 3303-3308. 
Dong, A., Huang, P., Caughey, W.S. (1992) Redox-dependent changes in $\beta$-extended chain and turn structures of cytochrome $c$ in water solution determined by second derivative Amide I infrared spectra. Biochemistry, 31, 182-189.

Duce, C., Ghezzi, L., Onor, M., Bonaduce, I., Colombini, M.P., Tiné, M.R., Bramanti, E. (2012) Physico-chemical characterization of protein-pigment interactions in tempera paint reconstructions: casein/cinnabar and albumin/cinnabar. Anal Bioanal Chem, 402, 2183-2193.

Duce C, Bramanti E, Ghezzi L, Bernazzani L, Bonaduce I, Colombini MP, Spepi A, Biagi S, Tine MR. (2013) Interactions between inorganic pigments and proteinaceous binders with reference paint reconstructions. Dalton Trans 42: 5975-5984.

Erhardt D, Tumosa CS, Mecklenburg MF. (2005) Long-Term Chemical and Physical Processes in Oil Paint Films. Stud Conserv 50: 143-150.

Fein JB, Daughney CJ, Yee N, Davis TA. (1997) A chemical equilibrium model for metal adsorption onto bacterial surfaces. Geochim Cosmo Acta, 61, 3319-3328.

Furlan PY, Scott SA, Peaslee MH. (2007) FTIR-ATR Study of pH Effects on Egg Albumin Secondary Structure. Spectroscopy Letters, 40, 475-482.

Goormaghtigh E, Gasper R, Bénard A, Goldsztein A, Raussens V. (2009) Protein secondary structure content in solution, films and tissues: Redundancy and complementarity of the information content in circular dichroism transmission and ATR FTIR spectra. Biochim Biophys Acta 1794: 1332-1343.

Goulas A, Triplett EL, Taborsky G. (1996) Oligophosphopeptides of varied structural complexity derived from the egg phosphoprotein, phosvitin. J Protein Chem 15: 1-9.

Haris PI, Severcan F. (1999) FTIR spectroscopic characterization of protein structure in aqueous and non-aqueous media. J Mol Catal B Enzym 7: 207-221.

Hevonoja T, Pentikäinen MO, Hyvönen MT, Kovanen PT, Ala-Korpela M. (2000) Structure of low density lipoprotein (LDL) particles: Basis for understanding molecular changes in modified LDL. Biochim Biophys Acta 1488: 189-210.

Jackson M, Mantsch HH. (1992) Artifacts Associated with the Determination of Protein Secondary Structure by ATR-IR Spectroscopy. Appl Spectrosc 46: 699-701.

Kong J, Yu S. (2007) Fourier Transform Infrared Spectroscopic Analysis of Protein Secondary Structures. Acta Biochim Biophys Sinica 39: 549-559.

Kumpula LS, Kumpula JM, Taskinen MR, Jauhiainen M, Kaski K, Ala-Korpela M. (2008) Reconsideration of hydrophobic lipid distributions in lipoprotein particles. Chem Phys Lipids 155: 57-62 and references therein.

Li-Chan ECY, Powrie WD, Nakai S. (1995) In: Stadelmen, WJ, Cotterill OJ (Eds.) Egg Science and Technology. Food Products Press, New York: 105-175. 
Lopez G, Martinez R, Gallego J, Tarancon MJ, Carmona P, Fraile MV. (2000) Infrared Spectroscopy of Lipoproteins: A Comparative Study of Normal and Diabetic Plasma Lipoproteins. Appl Spectrosc 54: 1771-1776.

Maziak DE, Do MT, Shamji FM, Sundaresan SR, Garth Perkins D, Wong PTT. (2007) Fourier-transform infrared spectroscopic study of characteristic molecular structure in cancer cells of esophagus: An exploratory study. Cancer Detection and Prevention 31: 244-253.

Mazzeo R, Prati S, Quaranta M, Joseph E, Kendix E, Galeotti M. (2008) Attenuated total reflection micro FTIR characterization of pigment-binder interaction in reconstructed paint films. Anal Bioanal Chem 392: 65-76.

Meilunas RJ, Bentsen JG, Steinberg A. (1990) Analysis of aged paint binders by FTIR Spectroscopy. Stud Conserv 35: 33-51.

Mine Y, Zhang H. (2013) In: Eskin NA, Shahidi F (eds) Biochemistry of Foodds, $3^{\text {rd }}$ edn. Academic press, London: 215 - 241, and reference therein.

Miyazawa T, Blout ER. (1961) The Infrared Spectra of Polypeptides in Various Conformations: Amide I and II Bands. J Am Chem Soc 83: 712-719.

Nahar S, Tajmir-Riahi HA. (1996) Complexation of heavy metal cations $\mathrm{Hg}, \mathrm{Cd}$ and $\mathrm{Pb}$ with proteins of PSII: evidence for metal-sulfur binding and protein conformational transition by FTIR spectroscopy. J Coll Interf Sci 178: 648 - 656.

Nara M, Morii H, Tanokura M. (2013) Coordination to divalent cations by calcium-binding proteins studied by FTIR spectroscopy. Biochim Biophys Acta 1828: 2319-2327.

Omoike A, Chorover J. (2004) Spectroscopic Study of Extracellular Polymeric Substances from Bacillus subtilis: Aqueous Chemistry and Adsorption Effects. Biomacromolecules 5: 1219-1230.

Omoike A, Chorover J, Kwon KD, Kubicki JD. (2004) Adhesion of Bacteria Exopolymers to $\alpha-\mathrm{FeOOH}$ : Inner-Sphere Complexation of Phosphodiester Groups. Langmuir 20: 1110811114.

Parikh SJ, Chorover J. (2006) ATR-FTIR Spectroscopy Reveals Bond Formation During Bacterial Adhesion to iron oxide red. Langmuir 22: 84-92-8500.

Pelton JT, McLean LR. (2000) Spectroscopic Methods for Analysis of Protein Secondary Structure. Anal Biochem 277: 167-176.

Phoenix VR, Martinez RE, Konhauser KO, Ferris FG. (2002) Characterization and Implications of the Cell Surface Reactivity of Calothrix sp. Strain KC97. Appl Environ Microb 68: 4827-4834. 
Quing H, Yanlin H, Fenlin S, Zuyi T. (1996) Effects of $\mathrm{pH}$ and metal ions on the conformation of bovine serum albumin in aqueous solution. An Attenuated Total Reflection (ATR) FTIR spectroscopic study. Spectrochim Acta A 52: 1795-1800.

Rajkhowa R, Hu X, Tsuzuki T, Kaplan DL, Wang X. (2012) Structure and Biodegradation Mechanism of Milled Bombyx mory Silk. Biomacromolecules 13: 2503-2512.

Salvadó, N., S. Butí S, J. Nicholson J, H. Emerich H, A. Labrador A, Pradell T. (2009) Identification of reaction compounds in micrometric layers fom gothic paintings using combined SR-XRD and SR-FTIR. Talanta 79: 419-428.

Schwertmann U, Cornell RM. (1996) The Iron Oxides. VCH Weinheim.

Simón-Vázquez R, Lozano-Fernández T, Peleteiro-Olmedo M, González-Fernández A. (2014) Conformational changes in human plasma proteins induced by metal oxidenanoparticles. Colloid Surf B: Biointerfaces 13: 198-206.

Susi, H., Byler, D.M. (1986) Resolution-enhanced fourier transform spectroscopy of enzymes. Methods Enzymol., 130, 290-311.

Tantipolphan R, Rades T, McQuillan AJ, Medlicott NJ. (2007) Adsorption of bovine serum albumin (BSA) onto lecithin studied by attenuated total reflectance Fourier transform infrared (ATR-FTIR) spectroscopy. Int J Pharm 337: 40-47.

Tejedor-Tejedor MI, Anderson MA. (1990) Protonation of Phosphate on Surface of Goethite as Studied by CIR-FTIR and Electrophoretic Mobility. Langmuir 6: 602-611.

Ulrichs T, Drotleff AM, Ternes W. (2015) Determination of heat-induced changes in the protein secondary structure of reconstituted livetins (water-soluble proteins from hen's egg yolk) by FTIR. Food Chem 172: 909-920.

Van der Weerd J, van Loon A, Boon JJ. (2005) FTIR studies of the Effects of Pigments on the Ageing of Oil. Stud Conserv 50: 3-22.

Venyaminov SY, Kalnin NN. (1990) Quantitative IR spectrophotometry of peptide compounds in water $\left(\mathrm{H}_{2} \mathrm{O}\right)$ solutions. II. Amide absorption bands of polypeptides and fibrous proteins in $\alpha-, \beta-$, and random coil conformations. Biopolymers 30: 1259-1271.

William, R.J.P., da Silva Frausto, J.J.R. (1996) The natural selection of the chemical elements. Oxford, Oxford University Press. 


\subsubsection{Atomic force microscopy - nanoindentation}

Atomic force microscopy in peak-force tapping mode has been used for the characterization of morphological and mechanical properties of micro-samples collected from egg tempera and egg yolk-oil emulsion reconstructed model paint specimens with 30\%wt pigment content. Peak-force tapping mode allows collecting topological graphs in different modes during one same scan that allow collecting values of the Young's Modulus $(E)$ pixel by pixel. This type of measurements exhibits a good reproducibility in view of the computed standard deviations in the range $0.01-0.18 \mathrm{GPa}$. Study of the mechanical properties of a painting at microscopical scale enables the evaluation of the degradation processes that have taking place in the painting due to ageing and biodeterioration (Raghavan et al., 2000; Biggs et al., 2001; Doménech-Carbó, 2008).

Paint properties are determined by both the type of pigment and binder. As previously mentioned, there are other parameters that must be considered: i) the PVC; ii) the particle size of the pigment grains due to its influence in the inter-particle forces occurring in the pigmentbinder interactions; and iii) the dried cross-linked matrix (binding medium), this latter in low amounts has a direct influence on the cohesion of the film. Paint films with high PVC in most of the cases exhibit the highest $E$ and usually are the most brittle films (Doménech-Carbó et al., 2013; Tumosa and Mecklenburg, 2013).

\subsubsection{Binding media}

The film of pure egg yolk tempera, exhibits a smooth grainy carpet surface (Figure 8.1.4.1.1a) with different structures; smooth areas (see square Figure 8.1.5.5.1a), are alternated with rounded features protruding the surface $(\varnothing$ at ca. $1 \mu \mathrm{m})$ (see circles in Figure 8.1.4.1.1a), which are associated to film granules and spheres from egg yolk (Dauphas et al., 2007). These insoluble denser protein-lipid particles can be better identified with the height image mode, shown as a 3D plot in Figure 8.1.4.1.1b (arrows). Presence of some micropores as result of the water evaporation during the drying process are also recognized (see stars in Figure 8.1.4.1.1a).

A more irregular surface is observed in the film prepared with egg yolk-oil emulsion at microscale, where a two-phase system can be observed (Figure 8.1.4.1.1c and d). Areas of the film corresponding to egg yolk and oil phases could be differentiated from each other one by the darker color and bright color, respectively, in the 3D height image (Figure 8.1.4.1.1d) where the bright regions are the highest areas in the film surface while the darker regions are associated to depressions and pores. This particular appearance of the film could be associated to the two-phases corresponding to the emulsified protein-oil system that takes place during the drying of the film. Some rounded features, attributed to granules and spheres present in egg yolk (see circles in Figure 8.1.4.1.1c), were also observed. These features present variable heights ranging from 0 to $120 \mathrm{~nm}$. 


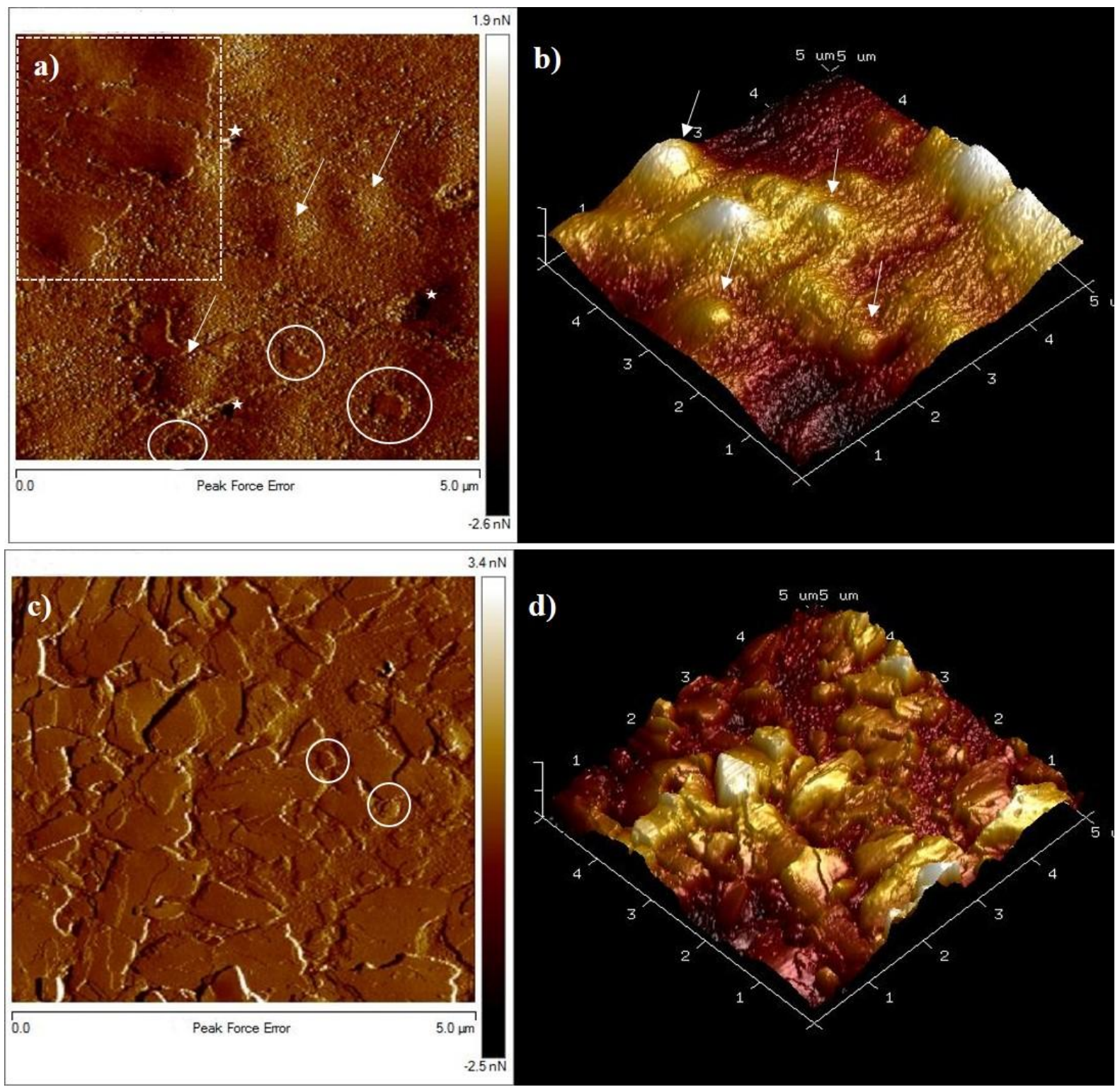

Figure 8.1.4.1.1. Topological graphs obtained in peak-force error mode and 3D height topographic mode for: egg tempera (a and b) and egg yolk-oil emulsion (c and d) films.

Table 8.1.4.1.1 summarizes the $E$ values obtained by AFM-nanoindentation for pure egg yolk tempera (Y@BLANK) and egg yolk-oil oil emulsion (YO@BLANK) films. The highest $E$ value was obtained for egg yolk tempera film, whereas egg yolk-oil has the lowest E value, this behavior can be attributed to the presence of linseed oil, which is well known for the formation of flexible paint films. Reproducibility of the results appears satisfactory in view of the calculated standard deviations. 
Table 8.1.4.1.1. Young's Modulus obtained for the pure binding media.

\begin{tabular}{l|l}
\hline Specimen & Young's Modulus (GPa) \\
\hline \hline$Y$ & $0.30 \pm 0.04$ \\
$Y O$ & $0.10 \pm 0.01$ \\
\hline
\end{tabular}

\subsubsection{Reconstructed model paint specimens}

\section{Egg yolk tempera reconstructed model paint specimens}

The topological graph obtained for the $\mathrm{Y} @ \mathrm{Fe}_{30}$ film exhibited a more rough and uneven surface at microscale if compared to the Y specimen (Figure 8.1.4.2.1a). Earth pigments are well known for the formation of rough paint films due to the small pigment particle size. Some micro-pores were observed on the surface of the film (see arrows), which can be attributed to the water evaporation during the drying of the film. Granules were also observed in the surface of the film (see circles in Figure 8.1.4.2.1a). The roughness of the film surface is well appreciated in the 3D height image with a variable height ranging from 0 to $62 \mathrm{~nm}$ (Figure 8.1.4.2.1b). In agreement with the images obtaiend by FESEM, iron oxide red pigment particles are well embedded by the binder.

The topological graph corresponding to $\mathrm{Y} @ \mathrm{Pbm}_{30}$ specimen shows the surface of the film in the junction between large pigment grains of massicot (at ca 10-20 $\mu \mathrm{m}$ ). The pigment grains are covered by a smooth layer of binding medium (see square in Figure 8.1.4.2.1c). The morphology of the junction can be better seen in the 3D height image (Figure 8.1.4.2.1d) in which the junction has a depth ranging from -10 to $45 \mathrm{~nm}$.

The uneven surface obtained for $\mathrm{Y} @ \mathrm{Zn}_{30}$ is dominated by egg yolk granules of approximately $\varnothing: 1-2 \mu \mathrm{m}$. (see arrows in Figure 8.1.4.2.1e). Some pigment grains are also seen in the surface of the film specimen (see square in Figure 8.1.4.2.1e). Granules are well appreciated in the 3D height image, with variable height ranging from $34-579 \mathrm{~nm}$ (Figure 8.1.4.2.1f)

The $\mathrm{Y} @ \mathrm{Cd}_{30}$ exhibited a surface composed of a variety of domains that confers some roughness at nanoscale to this film (Figure 8.1.4.2.1g and $\mathrm{h}$ ). The appearance of these domains in the surface could be result of some kind of phase separation in the $\mathrm{Y} @ \mathrm{Cd}_{30}$ specimen, in which the pigments grains are concentrated at the bottom of the film while the binder creates a superficial layer. In the 3D height image can be better observed the pigment grain protrusions (brighter areas in the micrograph (see arrow in Figure 8.1.4.2.1h), with a variable height ranging from -15 to $131 \mathrm{~nm}$. 


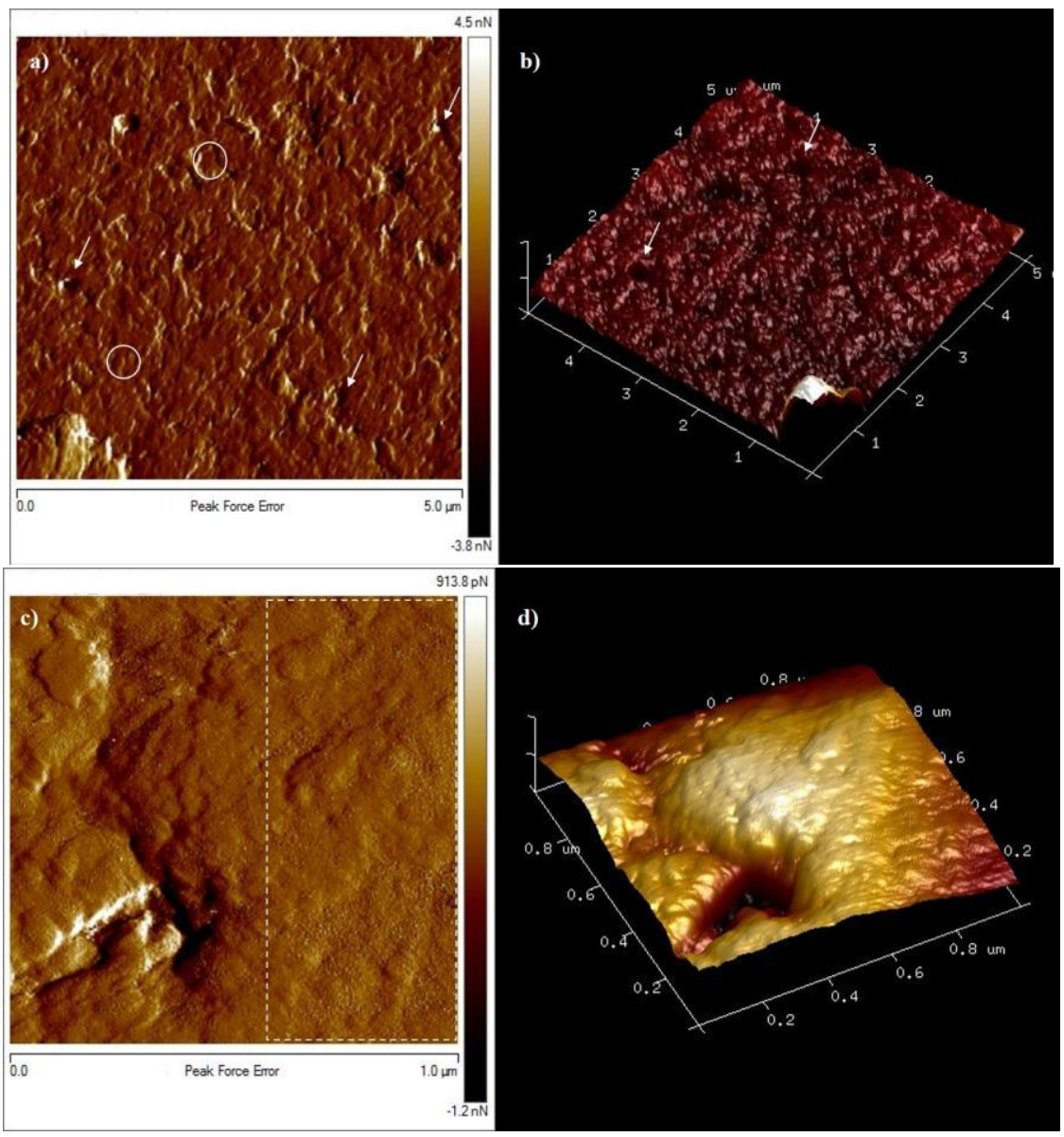




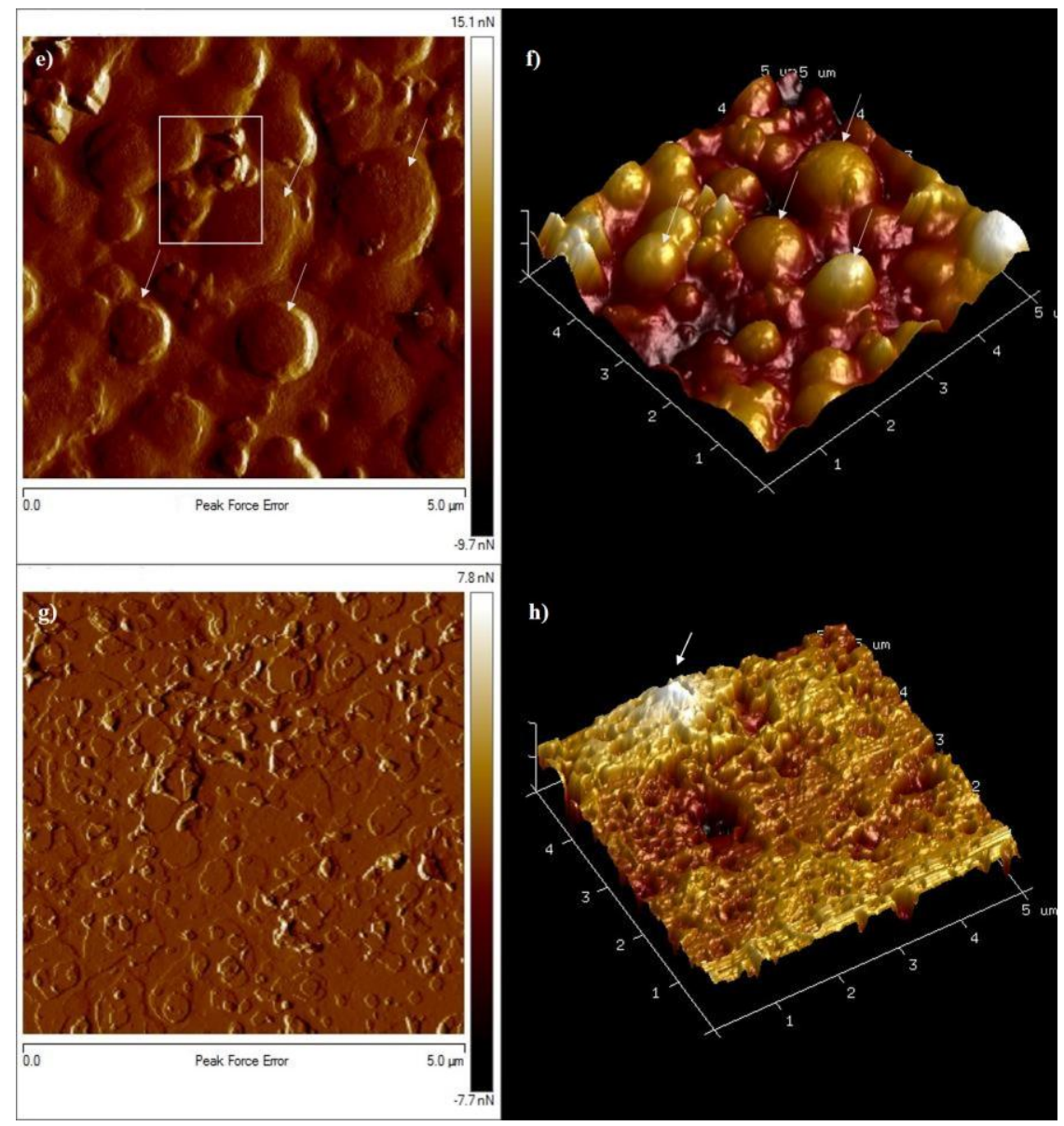

Figure 8.1.4.2.1. Topological graphs obtained in peak-force error for the egg yolk tempera reconstructed model paint specimens (left) and 3D height image mode (right): a) and b) $\mathrm{Y} @ \mathrm{Fe}_{30} ; \mathrm{c}$ ) and d) $\mathrm{Y} @ \mathrm{Pbm}_{30}$; e) and f) $\mathrm{Y} @ \mathrm{Zn}_{30} ; \mathrm{g}$ ) and h) $\mathrm{Y} @ \mathrm{Cd}_{30}$. Image scan size is $5 \mu \mathrm{m}^{2}\left(\mathrm{Y} @ \mathrm{Fe}_{30}, \mathrm{Y} @ \mathrm{Zn}_{30}, \mathrm{Y} @ \mathrm{Cd}_{30}\right)$ and $1 \mu \mathrm{m}^{2}\left(\mathrm{Y} @ \mathrm{Pbm}_{30}\right)$.

The nanoindentation test has revealed a significant increase in the $E$ value of the egg yolk tempera reconstructed model paint specimens when compared with the value obtained in the pure egg yolk tempera film. Table 8.1.4.2.1, summarizes the $E$ values obtained in the series of egg yolk tempera reconstructed model paint specimens. The increase in the $E$ value obtained for all the paint film specimens is obviously associated to the presence of the pigment. The highest value of $E$ was obtained on the $\mathrm{Y} @ \mathrm{Zn}_{30}$ specimen. This result is coherent with the painting practice in which paints prepared with this pigment are usually described as brittle compared with paint films prepared with other pigments (Mecklenburg et al. 2005). Y@ $@ \mathrm{Pbm}_{30}$ and $\mathrm{Y} @ \mathrm{Fe}_{30}$ showed similar $E$, being the massicot paint specimen which exhibited the higher value. That could be associated to the bigger pigment particle size. In contrast, cadmium yellow reconstructed model paint specimen exhibited the lowest $E$ value. This result is associated to the particular morphology of this paint film whose surface (until a few $\mu \mathrm{m}$ depth) was notably enriched in organic components observed in the AFM micrographs and in the secondary electron images obtained by FESEM (see Fig. 8.1.4.2.2). This layer could have undergone autoxidation/polymerization reactions in contact with the atmospheric oxygen thus resulting in a well cross-linked layer that improves flexibility thus, lowering the $E$ value. 


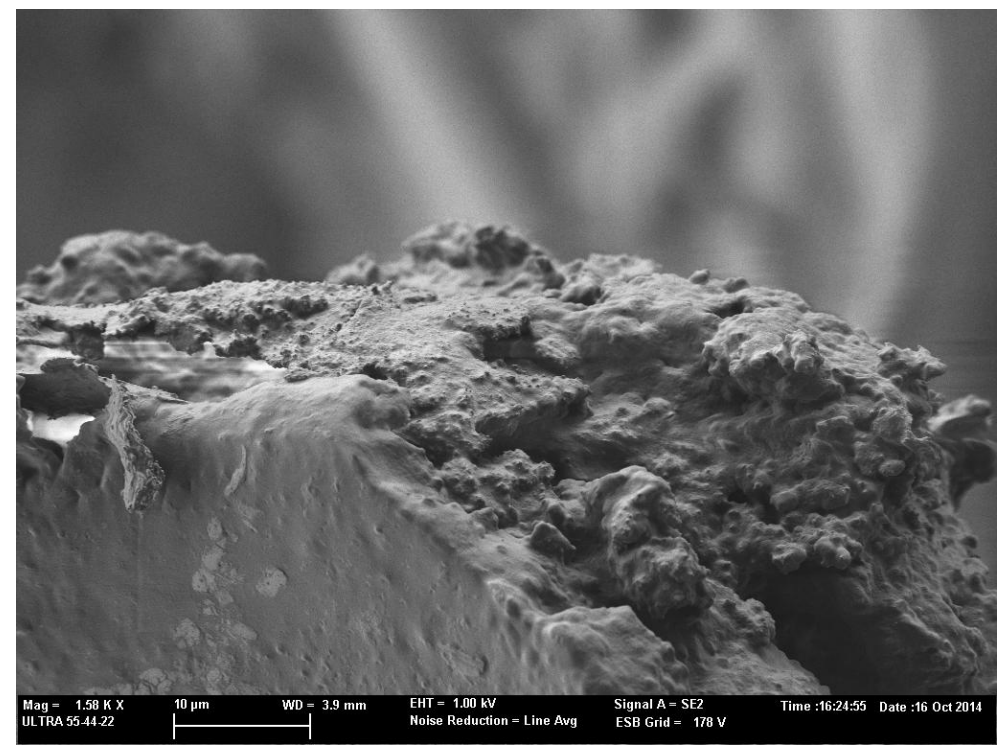

Figure 8.1.4.2.2.- Secondary electron image obtained by FESEM in the cross section of the cadmium yellow reconstructed model paint specimen $\mathrm{Y} @ \mathrm{Cd}_{30}$.

Table 8.1.4.2.1. Summary of values of Young's Modulus and the corresponding standard deviation obtained for the egg yolk tempera reconstructed model paint specimens.

\begin{tabular}{l|l}
\hline Specimen & Young's Modulus $(G P a)$ \\
\hline \hline$Y @ B L A N K$ & $0.30 \pm 0.04$ \\
\hline \hline$Y @ F e_{30}$ & $1.32 \pm 0.07$ \\
\hline$Y @ P b m_{30}$ & $1.71 \pm 0.08$ \\
\hline$Y @ Z n_{30}$ & $4.25 \pm 0.21$ \\
\hline$Y @ C d_{30}$ & $0.70 \pm 0.26$ \\
\hline
\end{tabular}

It is obvious that the pigment plays an important role in the mechanical behavior of the egg yolk tempera films. As previously described in the prior section, series of tempera paint films prepared at $30 \% \mathrm{wt}$ pigment content exhibited, in general, suitable PVC. Thus, differences between $\mathrm{E}$ values obtained in the reconstructed tempera paint films should be associated to other factors such as particle size, and shape that also influence the packaging of the pigment in the film and, at lesser extent, the affinity between binder and pigment. Apparently, the pigment alters the protein-protein bonds, producing changes in the protein conformational structures to form protein-pigment bonds and modify the aggregation of protein chains. This result, in the formation of more rigid protein structures and is reflected in the loss of elasticity. Other important aspect that conditions the mechanical behavior of the film is the ability of the pigment to complex amino acid residues from proteins and promote the hydrolysis of triacylglycerols and phospholipids and the subsequent formation of metal soaps. It is well known the ability of verdigris and zinc white (highest $E$ values exhibited in the present study) to promote formation of metal soaps at short term. This same behavior has 
been described for lead white at long term (Tumosa and Mecklenburg, 2005). All these processes will be discussed in the following sections of the present report.

\section{Egg yolk-oil emulsion reconstructed model paint specimens}

In general, the model paint specimens prepared with egg yolk-oil emulsion exhibit smoother surface (Figure 8.1.4.2.3) than those prepared with egg yolk tempera model paint. In the $\mathrm{YO} @ \mathrm{Fe}_{30}$ specimen pigment grains are identified forming aggregates that slightly protrude on the surface (see circles in Figure 8.1.4.2.3a). Apparently, the binder creates a superficial layer conferring a uniformity and smoothness to the surface of the film. A dust deposit is observed in the upper corner of the height image (Figure 8.1.4.2.3b), with height ranging from 68 to $304 \mathrm{~nm}$.

Micrographs obtained for the $\mathrm{YO} @ \mathrm{Pbm}_{30}$ shows an uneven surface, where a granules and spheres were identified alone (see circle in Figure 8.1.4.2.3c) or in aggregates that form protrusions ranging from $68-360 \mathrm{~nm}$ well recognized using the 3D height image with height (see arrows in Figure 8.1.4.2.3d).

The topological graph obtained in peak-force error mode for the $\mathrm{YO} @ \mathrm{Cd}_{30}$ specimen show a smooth and uniform surface (Figure 8.1.4.2.3k), but in the 3D height image a porous or grainy surface appearance can be observe (Figure 8.1.4.2.31), with height ranging from 11 to $76 \mathrm{~nm}$. This aspect could be associated to pigment protrusions as well as granules and spheres.

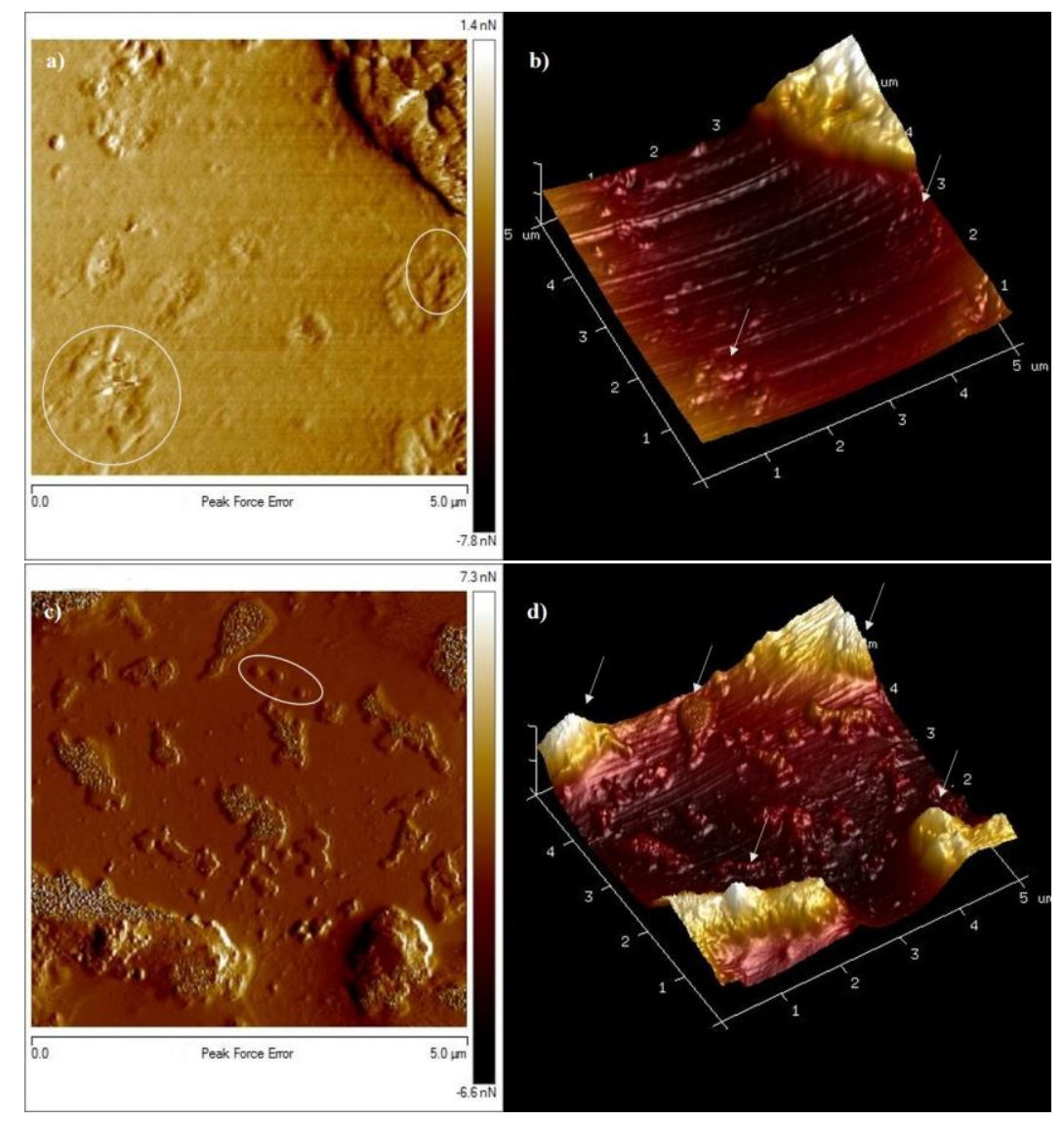




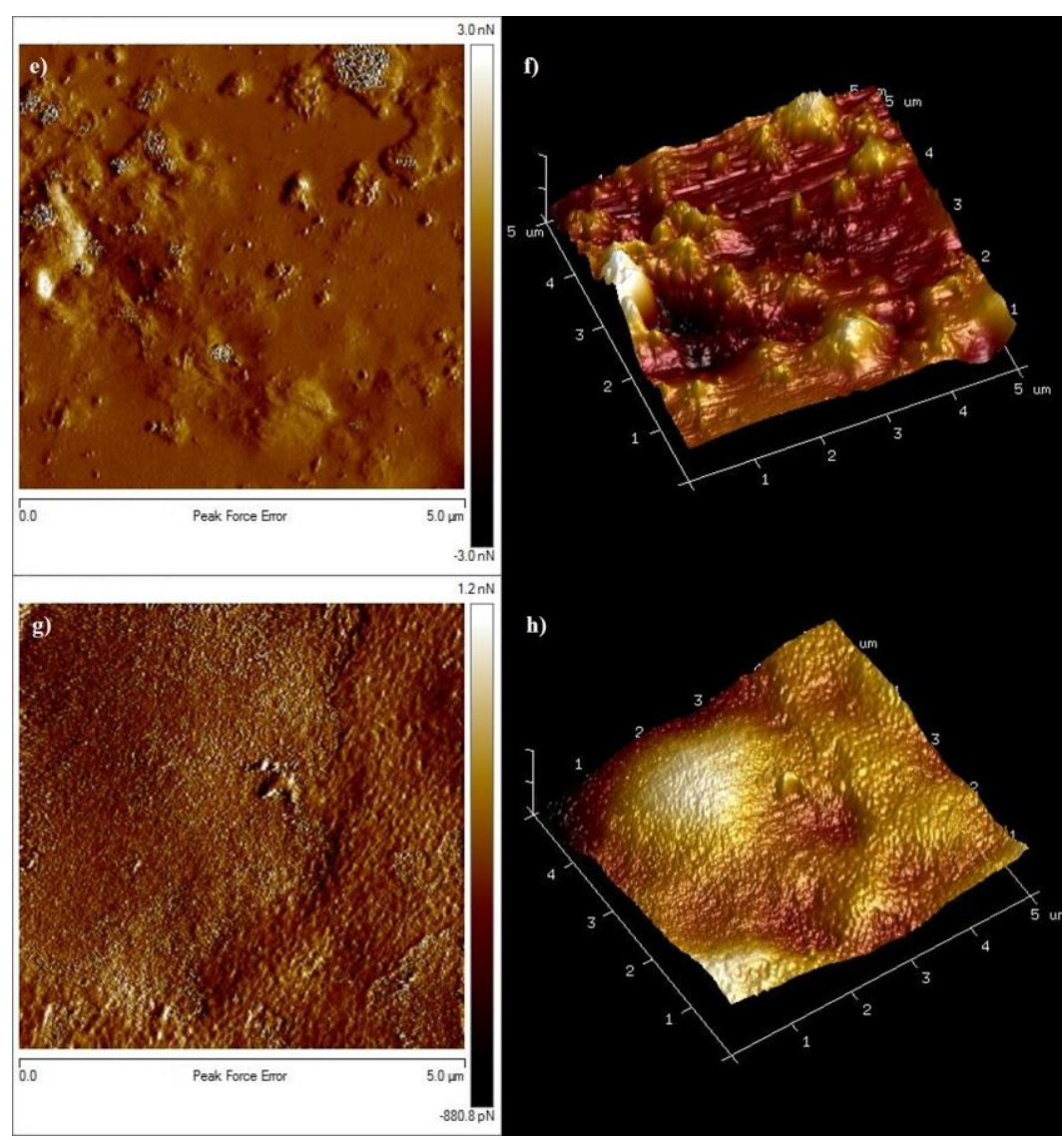

Figure 8.1.4.2.3. Topological graphs obtained in peak-force error for the egg yolk-oil emulsion reconstructed model paint specimens (left) and 3D height image (right): a) and b) $\mathrm{YO} @ \mathrm{Fe}_{30}$; c) and d) $\mathrm{YO} @ \mathrm{Pbm}_{30}$; e) and f) $\mathrm{YO} @ \mathrm{Zn}_{30} ; \mathrm{g}$ ) and h) YO@ $\mathrm{Cd}_{30}$. Image scan size is $5 \mu \mathrm{m}^{2}$.

$E$ values obtained in the egg yolk-oil emulsion series of model paint specimens are summarized in Table 8.1.4.2.2. In general, all the egg yolk-oil emulsion reconstructed model paint specimens exhibit lower $E$ values than those from the egg yolk tempera series. It should be note that the lower the $E$ value, indicates that higher elasticity is exhibited by the paint film. Thus, the decrease in E values in this series with the concomitant gain in elasticity is attributed to the presence of the linseed oil, which is well known for the formation of elastic paint films.

On the other hand, Young's moduli obtained for the egg yolk-oil emulsion model paint specimens are similar to that of the YO specimen (Table 8.1.4.2.4), which confirms that oil is the responsible material for the gain in flexibility. Zinc white paint specimen exhibit the highest increase in the $E$ value for the egg yolk-oil emulsion series, which is consistent with the results obtained in the egg yolk tempera series and with data reported in literature for fresh and aged oil paint films, which are in the range 0.5 to $13.6 \mathrm{GPa}$ (Mecklenburg et al., 2005, Salvant et al. 2011). 
Table 8.1.4.2.2. Young's Modulus values and standard deviation obtained for the egg yolk-oil reconstructed model paint specimens.

\begin{tabular}{l|l}
\hline Specimen & Young's Modulus (GPa) \\
\hline \hline$Y O$ & $0.10 \pm 0.01$ \\
\hline \hline$Y O @ \mathrm{Fe}_{30}$ & $0.12 \pm 0.00$ \\
\hline$Y O @ \mathrm{Pbm}_{30}$ & $0.13 \pm 0.01$ \\
\hline$Y O @ \mathrm{Zn}_{30}$ & $0.16 \pm 0.01$ \\
\hline$Y O @ \mathrm{Cd}_{30}$ & $0.13 \pm 0.04$ \\
\hline
\end{tabular}




\subsubsection{Final Considerations}

Using AFM nanoindentation, it has been possible to measure Young's Moduli of a series of egg yolk tempera and egg yolk-oil emulsion reconstructed model paint specimens. The advantage of this technique compared to conventional mechanical tests performed in tensile testers is the possibility of measuring $E$ values in solid materials such as tempera paint films in which tensile testing is hardly performed owing to the difficulty of obtaining paint strips of the suitable consistence for carrying out the test due to their brittleness.

AFM nanoindentation is a sensitive and useful method to study the changes occurring over the paint film surface at micro- and nanoscale. The AFM nanoindentation technique measures Young's modulus in peak-force tapping mode as a function of indentation depth. For this reason, $E$ values obtained with this technique, in the range of GPa are not in the same order that those obtained in conventional tensile tests in the range of MPa. Nevertheless, in science conservation studies absolute $E$ values are not often required and relative values can provide the suitable data for evaluating the behavior of the painting on ageing or biodeterioration. Therefore, the AFM-indentation technique is an excellent analytical tool that can be applied to laboratory specimens as well as to artworks to check the behavior of the painting due to its character micro- or nanoinvasive.

Concerning the results obtained in the two series of model paint specimens studied, it can be concluded:

- In general, an increment in the $E$ value attributed to the pigment-binder interactions in all the paint specimens was observed if compared with the $E$ values from the pure binding media. This increment in the $E$ values obtained in the reconstructed model paint specimens' is mainly due to the presence of pigment grains notably harder than the binding medium. The differences found between paint films prepared with the same binder and different pigments are due to the type of pigment, grain size and PVC, among other factors.

- As expected, higher $E$ values have been found in the egg yolk tempera series than in the egg yolk-oil emulsion series due to the ability of the linseed oil for forming a cross-linked network that enhances flexibility to the film.

- As also expected, the highest $E$ values for both egg yolk tempera and egg yolk-oil emulsion series have been obtained in the zinc white and massicot specimens. These pigments are well known by its ability for forming complexes with amino acid residues from proteins and promoting the hydrolysis of triacylglycerols and phospholipids and the subsequent formation of metal soaps, which results in the alteration of the binder network in the paint and the concomitant loss in flexibility of the film.

Despite this, the reproducibility of the results appears satisfactory in view of the computed standard deviations ( \pm 0.00 to $0.26 \mathrm{GPa}$ ). 


\subsubsection{References}

Biggs, S. Lukey, C.A., Spinks, G.M., Yau, S.T. (2001) An atomic force microscopy study of weathering of polyester/melamine paint surfaces. Progress in organic coatings, 42, 49-58.

Dauphas, S., Beaumal, A., Gunning, P., Mackie, A., Wilde, P., Vié, V., Riaublanc, A., Anton, M. (2007) Structure modification in egg yolk low density lipoproteins layers between 30 and $45 \mathrm{mN} / \mathrm{m}$ observed by AFM. Colloids and Surfaces B: Biointerfaces, 54, 241-248.

Doménech-Carbó, M.T. (2008) Novel analytical methods for characterizing binding media and protective coatings in artworks. Analytical Chimica Acta, 62, 109-139.

Doménech-Carbó, M.T., Silva, M.F., Aura-Castro, E., Doménech-Carbó, A., Fuster-López, L., Gimeno-Adelantado, J.V., Kröner, S., Martínez-Bazán, M.L., Más-Barberá, X., Mecklenburg, M.F., Osete-Cortina, L., Yusá-Marco, D.J. (2013) Multitechnique approach to evaluate cleaning treatments for acrylic and polyvinyl acetate paints. In New Insights into the Cleaning of Paintings: Proceedings from the cleaning 2010 International Conference, Universidad Politécnica de Valencia and Museum Conservation Institute, Washington, DC, 125-134.

Mecklenburg, M.F., Tumosa, C.S., Erhardt, D. (2005) The changing mechanical properties of aging oil paints. In Materials Issues in Art and Archeology VII: Materials Research Society Symposium, held November 30 - December 3, 2004, Boston, Mass.: proceedings, Materials Research Society, 23-24.

Nahar S, Tajmir-Riahi HA. (1996) Complexation of heavy metal cations $\mathrm{Hg}, \mathrm{Cd}$ and $\mathrm{Pb}$ with proteins of PSII: evidence for metal-sulfur binding and protein conformational transition by FTIR spectroscopy. J Coll Interf Sci 178: 648 - 656.

Raghavan, D., Gu, X., Nguyen, T., Van Landingham, M., Karim, A. (2000) Mapping polymer heterogeneity using atomic forcé microscopy phase imaging and nanoscale. Macromolecules, 33, 2573-2583.

Salvant, J., Barthel, E., Menu, M. (2011) Nanoindentation and the micromechanics of Van Gogh oil paints. Applied Physics A: Materials Science \& Processing, 10, 509-515.

Tumosa, C.S., Mecklenburg, M.F. (2005) The influence of leads ions on the drying of oils. Studies in Conservation, 50, 39-47.

Tumosa, C.S., Mecklenburg, M.F. (2013) Oil paints: the chemistry of drying oils and the potential for solvent disruption. Smithsonian Contributions to Museum Conservation, 3, 5158. 


\section{Part III. Characterization of the biodeterioration with fungi and bacteria on tempera painting}


9. MATERIALS AND METHODS 


\section{1. Reconstructed model paint specimens}

\section{1. 1. Reference materials}

Iron oxide red, cadmium yellow, verdigris and lead white, fresh hen's egg and cold pressed linseed oil (Kremer) were used as reference materials for preparing the series of model paint films. Table 9.1.1, summarizes the set of pigments used in this study. All of them are mentioned in almost all the source materials and catalogue lists of pigments from ancient times to the present (Cennini, 1988; Gettens and Stout, 1966; Mayer; Ward, 2008). The pigment selection for this study was made considering the electroactive capacity and the transparent behavior to IR analytical techniques. Particularly interesting are the verdigris and lead white pigments due to their toxicity and different biocide effect properties (Bilardi, 2009; Gettens et al., 1993).

Table 9.1.1.1. List of the pigments used for the preparation of the reconstructed tempera paint specimens and the composition declare by the manufacturer.

\begin{tabular}{|lll|}
\hline Pigment common name & Chemical composition & Supplier \\
\hline Cadmium yellow & Cadmium sulphide $(\mathrm{CdS})$ & Kremer \\
\hline Iron oxide red & Ferric oxide $\left(\mathrm{Fe}_{2} \mathrm{O}_{3}\right)$ & Kremer \\
\hline Verdigris & $\begin{array}{l}\text { Dibasic acetate of copper } \\
\left(\mathrm{Cu}\left(\mathrm{C}_{2} \mathrm{H}_{3} \mathrm{O}_{2}\right) \cdot 2 \mathrm{Cu}(\mathrm{OH})_{2}\right)\end{array}$ & Kremer \\
\hline Lead white & $\begin{array}{l}\text { Basic carbonate of lead } \\
\left(2 \mathrm{PbCO}_{3} \cdot \mathrm{Pb}(\mathrm{OH})_{2}\right)\end{array}$ & Kremer \\
\hline
\end{tabular}

\section{1. 2. Reconstructed model paint specimens' preparation}

Two series of tests specimens containing egg and egg oil emulsion as binding medium mixed with iron oxide, verdigris, lead white and cadmium yellow have been prepared (Table 9.1.2.1). 
Reconstructed whole egg tempera paint films (EG) and whole egg-linseed oil emulsion (EO) were prepared by mixing the pigment with the appropriate amount of whole egg and whole egg-linseed oil emulsion (1:1) until suitable consistence (30 wt\% composition of pigment). Pigment concentration was considered appropriate for the growth of microorganisms. The paint films were dried at room temperature during 3 months $\left(21^{\circ} \mathrm{C}, 50 \% \mathrm{RH}\right)$. Thickness of the films was in the range $0.3-0.5 \mathrm{~mm}$.

Table 9.1.2.1. Reconstructed model paint specimens used in the study of the interactions between the binding medium and the pigment.

\begin{tabular}{|c|c|c|c|c|c|}
\hline \multirow{2}{*}{ Binding media } & \multirow{2}{*}{$\begin{array}{c}\text { Pigment } \\
\text { content } \\
(w \mathrm{w})\end{array}$} & \multicolumn{4}{|c|}{ Pigments } \\
\cline { 3 - 6 } & & Iron oxide & Verdigris & Lead white & $\begin{array}{c}\text { Cadmium } \\
\text { yellow }\end{array}$ \\
\hline Egg (EG) & 30 & $\mathrm{EG@Fe}$ & $\mathrm{EG} @ \mathrm{Cu}$ & $\mathrm{EG} @ \mathrm{~Pb}$ & $\mathrm{EG} @ \mathrm{Cd}$ \\
\hline Egg oil emulsion (EO) & 30 & $\mathrm{EO} @ \mathrm{Fe}$ & $\mathrm{EO} @ \mathrm{Cu}$ & $\mathrm{EO} @ \mathrm{~Pb}$ & $\mathrm{EO} @ \mathrm{Cd}$ \\
\hline
\end{tabular}

\section{1. 3. Biodeterioration of the reconstructed model paint specimens by microorganisms}

\section{1. 3. 1. Microorganisms}

The microorganisms studied were recognized biodeterioration agents, selected after an extensive review of the literature (López-Miras 2013; Ciferri, 1999; Giacobini, 1981; Giacobini and De Cicco, 1988; Giacobini et al., 1991; Ross, 1963; Seves et al., 1996; Strelczyc, 1981; Walsh, 2001; Zyska, 2002). Fungi and bacteria that could originate biodeterioration processes in paints were chosen. All of the species studied are ubiquitous saprophytes, commonly found in the air, and they came from stock collections belonging to the Spanish Collection of Type Cultures (CECT, Universidad de Valencia, Valencia, Spain).

The microorganisms used were:

Fungus: Aspergillus niger (An) (CECT-2008); Acremonium chrysogenum (Ac) (CECT 2723); Penicillium chrysogenum (Pc) (CECT-2306); Mucor rouxii (Mr) (CECT-2655); Trichoderma pseudokoningii (Tp) (CECT-2937).

Bacterium: Bacillus amyloliquefaciens (Ba) (CECT-493), Arthrobacter oxydans (Ao) (CECT-386) and Streptomyces cellulofans (Sc) (CECT 3242).

Preparation of fungi cultures.

To obtain fungal spores, fungi were grown on Potato Dextrose Agar (PDA, Scharlau, Barcelona, Spain) over a total period of one week at $28^{\circ} \mathrm{C}$ and spores were collected by washing the solid culture with $0.1 \%$ Tween 80 (Aldrich) solution and filtering through sterile glass wool. The resulting suspensions of spores were centrifuged three times and the 
supernatants were discarded in order to avoid any residue from the culture medium or rest of mycelia. Finally, spores were re-suspended in $1 \mathrm{~mL}$ ultrapure water and spores suspensions were adjusted to $10^{5}-10^{6}$ spores $\mathrm{mL}^{-1}$.

\section{Preparation of bacteria cultures.}

Bacteria were grown on cultural plates of Triptych Soy Broth (TSB, Scharlau) medium and were incubated at $28^{\circ} \mathrm{C}$ for 24 hours. Cultures were re-suspended in $2 \mathrm{~mL}$ of $0.1 \%$ Tween 80 solution. After centrifugation carried out for removing possible remains of the solid culture medium, bacterial suspensions were adjusted to $10^{7}$ cells $\mathrm{mL}^{-1}$.

\section{1. 3. 2. Microbial inoculation of the reconstructed model paint specimens}

Reconstructed paint films prepared as egg yolk tempera (EG) and egg + oil emulsion (EO) were inoculated with three separated drops of $20 \mu \mathrm{L}$ of each fungal and bacterial suspension using a micropipette, so that they covered a defined area $\left(\sim 20 \mathrm{~mm}^{2} / \mathrm{drop}\right)$ of the solidified model paint. After inoculation, each paint film was placed in the center of a Petri dish and incubated in darkness for 40 days at $28^{\circ} \mathrm{C}, 80 \%$ relative humidity. Thus, series of biodeteriorated reconstructed paint films were obtained (EG@pigment_microorganism). Paint films inoculated with $20 \mu \mathrm{L}$ of sterile ultrapure water and incubated under the same conditions were used as controls (EG@pigment_B). After incubation, the microbial biomass was completely separated from the surface of the reconstructed model paint films in two steps, (1) mechanical removing mycellus, spores, etc. by carefully rolling a sterile cottonswab on the biodeteriorated area. Eventually, sterile microscapel was used for removing some small craquelure detached of the paint film as consequence of the microbial action. (2) Rising with sterile water for removing the biomass that still could remain.

Table 9.1.3.2.1. Reconstructed model paint specimens used in the study of biodeterioration.

\begin{tabular}{|c|c|c|c|c|c|c|c|c|}
\hline Specimen & \multicolumn{5}{|c|}{ Fungi } & \multicolumn{3}{|c|}{ Bacteria } \\
\hline \multicolumn{9}{|c|}{ Egg tempera reconstructed model paint specimens } \\
\hline EG@Fe_B & EG@Fe_Ac & EG@Fe_An & $\mathrm{EG} @ \mathrm{Fe} \_\mathrm{Mr}$ & EG@Fe_Pc & EG@Fe_Tp & EG@Fe_Ao & EG@Fe_Ba & EG@Fe_Sc \\
\hline EG@Cu_B & EG@Cu_Ac & EG@Cu_An & EG@Cu_Mr & EG@Cu_Pc & EG@Cu_Tp & EG@Cu_Ao & $\mathrm{EG} @ \mathrm{Cu} \_\mathrm{Ba}$ & EG@Cu_Sc \\
\hline EG@Pb_B & EG@Pb_Ac & EG@Pb_An & EG@Pb_Mr & EG@Pb_Pc & EG@Pb_Tp & EG@Pb_Ao & EG@Pb_Ba & EG@Pb_Sc \\
\hline EG@Cd_B & EG@Cd_Ac & EG@Cd_An & EG@Cd_Mr & EG@Cd_Pc & EG@Cd_Tp & EG@Cd_Ao & EG@Cd_Ba & EG@Cd_Sc \\
\hline \multicolumn{9}{|c|}{ Egg oil emulsion reconstructed model paint specimens } \\
\hline $\mathrm{EO} @ \mathrm{Fe} \_\mathrm{B}$ & $\mathrm{EO} @ \mathrm{Fe} \_\mathrm{Ac}$ & EO@Fe_An & $\mathrm{EO} @ \mathrm{Fe} \_\mathrm{Mr}$ & EO@Fe_Pc & EO@Fe_Tp & EO@Fe_Ao & EO@Fe_Ba & $\mathrm{EO} @ \mathrm{Fe} \_\mathrm{Sc}$ \\
\hline EO@Cu_B & $\mathrm{EO} @ \mathrm{Cu} \_\mathrm{Ac}$ & EO@Cu_An & EO@Cu_Mr & EO@Cu_Pc & EO@Cu_Tp & EO@Cu_Ao & $\mathrm{EO} @ \mathrm{Cu} \_\mathrm{Ba}$ & EO@Cu_Sc \\
\hline EO@Pb_B & EO@Pb_Ac & EO@Pb_An & $\mathrm{EO} @ \mathrm{~Pb} \_\mathrm{Mr}$ & EO@Pb_Pc & EO@Pb_Tp & EO@Pb_Ao & EO@Pb_Ba & EO@Pb_Sc \\
\hline EO@Cd_B & EO@Cd_Ac & EO@Cd_An & EO@Cd_Mr & EO@Cd_Pc & EO@Cd_Tp & EO@Cd_Ao & EO@Cd_Ba & EO@Cd_Sc \\
\hline
\end{tabular}




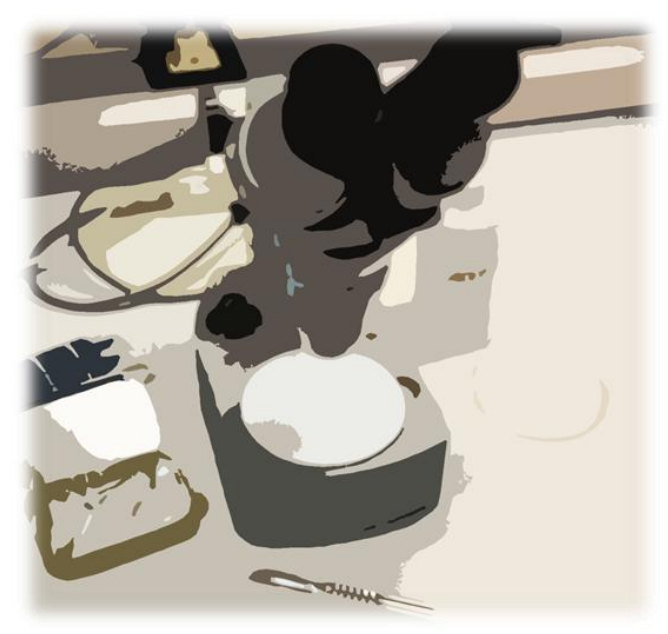

\section{2. Analytical techniques}

\section{2. 1. Weight measurements}

See section 7.2.1

\section{2. 2. Optical microscopy}

\section{Principle}

The use of optical microscope in the field of conservation and restoration of cultural heritage is well known. Optical microscope enables to observe the details of flat and rough surfaces of artwork materials, but with greater clarity and magnification. The most commonly used microscope in the identification of historical objects it is a double lens system. By using the suitable optical configuration in the microscope recognition of the properties of pigments can be carried out optical. Images can be registered by means a camera adapted. Several optical configurations that include episcopic and diascopic illumination using both plane parallel polarized light or cross polarized light, can be used depending on the type of material examined and the preparation methodology (i.e. particles dispersed in a mounting medium, thin section, cross-section).

\section{Equipment}

The surface of the specimens was examined with a Leica S8APO microscope using episcopic illumination in the range $\mathrm{x} 10-\mathrm{x} 80$ magnification.

\section{2. 3. Fourier Transformed Infrared Spectroscopy in Attenuated Total Reflectance mode (FTIR-ATR)}

See section 7.2.2 


\section{2. 4. Field Emission Scanning Electron Microscopy (FESEM)}

See section 7.2.3

\section{2. 5. Atomic Force Microscopy - nanoindentation (AFM - NI)}

See section 7.2.4

\section{2. 6. Electrochemical techniques}

\section{2. 6. 1. Voltammetry of Microparticles (VMP)}

\section{Principle}

The voltammetry of immobilized particles allows the identification, quantification and structural information of components on solid micro- or nano-samples from work of art as: paints, sculptures, textiles, ceramics, etc. Voltammetry of microparticles (VMP), a solid-state electrochemistry technique developed by Scholz et al. (Scholz et al. 2014) is highly sensitive to the electrochemical response of graphite electrodes modified with microparticulated samples (Doménech-Carbó 2010).

VMP is based on the record of the current $i$ flowing across an electrochemical cell under the application of a given time-depending potential $E$. A voltage is applied between the working electrode and an auxiliary electrode, and the potential of the working electrode is measured $v s$. the reference electrode possessing a constant and known potential. The current flowing through the working and auxiliary electrode is the response to the potential of the working electrode. Generally, a three electrode arrangement is used (Figure 9.2.6.1.1), where a potentiostat controls the potential making the current to flow between the working and auxiliary electrode, a vey negligible part of the current pass through the reference electrode (usually: $\mathrm{AgCl} / \mathrm{Ag}$ or $\mathrm{Hg}_{2} \mathrm{Cl}_{2} / \mathrm{Hg}$ ) (Scholz and Meyer, 1998; Scholz et al., 2014; DoménechCarbó et al. 2009; 2013; Doménech-Carbó, 2010). 


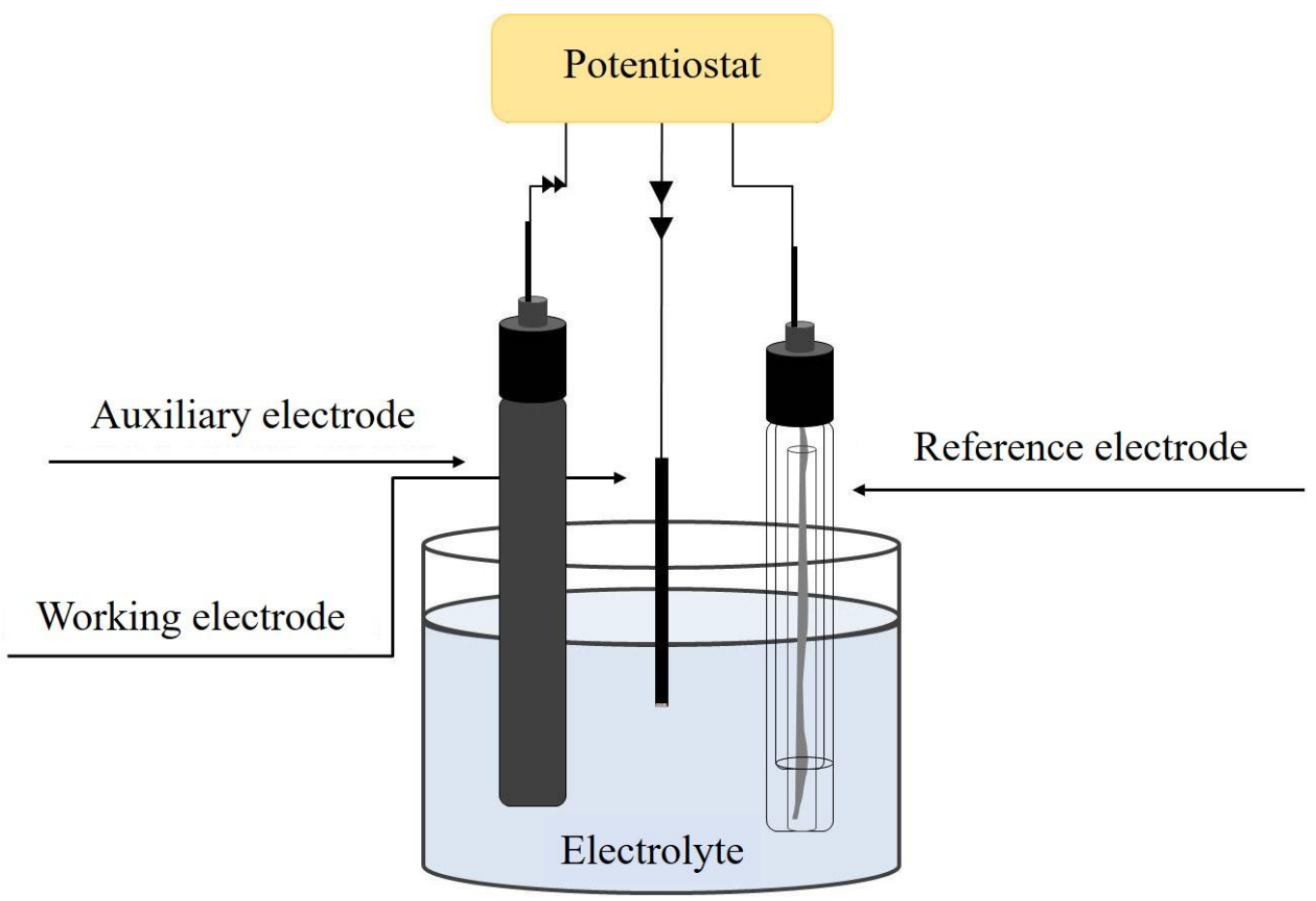

Figure 9.2.6.1.1. Three electrode arrangement voltammetric cell.

Immobilization of solid particles on an electrode surface is by embedding them mechanically in a soft electrode surface. Abrasion from solids is the most used technique, but a number of other immobilization techniques have been developed (Grygar et al., 2001)

Compact crystal electrode $(C E)$ : is a compact body, such as pellet, disk, or rod made of the material to be studied, used as the working electrode. CEs are only suitable for good electric conductors, such as metals.

Composite electrodes: contain the solid to be studies mixed with a conductive additive (usually carbon black or milled graphite) and possibly a binder to improve mechanical properties of the composite. The mixture is pressed to a current collector, such a metal mesh or plate.

Film electrodes with embedded particles: a powder sample can be immobilized on an electrode surface by evaporation of its dispersion in an appropriate solvent with an addition of a polymer "glue". This technique became particularly popular in studies of clay-modified electrodes.

Direct immobilization of solid particles: a powder sample can be directly deposited on an electrode surface without the necessity of mechanical pretreatment or the presence of additive. The VMP procedure is based on a mechanical (abrasive) deposition of traces of samples on a sufficiently soft working electrode, as, paraffin-impregnated graphite or pencil lead. These paraffin impregnated graphite electrodes (PIGEs) are fabricated from graphite rods. These rods may have different sizes, but those $50 \mathrm{~mm}$ long and $5 \mathrm{~mm}$ in diameter have the best handling properties. 
Detection protocols used in this study

Cyclic Voltammetry $(\mathrm{CV})$ is one of the most versatile electroanalytical technique for the study of the mechanisms and rates of oxidation/reduction processes, in particular for organic and organometallic systems. This method is generally the first technique selected for an electrochemical analysis in the fields of electrochemistry, inorganic chemistry, organic chemistry and biochemistry. The capability of CV for rapidly observing the redox behavior over a wide potential range make it a valuable technique. Often, cyclic voltamperograms (CVs) reveal the presence of intermediates in the oxidation/reduction reactions.

$\mathrm{CV}$ consists of cycling the potential of an electrode, which is immersed in an unsaturated solution, and measuring the resulting current. The potential of this working electrode is controlled vs. the reference electrode such as a saturated silver/silver chloride electrode $(\mathrm{Ag} / \mathrm{AgCl})$. The controlling potential which is applied across these two electrodes can be considered an excitation signal. A CVs is obtained by measuring the current at the working electrode during the potential scan. The current can be considered the response signal to the potential excitation signal. The voltammogram is a display of current (vertical axis) vs. potential (horizontal axis). Because the potential varies linearly with time, the horizontal axis can also be thought of as a time axis. A typical voltammogram is shown in Figure 9.2.6.1.2 for a platinum working electrode in a solution containing an electroactive species immersed in a supporting electrolyte. The initial potential of $0.80 \mathrm{~V}$ applied at $(A)$ is chosen to avoid any electrolysis of the electroactive species when the electrode is switched on. The potential is then scanned negatively, forward scan, as indicated by the arrow. When the potential is sufficient negative to reduce the electroactive species, cathodic current is indicated at $(B)$ due to the electrode reduction process of the electroactive species. The cathodic current increase rapidly $(B-D)$ until the concentration of the reduced electroactive species process at the electrode surface is substantially diminished, causing the current to peak $(D)$. The current then decays $(D-G)$ as the solution surrounding is depleted of reduced electroactive species.

The scan direction is switched to positive at $-0.15 \mathrm{~V}(F)$ for the reverse scan. The potential is still sufficient negative to reduce, so cathodic current continues even though the potential is now scanning in the positive direction. When the electrode becomes a sufficiently strong oxidant, the electroactive species, which has been accumulating adjacent to the electrode, can now be oxidized. This causes anodic current $(I-K)$. The anodic current rapidly increases until the surface concentration of the electroactive species deposits is diminished, causing the current to peak $(J)$. The current then decays $(J-K)$ as the solution surrounding the electrode is depleted of oxidized electroactive species. The first cycle is completed when the potential reaches $+0.80 \mathrm{~V}$. Generally, the first scan recorded cycles differ slightly, and only after $3-4$ cycles do the CVs approach constant response (Kissinger and Heineman, 1983; DoménechCarbó et al., 2009). 


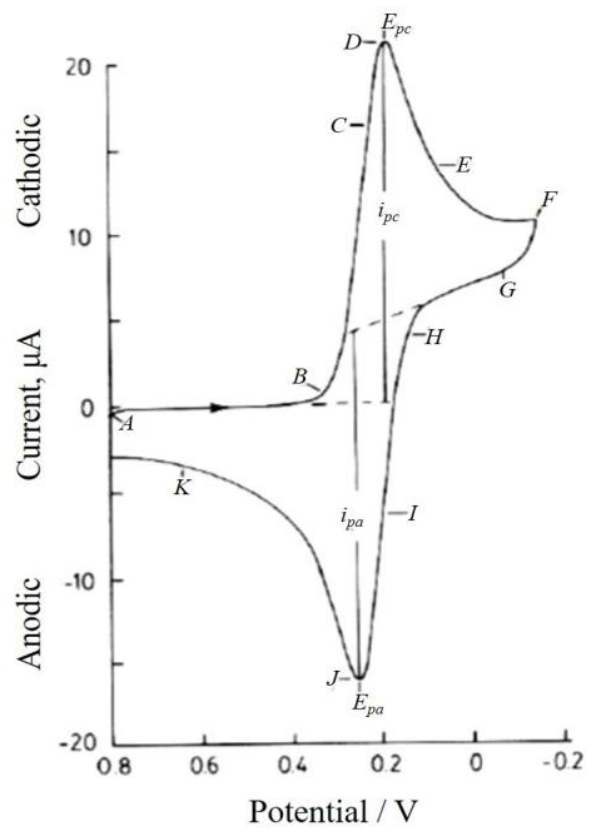

Figure 9.2.6.1.2. Typical morphology of the cathodic and anodic waves obtained for a cyclic voltammogram. The anodic peak potential $\left(\mathrm{E}_{\mathrm{pa}}\right)$, anodic peak current $\left(i_{\mathrm{pa}}\right)$, cathodic peak potential $\left(\mathrm{E}_{\mathrm{pc}}\right)$ and cathodic peak current $\left(i_{\mathrm{pc}}\right)$ are market.

Square wave voltammetry $(S W V)$ was developed by combining the high-amplitude, highfrequency square wave with the fast staircase waveform. Figure 9.2.6.1.3, shows the potential-time waveform of SWV. Each square-wave period occurs during one staircase period $\tau$. The frequency of excitation signals if $f=1 / \tau$, and the pulse duration is $t_{\mathrm{p}}=\tau / 2$. The square-wave amplitude, $E_{s w}$, is one-half of the peak-to-peak amplitude, and the potential increment $\Delta E$ is the step height of the staircase waveform. The scan rate is defined as $\Delta E / \tau$. Relative to the scan direction, $\Delta E$, forward and backward pulses can be distinguished. The currents are measured at the end of each pulse and the difference between the currents measured on two successive pulses is recorded as a net response. In addition, the two components of the net response, i.e., the currents of the forward and backward series of pulses, respectively, can be displayed as well. The currents are plotted as a function of the corresponding potential of the staircase waveform (Lovrić, 2010). 


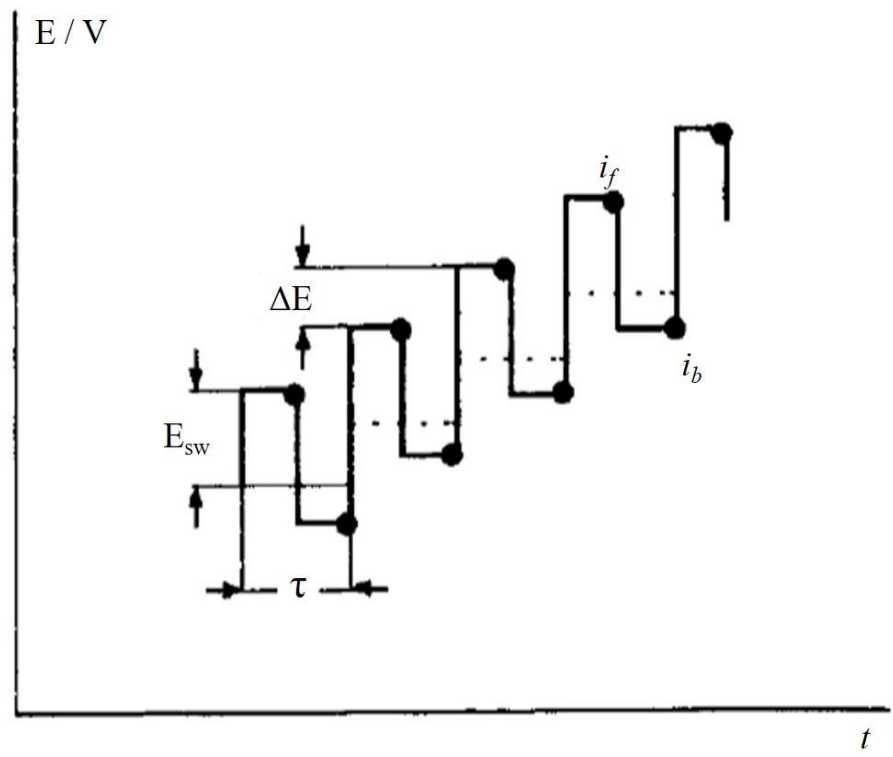

Figure 9.2.6.1.3. Scheme of the square-wave excitation signal, where $E_{\mathrm{sw}}=\mathrm{SW}$ amplitude; $\Delta E=\mathrm{scan}$ increment; $\tau=\mathrm{SW}$ period; $i_{f}=$ forward current; $i_{b}=$ backward current.

\section{Equipment}

Electrochemical experiments were performed at $298 \mathrm{~K}$ in a three-electrode cell under argon atmosphere using a CH I660C device (Cambria Scientific, Llwynhendy, Llanelli UK). A platinum wire counter-electrode and an $\mathrm{Ag} / \mathrm{AgCl}(3 \mathrm{M} \mathrm{NaCl})$ reference electrode completed the three-electrode arrangement (Figure 9.2.6.1.4).

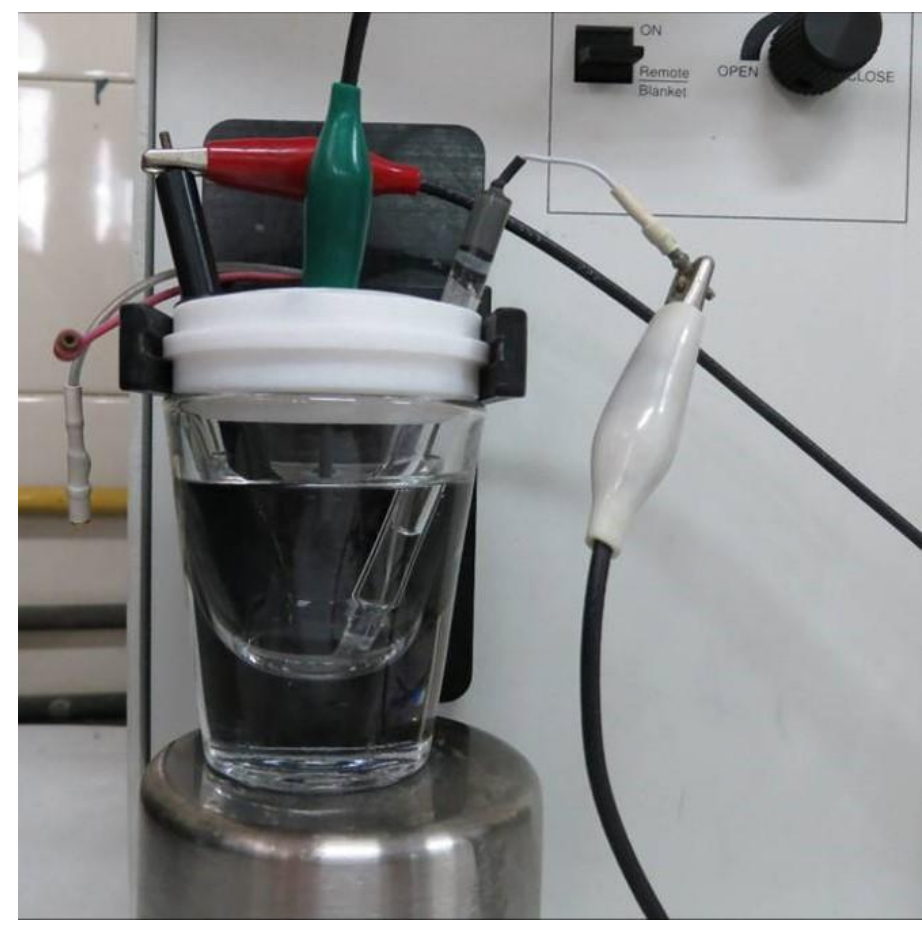

Figure 9.2.6.1.4. VMP equipment used in this study. 
Square wave voltammograms (SWVs), and cyclic voltammograms (CVs) were used as detection modes using abrasive VMP protocols (Doménch-Carbó et al., 2009; DoménchCarbó, 2010; Ortiz-Miranda et al., 2016; Ortiz-Miranda et al., 2017).

Specimens' analysis procedure

$0.25 \mathrm{M}$ sodium acetate buffer (Panreac) at $\mathrm{pH} 4.75$ was used as a supporting electrolyte. Importantly, the electrolyte solution was renewed after each electrochemical run to avoid contamination due to the ions eventually released to the solution phase during electrochemical turnovers. Commercial paraffin-impregnated graphite bars of (Staedtler 200 HB type, $68 \%$ wt graphite, diameter $2 \mathrm{~mm}$ ) were used. Prior to the series of runs for each material or sample, a conditioning protocol was used to increase repeatability. The electrode surface was polished with alumina, rinsed with water and polished by pressing over paper.

For electrode modification, an amount of 1-2 mg of the sample was extended on an agate mortar forming a spot of finely distributed material. Then the lower end of the graphite electrode was gently rubbed over that spot of sample and finally rinsed with water to remove ill-adhered particles. Sample-modified graphite bars were then dipped into the electrochemical cell so that only the lower end of the electrode was in contact with the electrolyte solution. This procedure provides an almost constant electrode area and reproducible background currents.

\section{2. 6. 2. Atomic Force Microscopy-Voltammetry of microparticles (AFM-VMP)}

\section{Principle}

The development of this surface-structure-sensitive technique has made possible the performance of detailed studies of the surface chemistry, morphology, three dimensional structure and electrochemical response of artistic materials.

AFM-VMP is a technique developed by A. Doménech-Carbó and M.T. Doménech-Carbó inspired in the electrochemical atomic force microscopy (EC-AFM). This latter is a scanned probe microscopy technique that has proven to be a powerful instrument for the quantitative investigation of a wide range of processes that occur at interfaces (Barker et al. 1999; Bard et al. 1994; 1991). The probe tip in EC - AFM is an ultramicroelectrode, which typically has a characteristic dimension in the $0.1-10 \mu \mathrm{m}$ range (Wightman and Wipf 1989; Anne et al. 2009) The amperometric, or potentiometric, response of the ultramicroelectrode tip is recorded as the probe is scanned either normal to the interface of interest (tip approach measurements) or over the interface typically at some fixed height (for imaging purposes) or is held in a fixed position with respect to the substrate (for time-dependent measurements). For imaging experiments with amperometric tips, the EC - AFM current responses recorded as a function of tip positions depends on both the substrate topography and reactivity, with a spatial resolution typically governed by the electrode dimensions (Barker et al. 1999; Bard et al. 1994; 1991). 


\section{Equipment}

A Multimode AFM (Digital Instruments VEECO Methodology Group, USA) with a NanoScope IIIa controller and equipped with a J-type scanner (maximum scan size of $150 \mu \mathrm{m} \times 150 \mu \mathrm{m} \times 6 \mu \mathrm{m})$ was used. The topography of the samples was studied in contact mode. An oxide-sharpened silicon nitride probe Olympus, VEECO Methodology Group, model NP-S has been used with a V-shaped cantilever configuration. The spring constant is $0.06 \mathrm{~N} / \mathrm{m}$ and the tip radius of curvature is $5-40 \mathrm{~nm}$. For electrochemical measurements, the AFM was coupled to a Digital Instruments Universal Bipotentiostat (VEECO Methodology group, USA). In AFM-VMP a three electrode arrangement is used adapted to the AFM instrument. The working electrode is a flat conducting graphite plate similar to that used for placing samples in the AFM. The microparticulate sample is abrasively fixed to the graphite plate so that the tip of the AFM can scan the surface of the sample during the potent stat scan the potential in the interval programmed. A drop of electrolyte is added and the voltage between the auxiliary electrode and the working electrode is started at the same time that the tip of the AFM scans the surface of the working electrode. In this way, morphological changes in the particles of sample deposited on the graphite plate as result of the oxidation or reduction processes taking place during the potential scanning can be recorded at micro and nanoscale.

\section{Specimens' analysis procedure}

For performing the study specimens were prepared by fixing the samples on a graphite plate. Selected grains of the sample were transferred to the surface of the graphite plate with the help of a microscalpel. Particles not appropriately fixed to the graphite surface were removed by applying a gentle dry air stream. The coupled AFM-electrochemical experiments were performed after placing a drop $(500 \mu \mathrm{L})$ of previously deaerated $0.50 \mathrm{M} \mathrm{NaAc} / \mathrm{HAc}$ aqueous buffer ( $\mathrm{pH}$ 4.75). AFM images were taken in scanning and topographic AFM modes at selected intervals during electrochemical turnovers. For all samples, several images were recorded at different locations to verify the repeatability of the observed features.

\section{2. 6. 3. Scanning Electrochemical Microscopy (SECM)}

\section{Principle}

Scanning electrochemical microscopy is a powerful technique used for the topographical analysis and quantitative investigation of interfacial physicochemical processes with a wide range of applications, including studies of corrosion and biological systems, etc. The current flows through an ultramicroelectrode (UME) tip (diameter: $10 \mu \mathrm{m}$ or less), a working electrode in a three electrode cell. The tip is immersed in a solution and is moved near a conductive, semi-conductive, or insulating substrate under study. The electrochemical cell usually contains an auxiliary and reference electrode in addition to the tip and the substrate. The current is carried by redox processes at tip and substrate and is controlled by electron transfer kinetics at the interfaces and mass transfer processes in solution, allowing measurements in the range of $1 \mathrm{~nm}$ to $10 \mu \mathrm{m}$ (Bard et al. 1989; Edwards et al. 2006). 


\section{Equipment}

Experiments were performed with $\mathrm{CH}$ 920c equipment using a microdisk platinum electrode tip ( $\mathrm{CH} \mathrm{49,} \mathrm{diameter} 20 \mu \mathrm{m}$ ) and a Pt substrate electrode. The bipotentiostat mode was used to apply potentials to the tip $\left(E_{\mathrm{T}}\right)$ and the electrode substrate $\left(E_{\mathrm{S}}\right)$.

Specimens' analysis procedure

SECM experiments were performed on deposits of the studied materials on a graphite plate acting as a substrate electrode in contact with $5.0 \mathrm{mM} \mathrm{K} \mathrm{K}_{4} \mathrm{Fe}(\mathrm{CN})_{6}$ solution in $0.25 \mathrm{M} \mathrm{HAc} / \mathrm{NaAc}$ (pH 4.75). 


\section{2. 7. References}

Anne, A., Demaille, C., Goyer, C. (2009) Electrochemical Atomic Force Microscopy using a tip-attached redox mediator. Proof-of-concept and perspective for functional probing of nanosystems. ACS Nano, 3(4), 819-827 doi: 10.1021/nn8007788

Attwood, D. (2007) Soft X-rays and extreme ultraviolet radiation: principles and applications. Cambridge University press.

Bard, A.J., Fan, F.R., Kwak, J., Lev, O. (1989) Scanning electrochemical microscopy. Introduction and principles. Anal. Chem., 61, 132-138.

Bard, A.J., Fan, F.R., Mirkin, M.V. (1994) In Electroanalytical Chemistry. Bard, A.J. (ed), Marcel Dekker: New York, Vol. 18, 243-373.

Bard, A.J., Fan, F.R., Pierce, D.T., Unwin, P.R., Wipf, D.O., Zhou, F. (1991) Chemical imaging of surfaces with the scanning electrochemical microscope. Science, 254, 68-74.

Barker, A.L., Gonsalves, M., Macpherson, J.V., Slevin, C.J., Unwin, P.R. (1999) Scanning electrochemical microscopy: beyond the solid/liquid interface. Anal. Chim. Acta, 385, 223240.

Bilardi, C.R. (2009) The red church or the art of Pennsylvania German Braucherei. Los Angeles: Pendraig Publishing.

Bunsen, R.W., Roscoe, H.E. (1859) Philos Trans R Soc Lond 149:879-926

Ciferri O. (1999) Microbial degradation of paintings. Appl. Environ. Microbiol. 65, 879-885.

Doménech-Carbó, A. (2010) Electrochemistry for conservation science. J Solid Sate Electrochem, 14, 349-351. Doi: 10.1007/s10008-009-0934-y

Doménech-Carbó, A., Doménech-Carbó, M.T., Costa, V. (2009) Electrochemical Methods for Archaeometry, Conservation and Restoration. In: Scholz, F. (ed.) Monographs in Electrochemistry Series. Berlin-Heidelberg, Germany: Springer.

Doménech-Carbó, A., Labuda, J., Scholz, F. (2013) Electroanalytical chemistry for the analysis of solids: characterization and classification (IUPAC Technical Report). Pure Appl. Chem., 85, 609-631.

Doménech-Carbó, M.T. (2008) Novel analytical methods for the characterizing binding media and protective coatings in artworks. Analytica Chimica Acta, 621, 109-139.

Edwards, M.A., Martin, S., Whitworth, A.L., Machperson, J.V., Unwin, (2006) Scanning electrochemical microscopy: principles and applications to biophysical systems. Physiological Measurements, 27, 63-108.

Farida, B., Tatiana, D., Diethelm, J. (2003) Nanoscale mapping of the mechanical properties of polymer surfaces by means of AFM noise analysis: spatially resolved fibrillation of latex films. Langmuir, 19, 10247-10253.

Gettens, R.J., Kühn, H., Chase, W.T. (1993) Lead White. In: A. Roy ed. Artist's Pigments, Vol.2, Oxford University Press, 67-81. 
Giacobini, C., Firpi, M. (1981) Problemi di microbiologia nei dipinti su tela. In: Opificio delle Pietre Dure e Laboratorio di Restauro di Firenze. Atti del Convenzione sul Restauro delle Opere d'Arte. Florence, Italy: Edizioni Polistampa, 203-211.

Giacobini, C., De Cicco, M.A., Tiglie, I., Accardo, G. (1988) Actinomycetes and biodeterioration in the field of fine art. In: Houghton DR, Smith RN, Eggins HOW eds. Biodeterioration. New York, NY: Elsevier, 7, 418-423.

Giacobini, C., Pedica, M., Spinucci, M. (1991) 31 Problems and future projects on the study of biodeterioration: mural and canvas paintings. In: Proceedings of the 1st International Conference on the Biodeterioration of Cultural Property. New Delhi, India: Macmillan India, 275-286.

Goldstein, J., Newbury, D. E., Echlin, P., Joy, D. C., Romig Jr, A. D., Lyman, C. E., Fiori, C., Lifshin, E. (2012). Scanning electron microscopy and X-ray microanalysis: a text for biologists, materials scientists, and geologists. Springer Science \& Business Media.

Grygar, T., Marken, F., Schröder, U., Scholz, F. (2002) Electrochemical analysis of solids. A review. Collection of Czechoslovak chemical communications, 67, 163-208.

Kissinger, P.T., Heineman, W.R. (1983) Cyclic voltammetry. J. Chem. Educ., 60, 702-706.

López-Miras, M., Piñar, G., Romero-Noguera, J., Bolivar-Galiano, F.C., Ettenauer, J., Sterflinger, K., Martín-Sánchez, I. (2013) Microbial communities adhering to the obverse and reverse sides of an oil painting on canvas: identification and evaluation of their biodegradative potential. Aerobiologia, 29, 301-314.

Lovrić, M. (2010) Square-wave voltammetry. In Electroanalytical Methos, Springer, Berlin:Heidelberg, 121-145.

Ortiz-Miranda, A.S., Doménech-Carbó, A., Doménech-Carbó, M.T., Osete-Cortina, L., Bolívar-Galiano, F., Martín-Sánchez, I., López-Miras, M.M. (2016) Electrochemical characterization of biodeterioration of paint films containing cadmium yellow pigment. J. Solid State Electrochem., 20, 3287-3302.

Ortiz-Miranda, A.S., Doménech-Carbó, A., Doménech-Carbó, M.T., Osete-Cortina, L., Bolívar-Galiano, F., Martín-Sánchez, I. (2017) Analyzing chemical changes in verdigris pictorial specimens upon bacteria and fungi biodeterioration using voltammetry of microparticles. Heritage Science, 5, 8 .

Ross, R.T. (1963) Microbiology of paint films. Adv. Appl. Microbiol. 5, 217-234.

Sholz, F., Meyer, B. (1998) Voltammetry of solid microparticles immobilized on electrode surfaces. Electroanal. Chem., 20, 1-86.

Scholz, F., Schröder, U., Gulabowski, R., Doménech-Carbó, A. (2014) Electrochemistry of immobilized particles and droplets, $2^{\text {nd }}$ edit. Berlin-Heidelberg: Springer.

Seves, A.M., Sora, S., Ciferri, O. (1996) The microbial colonization of oil paintings. A laboratory investigation. Int. Biodeter. Biodegr., 37, 215-224. 
Strelczyc, A. (1981) Paintings and sculptures. In: Rose AH ed. Microbialdeterioration. London, UK: Academic, 203-234.

Walsh, J.H. (2001) Ecological considerations of biodeterioration. Int. Biodeter. Biodegr., 48, 16-25.

Wightman, R.M., Wipf, D.O. (1989) In Electroanalytical Chemistry. Bard, A.J. (ed.), Marcel Dekker: New York, 1989; Vol. 15

Zyska, B.J. (2002) Problems of microbial deterioration of materials in Eastern Europe. Int. Biodeter. Biodegr., 49, 73-83. 
10. RESULTS AND DISCUSSION 
10.1. Characterization of the biodeterioration patterns 


\subsubsection{Pigments}

As in the study of the characterization of the pigment-binder interactions, a preliminary step aimed at the study if the pigments selected in this research by means of FESEM-EDX was performed. For the characterization of iron oxide red and cadmium yellow see Section 8.1.1.

\section{Verdigris}

Neutral verdigris pigment particles are composed of tabular crystals with rhombic and hexagonal faces with particle size usually $1-30 \mu \mathrm{m}$. Secondary electron image obtained for neutral verdigris used in this study is shown in Figure 10.1.1.1 (up). Particles can vary depending upon the method of manufacture, for instance well-crystalized verdigris particles appear like shards of pointed needles. Whereas, particles that have not undergone crystallization may appear like transparent grains (Kühn, 1993). X-ray spectrum obtained for neutral verdigris is shown in Figure 10.1.1.1 (down) where characteristic emission lines of this pigment at $1.00,8.00$ and $8.90 \mathrm{keV}$ are easily recognize.
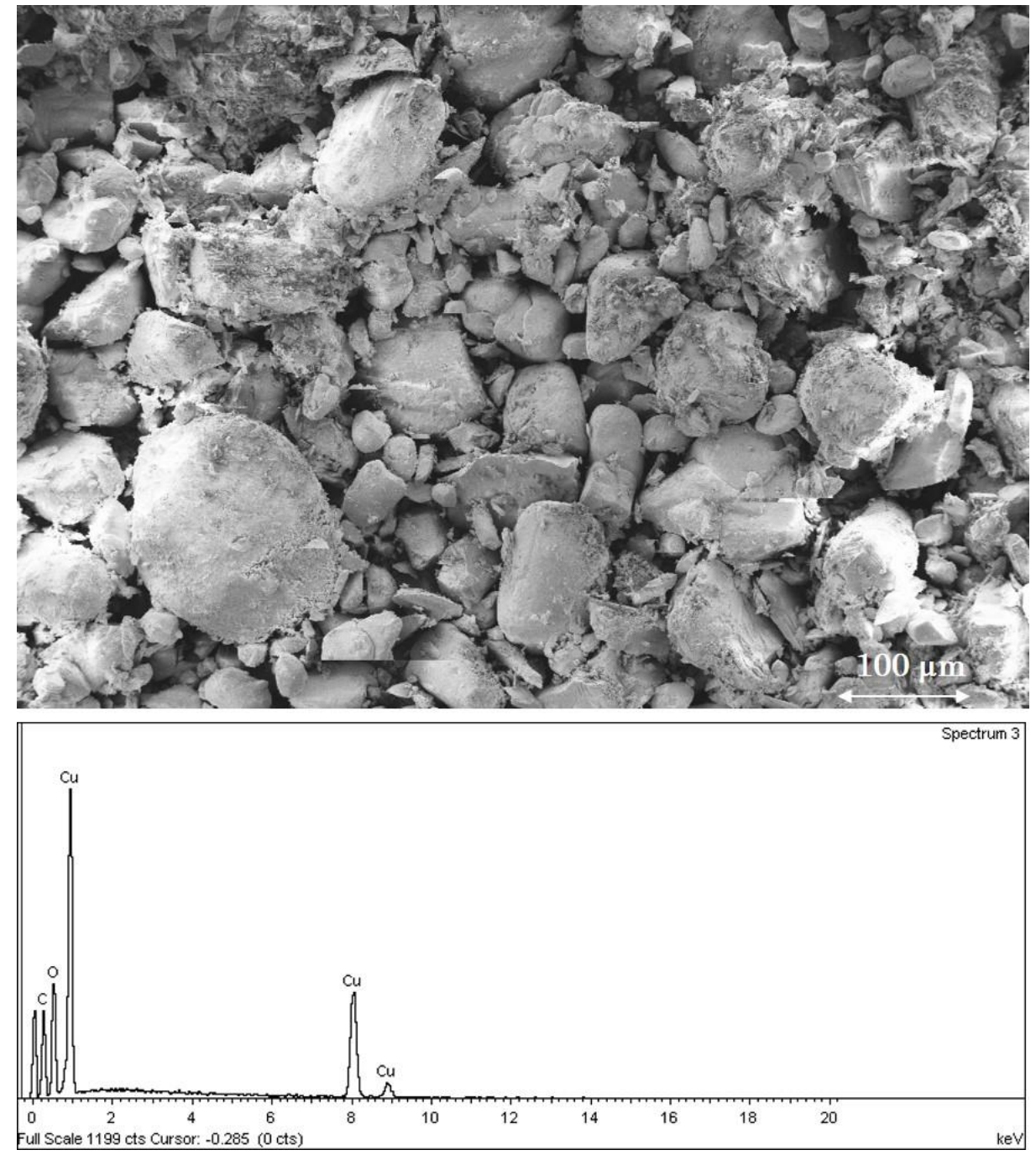

Figure 10.1.1.1. Secondary electron image obtained for verdigris pigment (up) and X-ray spectrum (down). 


\section{Lead white}

Figure 10.1.1.2 (up), shows the secondary electron image obtained for lead white pigment rounded particles, which are uniform in size, varying from $1-2 \mu \mathrm{m}$. At higher magnifications, individual grains are often tubular and hexagonal in outline (Gettens et al., 1993). Characteristic emission lines for this pigment at 1.90, 2.40, 10.40 and $12.60 \mathrm{keV}$ were observed in the X-ray spectrum (Figure 10.1.1.2 down)
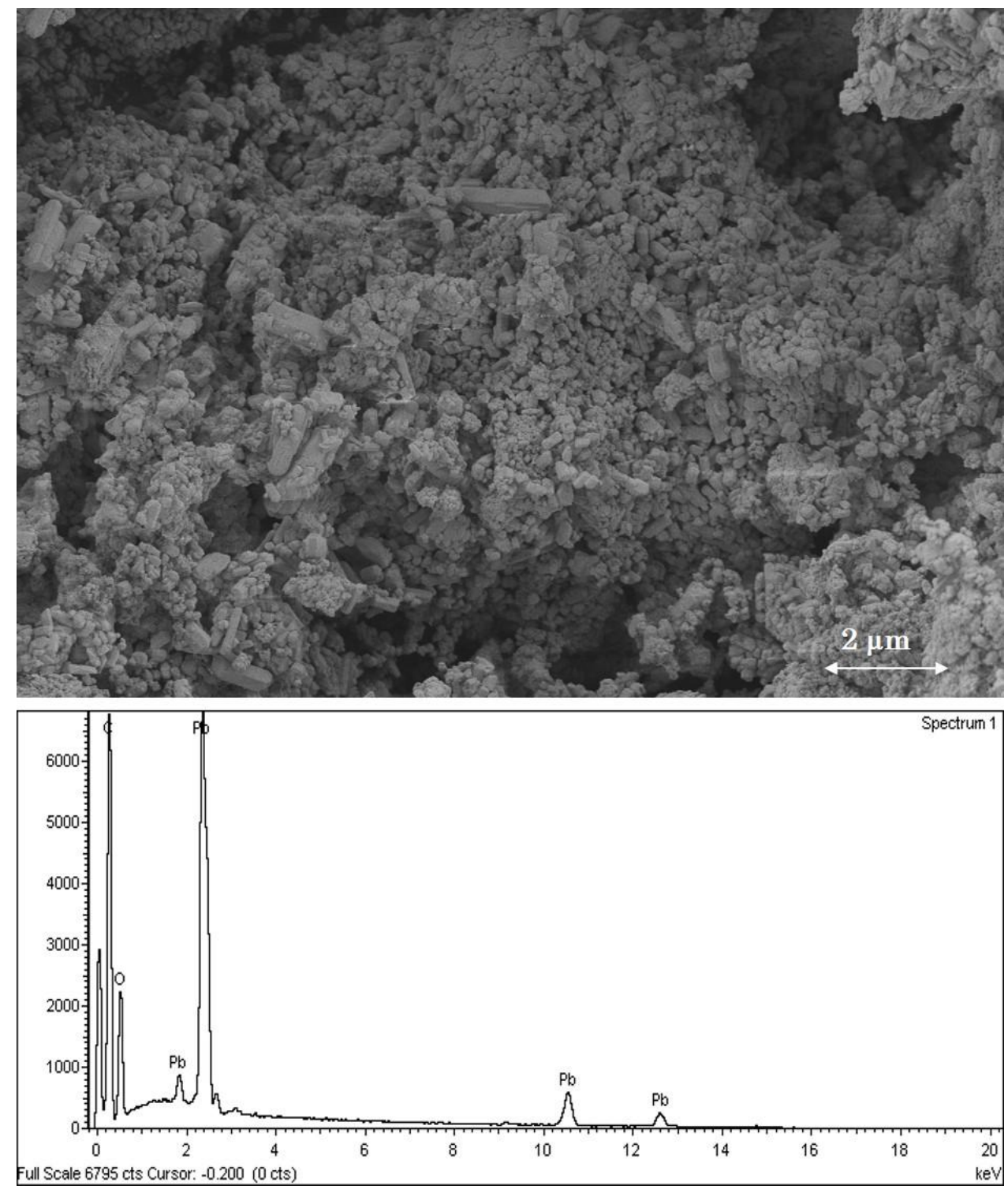

Figure 10.1.1.2. Secondary electron image obtained for lead white pigment (up) and X-ray spectrum (down). 


\subsubsection{FESEM}

Images of the surface of the specimens prepared as model paint films presented in this section were taken after a partial elimination of the biomass by weakly rolling a cotton-swab impregnated in deionized water.

\subsubsection{Characterization of the uninoculated reconstruscted model paint specimens}

\section{Egg tempera reconstructed model paint specimens}

The micromorphology of EG@Fe reconstructed tempera paint film show an irregular surface with abundant pigment grains, surrounded by the binder, that protrude the surface forming aggregates (Figure 10.1.2.1.1).

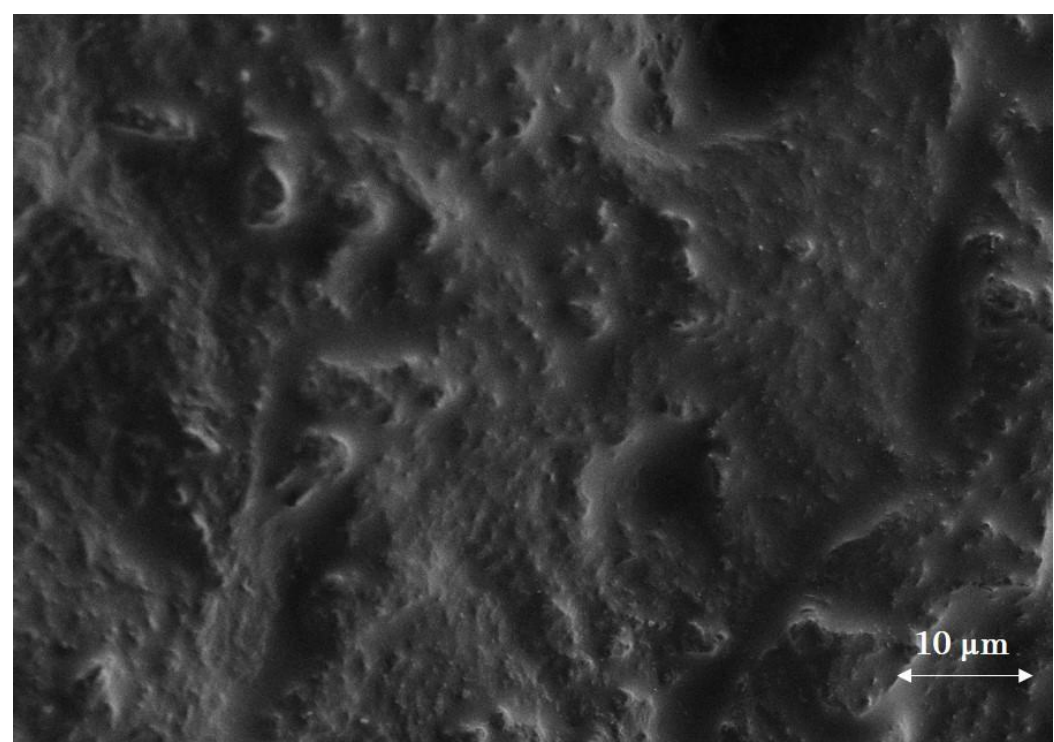

Figure 10.1.2.1.1. Secondary electron image obtained for the EG@Fe reconstructed model tempera paint specimen.

The EG@Cu exhibits, in general, a film with a uniform surface of binding medium. (Figure 10.1.2.1.2). Some pores can be observed over the surface produced during the drying of the film (see arrow). In addition, spherical features associated with dense protein-lipid particles characteristic of egg yolk slightly protrude through the paint film surface (see square). 


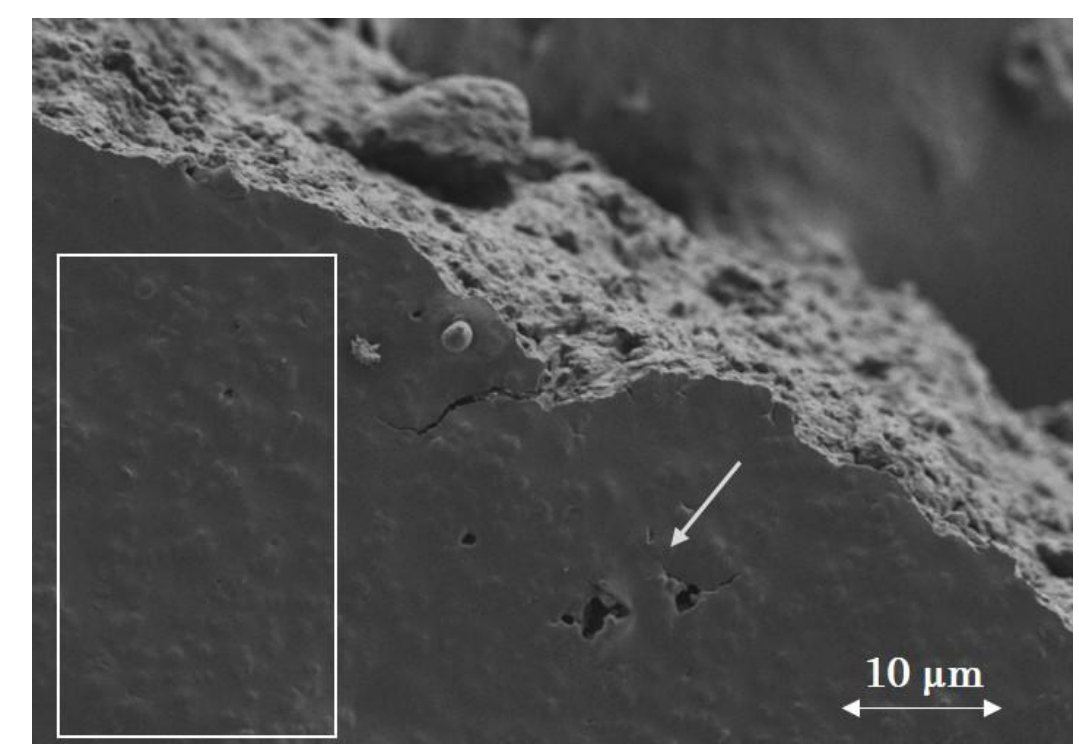

Figure 10.1.2.1.2. Secondary electron image obtained for the EG@ Cu reconstructed model tempera paint specimen.

Figure 10.1.2.1.3 shows the electron secondary images of the EG@Pb specimen. In general, the surface of the reconstructed model paint film specimens appears uniform with abundant pigment protrusions (Figure 10.1.2.1.3a). Also, a few spheres and granules, typical multiscale structures of egg yolk, were identified in the examined cross section shown in Figure 10.1.2.1.3b and c (see arrows) for specimens EG@Pb.
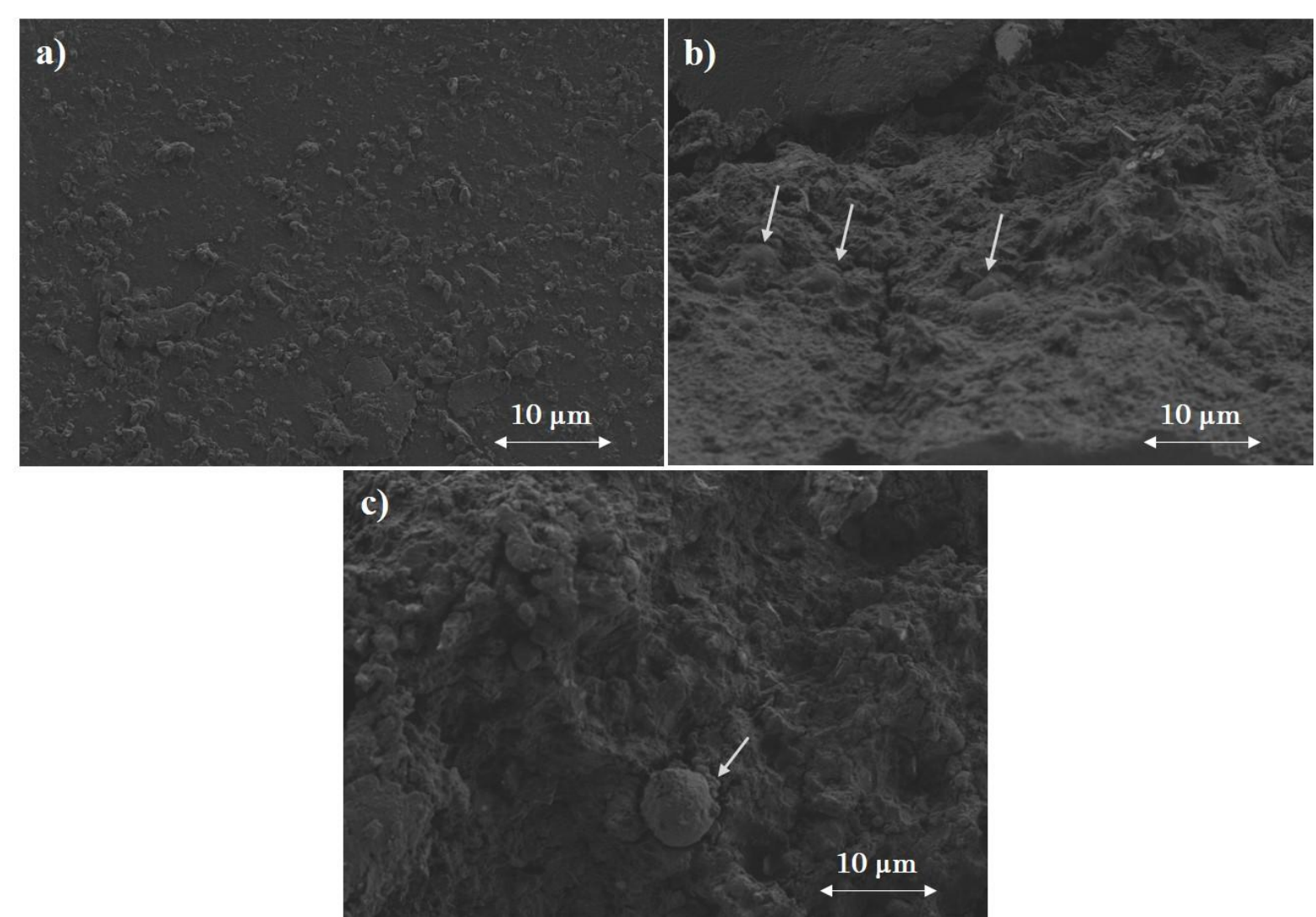

Figure 10.1.2.1.3. Secondary electron images obtained for the EG@Pb reconstructed model tempera paint specimens a) surface, b) cross-section and c) denser protein particle. 
Figure 10.1.2.1.4 shows the secondary electron image of the surface EG@Cd. A continuous surface with some pigment grains aggregates, are recognized protruding in the surface. In contrast to the EG@Cu and EG@Pb specimens, no spheres and granules, typical multiscale structures of egg were identified for the EG@Cd specimen.

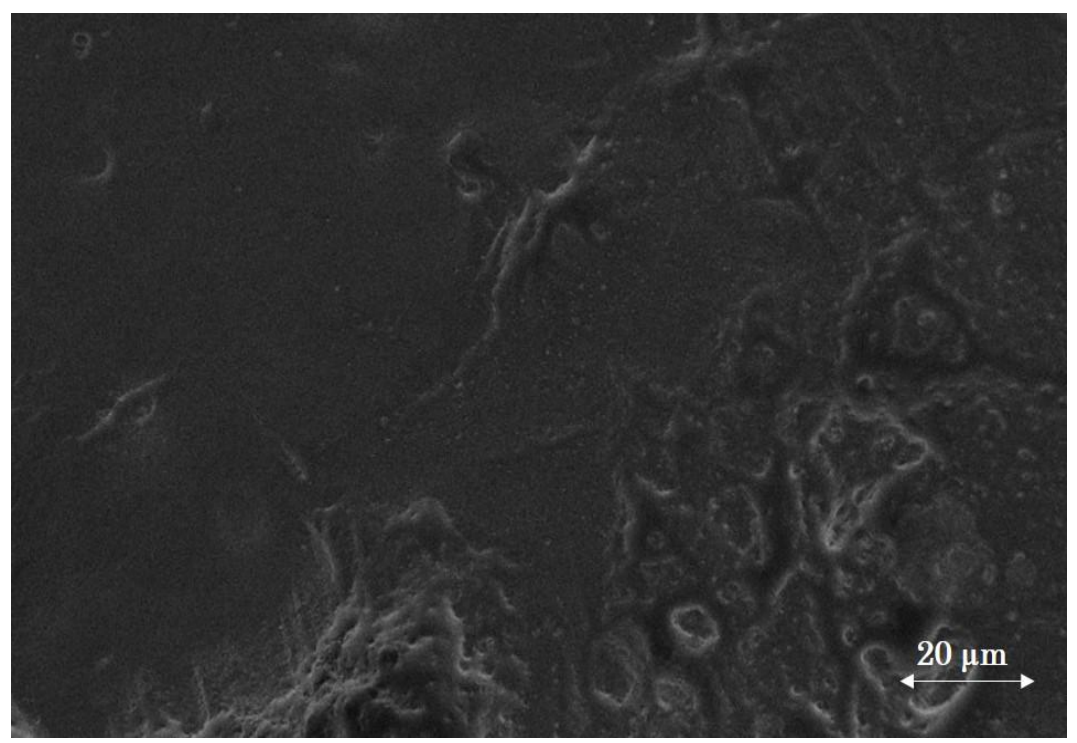

Figure 10.1.2.1.4. Secondary electron image obtained for the EG@Cd reconstructed model tempera paint specimen.

Egg oil emulsion reconstructed model paint specimens

EO@Fe specimen showed a more regular surface than that of the EG@Fe specimen with a few pigment grains protrusions (see arrows in Figure 10.1.2.1.5).

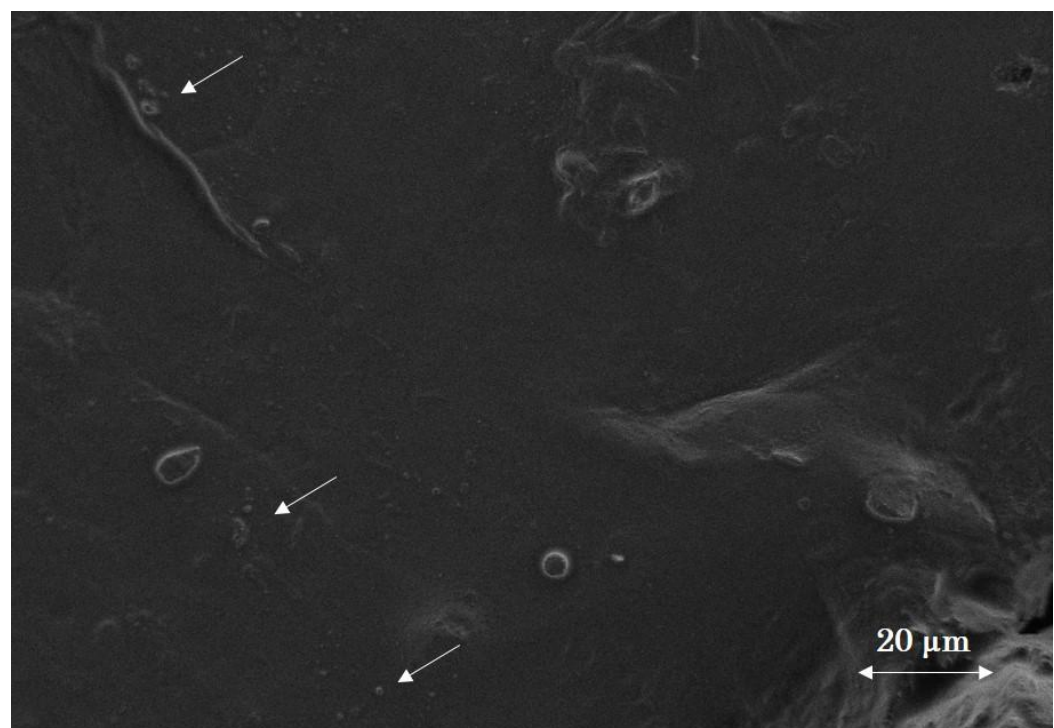

Figure 10.1.2.1.5. Secondary electron image showing the surface of the EO@Fe reconstructed model tempera paint specimen. 
The surface of the EO@ $\mathrm{Cu}$ specimens was irregular as can be seen in Figure 10.1.2.1.6a. Cracks (see arrows) and micropores (see stars) attributed to the stretching forces that occurs in the paint film as consequence of the dehydration-oxidation-polymerization processes associated to the drying of the film were observed. Figure 10.1.2.1.6b shows a spherical insoluble denser protein-lipid particle (see circle) and microcrystals associated to copper soaps but also to copper-protein complexes formed as result of the pigment binder interactions (see arrows). Formation of copper-oleates and copper-protein compounds as result of the pigment-binder interactions in paintings have been widely described (Kühn, 1993; Ioakimoglou et al., 1999; Buti et al., 2013; Castro et al., 2008; Conti et al., 2014; Santoro et al., 2014)
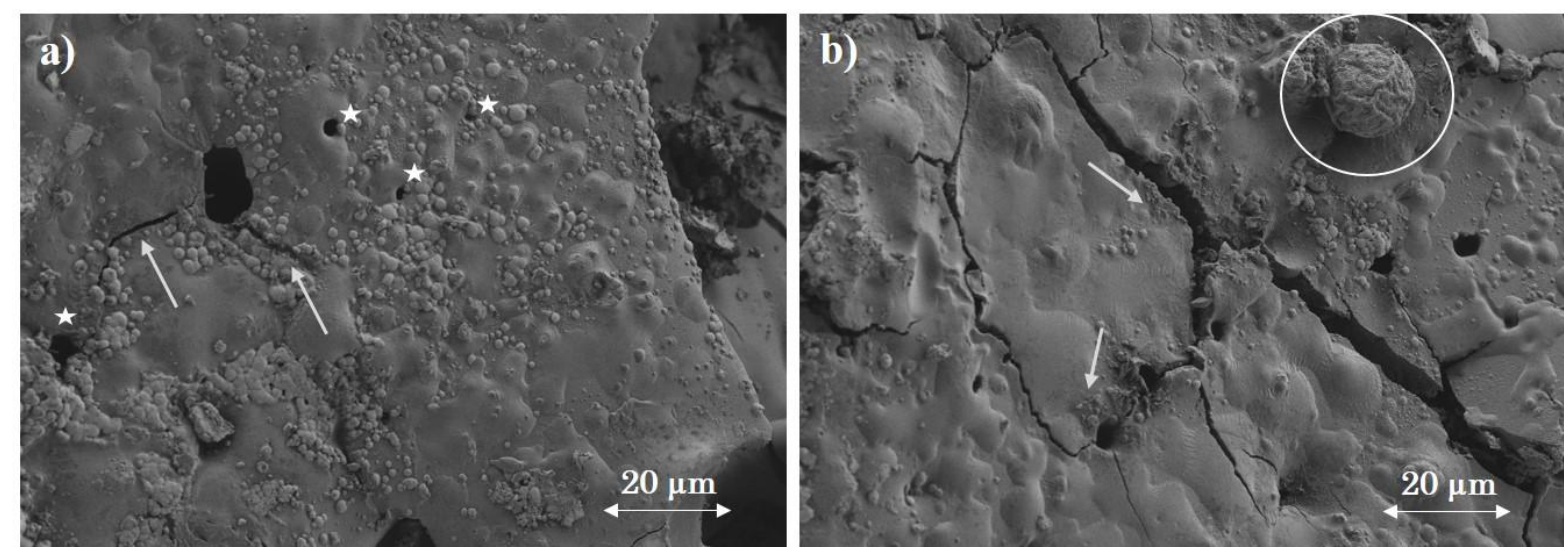

Figure 10.1.2.1.6. Secondary electron images showing the surface of the EO@Cu reconstructed model tempera paint specimens.

Figure 10.1.2.1.7a shows secondary electron image obtained for the surface of the EO@Pb reconstructed model paint specimens, exhibits a surface as in the egg yolk specimens (section 8.1.2) with some pigment protrusions thus denoting a low PVC. Some insoluble denser protein-lipid particles can be hardly inferred through the surface (see arrow in Figure 10.1.2.1.7a). The pigment aggregates embedded in the binding medium can be seen in the cross-section image (Figure 10.1.2.1.7b).

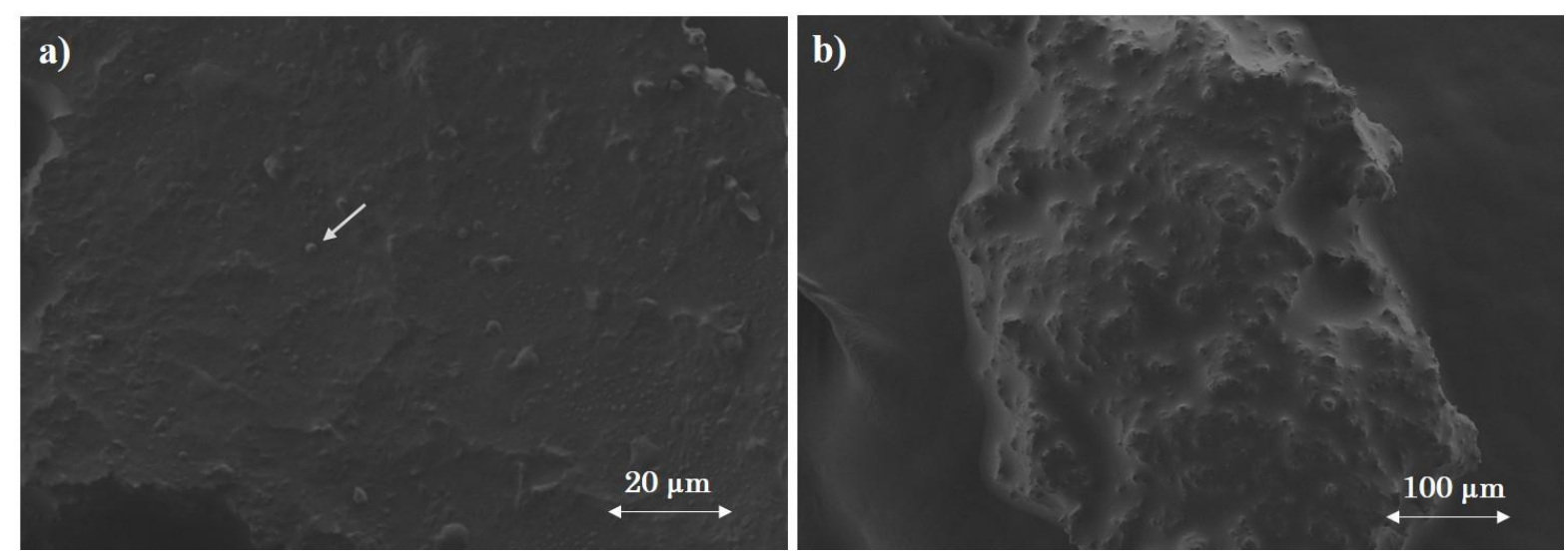

Figure 10.1.2.1.7. Secondary electron images showing the surface of the EO@Pb reconstructed model tempera paint specimens. 
Figure 10.1.2.1.8 shows the secondary electron images obtained in the EO@Cd reconstructed model paint specimen in which pigment aggregates embedded by the binder can be observed (arrows). Similarly, to the rest of specimens prepared as emulsions, spheres and granules typical of egg microstructures are hardly here identified due to the presence of linseed oil (see square in Figure 10.1.2.1.8).

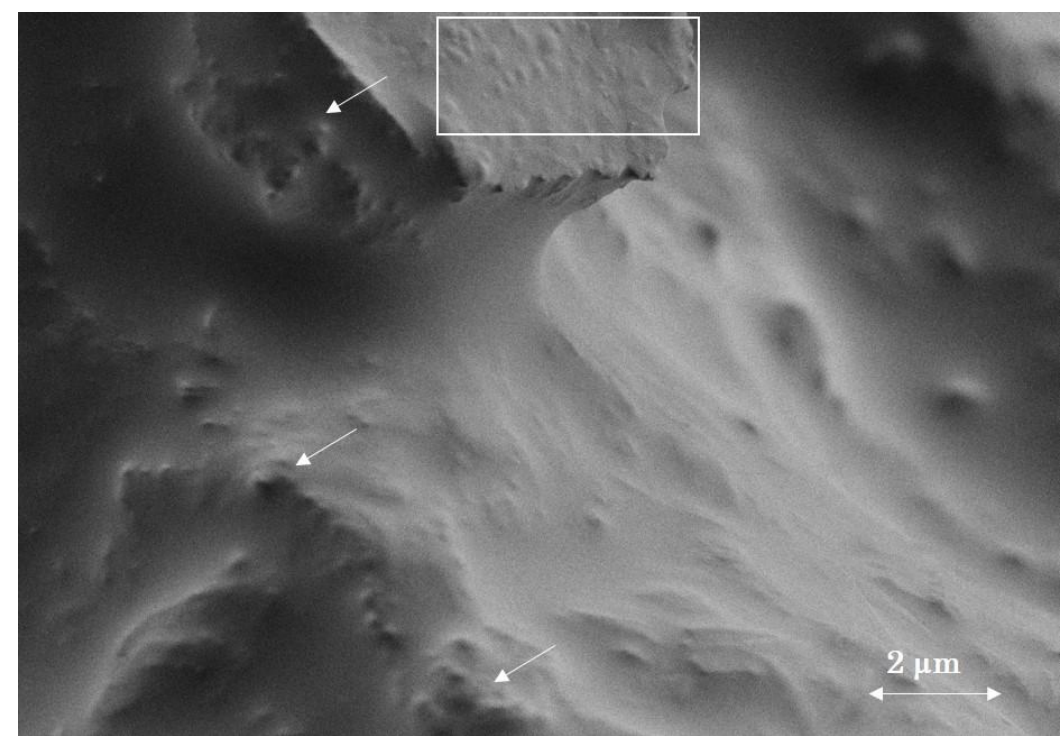

Figure 10.1.2.1.8. Secondary electron image showing the surface of the EO@Cd reconstructed model tempera paint specimen.

10.1.2.2. Characterization of the inoculated reconstruscted model paint specimens

10.1.2.1. Egg tempera reconstructed model paint specimens

\section{Iron oxide red}

Microerosion of the paint film surface promoted by the microbial attack was observed in all specimens. Figure 10.1.2.2.1.1, shows as an example, the secondary electron images obtained for the iron oxide red egg tempera reconstructed model paint inoculated with Acremonium chrysogenum (EG@Fe_Ac) and Aspergillus niger (EG@Fe_An). Aggregates of fungal spores can be seen in the surface of the EG@Fe_Ac (Figure 10.1.2.2.1.1a). 

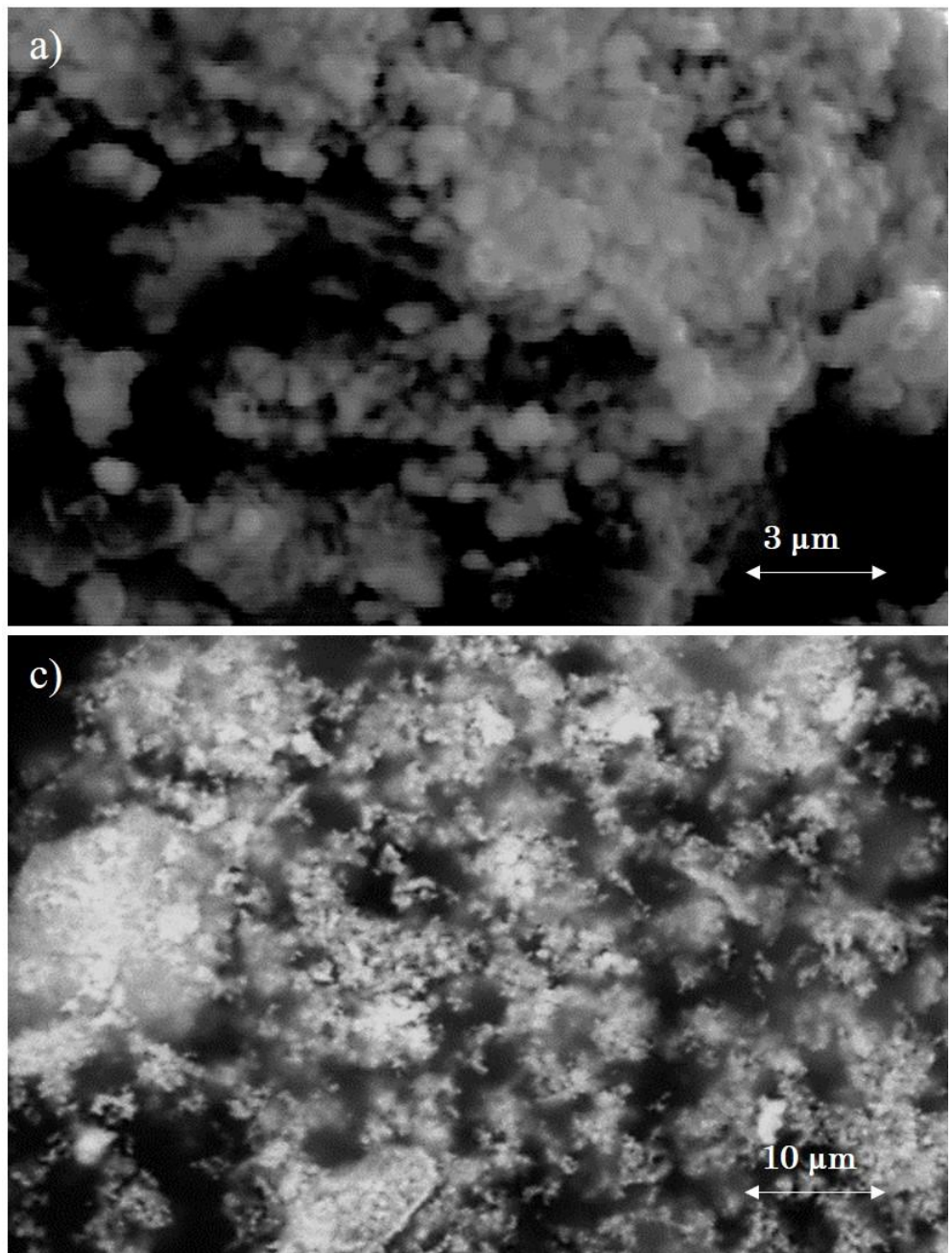

Figure 10.1.2.2.1.1. Secondary electron image obtained in a) EG@Fe_Ac and b) EG@Fe_An reconstructed model tempera paint specimens

Most significant changes observed in the specimen inoculated with bacteria were obtained for the specimen inoculated with the eubacteria Bacillus amyloliquefaciens (EG@Fe_Ba), where abundant microerosion as result of the microbial attack can be seen in Figure 10.1.2.2.1.2. A similar behavior was also observed in the specimens inoculated with actinobacteria Arthrobacter oxydans and Streptomyces cellulofans. 


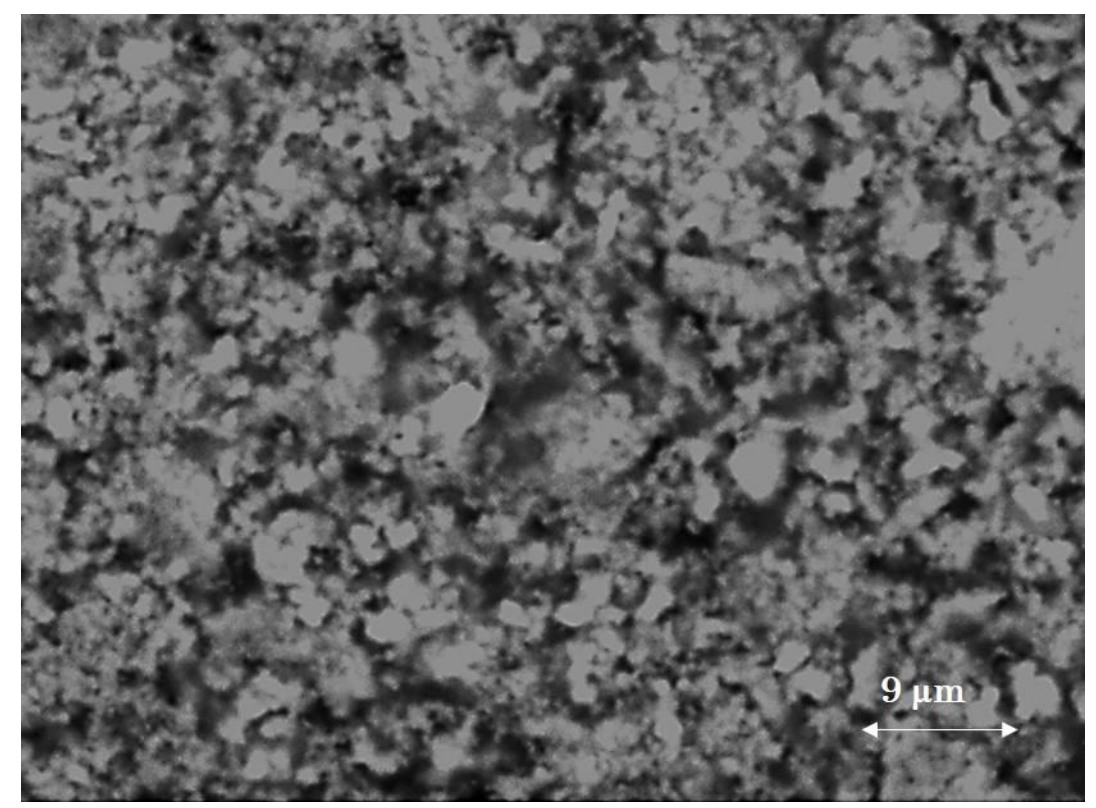

Figure 10.1.2.2.1.2. Secondary electron image obtained in a) EG@Fe_Ba reconstructed model tempera paint specimens

\section{Verdigris}

Some changes in the surface morphology are observed in the EG@Cu specimens inoculated with fungi that illustrate the effect of fungi growing in this paint film. Figure 10.1.2.2.1.3, shows the EG@Cu_Ac specimen inoculated with Acremonium chrysogenum, where spores are strongly adhered to the binding medium. The secondary electron images obtained for the EG@Cu_An specimen inoculated with Aspergillus niger show a surface with fungal spores connected by strands (Figure 10.1.2.2.1.4a). In addition, granules are also observed that protrude to the surface of the film (see square in Figure 10.1.2.2.1.4b). Increase in the presence of granules protruding to surface, if compared to the uninoculated specimen, confirms the bioerosion produced by this microorganism to the paint film surface. 


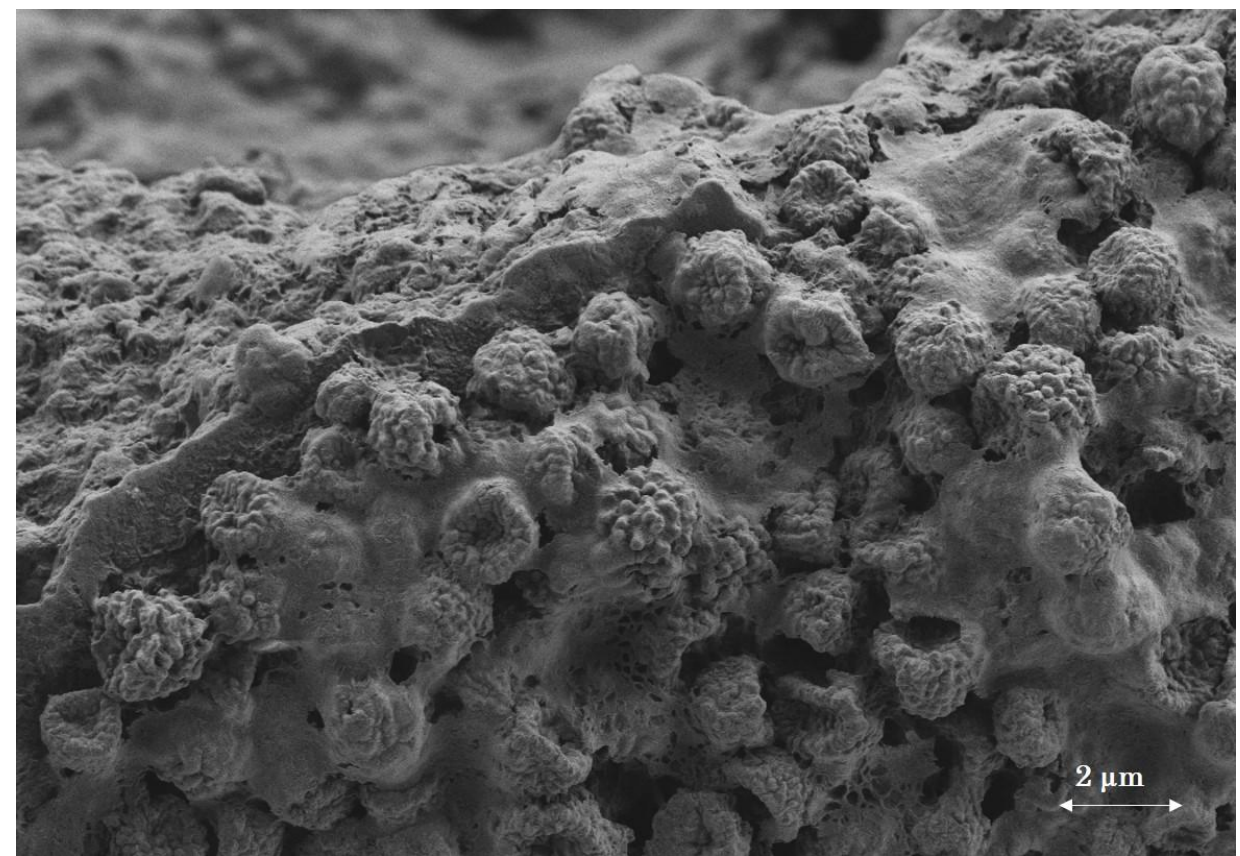

Figure 10.1.2.2.1.3. Secondary electron image obtained in $\mathrm{EG@Cu \_ Ac} \mathrm{reconstructed} \mathrm{model} \mathrm{tempera} \mathrm{paint} \mathrm{specimen}$ showing an aggregate of fungal spores.

In the EG@Cu_Mr specimen inoculated with Mucor rouxii, fungal spores are observed over the surface as well as microcrystals of nanometric size spread on the surface of the film (Figure 10.1.2.2.1.4c) and forming irregular aggregates around the spores of the fungus (arrows in Figure 10.1.2.2.1.4d). Surface of the specimen inoculated with Penicillium chrysogenum was dominated by the presence of cracks and irregular aggregates alternated with spores and insoluble denser protein-lipid nanoparticles (see circles in Figure 10.1.2.2.1.4e). Granules and spheres are well identified in the Figure 10.1.2.2.1.4f (arrows). 

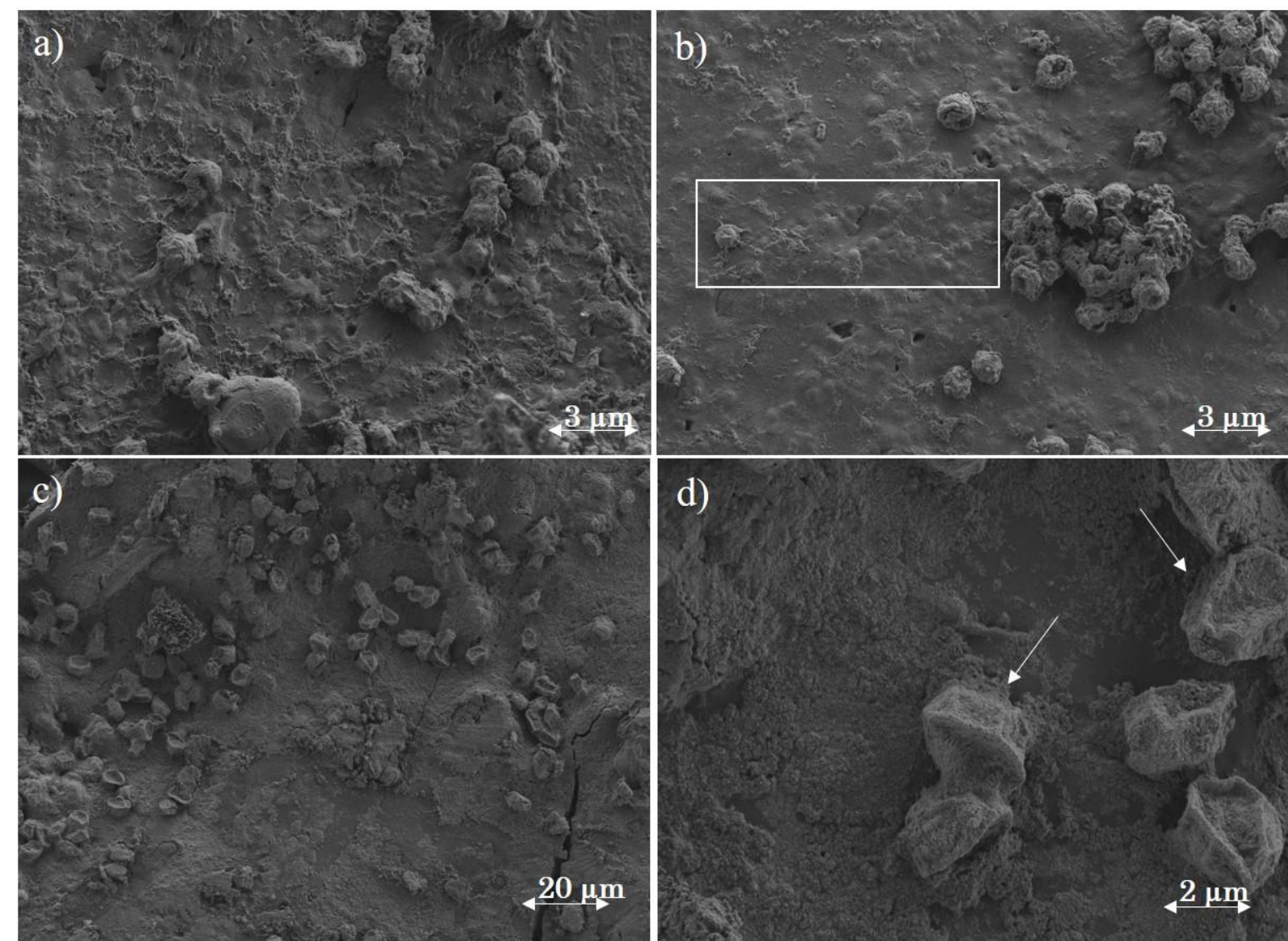

d)
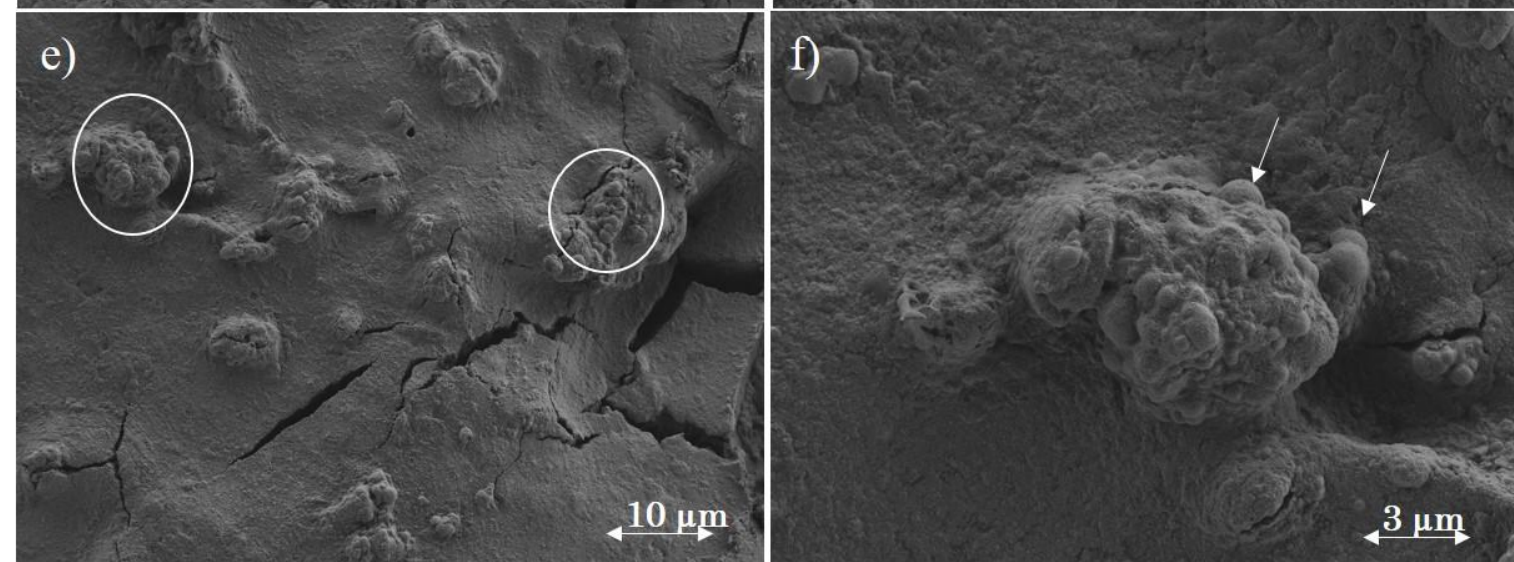

Figure 10.1.2.1.4. Secondary electron image obtained in: a) and b) EG@Cu_An; and c) and d) EG@Cu_Mr; and e) and f) EG@Cu_Pc reconstructed model tempera paint specimens.

Bioerosion at microscale promoted by the microbial attack was observed in the surface of the EG@Cu_Tp specimen inoculated with Trichoderma pseudokoningii (see arrows in Figure 10.1.2.2.1.5). In addition, fungal spores' aggregates are surrounded by pigment microcrystals as in the specimen inoculated with Mucor rouxii (see circle in Figure 10.1.2.2.1.5). Cracks attributed to the stretching forces that occur in the paint film as consequence of the drying processes were observed in various inoculated paint films (Figure 10.1.2.2.1.4c, e and Figure 10.1.2.2.1.5). 


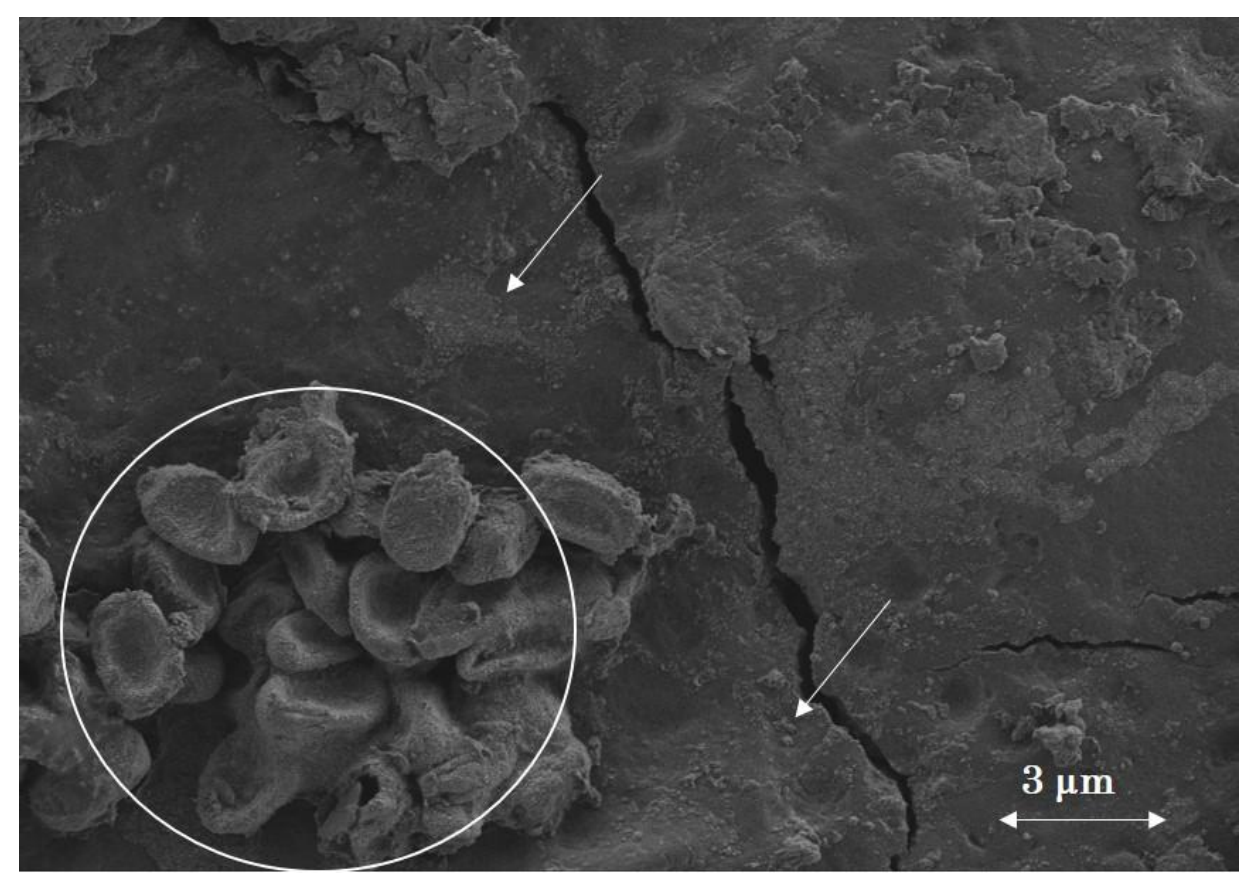

Figure 10.1.2.2.1.5. Secondary electron image obtained in EG@Cu_Tp showing an aggregate around fungal spores (circle) and microerosion (arrows).

Figure 10.1.2.2.1.6 shows the secondary electron images obtained for specimen inoculated with Arthrobacter oxydans (EG@Cu_Ao) and Streptomyces cellulofans (EG@Cu_Sc) where the formation of a thin layer of biomass can be observed over the surface of the paint films (Figure 10.1.2.2.1.6a and c, respectively). A biofilm is mainly composed of water (80 95\%), extracellular polymer substance (EPS) that contribute $85-98 \%$ of the organic matter, the microorganism, entrapped organic and inorganic particles, substance attached to EPS, cells or particles and substances dissolved in the interstitial water (Flemming, 1998). These biofilms are formed reverently surrounding pores and holes (de Beer et al., 1994), which is in agreement with that observed in most of the paint films inoculated with bacteria and fungi studied. On the other hand, the bacterium Arthrobacter oxydans seems to be active in the consumption of the compounds composing granules and spheres as denoted by abundant rests of this microorganism that appear attached to these egg microstructures (see circles in Figure 10.1.2.2.1.6b). A detail of the surface of the paint film with some Streptomyces cellulofans microorganisms adhered to the surface of the paint is shown in Figure 10.1.2.2.1.6d). 

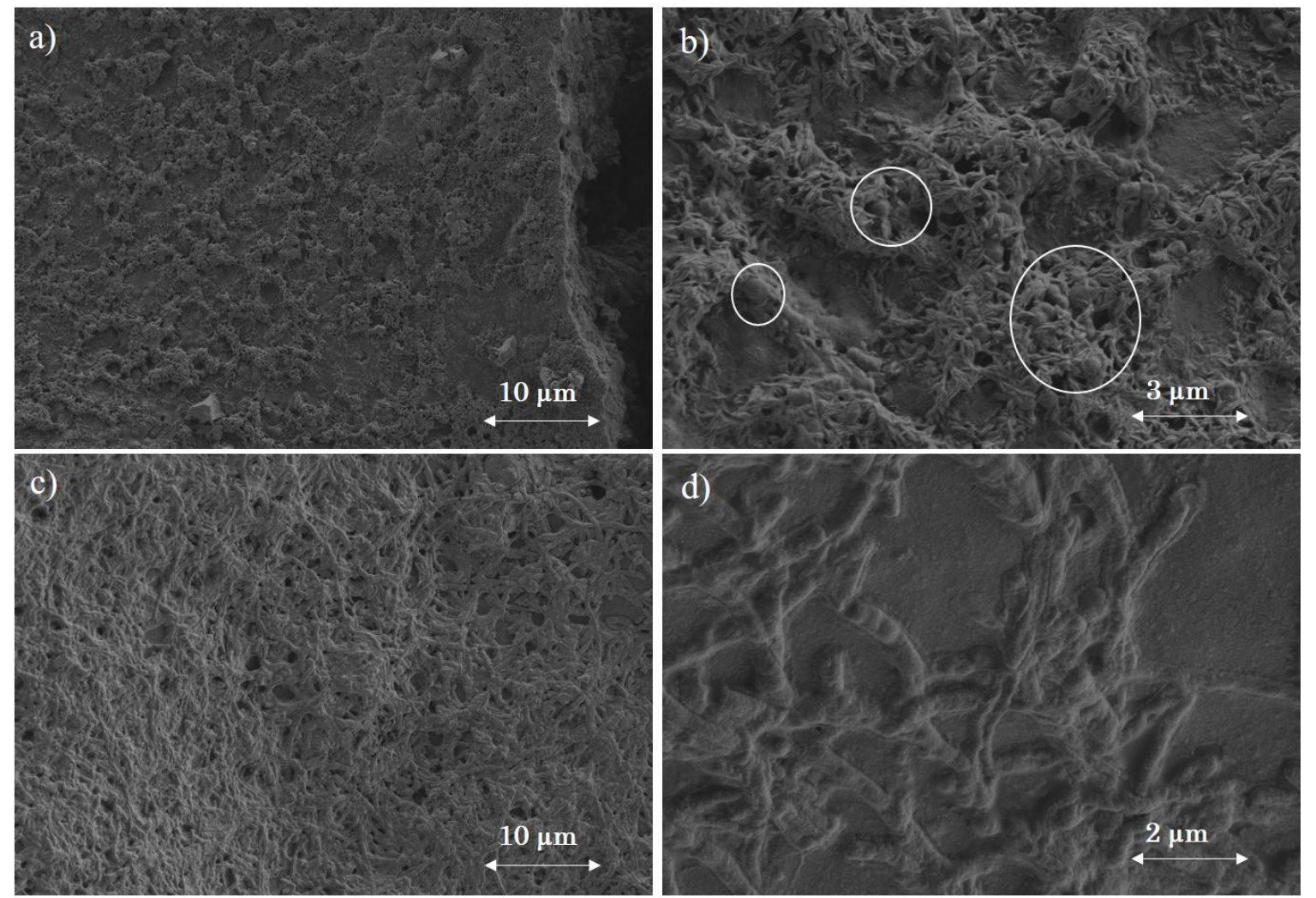

Figure 10.1.2.2.1.6. Secondary electron image obtained in: a) and b) EG@Cu_Ao; and c) and d) EG@Cu_Sc reconstructed model tempera paint specimens.

The secondary electron images obtained for the EG@Cu_Ba specimen inoculated with the eubacterium Bacillus amyloliquefaciens are shown in Figure 10.1.2.2.1.7. Microerosion produced by the microbial attack to the paint film can be observed in the Figure 10.1.2.2.1.7a. This microorganism is active in the consumption of denser protein-lipid particle as is illustrated in the Figure 10.1.2.2.1.7b (arrow) that shows one of these rounded particles partially broken down by the action of the microorganism. 

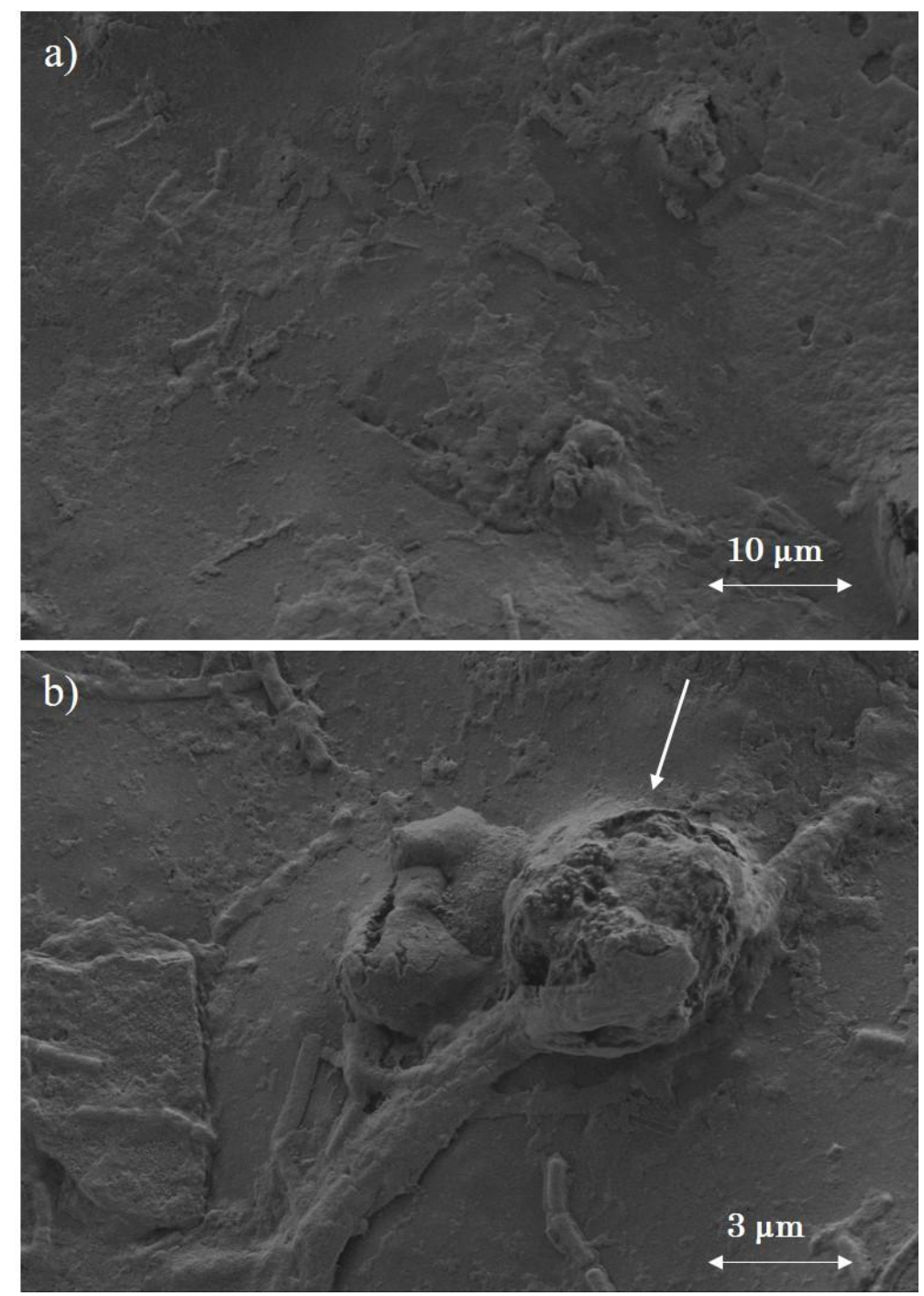

Figure 10.1.2.2.1.7. Secondary electron image obtained in EG@Cu_Ba reconstructed model tempera paint specimens.

\section{Lead white}

The secondary electron images obtained in the surface of the EG@Pb_Ac specimen inoculated with Acremonium chrysogenum illustrate that this fungus promotes the formation of free fatty acids (Figure 10.1.2.2.1.8a (arrows)) (Mills et al., 2008; Tempest et al., 2010). These images are in agreement with the results obtained by FTIR that reported a high content in free fatty acids. Cracks ascribed to the shrinkage produced during the drying of the paint film are observed in the surface of the paint film inoculated with Aspergillus niger (EG@Pb_An) along which grains of pigment that are protruding on the surface (arrow in Figure 10.1.2.2.1.8b). A similar behavior was observed in the paint film inoculated with Penicillium chrysogenum (circle in Figure 10.1.2.2.1.8d). In the surface of the EG@Pb_Mr paint film specimen inoculated with Mucor rouxii, pigment-binder aggregates can be seen embedded by a biofilm layer formed by the microorganism (arrows in Figure 10.1.2.2.1.8c). No features associated to microbial attack were recognized in the specimen inoculated with Trichoderma pseudokoningii. 

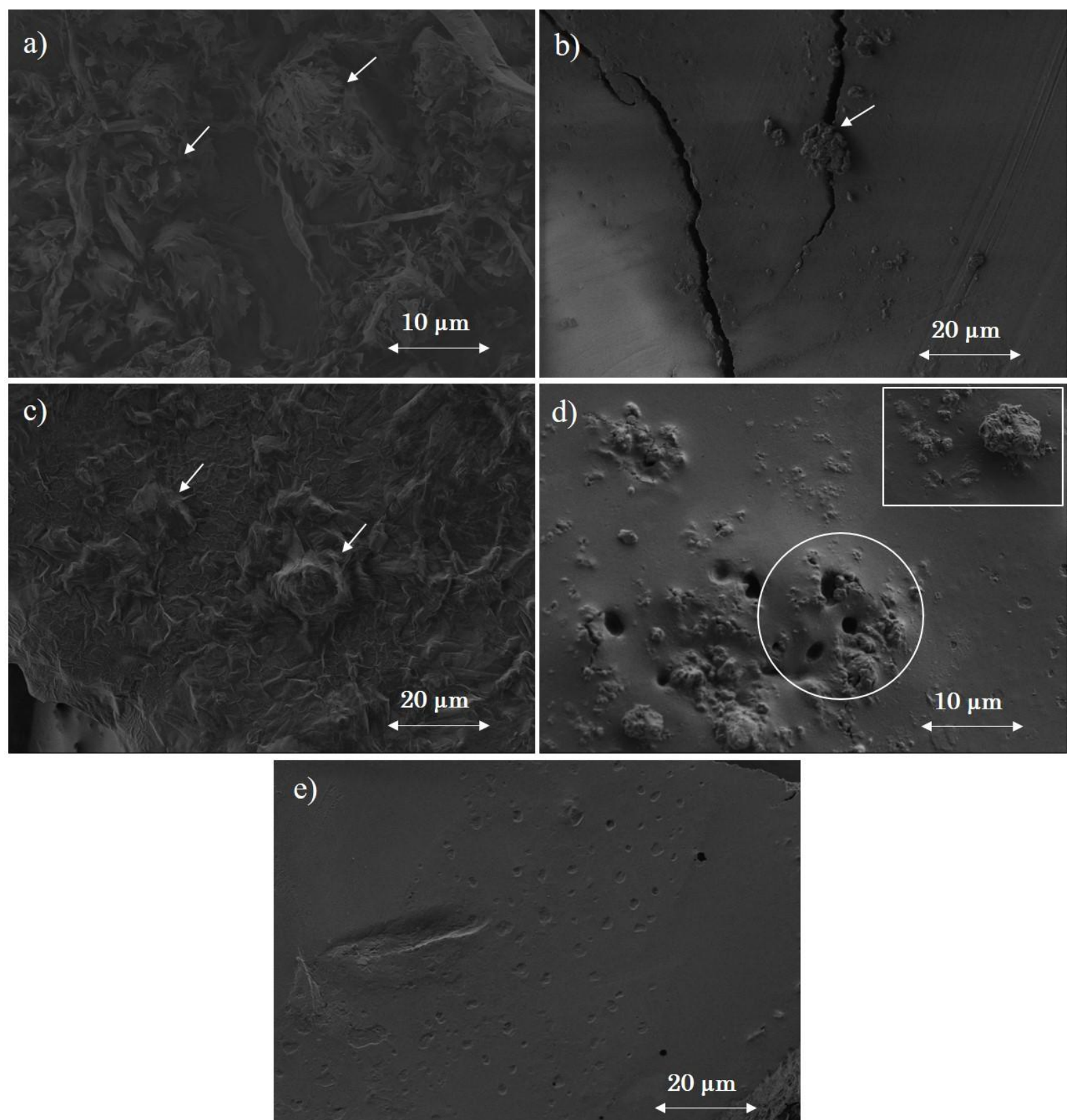

Figure 10.1.2.2.1.8. Secondary electron image obtained in: a) EG@Pb_Ac, b) EG@Pb_An, c) EG@Pb_Mr, d) EG@Pb_Pc, and e) EG@Pb_Tp reconstructed model tempera paint specimens.

The surface of the specimen inoculated with actinobacteria Arthrobacter oxydans (EG@Pb_Ao) shows abundant features associated to the actuation of this bacterium on the rounded egg microparticles and granules (arrows in Figure 10.1.2.2.1.9a). A detail of the morphology of these deteriorated particles can be seen in Figure 10.1.2.2.1.9b. In the EG@Pb_Sc can be observed spherical features associated with denser protein-lipid particles (less than $4 \mu \mathrm{m} \varnothing$ ) partially emerging from some micropores (arrows in Figure 10.1.2.2.1.9c). 

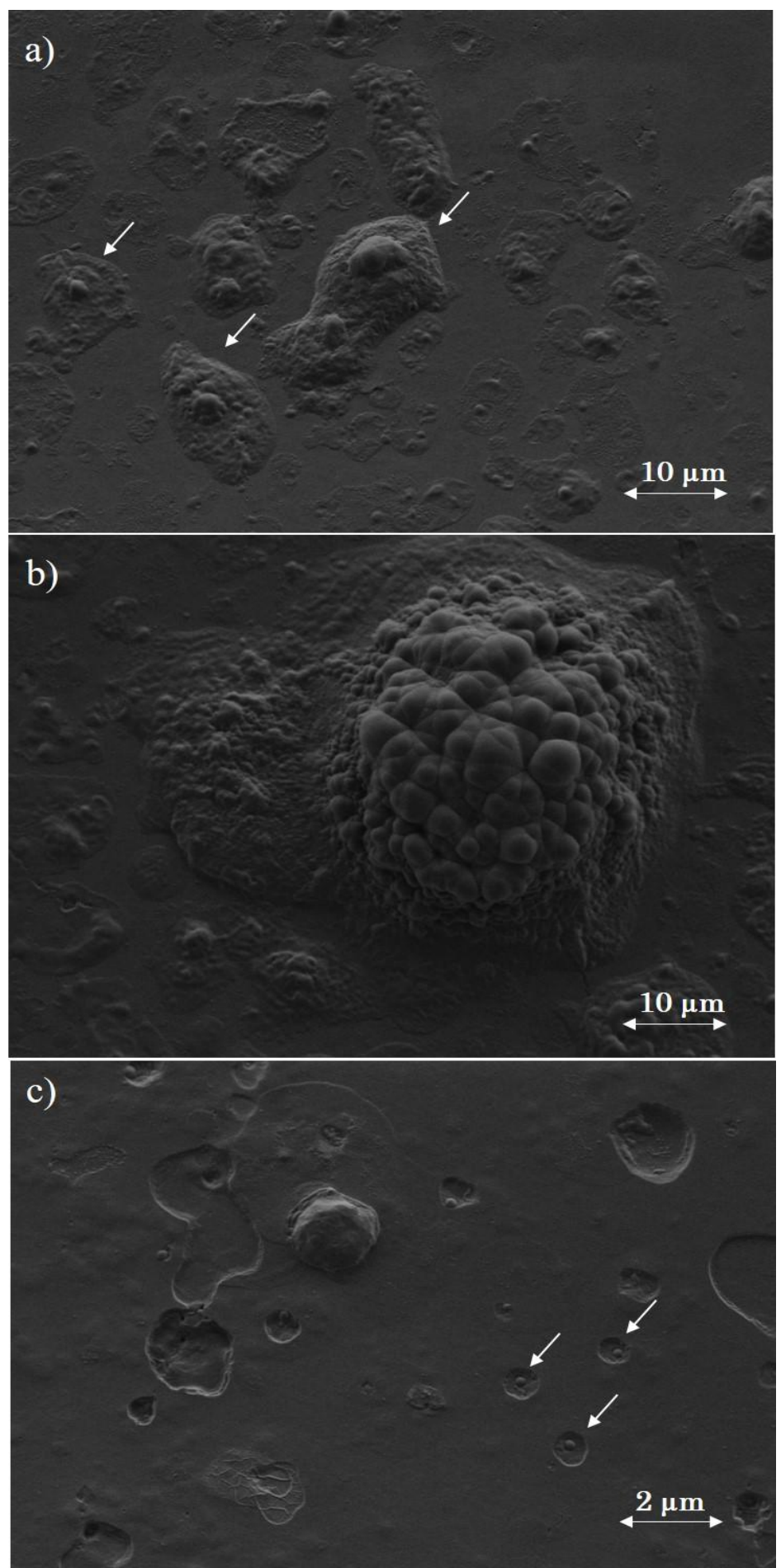

Figure 10.1.2.2.1.9. Secondary electron image obtained in: a) and b) EG@Pb_Ao; c) EG@Pb_Sc reconstructed model tempera paint specimens.

\section{Cadmium yellow}

Figure 10.1.2.2.1.10a, shows the secondary electron image obtained for the specimen inoculated with Acremonium chrysogenum (EG@Cd_Ac) where abundant fungal spores are observed. Some features probably associated to cadmium-binder complexes that are migrated to the surface of the film can be also observed (square in Figure 10.1.2.2.1.10a). Fungal 
spores (around Ø: $1 \mu \mathrm{m}$ ) were also observed in the surface of the specimen inoculated with Aspergillus niger (EG@Cd_An) (Figure 10.1.2.2.1.10b), these spores often are attached to an insoluble denser protein-lipid particle (arrow in Figure 10.1.2.2.1.10b). Microerosion promoted by the inoculation with Mucor rouxii (EG@Cd_Mr) as well as irregular protrusions of aggregates (stars) can be seen in Figure 10.1.2.1.10c. Protrusions were also observed in the specimen inoculated with Penicillium chrysogenum (EG@Cd_Pc) (arrow in Figure 10.1.2.2.1.10d). Features associated to the formation of cadmium-binder complexes (arrow) are the most significant changes observed in the specimen inoculated with Trichoderma pseudokoningii (EG@Cd_Tp) (Figure 10.1.2.2.1.10e).
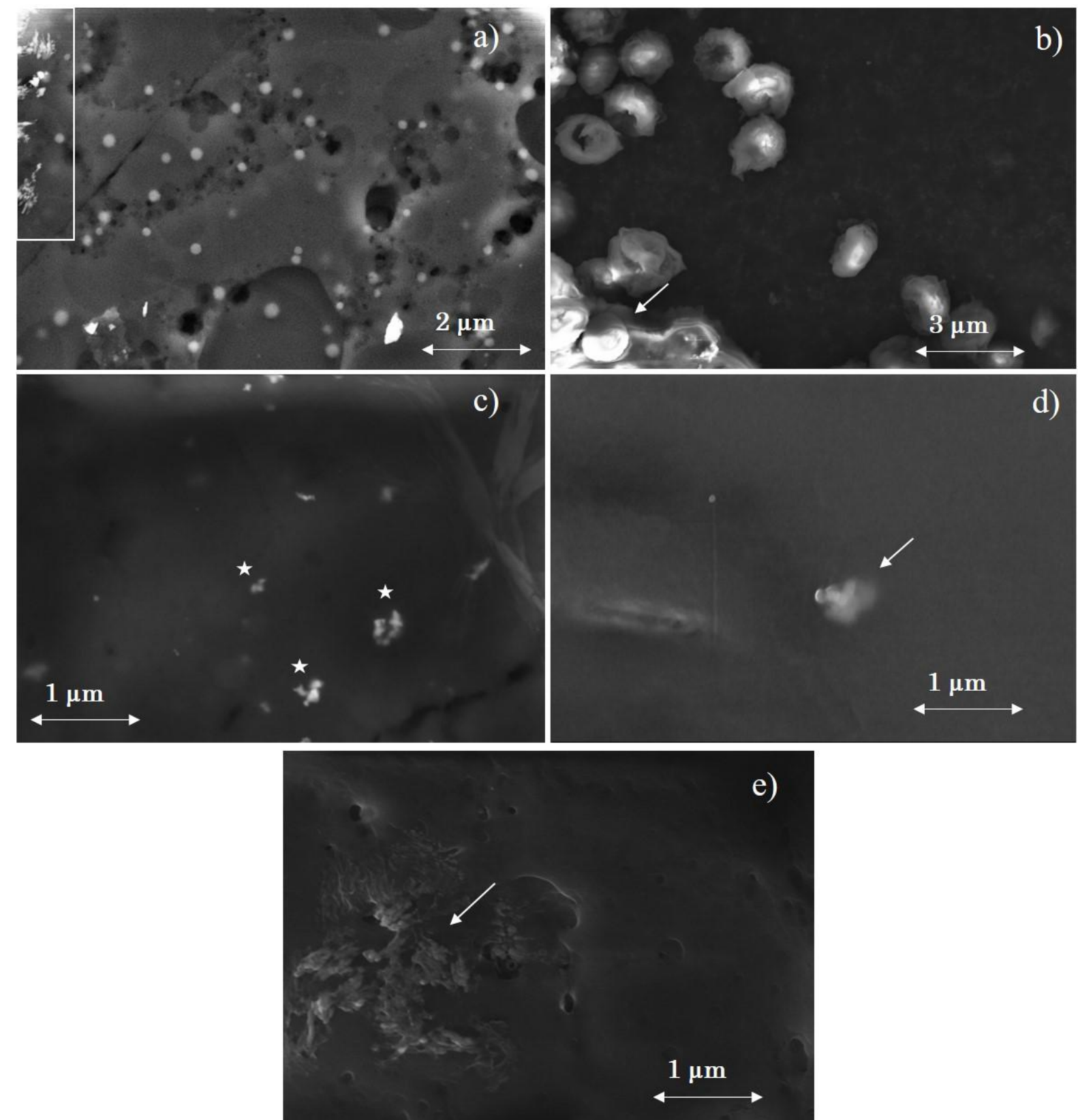

Figure 10.1.2.2.1.10. Secondary electron image obtained in: a) EG@Cd_Ac, b) EG@Cd_An, c) EG@Cd_Mr, d) EG@Cd_Pc, and e) EG@Cd_Tp reconstructed model tempera paint specimens. 
Cadmium yellow egg tempera reconstructed model paint specimens inoculated with Arthrobacter oxydans (EG@Cd_Ao) and Streptomyces cellulofans (EG@Cd_Sc) actinobacteria and Bacillus amyloliquefaciens (EG@Cd_Ba) eubacterium, exhibit a surface covered by a biofilm (Figure 10.1.2.2.1.11).
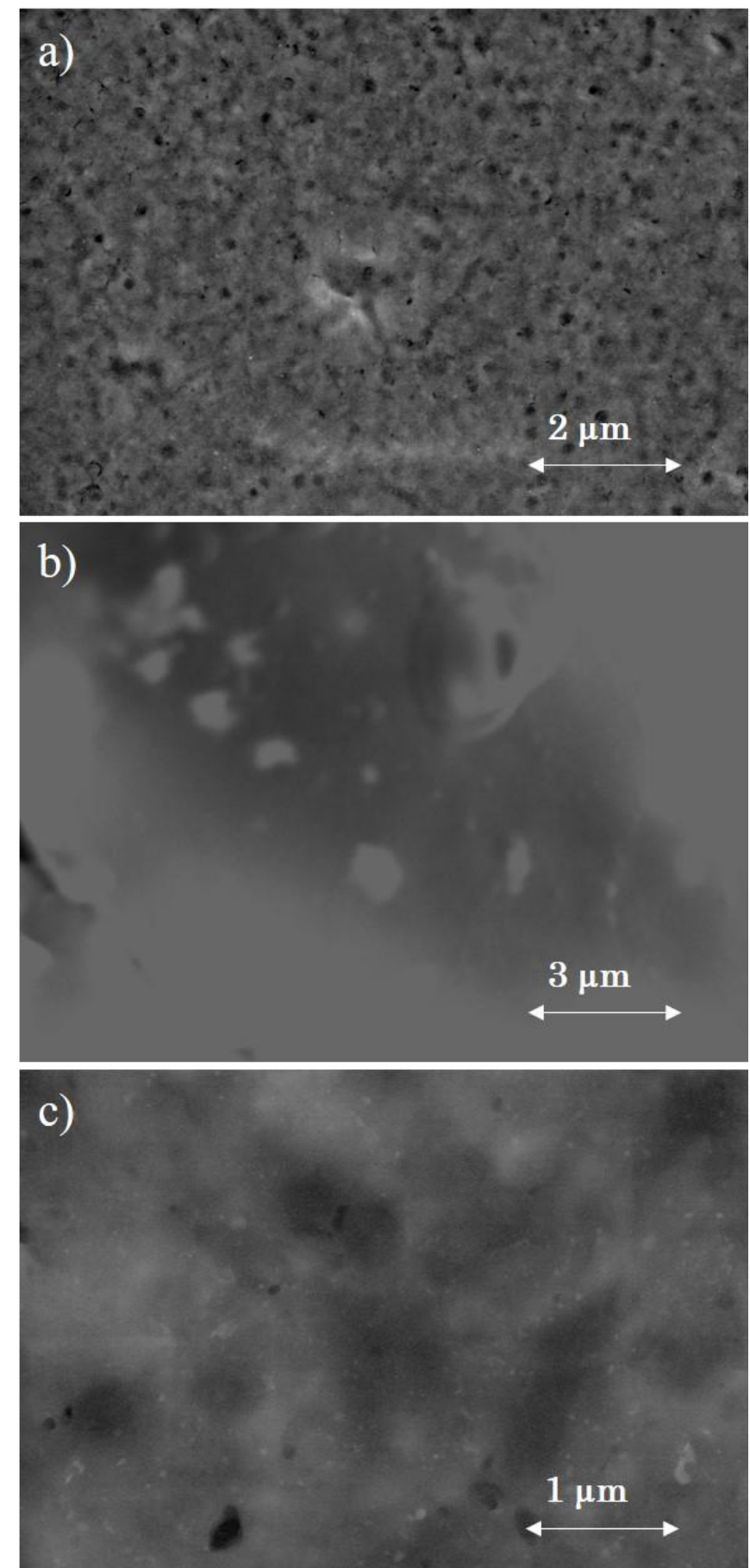

Figure 10.1.2.2.1.11. Secondary electron image obtained in a) EG@Cd_Ao, b) EG@Cd_Ba and c) EG@Cd_Sc reconstructed model tempera paint specimens. 
10.1.2.2.2. Egg oil emulsion reconstructed model paint specimens

\section{Iron oxide red}

As in the iron oxide red egg tempera reconstructed model paint films, most significant changes observed in the iron oxide red egg oil emulsion reconstructed model paint film were microerosion of the paint film surface promoted by the microbial attack. Figure 10.1.2.2.2.1, shows the secondary electron image obtained for the specimens inoculated with Mucor rouxii fungus (EO@Fe_Mr) (a) and Streptomyces cellulofans (EO@Fe_Sc) bacterium (b). In addition, aggregates of pigment grains can be seen protruding the paint film surface through the microcracks produced during the drying of the film (arrows in Figure 10.1 2.2.2.1a).
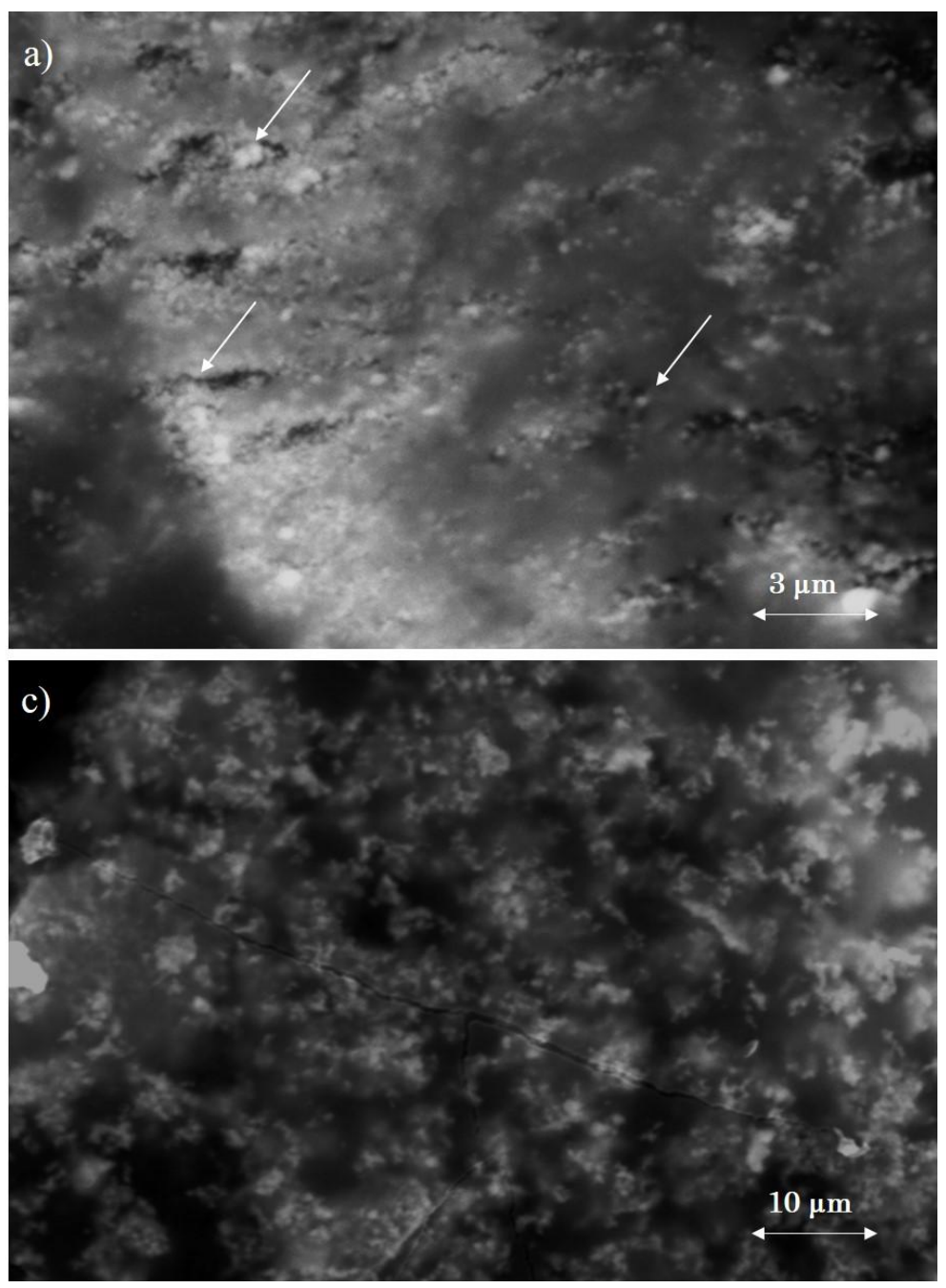

Figure 10.1.2.2.2.1. Secondary electron image obtained in a) EG@Cd_Mr fungus, and b) EG@Cd_Sc bacterium reconstructed model egg oil emulsion paint specimens. 


\section{Verdigris}

The surface of the specimens inoculated with fungi showed, in general, a more irregular surface than that of the egg tempera paint films as can be seen in Figure 10.1.2.2.2.2. Apart of the increase of microcracks, abundant aggregates of microcrystal around spores of the fungi were observed in the surface of films inoculated with Acremonium chrysogenum (EO@Cu_Ac) (square in Figure 10.1.2.2.2.2a) and Aspergillus niger (EO@Cu_An) (circles in Figure 10.1.2.2.2.2b). Abundant micropores associated with the water evaporation during the drying process can also be observed in the paint films inoculated with fungi (stars in Figure 10.1.2.2.2.2).
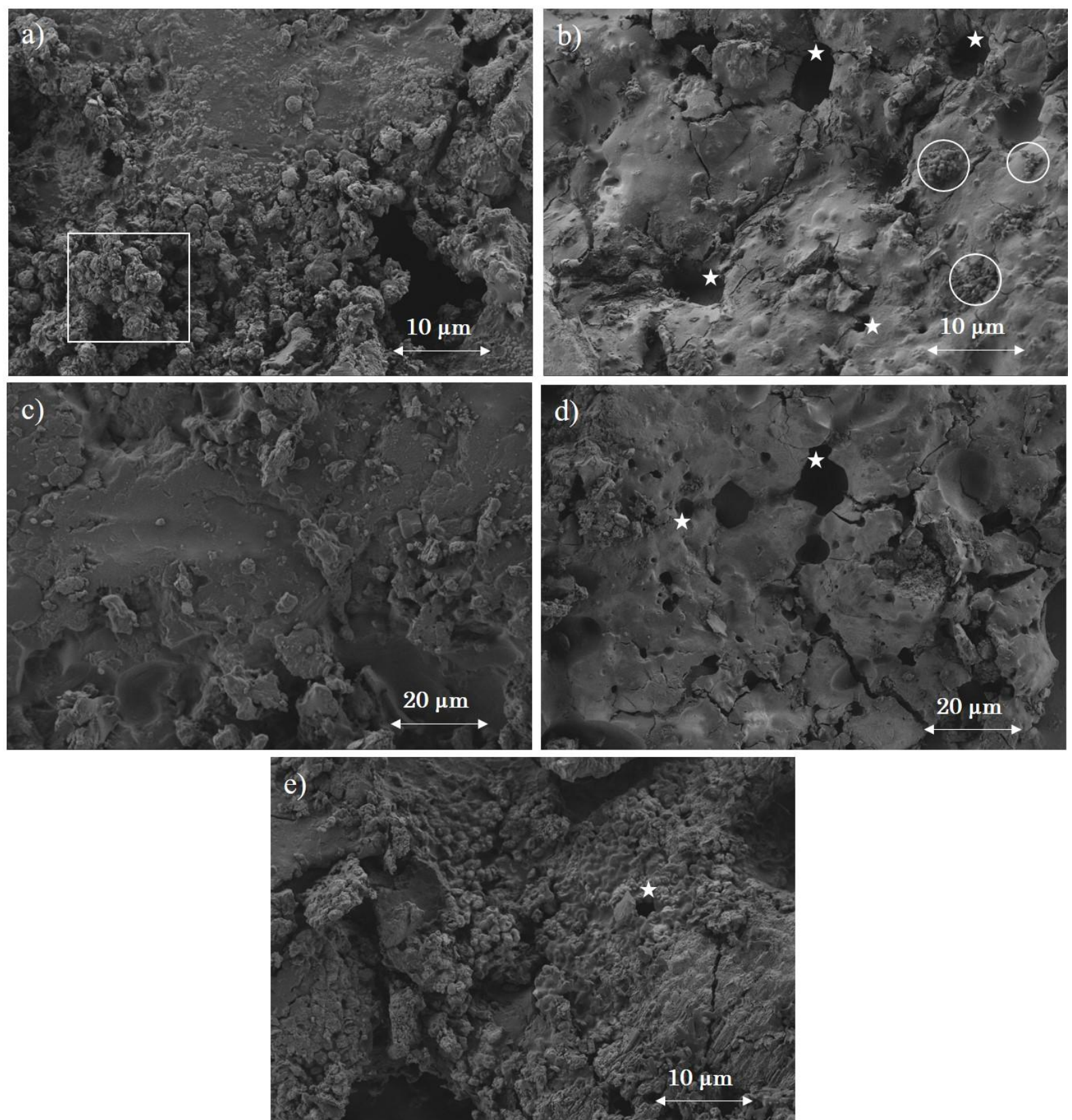

Figure 10.1.2.2.2.2. Secondary electron image obtained in: a) EO@Cu_Ac, b) EO@Cu_An, c) EO@Cu_Mr, d) EO@Cu_Pc, and e) EO@Cu_Tp reconstructed model emulsion paint specimens. 
A similar behavior was observed in the specimens inoculated with bacteria. Figure 10.1.2.2.2.3, shows the secondary electron image obtained for the EO@ $\mathrm{Cu}$ specimen inoculated with Arthrobacter oxydans, where formation of aggregates of microparticles associated with copper-binder complexes (arrow) in this paint.

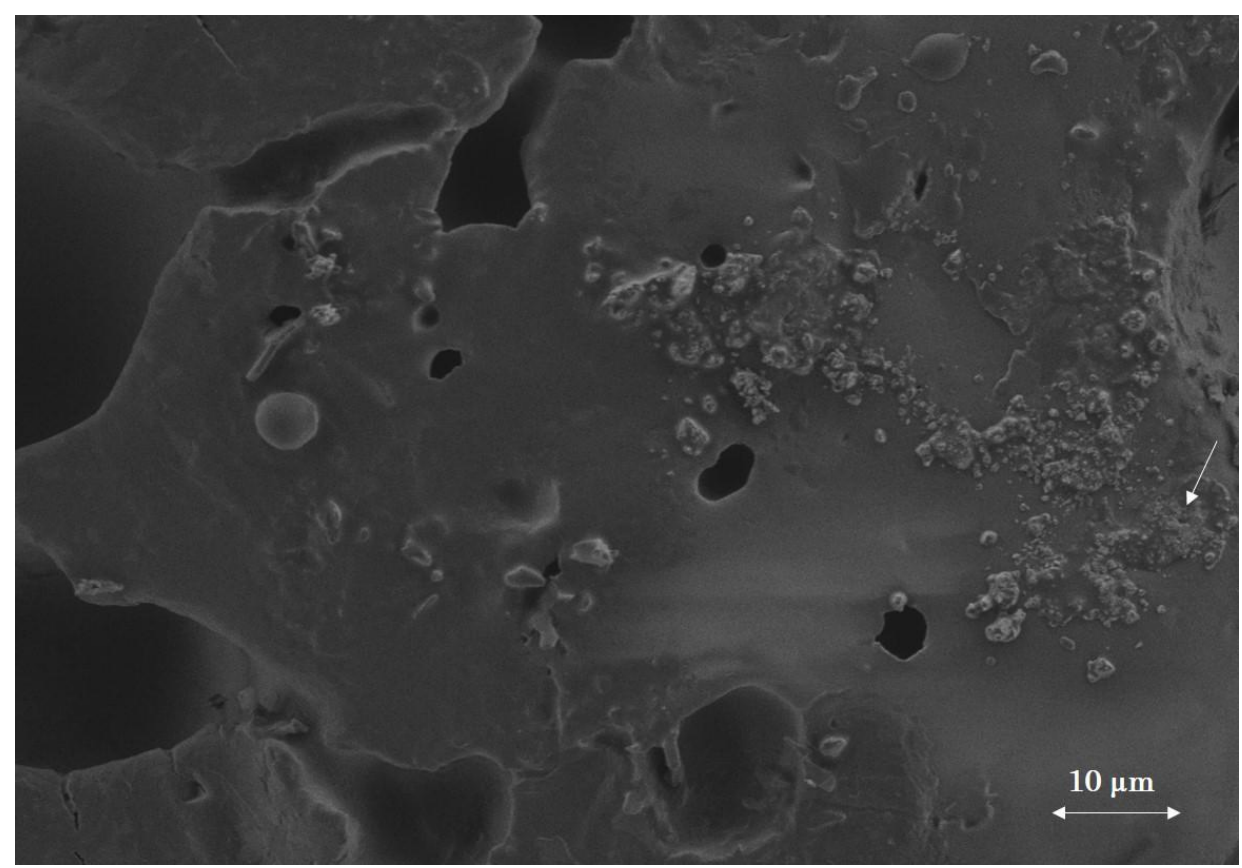

Figure 10.1.2.2.2.3. Secondary electron image obtained in EO@Cu_Ao reconstructed model emulsion paint specimens.

\section{Lead white}

In the specimen inoculated with Acremonium chrysogenum the surface is covered by a biofilm created by this microorganism (Figure 10.1.2.2.2.4a). A similar behavior to that previously described for the EG@Pb_Sc specimen, was observed in the specimen inoculated with Aspergillus niger, (Figure 10.1.2.2.2.4b). In addition, deposits ascribed to the formation of lead-binder complexes promoted by this fungus are observed (arrow in Figure 10.1.2.2.2.4b).

A biofilm formed by the microorganism can be observed in the specimens inoculated with Mucor rouxii and Penicillium chrysogenum (arrows in Figures 10.1.2.2.2.4 c and d). The surface of the specimen EO@Tp inoculated with the fungus Trychoderma pseudokoningii (Figure 10.1.2.2.2.4e) is abundantly protruded by small spherical features that are associated with dense protein-lipid particles characteristics of egg surrounded by rests of microorganisms. 

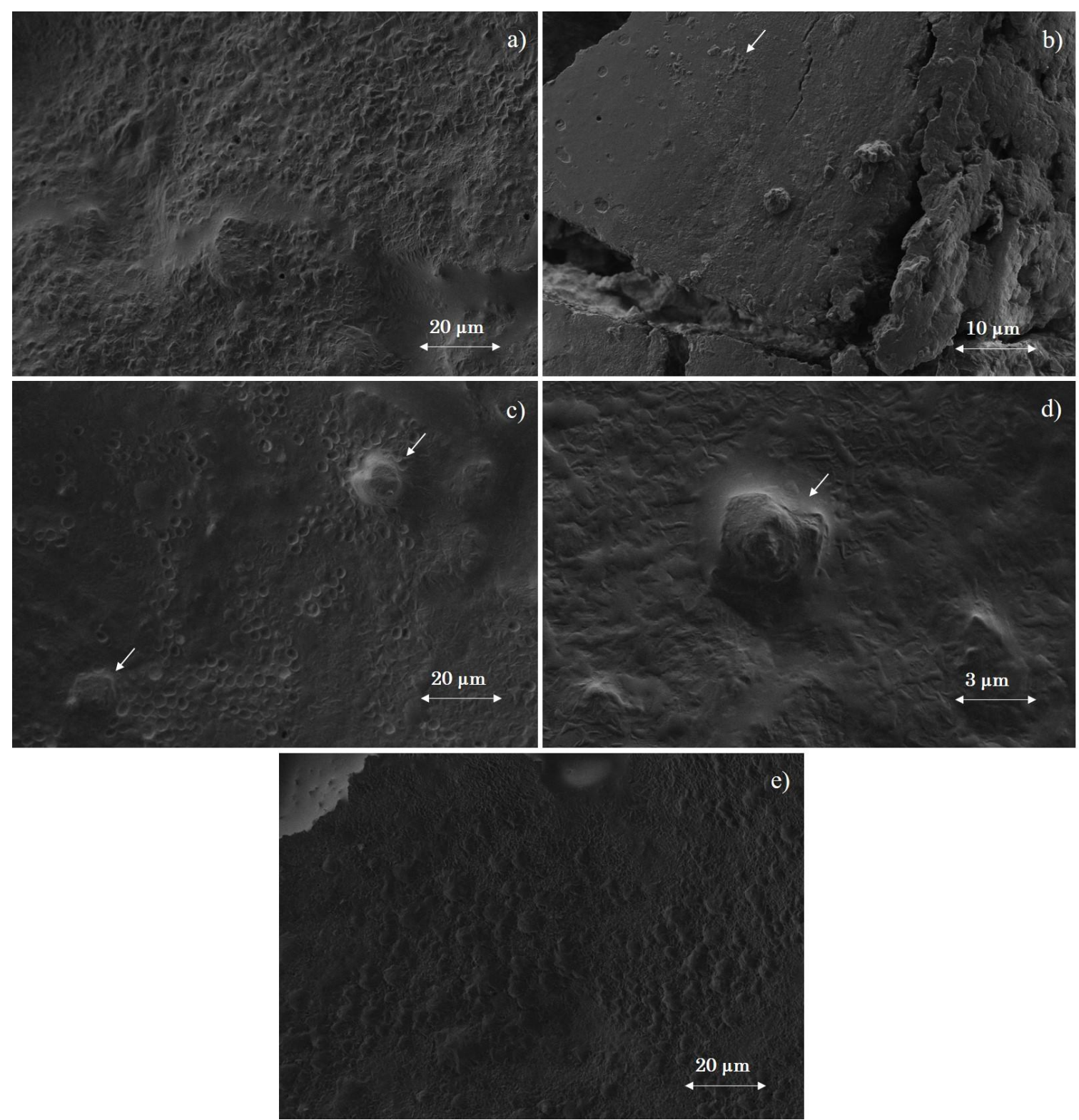

e)

Figure 10.1.2.2.2.4. Secondary electron image obtained in: a) EO@Pb_Ac, b) EO@Pb_An, c) EO@Pb_Mr, d) EO@Pb_Pc, and e) EO@Pb_Tp reconstructed model emulsion paint specimens.

Figure 10.1.2.2.2.5, shows the aspect of the surface of the model paint films inoculated with Arthrobacter oxydans (EO@PB_Ao), Bacillus amyloliquefaciens (EO@Pb_Ba) and Streptomyces cellulofans (EO@Pb_Sc). Abundant microcrack are observed in the surface of the EO@Pb_Ao and EO@Pb_Ba specimens (Figure 10.1.2.2.2.5a and b, respectively). Protrusions of pigment-binder aggregates, whose formation has been probably favored by the microbial attack, can be seen in Figure 10.1.2.2.2.5a (arrow). Irregular aggregates of microcrystals (stars) and insoluble denser protein-lipids particles (arrows) are observed in the surface of the EO@Pb_Ba specimen (Figure 10.1.2.2.2.5b). In addition, microorganism attached to the external layer of an insoluble denser protein-lipid particle can be observed in detail in the secondary electron image obtained in the EO@Pb_Ba specimen (square in Figure 10.1.2.2.2.5b). Microerosion was observed in the EO@Pb_Sc specimen, where 
irregular pigment-binder aggregates can be seen embedded in the biofilm the (arrow in Figure 10.1.2.2.2.5c).
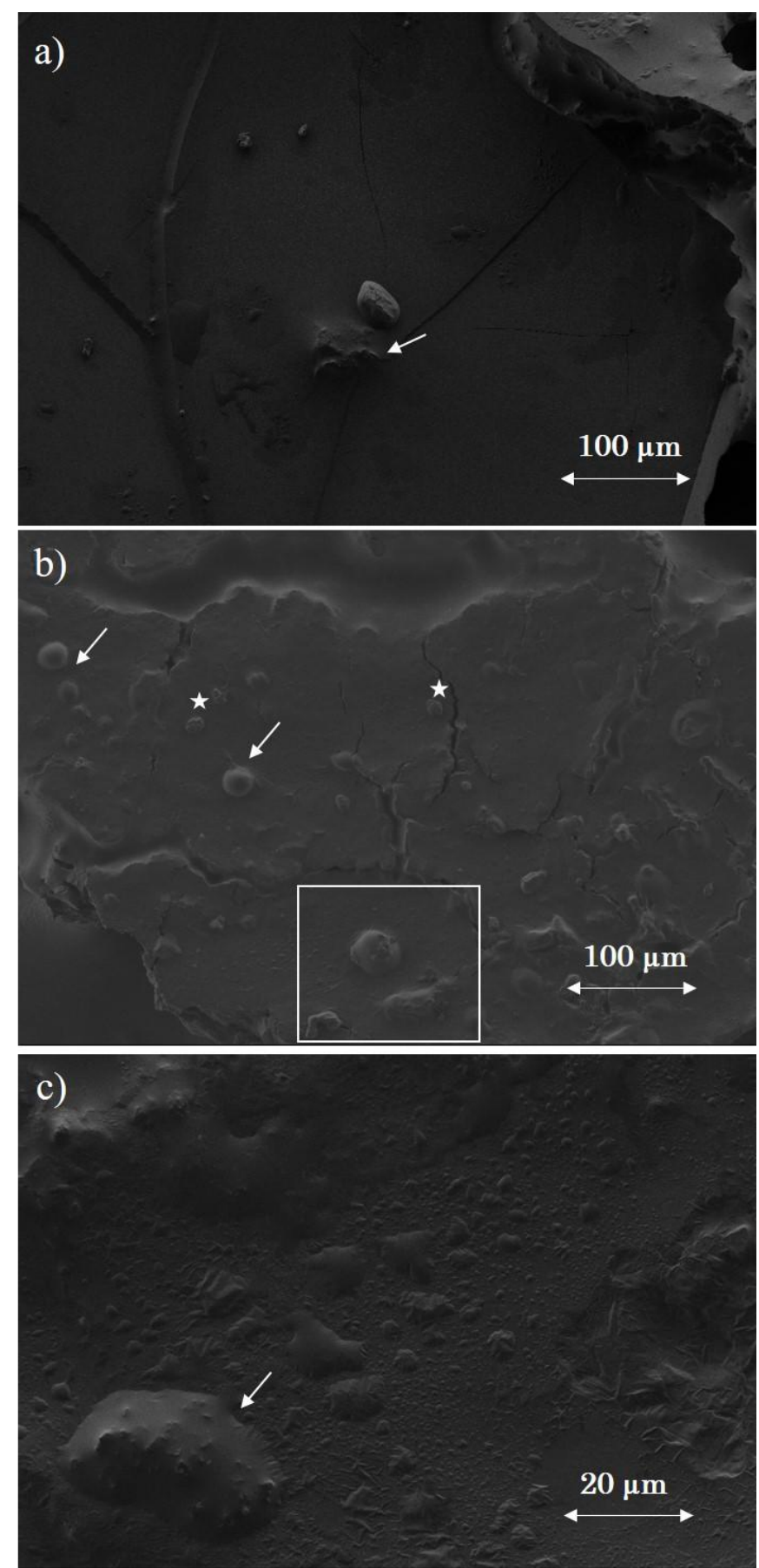

Figure 10.1.2.2.2.5. Secondary electron image obtained in: a) EO@Pb_Ao, b) EO@Pb_Ba and c) EO@Pb_Sc reconstructed model emulsion paint specimens.

\section{Cadmium yellow}

Irregular protrusions of aggregates of pigment grains were observed in all the EO@Cd specimen inoculated with fungi, particularly in the paint films inoculated with Acremonium chrysogenum (EO@Cd_Ac), Penicillium chrysogenum (EO@Cd_Pc) and Trichoderma 
pseudokoningii (EO@Cd_Tp) (stars in Figures 10.1.2.2.2.6a, d and e, respectively). Fungal spores are clearly identified in the surface of the paint film inoculated with Aspergillus niger (EO@Cd_An), where microcracks (arrow) and irregular protrusions (stars) can be also observed in Figure 10.1.2.2.2.6b. Different morphology can be observed in the surface of the paint film specimens inoculated with Mucor rouxii (EO@Cd_Mr) and Trichoderma pseudokoningii (EO@Cd_Tp) where the microerosion due to the microbial attack reaches a major extent (Figures 10.1.2.2.2.6c and e, respectively).
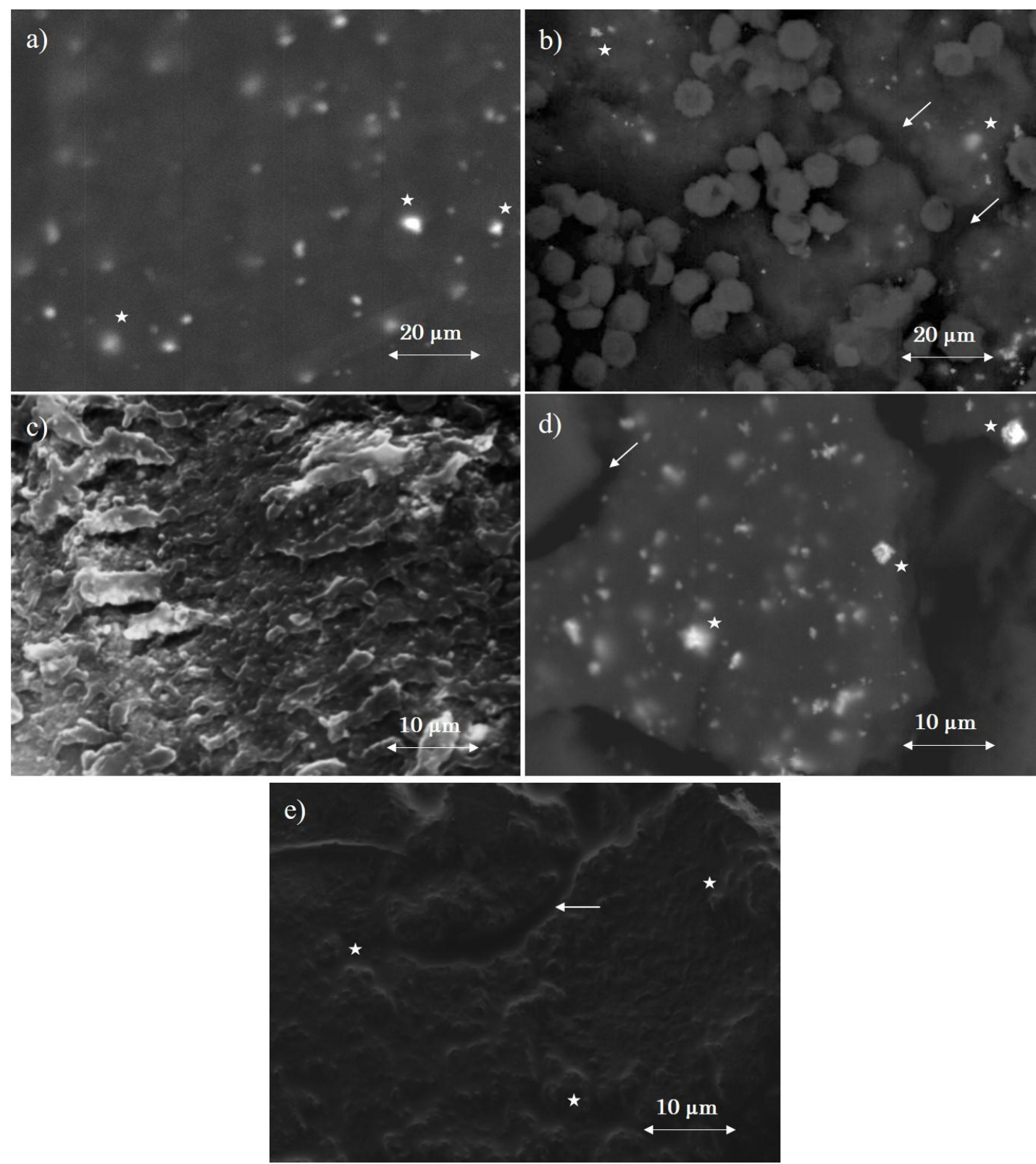

Figure 10.1.2.2.2.6. Secondary electron image obtained in: a) EO@Cd_Ac, b) EO@Cd_An, c) EO@Cd_Mr, d) EO@Cd_Pc, and e)EO@Cd_Tp reconstructed model egg oil emulsion paint specimens.

Most significant changes observed in the EO@Cd paint films inoculated with bacteria, are associated to the presence of irregular protrusions of pigment aggregates promoted by the microorganisms microerosion as can be seen in Figure 10.1.2.2.2.7 (arrows). In addition, insoluble denser protein-lipid particles can be seen in the surface of the paint film inoculated 
with Bacillus amyloliquefaciens (EO@Cd_Ba). Presence of these insoluble denser proteinlipid particles, not found in the uninoculated specimen, confirms the bioerosion produced by this microorganism to the paint film surface (circles in Figure 10.1.2.2.2.7b).
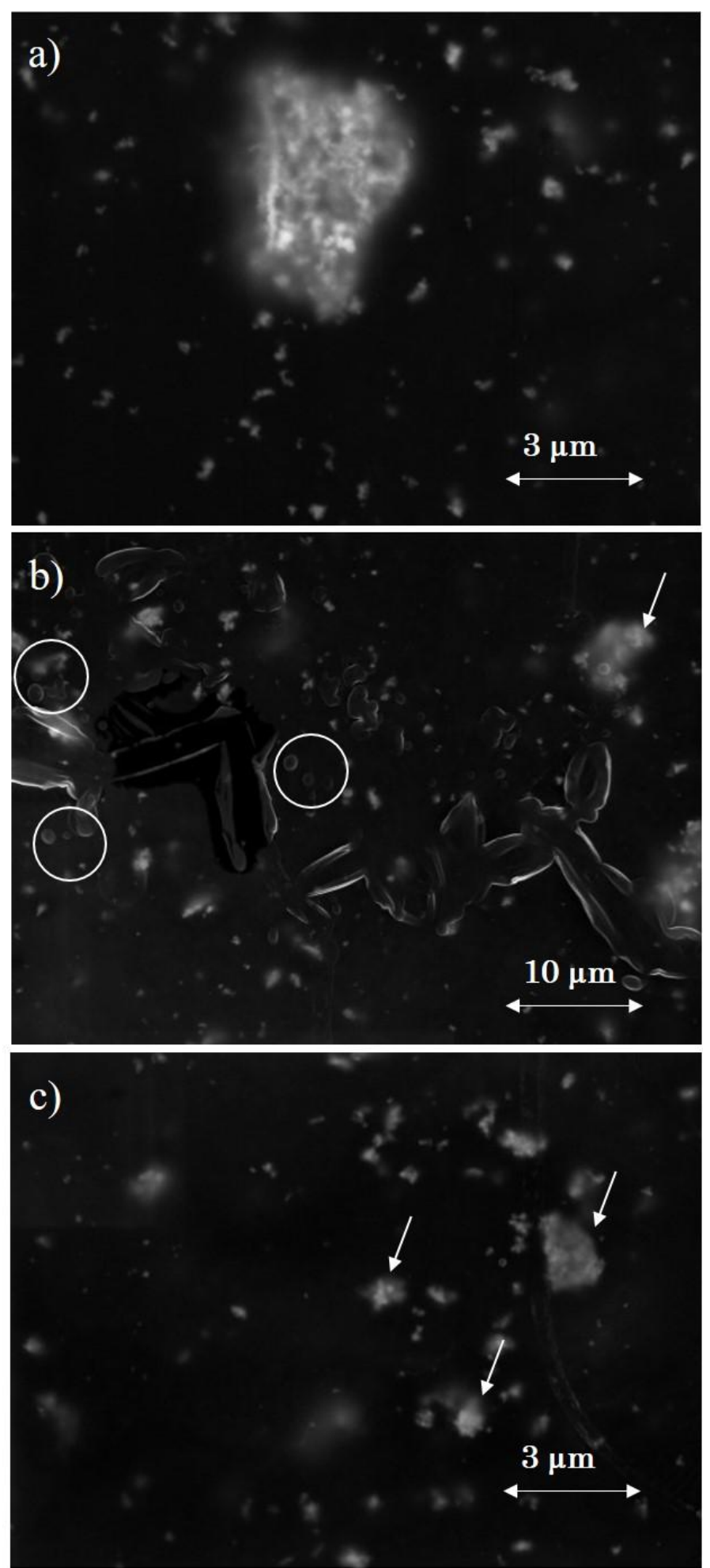

Figure 10.1.2.2.2.7. Secondary electron image obtained in a) EO@Cd_Ao, b) EO@Cd_Ba and c) EO@Cd_Sc reconstructed model egg oil emulsion paint specimens. 


\subsubsection{Final Considerations}

Inoculation of paint films consisted of applying a drop of water containing the different microorganisms used in this study followed by incubation in a chamber maintained at a high level of humidity. Contact of the dried paint film with the aqueous phase can induce changes in the structure of the film. First of all, hydrolysis of triglycerides can be promoted resulting in releasing of notable amounts of fatty acids. The hydrolysis of proteins can also take place resulting in the cleavage of the protein molecules, whose shorter fragments can also migrate to the aqueous phase as the evaporation of the drop is carried out in brief period, the final result is the appearance of the micropores and the migration of the solubilized species from the bulk of the film to the surface, where they are concentrated and - or vaporized at more or less extent. These released short chain molecules containing carboxylic groups can react with metallic ions solubilized from the solid pigment grains in contact with the aqueous medium and then form metal-protein, metal, amino acid complexes and metal-soaps. After this, the bacteria and fungi start their attack, settling the external surface enlarging cracks and pores and thus favoring the migration of the hydrolyzed substances and metal complexes to the surface of the paint film.

The results obtained confirm that attack of fungi and bacteria on reconstructed paint films produces microerosion of the film surface. This deterioration activity was more evident in the egg tempera paint film specimens. In particular, protrusions of metal complexes were most abundantly observed in the verdigris and lead white specimens, which confirms that these pigments, both of carbonate type, are especially sensitive to solubilization with the concomitant formation of metal complexes with the hydrolysis-released products also promoted by the microbial attack.

In most of the cases, bacteria were particularly active in the biodeterioration of paint films. These microorganisms, seem to be especially active in the consumption of the compounds composing granules and spheres. Loss of the external layer of rounded egg microstructures was observed in specimen inoculated with Arthrobacter oxydans actinobacteria and Bacillus amyloliquefaciens eubacteria.

Comparison of the surface aspect of the paint films inoculated with fungi and the paint films inoculated with bacteria shows that the surface of the paint films inoculated with fungi was dominated by the presence of fungal spores. In contrast, the paint films specimens inoculated with bacteria shows a formation of a conditioning biofilm which confirms that bacterial microbial attack reaches a major extent. Formation of this biofilm result in the alteration of the underlaying substrate.

In general, most significant changes were observed in the egg tempera paint films. In particular, Acremonium chrysogenum was highly active on the paint films prepared with verdigris and lead white. Inoculation promotes the formation of free fatty acids and pigmentbinder aggregates to a major extent in the egg tempera paint films. Most significant change observed in the egg oil emulsion paint films was the presence of egg microparticles and granules on the surface of the film, not found in the uninoculated specimen, which confirms the bioerosion produced by the microorganisms to the paint film surface. 
In all of the cases, deterioration produced at micro- and nano-scale by microbial attack to a paint film is irreversible and it became macroscopically with time.

\subsubsection{References}

De Beer, D., Stoodley, P., Roe, F., Lewandowski, Z. (1994) Effects of biofilm structures on oxygen distribution and mass transport. Biotechnology and bioengineering, 43, 1131-1138.

Flemming, H.C. (1998) Relevance of biofilms for the biodeterioration of surfaces of polymeric materials. Polymeric Degradation and Stability, 59, 309-315.

Mills, L., Burnstock, A., de Groot, S., Megens, L., Bisschoff, M., van Keulen, H., Duarte, F., van den Berg, K.J. (2008) Water sensitivity of modern artists' oil paints. ICOM Committee for conservation, 2, 651-659.

Tempest, H., Burnstock, A., Saltmarsh, P., van den Berg, K.J. (2010) Sensitivity of oil paint surfaces to aqueous and other solvents. In New Insights into the cleaning of paintings. Proceedings from the cleaning 2010 International Conference, Valencia, Vol. 3, 107-114. 


\subsubsection{FTIR spectroscopy}

10.1.3.1. Characterization of the uninoculated egg tempera and egg oil emulsion reconstructed model paint specimens

The second series of reconstructed model paint specimens includes two sub-series prepared simply at $30 \mathrm{wt} \%$ pigment content: the first one (EG@pigment) is a tempera prepared with whole egg whereas the second subseries is an egg oil emulsion (1:1) prepared with whole egg (EO@ pigment). The pigments chosen were iron oxide red $(\mathrm{Fe})$, lead white $(\mathrm{Pb})$, verdigris $(\mathrm{Cu})$ and cadmium yellow $(\mathrm{Cd})$. This second series was prepared as control specimens for a latter inoculation with microorganisms. Characterization of the changes attributed to the pigment-binder is crucial for the subsequent characterization of the changes induced by the inoculation with microorganisms.

\section{Egg film specimen}

Whole egg composition includes a wide variety of chemical components as: water, protein and lipids. These compounds exhibit IR absorption bands overlapped which results in a complex IR absorption spectrum. As previously described, for the egg yolk and egg yolk-oil emulsion specimens deconvolution and second derivative techniques have been applied for discriminating compounds and conformations of proteins.

\section{Proteins}

Similar to the egg yolk spectrum the whole egg (EG) spectrum is dominated by the bands associated to the mixture of proteins (Figure 10.1.3.1.1). Characteristic vibrational bands ascribed to amide A $\left(3278 \mathrm{~cm}^{-1}\right)$, amide B $\left(3069 \mathrm{~cm}^{-1}\right)$, amide $\mathrm{I}\left(1700-1600 \mathrm{~cm}^{-1}\right)$ and amide II (1600-1500 $\left.\mathrm{cm}^{-1}\right)$ have been identified. Position of the average frequency of the main component of the amide I band about $1629 \mathrm{~cm}^{-1}$ indicates the $\beta$-sheet conformation is prevalent in these proteins in dried state, as observed in the egg yolk (Furlan et al., 2007; Pelton and McLean, 2000).

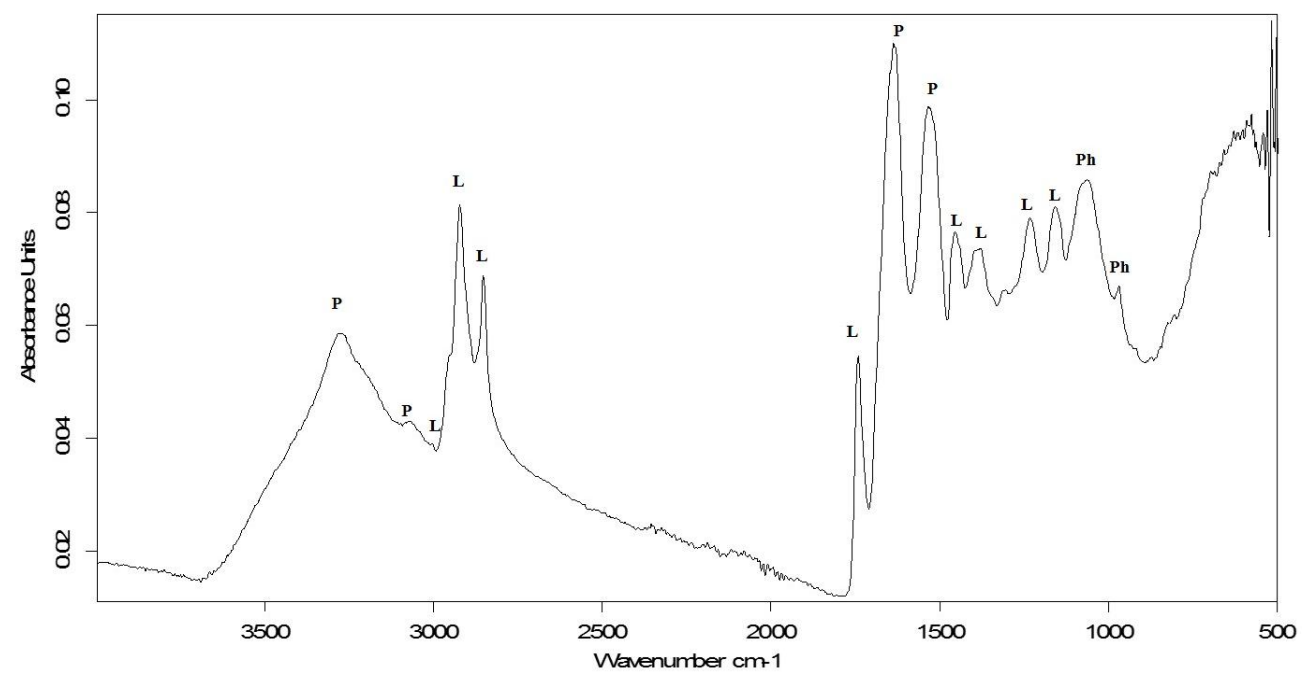

Figure 10.1.3.1.1. IR absorption spectra obtained from pure whole egg (EG). Assignment of representative bands: proteins $(\mathrm{P})$; neutral lipids $(\mathrm{L})$; and phospholipids $(\mathrm{Ph})$. 
Significant contribution of $\alpha$-helix conformation is suggested by the secondary maxima found at $1653 \mathrm{~cm}^{-1}$ and shoulders at 1648 and $1655 \mathrm{~cm}^{-1}$. Shoulder at $1637 \mathrm{~cm}^{-1}$ is ascribed to random coil (unordered) conformation. Second derivative spectrum obtained in the amide I region enables a more detailed description of the secondary structure of these proteins with overlapped bands at 1668, 1674 and $1683 \mathrm{~cm}^{-1}$, associated to turns. B-sheet conformation also exhibits overlapped bands at 1630 and $1625 \mathrm{~cm}^{-1}$ that arise from intramolecular $\mathrm{C}=\mathrm{O}$ vibrations. Bands at 1625, 1618, 1612 and $1694 \mathrm{~cm}^{-1}$ have been associated to intermolecular hydrogen bonding aggregated proteins, antiparallel $\beta$-sheet conformation and aromatic ring vibrations of tyrosine residues in LDL and HDL proteins.

The calculated percentages of each of these conformational structures estimated from the FSD are shown in Table 10.1.3.1.1. In agreement with the position of the maxima of the amide I band at $1629 \mathrm{~cm}^{-1}$, $\beta$-sheet is prevalent in dried egg with remarkable contribution of $\alpha$-helix conformation (Figure 10.1.3.1.2).

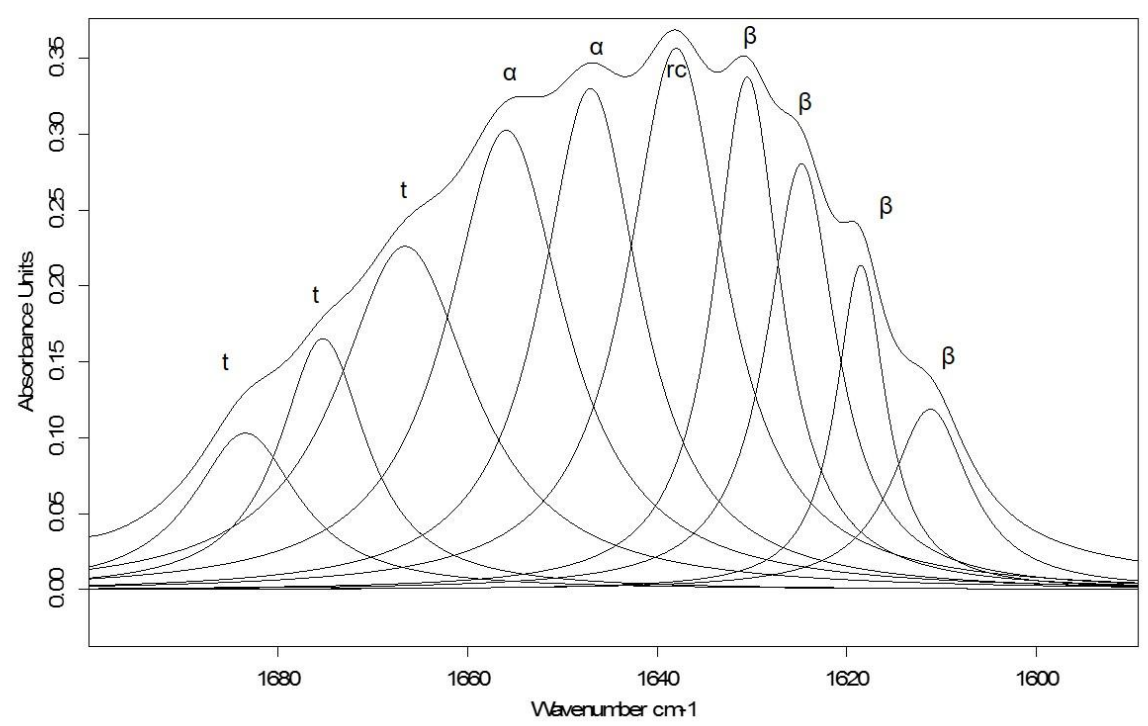

Figure 10.1.3.1.2. Amide I curve fitted band for EG with fitted band components. Assignment of bands conformations: $\beta$ sheet $(\beta)$, random coil $(\mathrm{rc}), \alpha$-helix $(\alpha)$ and turns $(\mathrm{t})$.

Maximum of amide II bands at $1535 \mathrm{~cm}^{-1}$ with shoulder at $1508 \mathrm{~cm}^{-1}$ also confirms the prevalence of a $\beta$-sheet structure in dried egg yolk proteins (Pelton and McLean, 2000; Miyazawa and Blout, 1961).

Neutral lipids (NLs)

Triglycerides present in whole egg exhibit characteristic IR bands of methyl and methylene groups at $2957_{\mathrm{sh}}, 2922,2872_{\mathrm{sh}}$ and $2852 \mathrm{~cm}^{-1}$. Band at $3004 \mathrm{~cm}^{-1}$ is ascribed to unconjugated double bonds from fatty acids together with the trans and cis out of plane deformation vibrations at 968 and $722 \mathrm{~cm}^{-1}$. Band at $1745 \mathrm{~cm}^{-1}$ is ascribed to $\mathrm{C}=\mathrm{O}$ stretching motion of ester group of triacylglycerol, diacylglycerol and PL molecules. FSD and second derivative spectra identify bands at 1736 and $1719 \mathrm{~cm}^{-1}$ within the unresolved band pattern in the range 
$1740-1710 \mathrm{~cm}^{-1}$, these bands have been attributed to triglycerides derived from aldehydes and ketones (Figure 10.1.3.1.3).

Hydrolysis of PLs in aqueous environments can involve releasing of free fatty acids (Miyazawa and Blout, 1961, Cagnasso et al., 2010). Characteristic features of free fatty acids appearing at $1701-1710 \mathrm{~cm}^{-1}$ were not found suggesting that hydrolysis reaction has not taken place at large extent at this initial stage of the natural ageing of the egg film.

Bands at $1457 \mathrm{~cm}^{-1}$ is mainly assigned to scissoring vibrations of $-\mathrm{CH}_{2}$ groups (Salvadó et al., 2009; van der Weer et al., 2005, Maziak et al., 2007), whereas band at $1377 \mathrm{~cm}^{-1}$ is assigned to umbrella mode vibrations of $\mathrm{CH}_{3}$ groups (van der Weer et al., 2005). Bands at 1233, 1160 and $1099 \mathrm{~cm}^{-1}$ are related to diverse stretching vibrations of C-O bonds in triglycerides (Meilunas et al., 1990; Salvadó et al., 2009; van der Weer et al., 2005).

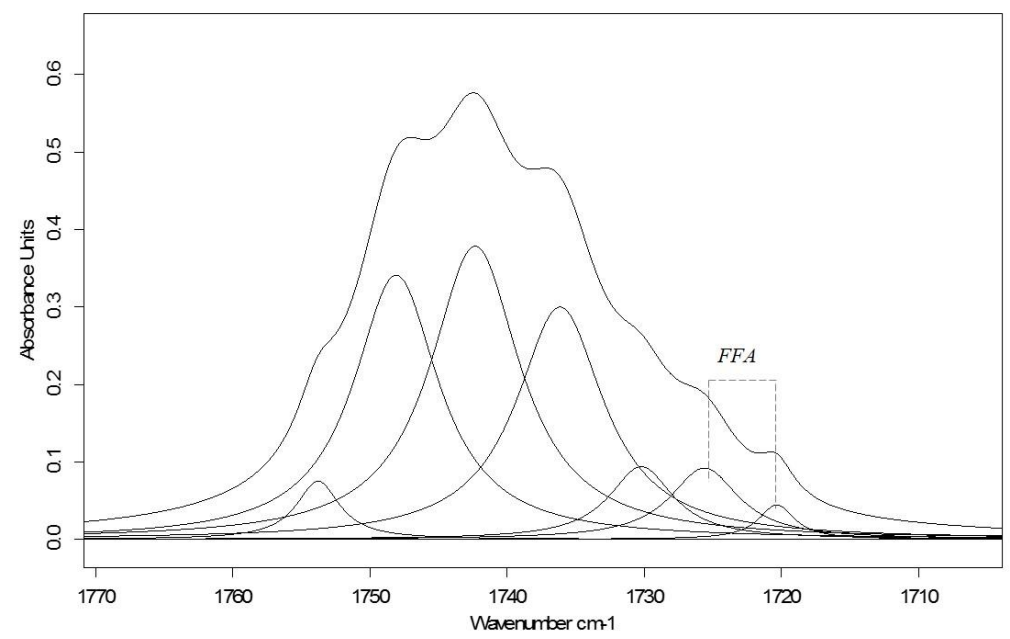

Figure 10.1.3.1.3. Carbonyl curve fitted band for EG specimen with fitted band components.

Phospholipids (PLs)

PLs present in whole egg contribute to the methyl, methylene and carboxylate bands described for NLs. Shoulder at $1736 \mathrm{~cm}^{-1}$ has been assigned to stretching vibration of carbonyl group in PLs (Cagnasso et al., 2010; Tantipolphan et al., 2007). The second derivative of the band at $1233 \mathrm{~cm}^{-1}$, allow the identification of a shoulder at $1220 \mathrm{~cm}^{-1}$ attributed to antisymmetric stretching of $\mathrm{PO}_{2}^{-}$. Presence of carboxylic moieties are also confirmed by the weak band at $1415 \mathrm{~cm}^{-1}$ (Cagnasso et al., 2010; van der Weer et al., 2005; Omoike et al., 2004) associated to the diversification in deprotonated carboxylated anion of acidic species formed from NLs, PLs proteins together with contribution from $\left(-\mathrm{CH}_{2}-\mathrm{COOR}\right)$ stretch of the PLs (Cagnasso et al., 2010).

Cholesterol

Features corresponding to cholesterol were identified at $1055 \mathrm{~cm}^{-1}$ and $952 \mathrm{~cm}^{-1}$ assigned to the $-\mathrm{C}-\mathrm{O}$ stretching vibrations of the saturated secondary alcohol groups and to the $-\mathrm{CH}_{2}$ rocking vibration of backbone, respectively. 


\section{Egg tempera reconstructed model paint specimens}

As in the previously discussed egg yolk tempera reconstructed model paint specimens (Y@Pigment ${ }_{75}$ ) IR spectra obtained were dominated by the bands ascribed to the amide A, amide I, amide II, methyl/methylene and carbonyl groups in egg proteins.

\section{Iron oxide red reconstructed model paint specimen}

IR spectrum of EG@Fe is close to that of the $\mathrm{Y} @ \mathrm{Fe}_{75}$ specimen prepared with egg yolk with a general decrease of intensity due to the scattering effect of the pigment (Figure 10.1.3.1.4).

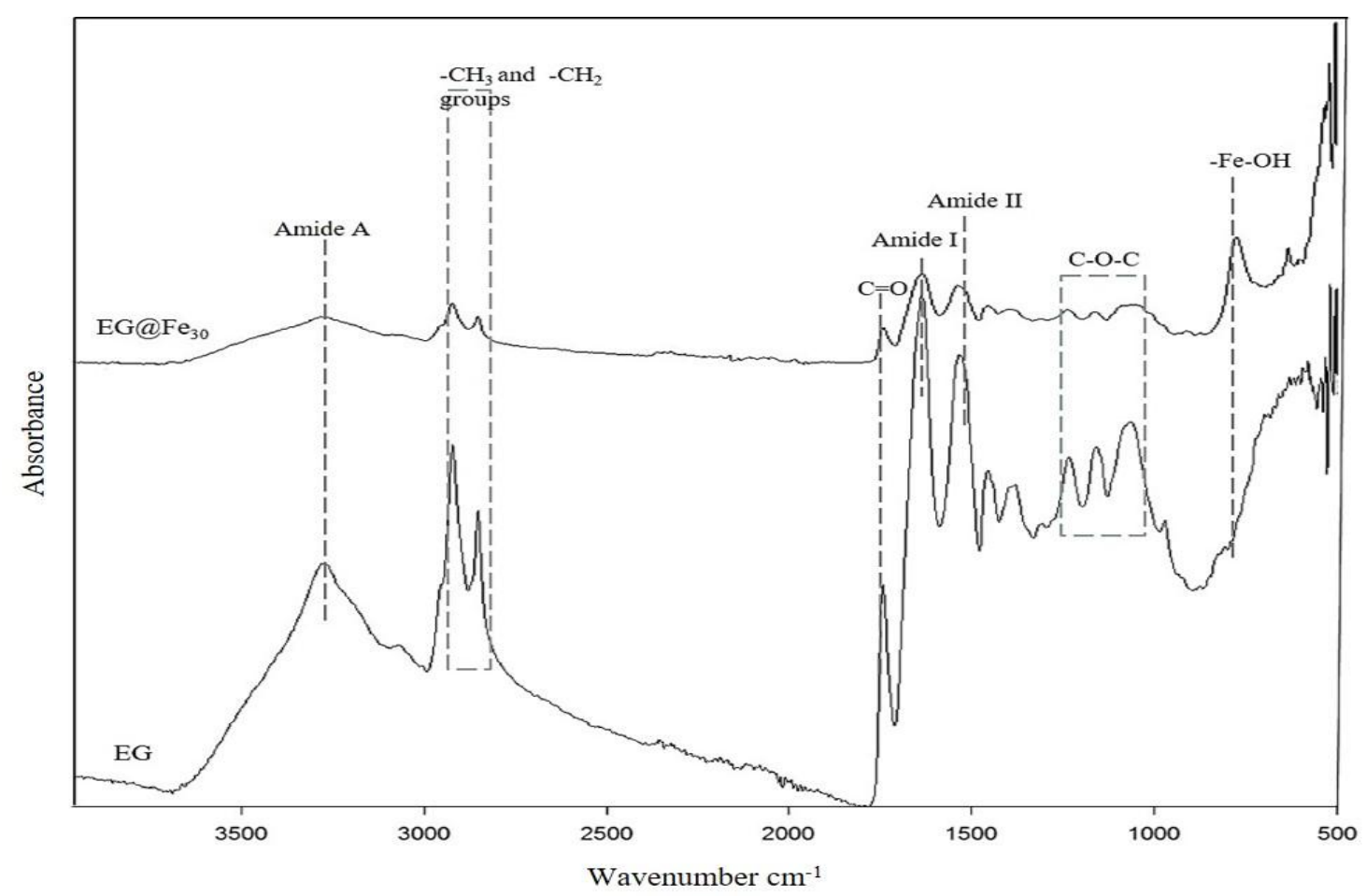

Figure 10.1.3.1.4. IR spectra of EG@Fe reconstructed model paint specimen compared with that from the EG specimen.

\section{Proteins}

No significative changes were observed for the EG@Fe. After deconvolution of the amide I band the major components were $\alpha$-helix (max. $1652 \mathrm{~cm}^{-1}$ ), intermolecular $\beta$-sheet (max. $1621 \mathrm{~cm}^{-1}$ ), intramolecular $\beta$-sheet (max. $1633 \mathrm{~cm}^{-1}$ ), turns $/ \beta$-sheet $\left(\max .1683 \mathrm{~cm}^{-1}\right.$ ), and random coil (max. $1644 \mathrm{~cm}^{-1}$ ). Self-deconvolution and curve fitting methods allow the quantitative analysis of the protein secondary structure components (Figure 10.1.3.1.5). Results show a decrease in the helical and random coil components accompanied by an increase of the turns conformation as well as an increase in the contribution of intramolecular $\beta$-sheet, with the corresponding decrease of intermolecular $\beta$-sheet conformation (see Table 10.1.3.1.1) 


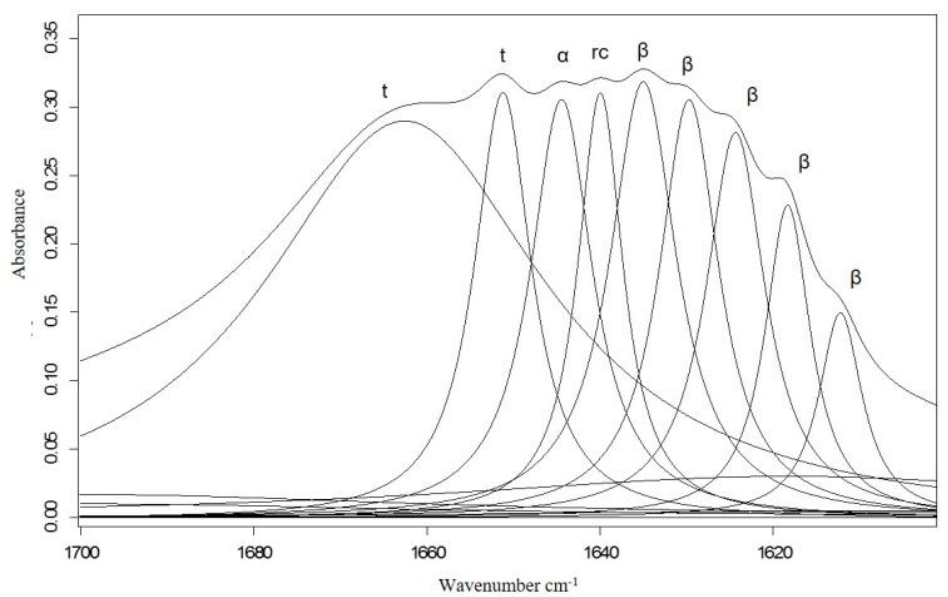

Figure 10.1.3.1.5. Amide I curve fitted band for EG@Cd specimen with fitted band components. Assignment of bands conformations: $\beta$-sheet $(\beta)$, random coil (rc), $\alpha$-helix $(\alpha)$ and turns (t).

Band attributed to tyrosine residues, in metal-protein complexation was slightly shifted from $1612 \mathrm{~cm}^{-1}$ to $1615 \mathrm{~cm}^{-1}$ (Nahar and Tajmir-Riahi, 1996). Appearance of the shoulder at 1557 $\mathrm{cm}^{-1}$ attributed to the asymmetric stretch of $\mathrm{CO}_{2}^{-}$group in carboxylate metal complexes observed in the Y@ $\mathrm{Fe}_{75}$ was also obtained for the EG@Fe specimen.

Table 10.1.3.1.1. Percent area contribution of amide I components for whole egg specimen and EG@Fe, EG@Cu,EG@Pb and EG@Cd reconstructed egg tempera model paint specimens.

\begin{tabular}{|c|c|c|c|c|c|c|}
\hline \multirow{2}{*}{$\begin{array}{c}\text { Predominat } \\
\text { conformations }\end{array}$} & Frequency range & \multicolumn{5}{|c|}{ Reconstructed model paint specimens } \\
\cline { 3 - 6 }$\left(\mathbf{c m}^{-1}\right)$ & EG & EG@ Fe & EG@Cu & EG@Pb & EG@Cd \\
\hline Intermolecular $\beta$-sheet & $1611-1625$ & 20 & 30 & 9 & 13 & 26 \\
\hline Intramolecular $\beta$-sheet & $1625-1637$ & 10 & 10 & 18 & 8 & 20 \\
\hline Random coil & $1637-1645$ & 18 & 2 & 8 & 14 & 20 \\
\hline$\alpha$-helix & $1645-1662$ & 27 & 4 & 42 & 33 & 24 \\
\hline Turns & $1662-1690$ & 24 & 54 & 23 & 33 & 10 \\
\hline
\end{tabular}

NLs and PLs

In contrast with the $\mathrm{Y} @ \mathrm{Fe}_{75}$ specimen, absorption bands bellow $1710 \mathrm{~cm}^{-1}$ associated to the presence of carboxylic acids from NLs and PLs formed upon oxidation were not found for the EG@Fe specimen, that can be attributed to the lower pigment content in this specimen.

Curve fitting of the absorption bands attributed to the stretching vibrations of carbonyl groups $\left(1800-1700 \mathrm{~cm}^{-1}\right)$ was made. Ratios obtained are summarizes in Table 10.1.3.1.2. As it can be seen by the low value obtained this iron oxide red pigment at this lower concentration in this specimen has scarcely promoted hydrolysis of triglycerides. 
Table 10.1.3.1.2. $\mathrm{I}_{\mathrm{FFA}} / \mathrm{I}_{\mathrm{E}}$ values for the EG and the reconstructed model paint specimens at $30 \mathrm{wt} \%$.

\begin{tabular}{|c|c|}
\hline Specimens & $\mathbf{I}_{\mathbf{F F A}} / \mathbf{I}_{\mathbf{E}}$ \\
\hline EG & 0.08 \\
\hline EG@Fe & 0.02 \\
\hline EG@Cu & 0.16 \\
\hline EG@Pb & 0.18 \\
\hline EG@Cd & 0.006 \\
\hline
\end{tabular}

Weak absorption shoulder at $1575 \mathrm{~cm}^{-1}$ associated to stretching vibrations of metalcarboxylate complexes from PLs and NLs was observed in the EG@Fe specimen in addition to the shoulder at $1557 \mathrm{~cm}^{-1}$ associated to carboxylate metal complexes from protein residues.

No changes were observed for the bands assigned to $v_{a s} \mathrm{PO}_{2}^{-}$and $v_{s} \mathrm{PO}_{2}^{-}$. (Cagnasso et al., 2010).

\section{Verdigris reconstructed model paint specimen}

The IR spectrum of this specimen was dominated by the band characteristic of stretching vibrations of amide A and methyl/methylene, carbonyl and amide I groups in egg proteins together with vibrations of neutral verdigris, namely, $3473 \mathrm{~cm}^{-1}(v \mathrm{OH}), 1596_{\mathrm{sh}} \mathrm{cm}^{-1}(v$ $\mathrm{COO}), 1441_{\mathrm{sh}}$ and $1405 \mathrm{~cm}^{-1}(v \mathrm{COO}), 668 \mathrm{~cm}^{-1} \delta$ (OCO), $613 \mathrm{~cm}^{-1}$ ( $\left.\pi \mathrm{COO}\right)$ (Figure 10.1.3.1.6)

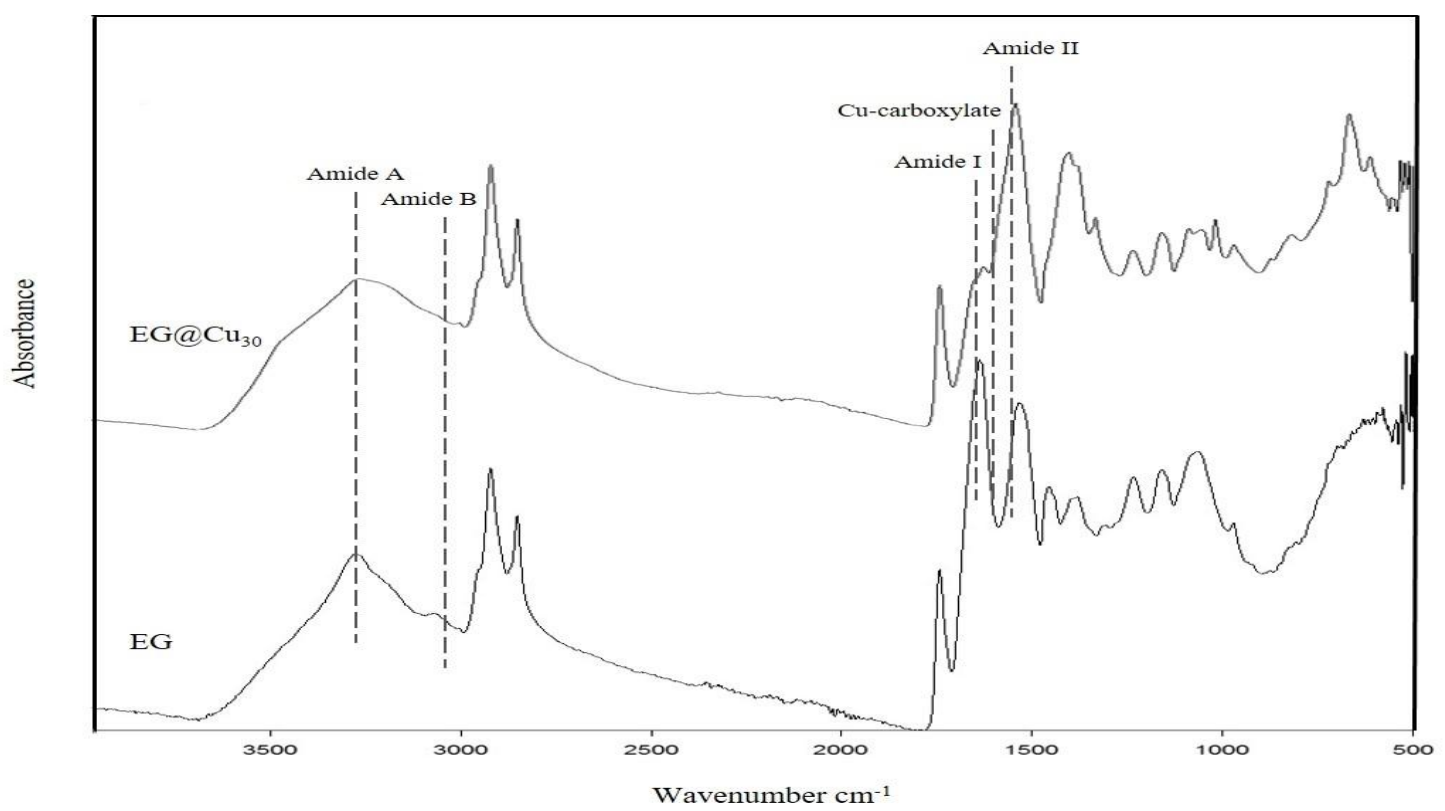

Figure 10.1.3.1.6. IR spectra obtained for EG@Cu reconstructed model paint specimen compared with that from the EG specimen.

\section{Proteins}

No significative changes were observed for the band assigned to amide A at $3278 \mathrm{~cm}^{-1}$ and the band at $3069 \mathrm{~cm}^{-1}$ associated with the amide $\mathrm{B}, \mathrm{N}-\mathrm{H}$ resonance between amide II 
overtone and $\mathrm{N}-\mathrm{H}$ stretch. The most significant differences in bands associated with protein were found in the amide I region, (1800-1500 $\left.\mathrm{cm}^{-1}\right)$, where a notable decrease of intensity was observed in comparison with the EG specimen. The decrease of the intensity of this band in the IR spectrum can be related to a breakdown of the protein chains according to prior studies devoted to the effect of verdigris in egg tempera medium (Conti et al., 2014; Prati et al., 2016). A redshift of the maximum of the amide I band from 1633 to $1628 \mathrm{~cm}^{-1}$ was also observed. Secondary maximum exhibited by the amide I band at $1651 \mathrm{~cm}^{-1}$ in the EG specimen occurs at lower spatial frequencies of 1646 and $1650 \mathrm{~cm}^{-1}$ in EG@Cu specimen. This sub-band in the amide I region has been associated with $\alpha$-helix conformations and the downshifting of its position can be related to the increase of the helix length and its bending in coiled coils but also to the increase of the exposition of the helix to the external medium (aqueous plasma and pigment) (Duce et al., 2013).

The amide I band was deconvolved to determine the fraction of the $\beta$-sheet conformation (Figure 10.1.3.1.7). A notable increase of the percent area contribution of intramolecular $\beta$ sheet conformation was observed as well as a decrease in the contribution of the intermolecular $\beta$-sheet conformation (see Table 10.1.3.1.1). The curve-fitting showed an increase in the helical structure contribution accompanied of a decrease in the percent area contribution of the random coil conformation. The deconvolved spectrum obtained for the EG@Cu specimen showed several component bands at 1674, 1668, 1661 and $1653 \mathrm{~cm}^{-1}$ for the $\alpha$-helix conformation as well as bands at $1636,1629,1624$ and $1619 \mathrm{~cm}^{-1}$ for the $\beta$-sheet component. Bands at 1648 and $1642 \mathrm{~cm}^{-1}$ for random coil structure and bands at 1694 and $1682 \mathrm{~cm}^{-1}$ for turns structure were also identified.

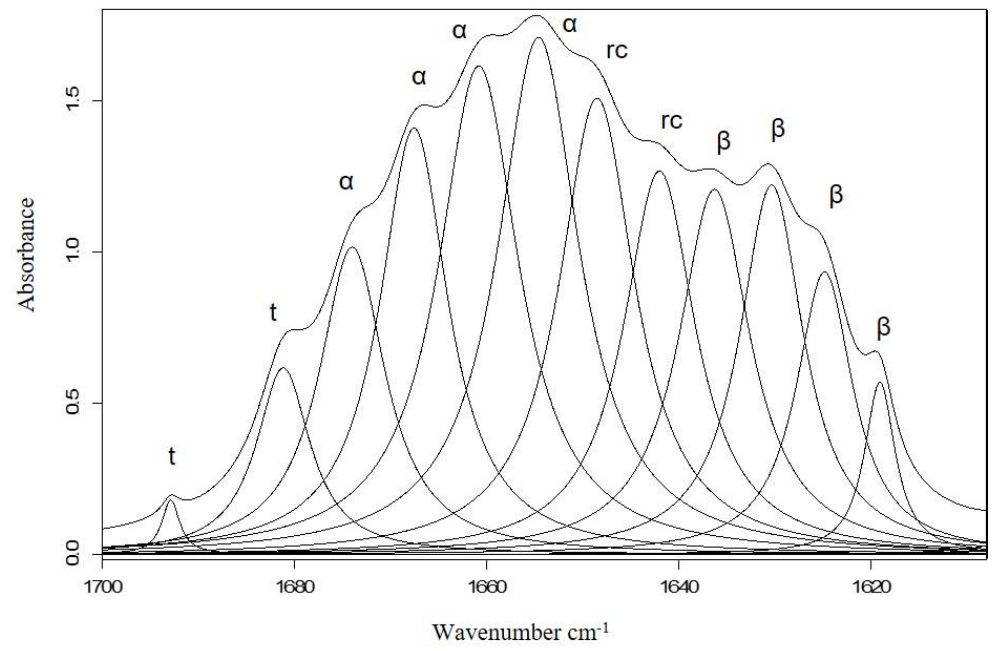

Figure 10.1.3.1.7. Amide I curve fitted band for EG@Cu specimen with fitted band components. Assignment of bands conformations: $\beta$-sheet $(\beta)$, random coil $(\mathrm{rc}), \alpha$-helix $(\alpha)$ and turns $(\mathrm{t})$.

Apart from those changes observed in the amide I region, increase in the intensity of the amide II band in the $1480-1580 \mathrm{~cm}^{-1}$ region was observed. Maximum at $1531 \mathrm{~cm}^{-1}$ ( $\beta$-sheet conformations) is blue-shifted to $1543 \mathrm{~cm}^{-1}$ (helical conformations). This increase is associated with the formation of $\mathrm{Cu}$-carboxylate complexes whose IR bands at $1585 \mathrm{~cm}^{-1}$ overlaps with the amide II band.

NLs and PLs 
A notable decrease in the shoulder appearing in the range $1700-1710 \mathrm{~cm}^{-1}$ in the EG specimen is observed in EG@ $\mathrm{Cu}$ specimen. This band is ascribed to the stretching vibrations of the carboxylic groups from free fatty acids that should be released from the lipids and phospholipids of egg as result of hydrolysis processes. The reduction in the intensity of these IR band can be directly correlated with the increase in the intensity of the IR band associated with the copper-protein complexes and copper soaps. Curve fitting of the deconvolved bands in the region $1800-1700 \mathrm{~cm}^{-1}$ related to the stretching vibrations of carbonyl groups was also carried out (Figure 10.1.3.1.8) The low $\mathrm{I}_{\mathrm{FFA}} / \mathrm{I}_{\mathrm{E}}$ ratio obtained together with the intense shoulder at $1585 \mathrm{~cm}^{-1}$ ascribed to $\mathrm{Cu}$-carboxylate complexes with fatty acids and protein residues (Mazzeo et al., 2008; Švarcova et al., 2014, Quing et al., 1996; Nara et al., 2013, Williams, 1993; Williams et al., 1996; Guthrie and Laurie, 1968) for this specimen (see Table 10.1.3.1.2) suggests that pigment is promoting the hydrolysis of the triglycerides but the fatty acids released are mostly complexed with copper ions.

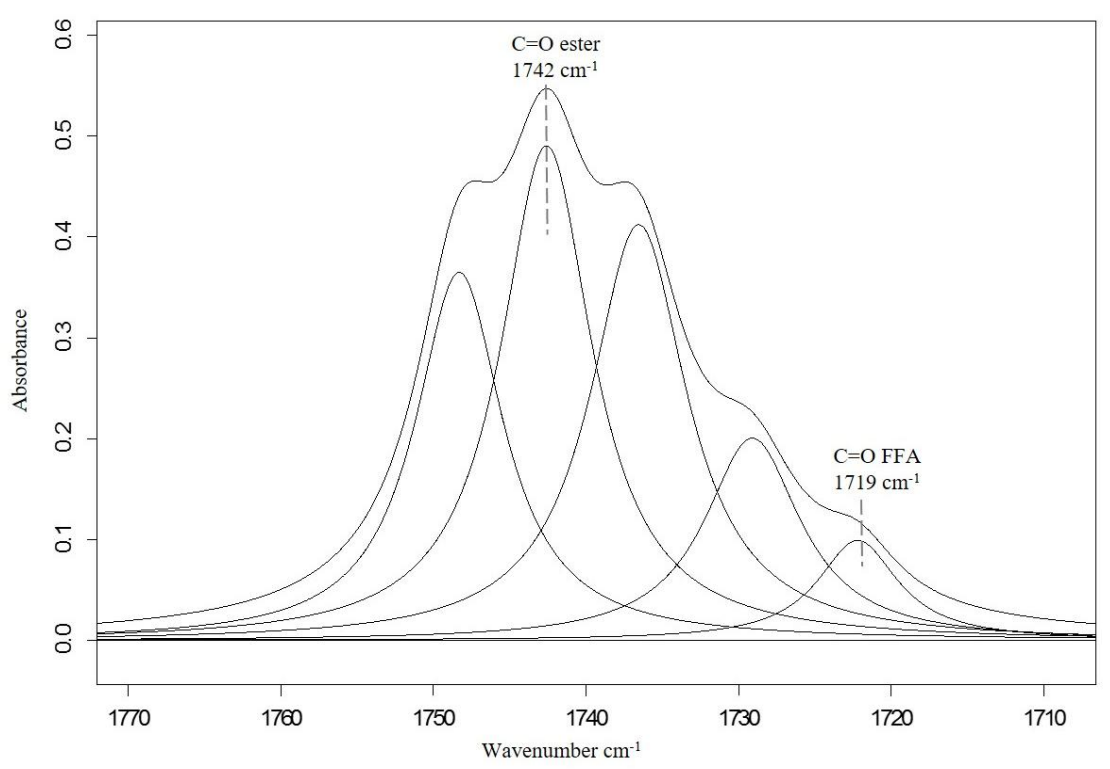

Figure 10.1.3.1.8. Carbonyl curve fitted band for EG@Cu specimen with fitted band components.

Other changes associated to the PLs-metal interactions for the EG@ $\mathrm{Cu}$ specimens were a blue-shifting of the bands at $1063 \mathrm{~cm}^{-1}$ and $1086 \mathrm{~cm}^{-1}$ to $1068 \mathrm{~cm}^{-1} 1087 \mathrm{~cm}^{-1}$, respectively. The first band is attributed to the $v_{\mathrm{s}}(\mathrm{P}-\mathrm{O}-\mathrm{C})$ terminal phosphate. While the shift of the latter band is associated to $v_{\mathrm{s}}\left(\mathrm{PO}_{2}^{-}\right)$indicate the PLS-metal interactions of phosphate groups, deriving principally from phosphodiester. Confirmation of the $\mathrm{P}-\mathrm{O}-\mathrm{X}(\mathrm{X}=$ metal atom) bond was possible due to the presence of the weak band at $970 \mathrm{~cm}^{-1}$ attributed to the interactions of the polar phosphate present in PLs and the phosphorylated lipoproteins present in HDLs, able to bond pigment grains surface (Cagnasso et al., 2010; Omoike et al., 2004; Parikh and Chorover, 2006; Tejedor-Tejedor and Anderson, 1990).

\section{Cholesterol}

A red-shift of the band attributed to the $-\mathrm{C}-\mathrm{O}$ stretching vibrations of alcohol group at 1056 $\mathrm{cm}^{-1}$ was observed. This change is associated to the oxidation processes undergone by this molecule during the drying process, that in presence of pigments result in the appearance of a series of cholesterol oxidation products (COPs). 


\section{Lead white reconstructed model paint specimen}

IR spectrum obtained in EG@Pb specimen is dominated by the stretching vibrations bands associated to the egg protein components accompanied by the stretching vibrations of hydroxyl $\left(3533 \mathrm{~cm}^{-1}\right)$ and carbonate group $\left(1398,1045,679 \mathrm{~cm}^{-1}\right)$ in lead white (Figure 10.1.3.1.9).

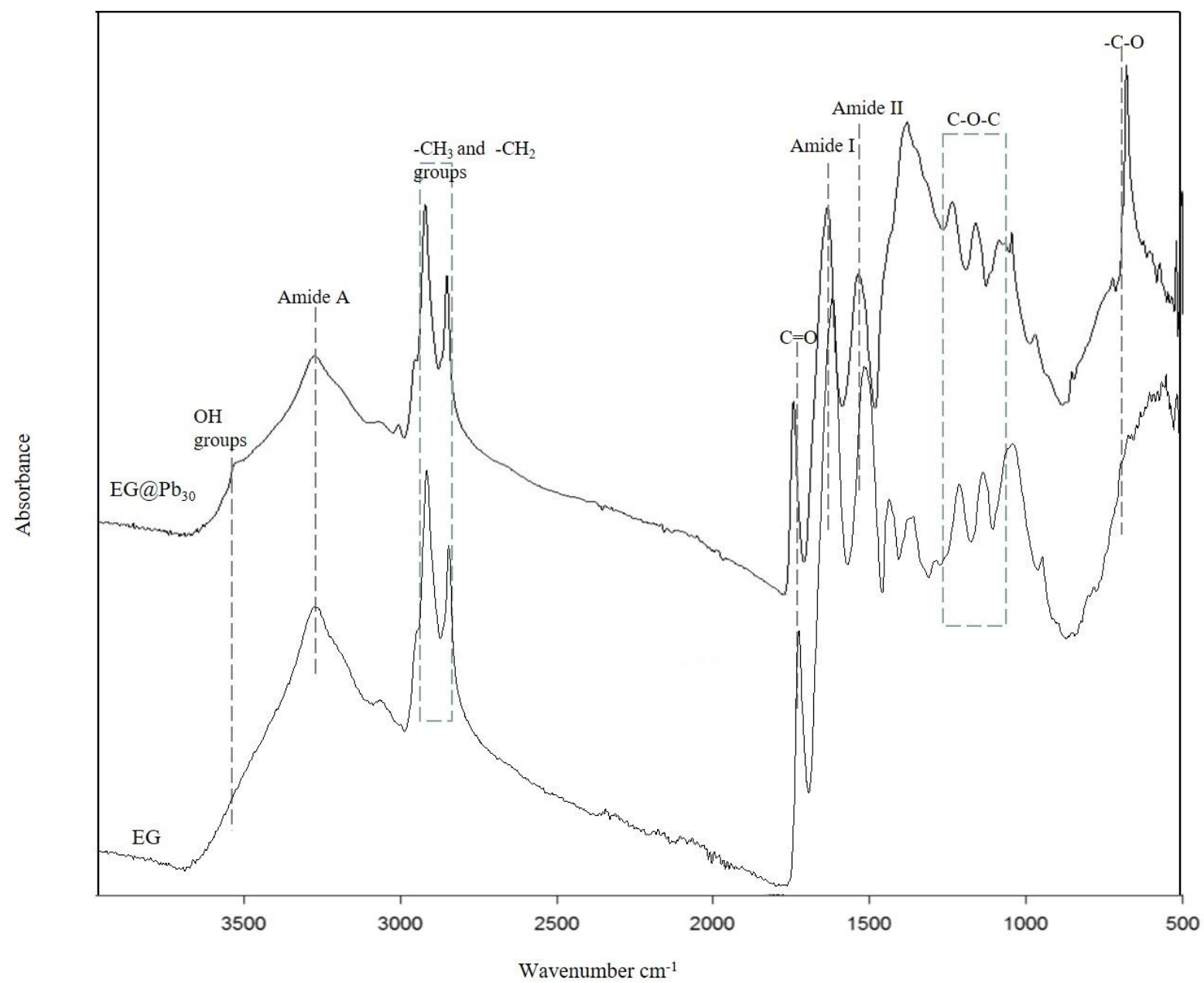

Figure 10.1.3.1.9. IR spectra obtained for EG@Pb reconstructed model paint specimen compared with that from the EG specimen.

\section{Proteins}

IR spectrum of EG@ $\mathrm{Pb}$ reconstructed model paint specimen in the $1800-1500 \mathrm{~cm}^{-1}$ region showed a slightly blue-shift of the maximum of the amide I band from $1632 \mathrm{~cm}^{-1}$ in EG to $1636 \mathrm{~cm}^{-1}$ in EG@Pb, which evidences changes in the $\beta$-sheet conformation as consequence of the presence of the pigment. The secondary maximum of the amide I band at $1651 \mathrm{~cm}^{-1}$ is less evident in EG@Pb specimen. This sub-band in the amide I region is associated with $\alpha$ helix conformations. Deconvolution and second derivative spectrum of amide I band enabled identification of the sub-bands corresponding to the different protein conformations. These components are assigned to the intermolecular $\beta$-sheet $\left(1611,1619,1625,1685\right.$ and $1693 \mathrm{~cm}^{-}$ $\left.{ }^{1}\right)$, intramolecular $\beta$-sheet $\left(1630 \mathrm{~cm}^{-1}\right)$, random coil $\left(1638 \mathrm{~cm}^{-1}\right)$, $\alpha$-helix $(1647,1654,1661$ $\mathrm{cm}^{-1}$ ) and turns $\left(1668 \mathrm{~cm}^{-1}\right.$ ) (Figure 10.1.3.1.10). Besides, deconvolution and curve fitting (see Table 10.1.3.1.1) showed a significative decrease of the intermolecular $\beta$-sheet 
contribution in parallel to an important increase of the $\alpha$-helix and turns conformation contribution. These results suggest interaction between egg proteins and metal centers in the surface of the pigment grains similar to the behaviors previously reported for the $\mathrm{EG} @ \mathrm{Cu}$ specimens.

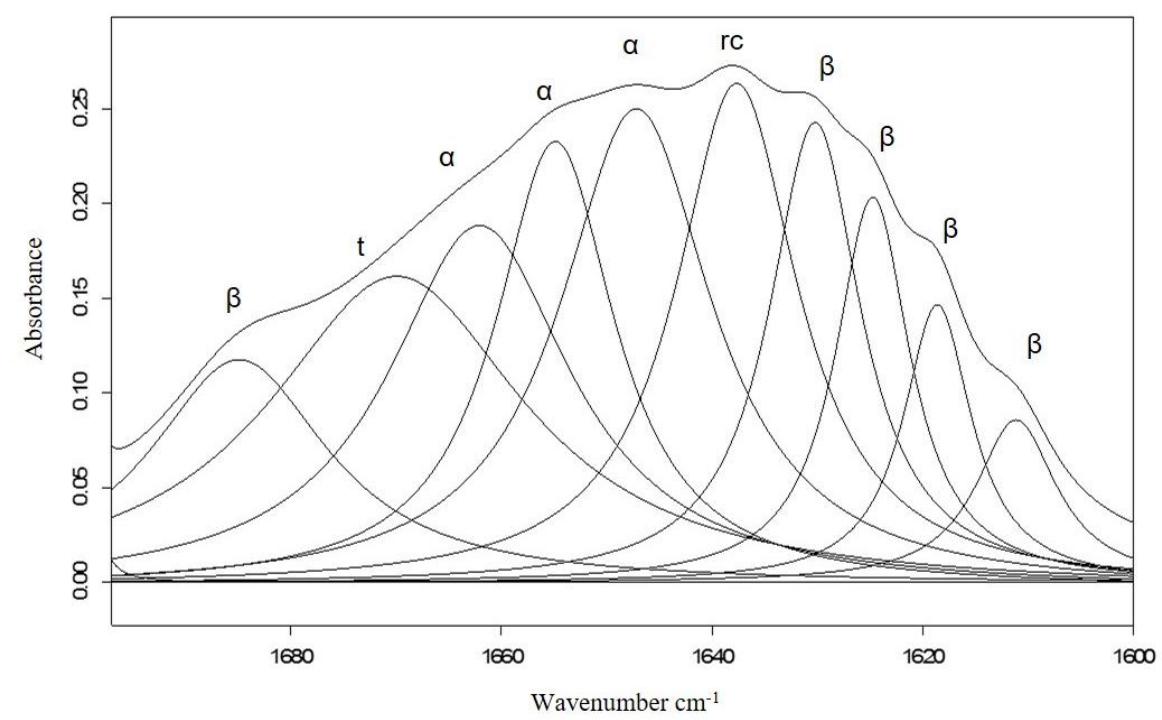

Figure 10.1.3.1.10. Amide I curve fitting of EG@Pb specimen with fitted band components. Assignment of bands conformations: $\beta$-sheet $(\beta)$, random coil $(\mathrm{rc}), \alpha$-helix $(\alpha)$ and turns $(\mathrm{t})$.

Similarly, to amide I band the maximum of the amide II band in paint films appears slightly blueshifted from the value $1531 \mathrm{~cm}^{-1}$ reported in EG to $1541 \mathrm{~cm}^{-1} \mathrm{EG} @ \mathrm{~Pb}$. This change is associated with the contribution of the stretching band of lead soaps formed by combination of $\mathrm{Pb}(\mathrm{II})$ ions with the fatty acids hydrolysed from the egg. Stretching vibrations of $\mathrm{Pb}$ carboxylate band in lead palmitates and stearates has been reported to $1541 \mathrm{~cm}^{-1}$. Appearance of a new band at $1525 \mathrm{~cm}^{-1}$ attributed to $\mathrm{Pb}$-tyrosine interactions was also observed in the EG@Pb specimen.

In contrast with the $\mathrm{Y} @ \mathrm{Pbm}_{75}$ specimen shoulders at 1574 and $1557 \mathrm{~cm}^{-1}$ attributed to metalprotein complexes were not observed in the EG@Pb specimen, this is probably associated to the low pigment concentration. Moreover, bands attributed to lead carboxylate and lead carbonate were also identified at 1400, 1046, 852 and $680 \mathrm{~cm}^{-1}$ (van der Weerd et al., 2005).

NLs and PLs

The bands bellow $1710 \mathrm{~cm}^{-1}$ ascribed to free fatty acids released from NLs suggest their hydrolysis. Blue-shift of bands attributed to the $v_{a s} \mathrm{PO}_{2}^{-}$(from 1233 to $1234 \mathrm{~cm}^{-1}$ ) and $v_{\mathrm{s}} \mathrm{PO}_{2}^{-}$ (from 1086 to $1088 \mathrm{~cm}^{-1}$ ) confirm the PLs-metal formation. Band at $1063 \mathrm{~cm}^{-1}$ was also blueshifted to $1067 \mathrm{~cm}^{-1}$, this band is associated to the $\mathrm{v}_{\mathrm{s}} \mathrm{P}-\mathrm{O}-\mathrm{C}$. 
EG@Cd exhibited an IR spectrum dominated by the amide A $\left(3300 \mathrm{~cm}^{-1}\right)$, amide I $\left(1635 \mathrm{~cm}^{-}\right.$ $\left.{ }^{1}\right)$, and amide II $\left(1537 \mathrm{~cm}^{-1}\right)$ bands and the $-\mathrm{CH}_{3}$ and $-\mathrm{CH}_{2}$ stretching vibrations (2924 and $2858 \mathrm{~cm}^{-1}$ ) (Figure 10.1.3.1.11).

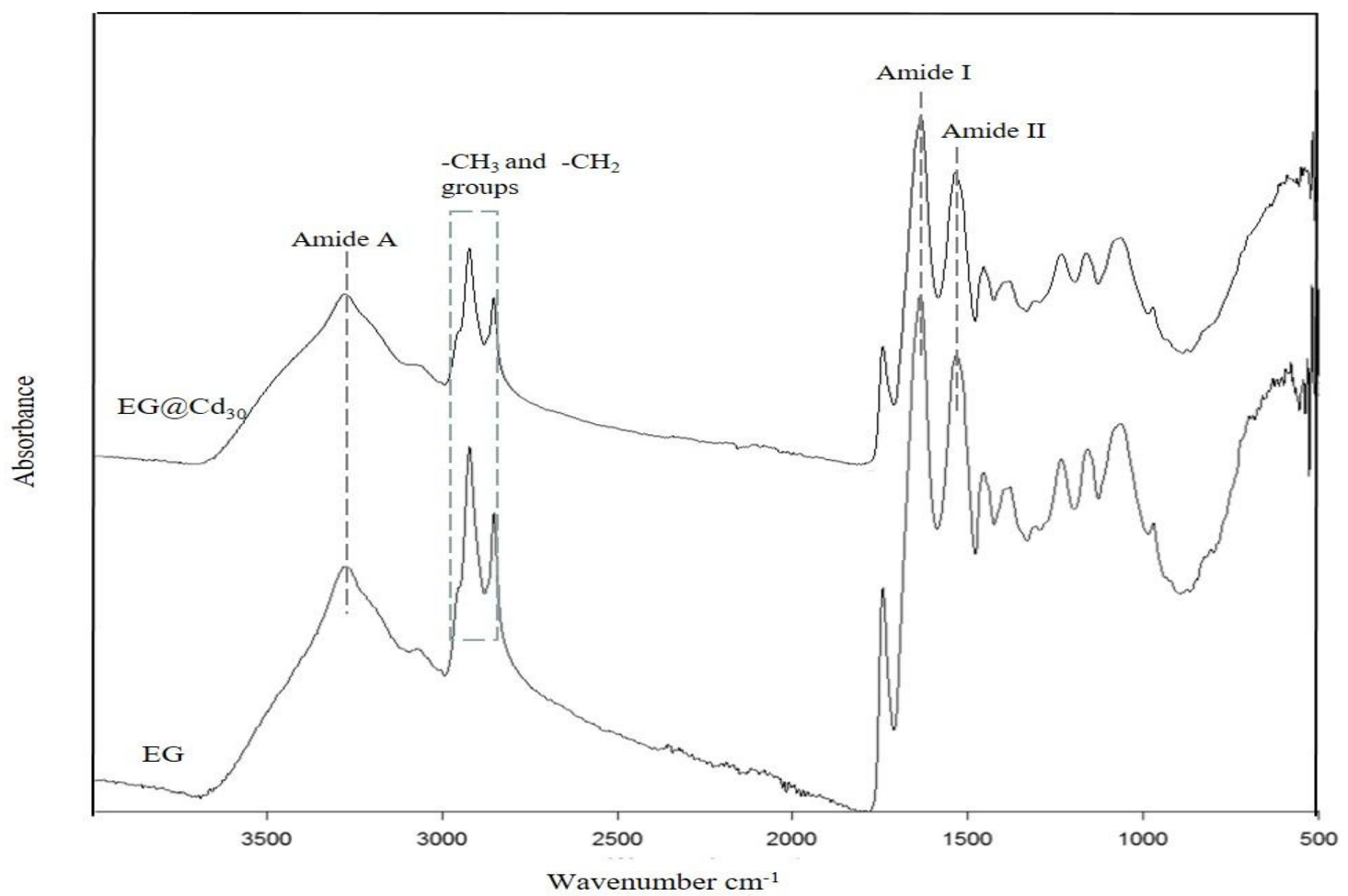

Figure 10.1.3.1.11. IR spectra obtained for the EG@Cd compared to the EG specimen.

Proteins

The position of the conformation sub-bands was determined from the deconvolved IR spectrum as in the previously presented specimens. IR spectrum of EG@Cd shows typical profile characteristics of $\beta$-sheet conformation predominant with a prominent maximum centered at $1635 \mathrm{~cm}^{-1}$ in EG@Cd, ascribed to intramolecular $\beta$-sheet conformations. The secondary maximum at $1643 \mathrm{~cm}^{-1}$ in EG@Cd is ascribed to the random coil conformation. Maximum at $1652 \mathrm{~cm}^{-1}$ with shoulders at 1658 and $1660 \mathrm{~cm}^{-1}$ were ascribed to helical conformation. Shoulders at 1625 and $1619 \mathrm{~cm}^{-1}$ are ascribed to intermolecular $\beta$-sheet structures, whereas shoulders at 1668, 1674, 1683 and $1694 \mathrm{~cm}^{-1}$ are ascribed to turn conformations. Figure 10.1.3.1.12, shows the fitted band components obtained for the amide I band after curve fitting process. Percent area contribution of each conformation is summarized in Table 10.1.3.1.1, an increase in the intramolecular $\beta$-sheet structure contribution accompanied of a decrease in the percent area contribution of the intermolecular $\beta$-sheet and turns $/ \beta$-sheet conformation is reported. 


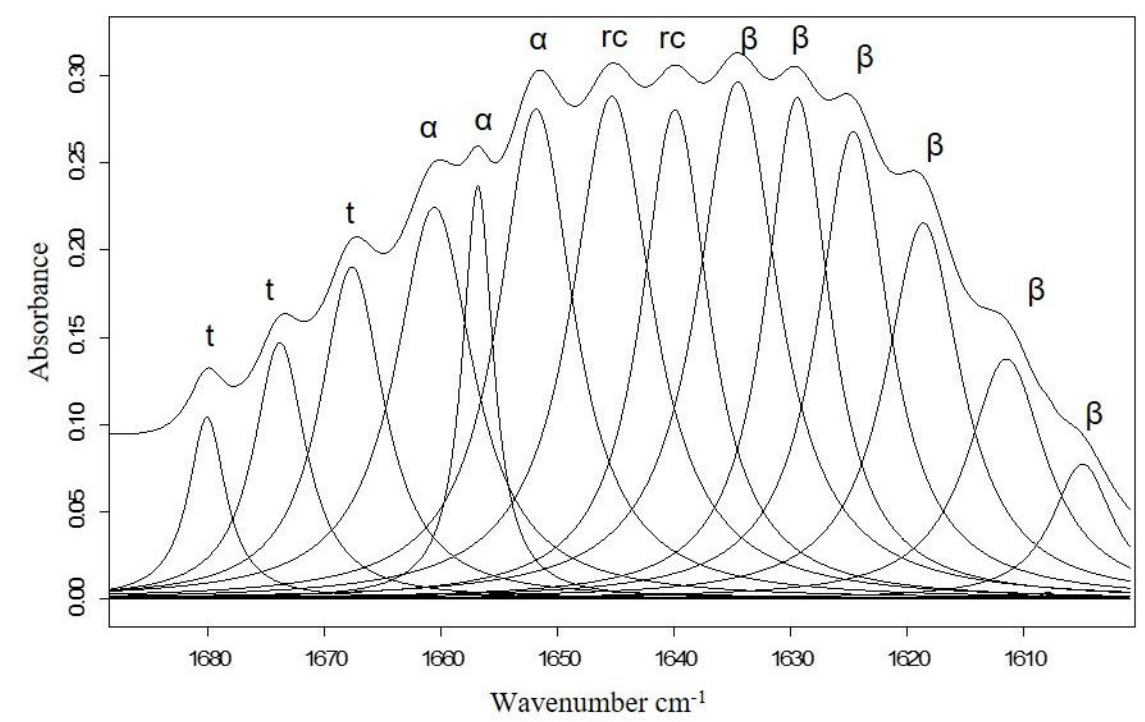

Figure 10.1.3.1.12. Amide I curve fitting of EG@Cd specimen with fitted band components. Assignment of bands conformations: $\beta$-sheet $(\beta)$, random coil $(\mathrm{rc}), \alpha$-helix $(\alpha)$ and turns $(\mathrm{t})$.

A new band at $1535 \mathrm{~cm}^{-1}$ is attributed to the interaction of Cd-carbonyl groups in proteins, this band was previously observed in the $\mathrm{Y} @ \mathrm{Cd}_{75}$ specimen. Nevertheless, formation of metal-protein complexes could not be ascertained unambiguously due to the overlapping with the amide II that occurs at the same frequency range $\left(1500\right.$ to $\left.1600 \mathrm{~cm}^{-1}\right)$.

NLs and PLs

Ester groups in triglycerides $\mathrm{C}=\mathrm{O}$ stretching vibrations exhibit bands at $1743 \mathrm{~cm}^{-1}$ and shoulder at $1736 \mathrm{~cm}^{-1}$ attributed to phospholipids. C-O stretching pattern at 1234, 1163, and $1086 \mathrm{~cm}^{-1}$, characteristic of ester groups was also identified. The hydrolysis of triglycerides at lower extent was confirmed in EG@Cd by the appearance of several shoulders in the range $1720-1700 \mathrm{~cm}^{-1}$ ascribed to free fatty acids released as result of the hydrolysis of egg triglycerides. $\mathrm{I}_{\mathrm{FFA}} / \mathrm{I}_{\mathrm{E}}$ ratio confirms that hydrolysis of triglycerides was slightly promoted by the pigment (see Table 10.1.3.1.2).

No changes were observed for those bands associated to the ${ }_{\mathrm{s}} \mathrm{P}-\mathrm{O}-\mathrm{C}$ terminal phosphate and $\mathrm{v}_{\mathrm{s}} \mathrm{PO}_{2}^{-}$, which shift is indicative of PLs-metal interactions of phosphate groups, deriving from protein phosphodiesters. While appearance of a weak band in the $100-970 \mathrm{~cm}^{-1}$ region attributed to the $\mathrm{P}-\mathrm{O}-\mathrm{X}(\mathrm{X}=\mathrm{Cd}, \mathrm{Fe}, \mathrm{Pb}, \mathrm{Zn}$ atom $)$ was observed.

\section{Egg oil emulsion film specimen}

Egg oil emulsion film specimen IR spectrum was dominated for the bands characteristic of the proteinaceous medium, amide A $\left(3278 \mathrm{~cm}^{-1}\right)$, amide I $\left(1637 \mathrm{~cm}^{-1}\right)$ and amide II $\left(1536 \mathrm{~cm}^{-}\right.$ $\left.{ }^{1}\right)$, accompanied by bands characteristic of linseed oil such as methyl/methylene $\left(2948^{\text {sh }}\right.$, $29222870^{\text {sh }}$ and $2852 \mathrm{~cm}^{-1}$ ), carbonyl groups (1744 and $1720 \mathrm{~cm}^{-1}$ ), C-O stretching vibrations at 1235,1163 and $1097 \mathrm{~cm}^{-1}$ and shoulder at $3459 \mathrm{~cm}^{-1}$ assigned to the stretching 
of alcohol and hydroperoxide bonds formed as a result of the polymerization occurring in the oil during drying (Figure 10.1.3.1.13).

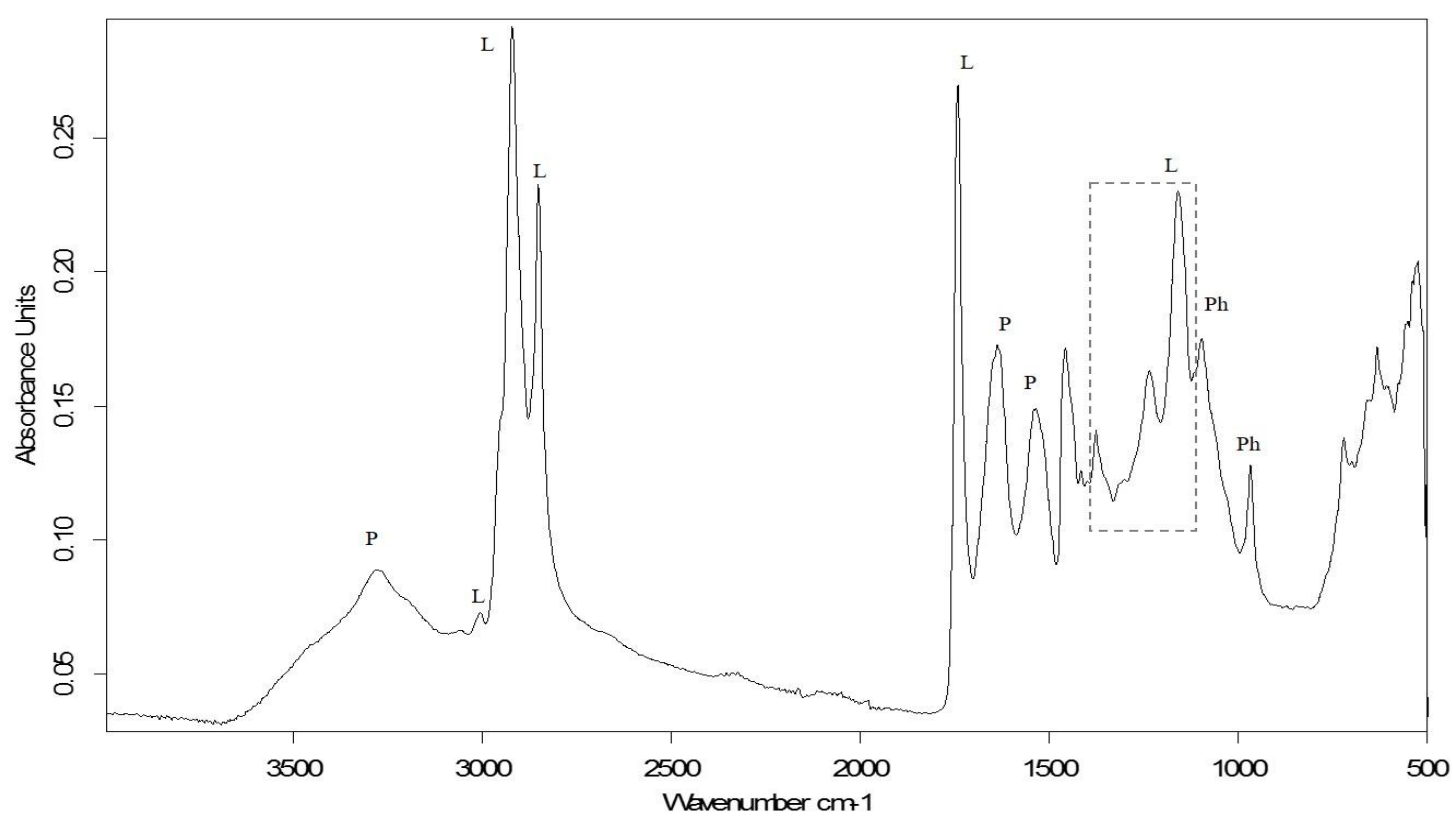

Figure 10.1.3.1.13. IR absorption spectra obtained from pure whole egg (EO). Assignment of representative bands: proteins $(\mathrm{P})$; neutral lipids $(\mathrm{L})$; and phospholipids $(\mathrm{Ph})$.

\section{Proteins}

Characteristic vibrational bands from the amide A $\left(3278 \mathrm{~cm}^{-1}\right)$, amide $\mathrm{B}\left(3055 \mathrm{~cm}^{-1}\right)$, amide I and amide II have been identified. In contrast to whole egg, the average frequency position of the main component of the amide I band in the egg oil was located at $1637 \mathrm{~cm}^{-1}$ associated to the random coil conformation. This conformation change could be related to the oxidation of $\mathrm{C}=\mathrm{C}$ from the linseed oil, which absorbs in the $1620-1690 \mathrm{~cm}^{-1}$ region, contributing to an increase in this conformation band intensity (Duce et al., 2012) (Figure 10.1.3.1.14).

Shoulders at 1652 and $1658 \mathrm{~cm}^{-1}$ are associated to $\alpha$-helix structure and sub-band at $1683 \mathrm{~cm}^{-}$ ${ }^{1}$ is associated to turns. Sub-bands at 1618 , and $1625 \mathrm{~cm}^{-1}$ are associated to intermolecular hydrogen bonding aggregated proteins, antiparallel $\beta$-sheet conformation and aromatic ring vibrations of tyrosine residues in LDL and HDL. Other sub-band at $1630 \mathrm{~cm}^{-1}$ is associated to intermolecular $\mathrm{C}=\mathrm{O}$ vibrations. 


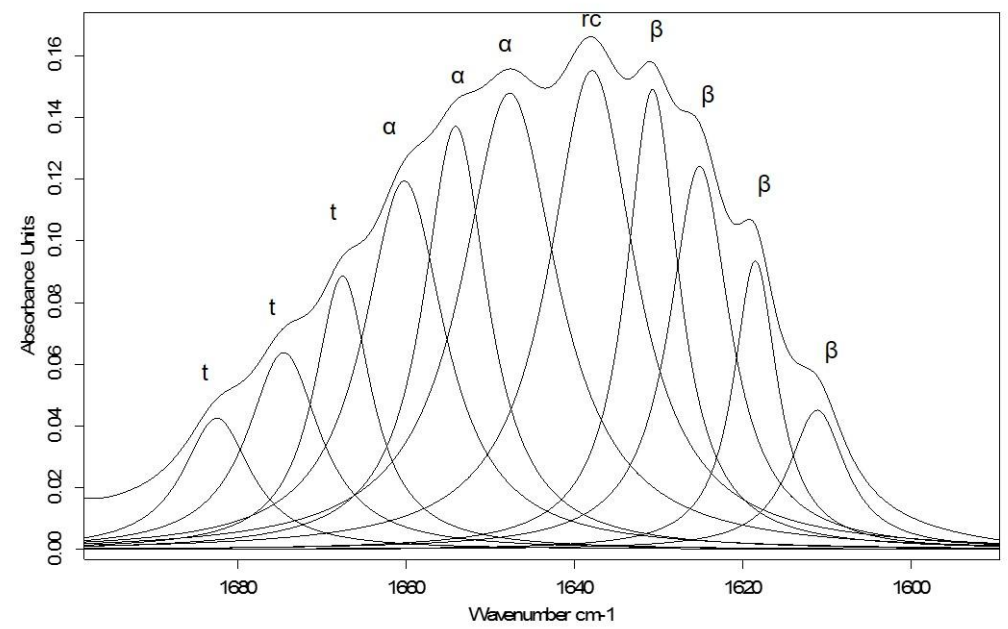

Figure 10.1.3.1.14. Amide I curve fitted band for EO with fitted band components. Assignment of bands conformations: $\beta$ sheet $(\beta)$, random coil $(\mathrm{rc}), \alpha$-helix $(\alpha)$ and turns $(\mathrm{t})$.

As with the EG specimen's, deconvolution and curve fitted procedures allow the quantification of the amide I conformation percent contribution. Comparing these results with the obtained for the EG specimen an important increase of the $\alpha$-helix conformation accompanied with a decrease in the turn conformation contribution. This suggests the formation of a more compact structure of the protein molecules that now are coexisting with polymerized triglyceride networks. No significant variations were obtained for the other conformations (see Table 10.1.3.1.3).

Table 10.1.3.1.3. Percent area contribution of amide I components for EG and EO specimens.

\begin{tabular}{|c|c|c|c|}
\hline \multirow{2}{*}{ Predominat conformations } & \multirow{2}{*}{ Frequency range $\left(\mathbf{c m}^{-1}\right)$} & EG & EO \\
\cline { 3 - 4 } & & 20 & 20 \\
\hline Intermolecular $\beta$-sheet & $1611-1625$ & 10 & 8 \\
\hline Intramolecular $\beta$-sheet & $1625-1637$ & 18 & 21 \\
\hline Random coil & $1637-1645$ & 27 & 38 \\
\hline$\alpha-$ helix & $1645-1662$ & 24 & 13 \\
\hline Turns & $1662-1682$ & \multicolumn{2}{|}{} \\
\hline
\end{tabular}

The amide II band maximum absorption band at $1536 \mathrm{~cm}^{-1}$ is attributed to the $\mathrm{N}-\mathrm{H}$ bending vibrations of amide groups of the peptide backbone in proteins. The $\beta$-sheet conformation was the dominant structure obtained for the amide II by means of FSD, as in the EG specimen.

NLs and PLs

The relative increase in the $\mathrm{C}=\mathrm{O}$ stretching vibration at $1742 \mathrm{~cm}^{-1}$ when compared to the IR spectrum obtained for EG specimen is coherent with the presence of abundant triglycerides from the linseed oil. Figure 10.1.3.1.15, shows the free fatty acid contribution obtained in the EO specimen after deconvolution. The band at $1235 \mathrm{~cm}^{-1}$, is attributed to the $-\mathrm{C}-\mathrm{O}$ of triglyceride ester linkage of NLs (Salvadó et al., 2009; van der Weerd et al., 2005) and to asymmetric stretching of $\mathrm{PO}_{2}^{-}$. 


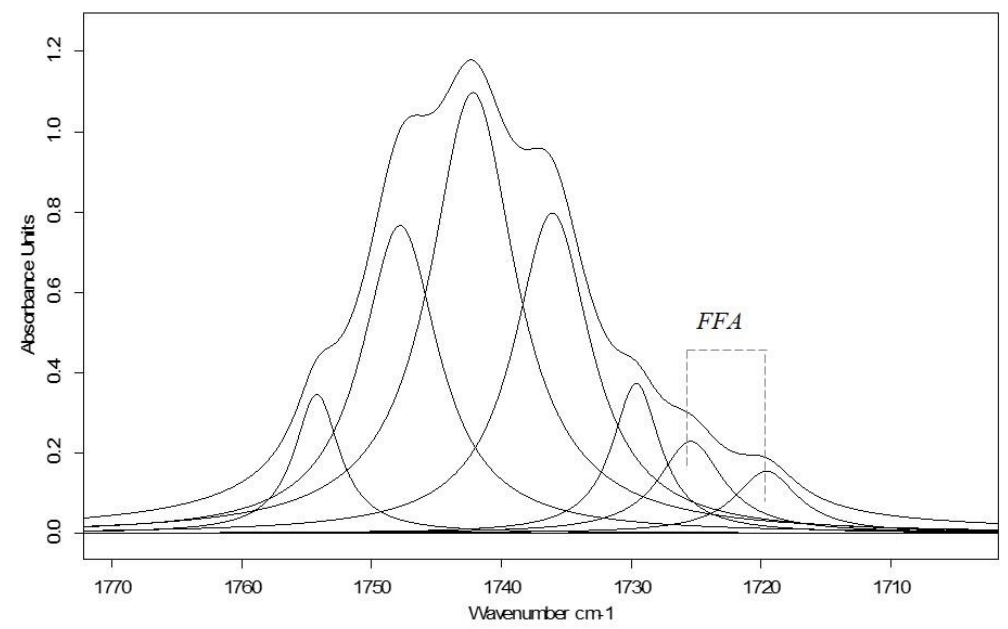

Figure 10.1.3.1.15. Carbonyl curve fitted band for EO specimen with fitted band components

Carboxylic moieties were also confirmed in the EO specimen by the weak band at $1416 \mathrm{~cm}^{-1}$ (Cagnasso et al., 2010; van der Weerd et al., 2005; Omoike et al., 2004) associated to the diversification in deprotonated carboxylated anion of acidic species formed from NLs, PLs proteins together with contribution from $\left(-\mathrm{CH}_{2}-\mathrm{COOR}\right)$ stretch of the PLs, phosphatidylcholine (PC) (Cagnasso et al., 2010). Only one band associated to terminal phosphate vibrations at $1141 \mathrm{~cm}^{-1}$ was identified in the EO specimen, when compared to the EG specimen. The band at $1061 \mathrm{~cm}^{-1}$ attributed to $v_{\mathrm{s}}(\mathrm{P}-\mathrm{O}-\mathrm{C})$ terminal phosphate vibrations of the phosphatidic acid (Cagnasso et al., 2010) and band at $967 \mathrm{~cm}^{-1}$ associated to $\left(\mathrm{N}-\mathrm{CH}_{3}\right)$ asymmetric stretch (Cagnasso et al., 2010; Tantipolphan et al., 2007) were identified as in the EG specimen.

\section{Cholesterol}

A band corresponding to cholesterol was identified at $1052 \mathrm{~cm}^{-1}$ attributed to the $-\mathrm{C}-\mathrm{O}$ stretching vibrations of the saturated secondary alcohol groups.

\section{Egg oil emulsion reconstructed model paint specimens}

The egg oil emulsion paint specimens exhibited IR spectra dominated by the bands associated to egg protein and lipid components: amide $\mathrm{A}$, amide I and amide II groups and the methyl/methylene and ester triglyceride groups (Figure 10.1.3.1.16). 


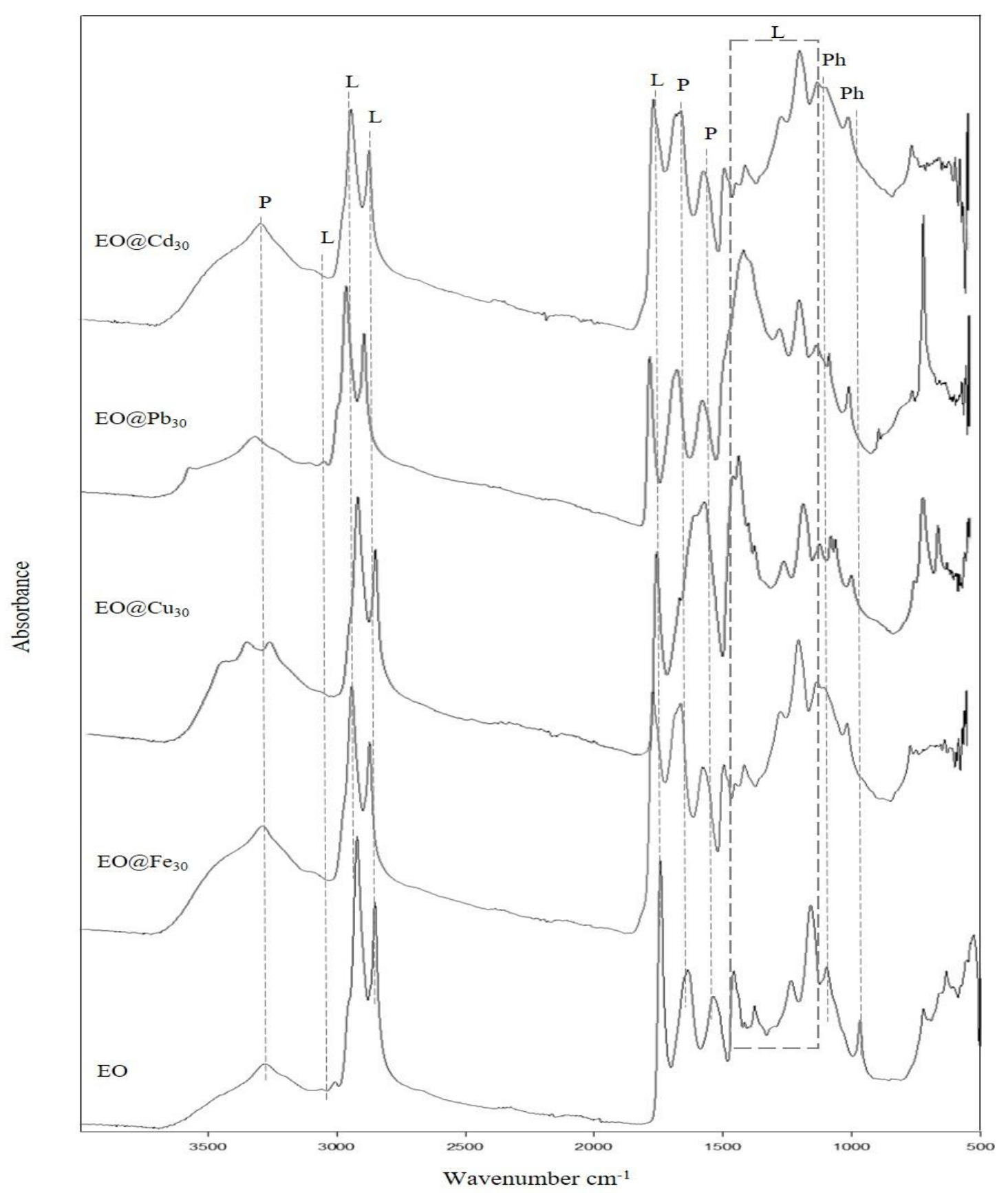

Figure 10.1.3.1.16. IR spectra obtained from the series of egg oil emulsion paint specimens prepared at $30 \mathrm{wt} \%$ pigment content. Pure egg oil emulsion (EG), iron oxide red (EO@Fe), verdigris $(\mathrm{EO} @ \mathrm{Cu})$, lead white( $\mathrm{EO} @ \mathrm{~Pb})$ and cadmium yellow (EO@Cd). Assignment of representative bands: protein (P); NLs (L); and PLs (Ph).

Iron oxide red reconstructed model paint specimen

IR spectrum of the EO@Fe specimen exhibits high scattering effect produced by the pigment. The spectrum was dominated by the amide A $\left(3277 \mathrm{~cm}^{-1}\right)$, amide I $\left(1651 \mathrm{~cm}^{-1}\right)$, and amide II $\left(1541 \mathrm{~cm}^{-1}\right)$ bands and the $-\mathrm{CH}_{3}$ and $-\mathrm{CH}_{2}$ stretching vibrations (2923 and $\left.2853 \mathrm{~cm}^{-1}\right)$ 
accompanied by the $\mathrm{C}-\mathrm{O}$ stretching vibrations at 1235,1165 and $1097 \mathrm{~cm}^{-1}$ from the triglycerides (Figure 10.1.3.1.17).

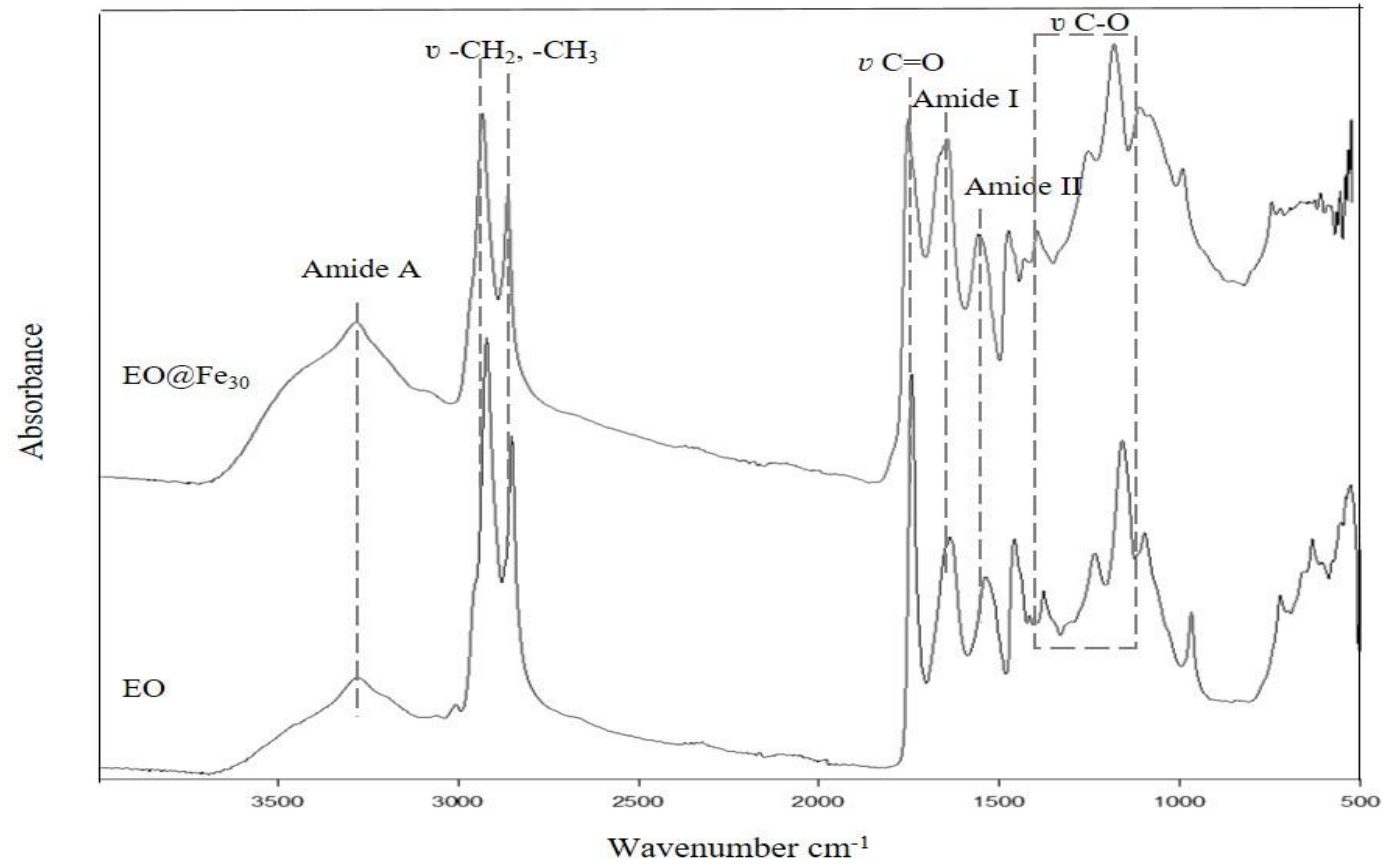

Figure 10.1.3.1.17. IR spectra obtained for the EO@Fe reconstructed model paint specimen compared with that from the EO specimen.

Proteins

In the case of the EO@Fe specimen the maximum of the amide I band was located at 1627 $\mathrm{cm}^{-1}$, in the intramolecular $\beta$-sheet region. As in the YO@ $\mathrm{Fe}_{75}$ specimen redshift of this band is indicative of interaction between the pigment and the protein residues. FSD and curve fitting confirmed that the predominant conformation was intramolecular $\beta$-sheet (1627 and $1637 \mathrm{~cm}^{-1}$ ) with a percent contribution of 39\% (Table 10.1.3.1.4). The increase of this conformation can be related to the absence of random coil and turns conformations. This behavior has seen previously described for some of specimens prepared to a higher pigment content and is attributed to the partial disruption in protein-protein intermolecular interactions due to the presence of the pigment. Intermolecular $\beta$-sheet and $\alpha$-helix conformation bands at 1619 and $1654 \mathrm{~cm}^{-1}$, were also assigned after FSD and curve fitting (Figure 10.1.3.1.18). No significant changes were observed in the amide II band that exhibited maximum centered at $1541 \mathrm{~cm}^{-1}$. 


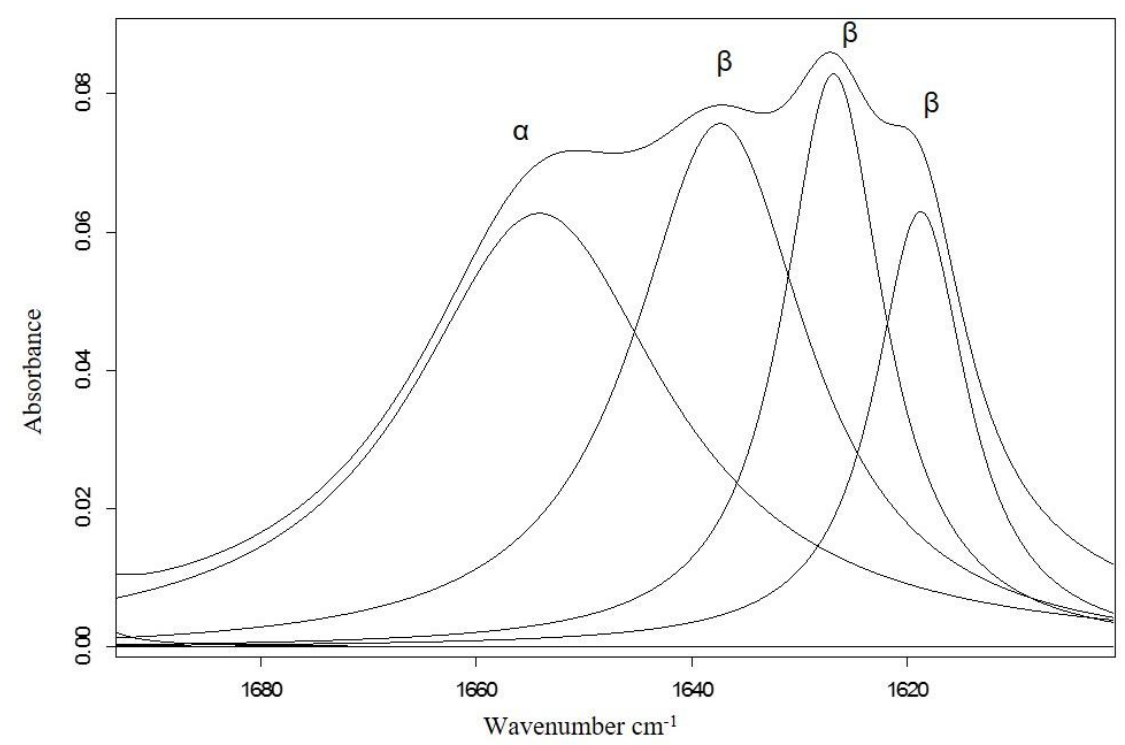

Figure 10.1.3.1.18. Amide I curve fitting of EO@Fe specimen with fitted band components. Assignment of bands conformations: $\beta$-sheet $(\beta)$ and $\alpha$-helix $(\alpha)$.

Table 10.1.3.1.4. Percent area contribution of amide I components for whole egg specimen and EO@Fe,EO@Cu,EO@Pb and EO@Cd reconstructed egg tempera model paint specimens.

\begin{tabular}{|c|c|c|c|c|c|c|}
\hline $\begin{array}{c}\text { Predominat } \\
\text { conformations }\end{array}$ & $\begin{array}{c}\text { Frequency } \\
\text { range }\left(\mathrm{cm}^{-1}\right)\end{array}$ & EO & 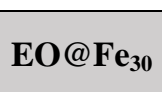 & $\mathbf{E O} @ \mathbf{C u}_{30}$ & $\mathbf{E O} @ \mathrm{~Pb}_{30}$ & $\mathbf{E O} @ \mathbf{C d}_{30}$ \\
\hline Intermolecular $\beta$-sheet & $1611-1625$ & 20 & 13 & 4 & 5 & 21 \\
\hline Intramolecular $\beta$-sheet & $1625-1637$ & 8 & 39 & - & 36 & 8 \\
\hline Random coil & $1637-1645$ & 21 & - & - & - & 15 \\
\hline$\alpha$-helix & $1645-1662$ & 38 & 48 & 8 & 47 & 55 \\
\hline Turns & $1662-1682$ & 13 & - & 88 & 12 & - \\
\hline
\end{tabular}

\section{NLs and PLs}

The most significant change observed was the new absorption band at $1708 \mathrm{~cm}^{-1}$ attributed to the presence of free fatty acids. Deconvolution allows to calculate the $\mathrm{I}_{\mathrm{FF}} / \mathrm{I}_{\mathrm{E}}$ ratio. (Table 10.1.3.1.5). It can be seen, that the presence of the pigment results in a slight increase of the content of free fatty acids but at lesser extent than in the $\mathrm{YO} @ \mathrm{Fe}_{75}$ specimen (1.29) with higher pigment content.

Table 10.1.3.1.5. $\mathrm{I}_{\mathrm{FFA}} / \mathrm{I}_{\mathrm{E}}$ values for the $\mathrm{EO}$ and the reconstructed model paint specimens at $30 \mathrm{wt} \%$.

\begin{tabular}{|c|c|}
\hline Specimens & $\mathbf{I}_{\mathbf{F F A}} / \mathbf{I}_{\mathbf{E}}$ \\
\hline $\mathrm{EO}$ & 0.08 \\
\hline $\mathrm{EO} @ \mathrm{Fe}$ & 0.41 \\
\hline $\mathrm{EO} @ \mathrm{Cu}$ & 0.15 \\
\hline $\mathrm{EO} @ \mathrm{~Pb}$ & 0.01 \\
\hline $\mathrm{EO} @ \mathrm{Cd}$ & 0.21 \\
\hline
\end{tabular}


Band at $1143 \mathrm{~cm}^{-1}$ attributed to terminal phosphate vibrations was observed for this specimen. Band at $997 \mathrm{~cm}^{-1}$ is attributed to the formation of a $\mathrm{P}-\mathrm{OFe}$ inner-sphere complex was not observed in the EO@Fe specimen, probably due to the low pigment content in combination with the presence of linseed oil.

\section{Verdigris reconstructed model paint specimen}

The IR spectrum is dominated by bands characteristic of stretching vibrations of egg protein components as amide A $\left(3269 \mathrm{~cm}^{-1}\right)$ and methyl/methylene $\left(2923\right.$ and $\left.2852 \mathrm{~cm}^{-1}\right)$, carbonyl and amide $\mathrm{I}\left(1650 \mathrm{~cm}^{-1}\right)$ groups in egg proteins together with stretching vibrations of hydroxyl and $\mathrm{Cu}$-carboxylate groups in neutral verdigris (Figure 10.1.3.1.19).

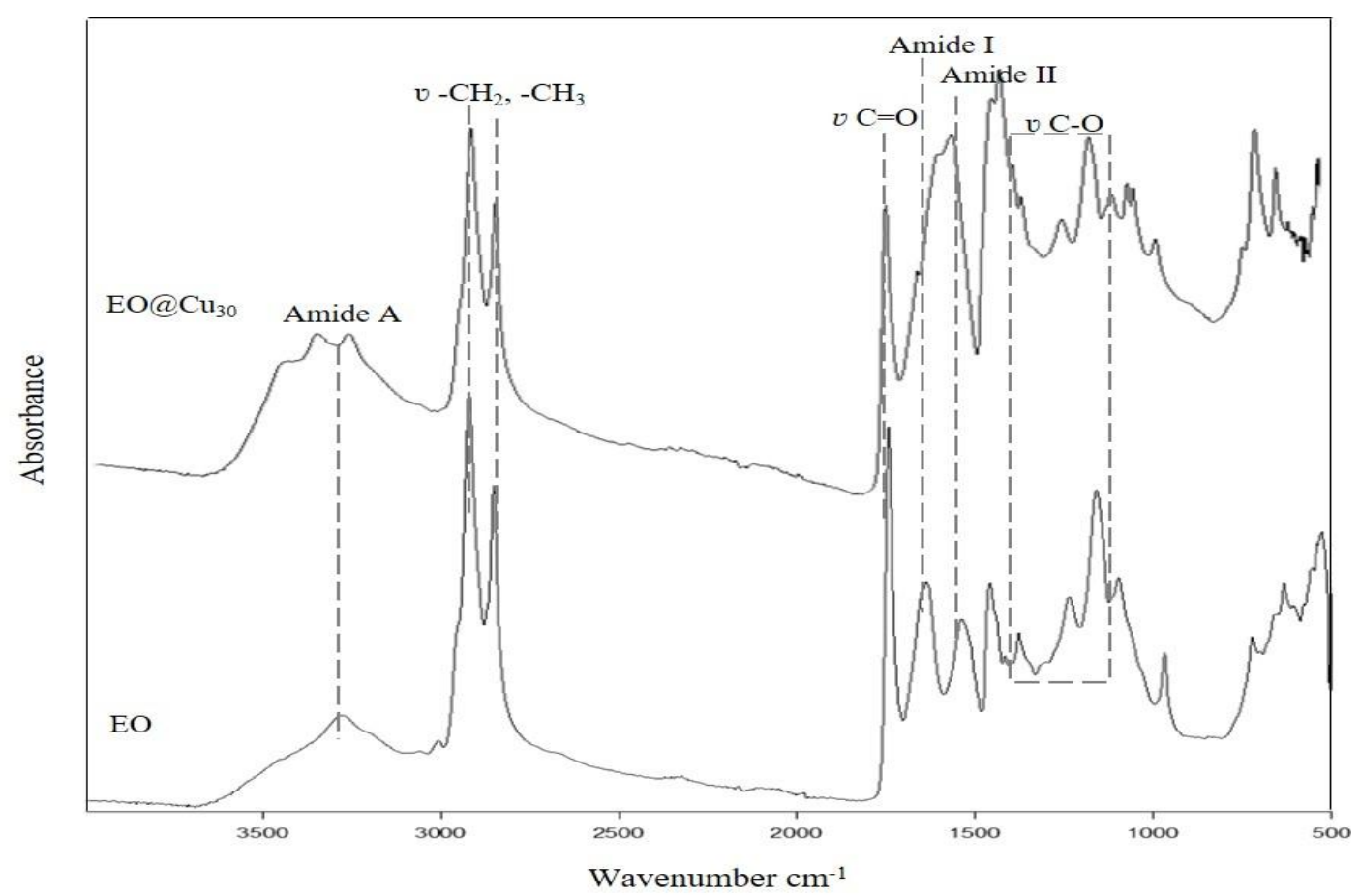

Figure 10.1.3.1.19. IR spectra obtained for the EO@ $\mathrm{Cu}$ reconstructed model paint specimen compared with that from the EO specimen.

\section{Protein}

Amide I band at $1651 \mathrm{~cm}^{-1}$ in pure egg oil emulsion specimen occurs at lower spatial frequencies of $1650 \mathrm{~cm}^{-1}$. This sub-band in the amide I region $\left(1720-1600 \mathrm{~cm}^{-1}\right)$ has been associated with the $\alpha$-helix conformations and the redshift of its position can be related to the increase of the helix length when the helix is bent in coiled coils (Duce et al., 2013). Despite that the shorter redshifted observed suggests that the presence of the drying oil reduces the interaction between protein and pigment. Deconvolution of the amide I band allows the characterization and quantification of the contribution of the different amide I conformations (Figure 10.1.3.1.20). Results obtained are summarized in Table 10.1.3.1.4. The significant increase of the turn conformation ( $88 \%$ ), could be ascribed to a change in the $\alpha$-helix conformation, due to an increase in the helix length, when the helix is bent in coiled coils and when the helix is exposed. Another relevant observation is the absence of intramolecular $\beta$ - 
sheet. Apparently copper pigment maintains intermolecular $\beta$-sheet instead of intramolecular conformations and switches the latter one into $\alpha$-helix structures (Duce et al., 2013).

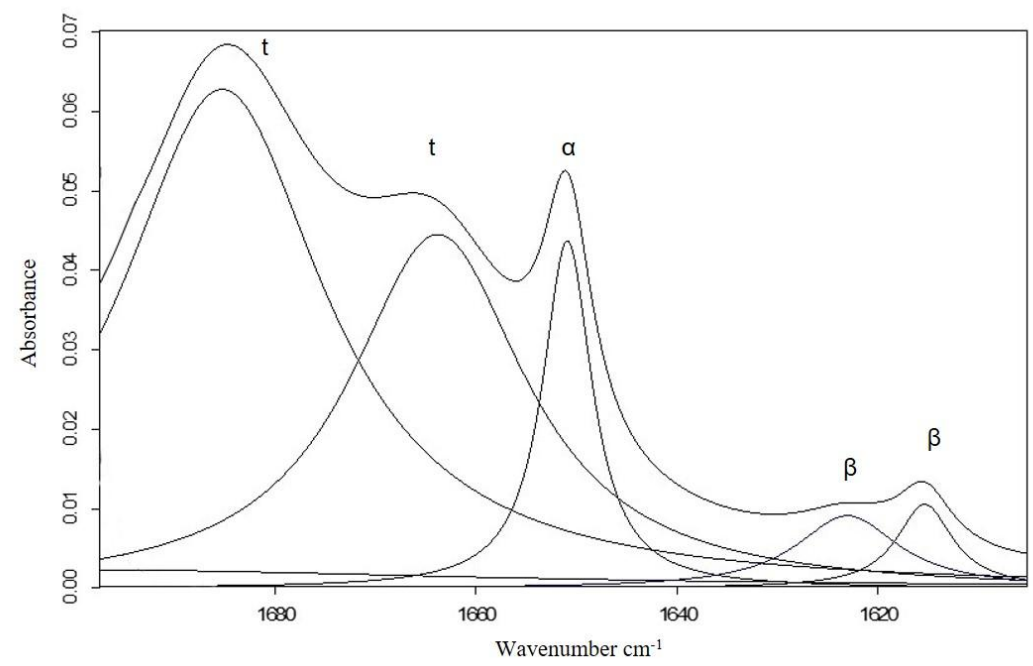

Figure 10.1.3.1.20 Amide I curve fitting of EO@Cu specimen with fitted band components. Assignment of bands conformations: $\beta$-sheet $(\beta)$, random coil (rc), $\alpha$-helix $(\alpha)$ and turns $(t)$.

A notable increase in the amide II region $\left(1480-1580 \mathrm{~cm}^{-1}\right)$ was observed in the EG@ $\mathrm{Cu}$ and EO@Cu IR spectra if compared to EO specimen. Maximum at $1536 \mathrm{~cm}^{-1}$ ( $\beta$-sheet conformations) is blueshifted to $1552 \mathrm{~cm}^{-1}$ (helical conformation), and shoulders at 1557 , 1572 , and $1585 \mathrm{~cm}^{-1}$ are also identified in the second derivative spectra. These features can be directly correlated with the interaction of the pigment with both lipid and proteinaceous components of the binders.

NLs and PLs

The shoulder at $1585 \mathrm{~cm}^{-1}$ has been related to the formation of complexes of $\mathrm{Cu}$ (II) with free fatty acids released from triacylglycerol and PLs in linseed oil and egg yolk (Mazzeo et al., 2008). A notable decrease in the shoulder $\left(1700-1720 \mathrm{~cm}^{-1}\right)$ ascribed to the stretching vibrations of the carboxylic group from free fatty acid that should be released from the lipid and PLs of egg and linseed oil as result of hydrolysis processes is observed. This behavior can be correlated with the increase in the intensity of the IR band associated with $\mathrm{Cu}$-protein complexes and $\mathrm{Cu}$-soaps. Deconvolution and curve fitting applied to this band region (Figure 10.1.3.1.15) confirm the low content in free fatty acids present in the EO@ $\mathrm{Cu}$ specimen (0.15) (see Table 10.1.3.1.5) if compared to other pigments. Nevertheless, it should be noted that this low value for the $\mathrm{I}_{\mathrm{EEF}} / \mathrm{I}_{\mathrm{E}}$ ratio is accompanied in both cases with a notable increase of the band at $1585 \mathrm{~cm}^{-1}$ associated with the complexation with of the released fatty acids with $\mathrm{Cu}$ ions. Therefore, this is the cause of this notably low content in free fatty acids. 


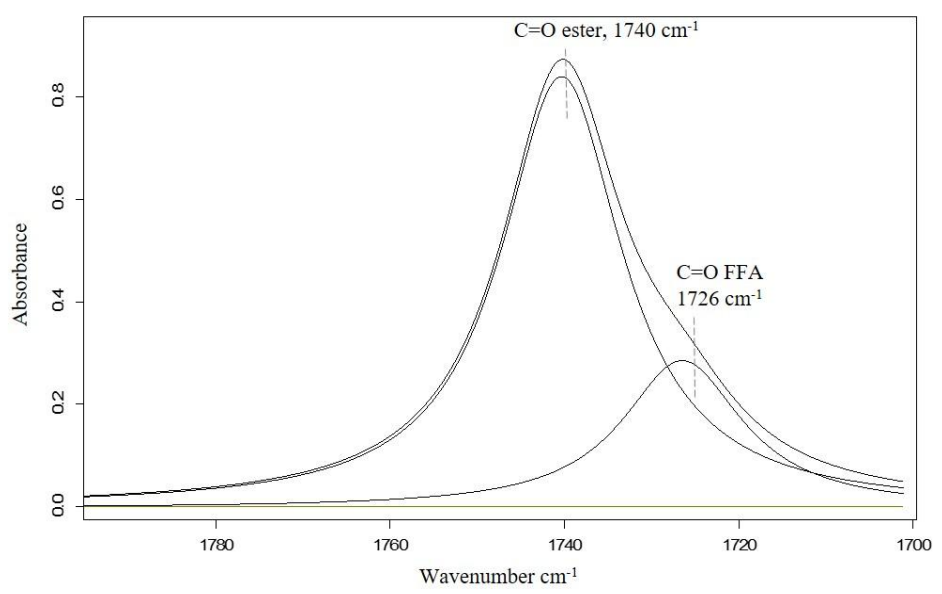

Figure 10.1.3.1.15. Carbonyl curve fitted band for EO@Cu specimen with fitted band components.

\section{Lead white reconstructed model paint specimen}

The spectrum is dominated by the stretching vibrations bands of amide $\mathrm{A}\left(3278 \mathrm{~cm}^{-1}\right)$, the amide I $\left(1636-1367 \mathrm{~cm}^{-1}\right)$ and amide II $\left(1536 \mathrm{~cm}^{-1}\right)$ characteristic of egg proteins as well as the stretching vibrations of methyl/methylene $\left(2919,2850 \mathrm{~cm}^{-1}\right)$, carboxylate groups $(1744$ $\mathrm{cm}^{-1}$ ) and C-O-C group (1233, 1160 and $\left.1099 \mathrm{~cm}^{-1}\right)$ in the triacylglycerol of egg and oil accompanied by the stretching vibrations of hydroxyl $\left(3533 \mathrm{~cm}^{-1}\right)$ and carbonate groups $\left(1398,1045,679 \mathrm{~cm}^{-1}\right)$ in lead white (Figure 10.1.3.1.16).

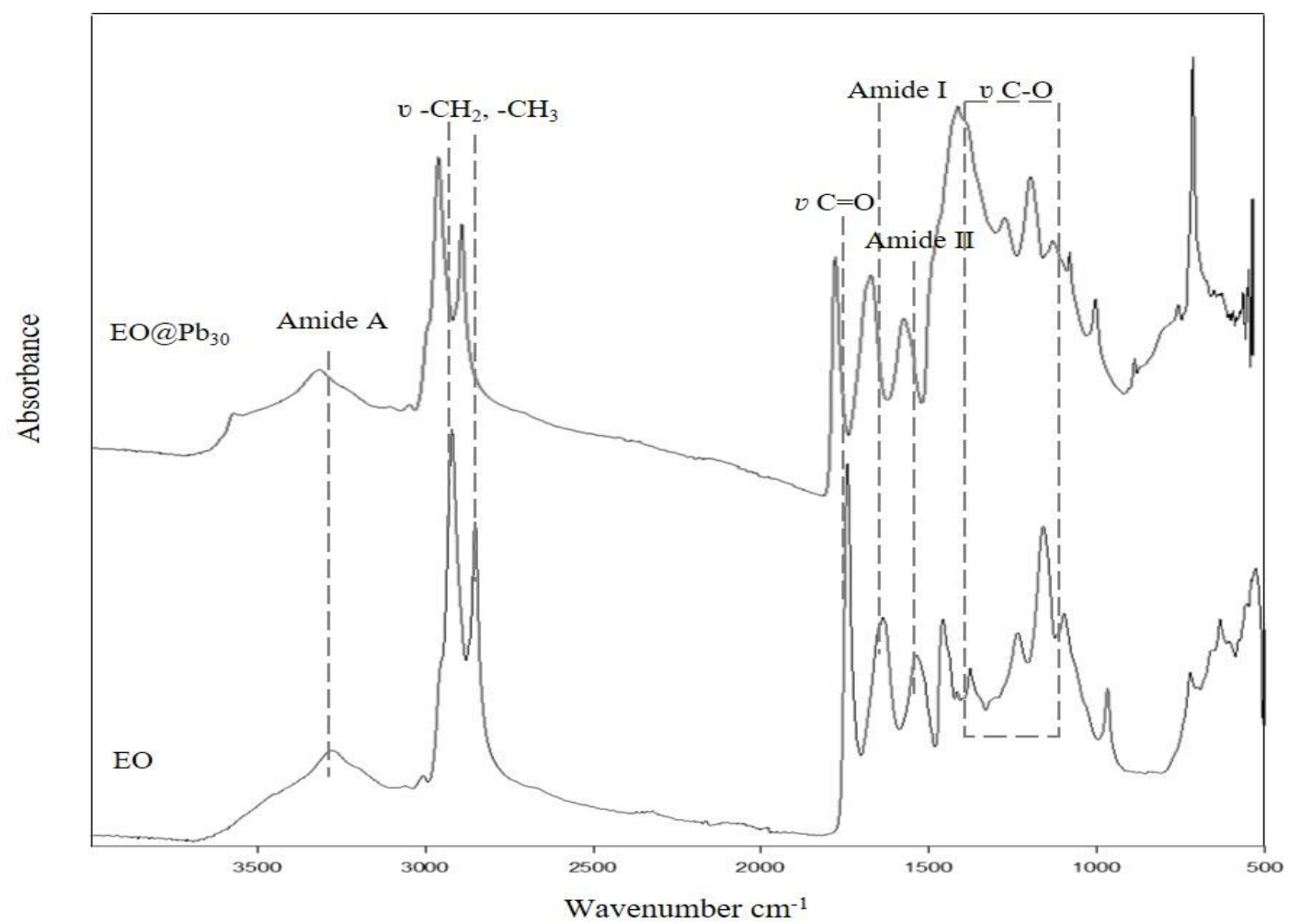

Figure 10.1.3.1.16. IR spectra obtained for the EO@Pb reconstructed model paint specimen compared with that from the EO specimen.

The relative intensity between the amide I and amide II bands and the stretching carbonyl band in the $1800-1500 \mathrm{~cm}^{-1}$ region is lower compared to the pure egg-oil emulsion specimen 
due to the contribution of triacylglycerol from the linseed oil in the egg oil emulsion. The maximum of the amide I band in the $\mathrm{EO} @ \mathrm{~Pb}_{30}$ specimen is slightly redshifted from $1639 \mathrm{~cm}^{-}$ ${ }^{1}$ to $1637 \mathrm{~cm}^{-1}$, evidencing changes in the $\beta$-sheet conformation promoted by the pigment. The secondary maximum exhibited by the amide I at $1651 \mathrm{~cm}^{-1}$ in the EO specimen is less evident in EO@Pb specimen. Deconvolution and curve fitting of the amide I band were performed in order to characterize the conformations composition and percent contribution (see Table 10.1.3.1.4). Results obtained demonstrate that the predominant conformations in this specimen are $\beta$-sheet and $\alpha$-helix (Figure 10.1.3.1.17). The increase in the percent contribution obtained for the intramolecular $\beta$-sheet $(36 \%)$ if compared to the EO specimen $(7 \%)$, confirms that the pigment is promoting the disruption of protein-protein interaction leading to the reduction of the intermolecular $\beta$-sheet conformation (5\%). Maxima of the amide I sub-bands was occurring at $1619 \mathrm{~cm}^{-1}$ (intermolecular $\beta$-sheet), 1628 and $1637 \mathrm{~cm}^{-1}$ (intramolecular $\beta$-sheet), 1650 and $1662 \mathrm{~cm}^{-1}$ ( $\alpha$-helix), and $1680 \mathrm{~cm}^{-1}$ (turns).

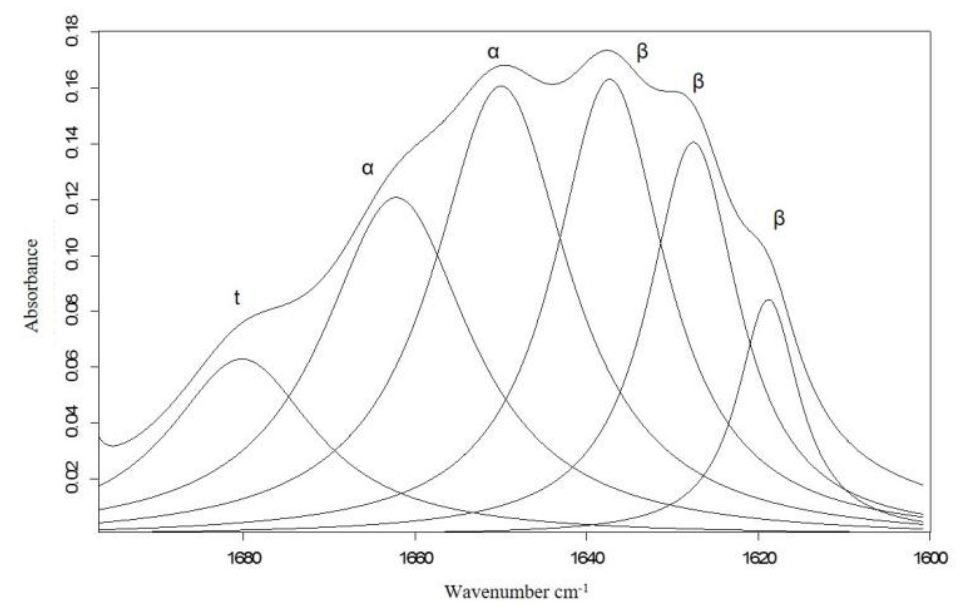

Figure 10.1.3.1.17. Amide I curve fitting obtained for EO@Pb specimen with fitted band components. Assignment of bands conformations: $\beta$-sheet $(\beta)$, random coil (rc), $\alpha$-helix $(\alpha)$ and turns $(\mathrm{t})$.

No significant changes were observed in the amide II band in the EO@Pb specimen with maximum at $1541 \mathrm{~cm}^{-1}$ attributed to $\beta$-sheet structures.

NLs and PLs

$\mathrm{C}=\mathrm{O}$ stretching vibration of ester groups in triglycerides is found at $1743 \mathrm{~cm}^{-1}$ accompanied of shoulder at $1736 \mathrm{~cm}^{-1}$ attributed to phospholipids (Figure 10.1.3.1.18). C-O stretching pattern at 1238, 1161, and $1096 \mathrm{~cm}^{-1}$ were also identified. Absence of bands associated with the hydrolysis of triglycerides in $\mathrm{EO} @ \mathrm{~Pb}$ ascribed to free fatty acids is reported. $\mathrm{I}_{\mathrm{FF}} / \mathrm{I}_{\mathrm{E}}$ ratio calculated confirms the hydrolysis of triglycerides present in NLs promoted by the pigment (see Table 10.1.3.1.5). The lower value of this ratio obtained for the EO@Pb (0.01) than for the EG@Pb specimen can be correlated with the formation of $\mathrm{Pb}$-protein complexes and $\mathrm{Pb}$ soaps in a similar way to that described for verdigris specimen. Indeed, stretching vibrations of $\mathrm{Pb}$-carboxylate band in lead-palmitate and stearate has been reported to $1541 \mathrm{~cm}^{-1}$, the assignment of this band is uncertainly ambiguously due to the overlapping with the amide II band, which absorbs in the same region. Shoulders at 1513 and $1508 \mathrm{~cm}^{-1}$ attributed to $\mathrm{Pb}$ carboxylate and $\mathrm{Pb}$-palmitate, were also observed (Mazzeo et al., 2008). 
No changes were observed for those bands associated to the $v_{\mathrm{s}} \mathrm{PO}_{2}^{-}\left(1235\right.$ and $\left.1139 \mathrm{~cm}^{-1}\right)$, which shift is indicative of PLs-metal interactions of phosphate groups, deriving from protein phosphodiesters.

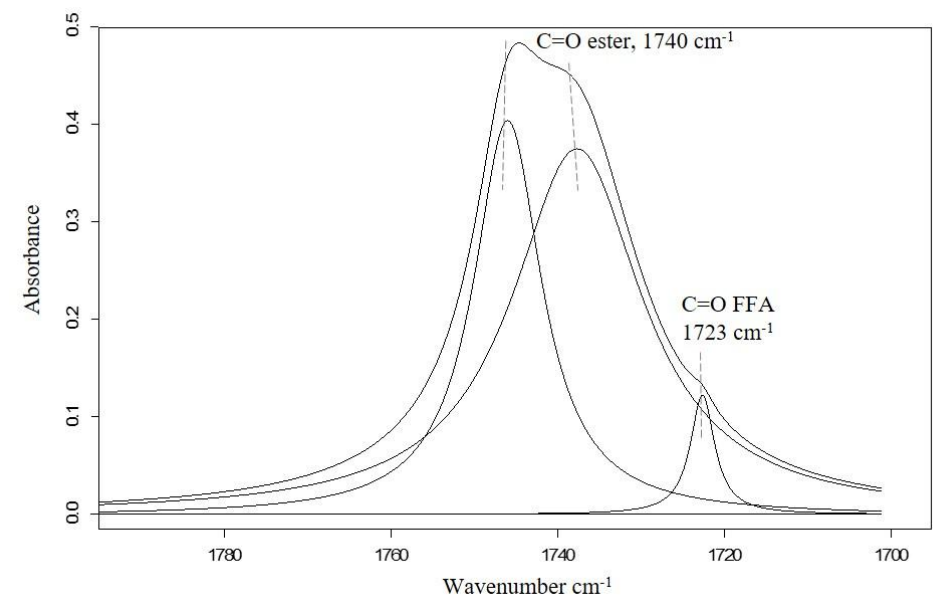

Figure 10.1.3.1.18. Carbonyl curve fitted band for $\mathrm{EO} @ \mathrm{Cu}_{30}$ specimen with fitted band components.

\section{Cadmium yellow reconstructed model paint specimen}

The EO@Cd IR spectrum was dominated by the amide A $\left(3280 \mathrm{~cm}^{-1}\right)$, amide I $\left(1628 \mathrm{~cm}^{-1}\right)$, and amide II $\left(1542 \mathrm{~cm}^{-1}\right)$ bands and the $-\mathrm{CH}_{3}$ and $-\mathrm{CH}_{2}$ - stretching vibrations (2923 and 2853 $\mathrm{cm}^{-1}$ ). Bands associated to the ester groups in triglyceride $\mathrm{C}=\mathrm{O}$ stretching vibrations at 1743 $\mathrm{cm}^{-1}$ and shoulder at $1720 \mathrm{~cm}^{-1}$ attributed to PLs, accompanied by C-O stretching pattern at 1233, 1162, and $1093 \mathrm{~cm}^{-1}$ (Figure 10.1.3.1.19). 


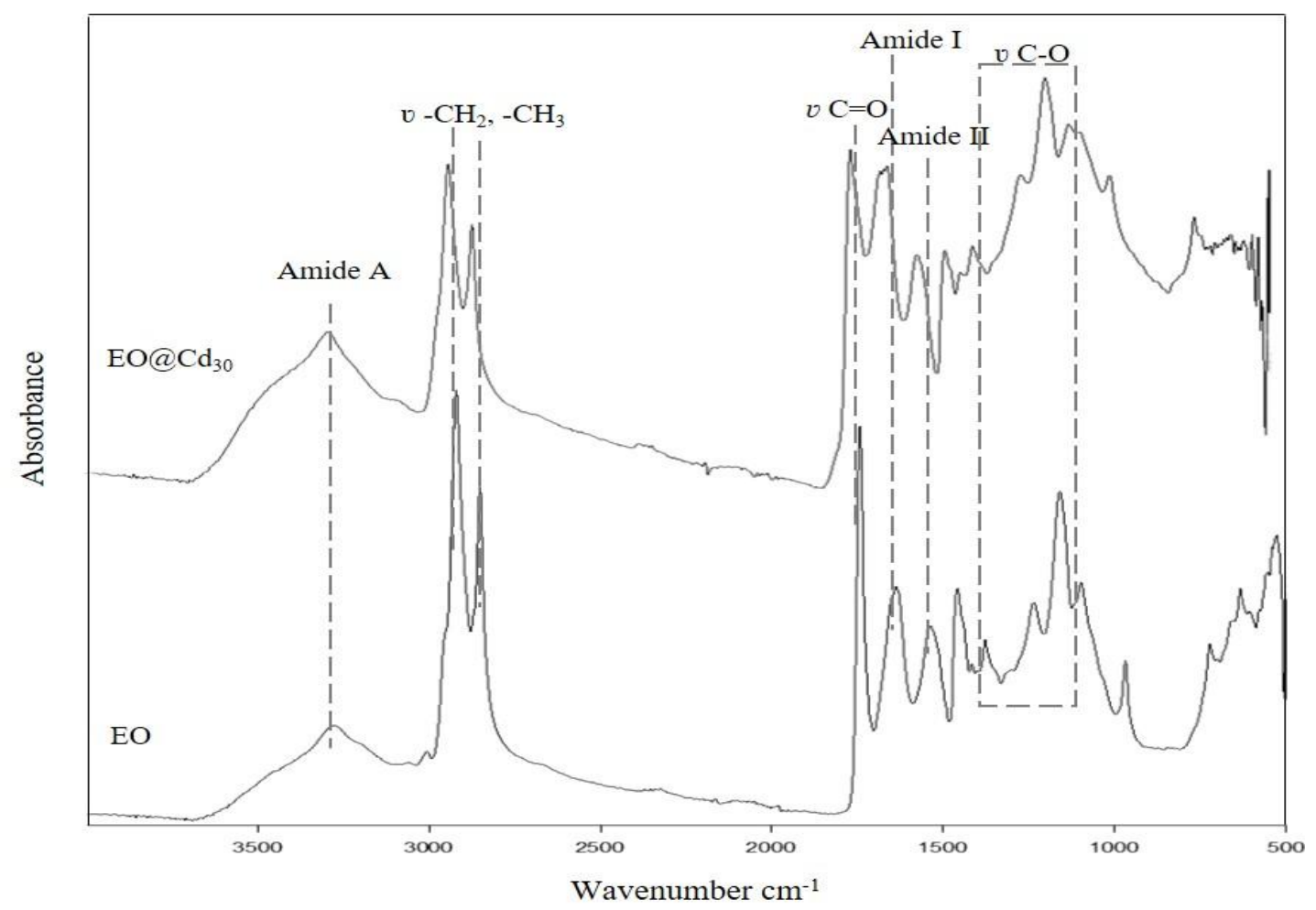

Figure 10.1.3.1.19. IR spectra obtained for the EO@Cd reconstructed model paint specimen compared with that from the EO specimen.

\section{Proteins}

Amide I band has its maximum at $1628 \mathrm{~cm}^{-1}$ in the $\beta$-sheet region. The redshift observed for the position of the maximum from 1651 to $1628 \mathrm{~cm}^{-1}$ is associated to changes in the $\beta$-sheet conformations of the protein molecules, occurring as a result of the appearance of intermolecular interactions of the protein molecules with pigment and/or the oil triglycerides and their oxidation and hydrolysis products. The secondary maximum at $1649 \mathrm{~cm}^{-1}$ is ascribed to the random coil conformation. FSD and curve fitting of the IR spectrum allows for the identification of the position of the sub-bands. Shoulders at 1611,1618 and $1625 \mathrm{~cm}^{-1}$ are ascribed to intermolecular $\beta$-sheet conformation, whereas shoulders at 1630, 1638 and $1653 \mathrm{~cm}^{-1}$ are ascribed to intramolecular $\beta$-sheet, random coil and $\alpha$-helix conformations, respectively (Figure 10.1.3.1.20). Percent contribution if the amide I conformations shows an increase of the $\alpha$-helix conformation which suggests the formation of a more open structure (see Table 10.1.3.1.4). While the increase of intermolecular $\beta$-sheet conformation may lead to the formation of aggregates. 


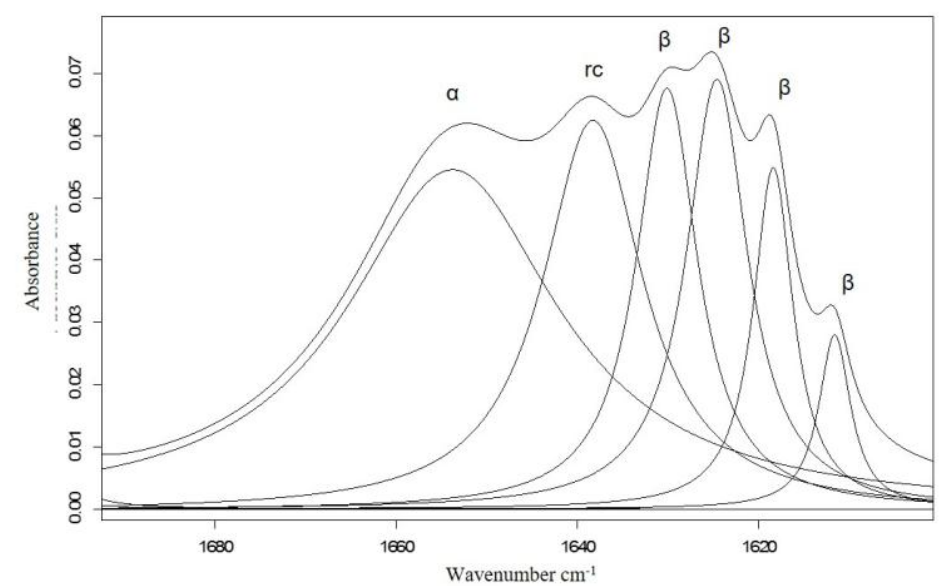

Figure 10.1.3.1.20. Amide I curve fitting of EO@Cd specimen with fitted band components. Assignment of bands conformations: $\beta$-sheet $(\beta)$, random coil (rc) and $\alpha$-helix $(\alpha)$.

NLs and PLs

The hydrolysis of triglyceride was confirmed in EO@Cd by the appearance of several shoulders in the range of $1736-1710 \mathrm{~cm}^{-1}$ ascribed to free fatty acids released as a result of the hydrolysis of oil and egg triglycerides. $\mathrm{I}_{\mathrm{FFA}} / \mathrm{I}_{\mathrm{E}}$ ratio confirms the hydrolysis of triglycerides present in NLs promoted by the pigment (see Table 10.1.3.1.5).

A downshift indicative of PLs-metal interactions of phosphate groups, deriving from protein phosphodiester was observed in the bands associated to the $\mathrm{v}_{\mathrm{s}} \mathrm{P}-\mathrm{O}-\mathrm{C}$ terminal phosphate phosphate and $v_{\mathrm{S}} \mathrm{PO}_{2}^{-}$. 
10.1.3.2. Characterization of the inoculated egg tempera and egg oil emulsion reconstructed model paint specimens

As a prior step, presence of unremoved rests of biological materials in the surface of the reconstructed model paint film specimens (fungi or bacteria biomass consisting of spores, endospores, vegetative or degraded cell walls, mycelia, conidia, etc.), which could interfere the identification of alteration processes occurring in the binding media or pigment was checked from the IR spectra obtained from samples excised in the inoculated paint specimens. IR spectra obtained in pure fungal materials in the high spatial frequency region are dominated by bands originated from the stretching vibrations of $-\mathrm{OH}$ and $-\mathrm{NH}$ groups of proteins and the stretching vibrations of methyl and methylene groups of lipids (Marey et al., 2001; Zotti et al., 2011). In the fingerprint region $\left(1800-500 \mathrm{~cm}^{-1}\right)$ the IR spectra are dominated by the strong carbohydrate band, the amide I and amide II. Moderate band at 1450 $\mathrm{cm}^{-1}$ ascribed to the asymmetric bending of $\mathrm{CH}_{3}$ groups in proteins is also observed together with moderate-weak bands at 1237 and $1082 \mathrm{~cm}^{-1}$ associated with stretching vibrations of $\mathrm{PO}_{2}^{-}$group of phospholipids (Bombalska et al., 2011). Characteristic band at $1600 \mathrm{~cm}^{-1}$ is sometimes recognized, which is associated with low-molecular-weight organic compounds due to fungal metabolites and decomposition of cell walls of dead fungi (Zotti et al., 2011). Nevertheless, strong band at $1064 \mathrm{~cm}^{-1}$ from carbohydrates is a satisfactory marker able to be used to detect the presence of the rest of fungal biomass deposited on the surface of the paint films. In the case of bacteria, the IR spectrum is dominated by bands of polysaccharides, protein, lipids and phospholipids. However, characteristic features at 1456 and $783 \mathrm{~cm}^{-1}$ of bacterial endospores associated to the pyridine-2,6-dicarboxylic (dipicolinic acid (DPA)) can be used for identifying the presence of rests of bacterial materials together with the polysaccharide bands (Bombalska et al., 2011, Goodacre et al., 2000).

Absence of the polysaccharides marker characteristic band at $1064 \mathrm{~cm}^{-1}$ for fungal material was observed in all the specimens inoculated with fungi, as well as the DPA marker characteristic band at $783 \mathrm{~cm}^{-1}$ indicative of bacterial material in the specimens inoculated with bacteria. The position of the characteristic bands of marker compounds of fungal and bacterial materials has been superimposed to denote the absence of biological material on the surface of the egg tempera and egg oil emulsion paint films (Figures 10.1.3.2.1.1, 10.1.3.2.1.4, 10.1.3.2.1.7, 10.1.3.2.1.10, 10.1.3.2.1.13, 10.1.3.2.1.16, 10.1.3.2.1.19, 10.1.3.2.1.22 for inoculated egg tempera specimens and 10.1.3.2.2.1, 10.1.3.2.2.4, 10.1.3.2.2.7, 10.1.3.2.2.9, 10.1.3.2.2.12, 10.1.3.2.2.15, 10.1.3.2.2.18, 10.1.3.2.2.21 for inoculated egg oil emulsion specimens).

10.1.3.2.1 Egg tempera reconstructed model paint specimens

\section{Iron oxide red}

Fungi

The effect of the fungi species used in this study on the egg tempera reconstructed model paint specimens has resulted, in general, in slight changes in the previously described IR 
bands for EG@Fe. The more remarkable changes have been observed in the $1800-500 \mathrm{~cm}^{-1}$ region (see Figure 10.1.3.2.1.1). Deconvolution and curve fitting methods applied on the amide I band for all the reconstructed model paint specimens inoculated with fungi was perform in order to quantify the protein secondary structure components (Figure 10.1.3.2.1.2). An important increase of the intramolecular $\beta$-sheet conformation was observed in all the specimens, as well as, an increase of the $\alpha$-helix with a corresponding decrease of the random coil conformation. A red shift of the amide I band maxima was observed in all the specimens inoculated with fungi, in agreement with the increase in the intramolecular $\beta$-sheet conformation observed after deconvolution. The most significant increment in the intramolecular $\beta$-sheet conformation was observed in the specimen inoculated with Acremonium chrysogenum. Table 10.1.3.2.1.1, summarizes the calculated percent area contribution of the conformations, for the EG@Fe reconstructed model paint specimens inoculated with fungi. Increase of the intramolecular $\beta$-sheet conformation has been associated to the partial disruption in protein-protein intermolecular interaction, probably promoted by the action of the fungi.

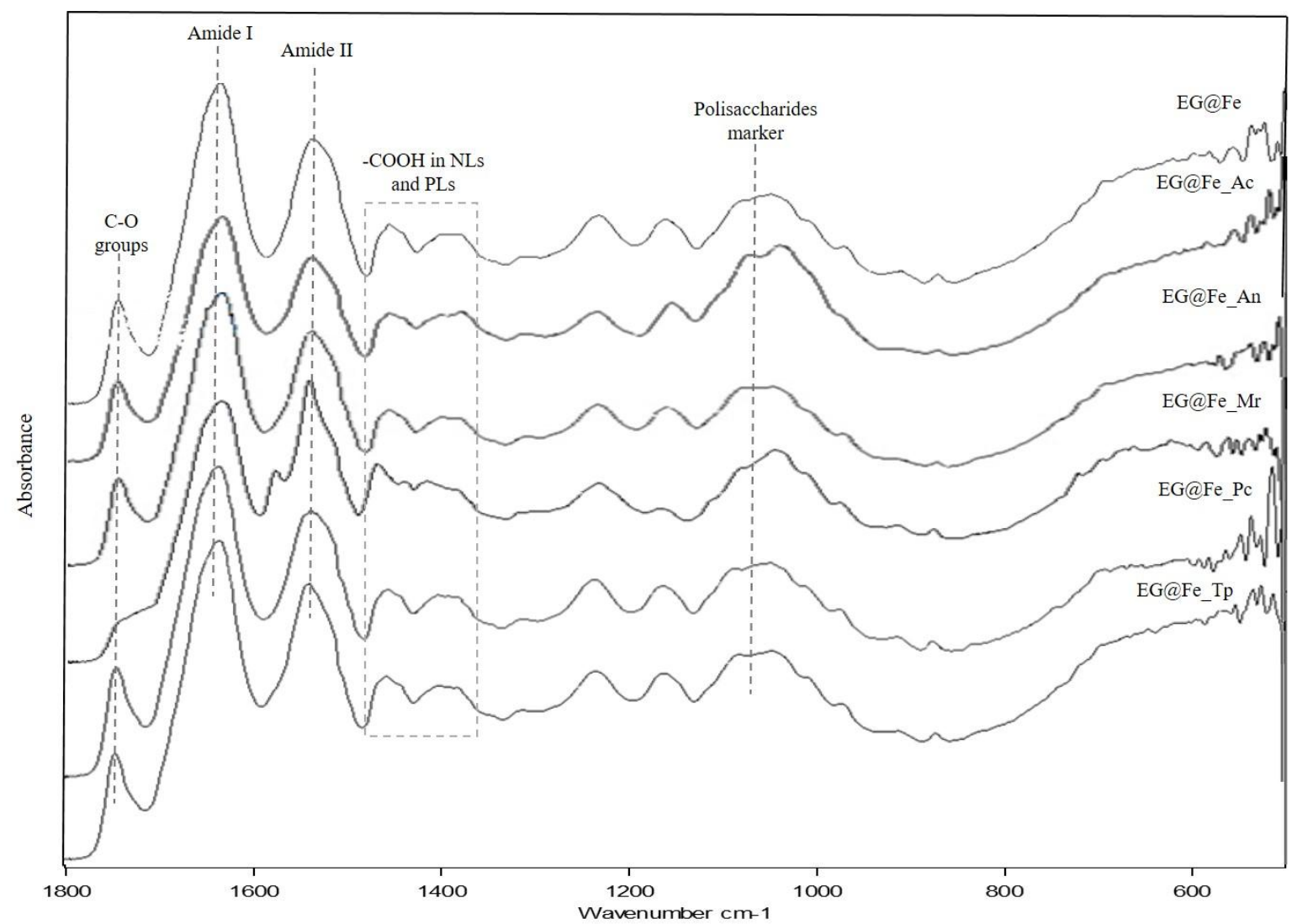

Figure 10.1.3.2.1.1. Detail of the $1800-500 \mathrm{~cm}^{-1}$ IR region and position of the bands characteristic and marker compounds fungal materials for the EG@Fe uninoculated and inoculated specimens.

$\mathrm{I}_{\mathrm{AII}} / \mathrm{I}_{\mathrm{AI}}$ ratio (Table 10.1.3.2.1.2) was calculated for the series of specimens studied, values higher than 1 should account for a contribution belonging to the presence of metal carboxylate (Mazzeo et al., 2008). Values higher than 1 were obtained for most of the specimens inoculated with fungi, these results suggest that microorganisms are promoting the hydrolysis of triglycerides, which subsequently could result in the formation of metal 
carboxylate in pigments able to undergo complexation. Conversely, a decrease in the $\mathrm{I}_{\mathrm{AII}} / \mathrm{I}_{\mathrm{AI}}$ ratio value is correlated with the formation of high molecular protein aggregates. A significant decrease in the intensity of the amide II/amide ratio after inoculation was observed for the EG@Fe_An and EG@Fe_Mr specimens, these changes demonstrating the formation of aggregates of a high molecular weight probably promoted by the action of fungi.
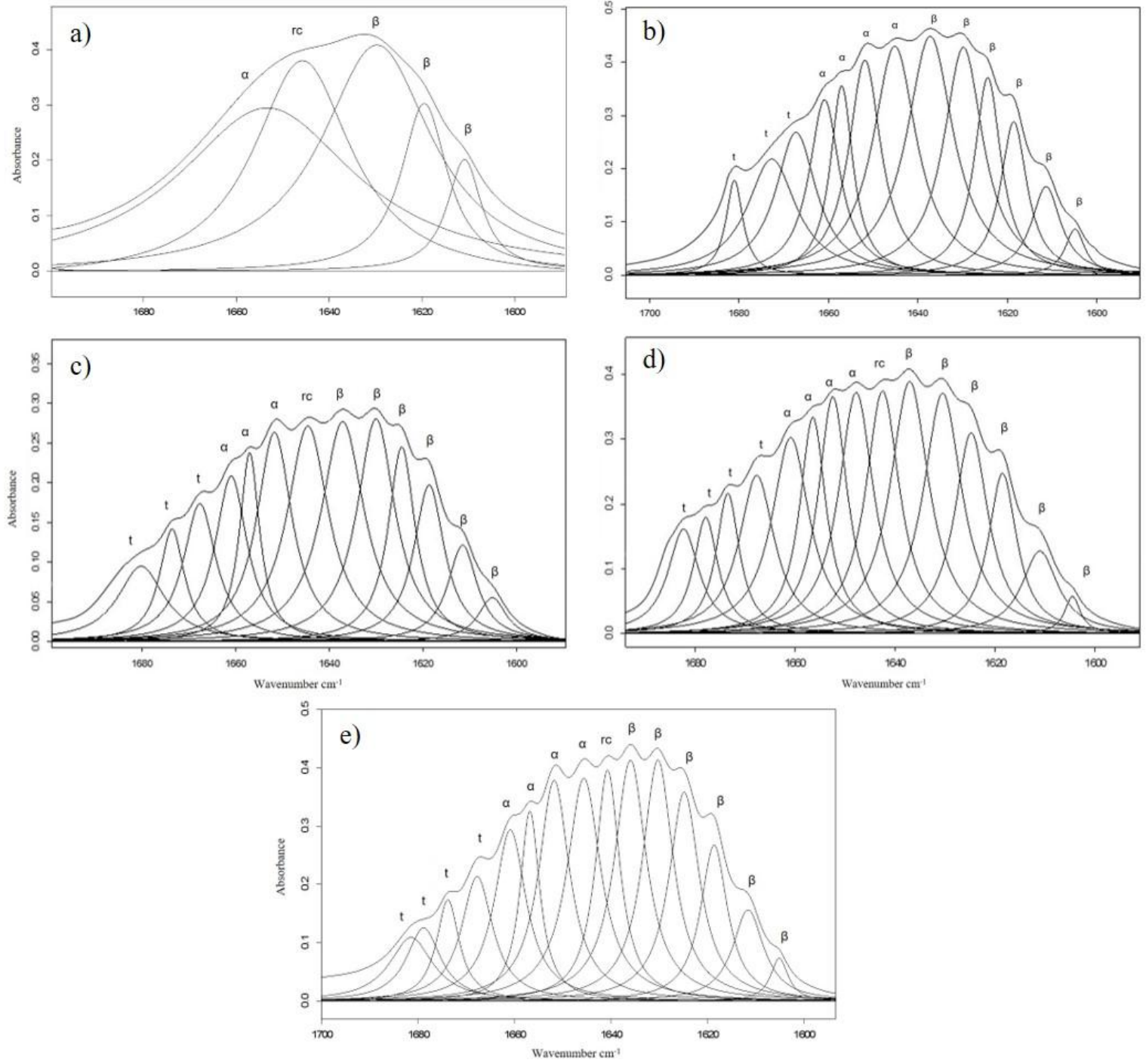

Figure 10.1.3.2.1.2. Amide I curve fitting band for EG@Fe inoculated specimens with: a) Acremonium chrysogenum, b) Aspergillus niger, c) Mucor rouxii, d) Penicillium chrysogenum, e) Trichoderma pseudokoningii fungi with fitted band components. Assignment of bands conformations: $\beta$-sheet $(\beta)$, random coil (rc), $\alpha$-helix $(\alpha)$ and turns (t). 
Table 10.1.3.2.1.1. Percent area contribution of amide I components for EG@Fe reconstructed model paint specimens uninoculated and inoculated with fungi.

\begin{tabular}{|c|c|c|c|c|c|c|}
\hline $\begin{array}{c}\text { Predominant } \\
\text { conformations }\end{array}$ & EG@Fe & EG@Fe_Ac & EG@Fe_An & EG@Fe_Mr & EG@Fe_Pc & EG@Fe_Tp \\
\hline $\begin{array}{c}\text { Intermolecular } \\
\beta \text {-sheet }\end{array}$ & 30 & 5 & 20 & 23 & 22 & 24 \\
\hline $\begin{array}{c}\text { Intramolecular } \\
\beta \text {-sheet }\end{array}$ & 10 & 33 & 30 & 29 & 25 & 22 \\
\hline Random coil & 2 & 6 & - & 13 & 8 & 5 \\
\hline$\alpha$-helix & 4 & 52 & 34 & 22 & 30 & 34 \\
\hline Turns & 54 & 5 & 13 & 13 & 15 & 14 \\
\hline
\end{tabular}

Table 10.1.3.2.1.2. $\mathrm{I}_{\mathrm{AII}} / \mathrm{I}_{\mathrm{AI}}$ and $\mathrm{I}_{\mathrm{FFA}} / \mathrm{I}_{\mathrm{E}}$ band ratios obtained for the iron oxide red egg tempera reconstructed model paint specimens uninoculated and inoculated with fungi.

\begin{tabular}{|c|c|c|}
\hline Specimen & $\mathbf{I}_{\mathbf{A I I}} / \mathbf{I}_{\mathbf{A I}}$ intensity ratio & $\mathbf{I}_{\mathbf{F F} A} / \mathbf{I}_{\mathbf{E}}$ ratio \\
\hline EG@Fe_B & 1.02 & 0.19 \\
\hline EG@Fe_Ac & 1.97 & 0.07 \\
\hline EG@Fe_An & 0.74 & 0.18 \\
\hline EG@Fe_Mr & 0.86 & 0.43 \\
\hline EG@Fe_Pc & 1.72 & 0.14 \\
\hline EG@Fe_Tp & 1.41 & 0.16 \\
\hline
\end{tabular}

FSD and curve fitting applied to the absorption bands attributed to the stretching vibrations of carbonyl groups (1800-1700 $\mathrm{cm}^{-1}$ ) allows the determination of the free fatty acids relative content (bands bellow $1709 \mathrm{~cm}^{-1}$ ) released from NLs and PLs in all the IR spectra obtained for the specimen inoculated with fungi (Table 10.1.3.2.1.2). Increase in the relative content of fatty acids if compared to the uninoculated specimen suggests that fungi are promoting the hydrolysis of the triglycerides present in NLs and PLs. The major FFA increase was observed in the paint film inoculated with Mucor rouxii (Figure 10.1.3.2.1.3). The presence of a shoulder at around $1557 \mathrm{~cm}^{-1}$ associated to carboxylate metal complexes (that results in the increase in the peak area of the overlapping AII band and the concomitant increase in the $\mathrm{I}_{\mathrm{AII}} / \mathrm{I}_{\mathrm{AI}}$ value) confirms the interactions between free fatty acids from NLs and PLs and carboxylate residues in proteins and the Fe-centers in the pigment produced by the action of the fungi. This increase is coherently accompanied of a reduction in the $\mathrm{I}_{\mathrm{FFA}} / \mathrm{I}_{\mathrm{E}}$ ratios for EG@Fe_Ac,EG@Fe_Pc and EG@Fe_Tp specimens. It should be noted that this reduction in the $\mathrm{I}_{\mathrm{FFA}} / \mathrm{I}_{\mathrm{E}}$ value could be also due to the enzymatic oxidation of the hydrolyzed long-chain fatty acids to form free fatty acid peroxides and then other volatile end-products, which is also favored by fungi (Kinderlerer, 1993; 1994). Thus, the lowest $\mathrm{I}_{\mathrm{FFA}} / \mathrm{I}_{\mathrm{E}}$ and highest $\mathrm{I}_{\mathrm{AII}} / \mathrm{I}_{\mathrm{AI}}$ values reported for the EG@Fe_Ac specimen are suggesting that this microorganism could be especially active in both metal complexation and enzymatic transformation of the released free fatty acids. In contrast, higher values of $\mathrm{I}_{\mathrm{FFA}} / \mathrm{I}_{\mathrm{E}}$ over that reported for the blank specimen found for $\mathrm{EG} @ \mathrm{Fe} \_\mathrm{Mr}$ (accompanied of a low $\mathrm{I}_{\mathrm{AII}} / \mathrm{I}_{\mathrm{AI}}$ value) suggests that the activity of this microorganisms is mainly resulting in the promotion of complexation reactions. 

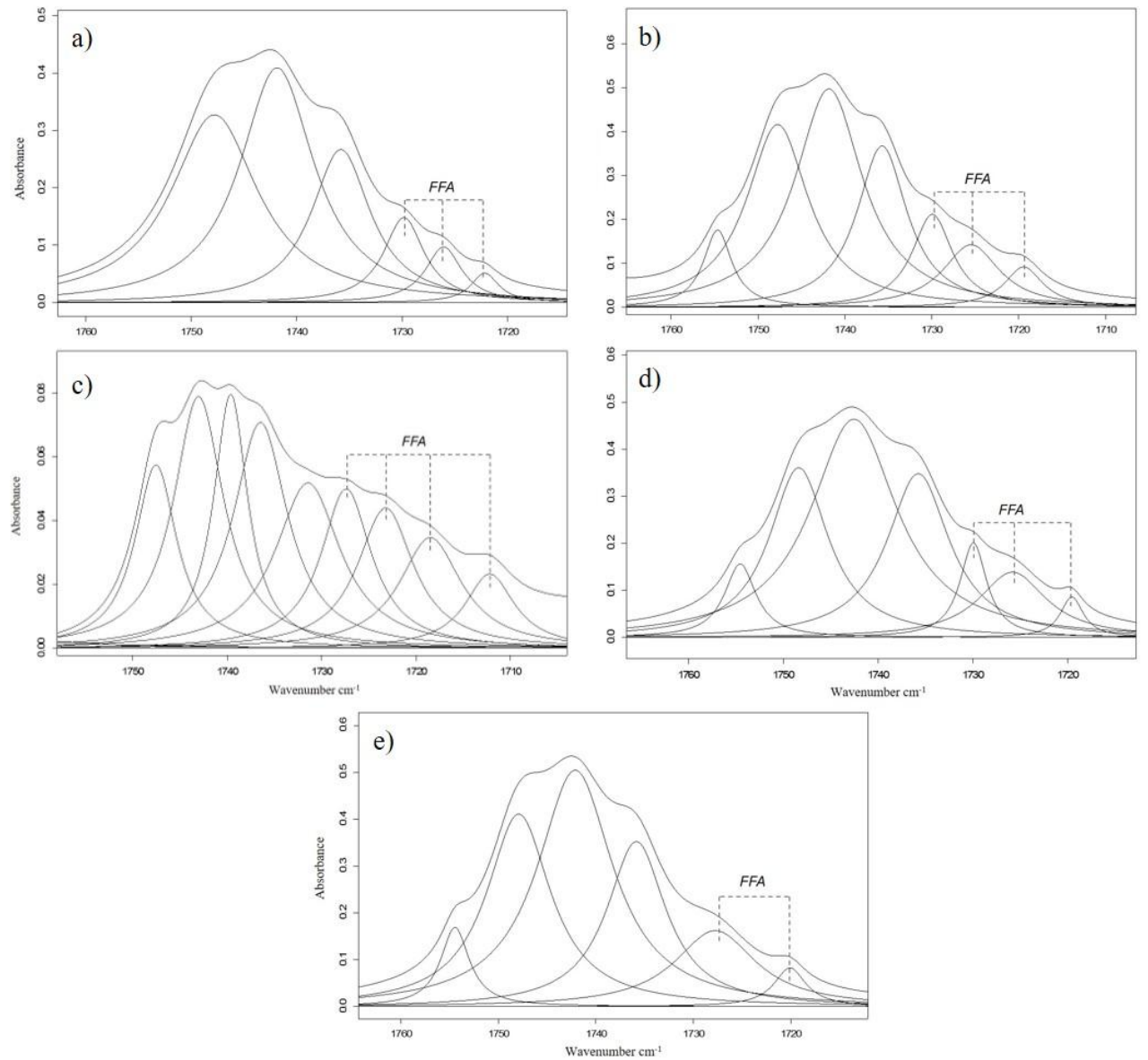

Figure 10.1.3.2.1.3. Carbonyl curve fitted band for EG@Fe inoculated specimen with: a) Acremonium chrysogenum, b) Aspergillus niger, c) Mucor rouxii, d) Penicillium chrysogenum, e) Trichoderma pseudokoningii fungi.

Increase of the band at $1040 \mathrm{~cm}^{-1}$ ascribed to P-OFe complexes was observed in the EG@Fe specimens inoculated with Acremonium chrysogenum and Mucor rouxii (Parikh and Chorover, 2006; Omoike et al., 2004) (Figure 10.1.3.2.1.4). 


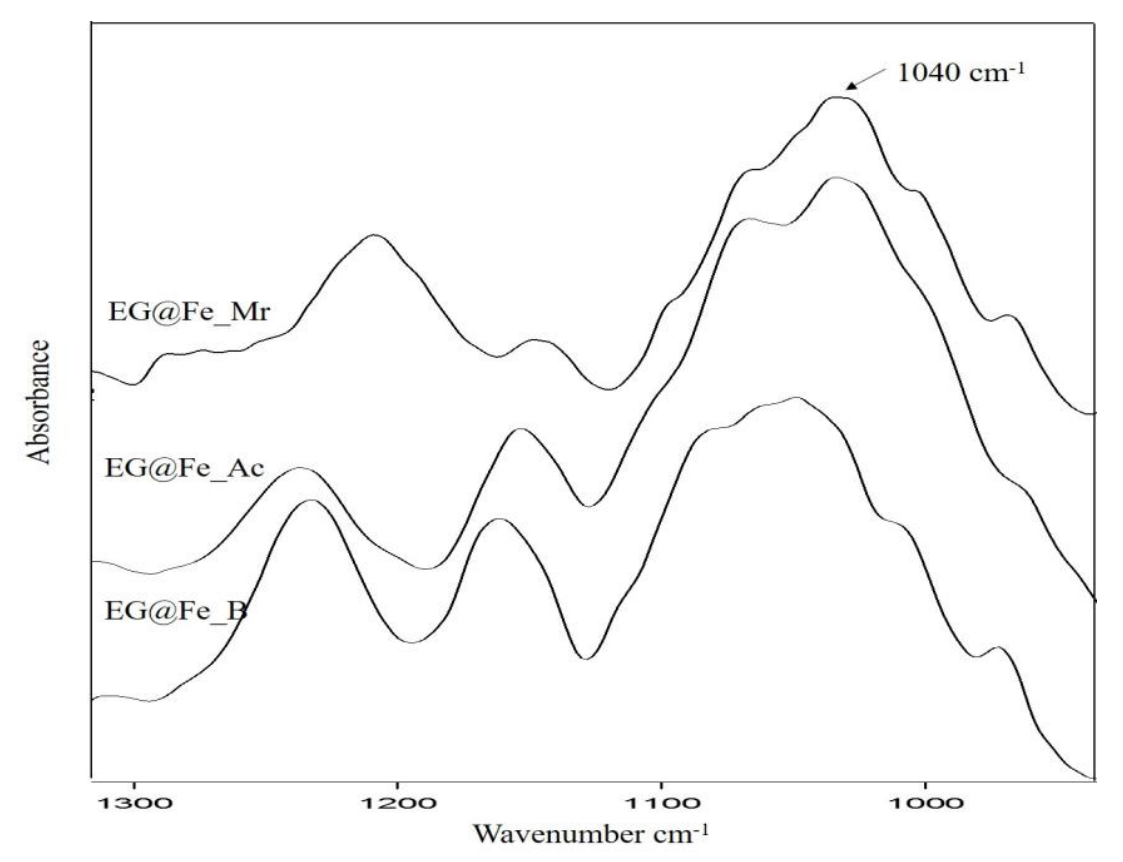

Figure 10.1.3.2.1.4. Detail of the $1040 \mathrm{~cm}^{-1}$ band absorbance in the IR spectra obtained for EG@Fe specimens inoculated with Acremonium chrysogenum (EG@Fe_Ac) and Mucor rouxii (EG@Fe_Mr) compared to the uninoculated specimen (EG@Fe_B).

\section{Bacteria}

The IR spectra obtained for the reconstructed model paint specimens inoculated with bacteria, were dominated for the bands ascribed to the amide A, amide I, amide II, methyl/methylene and carbonyl groups characteristic of the binding medium. Figure 10.1.3.2.1.5, shows in detail the $1800-500 \mathrm{~cm}^{-1}$ region where the more significant changes are observed as well as the bacterial characteristic band of marker compounds to denote the absence of biomass in the specimens. 


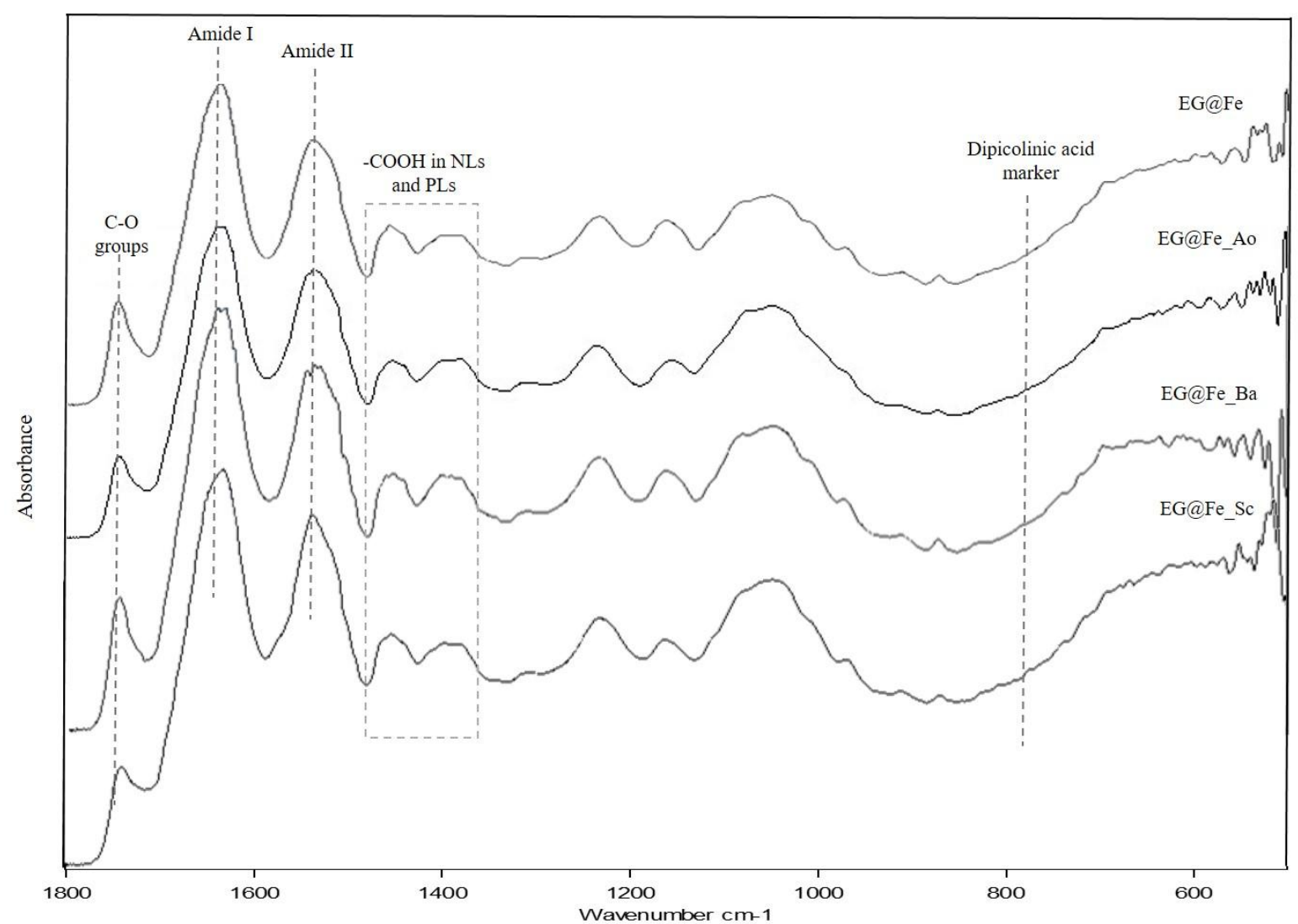

Figure 10.1.3.2.1.5. Detail of the $1800-500 \mathrm{~cm}^{-1}$ IR region and position of the bands characteristic and marker compounds bacterial materials for the EG@Fe uninoculated and inoculated specimens.

The IR spectra of the two EG@Fe specimens inoculated with the actinobacteria Streptomyces cellulofans and Arthrobacter oxydans exhibit similar behavior, both actinobacteria exhibit amide I maximum at $1630 \mathrm{~cm}^{-1}$ that evidence that intramolecular $\beta$-sheet is the prevalent conformation of this medium. Secondary maximum at $1652 \mathrm{~cm}^{-1}$, which is associated to the $\alpha$-helix, was also present in this IR spectrum. Redshift of the maximum of this band if compared to the EG@Fe_B specimen is associated to the increase of the helix length when the helix is exposed (Duce et al., 2013). The specimen inoculated with the eubacterium Bacillus amyloliquefaciens (EG@Fe_Ba) also exhibits an amide I maximum at $1630 \mathrm{~cm}^{-1}$, with a secondary maximum at $1655 \mathrm{~cm}^{-1}$. FSD and curve fitting of the amide I band confirms that $\beta$-sheet conformation was the prevalent conformation in all the specimens inoculated with bacteria (Figure 10.1.3.2.1.6). After quantification of the amide I sub-bands conformations contribution the most significant changes were observed in the EG@Fe_Ba andEG@Fe_Sc, with an important increase of the intramolecular conformation if compared to the EG@Fe_B specimen (Table 10.1.3.2.1.3). The increase of this conformation was accompanied with a decrease in the intermolecular $\beta$-sheet and random coil conformations in the EG@Fe_Ba specimen. In contrast, no changes in the intramolecular $\beta$-sheet contribution were observed in the EG@Fe_Ao specimen. These results suggest that the Bacillus amyloliquefaciens and Streptomyces cellulofans are promoting the partial disruption of the protein-protein intermolecular interactions. In agreement with these results are the high $\mathrm{I}_{\mathrm{AII}} / \mathrm{I}_{\mathrm{AI}}$ ratio values (Table 10.1.3.2.1.4), among which the most important increase was obtained for the EG@Fe_Ba specimen. 

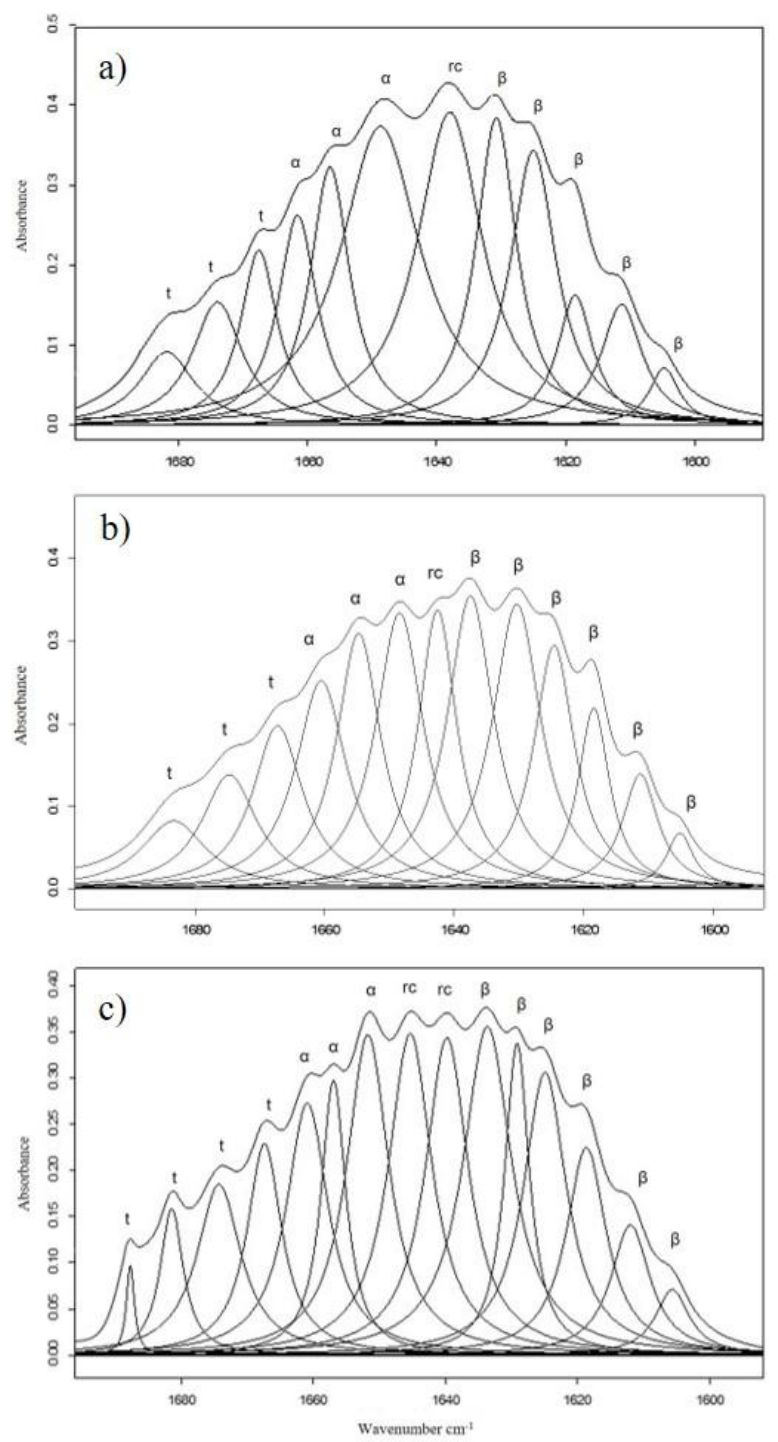

Figure 10.1.3.2.1.6. Amide I curve fitting band for EG@Fe inoculated specimens with: a) Arthrobacter oxydans, b) Bacillus amyloliquefaciens, c) Streptomyces cellulofans bacteria with fitted band components. Assignment of bands conformations: $\beta$-sheet $(\beta)$, random coil (rc), $\alpha$-helix $(\alpha)$ and turns ( $\mathrm{t})$.

Table 10.1.3.2.1.3. Percent area contribution of amide I components for EG@Fe reconstructed model paint specimens uninoculated and inoculated with bacteria.

\begin{tabular}{|c|c|c|c|c|}
\hline $\begin{array}{c}\text { Predominant } \\
\text { conformations }\end{array}$ & EG@Fe & EG@Fe_Ao & EG@Fe_Ba & EG@Fe_Sc \\
\hline Intermolecular $\beta$-sheet & 30 & 23 & 21 & 26 \\
\hline Intramolecular $\beta$-sheet & 10 & 8 & 25 & 17 \\
\hline Random coil & 2 & 19 & 6 & 20 \\
\hline$\alpha$-helix & 4 & 36 & 29 & 24 \\
\hline Turns & 54 & 14 & 18 & 13 \\
\hline
\end{tabular}


In agreement with the changes observed in the amide I and amide II region, are the changes observed in the carbonyl region associated to the stretching vibrations of carbonyl groups in NLs and PLs. Figure 10.1.3.2.1.7, shows the curve fitting band of the EG@Fe specimens inoculated with bacteria with the fitted band components. Increase in the relative contribution of the carbonyl groups from free fatty acids is more evident in the paint films inoculated with Bacillus amyloliquefaciens and Streptomyces cellulofans. On the other hand, all the specimens exhibit a new weak shoulder at $1557 \mathrm{~cm}^{-1}$ assigned to the asymmetric stretch of $\mathrm{CO}_{2}{ }^{-}$group in carboxylate metal complexes, but only the EG@Fe_Ba and EG@Fe_Sc specimens exhibit band at $1575 \mathrm{~cm}^{-1}$ (Figure 10.1.3.2.1.8). This band is associated to the stretching vibrations of metal-carboxylate groups formed from free fatty acids and carboxylate residues from proteins, and was more evident in the actinobacterium Streptomyces cellulofans inoculated paint film specimen, which also exhibited the major increase in the relative content of free fatty acids. These results confirm that bacteria are dramatically promoting the hydrolysis of triglycerides from NLs and PLs.

In addition, EG@Fe_Ba and EG@Fe_Sc shows an increase in the intensity of the bands at around $970 \mathrm{~cm}^{-1}$ associated to the stretching vibrations of $\mathrm{P}-\mathrm{O}-\mathrm{X},(\mathrm{X}=\mathrm{Fe})$ which confirms the interactions between the polar phosphate and the pigment surface, due to the action of the microorganisms.

Comparison of the $\mathrm{I}_{\mathrm{AII}} / \mathrm{I}_{\mathrm{AI}}$ and $\mathrm{I}_{\mathrm{FFA}} / \mathrm{I}_{\mathrm{E}}$ ratios of the inoculated specimens and blank indicates that microorganisms in EG@Fe_Ao and EG@Fe_Ba were active in promoting enzymatic transformation resulting in volatile end-products and metal complexation whereas in EG@Fe_Sc microorganism exhibited mainly hydrolyzing activity. 

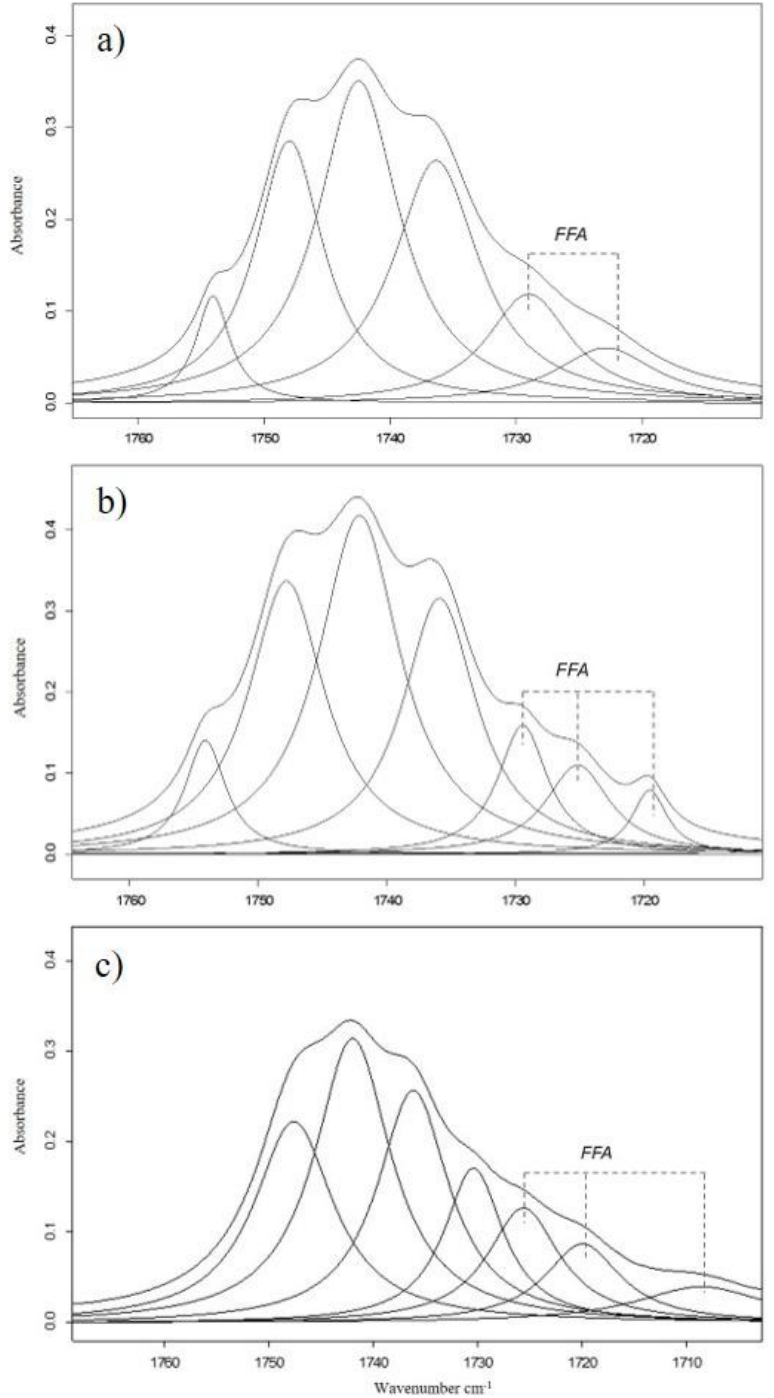

Figure 10.1.3.2.1.7. Carbonyl curve fitted band for EG@Fe inoculated specimen with: a) Arthrobacter oxydans, b) Bacillus amyloliquefaciens, c) Streptomyces cellulofans bacteria. 


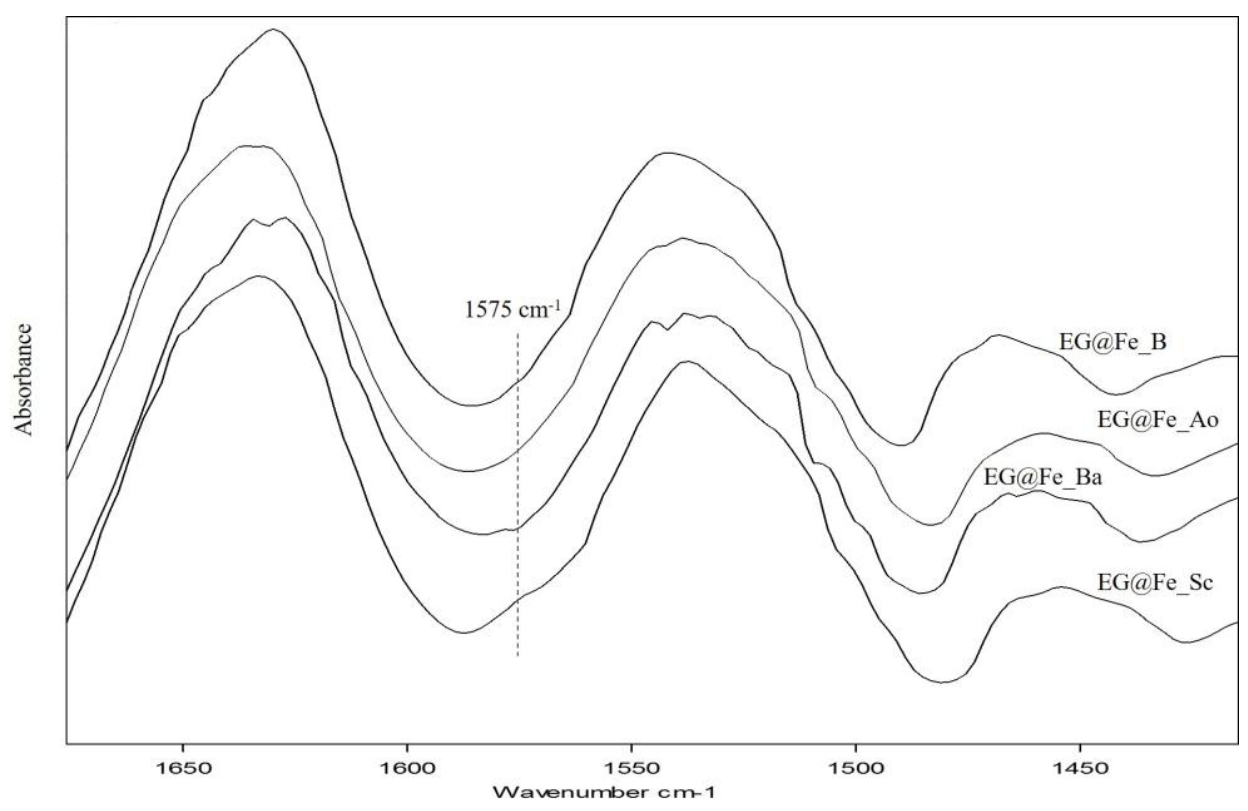

Figure 10.1.3.2.1.8. Detail of the $1700-1400 \mathrm{~cm}^{-1}$ IR region and position of the band at $1575 \mathrm{~cm}^{-1}$ associated to the stretching vibrations of metal-carboxylate groups formed from free fatty acids and carboxylate residues from proteins in the egg tempera paint films specimens inoculated with bacteria.

Table 10.1.3.2.1.4. $\mathrm{I}_{\mathrm{AII}} / \mathrm{I}_{\mathrm{AI}}$ and $\mathrm{I}_{\mathrm{FFA}} / \mathrm{I}_{\mathrm{E}}$ band ratios obtained for the iron oxide red egg tempera reconstructed model paint specimens uninoculated and inoculated with bacteria.

\begin{tabular}{|c|c|c|}
\hline Specimen & $\mathbf{I}_{\mathrm{AII}} / \mathbf{I}_{\mathbf{A I}}$ intensity ratio & $\mathbf{I}_{\mathbf{F F A}} / \mathbf{I}_{\mathbf{E}}$ ratio \\
\hline EG@Fe_B & 1.02 & 0.19 \\
\hline EG@Fe_Ao & 0.27 & 0.18 \\
\hline EG@Fe_Ba & 1.22 & 0.15 \\
\hline EG@Fe_Sc & 0.46 & 0.26 \\
\hline
\end{tabular}

\section{Verdigris}

\section{Fungi}

The effect of microorganism on the paint films has resulted, in general, in slight changes in the previously described IR bands for egg tempera associated to the amide I, amide II and carbonyl groups. Figure 10.1.3.2.1.9, shows a detail of the $1800-500 \mathrm{~cm}^{-1}$ region in the IR spectra where more remarkable changes have been observed for the egg tempera paint film specimens inoculated with fungi. No significant changes were observed for the band assigned to amide A $\left(3278 \mathrm{~cm}^{-1}\right)$, and the amide $\mathrm{B}\left(3069 \mathrm{~cm}^{-1}\right)$. In addition, the position of the characteristic bands of marker compounds of fungal materials has been superimposed to denote the absence of fungal biomass deposited on the surface of inoculated reconstructed paint films specimens. 


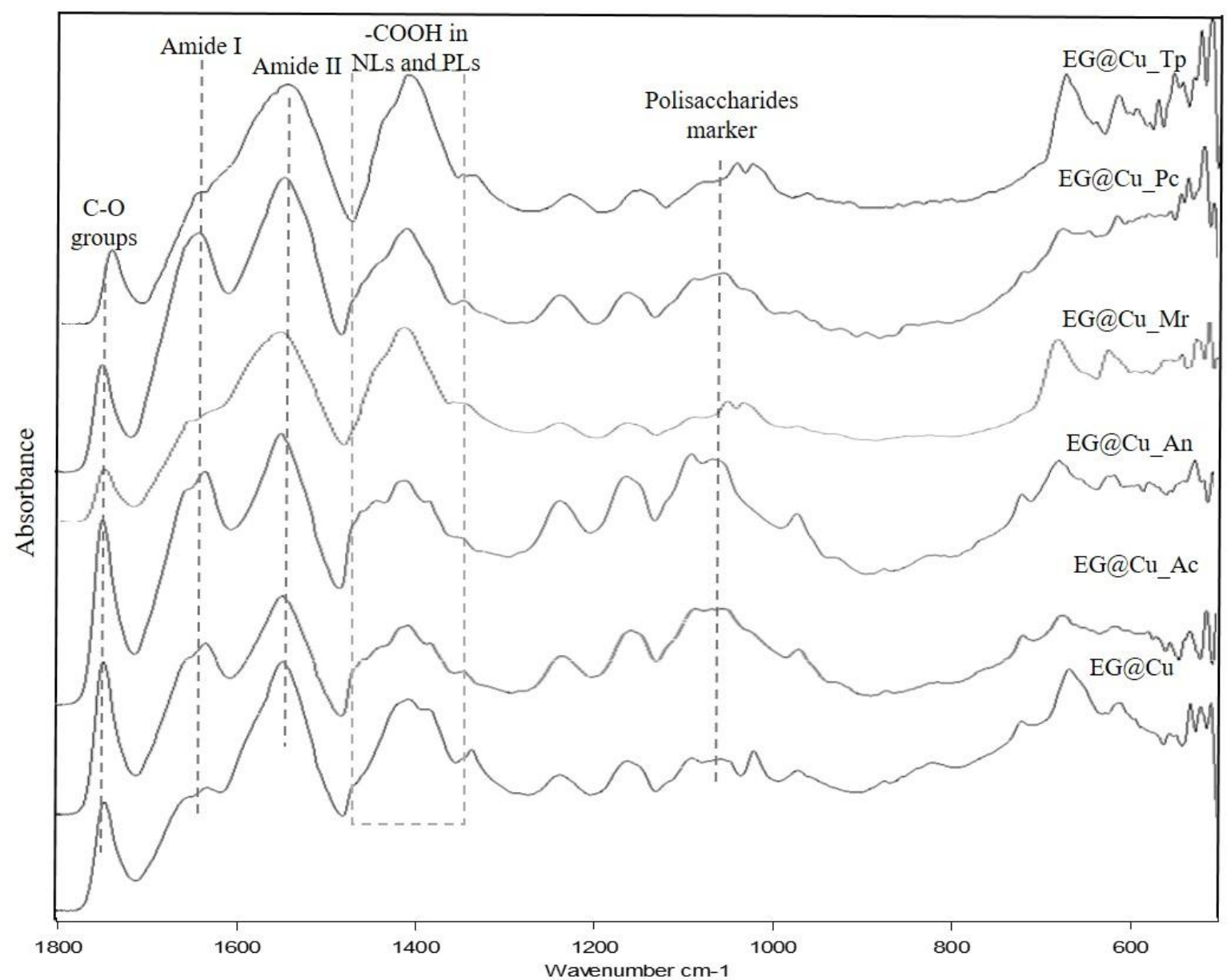

Figure 10.1.3.2.1.9. Detail of the $1800-500 \mathrm{~cm}^{-1}$ IR region and position of the bands characteristic and marker compounds fungal materials for the EG@Cu uninoculated and inoculated specimens.

In contrast with the EG@Fe specimens inoculated with fungi, which exhibit an increment on the intramolecular $\beta$-sheet conformation, the EG@ $\mathrm{Cu}$ inoculated specimens shows an increment in the random coil conformation contribution with the consequent decrease of the $\alpha$-helix conformation contribution (Figure 10.1.3.2.1.10). This behavior may be attributed to an extended helix which bent into coiled coils promoted by the action of the fungi to the binding medium. The most remarkable increment in the relative content of random coil conformation if compared to the EG@Cu_B specimen was observed in the specimens inoculated with Penicillium chrysogenum and Trichoderma pseudokoningii. These changes could be associated to the formation of more open structures that favors the interaction of the functional groups located in the side chains. The specimen inoculated with Aspergillus niger showed an opposite behavior, with no random coil conformation contribution and an increment of the $\beta$-sheet conformations contribution. Table 10.1.3.2.1.5, summarizes the calculated percent area contribution of the amide I components conformation for the $\mathrm{EG} @ \mathrm{Cu}$ reconstructed model paint specimens inoculated with fungi compared to the uninoculated specimen. In addition to the increment of random coil conformation observed in almost all the specimens inoculated with fungi, the EG@Cu_Mr shows an important decrease of the $\alpha$ helix conformation with a consequent increase of the turns conformation, which suggests that the microorganisms lead to the formation of more rigid cross-linked structures. 

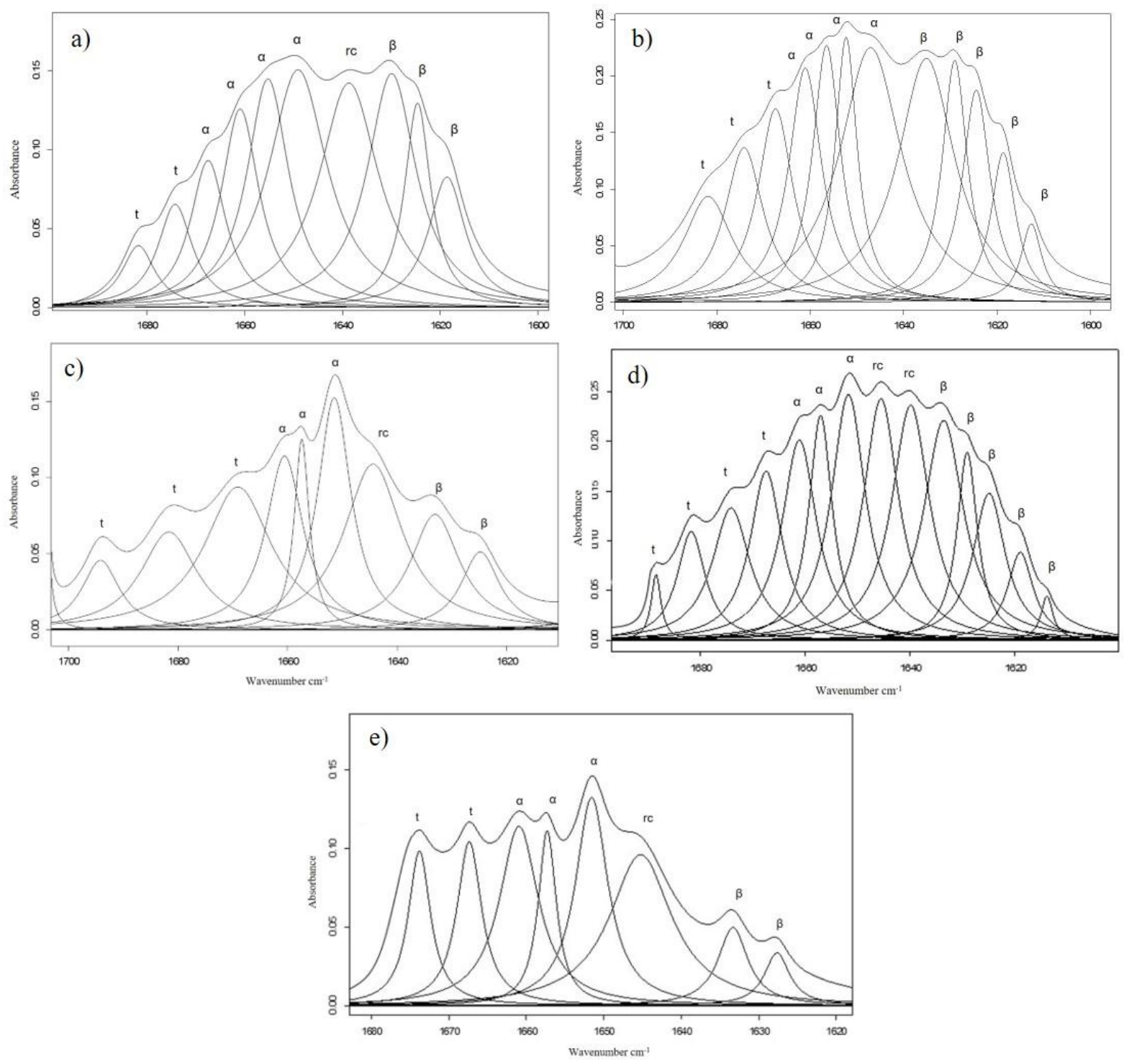

Figure 10.1.3.2.1.10. Amide curve fitting band for EG@Cu inoculated specimens with: a) Acremonium chrysogenum, b) Aspergillus niger, c) Mucor rouxii, d) Penicillium chrysogenum, e) Trichoderma pseudokoningii fungi with fitted band components. Assignment of bands conformations: $\beta$-sheet $(\beta)$, random coil (rc), $\alpha$-helix $(\alpha)$ and turns (t).

Notably, Acremonium chrysogenum fungus presented the highest value for the $\mathrm{I}_{\mathrm{AII}} / \mathrm{I}_{\mathrm{AI}}$ ratio among the specimens inoculated with fungus (Figure 10.1.3.2.1.10c) with a prominent maximum of the amide I band at $1628 \mathrm{~cm}^{-1}$ that evidences that $\beta$-sheet is the prevalent confirmation in this medium. Dominance of $\beta$-sheet conformation is in good correspondence with the scarce formation of $\mathrm{Cu}$-carboxylate complexes (absence of shoulder in the amide II band at $1585 \mathrm{~cm}^{-1}$ ). IR spectra obtained in the egg tempera specimens inoculated with Aspergillus niger, Mucor rouxii and Trychoderma pseudokoningii showed lower value for the $\mathrm{I}_{\mathrm{AII}} / \mathrm{I}_{\mathrm{AI}}$ intensity ratio (Table 10.1.3.2.1.4). In addition, the amide I band exhibited a decrease of the relative intensity of $\beta$-sheet to $\alpha$-helix sub-bands. In the IR spectra of the EG@Cu_Mr and EG@Cu_Tp specimens this change was accompanied by a splitting of the $\beta$-sheet subband in two overlapped components (plateau $1633-1620 \mathrm{~cm}^{-1}$ ) at $1633 \mathrm{~cm}^{-1}$ (intramolecular $\beta$-sheet) and $1620 \mathrm{~cm}^{-1}$ (intermolecular $\beta$-sheet). More appreciable shoulder of the amide II band at $1585 \mathrm{~cm}^{-1}$ was also observed for these paint films, which indicates that formation of 
$\mathrm{Cu}$-carboxylate complexes has taken place at significant extent promoted by an increase of the exposition of the protein chain to the external ionomeric layer (Figure 10.1.3.2.1.12). IR spectrum of the paint film inoculated with Penicillium chrysogenum showed an intermediate behavior characterized by the decrease of the relative intensity of the $\beta$-sheet to $\alpha$-helix subbands and a lesser blueshift of the maximum of the amide I band to $1633 \mathrm{~cm}^{-1}$. Shoulder at $1585 \mathrm{~cm}^{-1}$ in the amide II band was also less evident (Figure 10.1.3.2.1.12).

Table 10.1.3.2.1.4. Percent area contribution of amide I components for EG@Cu reconstructed model paint specimens uninoculated and inoculated with fungi.

\begin{tabular}{|c|c|c|c|c|c|c|}
\hline $\begin{array}{c}\text { Predominant } \\
\text { conformations }\end{array}$ & EG@Cu & EG@Cu_Ac & EG@Cu_An & EG@Cu_Mr & EG@Cu_Pc & EG@Cu_Tp \\
\hline $\begin{array}{c}\text { Intermolecular } \\
\beta \text {-sheet }\end{array}$ & 9 & 12 & 13 & 5 & 12 & - \\
\hline $\begin{array}{c}\text { Intramolecular } \\
\beta \text {-sheet }\end{array}$ & 18 & 17 & 23 & 11 & 17 & 12 \\
\hline Random coil & 8 & 18 & - & 19 & 23 & 34 \\
\hline$\alpha$-helix & 42 & 37 & 37 & 26 & 28 & 43 \\
\hline Turns & 23 & 16 & 28 & 39 & 19 & 11 \\
\hline
\end{tabular}

Table 10.1.3.2.1.5. $\mathrm{I}_{\mathrm{AII}} / \mathrm{I}_{\mathrm{AI}}$ and $\mathrm{I}_{\mathrm{FFA}} / \mathrm{I}_{\mathrm{E}}$ band ratios obtained for the verdigris egg tempera reconstructed model paint specimens uninoculated and inoculated with fungi.

\begin{tabular}{|c|c|c|}
\hline Specimen & $\mathbf{I}_{\mathrm{AII}} / \mathbf{I}_{\mathbf{A I}}$ intensity ratio & $\mathbf{I}_{\mathbf{F F}} / \mathbf{I}_{\mathbf{E}}$ ratio \\
\hline EG@Cu_B & 1.13 & 0.16 \\
\hline EG@Cu_Ac & 2.31 & 0.27 \\
\hline EG@Cu_An & 1.19 & 0.15 \\
\hline EG@Cu_Mr & 1.89 & 0.10 \\
\hline EG@Cu_Pc & 1.31 & 0.17 \\
\hline EG@Cu_Tp & 1.15 & 0.12 \\
\hline
\end{tabular}

Figure 10.1.3.2.1.11, shows the curve fitted band $\left(1800-1700 \mathrm{~cm}^{-1}\right)$ attributed to the stretching vibrations of carbonyl groups. Presence of free carboxylic acids from NLs and PLs were observed for all the specimens, being more evident in the EG@Cu_Ac (Table 10.1.3.2.1.5). Comparison of the $\mathrm{I}_{\mathrm{AII}} / \mathrm{I}_{\mathrm{AI}}$ and $\mathrm{I}_{\mathrm{FFA}} / \mathrm{I}_{\mathrm{E}}$ ratios of the inoculated specimens and blank indicates that microorganism in EG@ $\mathrm{Cu}_{-}$Ac promoted strongly hydrolysis and complexation, microorganisms in EG@Cu_An, EG@Cu_Mr and EG@Cu_Tp were especially active promoting both metal complexation and enzymatic transformation resulting in volatile end-products whereas microorganism in EG@ $\mathrm{Cu} P \mathrm{Pc}$ mainly promoted metalcomplexation. 

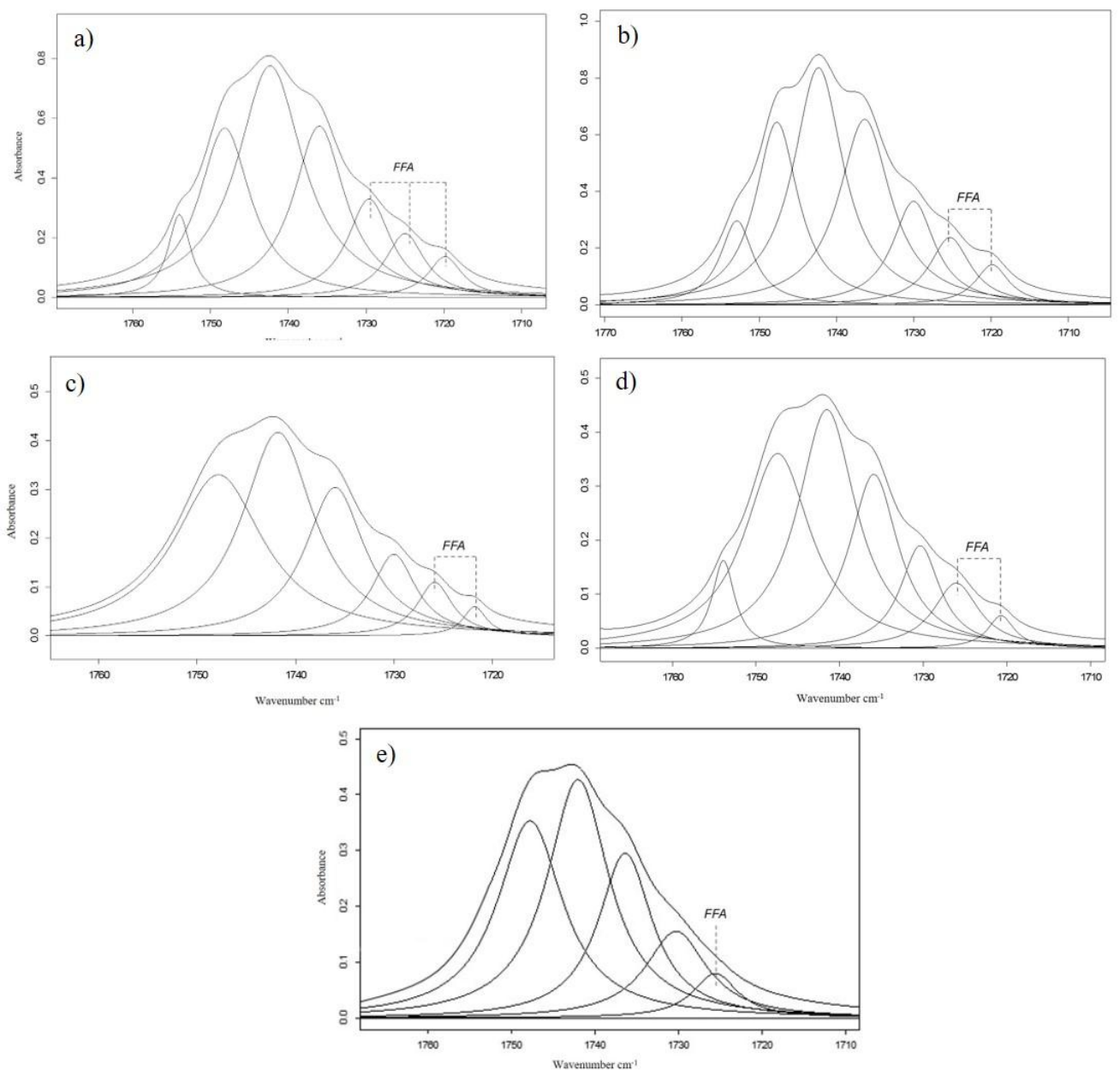

Figure 10.1.3.2.1.11. Carbonyl curve fitted band for EG@Cu inoculated specimen with: a) Acremonium chrysogenum, b) Aspergillus niger, c) Mucor rouxii, d) Penicillium chrysogenum, e) Trichoderma pseudokoningii fungi.

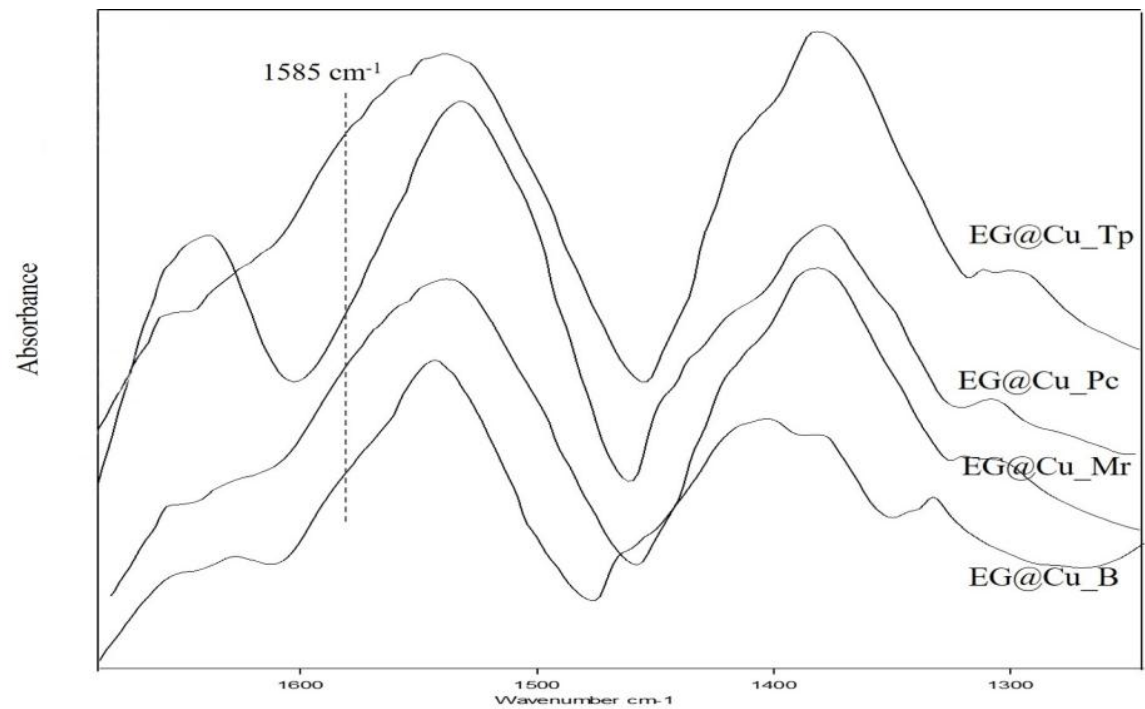

Figure 10.1.3.2.1.12. Detail of the $1700-1200 \mathrm{~cm}^{-1}$ IR region and position of the band at $1585 \mathrm{~cm}^{-1}$ associated to the stretching vibrations of $\mathrm{Cu}$-carboxylate complexes formed from free fatty acids and carboxylate residues from proteins in the egg tempera paint films specimens inoculated with Mucor rouxii (EG@Cu_Mr),Penicillium chrysogenum (EG@Cu_Pc) and Trichoderma pseudokoningii (EG@Cu_Tp) compared to the uninoculated specimen (EG@Cu_B). 


\section{Bacteria}

Figure 10.1.3.2.1.13, shows the $1800-500 \mathrm{~cm}^{-1}$ region where more significant changes are observed as well as the bacterial characteristic band of marker compounds to denote the absence of these compounds in the specimens.

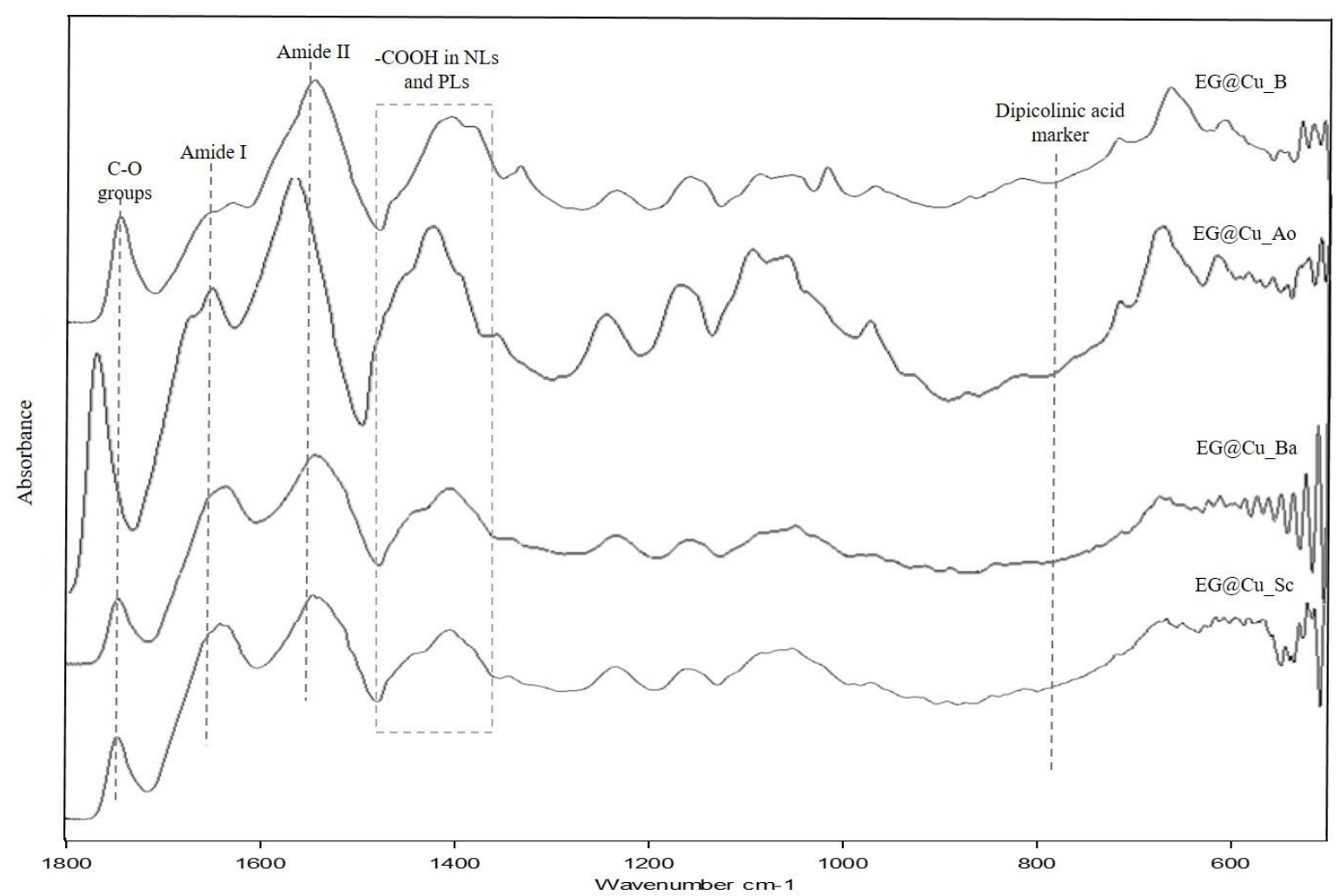

Figure 10.1.3.2.1.13. Detail of the $1800-500 \mathrm{~cm}^{-1}$ IR region and position of the bands characteristic and marker compounds bacterial materials for the EG@Fe uninoculated and inoculated specimens.

The EG@Cu of the two paint film specimens inoculated with the actinobacteria Streptomyces cellulofans and Arthrobacter oxydans exhibited similar behavior to the uninoculated specimen. In EG@Cu_Sc (Figure 10.1.3.2.1.14c), maximum of the amide I band was found at $1637 \mathrm{~cm}^{-1}$. This sub-band has been frequently associated to the more open random coil conformation. Secondary maxima at 1648 and $1628 \mathrm{~cm}^{-1}$, which are associated to $\alpha$-helix and $\beta$-sheet conformations, respectively, were also present in this IR spectrum. In contrast, $\beta$ sheet conformation was prevalent in EG@Cu_Ao and thus, this specimen exhibited slight increase in the relative intensity of the $\beta$-sheet to $\alpha$-helix sub-bands relative to the uninoculated film. In addition, absence of the random coil conformation contribution was observed after curve fitting (Table 10.1.3.2.1.6). A blueshift of the prevalent $\beta$-sheet subband to $1632 \mathrm{~cm}^{-1}$ together with a new secondary maximum at $1640 \mathrm{~cm}^{-1}$, ascribed to random coils, were the more remarkable features exhibited by the binding medium of the paint film inoculated with the eubacterium Bacillus amyloliquefaciens. The EG@Cu_Ba specimen exhibited the higher value of $\mathrm{I}_{\mathrm{AII}} / \mathrm{I}_{\mathrm{AI}}$ ratio (Table 10.1.3.2.1.7), which is in agreement with the decrease in the intramolecular $\beta$-sheet conformation observed due to changes in the metal- 
protein interactions promoted by the eubacterium. Comparison of the $\mathrm{I}_{\mathrm{AII}} / \mathrm{I}_{\mathrm{AI}}$ and $\mathrm{I}_{\mathrm{FFA}} / \mathrm{I}_{\mathrm{E}}$ ratios of the inoculated specimens and blank indicates that microorganism in EG@Cu_Ao and EG@Cu_Ba were especially active in deteriorating paint whereas microorganism in EG@Cu_Sc mainly promoted enzymatic transformation resulting en volatile end-products and metal-complexation.
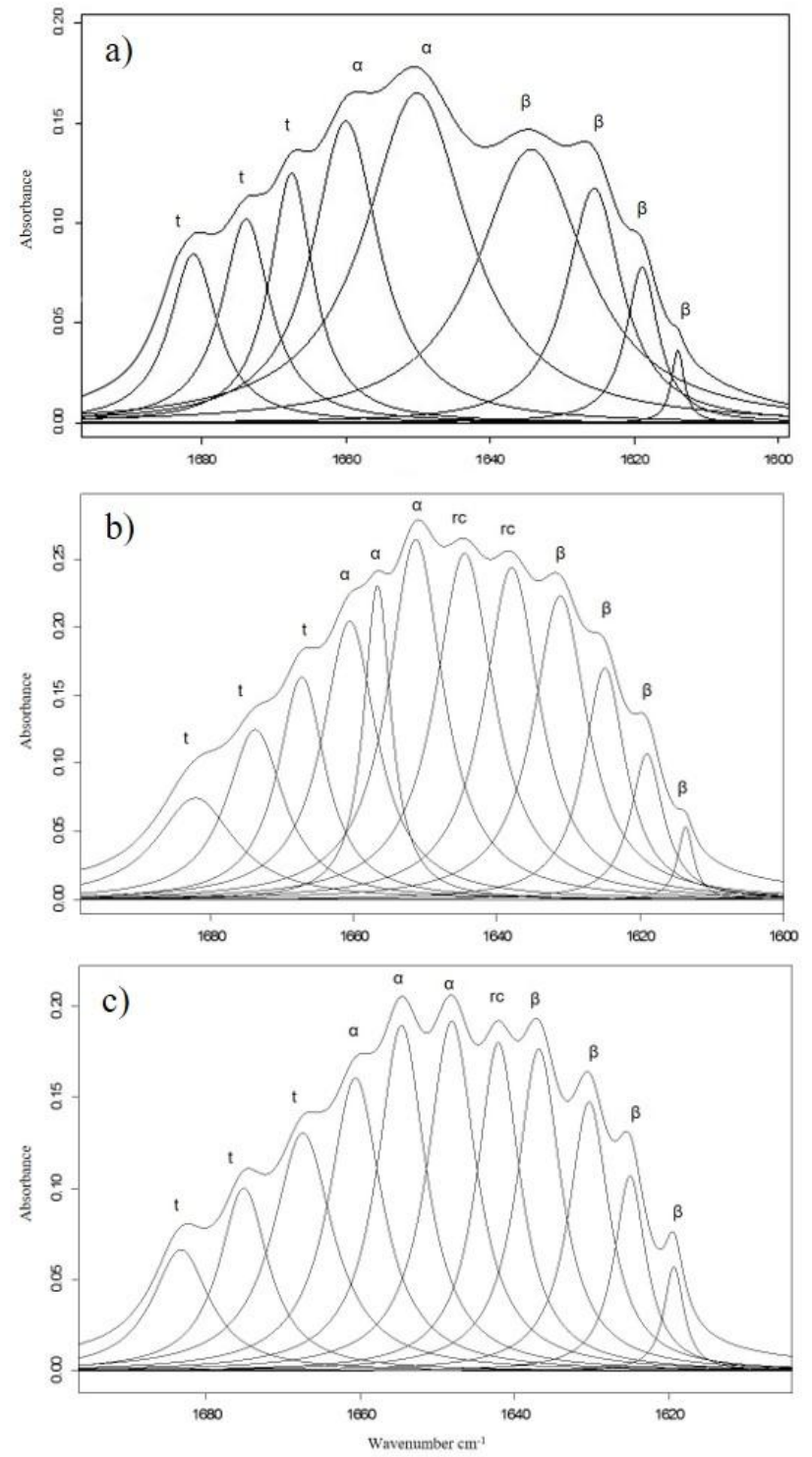

Figure 10.1.3.2.1.14. Amide I curve fitting band for EG@Cu inoculated specimens with: a) Arthrobacter oxydans, b) Bacillus amyloliquefaciens, c) Streptomyces cellulofans bacteria with fitted band components. Assignment of bands conformations: $\beta$-sheet $(\beta)$, random coil (rc), $\alpha$-helix $(\alpha)$ and turns $(\mathrm{t})$. 
Table 10.1.3.2.1.6. Percent area contribution of amide I components for EG@Cu reconstructed model paint specimens uninoculated and inoculated with bacteria.

\begin{tabular}{|c|c|c|c|c|}
\hline $\begin{array}{c}\text { Predominant } \\
\text { conformations }\end{array}$ & EG@Cu & EG@Cu_Ao & EG@Cu_Ba & EG@Cu_Sc \\
\hline $\begin{array}{c}\text { Intermolecular } \\
\beta \text {-sheet }\end{array}$ & 9 & 13 & 11 & 8 \\
\hline $\begin{array}{c}\text { Intramolecular } \\
\beta \text {-sheet }\end{array}$ & 18 & 27 & 13 & 21 \\
\hline Random coil & 8 & - & 25 & 9 \\
\hline$\alpha$-helix & 42 & 46 & 29 & 37 \\
\hline Turns & 23 & 14 & 22 & 25 \\
\hline
\end{tabular}

Table 10.1.3.2.1.7. $\mathrm{I}_{\mathrm{AII}} / \mathrm{I}_{\mathrm{AI}}$ and $\mathrm{I}_{\mathrm{FFA}} / \mathrm{I}_{\mathrm{E}}$ band ratios obtained for the verdigris egg tempera reconstructed model paint specimens uninoculated and inoculated with bacteria.

\begin{tabular}{|c|c|c|}
\hline Specimen & $\mathbf{I}_{\mathbf{A I I}} / \mathbf{I}_{\mathbf{A I}}$ intensity ratio & $\mathbf{I}_{\mathbf{F F A}} / \mathbf{I}_{\mathbf{E}}$ ratio \\
\hline EG@Cu_B & 1.13 & 0.16 \\
\hline EG@Cu_Ao & 1.35 & 0.07 \\
\hline EG@Cu_Ba & 1.80 & 0.07 \\
\hline EG@Cu_Sc & 0.80 & 0.06 \\
\hline
\end{tabular}

Figure 10.1.3.2.1.15, shows the curve fitting band of the EG@Cu specimens inoculated with bacteria with fitted band components for the carbonyl region associated to the stretching vibrations of metal-carboxylate groups. Increase in the fitted bands ascribed to carbonyl groups in free fatty acids is more evident in the paint film inoculated with the actinobacterium Streptomyces cellulofans. The three specimens inoculated with bacteria showed weak shoulder of $\mathrm{Cu}$-carboxylate complexed at $1585 \mathrm{~cm}^{-1}$. This band is associated to the stretching vibrations of metal-carboxylate complexes formed from free fatty acids and carboxylate residues from NLs and PLs, and was more evident in the actinobacterium Streptomyces cellulofans inoculated paint film specimen also exhibited high increase in the relative content of free fatty acids. These results confirm that bacteria are promoting the hydrolysis of triglycerides of NLs. All the specimens inoculated with bacteria exhibit lower $\mathrm{I}_{\mathrm{FFA}} / \mathrm{I}_{\mathrm{E}}$ ratio values if compared to the uninoculated specimen, this suggest that released free fatty acids become into metal-carboxylate complexes (Table 10.1.3.2.1.7). 

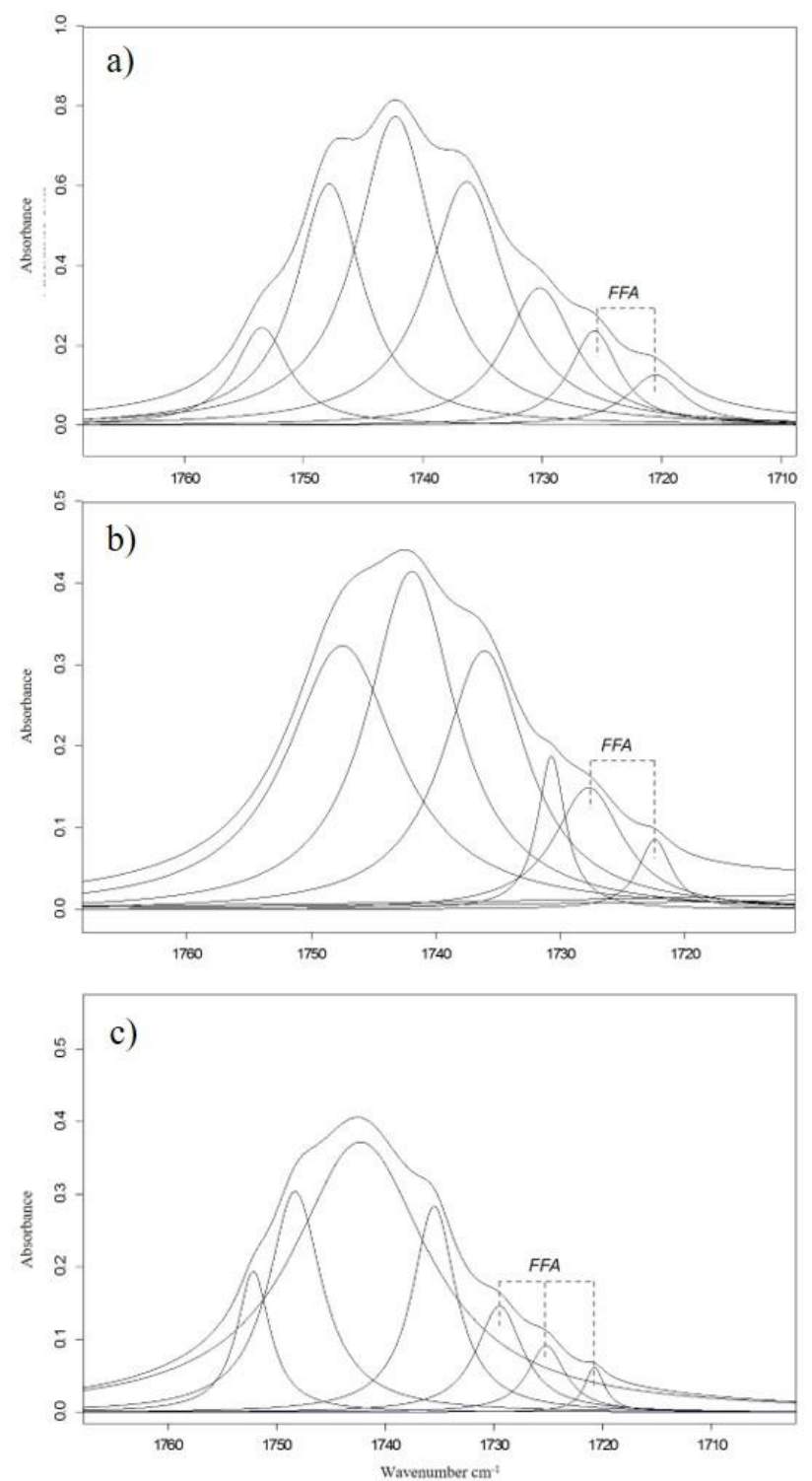

Figure 10.1.3.2.1.15. Carbonyl curve fitted band for EG@Cu inoculated specimen with: a) Arthrobacter oxydans, b) Bacillus amyloliquefaciens, c) Streptomyces cellulofans bacteria.

\section{Lead white}

\section{Fungi}

Figure 10.1.3.2.1.16, shows the $1800-500 \mathrm{~cm}^{-1}$ region in the IR spectra of EG@Pb specimens uninoculated and inoculated with fungi, where more significant changes were observed. As how was made for previous specimens, the position of the characteristic bands of the marker compounds of fungal materials has been placed over to signify the absence of these compounds in the specimens. 


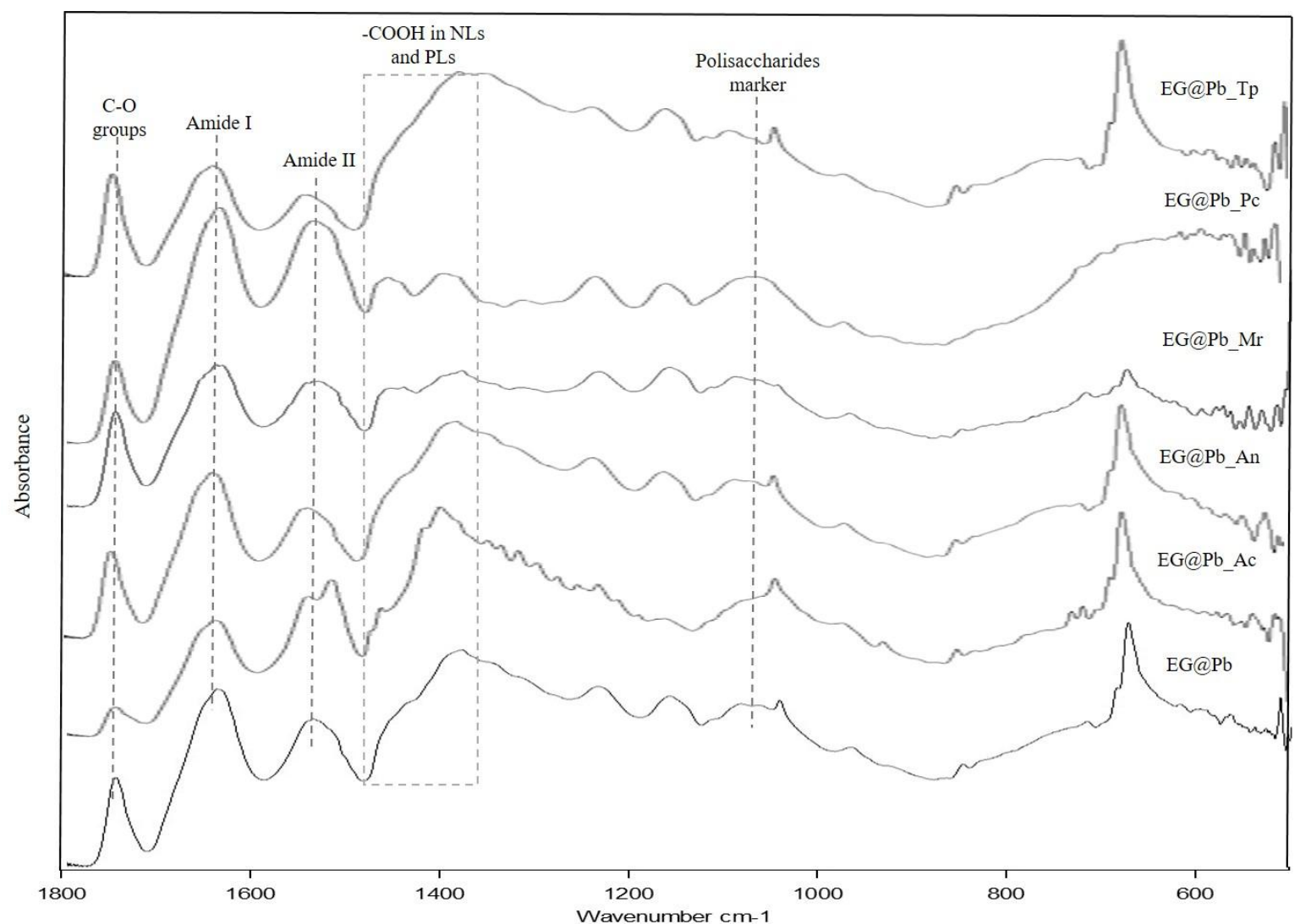

Figure 10.1.3.2.1.16. Detail of the $1800-500 \mathrm{~cm}^{-1} \mathrm{IR}$ region and position of the bands characteristic and marker compounds of fungal materials for the $\mathrm{EG} @ \mathrm{~Pb}$ uninoculated and inoculated specimens.

The amide I band occurring in the IR spectra of all the paint films inoculated with fungi and, in particular in those inoculated with Acremonium chrysogenum, Mucor rouxii and Trychoderma pseudokoningii fungi, exhibited a new sub-band at $1638 \mathrm{~cm}^{-1}$ that can be associated with the changes in the protein conformation related to the appearance of random coils conformation in the polypeptide chains (Figure 10.1.3.2.1.17). Splitting of the $\beta$-sheet sub-band in two overlapped components with maxima at $1625 \mathrm{~cm}^{-1}$ (intermolecular $\beta$-sheet) and $1630 \mathrm{~cm}^{-1}$ (intramolecular $\beta$-sheet) was observed. A blueshift of the $\alpha$-helix sub-band from 1651 to $1654 \mathrm{~cm}^{-1}$ took also place in the EG@Pb_Mr specimen (Figure 10.1.3.2.1.17c). These changes put in evidence the transformation of the polypeptide chains of the protein to more open structures that favors the interaction of the functional groups located in the side chains of the polypeptides with the external medium (Table 10.1.3.2.1.8). These changes are in agreement with the increase in the amide II/amide I intensity ratio observed in specimens inoculated with Acremonium chrysogenum, Mucor rouxii, Penicillium chrysogenum and Trichoderma pseudokoningii (Table 10.1.3.2.1.9). Concomitantly to the modification in the features of the amide I band, splitting of the amide II band in two sub-bands at 1540 and 1514 $\mathrm{cm}^{-1}$ was observed in the paint film inoculated with Acremonium chrysogenum (Figure 10.1.3.2.1.17). These changes are associated with the abundant formation of $\mathrm{Pb}$-carboxylate complexes from the released fatty acids from lipids and, especially, from acid residues of the protein chains, the latter promoted by the enhancement of the exposition of the protein chains in the ionomeric layer to the external medium rich in $\mathrm{Pb}$ (II) ions. This result is also consistent with the increase in the free fatty acids relative content as suggested by the appearance of 
overlapped bands at $1710-1700 \mathrm{~cm}^{-1}$ (Figure 10.1.3.2.1.18). FSD and curve fitting procedures allow the determination of the relative content of free fatty acids. The highest $\mathrm{I}_{\mathrm{FFA}} / \mathrm{I}_{\mathrm{E}}$ value obtained for the EG@Pb_Ac specimen confirms that Acremonium chrysogenum notably promotes the hydrolysis of the triglycerides present in the NLs and PLs (Table 10.1.3.2.1.9). The decrease observed in the $\mathrm{I}_{\mathrm{FFA}} / \mathrm{I}_{\mathrm{E}}$ values for the $\mathrm{EG} @ \mathrm{~Pb} \_\mathrm{An}, \mathrm{EG} @ \mathrm{~Pb} \mathrm{Mr}$, $\mathrm{EG} @ \mathrm{~Pb} \_\mathrm{Pc}$ and EG@Pb_Tp suggests that the released free fatty acids have formed metalcarboxylate complexes due to the complexation properties of lead white pigment. IR spectra of the paint films inoculated with Aspergillus niger and Penicillium chrysogenum exhibited profiles more similar to that of the uninoculated paint film and amide II band exhibited a weak shoulder at $1540 \mathrm{~cm}^{-1}$ in these paint films. That suggests that deteriorating activity of these two microorganisms on the binding medium has been less effective. Comparison of the $\mathrm{I}_{\mathrm{AII}} / \mathrm{I}_{\mathrm{AI}}$ and $\mathrm{I}_{\mathrm{FFA}} / \mathrm{I}_{\mathrm{E}}$ ratios of the inoculated specimens and blank indicates that microorganisms in EG@Pb_Mr, EG@Pb_Pc and EG@Pb_Tp were especially active promoting both metal complexation and enzymatic transformation resulting in volatile end-products whereas in EG@Pb_Ac microorganism mainly promoted hydrolysis followed by metal-complexation and EG@Pb_An promoted mainly enzymatic transformation of free fatty acids resulting in volatile end-products.
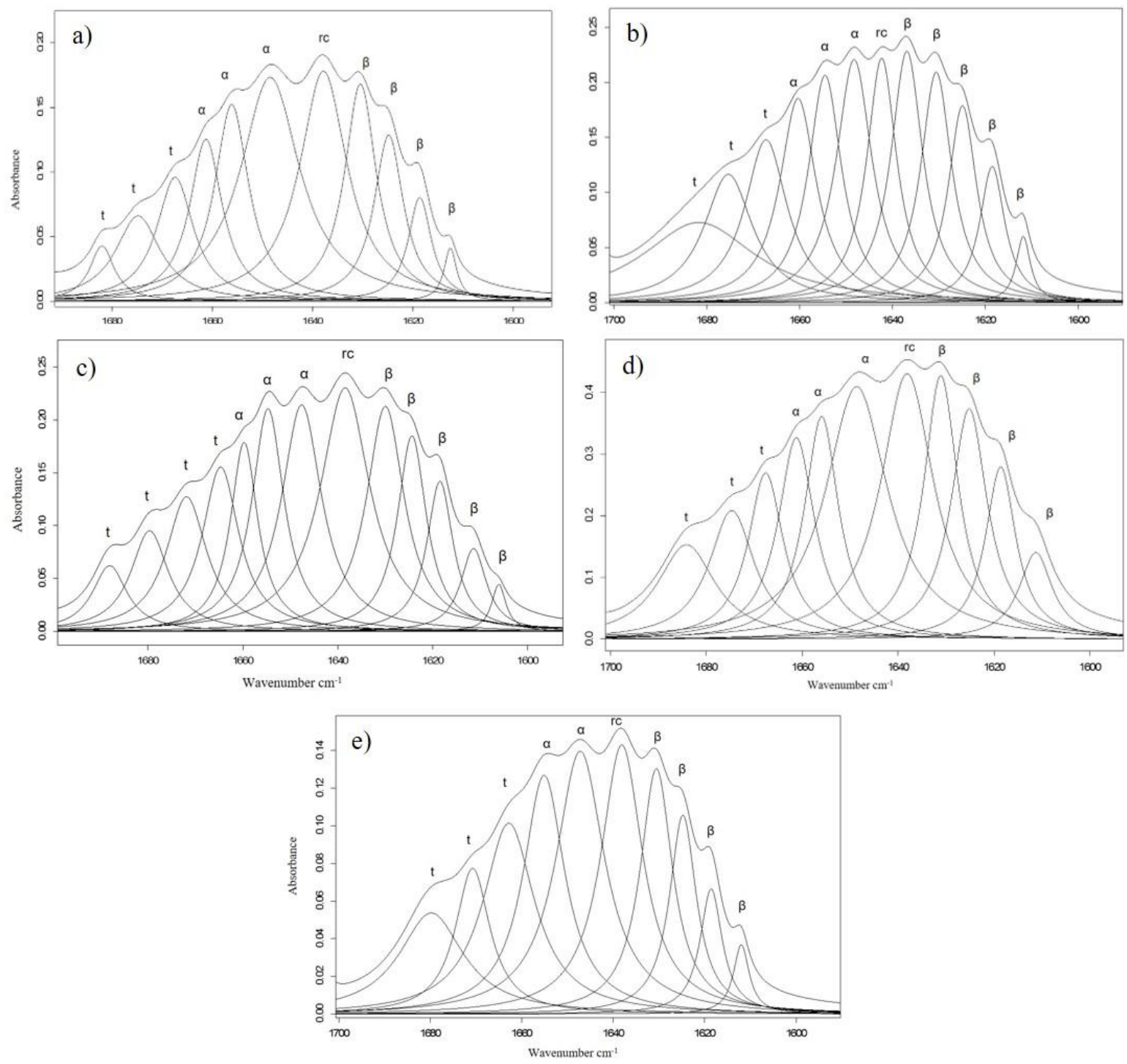
Figure 8.3.2.1.17. Amide I curve fitting band for EG@Pb inoculated specimens with: a) Acremonium chrysogenum, b) Aspergillus niger, c) Mucor rouxii, d) Penicillium chrysogenum, e) Trichoderma pseudokoningii fungi with fitted band components. Assignment of bands conformations: $\beta$-sheet $(\beta)$, random coil $(\mathrm{rc}), \alpha$-helix $(\alpha)$ and turns $(\mathrm{t})$.

Table 10.1.3.2.1.8. Percent area contribution of amide I components for EG@Pb reconstructed model paint specimens uninoculated and inoculated with fungi.

\begin{tabular}{|c|c|c|c|c|c|c|}
\hline $\begin{array}{c}\text { Predominant } \\
\text { conformations }\end{array}$ & EG@Pb & EG@Pb_Ac & EG@Pb_An & EG@Pb_Mr & EG@Pb_Pc & EG@Pb_Tp \\
\hline $\begin{array}{c}\text { Intermolecular } \\
\beta \text {-sheet }\end{array}$ & 13 & 14 & 15 & 16 & 20 & 13 \\
\hline $\begin{array}{c}\text { Intramolecular } \\
\beta \text {-sheet }\end{array}$ & 8 & 10 & 21 & 12 & 8 & 11 \\
\hline Random coil & 14 & 21 & 7 & 21 & 18 & 17 \\
\hline$\alpha$-helix & 33 & 41 & 27 & 26 & 34 & 29 \\
\hline Turns & 33 & 15 & 30 & 25 & 20 & 30 \\
\hline
\end{tabular}

Table 10.1.3.2.1.9. $\mathrm{I}_{\mathrm{AII}} / \mathrm{I}_{\mathrm{AI}}$ and $\mathrm{I}_{\mathrm{FFA}} / \mathrm{I}_{\mathrm{E}}$ band ratios obtained for the lead white egg tempera reconstructed model paint specimens uninoculated and inoculated with bacteria.

\begin{tabular}{|c|c|c|}
\hline Specimen & $\mathbf{I}_{\mathbf{A I I}} / \mathbf{I}_{\mathbf{A I}}$ intensity ratio & $\mathbf{I}_{\mathbf{F F A}} / \mathbf{I}_{\mathbf{E}}$ ratio \\
\hline EG@Pb_B & 0.73 & 0.18 \\
\hline EG@Pb_Ac & 1.73 & 0.19 \\
\hline EG@Pb_An & 0.72 & 0.06 \\
\hline EG@Pb_Mr & 1.00 & 0.07 \\
\hline EG@Pb_Pc & 0.84 & 0.04 \\
\hline EG@Pb_Tp & 0.91 & 0.09 \\
\hline
\end{tabular}



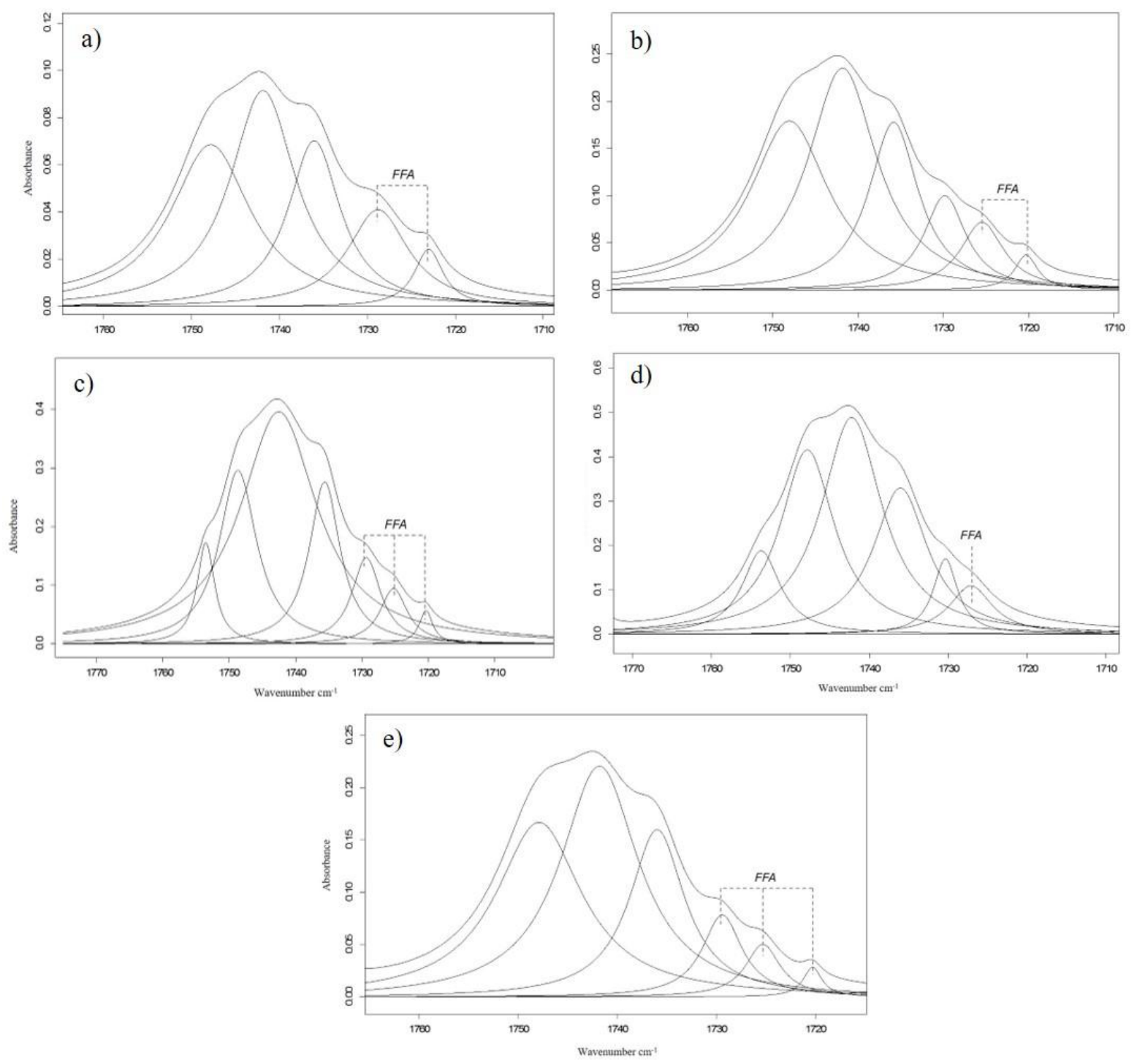

Figure 8.3.2.1.18. Carbonyl curve fitted band for EG@Pb inoculated specimen with: a) Acremonium chrysogenum, b) Aspergillus niger, c) Mucor rouxii, d) Penicillium chrysogenum, e) Trichoderma pseudokoningii fungi.

\section{Bacteria}

Detail of the $1800-500 \mathrm{~cm}^{-1}$ region of the IR spectra obtained for the paint films inoculated with bacteria are shown in Figure 10.1.3.2.1.19. Position of the characteristic band of marker compounds of bacterial materials is also included to denote the absence of biomass deposited on the surface of inoculated reconstructed paint films specimens. IR bands associated to amide I, amide II and carbonyl groups, where more significant changes are observed, are also marked. 


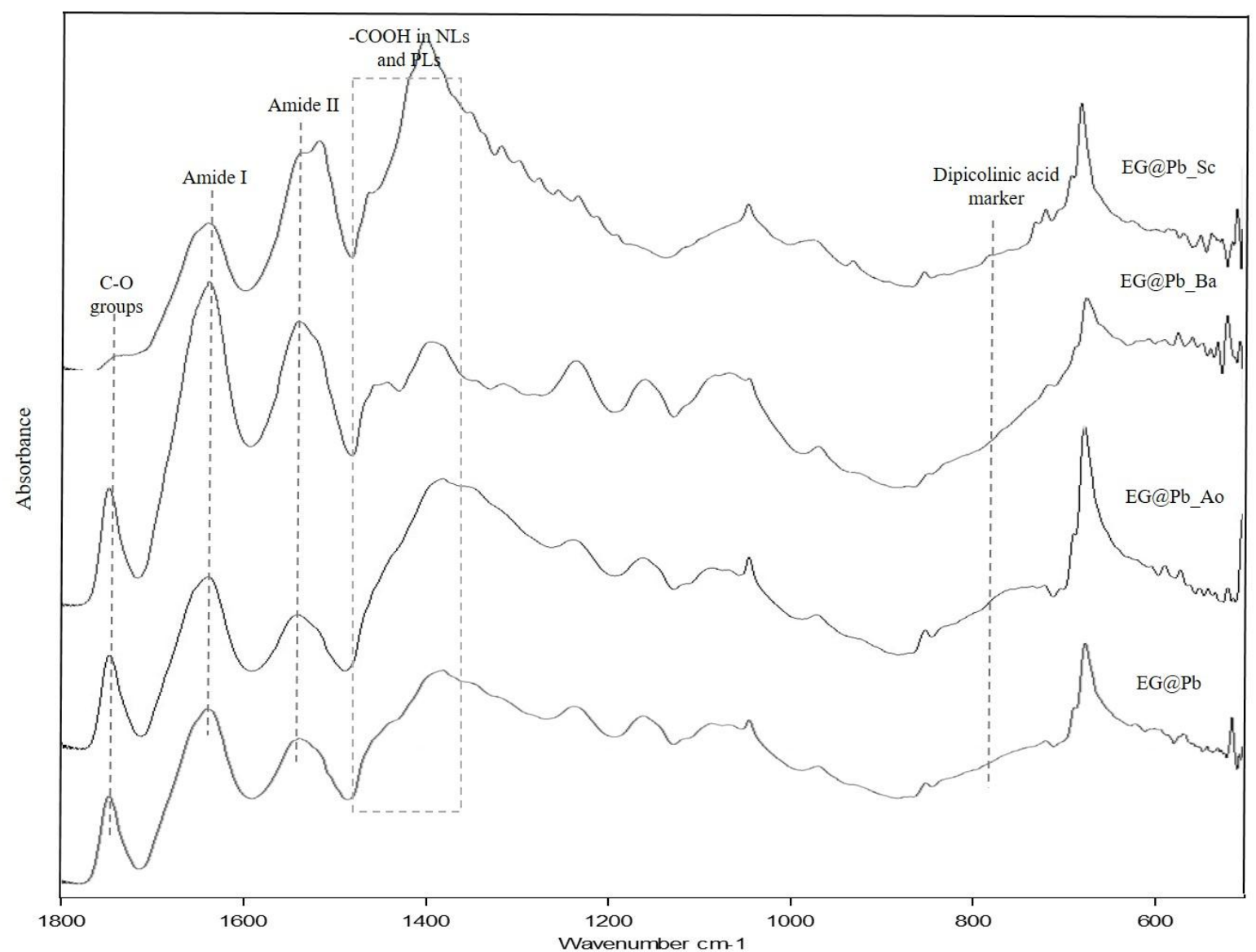

Figure 10.1.3.2.1.19. Detail of the $1800-500 \mathrm{~cm}^{-1}$ IR region and position of the bands characteristic and marker compounds bacterial materials for the EG@Pb uninoculated and inoculated specimens.

Streptomyces cellulofans was the bacterium that yielded the more remarkable changes in the binding medium of the paint film (Figure 10.1.3.2.1.19). IR spectrum of this actinobacterium exhibited maximum of the amide I band at $1637 \mathrm{~cm}^{-1}$ ascribed to $\beta$-sheet conformations. Second derivative FSD and curve fitting of the amide I band allow the identification of the sub-band with secondary maximum at $1655 \mathrm{~cm}^{-1}$, associated with $\alpha$-helix conformations, which was also present in this IR spectrum with increased intensity (Figure 10.1.3.2.1.20c). It is consistent with the intense bands at 1541 and $1514 \mathrm{~cm}^{-1}$ associated with the formation of $\mathrm{Pb}$-carboxylate complexes because $\alpha$-helix conformation, with its lateral chains more accessible to the external medium, promotes the formation of such complexes. Formation of $\mathrm{Pb}$-carboxylate in the EG@Pb_Sc was confirmed by the $\mathrm{I}_{\mathrm{FFA}} / \mathrm{I}_{\mathrm{E}}$ value obtained for this specimen (Table 10.1.3.2.1.10). This result is in agreement with the higher $\mathrm{I}_{\mathrm{AII}} / \mathrm{I}_{\mathrm{AI}}$ ratio value obtained for this specimen (Table 10.1.3.2.1.10). In contrast, $\beta$-sheet conformation was prevalent in EG@Pb_Ao and EG@Pb_Ba (Table 10.1.3.2.1.11). Accordingly, the IR spectra of such specimens showed a slight increase in the intensity of the shoulder at $1541 \mathrm{~cm}^{-1}$ ascribed to Pb-carboxylates, referred to the EG@Pb_B (Table 10.1.3.2.1.10). These results were confirmed with the curve fitting bands obtained for the specimens inoculated with bacteria in the carboxylic region (Figure 10.1.3.2.1.21), in which a slight increment of the bands ascribed to the free fatty acids was observed. Comparison of the $\mathrm{I}_{\mathrm{AII}} / \mathrm{I}_{\mathrm{AI}}$ and $\mathrm{I}_{\mathrm{FFA}} / \mathrm{I}_{\mathrm{E}}$ ratios of the inoculated specimens and blank indicates that the three microorganisms actively 
promoted metal complexation and enzymatic transformation resulting in volatile endproducts, especially Streptomyces cellulofans.
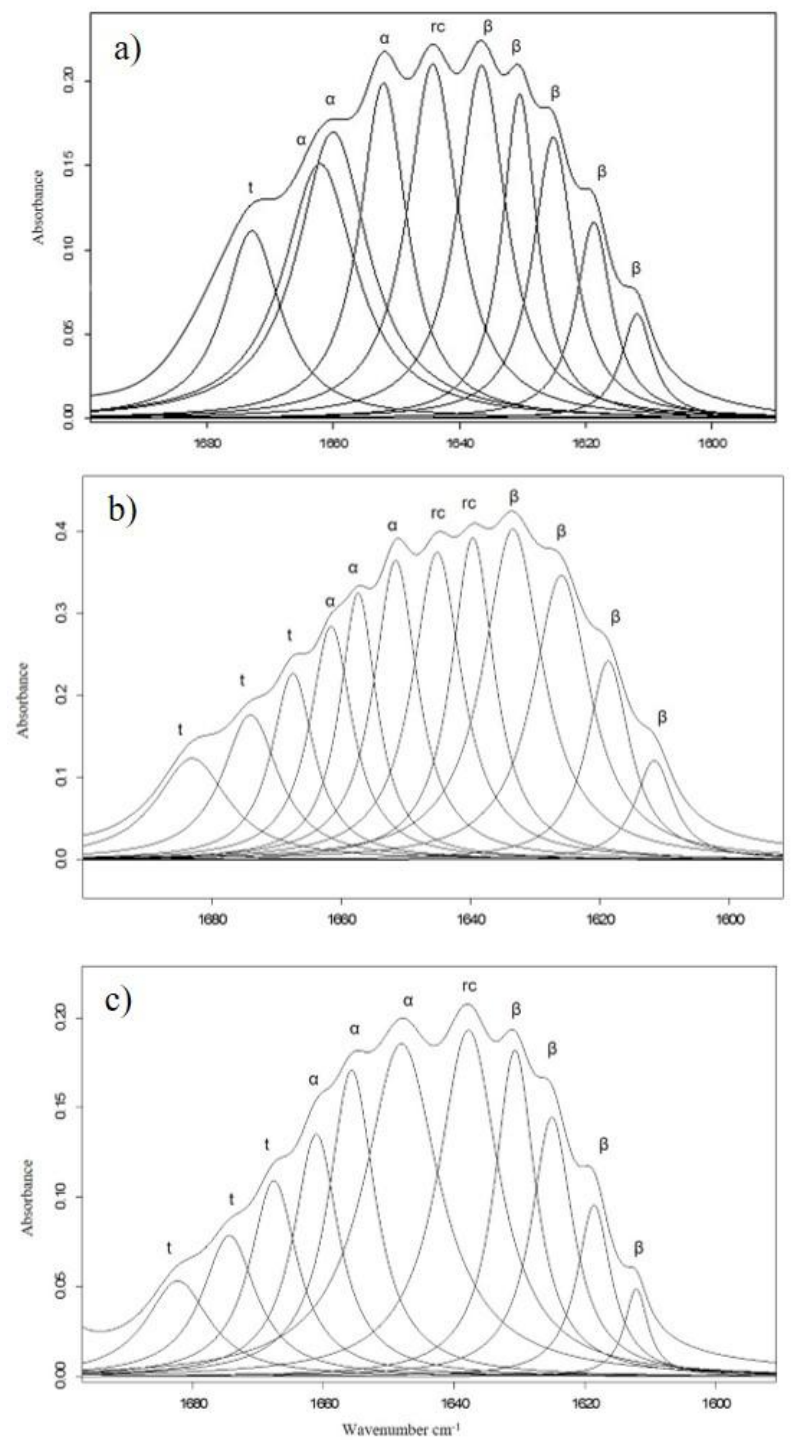

Figure 10.1.3.2.1.20. Amide I curve fitting band for EG@Pb inoculated specimens with: a) Arthrobacter oxydans, b) Bacillus amyloliquefaciens, c) Streptomyces cellulofans bacteria with fitted band components. Assignment of bands conformations: $\beta$-sheet $(\beta)$, random coil $(\mathrm{rc}), \alpha$-helix $(\alpha)$ and turns $(\mathrm{t})$.

Table 10.1.3.2.1.10. $\mathrm{I}_{\mathrm{AII}} / \mathrm{I}_{\mathrm{AI}}$ and $\mathrm{I}_{\mathrm{FFA}} / \mathrm{I}_{\mathrm{E}}$ band ratios obtained for the lead white egg tempera reconstructed model paint specimens uninoculated and inoculated with bacteria.

\begin{tabular}{|c|c|c|}
\hline Specimen & $\mathbf{I}_{\mathrm{AII}} / \mathbf{I}_{\mathrm{AI}}$ intensity ratio & $\mathbf{I}_{\mathbf{F F A}} / \mathbf{I}_{\mathbf{E}}$ ratio \\
\hline EG@Pb_B & 0.73 & 0.18 \\
\hline EG@Pb_Ao & 0.79 & 0.16 \\
\hline EG@Pb_Ba & 1.30 & 0.12 \\
\hline EG@Pb_Sc & 2.82 & 0.07 \\
\hline
\end{tabular}


Table 10.1.3.2.1.11. Percent area contribution of amide I components for EG @ Pb reconstructed model paint specimens uninoculated and inoculated with bacteria.

\begin{tabular}{|c|c|c|c|c|}
\hline $\begin{array}{c}\text { Predominant } \\
\text { conformations }\end{array}$ & EG@Pb & EG@Pb_Ao & EG@Pb_Ba & EG@Pb_Sc \\
\hline Intermolecular $\beta$-sheet & 13 & 20 & 9 & 6 \\
\hline Intramolecular $\beta$-sheet & 8 & 24 & 31 & 3 \\
\hline Random coil & 14 & 16 & 18 & 7 \\
\hline$\alpha$-helix & 33 & 33 & 22 & 15 \\
\hline Turns & 33 & 7 & 19 & 6 \\
\hline
\end{tabular}
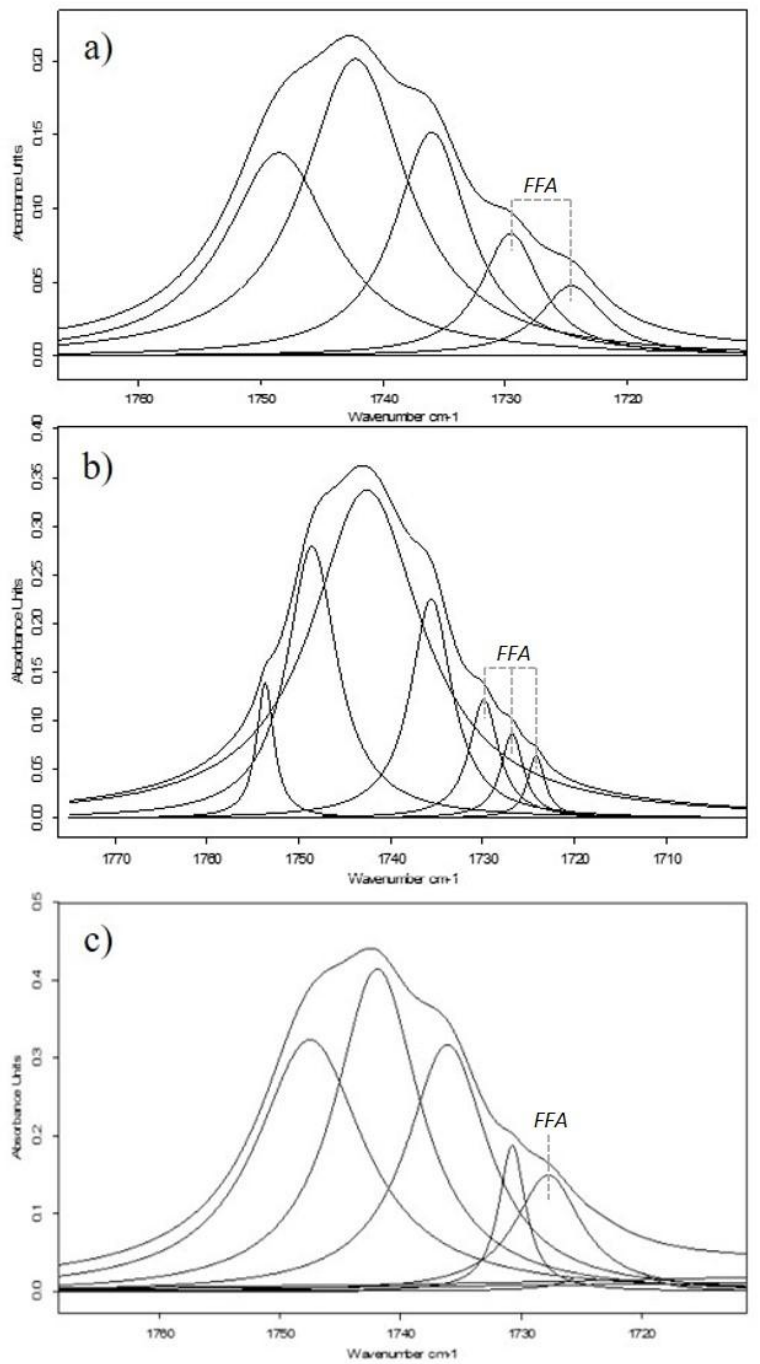

Figure 10.1.3.2.1.21. Carbonyl curve fitted band for EG@Pb inoculated specimen with: a) Arthrobacter oxydans, b) Bacillus amyloliquefaciens, c) Streptomyces cellulofans bacteria. 


\section{Cadmium yellow}

\section{Fungi}

Figure 10.1.3.2.1.22, shows the $1800-500 \mathrm{~cm}^{-1}$ region of the IR spectra of the reconstructed model paint specimens uninoculated and inoculated with fungi. The characteristic band of marker compounds in fungi is also marked to denote the complete removing of fungal biomass from the specimens.

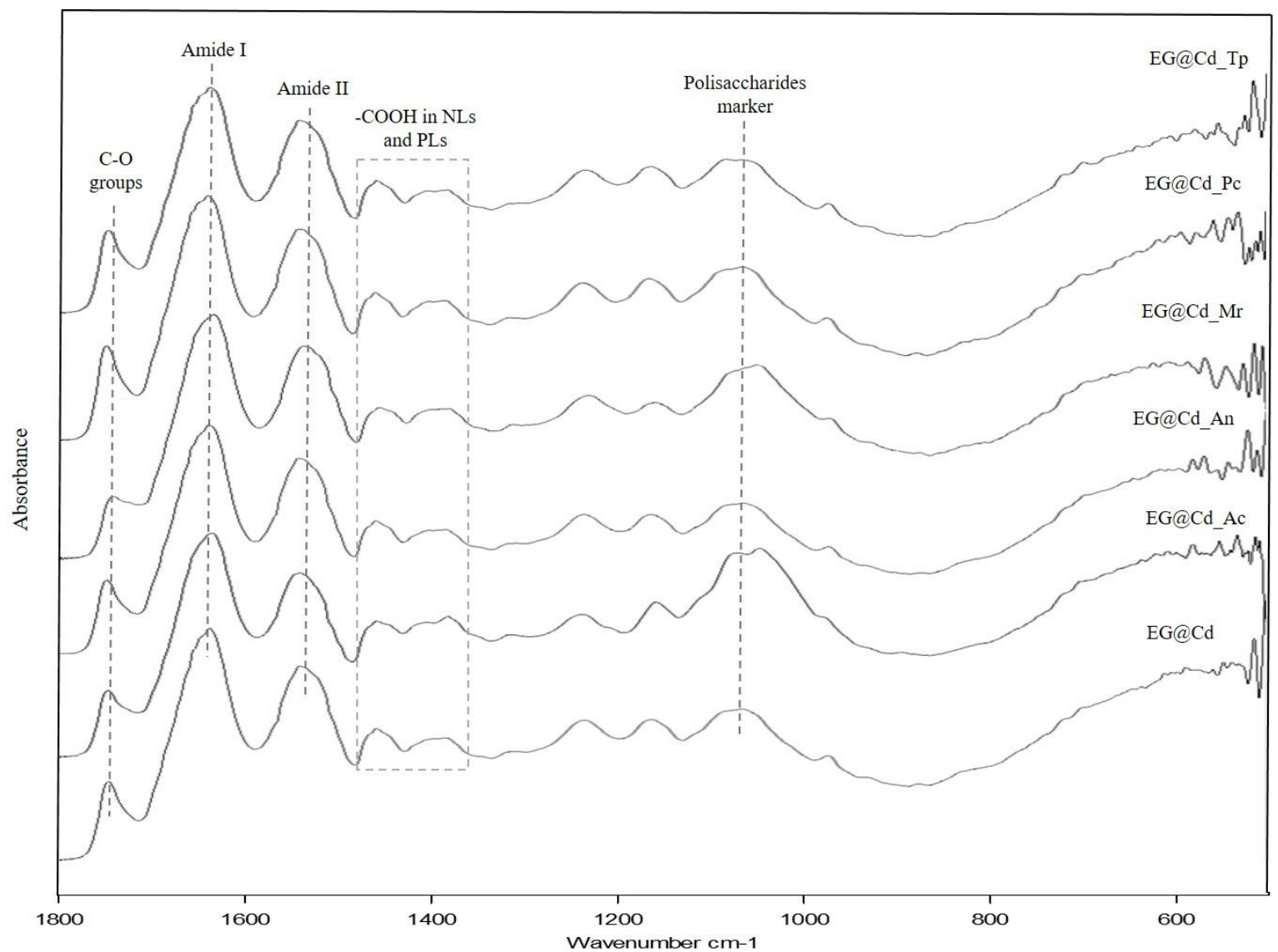

Figure 10.1.3.2.1.22. Detail of the $1800-500 \mathrm{~cm}^{-1}$ IR region and position of the bands characteristic and marker compounds fungal materials for the EG@Cd uninoculated and inoculated specimens.

Modification of the profile of the amide I band informs of alterations taking place in the secondary structure of proteins, which could be relied with the microbial degradative activity. The more remarkable changes were observed in the EG@Cd_Mr and the EG@Cd_Tp specimens (Figure 10.1.3.2.1.23c and e, respectively), in which the maximum of the IR band of the intramolecular $\beta$-sheet conformation redshifts from 1635 to $1633 \mathrm{~cm}^{-1}$. Values of percentage of conformation contribution calculated from FSD and curve fitting of the amide I band show a decrease of the intramolecular $\beta$-sheet conformation contribution for all the 
inoculated specimen, being more evident in the specimen inoculated with Trichoderma pseudokoningii. A notable increase of the intermolecular $\beta$-sheet conformation in the specimen inoculated with Trichoderma pseudokoningii is also observed (Table 10.1.3.2.1.12). Specimens inoculated with Acremonium chrysogenum and Penicillium chrysogenum exhibit an increment of the turn conformation contribution. This last result suggests that attack of these microorganisms results in an increase in the irregular structures and, in particular, in a partial opening of the ordered structure into random turns and bends.
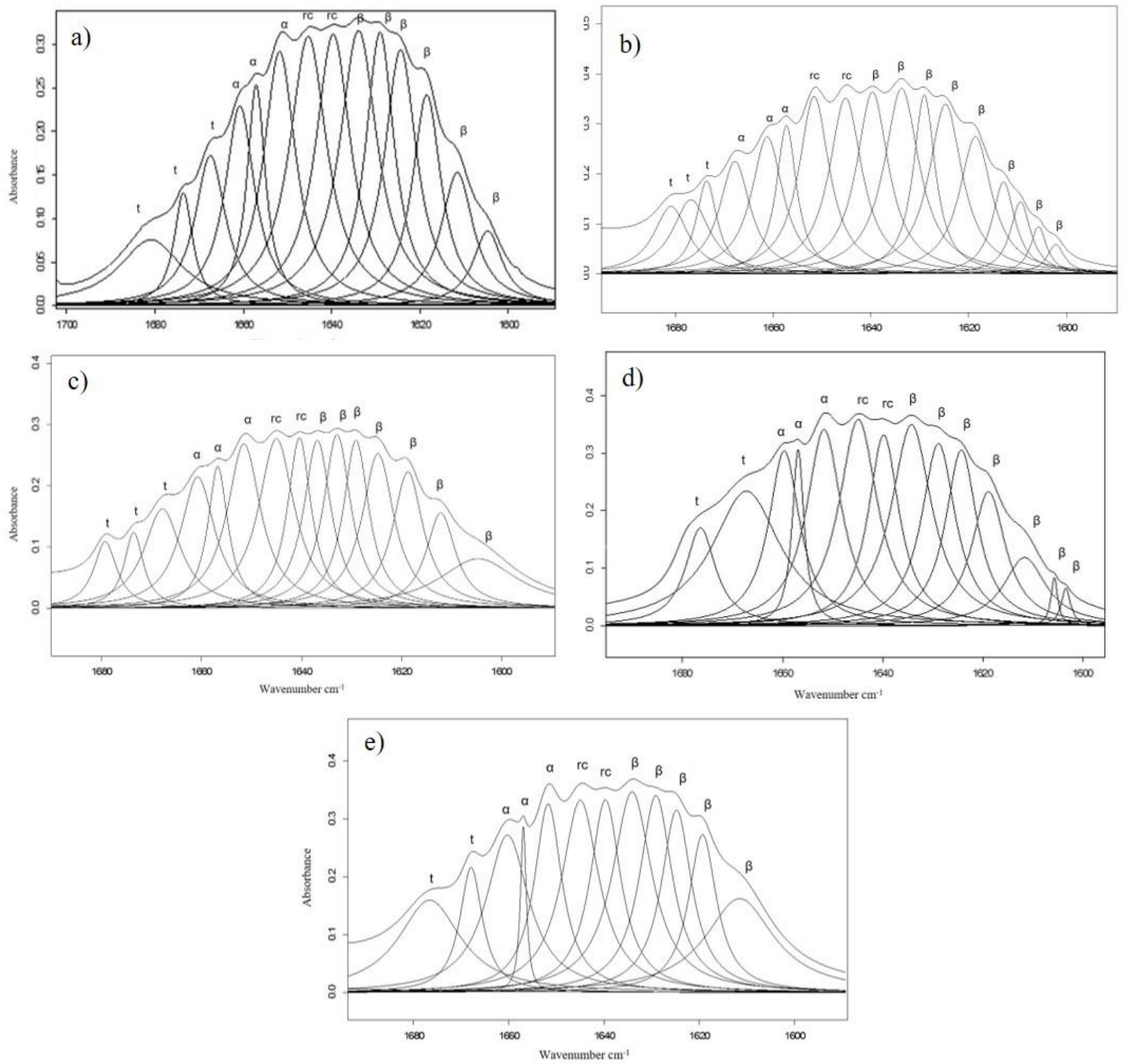

Figure 8.2.2.1.23. Amide I curve fitting band for EG@Cd inoculated specimens with: a) Acremonium chrysogenum, b) Aspergillus niger, c) Mucor rouxii, d) Penicillium chrysogenum, e) Trichoderma pseudokoningii fungi with fitted band components. Assignment of bands conformations: $\beta$-sheet $(\beta)$, random coil (rc), $\alpha$-helix $(\alpha)$ and turns (t). 
Table 10.1.3.2.1.12. Percent area contribution of amide I components for EG@Cd reconstructed model paint specimens uninoculated and inoculated with fungi.

\begin{tabular}{|c|c|c|c|c|c|c|}
\hline $\begin{array}{c}\text { Predominant } \\
\text { conformations }\end{array}$ & EG@Cd & EG@Cd_Ac & EG@Cd_An & EG@Cd_Mr & EG@Cd_Pc & EG@Cd_Tp \\
\hline $\begin{array}{c}\text { Intermolecular } \\
\beta \text {-sheet }\end{array}$ & 26 & 26 & 27 & 29 & 31 & 35 \\
\hline $\begin{array}{c}\text { Intramolecular } \\
\beta \text {-sheet }\end{array}$ & 20 & 18 & 17 & 19 & 14 & 12 \\
\hline Random coil & 20 & 20 & 20 & 17 & 18 & 17 \\
\hline$\alpha$-helix & 24 & 20 & 23 & 23 & 19 & 22 \\
\hline Turns & 10 & 16 & 14 & 12 & 18 & 14 \\
\hline
\end{tabular}

Bands in the $1800-1700 \mathrm{~cm}^{-1}$ region ascribed to free fatty acids released as result of the hydrolysis of triglycerides present in NLs promoted by the fungi were identified using FSD and curve fitting procedures. Figure 10.1.3.2.1.23, shows the curve fitted band for all the specimens inoculated with fungi. EG@Cd_Ac and EG@Cd_Mr specimens exhibit the major free fatty acids relative content, being more evident in the latter specimen (Figure 10.1.3.2.1.24). These results are in aggreement with the changes in the $\mathrm{I}_{\mathrm{AII}} / \mathrm{I}_{\mathrm{AI}}$ ratios obtained (Table 10.1.3.2.1.13), among which Mucor rouxii exhibited the major increase. Comparison of the $\mathrm{I}_{\mathrm{AII}} / \mathrm{I}_{\mathrm{AI}}$ and $\mathrm{I}_{\mathrm{FFA}} / \mathrm{I}_{\mathrm{E}}$ ratios of the inoculated specimens and blank indicates that microorganisms in EG@Cd_Mr, EG@Cd_Pc and EG@Cd_Tp were active promoting both metal complexation and enzymatic transoprmation resultin in volatile end-products whereas microorganisms in EG@Cd_An and EG@Cd_An mainly promoted hydrolysis and metalcomplexation. 

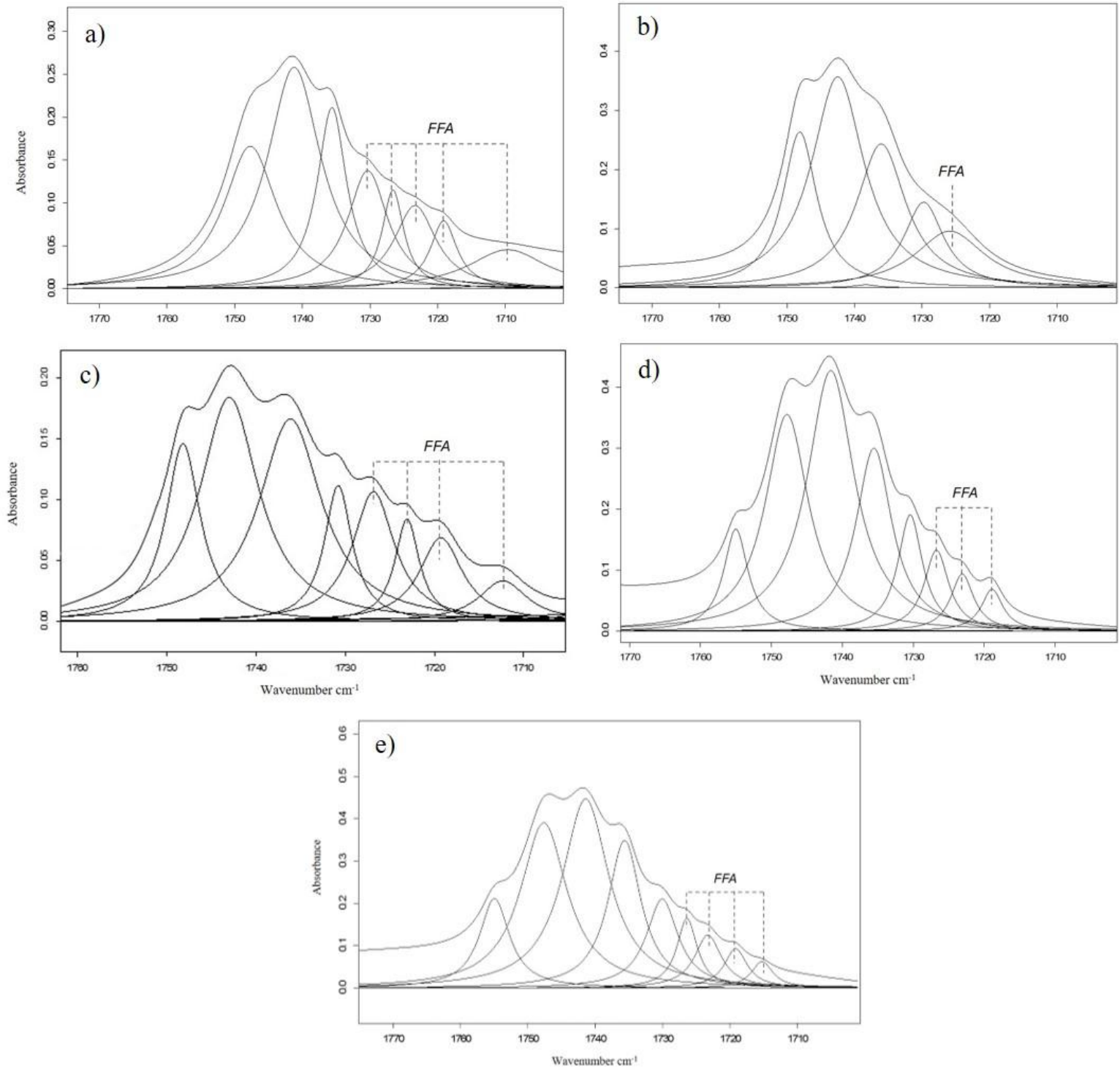

Figure 10.1.3.2.1.24. Carbonyl curve fitted band for EG@Cd inoculated specimen with: a) Acremonium chrysogenum, b) Aspergillus niger, c) Mucor rouxii, d) Penicillium chrysogenum, e) Trichoderma pseudokoningii fungi.

Table 10.1.3.2.1.13. $\mathrm{I}_{\mathrm{AII}} / \mathrm{I}_{\mathrm{AI}}$ and $\mathrm{I}_{\mathrm{FFA}} / \mathrm{I}_{\mathrm{E}}$ band ratios obtained for the cadmium yellow egg tempera reconstructed model paint specimens uninoculated and inoculated with fungi.

\begin{tabular}{|c|c|c|}
\hline Specimen & $\mathbf{I}_{\mathbf{A I I}} / \mathbf{I}_{\mathbf{A I}}$ intensity ratio & $\mathbf{I}_{\mathbf{F F A}} / \mathbf{I}_{\mathbf{E}}$ ratio \\
\hline EG@Cd_B & 0.32 & 0.36 \\
\hline EG@Cd_Ac & 0.36 & 0.46 \\
\hline EG@Cd_An & 0.33 & 0.34 \\
\hline EG@Cd_Mr & 0.68 & 0.30 \\
\hline EG@Cd_Pc & 0.41 & 0.28 \\
\hline EG@Cd_Tp & 0.48 & 0.28 \\
\hline
\end{tabular}




\section{Bacteria}

Figure 10.1.3.2.1.25, shows the $1800-500 \mathrm{~cm}^{-1}$ region of the IR spectra obtained for the reconstructed model paint specimens inoculated with bacteria where the bacterial characteristic band of marker compounds of bacterial biomass is also marked to denote the suppression of biomass in the surface of the specimens.

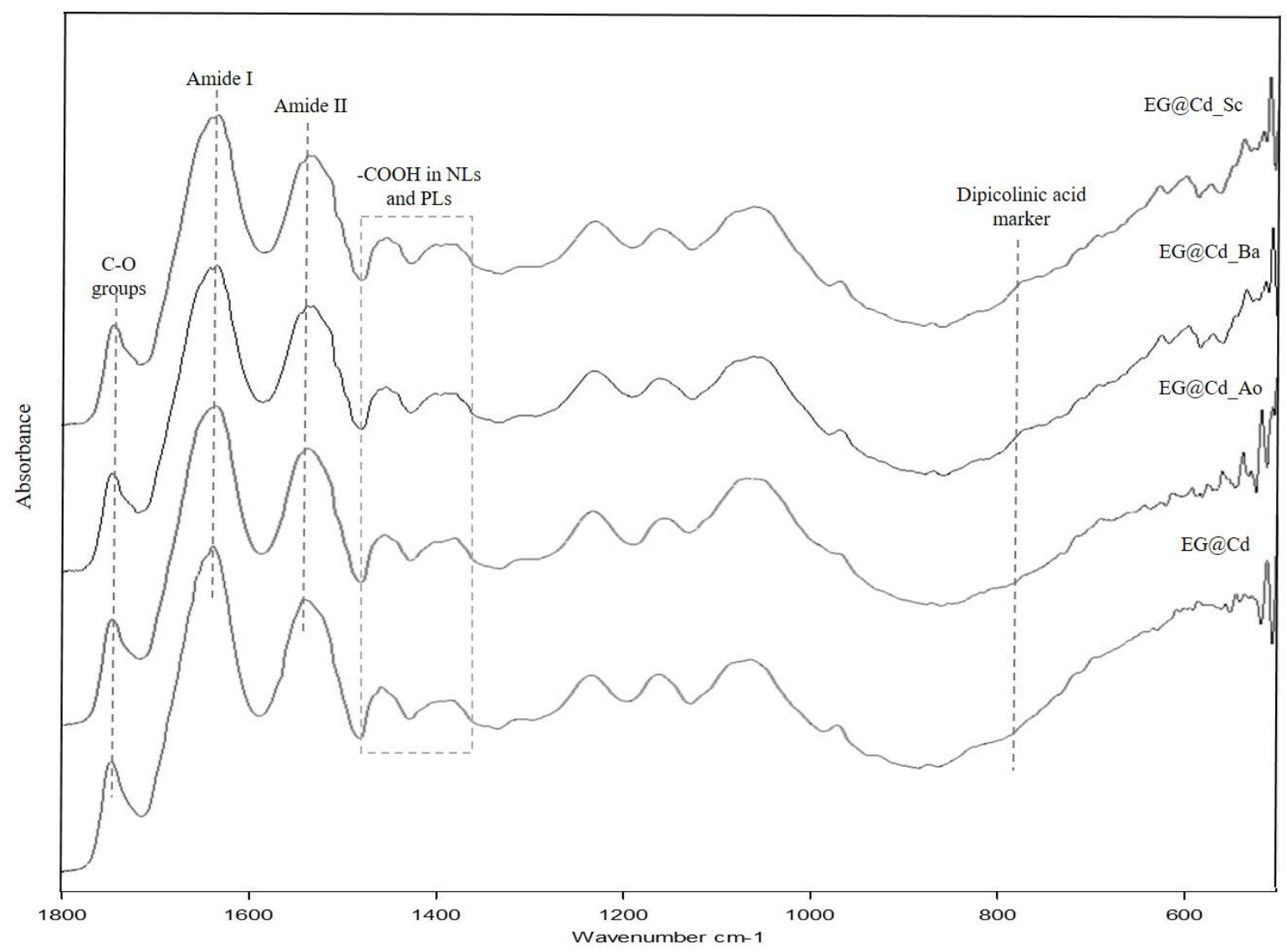

Figure 10.1.3.2.1.25. Detail of the $1800-500 \mathrm{~cm}^{-1}$ IR region and position of the bands characteristic and marker compounds bacterial materials for the EG@Cd uninoculated and inoculated specimens.

Comparison of the IR spectra of the EG@Cd bacteria inoculated specimens with the uninoculated one, shows that, in general, changes in this series of specimens prepared with cadmium yellow are less evident than those found for the rest of specimens. An important increase in the $\alpha$-helix conformation contribution was observed in the specimen inoculated with actinobacterium Arthrobacter oxydans, following literature increase of this conformation is associated with the formation of more crosslinked structures (Duce et al., 2013) (Table 10.1.3.2.1.14). The $\beta$-sheet conformation was the dominant secondary structure in all the inoculated specimens (Figure 10.1.3.2.1.26). The EG@Cd_Sc specimen exhibits no significant variation in the $\alpha$-helix conformation, but reports an increase of the intermolecular $\beta$-sheet conformation. Comparison of the results obtained for both actinobacteria used in this study suggests that Arthrobacter oxydans promotes the deterioration of the protein-protein interactions to a major extent. In the case of the specimen inoculated with the eubacterium 
EG@Cd_Ba, an increase of the turn conformation contribution was observed, increment of this conformation contribution is associated with the formation of more open structures that favors the interaction of the functional groups located in the side chains. These results are in agreement with the $\mathrm{I}_{\mathrm{AII}} / \mathrm{I}_{\mathrm{AI}}$ ratios obtained for this series. Here the higher values were obtained for the specimens inoculated with Arthrobacter oxydans and Bacillus amyloliquefaciens (Table 10.1.3.2.1.15).
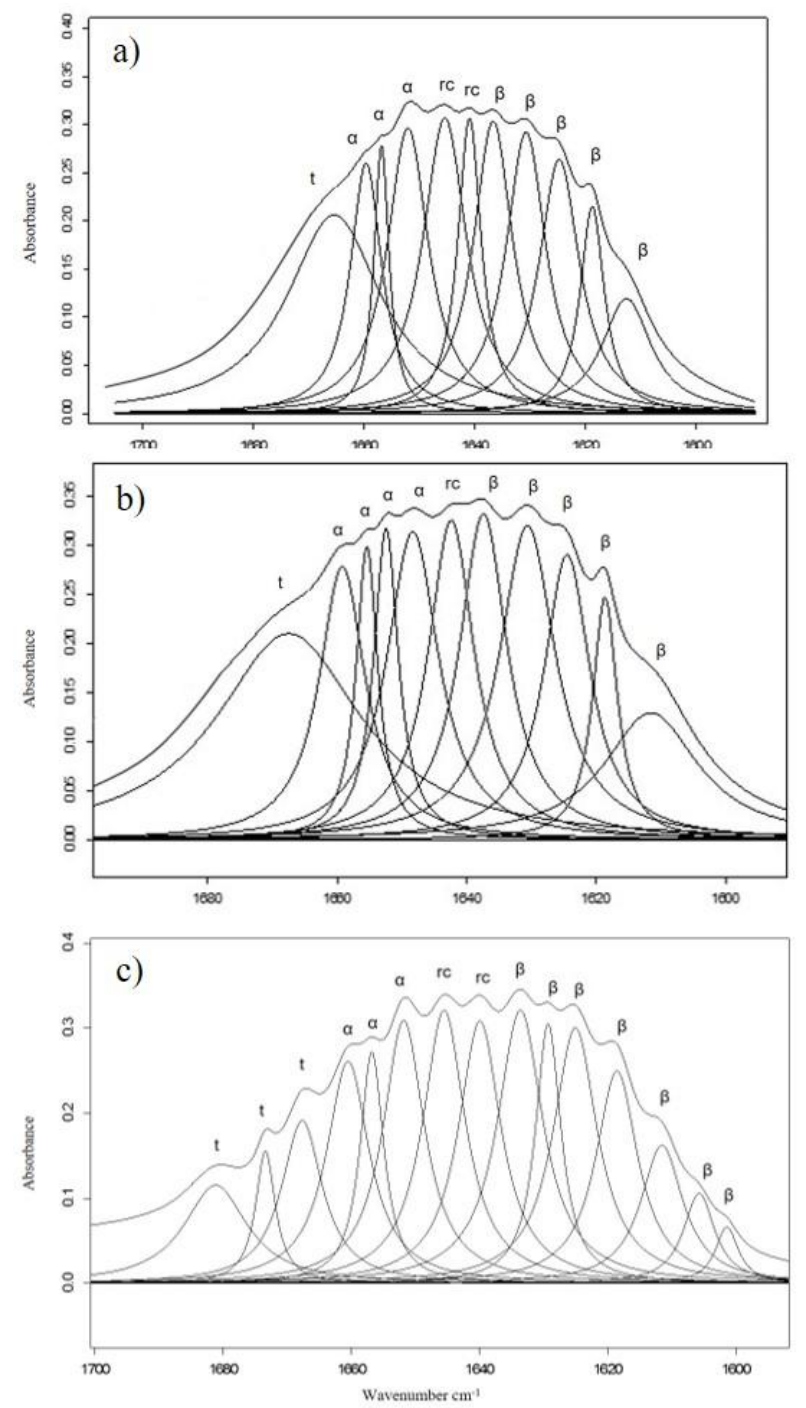

Figure 10.1.3.2.1.26. Amide I curve fitting band for EG@Cd inoculated specimens with: a) Arthrobacter oxydans, b) Bacillus amyloliquefaciens, c) Streptomyces cellulofans bacteria with fitted band components. Assignment of bands conformations: $\beta$-sheet $(\beta)$, random coil $(\mathrm{rc}), \alpha$-helix $(\alpha)$ and turns $(\mathrm{t})$. 
Table 10.1.3.2.1.14. Percent area contribution of amide I components for EG@Cd reconstructed model paint specimens uninoculated and inoculated with bacteria.

\begin{tabular}{|c|c|c|c|c|}
\hline $\begin{array}{c}\text { Predominant } \\
\text { conformations }\end{array}$ & EG@Cd & EG@Cd_Ao & EG@Cd_Ba & EG@Cd_Sc \\
\hline Intermolecular $\beta$-sheet & 26 & 12 & 26 & 30 \\
\hline Intramolecular $\beta$-sheet & 20 & 10 & 21 & 15 \\
\hline Random coil & 20 & 7 & 7 & 19 \\
\hline$\alpha$-helix & 24 & 22 & 18 & 22 \\
\hline Turns & 10 & 10 & 29 & 14 \\
\hline
\end{tabular}

Table 10.1.3.2.1.15. $\mathrm{I}_{\mathrm{AII}} / \mathrm{I}_{\mathrm{AI}}$ and $\mathrm{I}_{\mathrm{FFA}} / \mathrm{I}_{\mathrm{E}}$ band ratios obtained for the cadmium yellow egg tempera reconstructed model paint specimens uninoculated and inoculated with bacteria.

\begin{tabular}{|c|c|c|}
\hline Specimen & $\mathbf{I}_{\mathbf{A I I}} / \mathbf{I}_{\mathbf{A I}}$ intensity ratio & $\mathbf{I}_{\mathbf{F F A}} / \mathbf{I}_{\mathbf{E}}$ ratio \\
\hline EG@Cd_B & 0.32 & 0.36 \\
\hline EG@Cd_Ao & 1.19 & 0.10 \\
\hline EG@Cd_Ba & 1.24 & 0.11 \\
\hline EG@Cd_Sc & 0.36 & 0.48 \\
\hline
\end{tabular}

Figure 10.1.3.2.1.27 shows the curve fitting band and the fitted sub-bands obtained in the carbonyl region for the series of EG@Cd specimens inoculated with bacteria. All the specimen exhibited an increment on the $\mathrm{I}_{\mathrm{FFA}} / \mathrm{I}_{\mathrm{E}}$ ratio (Table 10.1.3.2.1.15). The most evident increase in the relative content of free fatty acids was observed in the EG@Cd_Sc specimen. These results confirm that bacteria are promoting the hydrolysis of triglycerides of NLs, in particular the Streptomyces cellulofans actinobacterium. In contrast, lower $\mathrm{I}_{\mathrm{FFA}} / \mathrm{I}_{\mathrm{E}}$ values were obtained for the specimens inoculated with Arthrobacter oxydans and Bacillus amyloliquefaciens, this suggests that free fatty acids released by this microorganism derived into Cd-carboxylate complexes and/or were loss as result of enzymatic transformation resulting in volatile end-products. The former is in agreement with the increment in the $\mathrm{I}_{\mathrm{AII}} / \mathrm{I}_{\mathrm{AI}}$ value obtained for these bacteria. 

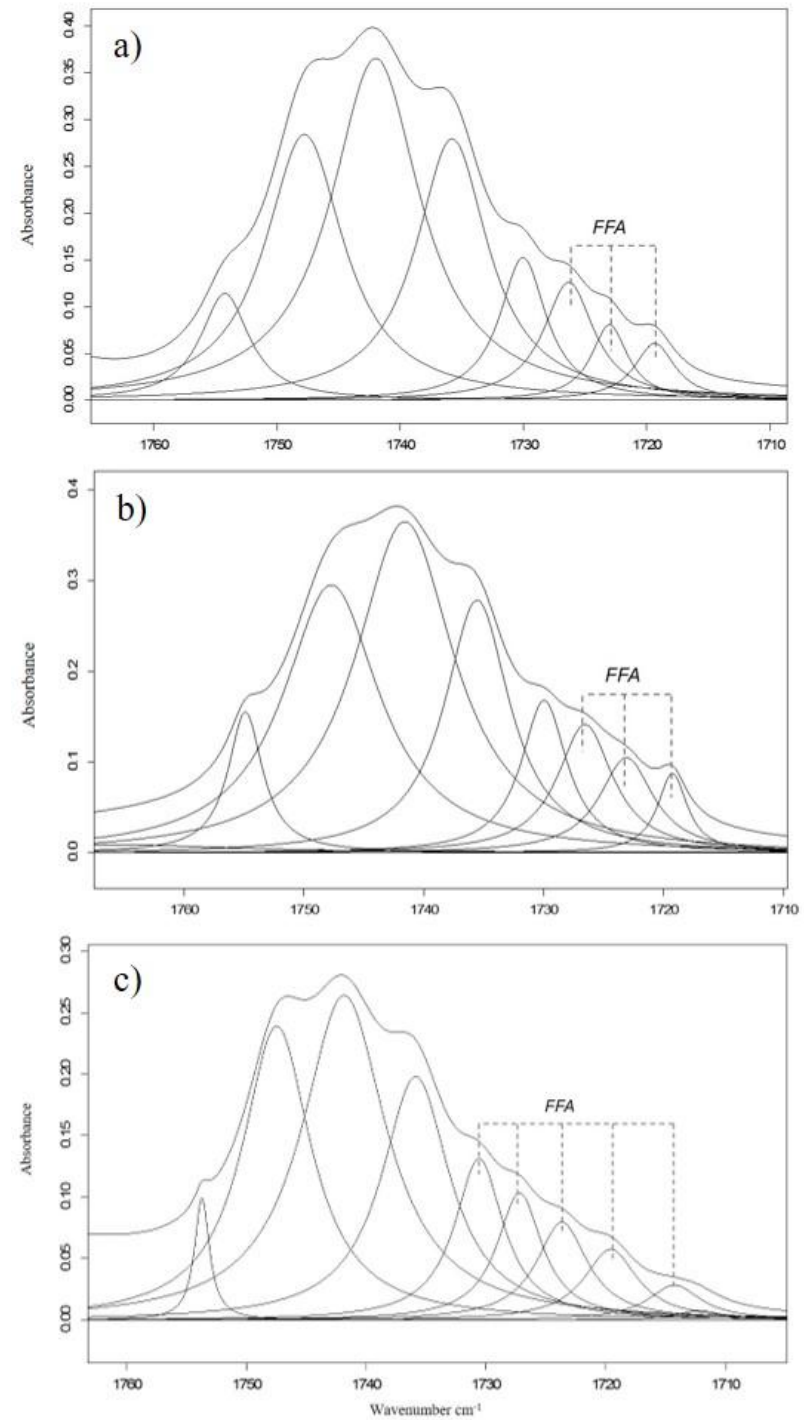

Figure 10.1.3.2.1.27. Carbonyl curve fitted band for EG@Cd inoculated specimen with: a) Arthrobacter oxydans, b) Bacillus amyloliquefaciens, c) Streptomyces cellulofans bacteria.

No changes were observed for those bands associated to the $v_{\mathrm{s}} \mathrm{P}-\mathrm{O}-\mathrm{C}$ terminal phosphate and $v_{\mathrm{s}} \mathrm{PO}_{2}{ }^{-}$deriving from protein phosphodiesters and indicative of PLs-metal interactions, in the EG@Cd specimens inoculated with fungi and bacteria. 
10.1.3.2.2. Egg oil emulsion reconstructed model paint specimens

\section{Iron oxide red}

Fungi

The EO@Fe specimens inoculated with fungi exhibited IR spectra similar to that found in the uninoculated specimen. The more remarkable changes have been observed in the 1800-500 $\mathrm{cm}^{-1}$ region (Figure 10.1.3.2.2.1). FSD and curve fitting methods applied on the amide I band for all the reconstructed model paint specimens inoculated with fungi were performed in order to quantify the protein secondary structure components.

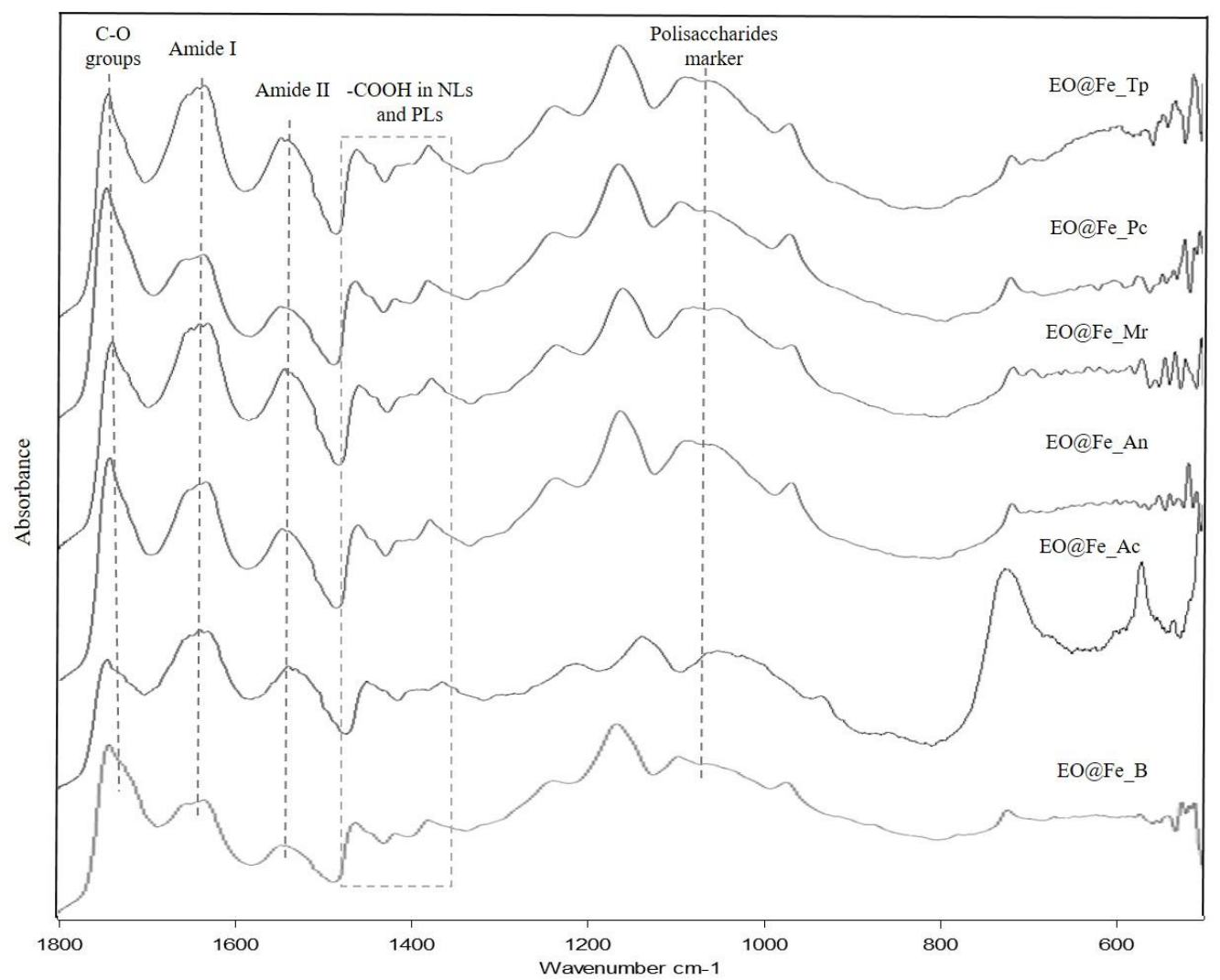

Figure 10.1.3.2.2.1. Detail of the $1800-500 \mathrm{~cm}^{-1}$ IR region and position of the bands characteristic and marker compounds fungal materials for the EO@Fe uninoculated and inoculated specimens.

The more remarkable changes in the amide I band occurring in the IR spectra were observed in the specimen inoculated with Acremonium chrysogenum and Mucor rouxii with a blueshift of the amide I band maxima at $1630 \mathrm{~cm}^{-1}$ attributed to $\beta$-sheet conformation to 1637 and 1645 $\mathrm{cm}^{-1}$, respectively. The rest of paint film specimens inoculated with fungi, exhibited subbands with maxima in the region $1640-1660 \mathrm{~cm}^{-1}$ where random coil and $\alpha$-helix conformation absorbs. Splitting of the $\beta$-sheet sub-band at $1629 \mathrm{~cm}^{-1}$ in two overlapped components intermolecular $\beta$-sheet and intramolecular $\beta$-sheet was also observed in all the specimens (Figure 10.1.3.2.2.2). Table 10.1.3.2.2.1, summarizes the percent contribution of 
each conformation obtained for all the EO@Fe specimens inoculated with fungi obtained by applying FSD and curve fitting. A decrease in the $\alpha$-helix conformation contribution and an increase in the intermolecular $\beta$-sheet conformation were observed when compared to the uninoculated specimen. These results suggest that the deterioration action of the fungi has been less effective in this series of specimens than in the tempera specimens, due to the presence of compact protein structures with increased aggregation that conversely results in lateral chains less accessible to the external lipidic phase formed in the emulsion. The specimen inoculated with Mucor rouxii and Penicillium chrysogenum exhibit the highest value for the random coil percentage contribution. The latter specimen also reports the highest relative content for the $\alpha$-helix conformation contribution if compared to the rest of the fungi under study. The presence of these open structures that favor the interaction of external agents with the functional groups located in the side chains of the polypeptide molecules promotes the formation of Fe-carboxylate complexes, in particular, in the EO@Fe_Pc paint film specimen. Comparison of the $\mathrm{I}_{\mathrm{AII}} / \mathrm{I}_{\mathrm{AI}}$ and $\mathrm{I}_{\mathrm{FFA}} / \mathrm{I}_{\mathrm{E}}$ ratios (Table 10.1.3.2.2.2) of the inoculated specimens and blank indicates that all the microorganisms were especially active promoting hydrolysis and metal complexation. In particular, Penicillium chrysogenum.
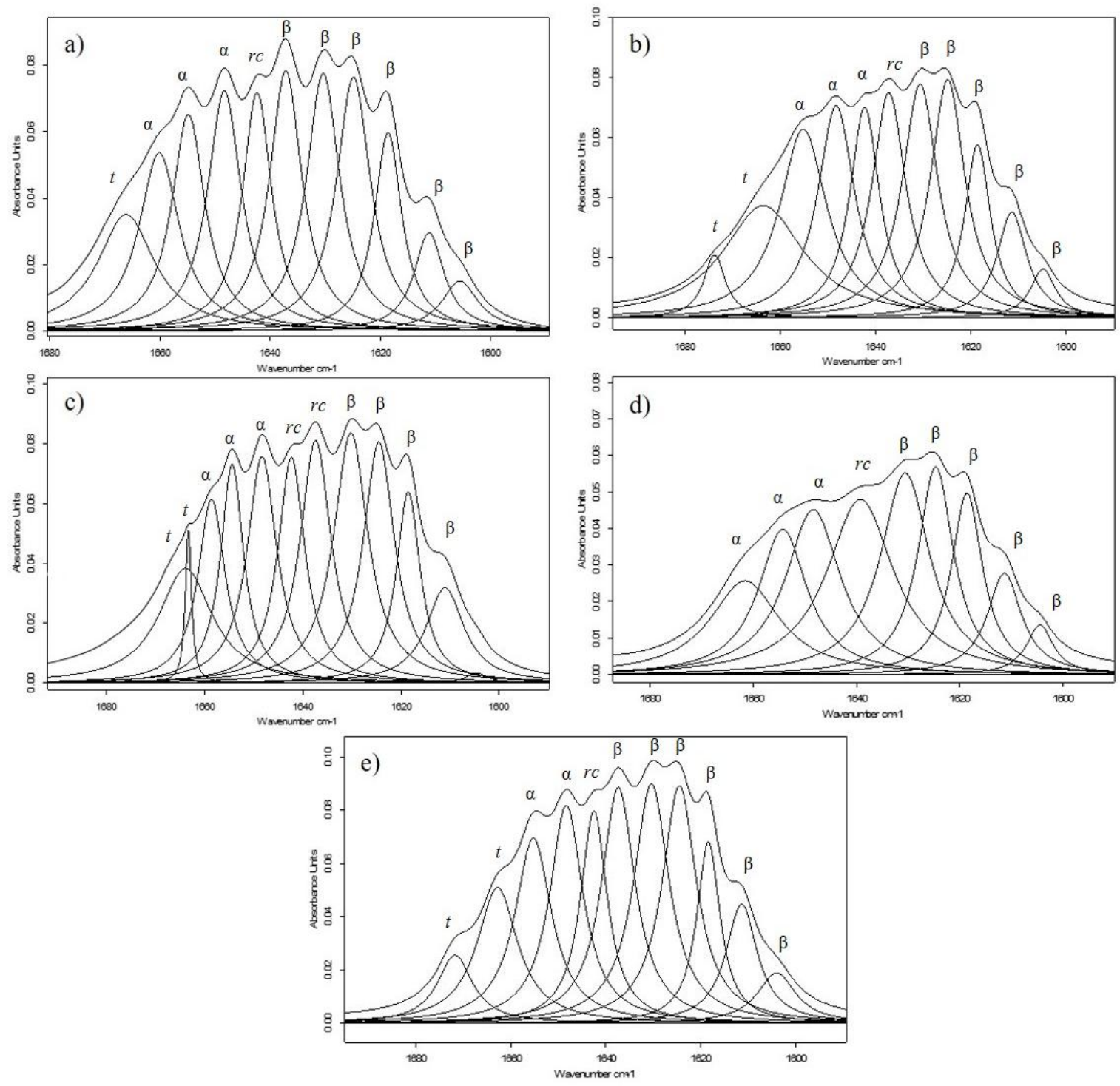
Figure 10.1.3.2.2.2. Amide curve fitting band for EO@Fe inoculated specimens with: a) Acremonium chrysogenum, b) Aspergillus niger, c) Mucor rouxii, d) Penicillium chrysogenum, e) Trichoderma pseudokoningii fungi with fitted band components. Assignment of bands conformations: $\beta$-sheet $(\beta)$, random coil $(\mathrm{rc}), \alpha$-helix $(\alpha)$ and turns $(\mathrm{t})$.

Table 10.1.3.2.2.1. Percent area contribution of amide I components for EO@Fe reconstructed model paint specimens uninoculated and inoculated with fungi.

\begin{tabular}{|c|c|c|c|c|c|c|}
\hline $\begin{array}{c}\text { Predominant } \\
\text { conformations }\end{array}$ & $\mathbf{E O} @ \mathbf{F e}$ & EO@Fe_Ac & EO@Fe_An & $\mathbf{E O} @ \mathbf{F e} \_\mathbf{M r}$ & $\mathbf{E O @ F e \_ P c}$ & EO@Fe_Tp \\
\hline $\begin{array}{c}\text { Intermolecular } \\
\beta \text {-sheet }\end{array}$ & 20 & 30 & 28 & 18 & 30 & 31 \\
\hline $\begin{array}{c}\text { Intramolecular } \\
\beta \text {-sheet }\end{array}$ & 24 & 25 & 23 & 28 & 16 & 26 \\
\hline Random coil & 15 & 7 & 6 & 20 & 21 & 6 \\
\hline$\alpha$-helix & 40 & 28 & 23 & 24 & 34 & 24 \\
\hline Turns & - & 9 & 19 & 11 & - & 13 \\
\hline
\end{tabular}

Table 10.1.3.2.2.2. $\mathrm{I}_{\mathrm{AII}} / \mathrm{I}_{\mathrm{AI}}$ and $\mathrm{I}_{\mathrm{FFA}} / \mathrm{I}_{\mathrm{E}}$ band ratios obtained for the iron oxide red egg oil emulsion reconstructed model paint specimens uninoculated and inoculated with fungi.

\begin{tabular}{|c|c|c|}
\hline Specimen & $\mathbf{I}_{\mathrm{AII}} / \mathbf{I}_{\mathbf{A I}}$ intensity ratio & $\mathbf{I}_{\mathbf{F F A}} \mathbf{I}_{\mathbf{E}}$ ratio \\
\hline EO@Fe_B & 1.25 & 0.75 \\
\hline EO@Fe_Ac & 1.58 & 0.81 \\
\hline EO@Fe_An & 1.88 & 0.79 \\
\hline EO@Fe_Mr & 1.75 & 0.79 \\
\hline EO@Fe_Pc & 1.57 & 0.96 \\
\hline EO@Fe_Tp & 2.36 & 0.86 \\
\hline
\end{tabular}

Two derivative features in the $840-660 \mathrm{~cm}^{-1}$ region associated to $\mathrm{Fe}(\mathrm{II})$-protein complexes due to a minor perturbation of the protein $\mathrm{C}-\mathrm{C}$ and $\mathrm{C}-\mathrm{S}$ stretching modes were also observed in the EO@Fe_Mr and EO@Fe_Pc specimens (Nahar and Tajmir-Riahi, 1995).

FSD and curve fitted band and sub-bands calculated in the series of specimens is showed in Figure 10.1.3.2.2.3. The higher $\mathrm{I}_{\mathrm{FFA}} / \mathrm{I}_{\mathrm{E}}$ was obtained for the EG@Pb_Pc, which confirms that Penicillium chrysogenum notably promotes the hydrolysis of the triglycerides present in the NLs and PLs if compared to the lower values obtained for the rest of fungi (Table 10.1.3.2.2.2). 

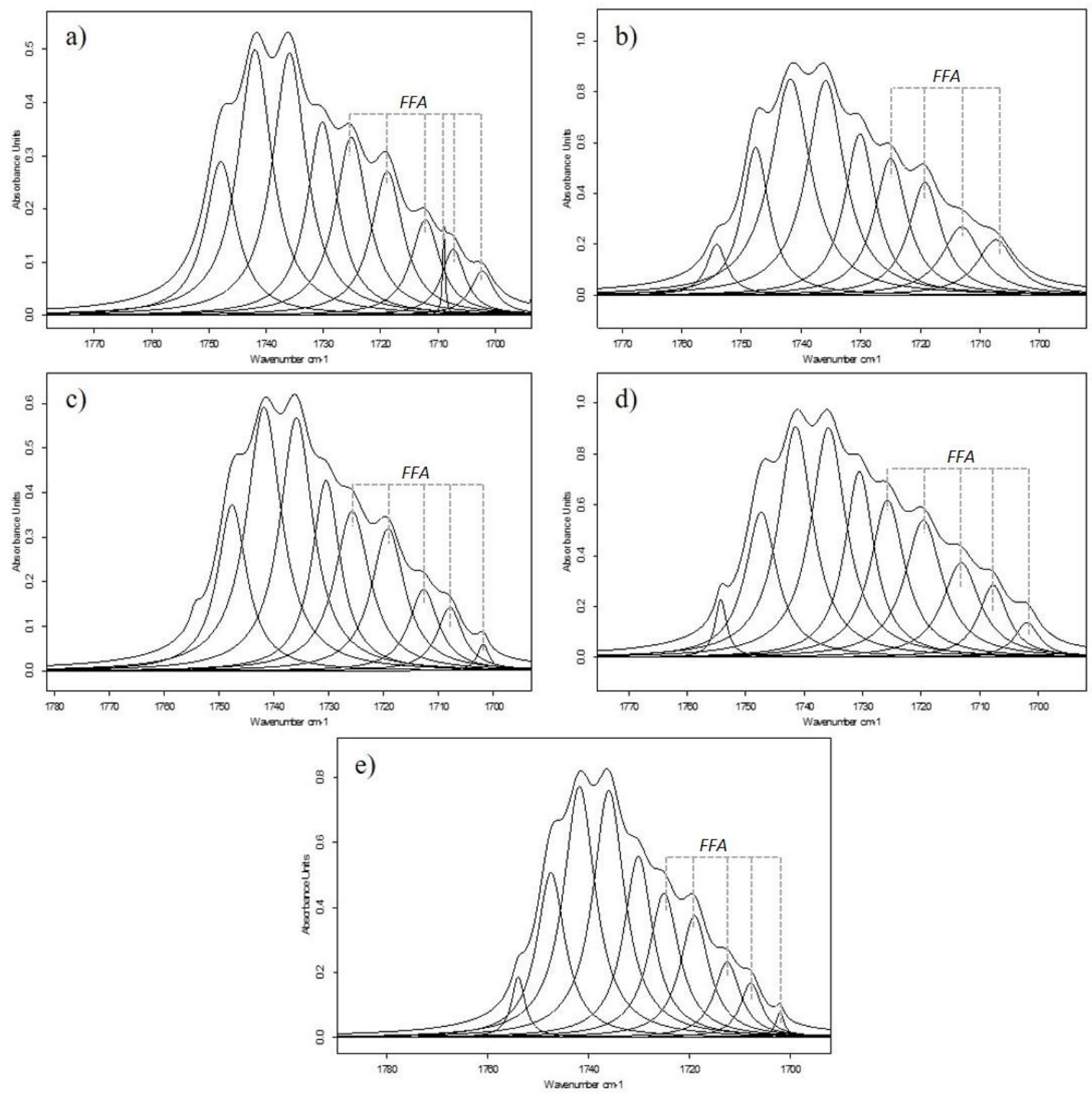

Figure 10.1.3.2.2.3. Carbonyl curve fitted band for EO@Fe inoculated specimen with: a) Acremonium chrysogenum, b) Aspergillus niger, c) Mucor rouxii, d) Penicillium chrysogenum, e) Trichoderma pseudokoningii fungi.

\section{Bacteria}

Figure 10.1.3.2.2.4, shows the $1800-500 \mathrm{~cm}^{-1}$ region of the IR spectra of the reconstructed model paint specimens inoculated with bacteria where bacterial characteristic band of marker compounds of bacteria materials is also market to denote the absence of biomass deposited on the surface of the specimens. 


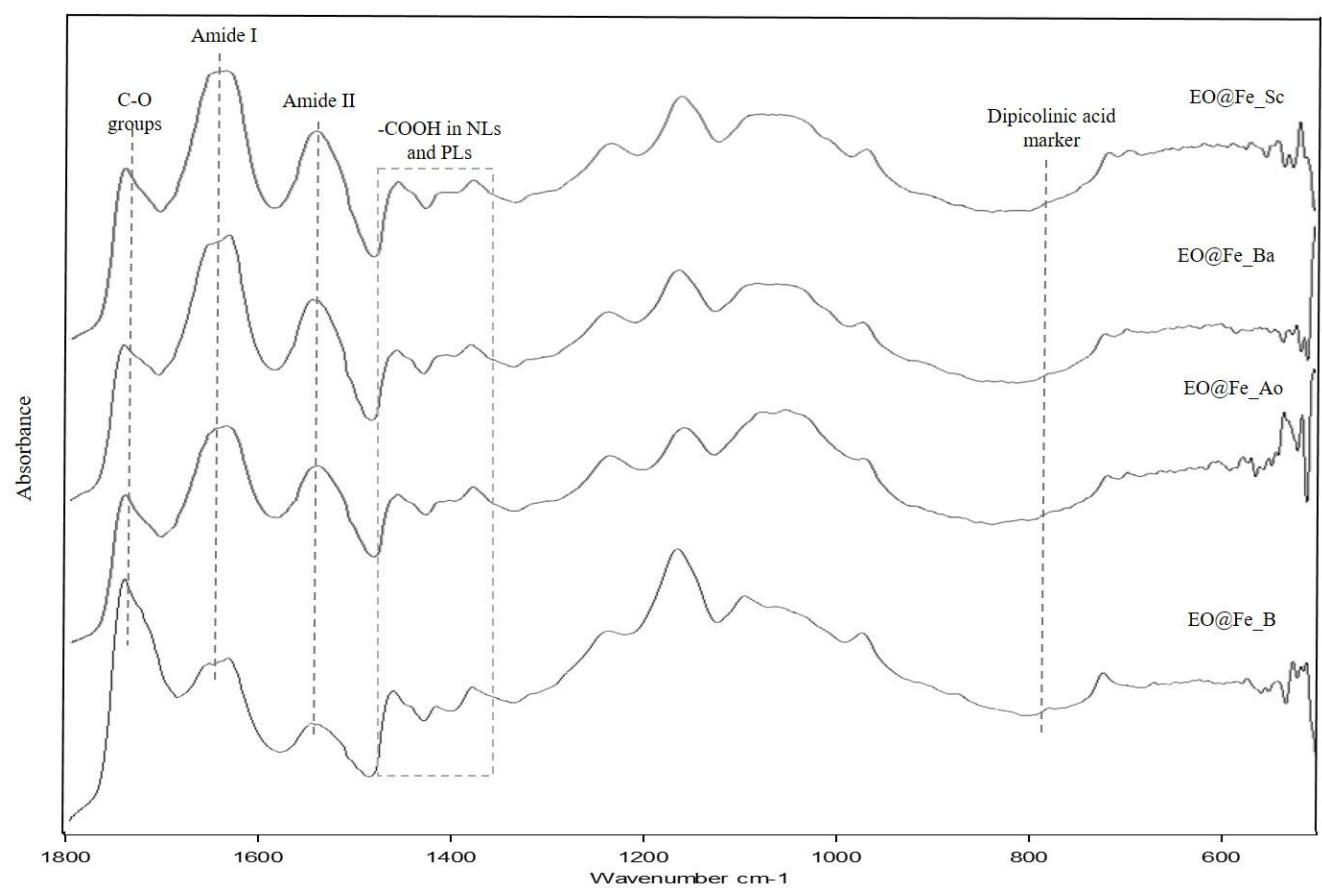

Figure 10.1.3.2.2.4. Detail of the $1800-500 \mathrm{~cm}^{-1}$ IR region and position of the bands characteristic and marker compounds bacterial materials for the EO@Cu uninoculated and inoculated specimens.

The IR spectra obtained for the series of EO@Fe specimens inoculated with bacteria are quite similar to the uninoculated specimen. A slight blueshift of the amide I band from 1630 to $1633 \mathrm{~cm}^{-1}$ was observed in all the specimens. Curve fitting of the amide I allow the identification of the protein secondary structures conformations, as in the paint films inoculated with fungi, the bacteria inoculated specimens show a decrease of the $\alpha$-helix conformation contribution (Figure 10.1.3.2.2.5). The conformation percent contribution of turns is also recognized (Table 10.1.3.2.2.3). The most significant changes were observed in the specimen inoculated with the actinobacterium Streptomyces cellulofans, which exhibits an important increment for the random coil conformation and a decrease of the intermolecular and intramolecular $\beta$-sheet conformation contribution. These results suggest that this bacterium promotes the formation of more open structures in which the side chain groups of the polypeptides are rearrangement in order to be more accessible to the external medium. This behavior is in agreement with the increment in the $\mathrm{I}_{\mathrm{AII}} / \mathrm{I}_{\mathrm{AI}}$ ratio observed in this specimen (Table 10.1.3.2.2.4). 

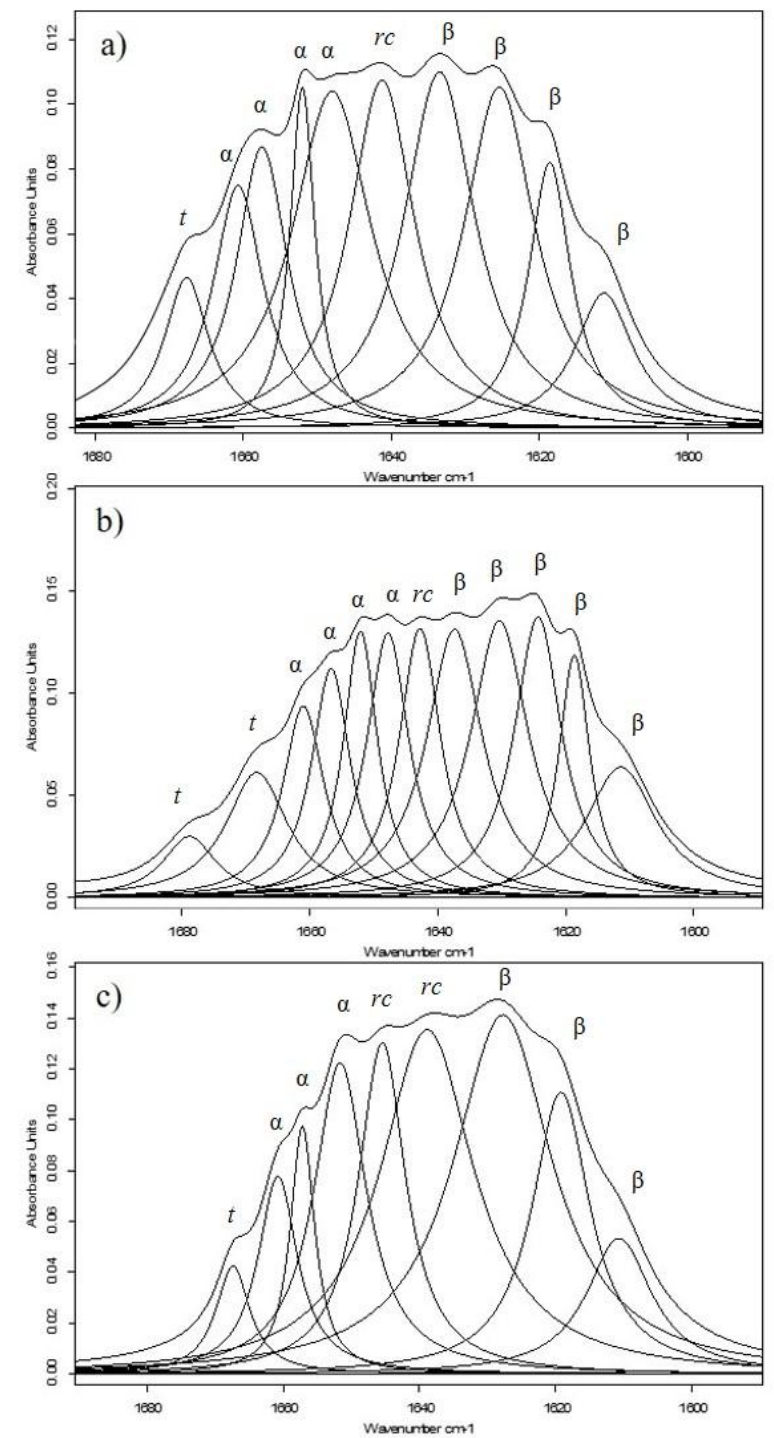

Figure 10.1.3.2.2.5. Amide I curve fitting band for EO@Fe inoculated specimens with: a) Arthrobacter oxydans, b) Bacillus amyloliquefaciens, c) Streptomyces cellulofans bacteria with fitted band components. Assignment of bands conformations: $\beta$-sheet $(\beta)$, random coil $(\mathrm{rc}), \alpha$-helix $(\alpha)$ and turns ( $\mathrm{t})$.

Table 10.1.3.2.2.3. Percent area contribution of amide I components for EO@Fe reconstructed model paint specimens uninoculated and inoculated with bacteria.

\begin{tabular}{|c|c|c|c|c|}
\hline $\begin{array}{c}\text { Predominant } \\
\text { conformations }\end{array}$ & EO@Fe & EO@Fe_Ao & EO@Fe_Ba & EO@Fe_Sc \\
\hline Intermolecular $\beta$-sheet & 20 & 33 & 28 & 16 \\
\hline Intramolecular $\beta$-sheet & 24 & 17 & 27 & 3 \\
\hline Random coil & 15 & 12 & 6 & 30 \\
\hline$\alpha$-helix & 40 & 34 & 26 & 20 \\
\hline Turns & - & 4 & 12 & 3 \\
\hline
\end{tabular}


Table 10.1.3.2.2.4. $\mathrm{I}_{\mathrm{AII}} / \mathrm{I}_{\mathrm{AI}}$ and $\mathrm{I}_{\mathrm{FFA}} / \mathrm{I}_{\mathrm{E}}$ band ratios obtained for the iron oxide red egg oil emulsion reconstructed model paint specimens uninoculated and inoculated with bacteria.

\begin{tabular}{|c|c|c|}
\hline Specimen & $\mathbf{I}_{\mathbf{A I I}} / \mathbf{I}_{\mathbf{A I}}$ intensity ratio & $\mathbf{I}_{\mathbf{F F A}} / \mathbf{I}_{\mathbf{E}}$ ratio \\
\hline EO@Fe_B & 1.25 & 0.75 \\
\hline EO@Fe_Ao & 1.36 & 0.69 \\
\hline EO@Fe_Ba & 2.24 & 0.71 \\
\hline EO@Fe_Sc & 2.96 & 0.89 \\
\hline
\end{tabular}

Figure 10.1.3.2.2.6, shows the curve fitted bands in the carbonyl region $\left(1800-1700 \mathrm{~cm}^{-1}\right)$. The results obtained confirms that Streptomyces cellulofans eubacterium promotes the formation of free fatty acids in a more effective way if compared to the other actinobacterium Arthrobacter oxydans whose deteriorating activity on the binding medium has been less effective. The high FFA relative content reported for EO@Fe_Sc is in agreement with the slightly increase observed in the band at $1377 \mathrm{~cm}^{-1}$. Intensity increment of this band is produced by the ester group hydrolysis and the release of FFA (Cagnasso et al., 2010). Comparison of the $\mathrm{I}_{\mathrm{AII}} / \mathrm{I}_{\mathrm{AI}}$ and $\mathrm{I}_{\mathrm{FFA}} / \mathrm{I}_{\mathrm{E}}$ ratios (Table 10.1.3.2.2.4) of the inoculated specimens and blank indicates that all the microorganisms were especially active promoting hydrolysis and metal complexation. In particular, Streptomyces cellulofans was also active in enzymatic transformation resulting in volatile end-products. 

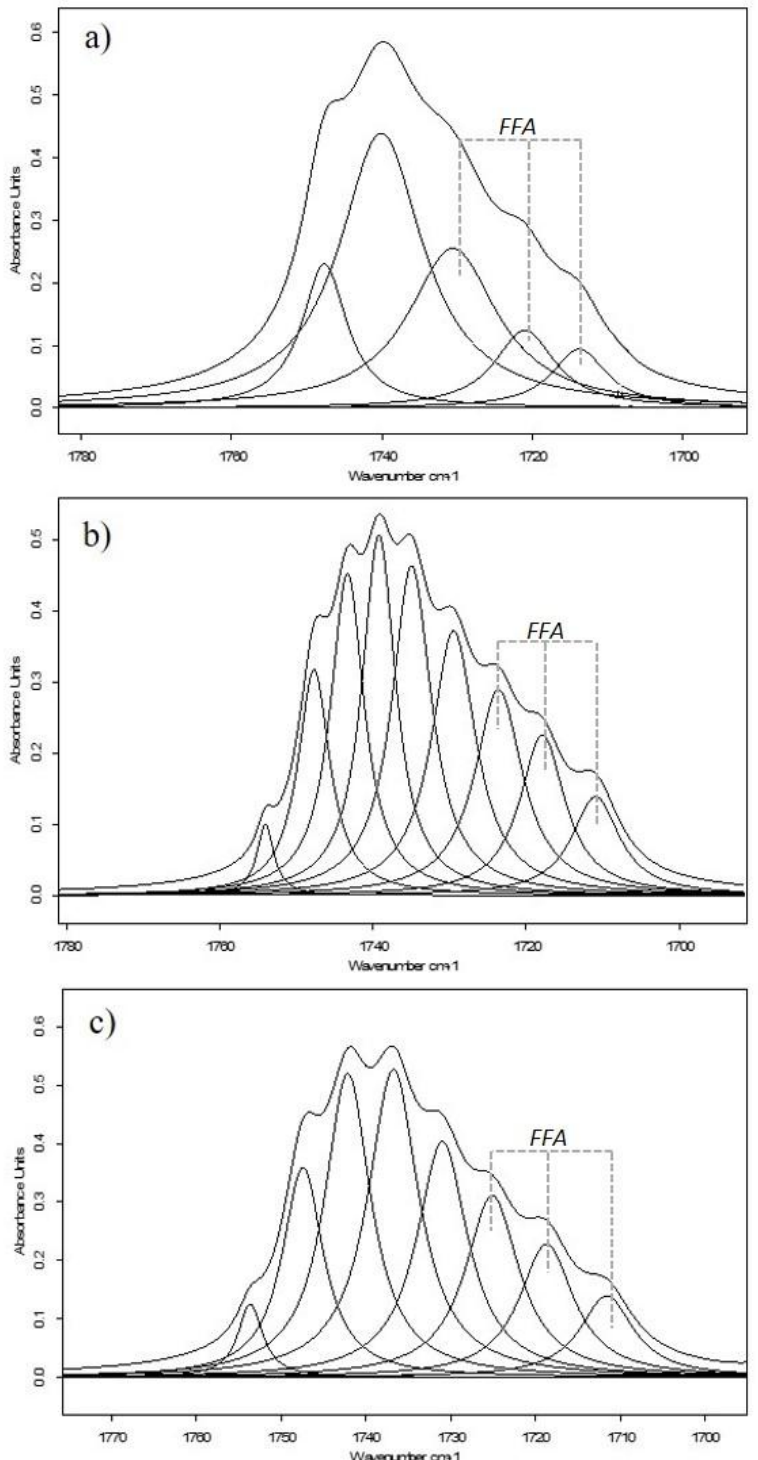

Figure 10.1.3.2.2.6. Carbonyl curve fitted band for EO@Fe inoculated specimen with: a) Arthrobacter oxydans, b) Bacillus amyloliquefaciens, c) Streptomyces cellulofans bacteria.

\section{Verdigris}

\section{Fungi}

The effect of microorganism on the paint films has resulted, in general, in slight changes in the previously described IR bands for egg tempera associated to the amide I, amide II and carbonyl groups. Figure 10.1.3.2.2.7, shows a detail of the $1800-500 \mathrm{~cm}^{-1}$ region in the IR spectra where more remarkable changes have been observed for the egg tempera paint film specimens inoculated with fungi. No significant changes were observed for the band assigned to amide A $\left(3278 \mathrm{~cm}^{-1}\right)$, and the amide B $\left(3069 \mathrm{~cm}^{-1}\right)$. Position of the characteristic band of marker compounds of fungal biomass is also included to denote the absence of biomass deposited on the surface of inoculated reconstructed paint films specimens 


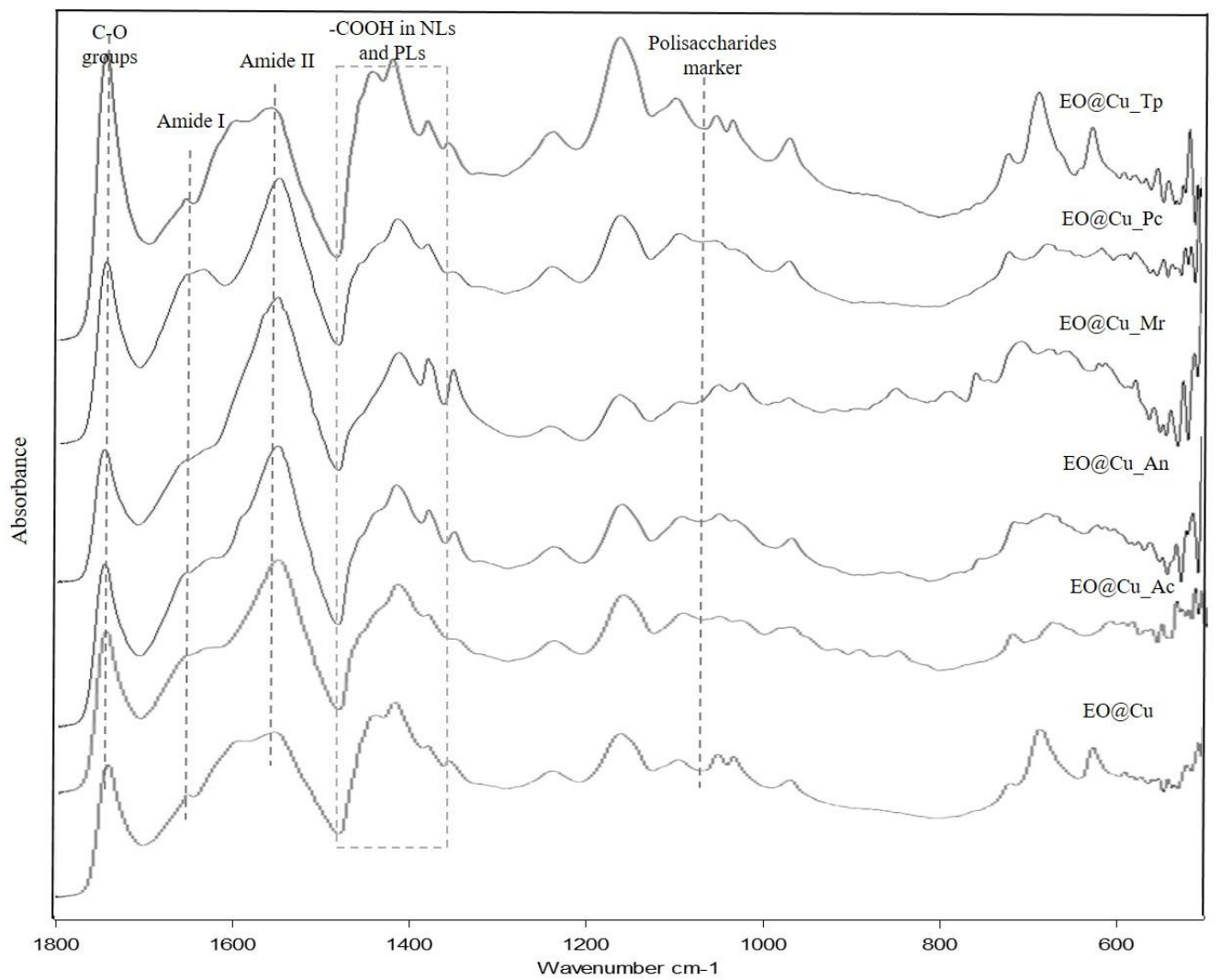

Figure 10.1.3.2.2.7. Detail of the $1800-500 \mathrm{~cm}^{-1}$ IR region and position of the bands characteristic and marker compounds fungal materials for the $\mathrm{EO} @ \mathrm{Cu}$ uninoculated and inoculated specimens.

The pain film inoculated with Trichoderma pseudokoningii presented a IR spectrum close to that of the uninoculated specimen with maximum of $\alpha$-helix conformation at $1648 \mathrm{~cm}^{-1}$ and $\beta$-sheet sub-band overlapped by the plateau appearing from verdigris and $\mathrm{Cu}$-carboxylate complexes (Figure 10.1.3.2.2.8). IR spectra obtained in paint films inoculated with Mucor rouxii, Acremonium chrysogenum and Aspergillus niger exhibited discernible maxima of $\beta$ sheet sub-band at $1621 \mathrm{~cm}^{-1}$ (Figure 10.1.3.2.2.8a, b and c, respectively). FSD and curve fitting applied on the IR spectra obtained for the inoculated specimens show prevalence of intramolecular $\beta$-sheet and random coil conformations in the $\mathrm{EO} @ \mathrm{Cu}_{-} \mathrm{Ac}, \mathrm{EO} @ \mathrm{Cu}_{-} \mathrm{An}$, $\mathrm{EO} @ \mathrm{Cu}_{-} \mathrm{Mr}$ and $\mathrm{EO} @ \mathrm{Cu}_{-} \mathrm{Pc}$ specimens accompanied of an increment in the $\alpha$-helix conformation in all the inoculated specimen with fungi (Table 10.1.3.2.2.5). These changes may be associated to the transformation of the protein and polypeptide chains into more open structures promoted the action of these microorganisms. Mucor rouxii could be considered the most aggressive microorganism in this type of paint film, based on the results summarized in the Table 10.1.3.2.2.5. The disappearance of intermolecular $\beta$-sheet conformation is correlated with an increase in the $\mathrm{I}_{\mathrm{AII}} / \mathrm{I}_{\mathrm{AI}}$ ratio (Table 10.1.3.2.2.6). Absence of this conformation characteristic of pure protein interactions has been associated to a disruption in the protein-protein intermolecular interactions (Duce et al., 2012, 2013; Mazzeo et al., 2008), which confirms that this microorganism is not only promoting hydrolysis of the binder but also affecting its structure at a higher extent if compared to the rest of $\mathrm{EO} @ \mathrm{Cu}$ specimens inoculated with fungi. 
Shoulder at $1585 \mathrm{~cm}^{-1}$ ascribed to $\mathrm{Cu}$-carboxylate complexes with fatty acids and amino acids was recognizable in the profile of the amide II band. Amide I band was well-resolved in the IR spectrum of the film inoculated with Penicillium chrysogenum with maximum in the $\beta$ sheet region at $1630 \mathrm{~cm}^{-1}$ accompanied with weak features characteristic of $\mathrm{Cu}$-carboxylate.
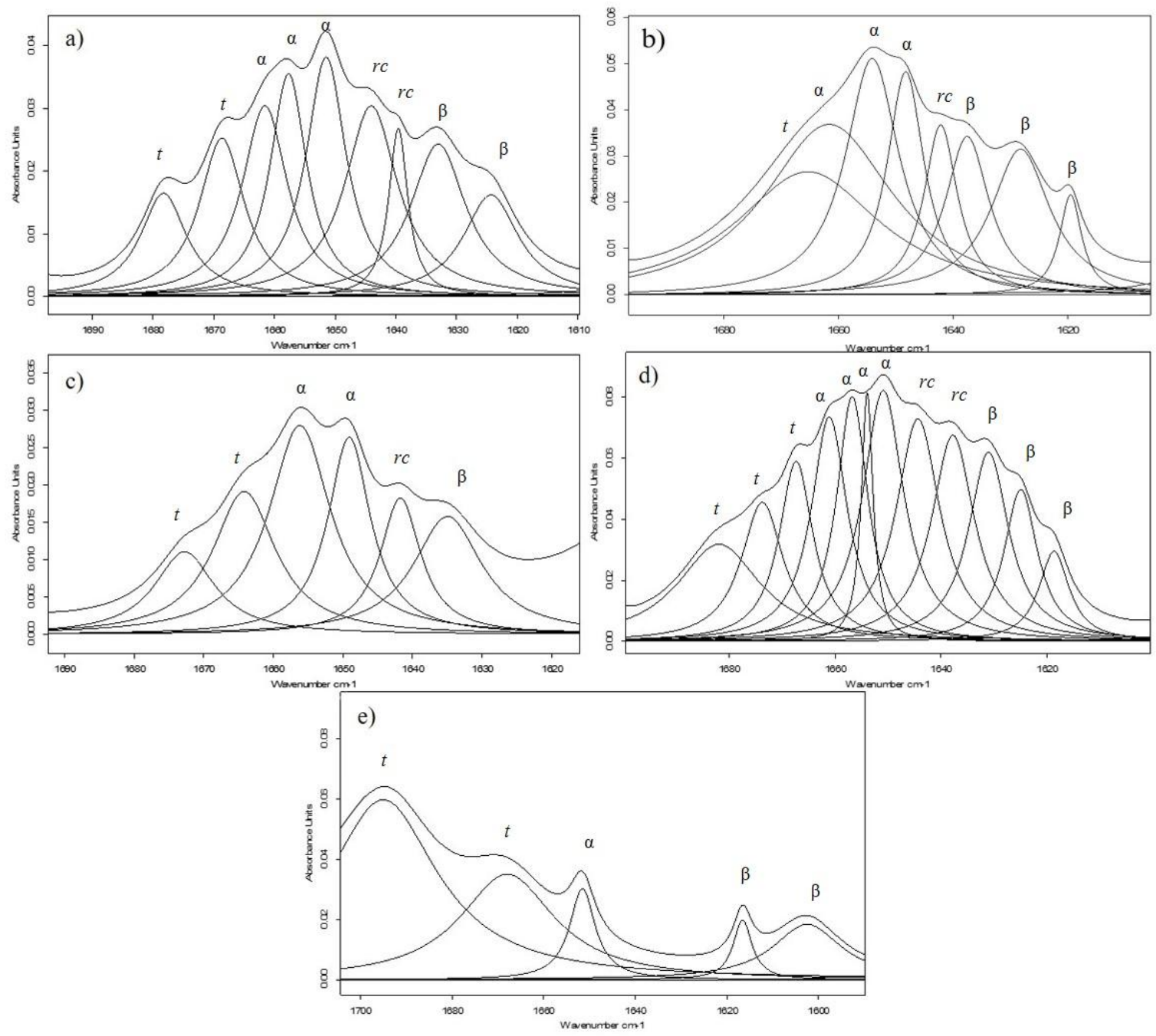

Figure 10.1.3.2.2.7. Amide curve fitting band for EO@Cu inoculated specimens with: a) Acremonium chrysogenum, b) Aspergillus niger, c) Mucor rouxii, d) Penicillium chrysogenum, e) Trichoderma pseudokoningii fungi with fitted band components. Assignment of bands conformations: $\beta$-sheet $(\beta)$, random coil (rc), $\alpha$-helix $(\alpha)$ and turns (t).

Table 10.1.3.2.2.5. Percent area contribution of amide I components for EO@ $\mathrm{Cu}$ reconstructed model paint specimens uninoculated and inoculated with fungi.

\begin{tabular}{|c|c|c|c|c|c|c|}
\hline $\begin{array}{c}\text { Predominant } \\
\text { conformations }\end{array}$ & EO@Cu & EO@Cu_Ac & EO@Cu_An & EO@Cu_Mr & EO@Cu_Pc & EO@Cu_Tp \\
\hline $\begin{array}{c}\text { Intermolecular } \\
\beta \text {-sheet }\end{array}$ & 17 & 10 & 3 & - & 10 & 14 \\
\hline $\begin{array}{c}\text { Intramolecular } \\
\beta \text {-sheet }\end{array}$ & - & 15 & 22 & 17 & 10 & - \\
\hline Random coil & - & 17 & 3 & 7 & 22 & - \\
\hline$\alpha$-helix & 7 & 36 & 42 & 48 & 30 & 5 \\
\hline Turns & 76 & 21 & 30 & 27 & 28 & 81 \\
\hline
\end{tabular}


Table 10.1.3.2.2.6. $\mathrm{I}_{\mathrm{AII}} / \mathrm{I}_{\mathrm{AI}}$ and $\mathrm{I}_{\mathrm{FFA}} / \mathrm{I}_{\mathrm{E}}$ band ratios obtained for the verdigris egg oil emulsion reconstructed model paint specimens uninoculated and inoculated with fungi.

\begin{tabular}{|c|c|c|}
\hline Specimen & $\mathbf{I}_{\mathrm{AII}} / \mathbf{I}_{\mathbf{A I}}$ intensity ratio & $\mathbf{I}_{\mathbf{F F A}} / \mathbf{I}_{\mathbf{E}}$ ratio \\
\hline EO@Cu_B & 2.50 & 0.22 \\
\hline EO@Cu_Ac & 1.32 & 0.23 \\
\hline EO@Cu_An & 1.84 & 0.19 \\
\hline EO@Cu_Mr & 1.68 & 0.18 \\
\hline EO@Cu_Pc & 1.21 & 0.22 \\
\hline EO@Cu_Tp & 1.73 & 0.23 \\
\hline
\end{tabular}

The inoculated egg oil emulsion paint films, similarly to the uninoculated specimen, exhibited characteristic $\mathrm{C}=\mathrm{O}$ stretching band at $1710-1700 \mathrm{~cm}^{-1}$ ascribed to free fatty acids that denote that hydrolysis of lipids has taken place at some extent. Curve fitting of the carbonyl band allows the quantification of the free fatty acids contribution associated to the action of each fungi (Figure 10.1.3.2.2.8). No significant changes were observed in the free fatty acids contribution if compared to the uninoculated specimen (Table 10.1.3.2.2.6). Comparison of the $\mathrm{I}_{\mathrm{AII}} / \mathrm{I}_{\mathrm{AI}}$ and $\mathrm{I}_{\mathrm{FFA}} / \mathrm{I}_{\mathrm{E}}$ ratios of the inoculated specimens and blank indicates that microorganisms in $\mathrm{EO} @ \mathrm{Cu}$ specimens exhibited reduced activity. This could be tentatively associated to the inhibitory effect of this pigment. 

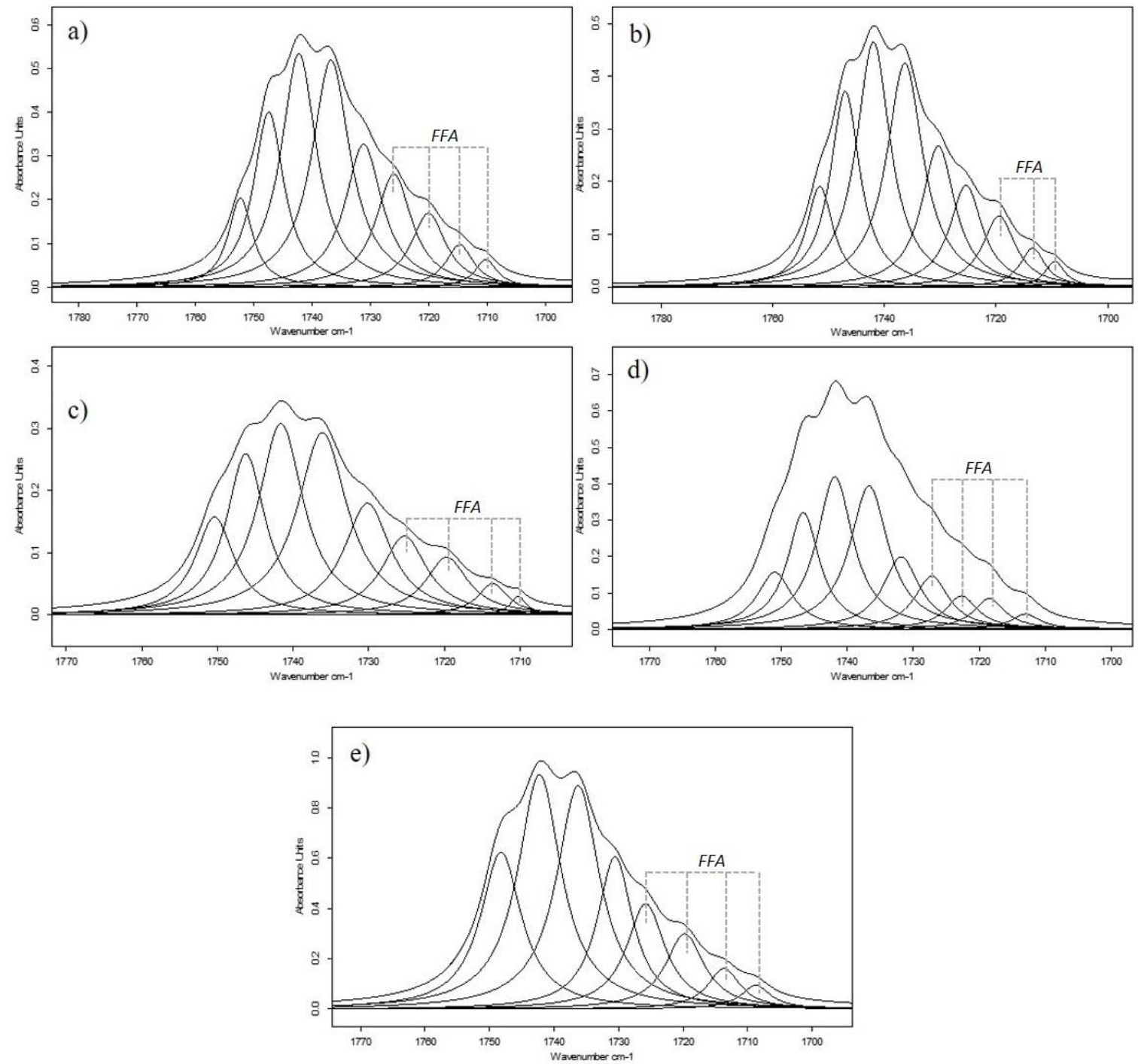

Figure 10.1.3.2.2.8. Carbonyl curve fitted band for EO@Cu inoculated specimen with: a) Acremonium chrysogenum, b) Aspergillus niger, c) Mucor rouxii, d) Penicillium chrysogenum, e) Trichoderma pseudokoningii fungi.

\section{Bacteria}

Figure 10.1.3.2.2.9, shows the $1800-500 \mathrm{~cm}^{-1}$ region of the IR spectra of the reconstructed model paint specimens uninoculated and inoculated with bacteria. The characteristic band of marker compounds in bacteria inoculated specimens is also marked to denote the complete removing of bacterial biomass from the specimens. 


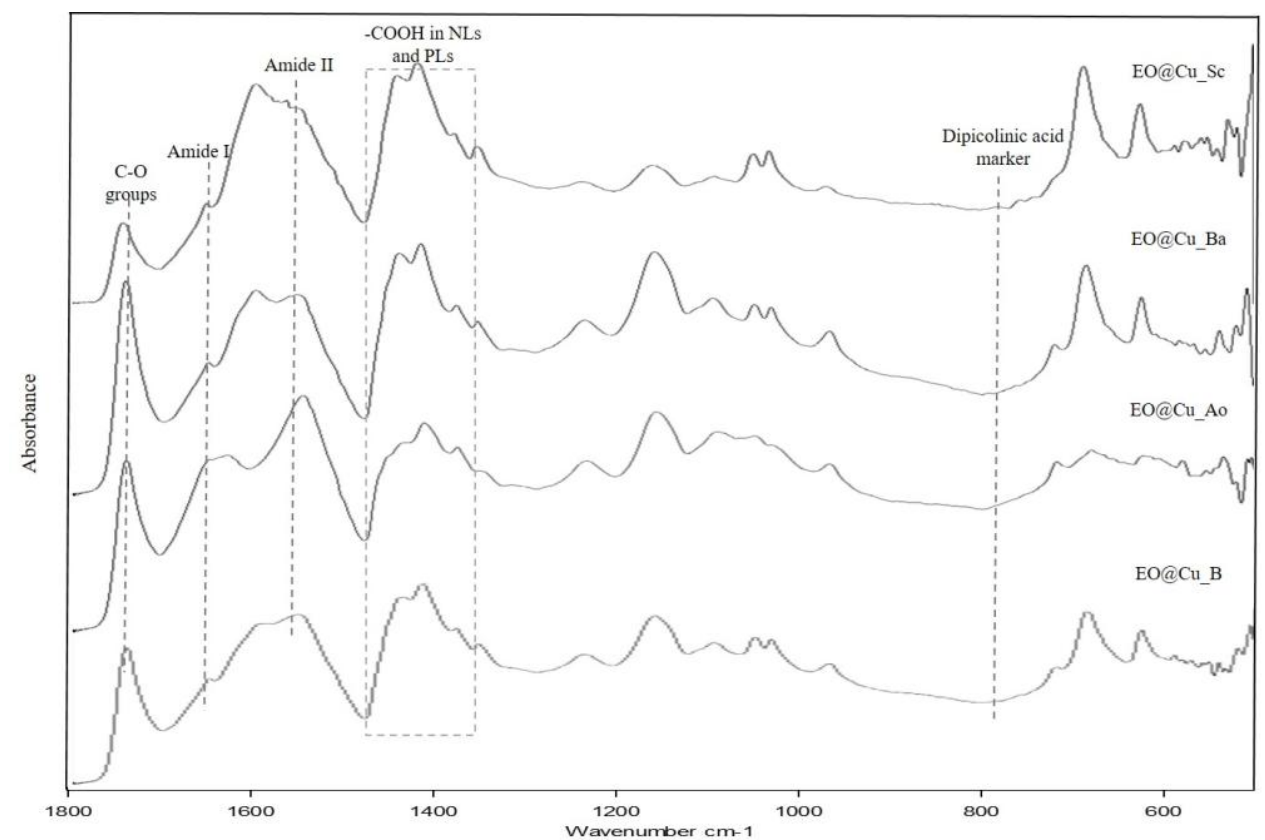

Figure 10.1.3.2.2.9. Detail of the $1800-500 \mathrm{~cm}^{-1}$ IR region and position of the bands characteristic and marker compounds bacterial materials for the $\mathrm{EO} @ \mathrm{Cu}$ uninoculated and inoculated specimens.

The IR spectra of the egg oil emulsion paint films inoculated with actinobacteria Arthrobacter oxydans and Streptomyces cellulofans exhibited different behavior. EO@Cu_Ao showed well resolved amide I band with maximum in the $\beta$-sheet region at 1628 $\mathrm{cm}^{-1}$ accompanied of $\alpha$-helix secondary maximum at $1648 \mathrm{~cm}^{-1}$. Cu-carboxylate complexes and verdigris bands were completely overlapped with amide II. In contrast, EO@Cu_Sc showed an IR spectrum quite similar to that of the EO@Cu_Ba corresponding to the eubacterium Bacillus amyloliquefaciens and close to that of the uninoculated specimen with maximum of $\alpha$-helix conformation at $1650 \mathrm{~cm}^{-1}$ and $\beta$-sheet sub-band overlapped by the plateau appearing band from verdigris and $\mathrm{Cu}$-carboxylate complexes. Quantification of the protein secondary structures was performed by applying FSD and curve fitting procedures (Figure 10.1.3.2.2.10). Table 10.1.3.2.2.7summarizes the values of percentage conformation contribution obtained for each paint film inoculated with bacteria. As previously mentioned, results found in the paint film inoculated with the eubacterium Bacillus amyloliquefaciens are very similar to those obtained for the uninoculated specimen. Increase in the $\alpha$-helix conformation contribution and decrease on the turns conformation contribution were observed. The most significant changes were obtained for the actinobacterium Arthrobacter oxydans where intramolecular $\beta$-sheet and random coils conformations were intensified. The increase of these two conformations combined with a decrease in the intermolecular $\beta$-sheet conformation contribution suggests that this actinobacterium promoted alteration in the protein-protein interactions, taking place at some extent the formation of more open structures in which functional groups present in the side chains of the polypeptides are more accessible. Increase of the $\mathrm{I}_{\mathrm{AII}} / \mathrm{I}_{\mathrm{AI}}$ value was obtained for $\mathrm{EO} @ \mathrm{Cu}_{-} \mathrm{Ba}$ and $\mathrm{EO} @ \mathrm{Cu} \mathrm{Cu}_{\mathrm{Sc}}$ specimens although this change is obscured by the overlapping with the band ascribed to $\mathrm{Cu}$ carboxylates (Table 10.1.3.2.2.8). 

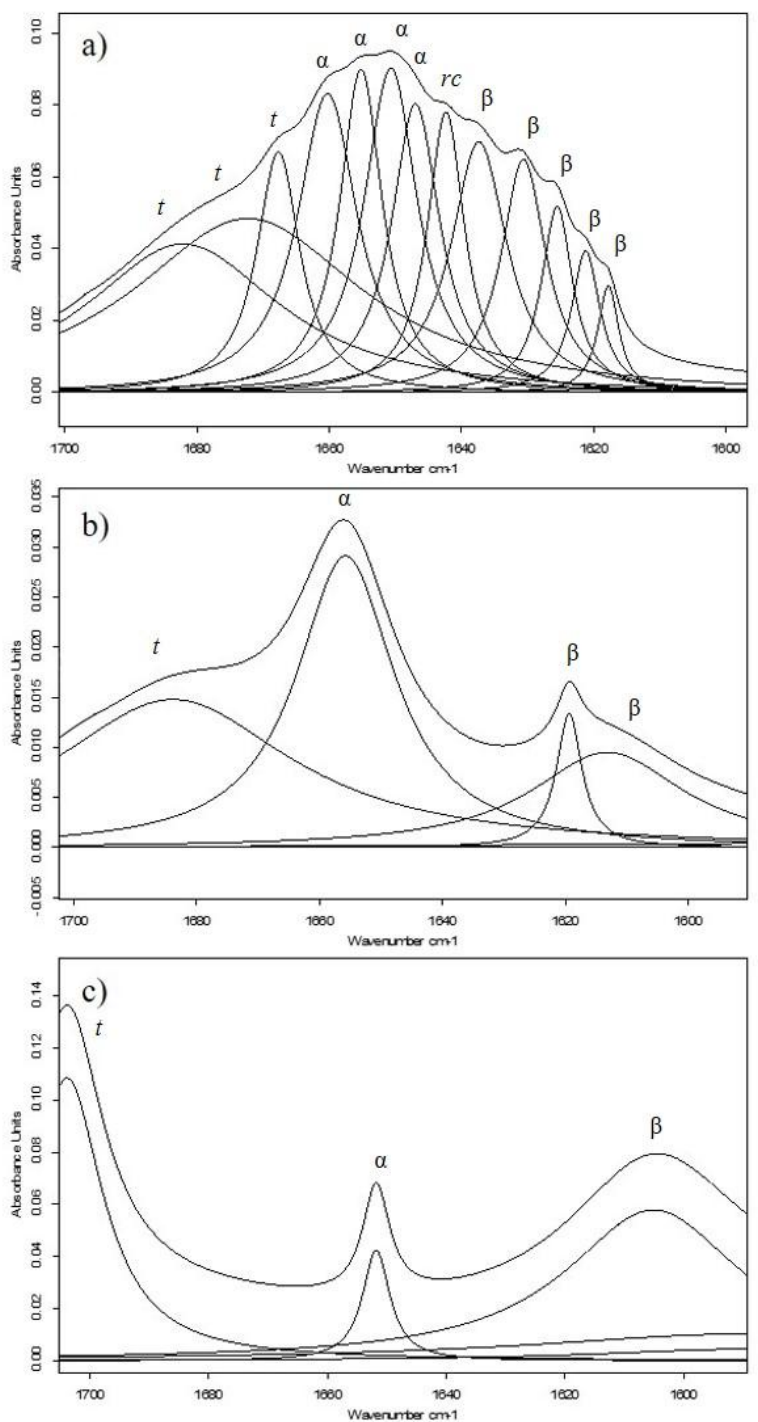

Figure 10.1.3.2.2.10. Amide I curve fitting band for $\mathrm{EO} @ \mathrm{Cu}$ inoculated specimens with: a) Arthrobacter oxydans, b) Bacillus amyloliquefaciens, c) Streptomyces cellulofans bacteria with fitted band components. Assignment of bands conformations: $\beta$-sheet $(\beta)$, random coil (rc), $\alpha$-helix $(\alpha)$ and turns $(\mathrm{t})$.

Table 10.1.3.2.2.7. Percent area contribution of amide I components for $\mathrm{EO} @ \mathrm{Cu}$ reconstructed model paint specimens uninoculated and inoculated with bacteria.

\begin{tabular}{|c|c|c|c|c|}
\hline $\begin{array}{c}\text { Predominant } \\
\text { conformations }\end{array}$ & EO@Cu & EO@Cu_Ao & EO@Cu_Ba & EO@Cu_Sc \\
\hline Intermolecular $\beta$-sheet & 17 & 6 & 19 & 53 \\
\hline Intramolecular $\beta$-sheet & - & 15 & - & - \\
\hline Random coil & - & 3 & - & - \\
\hline$\alpha$-helix & 7 & 26 & 35 & 6 \\
\hline Turns & 76 & 49 & 46 & 41 \\
\hline
\end{tabular}


Figure 10.1.3.2.2.11, shows the curve fitted band of the $\mathrm{EO} @ \mathrm{Cu}$ specimens inoculated with bacteria with fitted band components for the carbonyl groups from free fatty acids. Increase in the contribution of the sub-bands ascribed to free fatty acids is more evident in the paint film inoculated with the eubacterium Bacillus amyloliquefaciens (Table 10.1.3.2.2.8). The three specimens inoculated with bacteria showed features of $\mathrm{Cu}$-carboxylate complexes at $1585 \mathrm{~cm}^{-1}$. This band is associated to the stretching vibrations of metal carboxylated groups formed from free fatty acids and carboxylate residues from NLs and PLs. Presence of this band was more evident in the EO@Cu_Ba specimen. Comparison of the $\mathrm{I}_{\mathrm{AII}} / \mathrm{I}_{\mathrm{AI}}$ and $\mathrm{I}_{\mathrm{FFA}} / \mathrm{I}_{\mathrm{E}}$ ratios of the inoculated specimens and blank indicates that microorganisms in EO@Cu_Ba specimen exhibited slightly high hydrolyzing and complexing activity.
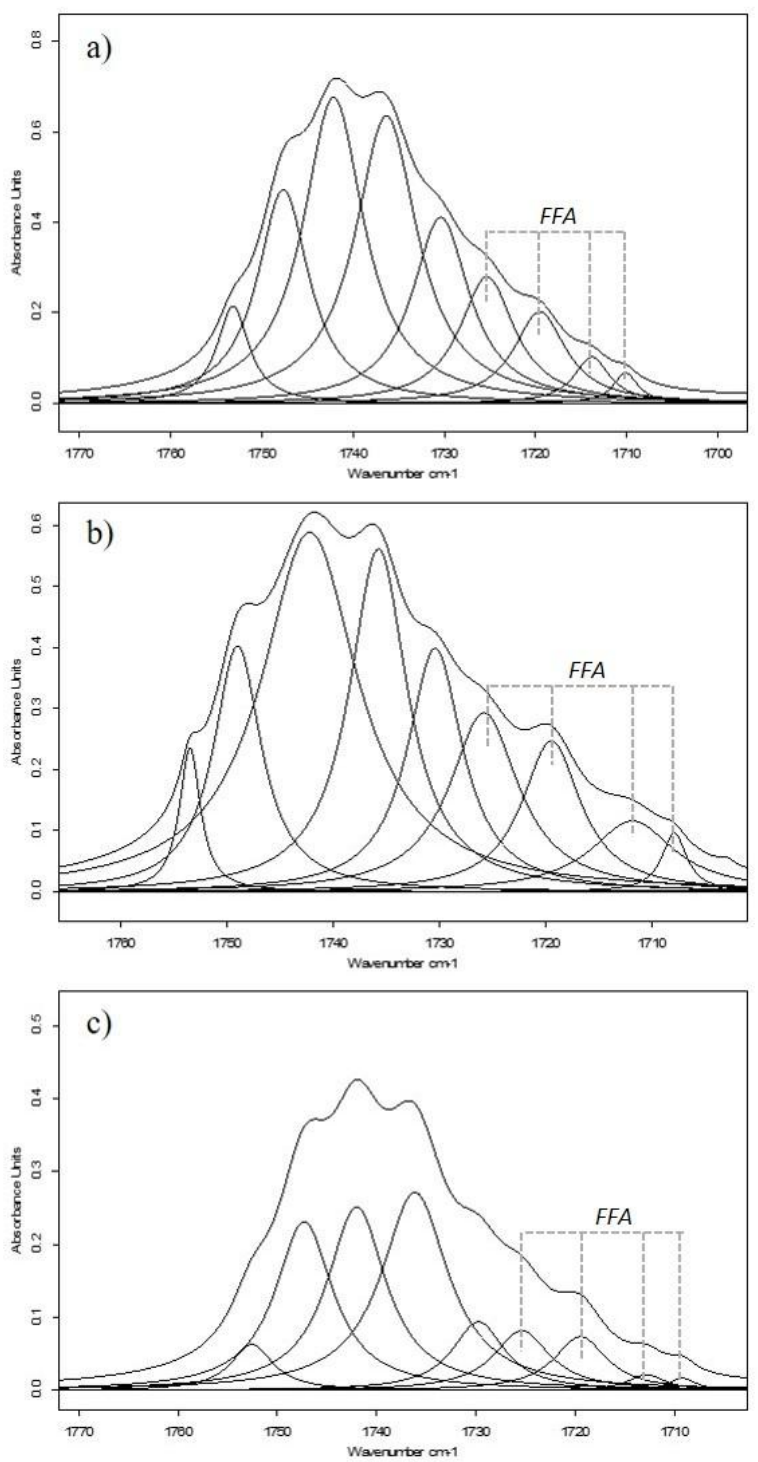

Figure 10.1.3.2.2.11. Carbonyl curve fitted band for EO@Cu inoculated specimen with: a) Arthrobacter oxydans, b) Bacillus amyloliquefaciens, c) Streptomyces cellulofans bacteria. 
Table 10.1.3.2.2.8. $\mathrm{I}_{\mathrm{AII}} / \mathrm{I}_{\mathrm{AI}}$ and $\mathrm{I}_{\mathrm{FFA}} / \mathrm{I}_{\mathrm{E}}$ band ratios obtained for the verdigris egg oil emulsion reconstructed model paint specimens uninoculated and inoculated with bacteria.

\begin{tabular}{|c|c|c|}
\hline Specimen & $\mathbf{I}_{\mathbf{A I I}} / \mathbf{I}_{\mathbf{A I}}$ intensity ratio & $\mathbf{I}_{\mathbf{F F A}} / \mathbf{I}_{\mathbf{E}}$ ratio \\
\hline EO@Cu_B & 2.50 & 0.22 \\
\hline EO@Cu_Ao & 2.58 & 0.19 \\
\hline EO@Cu_Ba & 2.83 & 0.32 \\
\hline EO@Cu_Sc & 2.66 & 0.18 \\
\hline
\end{tabular}

\section{Lead white}

\section{Fungi}

Figure 10.1.3.2.2.12, shows the $1800-500 \mathrm{~cm}^{-1}$ region in the IR spectra of EO@Pb specimens uninoculated and inoculated with fungi, where the more significant changes were observed. As in the previously described specimens, the position of the characteristic bands of the marker compounds of fungal materials has been placed over to signify the absence of these compounds in the specimens.

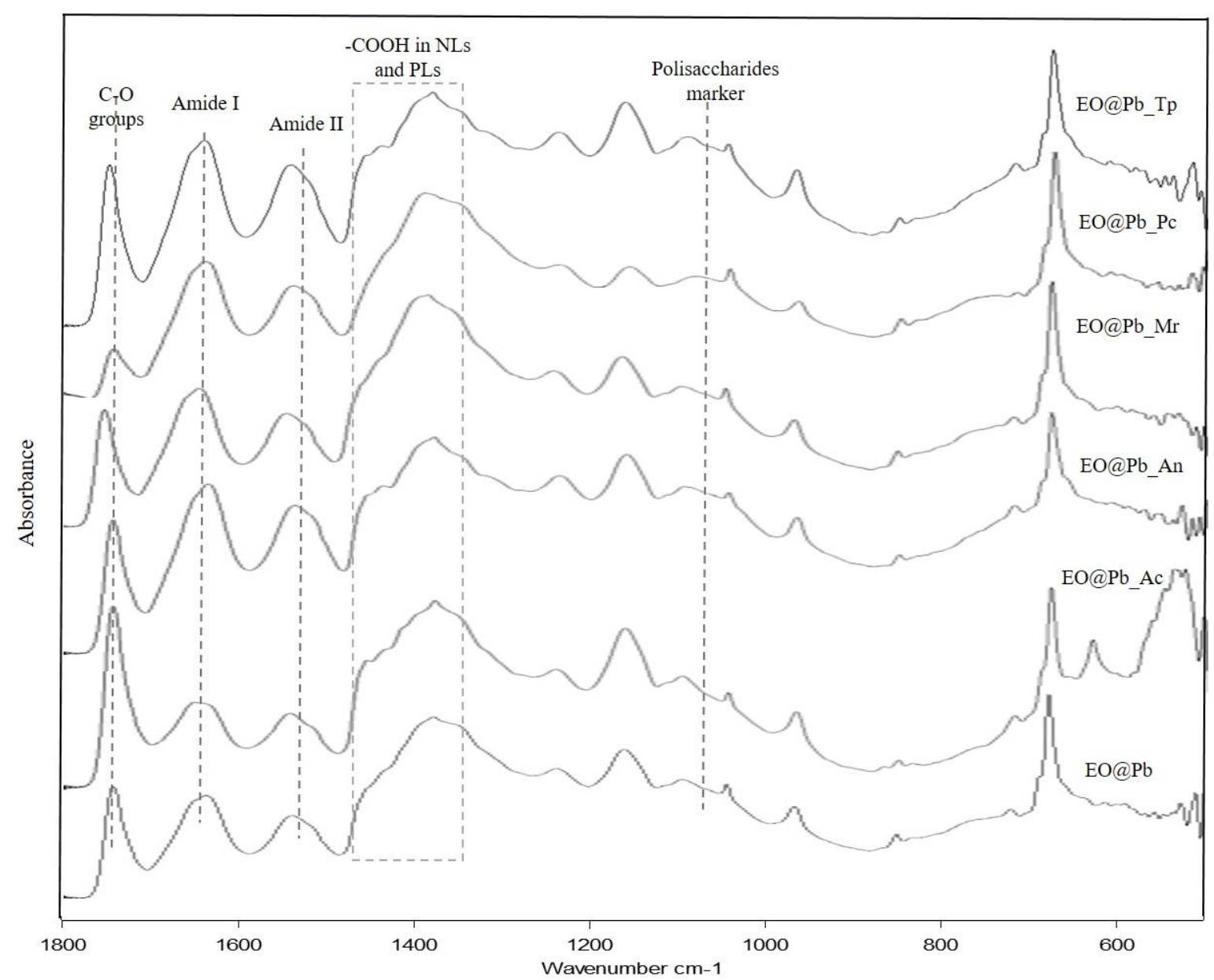

Figure 10.1.3.2.2.12. Detail of the $1800-500 \mathrm{~cm}^{-1}$ IR region and position of the bands characteristic and marker compounds fungal materials for the $\mathrm{EO} @ \mathrm{~Pb}$ uninoculated and inoculated specimens. 
Most significant changes obtained for the $\mathrm{EO} @ \mathrm{~Pb}$ specimen inoculated with fungi were obtained for the IR spectrum of EO@Pb_Ac which showed a blueshift of the maximum of the amide I band from 1651 to $1654 \mathrm{~cm}^{-1}$ that corresponds to the $\alpha$-helix conformation and a plateau at $1646-1637 \mathrm{~cm}^{-1}$ ascribed to the $\beta$-sheet sub-band. Amide II band exhibited a slight increase in the shoulder of the Pb-carboxylate stretching vibration at $1541 \mathrm{~cm}^{-1}$ when compared with that of the IR spectrum of EO@Pb_B. The rest of paint films inoculated with fungi presented an IR spectrum closer to that of the uninoculated specimen. After FSD and curve fitting of the amide I band, some changes in the protein secondary structure conformation contributions were observed (Figure 10.1.3.2.2.13). All the fungi inoculated specimens exhibited an increment of the intramolecular $\beta$-sheet conformation accompanied with the decrease and, in some cases, the absence of random coil conformation, except for EO@Pb_Pc. These results confirm that alteration of the microstructure of the binder is taking place at some extent. Changes in the position of the maximum of the amide I band for the specimen inoculated with Acremonium chrysogenum were also confirmed. FSD and curve fitting showed an important increment in the $\alpha$-helix conformation contribution for this paint film. Table 10.1.3.2.2.9, summarizes the values of the percent conformation contribution obtained for the uninoculated and inoculated EO@Pb specimens. 

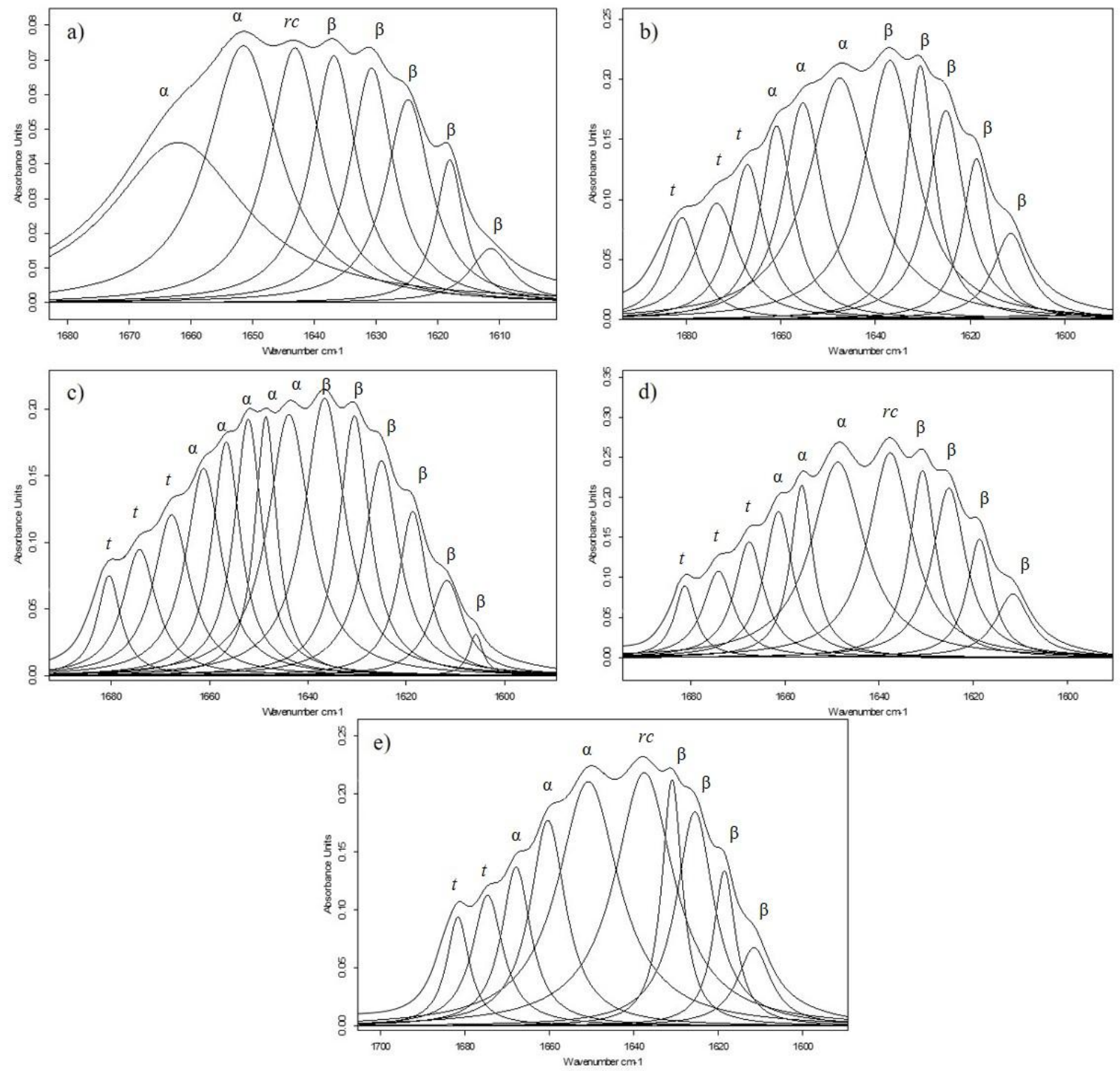

Figure 10.1.3.2.2.13. Amide curve fitting band for EO@Pb inoculated specimens with: a) Acremonium chrysogenum, b) Aspergillus niger, c) Mucor rouxii, d) Penicillium chrysogenum, e) Trichoderma pseudokoningii fungi with fitted band components. Assignment of bands conformations: $\beta$-sheet $(\beta)$, random coil (rc), $\alpha$-helix $(\alpha)$ and turns (t).

Table 10.1.3.2.2.9. Percent area contribution of amide I components for EO@Pb reconstructed model paint specimens uninoculated and inoculated with fungi.

\begin{tabular}{|c|c|c|c|c|c|c|}
\hline $\begin{array}{c}\text { Predominant } \\
\text { conformations }\end{array}$ & $\mathbf{E O} @ \mathbf{P b}$ & EO@Pb_Ac & EO@Pb_An & EO@Pb_Mr & EO@Pb_Pc & $\mathbf{E O} @ \mathbf{P b} \_\mathbf{T} p$ \\
\hline $\begin{array}{c}\text { Intermolecular } \\
\beta \text {-sheet }\end{array}$ & 18 & 15 & 21 & 22 & 23 & 21 \\
\hline $\begin{array}{c}\text { Intramolecular } \\
\beta \text {-sheet }\end{array}$ & 8 & 19 & 27 & 24 & 7 & 31 \\
\hline Random coil & 20 & 10 & - & - & 20 & - \\
\hline$\alpha$-helix & 36 & 56 & 38 & 40 & 38 & 36 \\
\hline Turns & 18 & - & 14 & 2 & 11 & 12 \\
\hline
\end{tabular}


Among the egg oil emulsion paint films inoculated with fungi, that prepared with Penicillium chrysogenum exhibited the more remarkable changes in its IR spectrum, which were mainly associated with the notable decrease in intensity of the $\mathrm{C}=\mathrm{O}$ stretching band at $1742 \mathrm{~cm}^{-1}$ and the appearance of a shoulder in the interval $1710-1701 \mathrm{~cm}^{-1}$ assigned to free fatty acids.

This feature denotes that hydrolysis of lipids has taken place extensively in this paint film. Hydrolysis promoted by Penicillium chrysogenum was confirmed after FSD and curve fitting of the carbonyl band in the region $1800-1690 \mathrm{~cm}^{-1}$ and $\mathrm{I}_{\mathrm{FFA}} / \mathrm{I}_{\mathrm{E}}$ ratio (Table 10.1.3.2.2.10). The results obtained show a high increase of the relative content of FFA in the EO@Pb_Pc specimen (Figure 10.1.3.2.2.14) when compared to the rest of inoculated specimens. In general, the prevalence of $\beta$-sheet as dominant conformation (a less accessible conformation) and the decrease of random coil conformation, is in accordance with the low FFA contribution observed in these specimens. Concomitantly, EO@Pb_Ac specimen exhibits an important increment of the $\alpha$-helix conformation contribution, a more accessible conformation. This specimen also report the highest $\mathrm{I}_{\mathrm{AII}} / \mathrm{I}_{\mathrm{AI}}$ value (Table 10.1.3.2.2.10).

In addition, increase of the bands in the $1070-1040 \mathrm{~cm}^{-1}$ range associated to the partial oxidation of terminal phosphate and aromatic side chains combined with an increase of the band at $1377 \mathrm{~cm}^{-1}$ suggest the presence of unprotonated carbonyl groups on free fatty acids (Cagnasso et al., 2010; Duce et al., 2012). Comparison of the $\mathrm{I}_{\mathrm{AII}} / \mathrm{I}_{\mathrm{AI}}$ and $\mathrm{I}_{\mathrm{FF}} / \mathrm{I}_{\mathrm{E}}$ ratios of the inoculated specimens and blank indicates that microorganisms in EO@Pb_Ac, EO@Pb_An, $\mathrm{EO} @ \mathrm{~Pb} \_\mathrm{Mr}$ and $\mathrm{EO} @ \mathrm{~Pb} \_\mathrm{Pc}$ were more active promoting enzymatic transformation resulting in volatile end-products and metal complexation.

Table 10.1.3.2.2.10. $\mathrm{I}_{\mathrm{AII}} / \mathrm{I}_{\mathrm{AI}}$ and $\mathrm{I}_{\mathrm{FFA}} / \mathrm{I}_{\mathrm{E}}$ band ratios obtained for the lead white egg oil emulsion reconstructed model paint specimens uninoculated and inoculated with fungi.

\begin{tabular}{|c|c|c|}
\hline Specimen & $\mathbf{I}_{\mathrm{AII}} / \mathbf{I}_{\mathbf{A I}}$ intensity ratio & $\mathbf{I}_{\mathbf{F F} A} / \mathbf{I}_{\mathbf{E}}$ ratio \\
\hline EO@Pb_B & 1.14 & 0.18 \\
\hline EO@Pb_Ac & 2.25 & 0.18 \\
\hline EO@Pb_An & 1.62 & 0.10 \\
\hline EO@Pb_Mr & 1.93 & 0.15 \\
\hline EO@Pb_Pc & 1.05 & 0.22 \\
\hline EO@Pb_Tp & 1.28 & 0.11 \\
\hline
\end{tabular}



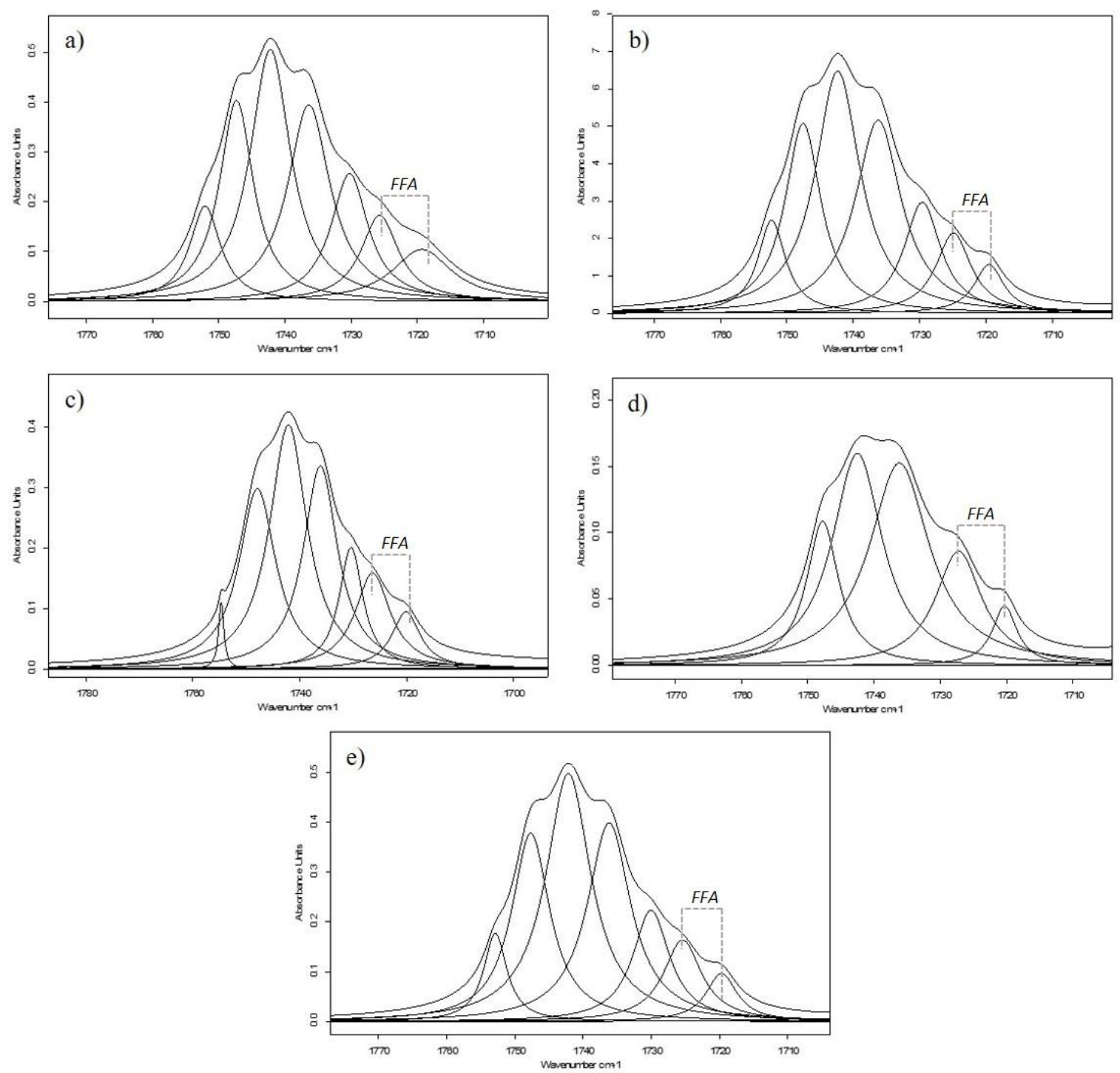

Figure 8.3.2.2.14. Carbonyl curve fitted band for EO@Pb inoculated specimen with: a) Acremonium chrysogenum, b) Aspergillus niger, c) Mucor rouxii, d) Penicillium chrysogenum, e) Trichoderma pseudokoningii fungi.

\section{Bacteria}

Figure 10.1.3.2.2.15, shows detail of the IR spectra $1800-500 \mathrm{~cm}^{-1}$ region obtained for the $\mathrm{EO} @ \mathrm{~Pb}$ specimen inoculated with bacteria, where more significant changes has been observed with the characteristic bacterial compound marker, which denotes the absence of bacterial material deposited on the surface of the paint films specimens. 


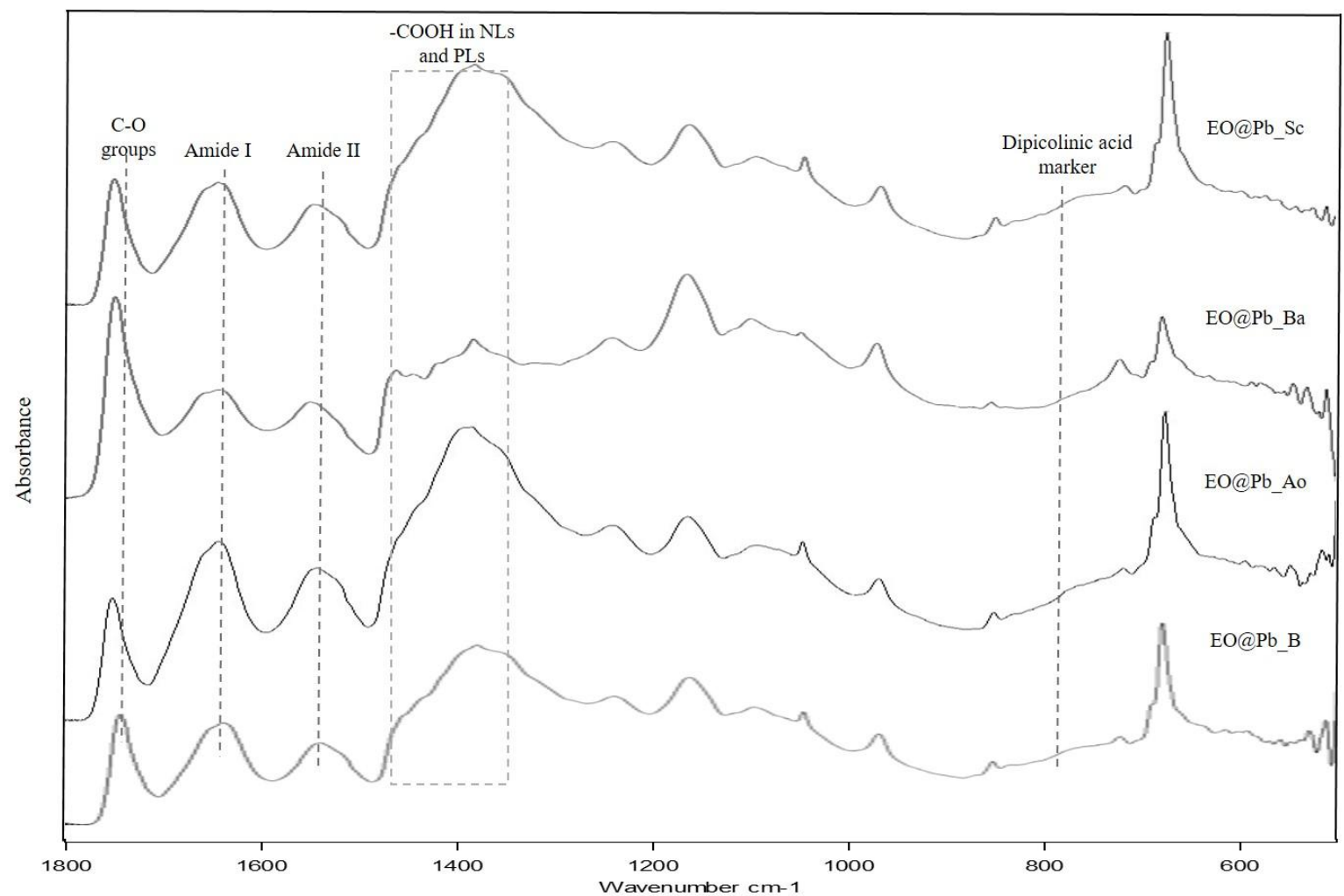

Figure 10.1.3.2.2.15. Detail of the $1800-500 \mathrm{~cm}^{-1}$ IR region and position of the bands characteristic and marker compounds bacterial materials for the $\mathrm{EO} @ \mathrm{~Pb}$ uninoculated and inoculated specimens.

The most significant changes obtained for the specimens inoculated with bacteria were observed in the specimen inoculated with the eubacterium Bacillus amyloliquefaciens. The profile of the amide I band was characterized by the increase of the intensity of the sub-band corresponding to the $\alpha$-helix conformation at $1650 \mathrm{~cm}^{-1}$ and the appearance of a plateau at $1637-1633 \mathrm{~cm}^{-1}$ ascribed to the random coil sub-band. The FSD and curve fitting of the amide I band carried out in the EO@PB_Ba (Figure 10.1.3.2.2.16b), showed that the dominant conformation was intramolecular $\beta$-sheet (Table 10.1.3.2.2.11). In correlation with these results is the high value of the $\mathrm{I}_{\mathrm{AII}} / \mathrm{I}_{\mathrm{AI}}$ intensity ratio (Table 10.1.3.2.2.12). 

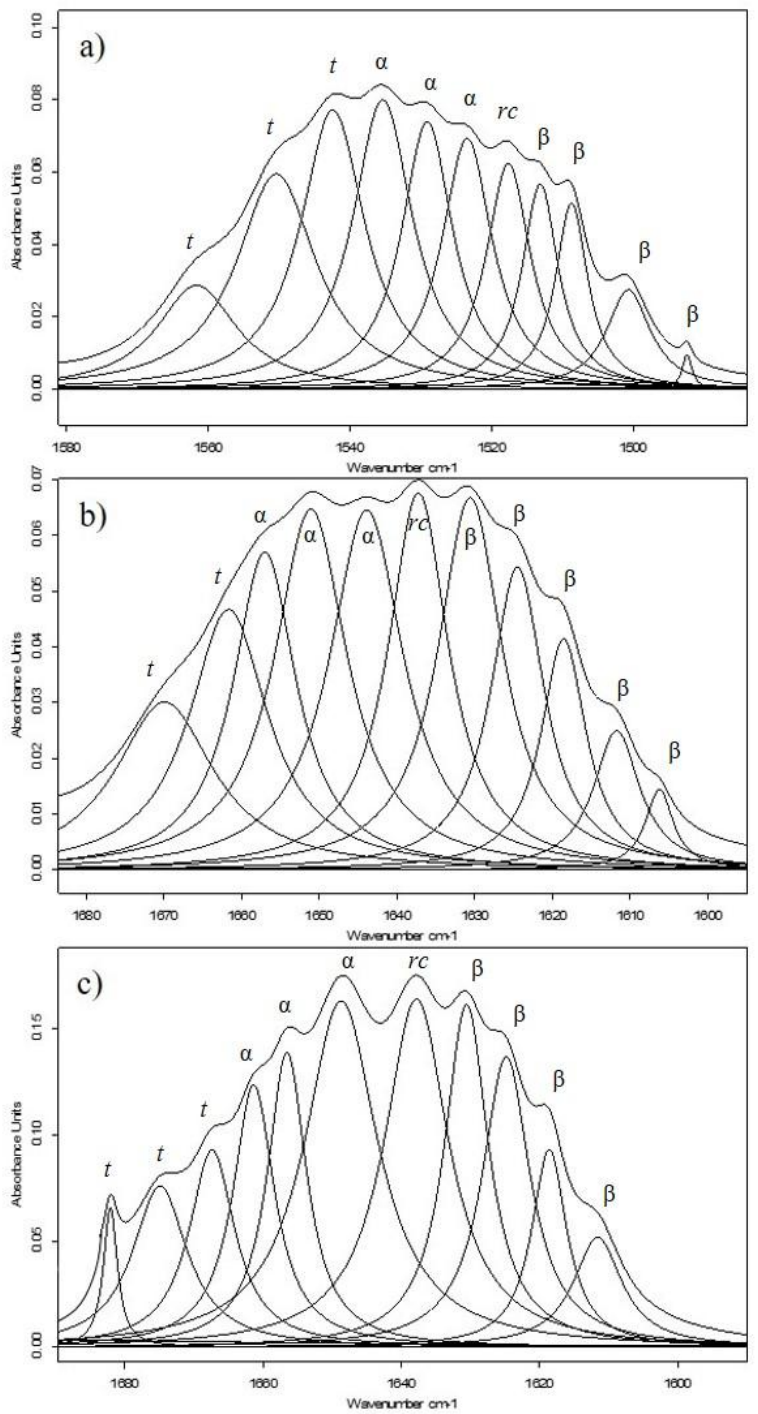

Figure 10.1.3.2.2.16. Amide I curve fitting band for EO@Pb inoculated specimens with: a) Arthrobacter oxydans, b) Bacillus amyloliquefaciens, c) Streptomyces cellulofans bacteria with fitted band components. Assignment of bands conformations: $\beta$-sheet $(\beta)$, random coil (rc), $\alpha$-helix $(\alpha)$ and turns $(\mathrm{t})$.

Table 10.1.3.2.2.11. Percent area contribution of amide I components for $\mathrm{EO} @ \mathrm{~Pb}$ reconstructed model paint specimens uninoculated and inoculated with bacteria.

\begin{tabular}{|c|c|c|c|c|}
\hline $\begin{array}{c}\text { Predominant } \\
\text { conformations }\end{array}$ & EO@Pb & EO@Pb_Ao & EO@Pb_Ba & EO@Pb_Sc \\
\hline Intermolecular $\beta$-sheet & 18 & 20 & 19 & 21 \\
\hline Intramolecular $\beta$-sheet & 8 & 9 & 26 & 9 \\
\hline Random coil & 20 & 19 & 14 & 20 \\
\hline$\alpha$-helix & 36 & 37 & 31 & 37 \\
\hline Turns & 18 & 15 & 10 & 13 \\
\hline
\end{tabular}

Main change in the amide I band found in the specimens inoculated with the actinobacteria Streptomyces cellulofans and Arthrobacter oxydans was due to the splitting of the $\beta$-sheet 
sub-band with the maximum of the band appearing at $1637 \mathrm{~cm}^{-1}$ and a shoulder at $1629 \mathrm{~cm}^{-1}$, which are ascribed to intramolecular and intermolecular $\beta$-sheet conformations, respectively (Figure 10.1.3.2.2.16a and c, respectively). Dominance of this structure, in which lateral chains are less accessible to the external medium, is in good correspondence with the scarce formation of $\mathrm{Pb}$-carboxylate (weak shoulder in the amide II band at $1541 \mathrm{~cm}^{-1}$ ). In agreement with this observation are the results obtained after FSD and curve fitting where no significant changes in the $\alpha$-helix and random coil conformations contribution are reported (Table 10.1.3.2.2.11).

Table 10.1.3.2.2.12. $\mathrm{I}_{\mathrm{AII}} / \mathrm{I}_{\mathrm{AI}}$ and $\mathrm{I}_{\mathrm{FFA}} / \mathrm{I}_{\mathrm{E}}$ band ratios obtained for the lead white egg oil emulsion reconstructed model paint specimens uninoculated and inoculated with bacteria.

\begin{tabular}{|c|c|c|}
\hline Specimen & $\mathbf{I}_{\text {AII }} / \mathbf{I}_{\mathbf{A I}}$ intensity ratio & $\mathbf{I}_{\mathbf{F F A}} / \mathbf{I}_{\mathbf{E}}$ ratio \\
\hline EO@Pb_B & 1.14 & 0.18 \\
\hline EO@Pb_Ao & 1.21 & 0.11 \\
\hline EO@Pb_Ba & 2.43 & 0.30 \\
\hline EO@Pb_Sc & 1.04 & 0.11 \\
\hline
\end{tabular}

The previously discussed results are in accordance with the results obtained after curve fitting of the carbonyl groups band $\left(1800-1690 \mathrm{~cm}^{-1}\right)$ region associated to the formation of metalcarboxylate (Figure 10.1.3.2.2.17). In contrast to the actinobacteria inoculated specimens (EO@Pb_Ao and EO@Pb_Sc), which exhibit no variations in the FFA contribution if compared to the uninoculated specimen, the eubacterium inoculated specimen (EO@Pb_Ba) exhibits an increment in the FFA relative content as well as an increment in the $\mathrm{I}_{\mathrm{FFA}} / \mathrm{I}_{\mathrm{E}}$ value (Table 10.1.3.2.2.12). These results are in agreement with the increase of $\mathrm{I}_{\mathrm{AII}} / \mathrm{I}_{\mathrm{AI}}$ ratio observed in this specimen, which suggest that this eubacterium promotes the hydrolysis of triglycerides and the metal complexation to a major extent if compared to the actinobacteria (Table 10.1.3.2.2.12). 

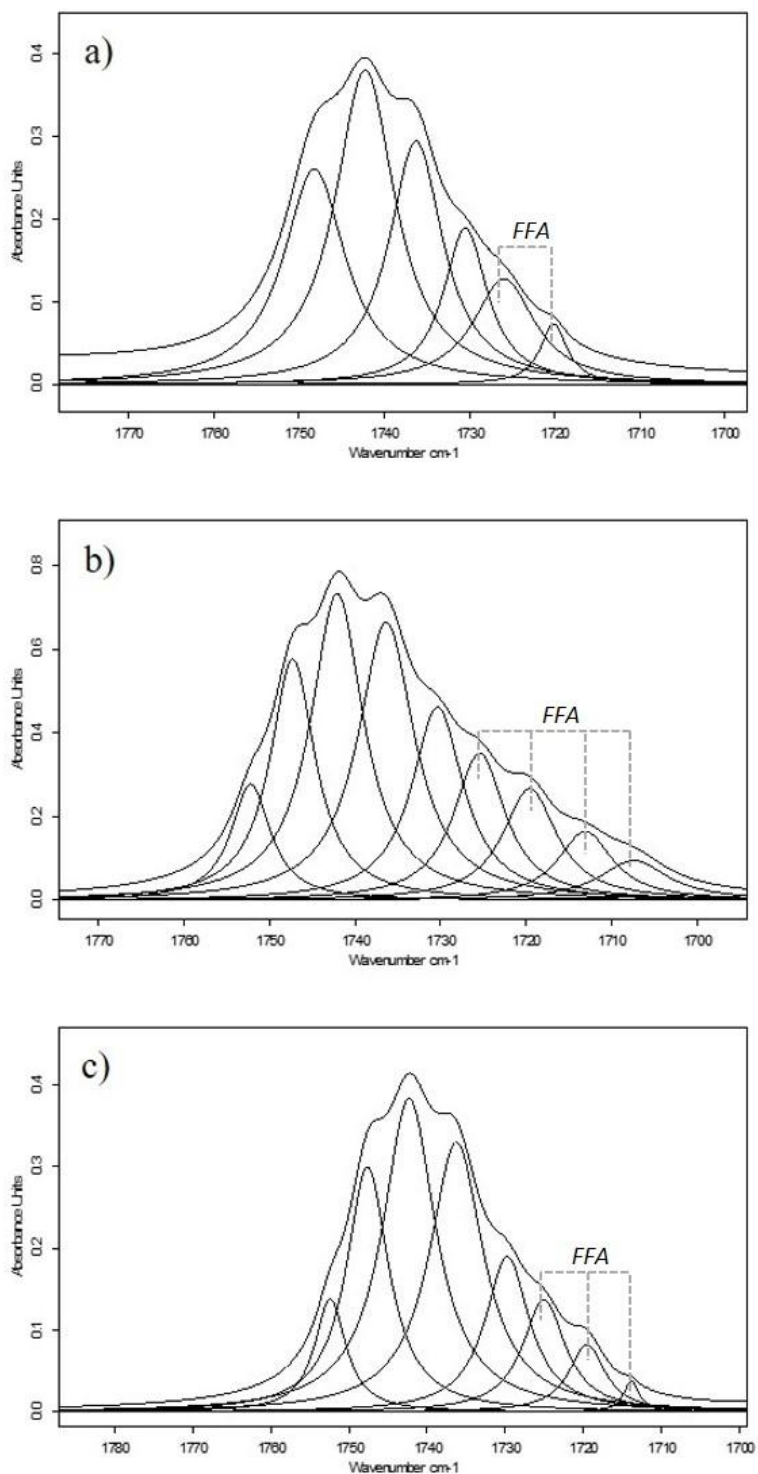

Figure 10.1.3.2.2.17. Carbonyl curve fitted band for EO@Pb inoculated specimen with: a) Arthrobacter oxydans, b) Bacillus amyloliquefaciens, c) Streptomyces cellulofans bacteria.

\section{Cadmium yellow}

Fungi

Figure 10.1.3.2.2.18, shows the $1800-500 \mathrm{~cm}^{-1}$ region of the IR spectra of the reconstructed model paint specimens uninoculated and inoculated with fungi. The characteristic band of marker compounds in fungi is also marked to denote the complete removing of fungal biomass from the specimens. 


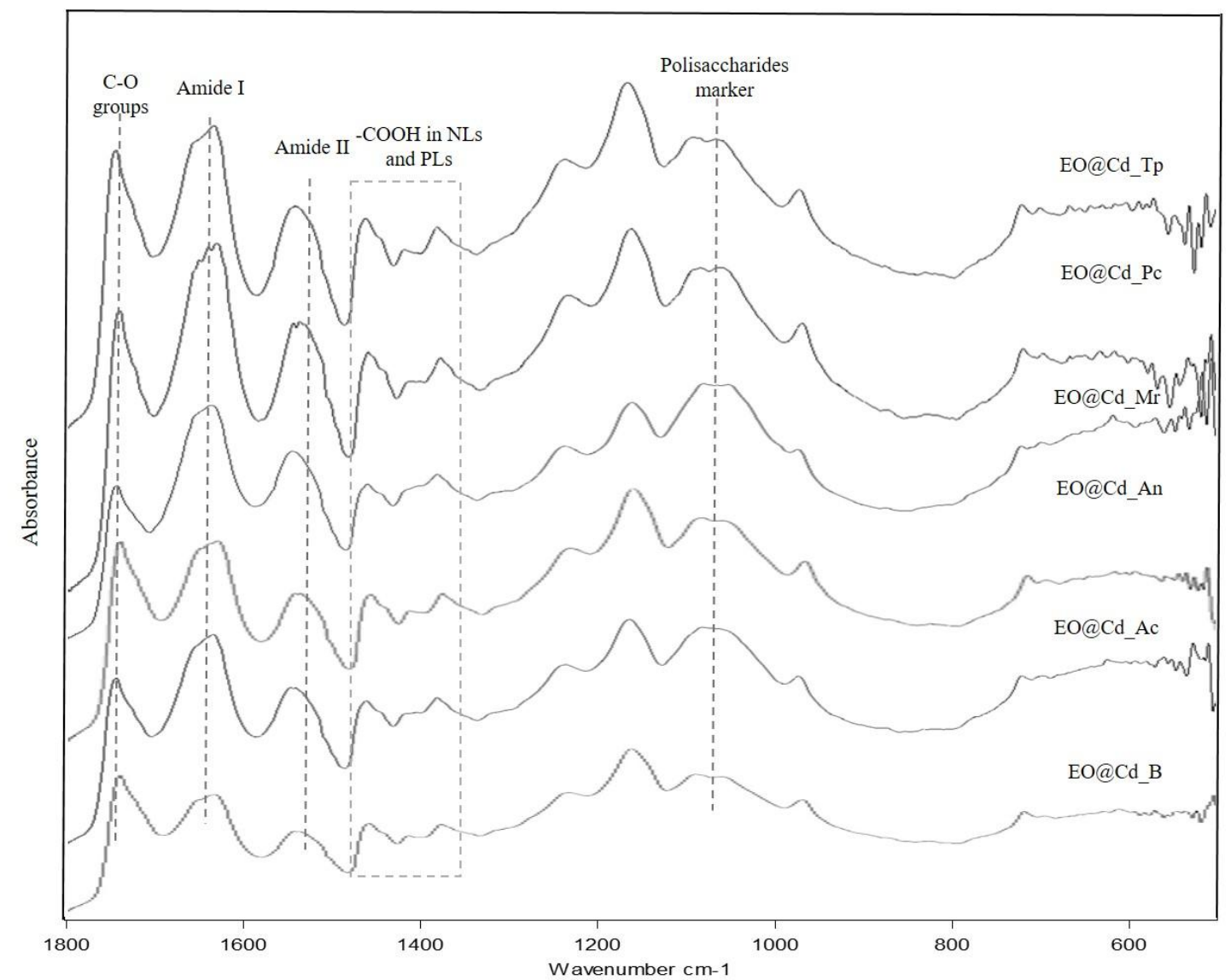

Figure 10.1.3.2.2.18. Detail of the $1800-500 \mathrm{~cm}^{-1}$ IR region and position of the bands characteristic and marker compounds fungal materials for the EO@Cd uninoculated and inoculated specimens.

Blueshifts of the maximum in the intramolecular $\beta$-sheet region from $1628 \mathrm{~cm}^{-1}$ to $1631 \mathrm{~cm}^{-1}$ for EO@Cd_Tp, to $1634 \mathrm{~cm}^{-1}$ for EO@Cd_An, EO@Cd_Mr, and EO@Cd_Pc and to 1636 $\mathrm{cm}^{-1}$ for EO@Cd_Ac were observed. Band associated with random coil conformations with maximum at $1640 \mathrm{~cm}^{-1}$ for EO@Cd_Ac and EO@Cd_Mr was recognized. FSD and curve fitting treatment also put in evidence the increase of the random coil and intramolecular $\beta$ sheet conformations of these inoculated paint films (Figure 10.1.3.2.2.19). $\beta$-sheet conformation was the dominant conformation in most of the inoculated specimens, with exception of the Trichoderma pseudokoningii specimen, which exhibited turns as dominant conformation (Figure 10.1.3.2.2.19e). Table 10.1.3.2.2.13, summarizes the percent contribution obtained for each protein conformation in the amide I band region. Increment of the percentage of the intermolecular $\beta$-sheet conformation sub-bands was observed in EO@Cd_An,EO@Cd_Ac and EO@Cd_Pc paint films specimens. The EO@Cd_Ac and EO@Cd_Mr specimens also exhibited an increment of the random coil conformation contribution compared with the uninoculated specimen (EO@Cd_B). Apparently, these microorganisms promote the formation of more open and accessible structures in which side chains groups could react with the external medium. The changes in conformation contribution observed in all the specimens are in agreement with the increase in $\mathrm{I}_{\mathrm{AII}} / \mathrm{I}_{\mathrm{AI}}$ values obtained. Higher values are found for EO@Cd_Ac and EO@Cd_Mr specimens (Table 10.1.3.2.2.14). 

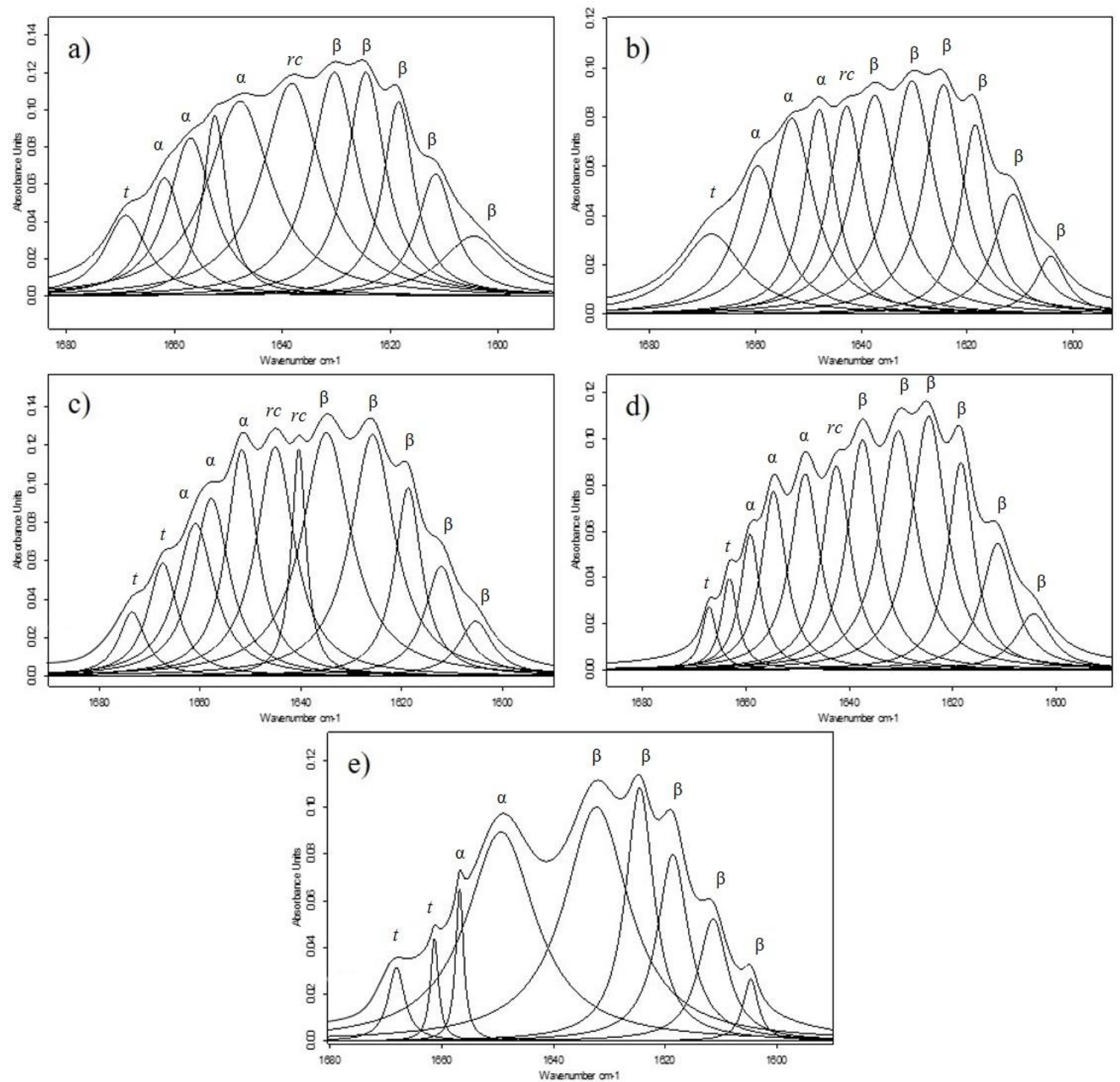

Figure 10.1.3.2.2.19. Amide curve fitting band for EO@Cd inoculated specimens with: a) Acremonium chrysogenum, b) Aspergillus niger, c) Mucor rouxii, d) Penicillium chrysogenum, e) Trichoderma pseudokoningii fungi with fitted band components. Assignment of bands conformations: $\beta$-sheet $(\beta)$, random coil $(\mathrm{rc}), \alpha$-helix $(\alpha)$ and turns $(\mathrm{t})$.

Table 10.1.3.2.2.13. Percent area contribution of amide I components for EO@Cd reconstructed model paint specimens uninoculated and inoculated with fungi.

\begin{tabular}{|c|c|c|c|c|c|c|}
\hline $\begin{array}{c}\text { Predominant } \\
\text { conformations }\end{array}$ & EO@Cd & EO@Cd_Ac & EO@Cd_An & EO@Cd_Mr & EO@Cd_Pc & EO@Cd_Tp \\
\hline $\begin{array}{c}\text { Intermolecular } \\
\beta \text {-sheet }\end{array}$ & 14 & 31 & 30 & 16 & 37 & 15 \\
\hline $\begin{array}{c}\text { Intramolecular } \\
\beta \text {-sheet }\end{array}$ & 28 & 13 & 27 & 41 & 27 & 18 \\
\hline Random coil & 9 & 18 & 7 & 15 & 8 & - \\
\hline$\alpha$-helix & 24 & 32 & 26 & 23 & 24 & 18 \\
\hline Turns & 9 & 5 & 9 & 6 & 4 & 50 \\
\hline
\end{tabular}


Changes in the region associated to the $\mathrm{C}=\mathrm{O}$ stretching bands $\left(1700-1800 \mathrm{~cm}^{-1}\right)$ were also recognized. The specimen inoculated with Mucor rouxii exhibited a notable decrease in intensity of this band when compared to the rests of the fungi inoculated paint films (Figure 10.1.3.2.2.20). Finally, a notable increase in the relative content of free fatty acids was also observed in paint films inoculated with Acremonium chrysogenum, Aspergillus niger and Mucor rouxii (relative growth of bands in the range of 1725-1700 $\mathrm{cm}^{-1}$ ) (Figure 10.1.3.2.2.20a, b and c, respectively). Presence of fatty acids could contribute to promote more unordered secondary structure in the protein molecules by being more loosened and unfolded in the more acidic solution. This more random structure is due to the repulsion between charged residues located in the vicinity in turns and bends. Table 10.1.3.2.2.14 summarizes the $\mathrm{I}_{\mathrm{FFA}} / \mathrm{I}_{\mathrm{E}}$ values obtained for this series of specimens. Comparison of the $\mathrm{I}_{\mathrm{AII}} / \mathrm{I}_{\mathrm{AI}}$ and $\mathrm{I}_{\mathrm{FFA}} / \mathrm{I}_{\mathrm{E}}$ ratios of the inoculated specimens and blank indicates that microorganisms in all the specimens were active in promoting both enzymatic transformation resulting in volatile end-products and metal complexation. In particular, Acremonium chrysogenu and Mucor rouxii.
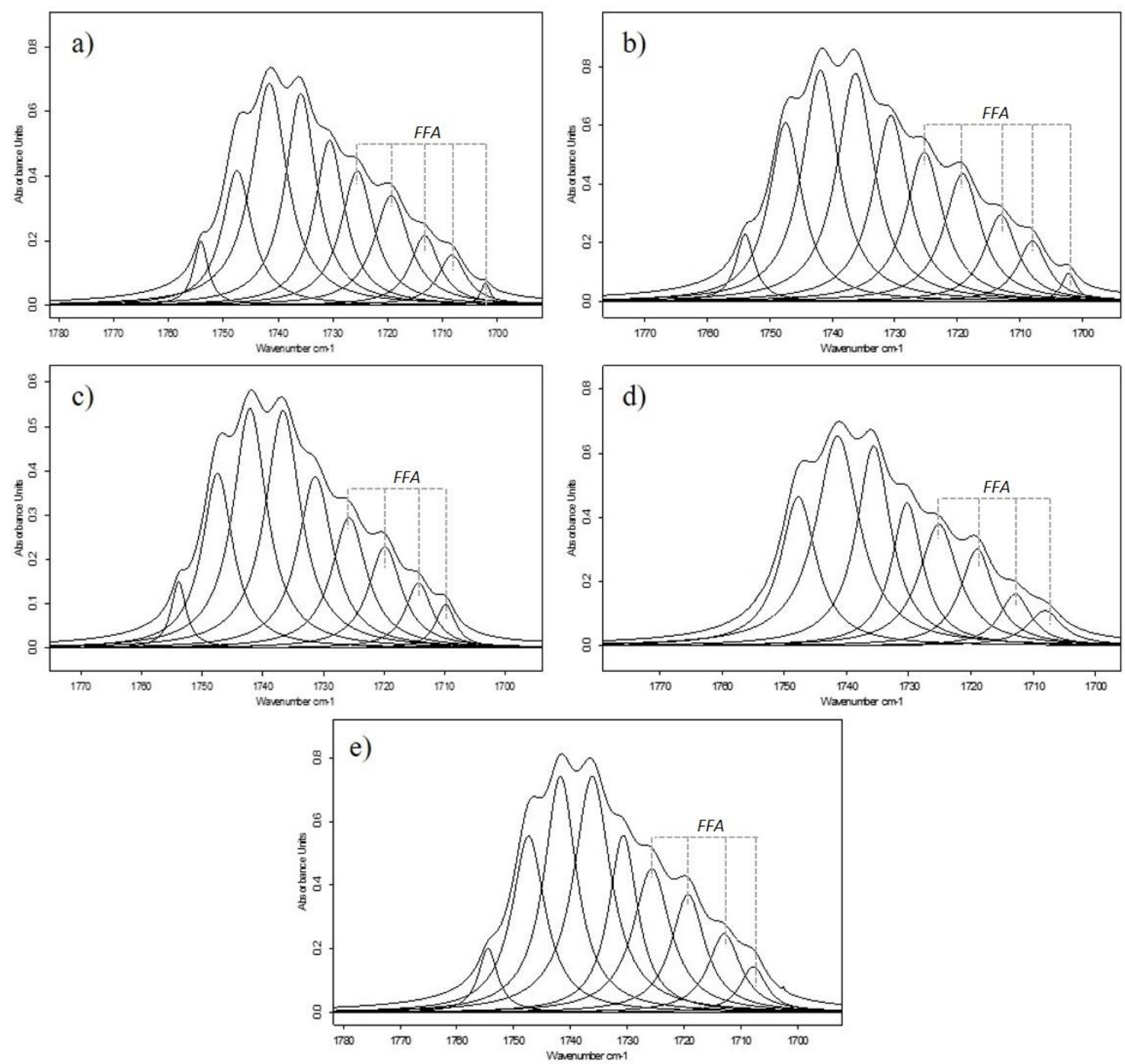

Figure 10.1.3.2.2.20. Carbonyl curve fitted band for EO@Cd inoculated specimen with: a) Acremonium chrysogenum, b) Aspergillus niger, c) Mucor rouxii, d) Penicillium chrysogenum, e) Trichoderma pseudokoningii fungi. 
Table 10.1.3.2.2.14. $\mathrm{I}_{\mathrm{AII}} / \mathrm{I}_{\mathrm{AI}}$ and $\mathrm{I}_{\mathrm{FFA}} / \mathrm{I}_{\mathrm{E}}$ band ratios obtained for the cadmium yellow egg oil emulsion reconstructed model paint specimens uninoculated and inoculated with fungi.

\begin{tabular}{|c|c|c|}
\hline Specimen & $\mathbf{I}_{\mathbf{A I I}} / \mathbf{I}_{\mathbf{A I}}$ intensity ratio & $\mathbf{I}_{\mathbf{F F A}} / \mathbf{I}_{\mathbf{E}}$ ratio \\
\hline EO@Cd_B & 1.09 & 0.49 \\
\hline EO@Cd_Ac & 1.95 & 0.44 \\
\hline EO@Cd_An & 1.15 & 0.34 \\
\hline EO@Cd_Mr & 2.06 & 0.46 \\
\hline EO@Cd_Pc & 1.48 & 0.38 \\
\hline EO@Cd_Tp & 1.93 & 0.46 \\
\hline
\end{tabular}

\section{Bacteria}

Figure 10.1.3.2.1.23, shows the $1800-500 \mathrm{~cm}^{-1}$ region of the IR spectra obtained for the reconstructed model paint specimens inoculated with bacteria where the bacterial characteristic band of marker compounds of bacterial biomass is also marked to denote the suppression of biomass in the surface of the specimens.

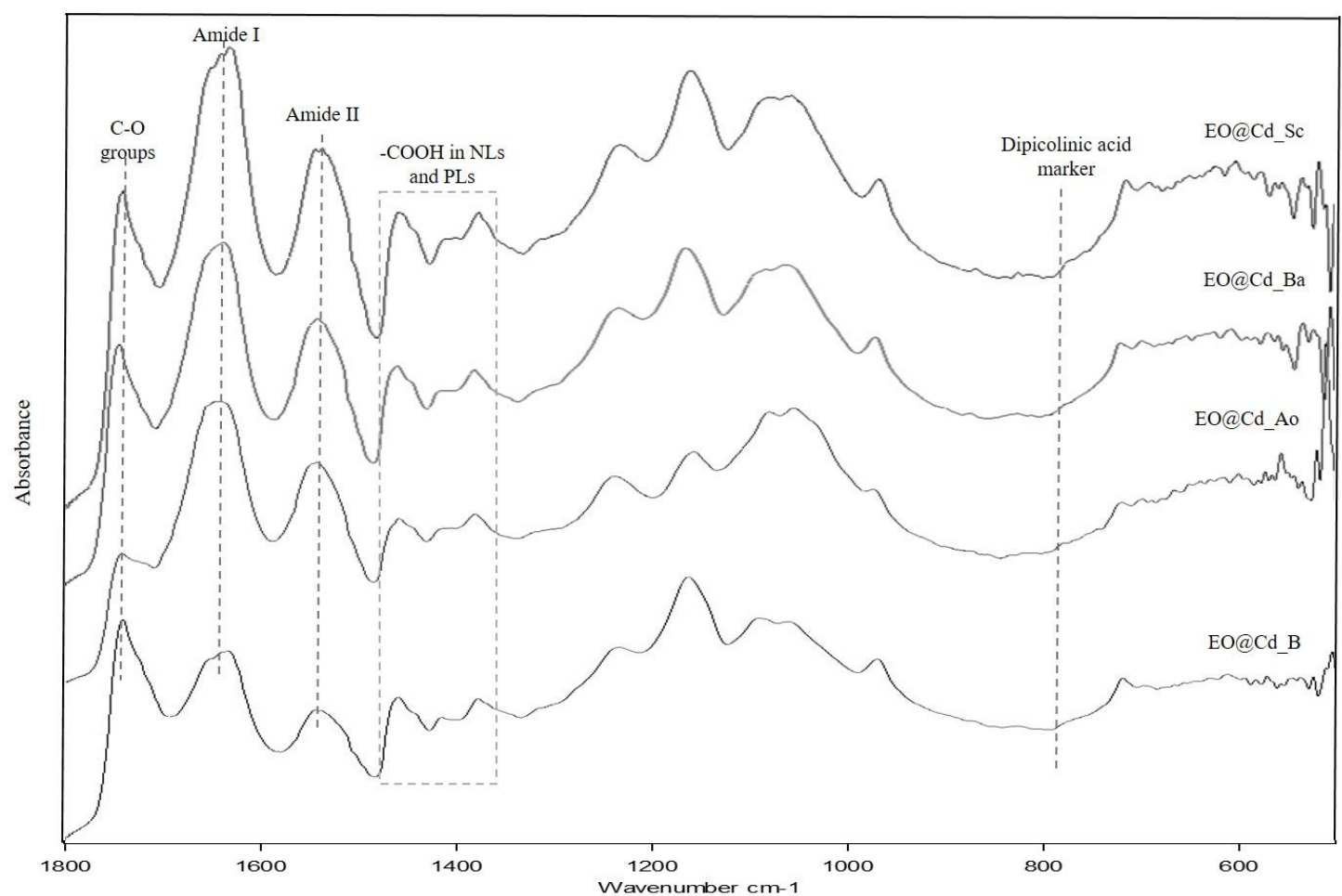

Figure 10.1.3.2.2.21. Detail of the $1800-500 \mathrm{~cm}^{-1}$ IR region and position of the bands characteristic and marker compounds bacterial materials for the EO@Cd uninoculated and inoculated specimens. 
The most significant change observed in the amide I region was the appearance of a new shoulder at around $1640 \mathrm{~cm}^{-1}$ ascribed to random coil conformations. Redshift of the $\beta$-sheet sub-band from $1628 \mathrm{~cm}^{-1}$ to around $1620 \mathrm{~cm}^{-1}$ was also observed in the three inoculated paint films specimens. FSD and curve fitting procedures (Figure 10.1.3.2.2.22) showed an increase in the contribution of random coil conformation. As in the specimens inoculated with fungi, the $\beta$-sheet conformation is dominant. (Table 10.1.3.2.2.15). The specimen inoculated with the eubacterium Bacillus amyloliquefaciens exhibited the highest increment in $\alpha$-helix conformation contribution as well as an increment in the $\mathrm{I}_{\mathrm{AII}} / \mathrm{I}_{\mathrm{AI}}$ intensity ratio (Table 10.1.3.2.2.16). That suggests that Bacillus amyloliquefaciens deteriorating activity on the binding medium promotes the formation of protein-metal complexes, because the increment in random coil and $\alpha$-helix conformations makes lateral chains more accessible to the external medium.
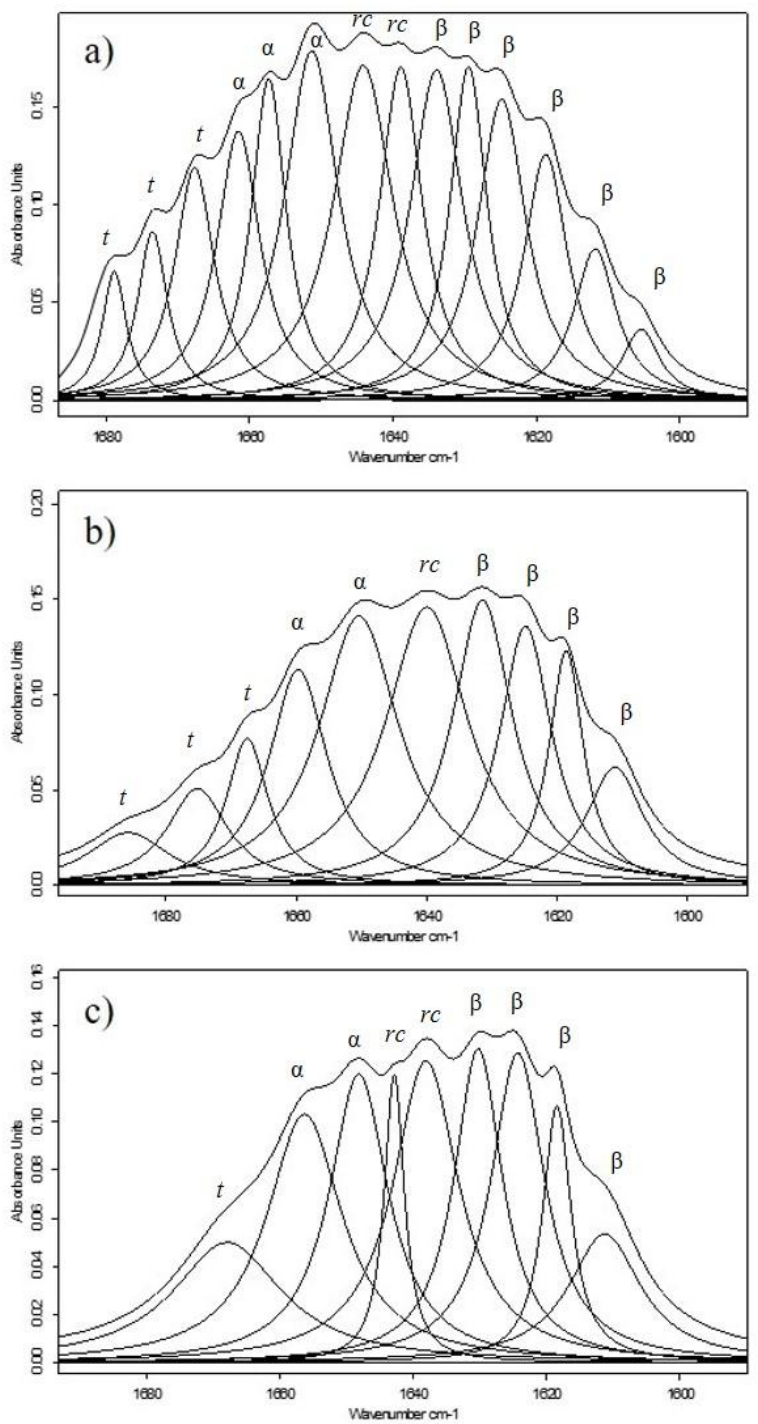

Figure 10.1.3.2.2.22. Amide I curve fitting band for EO@Cd inoculated specimens with: a) Arthrobacter oxydans, b) Bacillus amyloliquefaciens, c) Streptomyces cellulofans bacteria with fitted band components. Assignment of bands conformations: $\beta$-sheet $(\beta)$, random coil (rc), $\alpha$-helix $(\alpha)$ and turns $(\mathrm{t})$. 
Table 10.1.3.2.2.15. Percent area contribution of amide I components for EO@Cd reconstructed model paint specimens uninoculated and inoculated with bacteria.

\begin{tabular}{|c|c|c|c|c|}
\hline $\begin{array}{c}\text { Predominant } \\
\text { conformations }\end{array}$ & EO@Cd & EO@Cd_Ao & EO@Cd_Ba & EO@Cd_Sc \\
\hline Intermolecular $\beta$-sheet & 14 & 27 & 24 & 30 \\
\hline Intramolecular $\beta$-sheet & 28 & 16 & 12 & 9 \\
\hline Random coil & 9 & 21 & 21 & 19 \\
\hline$\alpha$-helix & 24 & 27 & 30 & 28 \\
\hline Turns & 9 & 9 & 13 & 14 \\
\hline
\end{tabular}

FSD and curve fitting of the carbonyl band shows an increase in the relative content of the bands associated to the free fatty acids in Bacillus amyloliquefaciens eubacterium specimen (Figure 10.1.3.2.2.23b). The lower contribution of free fatty acids observed in both actinobacteria Arthrobacter oxydans and Streptomyces cellulofans suggests that deteriorating activity of these two microorganisms on the binding medium has taken place to a lower extent (Figure 10.1.3.2.2.23a and c, respectively). As in the specimens inoculated with fungi, free fatty acids released as results of the hydrolysis of triglycerides promoted by the microorganisms, result in the formation of Cd-carboxylate. Table 10.1.3.2.2.16 shows the $\mathrm{I}_{\mathrm{FFA}} / \mathrm{I}_{\mathrm{E}}$ values obtained for the $\mathrm{EO} @ \mathrm{Cd}$ specimens inoculated with bacteria. 

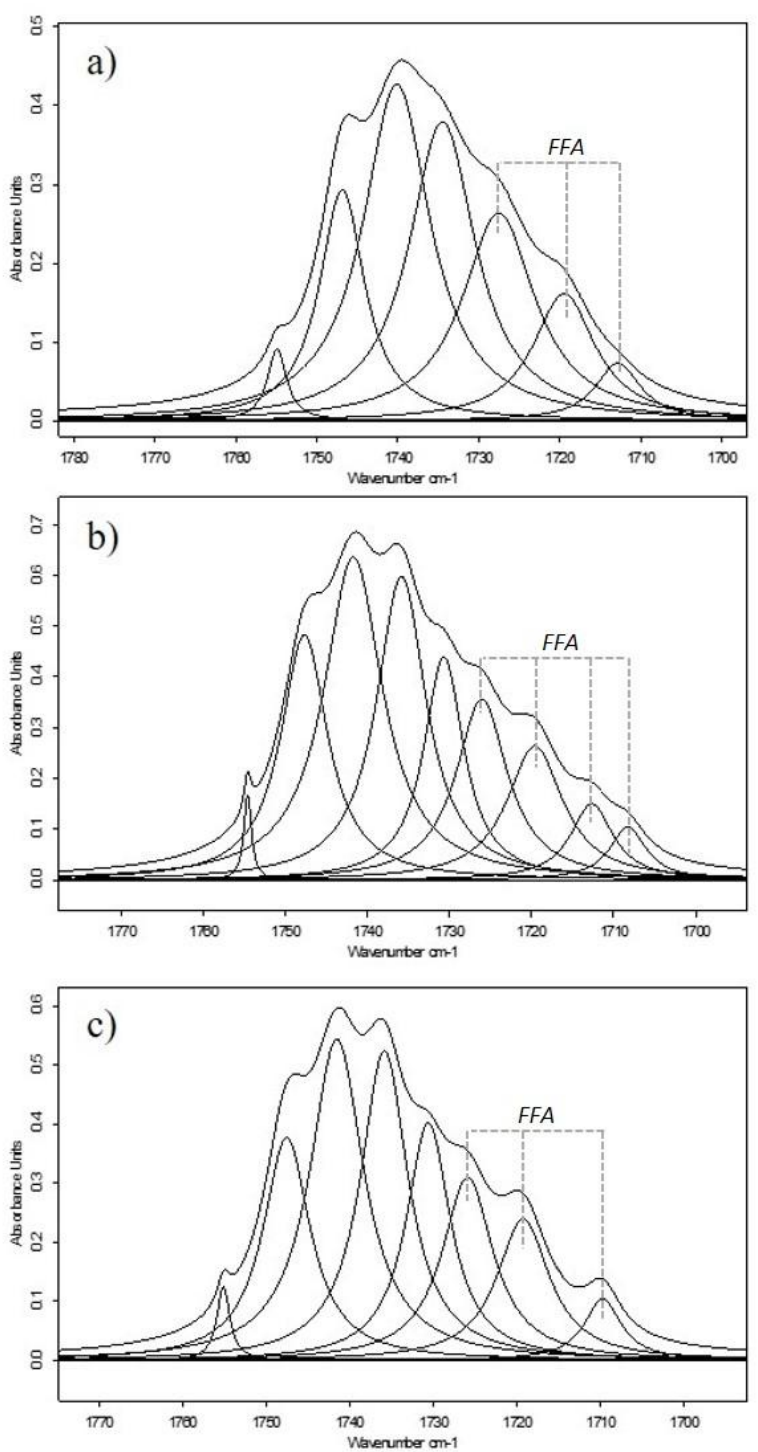

Figure 10.1.3.2.2.23. Carbonyl curve fitted band for EO@Cd inoculated specimen with: a) Arthrobacter oxydans, b) Bacillus amyloliquefaciens, c) Streptomyces cellulofans bacteria.

Table 10.1.3.2.2.16. $\mathrm{I}_{\mathrm{AI}} / \mathrm{I}_{\mathrm{AI}}$ and $\mathrm{I}_{\mathrm{FFA}} / \mathrm{I}_{\mathrm{E}}$ band ratios obtained for the cadmium yellow egg oil emulsion reconstructed model paint specimens uninoculated and inoculated with bacteria.

\begin{tabular}{|c|c|c|}
\hline Specimen & $\mathbf{I}_{\mathbf{A I I}} / \mathbf{I}_{\mathbf{A I}}$ intensity ratio & $\mathbf{I}_{\mathbf{F F A}} / \mathbf{I}_{\mathbf{E}}$ ratio \\
\hline EO@Cd_B & 1.09 & 0.49 \\
\hline Ao & 1.48 & 0.50 \\
\hline $\mathrm{Ba}$ & 2.13 & 0.69 \\
\hline $\mathrm{Sc}$ & 1.68 & 0.54 \\
\hline
\end{tabular}




\subsubsection{Discussion}

The above spectroscopic features, as expected, have put in evidence different behaviors depending on the binder type, the pigment and the biological agent. Nevertheless, the promotion of the hydrolysis of NLs and PLs and releasing of fatty acids and the subsequent formation of complexes with the free fatty acids as well as with the carboxylic residues in the protein chains can be pointed out as general trends as result of the deteriorating activity of the microorganisms. Another general trend concerns the breaking of protein chains resulting in shorter polypeptide chains. Although this result cannot be directly inferred from the results obtained from this spectroscopic study, the broadening as well as the variation in the area band ratio values for the stretching and deformation vibrations of the methyl and methylene groups in the $3000-2800 \mathrm{~cm}^{-1}$ and $1500-1300 \mathrm{~cm}^{-1}$ regions point out towards a fragmentation an increase in the multiplicity of proteinaceous molecules. These changes also favor the formation of metal-protein complexes with the carboxylate groups of acidic residues (glutamic and aspartic acid), the latter probably favored by the opening and unfolding of their secondary structure as consequence of the repulsion between charged residues due to the acidification of the medium. Thus, under the attack of both bacteria and fungi, random coil and $\alpha$-helix conformations increase in many of the inoculated reconstructed model paint specimens due to the coordination of proteins in aggregated and more disordered structures.

Concerning the results obtained in the two series of model paint specimens studied, it can be concluded:

- Uninoculated specimens: The main difference observed between the egg yolk tempera and the whole egg tempera is referred to the decrease in the ability for complexing metals observed in the whole egg tempera specimens where bands ascribed to metal carboxylate observed in $\mathrm{Y} @ \mathrm{Fe}_{75}$ and $\mathrm{Y} @ \mathrm{Cd}_{75}$, were not found in the EG@Fe and EG@Cd specimens. This different behavior is attributed to the diluting effect exerted by the white egg that lowers the concentration in NLs present in the egg yolk. In addition, most significant conformational changes were obtained in the verdigris and lead white paint films. Increase in the contribution of the $\alpha$-helix conformation was observed in the EG@Cu and EG@Pb specimens, which demonstrates that interaction between egg proteins and metal centers of the pigment take place at major extent in these specimens if compared to iron oxide red and cadmium yellow specimens. In addition, EO@Cu and EO@Pb specimens exhibit decrease in the intermolecular $\beta$ sheet with amide I band maximum ascribed to $\alpha$-helix conformation which confirms again the formation of metal-carboxylate complexes as in the egg paint film specimens.

- Influence of the type of pigment in the inoculated specimens: Verdigris and lead white are the two pigments that have reported a more significant release of free fatty acids followed by formation of metal-carboxylate soaps and metal-carboxylate complexes from protein residues. Interestingly, these latter changes are associated with 
transformations in the secondary structure of the proteins that can be summarized in a loss of aggregation between protein chains (decrease in the $\beta$-sheet intermolecular conformation) by disruption with the pigment and the ionomeric environment accompanied of an increase in the more open random coil conformation that favors the anchoring of metal ions. The fact that these both pigments are of the more soluble carbonate type in contrast with the more insoluble sulphide and oxide provably is favoring their dissolution and further complexation of the free metal ions. Different inhibitory activity of the pigments on the microorganisms is another factor influencing the results obtained. Thus the less evident changes observed in the verdigris egg-oil emulsion and in both cadmium yellow paint film specimens can be attributed to the high inhibitoring activity on microorganisms growing demonstrated by these pigments in prior studies (Babich and Stotzky, 1977).

- Influence of the binding medium in the inoculated specimens: The greater decrease observed in the $\mathrm{I}_{\mathrm{FFA}} / \mathrm{I}_{\mathrm{E}}$ ratio of most of the egg oil emulsion series has been associated to the larger transformation of lipids as a result of the enzymatic oxidation of the hydrolyzed long-chain fatty acids to form free fatty acid peroxides and then other volatile end-products promoted by the microorganisms. Secondly, metal complexation seems to have taken place at greater extent in egg tempera specimens as suggested by the slightly higher values reported for the $\mathrm{I}_{\mathrm{AII}} / \mathrm{I}_{\mathrm{AI}}$ ratio in this series. The hydrolysis of triglycerides and further loss of end-products of ketone and aldehyde type is also taking place at lesser extent in egg tempera films due to its particular microstructure with a variety of insoluble particles, with structure of micellar complexes in which triglycerides and cholesterol forms the core of the particle that is surrounded by an amphipathic surface monolayer of phospholipids and proteins that prevent the oxidation of triglycerides inside (Anton, 2013; Hevonoja et al., 2000; Kumpula et al., 2008).

- Influence of the microorganism in the inoculated specimens: The study carried out has confirmed that among the fungi, Acremonium chrysogenum has been highly active on both egg tempera and egg-oil emulsion specimens promoting hydrolysis followed by metal complexation and enzymatic oxidation of fatty acids from NLs and PLs present in the egg and oil and further transformation resulting in volatile end-products. Penicillium chrysogenum has been more active on egg-oil emulsion. Concerning bacteria behavior, Arthrobacter oxydans was active on copper pigment whereas Bacillus amyloliquefaciens exhibited activity on copper, lead and cadmium pigments prepared as egg-oil emulsions. It is remarkable the greater activity demonstrated by actinobacteria, especially Streptomyces cellulofans. 


\subsubsection{References}

Anton, M. (2013) Egg yolk: structures, functionalities and processes. J Sci Food Agr, 93, 2871-2880.

Babich, H., Stotzky, G. (1977) Sensitivity of various bacteria, including actinomycetes, and fungi to cadmium and the influence of $\mathrm{pH}$ on sensitivity. Applied and Environmental Microbiology, 33, 681-695.

Bombalska, A., Mularczyk-Oliwa, M., Kwásny, M., Włodarski, M., Kaliszewski, M., Kopczynski, K., Szpakowska, M., Trafny, E.A. (2011) Classification of the biological material with use of FTIR spectroscopy and statistical analysis. Spectrochim Acta A, 78, 1221-1226.

Cagnasso, M., Valter, B., Franchini, M.A., Chorover, J. (2010) ATR-FTIR studies of phospholipids vesicle interactions with $\alpha-\mathrm{FeOOH}$ and $\alpha-\mathrm{Fe}_{2} \mathrm{O}_{3}$ surfaces. Colloids and Surfaces B: Biointerfaces, 76, 456-467.

Duce, C., Ghezzi, L., Onor, M., Bonaduce, I., Colombini, M.P., Tine, M.R., Bramanti, E. (2012) Physico-chemical characterization of protein-pigment interactions in tempera paint reconstructions: casein/cinnabar and albumin/cinnabar. Anal Bional Chem, 402, 2183-2193.

Duce, C., Bramanti, E., Ghezzi, L., Bernazzani, L., Bonaduce, I., Colombini, M.P., Spepi, A., Biagi, S., Rosaria, M.T. (2013) Interactions between inorganic pigments and proteinaceous binders in reference paint reconstructions. Dalton Transactions, 42, 5975-5984.

Furlan, P.Y., Scott, S.A., Peaslee, M.H. (2007) FTIR-ATR study of pH effects on egg albumin secondary structure. Spectrosc Lett, 40, 475-782.

Goodacre, R., Shann, B., Gilbert, R.J., Timmis, E.M., McGrovern, A.C., Alsberg, B.K., Kell, D.B., Logan, N.A. (2000) Detection of the dipicolinic acid biomarker in Bacillus spores using curie-point pyrolysis mass spectrometry and fourier transform infrared spectroscopy. Anal Chem., 72, 119-127.

Hevonoja, T., Pentikäinen, M.O., Hyvönen, M.T., Kovanen, P.T., Ala-Korpela, M. (2000) Structure of low density lipoprotein (LDL) particles: basis for understanding molecular changes in modified LDL. Biochim Biophys Acta, 1488, 189-210.

Kinderlerer, J.L. (1993) Fungal strategies for detoxification of medium chain fatty acids. International biodeterioration \& biodegradation, 32, 213-224.

Kinderlerer, J.L. (1994) Degradation of the lauric acid oils. International biodeterioration \& biodegradation, $33,345-354$.

Kumpula, L.S., Kumpula, J.M., Taskinen, M.R., Jauhiainen, M., Kaski, K., Ala-Korpela, M. (2008) Reconsideration of hydrophobic lipid distribution in lipoprotein particles. Chem Phys Lipids, 155, 57-62.

Marey, L., Signolle, J.P., Amiel, C., Travert, J. (2001) Discrimination, classification, identification of microorganisms usinf FTIR spectroscopy and chemometrics. Vib Spectrosc, 26, 151-159. 
Mazzeo, R., Prati, S., Quaranta, M., Joseph, E., Kendix, E., Galeotti, M. (2008) Attenuated total reflection micro FTIR characterization of pigment-binder interaction in reconstructed paint films. Anal Bioanal Chem, 392, 65-76.

Nahar, S., Tajmir-Riahi, H.A. (1995) Do metal ions alter the protein secondary structure of light-harvesting complex of thylakoid membranes? Journal of Inorganic Biochemistry, 58, 223-234.

Omoike, A., Chorover, J., Kwon, K.D., Kubicki, J.D. (2004) Adhesion of bacterial exopolymers to $\alpha-\mathrm{FeOOH}$ : inner-spheres complexation of phosphodiester groups. Langmuir, 20, 11108-11114.

Parikh, S.J., Chorover, J. (2006) ATR-FTIR spectroscopy reveals bond formation during bacterial adhesion to iron oxide. Langmuir, 22, 8492-8500.

Zotti, M., Ferroni, A., Calvini, P. (2011) Mycological and FTIR analysis of biotic foxing on paper substrates. Int Biodeter Biodegr, 65, 569-578. 


\subsubsection{Atomic force microscopy - nanoindentation}

10.1.4.1. Egg tempera inoculated reconstructed model paint specimens

\section{Iron oxide red}

The topological graphs obtained for the inoculated paint film specimens showed a rough and uneven surface, which in most of the cases, was similar to the uninoculated specimen. Micropores attributed to the water evaporation during drying of the film were also observed in some of the inoculated specimens (see arrows in Figures 10.1.4.1.1a, b and d). The most significant changes associated to the morphology of the surface were observed in the specimen inoculated with the fungi Aspergillus niger (EG@Fe_An) (Figure 10.1.4.1.1c) whose surface exhibited microerosion and large protrusions if compared to the uninoculated specimen (Figure 10.1.4.1.2b). Table 10.1.4.1.1, shows the $E$ values obtained for the series of EG@Fe inoculated paint film specimens compared to the uninoculated specimen. As it can be seen, the EG@Fe_An paint film exhibits the major increase of the elastic modulus $E$ among the specimens inoculated with fungi (Table 10.1.4.1.1).
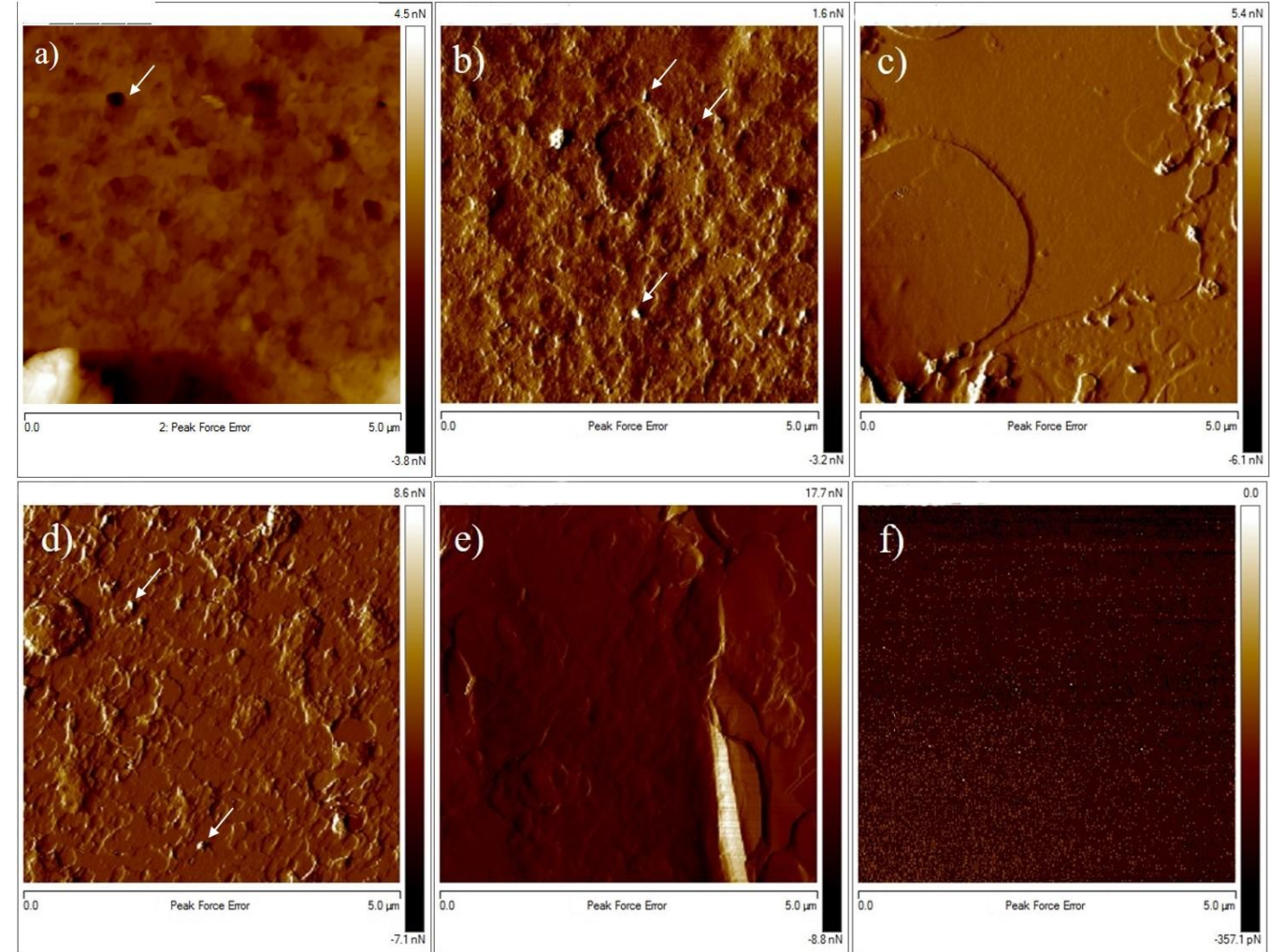

Figure 10.1.4.1.1. Topological graphs obtained in peak-force error for the iron oxide red egg tempera (EG@Fe) reconstructed model paint films uninoculated (a) and inoculated with: b) Acremonium chrysogenum (Ac), c) Aspergillus niger (An), d) Mucor rouxii (Mr), e) Penicillium chrysogenum $(\mathrm{Pc})$ and f) Trichoderma pseudokoningii (Tp) fungi. Image scan size is $5 \mu \mathrm{m}^{2}$. 

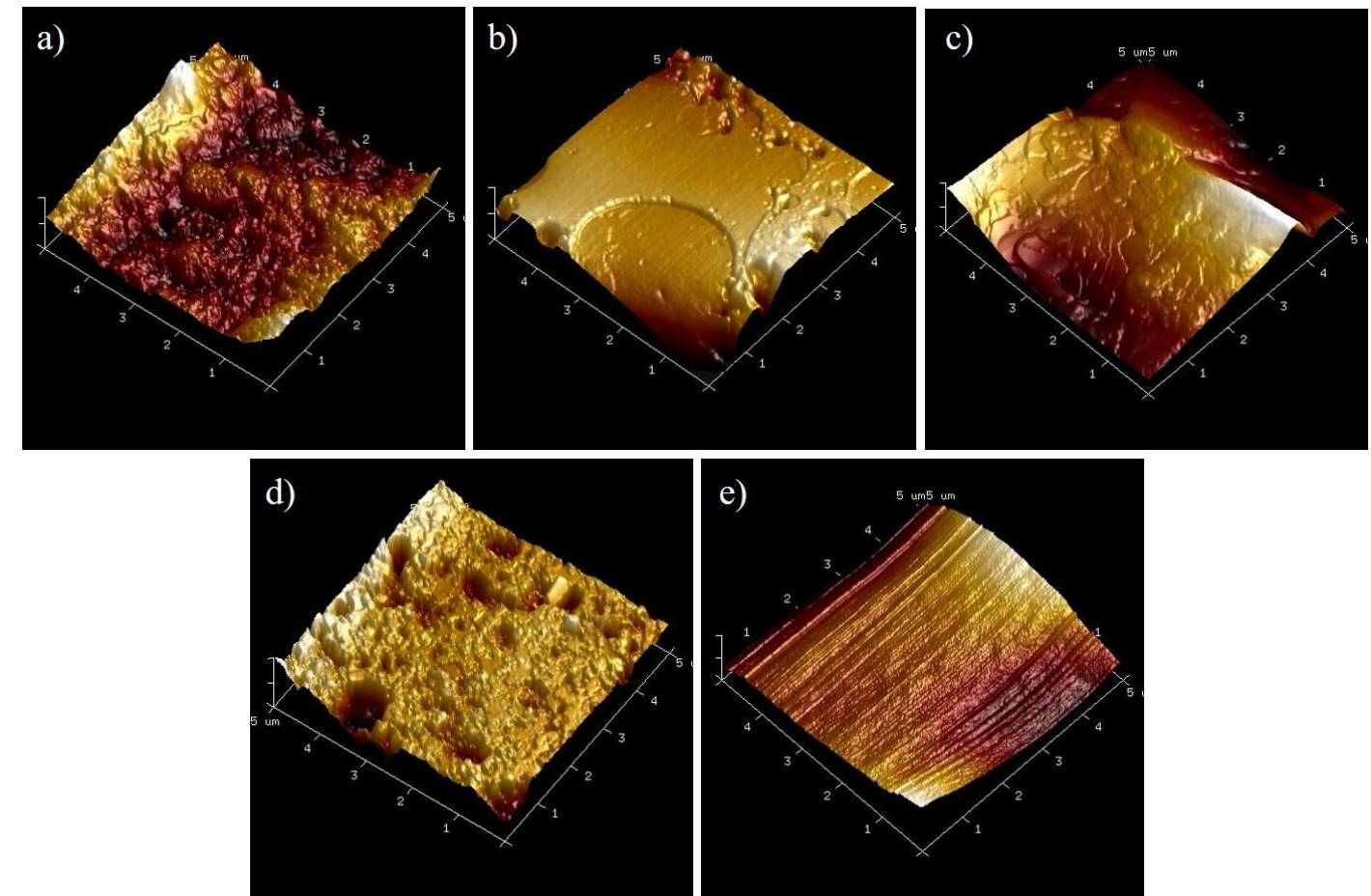

Figure 10.1.4.1.2. Topological graphs obtained in 3D height image mode for: a) EG@Fe_Ac, b) EG@Fe_An, c) EG@Fe_Mr,d)EG@Fe_Pc, and e) EG@Fe_Tp fungi. Image scan size is $5 \mu^{2}$.

In contrast, $E$ value for EG@Fe_Tp specimen was notably decreased whereas any significant change was observed in the $E$ value of the EG@Fe_Mr specimen and slighter decrease in $E$ was observed in the specimens inoculated with Acremonium chrysogenum and Penicillium chrysogenum fungi. The behavior of the latter specimens can be associated to the lesser extent of the deterioration effects that presented these specimens after incubation due to the more discontinuous distribution of the biofilm formed (Abe et al., 2011). The low value found for the EG@Fe_Tp specimen has been attributed firstly to the lesser effect of the microbial activity. This thinner and discontinuous biofilm formed on the surface of the paint film probably favored the diffusion of the aqueous medium through the paint film exerting a plasticizing effect. 
Table 10.1.4.1.1. Summary of values of Young's Modulus and the corresponding standard deviation obtained for the iron oxide red egg tempera reconstructed model paint inoculated specimens compared to the uninoculated specimen.

\begin{tabular}{|c|c|}
\hline Specimen & Young's Modulus (GPa) \\
\hline$E G @ F e \_B$ & $1.44 \pm 0.06$ \\
\hline \multicolumn{2}{|l|}{ Fungi } \\
\hline$E G @ F e \_A c$ & $0.99 \pm 0.08$ \\
\hline$E G @ F e \_A n$ & $1.86 \pm 0.10$ \\
\hline$E G @ F e \_M r$ & $1.29 \pm 0.03$ \\
\hline$E G @ F e \_P c$ & $0.98 \pm 0.03$ \\
\hline$E G @ F e \_T p$ & $0.37 \pm 0.04$ \\
\hline \multicolumn{2}{|l|}{ Bacteria } \\
\hline$E G @ F e \_A o$ & $2.04 \pm 0.19$ \\
\hline$E G @ F e \_B a$ & $1.26 \pm 0.07$ \\
\hline$E G @ F e \_S c$ & $0.46 \pm 0.02$ \\
\hline
\end{tabular}

Concerning the specimens inoculated with bacteria, the most significant changes associated to the morphology of the surface were observed in the specimens inoculated with actinobacterium Arthrobacter oxydans (EG@Fe_Ao) whereas EG@Fe_Sc and EG@Fe_Ba specimens exhibited a smoother surface eventually disrupted by some protrusion of pigment aggregates (see Figures 10.1.4.1.3a c). Nanoindentation test revealed an important increase for the value of $E$ in the specimen inoculated with the actinobacteria EG@Fe_Ao, notable decrease for EG@Fe_Sc and any remarkable change for EG@Fe_Ba. 

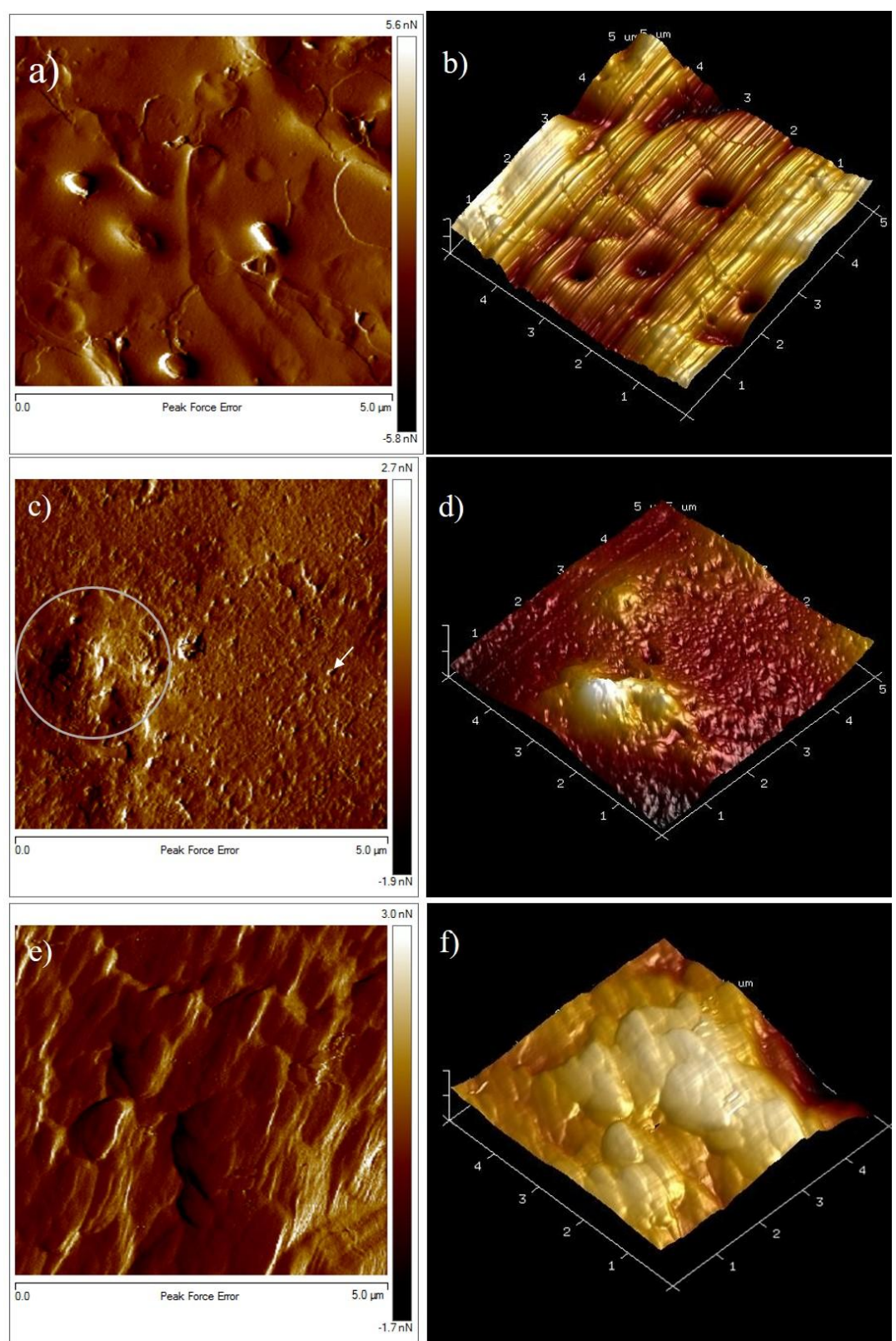

Figure 10.1.4.1.3. Topological graphs obtained in peak-force-error for the EG@Fe reconstructed model paint specimens inoculated with bacteria (left) and 3D height image mode (right): a) and b) Arthrobacter oxydans (EG@Fe_Ao); c) and d) Bacillus amyloliquefaciens (EG@Fe_Ba); and e) and f) Streptomyces cellulofans (EG@Fe_Sc). Image scan size is $5 \mu \mathrm{m}^{2}$. Pigment aggregates protruding the surface of the paint film are marked with a circle.

\section{Verdigris}

As with the $\mathrm{Y} @ \mathrm{Cu}_{30}$ specimen discussed in the section 8.1.5.2, was not possible to obtain topological graphs as well as Young's Modulus values for the inoculated specimens because the specimens were to brittle to permit manipulation with scalpel. As previously described the tip in contact with the pigment grains protruding from the surface made impossible to creep the tip over the sample in tapping mode. 


\section{Lead white}

Topological graphs of the surface of the lead white egg tempera reconstructed model paint specimens after inoculation with fungi is shown in Figure 10.1.4.1.4 together with that of the uninoculated specimen. An uneven surface is observed in the specimens inoculated with Acremonium chrysogenum (EG@Pb_Ac), Aspergillus niger (EG@Pb_An), Penicillium chrysogenum (EG@Pb_Pc) Mucor rouxii (EG@Pb_Mr) and Trichoderma pseudokoningii (EG@Pb_Tp) fungi (see Figure 10.1.4.1.4b, c, d, e and f, respectively). It is interesting to note that the micro-pores produced during the drying of the film observed in the uninoculated specimen (EG@Pb_B) are not appreciated in the specimens after incubation. On the other hand, new features such as fissures have been formed in most of the specimens, which are particularly deep in EG@Pb_Ac and EG@Pb_Pc specimens as can be seen in 3D graphs shown in Figures 10.1.4.1.5 a and d. These changes in morphology are attributed to the microbial actuation. Concomitantly, these last specimens exhibited an important increment in the $E$ value that confirms that bioerosion to the surface of the paint film is being promoted to major extent by these microorganisms if compared to the other fungi used in this study, which $E$ report a decrease in the $E$ value (Table 10.1.4.1.2). The decrease of the $E$ value obtained for the rest of specimens is attributed like in the case of iron oxide red to the plasticizing effect of the aqueous medium easier diffused in the less altered paint films.
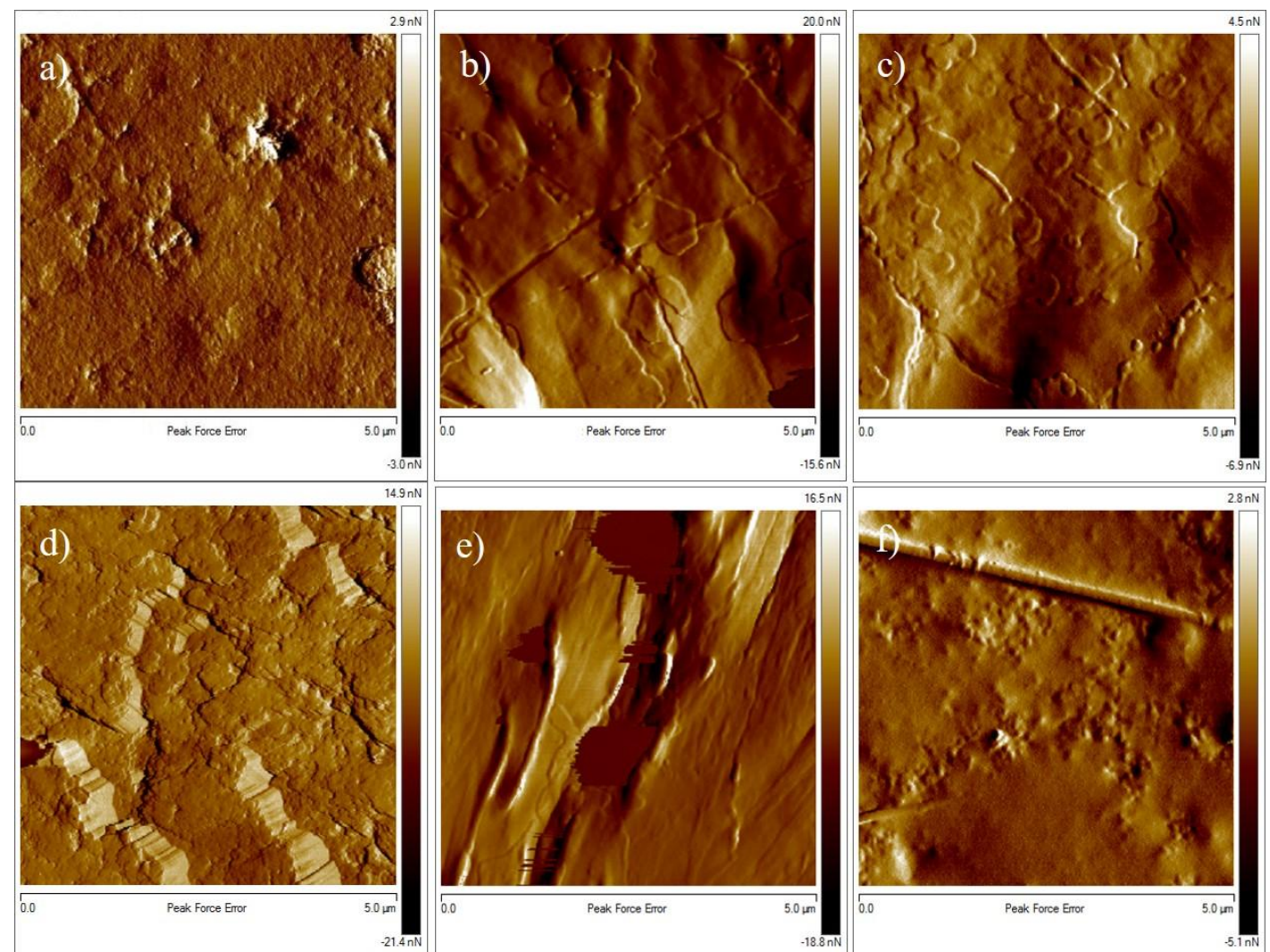

Figure 10.1.4.1.4. Topological graphs obtained in peak-force error for the lead white egg tempera (EG@Pb) reconstructed model paint films uninoculated (a) and inoculated with: b) Acremonium chrysogenum (Ac), c) Aspergillus niger (An), d) Mucor rouxii (Mr), e) Penicillium chrysogenum (Pc) and f) Trichoderma pseudokoningii (Tp) fungi. Image scan size is 5 $\mu \mathrm{m}^{2}$. 

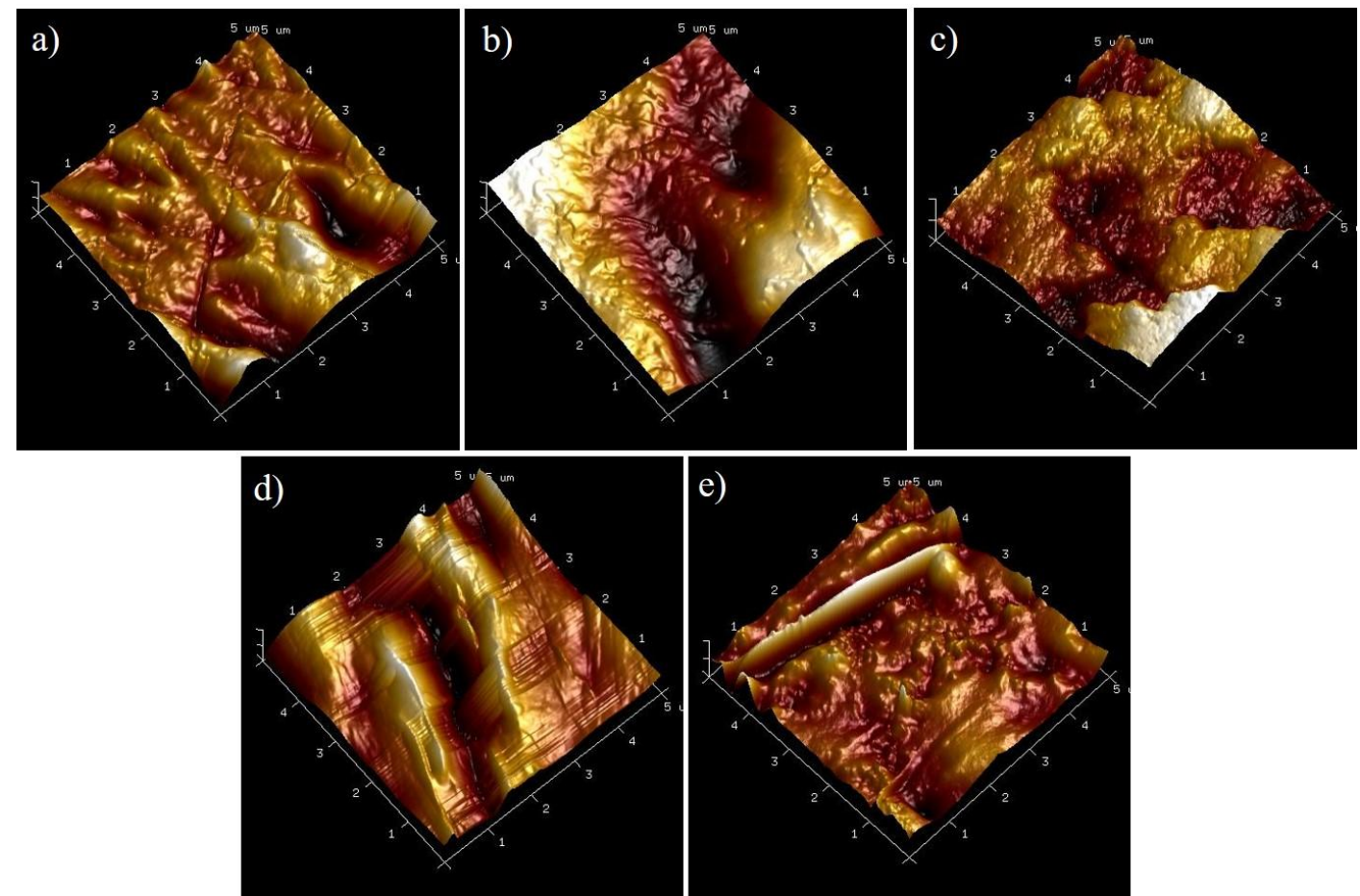

Figure 10.1.4.1.5. Topological graphs obtained in 3D height image mode for: a) EG@Pb_Ac, b) EG@Pb_An, c) EG@Pb_Mr,d)EG@Pb_Pc, and e) EG@Pb_Tp fungi. Image scan size is $5 \mu \mathrm{m}^{2}$.

Table 10.1.4.1.2 Summary of values of Young's Modulus and the corresponding standard deviation obtained for the lead white egg tempera reconstructed model paint inoculated specimens compared to the uninoculated specimen.

\begin{tabular}{ll}
\hline Specimen & Young's Modulus $(\mathbf{G P a})$ \\
\hline$E G @ P b \_B$ & $1.65 \pm 0.19$ \\
\hline $\boldsymbol{F}$ Fungi & \\
\hline \hline$E G @ P b \_A c$ & $2.79 \pm 0.21$ \\
\hline$E G @ P b \_A n$ & $1.50 \pm 0.09$ \\
\hline$E G @ P b \_M r$ & $1.13 \pm 0.02$ \\
\hline$E G @ P b \_P c$ & $2.86 \pm 0.12$ \\
\hline$E G @ P b \_T p$ & $0.91 \pm 0.06$ \\
\hline Bacteria & \\
\hline$E G @ P b \_A o$ & $3.28 \pm 0.23$ \\
\hline$E G @ P b \_B a$ & $2.29 \pm 0.11$ \\
\hline$E G @ P b \_S c$ & $1.74 \pm 0.16$
\end{tabular}


The topological graphs obtained for the EG@Pb specimens inoculated with bacteria exhibited a surface with globular features (Figure 10.1.4.1.6) associated to the actuation of the bacteria on the rounded egg microparticles and granules as previously identified by means FESEM examination (see i.e. Figure 8.2.2.1.9a). Among the three bacteria Arthrobacter oxydans seems to exhibit the higher deterioration activity, as it can be appreciated in the 3D height images obtained for the specimens (Figure 10.1.4.1.6). These results are in agreement with the $E$ values obtained for the specimen inoculated with bacteria. Increase in the $E$ value was reported for all the specimens, in particular for EG@Pb_Ao (Table 10.1.4.1.2).
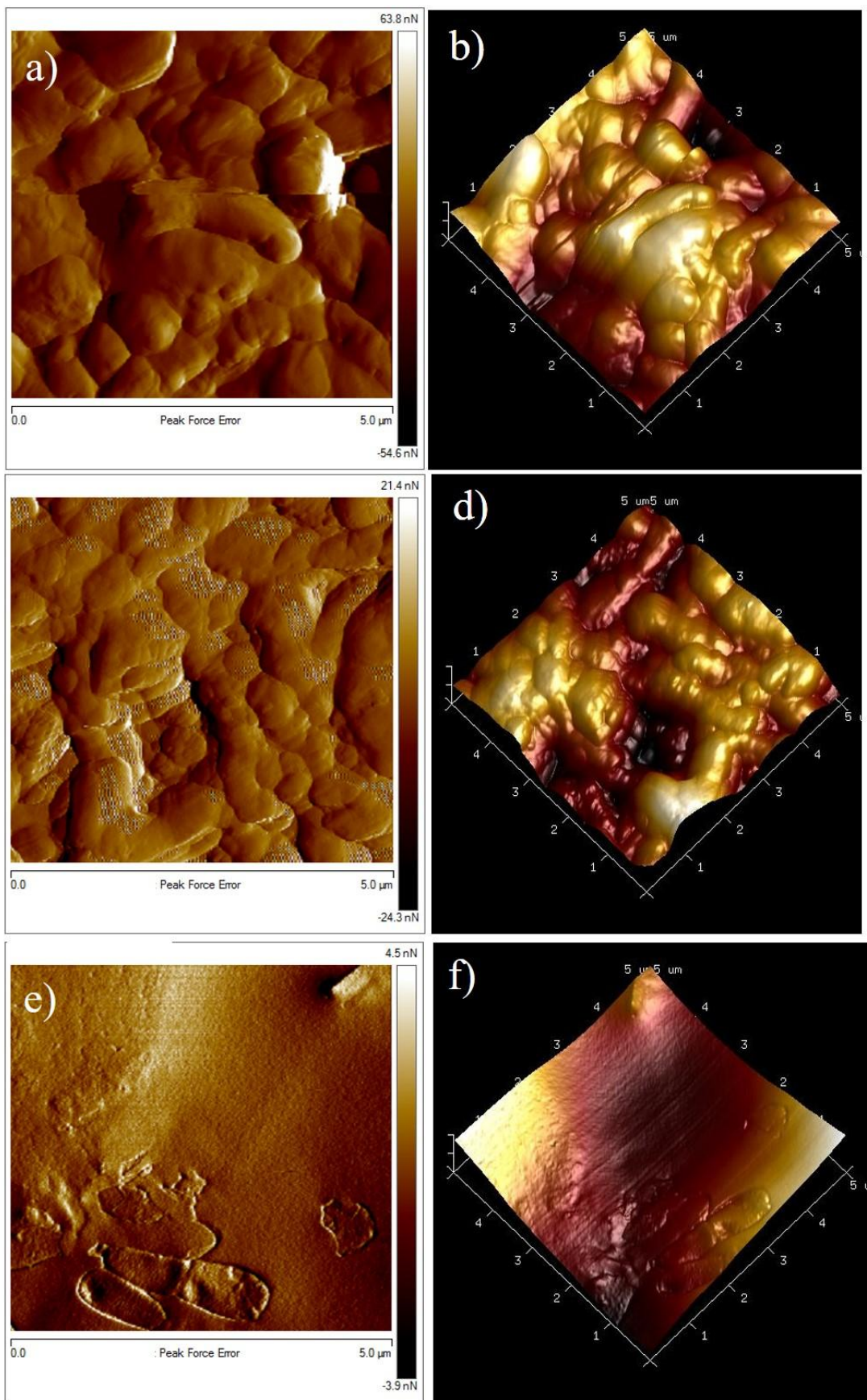

Figure 10.1.4.1.6. Topological graphs obtained in peak-force-error for the EG@Pb reconstructed model paint specimens inoculated with bacteria (left) and 3D height image mode (right): a) and b) Arthrobacter oxydans (EG@Pb_Ao); c) and d) Bacillus amyloliquefaciens (EG@Pb_Ba); and e) and f) Streptomyces cellulofans (EG@Pb_Sc). Image scan size is $5 \mu \mathrm{m}^{2}$. 


\section{Cadmium yellow}

The cadmium yellow specimens inoculated with Acremonium chrysogenum (EG@Cd_Ac), Aspergillus niger (EG@Cd_An), Mucor rouxii (EG@Cd_Mr) and Penicillium chrysogenum (EG@Cd_Pc) fungi exhibited grainy carpet surface quite different from the uninoculated (EG@Cd_B) specimen (Figure 10.1.4.1.7a). As described in the secondary electron images obtained by FESEM, these features can be associated to spores and rests of biomass and protrusions of small size developed as result of the microbial actuation (Figure 10.1.4.1.7 and 10.1.4.1.8). These results are in agreement with the increment in $E$ obtained in all the specimens inoculated with fungi being more evident in the specimens inoculated with Acremonium chrysogenum and Aspergillus niger fungi. Table 10.1.4.1.3 shows the $E$ value obtained for the series of inoculated specimens.
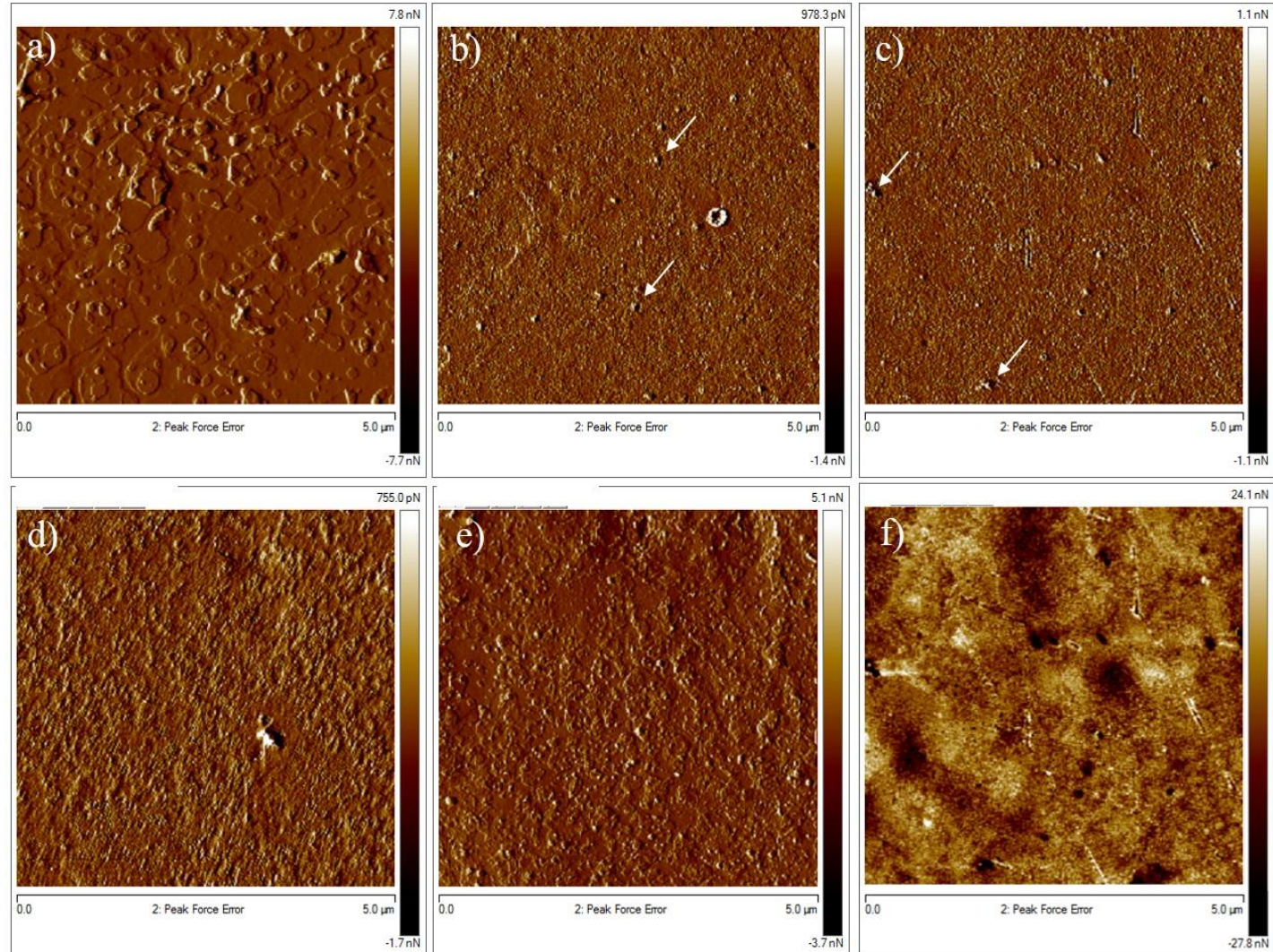

Figure 10.1.4.1.7. Topological graphs obtained in peak-force error for the cadmium yellow egg tempera (EG@Cd) reconstructed model paint films uninoculated (a) and inoculated with: b) Acremonium chrysogenum (Ac), c) Aspergillus niger (An), d) Mucor rouxii (Mr), e) Penicillium chrysogenum $(\mathrm{Pc})$ and f) Trichoderma pseudokoningii $(\mathrm{Tp})$ fungi. Image scan size is $5 \mu \mathrm{m}^{2}$. 

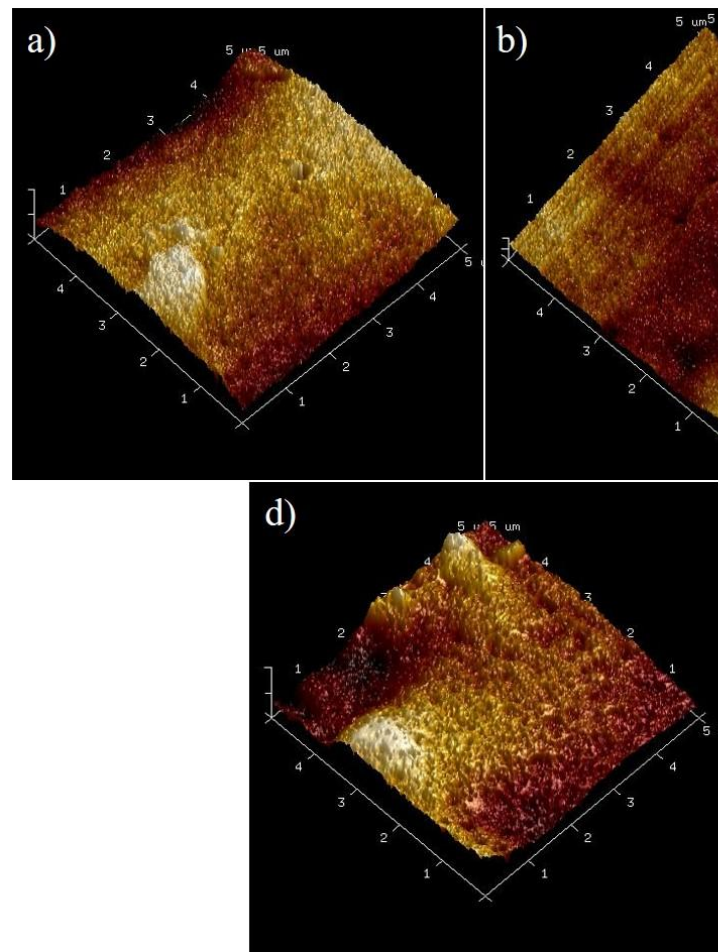

Figure 10.1.4.1.8. Topological graphs obtained in 3D height image mode for: a) EG@Fe_Ac, b) EG@Fe_An, c) EG@Fe_Mr,d)EG@Fe_Pc, and e) EG@Fe_Tp fungi. Image scan size is $5 \mu \mathrm{m}^{2}$.

Table 10.1.4.1.3. Summary of values of Young's Modulus and the corresponding standard deviation obtained for the cadmium yellow egg tempera reconstructed model paint inoculated specimens compared to the uninoculated specimen.

\begin{tabular}{l|l}
\hline Specimen & Young's Modulus $(\mathbf{G P a})$ \\
\hline \hline$E G @ C d \_B$ & $0.81 \pm 0.16$ \\
\hline \hline $\boldsymbol{F u n g i}$ & \\
\hline \hline$E G @ C d \_A c$ & $4.46 \pm 0.21$ \\
\hline$E G @ C d \_A n$ & $6.59 \pm 0.16$ \\
\hline$E G @ C d \_M r$ & $1.55 \pm 0.09$ \\
\hline$E G @ C d \_P c$ & $2.16 \pm 0.12$ \\
\hline$E G @ C d \_T p$ & $1.23 \pm 0.10$ \\
\hline \hline Bacteria & \\
\hline \hline$E G @ C d \_A o$ & $1.99 \pm 0.08$ \\
\hline$E G @ C d \_B a$ & $2.96 \pm 0.09$ \\
\hline$E G @ C d \_S c$ & $9.03 \pm 0.09$
\end{tabular}


A different topological graph were obtained in the surface of the specimens inoculated with bacteria (Figure 10.1.4.1.9). Activity of these microorganisms has promoted the appearance of micropores and fissures, the latter particularly large in the EG@Cd_Sc specimen (see Figure 10.1.4.1.9 f). Consequently, the highest $E$ value was reported for this specimen. These results are also in agreement with the high increment in the free fatty acids contribution observed by FTIR, associated to the hydrolysis of triglycerides promoted by this actinobacteria. (Figure 10.1.4.1.3).

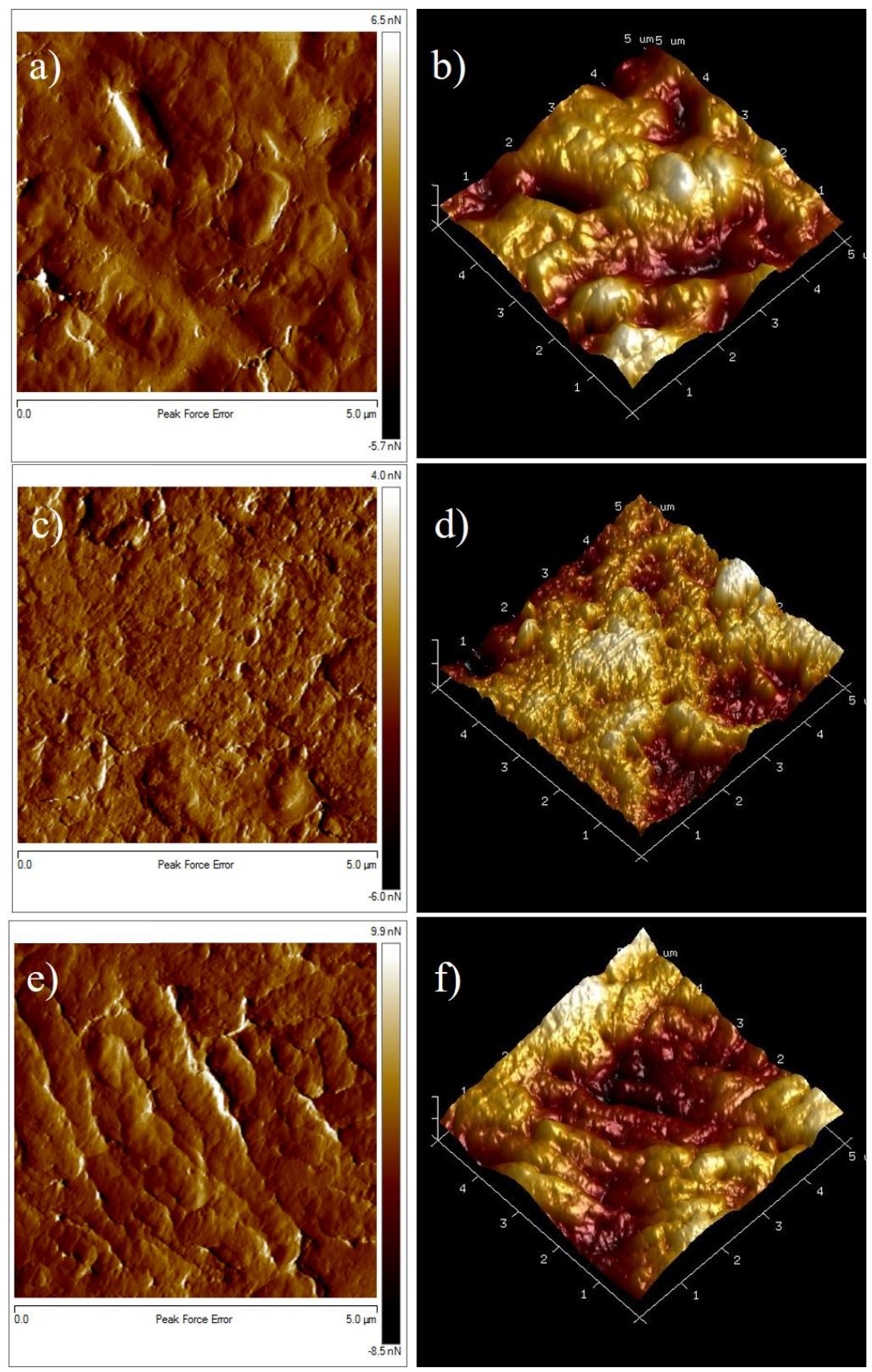

Figure 10.1.4.1.9. Topological graphs obtained in peak-force-error for the EG@Cd reconstructed model paint specimens inoculated with bacteria (left) and 3D height image mode (right): a) and b) Arthrobacter oxydans (EG@Cd_Ao); c) and d) Bacillus amyloliquefaciens (EG@Cd_Ba); and e) and f) Streptomyces cellulofans (EG@Cd_Sc). Image scan size is $5 \mu \mathrm{m}^{2}$. 
10.1.4.2. Egg oil emulsion inoculated reconstructed model paint specimens

\section{Iron oxide red}

A variety of micromorphologíes were identified in the series of specimens prepared with lead white and inoculated with fungi as it can be seen in the Figure 10.1.4.2.1. Microerosion promoted by the microbial attack has formed mainly cracks and fissures (Fig. 10.1.4.2.1 c and e). Aggregates of pigment grains (Fig. 10.1.4.2.1 f) and rounded features ascribed spores (Fig. 10.1.4.2.1 b) or egg yolk granules and spheres (Fig. 10.1.4.2.1 d) can be seen protruding the paint film surface.

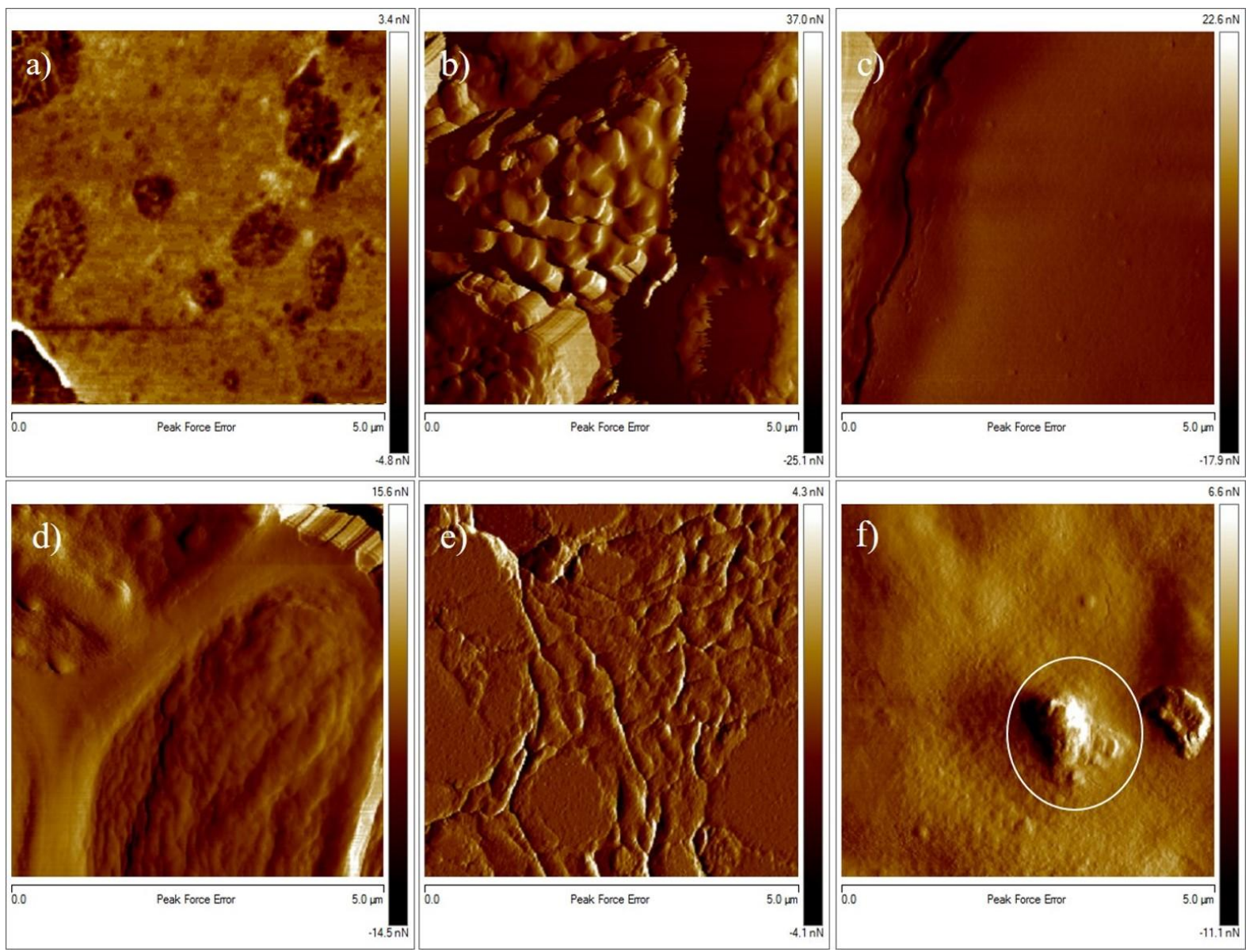

Figure 10.1.4.2.1. Topological graphs obtained in peak-force error for the iron oxide red egg oil emulsion (EO@Fe) reconstructed model paint films uninoculated (a) and inoculated with: b) Acremonium chrysogenum (Ac), c) Aspergillus niger (An), d) Mucor rouxii (Mr), e) Penicillium chrysogenum ( $\mathrm{Pc}$ ) and f) Trichoderma pseudokoningii (Tp) fungi. Image scan size is $5 \mu \mathrm{m}^{2}$. 

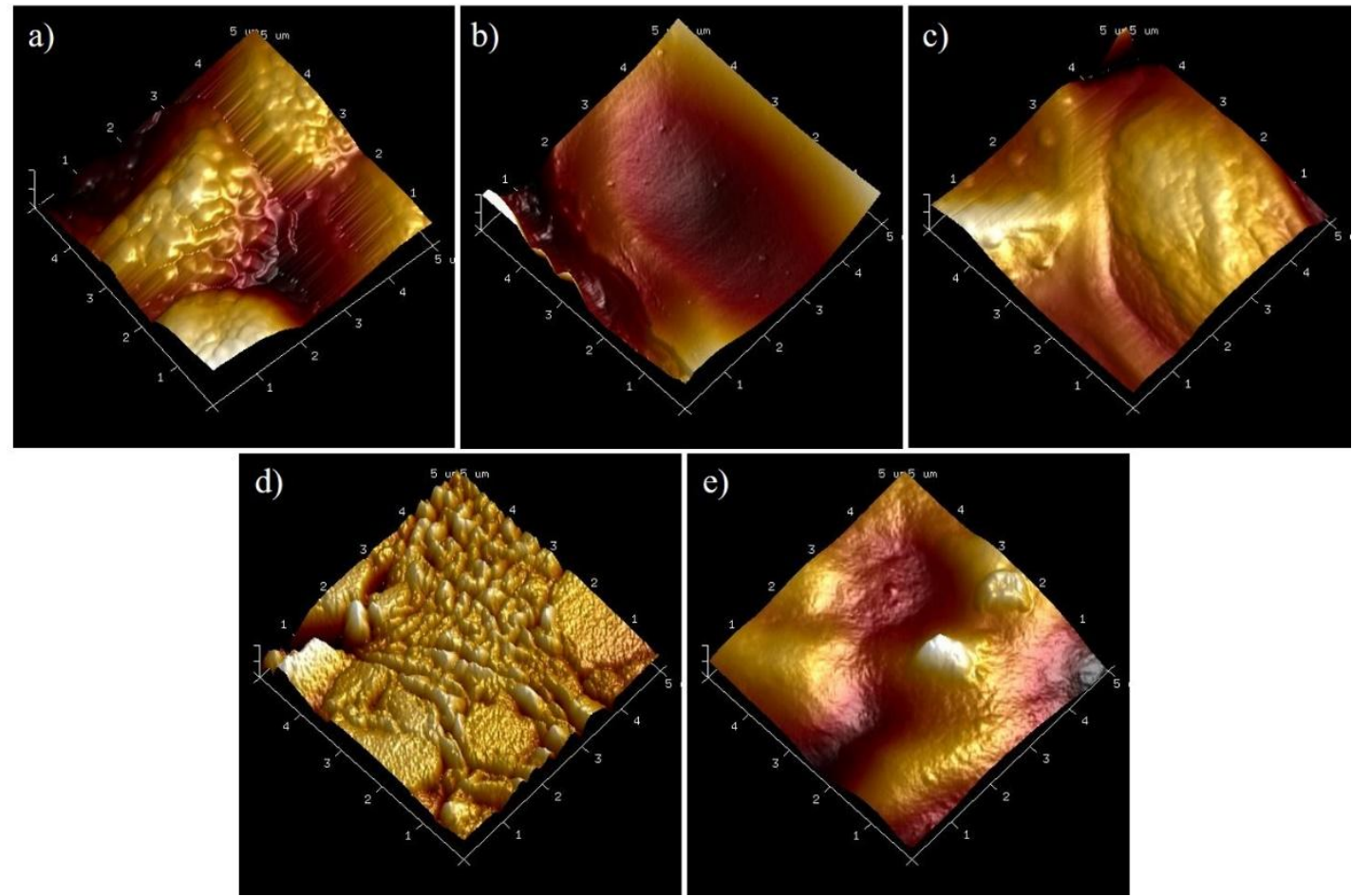

Figure 10.1.4.2.2. Topological graphs obtained in 3D height image mode for: a) EO@Fe_Ac, b) EO@Fe_An, c) EO@Fe_Mr,d)EO@Fe_Pc, and e) EO@Fe_Tp fungi. Image scan size is $5 \mu^{2}$.

Table 10.1.4.2.1 shows the variation in $E$ values obtained for the series of specimens inoculated with microorganisms compared to the uninoculated specimen. Increase in the $E$ value was observed in all the specimens inoculated with fungi, being notable in the specimen inoculated with Aspergillus niger(EO@Fe_An). 
Table 10.1.4.2.1. Summary of values of Young's Modulus and the corresponding standard deviation obtained for the iron oxide red egg oil emulsion reconstructed model paint inoculated specimens compared to the uninoculated specimen.

\begin{tabular}{|c|c|}
\hline Specimen & Young's Modulus (GPa) \\
\hline$E O @ F e \_B$ & $0.18 \pm 0.02$ \\
\hline \multicolumn{2}{|l|}{ Fungi } \\
\hline$E O @ F e \_A c$ & $0.26 \pm 0.08$ \\
\hline$E O @ F e \_A n$ & $2.86 \pm 0.11$ \\
\hline$E O @ F e \_M r$ & $1.20 \pm 0.06$ \\
\hline$E O @ F e \_P c$ & $0.52 \pm 0.02$ \\
\hline$E O @ F e \_T p$ & $1.75 \pm 0.04$ \\
\hline \multicolumn{2}{|l|}{ Bacteria } \\
\hline EO@Fe_Ao & $2.99 \pm 0.09$ \\
\hline$E O @ F e \_B a$ & $2.62 \pm 0.07$ \\
\hline$E O @ F e \_S c$ & $2.33 \pm 0.03$ \\
\hline
\end{tabular}

Topological graphs obtained for the specimens inoculated with bacteria also show appearance of microfissures and micropores (Figure 10.1.4.2.3). $E$ values obtained for this series are shown in Table 10.1.4.2.1. Bacteria inoculation has induced significant increment in the $E$ value. 


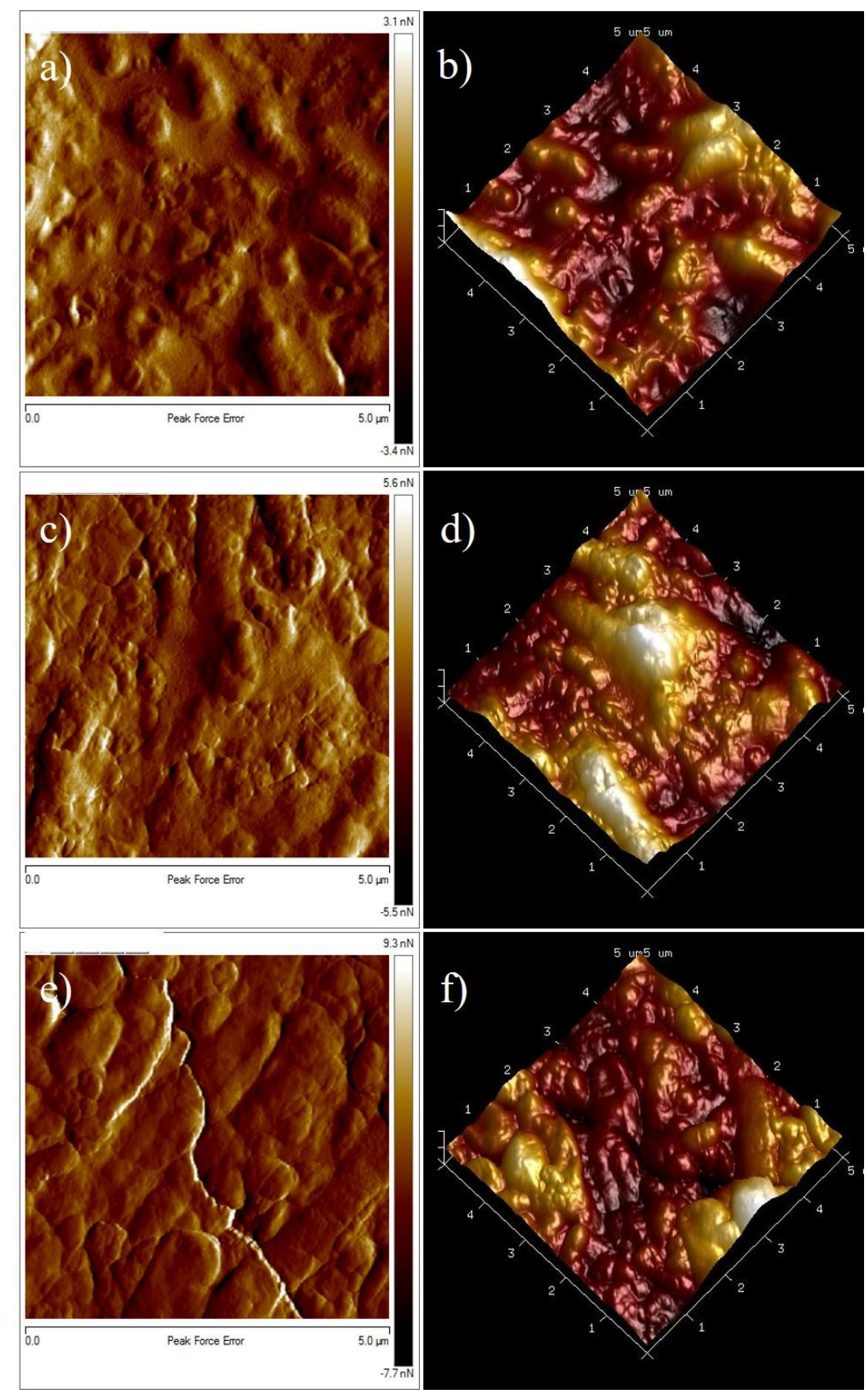

Figure 10.1.4.2.3. Topological graphs obtained in peak-force-error for the EO@Fe reconstructed model paint specimens inoculated with bacteria (left) and 3D height image mode (right): a) and b) Arthrobacter oxydans (EG@Pb_Ao); c) and d) Bacillus amyloliquefaciens (EG@Pb_Ba); and e) and f) Streptomyces cellulofans (EG@Pb_Sc). Image scan size is $5 \mu \mathrm{m}^{2}$.

\section{Verdigris}

This series of paint films specimens also presented large pigment grains protrusions through the paint film surface, which difficulted to creep the tip over the surface as reported for the egg tempera inoculated specimens. In agreement with the examination carried out by FESEM that showed a more irregular morphology for the specimens inoculated with fungi, 
topological graphs and $E$ values could be only obtained for the specimens inoculated with bacteria (Figure 10.1.4.2.4). It is important to mention that scan size for these specimens was limited to $1 \mu \mathrm{m}^{2}$ as with the uninoculated specimen due to the difficulty reported for the creep of the tip over the surface of larger areas. The most significant changes in the bacteria series were observed in paint specimens inoculated with the actinobacterium Streptomyces cellulofans.
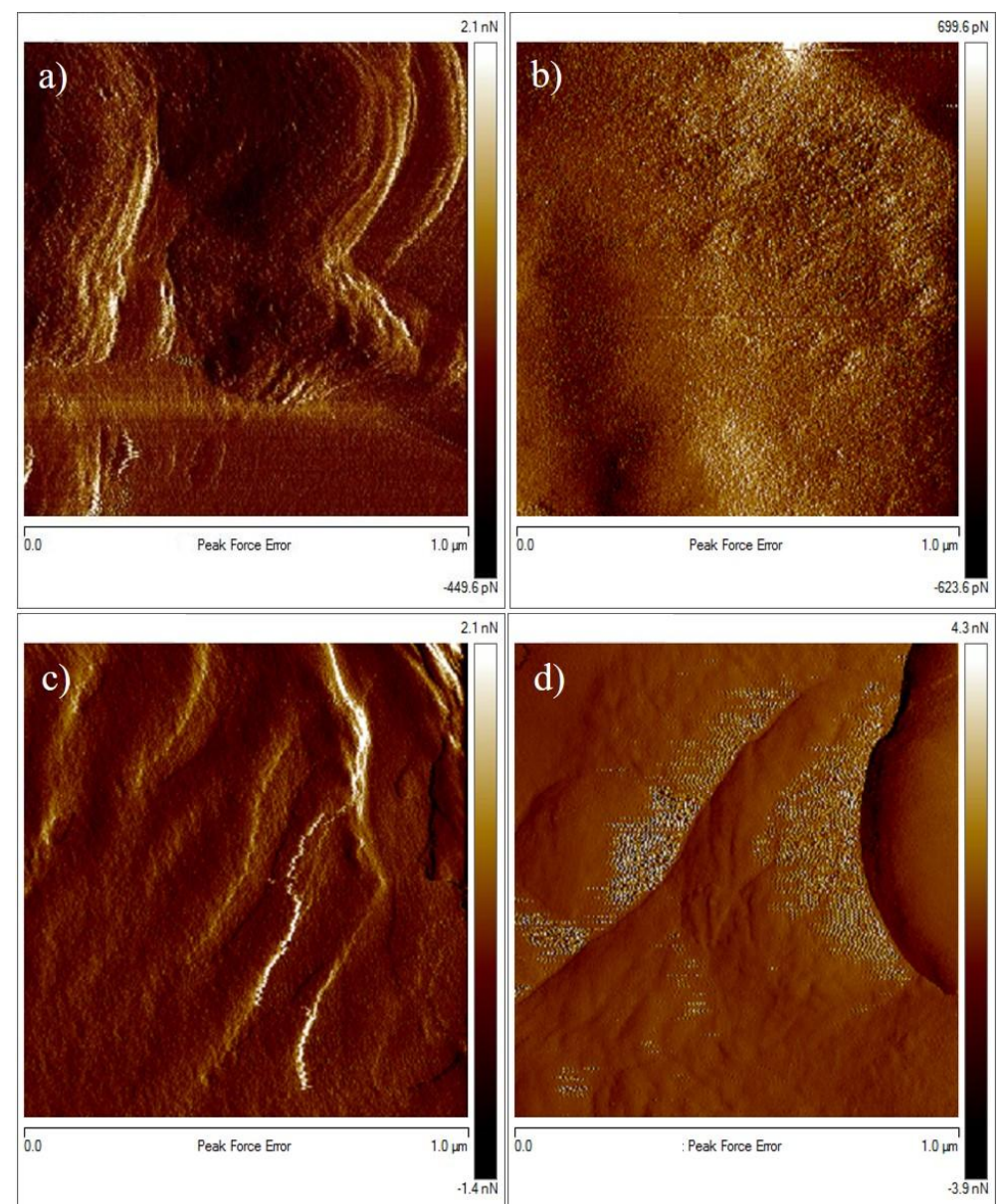

Figure 10.1.4.2.4. Topological graphs obtained in peak-force error for the verdigris egg oil emulsion (EO@ $\mathrm{Cu})$ reconstructed model paint films uninoculated (a) and inoculated with: b) Arthrobacter oxydans (Ao), c) Bacillus amyloliquefaciens (Ba), d) Streptomyces cellulofans (Sc) bacteria. Image scan size is $1 \mu \mathrm{m}^{2}$.
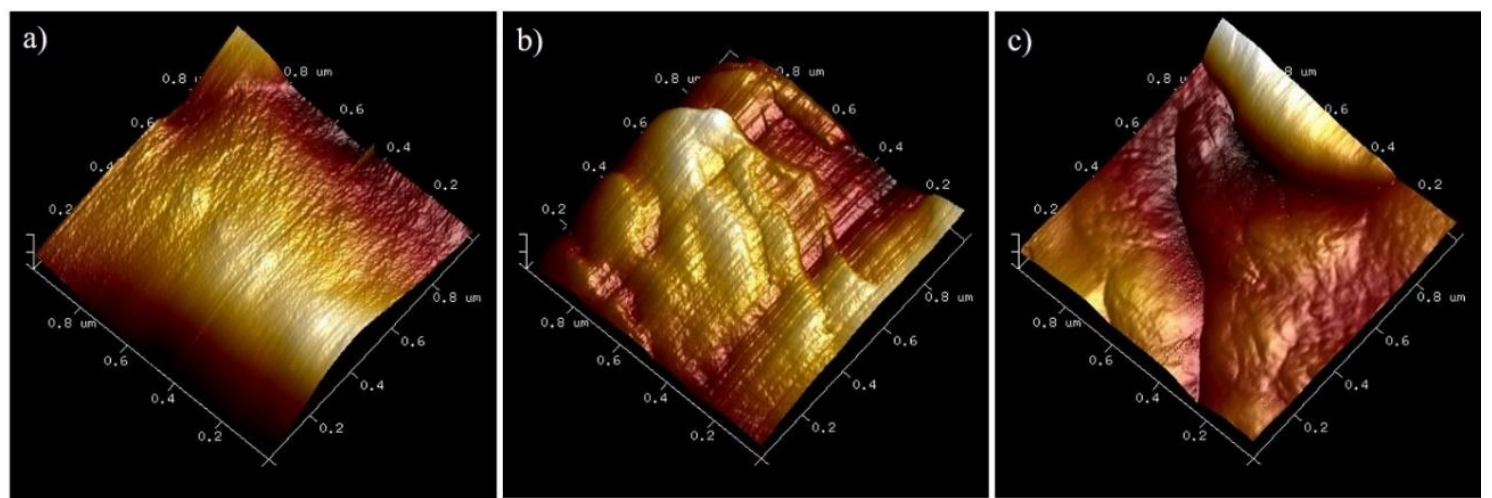

Figure 10.1.4.2.5. Topological graphs obtained in 3D height image mode for: a) EO@Cu_Ao, b) EO@Cu_Ba, and c) EO@Cu_Sc bacteria. Image scan size is $5 \mu \mathrm{m}^{2}$. 
The $E$ values obtained for the verdigris egg oil emulsion reconstructed model paint specimens inoculated with bacteria are shown in the Table 10.1.4.2.2, compared to the uninoculated specimen. The three specimens inoculated with bacteria exhibit an increment in the $E$ value, being more significant in EO@Cu_Sc specimen. These results are in agreement with the changes observed in the surface morphology.

Table 10.1.4.2.2. Summary of values of Young's Modulus and the corresponding standard deviation obtained for the verdigris egg oil emulsion reconstructed model paint inoculated specimens compared to the uninoculated specimen.

\begin{tabular}{ll}
\hline Specimen & Young's Modulus (GPa) \\
\hline \hline$E O @ C u \_B$ & $0.08 \pm 0.00$ \\
\hline Bacteria & \\
\hline \hline$E O @ C u \_A o$ & $0.10 \pm 0.00$ \\
\hline$E O @ C u \_B a$ & $0.59 \pm 0.02$ \\
\hline$E O @ C u \_S c$ & $1.44 \pm 0.03$ \\
\hline
\end{tabular}

\section{Lead white}

Topological graphs obtained for this series of specimens inoculated with fungi exhibited significant changes when compared to the uninoculated specimen, where a uniform surface with abundant pigment grains protrusions is observed (Figure 10.1.4.2.6). Cracks and fissures are recognized in the surface of the specimen EO@Pb_Pc (Figure 10.1.4.2.6 e). In the rest of specimens abundant protrusions ascribed to aggregates of pigment grains and metal complexes can be seen (i.e. circles in Figure 10.1.4.2.6 f). 

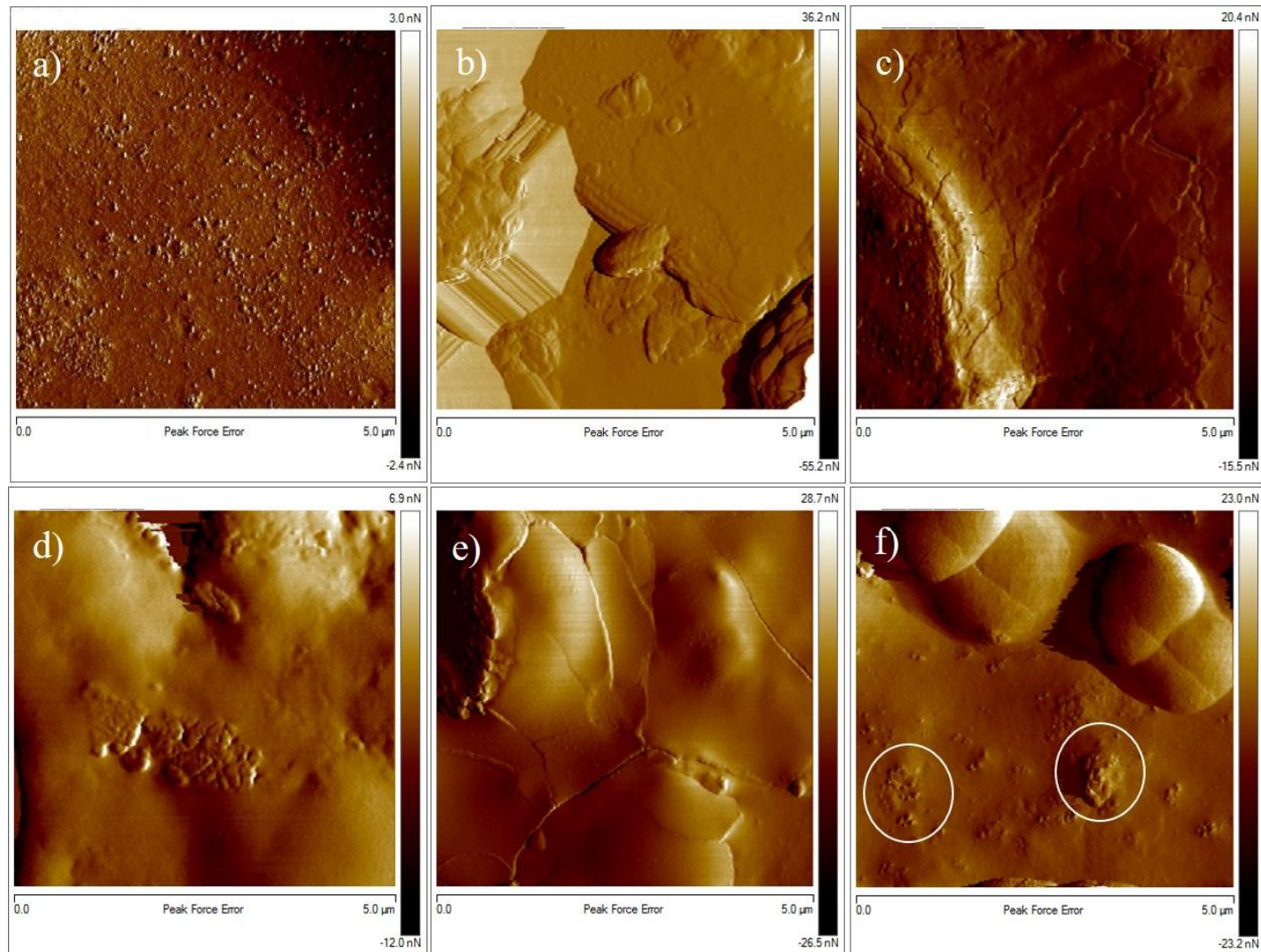

Figure 10.1.4.2.6. Topological graphs obtained in peak-force error for the lead white egg oil emulsion $(\mathrm{EO} @ \mathrm{~Pb})$ reconstructed model paint films uninoculated (a) and inoculated with: b) Acremonium chrysogenum (Ac), c) Aspergillus niger (An), d) Mucor rouxii (Mr), e) Penicillium chrysogenum ( $\mathrm{Pc}$ ) and f) Trichoderma pseudokoningii (Tp) fungi. Image scan size is $5 \mu \mathrm{m}^{2}$.
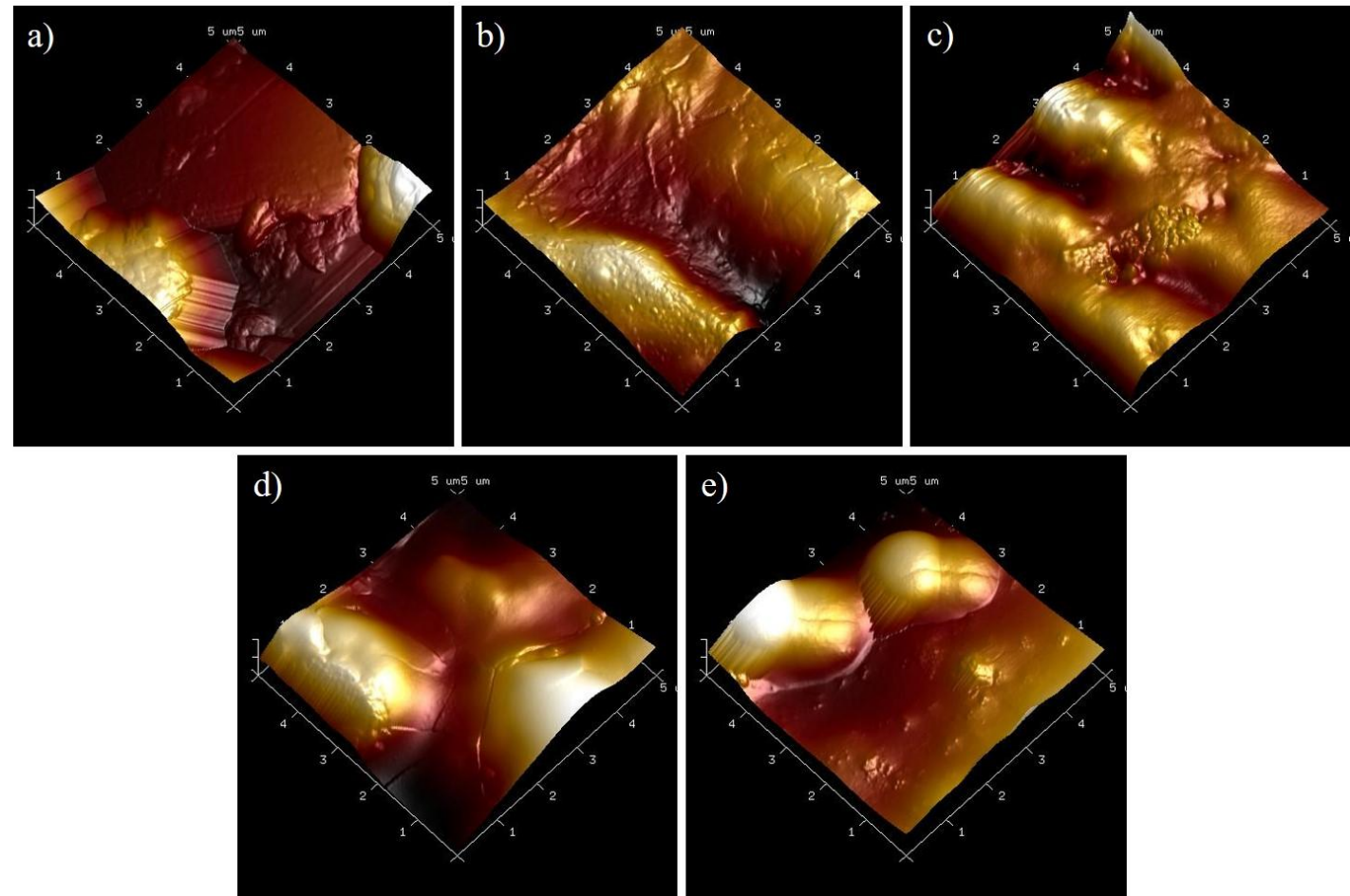

Figure 10.1.4.2.7. Topological graphs obtained in 3D height image mode for: a) EO@Pb_Ac, b) EO@Pb_An, c) $\left.\mathrm{EO} @ \mathrm{~Pb} \_\mathrm{Mr}, \mathrm{d}\right) \mathrm{EO} @ \mathrm{~Pb} \_\mathrm{Pc}$, and e) EO@Pb_Tp fungi. Image scan size is $5 \mu \mathrm{m}^{2}$. 
$E$ values obtained in the lead white egg oil emulsion series inoculated with fungi are shown in Table 10.1.4.2.3. In general, all the inoculated specimens exhibited an increase in the $E$ value, in particular, EO@Pb_Pc, which is consistent with the changes observed in the topological images.

Table 82.5.2.3. Summary of values of Young's Modulus and the corresponding standard deviation obtained for the lead white egg oil emulsion reconstructed model paint inoculated specimens compared to the uninoculated specimen.

\begin{tabular}{l|l}
\hline Specimen & Young's Modulus $(G P a)$ \\
\hline \hline$E O @ P b \_B$ & $0.14 \pm 0.02$ \\
\hline \hline Fungi & $0.45 \pm 0.06$ \\
\hline$E O @ P b \_A c$ & $0.49 \pm 0.09$ \\
\hline$E O @ P b \_A n$ & $0.50 \pm 0.06$ \\
\hline$E O @ P b \_M r$ & $1.04 \pm 0.12$ \\
\hline$E O @ P b \_P c$ & $0.33 \pm 0.08$ \\
\hline$E O @ P b \_T p$ & \\
\hline \hline Bacteria & $0.83 \pm 0.09$ \\
\hline$E O @ P b \_A o$ & $1.18 \pm 0.11$ \\
\hline$E O @ P b \_B a$ & $0.40 \pm 0.09$ \\
\hline$E O @ P b \_S c$ &
\end{tabular}

Similar behavior was observed in the topological graphs acquired in the specimen inoculated with the series of bacteria (Figure 10.1.4.2.8), where were identified cracks and fissures, in particular, in EO@Pb_Ao and EO@Pb_Ba specimens and abundant protrusions of pigment aggregates and other materials in agreement with the FESEM images. Concordantly, the major increment in the $E$ value was obtained for the $\mathrm{EO} @ \mathrm{~Pb} \_\mathrm{Ba}$ specimen Figure 10.1.4.2.8d. 

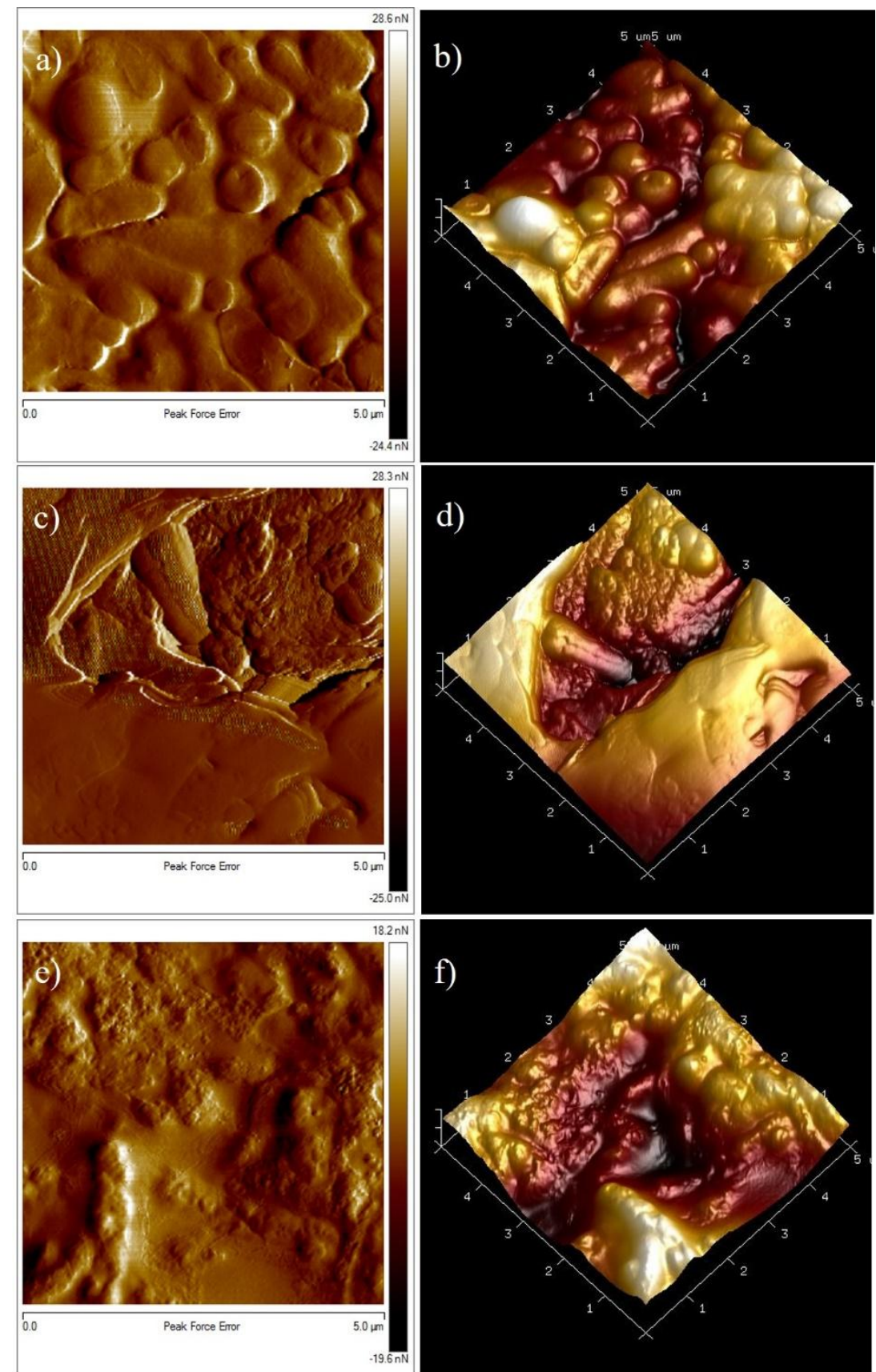

Figure 10.1.4.2.8. Topological graphs obtained in peak-force-error for the $\mathrm{EO} @ \mathrm{~Pb}$ reconstructed model paint specimens inoculated with bacteria (left) and 3D height image mode (right): a) and b) Arthrobacter oxydans (EO@Fe_Ao); c) and d) Bacillus amyloliquefaciens (EO@Fe_Ba); and e) and f) Streptomyces cellulofans (EO@Fe_Sc). Image scan size is $5 \mu \mathrm{m}^{2}$.

\section{Cadmium yellow}

Figure 10.1.4.2.9 shows the topological graphs obtained for the cadmium yellow egg oil emulsion reconstructed model paint specimens inoculated with fungi compared to the uninoculated specimen. Different, morphological changes are observed in all the specimens, large protrusions are recognized in the EO@Cd_Ac specimen (Figure 10.1.4.2.9b and Figure 10.1.4.2.10a) and cracks and micropoores are identified in EO@Cd_An, EO@Cd_Pc, and 
EO@Cd_Tp specimens (Figure 10.1.4.2.9 c, e, f and Figure 10.1.4.2.10b, d, e). Coalescent features rest of the seminal egg oil emulsion can be seen in the EO@Cd_Mr specimen (Figure 10.1.4.2.9d and Figure 10.1.4.2.10c).

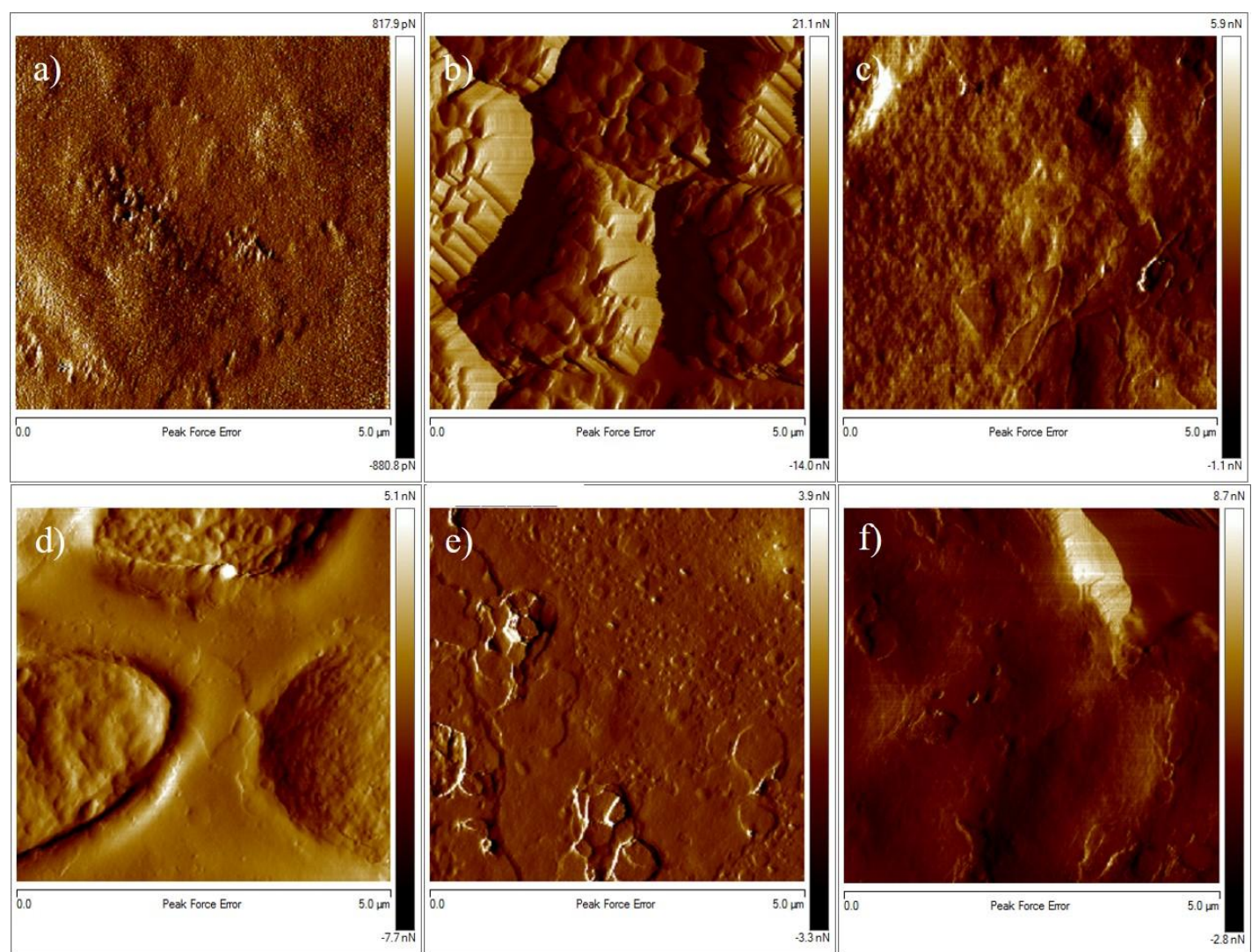

Figure 10.1.4.2.9. Topological graphs obtained in peak-force error for the cadmium yellow egg oil emulsion (EO@Cd) reconstructed model paint films uninoculated (a) and inoculated with: b) Acremonium chrysogenum (Ac), c) Aspergillus niger (An), d) Mucor rouxii (Mr), e) Penicillium chrysogenum $(\mathrm{Pc})$ and f) Trichoderma pseudokoningii $(\mathrm{Tp})$ fungi. Image scan size is $5 \mu \mathrm{m}^{2}$. 

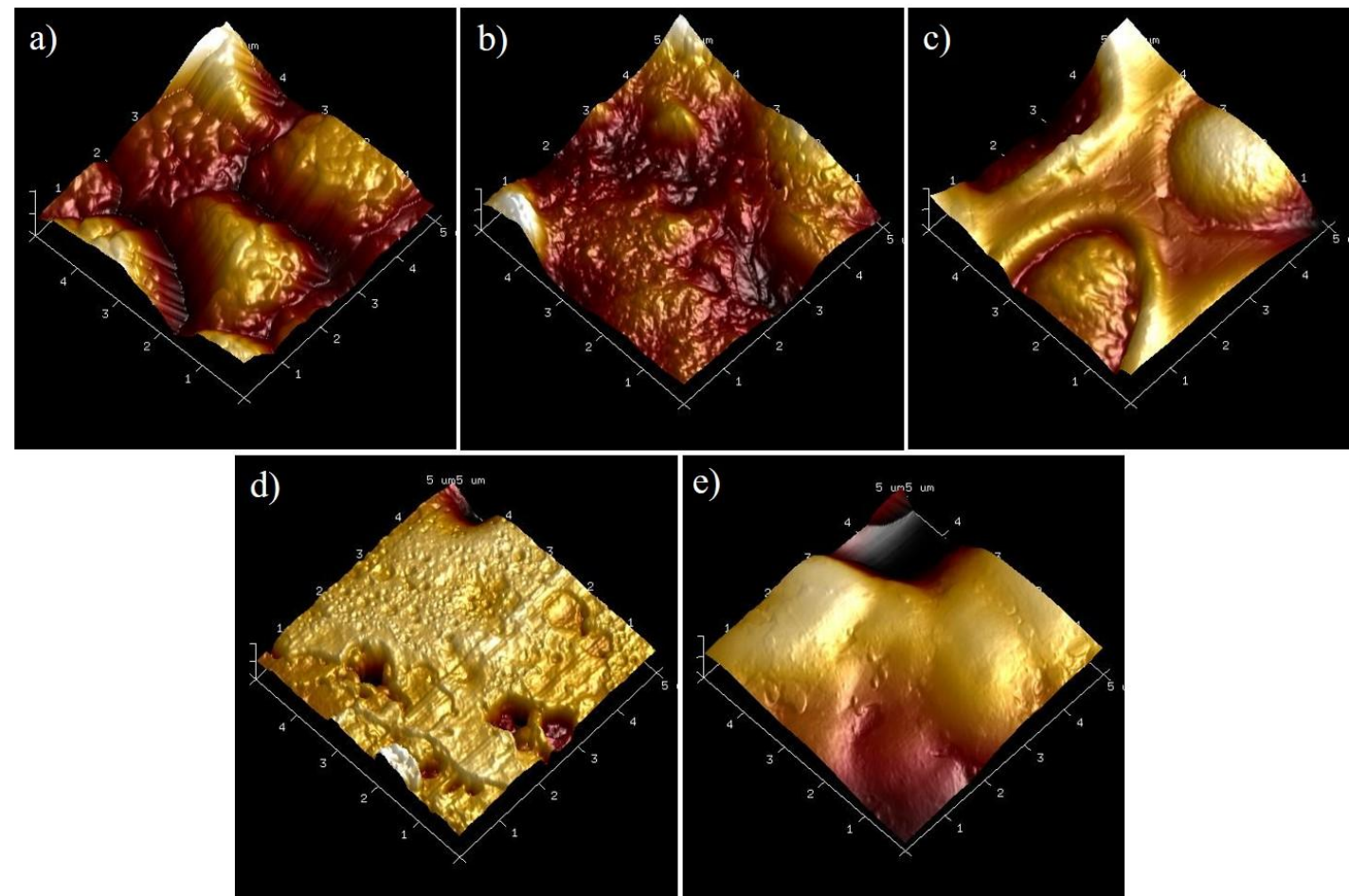

Figure 10.1.4.2.10. Topological graphs obtained in 3D height image mode for: a) EO@Cd_Ac, b) EO@Cd_An, c) EO@Cd_Mr, d)EO@Cd_Pc, and e) EO@Cd_Tp fungi. Image scan size is $5 \mu \mathrm{m}^{2}$.

Increment in the $E$ value was obtained for all the specimens inoculated with fungi (Table 10.1.4.2.4). Most significant variations were obtained for the EO@Cd_An, EO@Cd_Mr and EO@Cd_Pc specimens. Increment of E value found in the EO@Cd series are lower than the obtained for the series of egg tempera inoculated specimens prepared with cadmium yellow, but equally significant when compared to the $\Delta E$ values obtained for the series of specimens prepared with other pigments. 
Table 10.1.4.2.4. Summary of values of Young's Modulus and the corresponding standard deviation obtained for the cadmium yellow egg oil emulsion reconstructed model paint inoculated specimens compared to the uninoculated specimen.

\begin{tabular}{l|l}
\hline Specimen & Young's Modulus (GPa) \\
\hline \hline$E O @ C d \_B$ & $0.13 \pm 0.04$ \\
\hline \hline Fungi & $0.60 \pm 0.08$ \\
\hline EO@Cd_Ac & $3.05 \pm 0.16$ \\
\hline$E O @ C d \_A n$ & $1.98 \pm 0.09$ \\
\hline EO@Cd_Mr & $2.23 \pm 0.12$ \\
\hline EO@Cd_Pc & $0.77 \pm 0.10$ \\
\hline EO@Cd_Tp & \\
\hline \hline Bacteria & $3.71 \pm 0.12$ \\
\hline \hline EO@Cd_Ao & $1.72 \pm 0.09$ \\
\hline EO@Cd_Ba & $2.81 \pm 0.09$ \\
\hline$E O @ C d \_S c$ &
\end{tabular}

Topological images obtained for the cadmium yellow egg oil emulsion reconstructed model paint specimens inoculated with bacteria are shown in Figure 10.1.4.2.11. The paint films specimens inoculated with Arthrobacter oxydans (EO@Cd_Ao) and Streptomyces cellulofans (EO@Cd_Sc) actinobacteria exhibited micropores and fissures as well as protrusions (Figure 10.1.4.2.11 a,b and e,f ) whereas EO@Cd_Ba showed larger protrusion features. In agreement with that, the highest $E$ values were obtained for both actinobacteria (Table 10.1.4.2.4). 

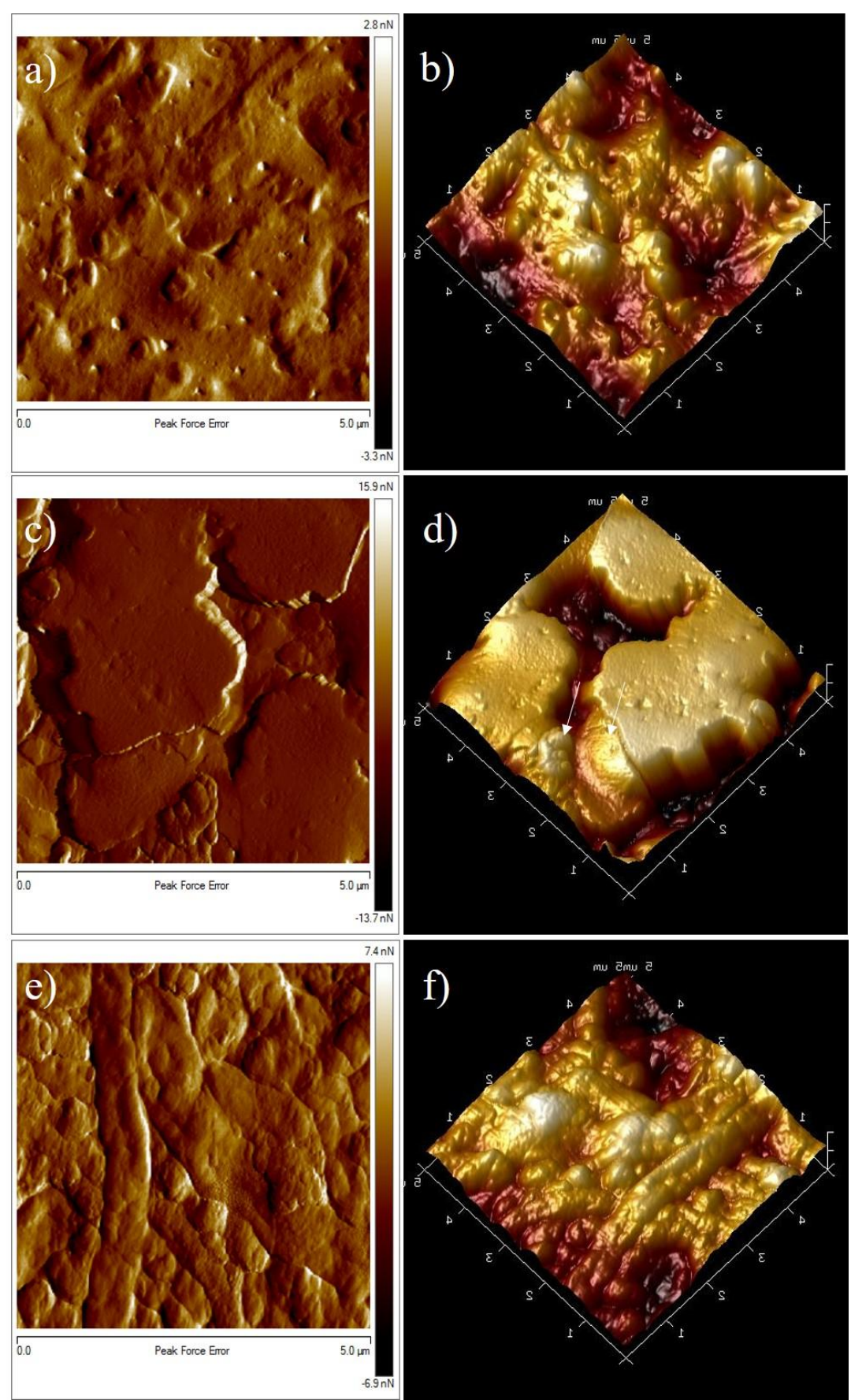

Figure 10.1.4.2.11. Topological graphs obtained in peak-force-error for the EO@Cd reconstructed model paint specimens inoculated with bacteria (left) and 3D height image mode (right): a) and b) Arthrobacter oxydans (EO@Cd_Ao); c) and d) Bacillus amyloliquefaciens (EO@Cd_Ba); and e) and f) Streptomyces cellulofans (EO@Cd_Sc). Image scan size is $5 \mu \mathrm{m}^{2}$. 
AFM nanoindentation is a sensitive and useful technique to characterize changes in both micro/nanomorphology of the surface and micro/nanomechanical properties of paint films submitted to microbiological attack with different type of fungi and bacteria. This technique has revealed a correlation between the changes in the morphological surface and the Young's modulus values obtained before and after incubation of microorganisms. Therefore, this technique has demonstrated again that is an excellent analytical tool that can be applied to the study of biodeterioration of painting specimens due to its micro- or nano-invasive characteristics.

Concerning the results obtained in the two series of reconstructed model paint film specimens after deterioration by biological attack with Acremonium chrysogenum, Aspergillus niger, Mucor rouxii, Penicillium chrysogenum and Trichoderma pseudokoningii fungi; and Arthrobacter oxydans, Bacillus amyloliquefaciens and Streptomyces cellulofans bacteria It can be concluded:

- After incubation with microorganisms, an increment in the $E$ value was observed in most of the paint film specimens, irrespectively of the pigment and the binding medium (tempera or emulsion). The alteration of the micromorphology of the surface of the paint films due to the microbial attack that results in microerosion with appearance of micropores, fissures and cracks results in a weakening of the paint film in its outer part and, concomitantly, in an increment in the $E$ value. It is well known that increase in the value of the Young's modulus at macroscale is associated with an increase in the stiffness of the paint film. Equivalently at microscale, this increase in the $E$ value can be associated to the weakening of the paint film solid structure due to the chemical alteration induced by the microorganisms mainly in the binder polymeric network, as demonstrated by the studies carried out by VMP and FTIR, and by the appearance of physical altered micromorphologies that also contribute to the loss of elastic properties in the film. Interestingly, in a few cases a decrease in the $E$ value was observed. This behavior was always accompanied of lower growing of microorganism colonies and lesser micromorphological changes observed in the paint film after incubation. The formation of a less compact biofilm probably has favored, in these cases, the diffusion of the aqueous medium used for suspending the microorganism cultures that has acted as plasticizer lowering the $E$ value.

- In most of the cases, larger changes in both micromorphology and $E$ values were observed in the specimen inoculated with bacteria. In particular, the actinobacterium Arthrobacter oxydans has been highly active on biodeteriorating all the specimens. That suggests that deterioration activity of bacteria is more intense than that of fungi. 
- Streptomyces cellulofans was especially active biodeteriorating verdigris egg oil emulsion specimen and cadmium yellow egg tempera specimen. That suggests that actinobacteria are more active biodeteriorant agents than eubacteria.

- Among fungi, Aspergillus niger was the species more active inducing largest changes in both types of egg tempera and egg-oil emulsion paint films prepared with iron oxide red, cadmium yellow and lead white. Penicillium chrysogenum was highly active on paint films prepared with lead white, thus suggesting that this microorganism is more resistant to the inhibitory effects of this pigment.

- Comparison between the $E$ values reported for paint films prepared with a same pigment and the two different binding media and subjected or not to incubation indicates that the highest $\Delta E$ values have been obtained for verdigris, lead white and cadmium yellow pigments in the series of egg tempera paints and for iron oxide in the oil emulsion series. That different behavior can be attributed to the more PVC in the iron oxide red films that reduces the amount of binding medium and thus limits the growing of microorganisms.

\subsubsection{References}

Abe, Y., Polyakov, P., Skali-Lami, S., Francius, G. (2011) Elasticity and physico-chemical properties during drinking water biofilm formation. Biofouling, 27, 739-750. 


\subsubsection{Voltammetry}

Cyclic voltammetry and square wave voltammetry were performed for each individual pigment and binding media, which were used as blanks for the identification of the changes caused by the interaction between the pigment and the binder as well as for the subsequent characterization of the changes caused by the deterioration with microorganisms. Characteristic voltammetric responses were obtained upon immersion of the electrodes modified with microsamples of the different specimens in air-saturated acetate buffer solution at $\mathrm{pH} 4.75(0.25 \mathrm{M} \mathrm{HAc} / \mathrm{NaAc})$. The data obtained will be finally compared with those obtained by more traditional techniques, in order to validate the results and the characterization of the alteration products. In order to test the possible use in field by means of portable equipments, no degasification of the electrolyte was performed.

\subsubsection{Binding media}

The morphology exhibited by the cyclic voltammograms (CVs) obtained for the binding media (egg and egg-linseed oil) under study attached to a graphite bar immersed into aqueous acetate buffer at $\mathrm{pH} 4.75$ solution are quite simple (Figure 10.1.5.1.1). Upon scanning the potential from $0.0 \mathrm{~V}$ vs. $\mathrm{Ag} / \mathrm{AgCl}$ in the negative direction (Figure 10.1.5.1.1), the voltammogram consisted of one cathodic peak at $-1.0 \mathrm{~V}\left(\mathrm{C}_{1}\right)$, followed in the subsequent anodic scan by weak oxidation shoulders at around $-0.65 \mathrm{~V}\left(\mathrm{~A}_{1}\right)$ and $+0.25 \mathrm{~V}$. These voltammograms are similar to those recorded at unmodified graphite electrodes so that the signal $\mathrm{C}_{1}$ can be attributed to the reduction of dissolved oxygen (oxygen reduction reaction, ORR), accompanied by weak signals associated to redox processes involving oxygen functionalities in the graphite surface (Chen and McCreery, 1996; Barisci, et al., 2000). The light differences in the intensity of the above voltammetric signals between egg and egg-linseed oil specimens can be attributed to the different degree of coverage of the surface of the graphite electrode. 


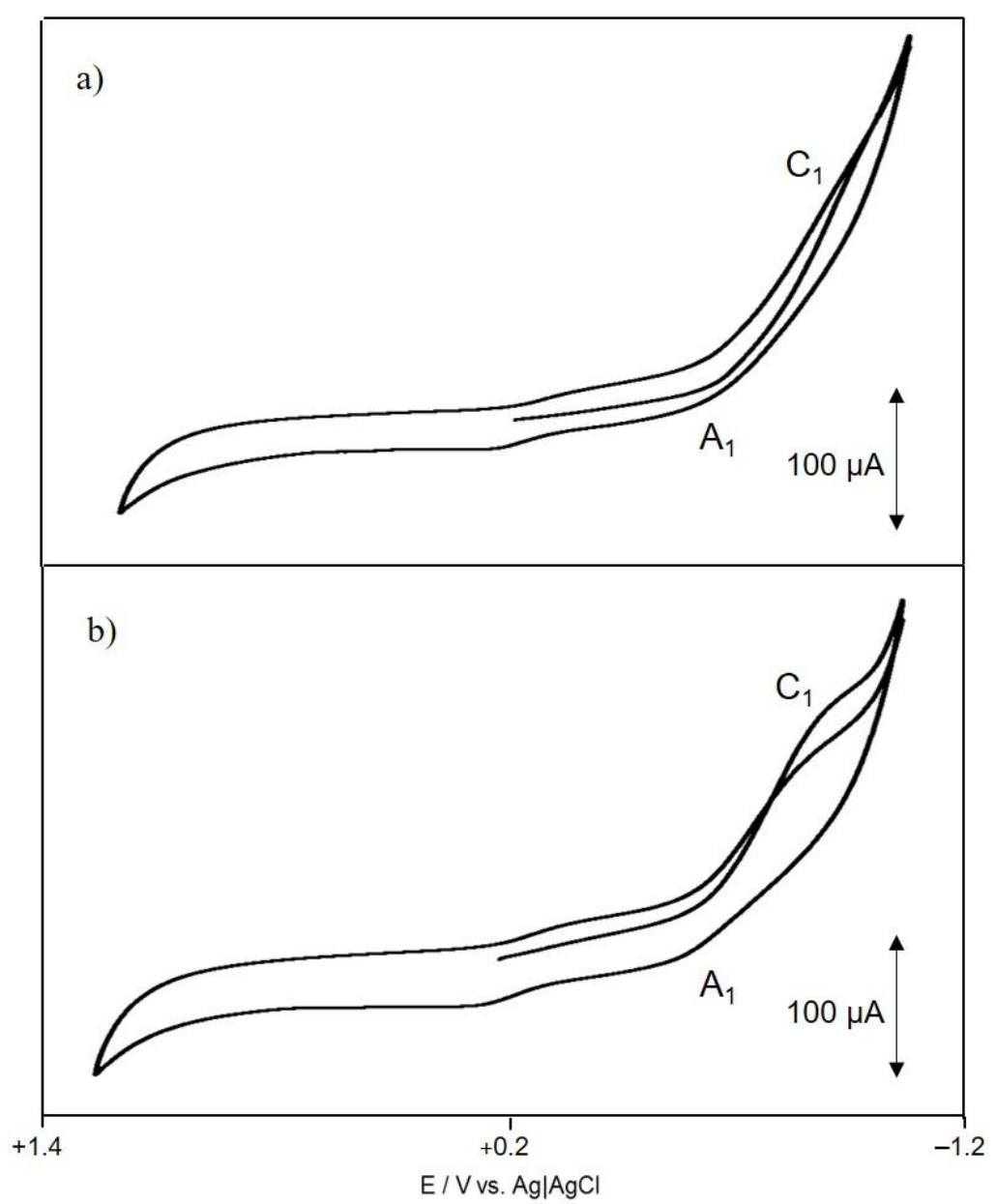

Figure 10.1.5.1.1. Negative-going CVs for: a) egg film specimen; and b) egg-linseed oil film specimen on graphite electrode immersed into $0.25 \mathrm{M}$ sodium acetate buffer, $\mathrm{pH} 4.75$. Potential scan rate $50 \mathrm{mV} \mathrm{s}^{-1}$.

\subsubsection{Pigments}

Iron oxide

The electrochemical analysis of earth-based specimens was performed using $0.10 \mathrm{M} \mathrm{HCl}$ as the electrolyte because this was previously found as providing well-defined signals for iron pigments and corrosion products (Doménech-Carbó et al., 2001, 2007a, 2013a).

The voltammogram of iron oxide red pigment shows two cathodic signals at +0.50 (I) and $+0.25 \mathrm{~V}$ vs. $\mathrm{Ag} / \mathrm{AgCl}$ (II) accompanied by weak shoulders at $-0.10 \mathrm{~V}$ (III) and $+0.87 \mathrm{~V}$ (IV) (Figure 10.1.5.2.1). The signals II and III can be associated to the reduction of ochre-type Fe(III)-oxide species with different degree of hydration and crystallinity. The process II can be represented as:

$\mathrm{Fe}_{2} \mathrm{O}_{3} \cdot \mathrm{nH}_{2} \mathrm{O}($ solid $)+6 \mathrm{H}^{+}(\mathrm{aq})+2 \mathrm{e}^{-} \rightarrow 2 \mathrm{Fe}^{2+}(\mathrm{aq})+(\mathrm{n}+3) \mathrm{H}_{2} \mathrm{O}$

whereas the process III can be ascribed to the reductive dissolution of goethite: 
$\mathrm{FeO}(\mathrm{OH})($ solid $)+3 \mathrm{H}^{+}(\mathrm{aq})+\mathrm{e}^{-} \rightarrow \mathrm{Fe}^{2+}(\mathrm{aq})+2 \mathrm{H}_{2} \mathrm{O}$

In turn, the signal I can be associated to the reduction of $\mathrm{Fe}(\mathrm{III})$ species passing to the solution as $\mathrm{Fe}(\mathrm{III})$-chloride complex species, a process which can tentatively be represented by means of the sequence:

$$
\begin{aligned}
& \mathrm{Fe}_{2} \mathrm{O}_{3} \cdot \mathrm{nH}_{2} \mathrm{O}(\text { solid })+6 \mathrm{H}^{+}(\mathrm{aq})+\mathrm{xCl}^{-}(\mathrm{aq}) \rightarrow \mathrm{FeCl}_{\mathrm{x}}^{(3-\mathrm{x})-}(\mathrm{aq})+(\mathrm{n}+3) \mathrm{H}_{2} \mathrm{O} \\
& \mathrm{FeCl}_{\mathrm{x}}^{(3-\mathrm{x})-}(\mathrm{aq})+\mathrm{e}^{-} \rightarrow \mathrm{FeCl}_{\mathrm{x}}^{(2-\mathrm{x})-}(\mathrm{aq}) \\
& (10.1 .5 .2 .4)
\end{aligned}
$$

Finally, the shoulder IV can be associated to the presence of Mn(IV), which accompanies iron species in earths (Doménech-Carbó et al., 2001, 2007a, 2013a).

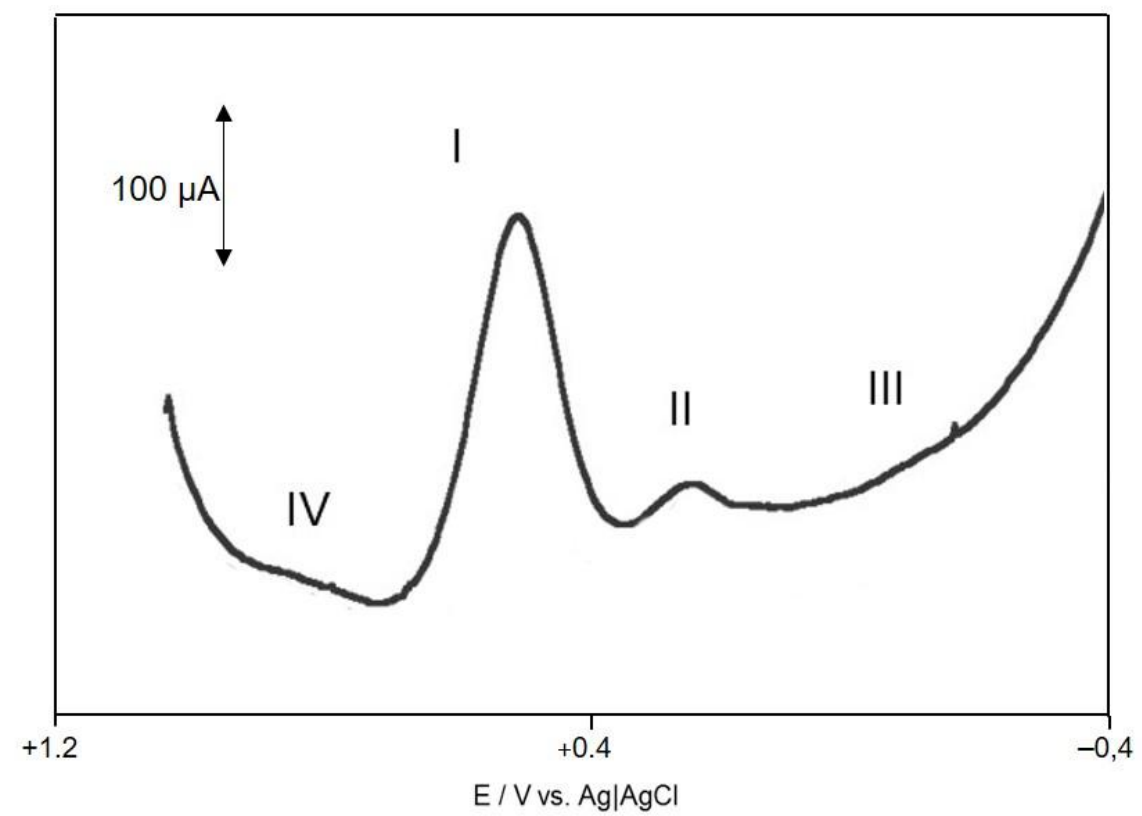

Figure 10.1.5.2.1. Square wave voltammograms at sample-modified graphite electrodes immersed into air-saturated $0.10 \mathrm{M}$ $\mathrm{HCl}$ for iron oxide particulate deposit. Potential scan initiated at $+1.05 \mathrm{~V}$ in the negative direction; potential step increment 4 $\mathrm{mV}$; square wave amplitude $25 \mathrm{mV}$; frequency $10 \mathrm{~Hz}$.

\section{Verdigris}

Figure 10.1.5.2.2, shows the $\mathrm{CV}$ of microparticulate deposits of verdigris attached to graphite bar immersed into aqueous acetate buffer at $\mathrm{pH} 4.75$. Upon scanning the potential from $0.0 \mathrm{~V}$ 
vs. $\mathrm{Ag} / \mathrm{AgCl}$ in the negative direction, the pigment displays two cathodic peaks at $-0.25\left(\mathrm{C}_{1}\right)$ and $-0.65 \mathrm{~V}\left(\mathrm{C}_{2}\right)$ which are followed, in the subsequent anodic scan, by a series of stripping peaks at around $+0.15-0.25 \mathrm{~V}\left(\mathrm{~A}_{2}\right)$ and $0.00-0.05 \mathrm{~V}\left(\mathrm{~A}_{1}\right)$. The peak $\mathrm{C}_{1}$ is clearly larger than the peak $C_{2}$ and is coupled to the group of signals $A_{1}$, as can be seen in CVs in which the potential is switched after passing the signal $\mathrm{C}_{1}$. Remarkably, the signals for ORR process were obscured in the presence of the pigment and no significant modifications were recorded between the voltammograms of verdigris-modified electrodes at air-saturated and degasified solutions.

Following literature, the peak $\mathrm{C}_{1}$ can be attributed to the reduction of pigment grains exposed to the graphite surface to $\mathrm{Cu}$ metal whereas the process $\mathrm{C}_{2}$ could be attributed to the reduction of $\mathrm{Cu}$ (II) ions which are reduced at the Cu-plated electrode surface. (Lange et al., 1993; Cepriá et al., 2005; Meepun et al., 2012). The signals $A_{1}$ and $A_{2}$ can unambiguously be attributed to the oxidative dissolution of metallic $\mathrm{Cu}$ formed in prior reductive steps, so that one can conclude that the process $\mathrm{C}_{1}$ consists of the two-electron reduction of verdigris to copper metal (Doménech-Carbó et al., 2000) as occurring for other copper pigments and corrosion products (Doménech-Carbó et al., 2009, 2016; Doménech-Carbó, 2010).

This process can be represented as:

$$
\left\{\mathrm{Cu}(\mathrm{Ac})_{2}\right\}_{\mathrm{solid}}+2 \mathrm{H}_{\mathrm{aq}}^{+}+2 \mathrm{e}^{-} \longrightarrow\{\mathrm{Cu}\}_{\text {solid }}+2 \mathrm{HAc}_{\mathrm{aq}}
$$

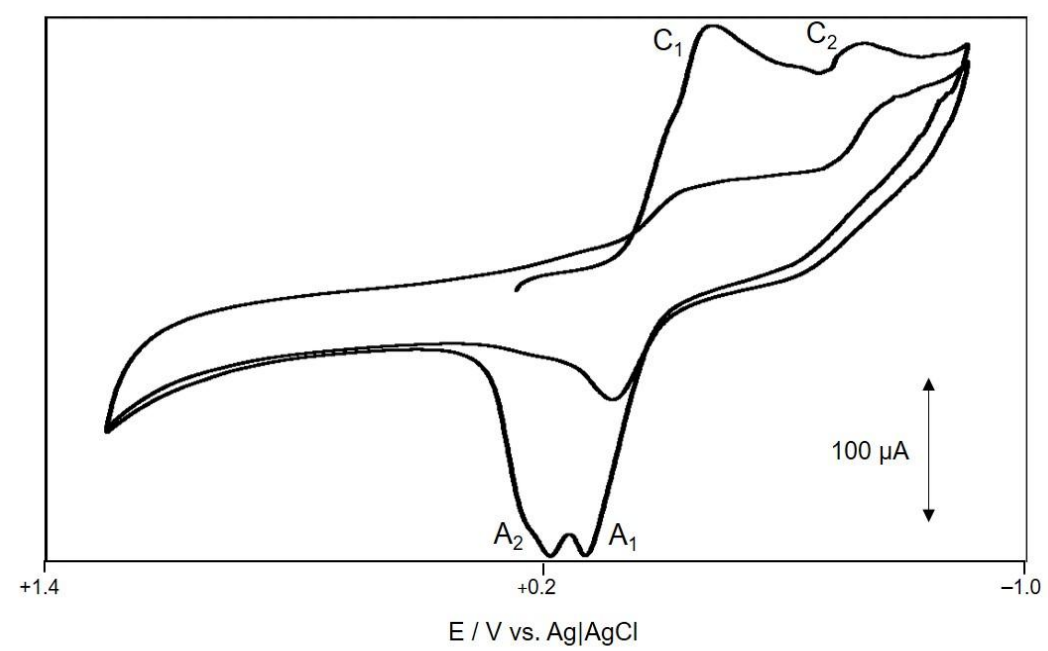

Figure 10.1.5.2.2. Negative-going $\mathrm{CV}$ for microparticulate deposit of $\mathrm{Cu}(\mathrm{II})$ on graphite electrode immersed into airsaturated $0.25 \mathrm{M}$ sodium acetate buffer, $\mathrm{pH} 4.75$. Potential scan rate $50 \mathrm{mV} \mathrm{s}^{-1}$.

The peak splitting appearing in the signals $A_{1}$ and $A_{2}$ can be attributed to the superposition of the oxidation processes of different deposits of metallic copper, during the negative-going potential scan, to $\mathrm{Cu}_{(\mathrm{aq})}{ }^{2+}$, a frequent feature in the voltammetry of copper, lead, and mercury minerals (Doménech-Carbó et al., 2016; Zarharchuk et al., 2000; Komorsky-Lovric et al., 1992; Arjmand and Adriaens, 2012; Beltagi and Ghoneim, 2009; Zou et al., 2012; Ogorevc et 
al., 1995; Oztekin et al., 2011). The formation of different copper deposits results from the superposition of different reductive process and can proceed via topotactic conversion of copper acetate into $\mathrm{Cu}$, as described for several lead compounds (Meyer et al., 1995; Hasse and Scholz, 2001) but can also involve intermediate species solution (Doménech-Carbó et al., 2007b).

Lead white

Figure 10.1.5.2.3 shows the CV of graphite electrode modified with microparticulate deposits of lead white in contact with $0.25 \mathrm{M} \mathrm{HAc} / \mathrm{NaAc}$ aqueous buffer, $\mathrm{pH} 4.75$. Upon scanning the potential from $+0.25 \mathrm{~V}$ vs. $\mathrm{Ag} / \mathrm{AgCl}$ in the negative direction, the pigment displayed two overlapped cathodic peak at around $-0.60 \mathrm{~V}$ preceding the rising current for hydrogen evolution reaction (HER) and a weak anodic signal at ca. $-0.50 \mathrm{~V}\left(\mathrm{~A}_{1}\right)$. As for verdigris, signals for ORR were masked by much more intense pigment signals. Data deconvolution was performed in order to increase peak resolution, thus obtaining (Figure 10.1.5.2.3a) two well-defined peaks at $-0.55\left(\mathrm{C}_{1}\right)$ and $-0.65\left(\mathrm{C}_{2}\right) \mathrm{V}$ preceding a rising current at ca. $-1.0 \mathrm{~V}$ which corresponds to the HER process $\left(C_{H}\right)$ (Figure 10.1.5.1.4a). Peaks $C_{1}$ and $C_{2}$ are well defined in the SWV voltammogram (Figure 10.1.5.2.3b). In the subsequent anodic scan, a predominant oxidation peak at $-0.50 \mathrm{~V}\left(\mathrm{~A}_{1}\right)$ was recorded. The reduction of lead white can be described in terms of the conversion of lead basic carbonate into metallic lead, as described for several lead compounds but also involving intermediate species in solution (DoménechCarbó et al., 2000, 2007b), the reduction process $C_{1}$ plus $C_{2}$ can be described as:

$$
\left\{\mathrm{Pb}_{3}\left(\mathrm{CO}_{3}\right)_{2}(\mathrm{OH})_{2}\right\}_{\text {solid }}+4 \mathrm{H}^{+}{ }_{\mathrm{aq}}+6 \mathrm{e}^{-} \longrightarrow 3\{\mathrm{~Pb}\}_{\text {solid }}+2 \mathrm{HCO}_{3}^{-}(\mathrm{aq})+4 \mathrm{H}_{2} \mathrm{O}
$$

The peak $A_{1}$ corresponds to the well-known oxidative dissolution of the deposit of lead metal electrochemically generated in the cathodic process $\mathrm{C}_{1}\left(\mathrm{~Pb}_{\text {solid }} \longrightarrow \mathrm{Pb}^{2+}{ }_{\text {aq }}+2 \mathrm{e}^{-}\right)$. This signal often looks like several superimposed signals, a feature which can be attributed to the superposition of the oxidation processes of different deposits of metallic lead, as described for verdigris pigment (Doménech-Carbó et al., 2007b). 


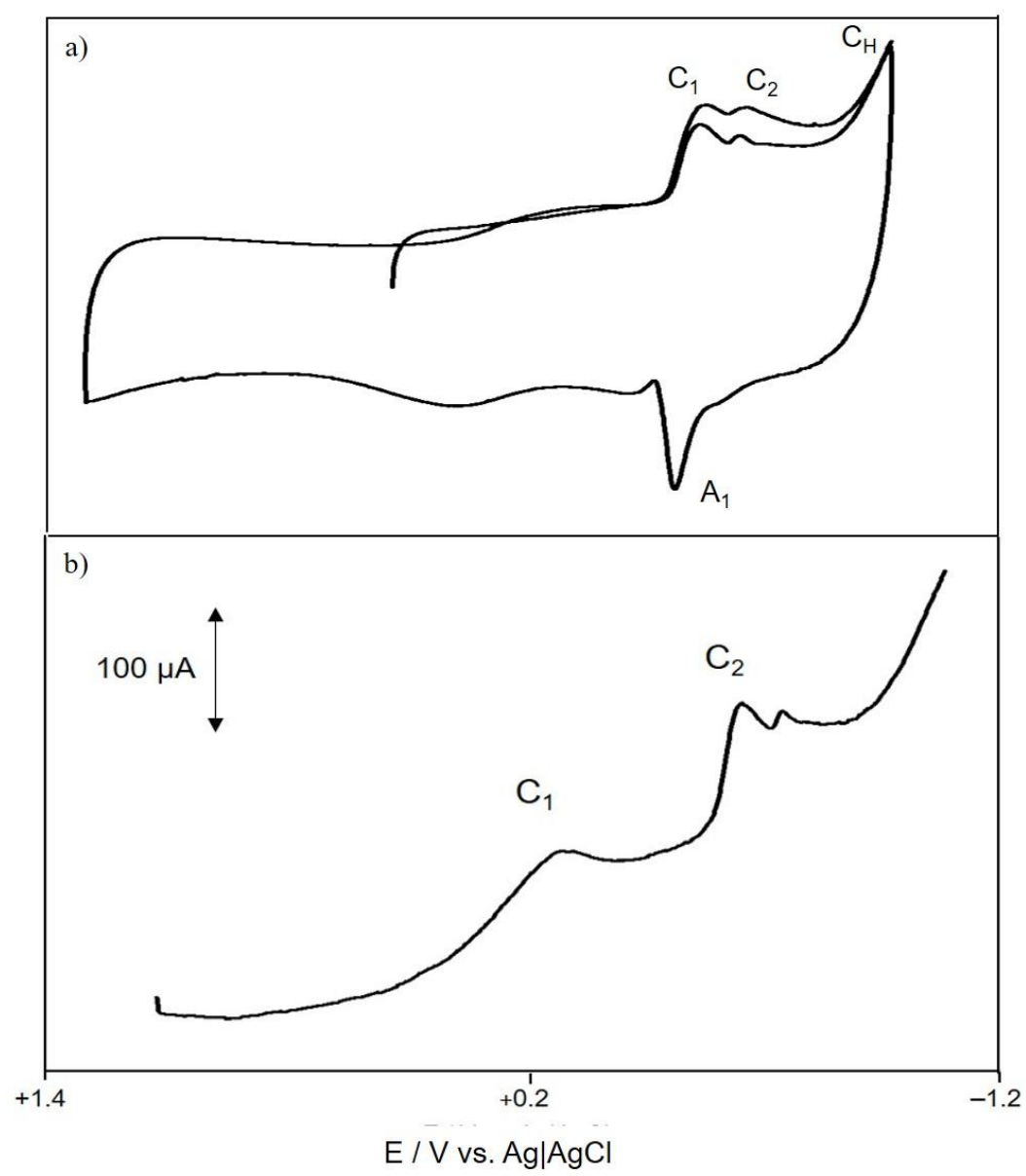

Figure 10.1.5.2.3. CV for microparticulate deposit of lead white on graphite electrode: a) negative-going CVs after deconvolution; potential scan rate $50 \mathrm{mV} \mathrm{s}^{-1}$, and b) negative-going $\mathrm{SWV}$ potential step increment $4 \mathrm{mV}$, square wave amplitude $25 \mathrm{mV}$, frequency $5 \mathrm{~Hz}$. Electrolyte: air-saturated $0.25 \mathrm{M}$ sodium acetate buffer, $\mathrm{pH} 4.75$

Cadmium yellow

Figure 10.1.5.2.4 shows the CV before (a) and after deconvolution (b) of a microparticulate deposit of cadmium yellow pigment on graphite electrode immersed into acetate buffer at $\mathrm{pH}$ 4.75. For the pure pigment a reduction wave at ca. $-1.0 \mathrm{~V}$ vs. $\mathrm{Ag} / \mathrm{AgCl}\left(\mathrm{C}_{1}\right)$ appears in the initial cathodic scan, accompanied by a shoulder at ca. $-1.2 \mathrm{~V}\left(\mathrm{C}_{2}\right)$, which precedes the rising current for solvent discharge (HER). In the subsequent anodic scan, a main oxidation signal at $-1.1 \mathrm{~V}\left(\mathrm{~A}_{1}\right)$ appears accompanied by a weaker signal at ca. $-0.7 \mathrm{~V}$. As in the precedent cases, no influence of dissolved oxygen was credited. Following literature (Lange et al., 1993; Scholz et al., 2014; Doménech-Carbó et al., 2013b; Cepriá et al., 2005; Meepun et al., 2012), the peak $C_{1}$ can be attributed to the reduction of $\mathrm{CdS}$ grains exposed to the graphite surface to $\mathrm{Cd}$ metal, which is subsequently oxidized, upon reversal of the potential scan, to $\mathrm{Cd}^{2+}{ }_{(\mathrm{aq})}$ in the stripping process $\mathrm{A}_{1}$. This process has been widely studied for cadmium determination in aqueous solution (Suciu et al., 2000; Beltagi and Ghoneim, 2009; Kruusma et al., 2004; Zhang et al., 2010; Oliveira et al., 2012; Koper and Grabarczyk, 2012). The $\mathrm{C}_{2}$ signal can be tentatively assigned to the reduction of $\mathrm{H}^{+}$and/or $\mathrm{Cd}^{2+}$ ions released during the reduction of $\mathrm{CdS}$ on the $\mathrm{Cd}$-plated graphite surface. The process $\mathrm{C}_{2} / \mathrm{A}_{2}$ can in principle be 
attributed to the reduction of protons to hydrogen adsorbed on the Cd-plated electrode surface and their subsequent reoxidation.

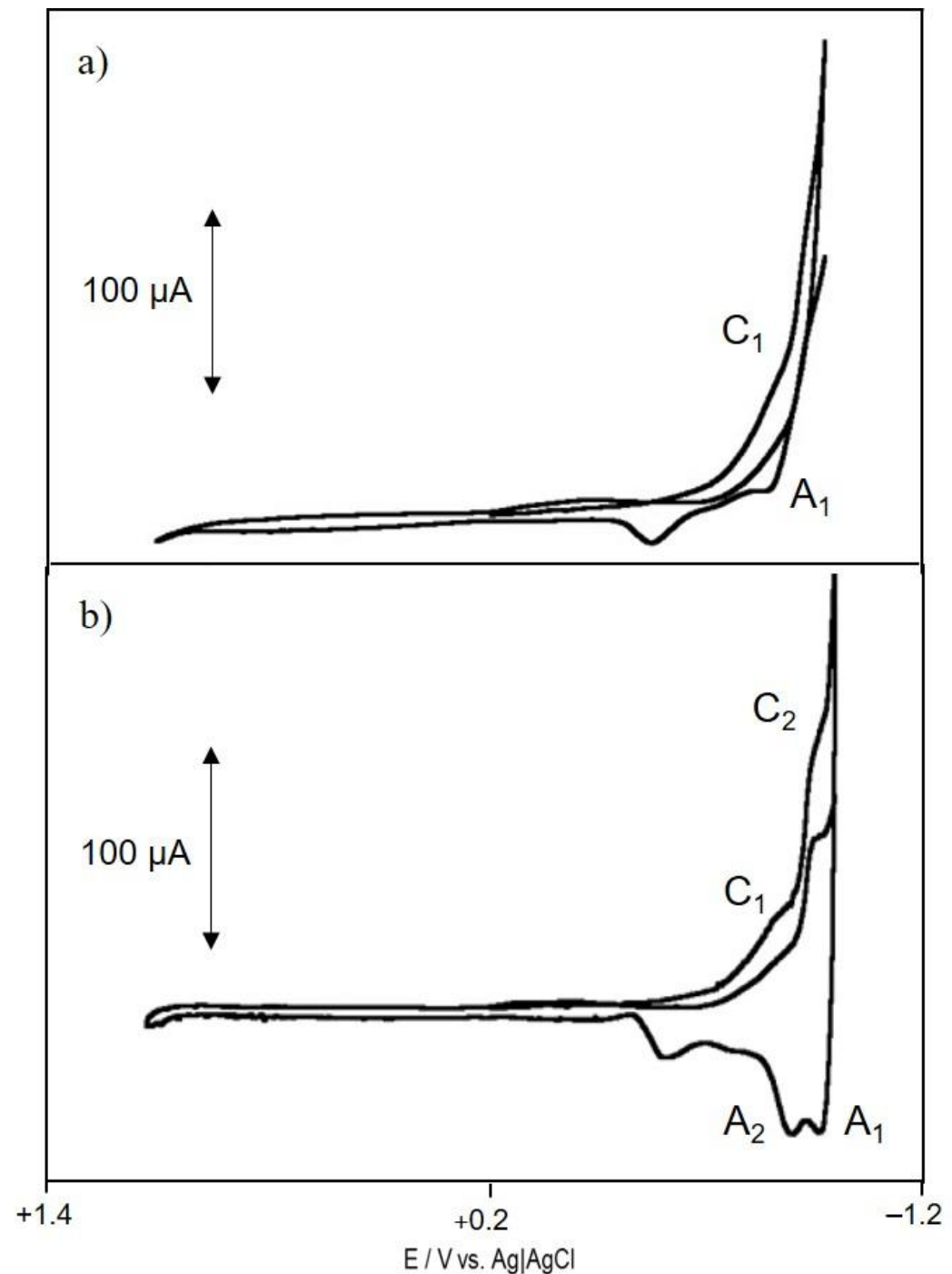

Figure 10.1.5.2.4. a) Negative-going CV for a microparticulate deposit of CdS on graphite bar and b) the same after semiderivative convolution. Potential scan rate $\mathrm{mV} \mathrm{s}^{-1}$.

10.1.5.3. Egg tempera reconstructed model paint specimens

Iron oxide

Figure 10.1.5.3.1, compares the square wave voltammograms recorded for deposits of iron oxide red pigment and EG@Fe specimens in contact with the indicate electrolyte.

The electrochemical processes should be interpreted in terms of the voltammetry of microparticles theoretical basis (Komorsky-Lovric et al., 1992; Scholz et al., 2014;) so that the redox process initiates at the pigment particle/base graphite electrode/electrolyte threephase junction. This implies that the appearance of voltammetric signals require the effective 
contact between the pigment grains with the graphite electrode and the electrolyte. Then, the presence of the binder determines, in principle a certain blocking of such contact.

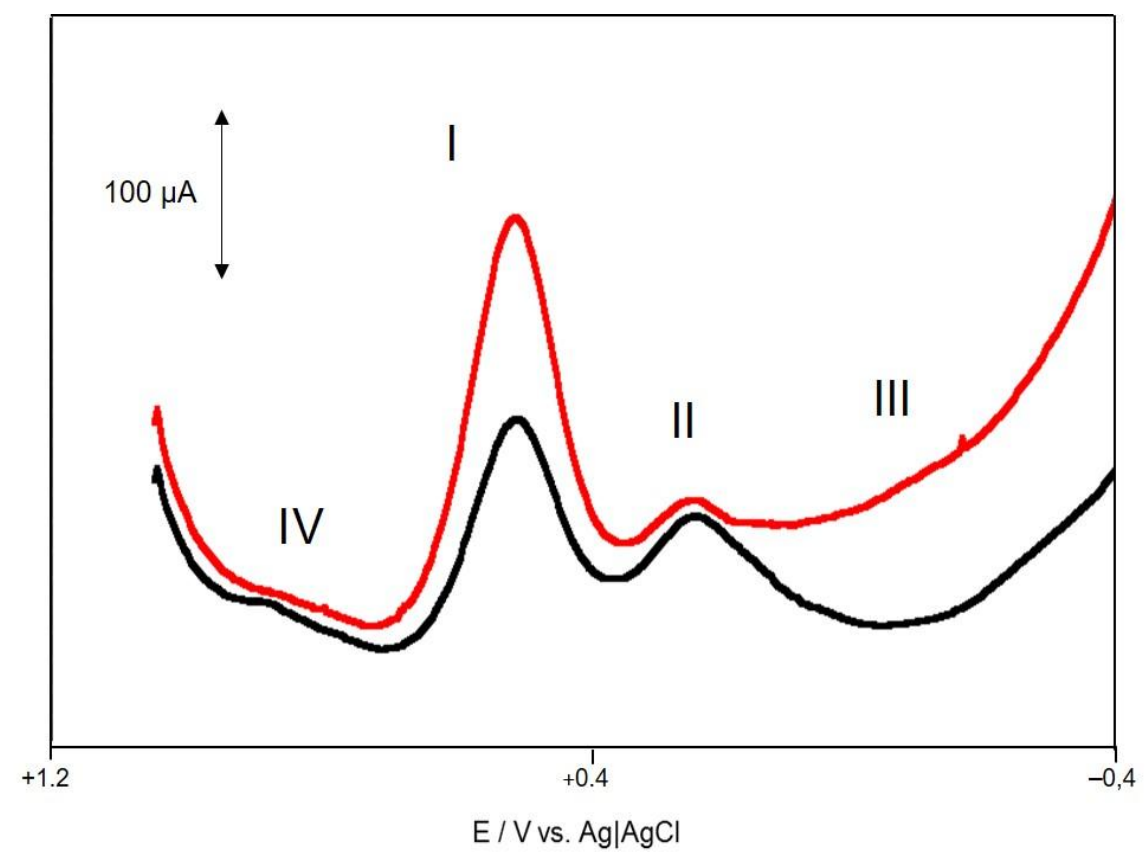

Figure 10.1.5.3.1. Square wave voltammograms at sample-modified graphite electrodes immersed into air-saturated $0.10 \mathrm{M}$ $\mathrm{HCl}$ for iron oxide particles (red line) and EG@Fe (black line). Potential scan initiated at $+1.05 \mathrm{~V}$ in the negative direction; potential step increment $4 \mathrm{mV}$; square wave amplitude $25 \mathrm{mV}$; frequency $10 \mathrm{~Hz}$.

Remarkably, the voltammograms of the EG@Fe specimens produced a drastic decrease of the signal III and lower the ratio between the signals I and II relative to the parent iron oxide particles. These features can be interpreted as the result of the blocking of the contact between the pigment grains and the electrolyte solution due to the presence of the binder.

\section{Verdigris}

The voltammetric response of the EG@Cu specimen exhibited significant variations relative to that of the pure pigment. This voltammetry can be described as resulting from the superposition of different electrochemical process and assuming that the paint film specimen is constituted by a more or less homogeneous distribution of pigment particles partially embedded by a layer of binder and an ionomeric layer, as described for lead pictorial layers (Doménech-Carbó et al., 2007b). As can be seen in Figure 10.1.5.3.2, in the initial cathodic scan $\mathrm{CV}$, the peak $\mathrm{C}_{1}$ became lowered relative to the signal $\mathrm{C}_{2}$ which was preceded by an additional cathodic signal at ca. $-0.4 \mathrm{~V}\left(\mathrm{C}_{3}\right)$. The peak $\mathrm{C}_{3}$ can be attributed to the reduction of $\mathrm{Cu}$ (II) species formed in the ionomeric layer accompanying the pigment particles. This layer would be particularly relevant for the proteinaceous binding media disposing of coordinating units. In the initial anodic scan voltammograms, the group of oxidative signals $\mathrm{A}_{1}$ only appears upon repetitive cycling the potential scan. The cathodic current at $-1.0 \mathrm{~V}$, attributable 
to proton discharge, was considerably enhanced, which can be associated to the formation of $\mathrm{Cu}$ metal as a result of the reduction of the copper pigment. The appearance of a weak anodic signal at ca. $-0.45 \mathrm{~V}\left(\mathrm{~A}_{3}\right)$ can be attributed to the oxidation of intermediate $\mathrm{Cu}(\mathrm{I})$ species, stabilized by interaction with the binding media, generated during the cathodic process $\mathrm{C}_{2}$.

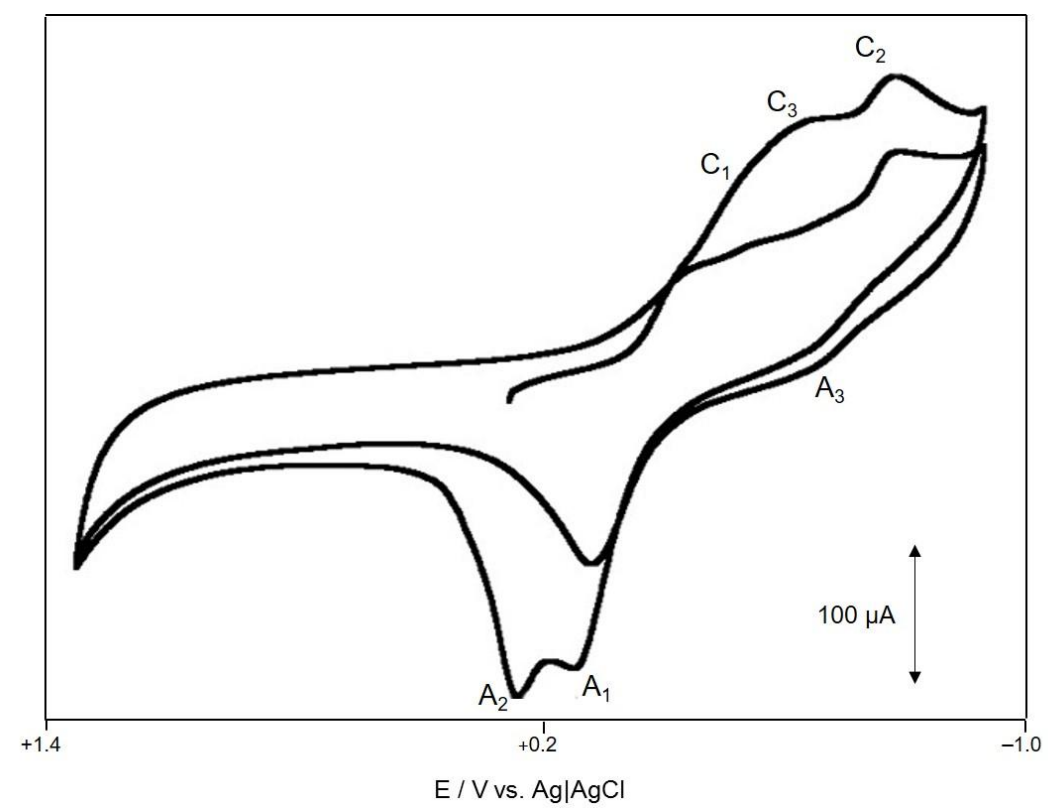

Figure 10.1.5.3.2. Negative-going CV for graphite electrode modified with EG@ Cu immersed into $0.25 \mathrm{M}$ sodium acetate buffer, $\mathrm{pH}$ 4.75. Potential scan rate $50 \mathrm{mV} \mathrm{s}^{-1}$.

Comparison of such data with those previously described for the pristine pigment suggests that the signal $\mathrm{C}_{1}$ corresponds to the proton-assisted reduction of the fraction of the pigment grains directly exposed to the electrode. This process involves the formation of an ionomeric layer around the pigment grain but also the partial release of 'free' copper ions into the same surrounding electrolyte solution then undergoing the reduction process $\mathrm{C}_{2}$. The process $\mathrm{C}_{3}$ can be associated to the reduction of copper complexes formed in the verdigris grain/binder boundary which presumably forms an ionomeric coverage around the pigment grains (different to that generated in the process $\mathrm{C}_{1}$ ) due to the coordinating ability of the proteinaceous medium. Table 10.1.5.3.1 summarizes the changes observed in the peak potential of the cathodic waves in EG@Cu if compared to the pure verdigris pigment.

The formation of metallic deposits influences the current of the HER process acting as catalytic centers for the same.

Table 10.1.5.3.1. Cathodic peak potentials for pure verdigris pigment and egg tempera model paint film EG@Cu attached to graphite electrodes in contact with $0.25 \mathrm{M} \mathrm{HAc} / \mathrm{NaAc}$ aqueous solution at $\mathrm{pH}$ 4.75. Variations in the intensity of the potential peaks in comparison with the pure pigment are indicated with arrows: decrease $(\downarrow)$ and increase $(\uparrow)$.

\begin{tabular}{c|ccc}
\hline \multirow{2}{*}{ Specimen } & \multicolumn{3}{|c}{ Peak potential (V vs. Ag/AgCl) } \\
& $\mathbf{C}_{\mathbf{1}}$ & $\mathbf{C}_{\mathbf{2}}$ & $\mathbf{C}_{\mathbf{3}}$ \\
\hline Pure verdigris & -0.25 & -0.65 & - \\
\hline EG@Cu & $-0.25 \downarrow$ & $-0.65 \downarrow$ & -0.40 \\
\hline
\end{tabular}


Lead white

In the voltammetric response of EG@Pb, Figure 10.1.5.3.3a, despite the similarity to that of the pure pigment, some significant differences can be observed. After deconvolution, is clearly appreciated that the cathodic region consisted of two peaks at $-0.60\left(\mathrm{C}_{1}\right)$ and $-0.80 \mathrm{~V}$ $\left(\mathrm{C}_{2}\right)$ whereas the signal $\mathrm{C}_{\mathrm{H}}$ was depleted and the peak $\mathrm{A}_{1}$ was broadened (Figure 10.1.5.3.3b). The above voltammetry can be described, as in the case of verdigris-based tempera paint films, as resulting from the superposition of the reduction of the fraction of pigment particles only partially embedded by the binder and the reduction of lead species existing in an ionomeric layer surrounding the pigment grains. This ionomeric layer is the result of the pigment-binder interaction, would be mainly composed by a more or less hydrated ensemble of $\mathrm{Pb}^{2+}$-protein complexes in the case of egg tempera specimens. Accordingly, the process $\mathrm{C}_{2}$ can be described as:

$$
\left\{\mathrm{Pb}^{2+}\left(\text { binding }^{2-}\right)\right\}_{\text {ionomeric layer }}+2 \mathrm{H}^{+} \text {aq }+2 \mathrm{e}^{-} \longrightarrow \quad\{\mathrm{Pb}\}_{\text {solid }}+\mathrm{H}_{2} \text { binding }
$$

Variation in the intensity of the process $\mathrm{C}_{\mathrm{H}}$, as well as the modification of the signal $\mathrm{A}_{1}$, can be attributed to the different shape and size distribution of the deposits of lead metal generated electrochemically. The enhanced observed in the signal attributed to the proton discharge is associated to the formation of relatively gross deposits of metallic lead due to the reduction of lead white grains (process $\mathrm{C}_{1}$ ). The electrocatalytic ability of lead metal deposited in the reduction of the ionomeric layer (process $C_{2}$ ) towards the HER process would be lower so that the enhancement of the peak $\mathrm{C}_{2}$ was in general accompanied by a decrease in the peak $\mathrm{C}_{\mathrm{H}}$. Table 10.1.5.3.2 summarizes the changes observed in the cathodic waves of EG@Pb relative to the pure lead white pigment. 


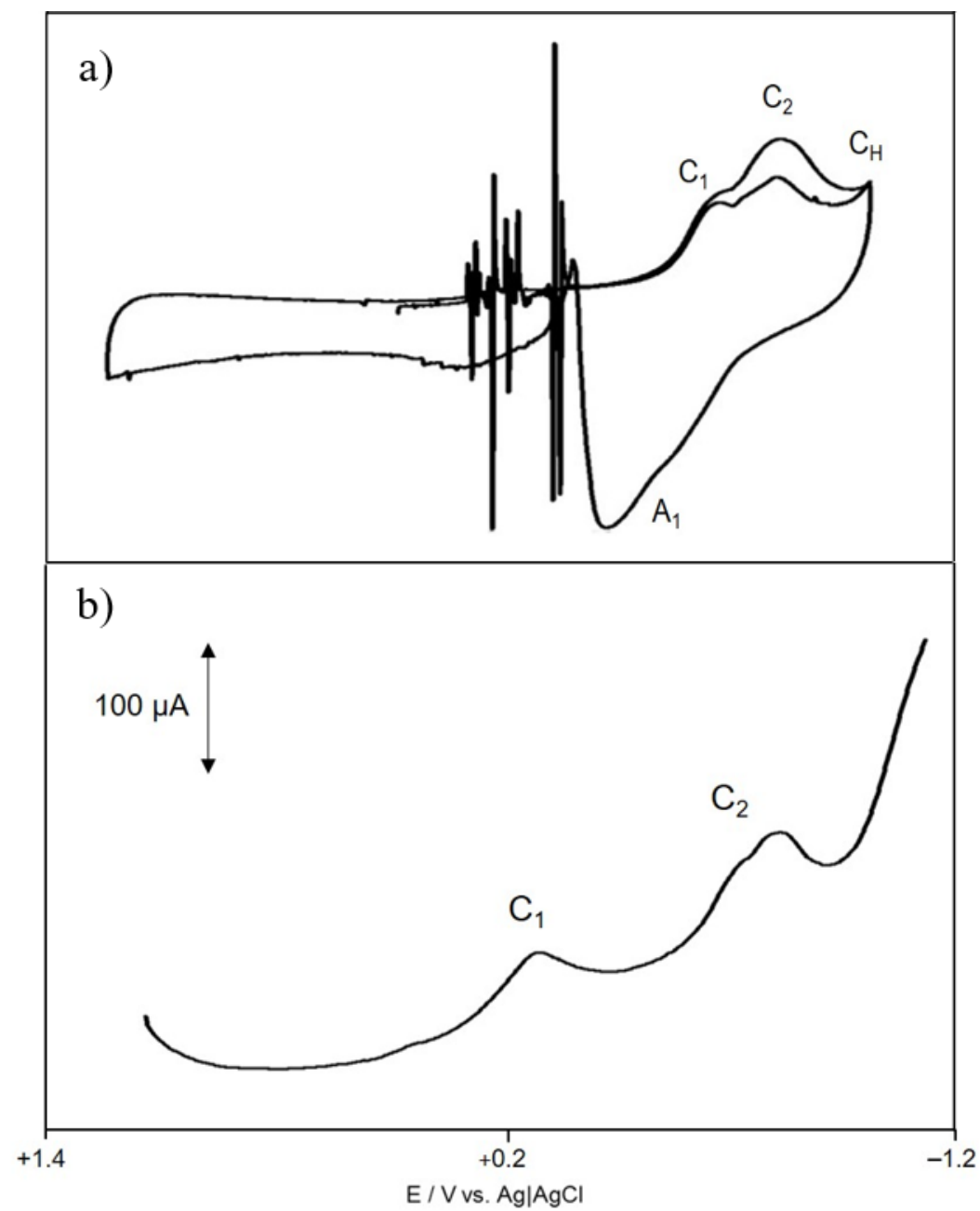

Figure 10.1.5.3.2. a) Negative-going CVs after deconvolution, potential scan rate $50 \mathrm{mV} \mathrm{s}^{-1}$, and b) negative-going SWV potential step increment $4 \mathrm{mV}$, square wave amplitude $25 \mathrm{mV}$, frequency $5 \mathrm{~Hz}$. of a graphite electrode modified with EG@Pb immersed into air-saturate d0.25 M sodium acetate buffer, pH 4.75

Table 10.1.5.3.2. Cathodic peak potentials recorded for pure lead white pigment and egg tempera model paint film EG@Pb immersed into air-saturated aqueous acetate buffer at $\mathrm{pH}$ 4.75. Variations in the intensity of the potential peaks in comparison with the pure pigment are indicated with arrows: decrease $(\downarrow)$ and increase $(\uparrow)$.

\begin{tabular}{c|ccc}
\hline \multirow{2}{*}{ Specimen } & \multicolumn{3}{|c}{ Peak potential (V vs. Ag/AgCl) } \\
& $\mathbf{C}_{\mathbf{1}}$ & $\mathbf{C}_{\mathbf{2}}$ & $\mathbf{C}_{\mathbf{H}}$ \\
\hline Pure lead white & -0.55 & -0.65 & -1.0 \\
\hline EG@Pb & -0.60 & -0.80 & $-1.0 \downarrow$ \\
\hline
\end{tabular}

\section{Cadmium yellow}

The voltammetry becomes significantly modified for EG@Cd paint specimen with respect to that of the parent pigment. As can be seen in Figure 10.1.5.3.4, the $\mathrm{C}_{2}$ shoulder disappears whereas the shape of the peaks $C_{1}$ and $A_{1}$ varies. A new cathodic process $\left(C_{3}\right)$ is recognized 
by the signal at $-0.70 \mathrm{~V}\left(\mathrm{C}_{3}\right)$ preceding the peak $\mathrm{C}_{1}$ at $-0.95 \mathrm{~V}$, the voltammetric profile remaining essentially unchanged in the second and successive potential scans. In the anodic region of the voltammogram, the stripping peak $A_{1}$ at $-0.75 \mathrm{~V}$ exhibited peak splitting and preceded a wider oxidation peak $\left(\mathrm{A}_{3}\right)$ at ca. $-0.50 \mathrm{~V}$ coupled to the peak $\mathrm{C}_{3}$.

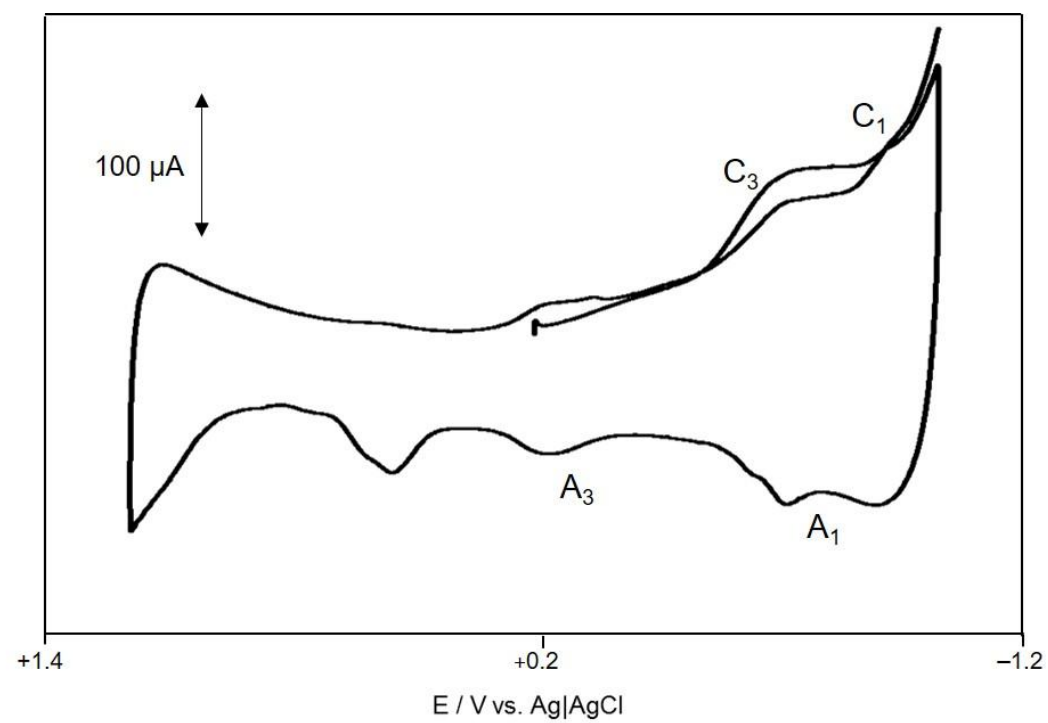

Figure 10.1.5.3.4. CVs for graphite electrode modified with EG@Cd immersed into air-saturated $0.25 \mathrm{M}$ sodium acetate buffer, $\mathrm{pH}$ 4.75. Negative-going $\mathrm{CV}$ after deconvolution. Potential scan rate $50 \mathrm{mV} \mathrm{s}^{-1}$.

This voltammetry can be described, as before, assuming that the EG@Cd specimen is constituted by a more or less homogeneous distribution of pigment particles partially embedded by a layer of binder and a hydrophilic layer, as described for lead pictorial layers (Doménech-Carbó et al., 2007b). Accordingly, the process $C_{1}$ can be attributed to the reduction of $\mathrm{CdS}$ particles in contact with the base graphite electrode and the electrolyte:

$\{\mathrm{CdS}\}_{\text {solid }}+2 \mathrm{H}^{+}$aq $+2 \mathrm{e}^{-} \longrightarrow\{\mathrm{Cd}\}_{\text {solid }}+\mathrm{H}_{2} \mathrm{~S}$

Additional cathodic peaks $\mathrm{C}_{3}$ appearing in EG@Cd specimen can be attributed to the reduction of the $\mathrm{Cd}$ compounds forming the ionomeric layer accompanying the pigment particles. The peak $\mathrm{C}_{3}$ is broadened, possibly as a result of the formation of an insulating layer of non-complexing binding medium, then producing an additional ohmic drop. Table 10.1.5.3.3 summarizes the changes observed in the peak potential of the cathodic signals in EG@Cd if compared to the pure CdS pigment.

Table 10.1.5.3.3. Cathodic peak potentials recorded for pure cadmium yellow pigment and egg tempera model paint film EG@Cd immersed into air-saturated aqueous acetate buffer at pH 4.75.

\begin{tabular}{c|ccc}
\hline \multirow{2}{*}{ Specimen } & \multicolumn{3}{|c}{ Peak potential (V vs. Ag/AgCl) } \\
& $\mathbf{C}_{\mathbf{1}}$ & $\mathbf{C}_{\mathbf{2}}$ & $\mathbf{C}_{\mathbf{3}}$ \\
\hline Pure cadmium yellow & -1.0 & -1.2 & - \\
\hline EG@Cd & -0.95 & - & -0.70 \\
\hline
\end{tabular}


10.1.5.4. Egg oil emulsion reconstructed model paint specimens

Iron oxide

In the case of EO@Fe specimens, the voltammetric profiles experienced also significant variations after inoculation. First of all, the voltammograms of the parent EO@Fe (see Figure 10.1.5.4.1) produced considerably weak signals I and II compared to those in EG@Fe. This suggests that the binder exerts an important barrier effect blocking almost entirely the contact between the pigment grains and the electrolyte.

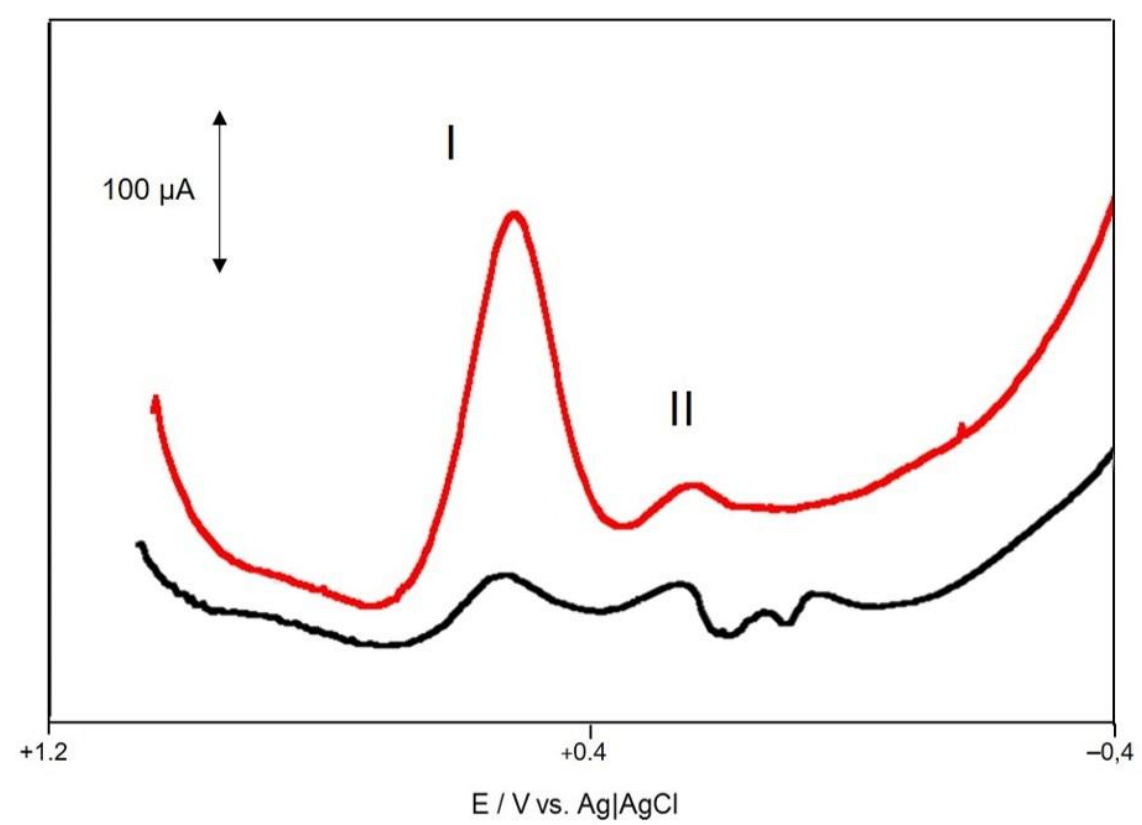

Figure 10.1.5.4.1. Square wave voltammograms at sample-modified graphite electrodes immersed into air-saturated $0.10 \mathrm{M}$ $\mathrm{HCl}$ for Square wave voltammograms at sample-modified graphite electrodes immersed into air-saturated $0.10 \mathrm{M} \mathrm{HCl}$ for iron oxide particles (red line) EO@Fe (black line). Potential scan initiated at $+1.05 \mathrm{~V}$ in the negative direction; potential step increment $4 \mathrm{mV}$; square wave amplitude $25 \mathrm{mV}$; frequency $10 \mathrm{~Hz}$.

\section{Verdigris}

The voltammetric response obtained for $\mathrm{EO} @ \mathrm{Cu}$ was similar to that of pure pigment, the peak $\mathrm{C}_{3}$ at $-0.35 \mathrm{~V}$ being almost entirely absent, but differing in the presence of peak $\mathrm{A}_{3}$ and the absence of important peak splitting in the anodic signal $\mathrm{A}_{1}$ where observed (Figure 10.1.5.4.2a and Table 10.1.5.4.1). The peak $\mathrm{C}_{1}$ is clearly larger than the peak $\mathrm{C}_{2}$, as can be seen using the square wave voltammetry (SWV, Figure 10.1.5.4.2b). 

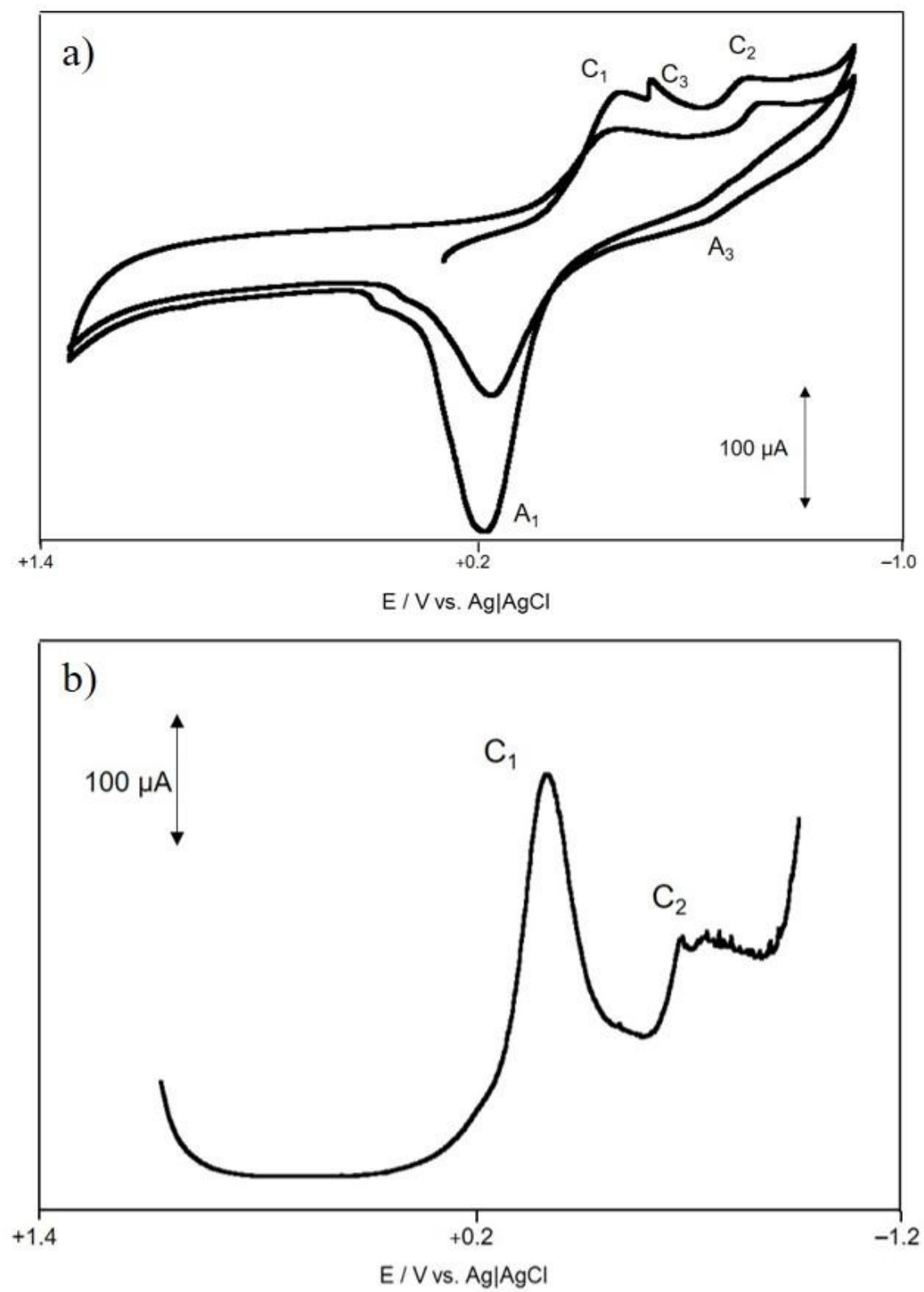

Figure 10.1.5.4.2. a) Negative-going CV, potential scan rate $50 \mathrm{mV} \mathrm{s}^{-1}$ and b) negative-going $\mathrm{SWV}$, potential step increment $4 \mathrm{mV}$, square wave amplitude $25 \mathrm{mV}$, frequency $5 \mathrm{~Hz}$, for graphite electrode modified with $\mathrm{EO} @ \mathrm{Cu}$ immersed into $0.25 \mathrm{M}$ sodium acetate buffer, $\mathrm{pH} 4.75$.

Table 10.1.5.4.1. Cathodic peak potentials recorded for pure verdigris pigment and egg-linseed oil emulsion model paint film EO@Cu immersed into air-saturated aqueous acetate buffer at pH 4.75.

\begin{tabular}{c|ccc}
\hline \multirow{2}{*}{ Specimen } & \multicolumn{3}{c}{ Potential (V) } \\
& $\mathbf{C}_{\mathbf{1}}$ & $\mathbf{C}_{\mathbf{2}}$ & $\mathbf{C}_{\mathbf{3}}$ \\
\hline Pure verdigris & -0.25 & -0.65 & - \\
\hline EO@ $\mathrm{Cu}$ & -0.25 & -0.65 & -0.35 \\
\hline
\end{tabular}




\section{Lead white}

The voltammetric response of the reconstructed model egg-linseed oil reconstructed model paint films was similar to that of egg tempera model paint specimen, as shown in Figure 10.1.5.4.3a. The most relevant features in the voltammograms of EO@Pb specimen were the increase of the peak $\mathrm{C}_{1}$ relative to the peak $\mathrm{C}_{2}$, and the peaks splitting in the anodic region at $-0.40\left(\mathrm{~A}_{1}\right)$ and $-0.50 \mathrm{~V}\left(\mathrm{~A}_{2}\right)$, that were clearly observed after deconvolution (Figure 10.1.5.4.3b).

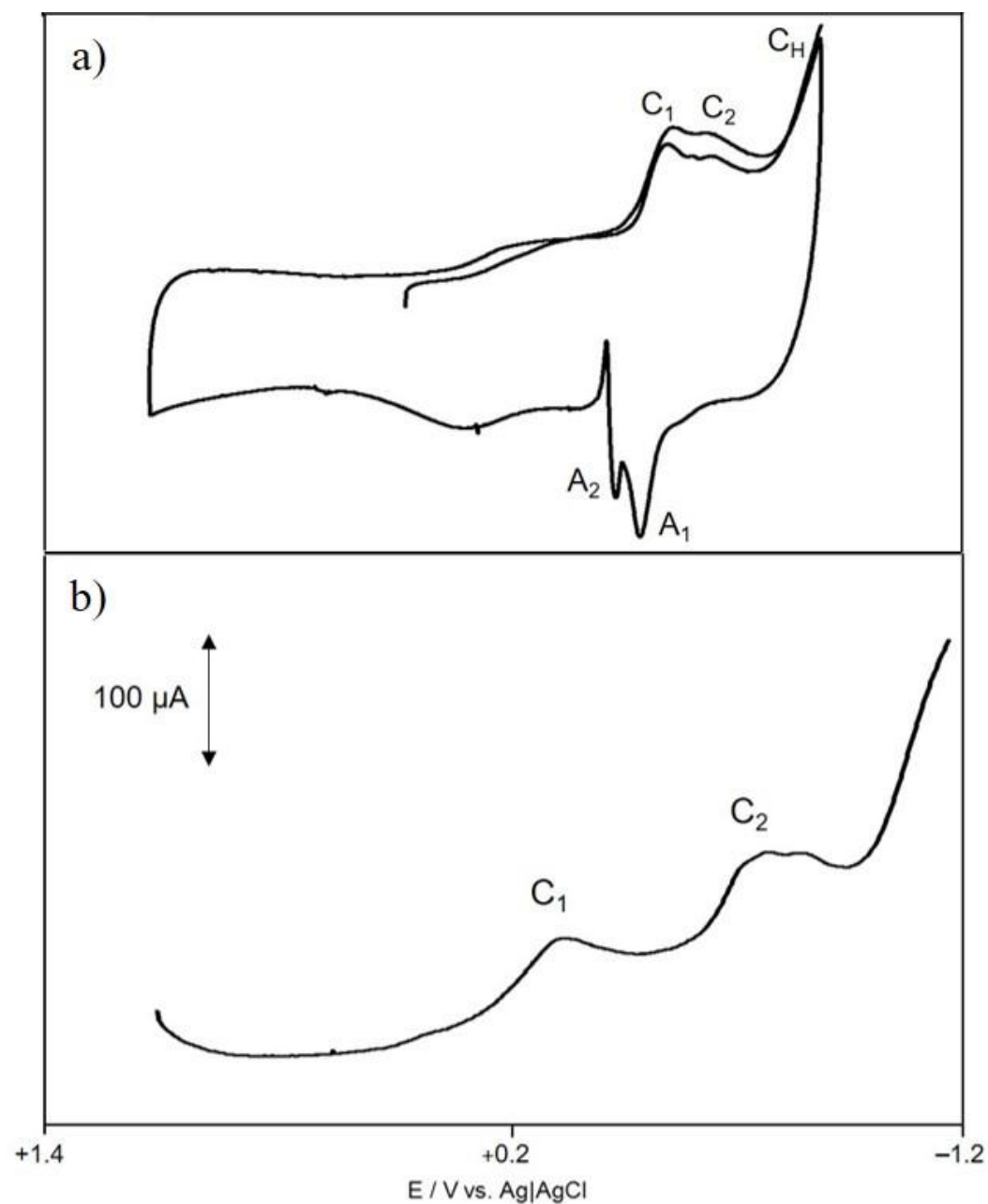

Figure 10.1.5.4.3. Voltammetry of graphite electrode modified with EO@ $\mathrm{Pb}$ immersed into air-saturated $0.25 \mathrm{M}$ sodium acetate buffer, $\mathrm{pH}$ 4.75. a) negative-going $\mathrm{CVs}$ after deconvolution (potential scan rate $50 \mathrm{mV} \mathrm{s}^{-1}$ ) and b) negative-going SWV potential step increment $4 \mathrm{mV}$, square wave amplitude $25 \mathrm{mV}$, frequency $5 \mathrm{~Hz}$.

These voltammetric features can be attributed to the superposition of two main factors: i) the increase in the exposition of the pigment particles as a result on the degradation of the binder (favoring the process $\mathrm{C}_{1}$ ), and ii) the possible release of $\mathrm{Pb}^{2+}$ ions accompanied by the formation of $\mathrm{Pb}(\mathrm{II})$-carboxylate complexes with the carboxylate units of the acidic residues in proteins and the released fatty-acid fraction of the binder. The reduction of such complexes, which can be represented as: 


$$
\left\{\mathrm{Pb}^{2+}\left(\mathrm{RCOO}^{-}\right)_{2}\right\}_{\text {soap }}+2 \mathrm{H}^{+}{ }_{\mathrm{aq}}+2 \mathrm{e}^{-} \longrightarrow\{\mathrm{Pb}\}_{\text {solid }}+2 \mathrm{RCOOH}
$$

would be superimposed to that of the pigment, thus resulting in an enhancement of the signal $\mathrm{C}_{1}$. The $\mathrm{Pb}$ deposit formed via this process would be different in grain shape and size distribution to that formed in the processes described by Eqs. 10.1.5.2.6 and 10.1.5.3.1 so that the subsequent oxidation results in the observed peak splitting in the anodic region.

Another interesting feature in voltammograms in Figure 10.1.5.4.3 is the variability in the current recorded at more negative potentials, corresponding to the hydrogen evolution reaction $\left(\mathrm{HER}, \mathrm{C}_{\mathrm{H}}\right.$ ). The intensity of this process will be dependent on the surface area of graphite exposed to the electrolyte solution but also on the catalytic effect exerted by the deposit of lead metal formed electrochemically in the processes $C_{1}$ and $C_{2}$ preceding the HER process (Doménech-Carbó et al. 2011), a situation also occurring for cadmium and copper pigments. The increase of this signal in the EO@Pb specimen if compared with the EG@Pb suggests that the reduction of pigment grains in egg oil emulsion specimens leads to abundant lead metal deposition.

Table 10.1.5.4.2. Cathodic peak potentials recorded for pure verdigris pigment and egg-linseed oil emulsion model paint film EO@Pb immersed into air-saturated aqueous acetate buffer at $\mathrm{pH} 4.75$. Variations in the intensity of the potential peaks in comparison with the pure pigment are indicated with arrows: decrease $(\downarrow)$ and increase $(\uparrow)$.

\begin{tabular}{c|ccc}
\hline \multirow{2}{*}{ Specimen } & \multicolumn{3}{|c}{ Potential (V) } \\
& $\mathbf{C}_{\mathbf{1}}$ & $\mathbf{C}_{\mathbf{2}}$ & $\mathbf{C}_{\mathbf{H}}$ \\
\hline Pure lead white & -0.60 & - & -1.0 \\
\hline $\mathrm{EO} @ \mathrm{~Pb}$ & $-0.60(\uparrow)$ & -0.70 & $-1.0(\downarrow)$ \\
\hline
\end{tabular}

Cadmium yellow

In the case of EO@ Cd specimens (Figure 10.1.5.4.4), the obtained CV is very similar to that obtained for EG@Cu. In the initial cathodic scan the peaks $\mathrm{C}_{1}$ and $\mathrm{C}_{3}$ remain while $\mathrm{C}_{2}$ disappears. In the anodic region, the peak splitting peak is more pronounced for $\mathrm{EO} @ \mathrm{Cd}$ with signals at $-0.80\left(\mathrm{~A}_{1}\right)$ and $-0.70 \mathrm{~V}\left(\mathrm{~A}_{2}\right)$, a feature apparently associated to the peak potential shift in the oxidative dissolution of $\mathrm{Cd}$ metal. As previously noted, this behavior can be interpreted as result of the formation of metallic deposits having different crystal shape and size during the reduction of CdS species, a feature which has been described in the solid-state electrochemistry of different metal compounds (Zakharchuk et al., 2000; Komorsky-Lovric et al., 1992; Arjmand and Adriaens, 2012). 


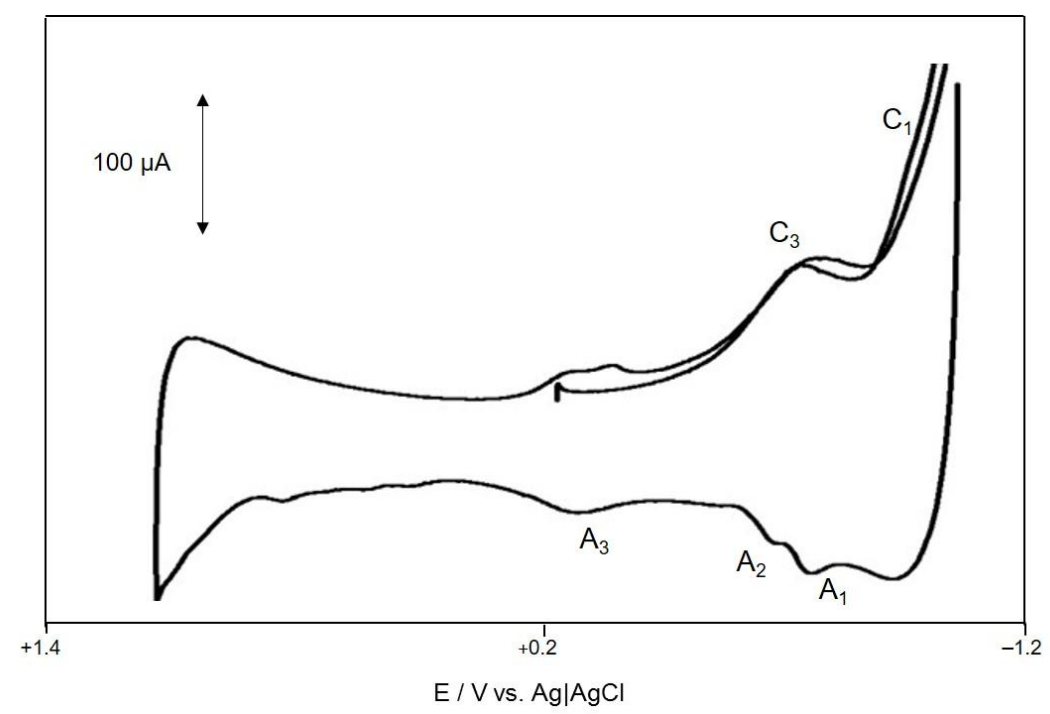

Figure 10.1.5.4.4. CV for graphite electrode modified with EO@ Cd immersed into air-saturated $0.25 \mathrm{M}$ sodium acetate buffer, $\mathrm{pH} 4.75$ after deconvolution Potential scan rate $50 \mathrm{mV} \mathrm{s}^{-1}$.

Table 10.1.5.4.3. Cathodic peak potentials recorded for pure verdigris pigment and egg-linseed oil emulsion model paint film EO@Cd immersed into air-saturated aqueous acetate buffer at $\mathrm{pH} 4.75$.

\begin{tabular}{c|ccc}
\hline \multirow{2}{*}{ Specimen } & \multicolumn{3}{|c}{ Potential (V) } \\
& $\mathbf{C}_{\mathbf{1}}$ & $\mathbf{C}_{\mathbf{2}}$ & $\mathbf{C}_{\mathbf{3}}$ \\
\hline Pure cadmium yellow & -1.0 & -1.2 & - \\
\hline EO@Cd & -0.95 & - & -0.70 \\
\hline
\end{tabular}




\subsubsection{Description of voltammetric processes}

In contact with aqueous acetate buffer, VMP data denote that in the presence of the binder, the voltammetric signals for pigments in reconstructed egg tempera and egg-linseed oil emulsion model paint specimens become modified, with the appearance of specific signals resulting from the pigment-binder association. Depending on the binder, the metal-centered signals become more or less modified.

In general, the above voltammetry can be described as resulting from the superposition of different electrochemical processes and assuming that the egg tempera and egg-linseed oil emulsion reconstructed model paint films were constituted by a more or less homogeneous distribution of pigment particles partially embedded by a hydrophobic layer of binder accompanied by a hydrophilic layer where the different metal compounds exist, as described in Figure 8.1.4.5.1. The process $\mathrm{C}_{1}$ can be attributed to the reduction of the pigment particles in contact with the base graphite electrode and the electrolyte. Additional peaks $\mathrm{C}_{3}$ appearing in BINDER@PIGMENT specimens can be attributed to the reduction of the pigment compounds forming the ionomeric layer accompanying the pigment particles.

a)

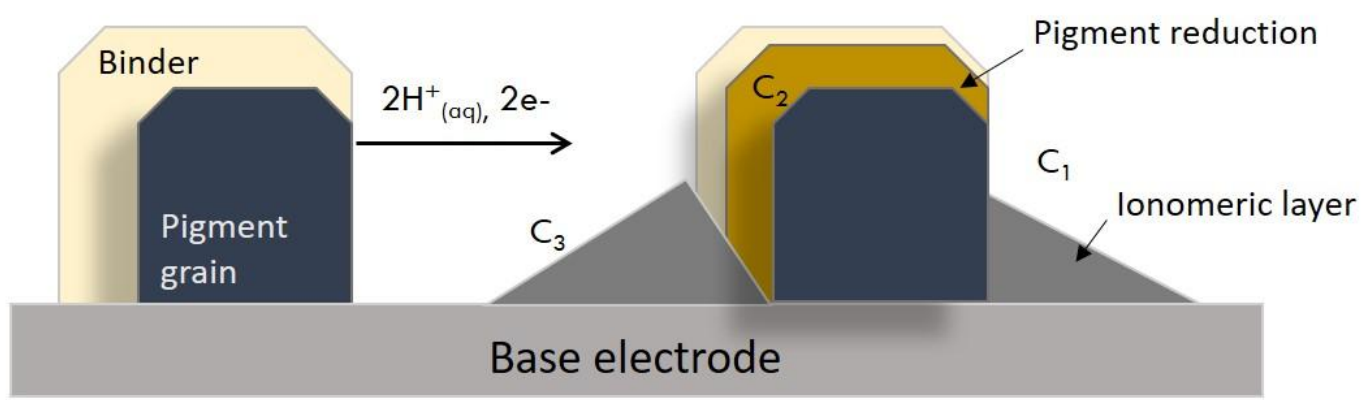

b)

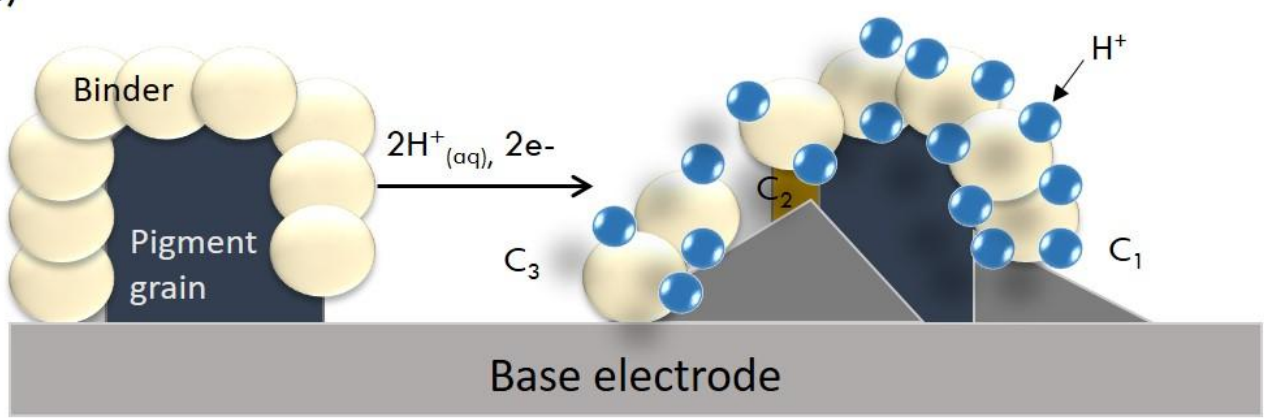

Figure 8.1.4.5.1. Scheme for the electrochemical reduction of pigment particles embedded into: a) egg and b) egg-oil binding media in contact with aqueous electrolyte. 
10.1.5.6. Complementary electrochemical techniques.

\subsection{Scanning electrochemical microscopy (SECM)}

Scanning Electrochemical Microscopy (SECM) was used in order to examine the surface redox reactivity of the reconstructed paint films. As a redox probe a $5 \mathrm{mM} \mathrm{K}_{4} \mathrm{Fe}(\mathrm{CN})_{6}$ solution in $0.25 \mathrm{M} \mathrm{HAc} / \mathrm{NaAc}$ at $\mathrm{pH} 4.75$ was employed. Examples of color maps obtained for EG and EO reconstructed paint films attached to a graphite plate in contact with $\mathrm{K}_{4} \mathrm{Fe}(\mathrm{CN})_{6}$ solution in acetate buffer is illustrated in Figure 10.1.5.6.1.1. Application to the tip of a potential high enough $\left(E_{\mathrm{T}}=+0.30 \mathrm{~V}\right)$ to promote the diffusion-controlled oxidation of $\mathrm{Fe}(\mathrm{CN})_{6}{ }^{4-}$ ions, yields a current response depending on the topography and conductivity of the substrate. The map colors yield positive feedback features corresponding to the pigment grains emerging from the binding medium which appears as an almost uniform negative feedback background. Apart from textural differences obtained for the EG@Cd_B and EO@Cd_B films (Figures 10.1.5.6.1.1a and c, respectively), in both cases, after application of a potential input of $-1.0 \mathrm{~V}$ during $5 \mathrm{~min}$ to the substrate, there appear significant changes in the map color (see arrows in Figures 10.1.5.6.1.1b and d, respectively), thus denoting that the reduction of CdS operates under these conditions. As a result of the application of this reductive potential input, the area of positive feedback features become diminished just such as embedded by a growing binding media.

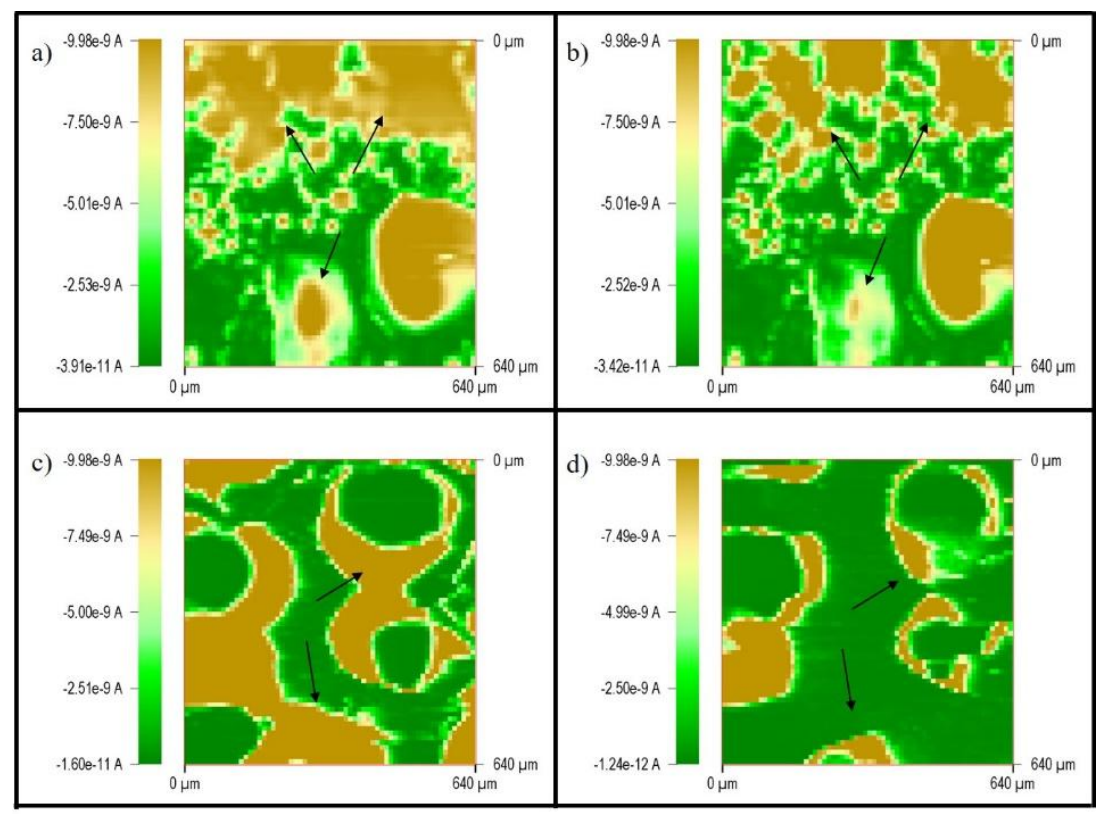

Figure 10.1.5.6.1.1. SECM map colors of a,b) sample of un-inoculated egg tempera paint film (EG@Cd_B) and c,d) sample of un-inoculated egg-oil emulsion paint film (EO@Cd_B) attached to a graphite plate in contact with electrode in contact with $5.0 \mathrm{mM} \mathrm{K}_{4} \mathrm{Fe}(\mathrm{CN})_{6}$ solution in $0.25 \mathrm{M} \mathrm{HAc} / \mathrm{NaAc}(\mathrm{pH} 4.75)$ before $(\mathrm{a}, \mathrm{c})$ and after $(\mathrm{b}, \mathrm{d})$ application of a potential input of $-1.0 \mathrm{~V}$ during $2 \mathrm{~min} . E_{\mathrm{T}}=+0.30 \mathrm{~V}$. 


\subsection{Atomic force microscopy - voltammetry of microparticles (AFM-VMP)}

To test the solid-state nature of the electrochemistry of pigments, experiments coupling Atomic Force Microscopy (FM) and VMP were performed upon application of reductive potential inputs to microparticulate deposits of the pigments attached to a graphite plate in contact with aqueous acetate buffer at $\mathrm{pH}$ 4.75. AFM images recorded before (Figures 10.1.5.6.2.1 a, b) and after (Figures 10.1.5.6.2.1 c, d) application of a potential input of $-1.0 \mathrm{~V}$ to an egg tempera reconstructed paint film during 5 min are shown in Figure 10.1.5.6.2.1. Apparently, the pigment grain, which is partially in contact with the base graphite plate, experiences a contraction process being reduced, at the end of the reductive step, to a grain whose volume is ca. one half of the volume of the original pigment grain. This result would be in agreement with data reported by Hasse and Scholz (2001) on in situ XRD (Zakharchuk et al., 2000) and AFM (KomorskyLovric et al., 1992) monitoring of the reduction of litharge, where the reduction of the mineral crystals involves a topotactic solid state transformation of lead oxide to lead metal without a morphological disintegration. This model would apply here, the volume contraction expected in the reduction of the pigment grains. Figure 10.1.5.6.2.1, shows the results obtained for CdS reduced to $\mathrm{Cd}$ being consistent with the different density of $\mathrm{CdS}\left(4.83 \mathrm{~g} \mathrm{~cm}^{-3}\right)$ and $\mathrm{Cd}(8.65 \mathrm{~g}$ $\mathrm{cm}^{-3}$ ). Interestingly, the topography of the binder surrounding the grain is smoothed in the vicinity of the same in agreement with the idea that the reductive process affecting the pigment particles starts at the pigment grain/base electrode/electrolyte three-phase junction.

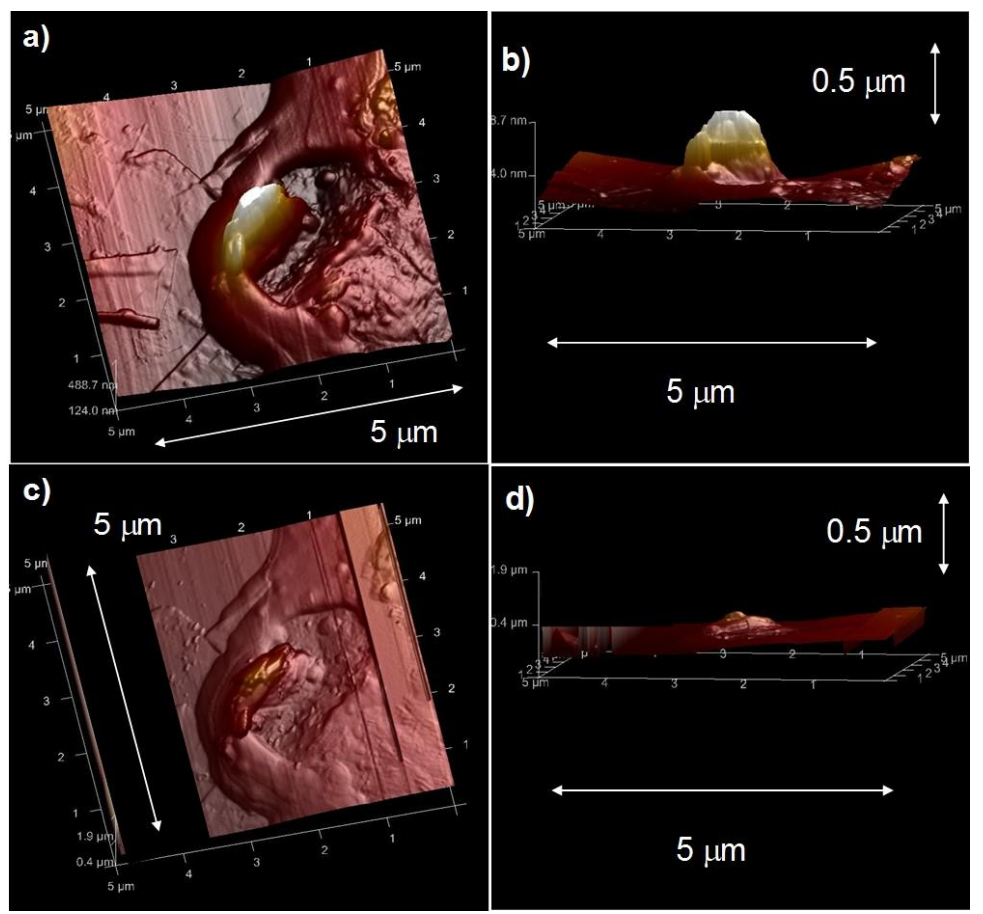

Figure 10.1.5.6.2.1. Topographic AFM images of a un-inoculated egg tempera paint film EG@Cd_B on a graphite plate in contact with $0.25 \mathrm{M}$ sodium acetate buffer, $\mathrm{pH} 4,75, \mathrm{a}, \mathrm{b}$ ) before, and c,d) after application of a potential step of $-1.0 \mathrm{~V}$ during $5 \mathrm{~min}$. 
The results obtained from these electrochemical techniques can be rationalized on considering that the EG and EO reconstructed paint films are constituted by a more or less homogeneous distribution of pigment particles more or less entirely embedded by a layer of more hydrophobic binding medium and a hydrophilic layer where resulting secondary metal forms exist, as described for pictorial specimens containing lead pigments (Arjmand and Adriaens, 2012). 
10.1.5.7. Voltammetry of microparticles testing of biodeterioration

10.1.5.7.1. Iron oxide red

The electrochemical analysis of the EG@Fe and EO@Fe inoculated with fungi and bacteria was performed using $0.10 \mathrm{M} \mathrm{HCl}$ as the electrolyte because this was previously used in the study of the control specimens and reference materials. As previously indicated, this electrolyte has provided well-defined signals in the study of iron pigments and corrosion products (Doménech-Carbó et al., 2001, 2007a, 2013a).

After inoculation, the voltammetric pattern of EG@Fe specimens showed significant changes. As can be seen in Figure 10.1.5.7.1.1, in the case of EG@Fe_An, the signal I is enhanced relative to the signal II whereas the shoulder III becomes lightly increased. These features are consistent with the idea that the biological attack partially destroys the blockage of the pigment particles exerted by the binder so that the voltammogram approaches to that of the pristine pigment. In contrast, for the specimens inoculated with Acremonium chrysogenum and Arthrobacter oxydans, the voltammogram becomes similar to that of EG@Fe, thus suggesting a weak biological attack. Interestingly, all other inoculated specimens produced a considerable increase of the peak II relative to the peak I. This suggests that the biological attack favors the route represented by Eq. (10.1.5.7.1.1) relative to that represented by Eqs. (10.1.5.7.1.2) and (10.1.5.7.1.3). Tentatively, this feature can be attributed to the partial blocking of the complexing by chloride ions (Eq. (10.1.5.7.1.2) associated to the presence of the binder and/or the decrease of the local $\mathrm{pH}$ by protonation of certain protein units.

Signal II:

$\mathrm{Fe}_{2} \mathrm{O}_{3} \cdot \mathrm{nH}_{2} \mathrm{O}($ solid $)+6 \mathrm{H}^{+}(\mathrm{aq})+2 \mathrm{e}^{-} \rightarrow 2 \mathrm{Fe}^{2+}(\mathrm{aq})+(\mathrm{n}+3) \mathrm{H}_{2} \mathrm{O}$

Signal I:

$\mathrm{Fe}_{2} \mathrm{O}_{3} \cdot \mathrm{nH}_{2} \mathrm{O}($ solid $)+6 \mathrm{H}^{+}(\mathrm{aq})+\mathrm{xCl}^{-}(\mathrm{aq}) \rightarrow \mathrm{FeCl}_{\mathrm{x}}{ }^{(3-\mathrm{x})-}(\mathrm{aq})+(\mathrm{n}+3) \mathrm{H}_{2} \mathrm{O}$

$\mathrm{FeCl}_{\mathrm{x}}^{(3-\mathrm{x})-}(\mathrm{aq})+\mathrm{e}^{-} \rightarrow \mathrm{FeCl}_{\mathrm{x}}^{(2-\mathrm{x})-}(\mathrm{aq})$ 


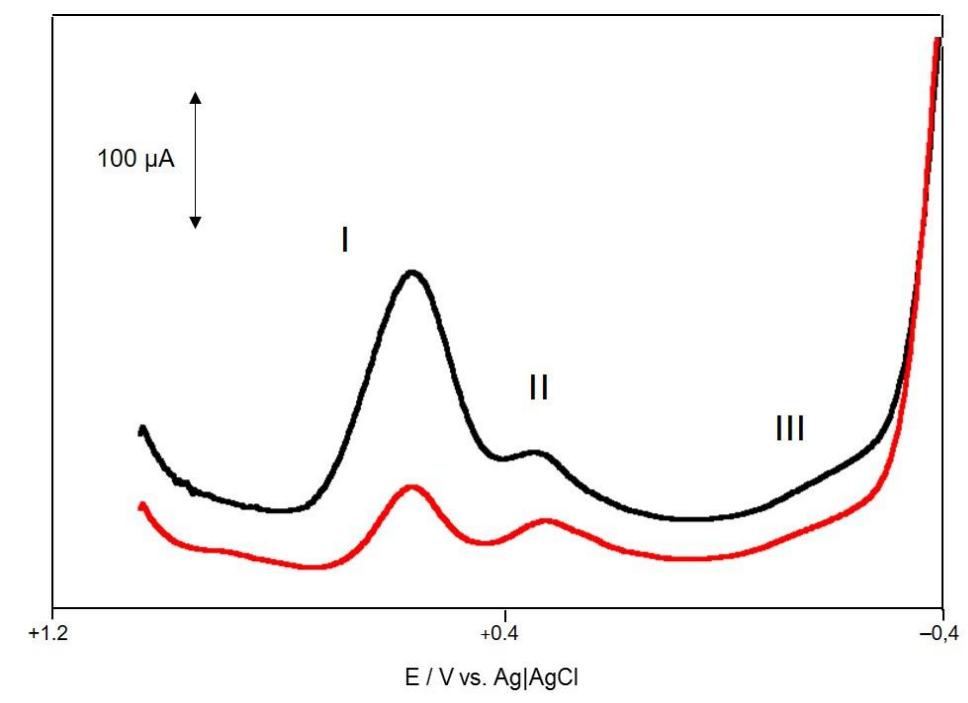

Figure 10.1.5.7.1.1. Square wave voltammograms at sample-modified graphite electrodes immersed into air-saturated 0.10 M HCl for EG@Fe_B (red line) and EG@Fe_An specimens (black line). Potential scan initiated at +1.05 V in the negative direction; potential step increment $4 \mathrm{mV}$; square wave amplitude $25 \mathrm{mV}$; frequency $10 \mathrm{~Hz}$.

In the case of EO@Fe specimens, the voltammetric profiles experienced also significant variations after inoculation. First of all, the voltammograms of the parent EO@Fe (see Figure 10.1.5.7.1.2) produced considerably weak signals I and II compared to those in EG@Fe. This suggests that the binder exerts an important barrier effect blocking almost entirely the contact between the pigment grains and the electrolyte. The specimens inoculated with Acremonium chrysogenum, reproduced this voltammetric pattern, thus suggesting that no significant biological attack occurred. In contrast, the specimens inoculated with fungi Aspergillus niger, Trichoderma pseudokoningii, Penicillium chrysogenum and Mucor rouxii; eubacteria Bacillus amyloliquefaciens; and actinobacteria, Arthrobacter oxydans, and Streptomyces cellulofans provided voltammetric responses such as in Figure 10.1.5.7.1.2, with peaks I and II appearing as well developed, although weaker than those recorded in the homologue EG@Fe inoculated specimens. This response can be considered as indicative of the appearance of a significant attack against the binder which allows the pigment grains for displaying a voltammetric response in contact with the electrolyte. 


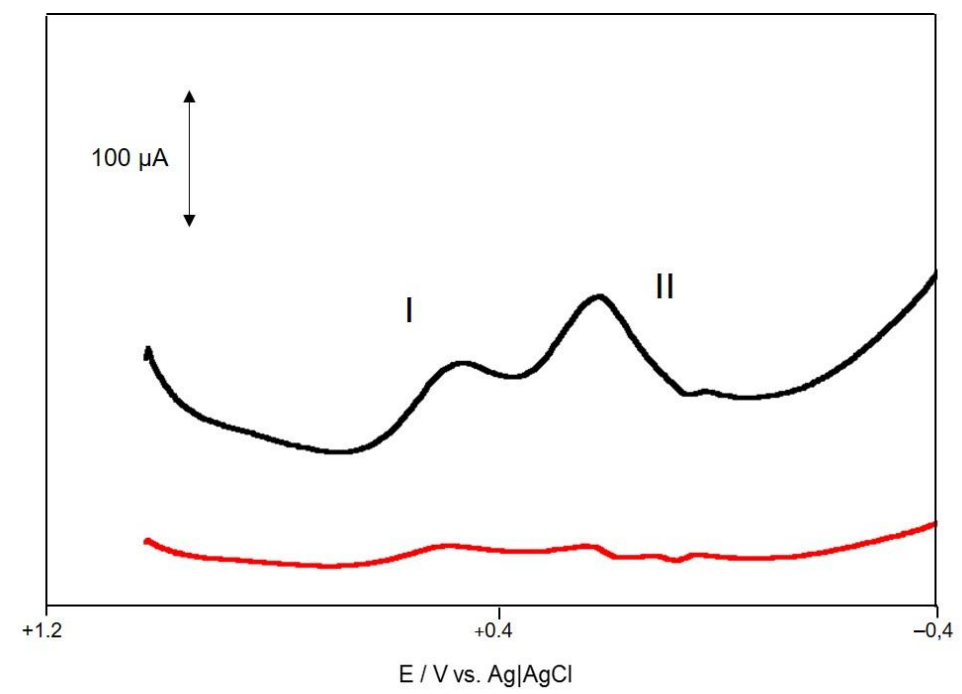

Figure 10.1.5.7.1.2. Square wave voltammograms at sample-modified graphite electrodes immersed into air-saturated 0.10 M HCl for EO@Fe_B (red line) and EO@Fe_Tp specimens (black line). Potential scan initiated at $+1.05 \mathrm{~V}$ in the negative direction; potential step increment $4 \mathrm{mV}$; square wave amplitude $25 \mathrm{mV}$; frequency $10 \mathrm{~Hz}$.

\subsection{Verdigris}

The voltammetric response of the reconstructed model paint film specimens was differently modified after inoculation. Significant changes were observed in the voltammograms obtained for the EG@Cu paint film specimens inoculated with Acremonium chrysogenum fungi and Arthrobacter oxydans actinobacteria as shown in Figure 10.1.5.7.2.1. The most relevant feature was the broadening of both the cathodic and anodic regions of the voltammograms with the appearance of an additional cathodic peak at ca. $-0.55 \mathrm{~V}\left(\mathrm{C}_{4}\right)$ strongly overlapped with signals $\mathrm{C}_{1}-\mathrm{C}_{3}$. Peaks $\mathrm{C}_{1}-\mathrm{C}_{4}$ can be resolved upon semi-derivative deconvolution of the current/potential curves (Figure 10.1.5.7.2.1b, d). 


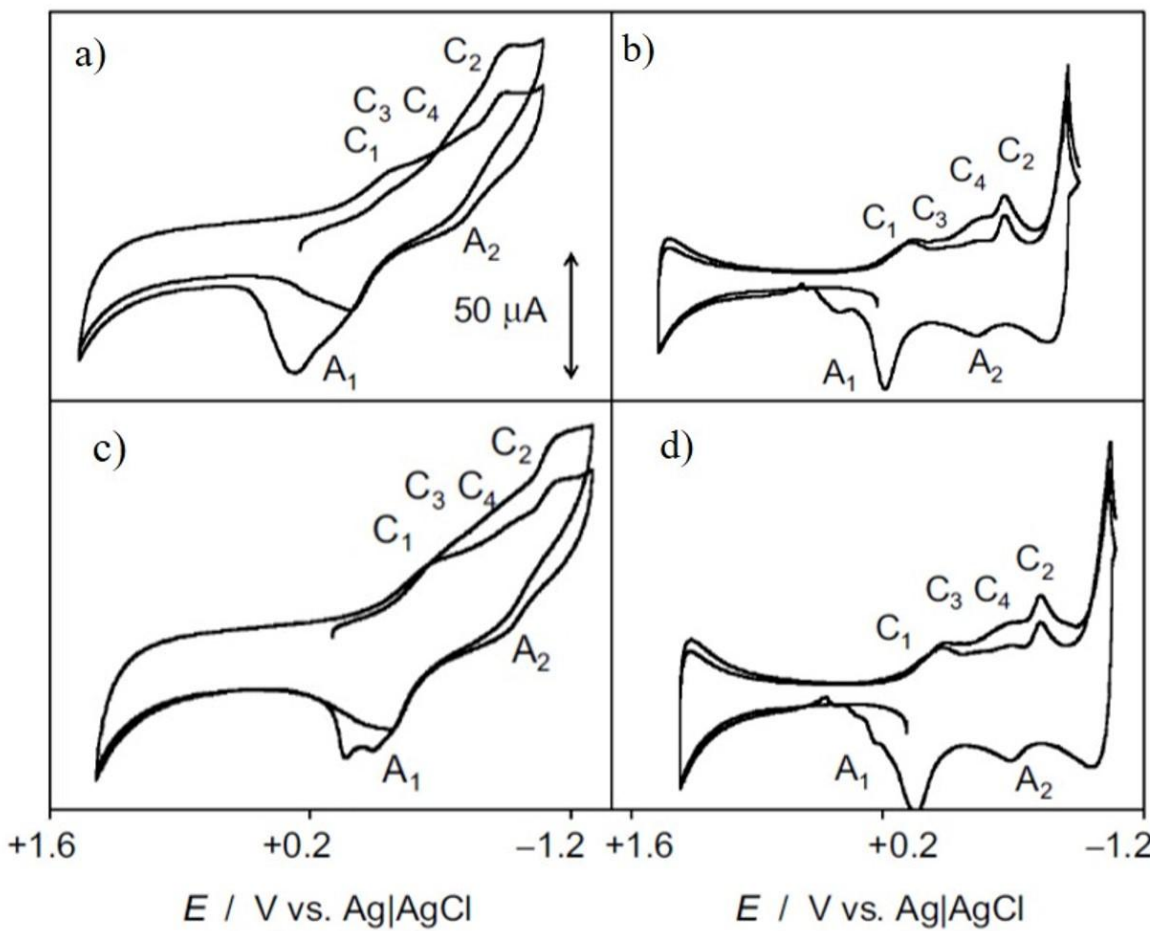

Figure 10.1.5.7.2.1. CVs of graphite electrodes modified with verdigris egg tempera paint films immersed into $0.25 \mathrm{M}$ sodium acetate buffer, $\mathrm{pH}$ 4.75, after inoculation with: a, b Acremonium chrysogenum (EG@Cu_Ac) fungi and c, d Arthrobacter oxydans (EG@Cu_Ao) actinobacteria. Voltammograms before (a, c) and after (b, d) semi-derivative convolution; potential scan rate $50 \mathrm{mV} \mathrm{s}-1$

CVs of graphite electrodes modified with EO@Cu paint films immersed into $0.25 \mathrm{M}$ sodium acetate buffer at pH 4.75 after inoculation with Mucor rouxii (EO@ $\mathrm{Cu}_{-} \mathrm{Mr}$ ) and Acremonium chrysogenum (EO@Cu_Ac) fungi; and Streptomyces cellulofans (EO@Cu_Sc) and Arthrobacter oxydans (EO@Cu_Ao) actinobacteria are shown in Figure 10.1.5.7.2.2. $\mathrm{EO} @ \mathrm{Cu}_{-} \mathrm{Mr}$ and $\mathrm{EO} @ \mathrm{Cu}_{-} \mathrm{Ac}$ specimens (Figure 10.1.5.7.2.2a, b) displayed similar voltammetric features characterized by the engrossment of the $\mathrm{C}_{1}$ peak being preceded by a shoulder at ca. $-0.12 \mathrm{~V}\left(\mathrm{C}_{5}\right)$, now strongly overlapped with $\mathrm{C}_{3}$ and $\mathrm{C}_{4}$ signals. In addition, an intensity decrease of the peak $\mathrm{C}_{2}$ and the appearance of two overlapping intense anodic peaks in the $\mathrm{A}_{1}$ region of potentials can be observed.

The most significative changes are observed for the $\mathrm{EO} @ \mathrm{Cu}$ paint films specimens inoculated with bacteria. Figure 10.1.5.7.2.2c, d show the voltammograms obtained for EO@Cu_Sc and EO@Cu_Ao which are representative of two apparently extreme behaviors. The CV of the former was similar to those of specimens inoculated with fungi. In contrast, the specimens inoculated with Arthrobacter oxydans produced a 'clean' voltammogram dominated by peaks $\mathrm{C}_{1}$ and $\mathrm{C}_{2}$ with no peak splitting in the signal $\mathrm{A}_{1}$. The voltammograms for Bacillus amyloliquefaciens, were intermediate between those of Streptomyces cellulofans and Arthrobacter oxydans. 


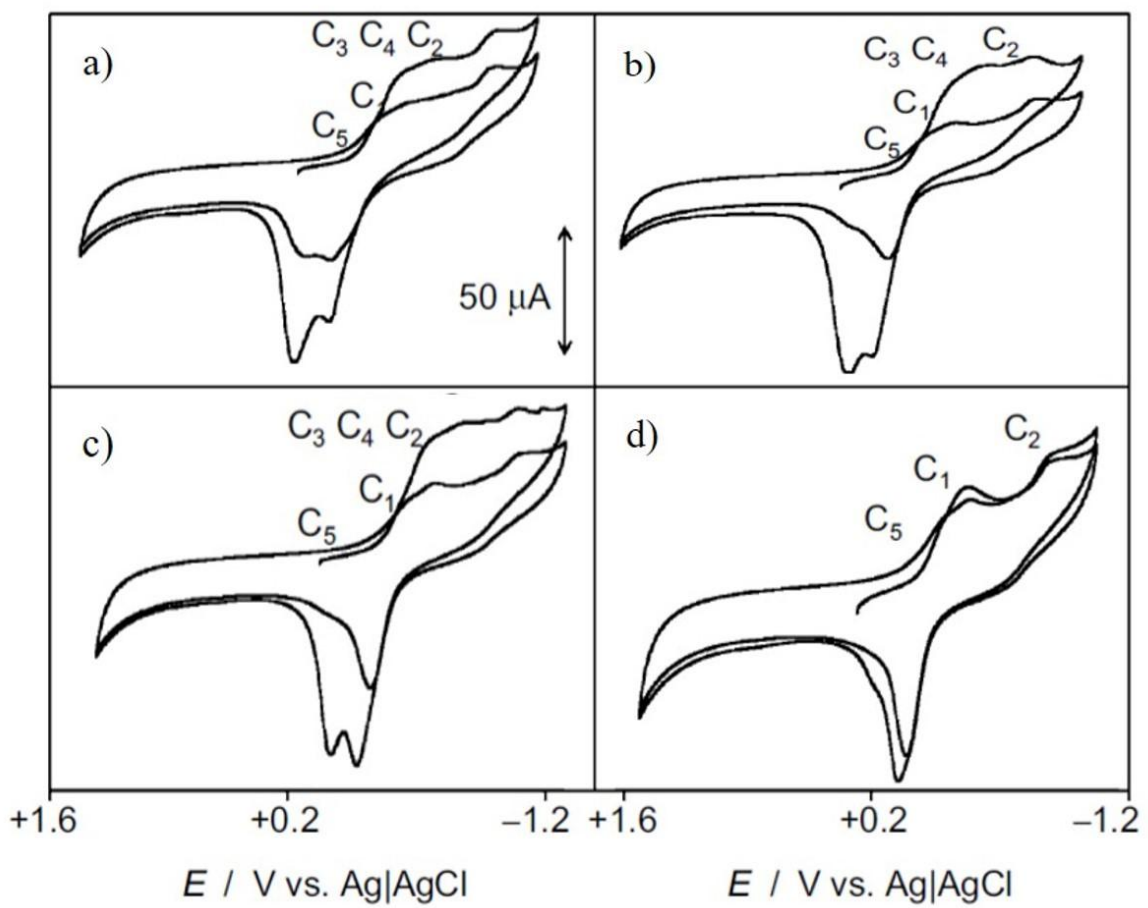

Figure 10.1.5.7.2.2. CVs of graphite electrodes modified with verdigris egg-oil emulsion paint films immersed into $0.25 \mathrm{M}$ sodium acetate buffer, pH 4.75 after inoculation with: a Mucor rouxii (EO@Cu_Mr) and, b Acremonium chrysogenum (EO@Cu_Ac) fungi and; c Streptomyces cellulofans (EO@Cu_Sc) and, d Arthrobacter oxydans (EO@Cu_Ao) bacteria. Potential scan rate $50 \mathrm{mV} \mathrm{s}-1$

The voltammetric features appearing after biological attack can be attributed to the superposition of two main factors: (i) the degradation of the binder resulting in an increased exposition of the verdigris particles favoring the process $\mathrm{C}_{1}$, and (ii) the increase of the ionomeric layer of $\mathrm{Cu}(\mathrm{II})$-binding compounds, thus increasing the intensity of the peak $\mathrm{C}_{3}$, promoting the appearance of a new signal $\mathrm{C}_{4}$, and retaining 'free' $\mathrm{Cu}^{2+}$ ions generated in the reductive step $\mathrm{C}_{1}$ with the concomitant decrease of peak $\mathrm{C}_{2}$. It is pertinent to note that, under our experimental conditions, the possible voltammetric response of electroactive metabolites in biofilm residuals and their occasional complexes with released copper ions should be considerably weaker than that of pigment-based species.

The observed changes in the voltammetric response of the films upon biodeterioration are in good agreement with the transformations taking place in the secondary structure of proteins observed by FTIR in the inoculated specimens, in particular, the increase in the random coils and $\mathrm{Cu}$-protein complexes. The cathodic shoulder $\mathrm{C}_{5}$ was characteristic of $\mathrm{EO} @ \mathrm{Cu}$ reconstructed paint film. This signal can be attributed to the reduction of $\mathrm{Cu}$ (II) soaps formed upon coordination with the carboxylate units of the oil fraction of the binder and is consistent with the intense IR band at $1585 \mathrm{~cm}^{-1}$ exhibited by the inoculated specimens corresponding to the asymmetric stretching vibrations of $\mathrm{Cu}$ (II)-fatty acid complexes formed in egg oil emulsion films inoculated with both bacteria and fungi. Accordingly, the reduction process $\mathrm{C}_{5}$ can be represented as: 
$\left\{\mathrm{Cu}^{2+}\left(\mathrm{RCOO}^{-}\right)_{2}\right\}_{\text {Cu soap }}+2 \mathrm{H}^{+}{ }_{\mathrm{aq}}+2 \mathrm{e}^{-} \rightarrow\{\mathrm{Cu}\}_{\text {solid }}+2 \mathrm{RCOOH}$

Interestingly, the formation of copper soaps (denoted by the shoulder $\mathrm{C}_{5}$ ) was a common factor for the attack of both fungi and bacteria to EO films, whereas the degradation of the proteinaceous fraction of the binder (denoted by peaks $\mathrm{C}_{3}, \mathrm{C}_{4}$ ) varied significantly from one species to another, being minimal in the case of Arthrobacter oxydans (compare Figures 10.1.5.7.2.1a, c with Figure 10.1.5.7.2.2d). This result is coherent with the IR spectrum obtained in this specimen that exhibited an intense and well-resolved amide I band.

\subsection{Lead white}

The voltammetric response of un-inoculated lead white egg tempera paint film (EG@Pb_B, Figure 10.1.5.7.3.1b), although similar to that of the pure pigment, exhibited some significant differences. Thus, the cathodic region consisted of two peaks at $-0.60\left(\mathrm{C}_{1}\right)$ and $-0.70 \mathrm{~V}\left(\mathrm{C}_{2}\right)$ whereas the signal $C_{H}$ was depleted and the peak $A_{P b}$ was broadened. The above voltammetry can be described, as in the case of verdigris-based films (Ortiz-Miranda et al., 2017), as resulting from the superposition of the reduction of the fraction of pigment particles only partially embedded by the binder and the reduction of lead species existing in an ionomeric layer surrounding the pigment grains. This layer, formed as a result of the pigment-binder interaction, would be mainly composed by a more or less hydrated ensemble of $\mathrm{Pb}^{2+}$-protein complexes in the case of EG specimens. Accordingly, the process $\mathrm{C}_{2}$ can be described as:

$\left\{\mathrm{Pb}^{2+}\left(\text { binding }^{2-}\right)\right\}_{\text {ionomeric layer }}+2 \mathrm{H}^{+}$aq $+2 \mathrm{e}^{-} \rightarrow\{\mathrm{Pb}\}_{\text {solid }}+\mathrm{H}_{2}$ binding

The most significant feature observed in the voltammetry of pictorial specimens inoculated with fungi and bacteria was the enhancement of the peak $\mathrm{C}_{2}$ accompanied with a decrease in the height of the process $\mathrm{C}_{\mathrm{H}}$, attributed to the electrocatalytic ability of lead metal deposited in the ionomeric layer. As can be seen in Figures 10.1.5.7.3.1c, d, the relative height of peaks $\mathrm{C}_{1}, \mathrm{C}_{2}$ changed relative to the un-inoculated specimens with concomitant changes in the height of peak $\mathrm{C}_{\mathrm{H}}$. 


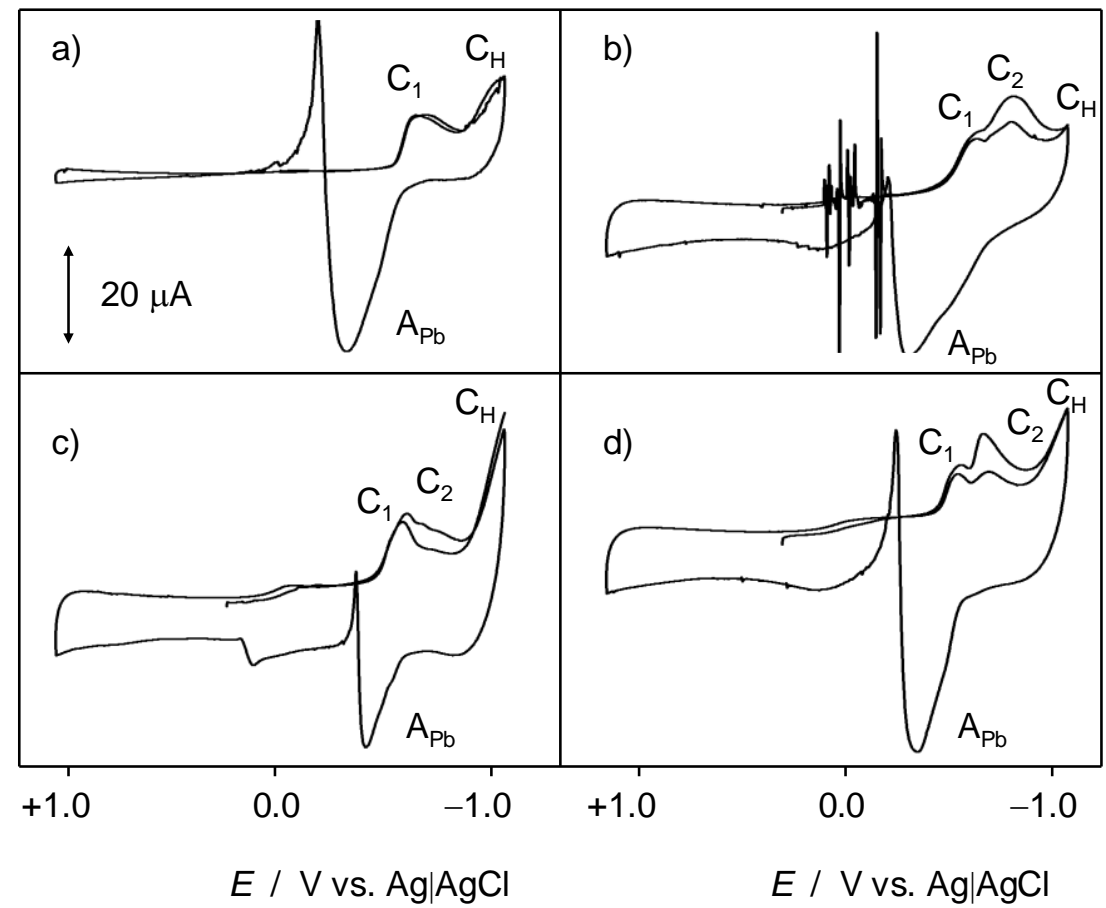

Figure 10.1.5.7.3.1. Cyclic voltammograms, after semi-derivative convolution, of microparticulate deposits of a) lead white and b-d) lead white egg tempera paint films, b) un-inoculated (EG@Pb_B) and inoculated with c) Acremonium chrysogenum (EG@Pb_Ac), d) Bacillus amyloliquefaciens (EG@Pb_Ba) attached to graphite bar immersed into $0.25 \mathrm{M} \mathrm{HAc} / \mathrm{NaAc}$ aqueous buffer, $\mathrm{pH}$ 4.75. Potential scan rate $50 \mathrm{mV} \mathrm{s}^{-1}$.

The voltammetric features observed in the reconstructed egg oil emulsion paint films was similar to that of the egg-based specimens. As shown in Figure 10.1.5.7.3.2, where the voltammograms of EO@Pb paint films, a) un-inoculated (EO@Pb_B) and b-d) inoculated with b) Mucor rouxii (EO@Pb_Mr), c) Penicillium chrysogenum (EO@Pb_Pc), d) Bacillus amyloliquefaciens (EO@Pb_Ba) are shown. The most relevant features in the voltammograms of EO specimens were the increase of the peak $\mathrm{C}_{1}$ relative to the peak $\mathrm{C}_{2}$, and the narrow habit of the peak $\mathrm{A}_{1}$. These changes can be attributed to the superposition of two main factors: i) the increase in the exposition of the pigment particles as result of the degradation of the binder, and ii) the possible release of $\mathrm{Pb}^{2+}$ ions accompanied by the formation of $\mathrm{Pb}(\mathrm{II})$ soaps with the carboxylate units of the fatty-acid fraction of the binder. The reduction of such soaps, which can be represented as:

$\left\{\mathrm{Pb}^{2+}\left(\mathrm{RCOO}^{-}\right)_{2}\right\}_{\text {soap }}+2 \mathrm{H}^{+}$aq $+2 \mathrm{e}^{-} \rightarrow\{\mathrm{Pb}\}_{\text {solid }}+2 \mathrm{RCOOH}$

would be superimposed to that of the pigment, thus resulting in an enhancement of the signal $\mathrm{C}_{1}$. These changes are in good agreement with the transformations taking place in the secondary structure of proteins observed in the inoculated specimens, in particular, the 
increase in the random coils and $\mathrm{Pb}$-protein complexes exhibited by the reconstructed egg tempera paint films derived from IR data.

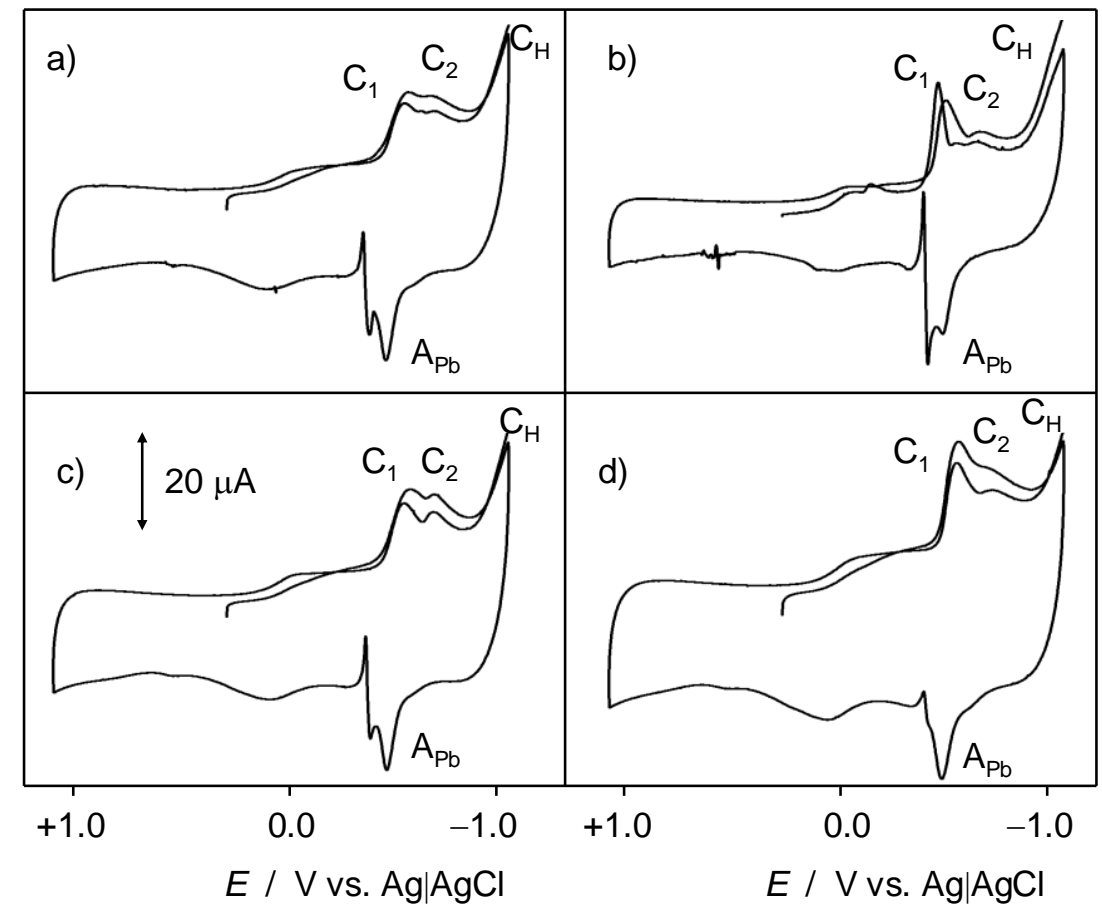

Figure 10.1.5.7.3.2. Cyclic voltammograms, after semi-derivative convolution, of microparticulate deposits of lead white egg oil emulsion paint films, a) un-inoculated (EO@Pb_B) and b-d) inoculated with b) Mucor rouxii (EO@ $\left.\mathrm{Pb} \_\mathrm{Mr}\right)$, c) Penicillium chrysogenum (EO@Pb_Pc), d) Bacillus amyloliquefaciens (EO@Pb_Ba) attached to graphite bar immersed into $0.25 \mathrm{M}$ $\mathrm{HAc} / \mathrm{NaAc}$ aqueous buffer, $\mathrm{pH}$ 4.75. Potential scan rate $50 \mathrm{mV} \mathrm{s}^{-1}$.

Another interesting feature in voltammograms in Figures 10.1.5.7.3.1 and 10.1 5.7.3.2 is the variability in the current recorded at more negative potentials, corresponding to the HER, $\mathrm{C}_{\mathrm{H}}$. The intensity variation of this process will be dependent on the surface area of graphite exposed to the electrolyte solution and on the catalytic effect exerted by the deposit of lead metal formed electrochemically in the processes $C_{1}$ and $C_{2}$ preceding the HER process. As will be further discussed (in 10.1.5.8.3), this signal can also be used for discriminating between different paint film types and biological agents.

\subsection{Cadmium yellow}

The voltammetry of the cadmium yellow egg tempera reconstructed paint films (EG@Cd) inoculated with both fungi and bacteria (Figure 10.1.5.7.4.1) was relatively close to that of the pure pigment (see section 10.1.5), with well-defined peak $\mathrm{C}_{2}$. Appearance of additional cathodic peaks at potentials more negative than $\mathrm{C}_{1}$, labeled as $\mathrm{C}_{5}$ and marked by arrows in Figure 10.1.5.7.4.1, and the appearance of peak splitting in peak $\mathrm{A}_{1}$, now accompanied by peak $A_{3}$, were the most significant differences observed. The process $C_{5}$ can be attributed to the reduction of CdS surface complexes associated to the proteinaceous fraction which was 
modified by the biological attack. This process can, in principle, be represented also by Eq. (10.1.5.7.4.1).

$\left\{\mathrm{Cd}^{2+}\left(\text { binding }^{2-}\right)\right\}_{\text {CdS ionomeric layer }}+2 \mathrm{H}^{+}$aq $+2 \mathrm{e}^{-} \rightarrow\{\mathrm{Cd}\}_{\text {solid }}+\mathrm{H}_{2}$ binding

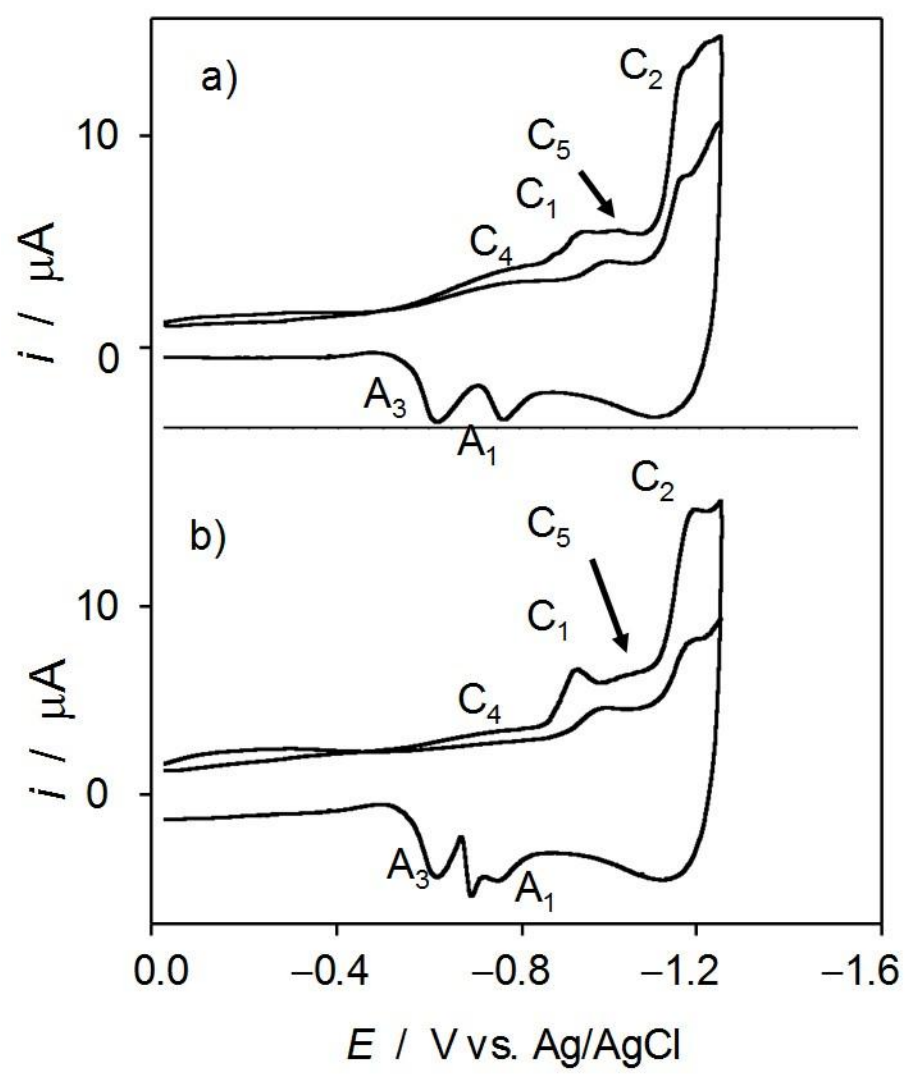

Figure 10.1.5.7.4.1. Cyclic voltammograms, after semi-derivative convolution, for graphite electrodes modified with EG@Cd paint film immersed into $0.25 \mathrm{M}$ sodium acetate buffer, $\mathrm{pH}$ 4,75 after inoculation with: a) the fungus Trichoderma pseudokoningii (EG@Cd_Tp); b) the bacterium Streptomyces cellulofans (EG@Cd_Sc). Potential scan rate $50 \mathrm{mV} \mathrm{s}^{-1}$.

Complementary information was obtained in the region of positive potentials with linear scan voltammograms. Figure 10.1.5.7.4.2 shows the linear voltammograms obtained for the a) pure pigment CdS, b) pure egg and reconstructed EG@Cd paint film c) uninoculated and d) inoculated with Aspergillus niger (EG@Cd_An). The pigment displays a well defined anodic peak at $+0.82 \mathrm{~V}\left(\mathrm{~A}_{\mathrm{CdS}}\right)$ preceded by a shoulder at ca. $+0.65 \mathrm{~V}$. Although sulfur electrochemistry is complicated (Colletti et al., 1994), the oxidation of CdS can be represented as:

$\{\mathrm{CdS}\}_{\text {solid }} \rightarrow\{\mathrm{S}\}_{\text {solid }}+\mathrm{Cd}^{2+}{ }_{\text {aq }}+2 \mathrm{e}^{-}$ 


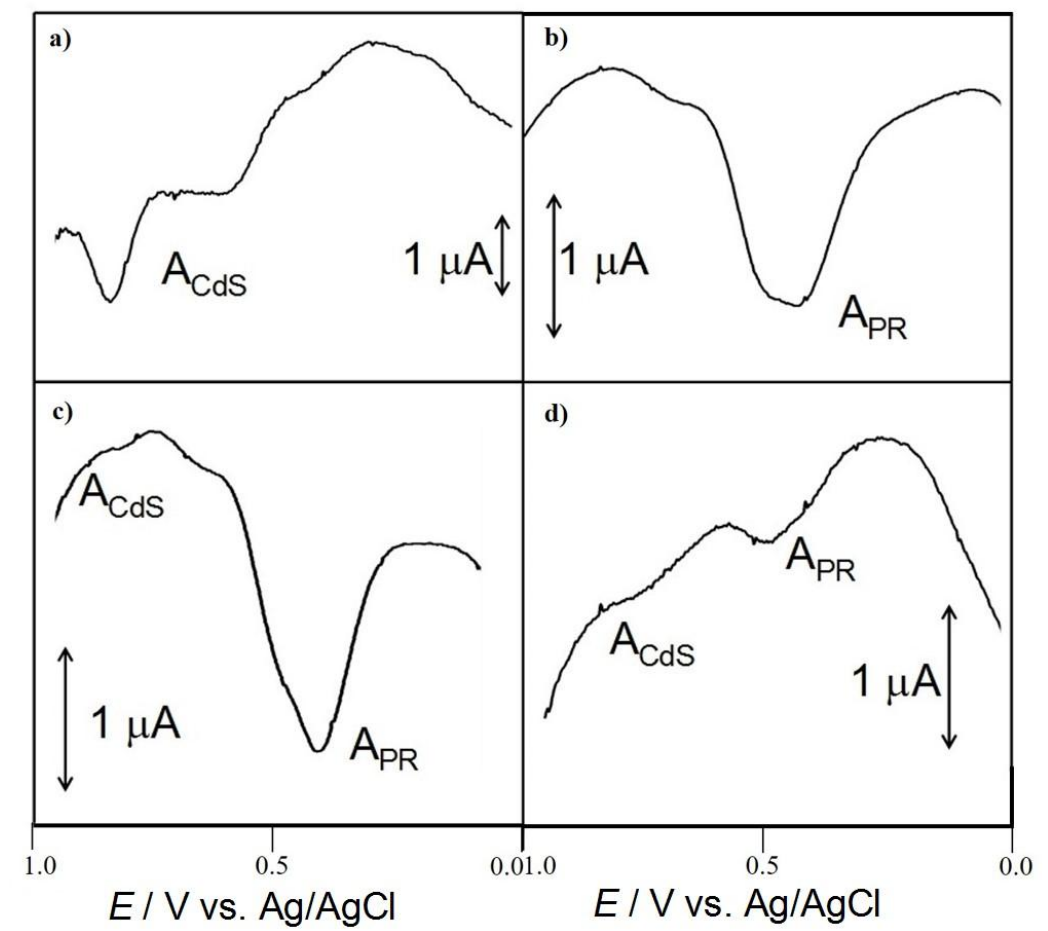

Figure 10.1.5.7.4.2. Linear scan voltammograms, after semi-derivative convolution, for: a) pure cadmium yellow b) pure egg, c) EG@Cd_B,d) EG@Cd_An paint film deposited on graphite in contact with $0.25 \mathrm{M}$ sodium acetate buffer, pH 4,75. Potential scan initiated at $0.0 \mathrm{~V}$ in the positive direction; potential scan rate $50 \mathrm{mV} \mathrm{s}^{-1}$.

Finally, reconstructed egg tempera paint films produce an oxidation signal consisting of overlapping voltammetric peaks centered at $+0.45 \mathrm{~V}\left(\mathrm{~A}_{\mathrm{PR}}\right)$, attributable either to the oxidation of metalloproteins (Gulaboski et al., 2012) and/or - SH units of proteins (Guidelli and Becucci, 2011). The un-inoculated egg tempera paint film (EG@blank) yields a voltammetric response dominated by the signal $A_{P R}$, whose profile is slightly modified, while the $A_{C d s}$ signal becomes considerably lowered. Consistently with the foregoing set of voltammetric data, the effect of fungi and bacteria on the voltammetry of EG@Cd paint film was similar, now significantly lowering both $\mathrm{A}_{\mathrm{CdS}}$ and $\mathrm{A}_{\mathrm{PR}}$ features.

Figure 10.1.5.7.4.3, shows CVs for the egg oil emulsion paint films after inoculation with two fungi, Aspergillus niger (EO@Cd_An) (Figure 10.1.5.7.4.3a) and Acremonium chrysogenum (EO@Cd_Ac) (Fig. 10.1.5.7.4.3b), eubacteria, Bacillus amyloliquefaciens (EO@Cd_Ba) (Fig. 10.1.5.7.4.3c) and actinobacteria Arthrobacter oxydans (EO@Cd_Ao) (Fig. 10.1.5.7.4.3d), respectively. The fungi attack leads to voltammograms displaying only the peak $\mathrm{C}_{1}$, accompanied of weak signal $\mathrm{C}_{4}$. In contrast, after bacteria attack, the voltammograms consist of 'clean' peaks $\mathrm{C}_{3}$ and $\mathrm{C}_{1}$ with no traces of peak $\mathrm{C}_{4}$. These results suggest that the bacteria deteriorating activity would be concentrated on the oil fraction of the binding medium so that the reduction of pigment particles $\left(\mathrm{C}_{1}\right)$ and their ionomeric layer $\left(\mathrm{C}_{3}\right)$ remain well-defined, while the signal $\mathrm{C}_{4}$ disappears. In contrast, fungi deteriorating activity affects both the ionomeric layer and the oil fraction, but is most concentrated in the 
proteinaceous fraction, so that peak $\mathrm{C}_{1}$ disappears while the signal $\mathrm{C}_{4}$ becomes significantly decreased.

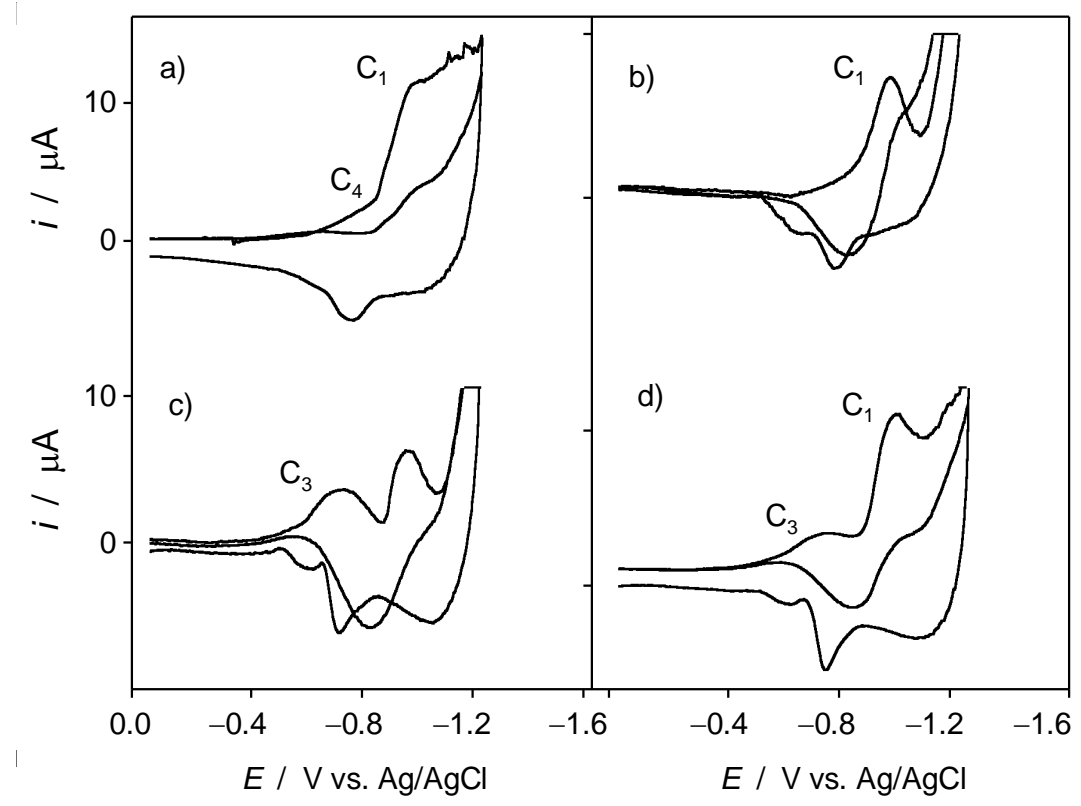

Figure 10.1.5.7.4.3. Cyclic voltammograms, after semi-derivative convolution, for graphite electrodes modified with egg-oil emulsion paint film (EO) immersed into $0.25 \mathrm{M}$ sodium acetate buffer, $\mathrm{pH} 4,75$ after incubation with: a) Aspergillus niger (EO@Cd_An); b) Acremonium crhysogenum (EO@Cd_Ac); c) Bacillus amyloliquefaciens (EO@Cd_Ba); d) Arthrobacter oxydans (EO@Cd_Ao). Potential scan rate $50 \mathrm{mV} \mathrm{s}^{-1}$.

The above-mentioned differences were confirmed with the linear scan voltammograms obtained for: a) EO, b) EO@Cd_B, c) EO@Cd_Ba eubacteria and EO@Cd_An fungus shown in Figure 10.1.5.7.4.4. The binder film (Fig. 10.1.5.7.4.4a) produces an oxidation signal at $-0.08 \mathrm{~V}\left(\mathrm{~A}_{\mathrm{LO}}\right)$, which could be tentatively attributed to the oxidation of tocopherols. These are components of linseed oil (Sutherland, 2013; Rossi et al., 2007) displaying a welldefined oxidative electrochemistry (Ziyatdinova et al., 2012). In the presence of CdS (Fig. 10.1.5.7.4.4b), this signal is accompanied by minor signals at $+0.45\left(\mathrm{~A}_{\mathrm{B} 1}\right)$ and $+0.60\left(\mathrm{~A}_{\mathrm{B} 2}\right)$ preceding the $\mathrm{CdS}$-centered oxidation $\left(\mathrm{A}_{\mathrm{CdS}}\right)$ at $+0.82 \mathrm{~V}$. These signals can be attributed to electrochemically oxidizable compounds resulting from the interaction between CdS and the binder. This would be consistent with results from Madani et al. (2011) on the effect of CdS on polymerization reactions. Interestingly, after bacterial attack (Fig. 10.1.5.7.4.4c), the $\mathrm{A}_{\mathrm{CdS}}$ and $A_{B 1}$ peaks disappear whereas the peak $A_{B 2}$ is enhanced. In contrast, fungi attack (Fig. 10.1.5.7.4.4d) results in the maintenance of peaks $A_{C d S}$ and $A_{B 2}$ peaks with lowering/disappearance of peak $\mathrm{A}_{\mathrm{B} 1}$. These results indicate that the presence of the pigment produce reaction chains in the binder resulting in products which react selectively with fungi and/or bacteria in the paint film. 


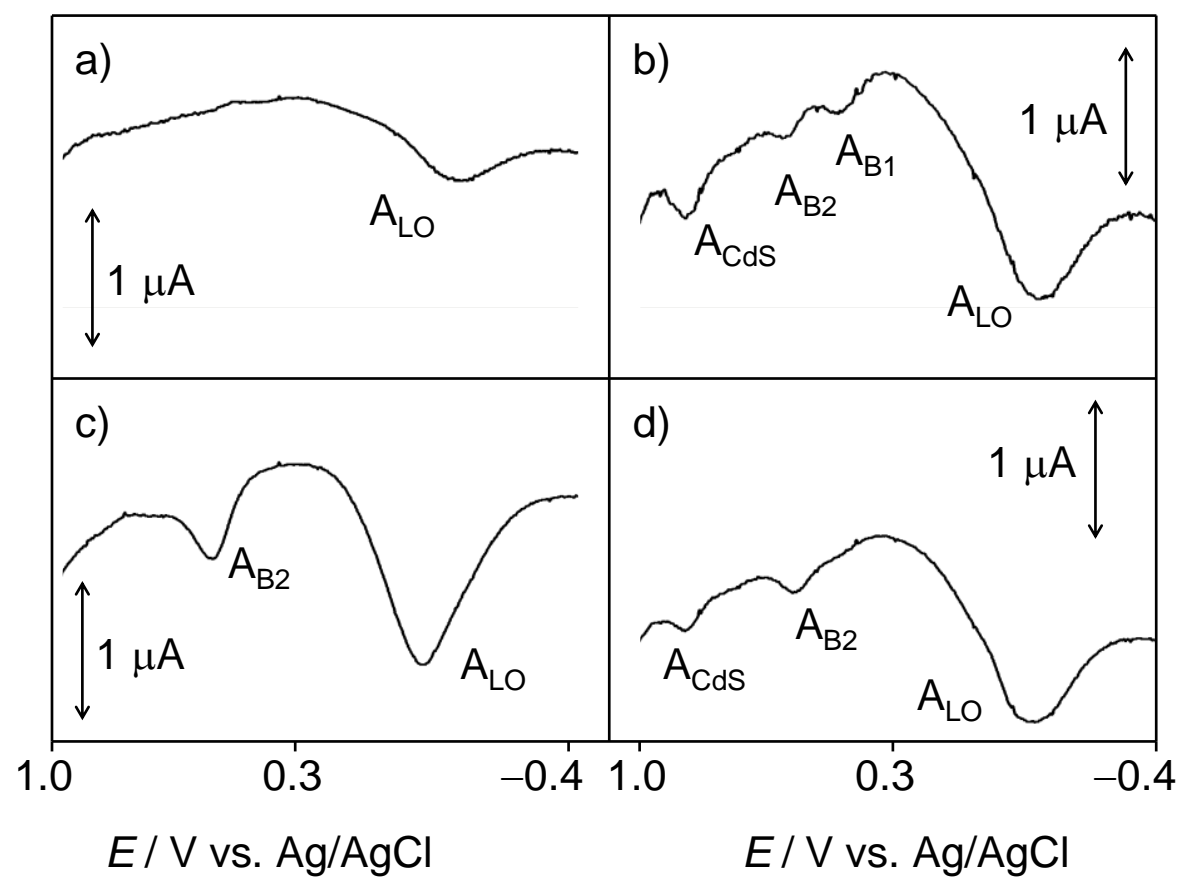

Figure 10.1.5.7.4.4. Linear scan voltammograms, after semi-derivative convolution, for films of: a) EO film b) EO@Cd_B, c) EO@Cd_Ba and d) EO@Cd_An, deposited on graphite in contact with $0.25 \mathrm{M}$ sodium acetate buffer, pH 4,75. Potential scan initiated at $-0.40 \mathrm{~V}$ in the positive direction; potential scan rate $50 \mathrm{mV} \mathrm{s}^{-1}$.

Upon comparing the above data with IR spectroscopy data, all these features would be consistent with the ascription of the voltammetric process $\mathrm{C}_{3}$ in EG@Cd_B specimens to the coordination of $\mathrm{CdS}$ to proteins mainly disposed in $\beta$-sheet conformation. Under attack of both bacteria and fungi, random coil conformations are increased, here appearing the peak $\mathrm{C}_{5}$ to the coordination of proteins in aggregated and more disordered structures to the pigment surface while the $\mathrm{C}_{3}$ signal disappears. In the case of the EO@Cd_B specimen, peak $\mathrm{C}_{4}$ would be associated to the reduction of $\mathrm{Cd}$ soaps formed as the result of complexation of $\mathrm{Cd}$ with the carboxylate groups of fatty acids of the linseed oil fraction. In such specimen, the attack of bacteria and fungi results in the formation of complexes with proteins, probably favored by the opening and unfolding of their secondary structure thus producing the reappearance of peak $\mathrm{C}_{3}$, this effect being more intense for bacteria than for fungi. 
10.1.5.8. Discrimination of biological agents

\subsection{Iron oxide red}

Figure 10.1.5.8.1.1, depicts the II/I peak current ratio $(i(\mathrm{II}) / i(\mathrm{I}))$ for iron oxide red pigment, EG@Fe_B and the inoculated with Acremonium chrysogenum (Ac), Aspergillus niger (An), Mucor rouxii $(\mathrm{Mr})$, Penicillium chrysogenum (Pc) and Trichoderma pseudokoningii $(\mathrm{Tp})$ fungi; and Arthrobacter oxydans (Ao), Bacillus amyloliquefaciens (Ba) and Streptomyces cellulofans $(\mathrm{Sc})$ bacteria specimens.

Figure 10.1.5.8.1.2 presents the variation of the peak current ratio between the signals II and I for iron oxide red, EO@Fe_B and the inoculated with Acremonium chrysogenum (Ac), Aspergillus niger (An), Mucor rouxii (Mr), Penicillium chrysogenum (Pc) and Trichoderma pseudokoningii (Tp) fungi; and Arthrobacter oxydans (Ao), Bacillus amyloliquefaciens (Ba) and Streptomyces cellulofans (Sc) bacteria specimens. Remarkably, in all cases with except Ac, the $i(\mathrm{II}) / i(\mathrm{I})$ ratio is larger than that for the parent EO@Fe_B. This enhancement can be associated to the factors previously discussed, here reinforced by the decrease of the local $\mathrm{pH}$ as a result of the protonation of the carboxylate units of the oil fraction of the binder. As a result, the acidity demanded by the Eq. (10.1.5.7.1.1) will be lower and the reduction of the pigment grains will proceed preferentially via process II (Eqs. (10.1.5.7.1.2 and 10.1.5.7.1.3).

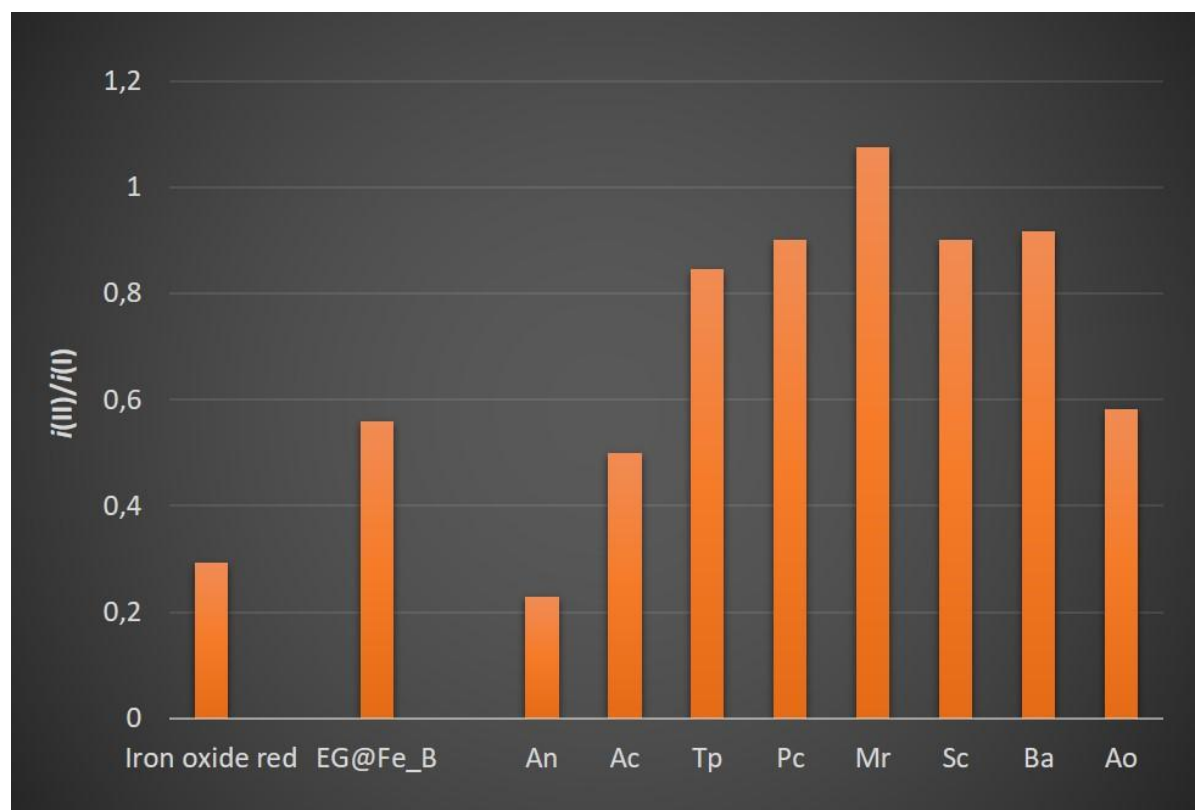

Figure 10.1.5.8.1.1. Variation of the peak current ratio between the signals II and I $(i(\mathrm{II}) / i(\mathrm{I}))$ for iron oxide red pigment, EG@Fe_B and the corresponding inoculated specimens. From voltammograms such as discussed in section 10.1.5.7.1. 


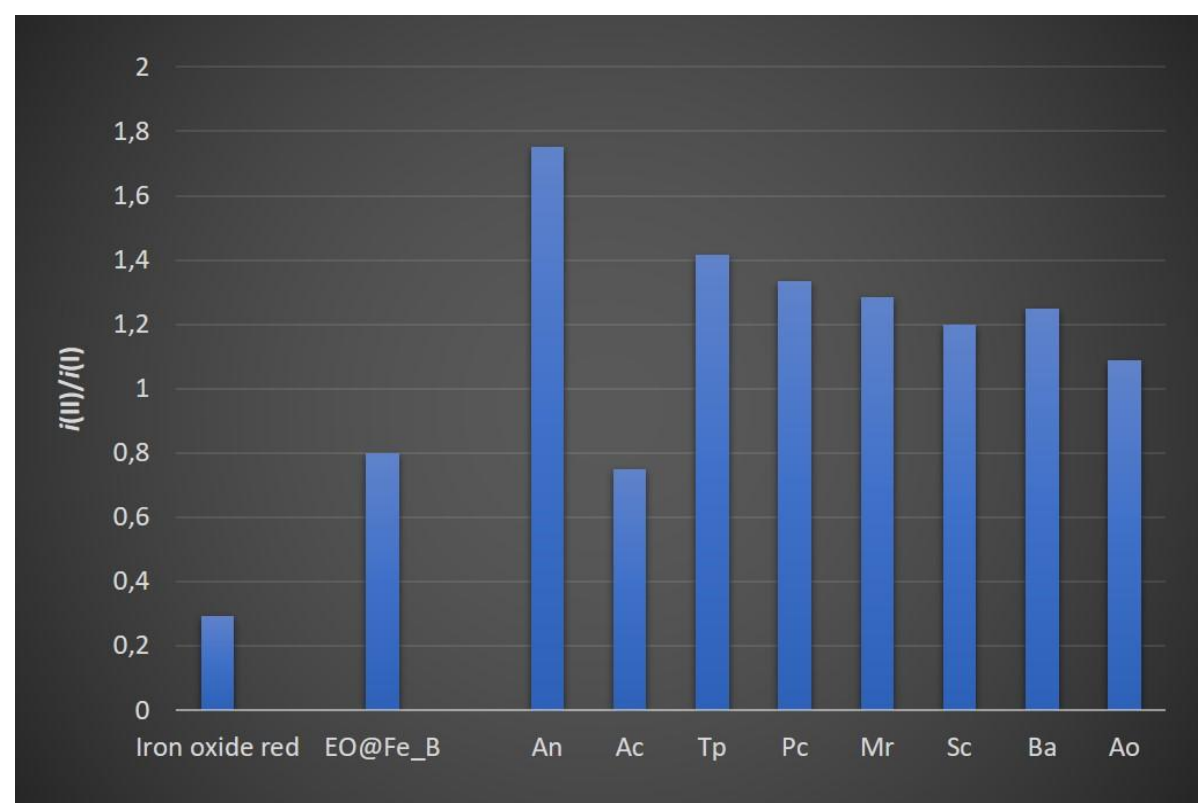

Figure 10.1.5.8.1.2 Variation of the peak current ratio between the signals II and I $(i(\mathrm{II}) / i(\mathrm{I}))$ for iron oxide red pigment, EG@Fe_B and the corresponding inoculated specimens. From voltammograms such as discussed in section 10.1.5.7.1.

\subsection{Verdigris}

In order to group the observed voltammetric responses, the ratios between the peak currents for the processes $\mathrm{C}_{2}$ and $\mathrm{C}_{1}, i_{p}\left(\mathrm{C}_{2}\right) / i_{p}\left(\mathrm{C}_{1}\right)$ and $\mathrm{C}_{3}$ plus $\mathrm{C}_{4}$ and $\mathrm{C}_{1},\left(i_{p}\left(\mathrm{C}_{3}\right)+i_{p}\left(\mathrm{C}_{4}\right)\right) / i_{p}\left(\mathrm{C}_{1}\right)$ were calculated. Based on current measurements from the base line definition depicted in Figure 10.1.5.8.2.1, these ratios can be considered as representative, respectively, of the extent of the release of $\mathrm{Cu}^{2+}$ ions, in turn roughly indicative of the accessibility of the verdigris grains to direct electrochemical reduction, and the extent of the biological attack on the proteinaceous fraction of the binder. Figure 10.1.5.8.2.2a shows experimental data for the deterioration activity of the studied biological agents on EG specimens, where the data points are concentrated in a relatively narrow region of the diagram with the exception of Acremonium chrysogenum. This suggests a common behavior for all the fungi and bacteria, which could be tentatively fitted to a linear tendency (dotted line). 


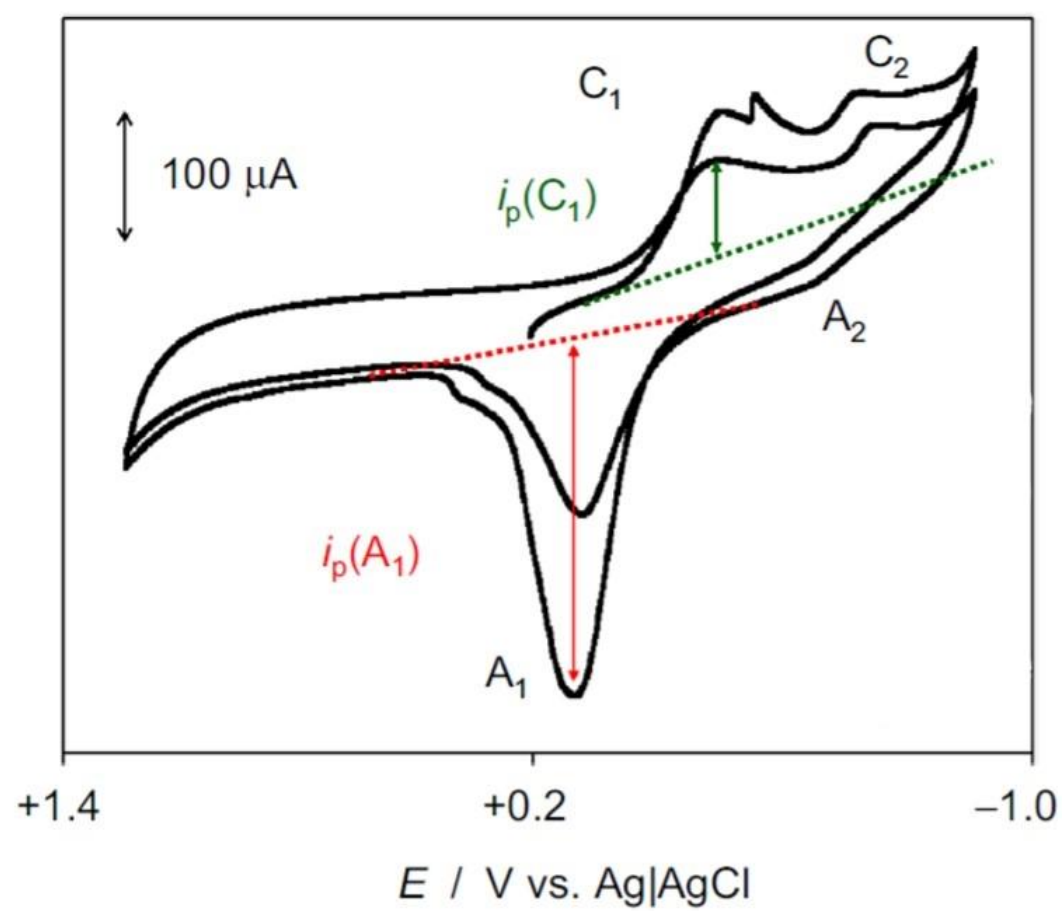

Figure 10.1.5.8.2.1. Cyclic voltammetry of EO@Cu_B attached to graphite bar immersed into 0.25 M HAc/NaAc aqueous buffer, $\mathrm{pH} 4.75$; potential scan rate $50 \mathrm{mV} \mathrm{s}-1$. The base lines for measuring peak currents are depicted.

Similarly, to the $i_{p}\left(\mathrm{C}_{2}\right) / i_{p}\left(\mathrm{C}_{1}\right)$ vs. $\left(i_{p}\left(\mathrm{C}_{3}\right)+i_{p}\left(\mathrm{C}_{4}\right)\right) / i_{p}\left(\mathrm{C}_{1}\right)$ representation the ratio between currents of the components of the anodic process $\mathrm{A}_{1}, i_{\mathrm{p}}\left(\mathrm{A}_{1}{ }^{\prime}\right) / i_{\mathrm{p}}\left(\mathrm{A}_{1}{ }^{\prime}\right)$ vs. $\left(i_{p}\left(\mathrm{C}_{3}\right)+\right.$ $\left.i_{p}\left(\mathrm{C}_{4}\right)\right) / i_{p}\left(\mathrm{C}_{1}\right)$ ratio for the inoculated $\mathrm{EG} @ \mathrm{Cu}$ specimens is shown in Figure 10.1.5.8.2.2b. In this case, the $i_{\mathrm{p}}\left(\mathrm{A}_{1}{ }^{\prime}\right) / i_{\mathrm{p}}\left(\mathrm{A}_{1}{ }^{\prime}\right)$ ratio is representative of the corresponding fraction of verdigris pigment grains exposed as result of the biological attack. Most of the data points in Figure 10.1.5.8.2.2b, are grouped in the same region, with exception of the Aspergillus niger inoculated specimen, which is clearly located in a separated region. These results suggest that there are specific behaviors relative to the deteriorating activity preferences of the microorganisms and to the sensibility of the biological agents to the biocide effect due to verdigris. It is known that copper salts act as relatively non-specific bactericide and fungicide (RED, 2009), where the cupric ion is the active species. The mode of action, after absorption into the fungus or bacterium, involves bonding to various chemical groups (imidazoles, phosphates, sulfhydryls, hydroxyls) presented in many proteins and disrupt the function of these proteins and enzymes, resulting cell damage and membrane leakage (Mirkovic et al., 2015). According to data plotted in Fig. 10.1.5.8.2.2, Acremonium chrysogenum would be highly sensitive to that effect. 

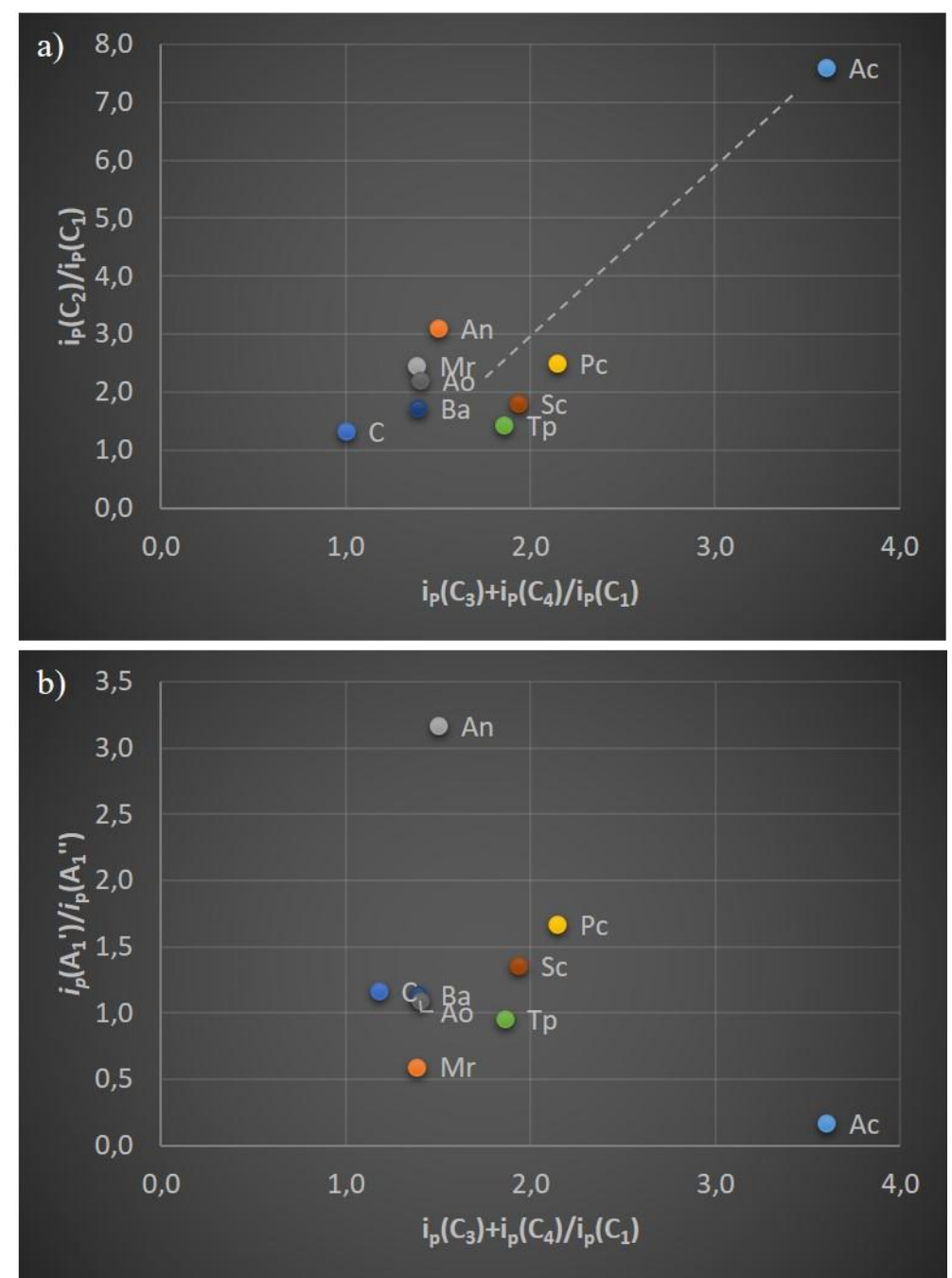

Figure 10.1.5.8.2.2. Plots of: a $i_{\mathrm{p}}\left(\mathrm{C}_{2}\right) / i_{p}\left(\mathrm{C}_{1}\right)$ vs. $\left(i_{\mathrm{p}}\left(\mathrm{C}_{3}\right)+i_{\mathrm{p}}\left(\mathrm{C}_{4}\right)\right) / i_{\mathrm{p}}\left(\mathrm{C}_{1}\right)$ and $\mathrm{b} i_{\mathrm{p}}\left(\mathrm{A}_{1}{ }^{\prime}\right) / i_{\mathrm{p}}\left(\mathrm{A}_{1}{ }^{\prime}\right)$ vs. $\left(i_{p}\left(\mathrm{C}_{3}\right)+i_{\mathrm{p}}\left(\mathrm{C}_{4}\right)\right) / i_{\mathrm{p}}\left(\mathrm{C}_{1}\right)$ for reconstructed verdigris egg tempera paint films after inoculation with biological species in this study. From $\mathrm{CVs}$ in conditions such as in section 10.1.5.7.2. Ac (EG@Cu_Ac), An (EG@Cu_An), Mr (EG@Cu_Mr), Pc (EG@Cu_Pc), Tp (EG@Cu_Tp), Ao (EG@Cu_Ao), Ba (EG@Cu_Ba), Sc (EG@Cu_Sc) and C (EG@Cu_B).

The plots of $i_{p}\left(\mathrm{C}_{2}\right) / i_{p}\left(\mathrm{C}_{1}\right)$ vs. $\left(i_{p}\left(\mathrm{C}_{3}\right)+i_{p}\left(\mathrm{C}_{4}\right)\right) / i_{p}\left(\mathrm{C}_{1}\right)$ (Figure 10.1.5.8.2.2a) and $i_{\mathrm{p}}\left(\mathrm{A}_{1}{ }^{\prime}\right) / i_{\mathrm{p}}\left(\mathrm{A}_{1}{ }^{\prime}\right)$ vs. $\left(i_{p}\left(\mathrm{C}_{3}\right)+i_{p}\left(\mathrm{C}_{4}\right)\right) / i_{p}\left(\mathrm{C}_{1}\right)$ (Figure 10.1.5.8.2.2b) obtained for the verdigris egg oil emulsion inoculated paint films specimens shows groups of data points consistent with linear dependences between the above pairs of peak current ratios (dotted lines in Figure 10.1.5.8.2.2). Apparently, in the case of the egg oil emulsion inoculated specimens, the hydrophobic oil fraction prevents the release and migration of $\mathrm{Cu}^{2+}$ ions from pigment grains, responsible of the biocide effect exerted by verdigris. This suggests that the fungi and/or bacteria be protected from the biocide species and then the specific differences in resistance will be minimized. In agreement with this hypothesis, height of the peak $\mathrm{C}_{2}$ relative to the peak $\mathrm{C}_{1}$ was larger in the $\mathrm{EG} @ \mathrm{Cu}$ specimens than in the $\mathrm{EO} @ \mathrm{Cu}$ specimens submitted to the same biological agents. 

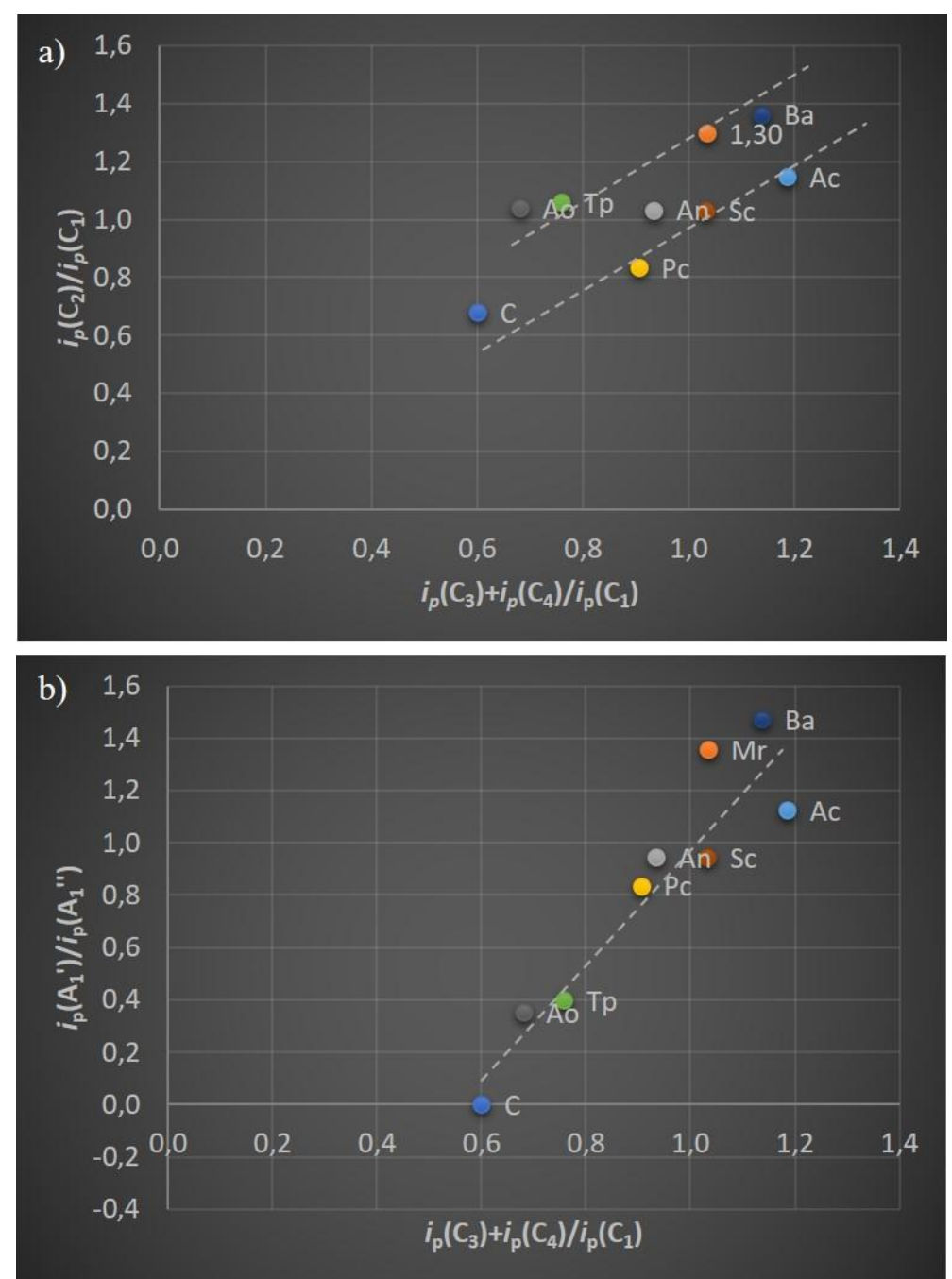

Figure 10.1.5.8.2.3. Plots of: a $i_{\mathrm{p}}\left(\mathrm{C}_{2}\right) / i_{p}\left(\mathrm{C}_{1}\right)$ vs. $\left(i_{\mathrm{p}}\left(\mathrm{C}_{3}\right)+i_{\mathrm{p}}\left(\mathrm{C}_{4}\right)\right) / i_{\mathrm{p}}\left(\mathrm{C}_{1}\right)$ and b $i_{\mathrm{p}}\left(\mathrm{A}_{1}{ }^{\prime}\right) / i_{\mathrm{p}}\left(\mathrm{A}_{1}{ }^{\prime}\right)$ vs. $\left(i_{p}\left(\mathrm{C}_{3}\right)+i_{\mathrm{p}}\left(\mathrm{C}_{4}\right)\right) / i_{\mathrm{p}}\left(\mathrm{C}_{1}\right)$ for reconstructed verdigris egg oil emulsion after inoculation with biological species in this study. From $\mathrm{CVs}$ in conditions such as in section 10.1.5.7.2. Ac (EO@Cu_Ac), An (EO@Cu_An), Mr (EO@Cu_Mr), Pc (EO@Cu_Pc), Tp (EO@Cu_Tp), Ao (EO@Cu_Ao), Ba (EO@Cu_Ba), Sc (EO@Cu_Sc) and C $\left(\mathrm{EO} @ \mathrm{Cu} \_\right.$B $)$.

\subsection{Lead white}

As previously mentioned, the concentration of exposed pigment and released metal forms will tend to reach stationary values. Then, the $i\left(\mathrm{C}_{1}\right) / i\left(\mathrm{C}_{2}\right)$ ratio should tend to a constant value which will depend of two factors: i) the initial concentration and ii) the type of biological agent. Figure 10.1.5.8.3.1, shows the experimental data obtained for the series of lead white reconstructed model paint specimens containing quite similar amount of biological agent attached to the graphite electrode surface. In the case of the EO@Pb specimes, all microorganisms used in this study exhibited a common response that fit into a linear dependence between $i\left(\mathrm{C}_{1}\right)$ and $i\left(\mathrm{C}_{2}\right)$ (Figure 10.1.5.8.3.1a). In contrast, the EG@Pb inoculated specimens deviate from the uninoculated (EG@Pb_B) specimen, with no common response between the inoculated and the uninoculated specimens (Figure 10.1.5.8.3.1b). These results confirm that there are specific variations depending on the biological agent. 

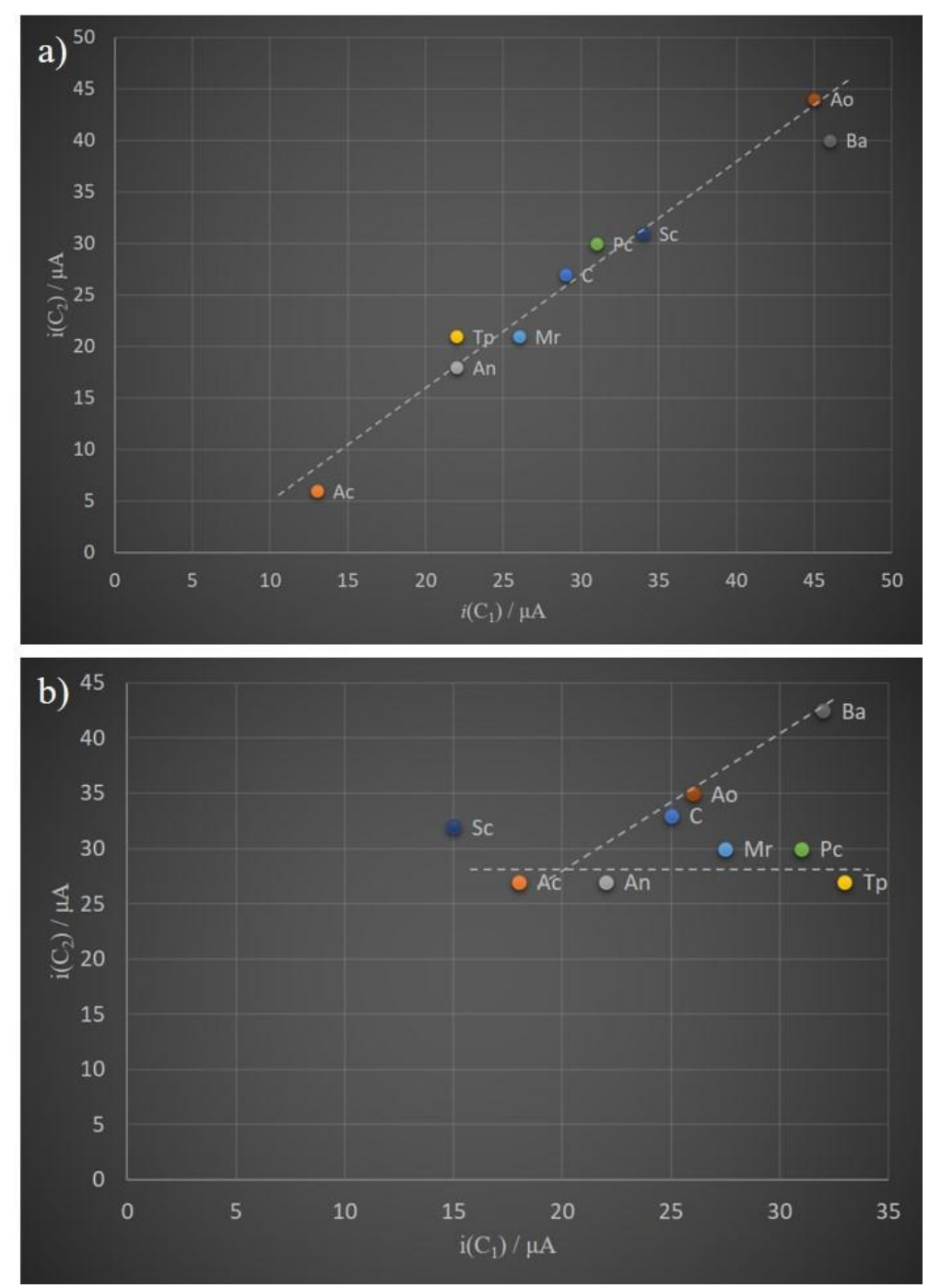

Figure 10.1.5.8.3.1. Experimental values of the peak currents for the processes $C_{1}$ and $C_{2}$ measured in cyclic voltammetric experiments (conditions such as in section 10.1.5.7.3) for a) egg-oil emulsion and b) egg lead white reconstructed paint films in this study. Lines correspond to expected variations consistent.

Besides, a refined grouping of the voltammetric responses was obtained on considering the intensity of the proton discharge current at the switching potential, $i\left(\mathrm{C}_{\mathrm{H}}\right)$. As previously denoted, this current is catalytically enhanced as a result of lead metal deposition at less negative potentials (Gopalakrishna et al., 1972; Panizza and Cerisola, 2003; Wu et al., 2005; Doménech-Carbó et al., 2011) but appears to be sensitive to changes in the metal electrodeposition depending on the composition of the film. Figure 10.1.5.8.3.2, shows the $i\left(\mathrm{C}_{\mathrm{H}}\right)$ vs. $i\left(\mathrm{C}_{1}\right)$ plots from currents measured in cyclic voltammetric experiments for lead white reconstructed paint films. The data points for inoculated specimens can be distributed into four linear dependences of $i\left(\mathrm{C}_{\mathrm{H}}\right)$ on $i\left(\mathrm{C}_{1}\right)$, corresponding to EG@Pb_fungi, EG@Pb_bacteria,EO@Pb_fungi and EO@Pb_bacteria samples. These results suggest that the voltammetric data obtained can discriminate between the binder (EG and EO) and the 
type of biological attack (fungi and bacteria), although no specific differences within each group of biological agents can be attained from these data.

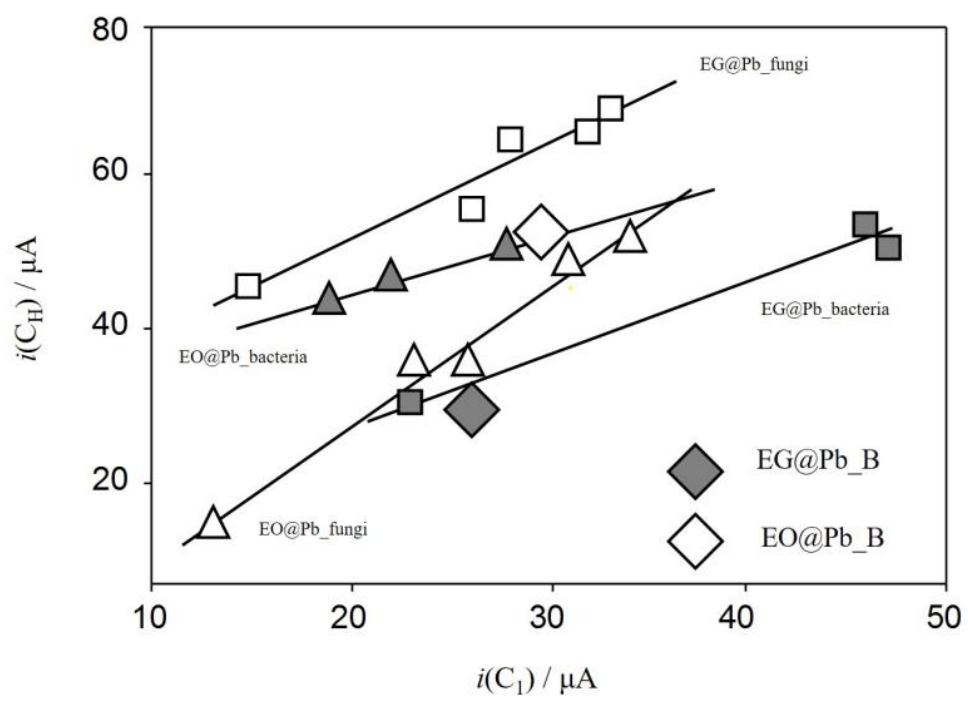

Figure 10.1.5.8.3.2. Plots of $i\left(\mathrm{C}_{\mathrm{H}}\right)$ vs. $i\left(\mathrm{C}_{1}\right)$ measured in cyclic voltammetric experiments (conditions such as in section 8.3.4.1.3) for lead white reconstructed paint films in this study. Lines correspond to linear fit of the different data sets for squares: EG@Pb_fungi, solid squares: EG@Pb_bacteria, triangles: EO@Pb_fungi, solid triangles: EO@Pb_bacteria.

\subsection{Cadmium yellow}

A similar discrimination to that described for the previous specimens can be obtained from voltammetric data obtained for the cadmium yellow specimens depicted in Figure 10.1.5.8.4.1. The data obtained for the inoculated EG@Cd specimens, exhibit a common behavior, which could be fitted to a linear tendency (dotted line in Figure 10.1.5.8.4.1a). This could be associated to the increase of more unordered conformation observed in the ATRFTIR analysis (section 10.1.3.2), where Bacillus amyloliquefaciens eubacteria, proved to be the most aggressive microorganisms. The values of the peak current ratio for the processes $\mathrm{A}_{\mathrm{B} 2}$ and $\mathrm{A}_{\mathrm{LO}}, i_{\mathrm{p}}\left(\mathrm{A}_{\mathrm{B} 2}\right) / i_{\mathrm{p}}\left(\mathrm{A}_{\mathrm{LO}}\right)$ (described in section 10.1.5.7.4), are plotted $v s$. the values of the peak current ratio for the processes $\mathrm{C}_{3}$ and $\mathrm{C}_{1}, i_{\mathrm{p}}\left(\mathrm{C}_{3}\right) / i_{\mathrm{p}}\left(\mathrm{C}_{1}\right)$, for inoculated egg oil emulsion paint films. In this case, the data points for bacteria-inoculated and fungi-inoculated films fall in clearly separated regions, thus suggesting the availability of voltammetric data for screening purposes.

These results can be considered as indicative that the bacteria deterioration activity was concentrated on the oil fraction of the binding medium and fungi deterioration activity was more abundant in the proteinaceous fraction. 

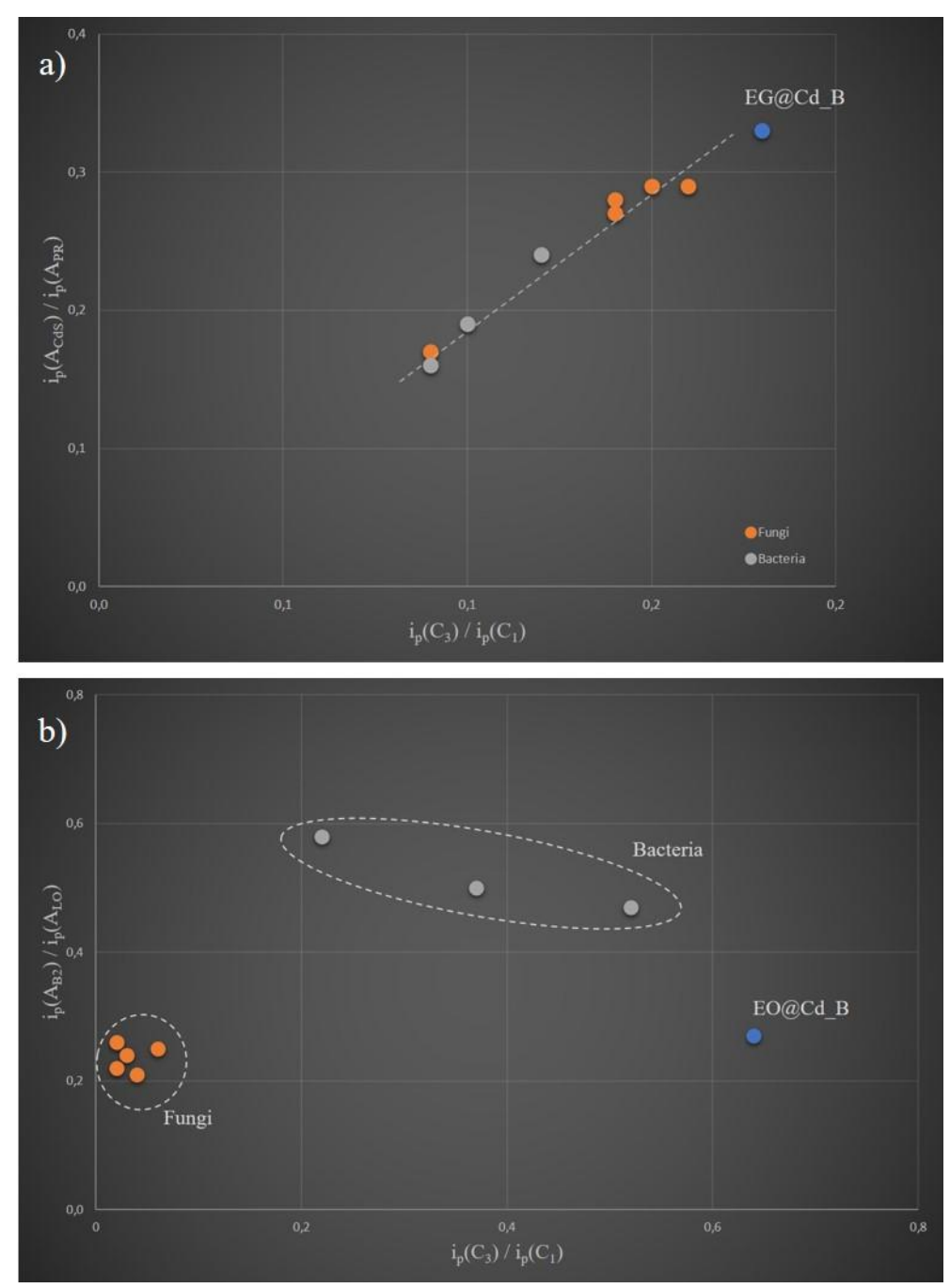

Figure 10.1.5.8.4.1. Plots of: a) $i_{\mathrm{p}}\left(A_{C d S}\right) / i_{\mathrm{p}}\left(A_{P R}\right)$ ratio vs. $i_{\mathrm{p}}\left(C_{3}\right) / i_{\mathrm{p}}\left(C_{l}\right)$ ratio of the series of inoculated egg tempera paint films and b) $i_{\mathrm{p}}\left(A_{B 2}\right) / i_{\mathrm{p}}\left(A_{L O}\right)$ ratio vs. $i_{\mathrm{p}}\left(C_{3}\right) / i_{\mathrm{p}}\left(C_{l}\right)$ ratio of the series of inoculated egg-oil emulsion paint films. Blue points: EG@Cd_B and EO@Cd_B; orange points: fungi-inoculated specimens; gray points: bacteria-inoculated specimens. 
Considering that the pictorial specimen layers studied are composed of a set of pigment grains $\mathrm{P}$ embedded into a binding medium $\mathrm{A}$, it can be assumed that pigment grains are partially surrounded by an ionomeric layer which results from the pigment-binder interaction. It will be assumed that the deterioration activity produced by a biological microorganisms $\mathrm{B}$, whose effective average concentration at a time $t$ after inoculation is $b(t)$. Based on the above-mentioned results, the main effect produced by the biological attack with microorganism is the degradation of the binder resulting in an increase of the fraction of exposed pigment and the ionomeric layer as well as the release of metal ions $\mathrm{M}^{2+}$ (where $\mathrm{M}=$ $\mathrm{Fe}, \mathrm{Cu}, \mathrm{Pb}$ and $\mathrm{Cd}$ the cases in this study) which at the same time exert a harmful effect on the biological agent.

To study the earlier short-time degradation stage when the initial population per volume unit $b_{0}$, is inoculated uniformly in the paint film, it will be assumed that during the interaction with the binder the population per volume unit of degrading biological agent grows. When the biological agent growth in a limited space, the population growth of B tends to a limiting concentration $b_{\text {lim. }}$. Then, let us assume that the biological agents are homogeneously distributed into a given area of the paint film specimens. Based on this hypothesis, the time evolution of the system will be studied assuming that in the system the involved time is long enough to homogenize: i) the distribution of the biological agent and ii) the released $\mathrm{M}^{2+}$ ions through the layer (i.e., neglecting biological agent migration and ion diffusive effects so that the system can be approximately treated in terms of homogeneous chemical kinetics). At the same time, this time is short enough to prevent the saturation of the biological agent on the paint film.

Then, the effective concentration of degraded binder, $a(t)$, can be expressed as a second-order rate law:

$$
\frac{\mathrm{d} a(t)}{\mathrm{d} t}=k_{\mathrm{ab}}\left[a_{\mathrm{o}}-a(t)\right] b(t)
$$

where $a_{\mathrm{o}}$ denotes the initial concentration of the binder in the paint film.

Consequently, the initial concentration of the inoculation $b_{0}$ of the biological agent $\mathrm{B}$, will follow a logistic curve, based on a mathematical approach widely used for describing growth processes (Su et al., 2016; Ibarra-Junquera et al., 2006; Ausloos and Petroni, 2009; Ausloos et al., 2011; Vitanov et a., 2010). Then, the concentration $b(t)$ of such agent at a time $t$ would be:

$$
\frac{\mathrm{d} b(t)}{\mathrm{d} t}=k_{\mathrm{b}} b(t)\left(b_{\mathrm{lim}}-b(t)\right)
$$


where $b_{\lim }$ denotes the maximum concentration of biological agent under the indicated conditions. Accordingly, the effective concentration of the biological agent at a time $t$ would be:

$$
b(t)=\frac{b_{o} b_{\max } e^{k_{b} t}}{b_{\max }-b_{o}\left(1-e^{k_{b} t}\right)}
$$

To reflect our experimental conditions, the rate law should incorporate the contribution of the time variation of the concentration of un-degraded binder and the deteriorating activity produced by the released $\mathrm{Pb}^{2+}$ ions. In this case, the resulting rate law can be expressed as:

$$
\frac{\mathrm{d} b(t)}{\mathrm{d} t}=k_{\mathrm{ab}}\left[a_{o}-a(t)\right] b(t)\left[b_{\mathrm{lim}}-b(t)\right]-k_{\mathrm{mb}} b(t) m(t)
$$

where $m(t)$ represents the concentration of $\mathrm{M}^{2+}$ ions released into the painting film (as 'free' ions and forming ionomeric layers around the pigment grains) as result of pigment biodeterioration. Accordingly, the rate laws for the effective concentration of exposed pigment, $p(t)$, and released metal ions, $m(t)$, can be expressed as:

$$
\begin{gathered}
\frac{\mathrm{d} p(t)}{\mathrm{d} t}=k_{\mathrm{ap}}\left[a_{o}-a(t)\right]\left[p_{o}-p(t)\right]-k_{\mathrm{mp}} p(t) m(t) \\
\frac{\mathrm{d} m(t)}{\mathrm{d} t}=k_{\mathrm{mp}} p(t) m(t)-k_{\mathrm{mb}} b(t) m(t)
\end{gathered}
$$

This means that the formation of exposed pigment grains and the release of metal ions forms can be regarded as consecutive processes. An approximate procedure for solving the above system of equations can be obtained upon considering that the sum of the concentrations of exposed pigment and the metal ions forming ionomeric coatings at a time $t$ equals to the corresponding sum at time zero, $p_{\mathrm{o}}+m_{\mathrm{o}}$ (i.e.: $p_{\mathrm{o}}+m_{\mathrm{o}}=p(t)+m(t)$ ). Then, if the population of biological agent is approximately fixed to its initial value, $b_{\mathrm{o}}$, Eq. (10.1.5.9.5) becomes:

$$
\frac{\mathrm{d} m(t)}{\mathrm{d} t}=\left[k_{\mathrm{mp}}\left(p_{\mathrm{o}}+m_{\mathrm{o}}\right)-k_{\mathrm{mb}} b_{\mathrm{o}}\right] m(t)-k_{\mathrm{mp}} m(t)^{2}
$$

Integration of Eq. (10.1.5.9.6) yields: 


$$
\ln \left[\frac{m(t)\left(R-m_{\mathrm{o}}\right)}{m_{\mathrm{o}}(R-m(t))}\right]=k_{\mathrm{mp}} t
$$

where $R=p_{\mathrm{o}}+m_{\mathrm{o}}-\left(k_{\mathrm{mb}} / k_{\mathrm{mp}}\right) b_{\mathrm{o}}$. The above equation corresponds to a logistic-type curve yielding for the concentration of released metallic species:

$$
m(t)=\frac{m_{\mathrm{o}} \operatorname{Re}^{\mathrm{k}_{\mathrm{mp}} \mathrm{t}}}{R-m_{\mathrm{o}}\left(1-e^{\mathrm{k}_{\mathrm{mp}} \mathrm{t}}\right)}
$$

Considering that the variation of concentration of exposed pigment is slow, $p(t)$ can be approximated by:

$$
p(t)=\frac{K_{a p} p_{o} a_{\mathrm{o}}\left[R-m_{o}\left(1-e^{\mathrm{k}_{\mathrm{mp}} \mathrm{t}}\right)\right]}{k_{m p} R m_{o} e^{k^{m p t}}-k_{a p} a_{\mathrm{o}}\left[R-m_{o}\left(1-e^{\mathrm{k}_{\mathrm{mp}} \mathrm{t}}\right)\right]}
$$

Taking into account the purpose of this study, is important to emphasize that voltammetric currents of peaks $\mathrm{C}_{1}$ and $\mathrm{C}_{2}$ in the studied paint specimens can be considered as representative of the concentrations $p(t)$ and $m(t)$; i.e.:

$$
\begin{array}{r}
i\left(\mathrm{C}_{1}\right)=g_{1} m(t) \\
i\left(\mathrm{C}_{2}\right)=g_{2} p(t)
\end{array}
$$

In the above presented equations, $g_{1}, g_{2}$, represent electrochemical constants depending on the specific response of the different metallic species used in this study and the amount of sample transferred onto the electrode surface.

Combining Eqs. (10.1.5.9.7) - (10.1.5.9.11), one obtains:

$$
\frac{i\left(C_{1}\right)}{i\left(C_{2}\right)}=\frac{g_{2}}{g_{1}} \frac{K_{a p} p_{\mathrm{o}} a_{\mathrm{o}} m_{o} e^{\mathrm{k}_{\mathrm{ab}} \mathrm{t}}}{k_{a p} a_{o}\left(m_{o}-R\right)+k_{a p} m_{o}\left(a_{o}-R\right) e^{\mathrm{k}_{\mathrm{ab}} \mathrm{t}}}=\frac{G e^{k_{m b} t}}{1+H e^{k_{m b} t}}
$$


The resulting equation corresponds to a s-shaped curve equivalent to a Verhulst-LotkaVolterra graph (Vitanov et al., 2010) and predicts a variation of the $i\left(\mathrm{C}_{1}\right) / i\left(\mathrm{C}_{2}\right)$ ratio with time. This equation can be correlated with the experimental data obtained inserting the appropriate values of the adjustable parameters $G, H$. The experimental data obtained for inoculation of egg tempera and egg oil emulsion reconstructed model paint specimens is depicted in the section 10.1.5.8. The results obtained for the EG specimen fitted well with the expected variation of $i\left(\mathrm{C}_{1}\right) / i\left(\mathrm{C}_{2}\right)$ on time according to Eq. (10.1.5.9.13) thus suggesting that, in spite of the number simplifying assumptions introduced in the model, it provides an in principle satisfactory description of experimental data.

In contrast, data for EO specimens differed clearly from the expected variation producing, as discussed previously (in section 10.1.5.8) a rapid growth of the $i\left(\mathrm{C}_{1}\right) / i\left(\mathrm{C}_{2}\right)$ ratio which subsequently appears to decay and is further lightly enhanced and stabilized. Apparently, in these specimens there is superposition between the proteinaceous and the oil fraction responses (described in Eqs. (10.1.5.9.2.4) - (10.1.5.9.13)), which requires a different treatement. In this case, the formation of exposed pigment particles and the release of metal forms are competing processes instead of consecutive. Accordingly, under the above conditions, integration of Eq. (10.1.5.9.4) yields:

$$
a(t)=a_{o}\left(1-e^{-k_{a b} b_{o} t}\right)
$$

If the release of metallic species is faster than the increment of exposed pigment, one can assume that the concentration of released metallic species grows proportionally to the degradation of the binder so that:

$$
\frac{i\left(C_{1}\right)}{i\left(C_{2}\right)}=U\left(1-e^{-v t}\right)
$$

where, as before, $U, v$ are adjustable parameters.

Finally, based on the experimental data obtained in this study, only a qualitative interpretation of the time variation of the $i\left(\mathrm{C}_{1}\right) / i\left(\mathrm{C}_{2}\right)$ ratio for EO specimens is possible. The initial variation can be fitted to Eq. (10.1.5.9.15), and the subsequent variation can be interpreted on assuming that, after this initial growing, the concentration of released lead species would decrease as a result of their consumption by the biological agent (always in the oil fraction). In the whole paint film, this decrease will be compensated by the slow increase of the $m(t) / p(t)$ ratio occurring in the proteinaceous fraction which will be predominating at long experimentation times. 


\subsubsection{Final considerations}

In view of the results obtained a possible explanation for the differences in the biological deterioration activity associated to the different pigments would be, in line with the foregoing set of considerations: i) the possible lower release of metal ions from the pigment grains, ii) the different transport ability of such ions in egg and egg oil films (Novakova et al., 2015); and iii) the possible major specificity of the toxic effect, which was more evident in the cadmium yellow and verdigris specimens, these last as highly unspecific (Mirkovik et al., 2015; Biswas et al., 2014; Montazerozohori et al., 2014, 2015; Negm et al., 2010). For our purposes, the relevant point to emphasize is that the biodegradation of paintings can be notably influenced in both the extent and the specificity of the biological attack by the nature of the pigment. 


\subsubsection{References}

Arjmand, F., Adriaens, A. (2012) Electrochemical quantification of copper-based alloys using voltammetry of microparticles: optimization of the experimental conditions. J Solid State Electrochem, 16, 535-543.

Ausloos, M., Petroni F. (2009) Statistical dynamics of religion evolutions. Physica A: Statistical Mechanics and its Applications, 388, 4438-4444.

Ausloss, M. (2011) Gompertz and Verhulst frameworks for growth and decay description. arXiv preprint arXiv:1109.1269.

Barisci, J.N., Wallace, G.G. and Baughman, R.H. (2000) Electrochemical studies of side-wall carbon nanotubes in aqueous solutions. Journal of Electroanalytical Chemistry, 488, 92-98.

Beltagi, A.M., Ghoneim, M.M. (2009) 2. Simultaneous determination of trace aluminum (III), copper (II) and cadmium (II) in water samples by square-wave adsorptive cathodic stripping voltammetry in the presence of oxide. J Appl Electrochem, 39, 627-636.

Biswas, F.B., Roy, T.G., Rahman, M.A., Emran, T.B. (2014) An in vitro antibacterial and antifungal effects of cadmium (II) complexes of hexamethyletraazacyclotetradecadiene and isomers of its saturated analogue. Asian Pac J Trop Med., 7, S534-S539.

Cepriá, G., García-Gareta, E., Pérez-Arantegui, J. (2005) Cadmium yellow detection and quantification by voltammetry of immobilized microparticles. Electroanalysis, 17, 10781084.

Chen, P., McCreery, R.L. (1996) Control of Electron Transfer Kinetics at Glassy Carbon. Electrodes by Specific Surface Modification. Anal. Chem., 68, 3958-3965.

Colletti, L.P., Teklay, D., Stickney, J.L. (1994) Thin-layer electrochemical studies of the oxidative underpotential deposition of sulfur and its application to the electrochemical atomic layer epitaxy deposition of CdS. J Electroanal Chem, 369, 145-152.

Doménech-Carbó, A., Doménech-Carbó, M.T., Gimeno, J.V., Bosch, F., Sauri, M.C., Sanchez, S. (2001) Electrochemistry of iron oxide pigments (earths) from pictorial microsamples attached to graphite/polyester composite electrodes. Analyst, 126, 1764-1772.

Doménech-Carbó, A., Doménech-Carbó, M.T., Edwards, H.G.M. (2007a) Identification of earth pigments in highly damaged frescoes by applying multivariative chemometric methods to solid state voltammetry. Electroanalysis, 19, 1890-1900.

Doménech-Carbó, A., Doménech-Carbó, M.T., Mas-Barberá, X. (2007b) Identification of lead pigments in nanosamples from ancient paintings and polychromed sculptures using voltammetry of nanoparticles/atomic force microscopy. Talanta, 71, 569-579.

Doménech-Carbó, A., Doménech-Carbó, M.T., Costa, V. (2009) Electrochemical methods for archaeometry, conservation and restoration (Monographs in Electrochemistry Series Scholz, F. (ed)), Springer, Berlin-Heidelberg. 
Doménech-Carbó, A. (2010) Electrochemistry for conservation science. J Solid State Electrochem, 14, 349-351.

Doménech-Carbó, A., Doménech-Carbó, M.T., Peiró-Ronda, M.A. (2011) Dating archaeological lead artifacts from measurement of the corrosion content using the voltammetry of microparticles. Anal. Chem., 83, 5639-5644.

Doménech-Carbó, A., Lastras, M., Rodriguez, F., Osete, L. (2013a) Mapping of corrosion products of highly altered archaeological iron using voltammetry of microparticles. Microchemical Journal, 106, 41-50.

Doménech-Carbó, A., Labuda, J., Scholz, F. (2013b) Electroanalytical chemistry for the analysis of solids: characterization and classification (IUPAC technical report). Pure Appl Chem, 85, 609-631.

Doménech-Carbó, A., Doménech-Carbó, M.T., Valle-Algarra, F.M., Gimeno-Adelantado, J.V., Osete-Cortina, L., Bosch-Reig, F. (2016) On-line database of voltammetric data of immobilized particles for identifying pigments and minerals in archaeometry, conservation and restoration (ELCHER database). Anal Chim Acta, 927, 1-12.

Guidelli, R., Becucci, L. (2011) Ion transport across biomembranes and model membranes. J Solid State Electrochem, 15, 1459-1470.

Gopalakrishna, M., Rao, M., Smith, F.R. (1972) Catalysis of electrolytic hydrogen evolution at lead by absorbed atomic hydrogen. J. Chem. Soc., Chem. Commun., 5, 266-268.

Gulaboski, R., Mirceski, V., Bogeski, I., Hoth, M. (2012) Protein film voltammetry: electrochemical enzymatic spectroscopy. A review on recent progress. J Solid State Electrochem, 16, 2315-2328.

Hasse, U., Scholz, F. (2001) In situ atomic force microscopy of the reduction of lead oxide nanocrystals immobilized on an electrode surface. Electrochem Commun, 3, 429-434.

Ibarra-Junquera, V., Monsivais, M.P., Rosú, H.C., López-Sandoval, R. (2006) A robust estimation of the exponent function in the Gompertz law. Physica A, 368, 225-231.

Komorsky-Lovric, S., Lovric M., Bond, A.M. (1992) Comparison of the square-wave stripping voltammetry of lead and mercury following their electrochemical or abrasive deposition onto a paraffin impregnated graphite electrode. Anal Chim Acta, 258, 299-305.

Koper, A., Grabarczyk, M. (2012) Simultaneous voltammetric determination of trace bismuth (III) and cadmium (II) in water samples by adsorptive stripping voltammetry in the presence of cupferron. J Electroanal Chem, 681, 1-5.

Kruusma, J., Nei, L., Hardcastle, J.L., Compton, R.G., Lust, E., Keis, H. (2004) Sonoelectroanalysis: anodic stripping voltammetric determination of cadmium in whole human blood. Electroanal, 16, 399-403. 
Lange, B., Scholz, F., Weiss, A., Shwedt, G., Behnert, J., Raezke, K-P. (1993) Abrasive stripping voltammetry. The electrochemical alternative for pigment analysis. Int Lab, 23, 2326.

Madani, A., Nessark, B., Boukherroub, R., Chehimi, M.M. (2011) Preparation and electrochemical behavior of PPy-CdS composite films. J Electroanal Chem, 650, 176-181.

Meepun, N., Siriket, S., Deimanee, S. (2012) Adsorptive stripping voltammetry for determination of cadmium in the presence of cupferron on a nafion-coated bismuth film electrode. Int J Electrochem Sci, 7, 10582-10591.

Meyer, B., Ziemer, B., Scholz, F. (1995) In situ X-ray diffraction study of the electrochemical reduction of tetragonal lead oxide and orthorhombic $\mathrm{Pb}(\mathrm{OH}) \mathrm{Cl}$ mechanically immobilized on a graphite electrode. J Electroanal Chem, 392, 79-83.

Mirkovic, B., Tanovic, B., Hrustic, J., Mihajlovic, M., Stevic, M., Delibasic, G., Vuksa, P., (2015) Toxicity of copper hydroxide, dithianon, fluazinam, tebuconazole and pyraclostrobin to Didymella applanata isolates from Serbia. J Environ Sci Health B, 50, 175-183.

Montazerozohori, M., Zahedi, S., Nasr-Esfahani, M., Naghiha, A. (2014) Some new cadmium complexes: antibacterial/antifungal activity and thermal behavior. J Ind Eng Chem, 20, 2463-2470.

Montazerozohori, M., Musari, S.A., Masoudiasl, A., Naghiga, A., Dusek, M., Kycerakova, M. (2015) Synthesis, spectral, crystal structure, thermal behavior, antimicrobial and DNA cleavage potential of two octahedral cadmium complexes: a supramolecular structure. Spectrochim Acta A., 137, 389-396.

Negm, N.A., Said, M.M., Morsey, S.M. (2010) Pyrazole derived cationic surfactants and their tin and copper complexes: synthesis activity, antibacterial and antifungal efficacy. J Surfact Deterg., 13, 521-528.

Novakova, K., Navratil, T., Sestakova, I., Lee, M.P., Vodickova, H., Zamecnikova, B., Sokolova, R., Bulickova, J., Gal, M. (2015) Characterization of cadmium ion transport across model and real biomembranes and indication of induced damage of plant tissues. Monatsch Chem Chem Mont., 146, 819-829.

Oliveira, M., Viswanathan, S., Morais, S., Delerue-Matos, C. (2012) Development of polyaniline microarray electrodes for cadmium analysis. Chem Papers, 66, 891-898.

Ortiz-Miranda, A.O., Doménech-Carbó, A., Doménech-Carbó, M.T., Osete-Cortina, L., Bolívar-Galiano, F., Martín-Sánchez, I. (2017) Analyzing chemical changes in verdigris pictorial specimens upon bacteria and fungi biodeterioration using voltammetry of microparticles. Heritage Science, 5, 8.

Panizza, M., Cerisola, G. (2003) Influence of anode material on the electrochemical oxidation of 2-naphthol: Part 1. Cyclic voltammetry and potential step experiments. Electrochim. Acta, $48,3491-3497$. 
Reregistration Eligibility Decision (RED) for Coppers. (2009) U.S. Environmental Protection Agency, Office of Prevention, Pesticides and Toxic Substances, Office of Pesticide Programs. Washington, D.C: U.S. Government Printing Office.

Rossi, M., Alamprese, C., Ratti, S. (2007) Tocopherols and tocotrienols as free radicalscavengers in refined vegetable oils and their stability during deep-fat frying. Food Chem, $102,812-817$.

Scholz, F., Schröder, U., Gulabowski, R., Doménech-Carbó, A. (2014) Electrochemistry of immobilized particles and Dropletst, $2^{\text {nd }}$ edition, Springer, Berlin-Heidelberg.

Su, K., Wang, C., Zhang, S., Liu, S. (2016) Lotka-Volterra equation based modeling of aerobic granulation process in sequencing batch reactors. Int. Biodeter. Biodegrad., 115, 4954.

Suciu, P., Vega, M., Roman, L. (2000) Determination of cadmium by differential pulse adsorptive stripping voltammetry. J Pharm Biomed Anal, 23, 99-106.

Sutherland, K., (2003) Solvent-Extractable components of linseed oil paint films. Stud Conserv, 48, 111-135.

Vitanov, N.K., Dimitrova, Z.I., Ausloos, M. (2010) Verhulst - Lotka - Volterra (VLV) model of ideological struggle. Physica A, 389, 4970-4980.

Wu, Y.M., Li, W.S., Long, X.M., Wu, F.H., Chen, H.Y., Yan, J.H., Zhang, C.R. (2005) Effect of bismuth o hydrogen evolution reaction on lead in sulfuric acid solution. J Power Sources, 144, 338-345.

Zakharchuk, N., Meyer, S., Lange B., Scholz, F. (2000) A comparative study of lead oxide modified graphite paste electrodes and solid graphite electrodes with mechanically immobilized lead oxides. Croat Chem Acta, 73, 667-704.

Zhang, W., Liu, Z., Zhu, S., Chen, J., Xu, G. (2010) Electrochemical stripping analysis of cadmium on tantalum electrode. Electrochem Commun, 12, 1291-1293.

Ziyatdinova, G., Morozov, M., Budnikov, H. (2012) MWNT-modified electrodes for voltammetric determination of lipophilic vitamins. J Solid State Electrochem, 16, 2441-2447. 


\section{FINAL CONCLUSIONS}




\section{Final Conclusions}

As summary of the final considerations established in the different sections of this $\mathrm{PhD}$ Project the following conclusions can be enunciated:

Study of interactions between pigment and binder:

- The study by FESEM has allowed to establish morphological differences between the different pigments and binders that can be determinant in the pictorial films behavior of pictorial films at the physico-chemical and microbiological level. In particular, differences have been observed in PVC, in the particle size and the aggregation state of the pigments which may have influenced in the cohesive properties of the binder.

- The FESEM technique has also allowed the identification of morphological characteristics of the tempera, in particular the granules and spheres characteristic of egg yolk as well as the different morphology of the lipidic and proteinic phases in the emulsion.

- The AFM-nanoindentation technique has been shown to be efficient in discriminating the relative mechanical properties of the different pictorial specimens at micro- and nano-scale, confirming the greater flexibility of the emulsion films and allowing to discriminate the effect of the different pigments in the mechanical properties at microscale of each of the pictorial techniques studied.

- FTIR spectroscopy has allowed the identification of changes in the secondary structure of egg proteins and has identified certain chemical transformations that take place between the pigment and each of the binders under study namely, release of fatty acids from triglyceride esters and the subsequent transformation into metal complexes as well as the complexation of the metal ions and with the acidic residues of the proteinic chains.

Study of biodeterioration:

- The FESEM study has allowed to establish the main micromorphological modifications induced by the different microorganisms in the different types of specimen studied, namely surface microerosion and appearance of protrusions associated with carboxylate type metal complexes. These alterations have taken place to a major extent in the egg tempera and, in particular, the complexation processes have been developed preferably with verdigris and lead white.

- The AFM technique has confirmed the observations made by FESEM. The application of the AFM-nanoindentation technique has shown, in general, a loss of flexibility (increase of $E$ ) in most specimens after inoculation with microorganisms that is associated with its deterioration activity. This deterioration activity has been shown to be more intense in the tempera than in the emulsion. It should be noted the atypical reduction in the value of $E$ observed in those specimens in which the growth of microorganism colonies was smaller and more irregular. This behavior is 
associated to the greater plasticizer effect exerted by the water of the aqueous suspension used as growth medium of the microorganism. The most efficient microorganisms in the loss of mechanical properties have been the fungi Acremonium chrysogenum and Penicillium chrysogenum; and the actinobacteria Arthrobacter oxydans and Streptomyces cellulofans.

- The FTIR spectroscopy has shown the changes induced by the deteriorating activity of microorganisms: fatty acid hydrolysis and its subsequent complexation with proteins and free fatty acids or the enzymatic transformation of the fatty acids to peroxides that are finally transformed into volatile compounds. These processes have been shown more intensely in tempera. The lower incidence of the microbial action in the emulsions despite its greater content in oil would be explained by the polymeric character of the molecules of triglyceride that makes difficult the microbial attack. Likewise, it has been possible to establish modifications in the secondary structure of the proteins as result of the microbial attack. The tempera series has shown the most significant changes while the most active pigments have been verdigris and lead white, probably due to their greater solubilization capacity. The most active species of microorganisms have been Acremonium chrysogenum in tempera and Penicillium chrysogenum in the emulsion; and the bacterium Streptomyces cellulofans.

- The electrochemical techniques have confirmed the previous effects observed with the other analytical techniques used, constituting a promising technique as a microinvasive alternative in the study of the biodeterioration of painting artworks. 


\section{ANNEXES}


Table 12.1. IR absorption band assignment for Y (pure egg yolk) specimen and Y @ Fe specimens prepared at 10, 30, 50 and 75 wt\%. Characteristics of the IR absorption bands referred to the $\mathrm{Y}$ specimen: sh: shoulder and sd: identified in the second derivative curve.

\begin{tabular}{|c|c|c|c|c|c|c|}
\hline \multicolumn{5}{|c|}{ Frequency $\left(\mathrm{cm}^{-1}\right)$} & \multirow{2}{*}{ IR bands assignment } & \multirow{2}{*}{ References } \\
\hline $\mathbf{Y}$ & $\mathbf{Y} @ \mathbf{F e}_{10}$ & $\mathbf{Y} @ \mathbf{F e}_{30}$ & $\mathbf{Y} @ \mathbf{F e}_{50}$ & $\mathbf{Y} @ \mathbf{F e}_{75}$ & & \\
\hline 3278 & 3278 & 3278 & 3278 & 3278 & Amide A, N-H stretch & Kong and Yu, 2007 \\
\hline 3069 & 3069 & 3069 & 3068 & 3068 & $\begin{array}{c}\text { Amide B, N-H Fermi resonance between amide II } \\
\text { overtone and N-H stretch }\end{array}$ & Kong and Yu, 2007 \\
\hline 3007 & 3007 & 3007 & - & - & $\begin{array}{l}\text { Cis-type unsaturated unconjugated C-H group } \\
(\mathrm{C}=\mathrm{C}-\mathrm{H} \text { stretch }) \text { in NLs and PLs }\end{array}$ & Meilunas et al., 1990 \\
\hline $2954^{\mathrm{sh}}$ & $2954^{\mathrm{sh}}$ & $2954^{\mathrm{sh}}$ & $2954^{\mathrm{sh}}$ & $2954^{\text {sh }}$ & Antisymmetric $\mathrm{CH}_{3}$ stretch & $\begin{array}{c}\text { van der Weerd et al., 2005; Meilunas et al., } \\
\text { 1990; Tantipolphan et al., } 2007\end{array}$ \\
\hline 2922 & 2922 & 2920 & 2920 & 2917 & Antisymmetric $\mathrm{CH}_{2}$ stretch & $\begin{array}{r}\text { van der Weerd et al., 2005; Meilunas et al., } \\
\text { 1990; Cagnasso et al., 2010; Tantipolphan } \\
\text { et al., 2007 }\end{array}$ \\
\hline $2872^{\text {sh }}$ & $2872^{\text {sh }}$ & $2872^{\text {sh }}$ & $2872^{\text {sh }}$ & $2872^{\text {sh }}$ & Symmetric stretch $\mathrm{CH}_{3}$ & Mazzeo et al., 2008 \\
\hline 2852 & 2852 & 2850 & 2850 & 2850 & Symmetric stretch $\mathrm{CH}_{2}$ & $\begin{array}{l}\text { van der Weerd et al., 2005; Meilunas et al., } \\
\text { 1990; Cagnasso et al., 2010; Tantipolphan } \\
\text { et al., 2007; Jackson and Mantsch, } 1992\end{array}$ \\
\hline 1743 & 1743 & 1741 & 1741 & 1740 & $-\mathrm{C}=\mathrm{O}$ stretch in NLs & $\begin{array}{l}\text { van der Weerd et al., 2005; Meilunas et al., } \\
1990\end{array}$ \\
\hline $1736^{\text {sh, sd }}$ & $1736^{\text {sh, sd }}$ & $1732^{\text {sh, sd }}$ & $1732^{\text {sh, sd }}$ & $1732^{\text {sh, sd }}$ & $\begin{array}{c}-\mathrm{C}=\mathrm{O} \text { stretch in PLs and in triglyceride derived } \\
\text { aldehydes and carbonyl moieties }\end{array}$ & $\begin{array}{c}\text { Cagnasso et al., 2010; Tantipolphan et al., } \\
\text { 2007; van der Weerd et al., 2005; Meilunas } \\
\text { et al., 1990 }\end{array}$ \\
\hline $1719^{\text {sh, sd }}$ & $1719^{\text {sh, sd }}$ & $1717^{\text {sh, sd }}$ & $1716^{\text {sh, sd }}$ & $1715^{\text {sh, sd }}$ & $\begin{array}{l}-\mathrm{C}=\mathrm{O} \text { stretch in triglycerides and glycerol-diacyl } \\
\text { esters; in carboxylic acids and in imide linkage } \\
\text { derived by oxidation of protein amide linkages }\end{array}$ & $\begin{array}{l}\text { van der Weerd et al., 2005; Meilunas et al., } \\
1990\end{array}$ \\
\hline- & - & - & $1709^{\text {sh, sd }}$ & $1709^{\text {sh, sd }}$ & $-\mathrm{C}=\mathrm{O}$ stretch in carboxylic acids & Meilunas et al., 1990 \\
\hline $1692^{\text {sh, sd }}$ & $1692^{\text {sh, sd }}$ & $1692^{\mathrm{sh}, \mathrm{sd}}$ & $1692^{\text {sh, sd }}$ & $1692^{\mathrm{sh}, \mathrm{sd}}$ & $\begin{array}{c}\text { Amide I a) turns and bends in proteins HDL and } \\
\text { LDL; b) antiparallel } \beta \text {-sheet in proteins: albumin and } \\
\text { livetins }\end{array}$ & $\begin{array}{l}\text { Susi and Byler, 1986; López et al., 2000; } \\
\text { Kong and Yu, 2007; Haris and Severcan, } \\
\text { 1999; Furlan et al., 2007; Ulrichs et al., } \\
\text { 2014 }\end{array}$ \\
\hline $1683^{\text {sh, sd }}$ & $1683^{\text {sh, sd }}$ & $1683^{\text {sh, sd }}$ & $1683^{\text {sh, sd }}$ & $1683^{\text {sh, sd }}$ & $\begin{array}{l}\text { Amide I turns and bends in proteins: livetins, } \\
\beta \text {-sheet/turns in LDL and HDL }\end{array}$ & $\begin{array}{l}\text { Kong and Yu, 2007; Dong et al., 1990; } \\
\text { Susi and Byler, 1986; Cabiaux et al., 1989; } \\
\text { Ulrichs et al., 2014; López et al., 2000 } \\
\end{array}$ \\
\hline $1673^{\mathrm{sh}, \mathrm{sd}}$ & $1673^{\text {sh, sd }}$ & $1674^{\text {sh, sd }}$ & $1674^{\text {sh, sd }}$ & $1674^{\text {sh, sd }}$ & $\begin{array}{l}\text { Amide I turns and bends in proteins: livetins, } \beta \text { - } \\
\text { sheet/turns in LDL and HDL }\end{array}$ & $\begin{array}{l}\text { Kong and Yu, 2007; Dong et al., 1990; } \\
\text { Susi and Byler, 1986; Cabiaux et al., 1989; }\end{array}$ \\
\hline
\end{tabular}




\begin{tabular}{|c|c|c|c|c|c|c|}
\hline & & & & & & Ulrichs et al., 2014; López et al., 2000 \\
\hline $1668^{\text {sh, sd }}$ & $1668^{\text {sh, sd }}$ & $1668^{\text {sh, sd }}$ & $1668^{\text {sh, sd }}$ & $1668^{\text {sh, sd }}$ & Amide I turns and bends in proteins livetins & $\begin{array}{c}\text { Kong and Yu, 2007; Dong et al., 1990; } \\
\text { Susi and Byler, 1986; Cabiaux et al., 1989; } \\
\text { Ulrichs et al., } 2014\end{array}$ \\
\hline $1661^{\mathrm{sh}, \mathrm{sd}}$ & $1661^{\text {sh, sd }}$ & $1661^{\text {sh, sd }}$ & $1661^{\text {sh, sd }}$ & $1661^{\text {sh, sd }}$ & $\begin{array}{l}\text { Amide I: a) } \alpha \text {-helix in proteins; b) turns in livetins } \\
\text { and LDL and HDL }\end{array}$ & $\begin{array}{l}\text { Cabiaux et al., 1989; Kong and Yu, 2007; } \\
\text { Ulrichs et al., 2014; López et al., } 2000\end{array}$ \\
\hline $1657^{\text {sh, sd }}$ & $1657^{\text {sh, sd }}$ & $1657^{\text {sh, sd }}$ & $1657^{\text {sh, sd }}$ & $1657^{\text {sh, sd }}$ & $\begin{array}{c}\text { Amide I: a) } \alpha \text {-helix in proteins; b) turns in livetins } \\
\text { and LDL and HDL }\end{array}$ & $\begin{array}{l}\text { Cabiaux et al., 1989; Kong and Yu, 2007; } \\
\text { Ulrichs et al., 2014; López et al., } 2000\end{array}$ \\
\hline 1652 & 1652 & 1652 & 1651 & 1651 & $\begin{array}{c}\text { Amide I } \alpha \text {-helix in proteins, membrane proteins, } \\
\text { livetins and HDL }\end{array}$ & $\begin{array}{l}\text { Kong and Yu, 2007; Haris and Severcan, } \\
\text { 1999; Dong et al., 1990; Susi and Byler, } \\
\text { 1986; Cabiaux et al., 1989; Ulrichs et al., } \\
\text { 2014; López et al., } 2000\end{array}$ \\
\hline $1648^{\text {sh, sd }}$ & $1648^{\mathrm{sh}, \mathrm{sd}}$ & $1648^{\text {sh, sd }}$ & $1648^{\text {sh, sd }}$ & $1648^{\text {sh, sd }}$ & $\begin{array}{l}\text { Amide I: a) } \alpha \text {-helix in proteins: albumin, livetins } \\
\text { and HDL and LDL; b) }-\mathrm{C}=\mathrm{C} \text { - in fatty acids and NLs }\end{array}$ & $\begin{array}{l}\text { Susi and Byler et al., 1986; Cabiaux et al., } \\
\text { 1989; Furlan et al., 2007; Ulrichs et al., } \\
\text { 2014; López et al., 2000; van der Weerd et } \\
\text { al., 2005 }\end{array}$ \\
\hline $1644^{\text {sh, sd }}$ & $1644^{\text {sh, sd }}$ & $1644^{\text {sh, sd }}$ & $1645^{\text {sh, sd }}$ & $1645^{\text {sh, sd }}$ & $\begin{array}{l}\text { Amide I random coils in proteins: albumin and } \\
\text { livetins }\end{array}$ & $\begin{array}{l}\text { Cabiaux et al., 1989; Furlan et al., 2007; } \\
\text { Ulrichs et al., 2014; López et al., 2000 }\end{array}$ \\
\hline $1633^{\text {sh, sd }}$ & $1633^{\text {sh, sd }}$ & $1633^{\text {sh, sd }}$ & $1633^{\text {sh, sd }}$ & $1633^{\text {sh, sd }}$ & $\begin{array}{l}\text { Amide I } \beta \text {-sheet and intramolecular } \beta \text {-sheet in } \\
\text { livetins }\end{array}$ & $\begin{array}{l}\text { Kong and Yu, 2007; Haris and Severcan, } \\
\text { 1999; Dong et al., 1990; Susi and Byler, } \\
\text { 1986; Furlan et al., 2007; Ulrichs et al., } \\
\text { 2014) }\end{array}$ \\
\hline 1629 & 1629 & 1629 & 1629 & - & $\begin{array}{c}\text { Amide I } \beta \text {-sheet in proteins: HDL and intramolecular } \\
\qquad \beta \text {-sheet in livetins }\end{array}$ & $\begin{array}{l}\text { Kong and Yu, 2007; Harris and Severcan, } \\
\text { 1999; Dong et al., 1990; Goormaghtigh et } \\
\text { al., 2009; López et al., 2000; Ulrichs et al., } \\
2014\end{array}$ \\
\hline $1625^{\text {sh, sd }}$ & $1625^{\text {sh, sd }}$ & $1626^{\text {sh, sd }}$ & $1627^{\text {sh, sd }}$ & $1628^{\text {sh, sd }}$ & $\begin{array}{c}\text { Amide I } \beta \text {-sheet in proteins: HDL and intramolecular } \\
\qquad \beta \text {-sheet in livetins }\end{array}$ & $\begin{array}{l}\text { Kong and Yu, 2007; Harris and Severcan, } \\
\text { 1999; Dong et al., 1990; Goormaghtigh et } \\
\text { al., 2009; López et al., 2000; Ulrichs et al., } \\
2014\end{array}$ \\
\hline $1621^{\text {sh, sd }}$ & $1621^{\mathrm{sh}, \mathrm{sd}}$ & $1621^{\text {sh, sd }}$ & $1621^{\mathrm{sh}, \mathrm{sd}}$ & $1621^{\text {sh, sd }}$ & $\begin{array}{l}\text { Amide I } \beta \text {-sheets in proteins; intermolecular } \beta \text {-sheet } \\
\text { in livetins and antiparallel } \beta \text {-sheet in albumin }\end{array}$ & $\begin{array}{c}\text { Kong and Yu, 2007; Harris and Severcan, } \\
\text { 1999; Ulrichs et al., 2014; Furlan et al., } \\
2007\end{array}$ \\
\hline
\end{tabular}




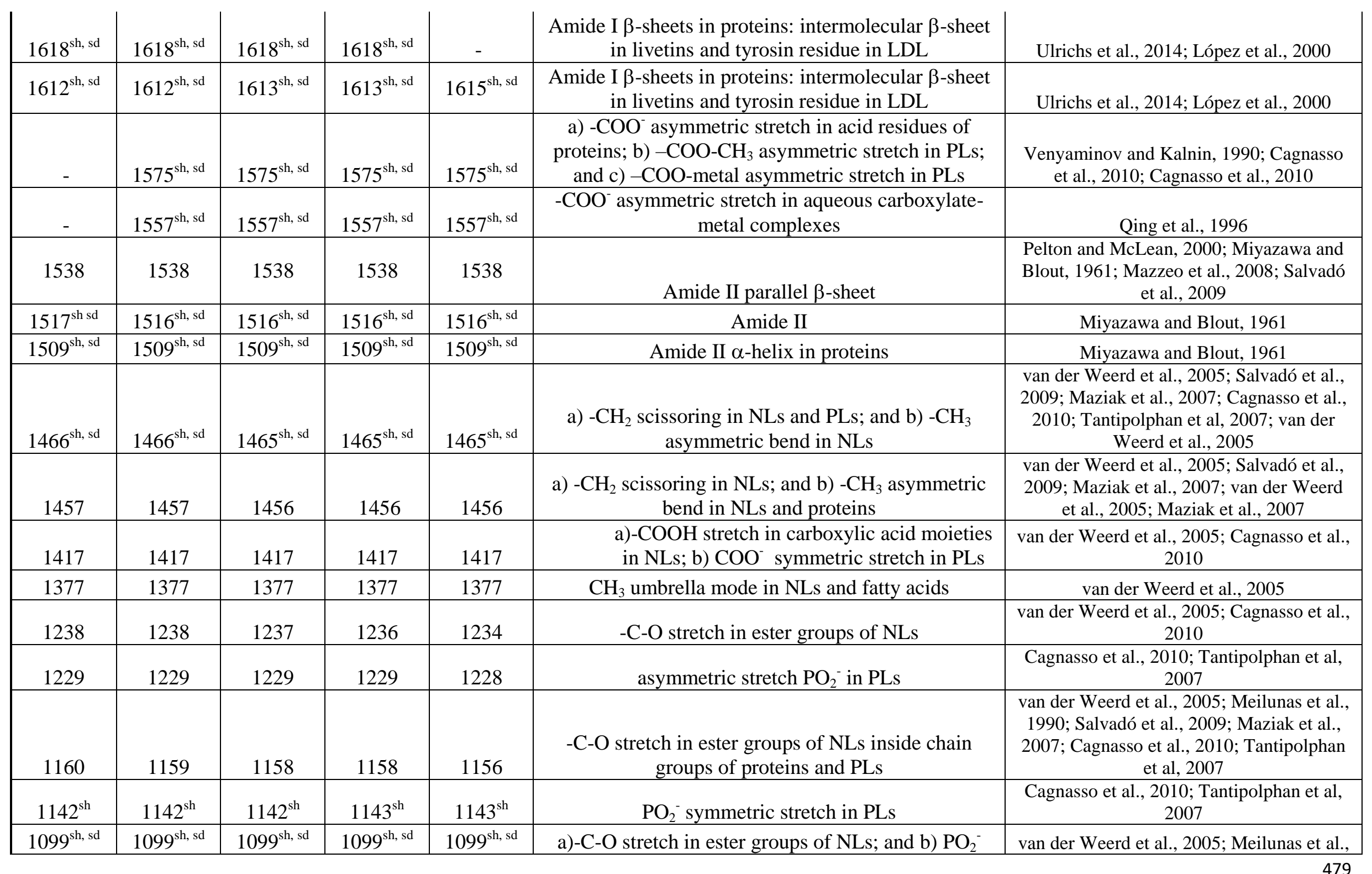




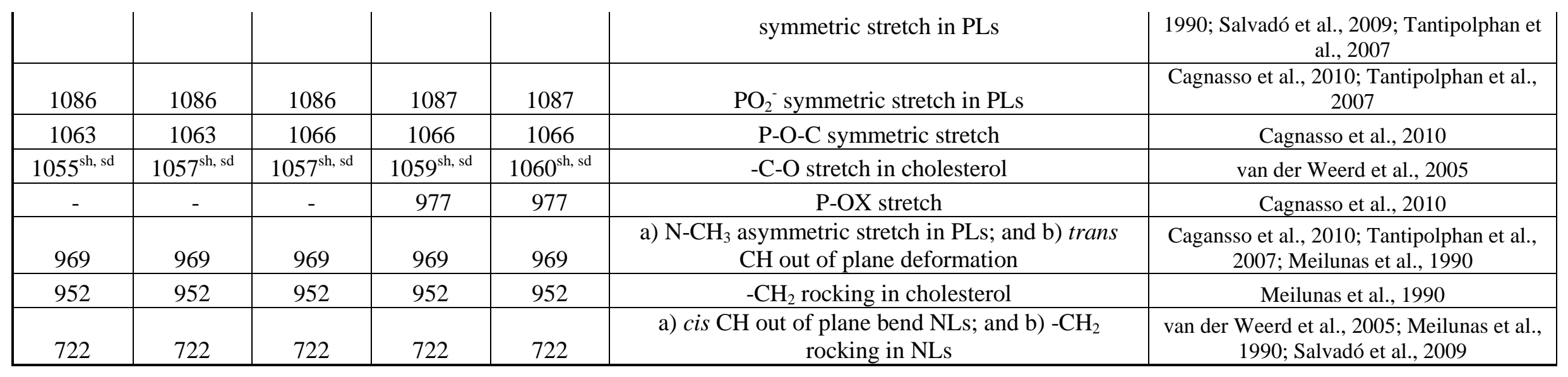


Table 12.2. IR absorption band assignment for Y (pure egg yolk) specimen and Y @ Pbm specimens prepared at 10, 30, 50 and 75 wt\%.

Characteristics of the IR absorption bands referred to the Y specimen: sh: shoulder and sd: identified in the second derivative curve.

\begin{tabular}{|c|c|c|c|c|c|c|}
\hline \multicolumn{5}{|c|}{ Frequency $\left(\mathrm{cm}^{-1}\right)$} & \multirow{2}{*}{ IR bands assignment } & \multirow{2}{*}{ References } \\
\hline $\mathbf{Y}$ & $\mathbf{Y} @ \mathbf{P b m}_{10}$ & $\mathbf{Y} @ \mathbf{P b m}_{30}$ & $\mathbf{Y} @ \mathbf{P b m}_{50}$ & $\mathbf{Y} @ \mathbf{P b m}_{75}$ & & \\
\hline- & - & - & $3525^{\text {sh }}$ & $3525^{\text {sh }}$ & OH- stretch secondary alcohols & Meilunas et al., 1990 \\
\hline 3278 & 3278 & 3278 & 3278 & 3278 & Amide A, N-H stretch & Kong and Yu, 2007 \\
\hline 3069 & 3069 & 3069 & 3069 & 3068 & $\begin{array}{c}\text { Amide B, N-H Fermi resonance between amide II } \\
\text { overtone and N-H stretch }\end{array}$ & Kong and $\mathrm{Yu}, 2007$ \\
\hline 3007 & 3007 & 3007 & 3007 & - & $\begin{array}{l}\text { Cis-type unsaturated unconjugated C-H group } \\
(\mathrm{C}=\mathrm{C}-\mathrm{H} \text { stretch) in NLs and PLs }\end{array}$ & Meilunas et al., 1990 \\
\hline $2954^{\text {sh }}$ & $2954^{\text {sh }}$ & $2954^{\text {sh }}$ & $2954^{\text {sh }}$ & $2954^{\text {sh }}$ & Antisymmetric $\mathrm{CH}_{3}$ stretch & $\begin{array}{l}\text { van der Weerd et al., 2005; Meilunas et } \\
\text { al., 1990; Tantipolphan et al., } 2007\end{array}$ \\
\hline 2922 & 2922 & 2922 & 2921 & 2920 & Antisymmetric $\mathrm{CH}_{2}$ stretch & $\begin{array}{l}\text { van der Weerd et al., 2005; Meilunas et } \\
\text { al., 1990; Cagnasso et al., 2010; } \\
\text { Tantipolphan et al., } 2007\end{array}$ \\
\hline $2872^{\text {sh }}$ & $2872^{\text {sh }}$ & $2872^{\text {sh }}$ & $2872^{\text {sh }}$ & $2872^{\text {sh }}$ & Symmetric stretch $\mathrm{CH}_{3}$ & Mazzeo et al., 2008 \\
\hline 2852 & 2852 & 2852 & 2852 & 2852 & Symmetric stretch $\mathrm{CH}_{2}$ & $\begin{array}{c}\text { van der Weerd et al., 2005; Meilunas et } \\
\text { al., 1990; Cagnasso et al., 2010; } \\
\text { Tantipolphan et al., 2007; Jackson and } \\
\text { Mantsch, } 1992 \\
\end{array}$ \\
\hline- & - & - & - & $1770^{\text {sh }}$ & $-\mathrm{C}=\mathrm{O}$ stretch (lactone) in NLs & Meilunas et al., 1990 \\
\hline 1743 & 1743 & 1743 & 1743 & 1740 & $-\mathrm{C}=\mathrm{O}$ stretch in NLs & $\begin{array}{l}\text { van der Weerd et al., 2005; Meilunas et } \\
\text { al., } 1990\end{array}$ \\
\hline $1736^{\text {sh, sd }}$ & $1736^{\text {sh, sd }}$ & $1736^{\text {sh, sd }}$ & $1736^{\text {sh, sd }}$ & $1736^{\text {sh, sd }}$ & $\begin{array}{c}-\mathrm{C}=\mathrm{O} \text { stretch in PLs and in triglyceride derived } \\
\text { aldehydes and carbonyl moieties }\end{array}$ & $\begin{array}{l}\text { Cagnasso et al., 2010; Tantipolphan et al., } \\
\text { 2007; van der Weerd et al., 2005; } \\
\text { Meilunas et al., } 1990\end{array}$ \\
\hline $1719^{\text {sh, sd }}$ & $1719^{\text {sh, sd }}$ & $1719^{\text {sh, sd }}$ & $1719^{\text {sh, sd }}$ & $1719^{\text {sh, sd }}$ & $\begin{array}{l}-\mathrm{C}=\mathrm{O} \text { stretch in triglycerides and glycerol-diacyl } \\
\text { esters in carboxylic acids and in imide linkage } \\
\text { derived by oxidation of protein amide linkages }\end{array}$ & $\begin{array}{l}\text { van der Weerd et al., 2005; Meilunas et } \\
\text { al., } 1990\end{array}$ \\
\hline- & - & - & - & 1713 & $-\mathrm{C}=\mathrm{O}$ stretch in carboxylic acids & Meilunas et al., 1990 \\
\hline $1692^{\mathrm{sh}, \mathrm{sd}}$ & $1692^{\text {sh, sd }}$ & $1692^{\text {sh, sd }}$ & $1692^{\text {sh, sd }}$ & $1692^{\text {sh, sd }}$ & $\begin{array}{l}\text { Amide I: a) turns and bends in proteins HDL and } \\
\text { LDL; b) antiparallel } \beta \text {-sheet in proteins: albumin }\end{array}$ & $\begin{array}{l}\text { Susi and Byler, 1986; López et al., 2000; } \\
\text { Furlan et al., 2007; Kong and Yu, 2007; }\end{array}$ \\
\hline
\end{tabular}




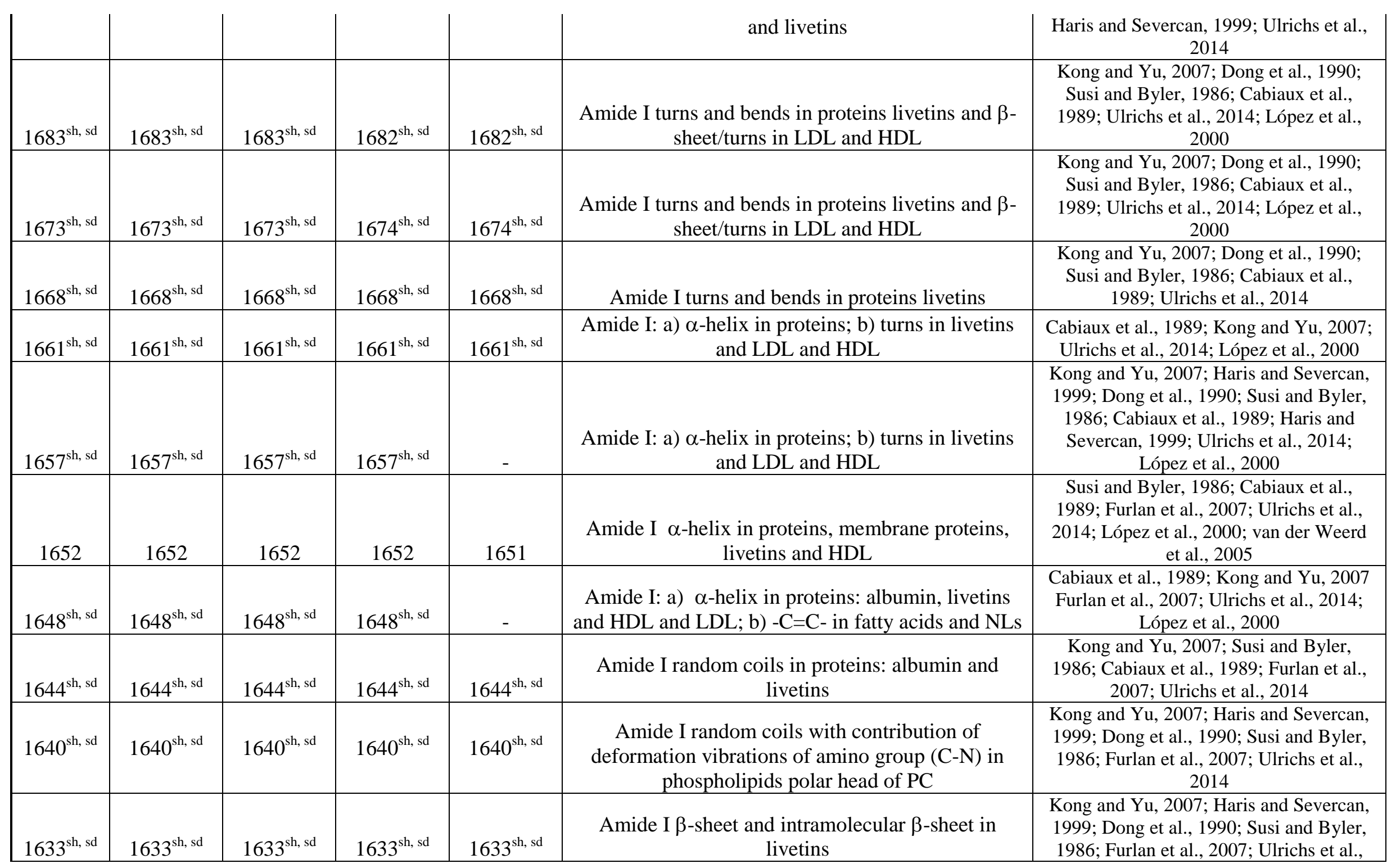




\begin{tabular}{|c|c|c|c|c|c|c|}
\hline & & & & & & 2007 \\
\hline 1629 & 1629 & 1629 & 1629 & - & $\begin{array}{l}\text { Amide I } \beta \text {-sheet in proteins: HDL and } \\
\text { intramolecular } \beta \text {-sheet in livetins }\end{array}$ & $\begin{array}{l}\text { Kong and Yu, 2007; Haris and Severcan, } \\
\text { 1999; Dong et al., 1990; Susi and Byler, } \\
\text { 1986; Goormaghtigh et al., 2009; López } \\
\text { et al., 2000; Ulrichs et al., 2014 }\end{array}$ \\
\hline $1621^{\mathrm{sh}, \mathrm{sd}}$ & $1621^{\mathrm{sh}, \mathrm{sd}}$ & $1621^{\mathrm{sh}, \mathrm{sd}}$ & $1621^{\mathrm{sh}, \mathrm{sd}}$ & $1620^{\mathrm{sh}, \mathrm{sd}}$ & $\begin{array}{l}\text { Amide I } \beta \text {-sheets in proteins; intermolecular } \beta \text { - } \\
\text { sheet in livetins and antiparallel } \beta \text {-sheet in albumin }\end{array}$ & $\begin{array}{c}\text { Kong and Yu, 2007; Rajkhowa et al., } \\
\text { 2012; Ulrichs et al., 2014; Furlan et al., } \\
\text { 2007 }\end{array}$ \\
\hline $1618^{\mathrm{sh}, \mathrm{sd}}$ & $1618^{\mathrm{sh}, \mathrm{sd}}$ & $1618^{\mathrm{sh}, \mathrm{sd}}$ & $1618^{\mathrm{sh}, \mathrm{sd}}$ & $1618^{\text {sh, sd }}$ & $\begin{array}{l}\text { Amide I } \beta \text {-sheets in proteins: intermolecular } \beta \text { - } \\
\text { sheet in livetins and tyrosin residue in LDL }\end{array}$ & Ulrichs et al., 2014; López et al., 2000 \\
\hline $1612^{\text {sh, sd }}$ & $1612^{\text {sh, sd }}$ & $1612^{\text {sh, sd }}$ & $1612^{\text {sh, sd }}$ & $1613^{\text {sh, sd }}$ & $\begin{array}{l}\text { Amide I } \beta \text {-sheets in proteins: intermolecular } \beta \text { - } \\
\text { sheet in livetins and tyrosin residue in LDL }\end{array}$ & Ulrichs et al., 2014; López et al., 2000 \\
\hline- & - & - & $1575^{\text {sh, sd }}$ & $1574^{\text {sh, sd }}$ & $\begin{array}{l}\text { a) - } \mathrm{COO}^{-} \text {asymmetric stretch in acid residues of } \\
\text { proteins; b) - } \mathrm{COO}-\mathrm{CH}_{3} \text { asymmetric stretch in PLs; } \\
\text { and c) }-\mathrm{COO}-\text { metal asymmetric stretch in PLs }\end{array}$ & $\begin{array}{c}\text { Venyaminov and Kalnin, 1990; Cagnasso } \\
\text { et al., } 2010\end{array}$ \\
\hline $1517^{\text {sh sd }}$ & $1517^{\text {sh sd }}$ & $1517^{\text {sh sd }}$ & $1516^{\text {sh sd }}$ & $1515^{\text {sh, sd }}$ & Amide II & Miyazawa et al., 1961 \\
\hline $1509^{\text {sh, sd }}$ & $1509^{\text {sh, sd }}$ & $1509^{\text {sh, sd }}$ & $1510^{\text {sh, sd }}$ & $1510^{\text {sh, sd }}$ & Amide II $\alpha$-helix in proteins & Miyazawa et al., 1961 \\
\hline $1466^{\mathrm{sh}, \mathrm{sd}}$ & $1466^{\text {sh, sd }}$ & $1466^{\text {sh, sd }}$ & $1465^{\text {sh, sd }}$ & $1464^{\text {sh, sd }}$ & $\begin{array}{l}\text { a) }-\mathrm{CH}_{2} \text { scissoring in NLs and PLs; and b) }-\mathrm{CH}_{3} \\
\text { asymmetric bend in NLs }\end{array}$ & $\begin{array}{l}\text { van der Weerd et al., 2005; Salvadó et al., } \\
\text { 2009; Maziak et al., 2007; Cagnasso et } \\
\text { al., 2010; Tantipolphan et al., 2007; van } \\
\text { der Weerd et al., 2005 }\end{array}$ \\
\hline 1457 & 1457 & 1457 & 1456 & 1456 & $\begin{array}{c}\text { a) }-\mathrm{CH}_{2} \text { scissoring in NLs; and b) }-\mathrm{CH}_{3} \text { asymmetric } \\
\text { bend in NLs and proteins }\end{array}$ & $\begin{array}{l}\text { van der Weerd et al., 2005; Salvadó et al., } \\
\text { 2009; Maziak et al., 2007; van der Weerd } \\
\text { et al., 2005; Maziak et al., } 2007\end{array}$ \\
\hline 1417 & 1417 & 1417 & 1417 & 1417 & $\begin{array}{l}\text { a)-COOH stretch in carboxylic acid moieties in } \\
\mathrm{NLs} \text {; b) } \mathrm{COO}^{-} \text {symmetric stretch in PLs }\end{array}$ & $\begin{array}{l}\text { van der Weerd et al., 2005; Cagnasso et } \\
\text { al., } 2010\end{array}$ \\
\hline
\end{tabular}




\begin{tabular}{|c|c|c|c|c|c|c|}
\hline 1377 & 1377 & 1377 & 1377 & 1377 & $\mathrm{CH}_{3}$ umbrella mode in NLs and fatty acids & van der Weerd et al., 2005 \\
\hline 1238 & 1238 & 1238 & 1236 & 1234 & $-\mathrm{C}-\mathrm{O}$ stretch in ester groups of NLs & $\begin{array}{l}\text { van der Weerd et al., 2005; Salvadó et al., } \\
2009\end{array}$ \\
\hline 1229 & 1229 & 1229 & 1228 & 1228 & Asymmetric stretch $\mathrm{PO}_{2}^{-}$in PLs & $\begin{array}{l}\text { Cagansso et al., 2010; Tantipolphan et al., } \\
2007\end{array}$ \\
\hline 1160 & 1160 & 1160 & 1157 & 1156 & $\begin{array}{c}-\mathrm{C}-\mathrm{O} \text { stretch in ester groups of NLs inside chain } \\
\text { groups of proteins, and PLs }\end{array}$ & $\begin{array}{c}\text { van der Weerd et al., 2005; Meilunas et } \\
\text { al., 1990; Salvadó et al., 2009; Maziak et } \\
\text { al., 2007; Cagansso et al., 2010; } \\
\text { Tantipolphan et al., } 2007 \\
\end{array}$ \\
\hline $1142^{\text {sh }}$ & $1142^{\mathrm{sh}}$ & $1142^{\text {sh }}$ & $1142^{\text {sh }}$ & $1144^{\text {sh }}$ & $\mathrm{PO}_{2}^{-}$symmetric stretch in PLs & Tantipolphan et al., 2007 \\
\hline $1099^{\text {sh, sd }}$ & $1099^{\text {sh, sd }}$ & $1099^{\text {sh, sd }}$ & $1099^{\text {sh, sd }}$ & $1099^{\text {sh, sd }}$ & $\begin{array}{l}\text { a)-C-O stretch in ester groups of NLs; and b) } \mathrm{PO}_{2}^{-} \\
\text {symmetric stretch in PLs }\end{array}$ & $\begin{array}{c}\text { van der Weerd et al., 2005; Meilunas et } \\
\text { al., 1990; Salvadó et al., 2009; } \\
\text { Tantipolphan et al., } 2007\end{array}$ \\
\hline 1086 & 1086 & 1086 & 1088 & 1088 & $\mathrm{PO}_{2}^{-}$symmetric stretch in PLs & $\begin{array}{l}\text { Cagansso et al., 2010; Tantipolphan et al., } \\
2007\end{array}$ \\
\hline 1063 & 1063 & 1065 & 1066 & 1067 & P-O-C symmetric stretch & Cagnasso et al., 2010 \\
\hline $1055^{\text {sh, sd }}$ & $1055^{\text {sh, sd }}$ & $1055^{\text {sh, sd }}$ & $1055^{\text {sh, sd }}$ & $1060^{\text {sh, sd }}$ & -C-O stretch in cholesterol & van der Weerd et al., 2005 \\
\hline- & - & - & 979 & 980 & $\mathrm{P}-\mathrm{OX}$ stretch & Cagnasso et al., 2010 \\
\hline 969 & 969 & 969 & 969 & 969 & $\begin{array}{l}\text { a) } \mathrm{N}_{-} \mathrm{CH}_{3} \text { asymmetric stretch in PLs; and b) trans } \\
\mathrm{CH} \text { out of plane deformation }\end{array}$ & $\begin{array}{l}\text { Cagansso et al., 2010; Tantipolphan et al., } \\
\text { 2007; Meilunas et al, } 1990\end{array}$ \\
\hline 952 & 952 & 952 & 951 & 951 & $-\mathrm{CH}_{2}$ rocking in cholesterol & Meilunas et al., 1990 \\
\hline 722 & 722 & 722 & 722 & 722 & $\begin{array}{l}\text { a) cis } \mathrm{CH} \text { out of plane bend NLs; and b) }-\mathrm{CH}_{2} \\
\text { rocking in NLs }\end{array}$ & $\begin{array}{l}\text { van der Weerd et al., 2005; Meilunas et } \\
\text { al., 1990; Salvadó et al., } 2009\end{array}$ \\
\hline
\end{tabular}


Table 12.3. IR absorption band assignment for Y (pure egg yolk) specimen and Y @Zn specimens prepared at 10, 30, 50 and 75 wt\%.

Characteristics of the IR absorption bands referred to the Y specimen: sh: shoulder and sd: identified in the second derivative curve.

\begin{tabular}{|c|c|c|c|c|c|c|}
\hline \multicolumn{5}{|c|}{ Frequency $\left(\mathrm{cm}^{-1}\right)$} & \multirow{2}{*}{ IR bands assignment } & \multirow{2}{*}{ References } \\
\hline $\mathbf{Y}$ & $\mathbf{Y} @ \mathbf{Z n}_{10}$ & $\mathbf{Y} @ \mathbf{Z n}_{30}$ & $\mathbf{Y} @ \mathbf{Z n}_{\mathbf{5 0}}$ & $\mathbf{Y} @ \mathbf{Z n}_{75}$ & & \\
\hline 3278 & 3278 & 3278 & 3278 & 3278 & Amide A, N-H stretch & Kong and Yu, 2007 \\
\hline 3069 & 3069 & 3068 & 3068 & 3068 & $\begin{array}{l}\text { Amide B, N-H Fermi resonance between amide } \\
\text { II overtone and N-H stretch }\end{array}$ & Kong and $\mathrm{Yu}, 2007$ \\
\hline 3007 & 3007 & 3007 & 3002 & - & $\begin{array}{l}\text { Cis-type unsaturated unconjugated C-H group } \\
(\mathrm{C}=\mathrm{C}-\mathrm{H} \text { stretch }) \text { in NLs and PLs }\end{array}$ & Meilunas et al., 1990 \\
\hline $2954^{\text {sh }}$ & $2954^{\text {sh }}$ & $2954^{\text {sh }}$ & $2954^{\text {sh }}$ & $2954^{\text {sh }}$ & Antisymmetric $\mathrm{CH}_{3}$ stretch & $\begin{array}{c}\text { van der Weerd et al., 2005; Meilunas et al., } \\
\text { 1990; Tantipolphan et al., } 2007\end{array}$ \\
\hline 2922 & 2922 & 2922 & 2922 & 2922 & Antisymmetric $\mathrm{CH}_{2}$ stretch & $\begin{array}{c}\text { van der Weerd et al., 2005; Meilunas et al., } \\
\text { 1990; Cagnasso et al., 2010; Tantipolphan } \\
\text { et al., 2007 }\end{array}$ \\
\hline $2872^{\text {sh }}$ & $2872^{\text {sh }}$ & $2872^{\text {sh }}$ & $2872^{\text {sh }}$ & $2872^{\text {sh }}$ & Symmetric stretch $\mathrm{CH}_{3}$ & Mazzeo et al., 2008 \\
\hline 2852 & 2852 & 2852 & 2852 & 2852 & Symmetric stretch $\mathrm{CH}_{2}$ & $\begin{array}{l}\text { van der Weerd et al., 2005; Meilunas et al., } \\
\text { 1990; Cagnasso et al., 2010; Tantipolphan } \\
\text { et al., 2007; Jackson and Mantsch, } 1992\end{array}$ \\
\hline 1743 & 1743 & 1743 & 1742 & 1741 & $-\mathrm{C}=\mathrm{O}$ stretch in NLs & $\begin{array}{l}\text { van der Weerd et al., 2005; Meilunas et al., } \\
1990\end{array}$ \\
\hline $1736^{\text {sh, sd }}$ & $1736^{\text {sh, sd }}$ & $1736^{\text {sh, sd }}$ & $1736^{\text {sh, sd }}$ & $1736^{\text {sh, sd }}$ & $\begin{array}{c}-\mathrm{C}=\mathrm{O} \text { stretch in PLs and in triglyceride derived } \\
\text { aldehydes and carbonyl moieties }\end{array}$ & $\begin{array}{c}\text { Cagnasso et al., 2010; Tantipolphan et al., } \\
\text { 2007; van der Weerd et al., 2005; Meilunas } \\
\text { et al., 1990 }\end{array}$ \\
\hline $1719^{\text {sh, sd }}$ & $1719^{\text {sh, sd }}$ & $1719^{\text {sh, sd }}$ & $1719^{\text {sh, sd }}$ & $1719^{\text {sh, sd }}$ & $\begin{array}{l}-\mathrm{C}=\mathrm{O} \text { stretch in triglycerides and glycerol-diacyl } \\
\text { esters; in carboxylic acids and in imide linkage } \\
\text { derived by oxidation of protein amide linkages }\end{array}$ & $\begin{array}{l}\text { van der Weerd et al., } 2005 \text { Meilunas et al., } \\
1990\end{array}$ \\
\hline- & $1709^{\text {sh, sd }}$ & $1709^{\text {sh, sd }}$ & $1709^{\text {sh, sd }}$ & $1709^{\text {sh, sd }}$ & $-\mathrm{C}=\mathrm{O}$ stretch in carboxylic acids & Meilunas et al., 1990 \\
\hline $1692^{\text {sh, sd }}$ & $1692^{\text {sh, sd }}$ & $1692^{\text {sh, sd }}$ & $1692^{\text {sh, sd }}$ & $1692^{\text {sh, sd }}$ & $\begin{array}{l}\text { Amide I: a) turns and bends in proteins HDL and } \\
\text { LDL; b) antiparallel } \beta \text {-sheet in proteins: albumin } \\
\text { and livetins }\end{array}$ & $\begin{array}{l}\text { Susi and Byler, 1986; López et al., 2000; } \\
\text { Kong and Yu, 2007; Haris and Severcan, } \\
\text { 1999) Furlan et al., 2007; Ulrichs et al., } \\
\text { 2014 }\end{array}$ \\
\hline $1683^{\text {sh, sd }}$ & $1683^{\text {sh, sd }}$ & $1683^{\text {sh, sd }}$ & $1683^{\text {sh, sd }}$ & $1683^{\text {sh, sd }}$ & $\begin{array}{c}\text { Amide I turns and bends in proteins livetins and } \\
\beta \text {-sheet/turns in LDL and HDL }\end{array}$ & $\begin{array}{c}\text { Kong and Yu, 2007; Dong et al., 1990; } \\
\text { Susi and Byler, 1986; Cabiaux et al., } 1989\end{array}$ \\
\hline
\end{tabular}




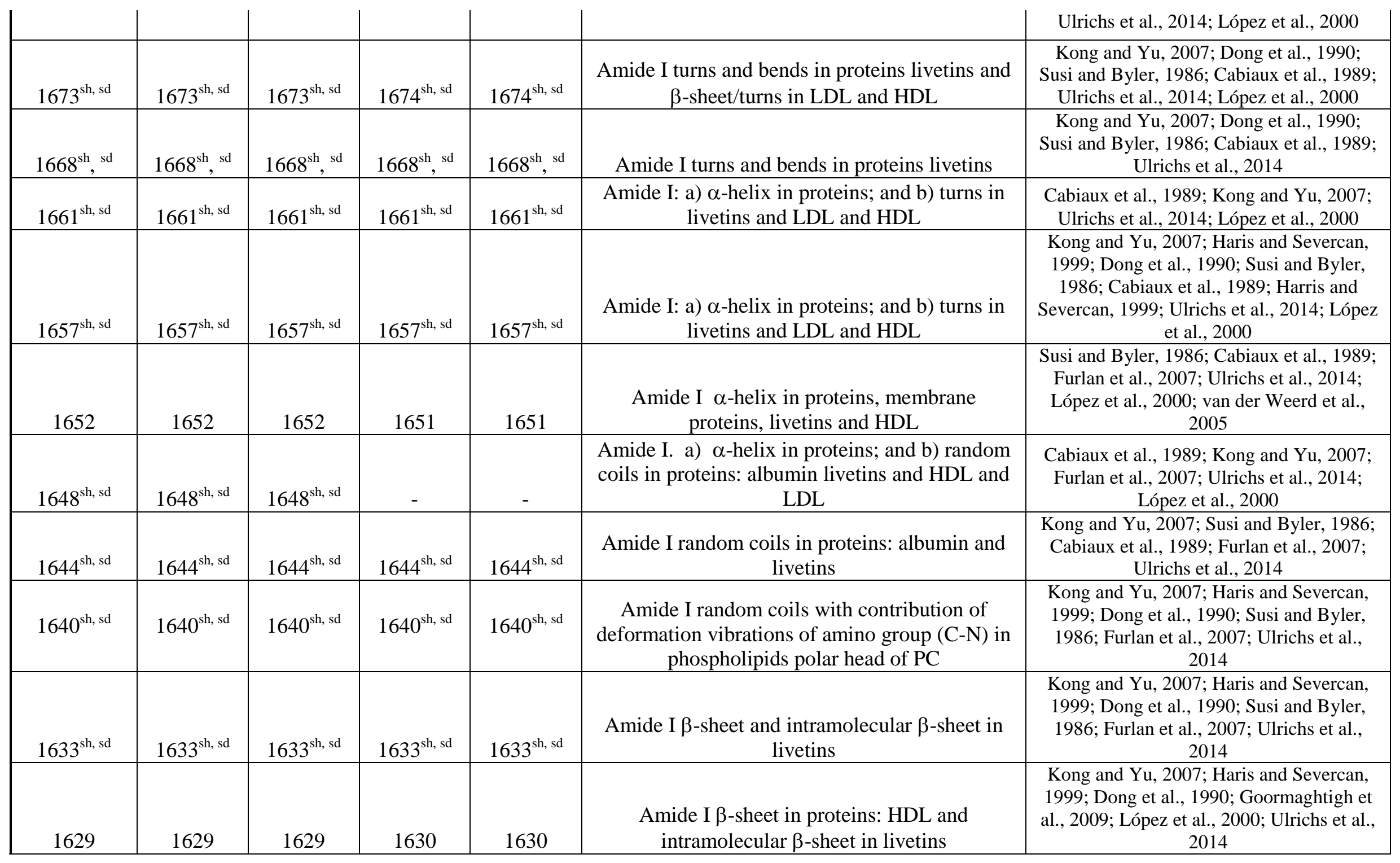




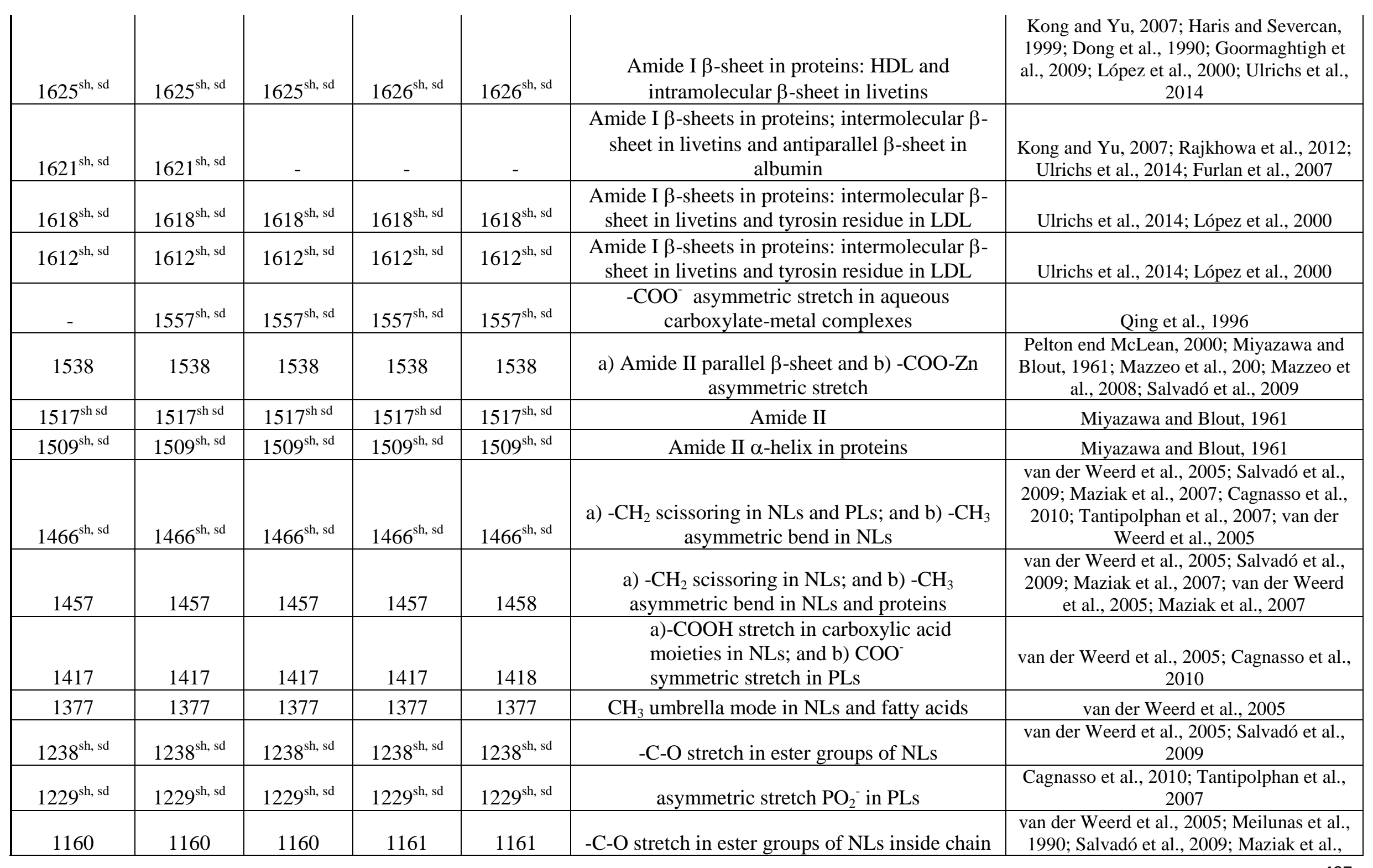




\begin{tabular}{|c|c|c|c|c|c|c|}
\hline & & & & & groups of proteins, and PLs & $\begin{array}{c}\text { 2007; Cagnasso et al., 2010; Tantipolphan } \\
\text { et al., } 2007\end{array}$ \\
\hline $1142^{\text {sh }}$ & $1142^{\text {sh }}$ & $1142^{\text {sh }}$ & $1142^{\text {sh }}$ & $1140^{\text {sh }}$ & $\mathrm{PO}_{2}^{-}$symmetric stretch in PLs & Tantipolphan et al., 2007 \\
\hline $1099^{\text {sh, sd }}$ & $1099^{\text {sh, sd }}$ & $1099^{\text {sh, sd }}$ & $1099^{\text {sh, sd }}$ & $1099^{\text {sh, sd }}$ & $\begin{array}{l}\text { a)-C-O stretch in ester groups of NLs; and b) } \\
\mathrm{PO}_{2}^{-} \text {symmetric stretch in PLs }\end{array}$ & $\begin{array}{c}\text { van der Weerd et al., 2005; Meilunas et al., } \\
\text { 1990; Salvadó et al., 2009; Tantipolphan et } \\
\text { al., 2007 }\end{array}$ \\
\hline 1086 & 1087 & 1088 & 1089 & 1089 & $\mathrm{PO}_{2}^{-}$symmetric stretch in PLs & $\begin{array}{l}\text { Cagnasso et al., 2010; Tantipolphan et al., } \\
2007\end{array}$ \\
\hline 1063 & 1063 & 1064 & 1065 & 1066 & P-O-C symmetric stretch & Cagnasso et al., 2010 \\
\hline $1055^{\text {sh, sd }}$ & $1055^{\text {sh, sd }}$ & $1056^{\text {sh, sd }}$ & $1058^{\text {sh, sd }}$ & $1058^{\text {sh, sd }}$ & -C-O stretch in cholesterol & van der Weerd et al., 2005 \\
\hline- & 976 & 976 & 976 & 976 & P-OX stretch & Cagnasso et al., 2010 \\
\hline 969 & 969 & 969 & 969 & 969 & $\begin{array}{l}\text { a) } \mathrm{N}^{-\mathrm{CH}_{3}} \text { asymmetric stretch in PLs; and b) } \\
\text { trans } \mathrm{CH} \text { out of plane deformation }\end{array}$ & $\begin{array}{c}\text { Cagnasso et al., 2010; Tantipolphan et al., } \\
\text { 2007; Meilunas et al., } 1990\end{array}$ \\
\hline 952 & 952 & 952 & 952 & 952 & $-\mathrm{CH}_{2}$ rocking in cholesterol & Meilunas et al., 1990 \\
\hline 722 & 722 & 722 & 722 & 722 & $\begin{array}{l}\text { a) cis } \mathrm{CH} \text { out of plane bend NLs; and b) }-\mathrm{CH}_{2} \\
\text { rocking in NLs }\end{array}$ & $\begin{array}{l}\text { van der Weerd et al., 2005; Meilunas et al. } \\
\text { 1990; Salvadó et al., } 2009\end{array}$ \\
\hline
\end{tabular}




\begin{tabular}{|c|c|c|c|c|c|c|}
\hline \multicolumn{5}{|c|}{ Frequency $\left(\mathrm{cm}^{-1}\right)$} & \multirow{2}{*}{ IR bands assignment } & \multirow{2}{*}{ References } \\
\hline $\mathbf{Y} @ \mathbf{B}$ & $\mathbf{Y} @ \mathbf{C d}_{10}$ & $\mathbf{Y} @ \mathbf{C d}_{30}$ & $\mathbf{Y} @ \mathbf{C d}_{\mathbf{5 0}}$ & $\mathbf{Y} @ \mathbf{C d}_{\mathbf{7 5}}$ & & \\
\hline 3278 & 3278 & 3278 & 3278 & 3278 & Amide A, N-H stretch & Kong and Yu, 2007 \\
\hline 3069 & 3069 & 3069 & 3069 & 3068 & $\begin{array}{l}\text { Amide B, N-H Fermi resonance between amide II } \\
\text { overtone and N-H stretch }\end{array}$ & Kong and Yu, 2007 \\
\hline 3007 & 3007 & 3007 & 3007 & 3007 & $\begin{array}{c}\text { Cis-type unsaturated unconjugated C-H group }(\mathrm{C}=\mathrm{C} \text { - } \\
\text { H stretch) in NLs and PLs }\end{array}$ & Meilunas et al., 1990 \\
\hline $2954^{\text {sh }}$ & $2954^{\text {sh }}$ & $2954^{\text {sh }}$ & $2954^{\text {sh }}$ & $2954^{\mathrm{sh}}$ & Antisymmetric $\mathrm{CH}_{3}$ stretch & $\begin{array}{c}\text { van der Weerd et al., 2005; Meilunas et al., } \\
\text { 1990; Tantipolphan et al., } 2007\end{array}$ \\
\hline 2922 & 2922 & 2922 & 2922 & 2921 & Antisymmetric $\mathrm{CH}_{2}$ stretch & $\begin{array}{c}\text { van der Weerd et al., 2005; Meilunas et al., } \\
\text { 1990; Cagnasso et al., 2010; Tantipolphan } \\
\text { et al., 2007 }\end{array}$ \\
\hline $2872^{\text {sh }}$ & $2872^{\text {sh }}$ & $2872^{\text {sh }}$ & $2872^{\text {sh }}$ & $2872^{\text {sh }}$ & Symmetric stretch $\mathrm{CH}_{3}$ & Mazzeo et al., 2008 \\
\hline 2852 & 2852 & 2852 & 2852 & 2852 & Symmetric stretch $\mathrm{CH}_{2}$ & $\begin{array}{l}\text { van der Weerd et al., 2005; Meilunas et al., } \\
\text { 1990; Cagnasso et al., 2010; Tantipolphan } \\
\text { et al., 2007; Jackson and Mantsch, } 1992\end{array}$ \\
\hline 1743 & 1743 & 1743 & 1742 & 1741 & $-\mathrm{C}=\mathrm{O}$ stretch in NLs & $\begin{array}{l}\text { van der Weerd et al., 2005; Meilunas et al., } \\
1990\end{array}$ \\
\hline $1736^{\text {sh, sd }}$ & $1736^{\text {sh, sd }}$ & $1736^{\mathrm{sh}, \mathrm{sd}}$ & $1736^{\text {sh, sd }}$ & $1736^{\text {sh, sd }}$ & $\begin{array}{c}-\mathrm{C}=\mathrm{O} \text { stretch in PLs and in triglyceride derived } \\
\text { aldehydes and carbonyl moieties }\end{array}$ & $\begin{array}{c}\text { Cagnasso et al., 2010; Tantipolphan et al., } \\
\text { 2007; van der Weerd et al., 2005; Meilunas } \\
\text { et al., } 1990\end{array}$ \\
\hline $1719^{\text {sh, sd }}$ & $1719^{\text {sh, sd }}$ & $1719^{\mathrm{sh}, \mathrm{sd}}$ & $1719^{\text {sh, sd }}$ & $1719^{\text {sh, sd }}$ & $\begin{array}{l}-\mathrm{C}=\mathrm{O} \text { stretch in triglycerides and glycerol-diacyl } \\
\text { esters; in carboxylic acids and in imide linkage } \\
\text { derived by oxidation of protein amide linkages }\end{array}$ & $\begin{array}{l}\text { van der Weerd et al., 2005; Meilunas et al., } \\
1990\end{array}$ \\
\hline- & - & - & $1709^{\text {sh, sd }}$ & $1709^{\text {sh, sd }}$ & $-\mathrm{C}=\mathrm{O}$ stretch in carboxylic acids & Meilunas et al., 1990 \\
\hline $1692^{\text {sh, sd }}$ & $1692^{\text {sh, sd }}$ & $1692^{\text {sh, sd }}$ & $1692^{\text {sh, sd }}$ & $1692^{\text {sh, sd }}$ & $\begin{array}{l}\text { Amide I: a) turns and bends in proteins HDL and } \\
\text { LDL; b) antiparallel } \beta \text {-sheet in proteins: albumin } \\
\text { and livetins }\end{array}$ & $\begin{array}{c}\text { Susi and Byler, 1986; López et al., 2000; } \\
\text { Kong and Yu, 2007; Haris and Severcan, } \\
\text { 1999; Furlan et al., 2007; Ulrichs et al., } \\
\text { 2014 }\end{array}$ \\
\hline
\end{tabular}




\begin{tabular}{|c|c|c|c|c|c|c|}
\hline $1683^{\text {sh, sd }}$ & $1683^{\text {sh, sd }}$ & $1683^{\text {sh, sd }}$ & $1682^{\text {sh, sd }}$ & $1682^{\text {sh, sd }}$ & $\begin{array}{c}\text { Amide I turns and bends in proteins livetins and } \\
\beta \text {-sheet/turns in LDL and HDL }\end{array}$ & $\begin{array}{l}\text { Kong and Yu, 2007; Dong et al., 1990; } \\
\text { Susi and Byler, 1986; Cabiaux et al., 1989; } \\
\text { Ulrichs et al., 2014; López et al., 2000 }\end{array}$ \\
\hline $1673^{\text {sh, sd }}$ & $1673^{\text {sh, sd }}$ & $1673^{\text {sh, sd }}$ & $1673^{\text {sh, sd }}$ & $1674^{\text {sh, sd }}$ & $\begin{array}{c}\text { Amide I turns and bends in proteins livetins and } \\
\beta \text {-sheet/turns in LDL and HDL }\end{array}$ & $\begin{array}{l}\text { Kong and Yu, 2007; Dong et al., 1990; } \\
\text { Susi and Byler, 1986; Cabiaux et al., 1989; } \\
\text { Ulrichs et al., 2014; López et al., 2000 }\end{array}$ \\
\hline $1668^{\text {sh, sd }}$ & $1668^{\mathrm{sh}, \mathrm{sd}}$ & $1668^{\text {sh, sd }}$ & $1668^{\text {sh, sd }}$ & $1668^{\text {sh, sd }}$ & Amide I turns and bends in proteins livetins & $\begin{array}{c}\text { Kong and Yu, 2007; Dong et al., 1990; } \\
\text { Susi and Byler, 1986; Cabiaux et al., 1989; } \\
\text { Ulrichs et al., } 2014\end{array}$ \\
\hline $1661^{\text {sh, sd }}$ & $1661^{\mathrm{sh}, \mathrm{sd}}$ & $1661^{\text {sh, sd }}$ & $1661^{\text {sh, sd }}$ & $1661^{\mathrm{sh}, \mathrm{sd}}$ & $\begin{array}{l}\text { Amide I: a) } \alpha \text {-helix in proteins; and b) turns in } \\
\text { livetins and LDL and HDL }\end{array}$ & $\begin{array}{l}\text { Cabiaux et al., 1989; Kong and Yu, 2007; } \\
\text { Ulrichs et al., 2014; López et al., } 2000\end{array}$ \\
\hline 1652 & 1652 & 1652 & 1652 & 1651 & $\begin{array}{c}\text { Amide I } \alpha \text {-helix in proteins, membrane } \\
\text { proteins, livetins and HDL }\end{array}$ & $\begin{array}{c}\text { Susi and Byler et al., 1986; Cabiaux et al., } \\
\text { 1989; Furlan et al., 2007; Ulrichs et al., } \\
\text { 2014; Lopez et al., 2000; van der Weerd et } \\
\text { al., 2005 }\end{array}$ \\
\hline $1640^{\text {sh, sd }}$ & $1640^{\text {sh, sd }}$ & $1639^{\text {sh, sd }}$ & $1638^{\text {sh, sd }}$ & $1638^{\text {sh, sd }}$ & $\begin{array}{l}\text { Amide I random coils with contribution of } \\
\text { deformation vibrations of amino group }(\mathrm{C}-\mathrm{N}) \text { in } \\
\text { phospholipids polar head of PC }\end{array}$ & $\begin{array}{l}\text { Kong and Yu, 2007; Haris and Severcan, } \\
\text { 1999; Dong et al., 1990; Susi and Byler, } \\
\text { 1986; Furlan et al., 2007; Ulrichs et al., } \\
2014\end{array}$ \\
\hline $1633^{\text {sh, sd }}$ & $1633^{\text {sh, sd }}$ & $1633^{\text {sh, sd }}$ & - & - & $\begin{array}{l}\text { Amide I } \beta \text {-sheet and intramolecular } \beta \text {-sheet in } \\
\text { livetins }\end{array}$ & $\begin{array}{c}\text { Kong and Yu, 2007; Haris and Severcan, } \\
\text { 1999; Dong et al., 1990; Susi and Byler, } \\
\text { 1986; Furlan et al., 2007; Ulrichs et al., } \\
2014 \\
\end{array}$ \\
\hline 1629 & 1629 & 1629 & 1629 & 1630 & $\begin{array}{l}\text { Amide I } \beta \text {-sheet in proteins: HDL and } \\
\text { intramolecular } \beta \text {-sheet in livetins }\end{array}$ & $\begin{array}{l}\text { Kong and Yu, 2007; Harris and Severcan, } \\
\text { 1999; Dong et al., 1990; Goormaghtigh et } \\
\text { al., 2009; López et al., 2000; Ulrichs et al., }\end{array}$ \\
\hline
\end{tabular}




\begin{tabular}{|c|c|c|c|c|c|c|}
\hline & & & & & & 2014 \\
\hline $1625^{\text {sh, sd }}$ & $1625^{\text {sh, sd }}$ & $1625^{\text {sh, sd }}$ & $1626^{\text {sh, sd }}$ & $1626^{\text {sh, sd }}$ & $\begin{array}{l}\text { Amide I } \beta \text {-sheet in proteins: HDL and } \\
\text { intramolecular } \beta \text {-sheet in livetins }\end{array}$ & $\begin{array}{c}\text { Kong and Yu, 2007; Harris and Severcan, } \\
\text { 1999; Dong et al., 1990; Goormaghtigh et } \\
\text { al., 2009; López et al., 2000; Ulrichs et al., } \\
\text { 2014 }\end{array}$ \\
\hline $1621^{\text {sh, sd }}$ & $1622^{\text {sh, sd }}$ & - & - & - & $\begin{array}{c}\text { Amide I } \beta \text {-sheets in proteins; intermolecular } \beta \text { - } \\
\text { sheet in livetins and antiparallel } \beta \text {-sheet in } \\
\text { albumin }\end{array}$ & Ulrichs et al., 2014; Furlan et al., 2007 \\
\hline $1618^{\text {sh, sd }}$ & $1618^{\text {sh, sd }}$ & $1618^{\text {sh, sd }}$ & $1618^{\text {sh, sd }}$ & $1618^{\mathrm{sh}, \mathrm{sd}}$ & $\begin{array}{l}\text { Amide I } \beta \text {-sheets in proteins: intermolecular } \beta \text { - } \\
\text { sheet in livetins and tyrosin residue in LDL }\end{array}$ & Ulrichs et al., 2014; López et al., 2000 \\
\hline $1612^{\mathrm{sh}, \mathrm{sd}}$ & $1612^{\mathrm{sh}, \mathrm{sd}}$ & $1612^{\mathrm{sh}, \mathrm{sd}}$ & $1612^{\mathrm{sh}, \mathrm{sd}}$ & $1612^{\mathrm{sh}, \mathrm{sd}}$ & $\begin{array}{l}\text { Amide I } \beta \text {-sheets in proteins: intermolecular } \beta \text { - } \\
\text { sheet in livetins and tyrosin residue in LDL }\end{array}$ & Ulrichs et al., 2014; López et al., 2000 \\
\hline 1538 & 1538 & $\begin{array}{l}1540 \\
1535\end{array}$ & $\begin{array}{l}1541 \\
1535\end{array}$ & $\begin{array}{l}1541 \\
1536 \\
\end{array}$ & $\begin{array}{l}\text { a) Amide II parallel } \beta \text {-sheet and b) -COO-Cd } \\
\text { asymmetric stretch }\end{array}$ & $\begin{array}{c}\text { Pelton and McLean, 2000; Miyazawa and } \\
\text { Blout, 1961; Mazzeo et al., 2008; Salvadó } \\
\text { et al., 2009 }\end{array}$ \\
\hline $1517^{\text {sh sd }}$ & $1517^{\text {sh sd }}$ & $1517^{\text {sh sd }}$ & $1517^{\text {sh sd }}$ & $1517^{\text {sh sd }}$ & Amide II & Miyazawa and Blout, 1961 \\
\hline $1509^{\text {sh, sd }}$ & $1509^{\text {sh, sd }}$ & $1509^{\text {sh, sd }}$ & $1509^{\text {sh, sd }}$ & $1509^{\mathrm{sh}, \mathrm{sd}}$ & Amide II $\alpha$-helix in proteins & Miyazawa and Blout, 1961 \\
\hline $1466^{\text {sh, sd }}$ & $1466^{\text {sh, sd }}$ & $1466^{\text {sh, sd }}$ & $1466^{\mathrm{sh}, \mathrm{sd}}$ & $1466^{\mathrm{sh}, \mathrm{sd}}$ & $\begin{array}{c}\text { a) }-\mathrm{CH}_{2} \text { scissoring in NLs and PLs; and b) }-\mathrm{CH}_{3} \\
\text { asymmetric bend in NLs }\end{array}$ & $\begin{array}{l}\text { van der Weerd et al., 2005; Salvadó et al., } \\
\text { 2009; Maziak et al., 2007; Cagnasso et al., } \\
\text { 2010; Tantipolphan et al, 2007; van der } \\
\text { Weerd et al., 2005 }\end{array}$ \\
\hline 1457 & 1457 & 1457 & 1458 & 1458 & $\begin{array}{c}\text { a) }-\mathrm{CH}_{2} \text { scissoring in NLs; and b) }-\mathrm{CH}_{3} \text { asymmetric } \\
\text { bend in NLs and proteins }\end{array}$ & $\begin{array}{c}\text { van der Weerd et al., 2005; Salvadó et al., } \\
\text { 2009; Maziak et al., 2007; van der Weerd } \\
\text { et al., 2005; Maziak et al., } 2007\end{array}$ \\
\hline 1417 & 1417 & 1417 & 1417 & 1418 & $\begin{array}{l}\text { a)-COOH stretch in carboxylic acid moieties in NLs; } \\
\text { and b) } \mathrm{COO}^{-} \text {symmetric stretch in PLs }\end{array}$ & $\begin{array}{l}\text { van der Weerd et al., 2005; Cagnasso et al., } \\
2010\end{array}$ \\
\hline 1377 & 1377 & 1377 & 1377 & 1377 & $\mathrm{CH}_{3}$ umbrella mode in NLs and fatty acids & (van der Weerd et al., 2005) \\
\hline $1238^{\text {sh, sd }}$ & $1238^{\text {sh, sd }}$ & $1238^{\text {sh, sd }}$ & $1238^{\text {sh, sd }}$ & $1236^{\mathrm{sh}, \mathrm{sd}}$ & $-\mathrm{C}-\mathrm{O}$ stretch in ester groups of NLs & $\begin{array}{l}\text { van der Weerd et al., 2005; Cagnasso et al., } \\
2010\end{array}$ \\
\hline $1229^{\text {sh, sd }}$ & $1229^{\text {sh, sd }}$ & $1229^{\mathrm{sh}, \mathrm{sd}}$ & $1229^{\text {sh, sd }}$ & $1229^{\text {sh, sd }}$ & asymmetric stretch $\mathrm{PO}_{2}^{-}$in PLs & $\begin{array}{l}\text { Cagnasso et al., 2010; Tantipolphan et al, } \\
2007\end{array}$ \\
\hline 1160 & 1160 & 1160 & 1160 & 1157 & $\begin{array}{l}-\mathrm{C}-\mathrm{O} \text { stretch in ester groups of NLs inside chain } \\
\text { groups of proteins, and PLs }\end{array}$ & $\begin{array}{c}\text { van der Weerd et al., 2005; Meilunas et al., } \\
\text { 1990; Salvadó et al., 2009; Maziak et al., } \\
\text { 2007 Cagnasso et al., 2010; Tantipolphan } \\
\text { et al, } 2007\end{array}$ \\
\hline
\end{tabular}




\begin{tabular}{|c|c|c|c|c|c|c|}
\hline $1142^{\text {sh }}$ & 1141 & 1142 & 1142 & $1143^{\text {sh }}$ & $\mathrm{PO}_{2}^{-}$symmetric stretch in PLs & Tantipolphan et al, 2007 \\
\hline $1099^{\text {sh, sd }}$ & $1099^{\text {sh, sd }}$ & $1099^{\text {sh, sd }}$ & $1099^{\text {sh, sd }}$ & $1099^{\text {sh, sd }}$ & $\begin{array}{c}\text { a)-C-O stretch in ester groups of NLs; and b) } \mathrm{PO}_{2}^{-} \\
\text {symmetric stretch in PLs }\end{array}$ & $\begin{array}{c}\text { van der Weerd et al., 2005; Meilunas et al., } \\
\text { 1990; Salvadó et al., 2009; Tantipolphan et } \\
\text { al, 2007 }\end{array}$ \\
\hline 1086 & 1086 & 1088 & 1087 & 1087 & $\mathrm{PO}_{2}^{-}$symmetric stretch in PLs & $\begin{array}{l}\text { Cagnasso et al., 2010; Tantipolphan et al, } \\
2007\end{array}$ \\
\hline 1063 & 1063 & 1064 & 1068 & 1068 & $\mathrm{P}-\mathrm{O}-\mathrm{C}$ symmetric stretch & Cagnasso et al., 2010 \\
\hline $1055^{\text {sh, sd }}$ & $1055^{\text {sh, sd }}$ & $1055^{\text {sh, sd }}$ & $1060^{\text {sh, sd }}$ & $1060^{\text {sh, sd }}$ & -C-O stretch in cholesterol & van der Weerd et al., 2005 \\
\hline- & - & 987 & 987 & 987 & P-OX stretch & Cagnasso et al., 2010 \\
\hline 969 & 969 & 969 & 969 & 969 & $\begin{array}{l}\text { a) } \mathrm{N}_{-} \mathrm{CH}_{3} \text { asymmetric stretch in PLs; and b) trans } \mathrm{CH} \\
\text { out of plane deformation }\end{array}$ & $\begin{array}{l}\text { Cagnasso et al., 2010; Tantipolphan et al, } \\
\text { 2007; Meilunas et al., } 1990\end{array}$ \\
\hline 952 & 952 & 952 & 952 & 952 & $-\mathrm{CH}_{2}$ rocking in cholesterol & Meilunas et al., 1990 \\
\hline 722 & 722 & 722 & 722 & 722 & $\begin{array}{l}\text { a) cis } \mathrm{CH} \text { out of plane bend NLs; and b) }-\mathrm{CH}_{2} \\
\text { rocking in NLs }\end{array}$ & $\begin{array}{l}\text { van der Weerd et al., 2005; Meilunas et al., } \\
1990\end{array}$ \\
\hline
\end{tabular}


Table 12.5. IR absorption band assignment for YO (pure egg yolk-oil emulsion) specimen and YO@Fe specimens prepared at $10,30,50$ and 75 wt $\%$. Characteristics of the IR absorption bands referred to the YO specimen: sh: shoulder and sd: identified in the second derivative curve.

\begin{tabular}{|c|c|c|c|c|c|c|}
\hline \multicolumn{5}{|c|}{ Frequency $\left(\mathrm{cm}^{-1}\right)$} & \multirow{2}{*}{ IR bands assignment } & \multirow{2}{*}{ References } \\
\hline YO & $\mathbf{Y O @ F e _ { 1 0 }}$ & YO@Fe & YO@Fe $\mathbf{F e}_{50}$ & $\mathbf{Y O @ F _ { 7 5 }}$ & & \\
\hline 3459 & 3459 & 3459 & - & - & vOH water & Conti et al., 2014 \\
\hline 3278 & 3278 & 3278 & 3278 & 3278 & Amide $\mathrm{A}, \mathrm{N}-\mathrm{H}$ stretch & Kong and Yu, 2007 \\
\hline 3055 & 3055 & 3055 & 3055 & - & $\begin{array}{l}\text { Amide B, N-H Fermi resonance between amide II } \\
\text { overtone and N-H stretch }\end{array}$ & Kong and $\mathrm{Yu}, 2007$ \\
\hline 3007 & 3007 & 3007 & - & - & $\begin{array}{l}\text { Cis-type unsaturated unconjugated C-H group } \\
(\mathrm{C}=\mathrm{C}-\mathrm{H} \text { stretch) in NLs and PLs }\end{array}$ & Meilunas et al., 1990 \\
\hline- & - & - & - & 2998 & Stretching vibrations of tertiary $-\mathrm{CH}$ groups & Meilunas et al., 1990 \\
\hline $2948^{\text {sh }}$ & $2948^{\text {sh }}$ & $2948^{\text {sh }}$ & $2948^{\text {sh }}$ & $2950^{\text {sh }}$ & Antisymmetric $\mathrm{CH}_{3}$ stretch & $\begin{array}{l}\text { van der Weerd et al., 2005; Meilunas et } \\
\text { al., 1990; Tantipolphan et al., } 2007\end{array}$ \\
\hline 2922 & 2922 & 2922 & 2922 & 2920 & Antisymmetric $\mathrm{CH}_{2}$ stretch & $\begin{array}{l}\text { van der Weerd et al., 2005; Meilunas et } \\
\text { al., 1990; Cagnasso et al., 2010; } \\
\text { Tantipolphan et al., 2007 } \\
\end{array}$ \\
\hline $2870^{\text {sh }}$ & $2870^{\text {sh }}$ & $2870^{\text {sh }}$ & $2870^{\text {sh }}$ & $2870^{\text {sh }}$ & Symmetric stretch $\mathrm{CH}_{3}$ & Mazzeo et al., 2008 \\
\hline 2852 & 2852 & 2852 & 2852 & 2850 & Symmetric stretch $\mathrm{CH}_{2}$ & $\begin{array}{l}\text { van der Weerd et al., 2005; Meilunas et } \\
\text { al., 1990; Cagnasso et al., 2010; } \\
\text { Tantipolphan et al., 2007; Jackson and } \\
\text { Mantsch, } 1992\end{array}$ \\
\hline 1744 & 1744 & 1743 & 1743 & 1740 & $-\mathrm{C}=\mathrm{O}$ stretch in NLs & $\begin{array}{c}\text { van der Weerd et al., 2005; Meilunas et } \\
\text { al., } 1990\end{array}$ \\
\hline- & - & - & & 1738 & -COO- in fatty acids & Meilunas et al., 1990 \\
\hline $1720^{\mathrm{sh}, \mathrm{sd}}$ & $1720^{\text {sh, sd }}$ & $1720^{\text {sh, sd }}$ & $1720^{\text {sh, sd }}$ & $1722^{\text {sh, sd }}$ & $\begin{array}{l}\text {-C }=\mathrm{O} \text { stretch in triglycerides and glycerol-diacyl } \\
\text { esters; in carboxylic acids and in imide linkage } \\
\text { derived by oxidation of protein amide linkages }\end{array}$ & $\begin{array}{l}\text { van der Weerd et al., 2005; Meilunas et } \\
\text { al., } 1990\end{array}$ \\
\hline- & - & - & - & $1707^{\text {sh, sd }}$ & $-\mathrm{C}=\mathrm{O}$ stretch in carboxylic acids & Meilunas et al., 1990 \\
\hline- & - & - & - & 1703 & $\begin{array}{c}\text {-COO- groups in fatty acids released from } \\
\text { triglycerides }\end{array}$ & Meilunas et al., 1990 \\
\hline $1680^{\text {sh, sd }}$ & $1680^{\text {sh, sd }}$ & $1680^{\text {sh, sd }}$ & $1680^{\text {sh, sd }}$ & - & $\begin{array}{l}\text { Amide I turns and bends in proteins: livetins, } \\
\beta \text {-sheet/turns in LDL and HDL }\end{array}$ & $\begin{array}{c}\text { Kong and Yu, 2007; Dong et al., 1990; } \\
\text { Susi and Byler, 1986; Cabiaux et al., } \\
\text { 1989; Ulrichs et al., 2014; López et al., } \\
2000\end{array}$ \\
\hline
\end{tabular}




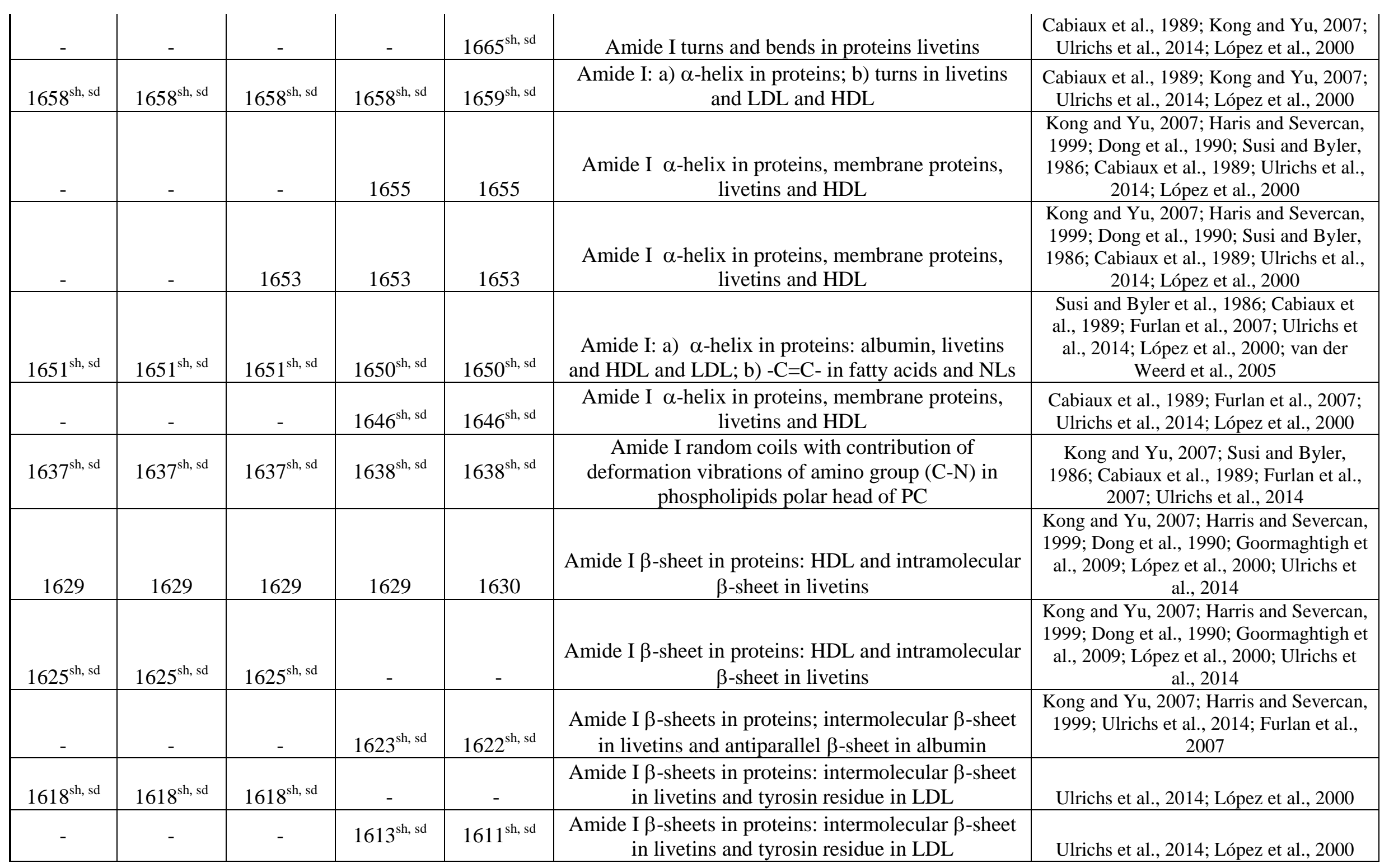




\begin{tabular}{|c|c|c|c|c|c|c|}
\hline - & - & 1609 & 1609 & 1609 & Amide I intermolecular $\beta$-sheet in proteins livetins & \\
\hline - & - & - & - & $1578^{\text {sh, sd }}$ & -COO-metal asymmetric stretch in PLs & $\begin{array}{l}\text { Venyaminov and Kalnin, 1990; Cagnasso } \\
\text { et al., 2010; Cagnasso et al., } 2010\end{array}$ \\
\hline 1536 & 1536 & 1536 & 1536 & 1535 & Amide II parallel $\beta$-sheet & $\begin{array}{l}\text { Pelton and McLean, 2000; Miyazawa and } \\
\text { Blout, } 1961\end{array}$ \\
\hline- & - & - & - & 1501 & Amide II & \\
\hline $1466^{\text {sh, sd }}$ & $1466^{\text {sh, sd }}$ & $1465^{\text {sh, sd }}$ & $1465^{\text {sh, sd }}$ & - & $\begin{array}{c}\text { a) }-\mathrm{CH}_{2} \text { scissoring in NLs and PLs; and b) }-\mathrm{CH}_{3} \\
\text { asymmetric bend in NLs }\end{array}$ & $\begin{array}{c}\text { van der Weerd et al., 2005; Salvadó et al., } \\
\text { 2009; Maziak et al., 2007; Cagnasso et } \\
\text { al., 2010; Tantipolphan et al, 2007; van } \\
\text { der Weerd et al., 2005 }\end{array}$ \\
\hline 1416 & 1416 & 1416 & 1416 & 1416 & $\begin{array}{l}v_{\mathrm{s}}(\mathrm{C}-\mathrm{O}) \text { vibrations in carboxylic acid } \\
\text { moieties in NLs }\end{array}$ & van der Weerd et al., 2005 \\
\hline- & - & - & 1400 & 1400 & $v_{\mathrm{as}}\left(\mathrm{CO}_{2}^{-}\right)$vibrations in PLs & Cagnasso et al., 2010 \\
\hline 1377 & 1377 & 1377 & 1377 & 1377 & $\mathrm{CH}_{3}$ umbrella mode in NLs and fatty acids & van der Weerd et al., 2005 \\
\hline 1235 & 1235 & 1235 & 1235 & 1235 & $-\mathrm{C}-\mathrm{O}$ stretch in ester groups of NLs & $\begin{array}{l}\text { van der Weerd et al., 2005; Cagnasso et } \\
\text { al., } 2010\end{array}$ \\
\hline 1163 & 1163 & 1163 & 1163 & 1162 & $\begin{array}{c}\text {-C-O stretch in ester groups of NLs inside chain } \\
\text { groups of proteins and PLs }\end{array}$ & $\begin{array}{c}\text { van der Weerd et al., 2005; Meilunas et } \\
\text { al., 1990; Salvadó et al., 2009; Maziak et } \\
\text { al., 2007; Cagnasso et al., 2010; } \\
\text { Tantipolphan et al, } 2007\end{array}$ \\
\hline $1097^{\text {sh, sd }}$ & $1097^{\text {sh, sd }}$ & $1097^{\text {sh, sd }}$ & $1097^{\text {sh, sd }}$ & $1097^{\text {sh, sd }}$ & $\begin{array}{l}\text { a)-C-O stretch in ester groups of NLs; and b) } \mathrm{PO}_{2}^{-} \\
\text {symmetric stretch in PLs }\end{array}$ & $\begin{array}{l}\text { van der Weerd et al., 2005; Meilunas et } \\
\text { al., 1990; Salvadó et al., 2009; } \\
\text { Tantipolphan et al., 2007 } \\
\end{array}$ \\
\hline 1065 & 1065 & 1065 & 1065 & - & P-O-C symmetric stretch & Cagnasso et al., 2010 \\
\hline $1052^{\text {sh, sd }}$ & $1052^{\text {sh, sd }}$ & $1050^{\text {sh, sd }}$ & $1050^{\text {sh, sd }}$ & - & $v_{\mathrm{as}} \mathrm{CO}, \delta \mathrm{CH}_{3}$ & van der Weerd et al., 2005 \\
\hline 1029 & 1029 & 1030 & 1030 & - & $v_{\mathrm{s}} \mathrm{CO}, \delta \mathrm{CH}_{3}$ & van der Weerd et al., 2005 \\
\hline- & - & - & - & 997 & P-OX stretch in inner-spheres complexes & Cagnasso et al., 2010 \\
\hline 967 & 967 & 967 & 967 & 966 & $\begin{array}{l}\text { a) } \mathrm{N}_{-} \mathrm{CH}_{3} \text { asymmetric stretch in PLs; and b) trans } \\
\mathrm{CH} \text { out of plane deformation }\end{array}$ & $\begin{array}{l}\text { Cagnasso et al., 2010; Tantipolphan et } \\
\text { al., 2007; Meilunas et al., } 1990\end{array}$ \\
\hline 722 & 722 & 722 & 722 & 722 & $\begin{array}{l}\text { a) cis } \mathrm{CH} \text { out of plane bend NLs; and b) }-\mathrm{CH}_{2} \\
\text { rocking in NLs }\end{array}$ & $\begin{array}{l}\text { van der Weerd et al., 2005; Meilunas et } \\
\text { al., 1990; Salvadó et al., 2009 }\end{array}$ \\
\hline
\end{tabular}


Table 12.6. IR absorption band assignment for YO (pure egg yolk-oil emulsion) specimen and YO@ Pbm specimens prepared at $10,30,50$ and 75 wt $\%$. Characteristics of the IR absorption bands referred to the YO specimen: sh: shoulder and sd: identified in the second derivative curve.

\begin{tabular}{|c|c|c|c|c|c|c|}
\hline \multicolumn{5}{|c|}{ Frequency $\left(\mathrm{cm}^{-1}\right)$} & \multirow{2}{*}{ IR bands assignment } & \multirow{2}{*}{ References } \\
\hline YO & YO@Pbm 10 & YO@Pbm 30 & YO@Pbm 50 & $\mathbf{Y O} @ \mathbf{P b m}_{75}$ & & \\
\hline 3459 & 3459 & - & - & - & vOH water & Conti et al., 2014 \\
\hline 3278 & 3280 & 3280 & 3280 & 3283 & Amide A, N-H stretch & Kong and Yu, 2007 \\
\hline 3055 & 3055 & 3055 & 3060 & 3064 & $\begin{array}{c}\text { Amide } \mathrm{B}, \mathrm{N}-\mathrm{H} \text { Fermi resonance between amide II } \\
\text { overtone and } \mathrm{N}-\mathrm{H} \text { stretch }\end{array}$ & Kong and Yu, 2007 \\
\hline 3007 & 3007 & 3007 & 3002 & - & $\begin{array}{l}\text { Cis-type unsaturated unconjugated C-H group } \\
(\mathrm{C}=\mathrm{C}-\mathrm{H} \text { stretch }) \text { in NLs and PLs }\end{array}$ & Meilunas et al., 1990 \\
\hline- & - & - & - & 2997 & Stretching vibrations of tertiary $-\mathrm{CH}$ groups & Meilunas et al., 1990 \\
\hline $2948^{\text {sh }}$ & $2948^{\text {sh }}$ & $2948^{\text {sh }}$ & $2950^{\text {sh }}$ & $2952^{\text {sh }}$ & Antisymmetric $\mathrm{CH}_{3}$ stretch & $\begin{array}{l}\text { van der Weerd et al., 2005; } \\
\text { Meilunas et al., 1990; } \\
\text { Tantipolphan et al., } 2007\end{array}$ \\
\hline 2922 & 2922 & 2922 & 2922 & 2922 & Antisymmetric $\mathrm{CH}_{2}$ stretch & $\begin{array}{l}\text { van der Weerd et al., 2005; } \\
\text { Meilunas et al., 1990; } \\
\text { Cagnasso et al., 2010; } \\
\text { Tantipolphan et al., 2007 } \\
\end{array}$ \\
\hline $2870^{\text {sh }}$ & $2870^{\text {sh }}$ & $2870^{\text {sh }}$ & $2870^{\text {sh }}$ & $2872^{\text {sh }}$ & Symmetric stretch $\mathrm{CH}_{3}$ & Mazzeo et al., 2008 \\
\hline 2852 & 2852 & 2852 & 2852 & 2852 & Symmetric stretch $\mathrm{CH}_{2}$ & $\begin{array}{l}\text { van der Weerd et al., 2005; } \\
\text { Meilunas et al., 1990; } \\
\text { Cagnasso et al., 2010; } \\
\text { Tantipolphan et al., 2007; } \\
\text { Jackson and Mantsch, } 1992 \\
\end{array}$ \\
\hline 1744 & 1744 & 1744 & 1743 & 1742 & $-\mathrm{C}=\mathrm{O}$ stretch in NLs & $\begin{array}{l}\text { van der Weerd et al., 2005; } \\
\text { Meilunas et al., } 1990\end{array}$ \\
\hline- & - & - & & 1738 & -COO- in fatty acids & Meilunas et al., 1990 \\
\hline $1720^{\text {sh, sd }}$ & $1720^{\text {sh, sd }}$ & $1720^{\text {sh, sd }}$ & - & - & $\begin{array}{l}-\mathrm{C}=\mathrm{O} \text { stretch in triglycerides and glycerol-diacyl } \\
\text { esters; in carboxylic acids and in imide linkage } \\
\text { derived by oxidation of protein amide linkages }\end{array}$ & $\begin{array}{c}\text { van der Weerd et al., 2005; } \\
\text { Meilunas et al., } 1990\end{array}$ \\
\hline $1680^{\mathrm{sh}, \mathrm{sd}}$ & $1680^{\mathrm{sh}, \mathrm{sd}}$ & $1680^{\text {sh, sd }}$ & $1680^{\text {sh, sd }}$ & $1678^{\text {sh, sd }}$ & $\begin{array}{c}\text { Amide I turns and bends in proteins: livetins, } \\
\beta \text {-sheet/turns in LDL and HDL }\end{array}$ & $\begin{array}{l}\text { Kong and Yu, 2007; Dong et } \\
\text { al., 1990; Susi and Byler, } \\
\text { 1986; Cabiaux et al., 1989; } \\
\text { Ulrichs et al., 2014; López et }\end{array}$ \\
\hline
\end{tabular}




\begin{tabular}{|c|c|c|c|c|c|c|}
\hline & & & & & & al., 2000 \\
\hline $1658^{\text {sh, sd }}$ & $1658^{\text {sh, sd }}$ & $1658^{\text {sh, sd }}$ & $1658^{\text {sh, sd }}$ & - & $\begin{array}{c}\text { Amide I: a) } \alpha \text {-helix in proteins; b) turns in livetins } \\
\text { and LDL and HDL }\end{array}$ & $\begin{array}{l}\text { Cabiaux et al., 1989; Kong and } \\
\text { Yu, 2007; Ulrichs et al., 2014; } \\
\text { López et al., 2000 }\end{array}$ \\
\hline $1651^{\mathrm{sh}, \mathrm{sd}}$ & $1651^{\text {sh, sd }}$ & $1651^{\text {sh, sd }}$ & $1651^{\text {sh, sd }}$ & $1651^{\text {sh, sd }}$ & $\begin{array}{l}\text { Amide I: a) } \alpha \text {-helix in proteins: albumin, livetins } \\
\text { and HDL and LDL; b) }-\mathrm{C}=\mathrm{C} \text { - in fatty acids and NLs }\end{array}$ & $\begin{array}{l}\text { Susi and Byler et al., 1986; } \\
\text { Cabiaux et al., 1989; Furlan et } \\
\text { al., 2007; Ulrichs et al., 2014; } \\
\text { López et al., 2000; van der } \\
\text { Weerd et al., 2005 }\end{array}$ \\
\hline $1637^{\text {sh, sd }}$ & $1637^{\text {sh, sd }}$ & $1637^{\text {sh, sd }}$ & - & - & $\begin{array}{c}\text { Amide I random coils with contribution of } \\
\text { deformation vibrations of amino group }(\mathrm{C}-\mathrm{N}) \text { in } \\
\text { phospholipids polar head of PC }\end{array}$ & $\begin{array}{l}\text { Kong and Yu, 2007; Susi and } \\
\text { Byler, 1986; Cabiaux et al., } \\
\text { 1989; Furlan et al., 2007; } \\
\text { Ulrichs et al., } 2014 \\
\end{array}$ \\
\hline- & - & - & $1634^{\text {sh, sd }}$ & $1634^{\text {sh, sd }}$ & $\begin{array}{c}\text { Amide I } \beta \text {-sheet in proteins: HDL and intramolecular } \\
\beta \text {-sheet in livetins }\end{array}$ & $\begin{array}{l}\text { Kong and Yu, 2007; Harris and } \\
\text { Severcan, 1999; Dong et al., } \\
\text { 1990; Goormaghtigh et al., } \\
\text { 2009; López et al., 2000; } \\
\text { Ulrichs et al., 2014 }\end{array}$ \\
\hline 1629 & 1629 & 1629 & 1630 & 1631 & $\begin{array}{c}\text { Amide I } \beta \text {-sheet in proteins: HDL and intramolecular } \\
\beta \text {-sheet in livetins }\end{array}$ & $\begin{array}{l}\text { Kong and Yu, 2007; Harris and } \\
\text { Severcan, 1999; Dong et al., } \\
\text { 1990; Goormaghtigh et al., } \\
\text { 2009; López et al., 2000; } \\
\text { Ulrichs et al., 2014 }\end{array}$ \\
\hline $1618^{\text {sh, sd }}$ & $1618^{\mathrm{sh}, \mathrm{sd}}$ & $1618^{\mathrm{sh}, \mathrm{sd}}$ & - & - & $\begin{array}{c}\text { Amide I } \beta \text {-sheets in proteins: intermolecular } \beta \text {-sheet } \\
\text { in livetins and tyrosin residue in LDL }\end{array}$ & $\begin{array}{l}\text { Ulrichs et al., 2014; López et } \\
\text { al., 2000 }\end{array}$ \\
\hline- & - & - & - & $1578^{\text {sh, sd }}$ & -COO-metal asymmetric stretch in PLs & $\begin{array}{l}\text { Venyaminov and Kalnin, 1990; } \\
\text { Cagnasso et al., 2010; } \\
\text { Cagnasso et al., 2010 }\end{array}$ \\
\hline 1536 & 1536 & 1536 & 1536 & 1538 & Amide II parallel $\beta$-sheet & $\begin{array}{l}\text { Pelton and McLean, 2000; } \\
\text { Miyazawa and Blout, } 1961\end{array}$ \\
\hline - & - & - & - & 1541 & a) Amide II parallel $\beta$-sheet; and b) - $\mathrm{COO}-\mathrm{Pb}$ & $\begin{array}{c}\text { Pelton and McLean, 2000; } \\
\text { Mazzeo et al., 2008; Mazzeo et }\end{array}$ \\
\hline
\end{tabular}




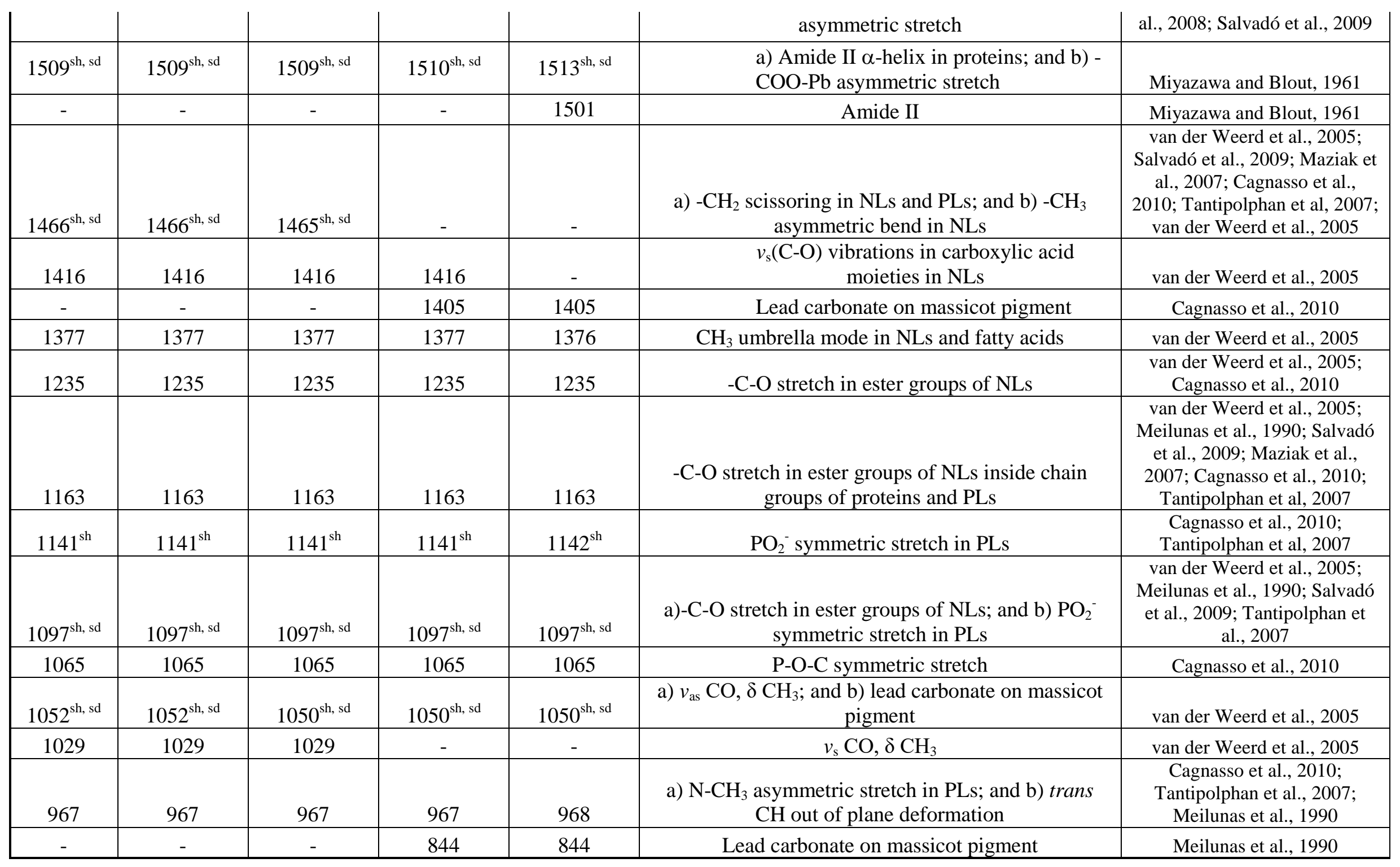




\begin{tabular}{|c|c|c|c|c|c|c|}
\hline 722 & 722 & 722 & 722 & 722 & $\begin{array}{l}\text { a) cis } \mathrm{CH} \text { out of plane bend NLs; and b) }-\mathrm{CH}_{2} \\
\text { rocking in NLs }\end{array}$ & $\begin{array}{l}\text { van der Weerd et al., 2005; } \\
\text { Meilunas et al., 1990; Salvadó } \\
\text { et al., } 2009\end{array}$ \\
\hline 699 & 699 & 699 & 697 & 696 & $\mathrm{CO}_{3}$ rocking deformations & Cagnasso et al., 2010 \\
\hline- & - & - & 681 & 681 & Lead carbonate on massicot pigment & Meilunas et al., 1990 \\
\hline
\end{tabular}

Table 12.7. IR absorption band assignment for YO (pure egg yolk-oil emulsion) specimen and YO@Zn specimens prepared at 10, 30,50 and 75 wt $\%$. Characteristics of the IR absorption bands referred to the YO specimen: sh: shoulder and sd: identified in the second derivative curve.

\begin{tabular}{|c|c|c|c|c|c|c|}
\hline \multicolumn{5}{|c|}{ Frequency $\left(\mathrm{cm}^{-1}\right)$} & \multirow{2}{*}{ IR bands assignment } & \multirow{2}{*}{ References } \\
\hline YO & YO@Zn $\mathbf{Z n}_{10}$ & YO@Zn & YO@Zn & YO@Zn 75 & & \\
\hline 3459 & 3459 & - & - & - & vOH water & Conti et al., 2014 \\
\hline 3278 & 3280 & 3283 & 3290 & 3298 & Amide A, N-H stretch & Kong and $\mathrm{Yu}, 2007$ \\
\hline 3055 & 3055 & 3055 & 3060 & 3065 & $\begin{array}{c}\text { Amide B, N-H Fermi resonance between amide II } \\
\text { overtone and N-H stretch }\end{array}$ & Kong and $\mathrm{Yu}, 2007$ \\
\hline 3007 & 3007 & 3007 & - & - & $\begin{array}{c}\text { Cis-type unsaturated unconjugated C-H group } \\
(\mathrm{C}=\mathrm{C}-\mathrm{H} \text { stretch }) \text { in NLs and PLs }\end{array}$ & Meilunas et al., 1990 \\
\hline $2948^{\text {sh }}$ & $2948^{\text {sh }}$ & $2948^{\text {sh }}$ & $2950^{\text {sh }}$ & $2952^{\text {sh }}$ & Antisymmetric $\mathrm{CH}_{3}$ stretch & $\begin{array}{c}\text { van der Weerd et al., 2005; } \\
\text { Meilunas et al., 1990; } \\
\text { Tantipolphan et al., 2007 }\end{array}$ \\
\hline 2922 & 2922 & 2922 & 2922 & 2923 & Antisymmetric $\mathrm{CH}_{2}$ stretch & $\begin{array}{c}\text { van der Weerd et al., 2005; } \\
\text { Meilunas et al., 1990; } \\
\text { Cagnasso et al., 2010; } \\
\text { Tantipolphan et al., 2007 }\end{array}$ \\
\hline- & - & - & - & $2898^{\text {sh }}$ & Stretching vibrations of tertiary $-\mathrm{CH}$ groups & Meilunas et al., 1990 \\
\hline $2870^{\text {sh }}$ & $2870^{\text {sh }}$ & $2870^{\text {sh }}$ & $2870^{\text {sh }}$ & $2870^{\text {sh }}$ & Symmetric stretch $\mathrm{CH}_{3}$ & Mazzeo et al., 2008 \\
\hline 2852 & 2852 & 2852 & 2852 & 2852 & Symmetric stretch $\mathrm{CH}_{2}$ & $\begin{array}{l}\text { van der Weerd et al., 2005; } \\
\text { Meilunas et al., 1990; } \\
\text { Cagnasso et al., 2010; } \\
\text { Tantipolphan et al., 2007; } \\
\text { Jackson and Mantsch, } 1992\end{array}$ \\
\hline 1744 & 1744 & 1744 & 1743 & 1740 & $-\mathrm{C}=\mathrm{O}$ stretch in NLs & $\begin{array}{c}\text { van der Weerd et al., 2005; } \\
\text { Meilunas et al., } 1990\end{array}$ \\
\hline $1720^{\text {sh, sd }}$ & $1720^{\text {sh, sd }}$ & $1720^{\text {sh, sd }}$ & - & - & $-\mathrm{C}=\mathrm{O}$ stretch in triglycerides and glycerol-diacyl & van der Weerd et al., 2005; \\
\hline
\end{tabular}




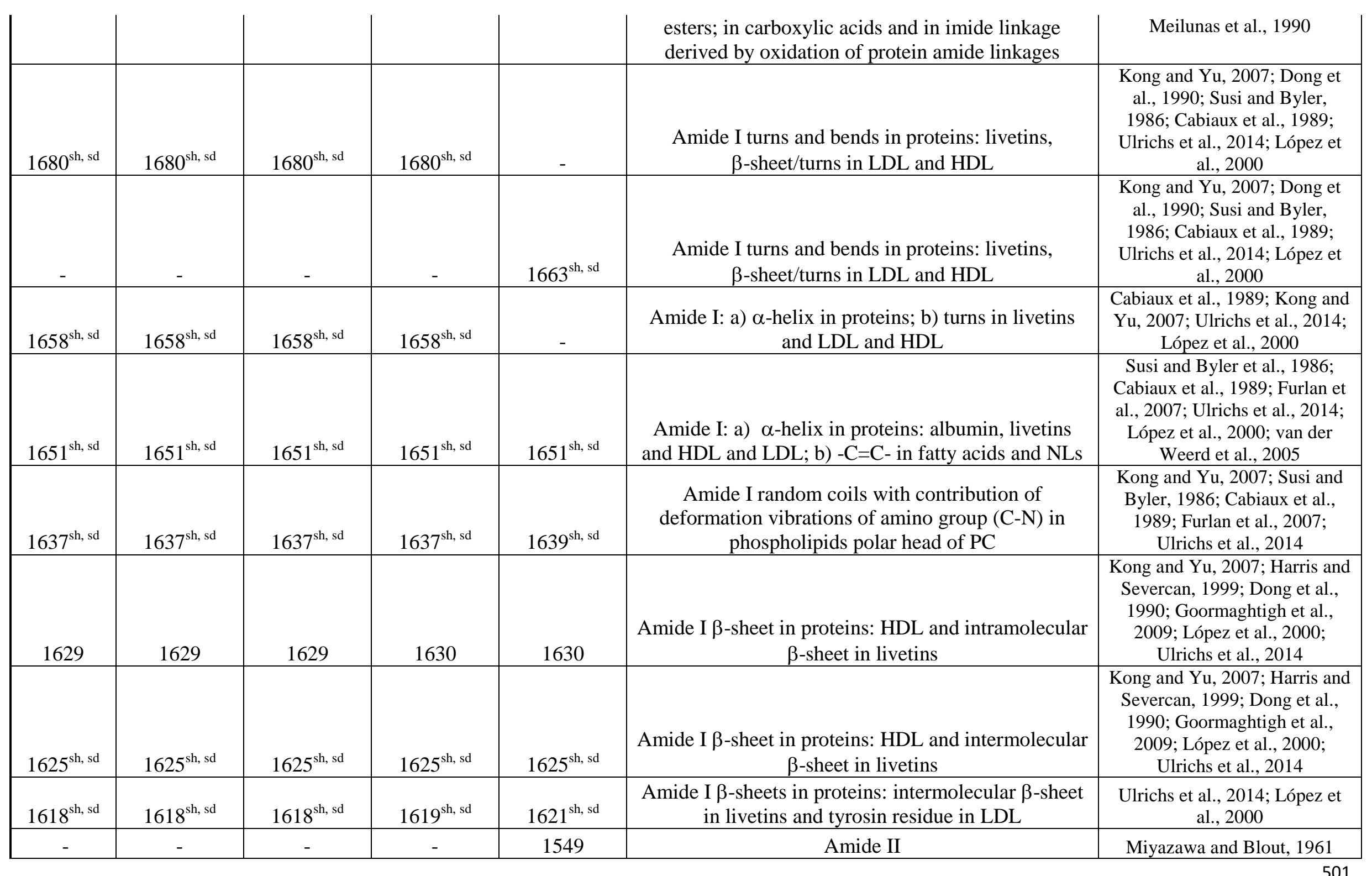




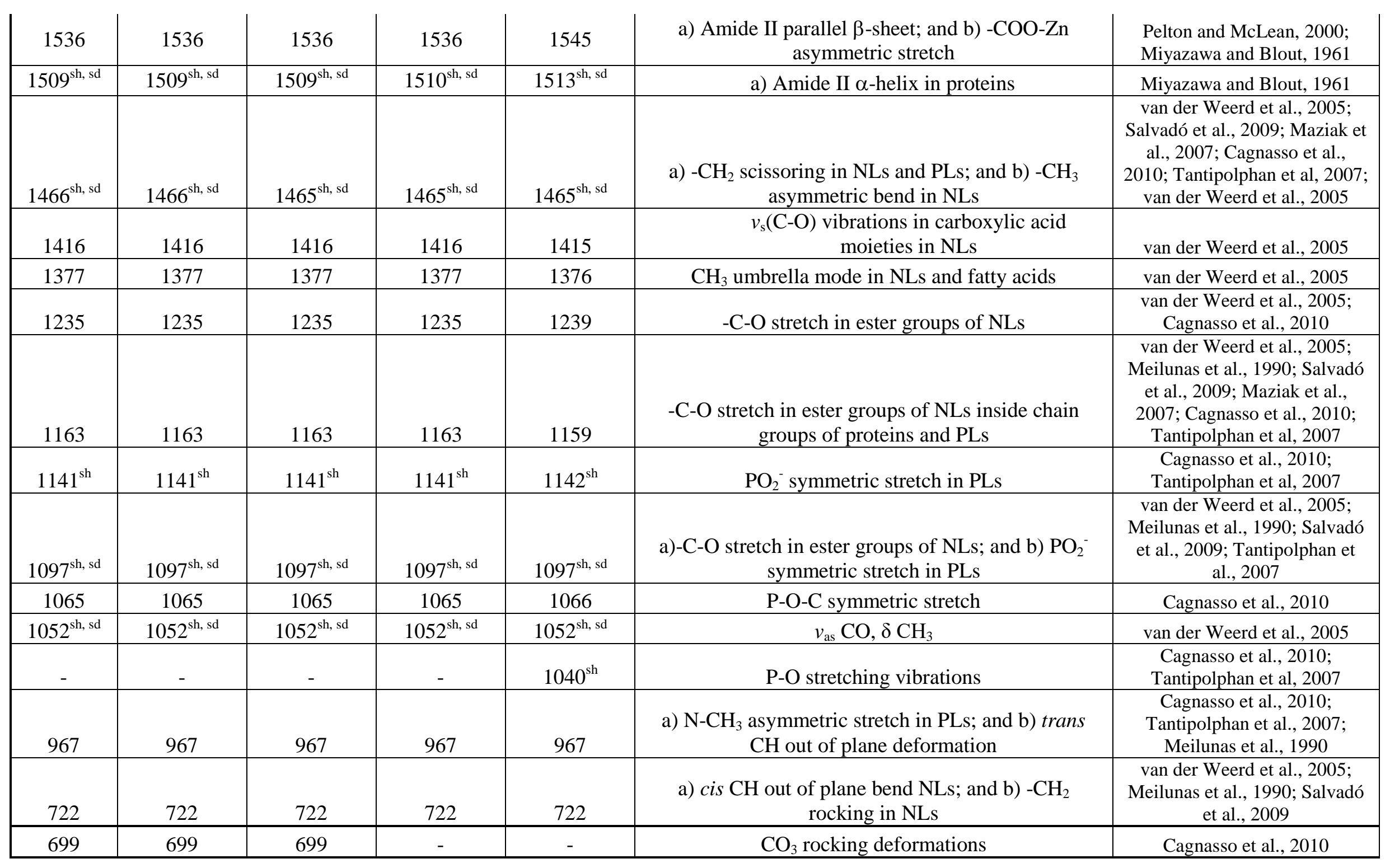




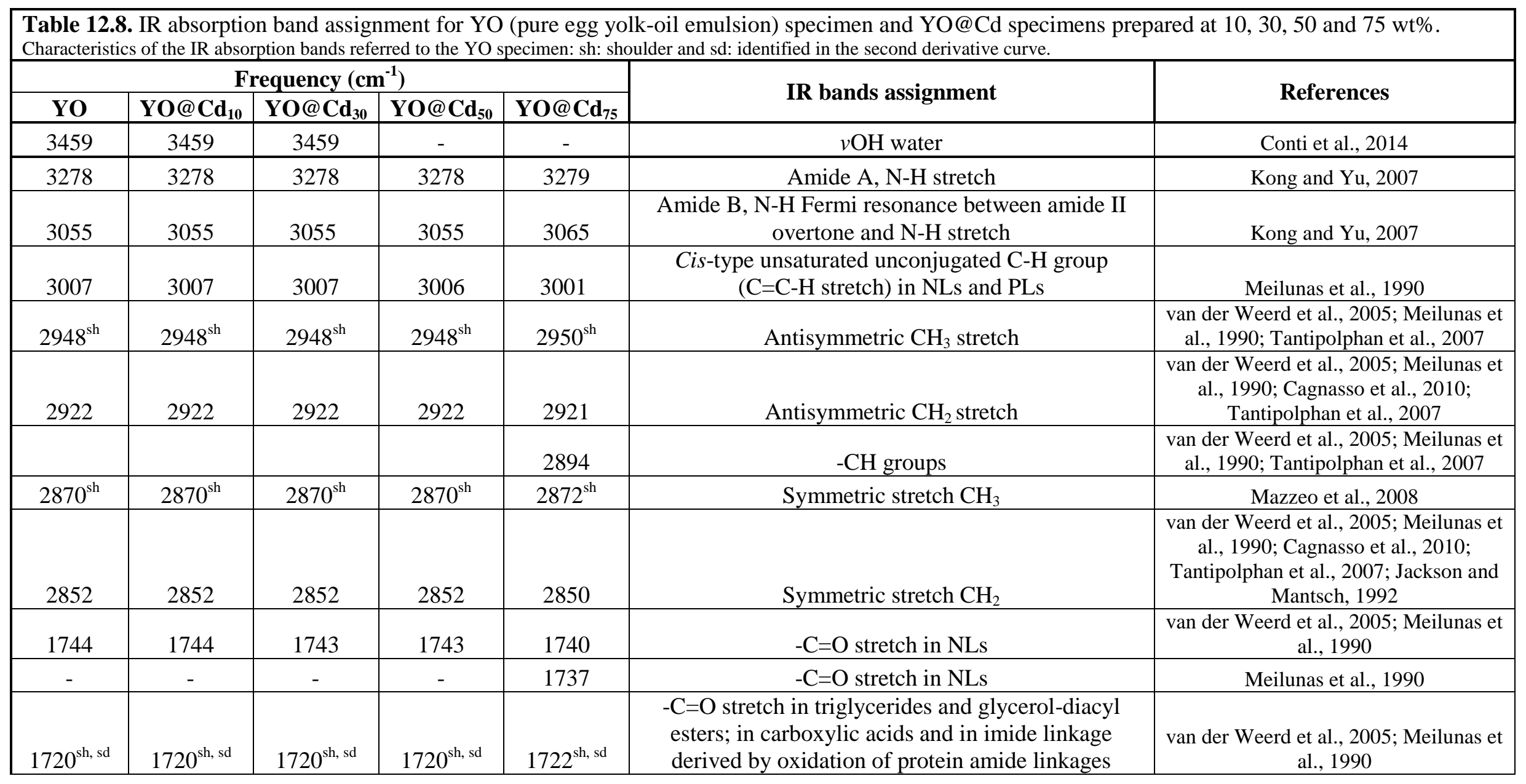




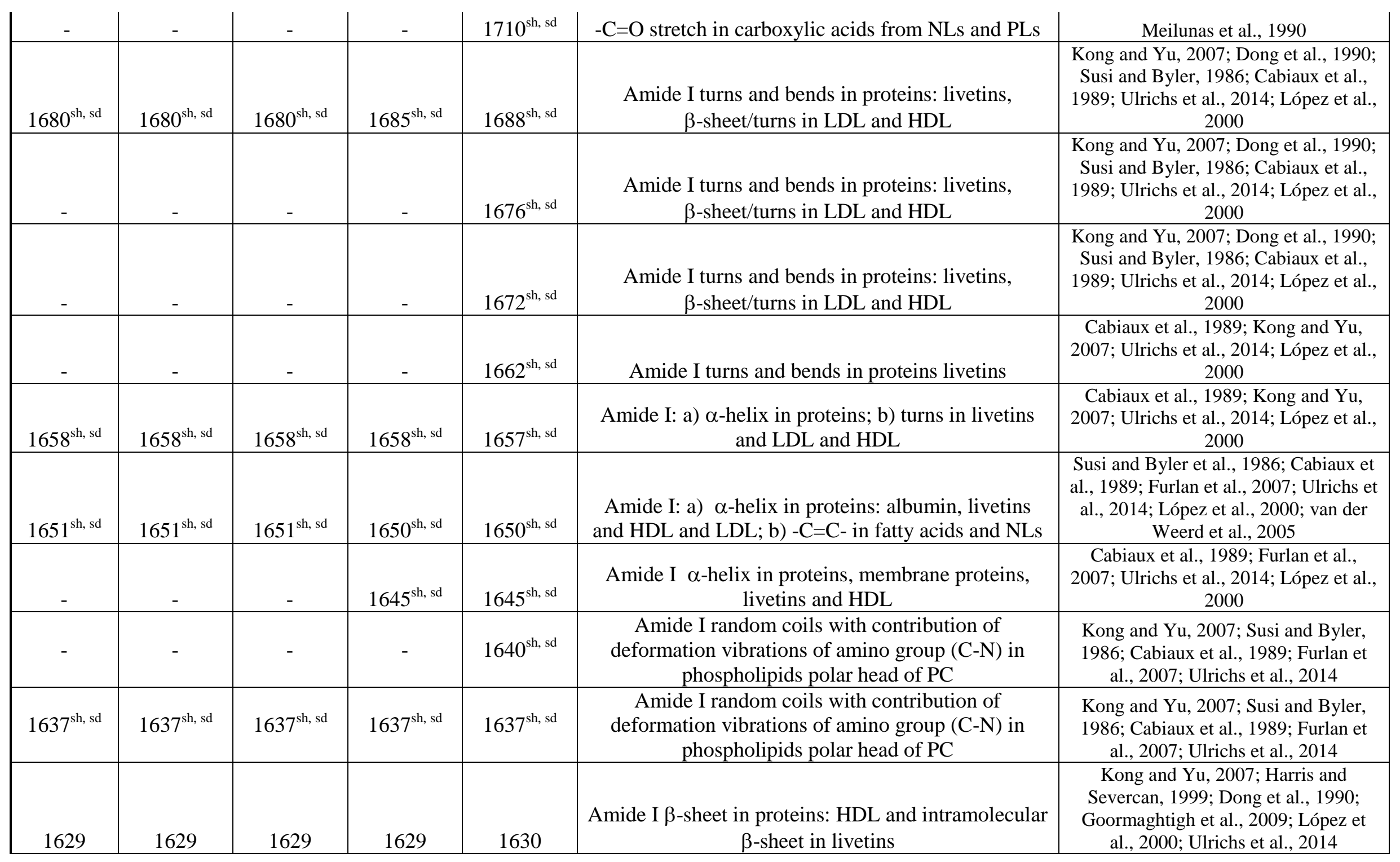




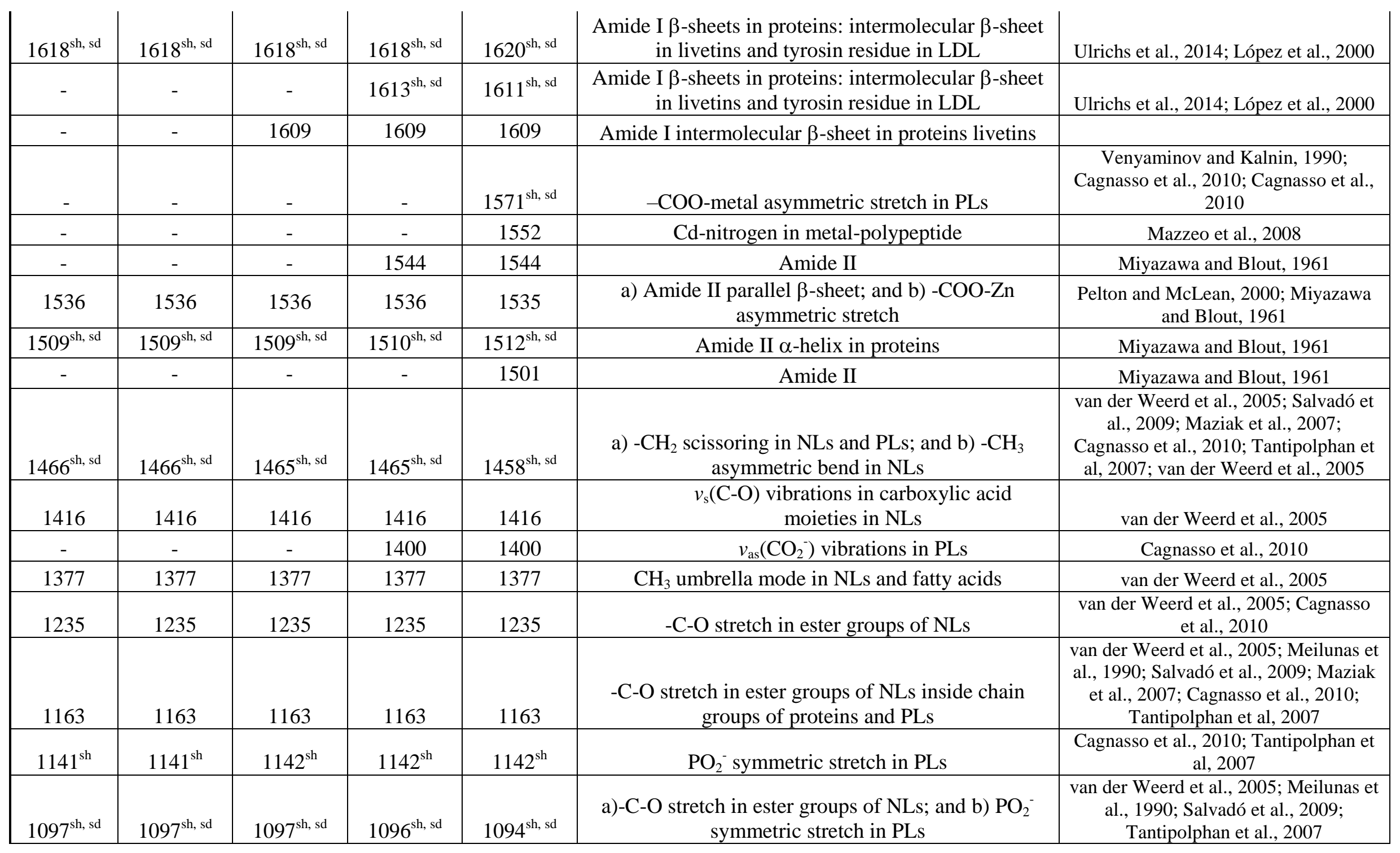




\begin{tabular}{|c|c|c|c|c|c|c|}
1065 & 1065 & 1065 & 1065 & 1057 & P-O-C symmetric stretch & Cagnasso et al., 2010 \\
\hline $1052^{\text {sh, sd }}$ & $1052^{\text {sh, sd }}$ & $1050^{\text {sh, sd }}$ & $1050^{\text {sh, sd }}$ & - & $v_{\text {as }} \mathrm{CO}, \delta \mathrm{CH}_{3}$ & van der Weerd et al., 2005 \\
\hline 1029 & 1029 & 1029 & 1029 & 1029 & $v_{\mathrm{s}} \mathrm{CO}, \delta \mathrm{CH}_{3}$ & van der Weerd et al., 2005 \\
\hline 967 & 967 & 967 & 967 & 967 & $\begin{array}{c}\text { a) } \mathrm{N}_{3} \mathrm{CH}_{3} \text { asymmetric stretch in PLs; and b) trans } \\
\text { CH out of plane deformation }\end{array}$ & $\begin{array}{c}\text { Cagnasso et al., 2010; Tantipolphan et } \\
\text { al., 2007; Meilunas et al., 1990 }\end{array}$ \\
\hline 722 & 722 & 722 & 722 & 721 & $\begin{array}{c}\text { a) cis } \mathrm{CH} \text { out of plane bend NLs; and b) -CH } \mathrm{CH}_{2} \\
\text { rocking in NLs }\end{array}$ & $\begin{array}{c}\text { van der Weerd et al., 2005; Meilunas et } \\
\text { al., 1990; Salvadó et al., 2009 }\end{array}$ \\
\hline 699 & 699 & 699 & 699 & 697 & $\mathrm{CO}_{3}$ rocking deformations & Cagnasso et al., 2010 \\
\hline
\end{tabular}


13. LIST OF ABBREVIATIONS 
A.D.:

AFM:

AFM-NI:

AFM-VMP:

ATR:

B.C.:

ca:

CPMA:

CV:

CVs:

DTMS:

DTMSMS:

EC-AFM:

EDXRF:

EE:

EG:

EO:

EPMA:

FESEM:

FSD:

FT:

FTIR:

GC:

GC-MS:

Hb:

HDLs:

HLH:

HPLC:

IgY:

IR:

KK:

LA-ICPMS:

LDIMS:

LDLs:

LIBS:

MALDI-TOF

$\mu$-FTIR:

H-Raman:

$\mu-X R D:$
After Christ

atomic force microscopy

atomic force microscopy nanoindentation

atomic force microscopy couple with voltammetry of microparticles attenuated total reflection

Before Christ

circa

color pigment manufactures association

cyclic voltammetry

cyclic voltammograms

direct temperature-resolved mass spectrometry

direct temperature resolved mass spectrometry and tandem mass spectrometry

electrochemical atomic force microscopy

energy- dispersive X-ray fluorescence

excitation emission

whole egg

whole egg-linseed oil emulsion

electron probe microanalyzers

field emission scanning electron microscopy

Fourier self-deconvolution

Fourier transform

Fourier transform infrared spectroscopy

gas chromatography

gas chromatography coupled with a mass spectrometer

hemoglobin

high-density-lipoproteins

helix-loop-helix

high performance liquid chromatography

immunoglobulin

infrared spectroscopy

Kramers- Krowing algorithm

laser ablation inductively coupled plasma mass spectrometry

laser desorption ionization mass spectrometry

low -density-lipoproteins

laser-induced breakdown spectroscopy

matrix assisted laser desorption ionization - time of flight mass

spectrometer

micro Fourier transform infrared spectroscopy

micro Raman

$\mathrm{X}$-ray microdiffractometry 
MOUSE:

MS:

MRS:

MW:

NEEs:

NMR:

PCA:

PIGE:

PIXE:

PL:

PLM:

PVA:

PVC:

PVT:

Py-GC-MS:

RH:

SECM:

SEM:

SEM-EDX:

SIMS:

SR $\mu$-XRF:

SWV:

SWVs:

TEM:

TEM/HRTEM:

Tg:

TOF-MS:

TOF-SIMS:

TXRF:

UIVFP:

UME:

UV:

VMP:

XRD:

XRF:

Y:

YO: mobile universal surface explorer

mass spectrometry

$\mu$-Raman spectroscopy

molecular weight

nanoelectrode ensembles

nuclear magnetic resonance

principal component analysis

paraffin impregnated graphite electrodes

particle induced X-ray emission

phospholipids

polarized light microscopy

polyvinyl acetate

pigment volume concentration

phosvitin

pyrolisis-silylation-gas chromatography-mass spectrometry

relative humidity

scanning electrochemical microscopy

scanning electron microscopy

scanning electron microscopy with energy dispersive X-ray analysis secondary ion mass spectrometry

synchrotron radiation based micro X-ray fluorescence spectrometry

square wave voltammetry

square wave voltammograms

transmission electron microscopy

TEM coupled with high-resolution transmission electron microscopy

glass-transition temperature

time of flight - mass spectrometer

time of flight - secondary ion mass spectrometry

total reflection X-ray fluorescence spectrometry

ultraviolet-induced visible fluorescence photography

ultramicroelectrode

ultraviolet radiation

voltammetry of microparticles

X-ray diffraction

$\mathrm{X}$-ray fluorescence elemental analysis

egg yolk

egg yolk-linseed oil emulsion 


\section{PUBLICATIONS}




\title{
Electrochemical characterization of biodeterioration of paint films containing cadmium yellow pigment
}

\author{
Annette S. Ortiz-Miranda ${ }^{1}$ - Antonio Doménech-Carbó ${ }^{2}$. \\ María Teresa Doménech-Carbó ${ }^{1} \cdot$ Laura Osete-Cortina $^{1}$ • Francisco M. Valle-Algarra $^{2}$. \\ Fernando Bolívar-Galiano $^{3}$ • Inés Martín-Sánchez ${ }^{4}$ • María del Mar López-Miras ${ }^{3}$
}

Received: 28 June 2016 /Revised: 25 July 2016 / Accepted: 29 July 2016 / Published online: 15 August 2016

(C) Springer-Verlag Berlin Heidelberg 2016

\begin{abstract}
The voltammetry of microparticles (VMP) methodology was used to characterize the biological attack of different bacteria and fungi to reconstructed egg tempera and egglinseed oil emulsion paint films containing cadmium yellow $(\mathrm{CdS})$, which mimic historical painting techniques. When these paint films are in contact with aqueous acetate buffer, different cathodic signals are observed. As a result of the crossing of VMP data with attenuated total reflectance Fourier transform infrared spectroscopy (ATR-FTIR), scanning electrochemical microscopy (SECM), field emission scanning electron microscopy (FESEM), and atomic force microscopy (AFM), these voltammetric signals can be associated with the reduction of $\mathrm{CdS}$ and different complexes associated to the proteinaceous and fatty acid fractions of the binders. After biological attack with different fungi (Acremonium chrysogenum, Aspergillus niger, Mucor rouxii, Penicillium chrysogenum, and Trichoderma pseudokoningii) and bacteria (Arthrobacter oxydans, Bacillus amyloliquefaciens, and Streptomyces cellulofans), the observed electrochemical signals experience specific modifications depending on the binder
\end{abstract}

Dedicated with deep admiration to Milivoj Lovrić and Šebojka Komorsky-Lovrić on the occasion of their 65 th birthday.

Antonio Doménech-Carbó

antonio.domenech@uv.es

1 Institut de Restauració del Patrimoni, Universitat Politècnica de València, Camí de Vera 14, 46022 València, Spain

2 Departament de Química Analítica, Universitat de València, Dr. Moliner, 50, 46100 Burjassot, València, Spain

3 Departamento de Pintura, Universidad de Granada, Granada, Spain

4 Departamento de Microbiología, Universidad de Granada, Granada, Spain and the biological agent, allowing for an electrochemical monitoring of biological attack.

Keywords Electrochemistry $\cdot$ Biodeterioration $\cdot$ Cadmium sulfide $\cdot$ Egg tempera $\cdot$ Egg-oil emulsion $\cdot$ FTIR

\section{Introduction}

Biodeterioration is a problem affecting paintings which is of crucial importance in the conservation of works of art. In the last decades, studies in the field of conservation of heritage on this subject are, in general, focused on the direct isolation and identification of the microbiological agents that act on the different components of the painting [1-3]. Attempts to correlate microbial growth with type of materials present in paintings have been made by placing pieces of painting prepared with different supports and binding media on suitable culture media further inoculated with microorganisms and incubated under laboratory conditions so that the extent of the microbial colonization could be evaluated [4]. An alternative strategy consisted of preparing mock paintings prepared according to the traditional recipes that are exposed to soil for promoting colonization by bacteria and fungi that were isolated, identified and used for reinfecting sterile mock paintings in order to determine their ability for colonizing paintings [5]. These studies have demonstrated that the composition of the different parts of the painting (support, ground, and paint layers) is determinant when the artwork undergoes a microbial attack. The type of support (canvas or panel) and binding medium (oil paints, temper, or watercolors) mainly determines the selective growing of microorganisms [6]. A wide range of species have been identified as potential colonizing agents of paintings. Among them are Alternaria, Aspergillus, Aureobasidium, Chaetomium, Cladosporium, 
Eurotium, Fusarium, Mucor, Cephalosporium (Acremonium), Penicillium, and Spicaria fungi and Bacillus, Arthrobacter, Acinetobacter, Stenotrophomonas, and Delftia bacteria [3, 7, 8].

Characterization of the damaging effects produced by these microbial agents has also been the aim of many studies, especially those affecting the organic compounds composing the support and the binding media [9]. These materials provide excellent substrates for the growth of microorganisms, in particular, fungi and most bacteria. It has been shown that the microorganism colonization in canvas painting starts in the organic materials present on the reverse side where the cellulosic support and proteinaceous binders come into contact. Sometimes, the chalk-rich ground can act as substrate for microbial growing [6]. The binding media present in the obverse side of the painting are susceptible to attack by transient airborne microorganisms such as bacteria and fungi which can accumulate on the painted surface for a long time as spores. Their further growth can result in the detachment of the paint layer from the support especially in conditions of high humidity [10]. Spots due to colored metabolic byproducts excreted by the microorganisms have also been frequently observed [11]. Laboratory experiments have demonstrated that $\alpha$ aminobutyric acid in combination with L-malic acid and glucose are the main products responsible for the fox spots [12-14]. Fungal amino acids, metabolic acids, sugars, and lipids and their breakdown products (fatty acids, glycerol) have also been found in fox spots. In these cases, the interaction of amino acids and sugars results in melanoidin, a colored substance, by a Maillard browning reaction. Fading of the paint layer is another degradation effect caused by the growth of bacteria and fungi in the paintings [11, 15].

Changes caused in the structure of paintings by microorganisms arise mainly from the enzymatic decomposition of their constituents, which results in the reduction of the mechanical strength of the support and loss of flexibility of paint layers [7, 8, 15-18]. Actinomycetes are known to produce many types of enzymes such as collagenases (proteases), which are capable of destroying collagen and gelatin-based binders by their hydrolytic activity. Collagenases cleave the collagen molecule into short peptides by hydrolysis at multiple sites along the triple helix. These enzymes are capable of recognizing small amino acid sequences in the protein chain and, therefore, act on active sites along the collagen molecule, which are dictated by the primary structure (amino acid sequence) rather than by the entire molecule configuration. $\beta$-collagenase, for instance, cleaves between the $\mathrm{X}$ and the glycine residues in specific sequences, (a)-glycine-A-B-glycine-C-alanine-, (b) -glycine-B-A-glycine-alanine-arginine-, (c) glycine-B-A-glycine-proline-hydroxyproline-, where A-, $\mathrm{B}-$, and $\mathrm{C}$ - are any of the amino acids present in collagen except glycine. After this, proteases cleave the short peptides released by the collagenase action to single amino acids [19].

The main enzymatic activities involved in the deterioration of oil paintings are due to lipases excreted by most fungi. These enzymes catalyze the hydrolysis of ester bonds of triacylglycerols at the interface between an insoluble substrate and water [20]. Different biochemical pathways for the degradation of lipids by microorganisms have been proposed [1]: (a) photooxidation or enzymatic oxidation of the hydrolyzed long-chain fatty acids to form free fatty acid hydroperoxides and then other pertinent end-products [21, 22], (b) the formation of methyl ketones and secondary alcohols from free medium-chain fatty acids resulting from metabolism by molds [21], (c) photooxidation or enzymatic oxidation of triacylglycerols to form triacylglycerol hydroperoxides and further hydrolysis to pass to free fatty acid hydroperoxides resulting in secondary and tertiary products [21].

As previously mentioned, microorganisms are also responsible for the deterioration of pigments. The fading of the pigments from the Prehistoric cave of Lascaux is the most outstanding example [23]. Divalent lead-containing pigments such as lead white can be transformed in four-valent leadoxides by bacteria [24].

In this context, the study of the biodeterioration of reconstructed paint films that mimic historical painting techniques can be of interest for gain of knowledge on the mechanisms of biodeterioration, the characterization of the esthetic changes induced in the painting due to the microorganism colonization, and for establishing its effect in the long-term preservation of the painting due to the loss of chemical and mechanical stability [25]. Classical methodologies for studying paint film biodeterioration are based on electron microscopy [26], chromatographic [22] and spectrophotometric [27-29] techniques. Here, we report for the first time the use of a complementary technique, the voltammetry of microparticles (VMP), for such studies. VMP is a solid-state electrochemical technique developed by Scholz et al. [30, 31], which provides analytical information of sparingly soluble insulating solids attached to inert electrodes immersed into suitable electrolytes. Among a variety of materials [32], this technique has been extensively applied in the field of conservation and restoration, as recently reviewed $[33,34]$.

In the current report, VMP has been used to monitor the deterioration of a series of reconstructed paint films containing cadmium yellow (CdS) bound with two traditional binding media, namely, egg tempera and egg-linseed oil emulsion, which were inoculated with selected fungi and bacteria whose ability for growing in paintings is well known $[3,7,8]$.

Proteinaceous materials and drying oils, either alone or mixed together, have been used since antiquity [35, 36]. Egg tempera has been used in paintings, altarpieces, and polychromed sculptures in the Middle Ages and, probably, in more ancient times [37]. The whole egg, the yolk, or the 
white is thus made as tempera medium. The egg tempera which is traditional and reflects the practice of many centuries is that made simply with the yolk of the egg. Depending on the degree of opacity to be obtained in the paint layer, the proportions of pigment and medium are adjusted and, if necessary, the whole thinned with water. In general, amounts of pigment around $50 \% \mathrm{w} / \mathrm{w}$ are used [36]. Moreover, in an attempt to obtain particular chromatic effects, artists often used tempera grassa, which consists of an emulsion formed by mixing drying oil and egg (whole or yolk) [35].

$\mathrm{CdS}$ is a modern pigment that displays a widely studied electrochemistry in solid state $[31,32,38]$. Cadmium yellow was selected as a pigment probe in this study due to its good electrochemical response and its low absorption and scattering in the IR region that enables a complementary study of the changes undergone by the organic binding medium by attenuated total reflectance-Fourier transform infrared spectroscopy (ATR-FTIR). The results obtained from VMP analysis have been complemented with those obtained upon coupling with atomic force microscopy (AFM-VMP) and scanning electrochemical microscopy (SECM). Electrochemical data have also been correlated with field emission scanning electron microscopy (FESEM).

\section{Experimental}

\section{Instrumentation}

Sodium acetate buffer $(0.25 \mathrm{M})$ (Panreac) at $\mathrm{pH} 4.75$ was used as a supporting electrolyte. Square wave voltammograms (SWVs) and cyclic voltammograms (CVs) were obtained using abrasive VIMP protocols (vide infra). Importantly, the electrolyte solution was renewed after each electrochemical run to avoid contamination due to cadmium ions eventually released to the solution phase during electrochemical turnovers. Commercial paraffin-impregnated graphite bars of Staedtler 200 HB type (68\% wt. graphite, diameter $2 \mathrm{~mm}$ ) were used. Prior to the series of runs for each material or sample, a conditioning protocol was used to increase repeatability. The electrode surface was polished with alumina, rinsed with water, and polished by pressing over paper. For electrode modification, an amount of 1-2 mg of the sample was extended on an agate mortar, forming a spot of finely distributed material. Then, the lower end of the graphite electrode was gently rubbed over that spot of sample and finally rinsed with water to remove ill-adhered particles. Samplemodified graphite bars were then dipped into the electrochemical cell so that only the lower end of the electrode was in contact with the electrolyte solution. This procedure provides an almost constant electrode area and reproducible background currents.
Electrochemical experiments were performed at $298 \mathrm{~K}$ in a three-electrode cell under argon atmosphere using a $\mathrm{CH}$ I660C device (Cambria Scientific, Llwynhendy, Llanelli UK). A platinum wire counter electrode and an $\mathrm{Ag} / \mathrm{AgCl}$ ( $3 \mathrm{M} \mathrm{NaCl}$ ) reference electrode completed the threeelectrode arrangement. SECM experiments were performed on deposits of the studied materials on a graphite plate acting as a substrate electrode in contact with $5.0 \mathrm{mM} \mathrm{K}_{4} \mathrm{Fe}(\mathrm{CN})_{6}$ solution in $0.25 \mathrm{M} \mathrm{HAc} / \mathrm{NaAc}$ ( $\mathrm{pH} 4.75$ ). Experiments were performed with $\mathrm{CH} 920 \mathrm{c}$ equipment using a microdisk platinum electrode tip ( $\mathrm{CH} 49$, diameter $20 \mu \mathrm{m}$ ) and a Pt substrate electrode. The bipotentiostat mode was used to apply potentials to the tip $\left(E_{\mathrm{T}}\right)$ and the electrode substrate $\left(E_{\mathrm{S}}\right)$. In situ AFM-monitored electrochemical experiments were performed with a multimode AFM (Digital Instruments VEECO Methodology Group, USA), with a NanoScope IIIa controller and equipped with a J-type scanner (max. scan size of $150 \times 150 \times 6 \mu \mathrm{m}$ ). The topography of the samples was studied in contact mode. An oxide-sharpened silicon nitride probe Olympus (VEECO Methodology Group, model NP-S) has been used with a V-shaped cantilever configuration. Transference of sample particles to a carbon plate and experimental conditions were similar to those previously described [39].

The IR spectra in the ATR mode of the powdered samples were obtained using a Vertex 70 FTIR spectrometer (Bruker Optik GmbH, Germany) with an FR-DTGS (fast recovery-deuterated triglycine sulfate) temperaturestabilized coated detector and a MKII Golden Gate ATR accessory. A total of 32 scans were collected at a resolution of $4 \mathrm{~cm}^{-1}$ and the spectra were processed using the OPUS/IR software. For performing the determination of the secondary structure of the egg yolk proteins, the main features of the commonly used procedure including Fourier self-deconvolution (FSD) has been applied. FSD of the IR spectra covering the amide I region (1595$1705 \mathrm{~cm}^{-1}$ ) was performed using Lorentzian line shape. Apodization with a Blackman-Harris function was always performed automatically at the same time in the software. FSD was performed using a bandwidth at half height of $13 \mathrm{~cm}^{-1}$ and a resolution enhancement factor of 2.4 . These values, commonly used for quantitatively estimating the protein secondary structures [40], were selected in an attempt to avoid possible random noise artifacts indistinguishable from amide bands.

Secondary electron images were obtained using a Zeiss FESEM (model ULTRA 55), operating with an Oxford-X Max X-ray microanalysis system controlled by Inca software. Image acquisition was done at the $1-\mathrm{kV}$ accelerating voltage. Samples were directly observed in order to avoid interference with the particulate structure of the coating element used for eliminating charging effects. 


\section{Reference materials and test specimens}

Cold pressed linseed oil and CdS (Kremer) and fresh hen's egg were used as reference materials for preparing the series of paint films. Reconstructed egg tempera paint films (EG) were prepared by mixing the pigment with the appropriate amount of egg until suitable consistence (30\% weight composition of pigment) and spreading this product on glass slides in order to form a thin film. The paint films were dried at room temperature for 4 weeks $\left(21{ }^{\circ} \mathrm{C}, 50 \% \mathrm{RH}\right)$. The thickness of the films was in the range of $0.3-0.5 \mathrm{~mm}$. Reconstructed egg + linseed oil emulsion paint films (EO) were prepared by mixing the pigment with the appropriate amount of an egg-linseed oil emulsion (1:1) (35\% weight composition of pigment). The reconstructed paint films were dried at room temperature for 4 weeks $\left(21{ }^{\circ} \mathrm{C}, 50 \% \mathrm{RH}\right)$. The thickness of the films was in the range of $0.3-0.5 \mathrm{~mm}$.

\section{Microorganisms and cultures}

Bacterial and fungal strains, obtained from the Spanish Collection of Type Cultures (CECT, Colección Española de Cultivos Tipo, Universidad de Valencia, Valencia, Spain), were chosen because they have been frequently found in biodeterioration studies of cultural heritage [8]. The selected fungi were as follows: Acremonium chrysogenum (Ac) (CECT 2718, ATCC 14615), Aspergillus niger (An) (CECT 2088, ATCC 9029), Mucor rouxii (Mr) (CECT 2655, ATCC 24905), Penicillium chrysogenum (Pc) (CECT 2306, ATCC 8537), and Trichoderma pseudokoningii (Tp) (CECT 2937). The selected bacteria were Arthrobacter oxydans (Ao) (CECT 386, ATCC 14358), Bacillus amyloliquefaciens (Ba) (CECT 493, ATCC 23842), and Streptomyces cellulofans (Sc) (CECT 3242, ATCC 29806).

Bacteria were grown on culture plates of trypticase soy agar (TSA, Scharlau) medium and were incubated at $28{ }^{\circ} \mathrm{C}$ for $24 \mathrm{~h}$. To obtain bacterial suspensions, cells from the liquid cultures were centrifuged and washed to remove possible remains of the culture medium. Bacterial suspensions were adjusted to $10^{7}$ cells $\mathrm{mL}^{-1}$. To obtain fungal spores, fungi were grown on potato dextrose agar (PDA, Scharlau, Barcelona, Spain) over a total period of 1 week at $28{ }^{\circ} \mathrm{C}$ and spores were collected by washing the culture with distilled water with $0.1 \%$ Tween 80 (Aldrich) and filtering through sterile glass wool. The resulting suspensions of spores were centrifuged three times, and the supernatants were discarded in order to avoid any residue from the culture medium or the rest of mycelia. Finally, spores were resuspended in $1-\mathrm{mL}$ ultrapure water and spore suspensions were adjusted to $10^{5}-10^{6}$ spores $\mathrm{mL}^{-1}$.

\section{Inoculation and incubation of paint specimens}

Reconstructed paint films prepared as EG and EO were inoculated with three separate drops of $20 \mu \mathrm{L}$ of each fungal and bacterial suspension. After inoculation, each paint film was placed in the center of a Petri dish and incubated in darkness for 40 days at $28{ }^{\circ} \mathrm{C}, 80 \%$ relative humidity. Thus, two series of biodeteriorated reconstructed paint films were obtained (EG@microorganism and EO@microorganism). Paint films inoculated with $20 \mu \mathrm{L}$ of sterile ultrapure water and incubated under the same conditions were used as controls (EG@Blank and EO@Blank). After incubation, the microbial biomass was completely separated from the surface of the reconstructed paint films in two steps, first by mechanical removing with a microscalpel and a cotton tongue and second with repeated rinsing with water.

\section{Results and discussion}

\section{Film micromorphology}

It is well known that microscopically, egg yolk has a variety of multiscale structures that are suspended in a yellowish and continuous fluid phase (plasma) [41]. This complex structure determines the formation of a paint layer from drying of egg yolk medium and egg-oil emulsions, which has been described as a process that involves two steps. A first step of evaporation of the water from the plasma takes place until reaching equilibrium with the humidity of the surrounding air. The loss of water results in the appearance of intermolecular empty spaces and loss of hydrogen bonding that force the molecules of protein to rearrange their chains to maximize their intrachain and interchain hydrogen bonding to replace lost hydrogen bonds to water. Spectroscopic studies have demonstrated that structural changes undergone by proteins on dehydration are predominantly related to conformational transitions that results in a final dried state in which the preferred conformation adopted by the protein is $\beta$-sheet, regardless of the initial conformation in the aqueous solution. This is due to the lower degree of solvation required by this conformation [41]. Thus, the protein molecules adopt more unordered conformations in which most side chain groups become now available with the consequent increase of the chemical activity of the protein molecule with other molecules (protein, triglycerides, metal ions solubilized from pigment grains, etc.) $[42,43]$. Finishing of the drying process has been proposed via a further step of formation of a protein network accompanied by coalescence and reticulation of glycerolipids [44] that results in a continuous medium that binds the pigment grains as can be seen in Fig. 1a, which shows the FESEM secondary electron image of the cross-section of an uninoculated egg tempera paint film. In this reconstructed paint film, the 

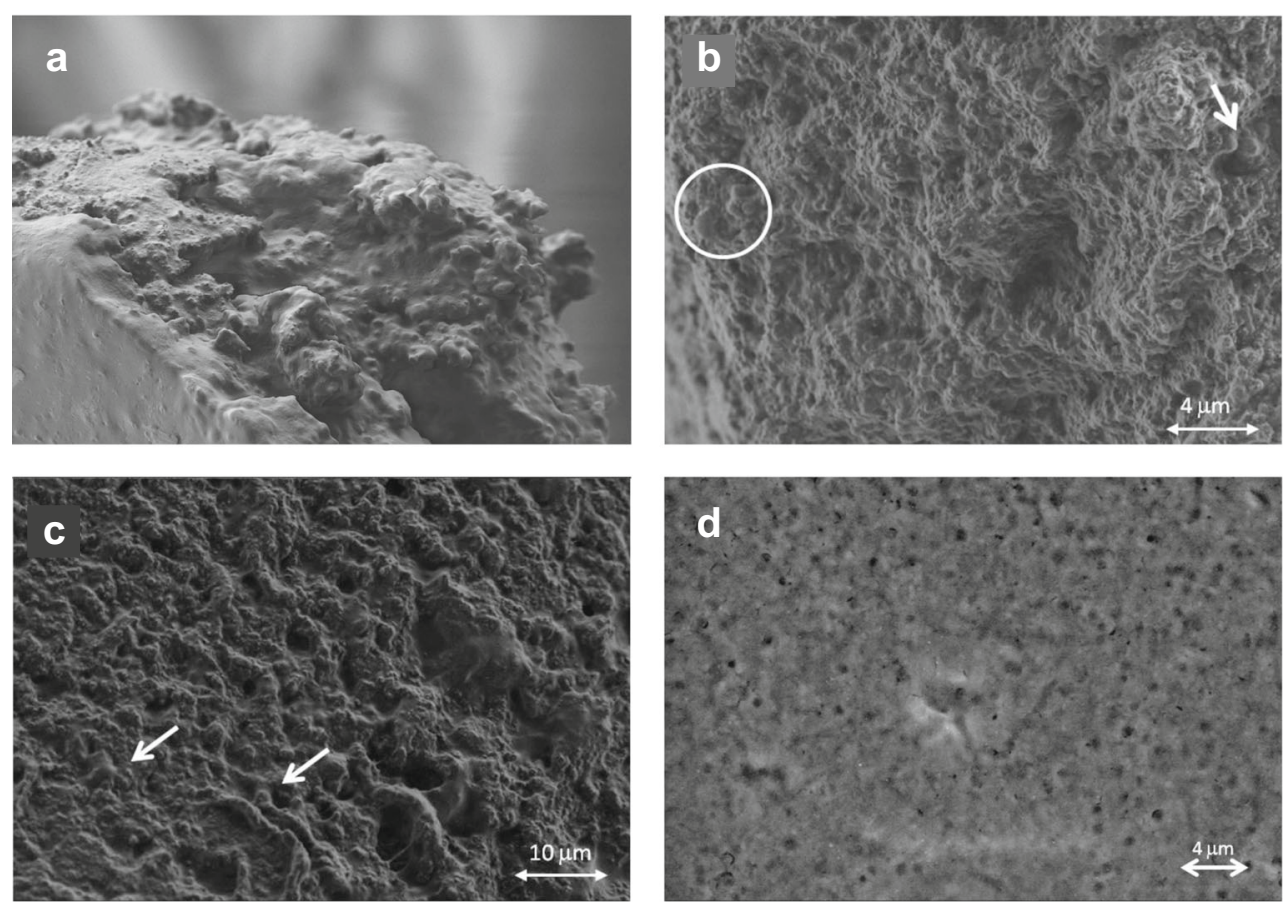

Fig. 1 Secondary electron images obtained with FESEM of a the cross section of a reconstructed egg tempera paint film (EG), b detail of the cross section of a reconstructed egg tempera paint film showing spheres

with diameter below $2 \mu \mathrm{m}$, c the cross-section of a reconstructed egg-oil emulsion paint film (EO), and $\mathbf{d}$ the surface of a reconstructed egg tempera paint film inoculated by Aspergillus niger (EG@An)

pigment grains, with sizes below $1 \mu \mathrm{m}$, are bound by a binder that mainly consists of dried egg yolk plasma. A number of spheres and granules, typical multiscale structures of egg yolk that are insoluble denser protein-lipid particles $(\varnothing 4-150 \mu \mathrm{m}$ and $\varnothing 0.2-2 \mu \mathrm{m}$, respectively) can also be identified in Fig. $1 \mathrm{~b}$ (see circle and arrow).

Figure 1c shows the FESEM secondary electron image of the cross-section of an uninoculated reconstructed egg-oil emulsion paint film. As it can be seen, the pigment grains are completely embedded by the binding medium that, in this case, is a mixture of polymerized linseed oil and egg yolk plasma. Presence of linseed oil results in a most complete embedding of pigment grains. Spheres and granules are here hardly identified (see arrows) due to the presence of linseed oil.

Inoculation of paint films consisted of applying a drop of water containing the different microorganisms in the study followed by incubation in a chamber maintained at a high level of humidity. Contact of the dried paint film with the aqueous phase can induce changes in the structure of the film. First of all, hydrolysis of triglycerides can be promoted resulting in releasing of notable amounts of fatty acids. The hydrolysis of proteins can also take place resulting in the cleavage of the protein molecules, whose shorter fragments can also migrate to the aqueous phase. As the evaporation of the drop is carried out in brief period, the final result is the appearance of the micropores and the migration of the solubilized species from the film core to the surface, where they are concentrated and/or vaporized at a more or less extent. After this, the bacteria and fungi start their attack, settling the external surface and pores, as can be seen in Fig. 1d.

\section{VMP, SECM, and AFM-VMP analysis}

Figure 2a shows the cyclic voltammogram of a microparticulate deposit of cadmium yellow pigment on graphite electrode immersed into acetate buffer at $\mathrm{pH} 4.75$. A reduction wave at ca. $-1.0 \mathrm{~V}$ vs. $\mathrm{Ag} / \mathrm{AgCl}\left(\mathrm{C}_{1}\right)$ accompanied by a shoulder at ca. $-1.2 \mathrm{~V}\left(\mathrm{C}_{2}\right)$, which precedes the rising current for solvent discharge, is recorded in the initial cathodic scan. In the subsequent anodic scan, a main oxidation signal at $-1.1 \mathrm{~V}\left(\mathrm{~A}_{1}\right)$ appears accompanied by a weaker signal at ca. $-0.7 \mathrm{~V}$. Following literature [31, 32, 38], the peak $\mathrm{C}_{1}$ can be attributed to the reduction of $\mathrm{CdS}$ to $\mathrm{Cd}$ metal, which is subsequently oxidized, upon reversal of the potential scan, to $\mathrm{Cd}^{2+}(\mathrm{aq})$ in the stripping process $\mathrm{A}_{1}$. This process has been widely studied for cadmium determination in aqueous solution [45]. The $\mathrm{C}_{2}$ signal can be tentatively assigned to the reduction of $\mathrm{H}^{+}$and/or $\mathrm{Cd}^{2+}$ ions released during the reduction of $\mathrm{CdS}$ on the Cd-plated graphite surface.

This voltammetry becomes significantly modified for samples excised from the reconstructed paint films. As can be seen in Fig. 2b, c, the $\mathrm{C}_{2}$ shoulder disappears whereas the shape of the peaks $\mathrm{C}_{1}$ and $\mathrm{A}_{1}$ varies. In the case of EG@Blank paint film (Fig. 2b), a new cathodic process is recognized by the 


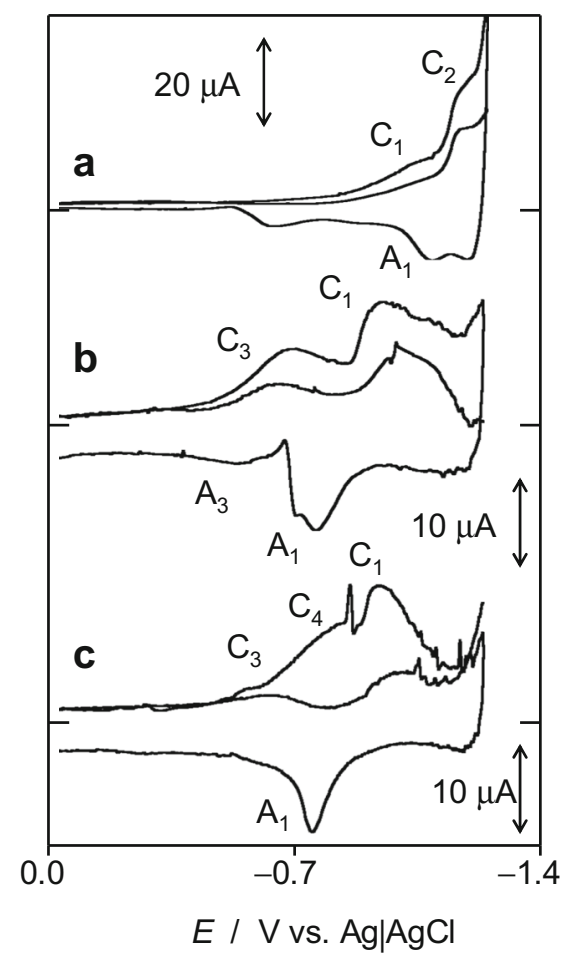

Fig. 2 Cyclic voltammograms, after semiderivative convolution of a a microparticulate deposit of CdS; $\mathbf{b}$ sample of uninoculated egg tempera paint film (EG@Blank); and c sample of uninoculated egg-oil emulsion paint film (EO@Blank) attached to graphite bar immersed into $0.25 \mathrm{M}$ sodium acetate buffer, $\mathrm{pH} 4.75$. Potential scan rate $50 \mathrm{mV} \mathrm{s}^{-1}$

signal at $-0.70 \mathrm{~V}\left(\mathrm{C}_{3}\right)$ preceding the peak $\mathrm{C}_{1}$ at $-0.95 \mathrm{~V}$, the voltammetric profile remaining essentially unchanged in the second and successive potential scans. For the EO@Blank specimens (Fig. 2c), the initial cathodic scan displays an additional signal at $-0.80 \mathrm{~V}\left(\mathrm{C}_{4}\right)$, which is overlapped to peaks $\mathrm{C}_{1}$ and $\mathrm{C}_{3}$ (weak), but in the second and successive scans, only peaks $\mathrm{C}_{1}$ and $\mathrm{C}_{3}$ remained. In all cases, upon increasing potential scan rate between 0.01 and $0.50 \mathrm{~V} \mathrm{~s}^{-1}$, the peaks $\mathrm{C}_{3}$ and $\mathrm{C}_{4}$ become enhanced relative to the peak $\mathrm{C}_{1}$, but the voltammetric profile becomes ill-defined. In the anodic region of the voltammogram of EG@Blank, the stripping peak $A_{1}$ at $-0.75 \mathrm{~V}$ exhibited peak splitting and preceded a wider oxidation peak $\left(\mathrm{A}_{3}\right)$ at ca. $-0.50 \mathrm{~V}$ coupled to the peak $\mathrm{C}_{3}$. In the case of EO@Blank, a unique anodic signal $\mathrm{A}_{1}$ was recorded, a feature apparently associated to the appearance of the peak $\mathrm{C}_{4}$ in the precedent cathodic scan. The presence of peak splitting and more or less pronounced peak potential shift in the oxidative dissolution of $\mathrm{Cd}$ metal can be interpreted as the result of the formation of metallic deposits having different crystal shape and size during the reduction of CdS species, a feature which has been described in the solid-state electrochemistry of different metal compounds [46-48].

The SECM examination of EG- and EO-reconstructed paint films attached to a graphite plate in contact with $\mathrm{K}_{4} \mathrm{Fe}(\mathrm{CN})_{6}$ solution in acetate buffer is illustrated in Fig. 3. Application to the tip of a potential high enough $\left(E_{\mathrm{T}}=+\right.$
$0.30 \mathrm{~V}$ ) to promote the diffusion-controlled oxidation of $\mathrm{Fe}(\mathrm{CN})_{6}{ }^{4-}$ ions yields a current response depending on the topography and conductivity of the substrate. The map colors yield an almost uniform negative feedback background, corresponding to the binding medium, accompanied by positive feedback features corresponding to the pigment grains emerging from the binding medium. Apart from textural differences between EG@CdS and EO@CdS films (Fig. 3a, c, respectively), in both cases, after application of a potential input of $-1.0 \mathrm{~V}$ for $2-5 \mathrm{~min}$, there appears significant changes in the map color (Fig. 3b, d, respectively), thus denoting that the reduction of CdS operates under these conditions. As a result of the application of this reductive potential input, the area of positive feedback features becomes diminished, such as being embedded by a growing binding media.

Figure 4 depicts the AFM images recorded before (Fig. 4a, b) and after (Fig. 4c, d) application of a potential input of $-1.0 \mathrm{~V}$ to an egg tempera-reconstructed paint film (EG@Blank) for 5 min. Apparently, the pigment grain, which is partially in contact with the base graphite plate, experiences a contraction process being reduced, at the end of the reductive step, to a grain whose volume is ca. one half of the volume of the original pigment grain. This result would be in agreement with data reported by Scholz et al. on in situ XRD [49] and AFM [50] monitoring of the reduction of litharge, where the reduction of the mineral crystals involves a topotactic solid-state transformation of lead oxide to lead metal without a morphological disintegration. This model would apply here, the volume contraction expected in the reduction of $\mathrm{CdS}$ to $\mathrm{Cd}$ being consistent with the different density of $\mathrm{CdS}\left(4.83 \mathrm{~g} \mathrm{~cm}^{-3}\right)$ and $\mathrm{Cd}$ $\left(8.65 \mathrm{~g} \mathrm{~cm}^{-3}\right)$. Interestingly, the topography of the binder surrounding the grain is smoothed in the vicinity of the same.

All these results can be rationalized on considering that the EG- and EO-reconstructed paint films are constituted by a more or less homogeneous distribution of pigment particles more or less entirely embedded by a layer of more hydrophobic binding medium and a hydrophilic layer where resulting secondary cadmium compounds exist, as described for pictorial specimens containing lead pigments [51]. Under VMP conditions, the voltammetric signals correspond to the particles in contact with the base graphite electrode and the electrolyte [31-33]. Accordingly, the CdS-centered reduction processes can be described respectively in terms of the following:

1. Peak $\mathrm{C}_{1}$ corresponds to the reduction of $\mathrm{CdS}$ grains exposed to the graphite surface:

$$
\{\mathrm{CdS}\}_{\text {solid }}+2 \mathrm{H}^{+}{ }_{\text {aq }}+2 \mathrm{e}^{-} \rightarrow\{\mathrm{Cd}\}_{\text {solid }}+\mathrm{H}_{2} \mathrm{~S}
$$



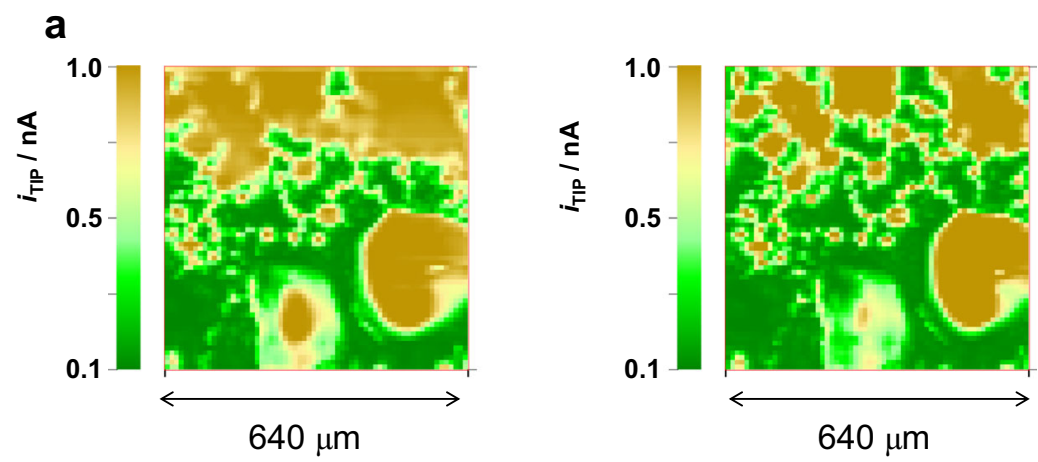

b
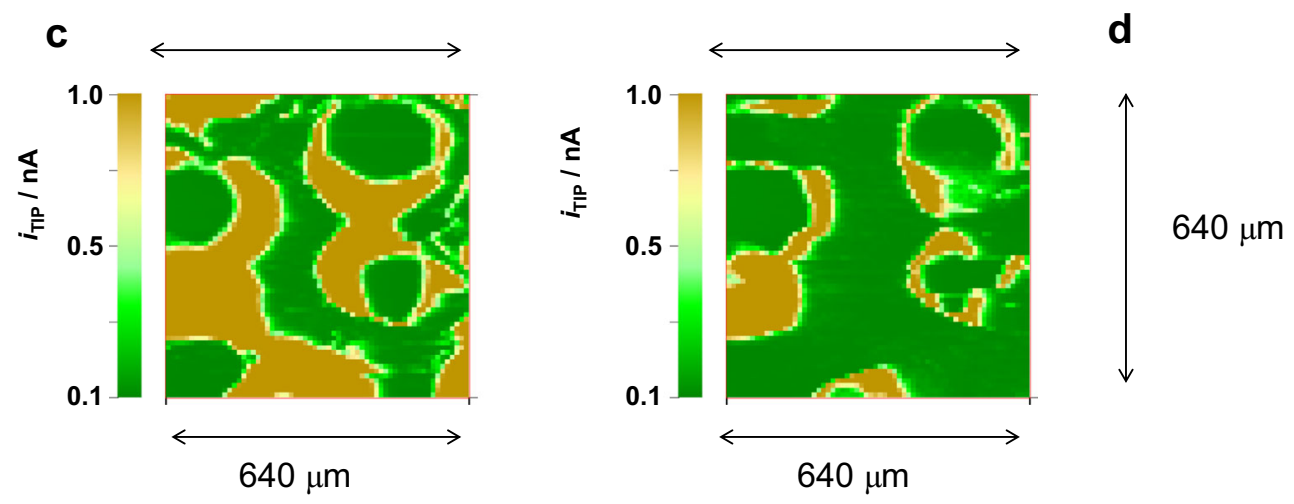

Fig. 3 SECM map colors of $\mathbf{a}, \mathbf{b}$ sample of uninoculated egg tempera paint film (EG@Blank) and c, d sample of uninoculated egg-oil emulsion paint film (EO@Blank) attached to a graphite plate in contact

with electrode in contact with $5.0 \mathrm{mM} \mathrm{K} \mathrm{K}_{4} \mathrm{Fe}(\mathrm{CN})_{6}$ solution in $0.25 \mathrm{M}$ $\mathrm{HAc} / \mathrm{NaAc}(\mathrm{pH} 4.75)$ before $(\mathbf{a}, \mathbf{c})$ and after $(\mathbf{b}, \mathbf{d})$ application of a potential input of $-1.0 \mathrm{~V}$ for $2 \mathrm{~min} ; E_{\mathrm{T}}=+0.30 \mathrm{~V}$
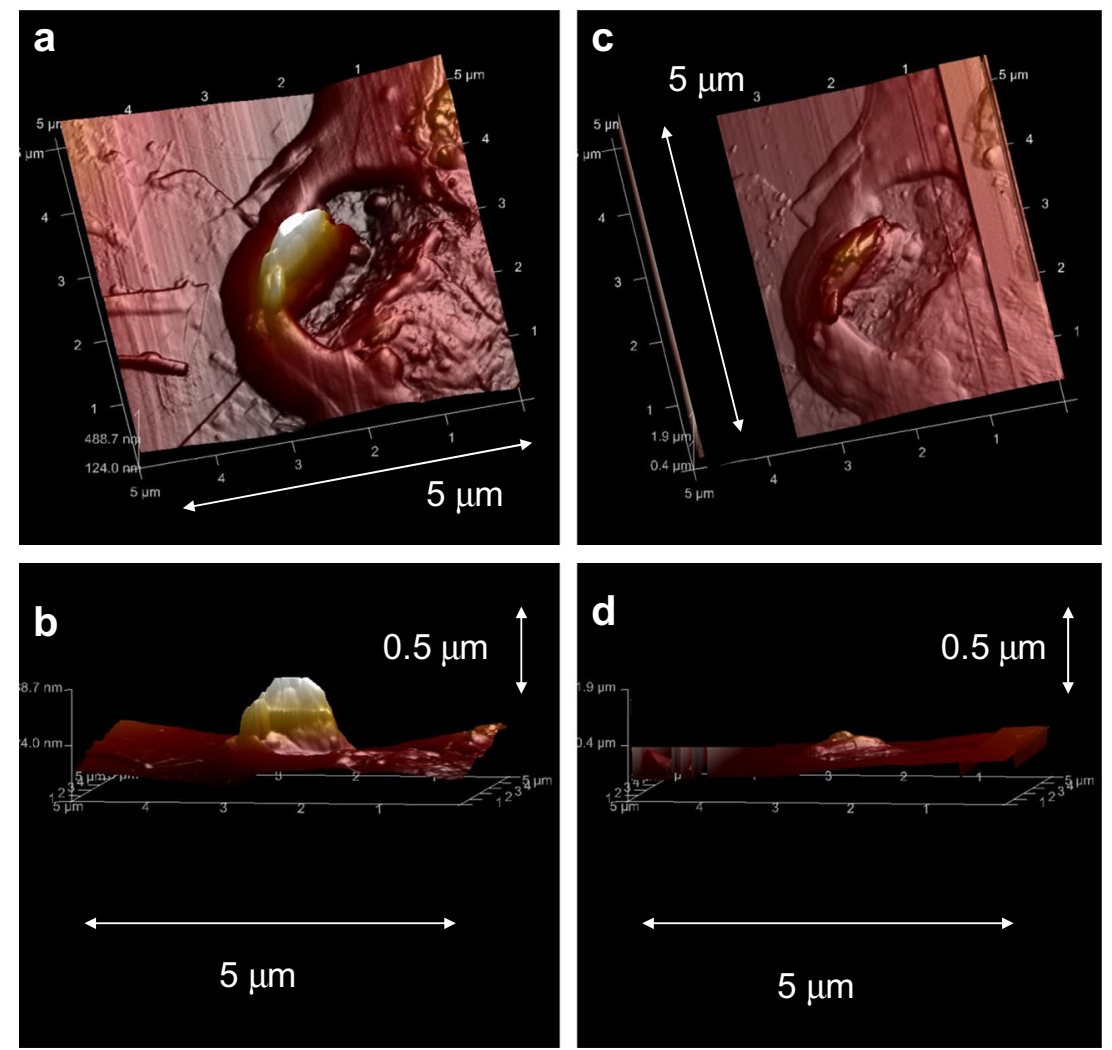

Fig. 4 Topographic AFM images of an uninoculated egg tempera paint film EG@Blank on a graphite plate in contact with $0.25 \mathrm{M}$ sodium acetate buffer, $\mathrm{pH} 4.75$; $\mathbf{a}, \mathbf{b}$ before and $\mathbf{c}, \mathbf{d}$ after application of a potential step of $-1.0 \mathrm{~V}$ for $5 \mathrm{~min}$ 
The subsequent oxidation of the $\mathrm{Cd}$ deposit to $\mathrm{Cd}^{2+}$ ions in the solution gives rise to the stripping peak $\mathrm{A}_{1}$.

2. Peak $\mathrm{C}_{3}$ appearing in the EG-reconstructed paint films can be attributed to the reduction of the $\mathrm{Cd}$ compounds forming the ionomeric layer accompanying the pigment particles. This layer, to some extent similar to that formed in the reduction of lead minerals [49-51], would be particularly relevant for the proteinaceous fraction of the binders (egg) disposing of coordinating units [52, 53]. The reduction process can be represented as follows:

$$
\begin{aligned}
& \left\{\mathrm{Cd}^{2+}\left(\text { binding }^{2-}\right)\right\}_{\mathrm{CdS} \text { ionomeric layer }}+2 \mathrm{H}^{+} \text {aq } \\
& +2 \mathrm{e}^{-} \rightarrow\{\mathrm{Cd}\}_{\text {solid }}+\mathrm{H}_{2} \text { binding }
\end{aligned}
$$

This process results in a deposit of $\mathrm{Cd}$ metal different to that resulting from the reduction $\mathrm{C}_{1}$. As previously noted, the appearance of different oxidative dissolution processes (peaks $A_{1}$ and $A_{3}$ ) can be attributed to the formation of different metal deposits in the previous electrochemical reduction of the different CdS species [46-48].

3. Peak $\mathrm{C}_{4}$, typical of EO-reconstructed paint film, would be representative of the reduction of $\mathrm{CdS}$ particles surrounded by binding media dominated by the linseed oil fraction of such specimens. Then, Cd soaps would appear where $\mathrm{Cd}$ (II)-carboxylate complexes were formed. The corresponding reduction process can be represented as follows:

$$
\begin{aligned}
& \left\{\mathrm{Cd}^{2+}\left(\mathrm{RCOO}^{-}\right)_{2}\right\}_{\text {Cd soap }}+2 \mathrm{H}^{+}{ }_{\text {aq }}+2 \mathrm{e}^{-} \rightarrow\{\mathrm{Cd}\}_{\text {solid }} \\
& \quad+2 \mathrm{RCOOH}
\end{aligned}
$$

The deposit of $\mathrm{Cd}$ metal formed here would be similar to that formed by the electrochemical reduction of bare $\mathrm{CdS}$ particles, so that it is oxidized at an identical or almost identical potential (peak $A_{1}$ ).

\section{VMP testing of biodeterioration}

The voltammetric response of the reconstructed paint films is differently modified after inoculation. Figure 5 shows the cyclic voltammograms for the egg-oil emulsion paint films after inoculation with two fungi, Aspergillus niger (EO@An) (Fig. 5a) and Acremonium chrysogenum (EO@Ac) (Fig. 5b), and two bacteria, Bacillus amyloliquefaciens (EO@Ba) (Fig. 5c) and Arthrobacter oxydans (EO@Ao) (Fig. 5d), respectively. One can observe that the fungi attack leads to voltammograms displaying only the peak $\mathrm{C}_{1}$ at $-1.0 \mathrm{~V}$ eventually accompanied of weak signal $\mathrm{C}_{4}$ at $-0.90 \mathrm{~V}$. In contrast, after bacteria attack, the voltammograms consist of "clean" peaks $\mathrm{C}_{3}$ at $-0.70 \mathrm{~V}$ and $\mathrm{C}_{1}$ at $-1.0 \mathrm{~V}$ with no traces of peak $\mathrm{C}_{4}$. The anodic region was dominated by a main stripping signal at potentials between -0.70 and $-0.80 \mathrm{~V}$ $\left(\mathrm{A}_{1}\right)$ often accompanied by a weak oxidation wave at $-0.60 \mathrm{~V}$ $\left(\mathrm{A}_{3}\right)$.

The voltammograms of the reconstructed egg tempera paint films (EG) inoculated with both fungi and bacteria (see Fig. 6) consisted of cathodic peaks at potentials of $-0.95\left(\mathrm{C}_{1}\right),-1.05\left(\mathrm{C}_{5}\right)$, and $-1.20\left(\mathrm{C}_{2}\right)$, followed by anodic peaks at $-0.70\left(\mathrm{~A}_{1}\right)$ and $-0.60 \mathrm{~V}\left(\mathrm{~A}_{3}\right)$. It is remarkable, the presence of the signal $\mathrm{C}_{2}$ and an additional cathodic signal at a potential more negative than $\mathrm{C}_{1}$, labeled as $\mathrm{C}_{5}$ (marked by arrows in Fig. 6), and the appearance of peak splitting in peak $A_{1}$. The peak $C_{5}$ can be attributed to the reduction of $\mathrm{CdS}$ surface complexes associated to the proteinaceous fraction which was modified by the biological attack (vide infra). This process can, in principle, be represented also by Eq. (2).

Consistently with the previous considerations, in EO paint films, bacteria attack would be concentrated on the most abundant oil fraction of the binding medium so that the reduction of pigment particles $\left(\mathrm{C}_{1}\right)$ and their ionomeric layer $\left(\mathrm{C}_{3}\right)$ remain well-defined, while the signal $\mathrm{C}_{4}$ disappears. On the contrary, fungi attack, although affecting both ionomeric and oil fractions, appears to be concentrated in the proteinaceous fraction, so that peak $\mathrm{C}_{3}$ entirely disappears while the signal $\mathrm{C}_{4}$ becomes significantly decreased.

Additional information can be obtained from electrochemical data in the region of positive potentials. Figure 7 compares linear scan voltammograms for (a) pure pigment CdS, (b) pure egg yolk, and reconstructed egg tempera paint films, (c) before EG@Blank and (d) after inoculation with Aspergillus niger (EG@An. The pigment displays a well-defined anodic peak at $+0.82 \mathrm{~V}\left(\mathrm{~A}_{\mathrm{CdS}}\right)$ preceded by a shoulder at ca. $+0.65 \mathrm{~V}$. Although sulfur electrochemistry is complicated [54], the oxidation of $\mathrm{CdS}$ can be represented as follows:

$$
\{\mathrm{CdS}\}_{\text {solid }} \rightarrow\{\mathrm{S}\}_{\text {solid }}+\mathrm{Cd}^{2+} \text { aq }+2 \mathrm{e}^{-}
$$

In turn, reconstructed egg tempera paint films produce an oxidation signal consisting of overlapping voltammetric peaks centered at $+0.45 \mathrm{~V}\left(\mathrm{~A}_{\mathrm{PR}}\right)$, attributable either to the oxidation of metalloproteins [55] and/or-SH units of proteins [56]. The uninoculated egg tempera paint film (EG@blank) yields a voltammetric response dominated by the signal $A_{P R}$, whose profile is slightly modified, while the $\mathrm{A}_{\mathrm{CdS}}$ signal becomes considerably lowered. Consistently with the foregoing set of voltammetric data, the effect of fungi on the voltammetry of EG paint film was similar, now significantly lowering both $\mathrm{A}_{\mathrm{CdS}}$ and $\mathrm{A}_{\mathrm{PR}}$ features.

In contrast, the voltammetry of inoculated reconstructed egg-oil emulsion paint films shows differences between fungi and bacteria. These can be seen in Fig. 8, where linear scan voltammograms for films of (a) pure egg + linseed oil 


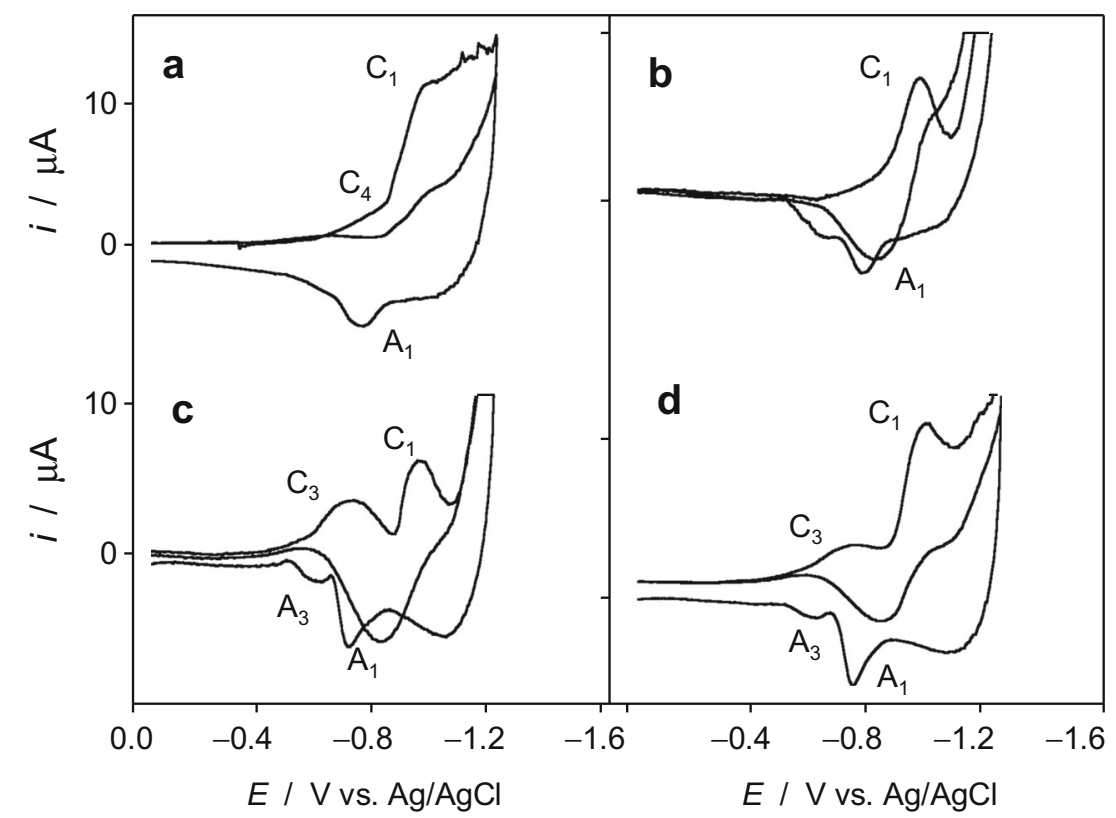

Fig. 5 Cyclic voltammograms, after semiderivative convolution, for graphite electrodes modified with egg-oil emulsion paint film (EO) immersed into $0.25 \mathrm{M}$ sodium acetate buffer, $\mathrm{pH} 4.75$, after incubation

with a Aspergillus niger (EO@An), b Acremonium chrysogenum (EO@Ac), c Bacillus amyloliquefaciens (EO@Ba), and d Arthrobacter oxydans (EO@Ao). Potential scan rate of $50 \mathrm{mV} \mathrm{s}^{-1}$

emulsion, (b) EO@Blank and reconstructed EO paint film inoculated with (c) Bacillus amyloliquefaciens (EO@Ba) and (d) Aspergillus niger (EO@ An) are depicted. The binder film (Fig. 8a) produces an oxidation signal at $-0.08 \mathrm{~V}\left(\mathrm{~A}_{\mathrm{LO}}\right)$, which could be tentatively attributed to the oxidation of tocopherols. These are components of linseed oil [57, 58], displaying a well-defined oxidative electrochemistry [59]. In the presence of CdS (Fig. 8b), this signal is accompanied by minor signals at $+0.45\left(\mathrm{~A}_{\mathrm{B} 1}\right)$ and $+0.60\left(\mathrm{~A}_{\mathrm{B} 2}\right)$ preceding the CdS-centered oxidation $\left(\mathrm{A}_{\mathrm{CdS}}\right)$ at $+0.82 \mathrm{~V}$. These signals can be attributed to electrochemically

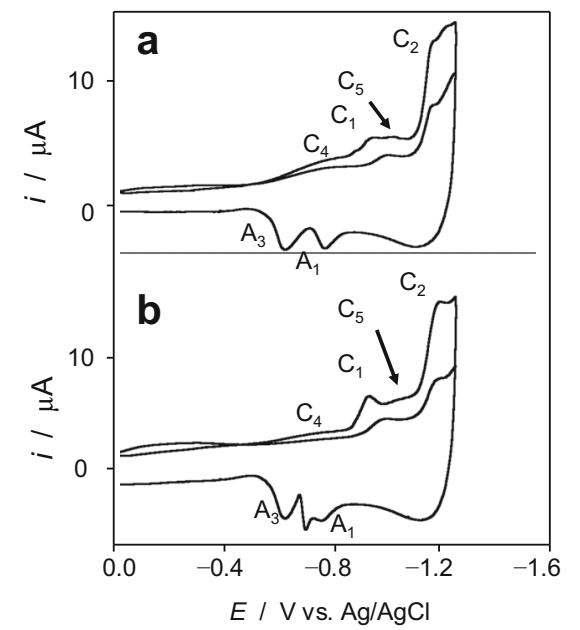

Fig. 6 Cyclic voltammograms, after semiderivative convolution, for graphite electrodes modified with egg tempera paint film immersed into $0.25 \mathrm{M}$ sodium acetate buffer (EG), $\mathrm{pH} 4.75$, after incubation with a the fungus Trichoderma pseodukoningii (EG@Tp) and b the bacterium Streptomyces cellulofans (EG@Sc). Potential scan rate of $50 \mathrm{mV} \mathrm{s}^{-1}$

oxidizable compounds resulting from the interaction between CdS and the binder. This would be consistent with results from Madani et al. [60] on the effect of $\mathrm{CdS}$ on polymerization reactions. Interestingly, after bacterial attack (Fig. $8 \mathrm{c}$ ), the $\mathrm{A}_{\mathrm{CdS}}$ and $\mathrm{A}_{\mathrm{B} 1}$ peaks disappear whereas the peak $A_{B 2}$ is enhanced. In contrast, fungi attack (Fig. 8d) results in the maintenance of peaks $\mathrm{A}_{\mathrm{CdS}}$ and $\mathrm{A}_{\mathrm{B} 2}$ with lowering/disappearance of peak $A_{B 1}$. These results indicate that the presence of
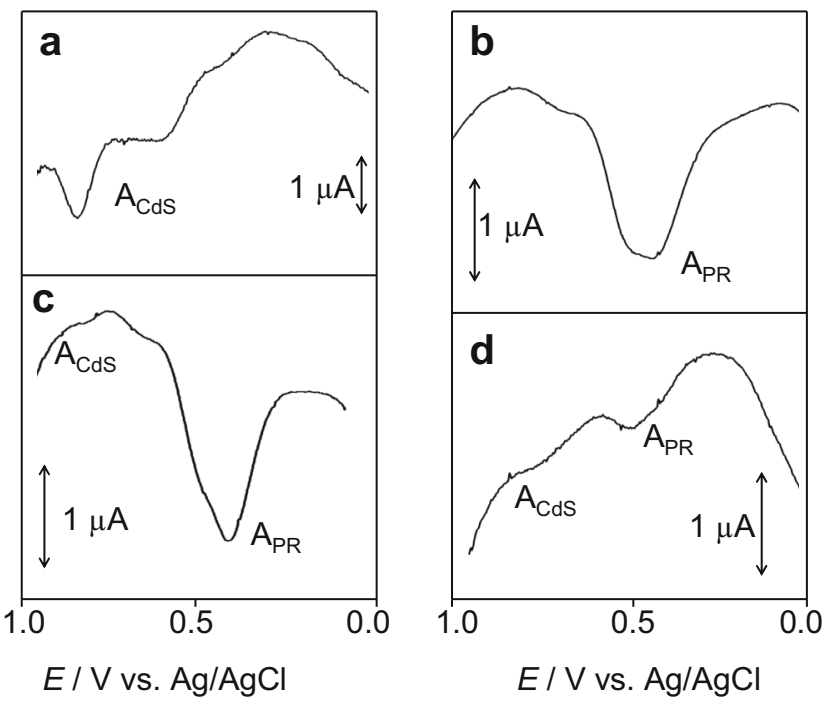

Fig. 7 Linear scan voltammograms, after semiderivative convolution, for a pure cadmium yellow, b pure egg yolk, c EG@Blank paint film, and d EG@An paint film deposited on graphite in contact with $0.25 \mathrm{M}$ sodium acetate buffer, $\mathrm{pH} 4.75$. Potential scan initiated at $0.0 \mathrm{~V}$ in the positive direction; potential scan rate of $50 \mathrm{mV} \mathrm{s}^{-1}$ 


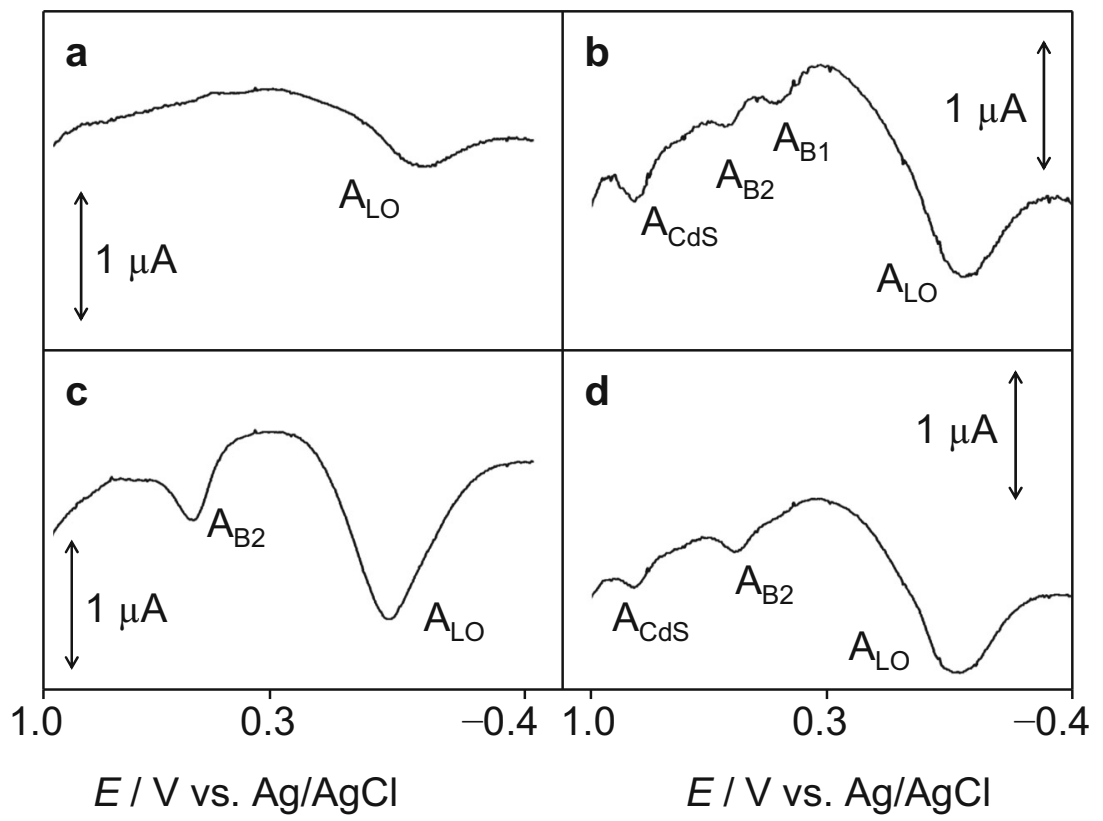

Fig. 8 Linear scan voltammograms, after semiderivative convolution, for films of a pure egg + linseed oil emulsion, b EO@Blank, c EO@Ba, and d EO@An, deposited on graphite in contact with $0.25 \mathrm{M}$

sodium acetate buffer, $\mathrm{pH} 4.75$. Potential scan initiated at $-0.40 \mathrm{~V}$ in the positive direction; potential scan rate of $50 \mathrm{mV} \mathrm{s}^{-1}$

the pigment produces reaction chains in the binder resulting in products which react selectively with fungi and/or bacteria in the paint film.

\section{FTIR spectroscopy}

In order to validate VMP analysis of biodeterioration, ATRFTIR spectroscopy was applied. This technique enables the recognition of changes in the chemical composition and structure of both triglycerides and proteins, conforming traditional binding media used in art so that it has been a useful complementary analytical technique in order to identify changes in the composition of the paint specimens [27, 61, 62]. Uninoculated egg tempera specimen (EG@Blank in Fig. 9) exhibited an IR spectrum dominated by the amide A $\left(3300 \mathrm{~cm}^{-1}\right)$, amide I $\left(1635 \mathrm{~cm}^{-1}\right)$, and amide II $\left(1537 \mathrm{~cm}^{-1}\right)$ bands and the $-\mathrm{CH}_{3}$ and $-\mathrm{CH}_{2}-$ stretching vibrations (2924 and $2858 \mathrm{~cm}^{-1}$ ) $[27,61,62]$. Bands associated to the ester groups in triglyceride $\mathrm{C}=\mathrm{O}$ stretching vibrations at $1742 \mathrm{~cm}^{-1}$ and shoulder at $1736 \mathrm{~cm}^{-1}$ attributed to phospholipids, accompanied by the $\mathrm{C}-\mathrm{O}$ stretching pattern at 1234 , 1163 , and $1086 \mathrm{~cm}^{-1}$, were also identified. The latter bands are prevalent in uninoculated egg plus linseed oil emulsion paint film (EO@Blank in Fig. 9). The hydrolysis of triglycerides was confirmed in both specimens EG@Blank and EO@Blank by the appearance of several shoulders in the range of $1736-1710 \mathrm{~cm}^{-1}$ ascribed to free fatty acids released as a result of the hydrolysis of oil and egg triglycerides [27, 28, 62].
Application of FTIR spectroscopy to the analysis of protein secondary structure is based on the sensitivity of peptide group IR absorptions to the protein chain conformations. These structural modifications can be observed in the amide I region, which exhibits the highest protein conformational sensitivity [63]. By contrast to the aqueous solutions, protein solid films exhibit a higher crystalline structure [64]. Our findings in this region, described below, are presented in terms of the position of the amide I sub-bands. The position of the subbands was determined from the deconvolved IR spectra (Fig. 10) [43]. Amide I bands of EG@Blank and EO@Blank show typical profile characteristics of $\beta$-sheet conformation predominant in dried globular proteins of albuminoid type [65] with a prominent maximum centered at $1635 \mathrm{~cm}^{-1}$ in EG@Blank and $1628 \mathrm{~cm}^{-1}$ in EO@Blank that, according to literature $[43,65,66]$, is ascribed to intramolecular $\beta$-sheet conformations. The redshift observed in the position at the maximum for egg-oil emulsion film could be associated to changes in the $\beta$-sheet conformations of protein molecules [66], probably occurring as a result of the appearance of intermolecular interactions of the protein molecules with the oil triglycerides and their oxidation and hydrolysis products [47]. The secondary maximum at $1643 \mathrm{~cm}^{-1}$ in EG@Blank and at $1648 \mathrm{~cm}^{-1}$ in EO@Blank is ascribed to the unordered (random coil) conformation [66]. Both specimensEG@Blank and EO@Blank exhibited secondary maxima at $1652 \mathrm{~cm}^{-1}$, with shoulders at 1658 and $1660 \mathrm{~cm}^{-1}$ ascribed to helical conformation [65]. Shoulders at 1625 and $1619 \mathrm{~cm}^{-1}$ are ascribed to intermolecular $\beta$-sheet structures 


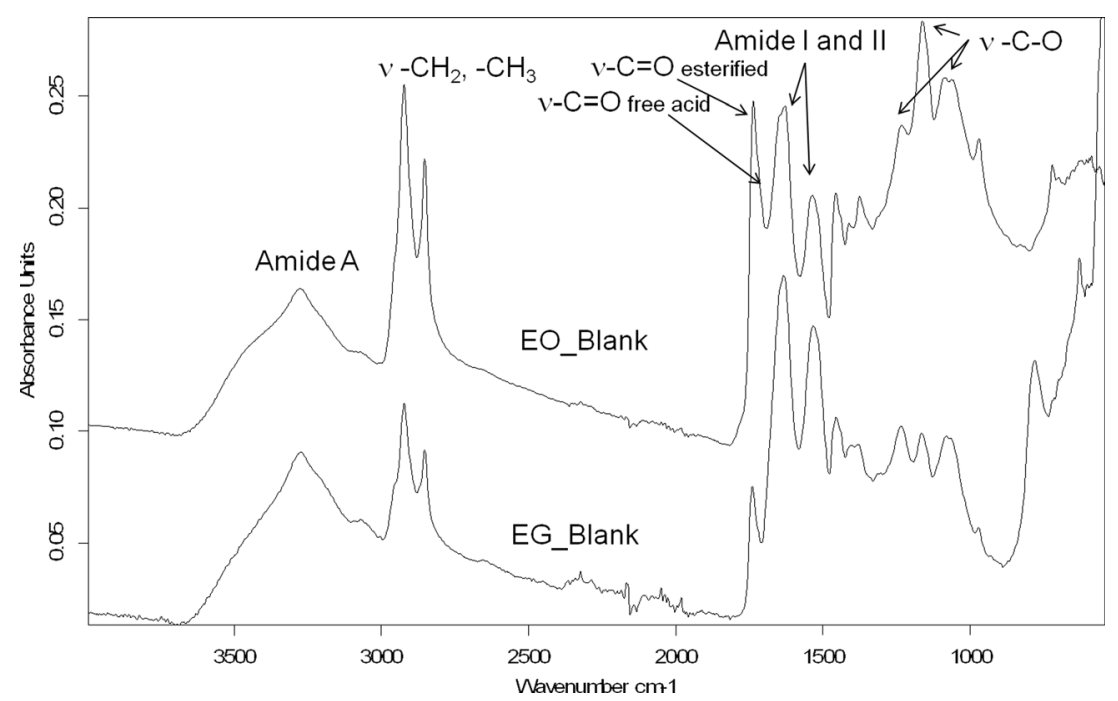

Fig.9 IR absorption spectra of EG@Blank- and EO@Blank-reconstructed paint films. Spectra are presented in staked mode

[67], whereas shoulders at $1668,1674,1683,1688$, and $1694 \mathrm{~cm}^{-1}$ are ascribed to $\beta$-turn conformations $[43,63]$.

Microbial attack in the reconstructed tempera films resulted in all cases in the decrease of the relative content in carbonyl band to amide I and II bands (see Table 1). This decrease is more evident in the series of reconstructed egg-oil emulsion films since this reduction in the carbonyl band has been associated to the loss of lipids as a result of the enzymatic oxidation of the hydrolyzed long-chain fatty acids to form free fatty acid hydroperoxides and then other volatile end-products. This hypothesis is confirmed by the increase in the content of free fatty acids formed as a consequence of the hydrolysis of the triglycerides and phospholipids observed from the enhancement of bands around $1725-1700 \mathrm{~cm}^{-1}$. The hydrolysis of triglycerides and further loss of end-products of ketone and aldehyde type is taking place at a lesser extent in egg yolk due to its particular microstructure with a variety of insoluble particles (see Fig. 1a), with structure of micellar complexes in which triglycerides and cholesterol forms the core of the particle that is surrounded by an amphipathic surface monolayer of phospholipids, proteins, and unesterified cholesterol [68-71] that prevent the oxidation of triglycerides inside.

Comparison of band area ratio obtained in the specimens inoculated with the selected fungi and bacteria shows that in general, bacteria are more efficient in promoting loss of lipids than fungi are, but clear differences appeared between the different tested species; thus, Mucor rouxii showed a particular ability for promoting deterioration of both types of paint films. whereas Trichoderma pseudokoningii produced a small or almost null deterioration (see Table 1). These results are in good agreement with those previously reported from oilvarnish specimens inoculated with several species of microorganisms, where a remarkable increase of the hydrolysis reactions was detected [72].
Changes in the proteinaceous materials present in the series of inoculated egg tempera paint films can be seen in Fig. 10a that shows the amide I bands of the blank (EG@Blank) and inoculated reconstructed egg yolk tempera paint films. Modification of the profile of this band inform of an alteration in the secondary structure of the proteins, which could be relied with the microbial degradative activity. Fungi exhibit more remarkable changes with redshift of the maximum in the intramolecular $\beta$-sheet region from 1635 to $1633 \mathrm{~cm}^{-1}$ for EG@Ac and EG@An and $1631 \mathrm{~cm}^{-1}$ for EG@Mr and EG@Tp. The band at $1625 \mathrm{~cm}^{-1}$ ascribed to intermolecular $\beta$-sheet conformations is also enhanced in specimens inoculated with fungi. These conformations are typical of aggregated proteins [65]. Enhancement of band ascribed to random coil conformations in the range of $1645-1648 \mathrm{~cm}^{-1}$ is also observed in the paint films inoculated with fungi. This last result suggests that attack of these microorganisms result in an increase in the irregular structures and, in particular, in a partial opening of the ordered structure into random turns and bends. This would be consistent with the disappearance of the peak $\mathrm{C}_{3}$ and the appearance of peak $\mathrm{C}_{5}$ in the corresponding voltammograms (see Fig. 6).

In the case of egg-linseed oil emulsion paint films (see Fig. 10b), the more remarkable changes observed in the shape of the amide I band of inoculated specimens were also found in reconstructed paint films inoculated with fungi. Blue shift of the maximum in the intramolecular $\beta$-sheet region from $1628 \mathrm{~cm}^{-1}$ to $1631 \mathrm{~cm}^{-1}$ for EO@Tp; $1634 \mathrm{~cm}^{-1}$ for EO@An, EO@Mr, and EO@Pc; and $1636 \mathrm{~cm}^{-1}$ for EO@Ac are observed. In all these specimens, new bands associated with random coil conformations were recognized at $1640 \mathrm{~cm}^{-1}$ for EO@An, EO@Mr, and EO@Tp; at $1645 \mathrm{~cm}^{-1}$ for EO@An, EO@Mr, and EO@Pc; and at $1647 \mathrm{~cm}^{-1}$ for EO@ Ac. Finally, a notable increase in the content of free fatty 

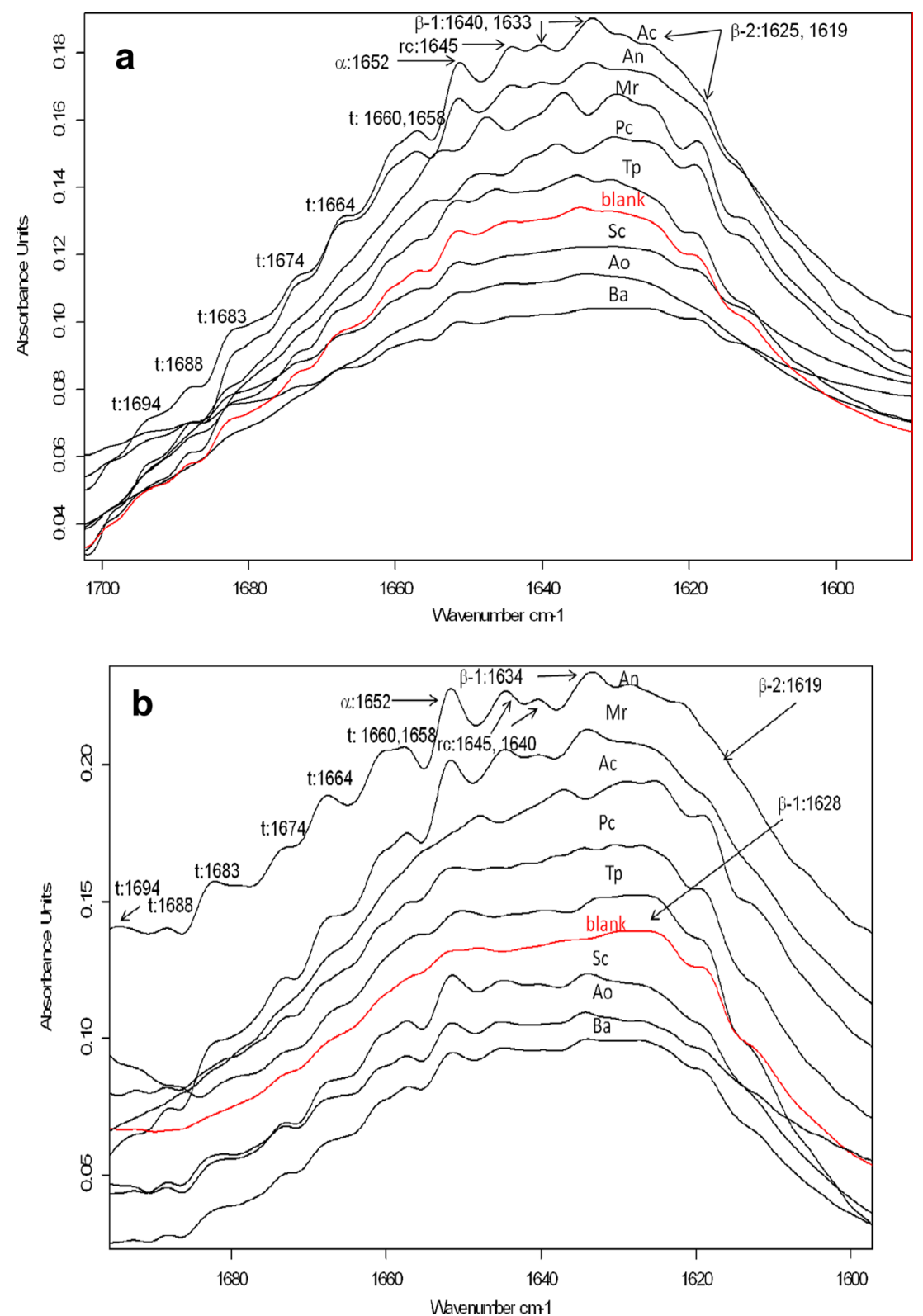

Fig. 10 a Detail of the deconvoluted amide I band obtained from the series of reconstructed egg tempera paint films. b Detail of the deconvoluted amide I band obtained from the series of reconstructed

egg-oil emulsion paint films. $\alpha$ helical conformations, $\beta-1$ intramolecular $\beta$-sheet, $\beta$-2 intermolecular $\beta$-sheet, $r c$ random coil, $t$ turns
Table 1 Band area ratios of the inoculated egg yolk tempera and egg-oil emulsion paint films

\begin{tabular}{|c|c|c|c|c|c|c|c|c|c|}
\hline \multirow[t]{2}{*}{ Band area ratio } & \multirow[b]{2}{*}{ Blank } & \multicolumn{5}{|c|}{ Fungi } & \multicolumn{3}{|c|}{ Bacteria } \\
\hline & & $\mathrm{Ac}$ & An & $\mathrm{Mr}$ & $\mathrm{Pc}$ & $\mathrm{Tp}$ & Ao & $\mathrm{Ba}$ & $\mathrm{Sc}$ \\
\hline \multicolumn{10}{|l|}{ Egg yolk } \\
\hline $\mathrm{C}=\mathrm{O} /$ amide $\mathrm{I}$ & 0.18 & 0.14 & 0.14 & 0.09 & 0.16 & 0.15 & 0.12 & 0.10 & 0.09 \\
\hline $\mathrm{C}=\mathrm{O} /$ amide II & 0.33 & 0.28 & 0.27 & 0.17 & 0.29 & 0.29 & 0.24 & 0.19 & 0.16 \\
\hline \multicolumn{10}{|l|}{ Emulsion } \\
\hline $\mathrm{C}=\mathrm{O} /$ amide $\mathrm{I}$ & 0.48 & 0.27 & 0.34 & 0.17 & 0.34 & 0.47 & 0.16 & 0.09 & 0.16 \\
\hline $\mathrm{C}=\mathrm{O} /$ amide II & 0.76 & 0.48 & 0.53 & 0.29 & 0.55 & 0.75 & 0.29 & 0.15 & 0.27 \\
\hline
\end{tabular}


acids is also observed in these specimens (relative growth of bands in the range of $1725-1700 \mathrm{~cm}^{-1}$ ). Presence of fatty acids could contribute to promoting new unordered conformations in the egg proteins characterized by being more loosened and unfolded due to the net positive charge in a more acidic solution. This net positive charge results in a more random structure due to the repulsion between turns and bends that increase the positive net charge [65].

\section{Discussion}

The above spectroscopic features can be used to discriminate the attack of fungi and bacteria on the reconstructed egg tempera and egg-linseed oil emulsion paint films. This is illustrated in Fig. 11a, where the values of the band area ratios of the stretching vibration of the $\mathrm{C}=\mathrm{O}$ group to amide $\mathrm{I}$ band, $A(\mathrm{C}=\mathrm{O}) / A($ amide $\mathrm{I})$, are plotted against the band area ratios of
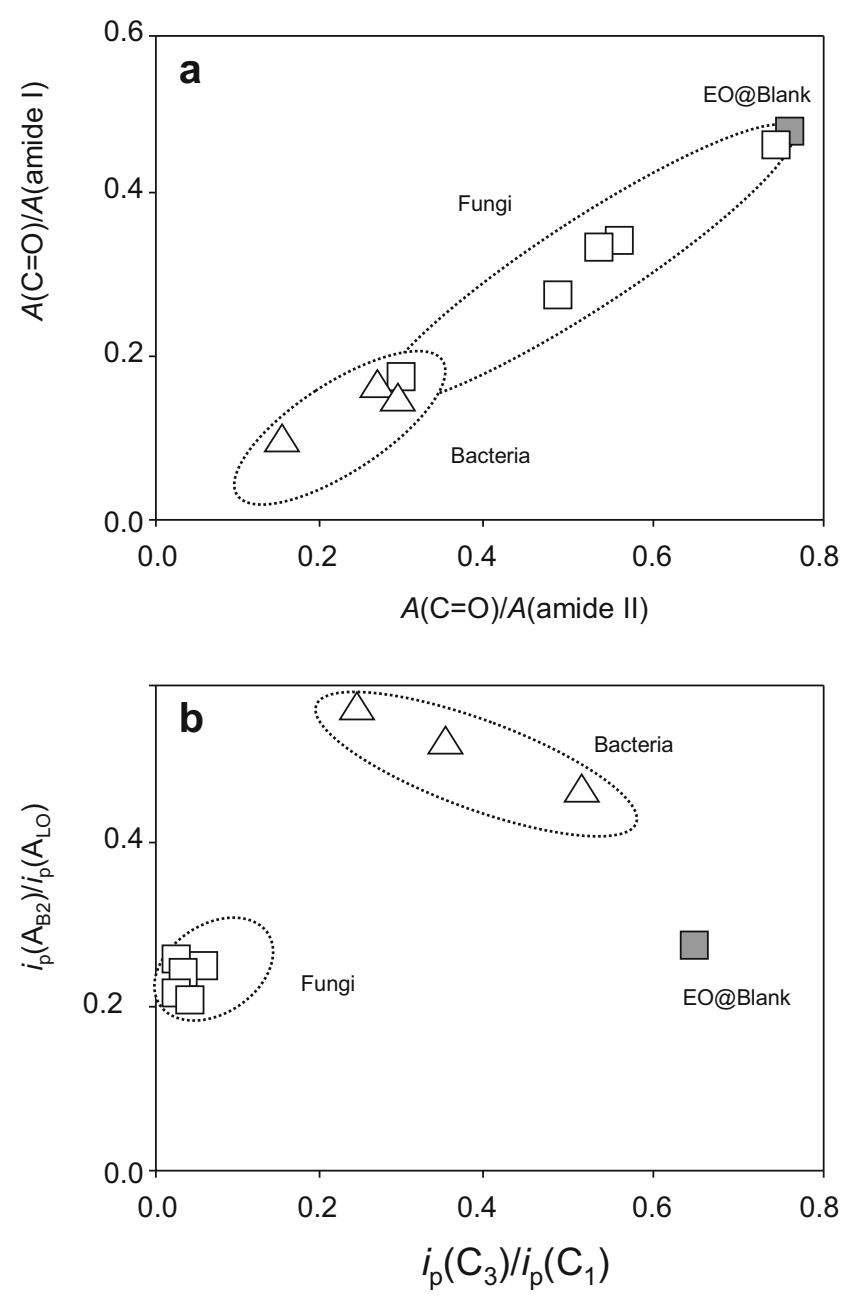

Fig. 11 Plots of a $A(\mathrm{C}=\mathrm{O}) / A$ (amide I) vs. $A(\mathrm{C}=\mathrm{O}) / A$ (amide I) band area ratios obtained from ATR-FTIR spectra of the series of reconstructed egg + linseed oil emulsion paint films (EO) and $\mathbf{b} i_{\mathrm{p}}\left(A_{B 2}\right) / i_{\mathrm{p}}\left(A_{L O}\right)$ ratio vs. $i_{\mathrm{p}}\left(C_{3}\right) / i_{\mathrm{p}}\left(C_{1}\right)$ ratio of the series of inoculated egg-oil emulsion paint films. Solid square: EO@Blank; squares: fungi-inoculated specimens; triangles: bacteria-inoculated specimens the stretching vibration of $\mathrm{C}=\mathrm{O}$ to amide II band, $A(\mathrm{C}=\mathrm{O}) /$ $A$ (amide II), for the series of inoculated egg-oil emulsion paint films. As can be seen in this figure, all data points fall in a narrow, apparently linear region in which the fungi- and bacteria-inoculated specimens can be grouped in separate zones.

A similar discrimination can be obtained from voltammetric data as depicted in Fig. 11b. Here, the values of the peak current ratio for the processes $\mathrm{A}_{\mathrm{B} 2}$ and $\mathrm{A}_{\mathrm{LO}}, i_{\mathrm{p}}\left(\mathrm{A}_{\mathrm{B} 2}\right) / i_{\mathrm{p}}\left(\mathrm{A}_{\mathrm{LO}}\right)$, are plotted vs. the values of the peak current ratio for the processes $C_{3}$ and $\mathrm{C}_{1}, i_{\mathrm{p}}\left(\mathrm{C}_{3}\right) / i_{\mathrm{p}}\left(\mathrm{C}_{1}\right)$, for inoculated egg-oil emulsion paint films, respectively. Now, the data points for bacteria-inoculated and fungi-inoculated films fall in clearly separated regions, thus suggesting the availability of voltammetric data for screening purposes. In fact, combination of ATR-FTIR and voltammetric data provide consistent separations of the specimens inoculated with fungi and bacteria as can be seen in Fig. 12, where the values of the $A(\mathrm{C}=\mathrm{O}) / A$ (amide $\mathrm{I}$ ) and $A(\mathrm{C}=\mathrm{O}) / A$ (amide II) ratios from ATR-FTIR and the value of the $i_{\mathrm{p}}\left(\mathrm{C}_{5}\right) / i_{\mathrm{p}}\left(\mathrm{C}_{1}\right)$ ratio from cyclic voltammograms for egg yolk tempera films are combined in a three-dimensional diagram. Such combination of data provide an unambiguous separation of films submitted to fungi and bacteria attack whose representative points fall in clearly separated regions of the diagram.

All these features would be consistent with the ascription of the voltammetric process $\mathrm{C}_{3}$ in $\mathrm{EG} @$ Blank specimens to the coordination of CdS to proteins mainly disposed in $\beta$-sheet conformation. Under the attack of both bacteria and fungi (see Fig. 6), random coil conformations are increased, here appearing the peak $\mathrm{C}_{5}$ to the coordination of proteins in aggregated and more disordered structures to the pigment surface while the $\mathrm{C}_{3}$ signal disappears (see the description of electrochemical processes in Table 2). In the case of the EO@CdS specimen, peak $\mathrm{C}_{4}$ would be associated to the

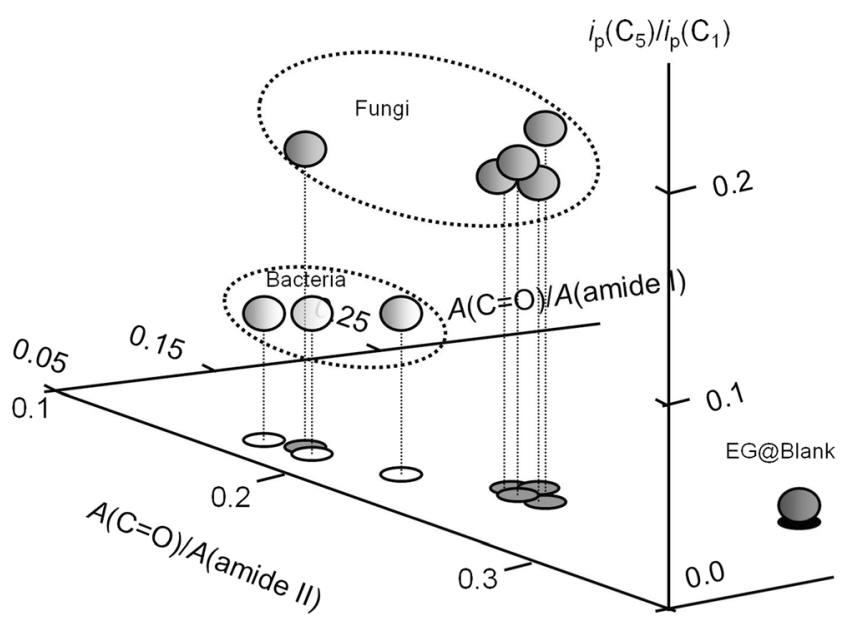

Fig. 12 Three-dimensional diagram showing the values of the $A(\mathrm{C}=\mathrm{O}) /$ $A$ (amide $\mathrm{I}$ ) and $A(\mathrm{C}=\mathrm{O}) / A($ amide II) ratios from ATR-FTIR and the value of the $i_{\mathrm{p}}\left(\mathrm{C}_{5}\right) / i_{\mathrm{p}}\left(\mathrm{C}_{1}\right)$ ratio from cyclic voltammograms for the series of inoculated egg tempera paint films 
Table 2 Summary of the electrochemical processes involved in the biodeterioration of reconstructed EG and EO paint films

\begin{tabular}{lll}
\hline Process & System & Description \\
\hline $\mathrm{C}_{1}$ & $\mathrm{CdS}$ & Reduction of bare CdS grains to Cd metal (Eq. (1)) \\
$\mathrm{C}_{3}$ & EG@Blank & Reduction of CdS surface complexes with proteins mainly in $\beta$-sheet conformation (Eq. (2)) \\
$\mathrm{C}_{4}$ & EO@Blank & Reduction of Cd(II)-carboxylates with fatty acids (Eq. (3)) \\
$\mathrm{C}_{5}$ & EG@fungi & Reduction of CdS surface complexes with proteins mainly in random coil conformation (Eq. (2)) \\
& EG@bacteria & \\
\hline
\end{tabular}

reduction of $\mathrm{Cd}$ soaps formed as the result of complexation of Cd with the carboxylate groups of fatty acids of the linseed oil fraction. In such specimen, the attack of bacteria and fungi results in the formation of complexes with proteins, probably favored by the opening and unfolding of their secondary structure thus producing the reappearance of peak $\mathrm{C}_{3}$ (see Fig. 5), this effect being more intense for bacteria than for fungi. Table 2 summarizes the description of electrochemical processes associated to the biodeterioration of uninoculated and inoculated reconstructed EG and EO paint films.

\section{Conclusions}

In contact with aqueous acetate buffer, VMP data denote that in the presence of the binder, the voltammetric signals for $\mathrm{CdS}$ in reconstructed egg tempera and egg-linseed oil emulsion paint films become modified, with the appearance of specific signals resulting from the pigment-binder association. Such voltammetric responses varied after attack with different fungi (Acremonium chrysogenum, Aspergillus niger, Mucor rouxi, Penicillium chrysogenum, and Trichoderma pseudokoningii) and bacteria (Arthrobacter oxydans, Bacillus amyloliquefaciens, and Streptomyces cellulofans). Combining VMP data with those from ATR-FTIR, SECM, FESEM, and AFM suggests that specific cathodic signals can be attributed to the reduction of $\mathrm{Cd}$ ions bound to proteins that have acquired a more open and unfolded conformation, and the reduction of $\mathrm{Cd}$ soaps formed as the result of complexation with the carboxylate groups of fatty acids of the linseed oil fraction. Depending on the binder and the biological agent, such signals become more or less modified after biodeterioration, then allowing for discriminating bacteria and fungi attacks. This multitechnique study also indicates that microbial attack results in the increase of the content of free fatty acids released from the catalyzed hydrolysis of triglycerides from oil and egg as well as in the breaking down of proteins accompanied by an increase in the irregular and open conformations adopted by the protein molecules. These results are in good agreement with the observed changes in the mechanical behavior of the inoculated specimens.

Acknowledgments This work has been performed by members of the microcluster Grupo de análisis científico de bienes culturales y patrimoniales y estudios de ciencia de la conservación (Ref. 1362) belonging to the Valencia International Campus of Excellence. Financial support is gratefully acknowledged from the Spanish "I+D+I MICINN" projects CTQ2014-53736-C3-1-P and CTQ2014-53736-C3-2-P supported by ERDF funds. The authors wish to thank Dr. José Luis Moya López and Mr. Manuel Planes Insausti (Microscopy Service of the Universitat Politècnica de València) for the technical support.

\section{References}

1. Ratledge C (1994) Biochemistry of microbial degradation. Springer, Berlin

2. Caneva G, Nugari MP, Salvadori O (2008) Plant biology for cultural heritage, the Getty Conservation Institute, Los Angeles

3. Sterflinger K (2010) Fungi: their role in deterioration of cultural heritage. Fungal Biol Rev 47-55 and references therein

4. Gargani G (1968) Fungus contamination of Florence art masterpieces before and after the 1966 disaster. In: Walters AH, Elphick JJ (eds) Biodeterioration of materials. Elsevier, Amsterdam, pp. 252-257

5. Seves AM, Sora S, Ciferr O (1996) The microbial colonization of oil paintings - a laboratory investigation. Int Biodeter Biodegr. 37 : 215-224

6. Tiano P (2002) Biodegradation of cultural heritage: decay mechanisms and control methods. University of Lisbon

7. Strzelczyk AB (2004) Observations on aesthetic and structural changes induced in polish historic objects by microorganisms. Int Biodeter Biodegr. 53:151-156

8. López-Miras M, Piñar G, Romero-Noguera J, Bolivar-Galiano FC, Ettenauer J, Sterflinger K, Martín-Sánchez I (2013) Microbial communities adhering to the obverse and reverse sides of an oil painting on canvas: identification and evaluation of their biodegradative potential. Aerobiologia 29:301-314

9. Koszewski A, Rymuza Z, Reuther F (2008) Evaluation of nanomechanical, nanotribological and adhesive properties of ultrathin polymer resist film by AFM. Micro Engn 85:1189-1192

10. Schabereiter-Gurtner C, Piñar G, Lubitz W, Rölleke S (2001) An advanced molecular strategy to identify bacterial communities on art objects. J Microbiol Meth 45:77-87

11. Florian MLE (1996) The role of the conidia of fungi in fox spots. Stud Conserv 41:65-75

12. Arai H, Matsui N, Matsumura N, Murakita H (1988) Biochemical investigations on the formation mechanisms of foxing. Stud Conserv 33:11-12 
13. Arai H, Matsumura N, Murakita H (1990) Microbiological studies on the conservation of paper and related cultural properties: part 9, induction of artificial foxing. Science for Conservation 29:25-34

14. Hayashi T, Namili M (1986) Role of sugar fragmentation in early stage browning of amino-carbonyl reaction of sugars with amino acids. Agr Biol Chem Tokyo 50:1965-1970

15. Allsopp D, Seal KJ, Gaylarde CC (2004) Introduction to biodeterioration, 2 edn. Cambridge University Press, Cambridge

16. Bock E, Sand W (1993) The microbiology of masonry biodeterioration. J Appl Bacteriol 74:503-514

17. Ciferri $\mathrm{O}$ (2002) The role of microorganisms in the degradation of cultural heritage. Rev Conserv 3:35-45

18. Van der Snickt G, Dik J, Cotte M, Janssens K, Jaroszewicz J, De Wolf W, Groenewegen J, Van der Loeff L (2009) Characterization of a degraded cadmium yellow (CdS) pigment in an oil painting by means of synchrotron radiation based X-ray techniques. Anal Chem $81: 2600-2610$

19. Child AM (1995) Microbial taphonomy of archaeological bone. Stud Conserv 40:19-30

20. Soliman NA, Knoll M, Abdel-Fattah YR, Schmid RD, Lange S (2007) Molecular cloning and characterization of thermostable esterase and lipase from Geobacillus thermoleovorans YN isolated from desert soil in Egypt. Process Biochem 42(2007):1090-1100

21. Kinderlerer JL (1994) Degradation of the lauric acid oils. Int Biodeter Biodegr 33(1994):345-354

22. van den Berg JDJ, van den Berg KJ, Boon JJ (2002) Identification of non-cross-linked compounds in methanolic extracts of cured and aged linseed oil-based paint films using gas chromatography-mass spectrometry. J Chromatogr A 950:195-211 and references therein

23. Lefèvre M (1974) La 'maladie verte' de Lascaux. Stud Conserv 19: 126-156

24. Petushkova JP, Lyalikova NN (1986) Microbiological degradation of lead-containing pigments in mural paintings. Stud Conserv 31:65-69

25. Breitbach AM, Rocha JC, Gaylarde CC (2011) Influence of pigment on biodeterioration of acrylic paint films in southern Brazil. $\mathrm{J}$ Coat Technol Res 8:619-628

26. Keune K, van Loon A, Boon JJ (2011) SEM backscattered-electron images of paint cross sections as information source for the presence of the lead white pigment and lead-related degradation and migration phenomena in oil paintings. Microsc Microanal 17: 696-701

27. Meilunas RJ, Bentsen JG, Steinberg A (1990) Analysis of aged paint binders by FTIR spectroscopy. Stud Conserv 35:33-51

28. Mazzeo R, Prati S, Quaranta M, Joseph E, Kendix E, Galeotti M (2008) Attenuated total reflection micro FTIR characterization of pigment-binder interaction in reconstructed paint films. Anal Bioanal Chem 392:65-76

29. Salvadó N, Butí S, Nicholson J, Emerich H, Labrador A, Pradell T (2009) Identification of reaction compounds in micrometric layers from gothic paintings using combined SR-XRD and SR-FTIR. Talanta 79:419-428

30. Scholz F, Meyer B (1998) Voltammetry of solid microparticles immobilized on electrode surfaces. Electroanal Chem 20:1-86

31. Scholz F, Schröder U, Gulabowski R, Doménech-Carbó A (2014) Electrochemistry of immobilized particles and Dropletst, 2 edn. Springer, Berlin-Heidelberg

32. Doménech-Carbó A, Labuda J, Scholz F (2013) Electroanalytical chemistry for the analysis of solids: characterization and classification (IUPAC technical report). Pure Appl Chem 85:609-631

33. Doménech-Carbó A, Doménech-Carbó MT, Costa V (2009) Electrochemical methods for Archaeometry, conservation and restoration (monographs in electrochemistry series Scholz F edit). Springer, Berlin-Heidelberg

34. Doménech-Carbó A (2010) Electrochemistry for conservation science. J Solid State Electr 14:349-351
35. Matteini M, Moles A (1989) La Chimica nel Restauro. Nardini, Firenze

36. Gettens RJ, Stout GL (1966) Painting materials. A short encyclopedia. Dover Publications, New York

37. Cennini C (1982) Il libro dell' arte. Akal, Madrid

38. Cepriá G, García-Gareta E, Pérez-Arantegui J (2005) Cadmium yellow detection and quantification by voltammetry of immobilized microparticles. Electroanalysis 17:1078-1084

39. Domínguez I, Doménech-Carbó A, Cerisuelo JP, López-Carballo G, Henández-Muñoz P, Gavara R (2014) Contact probe electrochemical characterization and metal speciation of silver LLDPE nanocomposite films. J Solid State Electrochem 18:2099-2110

40. Byler DM, Susi H (1986) Examination of the secondary structure of proteins by deconvolved FTIR spectra. Biopolymers 25:469-487

41. Chang CM, Powrie WD, Fennema O (1977) Microstructure of egg yolk. J Food Sci 42:1193-1200

42. Prestrelski SJ, Tedeschi N, Arakawa T, Carpenter JF (1993) Dehydration-induced conformational transitions in proteins and their inhibition by stabilizers. Biophys J 65:661-671

43. Boehm S, Abaturov LV (1977) Structural changes of methaemoglobin by dehydration. FEBS Lett 77:21-24

44. Karpowicz A (1981) Ageing and deterioration of proteinaceous media. Stud Conserv 26:153-160

45. Koper A, Grabarczyk M (2012) Simultaneous voltammetric determination of trace bismuth(III) and cadmium(II) in water samples by adsorptive stripping voltammetry in the presence of cupferron. $\mathrm{J}$ Electroanal Chem 681:1-5

46. Zakharchuk N, Meyer S, Lange B, Scholz F (2000) A comparative study of lead oxide modified graphite paste electrodes and solid graphite electrodes with mechanically immobilized lead oxides. Croat Chem Acta 73:667-704

47. Komorsky-Lovric S, Lovric M, Bond AM (1992) Comparison of the square-wave stripping voltammetry of lead and mercury following their electrochemical or abrasive deposition onto a paraffin impregnated graphite electrode. Anal Chim Acta 258:299-305

48. Arjmand F, Adriaens A (2012) Electrochemical quantification of copper-based alloys using voltammetry of microparticles: optimization of the experimental conditions. J Solid State Electrochem 16: 535-543

49. Meyer B, Ziemer B, Scholz F (1995) In situ X-ray diffraction study of the electrochemical reduction of tetragonal lead oxide and orthorhombic $\mathrm{Pb}(\mathrm{OH}) \mathrm{Cl}$ mechanically immobilized on a graphite electrode. J Electroanal Chem 392:79-83

50. Hasse U, Scholz F (2001) In situ atomic force microscopy of the reduction of lead oxide nanocrystals immobilised on an electrode surface. Electrochem Commun 3:429-434

51. Doménech-Carbó A, Doménech-Carbó MT, Mas-Barberá X (2007) Identification of lead pigments in nanosamples from ancient paintings and polychromed sculptures using voltammetry of nanoparticles/atomic force microscopy. Talanta 71:1569-1579

52. Eissler RL, Princen RH (1972) The interface between reactive pigment and binder matrix. J Electroanal Chem 37:327-336

53. Kuznetsov AM, Ulstrup J (1989) Protein dynamics and electronic fluctuation effects in electron transfer reactions of membrane-bound proteins and metalloprotein complexes. J Electroanal Chem 275: 289-305

54. Colletti LP, Teklay D, Stickney JL (1994) Thin-layer electrochemical studies of the oxidative underpotential deposition of sulfur and its application to the electrochemical atomic layer epitaxy deposition of CdS. J Electroanal Chem 369:145-152

55. Gulaboski R, Mirceski V, Bogeski I, Hoth M (2012) Protein film voltammetry: electrochemical enzymatic spectroscopy. A review on recent progress. J Solid State Electrochem 16:2315-2328

56. Guidelli R, Becucci L (2011) Ion transport across biomembranes and model membranes. J Solid State Electrochem 15:1459-1470 
57. Sutherland K (2003) Solvent-extractable components of linseed oil paint films. Stud Conserv 48:111-135

58. Rossi M, Alamprese C, Ratti S (2007) Tocopherols and tocotrienols as free radical-scavengers in refined vegetable oils and their stability during deep-fat frying. Food Chem 102:812-817

59. Ziyatdinova G, Morozov M, Budnikov H (2012) MWNT-modified electrodes for voltammetric determination of lipophilic vitamins. J Solid State Electrochem 16:2441-2447

60. Madani A, Nessark B, Boukherroub R, Chehimi MM (2011) Preparation and electrochemical behaviour of PPy-CdS composite films. J Electroanal Chem 650:176-181

61. Derrick MR, Stulik DC, Landry MJ (1999) Infrared spectroscopy in conservation science. Getty Conservation Institute, Los Angeles

62. van der Weerd J, van Loon A, Boon JJ (2005) FTIR studies of the effects of pigments on the aging of oil. Stud Conserv 50:3-22

63. Kong J, Yu S (2007) Fourier transform infrared spectroscopic analysis of protein secondary structures. Acta Bioch Bioph Sin 39:549-559

64. Haris PI, Severcan F (1999) FTIR spectroscopic characterization of protein structure in aqueous and non-aqueous media. J Mol Catal BEnzym 7:207-221

65. Furlan PY, Scott SA, Peaslee MH (2007) FTIR-ATR study of $\mathrm{pH}$ effects on egg albumin secondary structure. Spectrosc Lett 40:475-482
66. Dong A, Huang P, Caughey WS (1990) Protein secondary structures in water from second-derivative amide I infrared spectra. Biochemistry-US 29:3303-3308

67. Rajkhowa R, Hu X, Tsuzuki T, Kaplan DL, Wang X (2012) Structure and biodegradation mechanism of milled B. mori silk particles. Biomacromolecules 13:2503-2512

68. Anton M (2013) Egg yolk: structures, functionalities and processes. J Sci Food Agr 93:2871-2880

69. Hevonoja T, Pentikäinen MO, Hyvönen MT, Kovanen PT, AlaKorpela M (2000) Structure of low density lipoprotein (LDL) particles: basis for understanding molecular changes in modified LDL. Biochim Biophys Acta 1488:189-210

70. Kumpula LS, Kumpula JM, Taskinen MR, Jauhiainen M, Kaski K, Ala-Korpela M (2008) Reconsideration of hydrophobic lipid distributions in lipoprotein particles. Chem Phys Lipids 155:57-62 and references therein

71. Schneider H, Morrod RS, Colvin JR, Tattrie NH (1973) The lipid core model of lipoproteins. Chem Phys Lipids 10:328-353

72. Doménech-Carbó MT, Osete-Cortina L, de la Cruz-Cañizares J, Bolívar-Galiano F, Romero-Noguera J, Martín-Sánchez I, Fernández-Vivas MA (2006) Study of the microbiodegradation of terpenoid resin-based varnishes from easel painting using pirolisisgas chromatography-mass spectrometry and gas chromatographymass spectrometry. Anal Bioanal Chem 385:1265-1280 


\title{
Analyzing chemical changes in verdigris pictorial specimens upon bacteria and fungi biodeterioration using voltammetry of microparticles
}

\author{
Annette S. Ortiz-Miranda ${ }^{1}$, Antonio Doménech-Carbó ${ }^{*}$, María Teresa Doménech-Carbó ${ }^{1}$, Laura Osete-Cortina ${ }^{\text {, }}$ \\ Fernando Bolívar-Galiano ${ }^{3}$ and Inés Martín-Sánchez ${ }^{4}$
}

\begin{abstract}
It is reported the application of the voltammetry of microparticles (VMP), complemented with attenuated total reflectance Fourier transform infrared spectroscopy (ATR-FTIR) and field emission scanning electron microscopy (FESEM) techniques, to monitor the deterioration of verdigris pictorial specimens under the action of different biological agents. This methodology would be of application for identifying the type of biological agent causing deterioration of paintings, which is an important problem affecting cultural heritage. The analysis of biodeterioration processes is complicated by the fact that the action of microorganisms can affect both pigment and binding media. The deterioration of pictorial specimens combining verdigris with egg and egg-linseed oil binders by Penicillium chrysogenum, Aspergillus niger, Acremonium chrysogenum, Trychoderma pseudokoningi and Mucor rouxii fungi and Bacillus amyloliquefaciens, Arthrobacter oxydans and Streptomyces cellulofans bacteria were tested using sample-modified graphite electrodes immersed into aqueous electrolytes. A model is presented to describe the involved electrochemistry resulting in specific voltammetric features for the electrochemical reduction of verdigris associated to the proteinaceous and lipidic fractions of the binders. The experimental results and model proposed have been discussed and compared with those previously obtained for cadmium yellow reconstructed paint film specimens.
\end{abstract}

Keywords: Electrochemistry, Biodeterioration, Verdigris, Cadmium sulfide, Egg tempera, Egg-oil emulsion

\section{Background}

The growth of microorganisms is one of the major concerns in all museums worldwide due to the aesthetical and structural damage that it may cause. Artistic paintings are constituted of a wide range of organic and inorganic materials; most of these components are biodegradable. The analysis of biodeterioration processes affecting pictorial works of art is complicated by the fact that the action of microorganisms can affect both pigments and binding media. Since to nowadays, art treatises have detailed descriptions of these materials that

\footnotetext{
*Correspondence: antonio.domenech@uv.es

2 Departament de Química Analítica, Universitat de València, Dr. Moliner,

50, Burjassot, 46100 Valencia, Spain

Full list of author information is available at the end of the article
}

many microorganisms may utilize for growth such as polysaccharides, proteins, oils, waxes, etc. $[1,2]$.

In this context, the study of biodeterioration of pigment-containing paint films is of interest because of the changes induced in the visual appearance of the painting, but also by its effect in its long-term preservation due to the loss of chemical and mechanical stability [3]. In fact, pigments can act as inhibitors or catalysts in the drying of oils $[2,4,5]$, whereas fatty acids released from hydrolysis of triglycerides can form metal soaps with metal ions from some pigments [6-11] which can migrate through the semi-permeable paint system to the paint surface where they are mineralized and aggregate forming protrusions $[7,8]$.

In presence of microorganisms, plant gums, proteinaceous media and drying oils mainly undergo hydrolysis, 
which often is followed by oxidation processes. Additionally, crosslinking, condensation, and dehydration of amino acids can take place as consequence of microbial action or environmental agents [12]. Environmental deterioration of oil paint films can be also due to crosslinking reactions, oxidation of unsaturated acids and hydrolysis of glyceride bonds releasing free fatty acids, which can complex pigments forming metal soaps [6]. These processes can be accompanied by changes in the chemical composition and morphology of the pigments that can act as catalysts or react with the byproducts that result from the biodeterioration of the organic binders.

Although organic supports of paintings such as panels or canvas are more sensitive to the microbial colonization, paint layers composed of proteinaceous or polysaccharide binding media can be also the target of a variety of microorganisms. In particular, growing of microorganisms in paint layers in which verdigris was used has been observed in ancient pictorial artworks such as the Cinctorres Altarpiece (anonymous, fourteenth century, Cinctorres, Spain). Examination by FESEM enabled the identification of fungus spores located on the crack and pores formed in the surface of the painting. A number of based electron microscopy, spectroscopic and chromatographic techniques enable the study of the changes undergone by the binders under biological attack; however, the study of the minimal modifications often occurring in the pigment are difficult and analytical techniques highly selective and sensitive are required. Voltammetry of microparticles (VMP), a solid state electrochemistry technique developed by Scholz et al. [13] is highly sensitive to the electrochemical response of graphite electrodes modified with microparticulated samples of paint. Voltammetric profiles are not only sensitive to the pigment but also to other materials present in the sample, binding media in particular. Among a variety of materials $[14,15]$, this technique has been extensively applied in the field of conservation and restoration, as recently reviewed [16, 17]. In a previous report [18], we described the application of this methodology to characterize the biological attack of different species of bacteria and fungi to reconstructed egg tempera and egg-linseed oil emulsion paint films containing cadmium yellow (CdS). In the current report, we present a voltammetric study on the biological attack of a set of bacteria and fungi species to reconstructed paint films containing verdigris as a pigment aimed to assess the possibility of determining specific responses for the different types of biodegradation. The simplicity and versatility of the technique makes it potentially interesting for the study of biodeterioration of paintings. The pigment verdigris is particularly interesting because of (i) its frequent use in painting until the 19th [19] and (ii) its anti-fungal properties [20].
The voltammetric response of verdigris, which was previously used for identification purposes [21], was studied here in a series of reconstructed egg tempera and egg-linseed oil emulsion paint films submitted to biological attack with different fungi (Acremonium chrysogenum, Aspergillus niger, Mucor roxii, Penicillium chrysogenum, and Trichoderma pseudokoningii) and bacteria (Arthrobacter oxydans, Bacillus amyloliquefaciens, and Streptomyces cellulofans) typically involved in paint deterioration [22-30] and compared with the response of CdS-based films. Voltammetric data have been complemented with attenuated total reflectanceFourier transform infrared spectroscopy (ATR-FTIR) in order to gain information on the modification of chemical bonds of the binder upon biological attack and the formation of copper complexes. Field emission scanning electron microscopy (FESEM) was used for the examination of the prepared specimens. This technique, which provides enhanced resolution relative to conventional electron microscopy, was devoted to investigate the morphological changes occurred in the films during the biodeterioration.

\section{Experimental}

\section{Instrumentation}

Electrochemical experiments were performed at $298 \mathrm{~K}$ in a three-electrode cell under argon atmosphere using a $\mathrm{CH}$ I660C device (Cambria Scientific, Llwynhendy, Llanelli UK). A platinum wire counter-electrode and an $\mathrm{Ag} / \mathrm{AgCl}(3 \mathrm{M} \mathrm{NaCl})$ reference electrode completed the three-electrode arrangement.

$0.25 \mathrm{M}$ sodium acetate buffer (Panreac) at $\mathrm{pH} 4.75$ was used as a supporting electrolyte. Cyclic voltammograms (CVs) were obtained using abrasive VMP protocols. Importantly, the electrolyte solution was renewed after each electrochemical run to avoid contamination due to cadmium ions eventually released to the solution phase during electrochemical turnovers. Commercial paraffin-impregnated graphite bars of (Staedtler 200 HB type, $68 \%$ wt graphite, diameter $2 \mathrm{~mm}$ ) were used. Prior to the series of runs for each material or sample, a conditioning protocol was used to increase repeatability. The electrode surface was polished with alumina, rinsed with water and polished by pressing over paper. For electrode modification, an amount of 1-2 mg of the sample was extended on an agate mortar forming a spot of finely distributed material. Then the lower end of the graphite electrode was gently rubbed over that spot of sample and finally rinsed with water to remove illadhered particles. Sample-modified graphite bars were then dipped into the electrochemical cell so that only the lower end of the electrode was in contact with the electrolyte solution. This procedure provides an almost 
constant electrode area and reproducible background currents.

The IR spectra in the ATR mode of the powdered samples were obtained using a Vertex 70 Fourier-transform infrared spectrometer with an FR-DTGS (fast recovery deuterated triglycine sulphate) temperature-stabilised coated detector and a MKII Golden Gate Attenuated Total Reflectance (ATR) accessory. A total of 32 scans were collected at a resolution of $4 \mathrm{~cm}^{-1}$ and the spectra were processed using the OPUS/IR software.

Field emission scanning electron microscopy (FSEM). Secondary electron images were obtained using a Zeiss model ULTRA 55 operating with a Oxford-X Max X-ray microanalysis system controlled by Inca software. The analytical conditions were: $1 \mathrm{kV}$ accelerating voltage. Samples were directly observed in order to avoid interference with the particulate structure of the coating element used for eliminating charging effects.

\section{Reference materials and test specimens}

Cold pressed linseed oil, verdigris [synthetic copper(II) acetate, Kremer] and fresh hen's egg were used as reference materials for preparing the series of paint films. Reconstructed egg tempera paint films (EG) were prepared by mixing the pigment with the appropriate amount of egg until suitable consistence (30\% weight composition of pigment); and spreading this product on glass slides in order to form a thin film. The paint films were dried at room temperature during 4 weeks $\left(21{ }^{\circ} \mathrm{C}, 50 \% \mathrm{RH}\right)$. Thickness of the films was in the range $0.3-0.5 \mathrm{~mm}$. Reconstructed egg-linseed oil emulsion paint films (EO) were prepared by mixing the pigment with the appropriate amount of an egg-linseed oil emulsion (1:1) (35\% weight composition of pigment). The reconstructed paint films were dried at room temperature during 4 weeks $\left(21^{\circ} \mathrm{C}, 50 \% \mathrm{RH}\right)$. Thickness of the films was in the range $0.3-0.5 \mathrm{~mm}$.

\section{Microorganisms and cultures}

Bacterial and fungal strains, obtained from the Spanish Collection of Type Cultures (CECT, Colección Española de Cultivos Tipo, Universidad de Valencia, Valencia, Spain), were chosen because they have been frequently found in biodeterioration studies of cultural heritage [22-30]. The selected fungi were: Acremonium chrysogenum (Ac) (CECT 2718, ATCC 14615), Aspergillus niger (An) (CECT 2088, ATCC 9029), Mucor rouxii (Mr) (CECT 2655, ATCC 24905), Penicillium chrysogenum (Pc) (CECT 2306, ATCC 8537) and Trychoderma pseudokoningii (Tp) (CECT 2937). The selected bacteria were: Arthrobacter oxydans (Ao) (CECT 386, ATCC 14358), Bacillus amyloliquefaciens (Ba) (CECT 493, ATCC 23842) and Streptomyces cellulofans (Sc) (CECT 3242, ATCC 29806).
Bacteria were grown on culture plates of Trypticase Soy Agar (TSA, Scharlau) medium and were incubated at $28{ }^{\circ} \mathrm{C}$ for $24 \mathrm{~h}$. Cultures were re-suspended in $2 \mathrm{~mL}$ of $0.1 \%$ Tween 80 solution (Aldrich). After centrifugation carried out for removing possible remains of the solid culture medium, bacterial suspensions were adjusted to $10^{7}$ cells $\mathrm{mL}^{-1}$. To obtain fungal spores, fungi were grown on Potato Dextrose Agar (PDA, Scharlau, Barcelona, Spain) over a total period of 1 week at $28{ }^{\circ} \mathrm{C}$ and spores were collected by washing the solid culture with $0.1 \%$. Tween 80 solution and filtering through sterile glass wool. The resulting suspensions of spores were centrifuged three times and the supernatants were discarded in order to avoid any residue from the culture medium or rest of mycelia. Finally, spores were re-suspended in $1 \mathrm{~mL}$ ultrapure water and spores suspensions were adjusted to $10^{5}-10^{6}$ spores $\mathrm{mL}^{-1}$.

\section{Inoculation and incubation of paint specimens}

Reconstructed paint films prepared as egg yolk tempera (EG) and egg-oil emulsion (EO) were inoculated with three separated drops of $20 \mu \mathrm{L}$ of each fungal and bacterial suspension. After inoculation, each paint film was placed in the center of a Petri dish and incubated in darkness for 40 days at $28{ }^{\circ} \mathrm{C}, 80 \%$ relative humidity. Thus, two series of biodeteriorated reconstructed paint films were obtained (EG@microorganism and EO@microorganism). Paint films inoculated with $20 \mu \mathrm{L}$ of sterile ultrapure water and incubated under the same conditions were used as controls (EG@BLANK and EO@BLANK). After incubation, the microbial biomass was completely separated from the surface of the reconstructed paint films in two steps, (1) mechanical removing mycellums, spores, etc. by carefully rolling a sterile cotton-swab on the biodeteriorated area. Eventually, sterile microscalpel was used for removing some small craquelure detached of the paint film as consequence of the microbial action (see Fig. 1). (2) Rinsing with sterile water for removing the biomass that still could remain.

\section{Results and discussion FESEM examination}

Figure 1 shows the visual appearance of the surface of the uninoculated egg tempera paint film EG@BLANK (Fig. 1a) and the EG@Ac specimen after inoculationincubation and partial removing of the biomass (Fig. 1b). It can be seen that abundant spores of Acremonium chrysogenum are still covering the surface of the paint film. Figure 1c and d show the surface of the EG@Sc and EG@ Mr specimens, respectively, after inoculation-incubation and complete suppression of the biomass. It can be seen that a network of craquelures has been formed as result of the inoculation. Similarly, the visual appearance of the 

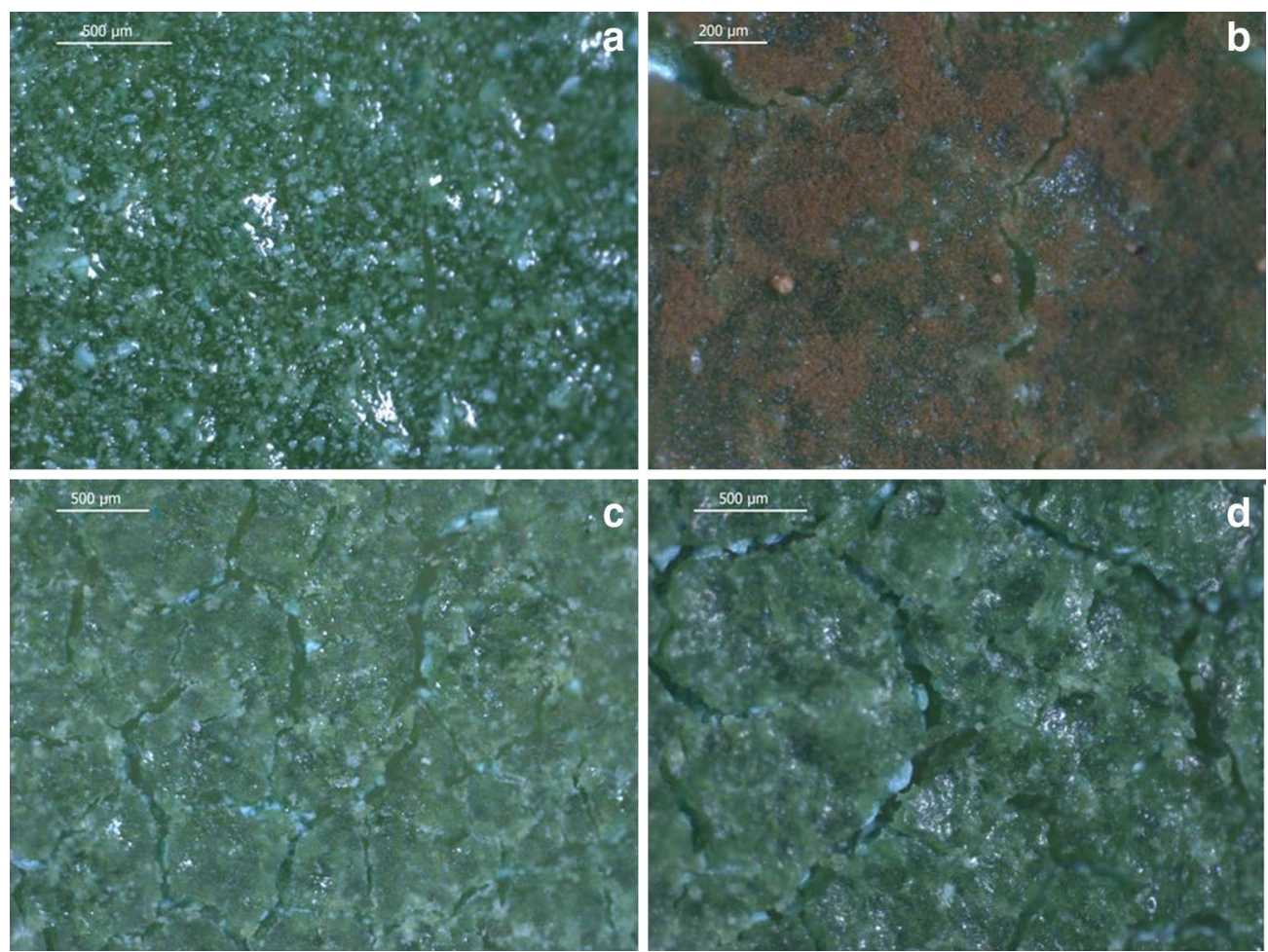

Fig. 1 Photograph of the surface of the reconstructed egg-tempera paint film specimens: a EG@BLANK, $\mathbf{b} E G @ A c$ after inoculation-incubation and cEG@Sc, dEG@Mr after inoculation-incubation and suppression of the biomass

reconstructed egg-oil emulsion paint films can be seen in Fig. 2. Spores of Trychoderma pseudokoningii are also covering the surface of the paint film but at lesser extent than in the egg tempera specimens (Fig. 2b). Growing of Bacillus amyloliquefaciens bacterium has resulted in a loss of the characteristic gloss of this type of films conferred by the oil (Fig. 2d).

Figure 3a shows the electron secondary image of the EG@BLANK un-inoculated specimen. The surface of the paint film is flat, eventually disrupted by small pores (asterisk) produced during the drying of the film and abundantly protruded by small spherical features (arrow) that are associated with dense protein-lipid particles (less than $4 \mu \mathrm{m}$ diameter) characteristic of egg yolk. Some changes in the surface morphology are observed in the EG@Tp specimen inoculated with Trychoderma pseudokoningii that illustrate the effect of fungi growing in the paint film (Fig. 3b). It can be seen that the surface of the film is microeroded (arrow) as consequence of the microbial attack, which has altered the substrate. Microcrystals of nanometric size are spread on the surface of the film and form irregular aggregates around the spores of the fungus (asterisk). They are supposed to be formed by rests of the binding medium altered by the fungus. A different aspect exhibits the surface of the
EG@Ba specimen inoculated with Bacillus amyloliquefaciens eubacterium that is shown in Fig. 3c. As it can be seen in the image, the microbial attack has resulted in the formation of microcracks (arrow) along which the grains of pigment are partially emerging. Microorganisms, in general, seem to be specially active on the consumption of proteins as shown in Fig. 4 in which it can be seen the aspect of a dense protein-lipid particle (arrow) after the bacterium attack. These particles consisted of a nucleus (a) mainly composed of triacylglycerols covered by a spherical layer of proteins (b). This structure is stabilized by phospholipids that are also located in the internal side of this external layer. In the image can be seen that part of this protein and phospholipid-rich external layer has been lost by the bacteria, whose features are still visible attached to the granule (c).

The egg-oil emulsion specimens showed, in general, a more irregular surface than that of the egg tempera paint films as can be seen in Fig. 5a. A number of cracks (arrow) are formed as consequence of the stretching forces that take place on the paint as consequence of the dehydration-oxidation-polymerization processes associated to the drying of the film. The combined action of these processes results in the macroscopical shrinkage of the film. The image also shows a sphere from the yolk 


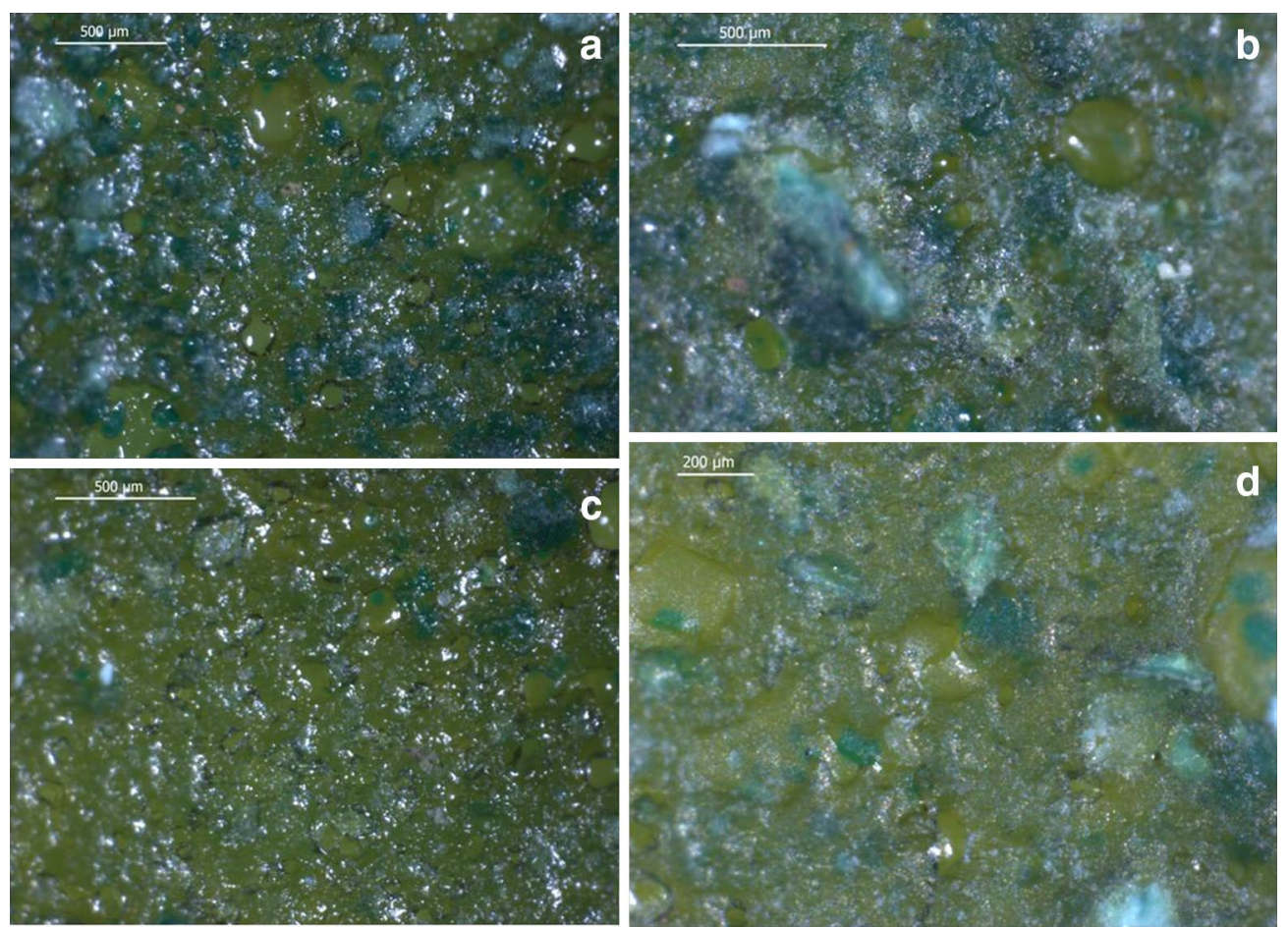

Fig. 2 Photograph of the surface of the reconstructed egg-tempera paint film specimens: a EO@BLANK, b EO@Tp after inoculation-incubation, c EO@Pc after inoculation-incubation and suppression of the biomass, $\mathbf{d}$ EO@Ba after inoculation-incubation and suppression of the biomass

(asterisk) and microcrystals mainly associated to copper soaps but also to copper-protein complexes formed as result of the interaction between the pigment and the binding medium (upper arrow). Apart from the increase of microcracks and irregular aggregates of microcrystals (lower arrow), similar micromorphology to the uninoculated paint film, with abundant aggregates of microcrystals is observed in the specimen EO@An inoculated with the fungus Aspergillus niger, which is shown Fig. 5b. Finally, Fig. $5 \mathrm{c}$ shows the aspect of the surface of the paint film EO@Ao inoculated with Arthrobacter oxydans bacterium. Activity of this microorganism has also promoted the formation of copper complexes in this paint film (arrow).

\section{FTIR spectroscopy \\ Uninoculated specimens}

This analytical technique has enabled the monitoring of the changes undergone by the two studied binders as consequence of the action of microorganisms tested. IR spectra of the EG and EO series of reconstructed paint films have been performed for obtaining complementary information to that provided by solid state electrochemistry technique. Figure 6 shows the IR spectra obtained in egg, EG@BLANK and EO@BLANK specimens. These spectra are dominated by bands characteristic of stretching vibrations of amide A and methyl/methylene, carbonyl and amide I groups in egg proteins together with stretching vibrations of hydroxyl and $\mathrm{Cu}$-carboxylate groups in neutral verdigris in the two last spectra. Of particular interest are the differences observed in the $1800-1500 \mathrm{~cm}^{-1}$ region. Thus, intensity of amide I band in EG@BLANK is significantly lower than that for pure egg. This band is associated with the stretching vibrations of $\mathrm{C}=\mathrm{O}(70-85 \%)$ and $\mathrm{C}-\mathrm{N}$ groups $(10-20 \%)$ and the position of this band is directly related to the backbone conformation of the polypeptide chains and the hydrogen bonding pattern. Therefore, the decrease of the intensity of this band in the IR spectra of both pigment-containing specimens can be related to a breakdown of the protein chains according to prior studies devoted to the effect of verdigris in egg tempera medium [31]. On the other hand, maximum of the amide I band appears slightly redshifted from 1633 to $1628 \mathrm{~cm}^{-1}$ in EG@BLANK evidencing changes in the $\beta$-sheet conformation of the proteins as consequence of the presence of pigment. Aggregated intermolecular $\beta$-sheets, rigid $\beta$-hairpin with specific turns structures or $\beta$-structures less accessible to the external medium or intermolecular contacts between extended chain segments are conformations ascribed to this $1610-1630 \mathrm{~cm}^{-1}$ lower range [32]. Secondary maximum exhibited by the amide I band at $1651 \mathrm{~cm}^{-1}$ in the 


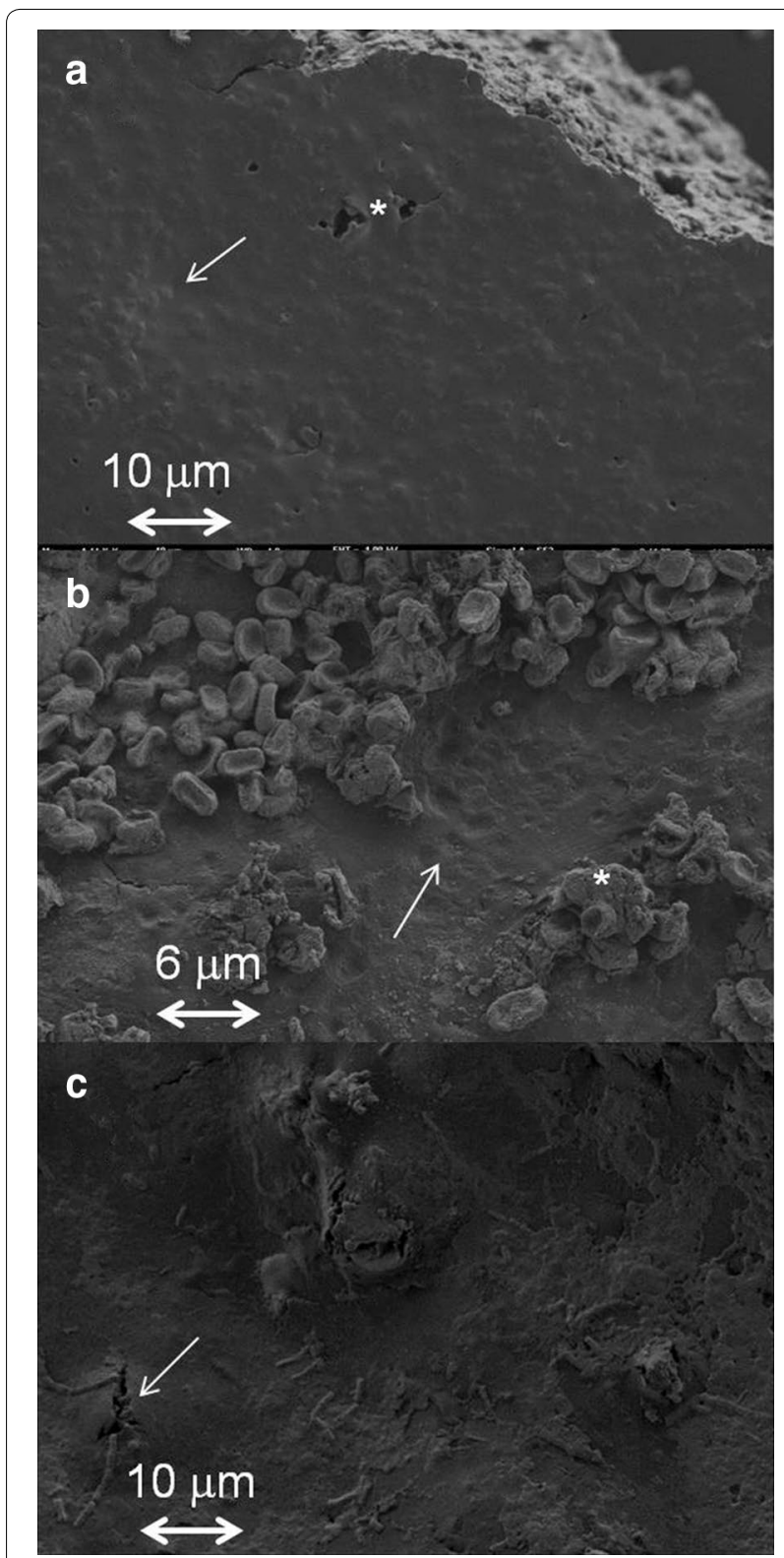

Fig.3 Secondary electron image obtained in: a EG@BLANK, showing pores (asterisk) and protrusions (arrow); b EG@Tp showing an aggregate around fungal spore (asterisk) and microerosins (arrow); c EG@Ba, showing microcracks (arrow)

pure egg specimen occurs at lower spatial frequencies of 1646 and $1650 \mathrm{~cm}^{-1}$ in EG@BLANK and EO@BLANK specimens. This sub-band in the amide I region has been associated with $\alpha$-helix conformations and the downshifting of its position can be related to the increase of the helix length and its bending in coiled coils but also to the increase of the exposition of the helix to the external medium (aqueous plasma and pigment) [32]. The shorter redshift observed in the EO@BLANK for this sub-band suggests that the presence of drying oil reduces the interaction between the protein and the pigment.

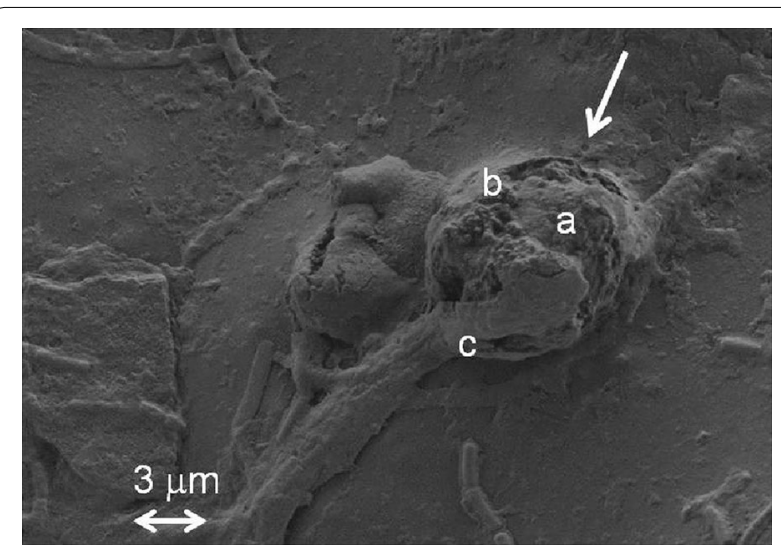

Fig. 4 Secondary electron image of sample EG@Ba. Detail of the alteration of a denser protein-lipid particle due to the selective action of the bacterium

The amide II band is found in the $1480-1580 \mathrm{~cm}^{-1}$ region and derives mainly from in-plane $\mathrm{N}-\mathrm{H}$ bending accompanied of $\mathrm{C}-\mathrm{N}$ and $\mathrm{C}-\mathrm{C}$ stretching vibrations [33]. A notable increase in the intensity of this band is observed in the IR spectra of both specimens containing pigment if they are compared with that of pure egg. Maximum at $1531 \mathrm{~cm}^{-1}$ ( $\beta$-sheet conformations) is blueshifted to 1543 and $1552 \mathrm{~cm}^{-1}$ (helical conformations) [34] in EG@BLANK and EO@BLANK, respectively. In addition, shoulders at 1557, 1572 and $1585 \mathrm{~cm}^{-1}$ are also identified in their second derivative spectra. These features can be directly correlated with the interaction of the pigment with both the lipid and proteinaceous components of the binders. Shoulder at $1585 \mathrm{~cm}^{-1}$ has been related to the formation of complexes of $\mathrm{Cu}(\mathrm{II})$ with free fatty acids released from triacylglycerols and phospholipids in linseed oil and egg yolk [6, 10]. Asymmetric stretching vibration due to the coordination of the carboxylic residues (glutamic and aspartic acid) in the protein molecules with divalent ions, according with data reported in literature, also occurs in the range 1590$1551 \mathrm{~cm}^{-1}[35,36]$. In addition, several studies are found in literature concerning the compounds that can be formed between copper ions and proteinaceous materials in which is described the ability of copper ions for coordinating with the carboxylic groups present in the side chains of the protein macromolecules thus facilitating the decarboxylation of proteins $[37,38]$ and the release of glutamic and aspartic acid [39].

A notable decrease in the shoulder appearing in the range $1700-1720 \mathrm{~cm}^{-1}$ in the egg specimen is observed in both EG@BLANK and EO@BLANK specimens. This band is ascribed to the stretching vibrations of the carboxylic groups from free fatty acids that should be released from the lipids and phospholipids of egg and linseed oil as result of hydrolysis processes. The reduction in the 

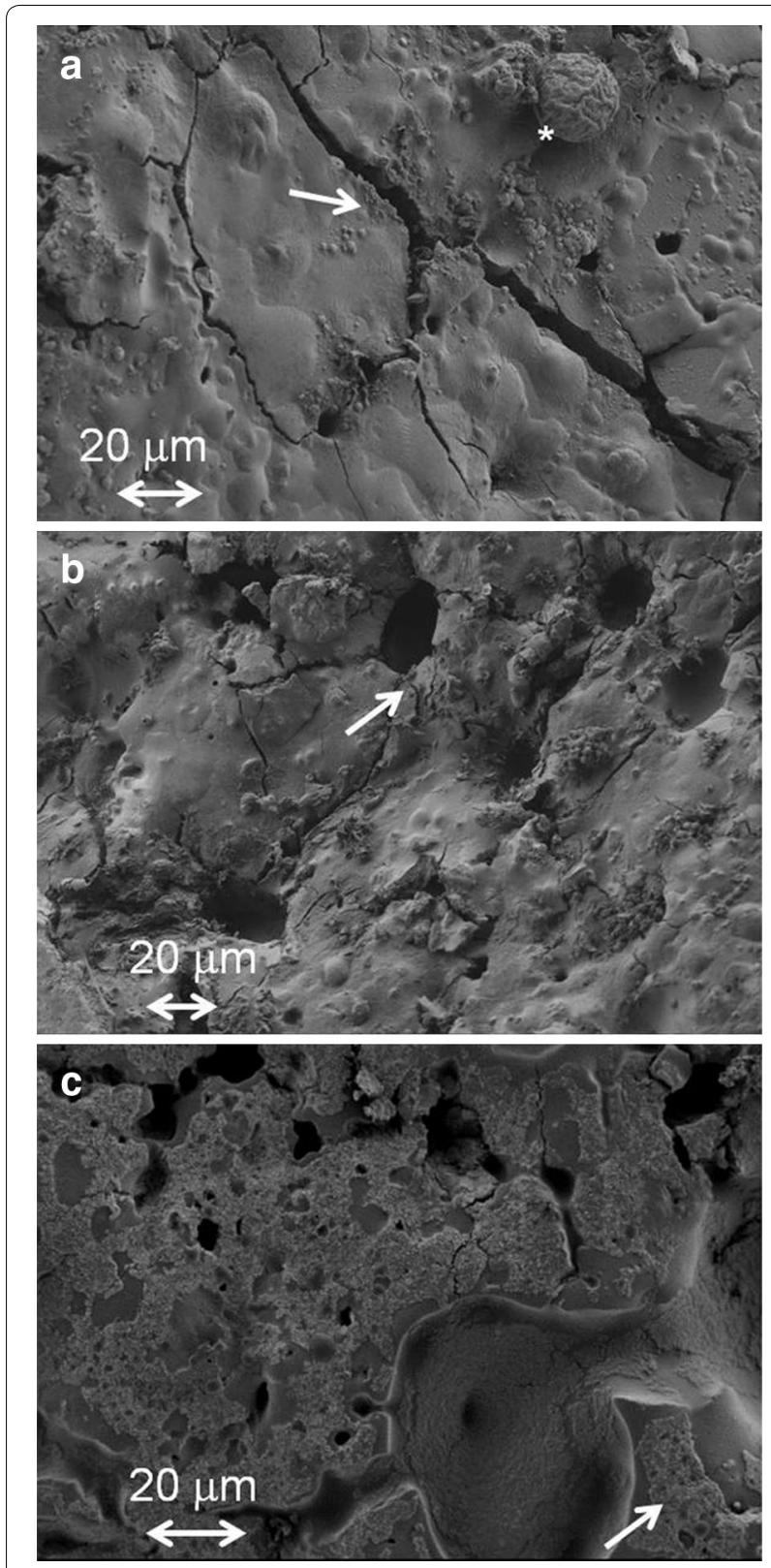

Fig. 5 Secondary electron image obtained in: a EO@BLANK showing cracks (arrow) and a microsphaeroidal feature (asterisk), b EO@An showing pores and aggregates of microcrystals (arrow); c EO@Ao showing irregular features presumed to be associated to the formation of copper complexes (arrow)

intensity of this IR band can be directly correlated with the increase in the intensity of the IR band associated with the copper-protein complexes and copper soaps.

\section{Inoculated specimens}

As a prior step, presence of unremoved rests of biological materials (fungi or bacteria biomass consisting of spores, endospores, vegetative or degraded cell walls, mycelia, conidia etc.), which could interfere the identification of alteration processes occurring in the binding media or verdigris pigment was checked from the IR spectra obtained from samples excised in the inoculated paint specimens. According to literature [40, 41], IR spectra obtained in pure fungal materials in the high spatial frequency region are dominated by bands originated from the stretching vibrations of $-\mathrm{OH}$ and $-\mathrm{NH}$ groups of proteins and the stretching vibrations of methyl and methylene groups of lipids. In the fingerprint region $\left(1800-500 \mathrm{~cm}^{-1}\right)$ the IR spectra are dominated by the strong carbohydrate band at $1064 \mathrm{~cm}^{-1}$ and the amide I and amide II bands at ca. $1635-38$ and $1540-46 \mathrm{~cm}^{-1}$, respectively. Moderate band at $1450 \mathrm{~cm}^{-1}$ ascribed to the to asymmetric bending of $\mathrm{CH}_{3}$ groups in proteins is also observed together with moderate-weak bands at 1237 and $1082 \mathrm{~cm}^{-1}$ associated with stretching vibrations of $\mathrm{PO}_{2}^{-}$group of phospholipids [42]. Characteristic band at $1600 \mathrm{~cm}^{-1}$ is sometimes recognized, which is associated with low-molecular-weight organic compounds due to fungal metabolites and decomposition of cell walls of dead fungi [41]. Occurrence of these same IR bands ascribed to proteins, lipids and phospholipids in egg hinders the use of the above mentioned IR bands for identifying rests of biological material on the paint films. Nevertheless, strong band at $1064 \mathrm{~cm}^{-1}$ from carbohydrates is a satisfactory marker able to be used to detect the presence of rest of fungal biomass deposited on the surface of the paint films. Analogous situation takes place with bacteria, which exhibit IR spectra dominated by bands of polysaccharides, proteins, lipids and phospholipids. However, characteristic features at 1456 and $783 \mathrm{~cm}^{-1}$ of bacterial endospores associated to the pyridine-2,6-dicarboxylic [dipicolinic acid (DPA)] can be used for identifying the presence of rests of bacterial materials together with the polysaccharide bands [42, 43].

Figure $7 \mathrm{a}$ shows a detail of the $1800-500 \mathrm{~cm}^{-1}$ region in the IR spectra of egg tempera paint film specimens EG@BLANK, EG@Pc and EG@Ao. The position of the characteristic bands of marker compounds of bacterial and fungal materials has been superimposed to denote the absence of these compounds in the specimens. Similarly, Fig. 7b shows in detail the IR spectra of egg-oil emulsion paint films EO@BLANK, EO@Ac, and EO@Sc. The absence of biological material on the surface of the egg-oil emulsion paint films is again confirmed.

The effect of microorganisms on the paint films has resulted, in general, in slight changes in the previously described IR bands for egg tempera and egg-oil emulsion media. The more remarkable changes have been observed in the $1800-1500 \mathrm{~cm}^{-1}$ region. Notably, Acremonium chrysogenum fungus presented the highest 


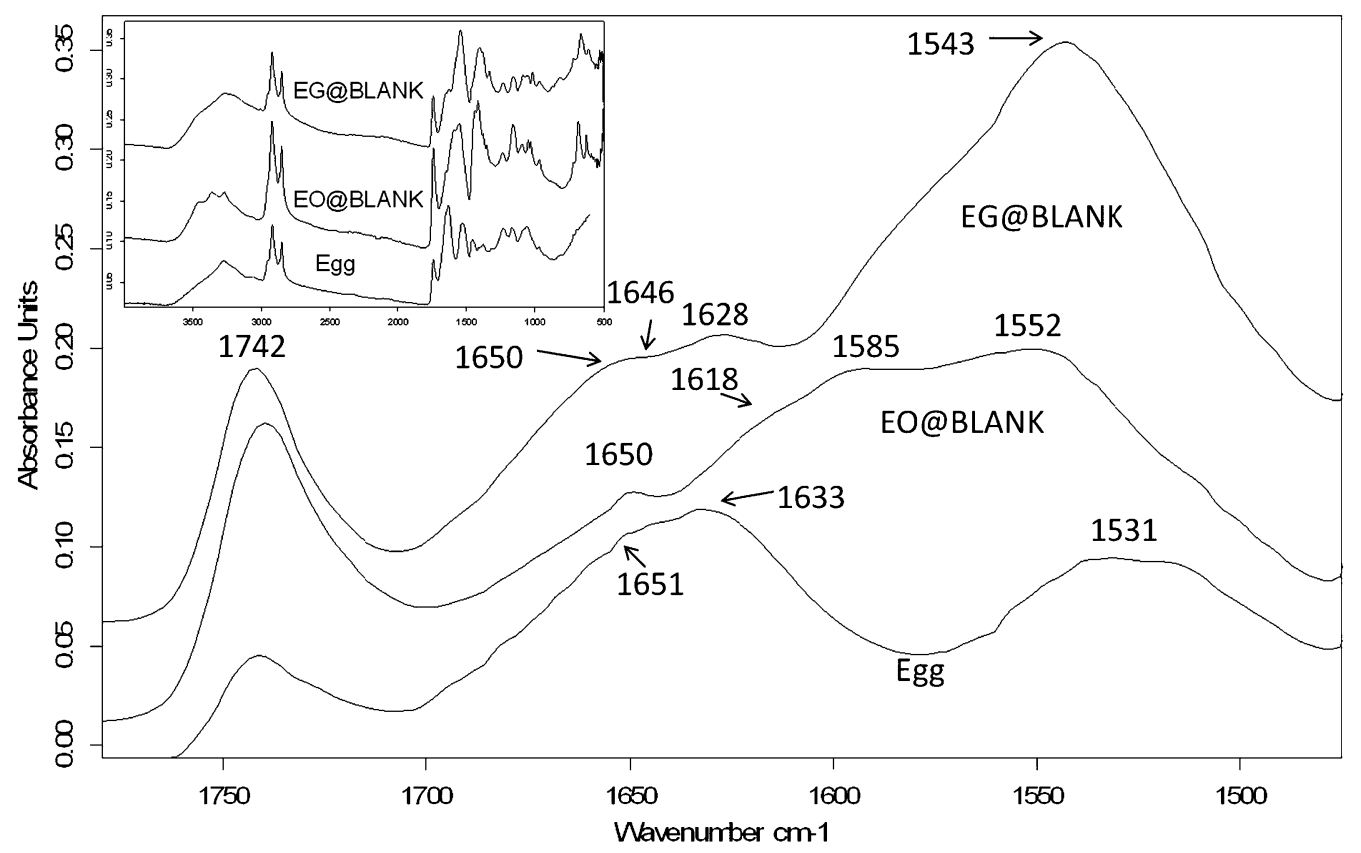

Fig. 6 IR spectra of pure egg and paint film specimens EG@BLANK and EO@BLANK

value for the amide I/amide II intensity ratio among the specimens inoculated with fungus (see EG@Ac spectrum shown in Fig. 8a) with a prominent maximum of the amide I band at $1628 \mathrm{~cm}^{-1}$ that evidences that $\beta$-sheet is the prevalent conformation in this medium. Dominance of this structure, in which lateral chains are less accessible to the external medium, is in good correspondence with the scarce formation of $\mathrm{Cu}$-carboxylate complexes (absence of shoulder in the amide II band at $1585 \mathrm{~cm}^{-1}$ ). IR spectra obtained in the egg tempera specimens inoculated with Aspergillus niger, Mucor rouxii and Trychoderma pseudokoningii showed lower value for the amide I/amide II intensity ratio. In addition, the amide I band exhibited a decrease of the relative intensity of $\beta$-sheet to $\alpha$-helix sub-bands. In the IR spectra of the two latter specimens this change was accompanied by a splitting of the $\beta$-sheet sub-band in two overlapped components (plateau $1633-1620 \mathrm{~cm}^{-1}$ ) at $1633 \mathrm{~cm}^{-1}$ (intramolecular $\beta$-sheet) and $1620 \mathrm{~cm}^{-1}$ (intermolecular $\beta$-sheet) as it can be seen in the EG@Mr spectrum shown in Fig. 8a. These changes put in evidence the transformation of the protein and polypeptide molecules to more open structures that favour the interaction of the functional groups located in the side chains of the polypeptides with the external medium. More appreciable shoulder of the amide II band at $1585 \mathrm{~cm}^{-1}$ was also observed for these paint films, which indicates that formation of $\mathrm{Cu}$-carboxylate complexes has taken place at significant extent promoted by an increase of the exposition of the protein chain to the external ionomeric layer (vide infra). IR spectrum of the paint film inoculated with Penicillium chrysogenum showed an intermediate behaviour characterized by the decrease of the relative intensity of the $\beta$-sheet to $\alpha$-helix sub-bands and a lesser blueshift of the maximum of the amide I band to $1633 \mathrm{~cm}^{-1}$. Shoulder at $1585 \mathrm{~cm}^{-1}$ in the amide II band was also less evident.

The egg tempera of the two paint film specimens inoculated with the actinobacteria Streptomyces cellulofans and Arthrobacter oxydans exhibited different behaviour. In EG@Sc (see Fig. 8a) maximum of the amide I band was found at $1637 \mathrm{~cm}^{-1}$. This sub-band has been frequently associated to the more open random coil conformation. Secondary maxima at 1648 and $1628 \mathrm{~cm}^{-1}$, which are associated to $\alpha$-helix and $\beta$-sheet conformations, respectively, were also present in this IR spectrum. In contrast, $\beta$-sheet conformation was prevalent in EG@ Ao and thus, this specimen exhibited slight increase in the relative intensity of the $\beta$-sheet to $\alpha$-helix sub-bands relative to the uninoculated film. A blueshift of the prevalent $\beta$-sheet sub-band to $1632 \mathrm{~cm}^{-1}$ together with a new secondary maximum at $1640 \mathrm{~cm}^{-1}$, ascribed to random coils, were the more remarkable features exhibited by the binding medium of the paint film inoculated with the eubacteria Bacillus amyloliquefaciens. The three specimens inoculated with bacteria showed weak shoulder of $\mathrm{Cu}$-carboxylate complexes at $1585 \mathrm{~cm}^{-1}$.

The inoculated egg-oil emulsion paint films, similarly to the uninoculated specimen, exhibited characteristic 

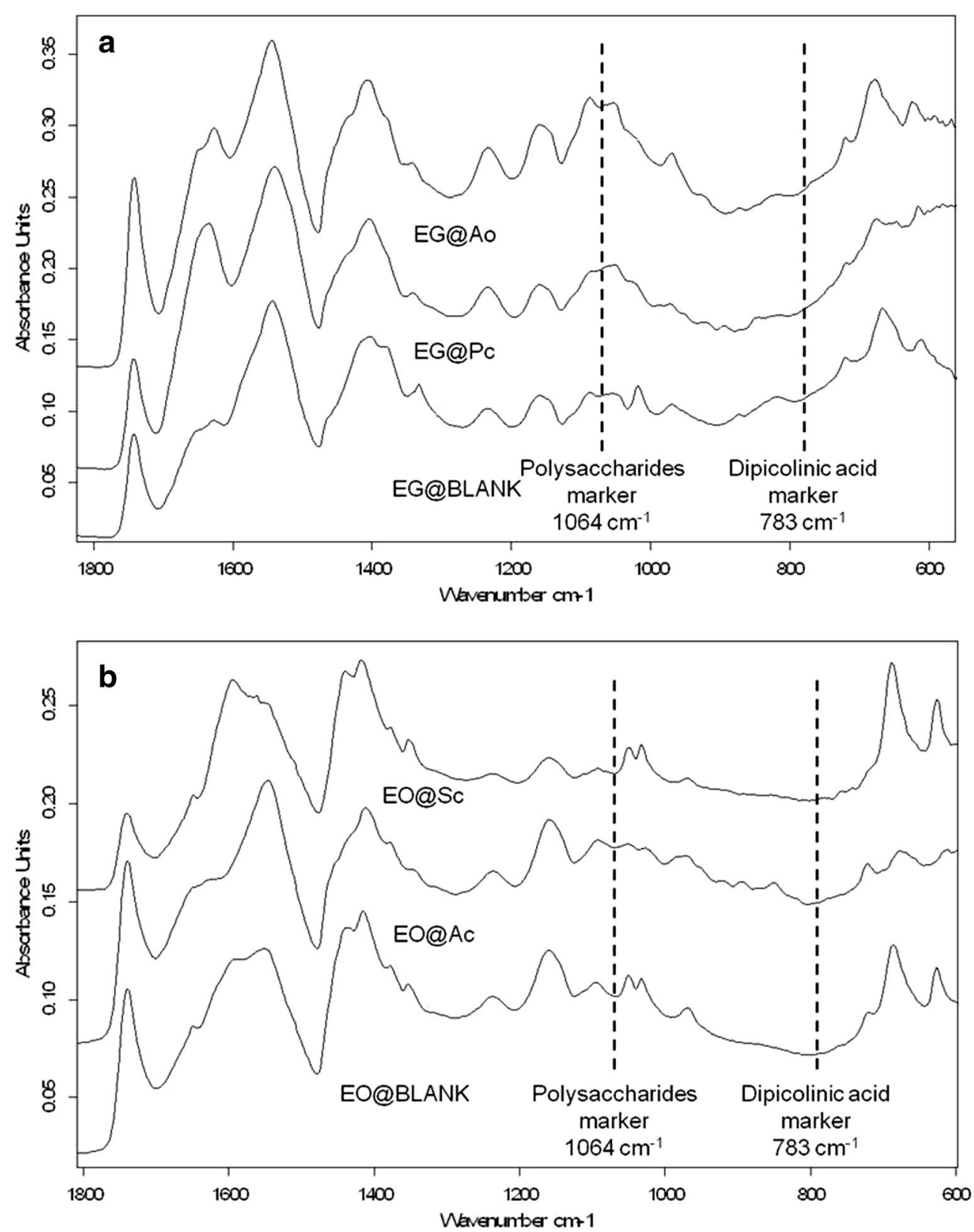

Fig. 7 Detail of the $1800-500 \mathrm{~cm}^{-1}$ IR region and position of the bands characteristic of marker compounds of bacterial and fungal materials: a egg tempera paint film specimens EG@BLANK, EG@Pc and EG@Ao, b egg-oil emulsion paint film specimens EO@BLANK, EO@Ac, and EO@Sc

$\mathrm{C}=\mathrm{O}$ stretching band at $1700-1705 \mathrm{~cm}^{-1}$ ascribed to free fatty acids that denote that hydrolysis of lipids has taken place at some extent. The paint film inoculated with Trychoderma pseudokoningii (see EO@Tp in Fig. 8b) presented a IR spectrum close to that of the blank specimen with maximum of $\alpha$-helix conformation at $1648 \mathrm{~cm}^{-1}$ and $\beta$-sheet sub-band overlapped by the plateau appearing at $1595-1585 \mathrm{~cm}^{-1}$ ascribed to the carboxylate stretching band from verdigris and $\mathrm{Cu}$-carboxylate complexes.
IR spectra obtained in paint films inoculated with Mucor rouxii, Acremonium chrysogenum and Aspergillus niger (see EO@An in Fig. 8b) exhibited discernible maximum of $\beta$-sheet sub-band at $1621 \mathrm{~cm}^{-1}$. Shoulder at $1585 \mathrm{~cm}^{-1}$ ascribed to $\mathrm{Cu}$-carboxylate complexes with fatty acids and amino acids was recognizable in the profile of the amide II band. Amide I band was well-resolved in the IR spectrum of the paint film inoculated with Penicillium chrysogenum with maximum in the $\beta$-sheet region at 

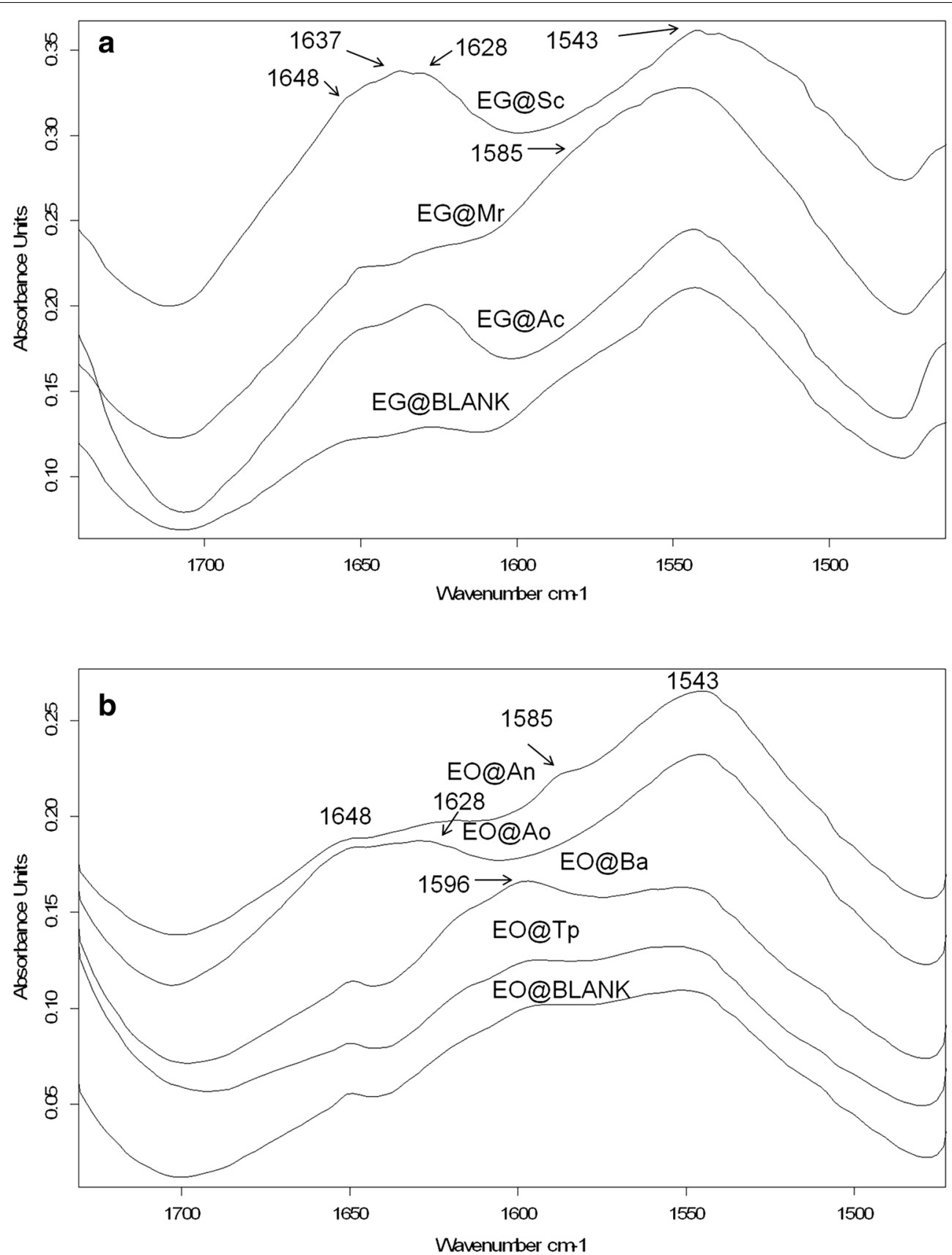

Fig. 8 a IR spectra of inoculated egg tempera paint film specimens EG@BLANK, EG@Sc, EG@Mr, EG@Ac. b IR spectra of inoculated egg-oil emulsion paint film specimens EO@BLANK, EO@An, EO@Tp, EO@Ao and EG@Ba

$1630 \mathrm{~cm}^{-1}$ accompanied with weak features characteristic of $\mathrm{Cu}$-carboxylates.

Similarly to that found for egg tempera specimens, the egg oil emulsion of the two paint film specimens inoculated with the actinobacteria Streptomyces cellulofans and Arthrobacter oxydans exhibited different behaviour. EO@Ao showed a well resolved amide I band with maximum in the $\beta$-sheet region at $1628 \mathrm{~cm}^{-1}$ (see EO@Ao in Fig. 8b) accompanied of $\alpha$-helix secondary maximum at $1648 \mathrm{~cm}^{-1}[44,45]$. Cucarboxylate complexes and verdigris bands were completely overlapped with amide II band. In contrast, EO@Sc showed an IR spectrum quite similar to that of the EO@Ba corresponding to the eubacteria Bacillus amyloliquefaciens and close to that of the uninoculated specimen. 


\section{VMP analysis}

Figure 9 shows the cyclic voltammograms (CVs) of microparticulate deposits of $(a, b)$ verdigris and $(c, d)$ un-inoculated verdigris egg tempera paint film (EO@Vd_ BLANK) attached to graphite bar immersed into aqueous acetate buffer at $\mathrm{pH}$ 4.75. Upon scanning the potential from $0.0 \mathrm{~V}$ vs. $\mathrm{Ag} / \mathrm{AgCl}$ in the negative direction (Fig. 9a), the pigment displays two cathodic peaks at $-0.25\left(\mathrm{C}_{1}\right)$ and $-0.70 \mathrm{~V}\left(\mathrm{C}_{2}\right)$ which are followed, in the subsequent anodic scan, by a series of overlapping tall peaks around $+0.20\left(\mathrm{~A}_{1}\right)$. The peak $\mathrm{C}_{1}$ is clearly larger than the peak $\mathrm{C}_{2}$, as can be seen using square wave voltammetry (SWV, Fig. $9 \mathrm{~b}$ ) and is coupled to the group of signals $A_{1}$, as can be seen in CVs in which the potential is switched after passing the signal $C_{1}$ (see Fig. 10 for un-inoculated verdigris egg-oil emulsion paint film (EG@BLANK)). Since, in the light of abundant literature on copper pigments and corrosion products $[16,17,46]$, the signal $A_{1}$ can unambiguously be attributed to the oxidative dissolution of metallic $\mathrm{Cu}$ formed in prior reductive steps, one can conclude that the process $\mathrm{C}_{1}$ consists of the two-electron reduction of verdigris. This process can be represented as:

$\left\{\mathrm{Cu}(\mathrm{Ac})_{2}\right\}_{\text {solid }}+2 \mathrm{H}_{\mathrm{aq}}^{+}+2 \mathrm{e}^{-} \rightarrow\{\mathrm{Cu}\}_{\text {solid }}+2 \mathrm{HAc}_{\mathrm{aq}}$

The peak splitting appearing in the signal $\mathrm{A}_{1}$ can be attributed to the superposition of the oxidation processes of different deposits of metallic copper, a frequent feature

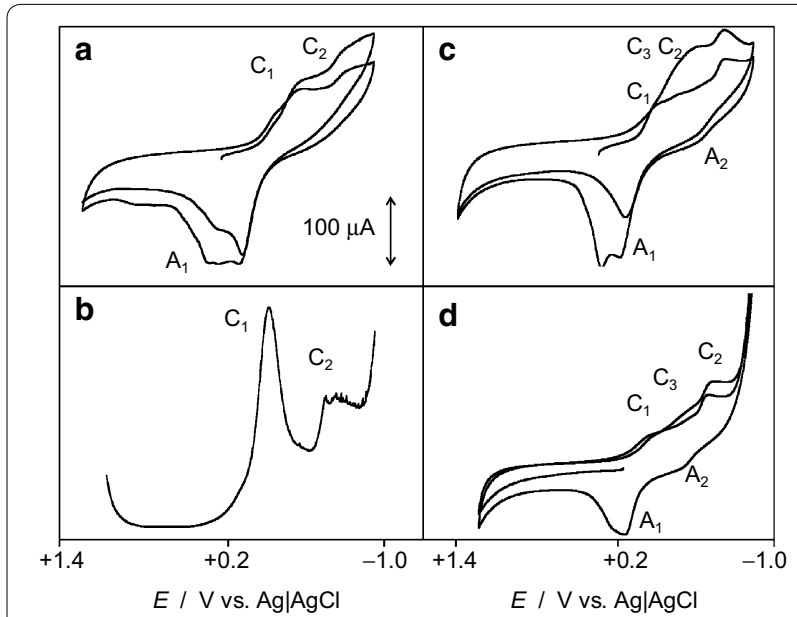

Fig. 9 Voltammetric response of microparticulate deposits of $\mathbf{a}, \mathbf{b}$ verdigris and $\mathbf{c}, \mathbf{d}$ un-inoculated verdigris egg tempera paint film (EG@BLANK) attached to graphite bar immersed into $0.25 \mathrm{M} \mathrm{HAc/}$ NaAc aqueous buffer, pH 4.75. a, c Negative-going CVs, potential scan rate $50 \mathrm{mV} \mathrm{s}^{-1} ;$ b negative-going SWV, potential step increment $4 \mathrm{mV}$, square wave amplitude $25 \mathrm{mV}$, frequency $5 \mathrm{~Hz}$; d positive going $\mathrm{CV}$, potential scan rate $50 \mathrm{mV} \mathrm{s}^{-1}$

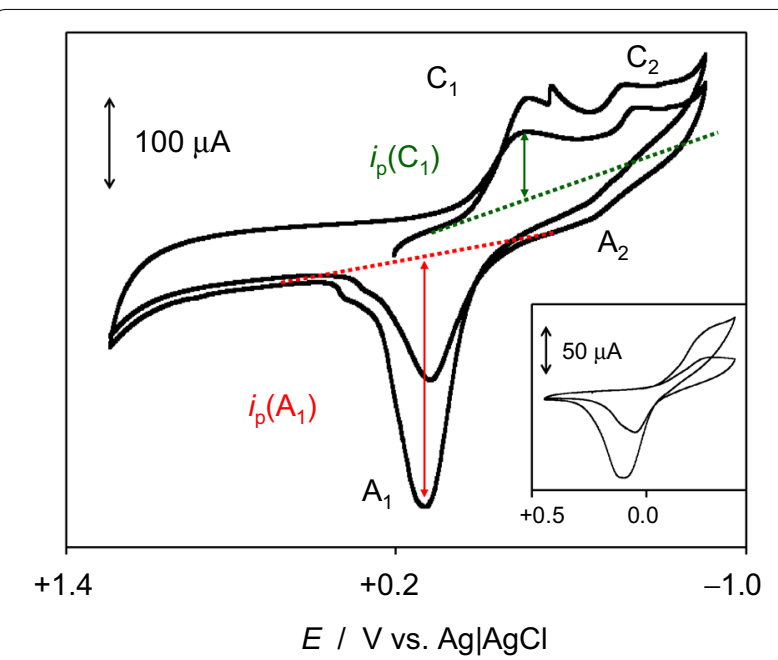

Fig. 10 Cyclic voltammetry of un-inoculated verdigris egg-oil emulsion paint film (EO@ BLANK) attached to graphite bar immersed into $0.25 \mathrm{M} \mathrm{HAc/NaAc}$ aqueous buffer, $\mathrm{pH} 4.75$; potential scan rate $50 \mathrm{mV} \mathrm{s}^{-1}$. Inset voltammogram recorded in the potential range where the $C_{1} / A_{1}$ couple appears. The base lines for measuring peak currents are depicted

in the voltammetry of copper, lead, and mercury minerals [46-49]. The formation of different copper deposits results from the superposition of different reductive process so that the process described by Eq. (1) can proceed via topotactic conversion of copper acetate into $\mathrm{Cu}$, as described for several lead compounds $[50,51]$ but also involving intermediate species in solution [52]. In turn, the cathodic process $\mathrm{C}_{2}$ can be assigned to the reduction of some $\mathrm{Cu}_{\mathrm{aq}}^{2+}$ ions generated during the precedent reductive step $\mathrm{C}_{1}$ at the $\mathrm{Cu}$-plated electrode.

The voltammetric response of un-inoculated verdigris egg tempera paint film (EO@BLANK) exhibited significant variations relative to that of the pure pigment. As can be seen in Fig. 9c, in the initial cathodic scan CVs, the peak $C_{1}$ became lowered relative to the signal $C_{2}$ which was preceded by an additional cathodic signal at ca. $-0.35 \mathrm{~V}\left(\mathrm{C}_{3}\right)$. These features were also recorded in the initial anodic scan CVs (Fig. 9d) where one can see that the group of oxidative signals $\mathrm{A}_{1}$ only appears after the occurrence of the reductive process $\mathrm{C}_{1}$. Interestingly, upon repetitive cycling the potential scan, the cathodic current at ca. $-1.0 \mathrm{~V}$, attributable to proton discharge, was considerably enhanced, a phenomenon which can be due to the catalytic effect exerted by the formation of relatively gross deposits of metallic copper. Another peculiar feature of verdigris containing paint films was the appearance of a weak anodic signal at ca. $-0.45 \mathrm{~V}\left(\mathrm{~A}_{2}\right)$. This signal can be attributed, tentatively, to the oxidation of intermediate $\mathrm{Cu}(\mathrm{I})$ species, stabilized by interaction with the binding media, generated during the cathodic 
process $\mathrm{C}_{2}$. The voltammetry of un-inoculated verdigris egg-oil emulsion paint film (EG@BLANK, Fig. 10) was similar to that of the pure pigment, the peak $C_{3}$ at $-0.35 \mathrm{~V}$ being almost entirely absent, but differing in the presence of peak $A_{2}$ and the absence of important peak splitting in the anodic signal $A_{1}$.

The above voltammetry can be described, as in the case of CdS-based films [18], as resulting from the superposition of different electrochemical process and assuming that the EG and EO reconstructed paint films were constituted by a more or less homogeneous distribution of pigment particles partially embedded by a hydrophobic layer of binder accompanied by a hydrophilic layer where different metal compounds exist, as described for pictorial specimens containing lead pigments [49, 52, 53]. In situ XRD [50] and AFM [51] studies coupled to VMP from Scholz et al., suggested that the reduction of litharge and other metal compounds to metal involved a solid state transformation of lead oxide to lead metal without a morphological disintegration, the advance of the reaction involving the formation of an intermediate layer containing metal atoms, hydroxide ions and water molecules. The peak $\mathrm{C}_{3}$ appearing in EG and EO reconstructed paint films can be attributed to the reduction of $\mathrm{Cu}$ (II) species formed in the ionomeric layer accompanying the pigment particles. This layer, to some extent similar to that formed in the reduction of lead minerals [50-53] would be particularly relevant for the proteinaceous fraction of the binders (egg) disposing of coordinating units [18]. In contrast with CdS-based reconstructed paint films, no drastic differences were found between the voltammetric response of EG and EO specimens before to be submitted to biological attack. Figure 11 depicts a scheme for interpreting the electrochemistry of verdigris-based paint films based on the description of Lovric, Scholz, Oldham and co-workers on the electrochemistry of ion-insertion solids [54-59]. In the studied specimens, the signal $C_{1}$ corresponds to the proton-assisted reduction of the fraction of the pigment grains directly exposed to the electrode so that the redox reaction starts at the particle/base electrode/ electrolyte three-phase junction. This process involves the formation of an ionomeric layer around the pigment grain but also the partial release of 'free' copper ions into the same and/or the surrounding electrolyte solution then undergoing the reduction process $C_{2}$. The process $C_{3}$ can be assigned to the reduction of copper complexes formed in the verdigris grain/binder boundary which presumably forms an ionomeric coverage around the pigment grains (different to that promoted electrochemically in the process $C_{1}$ ) as a result of the coordinating ability of the proteinaceous fraction.

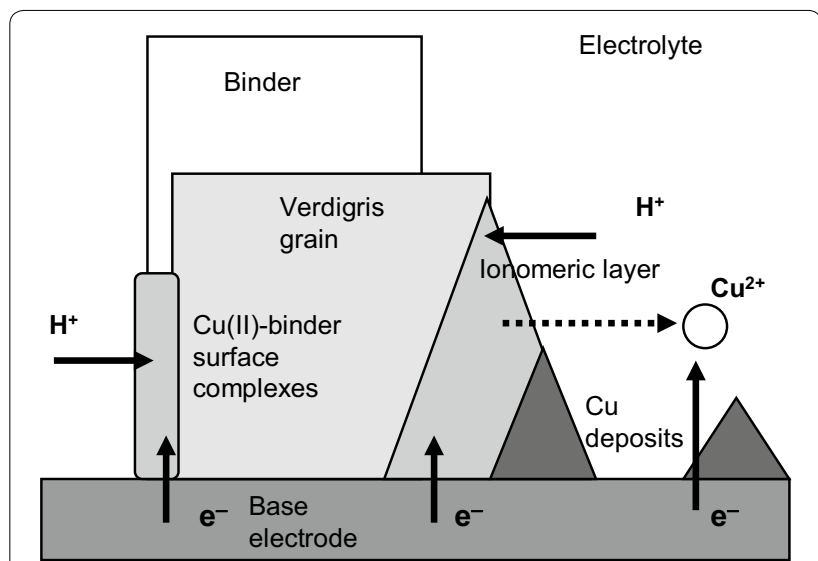

Fig. 11 Scheme for the electrochemical processes involved in the reduction of reconstructed verdigris/binder paint film specimens attached to graphite electrodes in contact with acidic aqueous electrolytes

$$
\begin{aligned}
& \left\{\mathrm{Cu}^{2+}\left(\text { binding }^{2-}\right)\right\}_{\mathrm{Vd} \text { ionomeric layer }} \\
& \quad+2 \mathrm{H}_{\mathrm{aq}}^{+}+2 \mathrm{e}^{-} \rightarrow\{\mathrm{Cu}\}_{\text {solid }}+\mathrm{H}_{2} \text { binding }
\end{aligned}
$$

\section{VMP testing of biodeterioration}

The voltammetric response of the reconstructed model paint films specimens was differently modified after inoculation. The voltammograms obtained for the verdigris egg paint film specimens inoculated with (a, b) Acremonium chrysogenum (EG@Ac) fungi and (c, d) Arthrobacter oxydans (EG@Ao) bacteria are shown in Fig. 12. The most relevant feature was the broadening of both the cathodic and anodic regions of the voltammograms with the appearance of an additional peak at ca. $-0.55 \mathrm{~V}$ $\left(C_{4}\right)$. Peaks $C_{1}-C_{4}$ can be resolved upon semi-derivative deconvolution of the current/potential curves (Fig. 12b, d).

$\mathrm{CVs}$ of graphite electrodes modified with verdigris egg-oil emulsion paint films immersed into $0.25 \mathrm{M}$ sodium acetate buffer, $\mathrm{pH} 4.75$ after incubation with: (a) Mucor rouxii (EO@Mr) and, (b) Acremonium chrysogenum (EO@Ac) fungi and; (c) Streptomyces cellulofans (EO@Sc) and, (d) Arthrobacter oxydans (EO@Ao) bacteria are shown in Fig. 10. Specimens inoculated with fungi (Fig. 13a, b) displayed similar voltammetric features characterized by the engrossment of the $\mathrm{C}_{1}$ peak, being preceded by a shoulder at ca. $-0.12 \mathrm{~V}\left(\mathrm{C}_{5}\right)$, now strongly overlapped with $\mathrm{C}_{3}$ and $\mathrm{C}_{4}$ signals, the lowering of the peak $C_{2}$ and the appearance of two overlapping intense anodic peaks in the $A_{1}$ region of potentials. The most significative changes are observed for the verdigris eggoil emulsion paint films specimens inoculated with bacteria. Figure 13c, d show the voltammograms obtained 


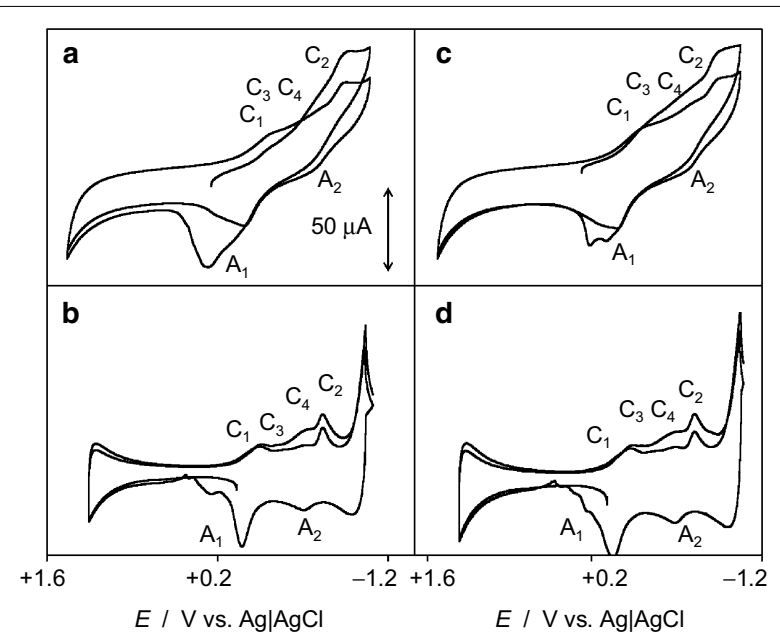

Fig. $12 \mathrm{CV}$ s of graphite electrodes modified with verdigris egg tempera paint films immersed into $0.25 \mathrm{M}$ sodium acetate buffer, $\mathrm{pH} 4.75$, after incubation with: a, b Acremonium chrysogenum (EG@Ac) fungi and $\mathbf{c}, \mathbf{d}$ Arthrobacter oxydans (EG@Ao) bacteria. Voltammograms before $(\mathbf{a}, \mathbf{c})$ and after $(\mathbf{b}, \mathbf{d})$ semi-derivative convolution; potential scan rate $50 \mathrm{mV} \mathrm{s}^{-1}$

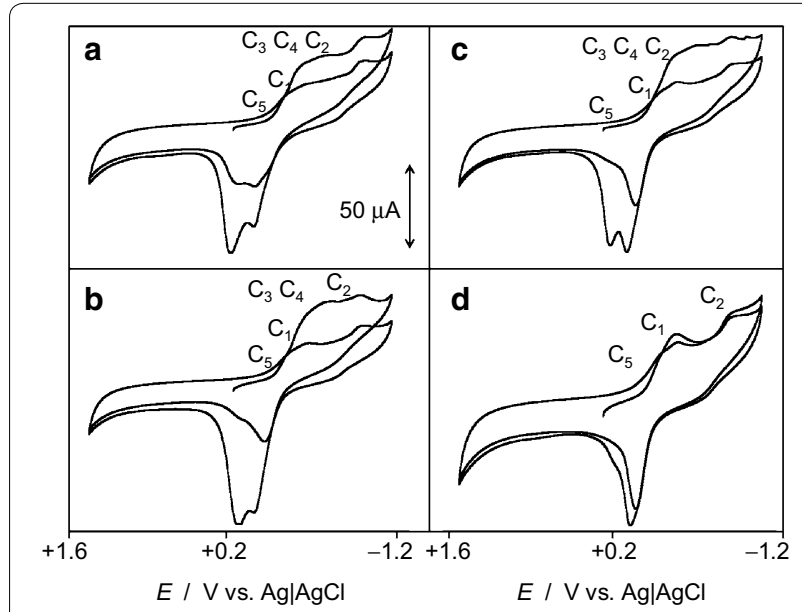

Fig. $13 \mathrm{CV}$ s of graphite electrodes modified with verdigris egg-oil emulsion paint films immersed into $0.25 \mathrm{M}$ sodium acetate buffer, $\mathrm{pH}$ 4.75 after incubation with: a Mucor rouxii (EO@Mr) and, b Acremonium chrysogenum (EO@Ac) fungi and; c Streptomyces cellulofans (EO@Sc) and, $\mathbf{d}$ Arthrobacter oxydans (EO@Ao) bacteria. Potential scan rate $50 \mathrm{mV} \mathrm{s}^{-1}$

for Streptomyces cellulofans and Arthrobacter oxydans which are representative of two apparently extreme behaviors. The $\mathrm{CV}$ of the former was similar to those of specimens inoculated with fungi. In contrast, the specimens inoculated with Arthrobacter oxydans produced a 'clean' voltammogram dominated by peaks $C_{1}$ and $C_{2}$ with no peak splitting in the signal $A_{1}$ in good agreement with the results obtained by FTIR spectroscopy.
The voltammograms for Bacillus amyloliquefaciens, were intermediate between those of Streptomyces cellulofans and Arthrobacter oxydans.

The voltammetric features appearing after biological attack can be attributed to the superposition of two main factors: (i) the degradation of the binder resulting in an increased exposition of the verdigris particles favoring the process $C_{1}$, and (ii) the increase of the ionomeric layer of $\mathrm{Cu}(\mathrm{II})$-binding compounds, thus increasing the intensity of the peak $C_{3}$, promoting the appearance of a new signal $\mathrm{C}_{4}$, and retaining 'free' $\mathrm{Cu}^{2+}$ ions generated in the reductive step $C_{1}$ with the concomitant decrease of peak $\mathrm{C}_{2}$. It is pertinent to note that, under our experimental conditions, the possible voltammetric response of electroactive metabolites in biofilm residuals and their occasional complexes with released copper ions should be considerably weaker than that of pigment-based species.

The observed changes in the voltammetric response of the films upon biodeterioration are in good agreement with the transformations taking place in the secondary structure of proteins observed in the inoculated specimens, in particular, the increase in the random coils (band at $1637 \mathrm{~cm}^{-1}$ ) and $\mathrm{Cu}$-protein complexes (band at $\left.1585 \mathrm{~cm}^{-1}\right)$. The cathodic shoulder $C_{5}$ was characteristic of EO reconstructed paint film. This signal can be attributed to the reduction of $\mathrm{Cu}(\mathrm{II})$ soaps formed upon coordination with the carboxylate units of the oil fraction of the binder and is consistent with the intense IR band at $1585 \mathrm{~cm}^{-1}$ exhibited by the inoculated specimens (see Fig. 8b) corresponding to the asymmetric stretching vibrations of $\mathrm{Cu}(\mathrm{II})$-fatty acid complexes formed in egg-oil emulsion films inoculated with both bacteria and fungi. A similar response was observed for CdS-based films; accordingly, the reduction process $C_{5}$ can be represented as:

$$
\begin{aligned}
& \left\{\mathrm{Cu}^{2+}\left(\mathrm{RCOO}^{-}\right)_{2}\right\}_{\text {Cu soap }} \\
& \quad+2 \mathrm{H}_{\mathrm{aq}}^{+}+2 \mathrm{e}^{-} \rightarrow\{\mathrm{Cu}\}_{\text {solid }}+2 \mathrm{RCOOH}
\end{aligned}
$$

Interestingly, the formation of copper soaps (denoted by the shoulder $\mathrm{C}_{5}$ ) was a common factor for the attack of both fungi and bacteria to EO films, whereas the degradation of the proteinaceous fraction of the binder (denoted by peaks $\mathrm{C}_{3}, \mathrm{C}_{4}$ ) varied significantly from one species to another, being minimal in the case of Arthrobacter oxydans (compare Fig. 12a-c with Fig. 13d). This result is coherent with the IR spectrum obtained in this specimen that exhibited an intense and well-resolved amide I band.

In order to group the observed voltammetric responses, the ratios between the peak currents for the processes $\mathrm{C}_{2}$ and $\mathrm{C}_{1}, i_{\mathrm{p}}\left(\mathrm{C}_{2}\right) / i_{\mathrm{p}}\left(\mathrm{C}_{1}\right)$ and $\mathrm{C}_{3}$ plus $\mathrm{C}_{4}$ and $\mathrm{C}_{1},\left(i_{\mathrm{p}}\left(\mathrm{C}_{3}\right)+i_{\mathrm{p}}\left(\mathrm{C}_{4}\right)\right) / i_{\mathrm{p}}\left(\mathrm{C}_{1}\right)$ were calculated. These ratios 
can be considered as representative, respectively, of the extent of the release of $\mathrm{Cu}^{2+}$ ions, in turn roughly indicative of the accessibility of the verdigris grains to direct electrochemical reduction, and the extent of the biological attack on the proteinaceous fraction of the binder. Figure 14a shows experimental data for the attack of the studied biological agents on EG specimens, using for peak current measurements the base lines depicted in Fig. 10. One can see in this figure that the data points are concentrated in a relatively narrow region of the diagram with the unique exception of Acremonium chrysogenum, thus suggesting a common behavior which could be tentatively fitted to a linear tendency (dotted line).

A similar, unclear situation was obtained in the representation for the ratio between peak currents of the two main components of the anodic signal $\mathrm{A}_{1}, i_{\mathrm{p}}\left(\mathrm{A}_{1}{ }^{\prime}\right) / i_{\mathrm{p}}\left(\mathrm{A}_{1}{ }^{\prime \prime}\right)$ vs. the $\left(i_{\mathrm{p}}\left(\mathrm{C}_{3}\right)+i_{\mathrm{p}}\left(\mathrm{C}_{4}\right)\right) / i_{\mathrm{p}}\left(\mathrm{C}_{1}\right)$ ratio for reconstructed verdigris egg tempera paint films after inoculation with biological species in this study (Fig. 14b). The $i_{\mathrm{p}}\left(\mathrm{A}_{1}{ }^{\prime}\right) / i_{\mathrm{p}}\left(\mathrm{A}_{1}{ }^{\prime \prime}\right)$ ratio can be taken as representative of the fraction of
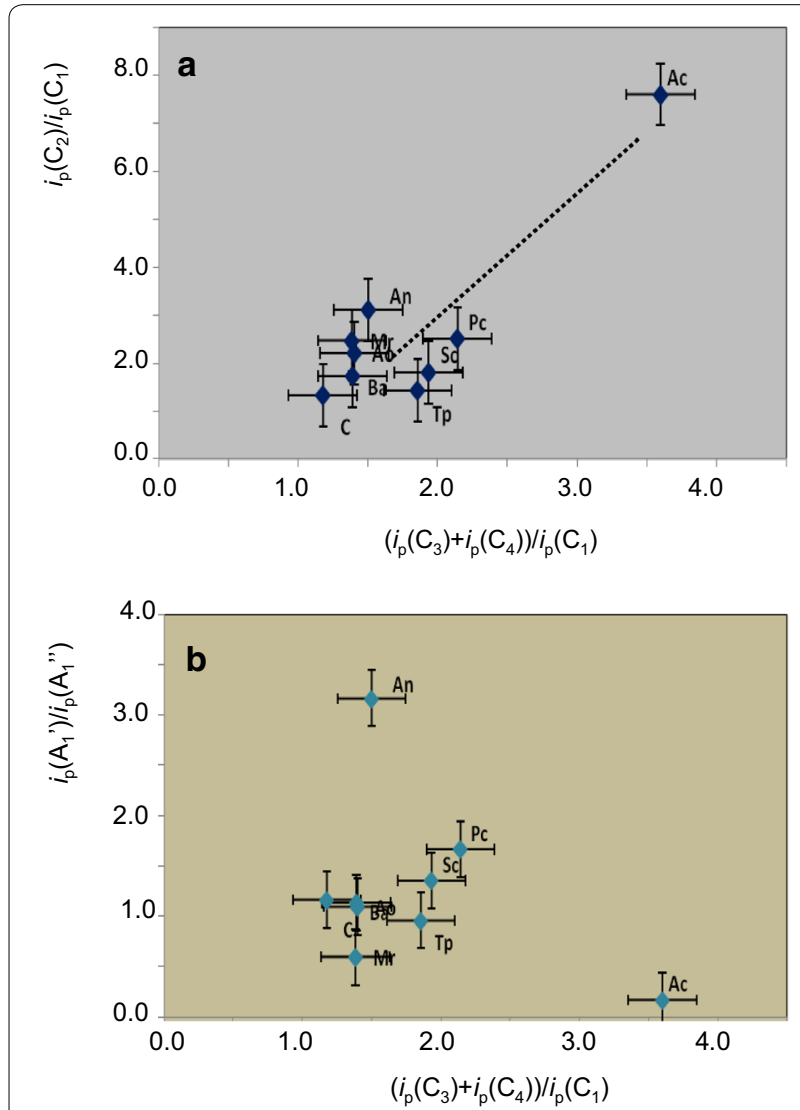

Fig. 14 Plots of: $\mathbf{a} i_{p}\left(C_{2}\right) / i_{p}\left(C_{1}\right)$ vs. $\left(i_{p}\left(C_{3}\right)+i_{p}\left(C_{4}\right)\right) / i_{p}\left(C_{1}\right)$ and $\mathbf{b}$ $i_{\mathrm{p}}\left(\mathrm{A}_{1}{ }^{\prime}\right) / i_{\mathrm{p}}\left(\mathrm{A}_{1}{ }^{\prime \prime}\right)$ vs. $\left(i_{\mathrm{p}}\left(\mathrm{C}_{3}\right)+i_{\mathrm{p}}\left(\mathrm{C}_{4}\right)\right) / i_{\mathrm{p}}\left(\mathrm{C}_{1}\right)$ for reconstructed verdigris egg tempera paint films after inoculation with biological species in this study. From CVs in conditions such as in Fig.4.Ac EG@Ac,AnEG@ An,MrEG@Mr,PcEG@Pc,TpEG@Tp, AoEG@Ao,BaEG@Ba, ScEG@Sc, EG@BLANKC exposed verdigris grains relative to the pigment altered as a result of the biological attack. Although the majority of data points in Fig. 14b are grouped in a relatively small region, Aspergillus niger falls in a clearly separated region (different behaviour was also observed in the IR spectrum of this specimen). These features suggest that there are highly specific behaviors relative to the biological attack. Such differences can be associated to the specificity of the sensibility of the biological agents to the biocide effect due to verdigris. It is known that copper salts act as relatively non-specific bactericide and fungicide [60] the cupric ion being the active species. The mode of action, after absorption into the fungus or bacterium, involves bonding to various chemical groups (imidazoles, phosphates, sulfhydryls, hydroxyls) presented in many proteins and disrupt the function of these proteins and enzymes, resulting cell damage and membrane leakage [61]. According to data in Fig. 14, Acremonium chrysogenum would be highly sensitive to that effect.

In the case of reconstructed verdigris egg-oil emulsion paint films submitted to biodeterioration, the plots of $i_{\mathrm{p}}\left(\mathrm{C}_{2}\right) / i_{\mathrm{p}}\left(\mathrm{C}_{1}\right)$ vs. $\left(i_{\mathrm{p}}\left(\mathrm{C}_{3}\right)+i_{\mathrm{p}}\left(\mathrm{C}_{4}\right)\right) / i_{\mathrm{p}}\left(\mathrm{C}_{1}\right)$ (Fig. 15a) and $i_{\mathrm{p}}\left(\mathrm{A}_{1}{ }^{\prime}\right) / i_{\mathrm{p}}\left(\mathrm{A}_{1}{ }^{\prime \prime}\right)$ vs. $\left(i_{\mathrm{p}}\left(\mathrm{C}_{3}\right)+i_{\mathrm{p}}\left(\mathrm{C}_{4}\right)\right) / i_{\mathrm{p}}\left(\mathrm{C}_{1}\right)$ (Fig. $\left.10 \mathrm{~b}\right)$ provide a grouping of data points consistent with linear dependences between the above pairs of peak current ratios (dotted lines in Fig. 15). Remarkably, in EO specimens, 'anomalous' responses for Acremonium chrysogenum and Aspergillus niger observed in EG specimens were absent, thus suggesting that the presence of the oil binder minimizes the factors influencing the aforementioned 'anomalous' responses. As an explanatory hypothesis, one can assume that the biocide effect exerted by verdigris would require the release and migration of $\mathrm{Cu}^{2+}$ ions from the pigment grains towards the biological agents. As far as the second phenomenon should be made difficult through the highly hydrophobic oil fraction, the fungi and/or bacteria would be protected from the biocide species and then the specific differences in resistance would be minimized. Consistently with this hypothesis, the height of the peak $\mathrm{C}_{2}$ relative to the peak $\mathrm{C}_{1}$ was larger in EG specimens than in EO specimens submitted to the same biological agent (compare Figs. 9a, 10b for EG@ Ac and EO@Ac), respectively.

In these circumstances, the attack of both fungi and bacteria was apparently similar in verdigris-based paint films, a feature in contrast with the behavior of CdSbased EG and EO paint films, where bacteria attack was concentrated on the most abundant oil fraction of the binding medium and fungi attack was concentrated on the proteinaceous fraction [18]. In view of the recognized antifungal effect of cadmium compounds [61-64], a possible explanation for the differences in the biological attack associated to the different pigments would be, in 

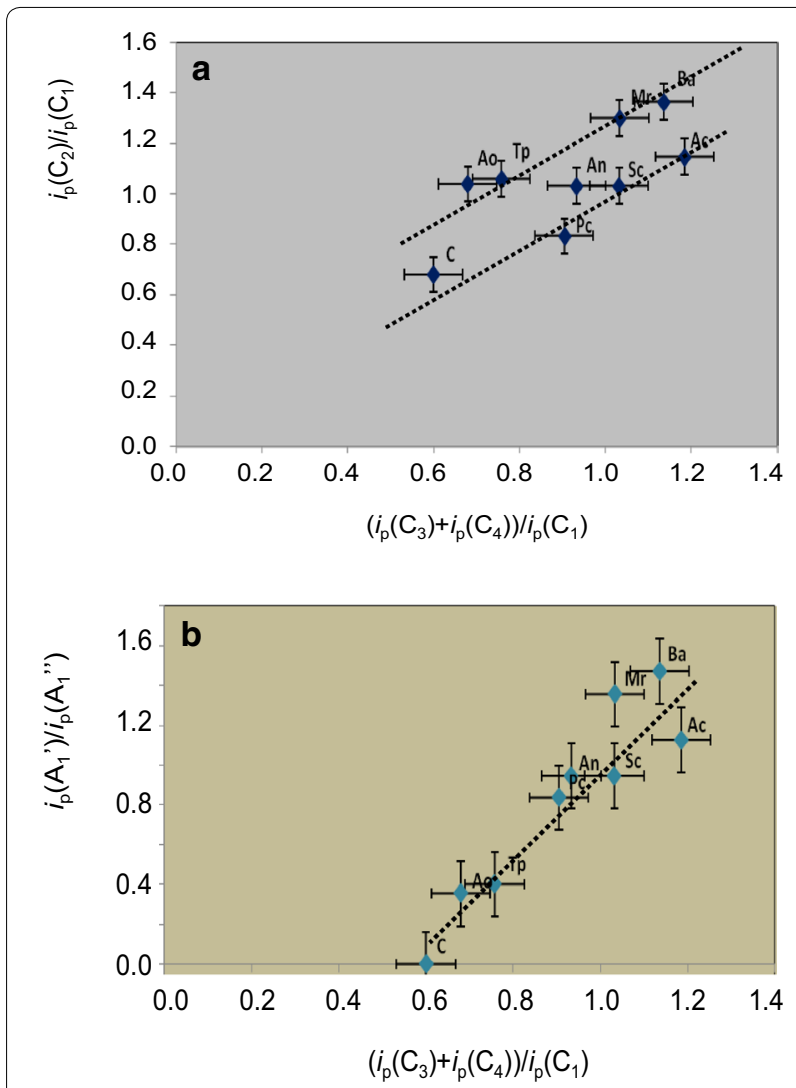

Fig. 15 Plots of: $\mathbf{a} i_{p}\left(C_{2}\right) / i_{p}\left(C_{1}\right)$ vs. $\left(i_{p}\left(C_{3}\right)+i_{p}\left(C_{4}\right)\right) / i_{p}\left(C_{1}\right)$ and $\mathbf{b}$ $i_{p}\left(A_{1}{ }^{\prime}\right) / i_{p}\left(A_{1}{ }^{\prime \prime}\right)$ vs. $\left(i_{p}\left(C_{3}\right)+i_{p}\left(C_{4}\right)\right) / i_{p}\left(C_{1}\right)$ for reconstructed verdigris egg-oil emulsion after inoculation with biological species in this study. From CVs in conditions such as in Fig. 5.Ac EO@Ac, AnEO@An, MrEO@Mr,PcEO@Pc,TpEO@Tp, Ao EO@Ao,BaEO@Ba, ScEO@Sc, EO@BLANKC

line with the foregoing set of considerations, the possible lower release of $\mathrm{Cd}^{2+}$ ions from $\mathrm{CdS}$ relative to the release of $\mathrm{Cu}^{2+}$ ions from verdigris, the different transport ability of such ions in egg and egg-linseed oil films [65], and the possible major specificity of the $\mathrm{Cd}^{2+}$ toxic effects relative to those of $\mathrm{Cu}^{2+}$, these last recognized as highly unspecific [61-64, 66]. For our purposes, the relevant point to emphasize is that the biodegradation of paintings can be notably influenced in both the extent and the specificity of the biological attack by the nature of the pigment.

\section{Conclusions}

The application of the voltammetry of microparticles (VMP) methodology leads to obtain characteristic voltammetric features for verdigris pigment in pictorial specimens combining verdigris and cadmium yellow with egg and egg-linseed oil binders by Penicillium chrysogenum, Aspergillus niger, Acremonium chrysogenum, Trychoderma pseudokoningi and Mucor rouxii fungi and
Bacillus amyloliquefaciens, Arthrobacter oxydans and Streptomyces cellulofans. In contact with aqueous acetate buffer, VMP data denote that in presence of the binder, the voltammetric signals for verdigris in egg and egglinseed oil binders become modified with appearance of specific signals resulting from the pigment-binder association. Depending on the binder; such signals become more or less modified after biodeterioration.

VMP data, supported by ATR-FTIR and FESEM data, suggest that the attack of fungi and bacteria on reconstructed paint films produces significant modifications in the secondary structure of proteins accompanied by release of $\mathrm{Cu}(\mathrm{II})$ ions, the latter enabling the formation of coordination species with carboxylic groups in the side chains of the protein molecules and released fatty acids which results in specific voltammetric features.

Voltammetric data indicate that there is no generic differences in the attack exerted by fungi and bacteria on reconstructed verdigris egg-linseed oil emulsion paint films whereas in the case of reconstructed egg paint films some individual species produced high (Aspergillus niger) and low (Acremonium chrysogenum) deterioration. These peculiar behaviors can be tentatively attributed to the combination of two factors: (i) the existence of individual high/low resistances to the biocide effect of the pigment, and (ii) the hydrophobicity of the oil fraction which made difficult the migration of $\mathrm{Cu}^{2+}$ ions presumably responsible for the biocide effect.

These results support the idea that biodeterioration of pictorial specimens is significantly sensitive to the nature of the pigment and can be electrochemically monitored using solid-state methodologies, as the proposed methodology of potential application for the micro-biological attack characterization.

\section{Authors' contributions}

AOM participated in the research design, prepared pictorial specimens and performed voltammetric analysis; ADC participated in the design and coordination of the study and modeled electrochemical data; MTDC participated in the design and coordination of the study and interpreted infrared and SEM data; LOC performed SEM and FTIR analysis and participated in data interpretation; FBG participated in the design and planning of the biodeterioration experiments; IMS prepared bacteria and fungi stains and performed inoculations. All authors read and approved the final manuscript.

\section{Author details}

${ }^{1}$ Institut de Restauració del Patrimoni, Universitat Politècnica de València, Camí de Vera 14, 46022 Valencia, Spain. ${ }^{2}$ Departament de Química Analítica, Universitat de València, Dr. Moliner, 50, Burjassot, 46100 Valencia, Spain. ${ }^{3}$ Departamento de Pintura, Universidad de Granada, Granada, Spain. ${ }^{4}$ Departamento de Microbiología, Universidad de Granada, Granada, Spain.

\section{Acknowledgements}

This work as been performed by members of the microcluster Grupo de análisis científico de bienes culturales y patrimoniales y estudios de ciencia de la conservación (Ref. 1362) belonging to the Valencia International Campus of Excellence. Financial support is gratefully acknowledged from the Spanish "I+D+I MINECO" projects CTQ2014-53736-C3-1-P and CTQ2014-53736-C3-2-P supported by ERDF funds. 


\section{Competing interests}

All authors declare that they have no competing interests.

Received: 6 October 2016 Accepted: 2 February 2017

Published online: 27 February 2017

\section{References}

1. Matteini M, Moles A. La Chimica nel Restauro. Firenze: Nardini; 1989.

2. Mills JS, White R. The organic chemistry of museum objects. London: Buttersworth; 1994

3. Breitbach AM, Rocha JC, Gaylarde CC. Influence of pigment on biodeterioration of acrylic paint films in Southern Brazil. J Coat Technol Res. 2011:8:619-28

4. Meilunas RJ, Bentsen JG, Steinberg A. Analysis of aged paint binders by FTIR Spectroscopy. Stud Conserv. 1990;35:33-51.

5. Mallégol J, Lemaire J, Gardette JL. Drier influence on the curing of linseed oil. Progr Org Coat. 2009;39:107-13.

6. Erhardt D, Tumosa CS, Mecklenburg MF. Long-term chemical and physical processes in oil paint films. Stud Conserv. 2005;50:143-50.

7. Keune K, van Loon A, Boon JJ. SEM backscattered-electron images of paint cross sections as information source for the presence of the lead white pigment and lead-related degradation and migration phenomena in oil paintings. Micros Microanal. 2011. doi:10.1017/S1431927610094444.

8. Plater MJ, De Silva B, Gelbrich T, Hursthouse MB, Higgitt CL, Saunders DR. The characterization of lead fatty acid soaps in "protusions" in aged traditional oil paint". Polyhedron. 2003;22:3171-9.

9. Robinet L, Corbeil MC. The characterization of metal soaps. Stud Conserv. 2003;48:23-40.

10. Mazzeo R, Prati S, Quaranta M, Joseph E, Kendix E, Galeotti M. Attenuated total reflection micro FTIR characterization of pigment-binder interaction in reconstructed paint films. Anal Bioanal Chem. 2008;392:65-76.

11. Salvadó N, Butí S, Nicholson J, Emerich H, Labrador A, Pradell T. Identification of reaction compounds in micrometric layers from gothic paintings using combined SR-XRD and SR-FTIR. Talanta. 2009;79:419-28.

12. Genestar C, Pons C. Earth pigments in painting: characterization and differentiation by means FTIR spectroscopy. Anal Bioanal Chem 2005;382:269-74

13. Scholz F, Meyer B. Voltammetry of solid microparticles immobilized on electrode surfaces. Electroanal Chem. 1998;20:1-86.

14. Scholz F, Schröder U, Gulabowski R, Doménech-Carbó A. Electrochemistry of Immobilized Particles and Droplets, 2nd edit. Berlin-Heidelberg: Springer; 2014.

15. Doménech-Carbó A, Labuda J, Scholz F. Electroanalytical chemistry for the analysis of solids: characterization and classification (IUPAC Technica Report). Pure Appl Chem. 2013;85:609-31.

16. Doménech-Carbó A, Doménech-Carbó MT, Costa V. Electrochemical methods for archaeometry, conservation and restoration (Monographs in Electrochemistry Series Scholz F Edit). Berlin-Heidelberg: Springer; 2009.

17. Doménech-Carbó A. Electrochemistry for conservation science. J Solid State Electrochem. 2010;14:349-51.

18. Ortiz-Miranda AS, Doménech-Carbó A, Doménech-Carbó MT, OseteCortina L, Bolívar-Galiano FF, Martín-Sánchez I, López-Miras MM. Electrochemical characterization of biodeterioration of paint films containing cadmium yellow pigment. J Solid State Electrochem. 2016;20:3287-302.

19. Kühn $\mathrm{H}$. Verdigris and copper resinate, in artists' pigments. In: Roy A editor. A handbook of their history and characteristics, vol. 2. Oxford: University Press; 1993.

20. Bilardi CR. The red church or the art of Pennsylvania German Braucherei. Los Angeles: Pendraig Publications; 2009.

21. Doménech-Carbó A, Doménech-Carbó MT, Moya-Moreno M, GimenoAdelantado JV, Bosch-Reig F. Identification of inorganic pigments from paintings and polychromed sculptures immobilized into polymer film electrodes by stripping differential pulse voltammetry. Anal Chim Acta. 2000:407:275-89.

22. Ciferri O. Microbial degradation of paintings Appl. Environ Microbiol. 1999;65:879-85

23. Giacobini C, Firpi M. Problemi di microbiologia nei dipinti su tela Opificio delle Pietre Dure e Laboratorio di Restauro di Firenze. Atti del
Convenzione sul Restauro delle Opere d'Arte. Florence: Edizioni Polistampa; 1981. p. 203-11.

24. Giacobini C, De Cicco MA, Tiglie I, Accardo G. Actinomycetes and biodeterioration in the field of fine art. In: Houghton DR, Smith RN, Eggins HOW, editors. biodeterioration, vol. 7. New York: Elsevier; 1988. p. 418-23.

25. Giacobini C, Pedica M, Spinucci M. 31 Problems and future projects on the study of biodeterioration: mural and canvas paintings. In: Proceedings of the 1st international conference on the biodeterioration of cultural property. New Delhi: Macmillan India; 1991. p. 275-286.

26. Ross RT. Microbiology of paint films. Adv Appl Microbiol. 1963;5:217-34

27. Seves AM, Sora S, Ciferri O. The microbial colonization of oil paintings. A laboratory investigation. Int Biodeter Biodegr. 1996;37:215-24.

28. Strelczyc A. Paintings and sculptures. In: Rose AH, editor. Microbialdeterioration. London: Academic; 1981. p. 203-34.

29. Walsh JH. Ecological considerations of biodeterioration. Int. Biodeter. Biodegr. 2001;48:16-25

30. Zyska BJ. Problems of microbial deterioration of materials in Eastern Europe. Int Biodeter Biodegr. 2002;49:73-83.

31. Khandekar N, Phenix A. Some observations on the effects of a selection of pigments on artificially aged egg tempera paint film. Los Angeles: Typescript, GCI Museum Research Laboratory; 1999.

32. Ducce C, Bramanti E, Ghezzi L, Bernazzani L, Bonaduce I, Colombini MP, Sepi A, Biagi S, Tine MR. Interactions between inorganic pigments and proteinaceous binders in reference paint reconstructions. Dalton Trans. 2013:42:5945-84 (and references therein)

33. Miyazawa T, Blout ER. The infrared spectra of polypeptides in various conformations: amide I and II bands. J Am Chem Soc. 1961:83:712-9.

34. Nevskaya YN, Chirgadze NA. Infrared spectra and resonance interaction of amide-I vibration of the antiparallel-chain pleated sheet. Biopolymers. 1976;15:637-48.

35. Qing H, Yanlin H, Fenlin S, Zuyi T. Effects of pH and metal ions on the conformation of bovine serum albumin in aqueous solution. An attenuated total reflection (ATR) FTIR spectroscopic study. Spectrochim Acta A. 1996;52:1795-800

36. Nara M, Morii H, Tanokura M. Coordination to divalent cations by calciumbinding proteins studied by FTIR spectroscopy. Biochim Biophys Acta. 2013;1828:2319-27.

37. Williams RJP. Copper-protein compounds in: the chemistry of the copper and zinc triads. Welch AJ, Chapman K, eds. Royal Society of Chemistry: Cambridge; 1993.

38. Williams RJP, da Silva Frausto JJR. The natural selection of the chemical elements. Oxford: Oxford Univ. Press; 1996.

39. Guthrie RE, Laurie SH. The binding of copper (II) to mohair keratin. Aust J Chem. 1968:21:2437-43.

40. Marey L, Signolle JP, Amiel C, Travert J. Discrimination, classification, identification of microorganisms using FTIR spectroscopy and chemometrics. Vib Spectrosc. 2001;26:151-9.

41. Zotti M, Ferroni A, Calvini P. Mycological and FTIR analysis of biotic foxing on paper substrates. Int Biodeter Biodegr. 2011;65:569-78.

42. Bombalska A, Mularczyk-Oliwa M, Kwásny M, Włodarski M, Kaliszewski M, Kopczynski K, Szpakowska M, Trafny EA. Classification of the biological material with use of FTIR spectroscopy and statistical analysis. Spectrochim Acta A. 2011:78:1221-6.

43. Goodacre R, Shann B, Gilbert RJ, Timmins EM, McGovern AC, Alsberg BK, Kell DB, Logan NA. Detection of the dipicolinic acid biomarker in Bacillus spores using curie-point pyrolysis mass spectrometry and fourier transform infrared spectroscopy. Anal Chem. 2000;72:119-27.

44. Kong J, Yu S. Fourier Transform infrared spectroscopic analysis of protein secondary structures. Acta Biochim Biophys Sinica. 2007;39:549-59.

45. Byler DM, Susi H. Examination of the secondary structure of proteins by deconvolved FTIR spectra. Biopolymers. 1986;25:469-87.

46. Doménech-Carbó A, Doménech-Carbó MT, Valle-Algarra FM, GimenoAdelantado JV, Osete-Cortina L, Bosch-Reig F. On-line database of voltammetric data of immobilized particles for identifying pigments and minerals in archaeometry, conservation and restoration (ELCHER database). Anal Chim Acta. 2016:927:1-12.

47. Zakharchuk N, Meyer S, Lange B, Scholz F. A comparative study of lead oxide modified graphite paste electrodes and solid graphite electrodes with mechanically immobilized lead oxides. Croat Chem Acta. 2000;73:667-704 
48. Komorsky-Lovric S, Lovric M, Bond AM. Comparison of the square-wave stripping voltammetry of lead and mercury following their electrochemical or abrasive deposition onto a paraffin impregnated graphite electrode. Anal Chim Acta. 1992;258:299-305.

49. Arjmand F, Adriaens A. Electrochemical quantification of copper-based alloys using voltammetry of microparticles: optimization of the experimental conditions. J Solid State Electrochem. 2012;16:535-43.

50. Meyer B, Ziemer B, Scholz F. In situ X-ray diffraction study of the electrochemical reduction of tetragonal lead oxide and orthorhombic $\mathrm{Pb}(\mathrm{OH}) \mathrm{Cl}$ mechanically immobilized on a graphite electrode. J Electroanal Chem. 1995;392:79-83.

51. Hasse U, Scholz F. In situ atomic force microscopy of the reduction of lead oxide nanocrystals immobilised on an electrode surface. Electrochem Commun. 2001;3:429-34

52. Doménech-Carbó A, Doménech-Carbó MT, Mas-Barberá X. Identification of lead pigments in nanosamples from ancient paintings and polychromed sculptures using voltammetry of nanoparticles/atomic force microscopy. Talanta. 2007;71:1569-79.

53. Doménech-Carbó A, Doménech-Carbó MT, Mas X, Ciarrocci J. Simultaneous identification of lead pigments and binding media in paint samples using voltammetry of microparticles. Arché. 2007;2:121-4.

54. Jaworski A, Stojek Z, Scholz F. A comparison of simulated and experimental abrasive stripping voltammetric curves of ionic crystals: reversible case. J Electroanal Chem. 1993;354:1-9.

55. Lovric M, Scholz F. A model for the propagation of a redox reaction thorough microcrystals. J Solid State Electrochem. 1997;1:108-13.

56. Lovric M, Hermes M, Scholz F. The effect of the electrolyte concentration in the solution on the voltammetric response of insertion electrodes. J Solid State Electrochem. 1998;2:401-4.

57. Oldham KB. Voltammetry at a three-phase junction. J Solid State Electrochem. 1998;2:367-77

58. Lovric M, Scholz F. A model for the coupled transport of ions and electrons in redox conductive microcrystals. J Solid State Electrochem. 1999:3:172-5.
59. Schröder U, Oldham KB, Myland JC, Mahon PJ, Scholz F. Modelling of solid state voltammetry of immobilized microcrystals assuming an initiation of the electrochemical reaction at a three-phase junction. J Solid State Electrochem. 2000;4:314-24.

60. Reregistration Eligibility Decision (RED) for Coppers. U.S. Environmental Protection Agency, Office of Prevention, Pesticides and Toxic Substances, Office of Pesticide Programs. Washington, DC: U.S. Government Printing Office; 2009.

61. Mirkovic B, Tanovic B, Hrustic J, Mihajlovic M, Stevic M, Delibasic G, Vuksa P. Toxicity of copper hydroxide, dithianon, fluazinam, tebuconazole and pyraclostrobin to Didymella applanata isolates from Serbia. J Environ Sci Health B. 2015;50:175-83.

62. Biswas FB, Roy TG, Rahman MA, Emran TB. An in vitro antibacterial and antifungal effects of cadmium(II) complexes of hexamethyltetraazacyclotetradecadiene and isomers of its saturated analogue. Asian Pac J Trop Med. 2014;7(S1):S534-9.

63. Montazerozohori M, Zahedi S, Nasr-Esfahani M, Naghiha A. Some new cadmium complexes: antibacterial/antifungal activity and thermal behavior. J Ind Eng Chem. 2014;20:2463-70.

64. Montazerozohori M, Musari SA, Masoudiasl A, Naghiga A, Dusek M, Kycerakova M. Synthesis, spectral, crystal structure, thermal behavior, antimicrobial and DNA cleavage potential of two octahedral cadmium complexes: a supramolecular structure. Spectrochim Acta A. 2015;137:389-96.

65. Novakova K, Navratil T, Sestakova I, Lee MP, Vodickova H, Zamecnikova B, Sokolova R, Bulickova J, Gal M. Characterization of cadmium ion transport across model and real biomembranes and indication of induced damage of plant tissues. Monatsch Chem Chem Mont. 2015;146:819-29.

66. Negm NA, Said MM, Morsey SM. Pyrazole derived cationic surfactants and their tin and copper complexes: synthesis activity, antibacterial and antifungal efficacy. J Surfact Deterg. 2010;13:521-8.

\section{Submit your manuscript to a SpringerOpen ${ }^{\circ}$ journal and benefit from:}

- Convenient online submission

- Rigorous peer review

- Immediate publication on acceptance

- Open access: articles freely available online

- High visibility within the field

- Retaining the copyright to your article 